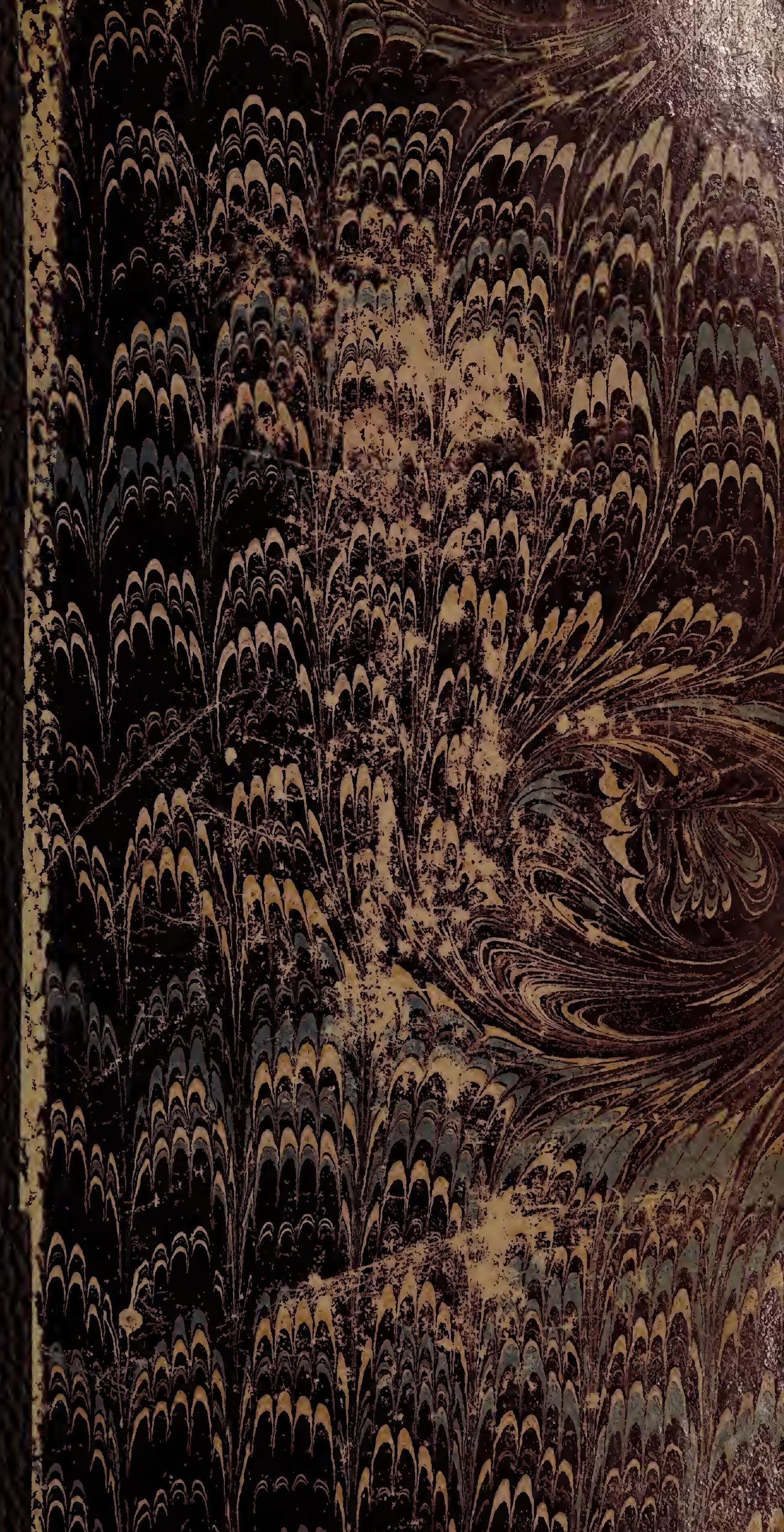




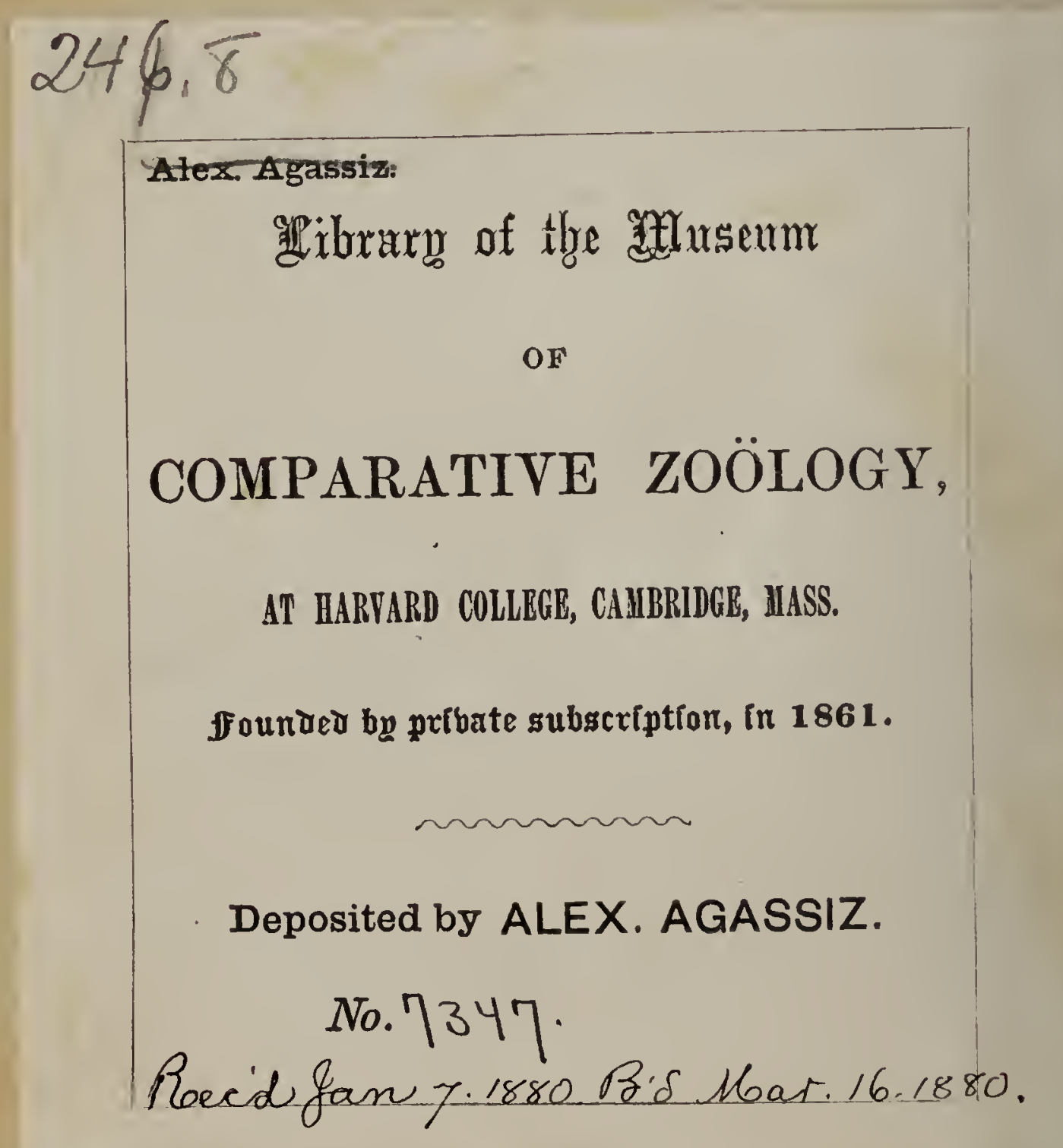


-

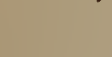

-

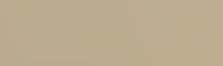



G UID E

D E

L'ÉLÈVE ET DU PRATIGIEN P0UR LES TRAVAUX PRATIQQUES

DE MICR0GRAPHIE 


\section{Droits de traduction réservés.}




\section{GUIDE}

DE

\section{L'ÉLEVE ET DU PRATIGIEN}

\section{POUR LES TRAYAUX PRATIOULS}

\section{DE MICROGRAPHIE}

COMPRENANT

\section{LA TECHNIQUE ET LES APPLICATIONS DU MICROSCOPE}

A L'HISTOLOGIE VÉGÉTALE

A la physiologie, a la Glinique, A L'hygiène

ET A LA MÉdEGINE LÉgaLE

PAR

\section{H. BEAUREGARD}

Docteur en médecine

Docteur ès sciences

Professeur agrégé à l'École supérieure de Pharmacie.

\section{GALIPPE}

Docteur en médecine Ancien chef des travaux pratiques de micrographie à l'Ecole supérieure de Pharmacie

Membre de la Société de biologie.

Avec 570 figures dans le texte.

\section{PARIS}

G. MASSON, ÉDITEUR

LIBRAIRE DE L'A AADÉME DE MÉDECINE

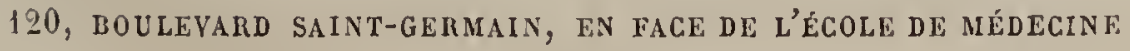




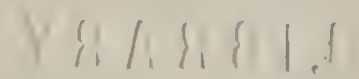

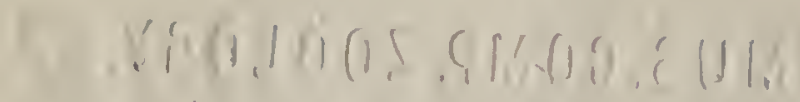

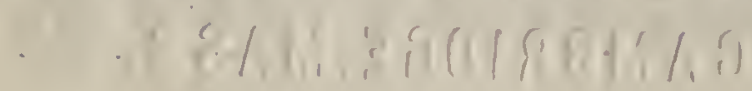




\section{Monsieur A. Chatin}

Diregteur de L'École de pharmagie, Membre de l'institut, etc.

Le temps n'est pas encore loin où deux ou trois élèves réunis dans une serre de l'École de Pharmacie, en plein été et sous les rayons ardents du soleil, s'exerçaient péniblement au maniement du microscope.

Si l'on compare le présent au passé, on peut mesurer le chemin parcouru.

A la place d'une serre chaude on voit de rastes laboratoires inondés de lumière; au lieu des rares élèves d'autrefois, deux cents jeunes gens, munis chacun d'un microscope et de ses accessoires, travaillent sous les yeux diligents de maîtres aussi instruits que bienveillants.

C'est grâce à votre initiative qu'un si grand progrès a été réalisé. Convaincu que l'instruction des élèves serait incomplète, si l'on ne mettait en œurre au laboratoire l'enseignement théorique reçu au cours, vous avez voulu qu'en sortant de l'école, un pharmacien fût armé de loutes pièces, pour faire face aux exigences multiples de sa profession; non pas de la profession pharmaceutique envisagée seulement dans son acception la plus res- 
treinte, la préparation et la vente des médicaments, mais dans ses nombreux points de contact avec les sciences naturelles, physiques, chimiques et biologiques.

Grâce à ces réformes utiles, grâce aussi au zèle et à la science de vos collaborateurs, le temps est venu où un pharmacien pourra porter sans faiblir devant les tribunaux, les lourdes responsabilités de l'expert et rendre les plus grands services aux comités locaux d'hygiène, par la multiplicité de ses connaissances.

Trois années passées dans les laboratoires d'application des Ecoles de pharmacie auront suffisamment discipliné la main et l'esprit, pour donner au pharmacien une place souvent prépondérante dans ces réunions administratives où sont débattues des questions si importantes pour l'hygiène des villes et des individus.

C'est pourquoi vous avez voulu que le microscope, qui est d'un si grand secours au chimiste, au naturaliste, au médecin, devînt, pour ainsi dire, l'auxiliaire et le compagnon de chaque jour du pharmacies!

Pour réaliser cette pensée éminemment pratique, une organisation, peut-être unique au monde, est sortie de vos mains; aujourd'hui chaque élève est exercé à faire des coupes microscopiques, à les monter, à les dessiner.

Cette réorganisation de l'enseignement devait avoir pour conséquence l'apparition de besoins nouveaux, au point de vue des ouvrages que les élèves consultent. Déjà des lacunes ont été comblées, d'autres le seront demain.

Nous avons pensé, en ayant maintes fois constaté la nécessité par nous-mêmes, que les élèves des travaux pratiques de micrographie avaient besoin d'un traité spécial, en raison de la multiplicité et de la diversité de leurs sujets d'élude. 
C'est pour répondre à ce desideratum que nous avons écrit ce manuel.

Dans la première partie, consacrée à l'histologie végétale, nous avons dû nous borner à un exposé de nos connaissances sur la structure des végétaux, nous préoccupant davantage de mettre sous les yeux du lecteur les idées ayant cours dans la science que de discuter leur degré d'exactitude.

Nous étions certains que cette distinction serait faite, avec l'indépendance et l'esprit scientifique qui caractérisent votre enseignement, par ceux qui ont charge de professer la Botanique.

Il nous aurait étẹ impossible de résumer en un volume les applications multiples de l'histologie végétale à la matière médicale, aux falsifications, et nous avons dî nous borner à des exemples généraux. Ces applications ont été l'objet de traités spéciaux qui sont entre toutes les mains. Il nous a suffi de mettre les élèves en situation de contrôler au laboratoire (rous conformant en cela à la direction imprimée par vous aux travaux pratiques) les notions théoriques développées dans les cours.

Il n'en était plus de même lorsque nous avons abordé les questions qui sont du domaine de l'histologie animale. Tandis que, dans la première partie, on suit le développement du végétal, dont chaque organe devient l'objet d'un chapitre spécial, formant ainsi avec les précédents un enchaînement naturel ; dans la seconde, au contraire, à chaque division correspondent des connaissances spéciales, empruntées à l'anatomie, à la zoologie, à la physiologie, à la pathologie ou à la météorologie, etc. Il ne serait pas possible d'exiger des élèves la lecture ni même la possession de tous les ouvrages ou mémoires spéciaux, où ils devraient étudier chacune de ces questions si complexes. 
Ce travail, nous l'avons fait pour eux.

Aucun lien n'existe entre les différents chapitres de cette seconde partie; il ne pouvait en être autrement pour rester dans les limites que nous nous étions tracées.

Chacun de ces chapitres forme un tout où l'état de la science est exposé aussi exactement que possible.

Comme nous l'avons dit maintes fois dans le cours de cet ouvrage, notre but a été de rendre exercées les mains entre lesquelles le microscope est appelé à rendre de si grands services à l'hygiène, à la médecine, à l'industrie.

Chaque fois que nous avons signalé une cause d'erreur, nous avons indiqué les moyens de l'éviter, mettant ainsi le lecteur en garde contre des accidents redoutables, surtout en médecine légale.

De nombreuses figures intercalées dans le texte serviront de points de repère, mais, nous voulons le répéter ici, on ne connaît bien que ce qu'on a étudié soi-même. C'est pourquoi nous avons tant insisté sur les méthodes générales de préférence aux cas particuliers dont la variation est infinie.

Nous avons voulu être utiles aux élèves et aux praticiens, l'arenir dira si notre but a été atteint.

Quel que soit le jugement que vous portiez sur ce manuel, nous espérons que vous voudrez bien en accepter la dédicace, certains que vous n'avez pas oublié, qu'à l'heure difficile où il fallut tout organiser, tout improviser, les auteurs, vos élèves, vous ont secondé de toutes leurs forces et de tout leur dévouement.
Dr H. Beauregard.
$D^{r}$ V. Galippe.

Paris, novembre 1879. 


\section{GUIDE}

DE

\section{L'ÉLÈVE ET DU PRATICIEN}

POUR LES TRAVAUX PRATIQUES

\section{DE MIGROGRAPHIE}

\section{CHAPITRE PREMIER}

\section{DES MIGROSGOPES ET DE LEUR EMPLOI.}

Nous entrerons immédiatement dans la description de ces instruments, renvoyant, pour ce qui a trait à la marche de la lumière à travers les lentilles, aux ouvrages de physique qui tous entrent dans de suffisants détails sur ce sujet. - Quant à ceux de nos lecteurs qui désireraient étudier à fond les divers problèmes de physique optique que soulève l'emploi des microscopes, nous les renvoyons à divers ouvrages qui traitent longuement de la matière à ce point de vue spécial. Tels sont l'ouvrage magistral de M. Ch. Robin (Traité du microscope de M. Ch. Robin. Paris, 1871) etle Traité des manipulations de physique (Paris, 1877), si remarquable par sa clarté et sa précision, que nous devons à notre savant et regretté maitre M. Buignet.

Ils consulteront également avec fruit le Microscope du $\mathrm{D}^{\mathrm{r}}$ Pelletan et le Manuel de MM. Mathias Duval et Lereboullet. 
On divise généralement les microscopes en : microscopes simples et microscopes composés.

Les premiers (loupes, doublets) ne peuvent donner que des grossissements relativement peu considérables.

Ils sont très-utiles pour les dissections d'objets d'un petit volume, parce qu'ils donnent des images droites de ces objets.

Les microscopes composés, au contraire, ont un pouvoir amplifiant qui peut devenir très-considérable. On les utilise donc dans l'étude de l'organisation intime des êtres. Mais ils donnent des images renversées des objets.

Nous allons dire quelques mots de ces instruments.

\section{MICROSCOPES SIMPLES.}

On distingue dans ce groupe d'instruments, caractérisés tous par ce fait qu'ils donnent des images droites et amplifiées des objets, les loupes et les doublets.

\section{§ I. LOUPES.}

Les loupes les plus simples consistent en une seule lentille convergente, à foyer d'autant plus court qu'on veut obtenir un plus fort grossissement. En prenant des lentilles à foyer très-court on pourrait donc amplifier considérablement les objets, mais on s'aperçoit très-rapidement qu'il y a une limite qu'on ne saurait dépasser. En effet, le champ de vision devenant plus restreint à mesure que la distance focale de la lentille diminue, l'image perd bientôt sa netteté.

Un autre inconvénient résulte de l'aberration de sphéricité qui devient très-sensible dans les lentilles à pouvoir grossissant un peu élevé.

Correction des loupes. - On arrive cependant à corriger cette aberration en supprimant les rayons lumineux qui arrivent à l'œil après avoir traversé les bords de la lentille. Pour cela on noircit les bords de la lentille, ou bien encore on interpose entre l'œil et la loupe un diaphragme qui ne laisse passer que les rayons du centre. On arrive ainsi, avec des grossissements assez puissants, à obtenir des images nettes. Il est vrai qu'elles sont moins éclairées. 
Coupes montées. - Les lentilles grossissantes, pour être facilement maniées, sont montées dans des armatures de modèles divers suivant les besoins. Ordinairement elles sont enchâssées dans des cercles de corne ou de laiton noirci.

Lorsqu'on veut employer ces loupes aux dissections fines, il convient de les adapter à des supports qui permettent le libre usage des deux mains. On a construit pour cela des pieds porte-loupe de différents modèles.

Diverses conditions doivent être exigées dans la construction de ces appareils. Le pied doit être muni de branches articulées de manière à permettre de diriger la loupe qu'on y fixe, dans tous les sens possibles. Il doit être très-lourd, pour assurer la stabilité indispensable à une bonne observation.

Ces conditions sont généralement remplies dans les divers modèles d'instruments que l'on construit. Le pied porte-loupe articulé à crémaillère de M. Nachet (fig. 1), ainsi du reste que maints autres modèles, répondent à tous les besoins. On doit toutefois, lorsqu'on fait l'acquisition d'un pareil instrument, s'inquiéter avec soin de

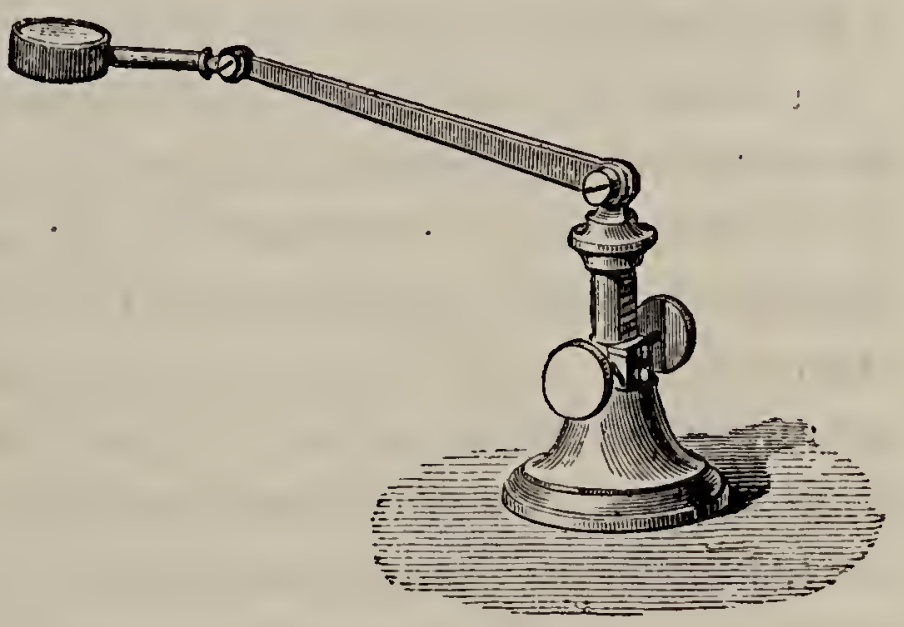

Fig. 1. l'état des articulations qui doivent être assez fortes pour supporter sans céder le poids des loupes que l'on désire y adapter, et en même temps n'ètre point trop scrrées, de manière à permettre un jeu facile des diverses parties de la branche.

Nous avons dit qu'avec une seule lentille on n'obtient que de faibles grossissements. Aussi construit-on de petites loupes de poche formées de plusieurs lentilles séparément enchàssées dans des cercles de corne ; ces lentilles ont un pouvoir grossissant différent, et en les superposant on peut obtenir des grossissements relativement considérables.

Loupe de Irewster, dite de Collington. - Nous mentionnons particulièrement la loupe de Brewster qui donne d'excel- 
lentes images et un fort grossissement. - Elle se compose d'un cylinảre de verre dont les extrémités présentent des courbures qui en forment un appareil grossissant. A sa partie médiane, le corps du cylindre est taillé de manière à donner à l'ensemble la forme d'un sablier. La surface taillée est noircie et joue le rôle d'un diaphragme qui livre passage aux seuls rayons du centre et arrête ceux de la circonférence. Enfin le cylindre de verre est enfermé dans un tube en cuivre muni d'un manche.

Emploi des loupes. - Pour regarder un objet à travers une loupe et l'apercevoir aussi amplifié que possible, on doit le pla cer entre le foyer et la lentille, très près du foyer. L'œil de l'observateur doit être placé de l'autre côté près de la lentille.

L'emploi des loupes offre deux avantages :

$1^{\circ}$ Amplification de l'image ;

$2^{\circ}$ Éclairage plus intense de l'image.

La lentille convergente qui forme la loupe permet en effet de voir distinctement à une petite distance un objet que sans elle l'œil ne voit nettement qu'à une distance de 22 centimètres (distance moyenne de la vue distincte). L'objet étant rapproché de l'œil, l'angle visuel augmente et par suite l'image est amplifiée. D'autre part elle est plus éclairée, car un certain nombre de rayons lumineux qui sans la lentille iraient frapper sur les côtés de l'œil, pénètrent par la pupille grâce à l'action convergente de l'intermédiaire employé.

D'après ce que nous venons de dire, il est superflu d'ajouter que les myopes sont favorisés dans l'étude des petits objets. Étant obligés pour voir nettement l'objet de le rapprocher davantage de la lentille, l'ouverture de l'angle visuel augmente, et en même temps la grandeur de l'image.

La loupe est un instrument très-utile dans beaucoup de recherches peu approfondies sur la structure des objets d'histoire naturelle. Pour suppléer à leur insuffisance manifeste dans beaucoup de circonstances, on a construit des instruments que nous allons décrire, et qui ont reçu le nom de doublets. 


\section{$\S 2$. DOUBLETS.}

Wollaston (1820) eut le premier l'idée de construire ces appareils. Modifiés plus tard par Chevalier, ils constituent aujourd'hui d'excellents instruments. La loupe, avons-nous dit, ne peut être utilisée pour obtenir des grossissements un peu forts parce qu'avec la courbure de la lentille augmente l'aberration de sphéricité. On en est réduit alors pour corriger cette aberration à n'employer que la partie centrale de la lentille, correction qui entraîne la diminution du champ de vision et de l'éclairage.

Pour construire le doublet on s'est fondé sur les principes suivants :

$\mathbf{1}^{\circ}$ Les lentilles plan-convexes donnent lieu, lorsqu'elles reçoivent les rayons lumineux par leur face plane, à une aberration de sphéricité moindre que les lentilles biconvexes.

$2^{\circ}$ Deux lentilles superposées produisent une aberration de sphéricité beaucoup moindre qu'une seule lentille dont la longueur focale est égale à celle de l'assemblage des deux premières (Robin, Microscope, loc. cit.).

Les doublets sont donc formés de deux lentilles plan-convexes superposées dont les faces planes sont tournées vers l'objet. De ces deux lentilles, l'inférieure est plus large que la supérieure. Entre elles on interpose un diaphragme. Le tout est monté dans une garniture qui maintient fixe l'écartement des diverses pièces. Les deux lentilles du doublet agissent quant au pouvoir amplifiant et à la formation de l'image comme une loupe dont la longueur focale serait égale à celle du système de ces lentilles agissant ensemble. Le doublet est donc un microscope simple.

Pour les dissections, ces doublets sont disposés sur des pieds de modèles divers. Le microscope simple que construit M. Verick nous a toujours paru d'un excellent emploi. Il se compose d'une colonne en cuivre, creuse et munie d'une crémaillère portant à son extrémité une branche en cuivre horizontale terminée par un anneau dans lequel on place le doublet. Cette branche horizontale est susceptible de mouve- 
ments de latéralité; de plus elle est formée de deux tubes emboîtés ; l'intérieur qui porte le doublet à son extrémité glisse à frottement doux dans le tube extérieur et est muni d'une vis de rappel comme un mouvement lent de microscope, de telle sorte que le doublet peut par son intermédiaire être dirigé en avant ou en arrière suivant le besoin.

A cette partie de l'appareil est jointe une platine percée en son centre d'une ouverture pour l'éclairage que l'on obtient au moyen d'un miroir articulé disposé au-dessous. Enfin de cha-

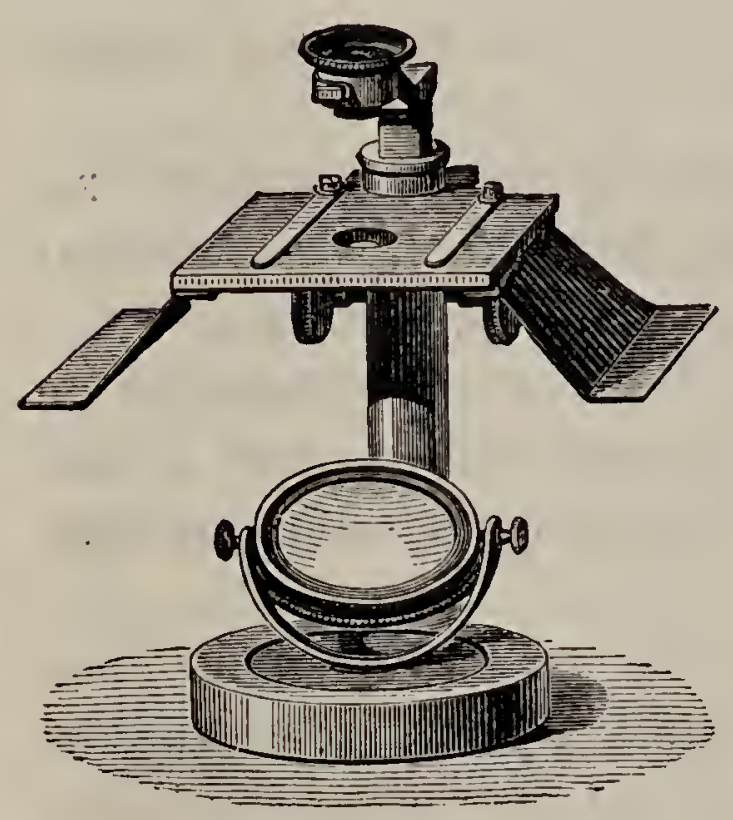

Fig. 2.

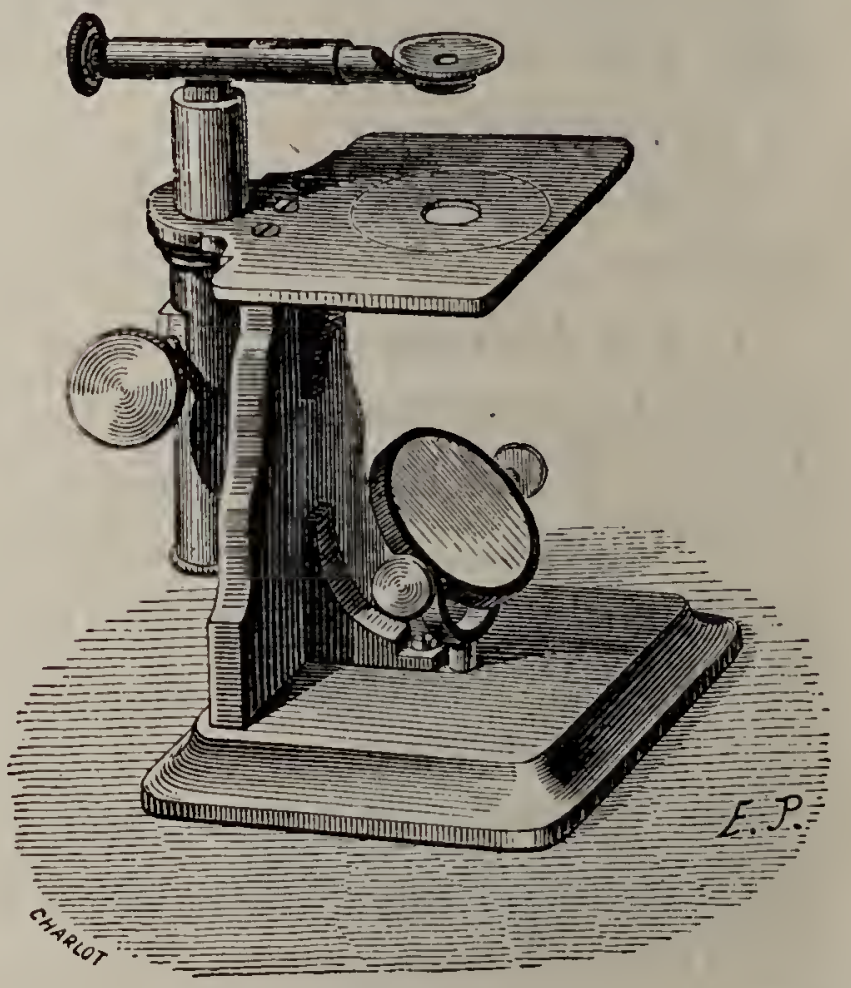

Fig. 3 .

que côté de la platine, se trouve un plan incliné, qui, en offrant aux mains un solide point d'appui, ajoute singulièrement à la sûreté des dissections. Ces plans inclinés sont soutenus par un bâti en bois dans lequel sont ménagés des tiroirs pour les pinces et autres accessoires, et pour les doublets.

Les modèles de Nachet (fig. 2) et de Chevalier (fig. 3), que nous reproduisons, sont également de bons instruments.

\section{MIGROSCOPES COMPOSÉS.}

Tandis que dans les microscopes simples l'image amplifiée est transmise à l'œil sans aucun intermédiaire, dans les mi- 
croscopes composés, l’image grossie par un premier jeu de lentilles qui a reçu le nom d'objectif (placé devant l'objet) est l'eprise avant d'arriver à l'œil par un second jeu de lentilles appelé oculaire (placé près de l'œil). Cet oculaire joue le rôle de loupe. Il amplifie l'image et la transmet finalement à la rétine. Les microscopes composés donnent des images renversées.

Deux parties sont à considérer dans un microscope: la partie optique et la partie mécánique.

A. partie optique du microscope composé.

Elle comprend : l'objectif et l'ocularre.

$\S 3$. OBJECTIF.

Les objectifs qui n'ont qu'un faible pouvoir amplifiant sont formés d'une seule lentille. Les objectifs à fort grossissement comportent généralement un jeu de trois lentilles plan-convexes achromatiques.

Pour rendre achromatiques les lentilles employées dans les microscopes, on compose chacune d'elles de deux verres différents collés ensemble à l'aide de térébenthine sèche. L'un de ces verres est en flint-glass, substance qui jouit d'un pouvoir dispersif assez grand à l'égard des couleurs du spectre; l'autre en crown-glass qui ne possède qu'un faible pouvoir dispersif. On donne au premier une forme plan-concave, et le second taillé en lentille biconvexe est à demi-enfoncé dans la concavité du premier. On oblient ainsi une lentille plan convexe achromatique, c'est-à-dire donnant une image blanche grâce à la compensation qui s'établit entre la lentille de flint divergente, fortement dispersive et la lentille de crown convergente et peu dispersive. Ajoutons que la forme planconvexe corrige également l'aberration de sphéricité du système de lentilles de l'objectif.

\section{§ 4. OCULAIRE.}

L'oculaire est toujours composé de deux lentilles plan-convexes non achromatisées et dont la convexité est tournée ver's 
l’objet. La lentille inférieure reçoit le nom de verre de champ, la lentille supérieure la plus voisine de l'œil est dite verre frontal, verre oculaire ou verre de l'cil. L'ensemble de ces deux lentilles est souvent appelé oculaire de Campani. Les deux verres qui le composent sont vissés aux deux extrémités d'un tube en laiton noirci à l'intérieur et portant un diaphragme au niveau du foyer du verre de l'œil.

L'emploi de la lentille de champ présente trois avantages: $1^{\circ}$ elle produit l'achromatisme de l'image; $2^{\circ}$ elle diminue l'aberration de sphéricité en rapprochant les rayons de l’axe des lentilles; $3^{\circ}$ elle augmente le champ du microscope en faisant pénétrer dans l'oculaire des rayons lumineux qui n'y seraient pas admis sans cette disposition (Voir pour la théorie du verre de champ, Robin, loc.cit., p. 132 et suiv.).

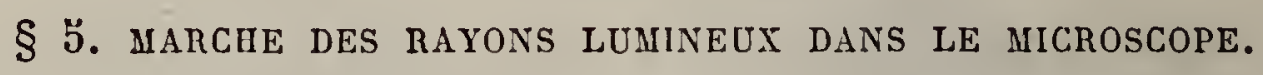

Supposons maintenant un petit objet placé devant l'objectif, un peu au delà de son foyer ; une image réelle amplifiée et renversée va se former de l'autre côté de l'objectif. - Mais l'oculaire doit être placé de manière que le verre de champ recueille les rayons lumineux qui ont traversé l'objectif avant que ceux-ci aient formé l'image. Le verre de champ vient donc augmenter l'effet de l'objectif, et donne finalement une image réelle renversée de l'objet, un peu plus petite, il est vrai, que ne l'aurait été la première. Cette image, grâce à la distance calculée entre le verre de champ et le verre de l'œil de l'oculaire, vient se faire en deçà du foyer principal de la lentille de l'œil.

Celle-ci agit alors comme une loupe et donne à l'œil de l'observateur une seconde image encore amplifiée et virtuelle; cette loupe ne redressant pas l'image donnée par l'objectif, l'objet est vu renversé.

\section{B. partie mécanique du microscope.}

Les modèles de microscopes sont aussi nombreux que les constructeurs, c'est dire qu'on en compte un très grand nombre. Ajoutons d'ailleurs qu'ils se valent tous à peu près, 
si l'on compare bien entendu les modèles sérieux. Nous décrirons pour simplifier le petit modèle de Verick, fort employé dans les laboratoires de l'École de pharmacie; ce microscope de construction très-simple peut rendre de bons services, et après l'avoir décrit il nous sera facile de montrer les perfectionnements dont il est susceptible, et de donner une rapide description des modèles plus compliqués de la série Verick et de celle de M. Nachet.

\section{$\S 6$. PETIT MICROSCOPE DE M. VERICK.}

Cet instrument comporte toutes les pièces essentielles des microscopes.

Il se compose d'un pied de fonte en forme de fer à cheval, sur lequel est fixée une colonne rigide qui porte à sa partie inférieure un miroir surmonté d'une platine pour placer l'objet à observer, et à sa partie supérieure une branche horizontale terminée par un anneau où se visse un tube creux en laiton. Ces diverses parties, pied, colonne, platine et tube creux ou canon, constituent le corps du microscope auquel il faut ajouter le tube qui porte l'oculaire à sa partie supérieure et l'objectif à son extrémité inférieure.

Tube. - Le tube en laiton mesure de 20 à 23 centimètres. Il se compose de deux tubes qui rentrent l'un dans l'autre, ce qui permet d'augmenter à un moment donné la longueur totale de l'instrument et par suite d'amplifier l'image.

A l'extrémité supérieure du tube se place l'objectif qui y entre à frottement doux; à son extrémité inférieure il: une pièce conique, c'est le cône muni d'une jvis pour l'objectif. Ce tube glisse à frottement doux dans le canon. Avec la main on le fera glisser en bas ou on le tirera en haut jusqu'à ce qu'on ait obtenu la mise au point approximative. Cela fait, pour avoir la mise au point exacte, on usera d'un mouvement lent obtenu au moyen d'une vis micrométrique logée dans la colonne du microscope et que l'on manœuvre à l'aide d'un pignon que porte son extrémité supérieure. Chaque tour de cette vis fait monter ou descendre d'une quantité très-faible le tube qui porte l'appareil optique. 
Platine. Miroir. Diaphragme. - La platine est ici une plaque de cuivre noirci, et percée en son centre d'une ouverture pour le passage des rayons lumineux réfléchis par un miroir articulé placé au-dessous. Cette platine porte en outre deux valets ou ressorts en laiton qui servent à maintenir les

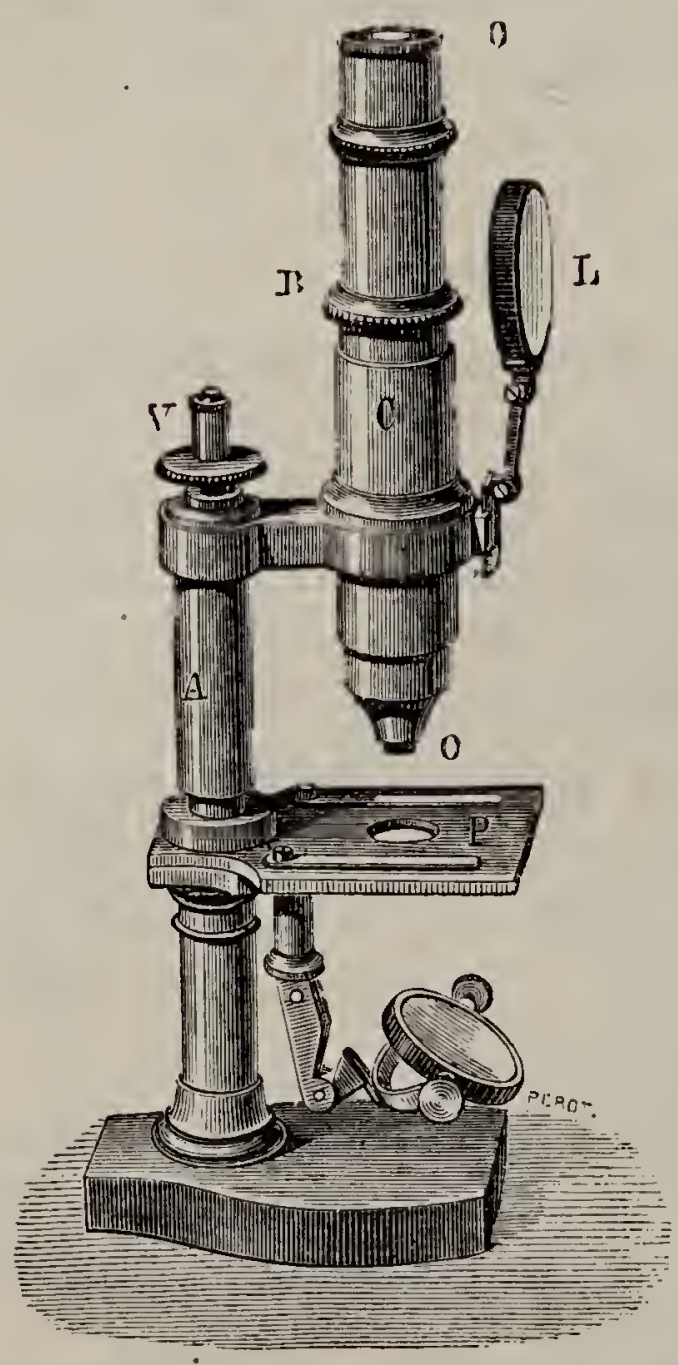

Fig. 4. préparations.

Enfin, au-dessous de la platine est fixé un disque é métal noirci, percé d'un certain nombre de trous circulaires de grandeurs variées. Par un simple mouvement de rotation on peut amener successivement 'chacun de ces trous au-dessous de l'ouverture de la platine. Cet accessoire ou diaphragme permet donc de rétrécir à volonté l'ouverture pratiquée au centre de la platine, et de modifier ainsi l'intensité de l'éclairage produit par le miroir.

Le microscope petit modèle droit de Nachet, qui aver, le précédent' a été adopté dans les laboratoires de l'École de pharmacie, en diffère d'une manière peu sensible. Le pied en laiton est plein (fig. 4). Il est accompagné en outre d'une loupe (L) pour l'examen des objets à la lumière réfléchie.

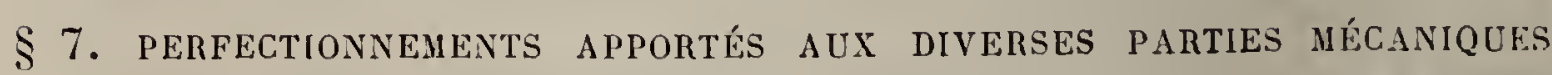
DES MICROSCOPES.

10 Colonne. - La colonne des microscopes que nous venons de décrirc est rigide et par conséquent maintient le tube dans une position verticale. On fait pour les microscopes plus compliqués des colonnes articulées de manière à pouvoir prendre une certaine inclinaison en entraînant la platine, le miroir et le tube (fig. $ّ)$. 
D'autre part, dans les grands modèles, le mouvement rapide du tube ne s'exécute pas seulement par tirage, il peut encore être obtenu au moyen d'une crémaillère fixée dans la colonne (fig. 6). Un pignon met en mouvement cette crémaillère qui entrâine avec elle de haut en bas ou de bas en haut tout le système optique. C'est là d'ailleurs un perfectionnement d'une imporlance secondaire, car avec un peu d'habitude on arrive à mettre au point avec une grande précision en ne faisant usage que du glissement.

$2^{\circ}$ Platine. - Dans les microscopes grand modèle, or remplace la platine fixe décrite plus haut par une platine dite tournante (fig. 7). Ces platines, par un mécanisme particulier, sont susceptibles. de tourner dans tous les sens autour de leur centre. Cette disposition peut rendre de réels services lorsqu'on veut par exemple dessiner un objet dans un sens déterminé, sans être obligé de déranger la plaque qui porte la préparation.

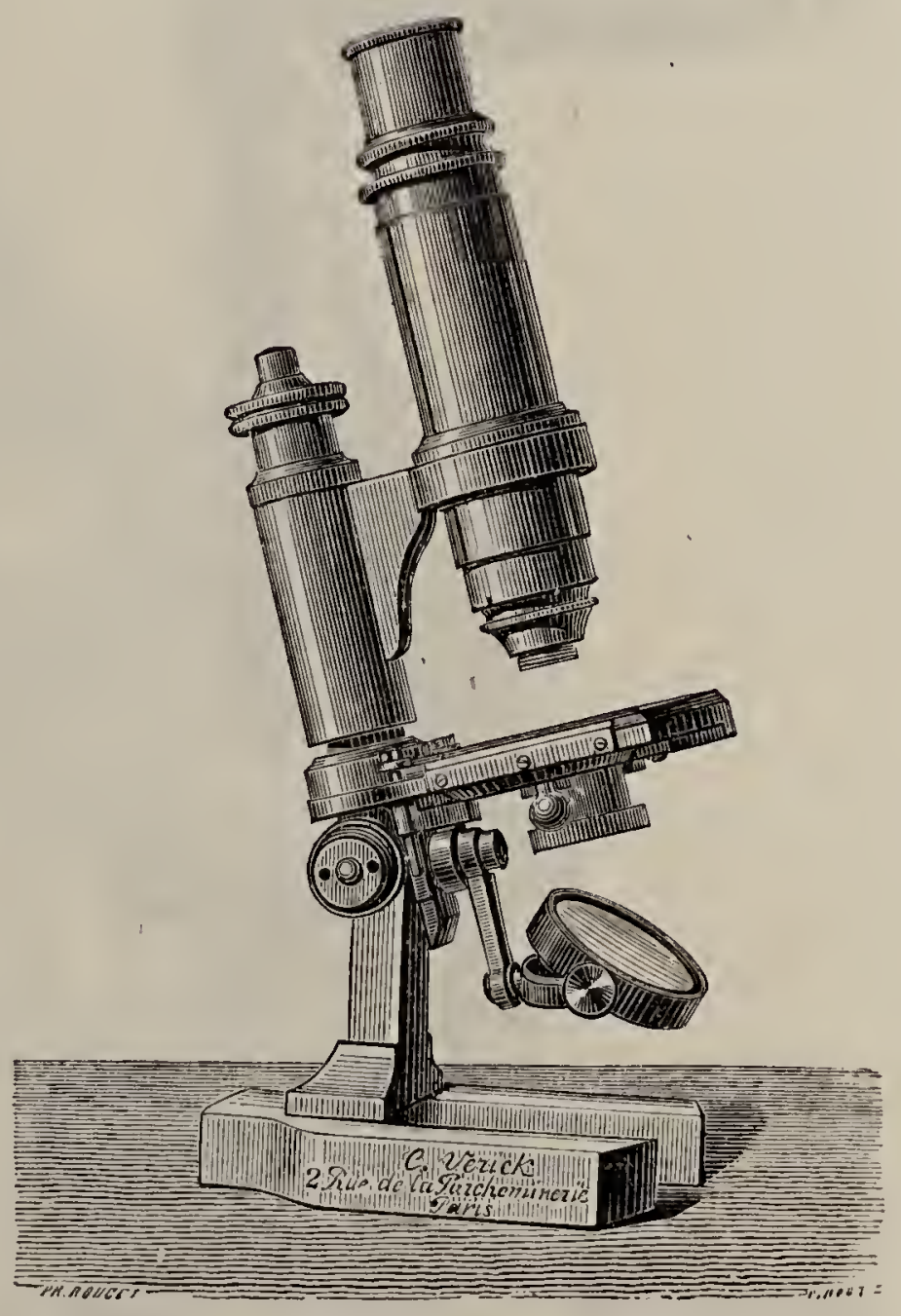

Fig.

On construit aussi pour certains modèles de microscopes des platines dites mobiles destinées à permettre de déplacer l'objet de très-petites quantités à la fois. Ces platines d'une utilité contestable ont en outre l'inconvénient grave de manquer de stabilité. Aussi l'observateur exercé préfère-l-il manœuvrer lui-même l'objet avec les doigts.

Cette platine mobile paraît cependant nécessaire dans certains cas où l'on a besoin de varier avec une grande préci- 
sion, la situation de l'objet examiné, ainsi que cela a lieu par exemple dans la méthode indiquée par M. Fouqué pour la détermination des formes géométriques des cristaux par l'intermédiaire de la lumière polarisée.

Ajoulons enfin que dans la plupart des microscopes la platine de métal est recouverte d'une plaque de glace noire qui

la met à l'abri de

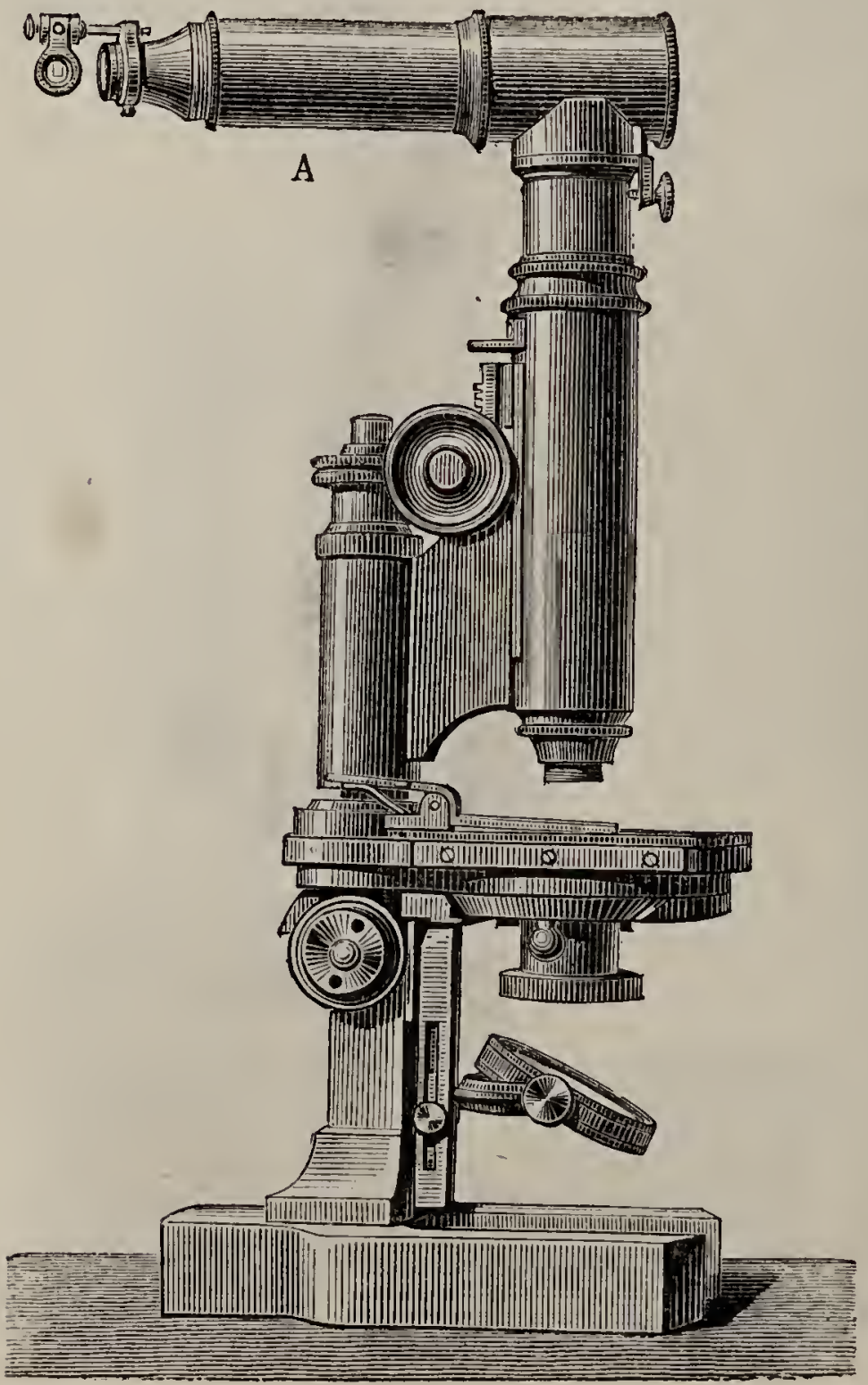

Fig. 6.

l'action des acides et réactifs divers dont l'emploi est si fréquent dans les recherches microscopiques.

Diaphragme. - Le diaphragme que nous avons décrit plus haut a l'inconvénient de déplacer l'orifice par lequel arrivent les rayons projetés par le miroir sur la préparation. Cet orifice se trouve reporté en effet un peu au-dessous du plan de l'orifice de la platine. De là, perte de lumière sensible, surtout lorsqu'on emploie les petits tıous du dia phragme. Pour obvier à cet inconvénient, on construit ce qu'on appelle le diaphragme à tube. Le modèle adopté par M. Verick nous paraît des plus simples (Voir fig. 6). C'est un tube en laiton muni à sa partie inférieure d'un collier moleté. Son ouverture supérieure représente le plus large orifice du diaphragme; si l'on veut diminuer cet orifice, on peut y introduire de plus petits tubes noircis dont 
CHAP. I. - DES MICROSGOPES ET DE LEUR EMPLOI.

l'orifice varie de grandeur. Pour maintenir cet appareil audessous de la platine, une plaque do laiton, portant un anneau où l'on fixe le diaphragme, s'engage entre deux portants disposés à cet effet sous la platine. Un piton sert à tirer ou à

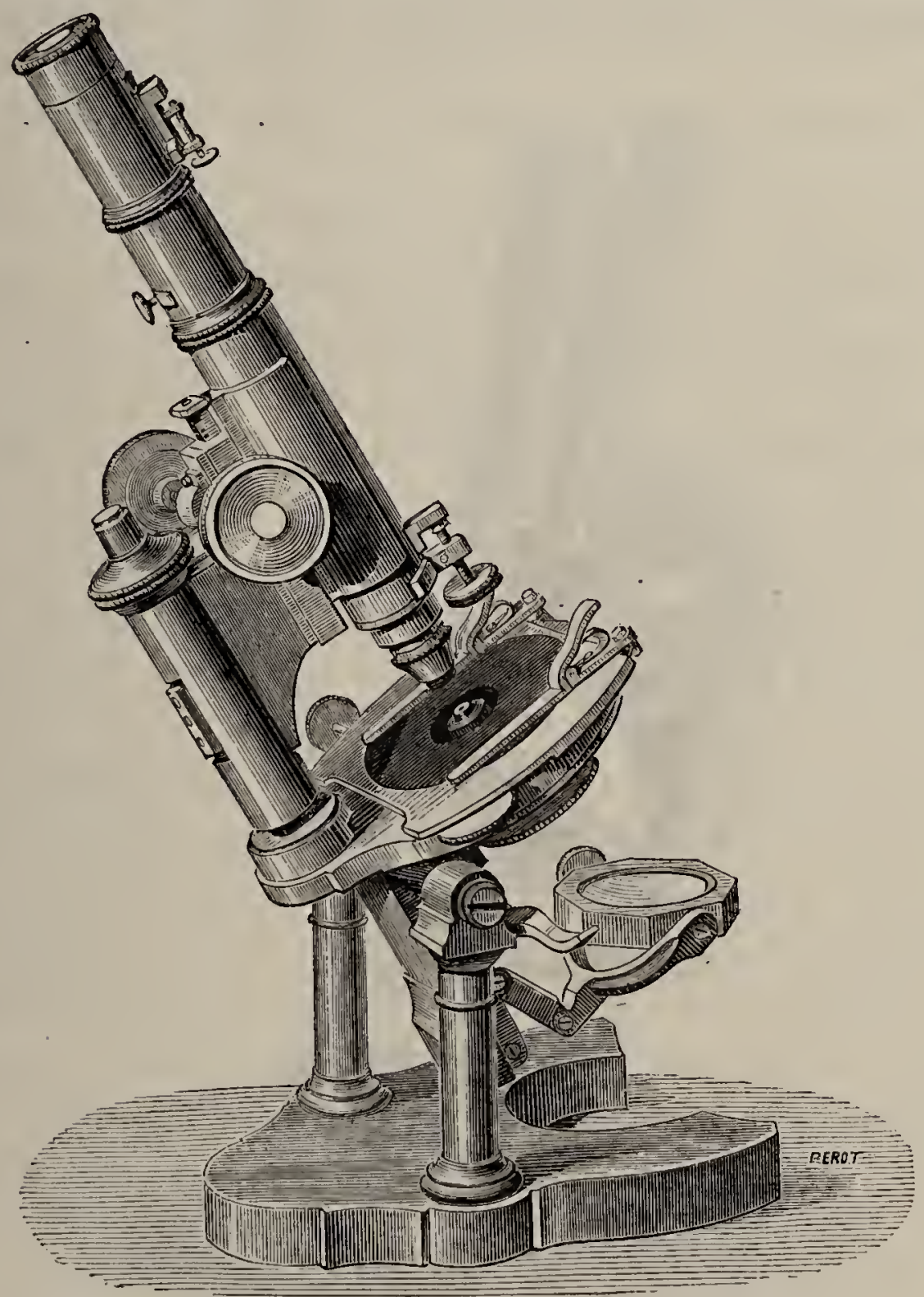

Fig. 7 .

enfoncer l'appareil; lorsque le tube est arrivé au-dessous de l'orifice de la platine, on le pousse en haut dans l'anneau où il glisse à frottement doux, et l'on amène l'orifice du diaphragme au niveau même de l'orifice de la platine. Le but est atteint. 
\$ 8. microscope binoculaire (fig. 8).

Ce microscope construit pour la première fois par $\mathrm{M}$. Nachet met en évidence les creux et les reliefs et donne par conséquent des images absolument exactes de l'objet, en

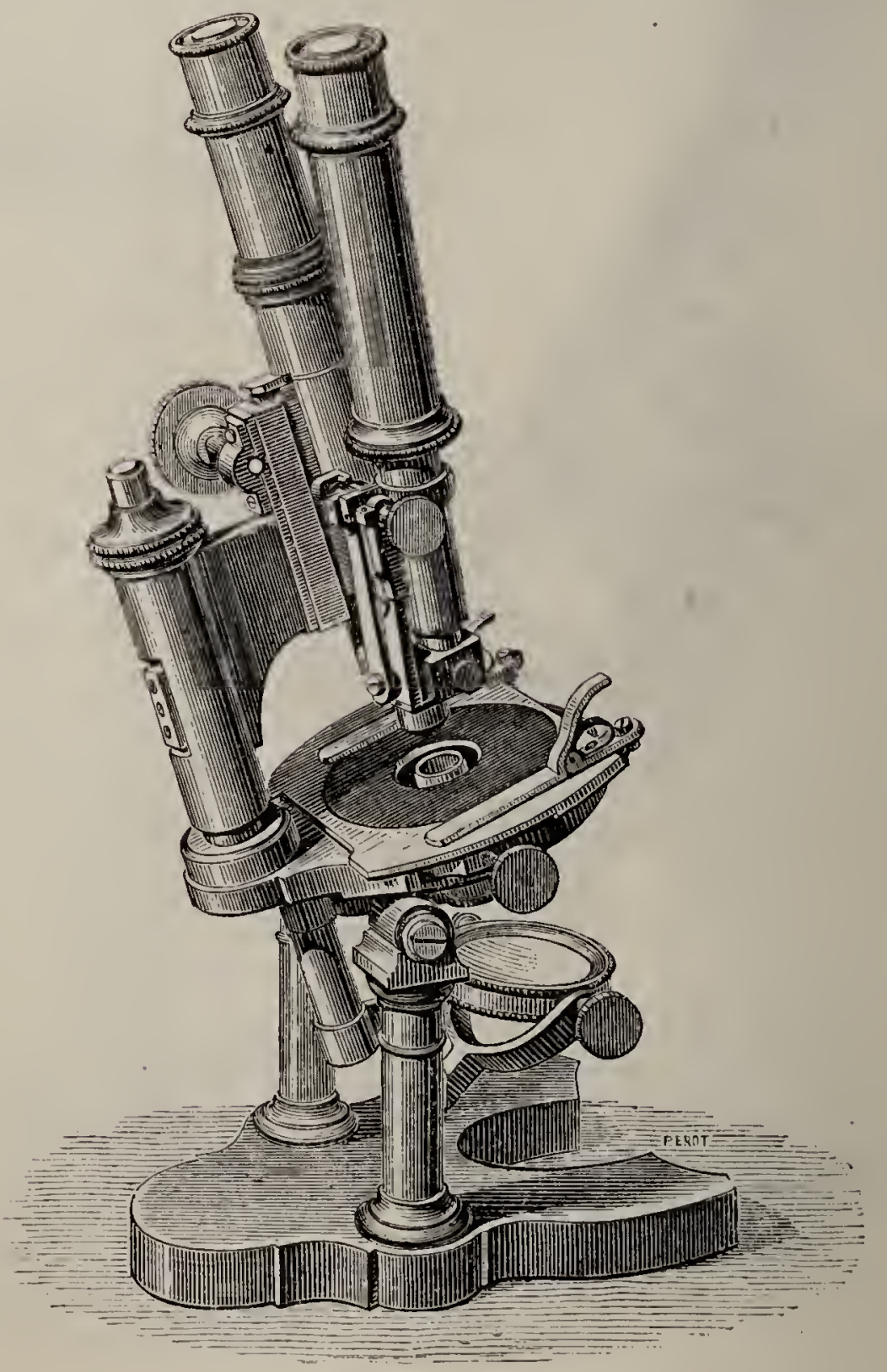

Fig. 8 .

même temps qu'une idée vraie des contour's, de l'épaisseur, du volume, etc. On comprend toutes les conséquences pratiques que l'on peut tirer de cel instrument (pour les détails, voir Robin, loc. cit., et J. Pelletan, le Microscope, son emploi et son applicalion. Paris, 187(i). 
§ 9. DU POUVOIR AMPLIFIANT DES MIGRoscopes.

Le pouvoir amplifiant ou grossissement d'un microscope est le rapport qui existe entre la grandeur absolue de l'objet et la grandeur absolue de l'image.

Pour amplifier l'image, l'observateur peut recourir à plusieurs moyens.

$1{ }^{\circ}$ C'est d'abord l'association des objectifs et des oculaires. Nous avons vu plus haut en effet que le grossissement n'est pas dû seulement à l'objectif, mais qu'il est également dû en grande partie à l'oculaire qui joue le rôle de loupe. Or, de même qu'il y a des séries d'objectifs donnant des grossissements divers, de même on a fait des séries d'oculaires dont le pouvoir amplifiant va en augmentant. On pourra donc avec un seul objectif et plusieurs oculaires obtenir une amplification croissante jusqu'à la limite assignée par le grossissement du plus fort oculaire. Si l'on a de plus une série d'objectifs, par la combinaison des objectifs les plus forts avec les oculaires les plus puissants, on obtiendra le grossissement le plus considérable possible avec ces lentilles.

Les objectifs et les oculaires sont désignés d'après leur grossissement par des chiffres $0,1,2,3$, etc. Notons également, car les commençants s'y trompent souvent, que dans les objectifs les plus forts, c'est-à-dire ceux qui donnent les grossissements les plus considérables, la lentille inférieure présente un très petit diamètre, tandis que les objectifs d'un faible pouvoir amplifiant ont une lentille inférieure d'un diamètre relativement grand.

D'après ce que nous venons de dire, on pourra donc obtenir divers grossissements, soit en variant les objectifs, soit en variant les oculaires. Mais en général il vaut mieux obtenir l'amplification aver les objectifs qu'avec les oculaires: L'observation démontre en effet que la perte de lumière occasionnée par l'emploi des nculaires puissants est à grossissement égal beaucoup plus sensible que lorsqu'on emploie de forts objectifs. Les forts objectifs offrent, il est vrai, dans leur emploi l'inconvénient de nécessiter l'usage de couvre-objets très 
minces, mais ce n'est là qu'un inconvénient relativement minime, bien qu'il constitue l'une des raisons qui empêchent de porter le grossissement au delà de certaines limites.

$2^{\circ} \mathrm{Un}$ autre moyen pour grossir les objets consiste dans l'allongement du corps du microscope. Cela devait être puisque plus on ćloigne l'oculaire de l'objectif, plus les rayons que reçoit le verre de champ sont divergents. Mais en même temps l'image devient diffuse. Pour allonger le tube du microscope il suffit de le tirer, car, ainsi que nous l'avons dit, dans la plupart des instruments de construction française, ce tube est formé de deux cylindres creux emboîtés à la manière des tubes d'une lorgnette. Il y a toutefois une limite à ce mode de grossissement, car lorsque le tube dépasse 25 centimètres et que l'oculaire employé a moins de 3 centimètres de longueur, la perte de lumière devient telle, qu'il est préférable d'en revenir à un grossissement moindre.

\section{$\S 10$. OBJECTIFS A MMERSION.}

Ces objectifs destinés à donner les plus forts grossissements ont été imaginés pour obvier à la brusque déviation que subissent les rayons lumineux, d'une part en traversant le couvreobjet pour entrer dans l'air, d'autre part en passant de l'air dans la lentille objective.

Le principe employé a été indiqué par Amici en 1844. Il consiste à interposer entre le verre mince couvre-objet et la lentille inférieure de l'objectif un corps transparent ayant à peu près le même indice de réfraction que le verre. Après des tâtonnements divers, on a reconnu que mieux qu'aucun autre corps (huile de pied de bœuf, essence d'anis et glycérine, etc.) l'eau distillée remplit les conditions désirées. La différence entre l'indice de réfraction de l'eau et celui de l'air est en effet beaucoup moindre que celle qui existe entre les indices de réfraction de l'air et du verre. De plus, l'eau distillée ne laisse aucun résidu sur les surfaces qu'elle recouvre.

Les lentilles à immersion augmentent l'éclairage, par suite de la suppression des brusques réfractions subies par les rayons lumineux qui peuvent alors entrer en plus grand nom- 
bre dans l'objectif; à cet avantage s'en joint un second; le foyer de la lentille objective se trouvant reculé par la substitution de l'eau à l'air (Voir Robin, loc. cil.), la mise au point devient plus aisée, chose très importante, quand on fait usage de forts grossissements.

Emploi. - Pour se servir des objectifs à immersion, on commence par nettoyer avec soin la lentille inférieure de l'objectif ainsi que le couvre-objet. Puis, avec un agitateur on prend une goutte d'eau distillée que l'on dépose sur la lentille objective. On dépose également une goutte de liquide sur le couvre-objet à l'endroit que l'on veut observer, et après avoir mis le tube du microscope en place, on le fait glisser jusqu’à ce que les deux gouttes d'eau, celle de l'objectif et celle du couvre-objet, se confondent. Il ne reste plus alor's qu'à mettre au point pour l'observation.

\section{$\S 11$. MESURE DU POU VOIR AMPLIFIANT DES MICROSCOPES.}

Pour mesurer le pouvoir amplifiant d'un système optique donné, il est nécessaire d'avoir à sa disposition des instruments particuliers qui ont reçu le nom de micromètres.

Micromètres. - Un micromètre est une plaque de verre sur laquelle sont gravés à l'aide de la machine à diviser et avec la plus grande précision des traits parallèles et d'un écartement parfaitement déterminé. On emploie pour la mesure des grossissements deux sortes de micromètres :

$1^{\circ}$ Le micromètre oljectif, qui porte des divisions répondant au centième de millimètre; ces divisions à peu près ịnvisibles à l'œil nu sont assez difficiles à placer sous l'objectif; on arrive cependant avec quelque exercice à le faire rapidement, surtout si l'on a. soin d'employer un éclairage un peu oblique.

$2^{\circ}$ Le micromètre oculaire est une plaque de verre qui porte ordinailement des divisions représentant des dixièmes de millimètre. Ce micromètre se place entre le verre de champ et le verre de l'œil de l'oculaire au même niveau que le diaphragme, c'est-à-dire au foyer même du verre de l’œil.

Mesure du pouvoir amplifint du microscope par le micro- 
mètre oculaire. - Nous n'indiquerons avec détails que ce procédé, le seul qui donne des résultats exacts.

Supposons tout d'abord que le verre de l'œil de l'oculaire employé grossisse exactement 10 fois. (C'est ce que les constructeurs s'attachent à obtenir pour les lentilles qu'ils réservent à leurs oculaires micrométriques). - Le micromètre oculaire étant placé comme nous l'avons dit plus haut, au foyer du verre de l'œil, puisque ses divisions mesurent des dixièmes de millimètre et que la loupe grossit 10 fois, chaque division du micromètre oculaire représentera un millimètre.

Si maintenant on place sous l'objectif le micromètre objectif, il suffira de voir combien chaque division de ce micromètre occupe de divisions du micromètre oculaire. Comme les divisions du micromètre objectif représentent des centièmes de millimètre, si une de ces divisions recouvre trois divisions dı micromètre oculaire, c'est qu'elle vaut après grossissement 3 millimètres; ce grossissement s'exprimera donc ainsi :

$$
\begin{gathered}
0^{\mathrm{mm}, 01} \times \mathrm{G}=3^{\mathrm{mm}}, 00 \\
\mathrm{G}=\frac{3,00}{0,01 .}=300
\end{gathered}
$$

Il faut conclure de l'expérience que le système optique employé (objectif et oculaire) grossit 300 fois.

Ce procédé donne des résultats parfâitement exacts, puisque l'image de l'échelle oculaire et celle du micromètre objectif se trouvent toutes les deux dans l'axe de l'instrument, superposées dans un même plan, au foyer mềme de la loupe, en sorte que pour des dimensions égales elles sous-tendent le même angle sur la rétine, par conséquent sont reportées par l'œil à la même distance.

La méthode que nous venons d'indiquer donne bien entendu le grossissement de tout le système optique. Si l'on voulait connaître le grossissement de chacune des deux pièces optiques (objectif et oculaire) prise séparément, on ne pourrait y arriver avec la même précision. Ces mesures d'ailleurs n'ont qu'un intérêt de curiosité scientifique. Il est en effet bien inutile de connaître le grossissement de 
l'objectif seul, puisqu'on ne peut se servir d'un microscope sans employer à la fois l'objectif et l'oculaire.

Il existe d'autres méthodes pour déterminer le grossissement des microscopes (méthode de la chambre claire, méthode de la double vue, etc.); mais elles sont toutes moins simples et surtout moins exactes que célle que nous venons d'exposer. Nous renvoyons pour leur description aux ouvrages cités plus haut.

\section{§ 12. MESURE DES OBJETS MICHOSCOPIQUES。}

On entend par grossissement de l'objet, non pas son grossiss sement cubique, mais son grossissement en diamètre. On ne mesure en effet que l'une de ses dimensions.

On peut employer pour la solution du problème, diverses méthodes; nous n'en indiquerons qu'une seule, la plus exacte et la plus simple.

Elle repose sur la connaissance du pouvoir amplifiant du système optique employé (1).

Ge pouvoir amplifiant, nous venons de le voir, est facile à déterminer.

Le micromètre oculaire étant disposé comme plus haut, on remplace dans l'opération précédente le micromètre objectif par le corps à mesurer (globules du sang, par exemple) et l'on note exactement combien ce corps occupe de divisions du micromètre oculaire. Supposons qu'il recouvre deux divisions et demie.

Son diamètre amplifié correspond donc à $2^{\mathrm{mm}}, 5$ (puisque nous admettons toujours que le verre de l'œil de l'oculaire grossit 10 fois). D'autre part, si le grossissement du système optique employé (objectif et oculaire) est 300 , le diamètre réel du glo-

(1) Lorsqu'on ne possède pas de micromètre objectif pour déterminer le pouvoir amplifiant d'un système optique donné, on peut se servir des tables dressées par les constructeurs, et qu'ils livrent en vendant l'instrument. Toutefois il est préférable de dresser soi-même cette table. Pour simplifier on aura soin demployer toujours le même oculaire micrométrique, et l'on n'oubliera pas de tenir compte de la longueur du tube du microscope, le pouvoir amplifiant variant considérablement avec cette longueur. 
bule sera $\frac{9.5}{300}=0007$ ou 7 millièmes de millimètre. Ainsi donc, d'une manière générale, le diamètre amplifié d'un objet est représenté par une fraction dont le numérateur est le nombre de millimètres que recouvre l'objet amplifié, tandis que le dénominateur est le grossissemeni, connu du microscope.

Nous n'entrerons pas dans de plus longs détails sur ces mesures du grossissemeñt, nous bornant à l'exposé des méthodes ci-dessus, établies pour la première fois par M. Robin (loc. cit.), méthodes qui sont en réalité les seules qui donnent des résultats exacts, en même temps qu'elles sont d'une application facile.

\section{§13. CHOIX D'UN MICROSCOPE.}

Les divers modèles que nous avons cités plus haut, dus à nos meilleurs constructeurs, sont tous de bons instruments; mais, que l'on n'entende pas par bon microscope un instrument compliqué. Les plus petits modèles peuvent être d'excellents instruments et rendre de très grands services s'ils répondent aux principales conditions que nous avons envisagées déjà et à celles que nous allons rappeler de nouveau.

Des qualités de l'obj ectif $-O n$ doit exiger des objectifs certaines qualités que Goring désigne des noms de pouroir définissant, pouvoir pénétrant et pouvoir résolvant.

$1^{\circ}$ Pouvoir définissant. - On nomme ainsi la propriété qu'ont les bons objectifs de donner des images à bords bien nets et bien définis; cette propriété dépend de la correction plus ou moins parfaite des aberrations de sphéricité et de réfrangibilité (Voir plus haut, page 7).

$2^{\circ}$ Pouvoir pénétrant. - Ciest la propriété qu'ont certains ob jectifs de faire distinguer avec netteté des parties de l'objet microscopique qui sont un peu en dehors du foyer. - Cette propriété des objectifs peut rendre des services, à condition que le pouvoir définissant ne soit pas diminué.

$3^{\circ}$ Pouvoir séparateur, résolvant ou analytique. - C'est la qualité qu'ont certains objectifs de donner avec netteté l'image de 
CHAP. I. - DES MICROSCOPES ET DE LEUR EMPLOI.

délicats détails des objets, stries, saillies, dépressions, etc. Cette qualité est malheureusement contraire aux deux précédentes, surtout à la pénétration. - Ajoutons que l'on doit préférer un objectif qui définit bien, à un objectif d'un grand pouvoir analytique.

Pour vérifier les qualités précédentes des objectifs que l'on

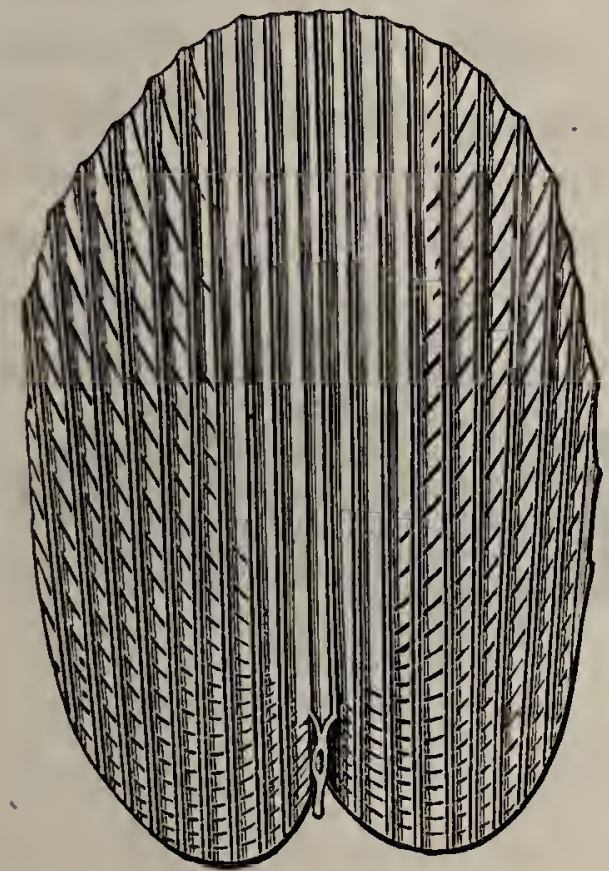

Fig. 9.

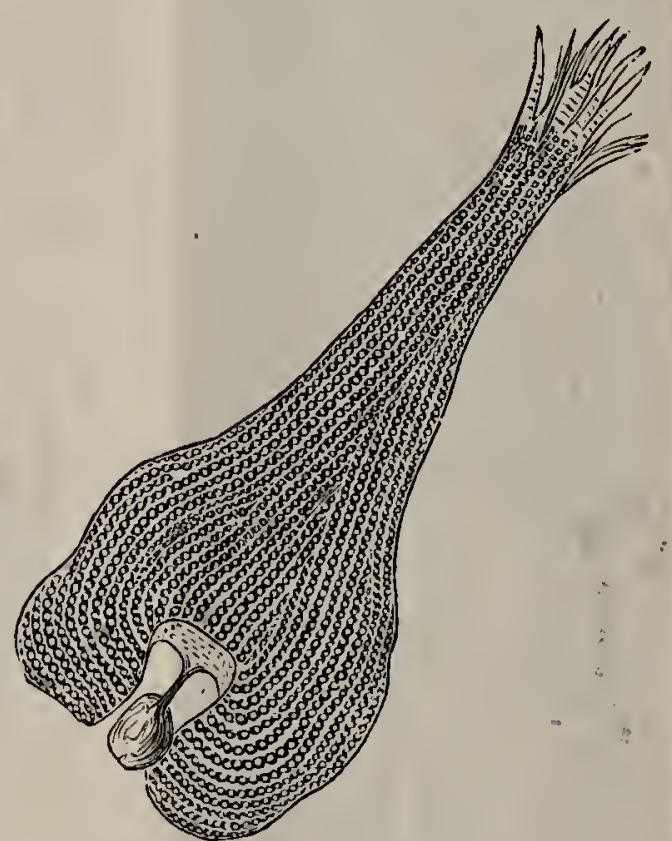

Fig. 10 .

possède, on se sert de préparations faites à l'aide d'animaux ou de végétaux microscopiques qui présentent des détails de structure généralement très-délicats, mais pourtant nettement définis. - Ces préparations reçoivent le nom de Test-Objets et servent principalement à vérifier les pouvoirs définissant et résolvant des objectifs.

Test-Objets. - L'un des plus anciens test-objets, qui n'est plus guère employé maintenant, est fourni par les écailles de la Forbicine, Lepisma, Saccharina, insecte Thysanoure (vulg.

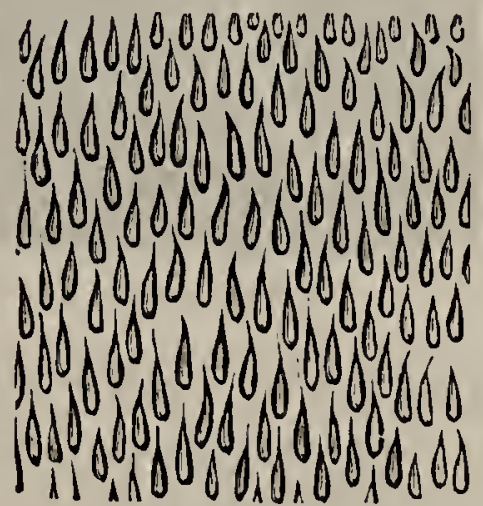

Fig. 11. poisson d'argent). Ces écailles présentent des stries longitudinales el des stries obliques par rapport à ces dernières (fig. 9). 
Les écailles cordiformes du petit papillon de chou, Pieris rapæe (fig. 10), ainsi que celles du Podura plumbea, sont d'un usage excellent. - Sur les premières on doit déterminer des rangées longitudinales de granulations semblables à de petites perles;

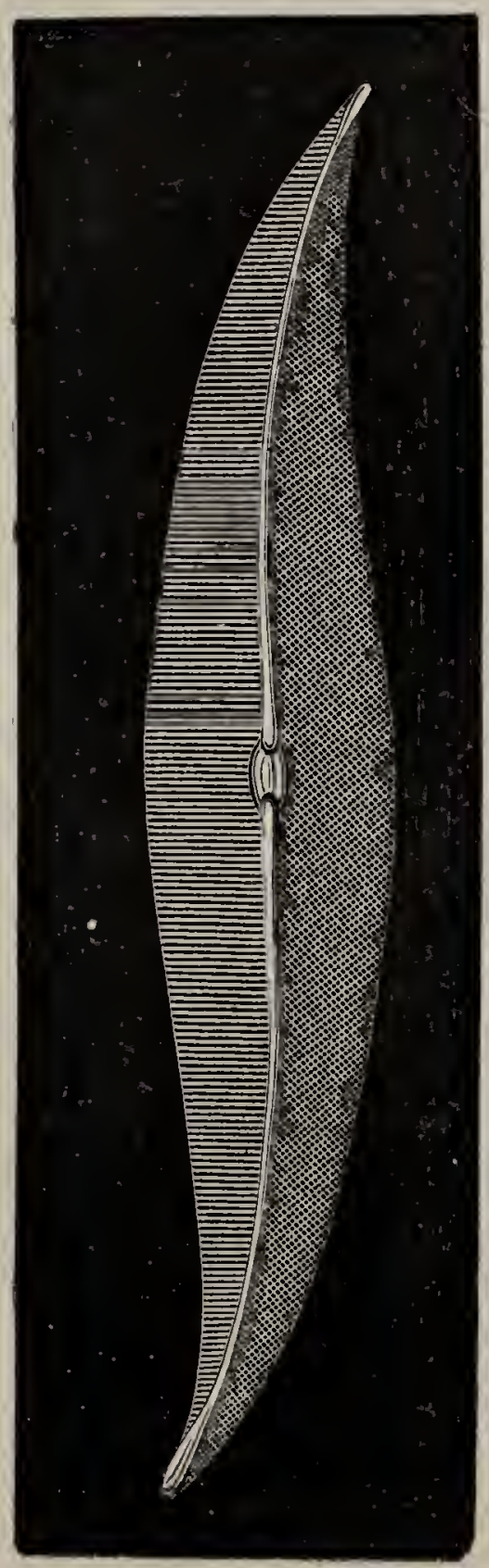

Fig. 12. sur les secondes, des marques en forme de virgules terminées par une pointe fine (fig. 11). Si l'objectif est très-bon, elles doivent de plus montrer une ligne médiane blanche pro-

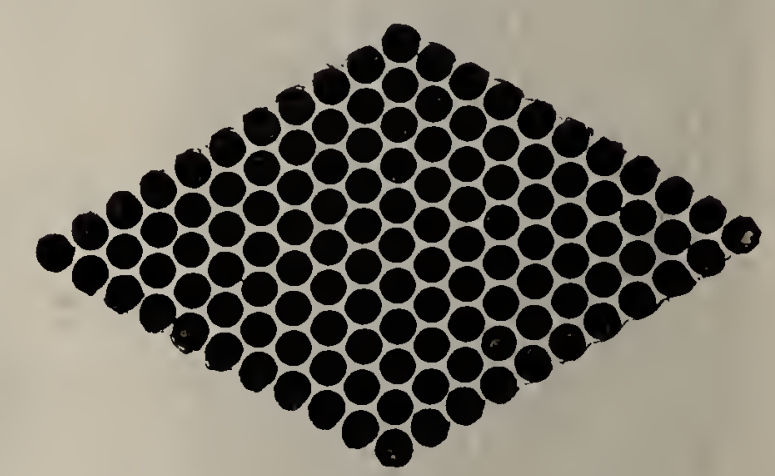

Fig. 13.

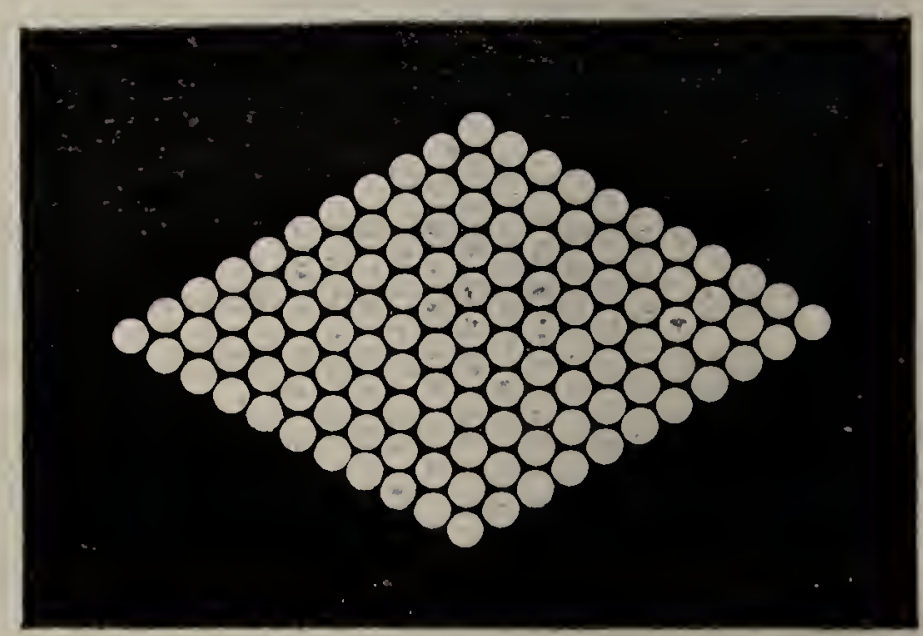

Fig. 14 .

duite par la réfraction de la substance mince et qu'un objectif incomplètement corrigé ou mal centré ne montrera jamais parfaitement (Robin, loc. cit.).

On se sert également beaucoup aujourd'hui, comme test-objets, des enveloppes siliceuses des Diatomées. - Dans l'emploi de ces test-objets on fait usage de la lumière oblique pour faire apparaître les stries les plus délicates. 
Le Pleurosigma angulatum (fig. 12) est un très-bon test pour la valeur d'objectifs puissants avec la lumière oblique. - Toutefois ces stries doivent se montrer de la façon la plus nette avec un bon objectif à immersion sous l'influence du simple éclairage central. Avec les objectifs puissants et l'éclairage oblique on aperçoit des lignes dont les unes se croisent transversalement sur l'enveloppe tandis que les autres ont une direction oblique. Avec de bons objectifs à immersion on voit que ces lignes, qui interceptent de petits espaces hexagonaux élégants et fort resserrés, sont en réalité des séries de ponctuations rondes (fig. 13 et 14). Le Surirella gemma, le

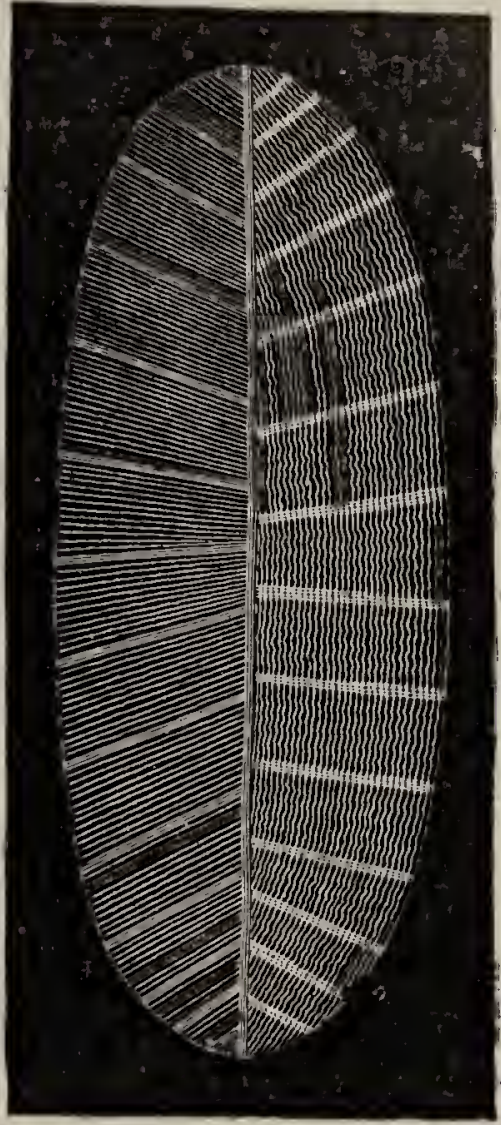

Fig. 15. Grammatophora subtilissima, le Navicula affinis (fig. 1s et 16) etc., sont des test-objets d'une exquise délicatesse.

\section{§ 14. DES QUALITÉS DE LA PARTIE MÉCANIQUE D'UN BON MiCROSCOPE.}

La forme du pied d'un microscope importe peu, ce qu'il faut exiger, c'est un pied lourd et pesant, condition absolument nécessaire pour la stabilité de l'instrument et la facilité des observations. Il n'est pas nécessaire que la colonne soit à inclinaison, cette modification n'ayant d'autre avantage que d'éviter à l'observateur de pencher la tête pendant l'examen microscopique, position un peu fatigante au début, mais à laquelle on s'habitue très-rapidement.

La plus grande attention doit être apportée à l'examen du tirage du tube et du mouvement de la vis micrométrique; le tirage doit s'effectuer facilement, avec douceur, en même temps que le tube reste assez fortement retenu dans le corps pour ne pas tomber sur la préparation ou se déplacer trop faci- 
lement. La vis micrométrique doit manœuvrer facilement. Enfin l'éclairage de l'objet doit absolument s'effectúer au moyen d'un miroir monté sur pied articulé de façon à pouvoir prendre la lumière dans tous les sens. Nous ne parlons que pour mémoire du centrage du microscope. Les bons constructeurs auxquels on doit toujours avoir recours ne livrent pas d'instruments défectueux sous ce rapport, et il serait d'ailleurs facile de s'apercevoir de ce défaut. Qu'on examine en effet avec le microscope monté le plus petit trou du diaphragme, si le centrage a été exactement fait, on devra apercevoir cette ouverture exactement au milieu du champ de vision.

\section{$\S 15$. SOINS A DONNER AU MICROSCOPE.}

Lorsqu'on est en possession d'un bon microscope, si l'on veut lui conserver toutes ses qualités, on doit l'entretenir avec toute la sollicitude possible.

$1^{\circ}$ Partie optique. - Pour les objectifs et les oculaires, il suffit de nettoyer les verres extérieurs. Celte opération pour les objectifs doit s'opérér de la façon suivante : on prend un linge très fin, de la mousseline ou de la toile fine usée, on en recouvre la pulpe du pouce dé la main gauche; puis, saisissant l'objectif avec la main droite, on pose doucement la lentille inférieure sur le linge et l'on fait tourner l'objectif en appuyant légèrement. Si l'on prenait de trop gros linges et si l'on appuyait trop fort en essuyant, on risquerait de rayer la lentille et de détériorer l'objectif. Lorsque la lentille inférieure de l'objectif est souillée de matière grasse, ou encore, comme cela arrive souvent, par les vernis employés dans les préparations, au lieu d'employer un linge sec, on humecte ce linge d'une goutte d'alcool, et l'on débarrasse ainsi l'objectif de toute impureté. Il faut avoir soin toutefois de n'employer jamais qu'une faible quantité d'alcool, de peur que ce liquide, ne venant à pénétrer dans l'objectif, dissolve le vernis qui sert à souder les deux verres de crown et de flint dont est formée la lentille.

Si la lentille supérieure de l'objectif paraît souillée de poussière, on se contentera avec un pinceau de la brosser légèrement. Nous recommandons également de se livrer aussi rare- 
ment que possible au soin de démonter l'objectif pour en nettoyer les diverses pièces: ce nettoyage exige trop de délicatesse et il vaut mieux confier de temps en temps l'instrument au construcleur pour lui faire subir un nettoyage complet, que de se livrer soi-même à cette opération.

Les soins que l'on doit apporter au nettoyage des lentilles de l'oculaire sont les mêmes que ceux que nous venons d'indiquer pour les objectifs.

D'ailleurs, pour éviter que les objectifs et les oculaires ne se remplissent de poussière, on doit toujours avoir soin de les renfermer dans les boîtes qui leur sont destinées, ou bien si l'on veut éviter de démonter le microscope après l'observation, il suffit de le recouvrir d'un globe de verre qui le mette à l'abri de toute détérioration.

$2^{\circ}$ Partie mécanique. - Après un usage un peu prolongé, il arrive souvent que le glissement du tube dans le canon du microscope s'opère avec difficulté. Au lieu d'un mouvement doux et moelleux on n'obtient plus qu'un mouvement dur et sac. cadé ; on risque alors, n’étant plus bien maître du glissement, d'écraser les préparations, et par suite aussi de détériorer l'objectif; pour rendre au tube son mouvement normal, il suffit, après l'avoir tiré hors du canon, de l'essuyer avec un linge bien sec, de manière à le débarrasser complètement d'une sorte d'enduit noirâtre qui le recouvre. Lorsque sa surface est redevenue polie, on l'enduit très légèrement d'huile de pied de bœuf au moyen d'un linge imprégné de cette substance, enfin on l'essuie encore au moyen d'un linge sec. La face interne du canon est également nettoyée, et, ces précautions prises, le glissement s'effectue avec facilité.

Ajoutons, pour terminer, que l'instrument ne doit jamais être renfermé dans sa boîte sans avoir été soigneusement essuyé avec un linge sec ou une peau de daim.

\section{$\S$ 16. MANIEMENT DU MICROSCOPE.}

Quand on veut observer un objet, on doit tout d'abord installer le microscope d'aplomb sur une table solide afin d'éviter autant que possible les trépidations, puis on procède avec méthode à l'observation. 
Avant de placer l'objet sur la platine on s'occupe de l'éclairage; puis la préparation étant disposée au-dessus de l'orifice de la platine, on procède à la mise au point.

$1^{\circ}$ Éclairage. - Quand on emploie la lumière du ciel, il faut éviter de projeter sur la préparation des rayons solaires qui donnent un éclairage tellement éblouissant qu'il est absolu-. ment impossible de s'en servir. Un ciel bleu n'est pas très propice aux observations microscopiques. La meilleure lumière est celle que donnent les nuages blancs élevés; les nuages gris donnent souvent si peu de lumière qu'il est nécessaire d'avoir recours à une lumière artificielle.

Ce qu'il faut exiger des lumières artificielles, c'est l'intensité et la fixité. Une flamme vacillante cause beaucoup de fatigue. On a construit des lampes spéciales pour l'éclairage au microscope, mais en réalité pour les observations ordinaires une bonne lampe carcel est amplement suffisante.

Ajoutons enfin que, lorsqu'on fait usage de grossissements puissants, on trouve un grand avantage à placer devant l'œil un écran. En effet, l'image étant assombrie par suite du fort grossissement que l'on emploie, on se trouve trè̀s gêné par les rayons lumineux qui, tombant sur l'oculaire et pénétrant-dans l'œil, rendent l'image déjà obscure encore plus confuse.

On peut observer l'objet soit au moyen de la lumière transmise, soit au moyen de la lumière réfléchie.

Éclairage par la lumière transmise. -1 . Éclairage direct. - - Il s'exécute au moyen du miruir fixé sous la platine. Un miroir plan suffit pour les faibles grossissements; dans le cas de puissants grossissements, on emploie le miroir concave.

Le microscope étant installé et le tube monté, on dirige le miroir en regard d'un nuage blanc ou d'une muraille blanche qui ne reçoit pas directement les rayons du soleil, et on lui donne l'inclinaison voulue pour qu'il envoie le faisceau réfléchi dans l'axe du microscope. On l'élève alor's ou on l'abaisse jusqu'à ce que le sommet du cône formé par les rayons réfléchis atteigne le plan de la platine où sera placée la préparation; on obtient alor's le maximum d'éclairage. 
Mais souvent on prérère n'avoir point une lumière très intense qui, en ébranlant trop vivement la rétine, l'empêche d'être impressionnée par l'ombre très pâle des contours délicats de certains éléments (cils vibratils, par exemple). On dit alors que les objets sont noyés dans la lumière. Pour diminuer l'éclairage, il suffit d'abaisser ou de relever un peu le miroir de manière à reporter au delà de l'objet le sommet du cône formé par lès rayons lumineux. - On y arriverait encore en supprimant une partie des rayons auxquels l'orifice de la platine livre passage. On emploie pour cela les diaphragmes dont nous avons parlé plus haut (page 12). Lorsqu'on emploie de forts grossissements, il est bon de faire usage des diaphragmes à petit orifice.

1. Éclairage oblique. - Souvent on peut faire apparaître par l'éclairage oblique des détails que l'on ne saisit qu'imparfaitement par l'éclairage direct. C'est ce qui a lieu par exemple quand on observe les stries fines de beaucoup de Diatomées. Pour obtenir cet éclairage, on se sert encore du miroir placé sous la platine, mais alors on étend les articulations qui le portent, et on l'incline de manière que le faisceau réfléchi, au lieu de se diriger suivant l'axe du microscope, soit rejeté sous un angle plus ou moins ouvert en dehors de cet axe. Pour procéder à cet éclairage, on doit avoir retiré tout diaphragme.

Écla irage par la lumière réfléchie. - Lorsque l'objet qu'on examine au microscope est opaque, on l'éclaire au moyen d'une loupe qu'on dispose de telle sorte que l'objet à observer se trouve à peu près à son foyer. Dans ces circonstances on ne peut faire usage que d'objectifs à faible grossissement, car les forts objectifs ayant un foyer très-court se trouvent très près de l'objet et empêchent l'arrivée de la lumière qu'on pourrait projeter au moyen de la lentille.

$2^{\circ}$ Mise an point. - Lorsque l'éclairage de l'objet a été obtenu comme nous venons de l'indiquer, on place la préparation sur la platine et l'on procède à la mise au point. Celte opération s'exécute, comme nous l'avons déjà dit, par deux mouvements : l'un, le mouvement rapide, qui consiste à faire glisser le tube du microscope dans l'anneau qui le contient; 
l'autre, le mouvement lent, qui s'exécute au moyen de la vis micrométrique.

Le mouvement rapide demande certaines précautions; en effet, en faisant descendre brusquement le tube du microscope on risque de briser la préparation entre l'objectif et la platine. Le commençant fera bien, avant d'appliquer l'œil à l'oculaire, de faire glisser le tube jusqu'au voisinage de la préparation, en surveillant celle-ci; quand il croira être arrivé assez près de la lamelle, il placera l'œil sur l'oculaire et, s'il aper'çoit assez nettement l'objet cherché, il terminera de mettre au point au moyen de la vis micrométrique. On verra dans quel sens on doit tourner la vis, à l'aspect que la préparation prend après un ou deux tours de vis. Si celle-ci devient plus nette, on continuera dans le sens adopté; si au contraire elle semble se troubler davantage, on changera le sens. $\mathrm{Si}$, après un certain nombre de tours de vis on n'apercevait point encore la préparation avec netteté, on devrait revenir au mouvement rapide et faire glisser un peu davantage le tube vers la préparation ou plus loin d'elle, car on ne doit pas oublier que la vis micrométrique ne doit servir que pour de très faibles distances à faire parcourir à l'appareil optique. D’ailleurs au bout d'un certain temps on arrive très-aisément à mettre exactement au point en se servant uniquement du mouvement de glissement du tube.

Lorsque la préparation est mise au point, on ne doit pas cesser de tenir la main sur le pignon qui fait manœuvrer la vis micrométrique. Cette seule position de la main décèle un observateur exercé. En effet toute préparation, si mince qu'elle soit, présentant toujours plusieurs plans superposés, il faut faire mouvoir presque continuellement la vis, de quantités très petites, il est vrai, de manière à élever ou abaisser l'objectif pour étudier la préparation dans toute son épaisseur.

En même temps que l'une des mains est occupée à faire mouvoir la vis micrométrique, l'autre ne reste pas inactive. On saisit en effet avec cette main le verre porte-objet, et on fait mouvoir la préparation de manière à en porter successivement toutes les parties sous l'objectif. Ce mouvement de glissement de la préparation sur la platine s'exécute en saississant 
le porte-objet entre le pouce et l'index de la main libre, le coude étant solidement fixé sur la table.

Les manœuvres que nous venons d'indiquer sont extrêmement faciles quand on observe avec un objectif d'un faible pouvoir grossissant. On ne risque point en effet d'écraser la préparation puisque le verre objectif doit être très éloigné de la préparation. Au contraire, lorsqu'on fait usage de forts grossissements, l'objectif se trouvant très rapproché de la préparation, sa mise au point offre de plus grandes difficultés. Aussi conseillons-nous, lorsqu'on veut examiner une préparation, de l'observer d'abord au moyen d'un objectif modérément puissant; on s'habitue alors à la manœuvre, et si l'on vient à employer un objectif plus puissant, l'observation gagne en précision. Le conseil que nous donnons ici s'applique encore à la circonstance suivante : lorsque l'objet qu'on doit examiner est très petit, il est souvent très difficile de le retrouver dans la préparation lorsqu'on se sert d'un objectif puissant. Au contraire, avec un faible grossissement, on a bien vite parcouru tout le champ de la préparation. Lorsqu'on aperçoit l'objet cherché, on le place autant que possible au centre même du champ du microscope, et l'on fixe la plaque de verre avec les valets. On change alors l'objectif, et si la préparation a été exactement placée dans le prolongement de l'axe du tube, on l'apercevra aussitôt que la mise au point aura été obtenue. Si l'on n'apercevait point immédiatement la préparation, de trèspetits mouvements de latéralité imprimés au porte-objet ne tarderaient pas à l'amener sous l'objectif.

Lorsque l'examen de l'objet microscopique est achevé, on doit relever légèrement le tube avant d'enlever la préparation. On risquerait en effet, sans cetle précaution, de souiller l'objectif qui est très rapproché du verre couvre-objet; une secousse maladroite imprimée à ce dernier suffirait à le déplacer, ct la lentille pourrait toucher le liquide qui sert à monter la préparation.

On se sert ordinairement de l'œil gauche pour l'examen microscopique. Ce n'est là d'ailleurs qu'une affaire d'habitude, l'œil droit pouvant être exercé aux mêmes observations. Quoi qu'il en soit, l'œil qui n'est pas employé doit 
être fermé, sans quoi on obtient des effets de double vue, qui sont très-gênants, et auxquels on ne s'habitue que très difficilement.

Quant à l'interprétation des images que l'on observe au microscope, c'est là, il faut bien le dire, la partie la plus importante dans la question qui nous occupe. L'exercice joue le plus grand rôle à ce sujet. Nous renvoyons pour les notions théoriques à l'ouvrage de M. Robin, page 444 et suivantes, loc. cit. Nous parlerons plus loin de certaines illusions d'optique contre lesquelles il est bon de se mettre en garde, et qu'il nous suffira d'ailleurs de signaler pour mettre le lecteur à l'abri des erreurs qui pourraient en naître.

\$ $1 \%$ Reproduction des images a L'Aide de LA Chambre clatre.

Lorsqu'on a obtenu une image nette d'un objet, il est bon d'en prendre le dessin. Gette opération peut s'exécuter au moyen d'instruments nommés chambres claires. Les modèles de ces appareils sont nombreux. La chambre claire d'Oberhauser (fig. 6) s'applique aux microscopes verticaux et les

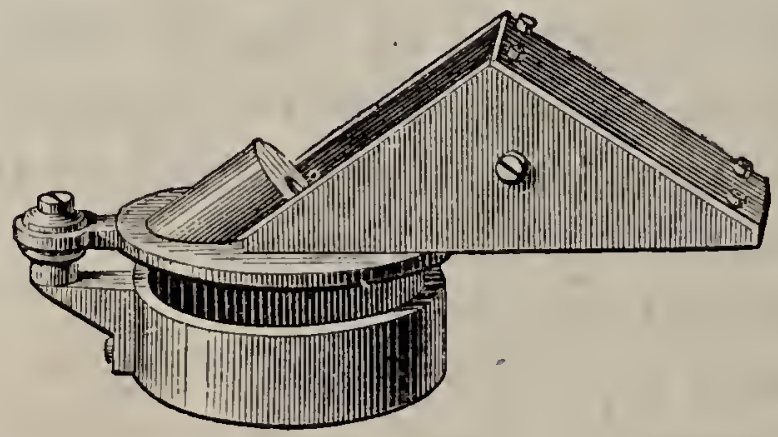

Fig. 17 .

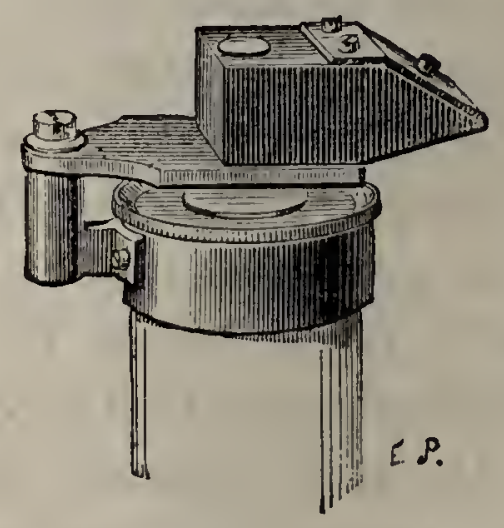

Fig. 18.

transforme en microscopes horizontaux. La chambre claire de Chevalier (fig. 17), celle de Nachet (fig. 18), s'appliquent également aux microscopes verticaux. Quelles que soient d'ailleurs les différences qui existent entre ces appareils, ils sont construits sur le même principe : faire pénétrer dans l'œil par une partie de la pupille l'image de l'objet et par une autre partie de la pupille, les rayons émanés du papier sur lequel on dessine et qui ont nécessairement subi une ou plusieurs réflexions. L'œil 
aperçoit à la fois et superpose l'image de l'objet et celle du papier.

Chambre claire. - La chambre claire de Nachet, qui s'applique aux microscopes verticaux et reporte néanmoins l'image sur un plan horizontal, est aujourd'hui la plus employée. Cette chambre claire se compose essentiellement d'un prisme dont la section est un parallélogramme, qui est fixé de telle sorte que l'une de ses faces obliques soit placée devant l'oculaire. Sur cette face est collé un autre petit prisme qui, recevant normalement les rayons sortant de l'oculaire, les renvoie aussi normalement sur le premier prisme. De la sorte, les rayons émanés de l'oculaire ne subissent pas de déviation.

D'autre part, les rayons émanés du papier, arrivent à l'œil parallèlement à ceux qui viennent de l'objet, mais après avoir subi deux réflexions totales sur les faces parallèles obliques du premier prisme.

Ges prismes sont logés dans une garniture métallique soutenue par un collier destiné à s'adapter au tube de l'oculaire.

Emploi. - Voici comment on procède pour faire usage de cette chambre claire : l'appareil étant adapté au tube du microscope, on place à droite du microscope, sur la table, la feuille de papier où doit être fait le dessin, et l'on saisit de la main droite le crayon dont on approche la pointe de la surface du papier ; l'œil appliqué au-dessus de l'ouverture de la chambre claire reçoit par une des moitiés de la pupille, les rayons partis de l'objet, et par.l'autre moitié ceux que le papier et la pointe du crayon lui envoient dans la même direction. On aperçoit donc à la fois et superposés le contour de l'image et la pointe du crayon; on n'a plus qu'à faire glisser cette dernière en suivant toujours bien l'image pour la reporter sur le papier.

Lorsqu'on n'est pas encore habitué à se servir de la chambre claire, les contours que l'on trace sont toujours plus ou moins tremblés. On arrive toutefois assez rapidement à obtenir des tracés nets et bien définis. Ce qui rend difficile aux commençants l'usage de la chambre claire, c'est qu'au moment où ils croient saisir les deux images du crayon et de l'objet superpo- 
sées, l'une de ces images disparaît. Cela tient le plus souvent à ce que l'une d'elles est, trop éclairée par rapport à l'autre.

Quand c'est le papier qui est trop éclairé, les nombreux rayons qu'il envoie à l'œil éblouissent la rétine et effacent l'impression produite par l'image plus sombre de l'objet. Le papier et le crayon apparaissent seuls alors. Si au contraire c'est l'objet qui est trop éclairé, l'image du papier et du crayon disparaissent. Le point capital est donc d'équilibrer les deux lumières en diminuant graduellement l'intensité de celle dont l'éclat prédomine.

La disparition de l'une des images peut encore tenir au peu de fixité de la tête de l'observateur alors qu'il n'est pas habitué à cet exercice. La tête se portant inconsciemment à droite ou à gauche, en avant ou en arrière, l'œil se déplace et il faut tâtonner pour retrouver la bonne positi on qu'on ne doit plus abandonner jusqu'à ce que le dessin soit achevé. G'est là une affaired'habitude.

Enfin, il ne faut pas oublier que la grandeur de l'image sur le papier augmente avec la hauteur de l'œil au-dessus de ce papier. Il faut s'arranger de manière à ce que cette hauteur soit invariable, si l'on veut avoir des observations comparables.

D'après ce que nous avons dit, le choix du papier à employer pour les dessins des images vues au microscope, doit être fait judicieusement. Le papier blanc donne souvent trop de lumière; on emploiera donc avec avantage les papiers de couleur grise, ou si l'on emploie un papier blanc on aura soin d'en affaiblir l'éclat en plaçant au-devant de lui un écran, ou tout autre objet qui projette de l'ombre à sa surface. Le grain du papier doit être très fin et sa surface lisse, car les contours des objets que l'on reproduit sont d'une très grande délicatesse. G'est pour la même raison que le choix des crayons est fort important. Ges crayons doivent être assez durs pour permettre des traits excessivement fins ; s'ils étaient trop mous, ils s'écraseraient et l'on obtiendrait des contours épais et mal définis. La pointe du crayon doit être entretenue aussi fine que possible. On y arrive très bien en usant la mine sur des papiers à émeri.

Les reproductions des images observées au microscope ont 
une très-grande importance. Pour l'étudiant c'est le meilleur moyen de se graver dans l'esprit les particularités qu'il étudie. En faisant le dessin il observe souvent bien des choses qui lui échappaient; il cherche, pour mieux voir ce qui lui paraît obscur et compléter son dessin, à faire de meilleures préparations et il acquiert ainsi bien vite une grande habileté. Plus tard, un dessin exact est indispensable pour corroborer une observation personnelle et faire saisir clairement une explication. Ces dessins, pour avoir une valeur réelle, exigent-plusieurs qualités.

Tout d'abord le dessin doit être parfaitement exact, c'est-àdire, que ses contours doivent représenter sans aucune différence ceux de l'image vue au microscope.

Il doit être la reproduction fidèle de ce qui existe et de ce que l'on voit, et non pas, comme on le fait trop souvent, une sorte de schéma, c'est-à-dire la reproduction d'une idée. Des dessins artistiques ne sont pas à dédaigner, mais il faut se défier du trop grand désir de faire quelque chose qui plaise à l'œil ; on est alors souvent entraîné à s'écarter de l'exacte vérité ; sans vouloir insister trop longtemps sur ce sujet, nous croyons cependant nécessaire de donner ici quelques notions au sujet de la manière dont on doit opérer.

Il est bon, lorsqu'on représente l'image d'une préparation, d'en prendre deux dessins, l'un d'ensemble, l'autre des détails.

Le dessin d'ensemble présente de grandes difficultés, d'autant plus que l'objet tout entier offre souvent un trop grand diamètre pour être facilement représenté au moyen de la chambre claire. De plus il demande un peu de goût artistique. Outre les rapports de grandeur et de forme à observer, on doit tenir compte encore de la position de l'objet, de la perspective, des ombres, etc. ; la question des ombres est surtout importante quand il s'agit d'objets opaques; on a alors l'habitude d'éclairer l'objet du côlé gauche, l'ombre doit donc être portée du côté droit. On pourrait croire que lorsqu'on examine des coupes très-fines, il n'y a pas d'ombres. C'est là une erreur ; l'ombre en effet est encore sensible au bord de l'ouverture des vaisseaux, ou des cellules dans les coupes des tissus. Plus la lumière tombe normalement sur la coupe, plus les ombres sont faibles il est vrai, mais il ne faut pas oublier GUIDE DE MICROGRAPUIE. 
que pour apercevoir très-nettement des coupes excessivement fines, on éclaire un peu obliquement, et alors les ombres deviennent plus sensibles. Or, toutes ces ombres doivent être reproduitesdans le dessin, et si l'on a soin de les bien appliquer comme on les voit, on obtient des représentations très fidèles des objets. Lorsque le dessin d'ensemble est terminé, on s'occupe de reproduire à un plus fort grossissement les particularités les plus intéressantes de la préparation.

Un bon dessin d'une image microscopique est donc la preuve d'une observation attentive; et l'on peut dire qu'avec de la patience tout observateur peut devenir rapidement un bon dessinateur. Pour notre part, nous avons vu dans les laboratoires de l'École de pharmacie des élèves sérieux acquérir trèsrapidement un véritable talent, et l'on pouvait suivre avec le plus grand intérêt, à la fin de l'année, sur l'ensemble de leurs dessins, les progrès qu'ils avaient faits uniquement par la patience et l'observation.

Il est bon d'accompagner les dessins de la valeur du grossissement avec lequel ils ont été exécutés.

\section{$\S 18$. APPAREILS ACCESSOIRES.}

\section{A. instruments poụr faire les coupes.}

Les objets que l'on observe au microscope sont généralement trop épais pour pouvoir être examinés sans préparation par la lumière transmise. On les réduil alors en tranches minces au moyen d'instruments divers appropriés au volume des objets et à leur dureté.

$1^{\circ}$ Rasoirs. - Les rasoirs employés à faire les coupes des tissus animaux et végétaux doivent être d'excellente qualité et bien trempés. Il est Joon de les choisir avec une face plane; le tranchant des rasoirs s'use rapidement, et comme on ne peut faire de bonnes coupes qu'à la condition d'aroir un tranchant très fin, il est nécessaire de les affiler à chaque préparation. Le plus souvent il suffit de les passer plusieurs fois sur une boune pierre à aiguiser, puis sur le cuir à affiler. Nais de temps en temps il faut aiguiser son rasoir à fond, si l'on peut s'expri- 
mer ainsi, et il n'est que trop vrai de dire qu'il n'existe à Paris aucun fabricant d'instruments de chirurgie (ce sont eux qui fabriquent les rasoirs en question), qui soit capable de livrer un rasoir en bon élat. Il vaut bien mieux s'habituer soi-même à ce travail ; voici un excellent procédé que M. Duchartre enseigne dans ses conférences au laboratoire de botanique de la Sorbonne et que nous ne saurions trop recommander. On se procure un disque de verre dépoli, et deux ou trois numéros des plus fins tripolis. Le rasoir ayant été aiguisé sur une bonne pierre, on le passe successivement sur deux ou trois pâtes de plus en plus fines de tripoli et d'huile, puis finalement sur le disque de verre dépoli recouvert d'une mince couche d'huile. On essuie le rasoir, et si l'opération a été faite avec soin, on obtient un excellent tranchant.

$2^{\circ}$ Microtomes. - Le rasoir est un bon instrument pour faire les coupes sur les objets qui n'offrent pas une trop grande résistance. Mais si l'on a affaire à des corps durs (tiges, racines, etc.), la résistance qu'opposent ces corps au rasoir devient un obstacle fâcheux. La main qui dirige le rasoir, tout occupée à vaincre l'obstacle, change insensiblement de direction, el l'on obtient des coupes d'épaisseur diverse en différents points, et obliques plus ou moins par rapport à la direction que l'on désire leur donner. D'autre part il est difficile de maintenir entre les doigts l'objet qui résiste au rasoir; aussi a-t-on construit divers instruments qui tendent à supprimer ces causes d'imperfection des coupes. Le plus simple, et à coup sûr l'un des plus commodes, est le microtome à main de M. Ranvier: Get appareil se compose d'une platine circulaire en métal recouverte ou non d'une lame de verre. Au centre de cette platine est une ouverture circulaire qui est en même temps l'orifice d'un cylindre de Jaiton fixé perpendiculairement au-dessous de la platine. C'est dans ce cylindre que l'on place la préparation fixée, comme on le dira plus loin, dans la moelle de sureau ou la paraffine. A la partie inférieure du cylindre se trouve une vis graduée terminée supérieurement par un plateau sur lequel repose l'objet à diviser; on tient l'instrument à pleine main par le cylindre, et en tournant la vis d'une quantité convenable, on fait affleurer l'objet au 
niveau du plan de la platine. Avec un rasoir à face plane on fait une première coupe pour égaliser la surface de l'objet; puis en tournant la vis, on soulève l'objet. La face plane du rasoir étant exactement maintenue appliquée sur la

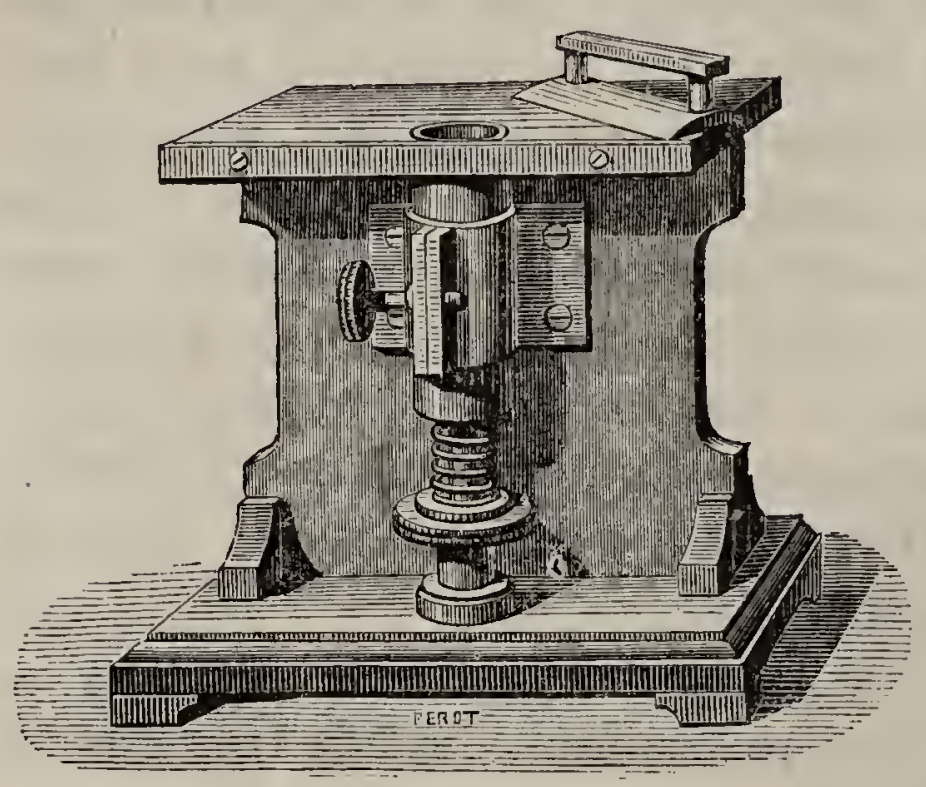

Fig. 19 .

platine, on coupe toute l'épaisseur de l'objet qui dépasse au-dessus de la platine. On peut obtenir ainsi des coupes aussi fines que l'on veut, et si l'objet a été bien assujetti dans le cylindre du microtome, il ne se dérangera pas, même s'il présente une certaine dureté, et la coupe conservera le sens qu'on aura voulu lui donner. On livre avec le microtome des cylindres de cuivre de plus petite ouverture qu'on introduit dans le précédent lorsqu'on veut agir sur de petits objets qu'il serail difficile de maintenir dans un cylindre d'un trop grand diamètre. Le microtome de M. Nachet que nous reproduisons ici (fig. 19) repose sur les mêmes principes.

\section{B. ACGESSOIRES DIVERS.}

$1^{\circ}$ Pinces, ciseaux, aiguilles, etc. - Quand on fait des préparations microscopiques, il faut être muni de pinces diverses, les unes droites, les autres courbes; de ciseaux qui ne sont autres d'ailleurs que ceux qu'on emploie en général dans les dissections. Enfin pour dissocier les éléments sur les porteobjets avant de les examiner, ou pour les dissections à la loupe, on se sert d'aiguilles montées qu'il faut choisir inflexibles et à pointes très-acérées. On se sert également dans certains cas d'aiguilles tranchantes, dans le genre des aiguilles à cataracte et d'aiguilles courbes ou terminées d'un crochet à leur extrémité. 
$2^{\circ}$ Cristallisoirs, verres de montre, etc. - On emploiera pour placer les coupes avant de. les monter de petits baquets de verre semblables à des cristallisoirs, ou des verres de montre. Tantôt on y laissera les coupes prur leur faire subir l'influence de réactifs divers, tantôt pour qu'elles s'y étalent à l'aise dans le véhicule choisi, avant d'être placées sur le porte-objet.

$3^{\circ}$ Plaques ou lames de verre. - On en emploie de deux sortes: les unes. sur lesquelles on dépose l'objetà observer, reçoivent le nom de lames porte-objets; les autres, qui servent à recouvrir les préparations sont, appelées lamelles ou couvre-objets.

\section{Lames porte-objets.}

Elles doivent être en verre parfaitement poli et planes sur les deux faces. Leur épaisseur ne doit pas dépasser 1 à 2 millimètres. Elles sont généralement taillées sous forme de bandes de 72 à 70 millimètres de longueur sur 24 à 200 millimètres en largeur. D'ailleurs ces dimensions peuvent être augmentées suivant les besoins.

\section{Lamelles ou couvre-objets.}

Ces lamelles sont carrées ou circulaires. Leur épaisseur doit être appropriée au grossissement que l'on emploie. Les plus minces seront réservées pour les forts grossissements.

La délicatesse même de ces lamelles exige certaines précautions dans leur maniement. Comme les porte-objets, les couvreobjets doivent, avant d'être employés, être soigneusement nettoyés afin qu'aucune poussière ou impureté ne les souille. Les porte-objets sont faciles à nettoyer. S'ils sont gras, une goutte d'alcool leur rendra leur transparence. Pour les couvreobjets, on devra, après les avoir plongés dans l'eau ou l'alcool, les étendre sur plusieurs doubles de papier buvard, les y laisser sécher, puis les passer délicatement sur un linge fin tenu entre le pouce et l'index. Avec un peu d'habitude on arrive très vite à les nettoyer sans les briser.

L'utilité des lamelles dans les observations microscopiques est incontestable. Non seulement elles protègent les préparations contre la poussière, mais encore elles empêchent l'évaporation ou l'altération des véhicules employés pour mon- 
ter les préparations. Enfin et surtout, l'usage essentiel des couvre-objets est de faire que, dans les préparations vues à l'aide de la lumière transmise, la surface d'entrée et la surface de sortie des rayons lumineux soient parallèles. Sans le couvre-objets, la direction des rayons sortant de la préparation pour pénétrer dans l'objectif ne serait pas parallèle à la direction de leur incidence; ils seraient déviés à leur émergence dans l'air en diverses directions, proportionnellement aux courbures et à l'irrégularité des surfaces des objets qu'ils traversent. Tous n'iraient plus frapper l'objectif, ou, ne lui arrivant plus parallèlement, ils ne donneraient qu'une image confuse des corps. Il est du reste facile de le constater en examinant successivement la même préparation à découvert, puis avec une lamelle.

\section{$\S 19$. PRÉPARATION DES OBJETS MICROSCOPJQUES.}

Nous ne nous occuperons dans ce paragraphe que de la préparation des éléments et des tissus des végétaux. Les détails nécessaires aux préparations animales que comporte cet ouvrage seront exposés plus loin.

Lorsqu'on veut examiner au microscope un tissu ou quelque partie de plante, il faut avoir recours à une série de préparations que nous allons décrire:

$1^{\circ}$ Si l'objet à examiner présente une certaine épaisseur, el qu'on veuille en étudier la structure intime, il faut pratiquer des coupes minces sur cet objet; ou faire des dilacérations, s'il y a lieu;

$2^{\circ}$ Les coupes doivent ensuite être soumises aux réactifs convenables;

$3^{\circ}$ Enfin la préparation doit être montée pour l'observation, c'est-à-dire placée dans un liquide conservateur, recouverte d'une lamelle, que l'on scelle au porte-objet de manière à éviter l'évaporation ou l'altération du liquide choisi comme véhicule.

Nous allons décrire en détail ces diverses opérations :

$1^{\circ}$ Exécution des coupes minces. - Plusieurs conditions doivent être remplies si l'on veut obtenir de bonnes coupes: 
1. Il faut avoir de bons instruments; nous avons indiqué plus haut quelles sont les qualités que l'on doit en exiger;

2. Il faut agir sur des corps d'une consistance déterminée. On n'obtiendra jamais de bonnes coupes sur des corps mous; les corps très durs présentent également de grands obstacles. Il faut autant que possible agir sur des corps assez consistants pour se laisser trancher sans céder devant l'instrument, et assez tendres pour ne pas lui résister trop énergiquement.

-Pour atteindre ce but, on durcit les corps mous au moyen, de réactifs appropriés (voir page 43), et l'on ramollit les corps durs soit par l'ébullition dans l'eau (graines sèches), soit par macération dans une eau alcaline (bois durs).

Les coupes sur les objets friables sont extrêmement délicates à opérer. On se trouvera bien de les enrober dans un corps qui en agglutine les diverses parties (paraffine, gomme, etc., voir page 41); on agira de même pour les corps pulvérulents (spọres, pollen).

Quoi qu'il en soit, lorsqu'on a obtenu la consistance désirable, on peut commencer à pratiquer les coupes. On se rend bien compte du sens dans lequel on veut les diriger et l'on agit comme il suit :

Lorsque l'objet est d'un fort volume, on peut le tenir à la main, mais s'il présente un faible volume, on doit recourir à une installation particulière. Si l'objet n'est pas trop dur, on peut l'enfermer entre deux morceaux de moelle de sureau ou de liège. Voici comment cela se pratique : on prend un cylindre de moelle de sureau assez long pour être facilement tenu entre les doigts, et on le fend en deux. Puis au moyen d'une tige rigide quelconque, on détermine par pression, à l'une des extrémités de l’un des demi-cylindres ainsi obtenus, une petite cavité de grandeur suffisante pour y placer l'objet. Celuici étant logé dans la position exacte qu'on veut lui donner, on superpose par leurs faces planes les deux demi-cylindres de sureau, et les tenant entre les doigts de façon qu'ils ne se séparent pas, on plonge à plusieurs reprises dans l'eau ou l'alcool l'extrémité où se trouve l'objet à diviser. La moelle de sureau se gonfle, presse sur l'objet qu'elle renferme et le main-, 
tient ainsi solidement fixé (1). On n'a plus qu'à pratiquer les coupes avec le rasoir. Pour cela, saisissant le rasoir de la main droite, en même temps que la main gauche tient le cylindre de moelle de sureau, on applique la face plane du rasoir sur la surface libre du sureau, et d'un premier coup on enlève une tranche mince. Ce premier coup de rasoir a pour but de bien égaliser la surface à couper; du même coup on obtient une surface bien nette de l'objet. Il s'agit maintenant de mener les autres coupes de telle sorte qu'elles aient dans toute leur étendue la même épaisseur. Il faut donc que le rasoir dans sa marche suive toujours la même direction. On y arrive assez facilement, si en même temps qu'on fail avancer la lame, on se préoccupe de toujours en sentir la face plane inférieure en contact avec l'index de la main qui tient l'objet. Avec un peu d'habitude on arrive ainsi parfaitement à donner au rasoir une direction constante. Quand on fait ces coupes à main levée, les coudes doivent être parfaitement libres, et rapprochés du corps; le cylindre de moelle tenu entre l'index et le pouce dans une position perpendiculaire au plan de la table sur laquelle on opère, et le plat du rasoir parallèle à ce même plan. On devra toujours tremper le rasoir dans l'eau ou l'alcool avant de pratiquer la section; on risque sans cela de détériorer les coupes que l'on obtient.

Les commençants ont l'habitude d'examiner chaque coupe qu'ils viennent de faire. C'est là un grand tort; les premières coupes en effet ne sont jamais parfaites. Il faut pour ainsi dire que la main se fasse à l'opération qu'on exige d'elle. Aussi doit-on faire de nombreuses coupes, et l'on verra que les dernières sont toujours bien plus fines et plus propices à l'examen. Cependant, comme il ne faut rien perdre, on aura soin de réunir dans un petit baquet de verre rempli d'eau toutes les coupes que l'on fait, puis quand on en aura fait un grand nombre, on choisira les meilleures pour les observer et les conserver. Les coupes trop épaisses seront également exami-

(1) Si l'objet n'offre pas beaucoup de résistance, comme il pourrait être écrasé par le gonflement de la moelle de sureau, on le place dans une petite cavité obtenue, non plus par simple pression, mais en enlevant un morceau de moelle. 
nées, et si on leur trouve quelque intérêt, on recommencera sur un nouvel échantillon des coupes que l'on s'attachera surtout à obtenir fines au niveau de l'endroit où les premières avaient été mal réussies.

Coupes dans la paraffine. - Lorsque les objets sont très durs, la moelle de sureau ne peut être utilisée; on peut alors opérer de la manière suivante : après avoir desséché l'objet à préparer, de manière à priver complètement sa surface d'humidité, on le trempe dans la paraffine fondue, ou dans un mélange de cire et d'axonge (il est bon, quand on se sert de paraffine, de l'additionner d'un peu d'axonge). Puis on le retire pour laisser solidifier à sa surface une première couche de paraffine. En trempant ainsi le même objet à plusieurs reprises, on obtient bientôt un petit bloc de paraffine contenant le tissu à trancher, dont on a eu soin de déterminer la position exacte, afin de pouvoir plus tard diriger les coupes dans le sens convenable.

Ce bloc de paraffine est encore trop petil pour être aisément tenu entre les doigts; on le fixe alors au moyen de la même substance fondue sur un bouchon de liège, et on le dispose dans la cavité d'un tube en laiton. On coule autour une certaine quantité de paraffine fondue, et après refroidissement, on retire du tube une petite bougie contenant l'objet à trancher.

Si l'on fait usage du microtome, le cylindre de l'appareil servira de tube où l'on coulera la paraffine.

Pour faire des coupes sur les poils, les filaments de lin, de chanvre, elc., on en forme des faisceaux que l'on trempe dans la paraffine et que l'on prépare comme il vient d'être dit.

Lorsque les coupes ont été faites, il faut les débarrasser de la paraffine qui les souille. Pour cela, on les place dans la térébenthine, on les y laisse séjourner quelque temps, puis on les porte dans l'éther, et quand elles sont bien débarrassées du corps étranger, on les monte.

Coupes dans la gomme. - On peut remplacer la paraffine par une solution épaisse de gomme dans laquelle on laisse séjourner l'objet pendant quelques heures. Lorsqu'il est bien imprégné de gomme, on le plonge dans l'alcool à 90. La gomme 
durcit au bout de quelque temps. On peut alors pratiquer des coupes qu'il suffil de laisser séjourner dans l'eau pour les débarrasser de la gomme.

$2^{\circ}$ Dilacération. - Gertains objets ont besoin d'être dilacérés pour être examinés au microscope (filaments de lin, chanvre, etc.). Cette opération se prépare au moyen de réactifs appropriés, et s'effectue au moyen des aiguilles. Pour obtenir de bonnes dilacérations, on doit opérer sur de très petites portions de l'objet. Tandis qu'on le maintient fixe avec une aiguille, on opère avec l'autre des tractions légères et répétées, dans une direction telle qu'on sépare les éléments sans les briser. Gette opération demande une grande patience pour être bien faite.

\section{§ 20. RÉACTIFS.}

Nous donnerons ici une indication sommaire des principaux réactifs employés dans les obsẻrvations microscopiques des végétaux, renvoyant pour leur mode d'emploi aux détails circonstanciés que nous donnons dans le cours de l'ourrage.

Les réactifs utilisés pour l'étude des éléments et des tissus ou organes végétaux peuvent se classer de la manière suivante: d'après leur action, on distingue des réactifs colorants, durcissants, altérants.

réactifs colorants. - Carmin. - 1 ă à 30 centigrammes de carmin sont dissous dans la quantité d'ammoniaque roulue pour avoir une liqueur neutre, et on ajoute 30 grammes d'eau distillée. On filtre et on additionne de 30 grammes de glycérine et de 8 à 10 grammes d'alcool. Beaucoup d'autres formules ont été proposées; ce qu'il faut rechercher, c'est que la solution ne soit pas alcaline. Le carmin colore le protoplasma et le nucléus.

Eau iodée. - L'eau iodée que l'on obtient en laissant un excès d'iode en contact avec de l'eau distillée sert à déceler la présence de l'amidon. Associée à l'acide sulfurique, elle colore la cellulose en violet. L'eau iodée colore en jaune le protoplasma.

Chlorure de zinc iodé. - Réactif de la cellulose.

On peut préparer ce réactif de plusieur's manières; voici le 
procédé de M. Radlkofer. On fait à la température ordinaire, une solution de zinc dans l'acide chlorhydrique, on évapore à une température qui ne dépasse pas $100^{\circ}$, et on l'amène à l'état d'un sirop dont la densité soit égale à 2.0 ; on étend alors ce sirop jusqu'à le réduire à la densité de 1.8, en y ajoutant 12 parties d'eau pour 100 de solution. Dans 100 parties du liquide ainsi obtenu, on dissout, à une douce chaleur, 6 parties d'iodure de potassium et autant d'iode qu'il peut en prendre. Ainsi préparée, la solution de chlorure de zinc iodé a la consistance sirupeuse de l'acide sulfurique concentré; elle est colorée en brun jaunâtre clair. On peut l'étendre à différents degrés, selon le besoin, son action variant sensiblement avec sa concentration.

Acide nitrique. - Colore en jaune les matières azotées, surtout si l'on fait suivre son action de l'addition d'un peu d'ammoniaque.

Réactif de Milon, nitrite de mercure. - Ce réactif, qui colore en rouge les matières azotées, se prépare en dissolvant du mercure pur dans un poids égal d'acide azotique. La réaction s'établit à froid; à la fin on chauffe pour achever la dissolution du mercure. On étend ensuite la liqueur de deux volumes d'eau pour un volume de la dissolution mercurielle.

Nous indiquerons en lieu utile les réactifs colorants propres à certaines substances et que l'on obtient par l'action successive de plusieurs agents chimiques.

Réactifs durcissants. - Alcool. - L'alcool à $90^{\circ}$ durcit les tissus et coagule le protoplasma. Plus concentré, son action coagulante diminue, son action durcissante augmente. Nous verrons plus loin tout le parti qu'on peut tirer de ce réactif.

réactifs altérants. - Acide sulfurique. - S'il est assez concentré, il dissout la cellulose. Associé au sucre ou à l'iode, il devient un réactif colorant.

Acide acétique. - Get acide est employé pour éclaircir les coupes en les rendant plus transparentes, et pour décomposer le carbonate de chaux dont on veut caractériser la présence dans certains tissus végétaux.

Potasse. - Employée pour dissoudre la matière incrustante des cellules, etc. 
Oxyde de cuivre ammoniacal. - Dissout la cellulose. Ce réactif se prépare en dissolvant de l'ox́yde de cuivre récemment précipité et encore humide dans de l'ammoniaque liquide.

Chlorate de potasse. - Il sert dans le procédé de macération de Schulze. On prend l'objet:que l'on coupe en tranches minces. On les dépose sur le porte-objet et on les couvre d'une quantité de chlorate de potasse égale à leur volume, puis on ajoute quelques gouttes d'acide nitrique. La lame de verre est ensuite exposée pendant une à trois minutes à la chaleur d'une lampe à alcool. Après la réaction, on lave, en répandant à plusieurs reprises de l'eau au moyen d'un pinceau, sur la préparation. On parvient de cette façon à isoler les cellules. La macération de Schulze doit toujours se faire loin du microscope, les vapeurs qui se dégagent pouvant endommager les lentilles.

Lorsqu'on a procédé à l'application du réactif, il s'agit de monter la préparation, c'est-à-dire de la placer dans un véhicule approprié sur le porte-objet, et de la recouvrir d'une lamelle. Le véhicule a pour but d'une part de conserver la préparation, d'autre part de constituer un milieu entre les deux lamelles, dont l'indice de réfraction se rapproche de celui du verre; sans ce liquide l'effet du couvre-objet sur l'émergence des rayons transmis, dont nous avons parlé plus haut, serait à peu près nul.

\section{§ 21. véHicules ou Liquides CONSERvateurs.}

Les véhicules employés pour conserver les préparations végétales ne sont pas très-nombrieux. On est guidé dans leur choix par la nature de la préparation que l'on veut conserver. Mais il faut bien se rappeler que certains de ces véhicules qui sont inoffensifs pour une préparation donnée, deviennent de véritables réactifs pour d'autres, ainsi que nous allons le montrer.

Les liquides conservateurs les plus employés sont les suivants.

GIycérine. - On emploie la ajglycérine pure et neutre. Ce liquide agit à la fois comme conservateur et comme éclaircissant. 
CHAP. I. - DES MICROSCOPES ET DE LEUR EMPLOI. · $40 ̈$

Sa densité étant assez considérable, on ne doit pas l'employer pure lorsqu'on veut conserver sans altération des coupes de jeunes tissus, car elle contracterait le protoplasma. On l'additionne d'eau ou l'on se sert d'un autre véhicule. La glycérine est souvent additionnée de quelques gouttes d'acide acétique.

Alcool. - Il ne peut être employé puir parce qu'il agit comme réactif ; on peut en former néanmoins divers liquides conservateurs.

L'alcool créosoté. - A été employé par Thwaites pour la préparation des algues avec leur matière colorante.

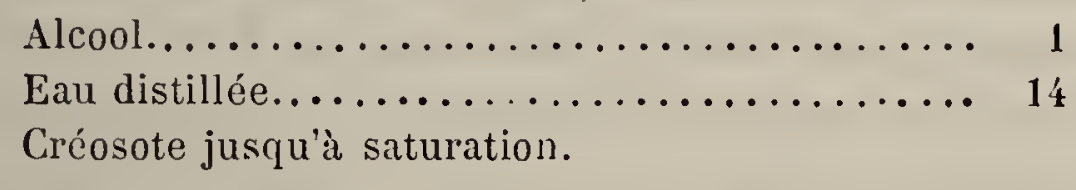

On filtre et on laisse reposer.

Eau camphrée. - Ce liquide est souvent employé pour la conservation des algues ou des préparations délicates que la glycérine pourrait altérer. On peut le préparer au moyen de l'eau et de l'alcool camphré jusqu'à précipité, ou mieux, afin d'éliminer l'alcool, en laissant dans un flacon rempli d'eau un excès de camphre en poudre, et en agitant de temps en temps.

Chlorure de calcium. - S'emploie en dissolution peu concentrée.

Chlorure de calcium sec.......... 1 partie.

Eau distillée.................. 3 -

Ge véhicule ne doit pas être employé pour conserver les préparations qui renferment de l'amidon.

Laque de Copal et IBaume de Canada. - Servent aussi pour conserver les préparations microscopiques, principalement les coupes de bois.

Ifuile fine des horlogers. - Cette huile sert à conserver certaines préparations, pollen, spores, etc. Elle est préférable aux huiles essentielles de citron ou d'anis autrefois conseillées, qui ont l'inconvénient d'attaquer les vernis employés ì clore les préparations. 
§ 22. DE LA CONSERVATION DES PRÉPARATIONS.

Transport de la préparation sur le courre-objet. - Si l'objet est mince, on dépose sur un porte-objet bien propre une goutte du liquide conservateur que l'on veut employer, et avec une aiguille plate on soulève l'une des préparations que l'on choisit dans le nombre de celles que l'on a faites, et on la dépose après l'avoir desséchée sur un morceau de papier buvard fin, dans la goutte de liquide placée sur le porte-objet. Les pinces ne doivent pas être employées pour saisir les préparations, car elles les altèrent le plus souvent. Pour retrouver des préparations très petites déposées par exemple dans un verre de montre, on place ce vase sur un fond noir. Lorsque les préparations sont très délicates, il vaut mieux, pour les monter, plonger le porte-objet dans l'eau où elles baignent, le faire passer sous la coupe que l'on choisit, puis le relever doucement. La coupe est ainsi, sans aucune traction, déposée sur le verre.

Préparation de l'objet dans le liquide conservateur. $1^{\circ}$ L'objet mince ayant été déposé, comme nous venons de le dire, dans le liquide conservateur, il n'y a plus qu'à placer la lamelle ; cette opération exige beaucoup de soin et une certaine dextérité pour éviter d'une part que l'objet ne voyage dans la goutte de véhicule et n'atteigne les bords de la lamelle, d'autre part la formation de bulles d'air qui pourraient rester emprisonnées dans la préparation. L’objet étant convenablement placé, sans bulles d'air, on enlève avec un peu de papier buvard l'excès de liquide qui dépasse les bords de la lamelle et on lute comme nous allons l'indiquer. Lorsqu'on a pris l'habitude de ces préparations, on arrive très-exactement du premier coup à ne mettre sur le porte-objet que la quantité voulue de liquide pour remplir complètement l'espace limité par la lamelle. C'est là une condition que l'on doit s'attacher avec soin à obtenir, car s'il y a trop de liquide, il est toujour's délicat de l'enlever sans faire remuer la lamelle, et on risque. alors de déplacer la préparation. Si au contraire le liquide conservateur est en trop petite quantité, il reste de l'air entre la lamelle et le couvre-objet, ce qu'il faut éviter. Dans ce der- 
nier cas on déposerait une petite goutte de liquide conservateur contre l'un des bords de la lamelle, et l'excès seräit enlevé comme précédemment.

$2^{\circ}$ Lorsque l'objet à préparer n'est pas très mince, il risque d'être écrasé entre la lamelle et le couvre-objet; on est alors obligé de maintenir un certain écartement entre ces deux verres, et de faire ce qu'on appelle une cellule.

Pour cela, avant de déposer la préparation sur le couvreobjet, on place sur celui-ci un petit cadre que l'on fait soit avec de petites bandes de papier d'étain, soit avec des lames minces de caoutchouc ou de verre d'épaisseur variable avec la profondeur qu'on veut donner à la cellule. On limite ainsi un espace de grandeur convenable pour être exactement recouvert par la lamelle couvre-objet dont les bords s'appuient sur les bandes.

Mais les cellules les plus employées sont celles que l'on fait avec les vernis. On emploie généralement le vernis de bitume de Judée (voir page 48), et voici comment l'on procède. Au moyen d'un pinceau enduit de vernis, on trace à la main ou avec la tournette (1) sur le porte-objet un cadre dont on augmente l'épaisseur jusqu'au degré voulu, en superposant plusieurs couches de vernis. On dépose au centre une goutte du liquide conservateur dans lequel on place l'objet, puis on applique le couvre-objet. Un compresseur à faible ressort est alors appliqué de manière à déterminer l'adhérence entre les bords de la lamelle et le vernis. Il ne reste plus qu'à luter la préparation.

Élimination de l'air des préparátions. - Dans la préparation des objets microscopiques, l'un des principaux obstacles que l'on rencontre consiste dans la présence d'une grande quantité de bulles d'air retenues par l'objet (poils, tissus lacuneux, etc.). Or cetair devient très gênant pour l'observation, et toute préparation bien montée doit en être débarrassée. Plusieurs procédés peuvent être employés à cet effet.

(1) Ce petit instrument dont on se passe très aisément, se compose d'un disque en cuive qui tourne sur un pivot. On place la préparation au centre du disque; on pose l'extrémité du pinceau trempé de vernis en un point déterminé par le diamètre qu'on veut donner au cadre, et l'on fait tourner le disque. Le pinceau restant immobile décrit un cercle du diamètre voulu. 
Schacht (loc. cit.) indique le suivant. Avant de placer la préparation sur le porte-objet, on la plonge dans l'alcool, puis on la transporte dans l'eau et de là dans le véhicule dépusé sur la lame de verre. On peut encore employer l'acide acétique de la même manière, ou la chaleur en opérant comme il suit : On place l'objet dans une goutte d'eau sur un porte-objet, et on passe la lamelle à plusieurs reprises sur la flamme d'une lampe à alcool, on porte à l'ébullition, et on n'a plus qu'à monter la préparation comme précédemment.

Ces diver's procédés ne peuvent être toujours employés, car ils peuvent avoir quelque action nuisible sur les substances renfermées dans les cellules; on chasse alors l'air au moyen de la pompe pneumatique.

Vernis ou ciments. - On appelle vernis ou ciments des substances solides ou demi-solides qui servent à luter les préparations, c'est-à-dire à cimenter la lamelle sur le porte-objet. Pour appliquer les vernis on doit se servir de pinceaux de poils fins et bien taillés.

Vernis au bitume. - Ce vernis se prépare au moyen de bitume de Judée que l'on dissout dans l'essence de térébenthine et la benzine, ou dans tout autre liquide approprié. Le vernis suivant nous donne de bons résultats.

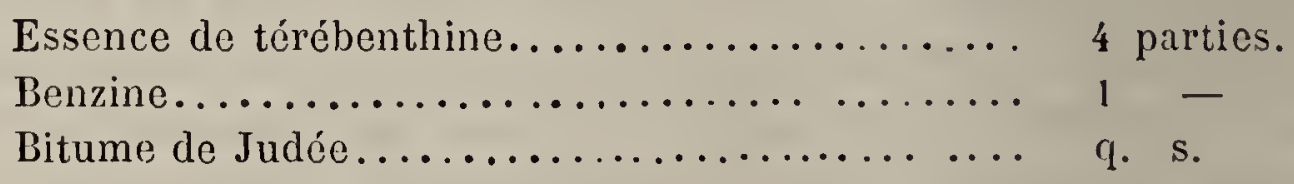

Pour obtenir un vernis de consistance crémeuse, il suffit de laisser digérer le bitume dans l'essence jusqu'à dissolution complète du bitume, en remuant de temps en temps. La formule précédente donne une préparation qui sèche assez vite et. n'est pas cassante. On lui donnerait encore plus de liant en y ajoutant quelques gouttes d'huile de lin.

Vernis à la laque. - Il se compose d'une disssolution de laque du commerce dans l'alcool. C'est un bon ciment.

Vernis au baume de Canada. - Ce vernis à peu près incolore est d'un bon usage. On le prépare de la manière suivante: on fait sécher au feu du baume de Canada jusqu'à ce qu'il soitabsolument durci et on le dissout dans l'essence de térébenthine 
rectifiée ou dans le chloroforme, de manière à obtenir un mélange sirupeux. Lorsqu'on emploie le baume de Canada pour sceller des préparations sèches, on peut l'employer sec de la manière suivante : l'objet ayant été déposé au milieu du porteobjet, on place à l'entour de petits fragments de baume solidifié. On saisit une lamelle et on la dépose sur.l'objet et les fragments de baume qui l'entourent. On chauffe doucement la préparation au-dessus d'une lampe à alcool : le baume fond et forme un cercle autour de l'objet. On appuie légèrement sur la lamelle et on laisse refroidir.

Poussières, bulles d'air, mouches volantes. - Les préparations ayant été faites comme nous venons de l'indiquer, on peut procéder à leur examen. (Il est bon d'étudier les préparations avant de les luter; si elles sont mauvaises, on les rejette ou on les améliore, ce qui ne saurait être fait, une fois le vernis posé.)

Lorsqu'on procède à l'examen des préparations, il est impossible d'éviter certaines illusions d'optique avec lesquelles on doit se familiariser. De ce nombre les unes sont dues :

$1^{\circ}$ Aux bulles d'air qui se présentent sous la forme de cercles de grandeur variable, colorés en noir sur les bords dans la lumière transmise, et en blanc à la lumière directe;

$2^{\circ}$ Aux grains de poussière, irréguliers, anguleux, souvent colorés;

$3^{\circ}$ Enfin d'autres qu'on appelle mouches volantes, sont tantôt des taches ou anneaux concentriques brillants et irisés, qui apparaissent surtout quand on a regardé le soleil ou un nuage brillant, ou qu'on s'est frotté les yeux trop fortement avant de les porter devant l'oculaire. Elles sont donc dues à un ébranlement de la réline.

D'autres mouches volantes apparaissent dans le champ du microscope sous la forme d'amas de petits globules parfaitement ronds, mélangés de quelques filaments pâles. Toutes ces images se meuvent en même temps que l'œil ; on reconnaîtra aisément que ces corps ne font pas partie de la préparation en faisant mouroir le porte-objet. Ces corps ne participeront pas au mouvement imprimé à la préparation. On arrive d'ail= 
leurs rapidement, avec un peu d'exercice, à laisser de côté ces images pour ne plus voir que l'objet lui-même.

Nous n'insisterons pas davantage sur les procédés mis en usage pour monter les préparations et les examiner. Ce que nous en avons dit doit suffire pour mettre tout observateur sérieux à même de se servir utilement d'un microscope, et l'on ne doit pas oublier que l'initiative personnelle joue un grand rôle dans ces observations. 


\section{HISTOLOGIE VÉGÉTALE}

\section{GHAPITRE II}

\section{ÉLÉMENTS ANATOMIQUES.}

"Le végétal est dans l'origine formé essentiellement d'un " simple tissu cellulaire qui subit des modifications diverses " par l'effet du développement (1). "

Gette assertion, émise pour la première fois par Mirbel, a été depuis pleinement confirmée. Nous n'avons donc à considérer qu'une seule espèce d'élément anatomique végétal, la cellule.

ÉTUDE DE LA GELLULE VÉGÉTALE.

ART. $1^{\text {er. }}$.

\section{Gẻnéralités.}

$\S 1^{\text {er. }}$

Synonymie : - Vésicule (Grew, 1682). - Utricule (Malpighi, 1686). - Vesicula, membranula, corticula (Leuwenhoeck, 1719). - Cellule (Mirbel, 1800).

Une cellule complète se compose de quatre parties distinctes (fig. 20, A), savoir :

(1) Mirbel, Mémoire sur l'origine, le développement et l'organisation du liber et du bois, in Mém. de l'Acad. roy. des sc. de Paris, 1827, t. VII. 
$1^{\circ}$ Une enveloppe ou paroi cellulaire;

$2^{\circ}$ Une masse fluide, généralement granuleuse, qui, au début, remplit la cavité de la cellule ; c'est le corps cellulaire, ou protoplasma;

$3^{\circ}$ Un noyau ou nucléus, renfermant un ou plusieurs corpuscules appelés nucléoles;

$4^{\circ}$ Enfin une substance liquide appelée suc cellulaire, qui n'apparaît que tardivement.

Le terme protoplasma, employé par H. Mohl pour désigner

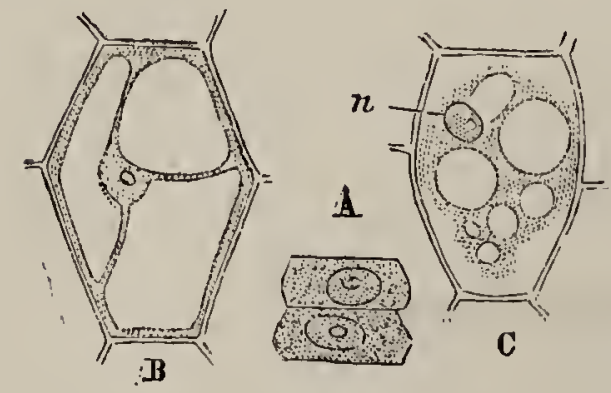

Fig. 20. - A, cellules jeunes prises au voisinage du point végétatif de la tige du romarin. $-B$ et $C$, cellules du parenchyme sous-épidermique de la tige du sedum telephium.en $\mathrm{C}$, le protoplasma légèrement rétracté montre de nombreuses vacuoles arrondies. - n, noyau. une partie bien définie de la cellule (1), ayant été depuis lors le sujet de confusions regrettables, nous croyons devoir faire remarquer que ce terme s'applique à la substance semi-gélatineuse, souvent granuleuse, qui remplit la cavité des très jeunes cellules, et qui plus tard, refoulée par le suc cellulaire, vient s'appliquer contre la paroi de l'élément et prend le nom d'utricule primordiale ou utricule protoplasmatique.

Ce qu'il faut entendre par le terme cellule. - - Le terme cellule ne saurait s'appliquer uniquement à l'élément composé des diverses parties que nous venons d'énumérer. En effet, l'une ou l'autre de ces parties peut manquer sans que pour cela l'élément anatomique perde son individualité histologique. Il est donc nécessaire de donner au terme cellule une plus large extension. Une masse protoplasmatique sans paroi est une cellule (zoospores, etc.). Une paroi sans protoplasma est

(1) "Je me crois autorisé, dit H. Molıl (Botanische Zeitung, 1843, et Ann. les sc. nat. de Paris, Bot., 1846, t. VI, p. 86), à donner le nom de protovlasma ì la substance demi-fluide azotée, jaunie par l'iode, qui est répandue dans les cavités cellulaires des plantes, nom qui se rapporte it sa fonction physiologique... c'est ce liquide qui lournit les premiers matériaux pour la formation du nucléus et de l'utricule primordiale. "Voir la discussion soulevée à ce sujet par Ch. Robin 1873. 
encor'e une cellule, mais, dans ce cas, ce n'est plus qu'un élément figuré; c'est une cellule qui a cessé d'exister en tant qu'élément vivant, car les propriétés végétatives lui font maintenant défaut; elles reposaient toutes dans le protoplasma.

Comme tout être vivant, la cellule naît, s'accroît et meurt. Nous l'étudierons dans ces trois stades, mais ceux-ci étant marqués par des modifications plus ou moins profondes dans l'état des parties constitutives de l'élément, il nous paraît nécessaire tout d'abord de caractériser aussi nettement que possible chacune de ces parties, pour en mieux suivre ensuite les transformations.

§ 2. Étude de la Nature chimigue du protoplasua et du NoYau. RÉACTIFS.

Sujets d'étude. - Pour cette étude on emploiera de préférence des tissus très jeunes, dont les éléments sont gorgés de protoplasma. On fera des coupes modérément fines sur les extrémités des tiges ou des racines. On pourra également appliquer les réactifs que nous allons indiquer aux zoospores d'un grand nombre de cryptogames. Ces zoospores en effet sont dépourvues de membrane d'enveloppe et presque uniquement formées de protoplasma. Enfin, si l'on veut agir sur de grandes quantités de protoplasma, on aura recours à certains champignons myxomicètes, dont une espèce très commune sur le tan et très facile à élever, l'æthalium septicum (1), sera un sujet d'étude à la portée de tous et d'autant plus convenable qu'il atteint des dimensions remarquables. Nous indiquerons d'ailleurs, dans le courant de cet exposé, divers exemples particulièrement instructifs.

Nature chimique du protoplasma. - Le protoplasma appartient au grand groupe des matières azotées ou albuminoïdes. Il s'organise en effet au moyen des quatre éléments,

(1) On se procure facilement la fleur de tan dans les tanneries. Pour conserver et élever ce champignon, il suffit de placer sur une assiette creuse une certaine quantité du tan qui le porte, puis, après l'avoir imbibé d'eau, de recouvrì d'une cloche af̣n d'empệcher l'évaporation. 
carbone, oxygène, hydrogène et azote. De composition un peu variable dans les différentes cellules où on l'étudie, il peut être considéré, d'après Hunt et Berthelot, comme un amide complexe formé par l'association de la glycolammine, de la leucine, de la tyrosine, etc., avec divers composés oxygénés qui appartiennent d'une part à la série des acides gras, d'autre part à la série benzoïque. La composition chimique du nucléus est la même, comme on devait s'y attendre, puisque celui-ci n'est autre chose que le résultat d’une sorte de condensation d'une portion du protoplasma.

Réactirs. Mode d'emploi. - Les réactifs sont ceux de toutes les matières azotées. Dans leur emploi il faut toutefois tenir compte du fait suivant:

Le protoplasma en pleine activité vitale ne se comporte pas de la même manière que le protoplasma qui a cessé de vivre. Le protoplasma vivant se montre en effet très réfractaire à la plupart des réactifs, et s'il paraît, dans certains cas, être influencé, c'est qu'il a été tué préalablement par le réactif employé. On peut s'assurer de ce fait de la manière suivante : que l'on prenne des solutions aqueuses, inoffensives par conséquent, de matières colorantes de fleurs ou de fruits, et l'on verra qu'il est impossible d'obtenir une coloration même très faible du proloplasma vivant ( $\mathbf{1}$ ). Vient-on au contraire à tuer ce dernier par l'addition d'alcool, par exemple, on observera bientôt une coloration. Bien plus, le protoplasma mort, s'emparant d'une grande quantité de matière colorante, devient bientôt plus foncé que la solution employée; et, à ce sujet, il est bon de noter que le noyau, portion condensée du protoplasma, s'empare par cela même d'une plus grande quantité de matière colorante, si bien qu'on peut le rendre très visible et nettement délimité dans les cellules où on ne l'apercevait d'abord que difficilement.

Les réactifs que l'on peut mettre en usage pour caractériser le protoplasma se peuvent diviser en trois groupes, d'après leur mode d'action :

(1) Que l'on examine d'ailleurs les tissus colorés si variés des corolles ou autres parties de plantes, et l'on y verra que la matière colorante répartie dans le suc cellulaire laisse parfaitement intact le protoplasma. 
Réactifs colorants.

- dissolvants.

- coagulants.

Réactifs colorants. $-1^{\circ}$ Le carmin, l'indigo, la cochenille sont absorbés avec avidité par le corps cellulaire et le noyau morts. On ne doil employer ces réactifs que dans les cas où le protoplasma n'est pas caché à l'observation par la présence d'une matière colorante propre à la cellule, et en particulier par la chlorophylle, qui remplit souvent à tel point les cellules, queles réactifs colorants ne sauraient être d'aucune utilité. Ces derniers pourront être usités dans les cas de cellules à protoplasma incolore, telles que celles qui forment les tissus de la plupart des champignons, ou dans les plantes plus élevées en organisation, les cellules épidermiques, les extrémités jeunes des rameaux, etc.

$2^{\circ}$ Le protoplasma étant traité par l'eau sucrée, puis l'excès de liquide enlevé au moyen d'un pinceau, si l'on fait intervenir l'acide sulfurique, on obtient une coloration qui varie du rose clair au rose-rouge. La même coloration résulte de l'emploi d'un excès d'acide sulfurique anglais concentré. Cette dernière réaction réussit particulièrement bien si l'on agit sur les cellules d'un tissu qui pendant un certain temps a été plongé dans l'alcool. On constate alors que le corps cellulaire privé d'eau et contracté sous l'influence de l'alcool se colore immédiatement en rouge vif par. l'acide sulfurique et se réunit rapidement au milieu de la cellule en une ou plusieurs gouttelettes d'aspect huileux.

$3^{\circ}$ Si l'on fait agir l'iode en dissolution, soit dans l'eau pure ou additionnée d'iodure de potassium, soil dans l'alcool, le protoplasma prend une coloration jaune-brun caractéristique

$4^{\circ}$ Le réactif suivant peut être également employé. Il consiste à imbiber le tissu avec une dissolution de sulfate de cuivre, puis, après avoir enlevé l'excès de liquide, à ajouter une goutte de potasse ; immédiatement le protoplasma prend une belle coloration violette.

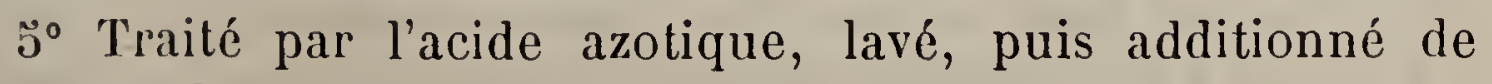
potasse, le protoplasma se colore en jaune plus ou moins orangé.. 
$6^{\circ}$ Le réactif de Millon (dissolution acide de nitrate mercurique) donne au protoplasma, avec l'aide de la chaleur, une couleur rouge foncé.

Réactifs dissolvants. - Alcalis. - Les alcalis dilués ont la propriété de rendre le protoplasma diffluent, et sem. blent le dissoudre, car, en perdant sa forme primitive et devenant homogène, il se confond avec le reste du contenu de la cellule. L'ammoniaque ordinaire, par exemple, d'après J. Sachs, dissout en deux heures le protoplasma et le noyau dans les cellules des fruits de courge. Mais ce n'est point là une destruction du protoplasma, car on peut le faire réapparaître : il suffit pour cela de neutraliser la préparation au moyen d'une goutte d'acide acétique, qui, avec addition ultérieure d'iode, précipite bientôt le protoplasma sous forme d'une masse jaune et granuleuse.

Il est à remarquer que les alcalis concentrés n'ont pas la même action que lorsqu'ils sont dilués. On peut laisser le protoplasma en contact avec une lessive concentrée de potasse, et celui-ci restera intact pendant des journées entières.

Réactifs coagulants. - Acides. - Les acides dilués, et particulièrement l'acide acétique, sont fréquemment employés pour déterminer la coagulation du protoplasma qui se rassemble alors au milieu de la cellule. Il est même à remarquer qu'un excès d'acide acétique finit par dissoudre le protoplasma en même temps qu'il rend le noyau plus brillant. Gette propriété rend l'acide acétique très utile pour éclaircir les préparations de tissus.

Alconl. - L'alcool agit de diverses manières sur le protoplasma, suivant son degré.

L'alcool absolu durcit les tissus, tue le protoplasma, mais ne le coagule que d'une manière peu sensible. Il fixe le protoplasma en l'état où il se trouvait au moment de l'emploi du réactif ; c'est là une action très précieuse, comme nous aurons plus tard de fréquentes occasions de le reconnaître. On pourrait employer dans le même but l'acide osmique.

L'alcool à $90^{\circ}$ se place au premier rang des réactifs coagulants. Sous l'influence de ce réactif, le protoplasma, diversement réparti dans la cellule, se contracte, revient sur luị- 
même, et se réunit en une masse comme frippée au milieu de la cavité cellulaire. C'est là d’ailleurs une réaction commune aux matières protéiques, mais elle est d'un grand secours dans les recherches micrographiques, en permettant de distinguer très nettement le protoplasma des diverses autres parties de la cellule, paroi et contenu liquide. Les préparations acquièrent sous cette influence une très grande clarté, et principalement dans l'étude des très jeunes tissus où l'abondance du protoplasma nuit à l'observation, on ne saurait trop conseiller d'user de ce réactif. Dans ces cas on ne fera pas agir l'alcool séparément sur chaque coupe, on procédera en plongeant dans l'alcool les parties de plantes à étudier et en les y laissant séjourner pendant quelques semaines. Ajoutons que, l'alcool donnant aux tissus une certaine dureté, on trouvera dans son emploi un sérieux avantage pour la pratique des coupes.

Chaleur. - Une température de $50^{\circ}$ coagule le protoplasma.

Si l'on va jusqu'à brûler le corps cellulaire, on perçoit une odeur ammoniacale qui dénote la nature azotée de la substance en expérimentation.

\section{§ 3. Étude de La NatUre ChImQUe de la membrane Cellulaire.}

Sujets d'étude. - On n'agira pas sur des tissus trop jeunes, chez lesquels les parois cellulaires n'ont pas encore acquis leur composition chimique définitive.

Les longues cellules du coton, ainsi que beaucoup de poils à parois peu épaisses, permettront d'obtenir des réactions caractéristiques. Les cellules des fruits pulpeux, celles de la moelle du sureau, enfin les cellules épidermiques de la partie inférieure des feuilles des Liliacées et Iridées, fourniront également d'excellents sujets d'étude.

Itéactifs; mode d'emploi. - Si l'on a essayé sur le protoplasma de cellules complètes les réactifs que nous venons d'indiquer, on a pu remarquer que ces réactifs n'agissent point ou agissent d'une tout autre manière sur la paroi cellulaire; c'est qu'en effet la composition chimique de cette membrane 
diffère essentiellement de celle que nous avons attribuée au protoplasma. Le plus souvent, la membrane cellulaire est formée de cellulose. Il y a toutefois quelques exceptions; la paroi des cellules des champignons, par exemple, est formée de fongine, principe isomère de la cellulose, mais qui ne.donne point les mêmes réactions (Voir Ch. Robin, Théorie cellulaire).

La cellulose se caractérise :

$1^{\circ}$ Par la coloration bleue qu'elle prend sous l'influence de l'eau iodée et de l'aride sulfurique.

L'emploi de ces réactifs exige certaines précautions. On devra, tout d'abord, traiter le tissu à examiner par une dissolution de carbonate de soude, dans laquelle on le fera bouillir pendant un temps variable avec la nature des éléments. Prenons pour exemple l'essai du réactif sur le coton. Après avoir soumis une portion déterminée de cette matière à l'ébullition pendant un quart d'heure dans la lessive susdite, ou bien encore après avoir plongé le coton pendant quelques secondes dans une solution concentrée de potasse, puis l'avoir lavé à l'eau distillée, nous en prenons une petite portion que nous desséchons avec soin entre plusieurs feuilles de papier buvard. Puis nous la plaçons sur un porte-objet, et nous déposons sur la préparation une ou deux gouttes de solution iodée. Après quelques minutes d'attente, alors que la masse est bien imprégnée, nous la desséchons de nouveau avec grand soin, et nous la traitons par une' ou deux gouttes de la liqueur sulfurique. Au bout d'un temps variable, et très rapidement si l'opération a été bien menée, les parois des cellules prennent une belle coloration bleue. Cette réaction paraîtra très inconstante, si on ne prend toutes les précautions que nous indiquons. Nous insistons particulièrement sur la nécessité d'absorber complètement l'excès de solution iodée; en effet, s'il reste de l'eau, l'acide sulfurique se trouvant dilué n'agit plus suffisamment, et l'on n'obtient pas la coloration bleue. Les membranes cellulaires prennent alors une teinte d'un jaune-brun plus ou moins foncé. Le réactif que nous venons d'indiquer ne donne pas une coloration bleue permanente aux parois des cellules. Peu à peu en effet la cel- 
lulose reprend sa cohésion, et la memibrane, passant d'abord au violet, perd bientôt toute coloration.

$2^{\circ}$ On emploie encore pour caractériser la cellulose le chlorure de zinc iodé (Voir page 45 ), qui lui fait prendre une belle teinte bleue. Ce réactif est d'un emploi peut-être plus sûr que le précédent, car il exige moins de précautions. On ne négligera pas toutefois, avant l'emploi du réactif, de faire agir la potasse sur le tissu à examiner. Si l'on opère sur le parenchyme d'une feuille, ou sur la moelle de sureau, il suffira de tremper ces tissus dans une solution concentrée de potasse. Le contact avec la potasse ne devra pas être prolongé au delà de quelques secondes, et on devra immédiatement laver la préparation dans l'eau avant de la traiter par le chlorure de zinc iodé. La potasse gonflant la cellulose la rend beaucoup plus sensible au réactif; aussi cette méthode nous a-t-elle donné d'excellents résultats. La coloration bleue est instantanée, aussi bien sur les tissus frais que sur la moelle de sureau sèche. Nous recommandons aux débutants pour cette étude la moelle de sureau qui, desséchée, ne présente plus qu'un amas de parois cellulosiques et se laisse aisément diviser en coupes très fines parfaitement propres à l'observation.

$3^{\circ}$ Enfin M. Schweiser de Zurich a indiqué l'emploi de l'oxyde de cuivre ammoniacal, qui a la propriété de dissoudre la cellulose.

Les diverses réactions que nous venons d'énumérer peuvent être modifiées lorsque, par suite du développement, la paroi cellulaire s'est notablement épaissie, et est devenue le siège de dépôts divers. Nous indiquons plus loin les moyens de reconnaître ces transformalions; ajoutons que même lorsque les parois sont très épaissies et modifiées, ces modifications portant principalement sur les couches externes, on retrouvera presque toujours à la face interne de la membrane cellulaire une couche qui prendra la coloration bleue par les réactifs susdits. Toutefois, comme dans ces circonstances la réaction est très délicate à obtenir, on fera bien au préalable de vider les cellules, ou encore de contracter le protoplasma par l'alcool, par exemple, afin de bien mettre en évidence la face interne de la membrane enveloppante. 
Enfin, lorsqu'au contraire la paroi des cellules est extrêmement mince, on fera bien, comme le conseille Schacht (1), de produire sur le protoplasma des contractions irrégulières au moyen d'eau sucrée ou d'un acide très dilué, ou encore d'une dissolution étendue de sel de cuisine; on verra alors la paroi, quelque mince qu'elle soit, se séparer comme une pellicule très légère du contenu de la cellule qui s'agglomère irrégulièrement.

Le suc cellulaire est un liquide aqueux tenant en suspension ou en dissolution des matières très diverses. Nous croyons donc devoir faire rentrer l'étude de ses réactions dans le chapitre que nous réservons à l'examen du contenu des cellules.

ART. 2.

\section{Étude de la génération des cellules.}

On admet généralement trois modes distincts de génération des cellules.

Dans l'un de ces modes il n'y a pas multiplication de la cellule mère, mais formation d'une seule cellule fille aux dépens de tout le contenu protoplasmatique de la cellule mère. Ce procédé a été désigné du nom de rajeunissement.

Dans les deux autres modes de génération, il y a multiplication de la cellule mère, et par suite individualisation de plusieurs cellules filles aux dépens de tout ou partie de la cellule mère. Lorsque tout le protoplasma de la cellule mère n'est pas employé pour la formation des cellules filles, il y a ce qu'on appelle formation libre ou genèse. Dans le cas où tout le protoplasma de la cellule mère sert à la formation des cellules filles, le procédé de multiplication diffère du précédent; il y a alors division; celle-ci est binaire si deux cellules filles seulement naissent de celte multiplication ; elle est multicellulaire simultanée dans le cas où plus de deux cellules filles sont le résultat de la division du protoplasma de la cellule mère.

(1) H. Schacht, Le microscope et son application spéciale, ì l'étucle de l'anatomie végétale, traduction en français par M. Dalimier. Pạris, 1875. 
Bien que paraissant très nettement définis, ces divers modes de génération des cellules ne sont point aussi distincts qu'on pourrait le croire. Nous verrons en effet par la suite qu'on rencontre un grand nombre de procédés intermédiaires aux procédés typiques énumérés plus haut ; peut-être pourrait-on les considérer tous comme des variétés du type de génération par division simple (Strasbürger, loc. cit.). Quoi qu'il en soit, nous allons décrire les trois principaux modes de génération que nous indiquons, en choisissant quelques exemples pour chacun de ces.cas. Dans cet exposé nous emprunterons largement aux recherches publiées récemment par M. Strasbürger (Ed. Strasbürger, Sur la formation et la division des cellules. Traduction de l'allemand par Jean-Jacques Kickx. Paris, 1876).

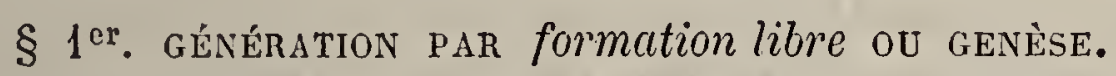

Su.jet; d'étude. - On trouvera de bons exemples de formation libre des cellules dans les corpuscules (archégones) fécondés des Conifères (Ephedra altissima, Gingko biloba, etc.). Ghez les Angiospermes on sait également que les premières cellules de l'albumen naissent par formation libre (1).

On observera particulièrement bien ce procédé de genèse dans le sac embryonnaire fécondé du Phaseolus multiflorus (pour l'extraction du sac embryonnaire et le mode opératoire voir plus loin), ou dans ceux particulièrement gros du Lis, de la Fritillaire, des Ornithogales, et en général chez les Liliacées, les Onagrariées et les Borraginées. On pourra faire également chez les Conifères de semblables observations de la formation libre des premières cellules de l'albumen (prothalle endogène), à condition toutefois d'opérer sur des individus dans la première année de fructification, longtemps avant la fécondation. Enfin la naissance des spores dans les thèques d'un certain nombre de champignons (Peziza et quelques Pyrénomycètes),

(1) Il existe toutefois certains de ces végétaux chez lesqucls même les premières cellules de l'albumen se forment par division binaire soit du sac chbryonnaire lui-même, soit d'une cellule unique qui s'en est séparéc (Hofmeister). 
ainsi que la formation des zoospores de quelques algues ( $\mathrm{Va}$ lonia utricularis), s'opérant par le même procédé de formation libre, on trouvera là des sujets d'étude faciles à se procurer.

Mode opératoire. - Pour arriver à faire ces délicates observations, il est bon d'employer certaines méthodes spéciales. Les préparations d'objets frais se prêtent mal à ces recherches, la fécule qui abonde dans les organes jeunes étant souvent un obstacle à des investigations approfondies; Strasbürger conseille de se servir de pièces durcies par un séjour prolongé dans l'alcool absolu. Les corpuscules des Conifères ou le sac embryonnaire des Phanérogames citées plus haut se laissent alors facilement enlever avec l'aiguille, manier à volonté et surtout diviser en coupes fines très propres à des recherches détaillées. De nombreuses particularités du protoplasma deviennent également plus apparentes qu'à l'état frais, en même temps que la structure des diverses formations à l'étude se conserve parfaitement sans altération. Non seulement l'alcool rend plus claires les préparations, mais son usage permet encore de suivre pas à pas les divers phénomènes qui président à la formation libre des cellules. Ce réactif en effet fixe pour ainsi dire les éléments dans l'état où ils étaient au moment où son action a été utilisée, et l'on peut obtenir ainsi des séries de préparations montrant toutes les phases par lesquelles passent les cellules avant d'arriver à leur individualisation. On devra donc, alors qu'on s'occupe de réunir les éléments propres à ces investigations, placer dans l'alcool des sujets à divers degrés de développement en notant avec soin ces divers degrés.

Bien que les résultats donnés par l'emploi de l'alcool soient plus précis et plus nombreux que ceux que l'on peut obtenir sur des sujets frais, on ne devra cependant pas négliger de faire le contrôle au moyen de pièces fraîches. Dans ce cas, comme l'eau et les autres véhicules le plus généralement employés pour les observations microscopiques ne manqueraient pas d'altérer les formations si délicates qui font le sujet de ces études, on devra employer un liquide approprié, soil le suc cellulaire du sac embryonnaire lui-même, quand cela sera possible, soit encore l'albumine d'œuf de poule. 
Nous renvoyons pour les méthodes générales d'isolement et de préparation des sacs embryonnaire, ainsi que des thèques et des sporanges, aux chapitres qui traitent spécialement de ces sujets.

\section{Examen du mode de genèse des cellules par formation li-} bre. - Dans ces recherches on doit se préoccuper, d'une part, des phénomènes qui peuvent précéder dans la cellule mère l'apparition des cellules filles; d'autre part, examiner l'ordre d'apparition des diverses parties constitutives des cellules filles et rechercher quel rôle elles jouent les unes par rapport aux autres.

Prenons comme exemple le développement par genèse des premières cellules de l'endosperme du Phaseolus multiflorus qu'il est facile de se procurer; nous observerons les phénomènes suivants, dont nous donnons la description d'après M. Strasbürger (Strasbürger, loc. cit.). Après la fécondation, le noyau de la cellule mère disparaît, et cette disparition précède immédiatement l'apparition des jeunes cellules. Si l'on opère sur des sujets frais, il suffit d'une coupe à travers le sac embryonnaire énucléé

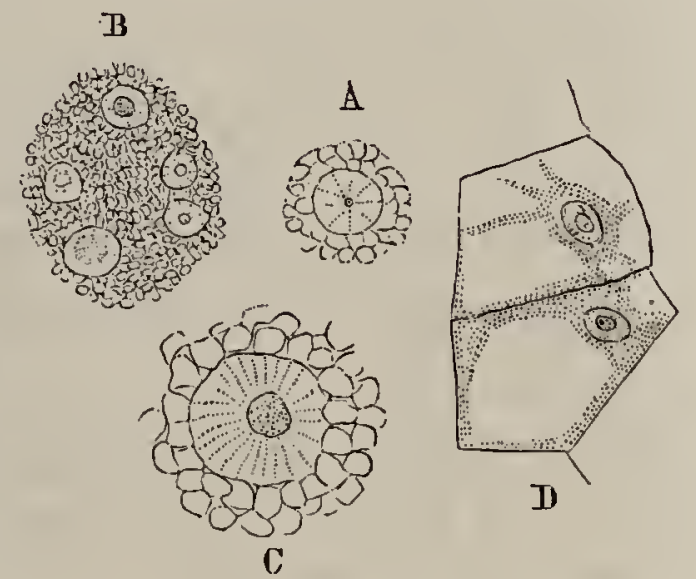

Fig. 21. - Formation libre des cellules de l'albumen du Phaseolus multiflorus d'àprès Strasbürger. pour voir s'écouler le protoplasma renfermant dans sa masse des noyaux entourés d'une zone plus ou moins granuleuse; ce sont de jeunes cellules à des états divers de développement (fig. 21, B). Mais on suivra bien mieux, comme nous l'avons dit, les phases successives de l'évolution cellulaire en faisant des coupes modérément fines sur des sacs embryonnaires préalablement traités par l'alcool absolu; ces coupes devront être plus particulièrement menées dans la région du sac embryonnaire la plus éloignée du micropyle. Près du micropyle en effet le protoplasma est plus dense et l'on ne distingue pas aussi facilement les jeunes cellules.

Sur ces coupes, et en se servant d'un fort grossissement (600 fois), on aperçoit tout d'abord de petits points brillants réfractant fortement la lumière et assez semblables à de fines 
gouttelettes d'huile; autour de chacun de ces points pris comme centre, se dessine en même temps une zone transparente de forme sphérique (fig. 21, A). C'est là la première ébauche d'une cellule. Dans le même sac embryonnaire, ou șur d'autres échantillons plus avancés dans leur développement, on constate que le centre brillant punctiforme s'accroît en même temps que la zone sphérique qui l'entoure dans laquelle on peut souvent voir la substance du protoplasma prendre une disposition manifestement rayonnante (fig. 21, G).

Par suite de l'évolution de la cellule, de nouveaux changements s'observent; le noyau qui est devenu plus considérable se creuse de quelques vacuoles; la partie périphérique de la zone sphérique qui l'entoure s'individualise en une couche membraneuse, tandis que le reste du protoplasma prend d'abord une disposition réticulée, puis finalement se retire vers l'extérieur, ne restant plus en rapport avec le noyau que par quelques tractus qui traversent la cellule; plus souvent encore le noyau qui est devenu ovoïde se rapproche également de la périphérie de la cellule (fig. 21, D). (Jusqu'à cette époque les jeunes cellules de l'endosperme étaient libres et écartées les unes des autres. Elles commencent alors à se rapprocher, et d'après M. Strasbürger, ce n'est qu'à partir du moment où les couches extérieures de deux cellules voisines sont arrivées au contact qu'on peut par le chlorure de zinc iodé déceler la présence d'une fine membrane de cellulose entre elles. Dès lors la cellule est complète.)

Le mode d'évolution que nous venons de décrire pour le Phaseolus multiflorus, pris comme type, peut donc se résumer ainsi quant à l'ordre de succession des phénomènes et à l'apparition des diverses parties de la cellule:

$1^{\circ}$ Disparition du noyau de la cellule mère (sac embryonnaire);

$2^{\circ}$ Apparition simultanée du corps celluiaire et du noyau; ce dernier est le centre d'attraction, et son influence se manifeste par la dispositiou rayonnante que prennent les granules protoplasmatiques;

$3^{\circ}$ Apparition de la membrane cellulosique.

Ces phases successives du développement sont peut-être 
plus faciles encore à suivre dans les corpuscules (archégones) des Conifères, où les noyaux des jeunes cellules apparaissent simultanément et sont dès leur première apparition plus développés que ceux des jeunes cellules de l'endosperme du Phaseolus multiflorus. Chez le Ginglo biloba, par exemple (Strasbürger), la résorption du noyau de la cellule mère est suivie de l'apparition de plus de trente noyaux entourés chacun d'une zone de protoplasma rayonnant.

Nous ne pourons entrer dans de plus nombreux détails que ne comporterait pas le cadre de notre ouvrage. Il suffira de répéter les observations sur le type que nous avons choisi pour être bientôt en mesure de constater soi-même les modifications qui se peuvent rencontrer dans ce mode de genèse par formation libre, soit que les nouvelles cellules manquent de noyau (spores des Pyrenomycètes. De Bary, Ueber die Fruchtentwickelung der Ascomycetes, 1863), soit encore que la cellule mère manque de noyau (certaines algues). Ce sont là des modifications qui prouvent que le rôle du noyau n'est pas absolument nécessaire dans la formation libre des cellules mais qui n'altèrent pas d'une manière profonde le type général que nous avons pris pour exemple.

§ 2. MODE DE FORMATION DES CELLULES PAR DIVISION.

\section{A. DIVISION BINAIRE.}

Ainsi que nous l'avons dit plus haut (page 60), deux cas sont à considérer dans le mode de division des cellules, car il peut y avoir division binaire ou division multicellulaire. Nous envisagerons tout d'abord le cas de division binaire qui est le cas typique et en même temps le procédé le plus fréquemment mis en usage dans la nature pour l'accroissement des tissus végétaux.

Sujets d'étude. - On conçoit d'après cela que les sujets d'étude soient nombreux. Nous n'en signalerons qu'un petit nombre, en ayant soin de les choisir parmi ceux qui donnent les résultats les plus nets. La moelle des dicotylédones (Sambucus, Helıanthus, Lysimachia, Polygonum, Silene), offre d'après M. HansGUIVE DE MIGHOGRAPHIE. 
tein des exemples de bipartition cellulaire. On pourra suivre également cette division binaire dans la formation des poils d'un certain nombre de végétaux, ceux des étamines du Tradescantia virginica ou de l'Ochrea des rumex sont particulièrement propres à ces observations; et si l'on a soin de les prendre assez jeunes, on peut trouver sur un seul d'entre eux toutes les phases principales de la division. La bipartition des jeunes cellules de l'endosperme du Phaseolus multiflorus, provenant elles-mêmes, comme nous l'avons dit d'une genèse; la formation des stomates de l'Iris pumila et de l'Hyacinthus orientalis, seront d'excellents sujets d'étude et qu'il est facile de se procurer. Enfin on suivra peut-être plus facilement encore cette division binaire des cellules chez les algues filiformes à longues cellules. G'est le Cladophora, qui servit à M. Mohl alors qu'il décrivit pour la première fois, en 183əั, ce mode de formation des cellules. Les Spirogyra longata, orthospira, setiformis, les Zygnema, Edogonium, Ulothrix zonata, complent également parmi les sujets préférés des savants qui ont contribué à la connaissance de ces phénomènes.

Toutefois les divers exemples que nous venons de citer ne sont pas tous également propres aux premières recherches. Dans beaucoup d'algues (Zygnema, Spirogyra quinina, etc.), le contenu des cellules, amidon, corps chlorophylliens, est tellement abondant qu'il empêche de bien suivre les diver'ses phases de la division. Nous conseillerons, sous ce rapport, le $S p i$ rogyra orthospira, qui se laisse facilement observer au. microscope.

Il faut encore tenir compte chez les algues de l'époque à laquelle se fait la division. Ainsi, les Cladophora offrent le double avantage d'être des algues très-communes, et de présenter à toute heure du jour des phases de labipartition. Le Spirogyra orthospira, au contraire ne se divise qu'à une heure avancée de la nuit, entre dix heures du soir et deux heures du matin. Ce serait là un inconvénient, mais nous indiquons plus loin un moyen très-simple imaginé par M. Strasbürger pour retarder la division jusqu'au matin. Enfin, lorsqu'on commence ces études, il est bon de prendre un exemple qui offre à l'examen toutes les phases du phénomène; il faut pour cela 
choisir une cellule mère munie d'un noyau dont le volume soit assez considérable, et qui soit plongé au milieu du protoplasma remplissant la cavité de la cellule. C'est alor's seulement que l'on peut prendre une idée très-nette du procédé typique de la division binaire et se rendre un compte exact du rôle que joue le noyau dans cette division. Ge rôle en effet, qui apparaît très-nettement, comme nous le verrons, dans les cas typiques offerts par des cellules constituées comme nous venons de le dire, tend à s'effacer plus ou moins et même à disparaître complétement dans d'autres circonstances. Le Spirogyra orthospira par exemple, que nous citons plus haut, sera parfaitement propice à l'examen de la division du noyau de la cellule mère, mais ce noyau est petit relativement à la cavité de la cellule; placé au centre de cette cavité il est donc assez éloigné des parois que tapisse le protoplasma; de là, une certaine indépendance entre le noyau et le reste de la cellule, aussi verrons-nous que son rôle dans la-division de celle-ci est considérablement amoindri. Ailleurs, le noyau de la cellule mère est petit et pariétal (EAdogonium tumidulum, Ulothrix zonata) son rôle paraît tout aussi rudimentaire que celui du noyau des Spirogyra. Enfin il peut arriver que la cellule mère soit dépourvue de noyau. C'est le cas des Cladophora. On ne devra donc pas choisir ces plantes comme point de départ pour la compréhension de la division binaire des cellules.

Pour ces diver'ses raisons nous conseillons d'examiner d'abord le développement des stomates de l'Iris pumila, ou de l'Hyacinthus orientalis, dans lesquels le noyau très-gros est englobé de toutes parts dans le protoplasma qui remplit la cavité des cellules (1).

Mode opératoire. - Comme pour l'examen de la formation l:bre des cellules, on peut étudier les procédés de division sur des sujets frais, mais les résultats sont sourent obscurs, et

(1) Nous laissons ici de côté tout ce qui a trait au dévcloppement de la paroi collulosique: en effet, d'après ce que nous avons dit plus haut, la cellule existe a partir du moment où la division du protoplasma est complète. La formation de la paroi n'est pour ainsi dire qu'une phase sccondaire de la vie de la cellule, aussi renvoyons-nous pour cette étude au chapitre qui traite spécialement du développement de la paroi cellulaire. 
l'on a tout avantage à employer l'alcool absolu pour fixer les cellules dans leurs divers états au moment de la division.

L'examen des pièces fraîches sera cependant nécessaire. On fera bien alors, pour ne laisser passer inaperçue aucune phase importante du développement, de dessiner de temps en temps ce que l'on observe, en ayant soin de noter l'époque précise où l'observation est faite. On comparera alors avec les résultats donnés par les sujets traités par l'alcool.

Lorsqu'on observe des algues vivantes, il faut avoir soin d'entretenir toujours sur le porte-objet une assez grande quantité d'eau sil'on veut suivre la division sur une seule cellule depuis le début jusqu'à la fin.

Pour réaliser autant que possible les conditions normales du développement des cellules, on pourra placer à côté du microscope, un peu plus haut que le porte-objet, un verre rempli d'eau, dont le contenu sera amené petit à petit jusqu'au bord du verre couvreur par un fil de coton, tandis que du côté opposé un autre fil débarrassera la préparation de l'excès de liquide.

Nous avons dit que la division du Spirogyra orthospira commençait à une heure assez avancée de la nuit, circonstance peu agréable si l'on songe que la durée du phénomène varie entre quatre et six heures. Pour obvier à cet inconvénient, divers procédés ont été mis en usage. Famintzin est arrivé à retarder le moment de la division jusqu'au jour, en éclairant fortement pendant toute la nuit les algues en expérience. Mais, pour réussir, il faut avoir à sa disposition dè sources de lumière assez intenses que l'on ne peut toujours se procurer : aussi recommandons-nous le moyen très-simple indiqué par Mi Strasbürger. Il suffit de placer les bocaux qui renferment les algues dans un milieı dont la températura soit inférieure à $+\breve{g ̆}^{\circ}$. La division alors ne s'opère pas. (Il en est ainsi du moins pour le Spirogyra orthospira.) Le lendemain matin, si l'on porte celles-ci dans une chambre chauffée, la division commence même sous la lumière directe du soleil.

Notons enfin que pour ces observations de la division des cellules il faut employer de forts grossissements (600 fois et plus). 


\section{Examen du mode de formation des cellules par division.}

- Nous prendrons comme exemple le développement des slomates de l'Iris pumila (Strasbürger, loc. cit.). Si l'on observe des préparations de pièces conservées dans l'alcool absolu, on pourra trouver sur une seule d'entre elles tous les états prin. cipaux par lesquels passent les cellules en division, et contrôler ainsi ce que montrent moins clairement d'ailleurs les cellules fraîches observées dans l'eau ou dans l'albumine. La cellule mère des cellules de bordure renferme d'abord un grand noyau avec un gros nucléole ou plusieurs plus petits. Ce noyau grossit en devenant homogène (fig 22, A). Puis, on voit apparaître dans sa masse deș stries granuleuses qui convergent vers ses deux pôles. Bientôt ces stries s'épaississent à l'équateur du noyau (fig. 22, B) et cet épaississement forme une sorte de disque qui divise

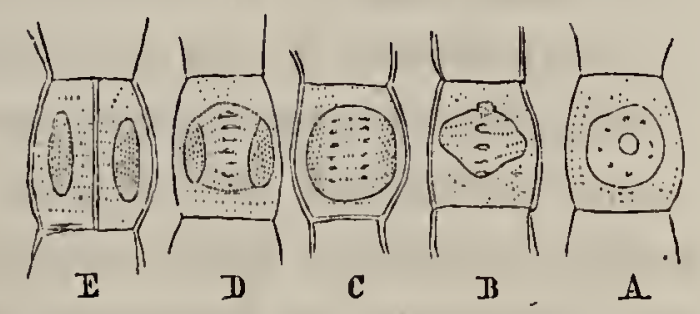

Fig. 22. - Formation par division des stomates de l'Iris pumila (Strasbürger). le noyau en deux parlies, c'est la plaque nucléoluire (Strasbürger,. Par la suite, cette plaque se dédouble et les deux segments nés de ce dédoublement s'écartent l'un de l'autre en se rapprochant des pôles du noyau (fig. 22, G). Toutefois ces deux segments ne deviennent pas complètement indépendants, ils sont reliés entre eux par de fines stries granuleuses qui proviennent de la partie médiane étirée de la plaque nucléolaire dont ils dérivent (fig. 22, G). Sułt la formation définitive des deux nouveaux noyaux correspondant chacun à l'une des deux moitiés écartées du noyau primaire.

Alor's commence la deuxième phase du phénomène. Dans les fils granuleux qui relient les deux segments de la plaque nucléolaire, et vers le milieu de leur longueur, apparaissent des épaississements en forme de bâtonnets qui par leur assemblage constituent une nouvelle plaque (plaque cellulaire, Strasbürger)(fig. 22, D). A partir de ce moment, la division de la cellule mère est opérée, à condition toutefois, comme il arrive fréquemment, que les fils granuleux qui relient les deux noyaux et au milieu desquels s'est formée la plaque cellulaire, 
atteignent parleur partie équatoriale la paroi de la cellule mère. De la sorte, en effel, la plaque cellulaire arrivera également jusqu'à la paroi et divisera ainsi en deux la cellule (fig. 22, E). Si ces fils n'arrivent pas jusqu'à la paroi, la plaque se complétera par une couche correspondante dans le protoplasma de la cellule, et la division sera bientôt opérée.

L'exemple de l'Iris pumila que nous avons choisi'se recommande, nous l'avons dit plus haut, par ce fait que le noyau primaire remplit presque à lui seul la cavilé de la cellule mère Dès lors les phénomènes de la division sont des plus simples, et nous venons de constater que le noyau y joue un rôle prépondérant. Dans d'autres cas cependant ce rôle s'efface et devient même à peu près nul. Cela arrive lorsque le noyau d'un petit volume relativement à la cavité de la cellule mère reste, au milieu de celle-ci, séparé du protoplasma pariétal par une couche plus ou moins épaisse de liquide cellulaire. Dans ces cas (endosperme du Phaseolus multiflorus et Spirogyra orthospira par exemple), la division du noyau étant terminée, celle de la cellule s'opère progressivement de la périphé rie au centre, commençant même avant la formation de la

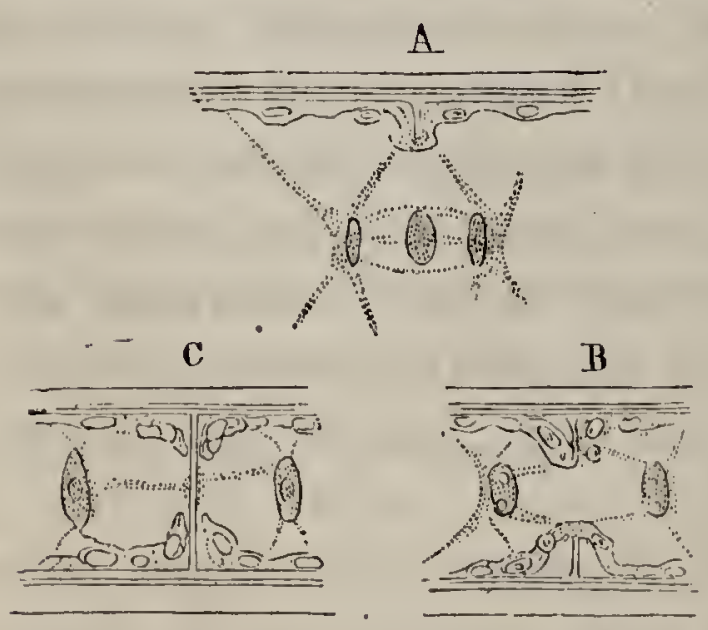

Firg. 23. - Formation de la cloison cellulaire dans la division des cellules du spirogyra orthospira (Strasbürger).

plaque cellulaire dans le noyau primaire, et alors, tantôt cette plaque cellulaire persistant (endosperme du Phaseolus) servira à compléter la plaque qui se forme dans le protoplasina pariétal et s'avance peu à peu jusqu'au noyau. Tantôt la plaque cellulaire du noyau étant rudimentaire et disparaissant bientôt (Spirogyra or thospira', la division du noyau et ceile du protoplasma de la cellule mère deviennent sensiblement

indépendantes. (Voir fig. 23.)

Quvi qu'il en soit, le Spirogyra orthospira n'en reste pas moins un des meilleurs exemples pour l'observation de la division du noyau. Sur ces algues vivantes et en disposant 
l'opération comme nous l'avons indiqué plus haut, on pourra, à l'aide d'un fort grossissement (600 fois environ), constater successivement les changements de forme du noyau de la cellule mère avant la division, son augmentation de volume, puis la formation de stries granuleuses, enfin l'apparition de la plaque nucléolaire à l'équateur du noyau. On pourra suivre la division de cette plaque en deux segments (1), puis l'écartement de ceux-ci qui s'opère si rapidement qu'on peut observer leur mouvement vers les pôles du noyau en se servant d'un fort grossissement. Entre temps la division de la cellule. commence par suite de l'apparition d'une plaque sombre dans le protoplasma périphérique (fig. 23). Cette division de la cellule se continuera ainsi jusqu'au centre, en même temps que les jeunes noyaux formés aux dépens de la plaque nucléolaire se différencieront davantage; et si une plaque cellulaire vient à se former dans le noyau primitif, résultant du retrait vers le centre de la cellule des granules qui constituaient les fils tendus entre les deux segments de la plaque nucléolaire, cette plaque cellulaire, nous l'avons dit, sera rudimentaire et dans tous les cas ne participera pas directement à la formation de la cloison protoplasmatique qui doit finalement diviser en deux la cellule mère.

Sans vouloir entrer dans plus de détails au sujet du mode de formation des cellules par division binaire, nous nous bornerons aux exemples typiques que nous renons d'indiquer, renvoyant pour le reste à l'ouvrage de M. Strasbürger(loc. cit.) et aux divers auteurs qui se sont occupés de ces questions (2).

\section{§ 3. ÉTUDE DE LA DIVISION MULTICELLULAIRE.}

Sujets d'étude. - Il suffit de savoir que ce procédé de division donne naissance à la plus grande partie des spores des Cryptogames supérieures ainsi qu'aux grains de pollen des Phanérogames. On choisira de préférence les plantes dont le

(1) Cette division commence environ quinze minutes après l'apparition dẹ la plaque.

(2) Hofmeister. Lehre von der Pflanzenzelle. H. Mohl. -- Weber. Die Vermehrung der Pflanz.(Diss. de 1835.) 
pollen est assez volumineux. Les Malvacées, les Onagrariées, les Liliacées. Les grains de pollen de l'Allium Narcissiflorum et ceux du Tropæolum majus, pourront être particulièrement pris comme premiers sujets d'étude, car ils montrent très-nettement les phénomènes de la division.

Mode opératoire. - Comme dans les cas précédents l'emploi de l'alcool donnera de bonnes préparations. On devra dès lors faire des coupes fines sur les anthères jeunes. Si l'on veut examiner des cellules fraîches, on pourra employer l'aiguille et la loupe montée pour dissocier les cellules mères des anthères, ou encore faire des coupes au rasoir. Dans tous les cas on aura soin de prendre de très-jeunes boutons et il suffira de faire des coupes sur ces très-jeunes fleurs pour obtenir en même temps des préparations des anthères et des cellules mères du pollen en état de division.

Examen. - Nous n'étudierons pas un cas particulier, car ce procédé de division paraît n'être qu'une abréviation d'une série de divisions binaires. Aussi trouve-t-on de

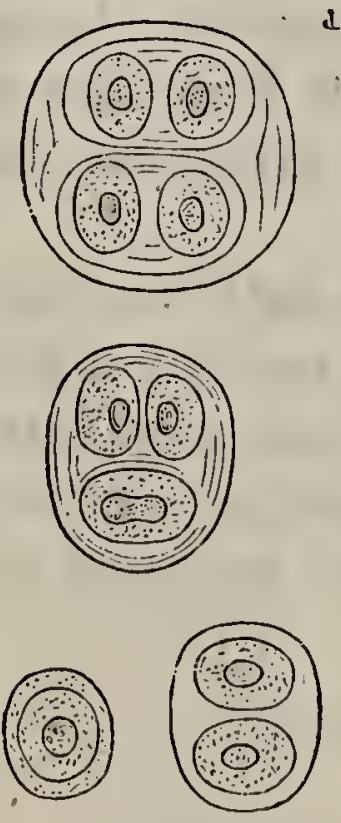

Fig. 24. nombreux états intermédiaires entre la division proprement dite telle que nous l'avons décrite et cet autre procédé, la formation libre, que l'on peut envisager commé une excessive abréviation du procédé de bipartition (Strasbürger). La division multicellulaire se rattache en effet à la division binaire par ce fait que tout le contenu de la cellule mère est employé dans la formation des cellules filles, et il se rattache d'autre part à la formation libre, par ce fait que le plus souvent le noyau primaire, qui ne peut se diviser à la fois en plus de deux parties, disparaît au moment de la division et est remplacé par le nombre voulu de nouveaux noyaux. Il arrive même souvent que les jeunes cellules se forment sans noyau.

Il est encore ici nécessaire de tenir compte de ce que devient plus tard la paroi de la cellule mère. Dans la plupart des grains de pollen et des spores des Cryptogames supérieures la membrane de la cellule mère se résorbe compléte- 
ment, et les jeunes cellules paraissent libres dès le principe. Dans d'autres grains de pollen, au contraire, ou bien elle ne se résout pas complétement, ou bien elle sert à relier les unes aux autres les quatre cellules nouvellement nées. (Certaines Algues (fig. 24) (Orchidées avec pollen à quatre divisions et plusieurs Éricacées) (1). Nous renvoyons pour plus de détails aux nombreux travaux publiés sur ce sujet (2).

§ 4. ÉtUde DU MODE DE Formation dES Celtules par rajeunissement.

Le rajeunissement ou formation pleine des cellules est caractérisé, nous l'avons dit plus haut, en ce que tout le contenu de la cellule mère est employé à la formation de la cellule fille. Ce mode de formation est accompagné le plus souvent de contraction du contenu de la cellule mère.

Sujets d'étude. - C'est ce procédé qui donne naissance aux zoospores d'un grand nombre d'algues (AEdogonium). (fig. 25), Colen chæte, Vaucheria sessilis, hamata, geminata, etc., aux zoospores de la plupart des Saprolégniées (3).

Mode opératoi re. - Prenons pour exemple la formation des zoospores du Vaucheria sessilis. Cette algue devra être observée particulièrement au printemps, on procédera pour son étude comme nous l'avons dit plus haut au sujet du Spirogyra orthospira (Voir page 68). D'ailleurs quelques filaments de cette algue placés sous le microscope suffiront souvent à montrer les divers états par lesquels passe la zoospore dans

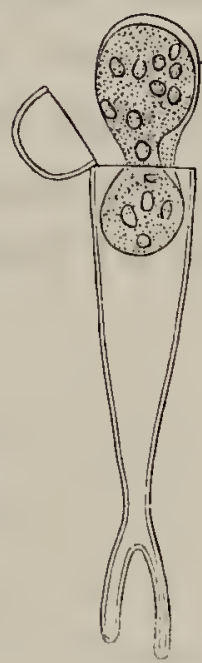

Fig. 25. - Tormaliou par rajcunissoment de la zouspore d'un Edo. gonium (Pringsheim). sa formation. En effet, cette algue est formée d'une seule cel-

(1) Voir pour plus de détails le chapitre, sur la formation des grains de pollen.

(2) Schacht (Bot. Zeitung, 1849 et 1850). Pringshcim, Pflanzenzelle, 185', Hofmeister, Die Lelire von der Pflanzenzelle, 1867. Sachs, Traité de Botanique, 1874. Strasburger, loc. cit., etc.).

(3) Cornu, Ann. des sc. nat. Bot., $5^{\mathrm{e}}$ série, t. XV, p. 38. Anim. spermatozoides des Cryptogames supérieures, ctc. 
lule assez allongée et remplie de protoplasma. Nais on trouvera des filaments dans lesquels le protoplasma se montrera complétement ramassé dans l'une des extrémités de l'algue qui aura pris un certain développement et un aspect claviforme. Sur d'autres filaments ou la formation cellulaire sera plus avancée, on pourra observer que la masse protoplasmatique, qui d'abord était de couleur verte s'est comme contractée, arrondie et en même temps a pris une teinte foncée. Enfin il ne sera pas rare de rencontrer des filaments vides, et l'on observera à l'une des extrémités une déchirure par laquélle s'est échappée la zoospore. On pourra même facilement assister au passage de celleci à travers la déchirure de la paroi de la cellule mère. Dans tous les cas nous conseillons, pour ne pas écraser les préparations, d'interposer entre le couvre-objet et le porte-objet, de petites bandes de papier qui éviteront que le verre-couvreur ne comprime les filaments délicats de l'algue. Sans cetle précaution, on risque d'écraser les jeunes zoospores. Celles-ci ont la forme de corps ovoïdes d'un brun noirâtre limités par une couche transparente couverte de cils vibratils.

C'est là un exemple typique de la formation d'une nouvelle cellule à l'aide du contenu tout entier de la cellule mère.

ART. 3.

\section{Étude de la cellule vivante.}

La cellule, après avoir pris naissance par l'un des procédés dont il vient d'être question constitue un être vivant, doué de propriétés, qui se nourrit et s'accroît jusqu'à atteindre un certain développement. Ce sont ces phénomènes de l'évolution cellulaire qu'il nous reste à étudier. Le protoplasma étant comme nous l'avons dit la partie essentielle de la cellule, c'est tout d'abord en lui que nous devons rechercher les manifestations de la vie de l'élément. 


\section{§ 1. PROTOPLASMA. NUCLÉUS.}

Propriétés physiques. - Le protoplasma est une substance incolore, de consistance gélatineuse, se présentant généralement comme une masse parsemée de granulations nombreuses et de grosseur variable. Rarement le protoplasma est homogène. Les cotylédons de l'Hélianthus en offrent cependant un exemple (Sachs). Toute cellule vivante pourra servir à constater ces propriétés.

Forme. - La forme du protoplasma n'est point définie. Elle varie à l'infini, et cela sous diverses influences dont les principales reposent dans les conditions mêmes de son existence :

$1^{\circ}$ Limité par une paroi, on le verra, si la cellule est jeune, remplir complétement la cavité de cette ce!lule. Il tend d'ailleurs à la forme sphérique ou ovoïde; c'est en effet la forme ordinaire des jeunes cellules qui sont nées par formation libre, et, lorsqu'une partie de sa masse se condense pour former un noyau, celui-ci prend la forme d'une masse homogène ou granuleuse, tantôt régulièrement arrondie, tantôt plus ou moins ovoïde; mais bientôt le suc cellulaire venant à se produire dans la cellule détermine au milieu de la masse protoplamastique de petites cavités, ou vacuoles (Voir fig. 20, G, page 52); le protoplasma est alor's rejeté contre la paroi cellulaire où il forme une couche continue apperée utricule azotée; des tractus protoplasmatiques traversent seuls alors la cavité cellulaire rattachant ainsi le noyau à la paroi protoplasmatique.

Utricule protoplasmatique ou azotée. - Cette nouvelle distribution du protoplasma dans la cellule constitue une modification dans la forme, amenée par les progrès du développement. Aussi ne s'étonnera-t-on pas de la retrouver dans toutes les cellules dont l'accroissement est assez avancé. Si la cavité de la cellule est très-grande, le revêtement interne formé par le protoplasma contre la paroi cellulaire pourra être difficile à aperce. voir, mais il sera facile de le mettre en évidence, car il existe toujours tant que les cellules sont vivantes. Il 'suffit, pour le 
faire apparaître, d'employer une goutte d'un acide faible, ou d'une liqueur alcaline, ou encore une solution de sucre ou de glycérine. Sous l'influence de ces réactifs, le protoplasma perd de son eau, se contracte et se détachant de la paroi cellulaire apparaît comme une fine membrane.

Pour observer l'utricule azotée et les tractus protoplasmatiques qui se rendent au noyau, on prendra de préférence des cellules dépourvues de chlorophylle. Lépiderme ou même le parenchyme de la partie inférieure des feuilles des Liliacées ou des Iridées seront très-convenables pour cette étude. On sépare l'épiderme par petites plaques que l'on soulève en un point au moyen d'une aiguille dirigée parallèlement au plan de la feuille, puis avec une pince on enlève par une traction modérée un lambeau de cet épiderme qu'il suffit de placer sous le microscope dans l'eau ou dans l'albumine d'œuf. Pour le parenchyme on devra faire sur la feuille quelques coupes minces. Sur les feuilles de l'Iris germanica par exemple, on voit très-bien dans les cellules allongées ou un peu polyédriques du parenchyme ou encore dans les cellules tabulaires de l'épiderme l'utricule azotée granuleuse lapissant la face interne de la paroi de cellulose.

De forts noyaux arrondis ou allongés présentant un ou deux gros nucléoles brillants et de nombreuses granulations se tiennent tantôt au milieu, tantôt contre la paroi de la cellule. Un grand nombre de tractus protoplasmatiques partent d'une couche plus ou moins mince de protoplasma qui entoure ces noyaux et vont en divergeant atteindre le protoplasma périphérique.

$2^{\circ}$ Le protoplasma libre affecte souvent aussi la forme de masses rondes ou ovoïdes. Il suffit pour s'en convaincre d'observer quelques algues telles que les Vancheria, Spirogyria, ou OEdogonium. On verra que les Zoospores qui en naissent et qui ne sont formées que d'une masse protoplasmatique, tout d'abord dépourvue de membrane d'enveloppe, affectent une forme ovoïde presque constante. Il en est de même des spores qui naissent dans les thèques d'un grand nombre de champignons. On reconnaît en outre dans ces divers exemples, qu'à sa périphérie le protoplasma se différencie en une 
couche plus ou moins épaisse hyaline, homogène, que M. Hanstein nomme couche membrane. D'autres champignons tels que les Myxomicètes qui sont formés d'une masse de protoplasma libre et dépourvu d'enveloppe, nous montrent que cette substance peut dans certaines conditions modifier sa forme; ces modifications se rattachent d'ailleurs à une propriété du protoplasma qui est la contractilité.

Contractilité. - La rétractilité et l'extensibilité sont les deux conditions d'existence de la contractilité. Les champignons myxomicètes offrent d'excellents sujets d'observations. Parmi ceux-ci, il est facile de se procurer la fleur duTan (OE thalium septicum). Ce champignon à une certaine époque de son existence consiste en une masse protoplasmatique, nue, jaunâtre ou brune, que l'on peut conserver en parfait état et dont on peut observer le développement en ayant soin de placer le tan humide sur lequel il vit, dans un vase plat que l'on recouvre d'une cloche pour éviter l'évaporation de l'eau. On voit alors ces masses protoplasmatiques se déplacer et parcourir assez rapidement des distances relativement grandes, il n'est besoin pour cela d'aucun appareil grossissant. Toutefois si l'on veut étudier plus à fond le phénomène, il suffira de placer sur le tan quelques porte-objets; bientôt l'une de ces plasmodies venant à se placer sur l'une des lames de verre, il suffira de la porter sous le microscope, et à l'aide d'un faible objectif on verra la masse protoplasmatique progresser par des mouvements connus du nom de mouvements amboide. Ces mouvements consistent en une extension de certaines parties de la plasmodie en forme de bras qui, venant à se toucher, puis à se confondre, déterminent de la sorte un véritable déplacement de toute la masse. En même temps de plus petits bras se forment de place en place qui se rétractent ensuite et qui semblent aider par leurs mouvements à la reptation de la plasmodiè. C'est là un excéllent exemple de contractilité. - Lorsque nous avons parlé plus haut (Voir p. 75 ) de la formation de l'utricule azotée, nous avons dit qu'une portion du protoplasma reste à l'état de tractus tendus entre le noyau et le protoplasma pariétal; ces tractus 
qui s'étendent parfois sur de grandes longueurs (cellules épidermiques allongées des feuilles de monocotylédonées) n'existeraient pas si le protoplasma ne jouissail d'une extensibilité manifeste. D'autre part, les phénomènes d'agrégation du protoplasma dans les poils glanduleux des Drosera (Voir Darwin, Planles insectivores) et dans les cellules de beaucoup de tissus fournissent de nombreux sujets d'étude pour l'observation de la contractilité du protoplasma. Il en est de même de la contraction du protoplasma dans la formation de cellules par rajeunissement ainsi que de la contraction qui donne naissance au noyau des cellules.

Examen des mouvements du protoplasma. - Le protoplasma vivant se meut; ces mouvements partiels ou de totalité ont reçu les noms de circulation et de rotation.

$1^{\circ}$ Circulation. - Lorqu'on examine au microscope l'OE thalium septicum, on constate dans la masse de la plasmodie, la production de courants dirigés dans des directions variées. Une substance fluide, granuleuse, ressortant sur le reste de la masse par une coloration plus pâle, se meut dans un sens déterminé; c'est comme le cours d'un ruisseau rapide; si la plasmodie, ce qui est fréquent, a absorbé quelque débris un peu volumineux des substances sur lesquelles elle rampait, on peut voir ce débris entraîné par le courant; c'est là ce qu'on appelle la circulation du protoplasma. On peut encore observer ce phénomène dans les cellules en pleine activité vitale; les courants parcourent alors non-seulement l'utricule azotée, mais encore les tractus protoplasmatiques, lantôt se rendant du noyau à la paroi, tantôt de la paroi au noyau.

$2^{\circ}$ Rotation. - D’autres mouvements désignés sous le nom de rotation du protoplasma consistent en des déplacements circulaires des masses protoplasmatiques entières que renferment les cellules. Pour observer la rotation, on aura recours avec avantage à la Valisneria spiralis. Pour cela, on fait une coupe pas trop mince dans la feuille de cette plante, et on l'observe en ayant soin de maintenir toujours sous le couvreobjet une assez grande quantité d'eau. Pour bien suivre les mouvements, on devra fixer de l'wil une granulation plus 
grosse ou remarquable par sa réfringence ou sa forme; on se rendra compte ainsi aisément du déplacement. Les exemples de cẹphénomè ne sont d'ailleurs très-nombreux. En règle générale, pour l'observer dins les organes peu compliqués (poils, Characées), il suffit de placer ceux-ci directement dans l'eau. Pour les herbes, on fera une section longitudinale que l'on placera également dans l'eau ordinaire. Enfin, pour l'observation dans les éléments (cellules ou vaisseaux) des arbustes et des arbres, il sera nécessaire de placer les sections longitudinales de la tige dans de l'eau gommée d'autant plus concentrée que la tige est plus ferme; grâce à cet artifice, M. Velten a pu manifester la rotation du protoplasma dans les cellules grillagées et dans les cellules de la région cambiale d'un grand nombre de végétaux. On devra dans toutes ces observations tenir compte de la température à laquelle on opère. Au-dessous de 10 degrés les mouvements se ralentissent à mesure que la température descend. Ils s'accélèrent entre 10 el 22 degrés; ils se ralentissent au delà pour cesser entre $4 \breve{5}$ et 48 degrés (Robin, Anat. et phys. cellulaires, p. 5ั37).

Sujets d'étude. - Outre le Valisneria spiralis, nous recommandons spécialement les Characées qui montrent avec une grande évidence la rotation du protoplasma. On choisira les Nitella de préférence aux Chara. Ces derniers, en effet, sont revêtus d'une écorce qui rend l'observation plus difficile. Les poils des racines d'Hydrocharis morsus, ainsi que ceux des étamines du Tradescantia (fig. 26) ou encore les poils étoilés du calice des fleurs d'Althœa rosea non encore épanouies sont également d'excellents sujets d'observation, à condition toutefois que ces poils soient

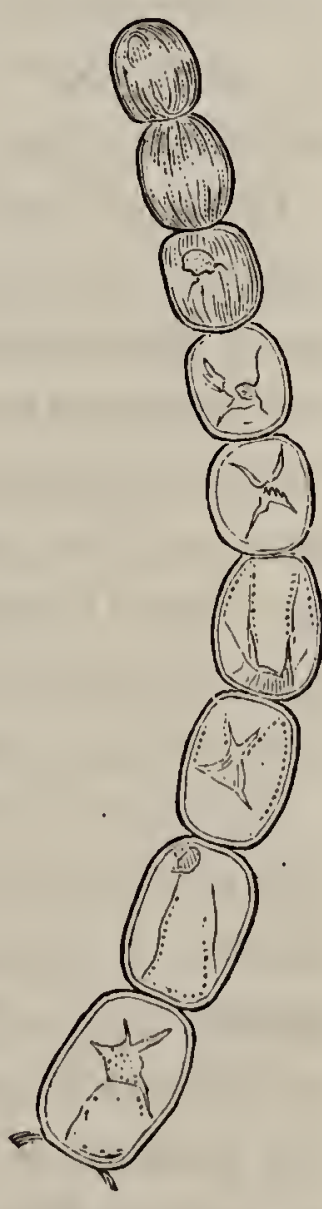

Fig. 26 . pris sur des individus en pleine végétation. M. Velten a observé la rolation dans les tiges des Sida, Heracleum, Astragalus, Pavia, Artemisia, etc., dans les cellules grillagées de l'OEsculus hippocastanum, dans les cellules de la région 
cambiale des Fraxinus excelsior, Sophora Japonica, Pavia neglecta, etc. (1).

Mouvements vibratiles et de locomotion. - Mouvement brownien. - On doit rapprocher des mouvements précédents certains mouvements que l'on rencontre particulièrement chez les Algues.

Les spores motiles et les anthérozoïdes d'un grand nombre de ceś végetaux (Vaucheria, OEdagonium) présentent sur leur surface de nombreux petits filaments animés de mouvements rapides qui les font progresser. Ces filaments hyalins ou cil; vibratiles sont répartis de façons très-diverses. On les verria rapprochés et recauvant toute la surface des Zoospores chez les Vaucheria sessilis et sericea. Chez les AEdogonium les cils forment une petite couronne à l'extrémité antérieure hyaline de la zoospore. Ailleurs il n'y a que deux cils dirigés souvent en sens contraire; c'est le cas le plus fréquent dans les anthérozoïdes.

D'autres mouvements curieux et faciles à observer sont ceux que présentent un grand nombre de conferves. Les Oscillaires par exemple, algues d'un vert bleuâtre, rectilignes, offrent des mouvements très-curieux d'oscillation qui se répètent à intervalles presque réguliers. Les filaments des Nostoc s'échappent de leur gangue par des mouvements comparables à ces derniers. Les Bacteries enfin présentent des mouvements oscillatoires, avec inflexions légères, et accompagnés de progression plus ou moins rapide.

Enfin on a donné le nom de mouvement brownien à une sorte d'oscillation sur place que présentent toutes les granulations ayant moins de כ̆ à 6 millièmes de millimètre d’épaisseur. Ce mouvement se manifeste à la condition que le liquide dans lequel se trouvent les granulations ne soit pas trop visqueux. II n'a aucune analogie avec les mouvements amiboïdes, ciliaires et autres dont il vient d'être question, et on le distingue du mouvement oscillatoire que possèdent les Bactéries et les Vibrioniens en général, à ce que l'ammoniaque fait cesser ce

(1) Velten : Uber die Verbreitung der Protoplasmabewegungen im Pflanzenreiche, Botanische Zeitung, 6 septembre 1872, p. 615. 
CHAPITRE II. - ÉLÉMENTS ANATOMIQUES.

dernier, landis que le même réactif n'a aucune action sur le mouvement Brownien.

ART. 4.

\section{Étude des produits d'élaboration du protoplasma.}

Sous ce titre nous étudierons successivement la cellulose et la paroi des cellules, la chlorophylle et le contenu des cellules.

\section{S I. EXAMEN DE LA PAROI DES CELLULES.}

Alors que les cellules sont encore très-jeunes, elles ne possèdent point en général de paroi de cellulose, et les réactifs ne peuvent en déceler l'existence; le plus souvent en effet la cellulose n'apparaît qu'après la naissance de la cellule sous forme d'une couche mince, hyaline; cependant dans quelques cas de division des cellules on peut voir apparaître la cellulose pendant la segmentation même du protoplasma de la cellule mère. C'est ce que l'on pourra observer par exemple dans le cas de la division des cellules de Spirogyra (Voir p. 70). Ici la plaque granuleuse cellulaire apparaît successivement sous forme d'anneaux concentriques qui s'emboitent les uns dans les autres et forment bientôt une cloison complète. Or si l'on emploie les réactifs appropriés, on verra que ces anneaux se clivent pour ainsi dire, donnant ainsi lieu à un espace dans lequel se dépose la cellulose sécrétée par le protoplasma. Celle-ci se forme donc successivement, et finalement elle constitue une membrane simple, complète, qui s'unit par son bord ì la couche interne d'épaississement de la paroi de la cellule mère (Strasbürger, loc. cit.). Quelle que soit d'ailleur's l'époque à laquelle apparaît la paroi cellulosique, celle-ci n'est d'abord que très-peu apparente. Nous avons indiqué ailleur's les procédés que l'on devra employer pour s'assurer de son existence. Mais la paroi cellulaire ne conserve généralement pas cel état. Le protoplasma vivant continue de sécréter de la cellulosée et dès lor's la paroi s'accroît graduellement, non pas comme on l'a cru longtemps par suite 
de la superposition de nouvelles couches de cellulose, mais par suite d'une véritable intussusception ou nutrition intime aux dépens des éléments élaborés par le protoplasma. Dans le cours de ce développement, deux phénomènes se produisent : d'une part, un accroissement en étendue de la paroi cellulaire, accroissement qui détermine la forme générale de l'élément; d'autre part, un accroissement en épaisseur, qui amène dans la structure propre de la membrane cellulosique des modifications plus ou moins profondes et variées. A l'étude de l'accroissement de la paroi cellulaire se rattachent donc l'étude de la forme des cellules et celle de la structure de leur paroi.

\section{EXAMEN DE LA FORME DES CELLULES.}

La forme typique de la cellule est la forme arrondie ou ovoïde; dans ce cas l'influence prépondérante revient au noyau qui joue le rôle d'un centre d'attraction vers lequel se groupent les molécules protoplasmatiques. Mais si plus tard le noyau pour une raison quelconque devient plus ou moins indépendant du protoplasma, la forme que revêtira la cellule sera soumise à d'autres influences. On a souvent invoqué le contact des cellules groupées en tissu. Il est certain que dans de telles conditions, les cellules sé gênant réciproquement, le développement en étendue de leur paroi se fait d'une manière plus ou moins irrégulière. Toutefois cette influence n'est pas absolument prépondérante. Il'suffit pour s'en convaincre de remarquer que le plus souvent dans un organe déterminé; les cellules qui le composent affectent toujours la même forme générale, et que côte à côte on voit des cellules de formes tout à fait différentes. Nous ne saurions indiquer de meilleur exemple de ce fait, que l'observation si facile à faire du mésophylle hétérogène de la plupart des feuilles. Les influences qui agissent sur la forme des cellules sont donc variées. Quoi qu'il en soit, pour faciliter l'étude des principaux types de cellules, on peut les classer en deux groupes distincts, savoir: les cellules courtes et les cellules longues. Les cellules courtes pourront, en outre, être subdivisées en cellules à con- 
tours géométriques et cellules à contours non géométriques.

Mode opératoire. - L'observation de ces divers types n'exige aucune préparation spéciale. Si l'on a affaire à des cellules vivant séparées et indépendantes, il suffira de les placer sur le porte-objet dans un véhicule approprié, eau, glycérine. Si les cellules à examiner sont réunies en tissu, on fera des coupes fines sur ce tissu, et on montera ces coupes comme il a été dit plus haut. Toutefois ou n'oubliera pas en règle générale que, pour prendre une connaissance exacte de la forme des cellules réunies en tissu, il ne suffit pas de faire une coupe dans un seul sens; on n'arriverait ainsi qu'à déterminer très-imparfaitement la forme de l'élément. On doit multiplier les coupes dans des directions diverses et toujours aroir soin, lorsqu'on fait une coupe dans un organe, de prendre un point de repère. Dans une tige par exemple on prendra comme point de repère l'axe de cette tige; dès lors si l'on veut étudier la forme des cellules du parenchyme médullaire, par exemple, on fera une première coupe perpendiculairement à l'axe, puis une seconde coupe parallèlement à cet axe. On se rendra compte ainsi $: 1^{\circ}$ de la forme de la cellule; si elle est courte, elle présentera un diamètre à peu près de même dimension dans les deux sens; si elle est allongée, l'un des diamètres l'emportera sur l'autre; $2^{\circ} \mathrm{du}$ sens dans lequel est placée la cellule, par rapport à l'axe de la tige.

Sujets d'étude. - Il va nous suffire d'indiquer pour chaque forme de cellules quelques exemples, qui bien mieux qu'aucune description permettent à l'observateur de prendre rapidement connaissance des modifications qu'entraîne le développement de la paroi dans la forme générale de la cellule.

\section{A. CELLULES COURTES.}

a. $\Lambda$ forme géométrique.

$1^{\circ}$ Cellules arrondies ou globuleuses. - Cellules ovoïdes. Ces formes s'observent presque constamment dans les cellules libres et non organisées en tissus, à condition toutefois qu'au moment où elles se sont formées, elles n'aient pas pris naissance réunies en grand nombre dans un étroit espace, 
car alors elles deviennent plus ou moins irrégulières; c'est ce que montrent les spores des Lycopodium et celle de beaucoup de Fougères dans lesquelles on trouve trois ou quatre faces planes tandis que le reste de la surface qui n'était point gèné dans son développement est sphérique.

Les spores d'un grand nombre d'algues, spores motiles (Vaucheria, OEdogonium, etc.), ou spores immobiles (Fucus vesiculosus, etc.). Les thécaspores d'un grand nombre de champignons et de lichens présentent, en général, l'exemple de cellules arrondies ou ovoïdes. On rencontre également cette

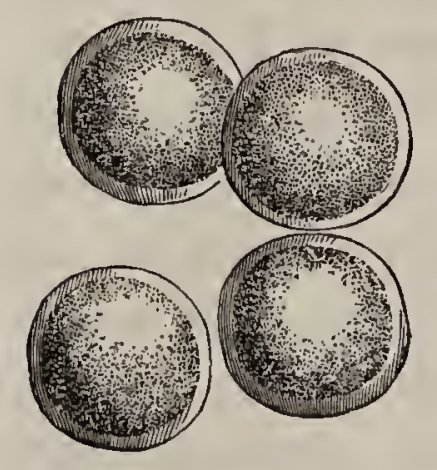

Fig. 27. - Pollen de Ranunculus repens. forme dans les tissus mous des plantes vertes. Une coupe mince à travers le parenchyme cortical d'un grand nombre de tiges, ou à travers les feuilles des Liliacées, montrera également des cellules qui, très peu serrées les unes contre les autres conservent leur forme sphérique. On peut étudier encore comme cellules sphéri. ques lesgrains de pollen d'un grand nombre de plantes (Graminées, Passisflores, Malvacées, etc.) (fig. 27).

$2^{\circ}$ Cellules polyédriques. - La forme polyédrique est celle qu'affectent en général les cellules groupées en tissu. En effet, par compression réciproque, les cellules s'aplatissent sur leurs faces en contact, et prennent alors

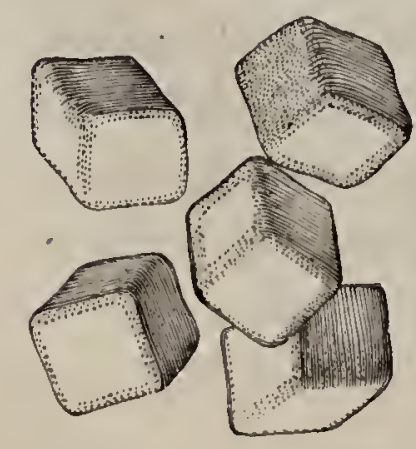

Fig. 28. - Pollen de Basella rubra. des formes variées.

Les formes les plus fréquentes son t le cube, le dodécaèdre et le rhomboèdre. Les cellules cubiques se reconnaissent au moyen des coupes, à leur section carrée. On les observe dans les épidermes de beaucoup de feuilles et de tiges, dans cerlains pollens (fig. 28). Les cellules dodécaédriques pourront être étudiées dans la moelle de sureau (fig. 29). Des coupes minces montreront une section hexagonale; mais, pour bien se rendre compte de la forme de ces éléments, nous conseillons de faire des coupes comprenant deux plans de cellules superposés. 
On trouve des cellules polyédriques dans la moelle de la plu. part des végétaux, dans le parenchyme cortical des tiges vertes et surtoui dans celui des pétioles d'un grand nombre de feuilles.

La forme rhomboédrique est parliculièrement intéressante: c'est elle, en effet, qui, sous le nom de cellules muriformes, concourt à la formation des rayons médullaires dans le bois des végétaux ligneux principalement, et d'autre part sous le nom

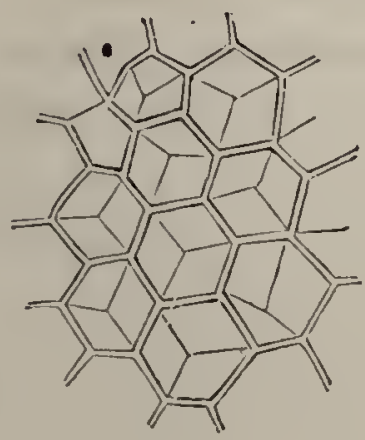

A

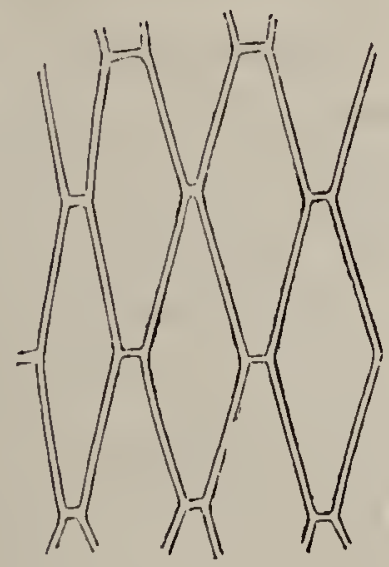

c

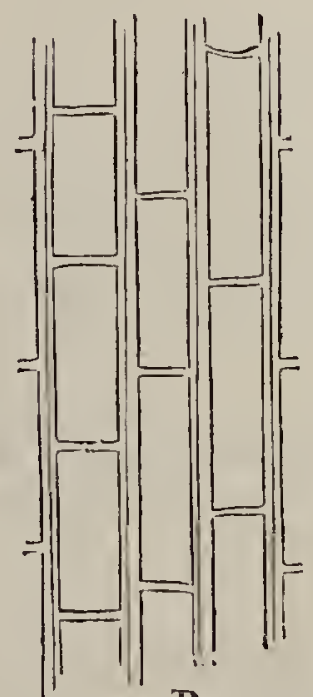

B

Fig. 29.

Fig. 30 .

Fig. 31 .

de cellules tabulaires, forme les tissus subéreux (liège du bouleau et du cerisier) et les couches épidermiques de la plupart des végétaux. Le plus souvent les épidermes des feuilles, des liges, des pièces du périanthe, etc., sont formés de cellules polyédriques aplaties dont les faces peuvent être losangiques (épiderme de jacinthe, fig. 30), hexagonales (Lilium candidum), ou encore rectangulaires (cellules épidermiques de la tulipe, fig. 31). Les cellules tabulaires, remarquables par cette localisation spéciale, peuvent d'ailleurs offrir des variétés de forme innombrables, et il nous paraît inutile d'insister davantage.

B. CELLULES A CONTOURS NON GÉOMETRIQUES.

Nous ne signalerons que quelques-unes des formes les plus intéressantes :

$1^{\circ}$ Cellules étoilées. - Un inégal développement en surface de la membrane cellulaire détermine, s’il se produit avec quelque 
régularité, des saillies disposées comme les branches d'une étoile, séparées par des angles rentrants plus ou moins prononcés. On rencontre cette forme de cellules dans le parenchyme central des tiges des Juncus effusus, glomeratus, etc. (fig. 32), ainsi que dans le parenchyme du pétiole du $N y m p h x a$, du $N e-$ nuphar, et dans les feuilles d'Helleborus, de Gladiolus, etc. Des

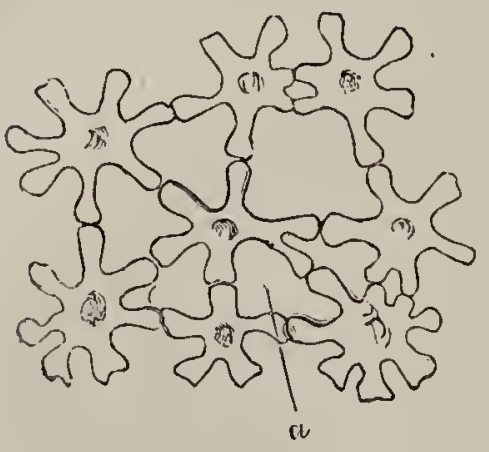

Fig. 32. - Cellules étoilées de la moelle du Juncus effusus. a. lacune produite par ces cellules. coupes très-minces sont nécessaires pour bien observer ces cellules, et il est absolument utile de donner à la section un sens convenable afin de ne point couper obliquement les cellules; on obtiendrait sans cette précaution des images de cellules tronquées et privées d'un certain nombre de leurs prolongements, ce qu'il faut éviter. D'autre part, comme ces sortes de cellules forment des tissus assez lâches, le débutant peu habitué à faire des coupes minces arrivera plus facilement au but en pratiquant ses coupes sur des portions de tiges traitées pendant un certain temps par l'alcool absolu, de façon à donner plus de consistance au tissu.

$2^{\circ}$ Cellules rameuses. - Comme précédemment, la forme de

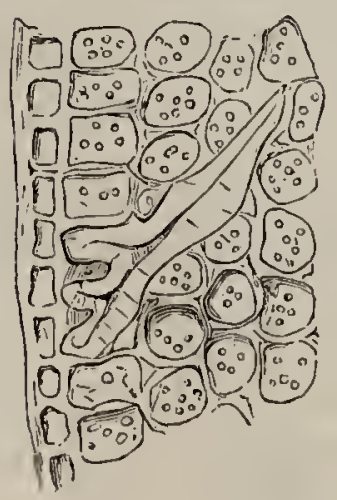

Fig. 33. - Une cellule rameuse à parois épaissies au milieu du parenchyme de la leuille du Camellia japonica. ces cellules est due à un développement inégal en différents points de la surface de la membrane cellulaire; mais ici ce développement s'est fait avec irrégularité. Un bon exemple de cellules rameuses est celui que l'on trouve dans le limbe d'un trèsgrand nombre de feuilles, principalement chez les Dicotylédonées. Au contact avec l'épiderme inférieur de ces feuilles on observe au moyen de coupes minces un parenchyme formé de cellules à contours très-irréguliers. Des cellules rameuses remarquables par leur grandeur el leur difformité se rencontrent encore isolées dans le parenchyme de certaines feuilles. Le mésophylle des feuilles du Camellia japonica,(fig. 33) présente un très-grand nombre de ces grandes 
cellules, isolées, à contours très-irréguliers. Ici, les parois des cellules se font de plus remarquer par leur grande épaisseur.

Dans ce groupe enfin doivent encore être classées maintes cellules de forme indéterminée, et particulièrement ces cellules pourvues de saillies et de bourgeonnements ou gemmes que l'on rencontre dans le tissu du chapeau de beaucoup de champignons et particulièrement chez les agarics et les bolets.

\section{CELLULES LONGUES.}

Ces cellules, caractérisées par le développement que prend l'une de leurs dimensions, sont tantôt cylindriques, tantôt prismatiques par pression réciproque. On peut distinguer deux types principaux qui se rattachent à ce groupe :

$1^{\circ}$ Les cellules allongées proprement dites, ou cellules filamenteuses, dont les parois sont généralement minces et les extrémités terminées par des plans horizontaux. Ces éléments se trouvent dans le parenchyme central de la tige d'un grand nombre de végétaux, particulièrement au voisinage du point végétatif, là où l'accroissement se fait rapidement. Elles sont dans ce cas placées parallèlement à l'axe du végétal. D'autres sont allongées horizontalement, c'est-ì-dire perpendiculairement à la direction longitudinale de l'organe végétal, par exemple dans les rayons médullaires de la plupart des bois (Abies, Quercus, Pinus, Fagus).

La plupart des conferves offrent également de bons exemples de cellules allongées, d'autant plus faciles à observer qu'elles ne demandent aucune préparation spéciale, et qu'elles ne forment jamais que des systèmes très-simples (fig. 34).

Un grand nombre de poils unicellulaires, tels que le coton, doivent également rentrer dans ce groupe.

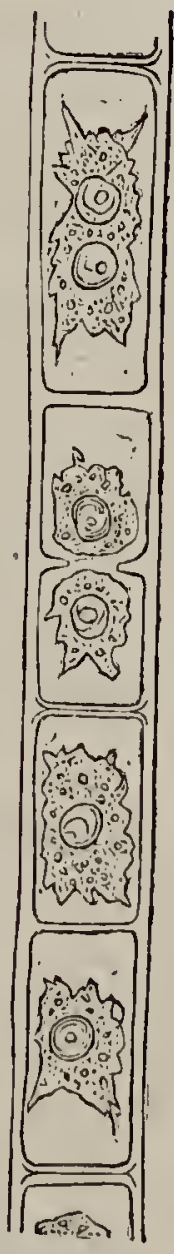

Fig. 34 .

20 Cellules fibreuses, clostres, fibres. - On a désigné sous ces dénominalions des cellules allongées, terminées en général par des plans obliques, ou dont les extrémités forment des pointes 
plus ou moins mousses. Elles rentrent pour la plus grande part dans la constitution du bois el du liber des plantes, et se font encore remarquer par l'épaisseur de leur paroi qui peut aller même jusqu'à obstruer complélement leur cavité centrale. Elles reçoivent dans le bois le nom de fibres ligneuses et dans le liber le nom de fibres libériennes. Pour les observer, on devra pratiquer des coupes longitudinales et transversales. Il sera même bon d'employer les moyens de dissociation que nous avons indiqués plus haut (page 42), car si l'on veut mesurer leur longueur, il est souvent difficile sur une coupe longitudinale de suivre leurs extrémités minces qui se perdent entre les fibres voisines avec lesquelles elles sont généralement très-intimement unies. Le plus souvent, les fibres libériennes qui se distinguent déjà des fibres ligneuses par leur localisation dans l'écorce, se distinguent encore par le diamètre très-petit de leur cavité centrale qui se réduit au point de n'apparaître plus que comme une ponctuation sur la coupe transversale. Les fibres du bois ne sont pas à l'ordinaire aussi épaissies. De plus les parcis des fibres libériennes sont généralement beaucoup plus réfringentes que cclles des fibres ligneuses. Enfin les faisceaux de fibres libériennes offrent sur les coupes transversales une apparence satinée que ne possèdent qu'à un bien moindre degré les fibreś ligneuses. Ces différences cependant ne sont pas constantes, et on ne saurait les considérer comme propres à établir une démarcation absolument tranchée entre ces deux ordres de fibres.

"ropriétés physiques. - Les fibres ou clostres, nous l'avons dit, concourent pour une part très-considérable à la formation des diverses parties de l'axe des végétaux; ce sont elles qui, grâce à leur ténacité, constituent pour ainsi dire la partie squelettique des plantes; on ne s'étonnera pas par suite de les voir manquer dans un grand nombre de végétaux à tige verte et molle où elles sont remplacées par des cellules allongées prismatiques ou cylindriques. Mais la ténacité n'est pas la seule propriété dont jouissent la plupart des fibres. Dans beaucoup de végétaux elles joignent à la ténacité la flexibilité, ce sont ces deux propriétés que l'industrie utilise dans la con- 
fection des tissus, cordages, etc. Ces éléments, ainsi que divers autres tels que les cellules allongées qui garnissent les graines du cotonnier, constituent les matières dites textiles. Nous croyons devoir entrer dans quelques détails au sujet des fibres considérées comme éléments textiles, car, leurs propriétés varient avec leur origine et leur nature. Nous emprunterons dans l'exposé qui va suivre au mémoire intéressant publié sur ce sujet par M. Vétillart (1).

\section{$\S$ II. MATIÈres TEXTILes vÉGÉtALIS.}

L'industrie européenne n'emploie couramment que quatre textiles retirés des plantes, ce sont : le lin, le chanvre, qui font l'objet de grandes cultures dans nos contrées; le jute, qui depuis quelques années a pris une place importante dans l'industrie; le coton, enfin, dont les centres de production sont l'Amérique et l'Asie. Ce dernier textile diffère comme nature des trois premiers, mais il rentre dans le groupe des cellules allongées aussi bien que les fibres.

Outre les substances textiles que nous venons d'énumérer il en est d'autres dont l'usage commence à se répandre, et qui acquièrent de jour en jour une plus grande importance. De ce nombre sont le chanvre pite ou aloès, produit par l'Agave americana, les fibres du Phormium tenax, celles de l'Alfa de nos colonies algériennes, celles enfin du Stipa tenacissima, etc.; beaucoup d'autres qui ne sont point encore arrivées sur nos marchés sont en usage dans les pays de production.

Aspect extérieur des fibres textiles. - Toutes lès matières textiles dont il est ici question sont produites soit par des Monocotylédones, soit par des Dicotylédones. Or, au premier abord, un cil exercé peut le plus souvent reconnaître à laquelle de ces deux origines se rapporte un faisceau de fibres donné. Les fibres des Monocotylédones sont généralement blanches ou d'une teinte fauve très-claire, et ont reçu en Angleterre le nom de fibres blanches. Ces fibres, soyeuses, bril-

(1) Études sur les filres végétales textiles cmployées dans l'inchustrie, par M. Vétillart. Paris, 1876. 
lantes et d'une grande pureté, doivent ces propriétés extérieures à leur mode de préparation. On n'emploie en effet pour les isoler des autres tissus de la plante que des moyens mécaniques, consistant en un broiement du végétal entre des pierres suivi de lavages à l'eau. Les fibres des Dicotylédones au contraire sont en général assez fortement colorées en brun. Beaucoup plus longues ordinairement que les premières, et enchevêtrées les unes dans les autres en même temps que fortement attachées au tissu qui les environne, elles nécessitent pour être isolées l'emploi du rouissage, ou macération dans l'eau, qui a pour but de détruire partiellement par la fermentation les matières et les tissus qui les enveloppent. Si l'opération est bien menée, les fibres se présentent agrégées sous formes de rubans plus ou moins étroits, propres, souples, brillants.

La valeur des fibres textiles variant suivant leurs propriétés, suivant.qu'elles sont plus ou moins tenaces et plus ou moins souples, on ne devra pas s'en tenir à un examen superficiel, mais recourir aux procédés plus sûrs que nous allons indiquer.

Examen des fibres textiles. Mode opératoire. - Sans nous arrêter aux moyens plus ou moins approximatifs et défectueux qui pendant longtemps ont été mis en usage dans l'examen des matières textiles, nous allons exposer avec quelques détails la méthode indiquée par M. Vétillart (loc. cit.).

Tout d'abord, et c'est là un point capital, avant de procéder à l'examen des matières en expérimentation, il faut leur faire subir une préparation qui a pour but de désagréger les éléments fibreux qui les composent. Pour cela on fait bouiliir pendant une demi-heure au moins les échantillons (filasse, fils, tissus) à examiner dans une lessive contẻnant environ 10 p. 100 de carbonate de potasse ou de soude. Cela fait, on lave l'échantillon à grande eau, et on le fait sécher. Si l'opération a été bien menée, les filaments se laissent aisément dissocier au moyen des aiguilles en leurs fibres composantes. On prélève alors sur la masse trois échantillons nécessaires à l'examen complet.

Le premier servira à l'essai par les réactifs que nous allons indiquer. 
J.e second à l'examen des fibres en long et à leur mensuralion.

Sur le troisième on fera des coupes transversales qui fourniront les caractères les plus importants et permettront de mesurer le diamètre des fibres, d'en apprécier la forme, la structure et par suite de les distinguer les unes des autres (Voir les procédés à employer pour ces coupes, page 41).

Réactifs. - Nous connaissons déjà les réactifs employés par M. Vétillart; c'est en effet l'action combinée de l’iode et de l'acide sulfurique que cet observateur propose pour caractériser les diverses sortes de fibres textiles. Bien que, à propos des caractères chimiques de la cellulose, nous soyons entrés dans certains détails au sujet du mode d'emploi de ces réactifs, nous croyons cependant devoir ici, au risque de nous répéter, indiquer avec précision la marche à suivre dans leur application à l'étude des malières textiles, convaincus par l'essai que nous en avons fréquemment fait, que certaines précautions que nous allons indiquer sont absolument indispensables à la réussite de l'opération.

Lorsqu'on emploie l'iode et l'acide sulfurique on observe que suivant leur nature les fibres se colorent en bleu ou en jaune. Celles dont les parois sont uniquement formées de cellulose pure, prennent la teinte bleue, elles prennent la teinte jaune lorsque leurs parois sont lignifiées ou souillées de matières azotées. Voici comment $\mathrm{M}$. Vétillart conseille de préparer les réactifs en question :

$1^{\circ}$ Dissolution d'iode. - On fait dissoudre un gramme d'iodure de potassium bien pur dans 100 grammes d'eau distillée. Puis, on ajoute un excès d'iode, de manière que le liquide en soit toujours saturé. On conserve la dissolution dans des flacons bouchés à l'émeri, en ayant soin de veiller à ce qu’il y ait toujours au fond du liquide quelques morceaux d'iode pour en assurer la saturation constante. Cette dissolution s'altère au bout de quelques mois; aussi devra-t-on en préparer peu à la fois et renouveler la préparation lorsque les réactions ne semblent plus aussi nettes.

$2^{\circ}$ Acïde sulfurique étendu. - L'acide sulfurique ne peut être employé pur, car il désagrégerait la cellulose ; voici la compo- 
sition qui semble donner les meilleurs résultats : Mélangez dans un flacon deux volumes de glycérine concentrée, et un rolume d'eau distillée; plongez le flacon dans l'eau froide jusqu'au niveau du liquide qu'il contient, et ajoutez peu à peu en agitant trois volumes d'acide sulfurique du commerce à $66^{\circ}$. Ce liquide s'altère rapidement. On peut lui rendre son énergie en l'additionnant de petites quantités d'acide sulfurique.

L'effet de la glycérine dans cette préparation est, comme le fait remarquer M. Vétillart, d'une grande importance.

Elle modère l'action de l'acide, de manière à ne pas déformer les préparations tout en leur donnant une coloration bien marquée après l'imprégnation par l'iode.

Ces réactifs étant préparés, si l'on veut en faire usage et obtenir des résultats constants, deux précautions indispensables doivent être observées, et sur lesquelles nous ne saurions trop insister :

$1^{\circ}$ La première de ces précautions est de n’opérer que sur des échantillons préalablement traités comme nous l'avons indiqué plus haut par une liqueur alcaline (Voir page 90). Ce traitement prépare pour ainsi dire la cellulose à recevoir l'action des réactifs, en la gonflant plus ou moins et la rendant plus pénétrable. Nous avons même obtenu d'excellents résultats en substituant au carbonate alcalin une dissolution concentrée de potasse ou de soude. M. Vétillart, il est vrai, craignant une action trop énergique, rejette l'emploi de ces réactifs; nous devons dire toutefois que daus maintes circonstances où nous n'obtenions point la coloration recherchée au moyen des réactifs et après traitement par les carbonates alcalins, nous avons pu l'obtenir après traitement par la potasse ou la soude caustique. Dans ce cas, pour éviter une action trop énergique qui détruirait les fibres, il faut avoir soin de ne les tremper que pendant quelques secondes dans la liqueur alcaline, et de les laver immédiatement à grande eau.

$2^{\circ}$ La deuxième précaution à prendre, sur laquelle nous insistons également, car elle nous paraît constituer un des principaux écueils à la réussite de l'opération, consiste à ne faire agir l'iode et l'acide sulfurique que sur des échantillons complétement privés d'eau. Si en effet on ne prend la précaution 
de dessécher complétement les filaments en expérience, on risque de n'obtenir aucune coloration. L'acide que l'on fait agir n'est pas concentré, et l'eau qui pourrait imprégner la préparation le diluerait encore et l'empêcherait de réagir sur la cellulose.

Ces précautions étant indiquées, voici le mode opératoire à suivre :

Sur un porte-objet, on dissocie au moyen des aiguilles, et aussi complélement que possible, quelques filaments de la matière à examiner. On imprègne la préparation de 2 ou 3 gouttes de la dissolution d'iode. On laisse le liquide pénétrer complétement les filaments et on l'aspire ensuite au moyen de petits morceaux de papier buvard. Nous recommandons même de les dessécher complétement en les comprimant fortement avec quelques doubles de papier de façon à les priver d'eau autant que faire se pourra. Alors on place sur la préparation un petit verre couvreur et on fait tomber quelques gouttes de la disso. lution d'acide sulfurique le long d'un des côtés du verre à recouvrir. Le liquide pénètre entre les deux lames en vertu de la capillarité et continue à s'avancer vers le côté opposé. Le long de ce dernier, on place, bien en contact avec l'arête du couvre-objet, un petit carré de papier buvard qui aspire le liquide dès qu'il arrive en ce point. Un courant s'établit dès lors d'un bord à l'autre du couvre-objet, chassant devant lui la dissolution d'iode qui pourrait se trouver encore libre dans la préparation. Les fibres ne tardent pas à se colorer en bleu, partout où la cellulose est pure; elles se colorent en jaune là où la cellulose est lignifiée ou pénétrée de matières azotées.

Pour s'assurer du bon état des dissolutions, on aura soin de toujours faire précéder ces recherches d'essais sur des échantillons de coton ou de lin pris comme étalons.

Enfin, les colorations obtenues ne persistant pas au delà de quelques heures, on devra avoir soin de compléter toutes les observations le plus promptement possible, et peu de temps après avoir fait les préparations.

En utilisant les données fournies à la fois par la mensuration des fibres en long et en travers ainsi que par leur forme générale et l'action des réactifs, M. Vétillart est parvenu à établir 
un certain nombre de caractères distinctifs d'une très-grande valeur entre les diverses espèces de fibres employées ou pouvant être employées comme textiles.

Nous allons indiquer ces caractères pour les plus importantes d'entre elles, en suivant dans cet exposé l'ordre adopté par l'auteur de la méthode. Nous formerons donc deux premiers groupes, suivant que les fibres usitées proviennent de plantes Dicotylédones ou de Monocotylédones, et nous étudierons dans chacun de ces groupes, d'une part les fibres qui se colorent en bleu par les réactifs ci-dessus indiqués, et d'autre part celles qui se colorent en jaune par le même traitement.

\section{$1^{0}$ DICOTYLÉDONES.}

$A$. Plantes dont les fibres libériennes se colorent en bleu par les réactifs.

$1^{0}$ Lin. Caractères physiques. - A l'examen dans la glycérine, après dissociation, les fibres

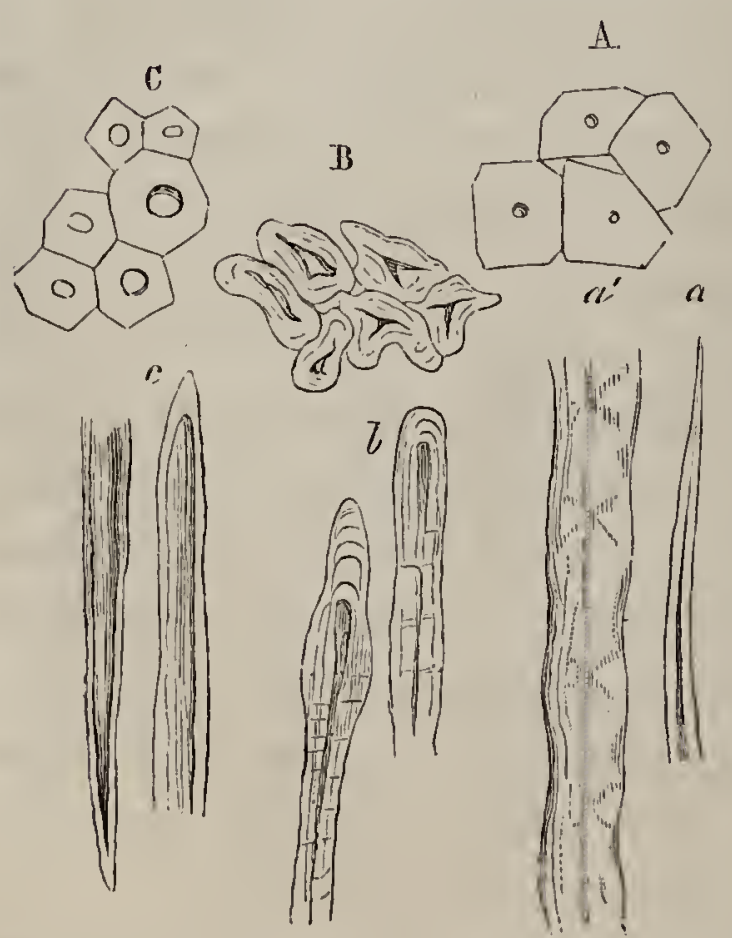

Fig. 35. - A. fibres de lin en coupe transversale. - $a$. extrémité d'une fibre. - $a^{\prime}$. Corps d'une fibre. - B. fibres de chanvres en coupc transversale. - $b$. extrémités de ces fibres. - C. fibres de jute en coupe transversale. $-c$. cxtrémités de ces fibres. (VÉTHLART.) du lin se présentent sous la forme de longs tubes à parois épaisses, très-réfringentes : limitant un canal d'une finesse extrême (fig. 35). - A un fort grossissement, ces fibres montrent des fissures très-déliées s'étendant suivant la longueur du canal. Ces fissures deviennent d'autant plus apparentes que le lin a été fatigué par de fréquents lessivages et un usage prolongé. Si on froisse les filaments de lin avant de les examiner, on constate au microscope la formation de renflements épars surles fibies $\left(a^{\prime}\right)$; ces renflements ne seraient autres que les plis de flexion produits par le froissement. Les fibres du lin mesurent en 
moyenne 25 à 30 millimètres de longueur sur $0^{\mathrm{mm}}, 020$ à

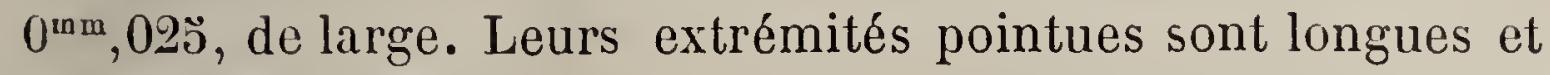
délicates (fig. 35̆,a).

Examen dans les réactifs. - Traitées par l'iode et l'acide sulfurique (p. 92) les fibres du lin se colorent en bleu et se font remarquer par leur grandetransparence; leur canal intérieur, quand il n'a pas disparu complétement comblé par l'épaississement des parois, apparaît comme une fine ligne jaune. Là où existent des renflements sur les fibres, on voit la coloration bleue plus intense affecter une disposition en croix assez curieuse (fig. $3 \check{3}, a^{\prime}$ ).

Si l'on fait des coupes transversales, celles-ci se reconnaîtront à leur forme polygonale (fig. 3ว̆, A); au centre on apercevra une petite ponctuation jaune, c'est la coupe du canal que les réactifs colorent en jaune, tandis que les parois colorées d'une belle teinte bleue laissent voir d'une façon très-ęnette leurs stries d'accroissement.

La qualité du lin varie suivant l'épaisseur plus ou moins grande de ses parois, et le degré de désagrégation amené par le rouissage.

$2^{\circ}$ Chanvre (Cannabis sativa). Caractères physiques. - Le chanvre, tel qu'il se présente sur nos marchés, est plus long, plus raide et plus grossier que le lin; sa couleur est variable. Tantôt jaune pâle ou vert, il peut être brun ou même noirâtre. Les fibres examinées au microscope présentent une longueur variable entre 15 et 25 millimètres. L'épaisseur moyenne est de $0^{\mathrm{mm}}, 022$.

Ces fibres, dont le diamètre est assez irrégulier, sont le plus souvent aplaties, quelquefois pleines et presque lisses à leur surface, d'autre fois cannelées. Elles présentent de nombreuses stries longitudinales et un canal souvent assez large, mais que l'abondance des stries ne permet pas toujours d'apercevoir nettement. Les pointes des fils du chanvre sont tantôt taillées en biseau, ou arrondies à leurs extrémités et présentent du reste des contours très-variés (fig. 35̃, B).

Examen des fibres au moyen des réactifs. - Sous l'influence des réactifs, ces fibres se colorent en bleu ou en violet. Souventaussi elles prennent une teinte verdátre, due à la pré- 
sence d'une membrane très-mince qui les enveloppe entièrement comme une gaîne et qui se colore en jaune, par l'iode et l'acide sulfurique. On met mieux en évidence l'existence de cette enveloppe en faisant agir les réactifs sur les coupes transversales des fibres. On aperçoit alors les sections polygonales plus ou moins régulières, colorées en bleu et entourées d'un mince filet jaune, qui les limite nettement. Cette fine bordure qui donne à chaque groupe de fibres l'aspect d'un émail cloisonné fait reconnaître au premier coup d'œil les tranches du chanvre même lorsque les coupes sont mal réussies. De plus, la cavité de ces fibres ne présente jamais de dépôt granuleux jaune semblable à celui qu'on trouve dans la cavité des fibres du lin. Enfin, les couches concentriques d'accroissement ressortent très-nettement sur ces coupes et prennent des teintes variées (fig. 3̋, B).

$3^{\circ}$ Unn. - Ce textile produit par le Crotalaria juncea est originaire des Indes et a été souvent importé sur nos marchés sous le nom de chanvre des Indes, ou chanvre brun de Bombay, ou de Madras. Il a été employé comme chanvre véritable; aussi est-il bon d'en connaître les caractères distinctifs.

Caractères physiques. - Les dimensions de ces fibres suffiraient à les distinguer des précédentes. Leur longueur en effet est beaucoup moindre et varie entre 7 et 8 millimètres. Leur largeur est en moyenne de $0^{\mathrm{mm}}, 003$. Leurs extrémités sont semblables à celles du lin. En présence des réactifs, les fibres de sunn se comportent à peu près de même que les fibres du chanvre, avec lesquelles on pourrait les confondre, mais leur cavité contrale présente fréquemment un dépôt jaune, et de plus, au milieu des groupes de fibres dont la section transversale affecte la forme d'un croissant, on aperçoit des faisceaux arrondis formant des réseaux à larges mailles d'un jaune foncé, où l'on reconnaît la section de vaisseaux spiralés. Ce sont là des indices de la préparation grossière de ce produit.

$4^{0}$ Coton. - Ce lextile présente des caractères très-tranchés, comme on devait s'y attendre, puisqu'il n'est point formé, comme les précédents, de fibres libériennes, mais de cellules allongées. 
Caractères physiques. - Vus en longueur, les poils du coton se montrent aplatis el souvent tortillés en tire-bouchon. lls forment des rubans dont les bords apparaissent comme deux bourrelets brillants très étroits par rapport à la largeur du ruban, ce qui indique le peu d'épaisseur des parois de ces cellules (fig. 36). Leurs extrémités ne sont pas pointues, mais généralement larges et arrondies.

La longueur des poils qui forment le coton est de 20 à 40 millimètres pour les'sortes dites longues soies, et de 10 à 20 millimètres pour les espèces courtes et communes.

Examen en présence des réactifs. - Ces éléments se colorent en bleu. Le canal présente quelques granulations jaunes dans le coton écru, mais ces granulations disparaissent lors qu'il a été blanchi. Les coupes transversales sont très ca-

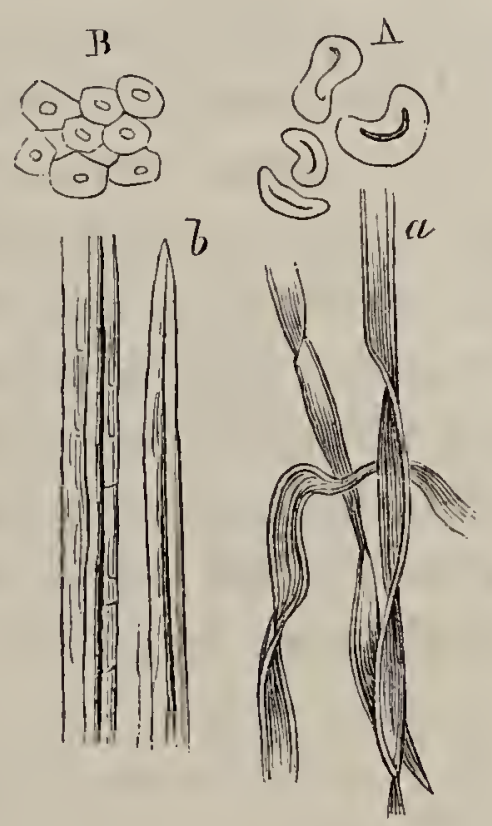

Fig. 36. - A. Coton, coupes transversales. $-a$. Poils vus en long. B. Phormium tenax, coupes transversales. - $b$. Extrémité et corps de fibre. (Vétillart.) ractéristiques; les sections se présentent toujours isolées, et leurs contours plus ou moins tourmentés leur donnent la forme d'un haricot ou d'un rein (fig. 36, A).

B. Plantes dont les fibres sont colorées en jaune par les réactifs.

Jute (Corchorus capsularis, C. olitorius, C. fuscus). - Ce textile originaire de l'Inde a été récemment introduit en Europe et il y occupe aujourd'hui une place importante. Ses usages sont cependant limités, car les tissus qu'il forme ne peuvent résister à une humidité prolongée, et présentent une très faible ténacité. Il y aurait donc fraude à le mélanger aux autres fibres textiles réservées à la confection des tissus qui peuvent être lavés. On emploie le jute dans la confection de toiles à sacs et à emballage ou encore de tapis et de rideaux estimés pour leur bon marché et les couleurs brillantes qu'ils peuvent acquérir par la teinture. 
Caractères physiques. - Examinées en long dans les liquides neutres, les fibres dejute montrent une paroi très réfringente et peu épaisse, circonscrivant une cavité centrale assez large (fig. 35 , G). Ces fibres sont très courtes; leur longueur varie entre $\mathbf{1}^{\mathrm{mm}}, \breve{5}$ et 5 millimètres. Ce fait explique pourquoi les tissus qu'elles donnenl sont peu tenaces et ne peuvent résister à une humidité prolongée sans se désagréger.

Les coupes transversales de ces fibres sont polygonales (fig. 3ö, G), à angles saillants; leur diamètre transversal moyen mesure $0^{\mathrm{mm}}, 022$. La coloration jaune qu'elles prennent sous l'influence des réactifs est un caractère excellent à joindre à ceux que l'on peut tirer de leur longueur et de leur diamètre.

Pour les autres fibres de Dicotylédonées se colorant en jaune par les réactifs, nous renvoyons au mémoire de M. Vétillart, l'emploi n'en étant pas encore très répandu.

\section{B. MONOCOTYLÉDONES.}

$1^{\circ}$ Plantes à fibres colorées en bleu par les réactifs.

$1^{0}$ Alfa (Stipa tenacissima). - Les fibres de cette plante sont fort usitées pour la fabrication du papier, principalement en Angleterre. - Leur longueur moyenne est de $1^{\mathrm{mm}}, \breve{a}$. Leur diamètre transversal de $0^{\mathrm{mm}}, 012$. Elles se colorent en bleu ou violet sous l'influence des réactifs (fig. 3T, A et B).

$2^{\circ}$ Sparte (Lygeum Spartum). - Sert aux mêmes usages que l'Alfa. Longueur moyenne des fibres $2^{\mathrm{mm}}$,̋̀. Diamètre trans-

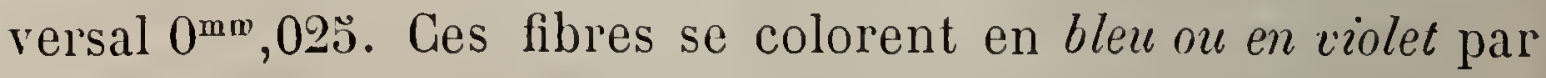
les réactifs.

$2^{\circ}$ Plantes à fibres colorées en jaune par les réactifs.

$1^{\circ}$ Phorminm tenax. - Nous ne ferons qu'indiquer cette plante qui ne se rencontre plus sur nos marchés (fig. 36). - Le jute, qu'on lui attribue fréquemment, provient, nous l'avons dit (Voir p. 97), d'une toute autre plante.

$2^{\circ}$ Chanvre Pite ou Aloès (Agave americana). - Les fibres de l'Agave sont courtes, à parois minces, et à cavité centrale très large et irrégulière (fig. 37, C). Elles sont renflées en leur 
milieu, et se terminent par des pointes larges, dont la forme la plus fréquente est celle d'une lame de sabre (fig. 37, D, $d$ ); elles sont quelquefois lobées ou trifurquées.

Leur longueur moyenne est de $2^{\mathrm{mm}}, \breve{s}$, leur largeur de $0^{\mathrm{mm}}$, (v24. Les réactifs les colorent en jaune.

Sans nous étendre davantage sur ces caractères, que l'on trouvera exposés avec détails dans le mémoire de M. Vétillart,
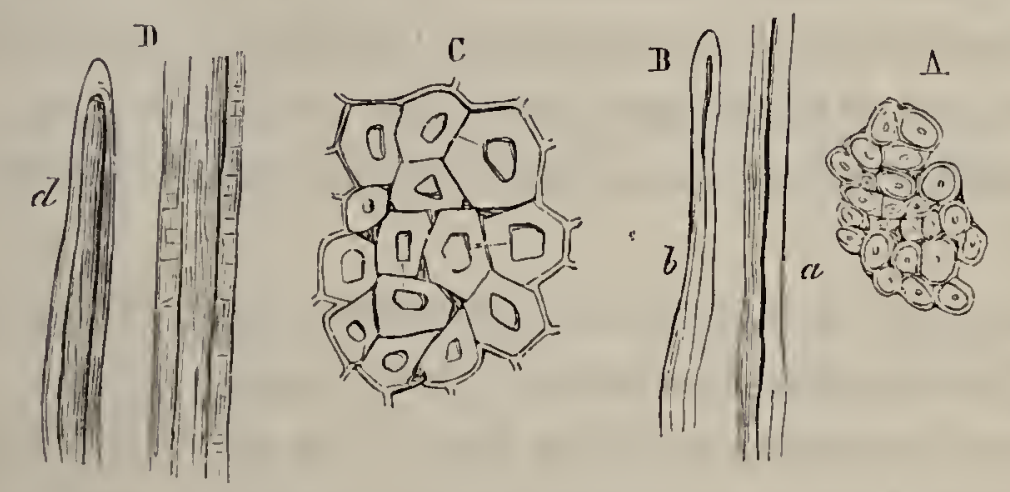

Fig. 37. - A. Fibres du Stipa tenaeissima ("Alfa), en coupe transver'sale. - B. Corps $(a)$ et extrémité des fibres $(b)$. - C. Pite ou aloès, coupe transversale de fibres. - D. Corps de la fibre. - $d$. Extrémité de la fibre.

(Vétillart.)

nous ferons remarquer que l'examen au moyen du microscope ne donne pas seulement des caractères distinctifs entre les différentes espèces de fibres; il permet encore de diviser d'une manière générale toutes ces fibres en deux classes bien tranchées par leurs caractères phyysiques. Les unes, celles qui se colorent en bleu par les réactifs, sont généralement longues, tenaces, souples, susceptibles dès lors de subir, sans se briser, des torsions nécessaires pour la confection des fils et des tissus. Elles résistent aux lavages.

Les autres, qui se colorent en jaune, sont raides, cassantes, et doivent être réservées dès lors pour d'autres usages quie la confection des tissus fins. - On en formera des toiles à sacs, des tapis, des cordages, etc.

Les résultats de cet examen sont donc multiples et, comme le fait remarquer M. Vétillart, montrent qu'il est possible au moyen de l'examen microscopique de déterminer à l'avance, et sans qu'aucune expérience souvent coùteuse ou rebutante ait été faite, la valeur d'une fibre donnée pour un usage déterminé. 
§ 3. ÉTUde DE L'ACcrorssenent EN ǴPAISSEUR de LA PAROI CELLULAiRE.

Les formes variées qu'affectent les éléments cellulaires sont le résultat de l'accroissement en surface de leur paroi. Mais, en étudiant une cellule à divers degrés de son développement, on constate que la couche cellulosique, qui n'était d'abord qu'une membrane mince et délicate, s'accroît peu à peu en épaisseur. Cet épaississement s'accompagne de deux formations :

$1^{\circ}$ De stries dont les unes sont concentriques par rapport à la cavité de l'élément, et les autres obliques ou parallèles à son grand axe ;

$2^{\circ}$ De marques variées qui s'observent aussi bien sur les cellules courtes que sur les cellules longues.

stries. - Les stries sont des lignes ou zones alternativement claires et obscures que l'cn aperçoit sur la coupe des parois épaissies d'un grand nombre de cellules. Ces stries d'inégale réfringence en se juxtaposant donnent à la coupe l'apparence d'une série de zones ou de couches emboîtées. Aussi pensat. on d'abord qu'elles étaient le résultat de la superposition successive de nouvelles couches venant renforcer la menbrane primitive. (H. Mohl.) Cette manière de voir, maintenant abandonnée, assignait donc aux parois cellulaires un mode d'épaississement par juxtaposition. M. Trécul a montré que cet épaississement était au contraire le résultat d'une véritable intussusception ou assimilation molécule à molécule par la membrane cellulaire de la substance cellulosique élaborée par le protoplasma.

Si des couches d'inégale réfringence apparaissent ainsi dans la paroi, c'est que celle-ci ne présente pas dans toutes ses parties un égal degré d'hydratation.

Là où la cellulose est très hydratée, elle apparaît sur les coupes sous la forme de lignes sombres, peu réfringentes. Vues à un fort grossissement, ces lignes présentent une légère teinte rosée. Là au contraire où la cellulose est paurre en eau, elle se présente en couches denses et réfringentes.

Direction des plans d'hydratation. -- La direction des stries varie dans les cellules différentes, et aussi dans la même cel- 
lule. - On en peut reconnaître trois systèmes principaux :

$1^{\circ}$ Les stries sont circulaires et concentriques par rapport à la cavité de la cellule. - On en constate l'existence dans l'épaisseur de la paroi, par des coupes transversales (fig. 38).

$2^{\circ}$ Les plans de cellulose sont étendus radialement de la face interne à la face externe de la membrane cellulaire. Elles déterminent alors dans l'épaisseur de la paroi des stries radiales et à la surface de cette paroi des stries longitudinales.

$3^{\circ}$ Enfin on peut observer un système de plans obliques par rapport aux faces de la paroi, sur lesquelles ils déterminent la formation de stries coupant sous des angles variés les stries longitudinales.

Les deux derniers systèmes de stries se rencontrent fréquemment réunis dans la même paroi cellulaire. De l'entrecroisement de ces plans de cellulose résulte alors une division de l'épaisseur de la membrane cellulaire en prismes, et l'apparition à la surface de cette membrane de figures losangiques variables de forme avec l'obliquité des plans les uns sur les autres.

Wtude. - On examine d'abord la surface des cellules afin de se rendre compte de la disposition des stries des deux derniers systèmes mentionnés plus haut. On fait ensuite des coupes minces à travers les parois afin de constater, s'il y a lieu, la présence des stries concentriques. On rencontre quelques cellules dans lesquelles les trois systèmes de stries se trouvent réunis. Leur examen est assez difficile.

Lorsqu'on examine des sections pratiquées sur des parois épaisses, il est bon de se tenir en garde contre un accident de préparation qui se présente fréquemment lorsque le rasoir dont on fait usage n'est pas parfaitement aiguisé: Le rasoir létermine dans ce cas des stries accidentelles qu'il ne faut pas confondre avec les précédentes. Il est d'ailleurs facile d'éviter cette erreur. - Les stries produites accidentellement sont plus déliées que les stries vraies d'accroissement; leurs limites sont également plus arrêtées, et ne présentent pas ce passage graduel que l'on trouve toujours entre les parties obscures et brillantes dans les zones d'accroissement. - Il suffit d'ailleurs de quelque habitude du microscope pour ne point 
se laisser abuser par l'accident de préparation que nous signalons.

Les couches d'accroissement des parois cellulaires ne se présentent pas toujours avec netteté. Pour les mieux mettre en évidence, on peut employer les substances colorantes (carmin, hématoxyline). Les couches de densité différente absorbant inégalement ces matières, on verra les stries se dessiner plus nettement.

L'emploi des acides et des alcalis fait avec ménagement permettra également de faire apparaître les stries dans des parois où elles étaient peu visibles. - Enfin il ne faut pas oublier que l'emploi de l'eau comme véhicule dans l'observation de ces stries peut avoir pour résultat de les faire disparaître; l'eau hydrate les couches qui le sont peu, et rend la paroi homogène.

Sujets d'études. - Les stries se rencontrent dans presque toutes les parois cellulaires dès qu'elles ont acruis un certain degré d'épaississement. - Nous ne citerons donc que quelques exemples qui nous paráissent plus particulièrement intéressants.

- On trouvera des couches concentriques très nettes dans les cellules libériennes du tubercule de Dahlia variabilis (fig. 38)

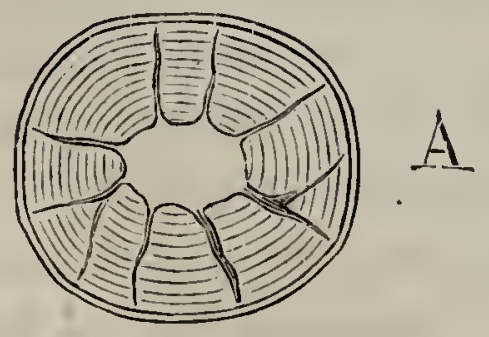

Fig. 38. - Cellule sclérenchymateuse. ainsi que dans les fibres de sclérenchyme répandues en si grand nombre dans certaines écorces, et particulièrement dans les écorces des quinquinas jaune et rouge.

Les cellules rameuses que l'on trouve dans les feuilles du Camellia japonica (fig. 33), les fibres des Pinus, etc., offrent des stries rayonnantes d'une observation facile sur les coupes transversales de leurs parois. Enfin, les cellules libériennes de la feuille du Hoya carnosa, celles des Apocynées, les poils des Opuntiées, et de diverses autres plantes sont de bons exemples pour l'étude des divers systèmes de stries obliques et concentriques. On pourra, pour l'examen des stries longitudinales, choisir les fibres de Lin et de Ghanvre. (Voir fig. 3ə̈.) Vues en surface, surtout après traitement par la potasse, ces fibres 
semblent comme décomposées en délicates fibrilles, tant les stries longitudinales sont nombreuses et nettement définies.

\section{$\S$ 4. MARQUES SUR LES PAROIS CELLULAIRES.}

Les marques dont nous allons parler sont comme les stries le résultat de modifications survenues dans la paroi au cours de son développement en épaisseur. Mais ces marques reconnaissent une autre origine que les stries. - Les marques proviennent en effet d'une irrégularité plus ou moins prononcée dans l'épaississement de la paroi. Si l'on examine à la lumière transmise des cellules dont l'épaisseur est sensiblement la même en tous les points de leur surface, la lumière traversant une membrane homogène ne donne aucune image particulière. Mais lorsque la paroi s'est irrégulièrement épaissie, les parties minces étant plus transparentes que les parties épaisses, la lumière qui les traverse est modifiée dans son intensité, et on voit apparaitre des marques diver-

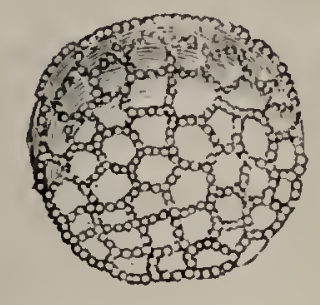

Fig. 39. - Pollen de Lis blanc.

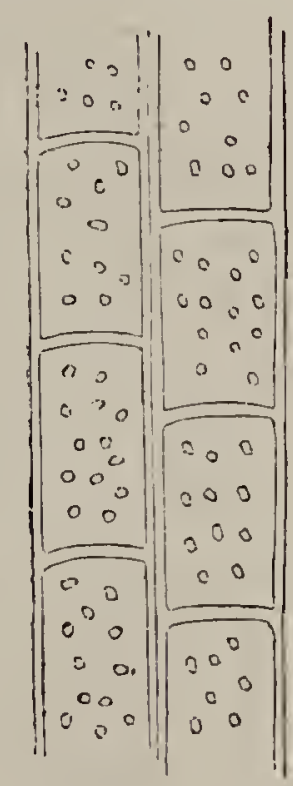

A

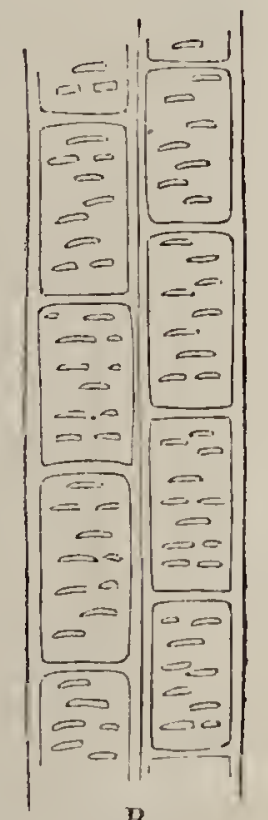

B

Fig. 40. - Fibres ponctuées et rayées.

ses. Les épaississements peuvent se faire à la face externe ou à la face interne de la paroi cellulaire. Les premiers constituent des lignes proéminentes reliées en réseau, des verrues, des pointes, ainsi qu'on en peut observer de nombreux exemples à la surface de diverses spores et de beaucoup de cellules de pollen (fig. 39).

Quant auxépaississements qui se produisent à la face interne de la paroi cellulaire, ils offrent deux cas à considérer : si les parties minces ne repréśentent qu'une faible étendue de la 
surface de la paroi, elles y apparaissent à la lumière transmise comme des ponctuations ou des raies (fig. 40). Si au contraire l'ensemble des parties non épaissies l'emporte, le fond de la paroi est mince et les parties épaissies forment à sa surface des proéminences de formes variées, anneaux, spirales, etc.

\section{A. LE FOND DE LA MeMbrane eST ÉPAISSi.}

Étude. - A ce cas se rattachent les cellules dites ponctuées, rayées, réticulées, d'après la forme qu'affectent les espaces épargnés par l'épaississement.

$1^{\circ}$ Cellules ponctuées. - Pourobserver les ponctuations, il convient de faire des coupes à travers les parois des cellules, car la forme et la manière d'être de ces ponctuations varient avec la plus ou moins grande épaisseur de la paroi.

Dans les cellules à parois minces, comme celles de la moelle de sureau par exemple, chaque ponc-

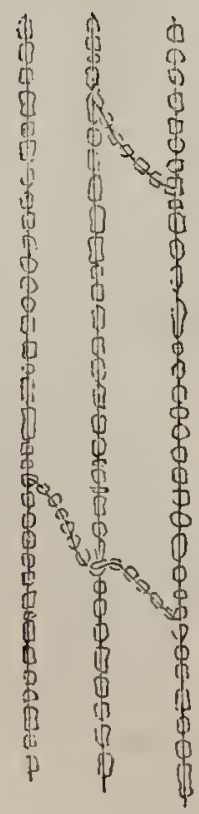

Fìg. 41. - Fibres ponetuées du Vinca Major, en coupe longitudinale. tuation apparaît, vue de face, comme un petit cercle, assez large. Si l'on examine la coupe de cette ponctuation, on constate qu'elle forme un petit canal creusé dans l'épaisseur de la paroi cellulaire. Ce canal très court ici, puisque la paroi est mince, est fermé extérieurement par la membrane cellulaire non épaissie, qu'on mettra mieux en évidence au moyen de l'iode et de l'acide sulfurique. (Voir p. כ̌8.)

Dans les cellules à parois plus épaisses comme les fibres du Vinca major (fig. 41) les ponctuations souvent très nombreuses sont plus pelites, mais aussi beaucoup plus profondes. Sur les coupes, ces ponctuations apparaissent dans l'épaisseur de la paroi comme de pelits canaux fins et déliés qui ont reçu le nom de canalicules ou canaux poreux, et qui s'étendent de sa face interne à sa face externe. - De semblables canaux correspondant à des ponc. tuations s'observent dans un grand nombre de végétaux. 
On les troure particulièrement larges, et profonds dans les cellules épaisses du périsperme du Phytéléphas, de la datte, etc. Dans certains cas, ces canaux se bifurquent et se ramifient dans. la paroi, c'est ce que montrent les cellules sclérenchymateuses des concrétions pierreuses des poires par exemple, ou encore les cellules sous-épidermiques de la tige souterraine du Pteris aquilina. De semblables canaux sont également bien développés dans les téguments de la graine de beaucoup de régétaux, dans la caroncule de la graine du Ricin, etc.

$2{ }^{\circ}$ Cellules aréolées-ponctuées. - Dans tous les exemples que nous avons signalés sous le nom de cellules ponctuées, chaque canalicule correspondant à une ponctuation présente un calibre à peu près uniforme dans toute sa longueur. Mais il arrive, dans certains cas, que le canalicule, très large dans sa partie roisine de la face externe de la paroi cellulaire, se rétrécit plus ou moins brusquement à mesure qu'il se rapproche de la face interne de cette paroi. Il en résulte que le canal poreux présente un orifice interne très petit qui projette une ponctuation sur l'orifice externe plus large. On observe alors, à la lumière trans. mise, ce qu'on appelle une ponctuation aréolée (fig. 42). Vue de face en effet, cette variété de marque se pré-

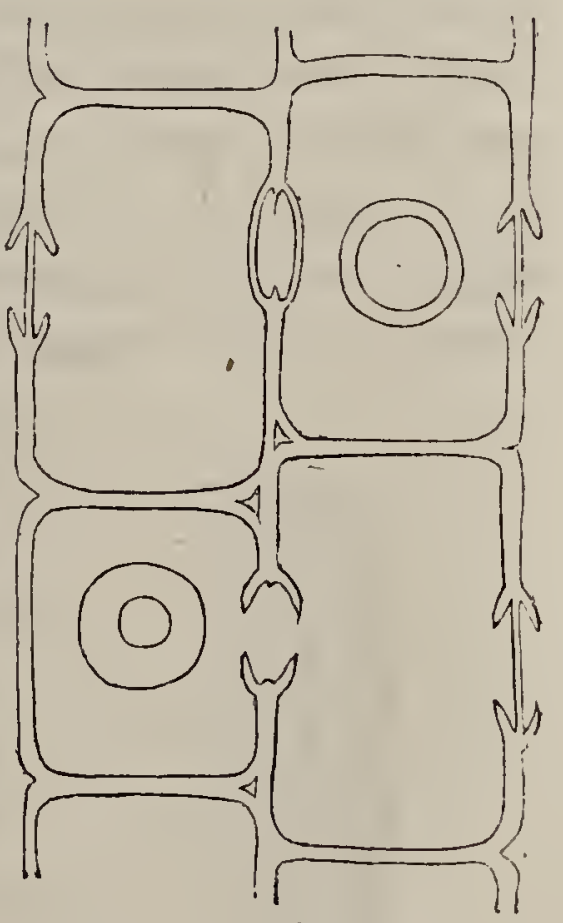

Fiğ. 42. - Cellules aréolées (1 bies). sente sous la forme d'un point brillant entouré d'une aire obscure, mais plus claire toutefois que le reste de la paroi. Cette apparence s'explique aisément. La lumière qui traverse l'orifice interne du cannalicule arrive à l'œil sans obstacle, et par suite plus intense que celle qui traverse l'orifice externe après avoir rencontré sur son chemin la roûte formée par l'épaississement de la paroi. Cette intéressante particularité dans le mode de déreloppement en épaisseur des parois cellulaires s'observe avec la plus grande netteté dans le bois des Conifères. Les vaisseaux du bois sont 
remplacés en effet dans ces végétaux par des fibres épaisses à larges ponctuations aréolées (fig. 42). Pour les étudier, nous conseillons de pratiquer des coupes fines transversales et longitudinales sur un éclat de Sapin. Les larges aréoles se montrent disposées en lignes longitudinales sur la paroi des fibres. Vue de face, chaque poncluation aréolée peut être assez exactement comparée à un verre de montre percé en son centre et enchâssé dans la paroi de la fibre. La coupe d'une de ces ponctuations représente une sorte d'entonnoir brusquement rétréci, dont l'oritice le plus large forme l'aréole, et l'orifice le plus petit, la ponctuation.

Les ponctuations simples ou aréolées de deux cellules voisines sont généralement en regard les unes des autres. Les cavités des deux cellules ne sont alors séparées que par une mince paroi; mais il peut arriver que cette membrane se résorbe, il y a alors communication directe entre les deux éléments. Une pareille communication s'établit fréquemment entre les fibres aréolées ponctuées des Conifères; plus rare entre les cellules ponctuées simples,

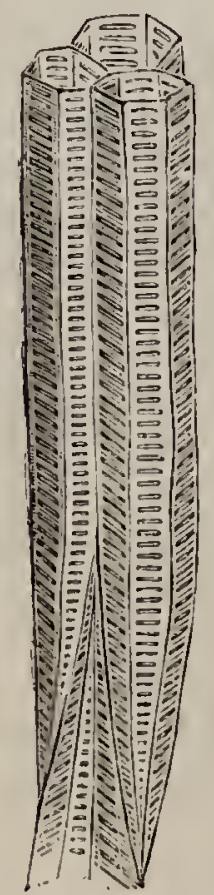

Fig. 43. - Vaisseaux scalariformes. on en trouve cependant des exemples dans les cellules à spirales des Sphag̣num et Dicranum, et dans les organes femelles de quelques espèces d'Algues (Schacht). On a alors affaire non plus à des ponctuations, mais à de véritables perforations des parois cellulaires.

Quant à la répartition des ponctuations, elle se fait généralement suivant une ligne spirale; les cellules allongées montrent particulièrement bien cette disposition (fig. 4oั, A).

$3^{\circ}$ Cellules rayées etréliculées.-Lorsque les parties de la paroi épargnées par l'épaississement atteignent une certaine étendue dans un sens, au lieu de ponctuations, on olsserve à la surface de la membrane des raies, qui peuvent être aréolées.par un mode de formation analogue à celui que nous avons décrit au sujet des ponctuations aréo- 
lées. Ces raies aréolées s'observent.très bien sur les vaisseaux dits scaluriformes des Fougères, et en particulier du Pteris aquilina (fig. 43), ainsi que sur les vaisseaux du tubercule de Dahlia variatilis. Dans ces deux dernières plantes on observe en outre des cellules qui présentent une modification particulière des marques, qui constitue ce qu'on appelle des ponctuations tournantes.

Vue de face, chaque ponctuation de ces cellules apparaît comme une ouverture arrondie traversée par une longue fente qui n'est autre que l'ouvèrture interne de la ponctuation aréolée. Il peut arriver alors que la fente interne change de direction par les progrès de l'épaississement, de manière que la ponctuation, vue de face, présente deux fentes en croix. Il est toutefois nécessaire de s'assurer que ces deux fentes appartiennent bien à la membrane d'une seule et même cellule, en isolant cette cellule par la macération. (Sachs, loc. cit.)

Enfin, on réserve le nom de cellules reticulées à certains éléments dans la paroi desquels, les raies transparentes augmentant en nombre, les portions épaissies apparaissent comme un réseau dont les mailles sont formées par les parties non épaissies. On en trouvera de bons exemples dans les cellules vasculaires du bois d'un grand nombre de végétaux, dans certaines cellules du thalle du Marchantia polymorpha, dans un grand nombre d'anthères, où ces cellules reçoivent le nom de cellules fibreuses. (Voir plus loin.) Enfin, à la face interne de l'enveloppe de la graine des diverses espèces de Daphné (1).

\section{B. LE FOND DE LA PAROI CELlUlaire eST MiNGE.}

Cellules annelées et spiralées (trachées). - Dans ce second groupe, les épaississements de la paroi y apparaissent comme des anneaux ou des spirales sculptés pour ainsi dire sur sa face interne. Ce que nous avons. dit déjà du mode d'épaississement de la paroi des cellules suffit à faire comprendre comment se produisent ces anneaux et ces spirales.

Situde. - Les parois annelies se rencontrent principalement

(1) Beauregard, Bull. Soc. bot., 1879. 
bien développées dans les cellules vasculaires des tiges de beau-

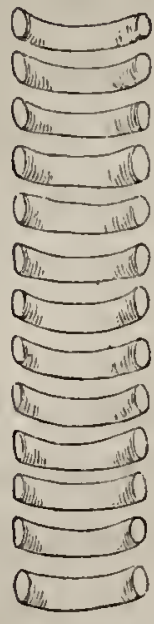

Fig. 44. - Anneaux d'un vaisseau annelé coupé en long (Zea Maïs). coup de Monocotylédonées. Dans le Zea Maïs par exemple, on obtiendra, par isolement ou par coupes longitudinales, des cellules vasculaires annelées d'un diamètre considérable (fig. 4y) où les anneaux atteignent une grande épaisseur.

Les épaississements spiralés sont fréquents et présentent des formes variées. Dans les vaisseaux spiralés ou trachées qui appartiennent aux faisceaux fibro-vasculaires du bois de la plupart des végétaux (fig. 40ั), ce sont des fils minces et déliés qui souvent se détachent de la paroi et se montrent dans les coupes comme des filaments isolés, enroulés en tirebouchon (fig. 46). Ces trachées sont dites déroulables lorsque les spires peuvent s'isoler de la paroi (fig. 46).

- Ailleurs la spirale forme une sorte de lame aplatie qui s'enroule dans l'intérieur de la cellule de manière à figurer
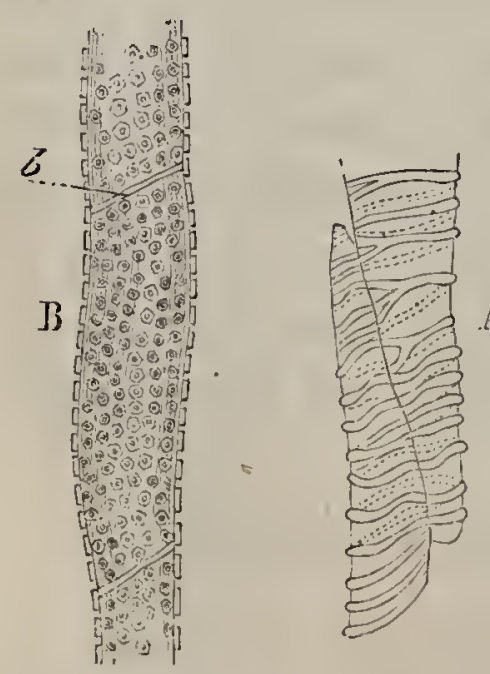

Fig. 43. - A. Union de deux cellules trachéemnes de la tige de Balsamine, d'après M. Duchartre. - B. Coupe longitudirale d'un vaisseau aréoléponctué pris dans le bois de la tige du Justicie A dathoda. - $b$. Restes de la cloison séparatrice des deux cellules vasculaires superposées. assez bien un escalier en limaçon. Ces sortes d'épaississements se voient dans les cellules d'un certain nombre de Gactées (Mamillaria, Echinocactus, etc.).

Enfin, il peut arriver que, sur la paroi d'une même cellule, deux ou plusieurs rubans s'enroulent en spirale de direction inverse. On en trouvera des exemples dans les élatères des Marchantia polymorpha, dans le Bananier, etc.

Les marques des parois cellulaires présentent encore bien des variétés de forme; nous ne les énumérerons pas ici, car nous aurons l'occasion dans le courant de cet ouvrage d'appeler l'attention sur les plus intéressantes d'entre elles. Nous signalerons seulement, en terminant, deux faits qui nous

paraissent dignes d'observation : c'est d'une part l'existence, 
sur une même paroi cellulaire, de ponctuations et d'anneaux ou de spirales (Daphné, Vigne, If, etc.); d'autre part, la localisation de l'épaississement à l’un des côtés de la cellule. Ce fait s'observe fréquemment sur l'épiderme des feuilles coriaces (Tiscum, Nerium, etc.), dans les cellules de la couche protectrice des racines des Monocotylédonées, etc.

§ כ̈. MODIFICATIONS DANS LA COMPOSITION DE LA PAROI CELLULAIRE.

La paroi des jeunes cellules est, comme nous l'avons vu, uniquement composée de cellulose. Mais par suite du développement elle peut subir de profondes modifications dans sa composition chimique, et cela particulièrement dans les cas où se produisent les épaississements dont nous avons parlé plus haut. Ces modifications répondentà trois phénomènes distincts connus sous les noms de lignification, cuticularisation et gélification.

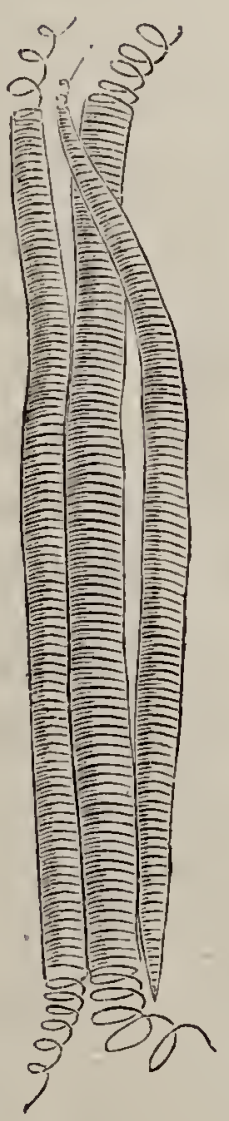

Fig. 46. -- Trachées déroulables.

$1^{0}$ Lignification. - La lignification résulte de l'encroûtement des parois cellulaires par certains principes dils ligneux ou incrustants (lignone, ligniréose, lignose, etc. Payen). Ces principes, particulièrement répandus dans les parois des éléments qui forment les parties ligneuses des végétaux, sont souvent accompagnés de composés calcaires ou siliceux (voir plus loin) ou encore de substances résineuses colorées en brun plus ou moins foncé.

L'épaississement des membranes cellulaires sous l'influence de ces dépôts peut devenir considérable, et la paroi se diviser alor's en plusieurs enveloppes distinctes par leur composition. - Dans les cellules ligneuses du Pinus sylvestris, par exemple, on distingue ainsi trois enveloppes. Une interne mince formée de cellulose, car elle devient bleue sous l'influence de l'iode et de l'acide sulfurique, et deux externes, encroûtées des substances susdites et qui ont perdu les caractères de la cellulose. Elles deviennent jaunes sous l'influence des mêmes réactifs. 
Étude. Réactifs. - Les principes ligneux réagissent en effet tout autrement que la cellulose pure. La potasse, qui attaque cette dernière, n'a aucune action sur les dépôts incrustants.L'acide sulfurique ne les dissout point, mais les noircit. (Payen.)

Ils sont solubles dans l'acide azotique et les hypochlorites, qui au contraire ne dissolvent pas la cellulose proprement dite.

Ils ne bleuissent sous l'influence de l'iode ni avant ni après l'action des acides. - Enfin les parois lignifiées ne se gonflent pas dans l'eau.

$2^{\circ}$ Cuticularisation. - Les parois de beaucoup de cellules libres (spores, grains de pollen) et la face externe d'un grand nombre de cellules épidermiques prennent souvent un épaississement considérable qui forme ce qu'on appelle la cuticule, sorte d'enveloppe protectrice, incapable de se gonfler dans l'eau et dont la composition est encore peu connue. Nous n'insisterons pas ici sur cette formation, que nous aurons plus loin l'occasion d'étudier avec détails. Nous ajouterons seulement que l'épaississement des parois cellulaires du liège paraît être dû à une modification semblable à celle qui donne lieu à la cuticule.

$3^{0}$ Gélification. - La membrane cellulaire présente dans certains cas une modification singulière qui consiste dans sa transformation en une substance gélatineuse plus ou moins épaisse. Cette transformation atteint de préférence les couches internes de la paroi cellulaire; nous croyons devoir insister quelque peu sur son étude, car c'est à elle que se rattachent les formations mucilagineuses et gommeuses.

Mucilages. Etude. - La transformation mucilagineuse des parois des cellules se rencontre dans un certain nombre de graines (Lin, Coing, P.yllium), dans l'albumen du Caroubier, etc. Dans la graine de Lin par exemple, ce sont les cellules de la couche la plus superficielle qui subissent la modification mucilagineuse. Ces cellules volumineuses et de forme cubique épaississent de bonne heure leurs parois et, tandis que la couche externe de ces épaississements, restant mince et élastique, revêt tous 
les caraclères de la cuticule, les couches internes se transforment en mucilage ( 1 ).

Le mucilage, de consistance cornée lorsqu'il est sec, se gonfle rapidement lorsqu'il est mis en présence de l'eau, et il en résulte une masse gélatineuse qui remplit la cavité de la cellule au point de faire éclater la cuticule. - On peut facilement observer ce gonflement des couches gélifiées des parois cellulaires en plaçant dans une goutte d'eau sous le microscope une mince coupe de graine de Lin.

L'abondant mucilage que donne la graine de Psyllium est dû à la gélification de toutes les cellules de ses tissus (téguments et albumen). Les cellules de l'emḅryon sont les seules qui ne participent point à cette modification. (G. Planchon, loc. cit.)

Tous les mucilages ne semblent toutefois pas résulter d'une modification siégeant dans la paroi cellulaire. C'est ainsi que, dans les écorces de cannelle, on rencontre des cellules à mucilage, dont les parois ne sont point altérées. Ces cellules siègent dans le parenchyme au voisinage des faisceaux libériens. (Planchon, loc. cit.) Le mucilage qu'elles renferment est très probablement dû à une transformation de la matière amylacée qu'elles ont contenue, comme cela a lieu pour la formation du mucilage qui remplit les lacunes des tubercules de certaines Aroïdées (2).

Gommes. Etude. - De même que les mucilages, les gommes résultent soit de la transformation directe des parois cellulaires, soit de la transformation du contenu amylacé des cellules. Au premier mode appartient la production de la gomme adragante.

Gommeadragante. - En effet, si l'on pratique des coupes sur les diverses espèces d'Astragales (A. verus, $A$. creticus, etc.) qui donnent la gomme adragante, on constate que les parois des cellules de la moelle et des rayons médullaires, d'abord minces, s'épaississent bientôtnotablement. Ces épaississements

(1) Frank, in Jahrb. botan., V. 1866.

(2) Trécul, Comptes rendus, 1875. Giraud, Étude comparative des gommes et des macilages, thèse de l'ícole supérieure de pharmacie de Paris. $15 i 5$. 
se transforment peu à peu de dehors en "dedans en une substance gélatineuse qui remplit bientôt la cellule. Tous ces amas mucilagineux s'échappent au dehors par des fentes de la tige, et, en se désséchant, prennent la consistance cornée que l'on connaît à la gomme adragante.

Il est intéressant de connaître cette origine pariétale de la gomme adragante, car elle explique les caractères qui distinguent ce produit des autres gommes.

Si l'on fait gonfler par l'eau un morceau de gomme adragante, et que l'on examine au microscope une portion de la masse mucilagineuse ainsi obtenue, on y reconnaît l'existence de nombreux débris de parois cellulaires faciles à caractériser par les réactifs. Les autres gommes sont amorphes et n'offrent aucune trace d'organisation. De plus on trouve souvent des grains d'amidon dans la gomme adragante, contrairement à ce qui a lieu pour les autres gommes.

Gommes arabique et du Sénégal. - Le mode de production de ces gommes n'est pas très exactement connu. - D'après Wigand, ce serait par un procédé analogue à celui qui donne la gomme adragante; d'après M. Martins (1), la production de la gomme arabique serait liée à la présence d'un parasite du genre Loranthus (I. Senegalensis).

Quoi qu'il en soit, les gommes qui nous occupent se dissolvent dans l'eau; elles ne présentent à l'examen microscopique ni amidon ni débris de parois cellulaires.

Gommes des Cerisiers et des Pruniers. - Cette gomme n'est pas, d'après les recherches de M. Prillieux(2), le résultat d'une transformation de la paroi des cellules ou des lacunes qui la renferment, mais le produit d'une élaboration spéciale, aux dépens de l'amidon et des substances contenues dans les cellules où se trouve cette gomme. La gomme des Cerisiers, (gomme nostras), se produit dans les cellules du parenchyme médullaire, dans les vaisseaux et dans des lacunes qui prennent généralement naissance dans le parenchyme des rayons

(1) Martins, Sur un mode particulier d'excrétion de la gomme arabique produite par l'Acacia Vereck du Sinégal. Revue des sciences naturelles de Montpellier, t. III.

(2) Prillieux, Ann. des sc.nat., $5^{0}$ série, t. I. 
médullaires. Ces lacunes, dépourvues de parois propres, sont entourées par un tissu spécial dont la formation coïncide avec l'apparition de la gomme. "Pendant que la gomme se produit, on observe, dans les cellules qui bordent la cavité des lacunes, une activité extraordinaire; elles grandissent, se développent, se multiplient, s'épaississent et se remplissent de fécule. "Il est probable que cette gomme se forme à l'aide des matières contenues dans ces cellules.

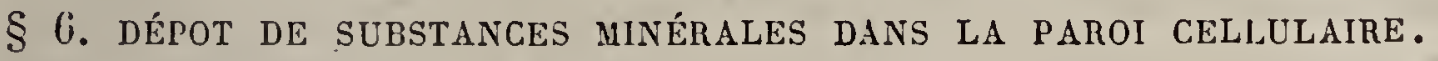

Les parois épaissies des cellules sont fréquemment le siège de dépôts de substances minérales qui les rendent incombustibles. Ces dépôts sont formés soit de silice, soit d'oxalate ou de carbonate de chaux.

Dépôt de silice. - La silice se rencontre principalement dans les épidermes. Elle forme alors à la plante un revêtement siliceux d'une grande dureté et très âpre au toucher. D'après M. Duval Jouve (Histoire naturelle des Equisetum de France. Paris, 1864), la silice dans les Equisetum selocalise particulièrement dans la portion extérieure cuticularisée des cellules épidermiques, à tel point qu'elle y remplace pour ainsi dire la cuticule; cet encroûtement ne se fait pas d'une manière uniforme; il en résulte une couche mamelonnée ou même, chez l'Equisetum hiemale, couverte de saillies plus ou moins irrégulières disposées en rangées transversales par rapport aux côtes longitudinales de la lige, et qui forment une sorte de râpe très dure, propre au polissage des métaux.

On observe également des dépôts siliceux dans les parois des cellules épidermiques des Calamus, dans celles de nombreuses Graminces et dans le parenchyme des feuilles des Ficus sycomorus, $F$. trashyphylla, Deutzia scabra, Celtis, Ulmus, Magnolia granaiflora, etc. (1).

Etude. - Pour obtenir de beaux squelettes siliceux, on peut avoir recours aux Diatomées.

Si l'on reut avoir le squelette siliceux des épidermes ou des

1) De Bary, IIandluch der physiologisch. Botanit,' 1577. Leipzigg). Mohl Bot. Zeitung, 1861. Rosanoff, Bot. Zeitung, 1871. 
parenchymes que nous venons de citer, on enlève des lambeaux d'épiderme ou l'on fait des coupes sur les tissus. On lave soigneusement ces préparations à l'acide nitrique et on les calcine sur une lame de platine. Sachs (Traité de Botanique, 1874) conseille la méthode suivante qui lui donne des résultats plus rapiàes: " On place de gros fragments du tissu, par " exemple de feuilles de Graminées, de tiges d'Equisetum, etc., " sur la lame de platine, dans une grosse goutte d'acide sulfu" rique concentré, et on chauffe dans la flamme ; l'acide noir" cit aussitôt et il se fait un vif dégagement de gaz; on chauffe "jusqu'à ce qu'il ne reste plus qu'une cendre pure et bien "blanche."

Dépôts d'oxalate de chaux. - Les dépôts d'oxalate de chaux dans les parois des cellules s'observent sous forme de granulations ou de cristaux distincts. S'ils siègent dans les cellules épidermiques, ils y occupent principalement les couches cuticulaires ;

On rencontre l'oxalate de chaux en petits cristaux dans la paroi épaissie des fibres sclérenchymateuses du Welwitschia mirabilis. Il est également très abondant dans beaucoup de Cupressinées et de Taxinées, dans les diverses espèces d'Ephedra, dans les feuilles des Dracæna reflexa, arborea, draco, du Sempervivum calcareum, dans diverses espèces de Mesembryanthemum, etc. Ces dépôts donnent à beaucoup d'épidermes. leur coloration blanc mat, et en particulier aux parties blanches des feuilles du Mesembryanthemum tigrinum. (De Bary, loc. cit.)

A ces incrustations directes de la paroi cellulaire se raltachent encore les cristaux maclés que l'on trouve dans la moelle des Kerria japonica et Ricinus communis, ainsi que dans le pétiole de diverses Aro:̈dées (Philodendron, Pothos, etc.). Ces macles, situées dans la cavité cellulaire, sont reliées à la paroi par des filaments de cellulose et revêtues d'une mince couche cellulosique. (Rosanoff, loc. cit.)

Étude. - On reconnaît l'oxalate de chaux à ses réactions et à sa forme cristalline. Insoluble dans l'acide acétique, il se dissout sans dégagement de gaz dans l'acide chlorhydrique.

L'oxalate de chaux revêt des formes cristallines très varićes, 
dérivées du système quadratique. Le plus souvent il cristallise en octaèdres présentant l'aspect d'enveloppes de lettres ou de sablier. Notcns en passant que l'oxalate de chaux qui se forme dans la cavité des cellules offre une cristallisation bien différente, appartenant au système clinorhombique.

Dépôts de carbonate de chaux. - Le carbonate de chaux ne forme jamais de cristaux définis comme l'oxalate de chaux; il se dépose en fines granulations qui se se réunissent en petites masses, tantôt à aspect cristallin, tantôt complètement amorphes. - Dans les parois des cellules de.beaucoup d'Algues marines (Acetabularia, Corallina, Melobesia, etc.), le carbonate de chaux se dépose à l'état de très fines granulations. Les dépôts les plus intéressants que forme cette substance sont ceux que l'on rencontre dans les épaississements des parois cellulaires des Urticées et des Acanthacées. Ils ont reçu le nom de Cystolithes (1).

Cystolithes des Urticées. - Ces formations ont été successivement étudiées par Meyen dans le Ficus elastica (1834), puis par Payen, Schacht, Weddel, Scheiden, etc. Pour étudier le développement des cystolithes; du Ficus elastica, par exemple, il faut faire des coupes sur les jeunes feuilles encore renfermées dans leur gaîne stipulaire. On constate alors que l'épiderme est formé d'une seule couche de cellules prismatiques qui toutes ont même grandeur et même forme, et sont recouvertes par la cuticule. Bientôt la plupart de ces cellules se subdivisent pai des cloisons tangentielles pour former un épiderme à quatre rangées de cellules. Les autres cellules qui ne se cloisonnent pas, épaississent leur paroi externe, et en même temps se gonflent et prennent la forme d'ampoules ovales qui s'enfoncent dans le parenchyme sousépidermique. Bientôt leur paroi épaissie développe (fig. 47) un prolongement cellulosique qui se renfle en massue et s'avance dans la cavité de l'ampoule. Ce prolongement en forme de stalactite acquiert la forme d'un corps ovoïde ou sphérique qui atteint le centre de la carité cellulaire et se montre bientôt recouvert de mamelons coniques. Cette masse

(1) Weddel, Ann. des sc. nat., $4^{\mathrm{e}}$ série, t. II. 
cellulosique s'imprègne de carbonate de chaux et reste attachée à la paroi qui l'a produite par une sorte de pédicelle cylindrique qui renfermerait de la silice (de Bary, loc. cit., fig. 47).

Les cystolithes des Urticées, bien que situés dans la cavité des cellules, sont donc en réalité formés par une expansion

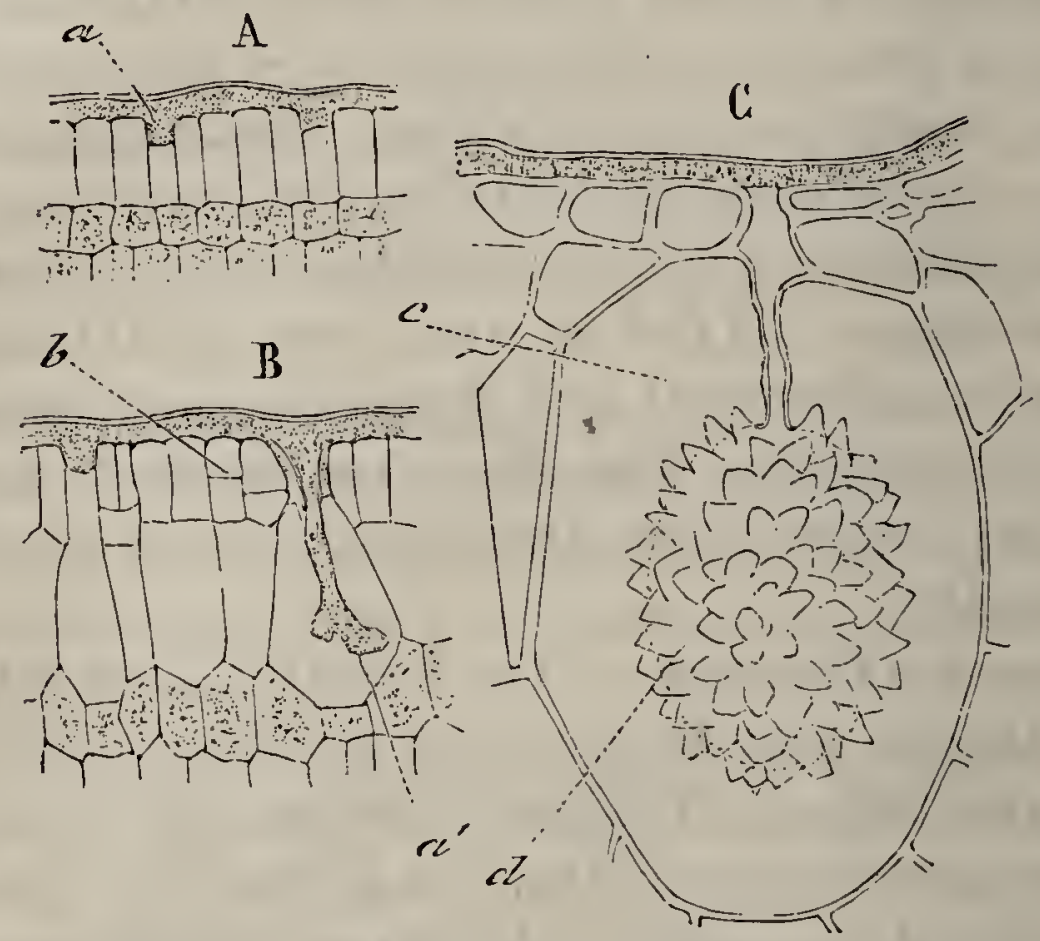

Fig. 47. - Déreloppement d'un cystolithe dans la feuille du Ficus elastica (d'après de Bary, loc. cit.).

A. Premier état. Développement en $a$ de la paroi externe de l'une des cellules. - B. $2^{e}$ stade. Cette cellule s'est développée en ampoule. - $a^{\prime}$ Développement du prolongement cellulosique. $-b$. Cellule en roie de division. - . C. État de complet développement. $-c$. Cellule en ampoule. $-d$. Cystolithe.

de la membrane cellulaire imprégnée de carbonate de chaux. Dans le Ficus elastica on rencontre ces formations à la face supérieure et à la face inférieure des feuilles. - Celles de la face inférieure sont toutefois moins nombreuses et plus petites. Dansles Ficus carica, monıana, ulmifolia où l'on trouve également des cystolithes, la paroi des cellules quiles renferment se continue au-dessus de la surface épidermique en un poil pointu plus ou moins long. Citons encore parmi les Urticées qui renferment des cystolithes dans l'épiderme, les diverses espèces de Pariélaire, les Bchmeria, Celtis morus, Broussonetia, Cannabis, Urtica. (Payen). On troure des cystolithes de forme ovale dans les Pilca decora, densiflora. (Weddel, loc. cit.) Dans 
l'Urtica macrophylla, les cystolithes sont fusiformes, à grand axe dirigé parallèlement à la surface épidermique.

C'ystolithes des Acan'hacées. - Chez les Acanthacées on trouve également de nombreux cystolithes dont le mode de formation est analogue à celui que nous venons de décrire chez les Urticées, mais leur forme est généralement diffé rente. Rarement arrondis (Justicia carnea, Schacht), ils sont le plus souvent fusiformes (Justicia adathoda,

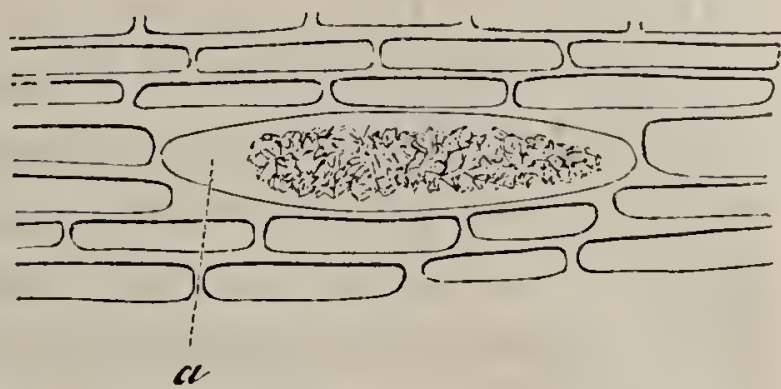

Fig. 48. - Cystolithe du Justicia adathoda dans le parenchyme 'cortical de la tige. La cellule $a$ qui renferme le cystolithe est, par sa forme, distincte des cellules environnantes. fig. 48). Dans ce dernier on les rencontre en grande abondance dans le tissu parenchymateux de la moelle et dans le parenchyme cortical principalement au voisinage des cellules sclérenchymateuses qui limitent extérieurement les faisceaux libéro-ligneux. (L'Acanthus mollis ne renferme pas de cystolithes.)

Pour terminer ce qui a trait aux cystolithes, ajoutons encore qu'on les rencontre dans l'Ulmus et le Dorsttnia. (Payen.) Mohl (But. Zeit. 1860) rattache aux cystolithes des plantes urticantes, les nodosités que l'on trouve à la base des poils des Borraginées et des Synanthérées.

Étude. - La composition des cystolithes se reconnaît aisément parl'usage des réactifs. L'acide acétique les fait disparaître avec un abondant dégagement de gaz. Aussi, lorsqu'on veut conserver des préparations de tissus renfermant des cystolithes, doit-on éviter avec soin de se servir de véhicules acides. La glycérine acide doit en particulier être rejetée, sous peine de voir au bout de quelques jours les cystclithes réduits à leur squelette cellulosique. 
ART. 5 .

\section{Gontenu des cellules.}

On trouve dans l'intérieur des cellules des substances de nature très variée et dont la présence est en rappor't avec l'activité vitale du protoplasma. Dans les cellules mortes, en effet, on ne trouve généralement rien autre chose que des gaz ou de l'air plus ou moins modifié dans sa composition. Il est à peu près impossible de classer toutes ces substances d'une manière satisfaisante. Les unes sont des produits de désassimilation (tannin, résines, huiles essentielles, etc.); les autres sont réservées à la nutrition du végétal (aleurone, amidon, graisses, etc.). Quelques-unes ne sont que très imparfaitement connues quant à leur rôle et à leur mode d'évolution. Nous étudierons parmi ces substances celles cui nous paraissent avoir le plus d'intérêt soit à cause du rôle physiologique qui leur est réservé, soit à cause de leur fréquence dans les cellules.

\section{$\S 7$. SUC CELLULAIRE. INULINE.}

Le suc cellulaire est le liquide qui remplit les vacuoles creusées dans le protoplasma. - Très riche en eau, ce liquide peut renfermer à l'état de dissolution diver'ses matières parmi lesquelles rentrent, en première ligne, le sucre, la gomme, la dextrine, l'inuline, différents sels, etc.

Etude. - Cn reconnaît la présence du sucre dans le suc cellulaire, au moyen de l'acide sulfurique concentré qui colore le liquide en rouge-rose.

On reconnaît la gomme et la dextrine par un précipité granuleux que l'alcool produit dans le suc clair des cellules. (Schacht, Le microscope et son application à l'anatomie végétale, 186.ّ.) Lorsque le suc cellulaire renferme un sel de chaux soluble, il est facile de le mettro en évidence au moyen d'une goutte d'acide sulfurique que l'on dépose sur la préparation. On voit bientôt apparaître de nombreuses aiguilles cristallines de sulfate de chaux.

Si l'on veut étudier comparativement le contenu de cellules voisines, on doit pratiquer sur le tissu en expérience descou- 
pes assez épaisses pour contenir un plan de cellules non déchirées par le rasoir. Si l'on ne prenait cette précaution, les liquides des diverses cellules se mélangeraient. On lave ensuite les coupes obtenues, avec de l'eau distillée, et alors seulement on a recours à l'emploi des réactifs. Ceux-ci doivent être employés isolément, chacun sur une préparation particulière et bien fraîche; si on les faisait agir successivement sur la même préparation, on opérerait mal, car ils peuvent gêner mutuellement leur action. (Schacht, loc. cit.)

Inuline. - Parmi les substances dissoutes dans le liquide cellulaire, il en est une que sa composition et son rôle physiologique rendent fort intéressante en la rapprochant des matières amylacées. Cette substance, qui a reçu le nom d'inuline, se rencontre principalement dans les racines des Composées (tubercules de Dahlia variabilis, Inula Helenium, Helianthus ubberosus, $H$. annuus, Leontodon, etc.). On la trouve également dans le suc cellulaire de certaines Algues commel'Acetabularia.

Etude. - On chercherait en vain cette substance dans les coupes de tissus frais, car, ainsi que nous l'avons dit, elle est en dissolution dans le suc cellulaire. On devra donc, pour la faire apparaître, se servir de réactifs appropriés. On se base, pour arriver à ce résultat, sur l'insolubilité de l'ínuline dans divers liquides tels que l'alcool, l'éther, les huiles grasses et volatiles, la glycérine pure, etc. - C'est généralement à l'alcool que l'on a recours. Mais il faut employer certaines précautions dans son usage. Si l'on traite des coupes de Dahlia par exemple par l'alcool absolu, on n'obtient qu'un précipité granuleux dù. à une soustraction trop rapide de l'eau du suc cellulaire. Les cristaux d'inuline n'ont point eu le temps de se former. - Si on a soin, au contraire, de modérer l'action de l'alcool, en plongeant par exemple les tissus pendant un certain temps dans ce liquide, avant de faire les coupes, les cellules s'imbibent lentement d'alcool, et l'on obtient de belles cristallisations d'inuline. - On obtiendrait le même résultat par la dessiccali on lente du tissu. - L'inuline, précipitée comme nous venons de l'indiquer, revêt un aspect tout particulier. - Les éléments cristallins qui la composent se groupent en rayonnant autour d'un centre commun, et forment des masses qui reçoivent le 
nom de sphéro-cristaux (fig. 49). Le volume de ces sphéro-cristaux est très variable. Tantôt assez petits pour être renfermés au nombre de trois ou quatre dans une même cavité cellulaire (fig. 49), ils deviennent quelquefois très volumineux, de telle

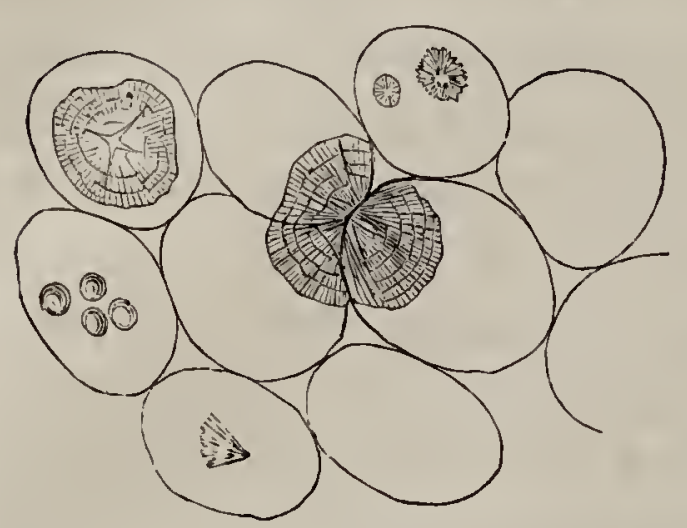

Fig. 49. - Inuline précipitce par l'alcool, dans les cellules du tubercule de l'Helianthus tuberosus. sorte qu'un sphéro-cristal remplit à lui seul deux ou trois cellules contiguës, son centre se trouvant être alors le plus souvent en un point de la paroi de séparation de ces cellules.

Réaciifs. - L'inuline, bien que semblable à l'amidon par sa composition chimique, en diflère par ses réactions. - Très soluble dans l'eau chaude, et assez soluble dans l'eau froide, elle n'est point colorée en bleu par l'iode. L'eau ne la gonfle point. Les acides nitrique et chlorhydrique la dissolvent et font apparaître dans sa masse des lignes fines circulaires et concentriques, par lesquelles se révèlent les couches qui se sont superposées pour lui donner naissance. (Duchartre, loc. cit.)

§ 8. AMIDON.

La matière amylacée, à certaines époques de la vie des végétaux, se réunit en quantité plus ou moins considérable en - des points déterminés de leurs tissus, et revêt dans l'intérieur des cellules l'apparence de grains dont le volume et la forme varient à l'infini. - Ces grains d'amidon, que l'on retrouve à peu près dans toutes les plantes, abondent principalement dans les tissus qui doivent concourir au développement du végétal. lls forment une sorte de réserve alimentaire qui sera utilisée au moment du besoin pour servir à la formation de nouveaux éléments. Les grains se détruisent alors molécule à molécule, comme on peut s'en convaincre en suivant leur disparition dans les cotylédons du haricol en germination.

Structure des grains d'amidon. - On a fait de nombreuses hypotheses au sujet de la structure des grains d'amidon. (Voir 
Duchartre, loc. cit.) On paraît aujourd'hui se rallier assez généralement à l'opinion émise par Nægeli (1). D'après cet auteur, le grain d'amidon se compose de deux substances: l'une qui prend une belle coloration bleue par l'iode, c'est la granulose; l'autre qui se colore en jaune par le même réactif, et reçoit le nom de cellulose amylacée. - On peut mettre en évidence cette structure du grain d'amidon en enlevant la granulose par un procédé quelconque; on obtient alors une sorte de squelette formé par la cellulose amylacée. - Pour séparer la granulose, il suffit de laisser les grains d'amidon macérer pendant quelques heures dans la salive, à une température de $0^{\circ}$. Ou encore, d'après Schulze, de les laisser pendant trois ou quatre jours vers $60^{\circ}$, en contact avec une solution concentrée de sel marin additionnée d'acide chlorhydrique. On obtient par ces méthodes un squelette de cellulose amylacée qui ne prend plus aucune coloration bleue par l'iode.

Développement et accroissement des grains d'amidon. - Le développement des grains d'amidon paraît se produire autour d'une sorte de noyau transparent (hile) formé de substance amylacée très aqueuse. - Il se forme ainsi de très petites masses sphériques que l'on observera très aisément en pratiquant quelques coupeś minces sur le tubercule de la Pomme de terre. - A côté de ces petites masses, qui représentent l'état le plus jeune que l'on connaisse, on trouvera des grains plus avancés dans leur développement qui établissent le passage entre les précédents et les grains tout à fait développés que l'on trouve en grand nombre. - On remarquera également que, plusieurs noyaux rapprochés venant à s'entourer de substance amylacée, il en résulte définitivement des grains composés, réunis par deux ou trois. Quoi qu'il en soit, l'accroissement de tous ces grains se fait par intussusception (Nægeli, loc. cit.), et non par dépôt successif de couches, comme le pourraient faire croire les zones concentriques de réfringence inégale que l'on aperçoit dans leur masse (fig. 50). Ces stries, semblablement à celles que l'on aperȩoit dans les parois épaissies de beaucoup de cellules (voir p. 100), sont le résultat

(1) NNœgeli, Die Stürkekömer, in Pfanzen physiol. Untersuch. 1 t5s. 
d'une hydratation inégale des diverses parties du grain d'amidon.

Forme des grains d'amidon. - Les grains d'amidon varient de configuration d'une plante à l'autre. - Leurs dimensions, quelquefois très petites, deviennent ailleurs relativement considérables. Le noyau est tantôt placé à l'une des extrémités du grain, lorsque le développement s'est fait d'un seul côté par rapport à ce noyau ; tantôt, au contraire, il est au milieu du grain, lorsque sun développement s'est fait également dans tous les sens. - Queilles que soient d'ailleurs ces différences, on peut établir d'une manière générale que, dans chaque espèce végétale, les grains ont une forme caractéristique et des dimension squi ne dépassent pas un certain maximum. Sans vouloir trop insister à cet égard, nous croyons cependant deroir donner quelques indications qui nous paraissent rentrer dans le cadre de notre ouvrage.

Au moyen de la configuration générale des grains d'amidon, on peut établir quelques subdivisions que nous allons rapidement indiquer.

$1^{\circ}$ midon des céréales. - Grains à forme arrondie lenticulaire ou polyédrique, - zones d'hydratation généralement peu visibles.

Amidon de Blé. - L'amidon de Blé se présente sous laforme de grains lenticulaires de $\check{0} 0 \mu$ de diamètre environ ; ils présentent un petit hile ponctiforme, soit en leur milieu, soit à l'une de leurs extrémités. - Les stries sont assez peu apparentes à la surface de ces grains, qui sont toujours accompagnés de nombreux granules beaucoup plus petits (fig. $50, \mathrm{~B}$ ). - Amidon de Seigle. - Grains arrondis, un peu plus gros que ceux du Blé, munis généralement d'un hile crucial ou étoilé (fig. ö1, A).

Amidon d'Orge. - Grains de même vollume que ceux du Seigle, mais à bords irréguliers, - hile à trois ou quatre rayons.

Amidon d'Avoine. - Grains polyédriques, de très petit diamètre, et réunis en masses arrondies, ovales ou elliptiques, qui ressemblent à des globules portant un réseau polyédrique sur leur surface. (Planchon, loc. cit.)

Amudon de Riz. - Grains polyédriques, très pelits, agglo- 
CHAPITRE II. - ÉLÉMENTS ANATOMIQUES.

mérés. - Présentant quelquefois un hile centrăl. - Sans action sur la lumière polarisẹe (fig. ŏ1, B).

Amidon de Maïs. - Grains polyédriques à face hexagonale, avec un hile central étoilé, assez semblables par suite aux

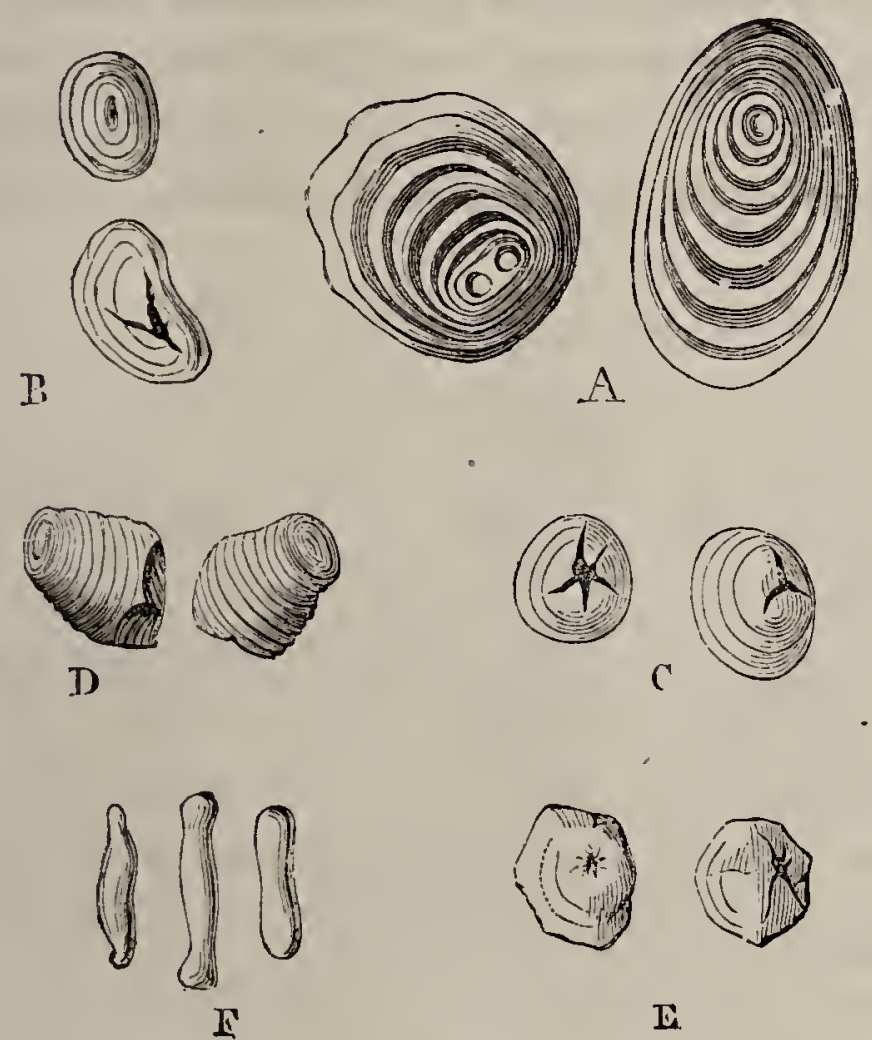

Fig. 50. - Fécules diverses. - A. Fécule de Pomme de terre. - B. Amidon de Blé. C. Fécule de Lentille. - D. Arrow-root. - E. Maïs. - F. Fécule de suc d'Euphorbia lathyris.

grains d'amidon de Riz, mais beaucoup plus gros que ces derniers. - Leur diamètre en effet atteint environ $30 \mu$ (fig. כ00, E).

$2^{\circ}$ Fécule de Pomme de terre. - Les grains de cette fécule sont très facilement caractérisés par lcur forme. Ils sont généralement ovoïdes et comme étirés à l'une de leurs extrémités, qui est plus mince et porte le hile (fig. วั0, A).

Ce grain présente des formes assez variées; tantôt assez régulièrement ovoïde, il prend ailleurs une forme à peu près triangulaire. - Les zones d'hỷdratation, toujours très fortement accusées, lui donnent assez bien l'aspect de la face supérieure d'une valve d'huître. Le grand diamètre de ces grains varie entre $0^{\mathrm{mm}}, 140$ et $0^{\mathrm{mm}}, 180$.

$3^{\circ}$ Fécules des Légumineuses. Forme allongée, quelquefois assez semblable à un rein, hile allongé dans le sens du grand axe du grain (fig. $ّ 1, C$ ). - Les grains des diverses fécules de Légumi- 
neuses se ressemblent beaucoup. - Le hile, allongé, devient souvent rameux par suite de la dessiccation des grains (fig. öl, G). Les zones d'hydratation sont généralement très nettes. Voici quelques dimensions données par Payen : gros Pois, $ّ 0 \mu .-$ Haricot, $63 \mu$. - Lentille, $67 \mu$. - Grosse Fève, 73 ..

$4^{\circ}$ Fécules d'arrow-root. - Ces fécules présentent des caractères distincts suivant leur provenance. L'arrow-root des Antilles, produit par le Maranta arundinacca, est formé de

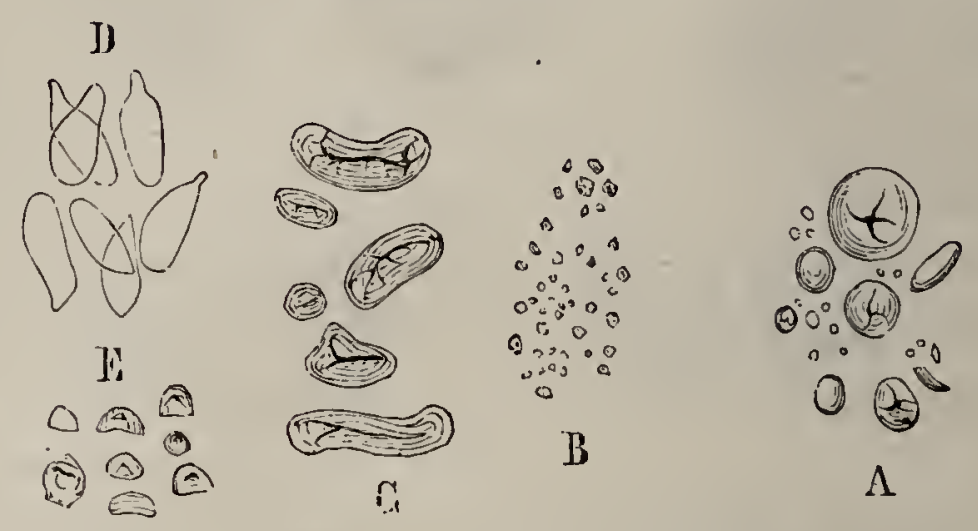

Fig. 51. - Diverses fécules (gross. 100 diam. enriron). - A. Amidon de Seigle. --

B. Farine de Riz. - C. Fécule des Légumineuses. - D. Arrow-root de Travancore. -

E. Fécule de tapioka.

grains simples, assez semblables à ceux de la Pomme de terre, mais plus petits. Leur diamètre ne dépasse guère $0_{-}^{\mathrm{mm}}, 140$. Le noyau est, de plus, généralement placé vers le milieu du grain.

L'arrow-root de Malabar ou de Travancore, fécule extraite des racines tubéreuses de divers Curcuma, est composé de grains aplatis et de configuration ovale ou allongée. - Ces grains sont généralement terminés à leur extrémité par une petite pointe obtuse qui porte le hile ponctiforme. Ces grains sont très minces et, par suite, d'une telle transparence qu'on les aperçoit parfaitementles uns à travers les autres (fig. 51 , D).

$5^{\circ}$ Fécules de sagou. - Ces fécules, extraites de divers Palmiers des genres Metroxylon et Raphia, subissent, avant d'être livrées au commerce, des préparations qui modifient les caractères des grains qui les composent.

Le sagou en granules, qui n'a pas subi l'action du feu, est formé de grains ovales, obtus, longs de 5 à 7 centièmes de millimètre. Le hile est situé à l'extrémité la moins large du 
grain, l'extrémité opposée porte de petites excroissances qui se détachent souvent en laissant à leur place des parties tronquées carrément ou même une impression en creux. (Planchon, loc. cit.)

Le sagou tapioca, qui a subi une température de $60^{\circ}$ à $90^{\circ}$ dans sa préparation, se distingue du précédent par la dilatation considérable du hile.

$6^{\circ}$ Fécules de Manihot. - On en distingue également de deux sortes :

La moussache ou amidon de Cassave, qui n'a pas subi l'action du feu, offre des grains généralement séparés, bien qu'originairement groupés par trois ou quatre. Ils ont en effet une partie convexe-arrondie, et, du côté opposé, soit une surface plane tronquant carrément le grain, soit une surface polygonale à trois ou quatre faces. La portion convexe porte à son extrémité un hile ponctiforme ou étoilé. Les zones d'hydratation sont peu visibles sur ces grains, qui mesurent de 2 à ò centièmes de millimètre. (Planchon, loc. cit.)

Le tapiolia ou fécule de Manihot traitée par la chaleur, est formé de grains à hile considérablement dilaté, et à téguments gonflés et plissós (fig. つั1, E).

Ctude des grains d'amidon. - L'examen des grains d'amidon est des plus simples : s'il s'agit de les rechercher dans un tissu, on fait une coupe mince à travers ce tissu, et on monte la préparation dans la glycérine ou dans l'eau.

Pour l'examen des fécules et des farines, on prélève sur la substance à étudier de petites quantités que l'on délaie dans l'eau froide, et l'on en fait des préparations que l'on soumet à l'observation. La forme des grains, la situation de leur noyau, leur diamètre sont autant de caractères qui seryent à les distinguer. Il est bon lontefois, lorsqu'on veut se livrer à un examen sérieux de fécules, d'avoir à sa disposition des types bien déterminés, avec lesquels on se guidera plus sûrement dans les recherches.

Les grains d'amidon présentent quelques réactions qu'il est bon de mettre en pratique.

$1^{\circ}$ Les grains d'amidon sont colorés en bleu par l'iode. Pour obtenil une bonne réaction, il faut employer des solu- 
tions iodées peu concentrées, sans quoi les grains prennent une teinte très foncée qui est gênante pour l'observation.

$2^{\circ}$ Action de la chaleur. - Si l'on vient à chauffer vers $55^{\circ}$ l'eau dans laquelle on a délayé de l'amidon, les grains se gonflent rapidement, mais cette réaction n’appartient qu'aux grains volumineux. Pour gonfler les petits grains, il faut chauffer jusqu'à $60^{\circ}$ environ (Nægeli). Si la température s'élève encore davantage, les grains finissent par éclater, et paraissent s'exfolier.

$3^{0}$ Action des alcalis. - Une dissolution étendue de potasse

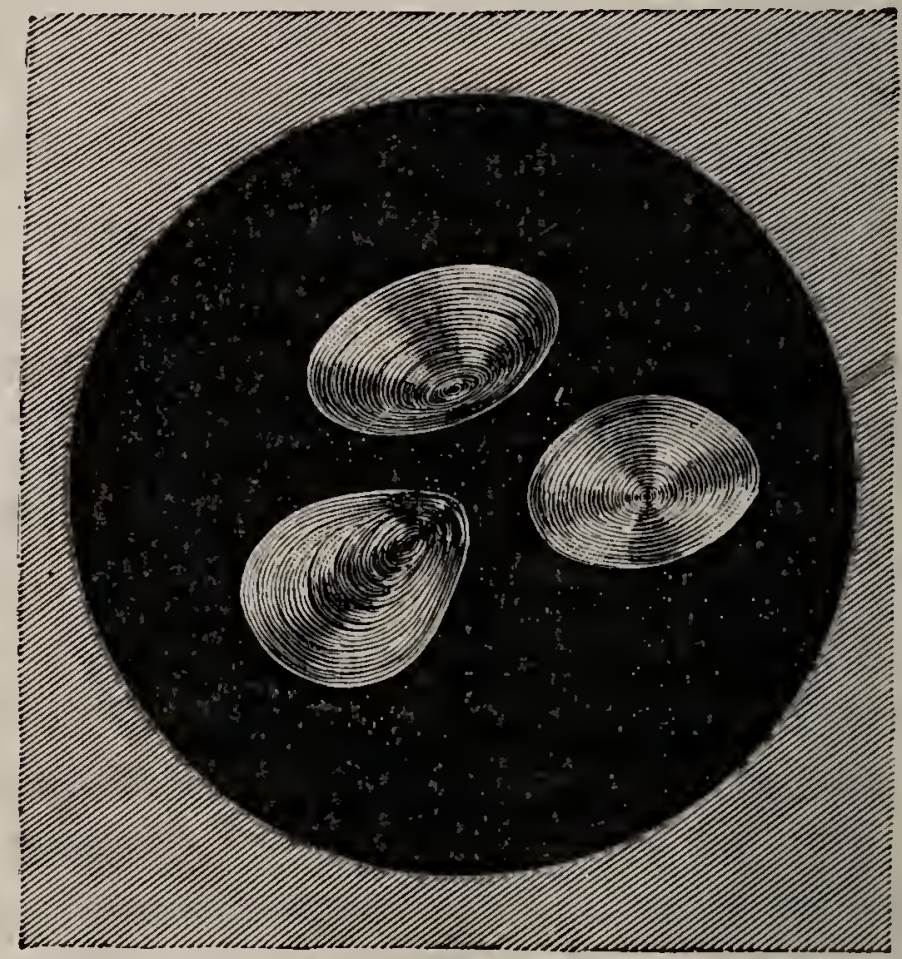

Fig. 52. - Fécule de Pomme de terre vue à la lumière polarisée.

ou de soude agit sur les grains d'amidon, de la même manière que l'eau chaude.

M. Donny a fondé sur cette réaction un procédé très sensible pour reconnaître un mélange de farine de Blé et de fécule de Pomme de terre. Une dissolution faible de potasse (1,כ p. 100) n'agissant que sur les gros grains de la fécule, ceux-ci prendront un énorme développement si on met la farine suspecte en contact avec ce réactif, tandis que les grains d'amidon de Blé seront à peine modifiés.

La dissolution iodée de chlorure de platine et l'oxyde de 
cuivre ammoniacal agissent sur les grains d'amidon comme les précédents réactifs.

$4^{\circ}$ Lumière polarisée. - L'usage de la lumière polarisée permet de retrouver le hile, lorsqu'il n'est point apparent à la lumière ordinaire. En effet, chaque grain d'amidon donne une croix avec les nicols croisés, et le point de croisement des deux bras de la croix correspond au noyau (fig. ว2). Rappelons encore que les grains d'amidon de $R i z$, ceux du Sparganium ramosum et en général tous ceux qui ont un diamètre inférieur à $0^{\mathrm{mm}}, 007$ sont sans action sur la luınière polarisée. Toutefois ils sont colorés en bleu par l'iode.

\section{$\S 9$. ALEURONE.}

L'aleurone, bien que paraissant jouer dans les plantes un rôle semblable à celui de l'amidon, a cependant une composition bien différente. Elle rentre en effet dans le groupe des matières albuminoïdes. .

Très répandue dans l'albumen des graines, elle offre dans sa configuration générale de grandes variations. Tantôt, elle est simplement formée de petits grains arrondis de matière protéique, et c'est ainsi qu'elle se présente dans les graines farineuses (Graminées, Phąséolées, Viciées, Ghâtaigniers, etc.); tantôt, au contraire, elle devient très complexe.

Dans le Berthollettia excelsa (noix de Para) par exemple, les grains de matière protéique sont très gros et renferment chacun un cristalloïde (1). Dans l'albumen du Ricinus communis les grains d'aleurone sont également volumineux et renferment un cristalloïde et un globoïde(fig. 53). Ces globoïdes sont de petites masses arrondies, mamelonnées, non cristallisées, formées de phosphate double de chaux et de magnésie. Enfin, dans l'Athusa cynapium M. Pfeffer (2) a trouvé des grains d'aleurone renfermant un cristalloïde et un cristal (oxalate de chaux).

(1) On appelle cristalloïdes des corps qui affectent des formes cristallines (cubes, tetraèdres, octaèdres, rhomboèdres, etc.), et que l'on trouve englobés dans le protoplasma (Pomme de terre) ou dans le noyau (Lathrea squamaria) des cellules. Ces corps sont uniquement formés de matière protéique ainsi qu'on peut s'en assurer par les réactifs. (Voir p. 20.)

(2) Pfeffer, Jahrlüch. füı Wiss. Botan., t. VIII, 1872. 
L'association d'un cristalloïde et d'un cristal paraît très rare. Le plus souvent le cristal semble remplacer le cristalloïde et peut être alors comme ce dernier accompagné d'un ou de plusieurs globoüdes (Vilis vinifera).

Dans tous les grains complexes dont il vient d'être question la matière protéique est réduite, le cristalloïde mis à part bien

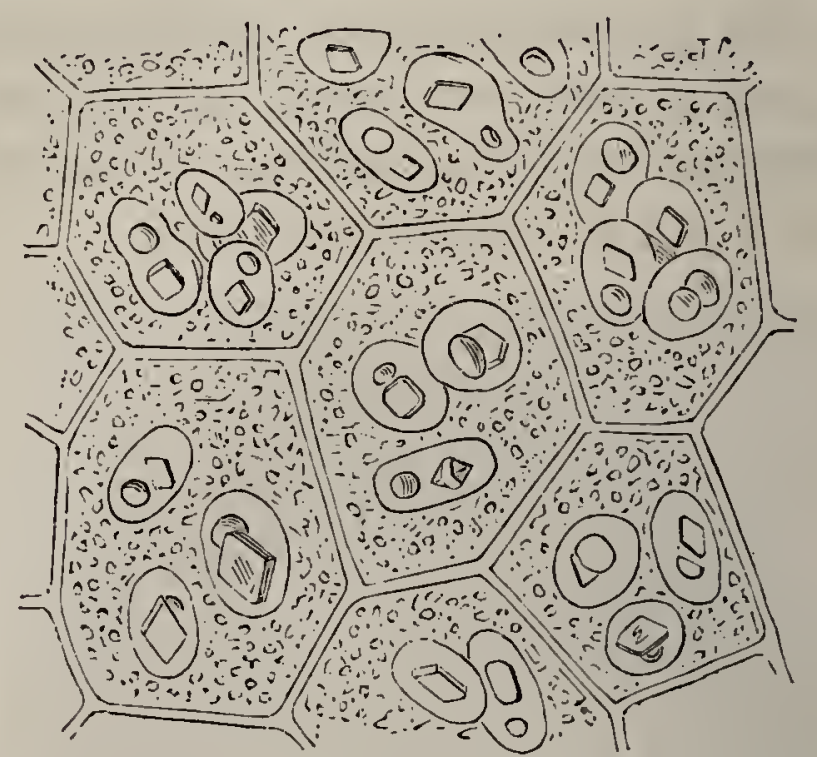

Fig. 53. - Grains daleurone avec gluboïdes et cristalloïdes au milieu des gouttelettes huileuses. Graine de ricin examinée dans la glycérine étendue. (Gross. 600.)

entendu, à une mince couche amorphe qui enveloppe le cristalloïde el le cristal ou les globoïdes (fig. 53 ).

Atude. Béactifs. - Pour reconnaître les diverses parties qui composent un grain d'aleurone, il est nécessaire de pouvoir les isoler, on y arrive au moyen des réactifs que nous allons indiquer :

$1^{\circ}$ Action de l'eau. - Ce liquide dissout le plus souvent la matière protéique des grains d'aleurone, mais n'attaque jamais les cristalloïdes. Ori pourra ainsi séparer ces deux parties, et étudier le crisialloïde à loisir. Dans le cas où l'enveloppe protéique ne serait pas soluble dans l'eau (Cynoglossum off.) on la dissoudrait au moyen d'une solution de phosphate de soude.

$2^{\circ}$ Action des acides. - Au moyen des acides on peut distinguer les globoïdes des cristaux. L'acide acétique dissout les premiers et est sans action sur les derniers.

$3^{\circ}$ Enfin les cristalloïdes se reconnaîtront aux caractères suivants: ils absorbent les matières colorantes; ils se gonflent 
rapidement sous l'influence d'une dissolution de potasse ou de soude. Ils se colorent en jaune par l'iode ; toutes ces réactions propres aux matières albuminoïdes les distinguent essentiellement des vrais cristaux.

\section{$\S 10$. COUleurs DEs plantes.}

Les couleurs variées que présentent les végétaux sont dues à des pigments colorés que l'on divise en trois groupes: l'un de ces groupes, sous le nom de série xanthique, comprend toutes les couleurs réparties entre le rouge et le jaune; une autre série, dite cyanique, renferme les couleurs comprises entre le bleu et le violet. Le troisième groupe enfin prend place entre les deux précédents. Il répond à la matière colorante verte des végétaux, c'est-à-dire à la chlorophylle.

Il nous est impossible d'entrer dans de grands détails au sujet de ces diverses matières colorantes. Nous nous bornerons donc à donner quelques notions essentielles.

$1^{\circ}$ Nalure des pigments colorés. - Il existe une différence assez remarquable dans la manière d'être des pigments des deux séries cyanique et xanthique. - Ces pigments, qui siègent dans la cavité des cellules, affectent dans la série xanthique la forme de granulations colorées (sauf dans les Dahlias jaunes), tandis, au contraire, que les pigments de la série cyanique sont généralement en solution dans le suc cellulaire. Ce n'est pas là toutefois une loi absolue. Nous venons de citer une exception pour la série xanthique; il en existe également à la manière d'être générale des pigments de la série cyanique. Dans les fleurs du Tillandsia amœna, de l'Adonis autummalis, etc., les pigments sont granuleux. Quoi qu'il en soit, la différence que nous venons de signaler supporte une certaine généralisation. Ajoutons enfin que le pigment chlorophyllien se rencontre le plus souvent à l'état de granules colorés en vert, mais quelquefois aussi en dissolution et colorant tout le protoplasma des cellules.

20 Localisation des pigments colorés. - La répartition des couleurs dans les tissus végétaux présente certaines particulaGUIDE DE MIGROGRAPHIE. 
rités qui ont été mises en lumière par les recherches de M. J. Chatin (1).

a. Dans les feuilles à coloration vraie, normale ou pérenne, le principe colorant semble être constamment ou presque constamment localisé dans les cellules de l'épiderme, probablement déchirées dans les cas très rares (Strobilanthes, Achyranthes, etc.) où cette matière a été vue dans les cellules du mésophylle. (Le chou rouge, d'après M. Morrèn, ferait exception à cette règle.)

Le pigment chlorophyllien au contraire n'occupe que très rarement les cellules épidermiques (Fougères, feuilles submergées). Il est répandu en quantité plus ou moins considérable dans les cellules du parenchyme des organes verts (feuilles, calices, tiges vertes, etc.).

b. Si dans une même feuille (Optisnemus), il existe à la fois des parties vertes, d'autres blanches (2) et d'autres roses ou rouges, on constate que les cellules du mésophylle contiennent dans le premier et le troisième cas des grains de chlorophylle, dans le second des grains incolores, tandis que les cellules épidermiques, vides dans le premier et le deuxième cas, renferment un liquide rose dans le troisième.

c. Dans les calices et corolles colorés, les matières colorantes sont localisées dans les cellules épidermiques.

$d$. Les colorations vernales des feuilles sont dues, comme les colorations pérennes, comme celles des fleurs, à des dépôts formés dans les cellules épidermiques.

$e$. Dans les colorations automnales, le principe colorant se trouve, non dans l'épiderme, mais dans les cellules du mésophylle.

Ce dernier énoncé trouve son explication dans la composition de la chlorophylle.

Composition chimique de la chlorophylle. - Gette matière

(1) J. Chatin, De la feuille. Thèse d'agrégation, 1874.

(2) Le blanc pur est généralement le résultat de l'interposition d'une certaine quantité d'air dans les cellules (Lis), le brillant métallique et le velouté sont dus à l'existence d'excroissances papilliformes à la surface de l'épiderme. Le jeu de la lumière sur ces papilles et sur la couche d'air retenu entre elles produit l'effet du chatoiement et du velouté (fig. 20). 
verte, découverte par Pelletier et Gaventou en 1818 et depuis étudiée successivement par Mulder, Morot, Frémy (1860), Filhol (1), etc., paraît être un mélange de deux matières, l'une jaune, l'autre bleu verdâtre, toutes deux solubles dans l'alcool, mais séparables au moyen de la benzine, qui dissout principalement la partie verte. Cette composition paraît, dans certains cas, susceptible d'altérations, au nombre desquelles se peut compter celle qui donne lieu à la coloration automnale des feuilles. C'est également par suite d'une altération des grains de chlorophylle que les jeunes fruits verts de Lycium barbarum, de Solanum pseudocapsicum, etc., deviennent jaunes ou rouges à la maturation (Kraus) (2).

Genèse et développement des corps chlorophylliens. - La chlorophylle se présente, avons-nous dit, le plus souvent à l'état de grains colorés en vert, qui ont reçu le nom de corps chlorophylliens. Ces grains paraissent essentiellement constitués par de petites masses de protoplasma (Chlorophore de Bohm) colorées par le pigment vert. Dans certains cas toutefois on trouve en outre, dans les corps chlorophylliens un peu volumineux, un ou plusieurs grains d'amidon ou des gouttelettes d'huile. Celte constitution de la chlorophylle s'explique aisément, lorsqu'on connaît le mode de genèse des grains qui la forment. Ces grains naissent en effet, comme par formation libre, du protoplasma des cellules.

Il est facile d'étudier la genèse des corps chlorophylliens dans les jeunes cellules des feuilles cotylédonaires des Phanérogames. En examinant l'utricule protoplasmatique de ces cellules, on voit qu'il présente d'abord une grande transparence. Puis apparaissent des taches, qui ne sont autres que la chlorophylle en formation. Toutes ces taches deviennent bientôt des grains arrondis qui forment à la face interne de la cellule comme un mamelonnement irrégulier. Plus tard, en se développant davantage, ces grains se pressent les uns contre les autres et deviennent plus ou moins régulièrement polyédriques. Lorsqu'ils se séparent, on croirait assister à une seg-

(1) Filhol, Ann. de chimie et de physique, etc., 1868.

(2) A. Kraus, Jahrbuch für wiss. Botanik, t. VIII, 1871. 
mentation du protoplasma. Une fois formés et devenus verts, les grains de chlorophylle s'accroissent par intussusception. Ils sont alors susceptibles, dans certains cas, de se multiplier par bipartition (Nitella, Bryopsis, Elodea. Sambucus, Impatiens, etc.), ce qui n'a rien d'étonnant, puisque, comme nous l'avons dit, le grain est essentiellement un amas de protoplasma vivant. Quant à la présence de l'amidon dans les corps chlorophylliens, elle paraît liée à la vie même du protoplasma. Le cadre de notre ouvrage ne nous permet pas d'entrer dans de plus longs détails à ce sujet.

Etude de la chlorophylle. - Pour étudier la chlorophylle, on aura tout avantage à opérer sur des végétaux étiolés ou sur des parties jaunes de plantes qui ne sont pas devenues complètement vertes par défaut de lumière. Les grains sont alors distants les uns des autres, et faciles à distinguer. Lorsqu'on se trouve en présence d'un végétal coloré ou non et qui paraît dépourvu de chlorophylle, il ne faut pas négliger de s'assurer au moyen de coupes de la réalité de cette apparence. En effet, đans les Floridées par exemple, qui sont colorées en rouge vif, et dans les Fucus, Laminaires et autres Algues colorées en brun, la chlorophylle existe, mais elle paraît manquer, parce qu'à la matière verte se mêlent des substances rouges ou jaunes. Ailleurs (Neottia, Limodorum, Orobanche), des plantes qui paraissent dépourvues de coloration verte renferment cependant de la chlorophylle.

On doit attacher également une certaine attention à la forme que revêt la chlorophylle dans les plantes. Le plus souvent elle est en granules répandus en grand nombre dans la cavité des cellules. Ailleurs, elle se dispose en larges bandes transversales dans chaque cellule (Conferva zonata), ou en étoiles à longs rayons (Zygnema), ailleurs encore, en spirales plus ou moins dentelées sur.leurs bords (Spirogyra).

L'eau agit rapidement sur les grains de chlorophylle dépourvus d'amidon. Elle les gonfle et fait apparaître dans leur intérieur des vacuoles plus ou moins grandes.

L'acide acétique jaunit les grains de chlorophylle. Cette réaclion est quelquefois employée pour rendre plus claires les préparations obscurcies par de grandes quantités de matière verte. 


\section{CHAPITRE III}

\section{ORGANES ÉLEMENTAIRES DÉRIVÉS DES GELLULES}

Sous cette dénomination nous comprenons les divers organes élémentaires que l'on connaît sous le nom de vaisseaux. - Tous dérivent immédiatement de la cellule, et participent à la constitution des tissus des plantes. Mais il existe entre eux, tant dans leur rôle physiologique que dans leur manière d'être générale, de telles différences que l'on a dû établir certains groupes que nous allons étudier. Nous passerons successivement en revue : les vaisseaux proprement dits, les vaisseaux utriculeux, les vaisseaux laticifères, et les vaisseaux criblés ou cellules grillagées, connus encore sous le nom de vaisseaux du liber.

ArT. 1.

\section{Vaisseaux proprement dits.}

Leur origine. - Les vaisseaux proprement dils résultent de la superposition de cellules allongées qui forment des files longitudinales parallèles à l'axe du végétal. Ces cellules conservent pendant un certain temps leur cloison transversale intacte, ainsi qu'il est facile de s'en convaincre par des coupes longitudinales dans les tissus ligneux en voie de développement. Mais bientôt, ces cloisons venant à se résorber plus ou moins complètement, les cavités de toutes les cellules superposées sont mises en communication directe les unes avec les autres, et leur ensemble forme une sorte de tube droit, ordinairement cylindrique, qui n'est autre qu'un vaisseau. Le protoplasma disparaît, et on ne trouve plus dans la cavité 
du vaisseau que de l'air ou un liquide aqueux (sève, au printemps [Hofmeister]).

Parois des vaisseaux. - Les vaisseaux étant formés de cellules, il est clair que tout ce que nous avons dit des parois - cellulaires s'applique également aux parois des vaisseaux. Toutefois les vaisseaux ne paraissent généralement pas susceptibles d'un épaississement aussi considérable que celui qui caractérise les parois des fibres, mais ils présentent toutes les diverses espèces de marques sur lesquelles nous avons

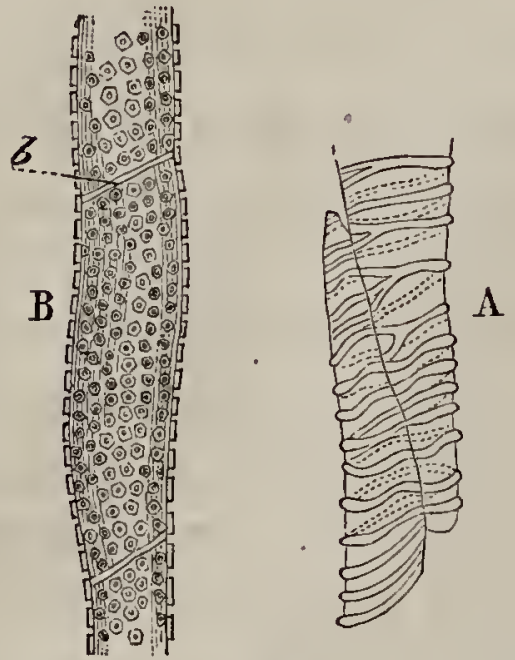

Fig. 54. - A. Union de deux cellules trachéennes de la tige de Balsamine, d'après M. Duchartre. - B. Coupe longitudinale d'un vaisseau aréolé ponctué pris dans le bois de la tige de Justitia Adathoda. - $b$. Restes de la cloison séparatrice des deux cellules vasculaires superposées. appelé l'attention page 20 et suivantes. Aussi désigne-t-on les vaisseaux sous les noms de $V$. ponctués, $V$. rayés, $V$. réticulés, $V$. annelés, $V$. spiralés. Ces derniers sont encore appelés trachées. Sans vouloir insister longuement, nous devons cependant dire quelques mots des parois transversales des cellules qui ont formé les vaisseaux. Tantôt, en effet, ces parois se résorbent complètement; c'est le cas le plus fréquent lorsqu'elles étaient horizontales. Il n'en reste plus alors qu'un bourrelet circulaire (fig. 54). Tantôt, au contraire, la résorption des parois transverses est incomplète; c'est ce qui arrive lorsqu'elles sont obliques par rapport au grand axe du vaisseau. Cette résorption se réduit à la formation de ponctuations ou de raies dans la paroi.

L'obliquité des cloisons séparatrices des cellules vasculaires peut devenir tellement prononcée que le vaisseau apparait plutôt comme un amas de cellules juxtaposées. Chacun des articles composants parait alors indépendant et a quelquefois été désigné du nom de trachéide (Fougères, Balsamine).

f́tude des vaisseaux. - On fera des coupes longitudinales afin d'étudier les parois et les marques des vaisseaux. Ces coupes seront dirigées dans la partie ligneuse des tiges. Il sera également nécessaire de pratiquer des coupes transver- 
sales pour prendre connaissance de la forme des vaisseaux et de leur diamètre.

Sujets d'itude. - Dans beaucoup de tiges ligneuses on trouvera réunies dans le bois les diverses variétés de vaisseaux que nous avons énumérées plus haut. Ils s'y trouvent alors dans un ordre déterminé.

Pour l'examen des vaisseaux ponctués, on recourra avec avantage aux tiges de calamus, chez lesquelles ces vaisseaux atteignent un tel diamètre que leurs orifices sont visibles à l'cil nu sur les coupes transversales.

De beaux exemples de vaisseaux rayés se rencontrent dans les tiges soulerraines des Fougères, et leurs raies aréolées y affectent une disposition tellement régulière qu'on les désigne sous le nom de vaisseaux scalariformes.

Pour les vaisseaux annelés, il conviendra de faire des coupes longitudinales sur la tige du Zea Maïs (fig. 44). Les anneaux, très développés en épaisseur, sont régulièrement distants les uns des autres.

Les trachées enfin se trouvent au voisinage de la moelle dans toutes les tiges de Dicotylédones et de Monocotylédones. Leur diamètre transversal est en général inférieur à celui de tous les autres vaisseaux.

ART. 2.

\section{Vaisseaux utriculeux. - Vaisseaux laticifères (1). - Latex.}

Les vaisseaux laticifères, ou réservoirs du latex, ont fait le sujet de recherches nombreuses de la part des botanistes les plus distingués, Unger, Hanstein, Moldenhawer, Lestiboudois, Trécul, Van Thiegem, etc. Ils sont maintenant bien connus, et il nous sera facile de retracer les principales particularités qui les distinguent.

(1) Trécul, Ann. Sc. natur., $5^{\mathrm{e}}$ série, t. V, VI, VII. - David, Ueber die Milchzellen der Euphorbiaceen. Breslau, 1872. - Van Thiegem, Mémoires sur les canaux sécreteurs des plantes (Ann. Sc. nat., Ve série, xvi, 187?). - J. Chatin, Du siège des substances actives. Thèse d'agrégation ì l'école de médecine, 1876. - Schacht, Die Milchsaftgefasse der Cariea, 1857. - Planchon, Histoire des drogues, t. II, p. 516. 
Origine des laticifères. - La question de leur origine a été en grande parlie traitée par Trécul qui a montré dans de nombreux travaux que ces éléments sont de nature cellulaire. Les laticifères dérivent de cellules disposées en séries simples ou rameuses qui, primitivement séparées par leurs cloisons transverses, ne forment bientôt plus qu'un canal unique lorsque ces cloisons se sont résorbées. Schacht a parfaitement décrit ce mode de formation dans les Morées. Nous recommanderons, pour suivre facilement la transformation des séries de cellules en tubes continus et anastomosés, la racine des Argemone, dont M. Trécul a fait une étude spéciale. (Trécul, Ann. Sc. nat., 丂丂ّ série, p. 49, t. V.) - On trouve là des " séries de cellules pleines d'un beau suc jaune, et trois à " cinq fois plus longues que larges. Un peu plus tard les pa" rois transversales qui séparent ces cellules superposées se " perforenl; elles disparaissent même entièrement pendant "que la fusion des parois latérales s'accomplit pour la trans"formation des laticifères en tubes parfaits. " Sur cette même racine on suivra très facilement la formation des anastomoses. On verra deux canaux émettre au même niveau des prolongements coniques qui se rencontrent bientôt par leurs sommets. Leurs parois se résorbant au point de contact et les parois latérales se fusionnant, la continuité des tubes se trouve ainsi établie.

Ces faits étant connus, on ne peut s'étonner de rencontrer, comme nous le verrons fréquemment dans les plantes à laticifères bien développés, des cellules isolées remplies également de suc coloré; bien plus, on ne peut s'empêcher de regarder comme un premier état des laticifères, comme un intermédiaire en un mot entre ces vaisseaux et les cellules, certains organes qui ont reçu le nom de vaisseaux utriculeux et dont nous allons dire quelques mots.

\section{$\S 1$. Vaisseaux utriculeux.}

On nomme ainsi de longues et larges cellules superposées et dont les cloisons persistent ou ne subissent qu'une résorption partielle. Ces éléments, qu'on rencontre dans un grand 
nombre de Monocotylédonées, constituent une forme typique à laquelle peuvent être également rattachés certains éléments propres aux Euphorbiacées et aux Convolvulacées.

Vaisseanx utriculeux des Monocotylédonées. - Parmi les Monocotylédonées, c'est principalement dans les plantes à oignon qu'on trouvera de bons exemples de vaisseaux utriculeux (Allium, fig. 5̌š), etc.). Il suffit, pour les observer, de faire des coupes dans le parenchyme de ces plantes. Les Aroïdées (Van Thiegem, loc. cit.) présentent également des vaisseaux utriculeux sous forme de cellules cylindriques plus larges et plus longues que celles du párenchyme environnant, et dont les parois transversales se résorbent quelquefois pour former des tubes. Ces vaisseaux utriculeux renferment des cristaux en ai-

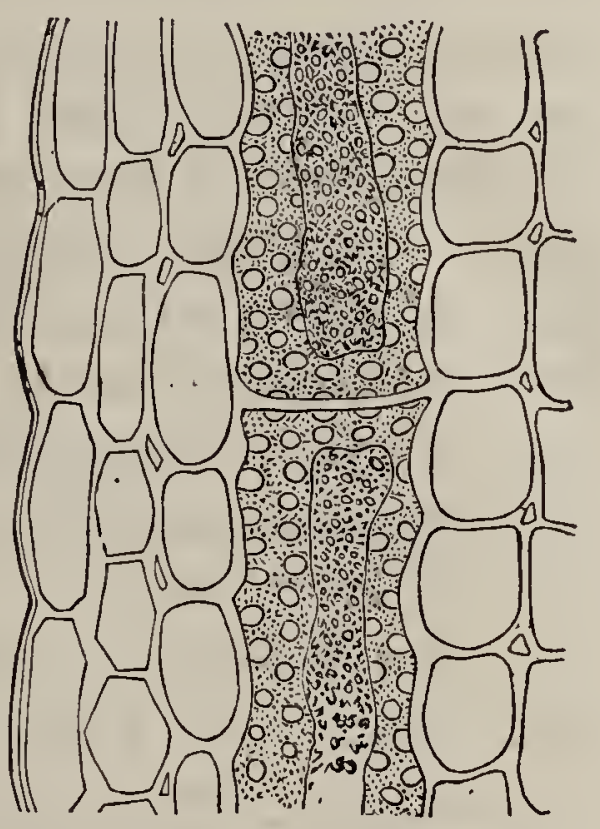

Fig. 55. - Vaisseau utriculcux. Coupe longitudinale à travers une écaille de bulbe d'Allium Cepa. Le latex du vaisseau a été coagulé par la potasse (d'après Sachs). guilles (raphides) et un suc incolore.

Euphorbiacées. - Dans les Euphorbiacées, les vaisseaux utriculeux se montrent comme de longues cellules isolées qui suivent la direction de la tige et envoient des branches latérales dans tous les sens. - Particulièrement répandus dans l'écorceet la moelle, ils forment de plus vers les nœuds de la tige et les coussinets des feuilles des ramifications très nombreuses, mais il ne s'établit point d'anastomoses entre eux. Ces vaisseaux utriculeux, qui renferment un abondant latex, sont encore remarquables d'après MM. Trécul (loc. cit.) et David (loc. cit.) en ce qu'à leur mode de formation cellulaire s'ajoute un accroissement particulier par élongation des parois (1).

Conrolvulacées. - MM. Trécul, Planchon, Fluckiger, etc.'

(1) Rappelons l'existence dans les Euphorbiacées de fibres libériennes ramifiées que l'on trouve dans l'écorce et la moelle, ct qui ont longtemps été considérées comme des éléments propres à transporter lo latex. 
ont également fait connaître l'existence des vaisseaux utriculeux dans les Convolvulacées. Dans le Jalap, le Turbith, la Scammonée, etc., on remarque sur des coupes transversales du parenchyme cortical de la racine et presque exclusivement dans la zone de ce parenchyme qui confine à la zone cambiale de grandes cellules à parois jaunâtres renfermant un latex à grains fins. Les cellules à latex des Convolvulacées sont parfois disposées les unes auprès des autres de manière à former un cercle continu. Si on les considère sur des coupes longitudinales, elles se montrent sous la forme d'éléments parfaitement distincts dans la plupart des cas (Calystegia Sepium), mais qui, chez certaines Convolvulacées, présentent une résorption partielle de leurs parois de séparation, tendant ainsi vers le type des laticifères vrais, dont l'étude va maintenant nous occuper.

\section{§. Vaisseaux Laticifíres.}

Caractères généraux. - Étude. - Les vaisseaux laticifères se présentent, sur des coupes longitudinales, comme des canaux allongés, pourvus d'une paroi propre et remplis d'un suc de couleur variable (appelé Latex). Ces canaux, trèsdistincts des vaisseaux proprement dits, sont caractérisés :

$1^{\circ}$ Par leur forme; en effet, tandis que les vaisseaux proprement dits sont régulièrement calibrés, le diamètre des laticifères est le plus souvent très irrégulier.

$2^{\circ}$ Par l'absence à peu près constante des marques qui existent si variées sur la paroi des vaisseaux proprement dits.

$3^{\circ}$ Par l'existence fréquente d'anastomoses et de ramifications.

Cette dernière particularité nécessite l'emploi de certaines précautions lorsqu'on étudie les vaisseaux laticifères. Aussi bien conduites que soient les coupes, le plan par lequel a passé le rasoir ne présente ordinairement que des tronçons de laticifères, surtout lorsque ceux-ci forment des réseaux serrés et à ramifications nombreuses. On devra donc chercher, pour les étudier plus complètement, à les isoler par coction soit dans l'acide nitrique, soit mieux encore dans la potasse. Si l'on fait des coupes, on aura soin d'éviter d'écraser les pièces sur lesquelles on opère ou de laver les coupes obtenues. On 
risquerait en effel d'enlever le latex, et celui-ci est souvent fort utile pour faire reconnaître au milieu des tissus les laticifères, qui d'après leur origine se confondent facilement avec les éléments parenchymateux qui les entourent.

Répartition des laticifères. - Quant à l'endroit où doivent se faire les coupes, on ne peut que d'une manière générale donner des indications à ce sujet, car, ainsi que nous le verrons, la place des laticifères varie avec les végétaux en observation.

C'est toutefois dans le tissu parenchymateux du végétal (parenchyme cortical et moelle) qu'on les trouve ordinairement en plus grand nombre. En les passant rapidement en revue dans les principales familles de plantes où on les a observés, nous donnerons du reste les détails nécessaires à leur observation.

Papavéracées. - Structure. - Distribution. - D'après les recherches de Trécul (loc. cit.), on trouve dans les laticifères des Papavéracées deux types de structure et de disposition. " D'après le premier type, les laticifères sont répartis surtout " au pourtour des faisceaux fibro-vasculaires des tiges aérien" nes et des feuilles (Chelidonium, Maclea, Sanguinaria). " D'après le second type, les laticifères existent seulement "dans le tissu sous-libérien des faisceaux fibro-vasculaires des " mêmes organes" (Papaver rhoas, somniferum, et Argemone grandiflora, ochroleuca, etc.).

Si dans le premier type on examine les laticifères du Chelidonium majus, on trouvera une répartition différente de ces canaux dans la tige et dans la racine. Dans la tige en effet on les trouve rarement par groupes. Ils sont généralement isolés et cheminent à des distances plus ou moins grandes les uns des autres. Dans la racine au contraire ils forment des réseaux à mailles souvent très serrées (fig. 56). Cet examen est très facile sur les racines fraîches du Chelidonium majus qui renferment un latex jaune très abondant. On fera des coupes tangentielles et des coupes radiales. Pour se rendre exactement compte de l'endroit où doit être menée la coupe, il suffit de diviser transversalement un morceau de la racine à examiner. Sur la section transversale obtenue on aperçoit alors des goultelettes de latex qui s'échappent de points bien déterminés et 
qui indiquent par suite très nettement la situation des éléments à étudier.

Nous venons de dire que les laticifères des racines du Chelidonium majus forment des réseaux. On remarquera que les cellules qui constituent ces réseaux sont quelquefois très courtes, surtout au voisinage de l'épiderme ; la même obser-

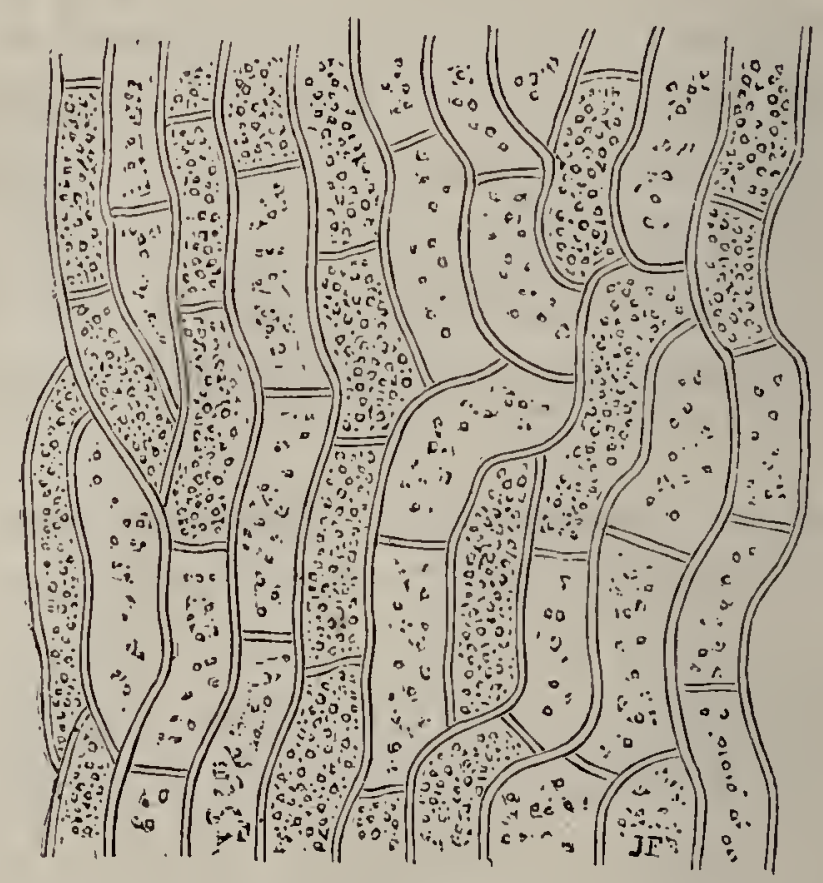

Fig. 56. - Laticiferes; coupe sur la racine du Chelidonium majus.

vation s'applique aux séries de cellules à latex des tiges et des pétioles, qui, suivant Trécul (loc. cit.), sont très propres à montrer le deuxième degré de perfectionnement des laticifères, puisqu'on y trouve souvent perforées les parois transversales qui séparent les cellules constituantes. Enfin dans le Chelidonium on trouve encore fréquemment des cellules isolées renfermant un suc jaune. Ces cellules sont les seuls éléments à suc coloré que l'on trouve dans le Glaucium flavum. Elles occupent dans les parties aériennes de cette plante la surface du liber, ou sont réparties au milieu de ses fibres externes; dans la racine, on en trouve répandues dans toute l'épaisseur de l'écorce, où elles peuvent même donner lieu à des tubes continus. (Trécul, loc. cit.)

Comme exemples du second type de répartition des latici. fères on pourra observer la tige du Papaver rhcas ou les capsules de nos pavots; on trouvera dans ces deux sujets 
d'excellents types de laticifères fréquemment anastomosés en réseaux d'une grande richesse.

Latex. - Le latex des Papavéracées est un liquide qui tient en suspension de nombreux globules. Sa coloration est variable : blanchâtre dans les Pavots, rouge dans la Sanguinaire, jaune dans le Chelidonium majus, il est à peine opalin dans l'Eschscholtzia.

Chicoracées. - Campanulacées. - Lobéliacées. - Dans la plupart des Chicoracées les laticifères occupent la moelle et le parenchyme cortical au voisinage du liber. Il y a cependant des Chicoracées qui ne possèdent pas de laticifères dans la moelle, exemples : Cichorium Intybus, Lampsana comm ., Hieracium prenanthoïdes, etc. (Trécul.)

Chez certaines Chicoracées on trouve aussi des laticifères à la face interne des couches libériennes, ce qui est le cas général pour les laticifères des Campanulacées et des Lobéliacées. Dans ces deux dernières familles les laticifères forment là un réseau parfait à mailles tantôt courtes et étroites, tantôt plus larges et très longues. Dans certaines espèces (Campanula medium) ces vaisseaux sont tellement multipliés qu'ils se touchent, et leur membrane, assez épaisse, est de plus remarquable par l'existence de nombreux pores qui, mettent ces laticifères en communication les uns avec les autres ei avec les cellules voisines.

Dans les Chicoracées également les laticifères sont extrêmement nombreux et ramifiés. Ils forment des sorles de trames lamelleuses que l'on peut facilement apercevoir sur des coupes fines, surtout si l'on a soin de traiter ces coupes par la potasse. Le tissu ambiant devenant transparent, les laticifères apparaissent avec toute la netteté désirable. Il est intéressant de noter encore, au sujet des Chicoracées, une disposition curieuse. On sait que fréquemment le moindre contact, la plus superficielle érosion suffit à faire écouler le latex blanc laiteux de ces plantes. Les réseaux laticifères sont pourtant, nous l'avons dit, assez profondément placés, puisqu'ils cheminent au voisinage du liber: M. Trécul donne l'explication suivante du phénomène :

Des mailles profondes du réseau s'élèvent des branches qui 
arrivent à l'épiderme, le traversent et ne se terminent que sous la cuticule. Que celle-ci subisse la moindre atteinte, et le latex s'écoulera.

Apocynées. sclépiadées. - Les laticifères parcourent ici la moelle et l'écorce, ainsi qu'on peut très bien l'observer dans le Vinca major (parties jeunes) et le Nerum Oleander. Dans les nœuds ils offrent de nombreuses ramifications et anastomoses. Hill, Schleiden, Schacht, etc., observant dans la moelle et le tissu parenchymateux de ces plantes des fibres libériennes isolées et ramifiées (Hoya carnosa, parenchyme de la feuille, etc.), considérèrent longtemps ces éléments comme chargés de transporter le latex. Trécul a montré que le suc que renferment ces fibres est bien différent du latex et renferme des granules incomparablement plus fins. La membrane des fibres est également très différente de celle des laticifères vrais.

Sapotées. - Les Mimusops balata et elata, l'Isonandra guttata, etc., renferment une grande quantité de latex porté par des vaisseaux qui occupent principalement le système cortical.

Urticées. - Le système des vaisseaux laticifères des Urticées (Ficus, Humulus) se rapproche beaucoup, au point de vue de sa répartition, de celui des Chicoracées. Les vaisseaux occupent particulièrement le parenchyme cortical au voisinage du liber et de la moelle.

Mais, au point de vue de l'arrangement, ces laticifères sont plutôt comparables à ceux des Papavéracées. Dans une grande partie de leur parcours, en effet, ces vaisseaux cheminent isolés et sans anastomoses, et ce n'est qu'aux nœuds et dans le parenchyme des feuilles (Ficus), où ils pénètrent en abondance, qu'ils se ramifient et s'anastomosent. Il peut arriver que quelques branches se continuent jusqu'à la surface épidermique, semblablement à ce qui se passe dans les Chicoracées.

Papayacées. - Les vaisseaux laticifères de ce groupe sont remarquables par leur situation dans le bois. De là ces vaisseaux envoient de nombreuses ramifications dont les unes s'appliquent contre les vaisseaux et les entourent, tandis que les autres, à travers les rayons médullaires, se dirigent d'une 
part vers la moelle, d'autre part dans le tissu parenchymateux corlical, où elles forment, au niveau des nœuds, de riches réseaux anastomotiques.

Ant. 3.

\section{Tubes cribreux.}

Les tubes cribreux (Sicbröhren), encore appelés tubes criblés, cellules grillagees, etc., furent découverts en 1837, par Hartig, dans le liber et furent considérés par lui comme faisant partie du faisceau vasculaire des Phanérogames. Comme les vaisseaux proprement dits, ces organes sont formés par la juxtaposition de cellules, dont les cloisons transverses deviennent ponctuées par suite d'une résorption partielle. Ges ponctuations donnent à ces cloisons l'aspect d'un grillage ou d'un crible, ce qui leur a fait donner les noms désignés ci-dessus. Parfois cependant les ponctuations se trouvent également sur les parois latérales; elles sont étroitement rapprochées et forment des groupes ou sortes de plaques d'un aspect tout à fait caractéristique.

Étude. - On pourra prendre comme premier sujet de recherches la tige du Cucurbita pepo qui possède un grand nombre de ces tubes cribreux situés aux faces interne et externe des faisceaux libéro-ligneux. On fera des coupes lon-

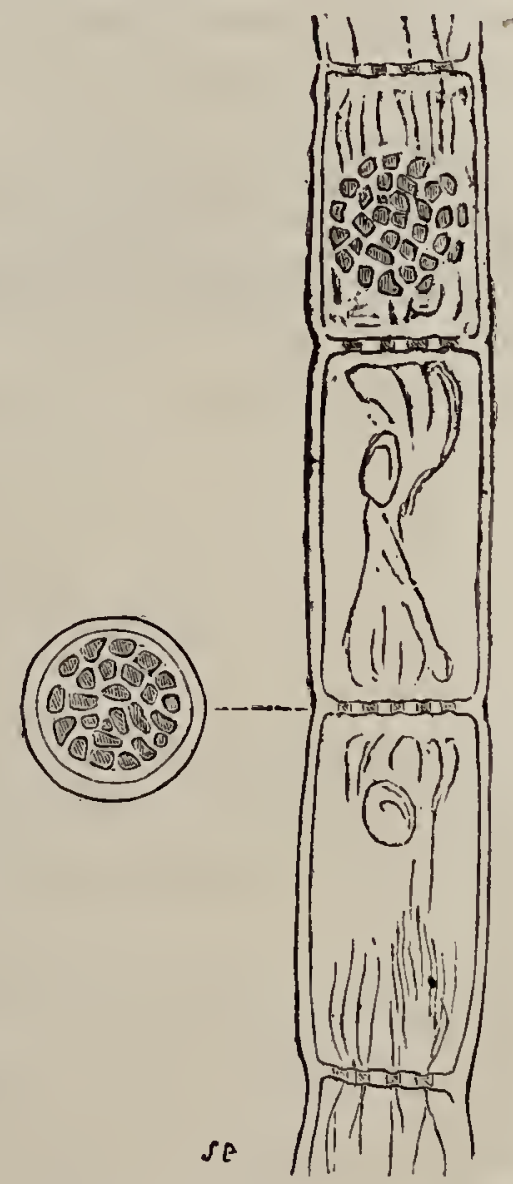

Fig. 57. - Tube cribreuux du Cucurbita pepo. gitudinales qui montreront le tube dans toute sa longueur, ainsi que la disposition plus ou moins oblique des cloisons transverses. Si l'on a eu soin de laisser pendant quelque temps les tiges dans l'alcool avant de pratiquer les coupes, on verra le contenu cellulaire rétracté comme le montre la figure, et en se servant d'un grossissement approprié, on pourra con- 
stater le passage de filaments protoplasmatiques à travers les ponctuations perforées des cloisons (fig. 57). Il s'établit en effet, lorsque les cellules grillagées sont arrivées à un certain développement, une communication directe entre les cellules superposées, aussi bien du reste qu'entre les cellules juxtaposées. Dans le premier cas, c'est par les cloisons transverses que s'établit la communication; dans le second cas, les plaques criblées des parois latérales servent d'intermédiaire.

On fera également des coupes transversales sur la tige du Cucurbita; sur ces coupes on pourra étudier les cloisons transverses; il s'en trouve toujours en effet un certain nombre au niveau des sections. Vues sur ces coupes, elles apparaissent comme des sortes de plaques arrondies percées de nombreuses petites ouvertures.

On trouve des tubes grillagés très développés dans les Cucurbita Pepo, Lagenaria vulgaris, Calamus Rotang, Polamogeton natans, Bignonia speciosa, Vitis vinifera, etc. 


\section{CHAPITRE IV}

ART. 1.

\section{Tissus.}

Les cellules, que nous avons étudiées jusqu'ici à l'état d'éléments isolés, se groupent le plus souvent pour former des assemblages que l'on désigne sous le nom de tissus. Elles affectent alors entre elles certains rapports qui méritent de fixer un moment notre attention.

\section{$\S 1 .-$ UNION DES CELlUI.ES EN TISSUS.}

Tantôt l'union des cellules en tissu est un résultat direct de leur mode de formation. Tantôt au contraire elle n'est qu'un phénomène secondaire plus ou moins indépendant de la naissance des cellules.

Premier cas. - Au premier cas se raltachent les tissus qui résultent de cellules formées par division. C'est ainsi que la plupart des jeunes tissus des plantes élevées en organisation se forment directement par cloisonnements ou divisions de cellules mères spéciales en cellules filles capables ellesmêmes de se diviser à leur tour. Certaines Algues pluri-cellulaires qu'on peut regarder comme des tissus ayant une vie propre et indépendante se forment également par division. Tel est le Spirogyra orthospira dont chaque cellule, en se cloisonnant comme nous l'avons indiqué plus haut, donne lieu à deux nouvelles cellules qui restent unies et forment dès 
lors partie du tissu de l'algue. Or si l'on examine les cloisons séparatrices qui se forment ainsi, on constate quelles sont simples et qu'au moins pendant un certain temps, la paroi qui sépare deux cavités cellulaires voisines est commune à ces deux cellules.

Deuxième cas. - L'union des cellules en tissu peut être regardée comme secondaire, lorsque ces cellules naissent par genèse ou formation libre. Ainsi dans la formation de l'albumen de la plupart des Phanérogames (fig. 21) on peut voir que les jeunes cellules constituées par une masse protoplasmatique et un noyau sont tout d'abord écartées les unes des autres. Ce n'est que plus tard qu'elles se rapprochent et finissent par se toucher. Ici d'ailleurs, comme dans le premier cas, la cloison séparatrice de deux cavités cellulaires voisines est simple, au moins dans le principe ; c'est une lamelle de cellulose sécrétée à la fois par les deux masses protoplasmatiques, et

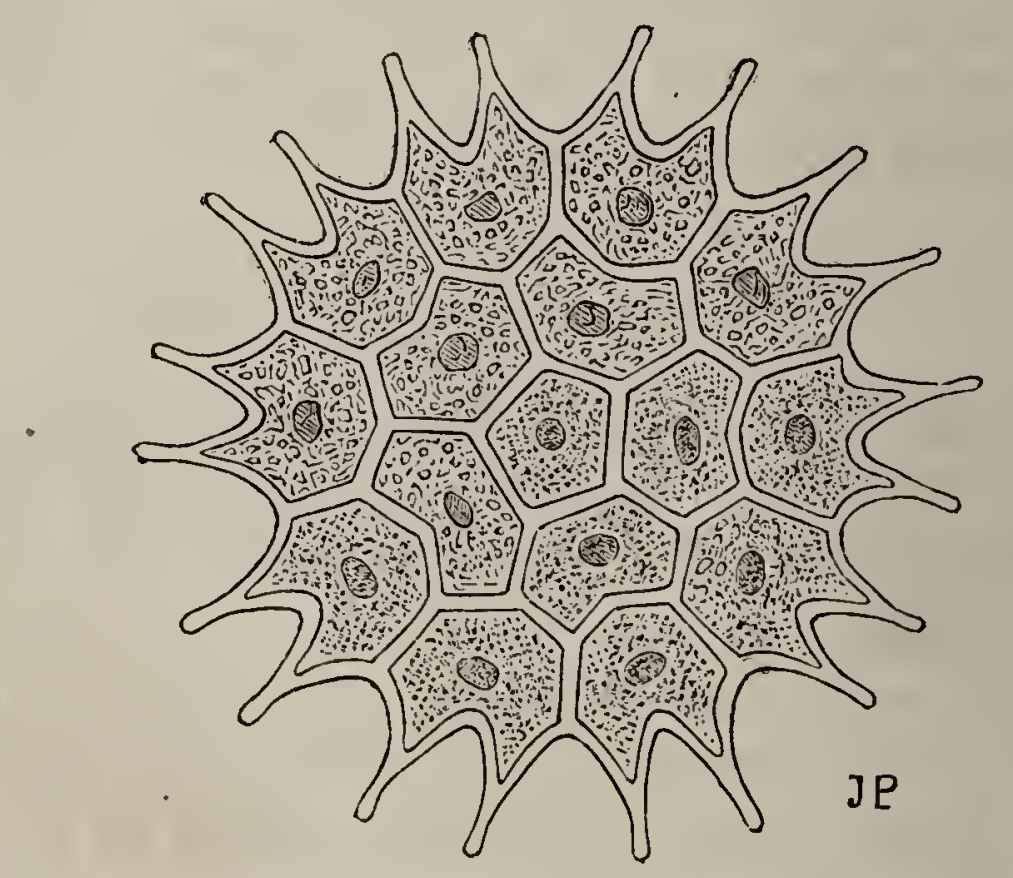

Fig. 58. - Pediastrum granulatum. Diam. 0nım,080 (d'après Pelletan).

dont on ne peut constater la présence au moyen du chlorure de zinc iodé que lorsque les couches extérieures du protoplasma des deux cellules se sont appliquées l'une sur l'autre. Il y a donc là soudure de deux cellules primitivement distinctes. On peut encore très facilement se rendre compte de cette union secondaire des cellules en tissu, par l'étude du 
Pediastrum granulatum (fig. 58), petite Algue que l'on rencontre parmi les enduits verdâtres qui recouvrent les corps submergés dans les eaux stagnantes. En suivant le développement de cette Algue, on peut voir chacune des cellules qui la composent, jouant le rôle de cellule mère, produire, par genèse, de 16 à 32 cellules filles qui, d'abord séparées, se soudent et reproduisent une Algue semblable. En examinant la figure que nous reproduisons, on peut se faire une bonne idée de cette formation de tissu par soudure et reconnaître que les cloisons qui séparent les cavités cellulaires sont simples et homogènes:

On peut donc établir que, quel que soit le mode de formation d'un tissu, les cloisons des cellules qui le composent sont simples au moins dans le principe. Mais par suite du développement les parois cellulaires se modifient plus ou moins profondément, et, si l'on examine un tissu âgé, l'aspect des cloisons cellulaires est bien différent. Ghaque cellule en effet paraît avoir une paroi propre plus ou moins épaisse et séparée de la paroi voisine par une cloison qui a reçu le nom de lamelle moyenne. Cette lamelle moyenne se voit en $a$ dans la figure วั9. Elle y est mince, et c'est ainsi également qu'elle se présente dans les tissus lignifiés; ailleurs au contraire elle est molle, facile à gonfler, comme gélatineuse (Fucacées, albumen du Ceratonia siliqua). Elle forme alors comme une sorte de matière intercellulaire au milieu de laquelle les cellulés semblent s'être creusé leur cavité. De là l'opinion longtemps admise, d'après laquelle les cellules seraient plongées dans une matière intercellulaire plus ou moins indépendante de leurs parois. Les connaissances que l'on possède aujourd'hui sur le développement des parois cellulaires permettent une plus juste appréciation de la nature de la lamelle moyenne. Elle n'est autre chose qu'une différenciation de la cloison commune pendant son épaississement, différenciation de même ordre que celle qui donne lieu à la formation des stries dans l'épaisseur des parois cellulaires (voir page 100). 
§ 2. - DÉdoublement des cloisons pRlmitives.

A l'origine les tissus, quel qu'en soit le mode de formation, sont continus; mais plus tard, les éléments qui les composent venant à se développer inégalement, leurs parois communes se dédoublent; de là des vides entre les cellules; le tissu, de compact qu'il était, devient plus ou moins lacuneux.

Les vides ainsi formés sont quelquefois très peu volumineux; ils apparaissent alors dès l'origine de la différenciation du
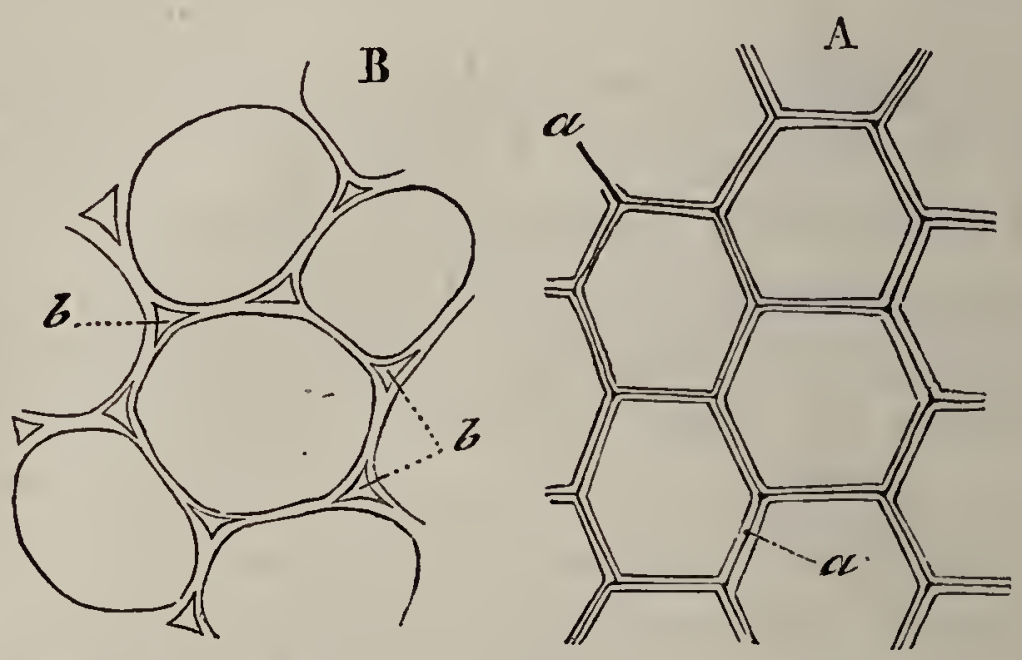

Fig. 59. - B. Tissu à cellules arrondies. $b, b$. Espaces intercellulaires. -- A. Tissu à cellules polyédriques. $a, a$. Lamelle moyenne.

tissu et seétendent le plus souvent entre les angles arrondis des cellules qui restent unies par la plus grande partie de leur surface (fig. 59, B). Ils forment ce que l'on appelle des interstices ou méats cellulaires et constituent de petits canalicules anguleux dont le nombre des faces répond au nombre des cellules qui les bordent $(b, b)$.

Si les parois cellulaires ainsi dédoublées s'accroissent de manière à s'écarter des parois voisines, le méat grandit et la cavité qui en résulte peut acquérir un développement considérable. C'est ainsi que se produisent les cavités aérifères et les réservoirs ou canaux sécréteurs, formations que nous allons étudier. 
ArT. 2.

\section{Cavités intercellulaires.}

Mode opératoire. - Pour étudier les cavités développées dans les tissus, on aura tout avantage à opérer sur des parties de plantes durcies dans l'alcool.

Les coupes minces sont en effet très difficiles à obtenir sur des sujets frais. On pourrait encore plonger le tissu à diviser dans la paraffine, de manière à en remplir tous les vides; on se débarrasserait de lá paraffine comme nous l'avons indiqué page 41. Enfin, on devra se mettre en garde contre la présence de l'air qui remplit souvent les cavités, et dont on a beaucoup de peine à se débarrasser lorsqu'on monte les préparations. Les coupes seront faites transversalement et longitudinalement par rapport à l'axe de la cavité.

Pour les sujets les plus propres aux observations, nous renvoyons aux nombreux exemples que nous signalons plus loin dans chaque cas particulier.

Les cavités se forment de deux manières différentes : ou par dissociation des cellules, ou par dilacération des masses cellulaires. On réserve en général le nom de canaux aux premières; les secondes sont dites lacunes. Ces formations sont destinées soit à transporter l'air à travers les tissus, soit à servir de réservoir à divers produits de sécrétion. Nous étudierons d'abord les cavités aérifères.

$$
\text { § 3. - Canaux aÉriféres. }
$$

Étude. - Les canaux aérifères peuvent prendre naissance de deux manières différentes. $1^{\circ}$ Dans le premier cas, ils sont dus au développement irrégulier de la surface des parois des cellules. Les points de contact entre celles-ci deviennent alors moins nombreux et les vides qui se forment donnent au tissu une consistance spongieuse. Les cellules dans ces tissus sont par conséquent fort irrégulières. Tels sont les tissus spongieux des tiges des Juncus effusus (fig. 32), glomeratus, etc., où les canaux sont circonscrits par les bras de cellules étoi- 
lées. Le tissu lacuneux de la face inférieure de la plupart des feuilles des Dicotylédonées est produit de la même manière, et circonscrit par les prolongements de cellules irrégulièrement développées.

$2^{\circ}$ Les canaux aérifères si développés dans la plupart des plantes aquatiques se forment d'une autre manière. Ils résultent d'un dédoublement des parois des très jeunes cellules, suivi d'un accroissement rapide des méats ainsi formés; accroissement qui devient tellement considérable que le parenchyme est réduit à de minces lamelles formées le plus souvent

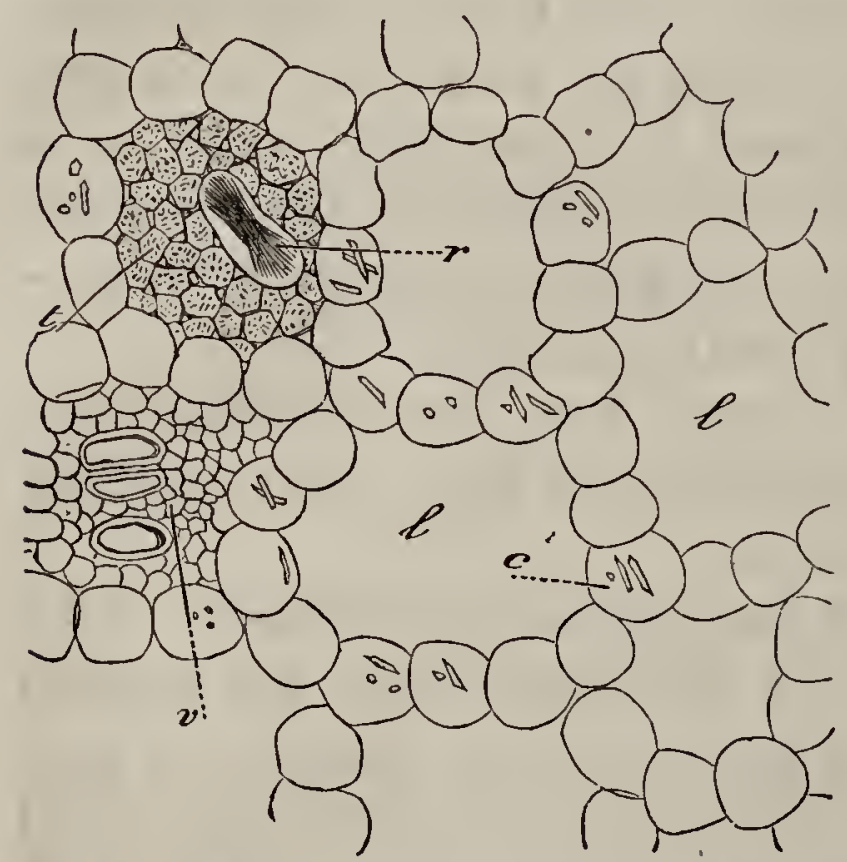

Fig. 60. - Portion de coupe transversale du pétiole de Calla palustris. - $r$. Cellule à raphides dans un tissu lacuneux $t$, à petites cellules, remplissant une des plus grandes lacunes du pétiole. $l$. Lacunes. $-c$. Cellule à cristaux. $-v$. Faisceau vasculairc comblant une lacune.

d'une seule assise de cellules, qui circonscrivent de grands canaux remplis d'air. A cette catégorie de canaux peuvent se rattacher ceux des tiges, racines et feuilles d'un grand nombre de plantes aquatiques et de marais : Marsiléacées, Salviniées, feuilles des Isoetes; Potamogeton, Hydrocharidees, Alismacées, Pontederia, Aroidées (Calla), Lemna, Hippuris, Trapa, Hottonia, Elatine, Utricularia, Menyanthées, Nymphéacées, Nelumbium, etc.

Dans la figure 60, qui représente en coupe transversale une portion de tissu du pétiole de Calla palustris on peut aisément se rendre compte du mode de formation de ces cavités aérifères. Les cellules dissociées, mais à parois régulières, arrondies, circonscrivent de grandes cavilés, $l, l$, dont le nombre et les dimensions sont tellement considérables, que le tissu cellulaire est réduit à l'état de lamelles formées chacune d'une scule assise de cellules. La forme des canaux aérifères est ici a:rondie irrégulièrement ou polyédrique sur la coupe transversale. Sur les coupes longiludinales on observerait que les cavités 
aérifères sont allongées et s'étendent sans discontinuité dans toute l'étendue du pétiole. Toutefois certains de ces canaux sont comblés, comme le montre la figure en $t$ et en $v$. En $v$ c'est un faisceau fibro-vasculaire; en $t$ se trouve un tissu de petites cellules remplies de chlorophylle et qui laissent entre elles, comme le montre la figure, de nombreux petits interstices à section triangulaire, remplis d'air. Dans ce tissu se rencontrent fréquemment des cellules à raphides (voir plus loin). Ce tissu, qui vient ainsi combler certaines lacunes, et qu'on retrouve presque constamment à côté des faisceaux vasculaires, forme de faux diaphragmes qui s'étendent sur une grande longueur. Dans les canaux aérifères du pétiole des Nymphéacées on trouve également de semblables pseudodiaphragmes qui se forment de la manière suivante : quel-

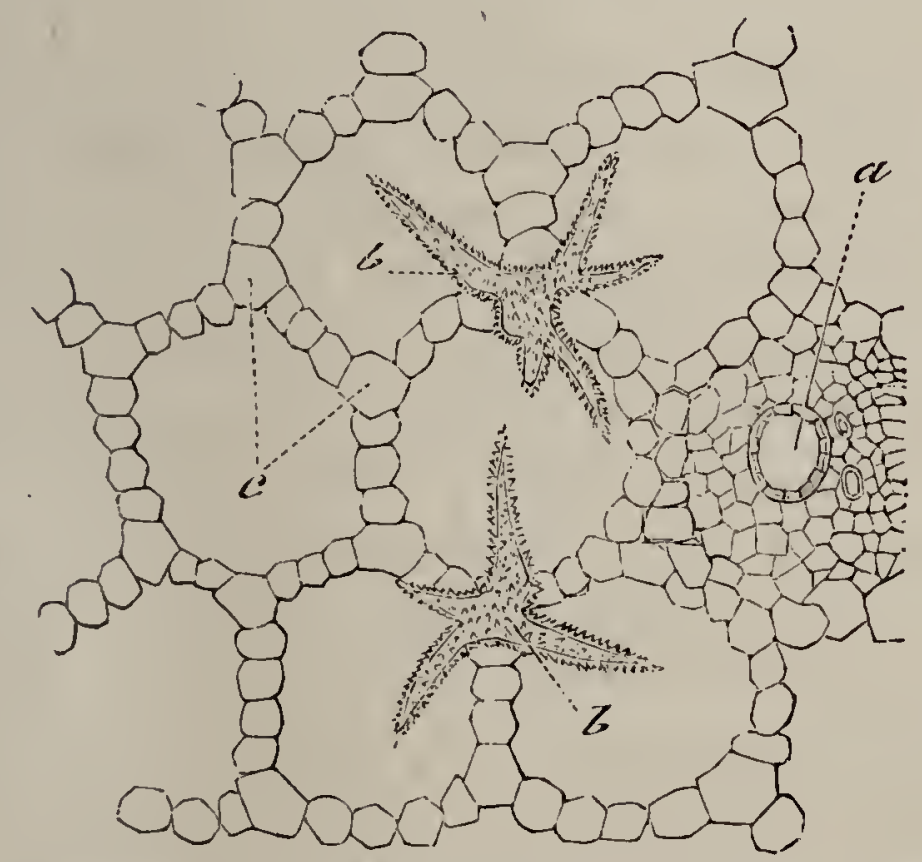

Fig. 61. - Coupe transversale du pétiole de Nymphxa alba. - a. Lacune du faisceau fibro-vasculaire. - $b, b$. Poils intérieurs. - $c$. Gellules d'angle.

ques cellules des lamelles du parenchyme s'avancent dans le canal voisin, et prennent la forme d'outres qui se ramifient, puis se cloisonnent et donnent ainsi naissance à de nombreuses cellules rameuses. Il en résulte un tissu lacuneux lâche qui obstrue plus ou moins le canal aérifère.

Les canaux aérifères des Nymphéacées sont encore remarquables à divers points de vue. Dans la portion de pétiole du Nymphxa alba, dont nous reproduisons (fig. 61) la 
coupe transversale, on peut remarquer, comme précédemment, que le tissu est réduit à des lamelles de cellules qui circonscrivent de larges cavités polyédriques. De plus, aux angles de ces cavités, les cellules qui les limitent se font remarquer par leur développement particulier. Ces cellules, en effet, plus grandes que toutes les autres, sont polyédriques, à coupe généralement hexagonale, dont trois faces correspondent chacune à une cavité, tandis que les trois autres faces s'unissent chacune à l'une des lamelles du tissu. Ces mêmes cellules d'angle deviennent souvent le point de départ de formations curieuses. Ge sont des sortes de poils que l'on rencontre d'ailleurs, d'une manière générale, dans les tiges à larges canaux aériens dépourvues de diaphragme. Ils en forment comme la partie squelettique. Les Pilularia, Rhizophora, Limnanthemum, etc., en renferment. Dans le Nymphæa alba. (fig. 61, b) ce sont des cellules étoilées, à branches pointues, munies d'épaisses parois mamelonnées. Chaque cellule envoie des branches dans trois ou quatre canaux voisins, branches qui se ramifient une ou deux fois. Les formations analogues des Limnanthemur se distinguent de celles des Nymphéacées en ce que les parois sont complètement lisses. Enfin dans diverses Aroildées, Pothos, Heteropsis, Monstera (Van Thiegem), on trouve également des poils d'une forme particulière. Toutes ces formations ont été désignées du nom de poils. Il y a là une erreur, car un poil est une formation essentiellement épidermique. Il est plus logique de les considérer comme des éléments sclérenchymateux du même ordre que ceux auxquels donne si fréquemment lieu le tissu fondamental des tiges. (De Bary, loc. cit.)

\section{§ 4. - Lacunes aÉrifìres.}

On a réservé le nom de lacunes à des cavités destinées au passage de l'air, comme les canaux dont il vient d'être question, mais qui se forment d'une manière toute différente. Les lacunes résultent, en effet, tantôt de la résorption d'éléments du tissu arrivés au terme de leur existence; tantôt d'un arrêt de développement d'une portion de tissu, suivi d'une dilacé- 
ration amenée par les tractions qu'opère le tissu voisin en se développant.

G'est ainsi que se forment les lacunes des feuilles des tiges et des racines de la plupart des Cypéracées et des Graminées, celles des feuilles des Sparganium, Typha, Iris pseudo-acorus, etc. Les lacunes axiles de la tige des Equisetum, celles des tiges dites fistuleuses des Ombellifères, des Composées, des Labiées, celles des feuilles et des pétioles des Allium, Asphodelus, etc., reconnaissent une même origine. Ces divers exemples montrent combien sont répandues ces sortes de cavités. La coupe transversale d'un entre-nœud développé d'Equisetum palustre que nous reproduisons (fig. 97) montre un exemple curieux de formation d'une de ces lacunes par destruclion de tissu. On voit encore en $r$ et $t$ la coupe de quelques vaisseaux, débris d'un faisceau en partie détruit. Cette destruction de tissu se répétant pour chaque faisceau détermine la formation d'une série de lacunes qui correspondent chacune à l'une des cannelures de la tige.

Les canaux et les lacunes qui se forment dans la masse des tissus ne servent pas toujours au transport de l'air. Il peut arriver que certaines cellules du tissu, venant à se spécialiser, deviennent le siège d'une sécrétion dont les produits se déversent dans les cavités voisines qui jouent alors le rôle de réservoirs. Comme pour les cavités aérifères, il faut ici établir une distinction entre les cavités qui résultent d'une simple dissociation de tissu, ce sont les canaux résineux, et celles qui succèdent à une dilacération accompagnée généralement de résorption des cellules sécrétantes; ce sont les réservoir's lacuneux. Nous allons étudier successivement ces deux formations.

§5. - Canaux résineux ou sécrétleurs (1).

Les canaux sécréteurs sont des organes qui, partout où ils se rencontrent, présentent des caractères de structure à peu

(1) Trécul, Ann. des sc. n., Bot., $5^{\text {e }}$ série, t. V et VI. - Van Thiegem, Ann. sc. nat., Bot., $5^{\mathrm{e}}$ série, t. XVI. - Hegelmayer, Bot. Zeitung, 187\%. Moynier de Villepoix, Recherches sur les canaux sécréteurs du fruit des 
près semblables. Ce sont des cavités intercellulaires sans paroi très développées en longueur et bordées dans toute leur étendue de cellules, distinctes des cellules environnantes tant par leur forme que par leur contenu. Ces cellules de bordure sont les parties actives de l'organe; ce sont elles qui sécrètent les produits de nature diverse suivant les plantes, produits qui viennent se réunir dans le canal voisin.

Étude. - Pour étudier les canaux sécréteurs, on devra pratiquer sur le tissu qui les renferme des coupes transversales et longitudinales par rapport à leur grand axe. L'examen des coupes transversales portera sur le nombre des cellules de bordure. Le plus souvent celles-ci ne forment qu'une seule assise; mais, dans certains cas, elles sont groupées en deux ou trois assises autour de la cavité. La forme des cellules, généralement ronde ou courbée en arc, l'épaisseur de leurs parois ordinairement peu considérable, enfin le contenu des cellules, le diamètre du canal, etc., sont autant de points qui devront être successivement étudiés.

Par les coupes longitudinales on se rendra compte de l'étendue du canal, qui apparaitra comme une cavité allongée bordée de chaque côté (fig. 62, D) par les cellules sécrétantes. On reconnaîtra également que le canal est continu dans tout son parcours et qu'il n'offre aucune ramification.

Notons que l'emploi de l'alcool pour durcir les tissus qui renferment des canaux résineux, bien qu'offrant certains avantages, présente aussil'inconvénient de dissoudre les produits de sécrétion huileux ou résineux. Il en résulte dans certains cas une plus grande difficulté pour la recherche des canaux résineux, surtout lorsque ceux-ci sont encore peu développés et au début de leur formation.

Mode de formation des canaux sécréteurs. - Pour cette étude on praliquera des coupes sur de jeunes tiges de Lierre ou sur des radicelles d'Ombellifères. Les canaux des fruits des Ombellifères pourront également servir de sujets d'étude. Sur des coupes transversales d'un jeune fruit de Myrrhis odorata

Ombellifères. Thèse de l'école de pharmacie. Paris, 1S7S. - C. E. Bertrand, Anatomie comparée des tiges et des feuilles chez les Gnétacées et les Conıfères. Ann.s. nat., Bot., 5 e série, t. XX, 1874. 
par exemple (fig. 62,B), on voit d'abord des groupes de quatre à cinq cellules qui se différencient des cellules du tissu ambiant par la délicatesse de leurs parois, leur forme et surtout leur contenu granuleux. Si le développement est peu avancé, ces cellules apparaîtront pressées les unes contre les autres $(s)$; un peu plus tard elles s'écartent, et un méat, premier ves-
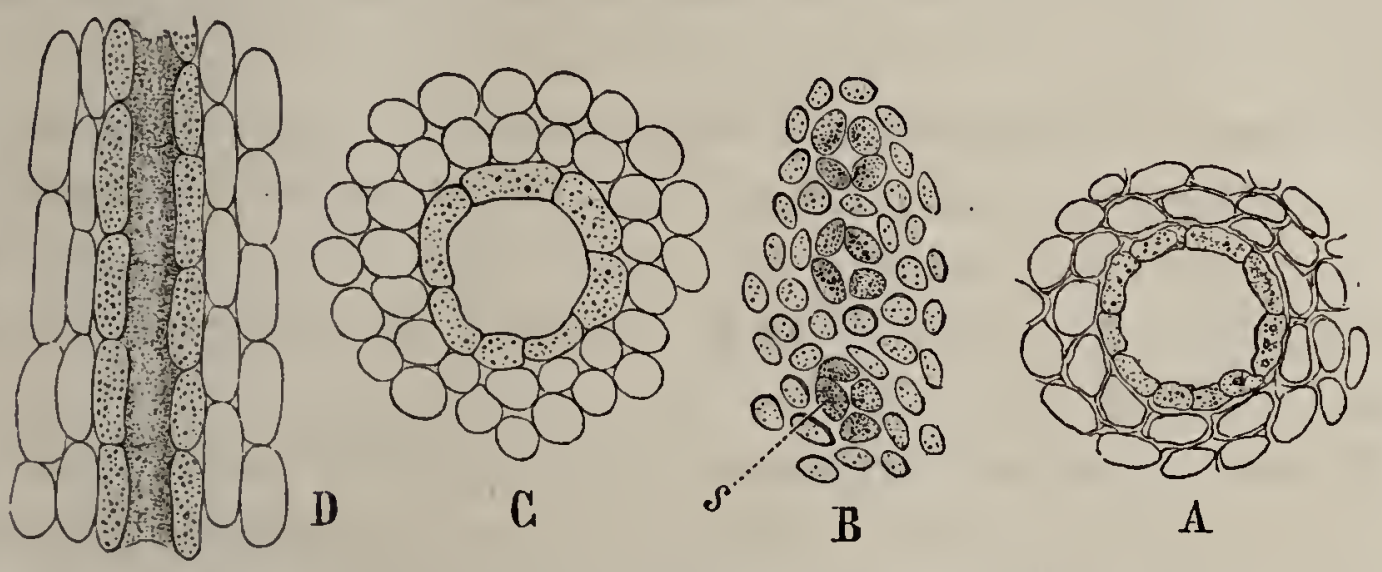

Fig. 62. - A. Canal résineux en coupe transversale, pris dans le parenchyme cortical au voisinage des vaisseaux libériens dans l'Aralia spinosa. - B. Canaux résineux en voie de développement dans le fruit du Myrrhis odorata (Moynier).-B. Cellules sécrètantes s'individualisant. - C. Canal sécréteur d'un fruit d'Ombellifère, en coupe trans versale. - D. Coupe longitudinale d'un canal résineux dans le Conium maculatum (Moynier).

tige du canal, se forme entre elles, comme on peut le voir également sur la figure B. Dans les tiges et les racines à canaux sécréteurs, les cellules de bordure forment également, tout d'abord, des groupes de quatre ou cinq cellules (Van Thiegem, loc. cit.). Plus tard, ces cellules se multipliant en même temps qu'elles s'écartent, on a bientôt sous les yeux, comme le montre la figure 62 en A et $\mathrm{C}$, un orifice large, celui du canal, bordé d'une couronne de cellules sécrétantes (1).

Il est encore un point fort intéressant sur sur lequel on doit porter la plus grande attention dans l'étude des canaux sécréteurs. Nous voulons parler de leur localisation. Le

(1) On conçoit que, pourque le canal puisse sc produire, il faut que le tissu ambiant subisse un accroissement transversal qui permette la formation d'un vide entre les cellules sécrétantes. Aussi ne s'étonnera.t-on pas de trouver dans la moelle du Pinus, par exemple, dont l'accroissement transversal est insensible, des groupes de cellules qui, par leur forme et leur contenu, ressemblent aux cellules de bordure des canaux résineux, mais qui ne s'ćcartent ccpendant pas pour constituer un canal. C'est qu'ici le bois déjà formé empêclie tout accroissement transversal de la moclle, et, par suite, la formation de cavités intercellulaires. (Saclıs, loc. cit.) 
siège de ces organes est en effet très variable; aussi croyonsnous devoir entrer dans quelques détails à ce sujet.

Les plantes qui renferment des canaux sécréteurs sont très nombreuses. On en trouve dans les Ombellifères, Araliacées, Térébinthacées, Composées, Clusiacées, Pittosporées, Burséracées, Aroïdées, Alismacées, Butomées, et dans certaines Fougères (Marattia) et Lycopodiacées (Hegelmayer, loc. cit.). Nous ne parlerons que des plus importantes.

$1^{0}$ Canaux résineux des Ombellifères. - Les canaux sécréteurs forment dans les plantes de la famille des Ombellifères un système continu s'étendant depuis la racine jusqu'aux fleurs; tous les organes de la plante, sauf les étamines, en sont abondamment pourvus.

Racine. - A part l'Opopanax et le Myrrhis odorata, on ne rencontre pas de canaux sécréteurs dans le système fibro-vasculaire de la racine des Ombellifères (Trécul., loc. cit.). Ils se tiennent généralement dans l'écorce, disposés en séries radiales (Heracleum, Eryngium giganteum, Seseli varium) ou en cercles concentriques régulier's (Opopanax chironium, Eryngium campestre, Foniculum vulg., Buplevrum angulosum, etc.). On en rencontre également dans la moelle.

La répartition des canaux résineux dans la racine des $0 \mathrm{~m}-$ bellifères est encore intéressante à étudier à un autre point de vue.

M. Van Thiegem (loc. cit.) a montré en effet que ces canaux se produisent en dehors des faisceaux vasculaires et libériens, aux dépens des cellules rhizogènes. Dès lors les radicelles ne peuvent naître que dans l'espace qui sépare ces deux ordres de faisceaux. G'est là une remarquable exception à la règle générale de formation des radicelles. Ajoutons, pour terminer, que les canaux que l'on rencontre dans la racine, lors de son premier développement, ne persistent pas tous. Ceux qui se trouvent à la partie externe des faisceaux libériens s'oblitèrent par suite du développement de ces faisceaux. Par contre de nouveaux canaux apparaissent dans les tissus de formation ultérieure. C'est ainsi que des canaux sécréteurs ne tardent pas à prendre naissance au milieu du parenchyme cortical de formation secondaire. 
Tige. - Dans la tige les canaux résineux sont répartis dans le tissu parenchymateux de la moelle, dans le parenchyme cortical d'une part au voisinage de l'épiderme et d'autre part non loin des faisceaux libéro-ligneux qu'ils accompagnent dans leur trajet. Tantôt ces derniers canaux sont englobés au milieu même des éléments des faisceaux, tantôt ils occupent leur face externe. Dans le genre Eryngium on en rencontre à la fois à la face externe et à la face interne des faisceaux. (Moynier de Villepoix, loc. cit.)

Dans leur parcours, les canaux résineux sont généralement dépourvus de ramifications, mais ils s'anastomosent aux nœuds.

Feuilles. - Dans les feuilles, le système sécréteur suit la même marche que dans la tige. Les canaux y occupent la face externe des faisceaux, le parenchyme foliaire et le tissu sousépidermique.

Ainsi, dans la feuille du Crithmum maritimum on peut voir, sur les coupes perpendiculaires à la surface du limbe, un canal à la face externe de chaque faisceau des nervures. Il y en a quatre à la face externe du faisceau de la nervure médiane. En même temps d'autres canaux complètement indépendants du système vasculaire se trouvent immédiatement au-dessous des cellules de l'épiderme. (Moynier, loc cit.)

Fleur. - Dans la fleur même disposition générale des canaux résineux. Les pédoncules floraux, les sépales, les pétales présentent toujours à la face externe de la nervure principale un canal oléo-résineux.

Fruit. - Les canaux résineux passent dans le fruit avec les faisceaux fibro-vasculaires; les uns vont former les canaux des côtes primaires (fig. 63, A, a,a), les autres pénètrent dans le carpophore où on les retrouve tantôt épars autour du faisceau fibro-vasculaire, tantôt englobés au milieu de ses éléments.

Les canaux des côtes primaires continuent leur trajet vers le style, soit directement, soit après s'être anastomosés par des branches horizontales avec les bandelettes et les canaux des côtes voisines.

Enfin les canaux sécréteurs du stylopode se continuent avec 
les faisceaux dans le funicule (ces canaux sont au nombre de quatre, régulièrement disposés autour du faisceau, dans le funicule de la graine du Smyrnium olusatrum. (Moynier, loc. cit.)

Bandelettes. - Quant aux bandelettes, il n'y aurait pas lieu, d'après les recherches de M. Moynier, de les différencier des canaux des côtes et de la tige. Elles ne constituent point un système sécréteur particulier. Leur nombre varie avec l'âge du fruit. Ainsi, dans un ovaire de Smyrnium olusatrum, de 1 millimètre de diamètre, où les bandelettes commencent seulementà apparaître, on en compte un nombre égal au nombre des vallécules, tandis que le fruit développé en possède une quarantaine.

Les bandeletles qui occupent (fig. $63, \mathrm{~A}, r$ ) le parenchyme du

B

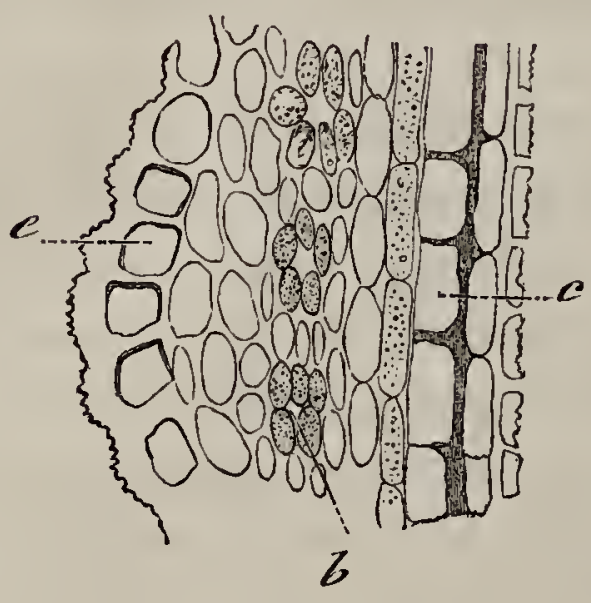

A

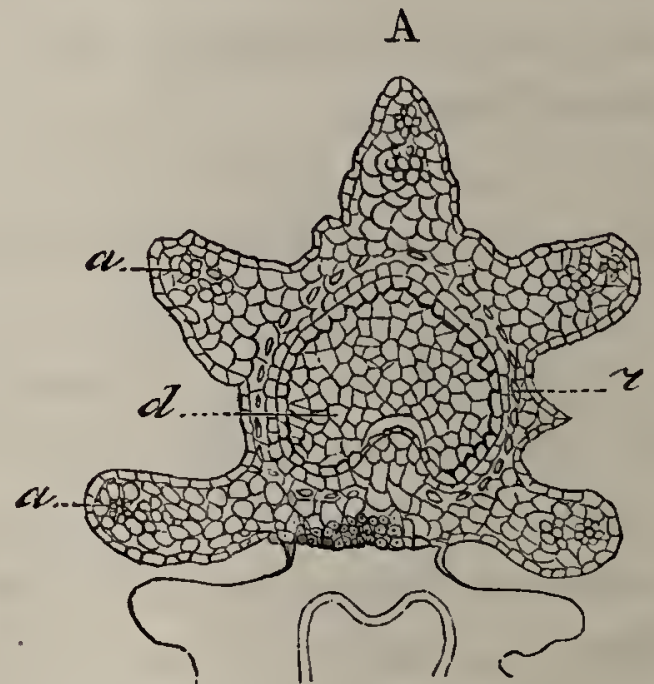

kig. 63. - A. Coupe transversale du fruit du Conium maculatum (jeune). -a. Canaux résineux des faisceaux. - $r$. Bandelettes formant un cercle à la face interne du fruit. d. Graine. - B. Coupe transversale à un fort grossissement d'une portion du même fruit.

- b. Canaux résineux (bandelettes). - $c$. Cellules épaisses au voisinage de l'albumen.

$-e$. Épiderme à cuticule épaisse. (Moynier.)

péricarpe, sont caractérisées par le grand développement qu'elles acquièrent en général, et par leur existence constante dans tous les fruits des Ombellifères. Le Scandix pecten Veneris et le Conium maculatum, qui longtemps ont été considérés comme dépourvus de bandelettes, ne font point exception à la règle. Nous reproduisons (fig. 63, B) d'après M. Moynier une coupe d'une portion du péricarpe du fruit du Conium maculatum, où l'on voit très nettement en $b$ les bandelettes, petites, mais nombreuses. On s'explique comment on avait 
nié leur existence, par ce fait, qu'elles ne sont plus visibles quand le fruit est arrivé à maturité (1).

Araliacées. - Ce que nous avons dit des canaux résineux dans les Ombellifères nous dispense d'entrer dans de longs détails au sujet des Araliacées. L'étroite affinité de ces deux familles se manifeste encore de la manière la plus évidente dans la constitulion et les caractères de leurs canaux résineux.

Dans la tige c'est particulièrement dans l'écorce au voisinage des fibres libériennes, entre celles-ci et le cambium d'un côté et le parenchyme cortical de l'autre, qu'on les rencontre. (G. Planchon, fig. 62, A.)

Dans la racine, leur situation donne lieu aux mêmes particularités que nous avons signalées au sujet des Ombellifères. (Van Thiegem, loc. cit.)

Composées. - On trouve des canaux sécréteurs dans la plupart des Composées (Trécul, loc. cit.; Van Thiegem). Les Chicoracées cependant font exception à cette règle, mais nous avons vu plus haut (page 141) que ces plantes possèdent des vaisseaux laticifères qui semblent par suite y remplacer les formations dont nous nous occupons en ce moment.

Notons à ce sujet que, d'après M. Van Thiegem, ces deux ordres d'éléments peuvent coexister dans quelques Chicoracées (Scolymus) et Cinarées (Cirsium, Lappa) (2). Ils sont alors répartis dans des systèmes différents de tissus. Les vaisseaux laticifères occupent le liber des faisceaux, et les canaux résineux se trouvent dans le parenchyme cortical. Ges canaux se font remarquer par leur ouverture toujours très étroite, ordinairement entourée par quatre cellules sécrétantes.

Conifères (3). - Gnétacées. - Dans les Gnétacées et les Co-

(1) L'existence des bandelettes dans les jeunes fruits de Conium maculatum et leur disparition dans la suite, concordent avec l'énergie plus grande des extraits de ciguë préparés avec les fruits jeunes comparativement aux extraits préparés avec les fruits mûrs.

(2) Le même fait a lieu dans certaines Aroïdées (Philodendron); les laticifères appartiennent à la région libérienne des faisceaux fibro-vasculaires, et les canaux sécréteurs au tissu fondamental, (Van Thiegem.)

(3) Meyen, Secretions-organe der Pflanzen, Berlin, 1837. - Karsten, Vegetationorgane der Palmen (Abh. Berl. Akad., 1847). - H. Schacht, Der Baum, $1^{\mathrm{e}}$ édition. - Wigand, Ueber die Desorganisation der Pflanzenzelle, Pringsh. Jahrb., Bd. III, 1861. - Dippel, Histologie der Coniferen (Bot. 
nifères, les appareils sécréteurs sont plus généralement connus sous le nom de glandes résinifères. Ce sont en effet des espaces intercellulaires clos de toutes parts par les cellules sécrétantes, et qui s'étendent sur une longueur plus ou moins considérable, et sont généralement indépendants les uns des autres. Le nom de lacunes que reçoivent quelquefois ces glandes est employé à tort, car leur mode de développement est absolument semblable à celui des canaux : "La membrane des " cellules qui vont prendre part à la formation d'une glande " s'épaissit un peu, puis s'amincit en même temps qu'elle se " dédouble; les cellules s'écartent, se séparent et commen" cent en même temps à sécréter de la résine. " (Bertrand, loc. cit.)

La figure 64 représente la coupe transversale de l'une de ces glandes. On peut voir que les cellules

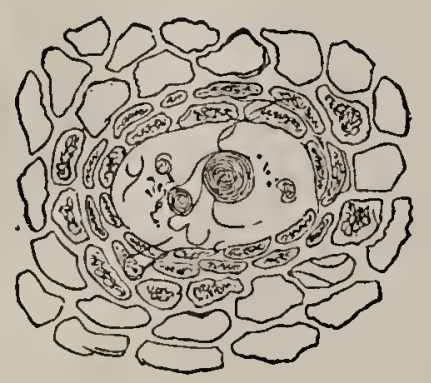
sécrétantes qui bordent le réserỵoir sont nombreuses, car elles forment deux rangées concentriques. La répartition des glandes résineuses dans les Conifères varie avec les espèces considérées. Les racines (1), les tiges, les Fig. 64. - Coupe transversale d'une glande résineuse (conifère).

vues. (Bertrand, loc. cit.) feuilles en renferment en général. Cependant chez les Gnétacées et le Taxus baccata, les feuilles en sont dépour-

Chez les Pinus et les Larix, ces glandes occupent le bois des faisceaux de la racine et de la tige, ainsi que le parenchyme cortical de la tige.

Chez les Abies et les Cedrus on les rencontre dans cette dernière région et de plus au centre de la racine.

Chez les Cupressus et les Thuya, les glandes occupent le parenchyme cortical de la tige et le liber des faisceaux de la racine et de la tige. Enfin dans le genre Taxus elles font détaut dạs l'une et l'autre de ces parties de l'axe. (Van Thiegem.)

Zeitung 1863). J. N. Müller, Pringsh. Jahrb., Bd. V. - Van Thiegem, loc. cit. C. E. Bertrand, loc. cit.

(1) On ne rencontre pas de glandes résineuses dans le parenchyme cortical des racines. 
Le contenu des glandes des Conifères est une oléo-résine sécrétée par le protoplasma dont elle ne se sépare qu'à la mort de celui-ci.

\section{§. - réservoirs Lacuneux.}

De même que les canaux ou espaces intercellulaires formés par dissociation peuvent devenir les réservoirs de substances sécrétées par les cellules dissociées, de même, les lacunes ou espaces intercellulaires formés par dilacération et résorption peuvent jouer le rôle de réservoirs où s'accumulent divers produits de sécrétion. Nous renvoyons pour l'étude de ces derniers au chapitre que nous consacrons à l'étude des organes glandulaires.

\section{§ 7. - FORMES ET SYSTÈMES De TISSUS.}

On distingue généralement deux formes principales de tissus: les parenchymes et les prosenchymes. - Tous deux présentent des variétés suivant la forme des éléments qui les composent.

Ainsi les parenchymes, qui sont les tissus formés de cellules courtes, peuvent être à cellules arrondies, ovoïdes, polyédriques, etc. Ce sont là autant de variétés.

Les prosenchymes, ou tissus fibreux, peuvent également comporter quelques variétés fondées sur l'épaisseur de la paroi des fibres, ou sur toute autre particularité.

On conçoit qu'il nous suffise de donner les quelques définitions qui précèdent, car nous sommes entré dans de suffisants détails tant au sujet de l'arrangement des cellules en tissu qu'au sujet des formes des cellules pour n'avoir pas à insister ici davantage.

Nous croyons cependant devoir appeler l'attention sur deux tissus que nous rencontrerons fréquemment; ce sont les tissus dits: sclérenchyme et méristème.

Les éléments des parenchymes ou des prosenchymes peuvent devenir très épais et à parois dures et lignịiées ; on les dit alors éléments scléreux (fig. 6ə̆) et le tissu qu'ils forment prend le nom de sclérenchyme (concrétions pierreuses des poires).

Enfin le terme méristème s'applique à un parenchyme dont les éléments sont susceptibles de se diviser pour engendrer de GUIDE DE MICROGRAPHIE. 
nouveaux tissus. Méristème est doncle synonyme de parenchyme générateur. On distingue généralement les méristèmes en méristème primitif et méristème secondaire. Cette distinction est

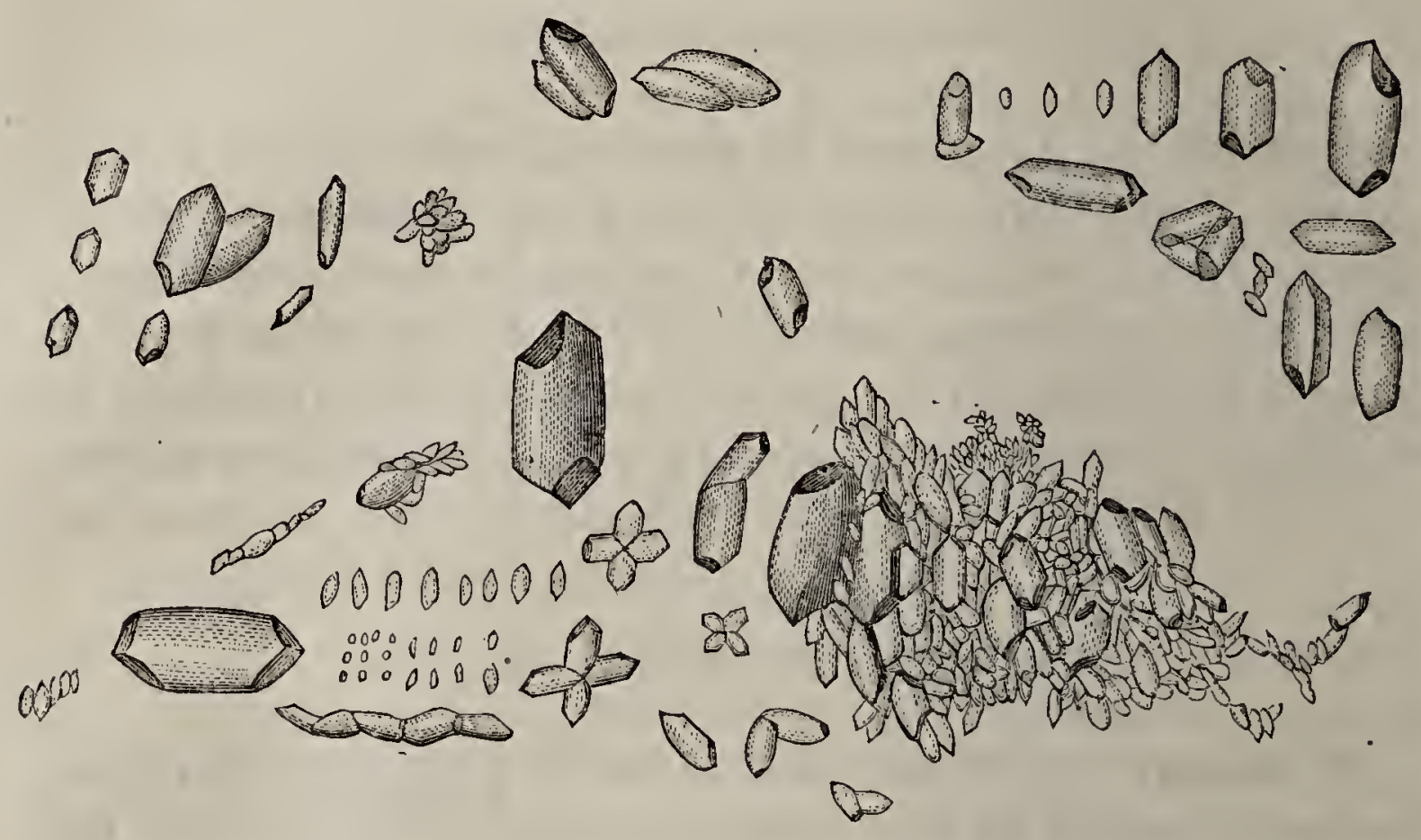

Fig. 65. - Cellule sclérenchymateuse.

utile; le méristème primitif étant celui qui précède toute formation (point végétatif de divers organes), tandis que le méristème secondaire est un tissu générateur qui prend naissance ultérieurement dans un tissu (phellogène, par exemple), ou une portion de tissu qui persiste à l'état de méristème au milieu des autres tissus, et continue à fonctionner pendant un temps plus ou moins long (cambium).

Les divers tissus dont il vient d'ètre question forment les organes des végétaux; nous pourrions donc dès maintenant entreprendre l'étude anatomique de ces organes. Mais les tissus se groupent dans ceux-ci de certaines manières pour former des systèmes de tissus qui, par leur généralité d'existence dans les organes et par leur's caractères fondamentaux bien définis, méritent d'être étudiés séparément. L'étude anatomique des organes n'en sera que plus brève ensuite.

Avec M. Sachs, nous considérerons trois systèmes de tissus : un système tégumentaire, un système fibro-vasculaire ou fasciculaire et un tissu fondamental. 
Art. 3.

\section{Système tẻgumentaire.}

Le système tégumentaire comprend un facteur à peu près constant, l'épiderme, tantôt constituant à lui seul l'appareil tégumentaire, tantôt accompagné de formations plus ou moins nombreuses et variées', liège, hypoderme, etc. Nous allons étudier successivement ces divers tissus.

\section{§ 8. - ÉPIDERME.}

L'épiderme est un tissu qui siège à la surface des divers organes des végélaux, où il joue le rôle d'un revêtement protecteur. Il possède des caractères bien définis, et se distingue encore par la présence, au milieu de ses éléments, de formations qui en sont des dérivés directs (stomates et poils) el qu'on ne trouve dans aucun autre tissu.

Etude. - Pour étudier l'épiderme il est nécessaire d'avoir recours à des coupes en même temps qu'à l'examen en surface. Les coupes comprendront l'épiderme ainsi qu'une partie des tissus sous-jacents, et seront dirigées normalement à la surface épidermique; pour l'examen en surface, on prépare des lambeaux d'épiderme que l'on soulève avec des pinces fines pour les séparer de l'organe qu'ils recouvrent. Cette opération s'exécute très aisément sur certains épidermes (face inférieure des feuilles des Fougères; pétales et tiges vertes, feuilles des Liliacées, Iridées, etc.); mais dans d'autres cas l'adhérence prononcée de l'épiderme aux tissus sous-jacents devient un obstacle souvent difficile à vaincre. Or il ne faut pas oublier que l'examen en surface d'un épiderme ne peul se faire avec fruit que si l'on est en possession de lambeaux assez étendus et parfaitement débarrassés de tout tissu élranger. Le tissu sous-épidermique, étant en général rempli de chlorophylle, s'opposerait à une bonne observation. Pour obrier à l'adhérence de l'épiderme aux tissus sous-jacents, il suffit le plus souvent de laisser macérer pendant quelques heures dans l'eau pure ou additionnée de quelques gouttes 
de lessive alcaline la partie de plante que recouvre l'épiderme à étudier. Bientôt cet épiderme se soulève et il devient alors facile d'en faire de bonnes préparations.

Dans tous les cas, lorsqu'on veut soulever un lambeau d'épiderme, on a tout avantage à procéder de la manière suivante : on commence par enfoncer une aiguille plate tangentiellement à l'organe et aussi près que possible de la surface épidermique. Cela fait, on retire l'aiguille et on introduit

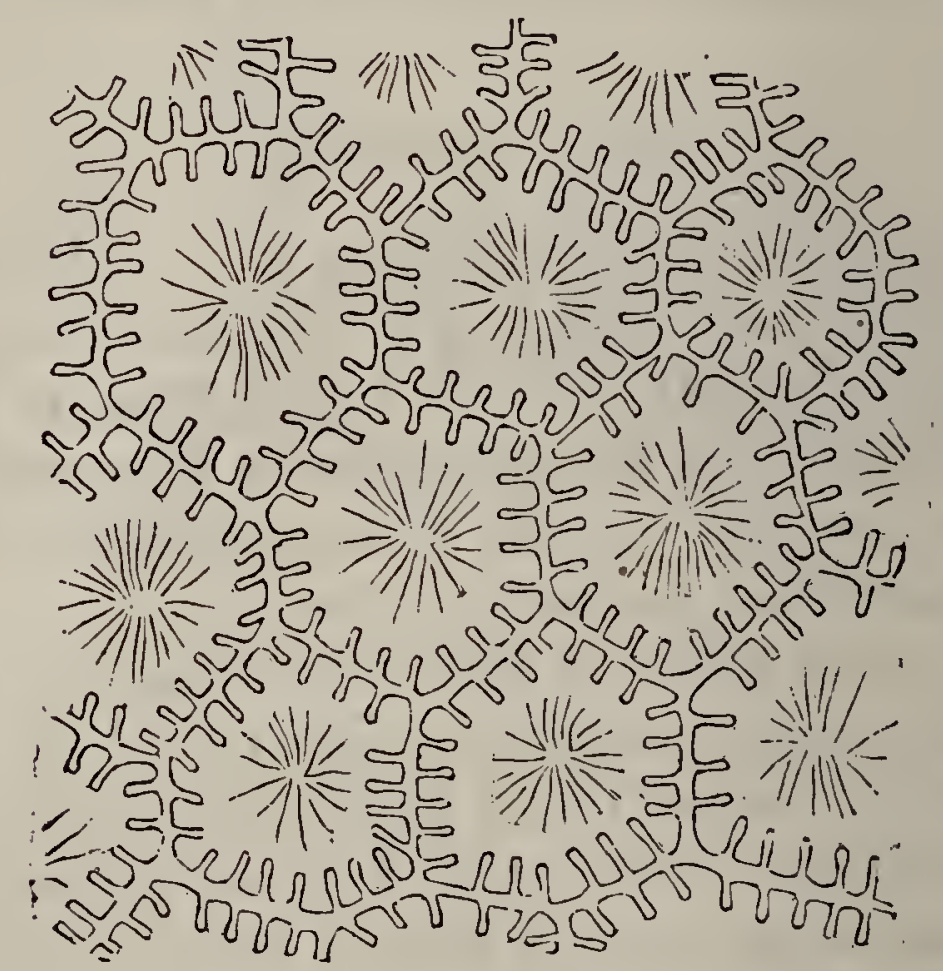

Fig. 66. - Épiderme des pétales du Pelargonium zonale.

à sa place l'un des mors d'une pince fine. Il suffit alors le plus souvent de légères tractions avec la pince pour obtenir des lambeaux très propres à l'observation.

L'épiderme manque à la surface de certains végétaux, chez les Cryptogames cellulaires par exemple. Ailleurs, ses caractères deviennent tellement semblables à ceux du parenchyme sousjacent (plantes submergées) qu'on en a longtemps niél'existence. Quoi qu'il en soit, l'épiderme est une formation d'une'existence très générale et qui possède des caractères très particuliers.

Pour qu'une étude del'épiderme soil complète, elle doit comprendre l'examen de la forme des cellules qui le composent, de leur mode de groupement, de leur contenu, de leurs réactions, l'étude enfin des stomates et des poils quel'on y peut rencontrer. 
$1^{\circ}$ Forme des cellules épidermiques. - Au moyen des coupes menées perpendiculairement à la surface des épidermes, on constate que les cellules qui les composent présentent généralement une épaisseur très faible en comparaison de l'étendue de leur surface.

C'est qu'en effet ces cellules affectent généralement la forme dite tabulaire.

Leurs contour's présentent de nombreuses variations, tantôt géométriques, tantôt irréguliers, dentelés (fig. 66), comme le montrent les épidermes de beaucoup de pétales, ou sinueux. - D’une manière générale, on peut dire que la forme des cellules épidermiques est en relation avec le mode d'accroissement des organes qu'elles recouvrent. Sur les parties des plantes dont le développement s'opère dans tous les sens à peu près également, comme les feuilles de la plupart des Dicotylédonées, on rencontre des cellules épidermiques à large surface, à contours généralement sinueux, semblablement aussi à ce qui se passe pour l'épiderme des frondes de Fougères (fig. 68). Ajoutons encore que, sur une même feuille, les cellules de l'épiderme inférieur sont souvent très différentes des cellules del'épiderme supérieur.

Dans la plupart des feuilles des Monocotylédonées, ainsi qu'à la surface des tiges vertes, qui offrent un grand développement dans le sens de la longueur, les cellules épidermiques prennent généralement une forme correspondante. Leurs contours se présentent sous l'aspect de

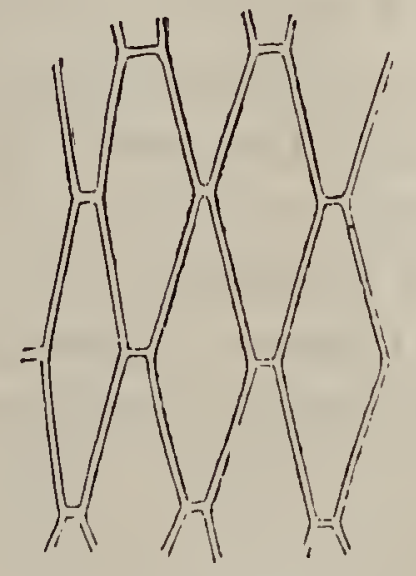

Fig. 67. - Épiderme d'une feuille d'Iris. rectangles ou de losanges allongés dans le sens de l'axe des parties de plante qu'elles recouvrent (fig. 67).

$3^{\circ}$ Mode de groupement des cellules épidermiques. - Qu'elles soient à contours réguliers géométriques ou à contours sinueux, les cellules épidermiques se groupent toujours de façon à se souder intimement, s'accolant les unes aux autres on s'engrenant, si bien que l'épiderme qui en résulte est une membrane continue. D'autre part, dans le plus grand nombre des cas, l'épiderme consiste en une seule assise de cellules. Il 
arrive cependant dans certains végétaux que, des cloisons tangentielles venant à se produire dans les cellules épidermiques, on trouve une ou deux assises nouvelles ou couches de renforcement qui s'interposent entre l'épiderme externe et les tissus sous-jacents. On trouve des exemples de ces épidermes à plusieurs assises de cellulessur les feuilles des Ficus, des Begonia, sur les tiges et les feuilles d'un grand nombre de Pipéracées.

$4^{\circ}$ Contenu des cellules épidermiques. - Les cellules de l'épiderme sont, à l'état jeune, remplies par le protoplasma au milieu duquel se trouve un noyau généralement volumineux. Plus tard, les cellules prenant un grand développement, le protoplasma ne forme plus qu'une mince couche à la face interne de la paroi cellulaire; le noyau occupe généralement alors le centre de la cellule; où il est facile de l'apercevoir. Souvent enfin on ne trouve plus dans les cellules épidermiques que le suc cellulaire, diversement coloré dans certains cas. (Voir plus haut, page 123, Siège de la matière colorante.)

Rappelons, à ce sujet, que la coloration des parties vertes des végétaux est indépendante de l'épiderme, qui ne renferme généralement pas de chlorophylle. Il n'y a d'exception à cette règle que pour les plantes submergées (Hydrillées, Cératophyllum) et la plupart des Fougères, qui présentent des grains de chlorophylle dans leurs cellules épidermiques (fig. 68).

Comme conséquence de l'absence de chlorophylle, notons également l'absence d'amidon dans ces éléments.

$$
\S 9 .- \text { cuticule. }
$$

A la surface de l'épiderme on observe une pellicule très mince, isolée pour la première fois par M. Brongniart. Cette pellicule, qui a reçu le nom de cuticule, recouvre la membrane externe des cellules et peut êure détachée soit par macération (feuilles du Chou), soit simplement avec l'aiguille (fleurs intérieures des figues).

L'épaisseur de la cuticule est peu considérable. Le plus souvent elle ne forme qu'un mince revêtement immédiatement appliqué sur la paroi des cellules. Il est très facile au moyen de coupes de s'assurer de son existence. 
Ailleurs, la paroi des cellules prend un développement considérable. Ce n'est pas que la cuticule elle-même se soit ainsi développée en épaisseur. Mais il s'est produit dans la membrane cellulaire des modifications chimiques profondes; cette mem-

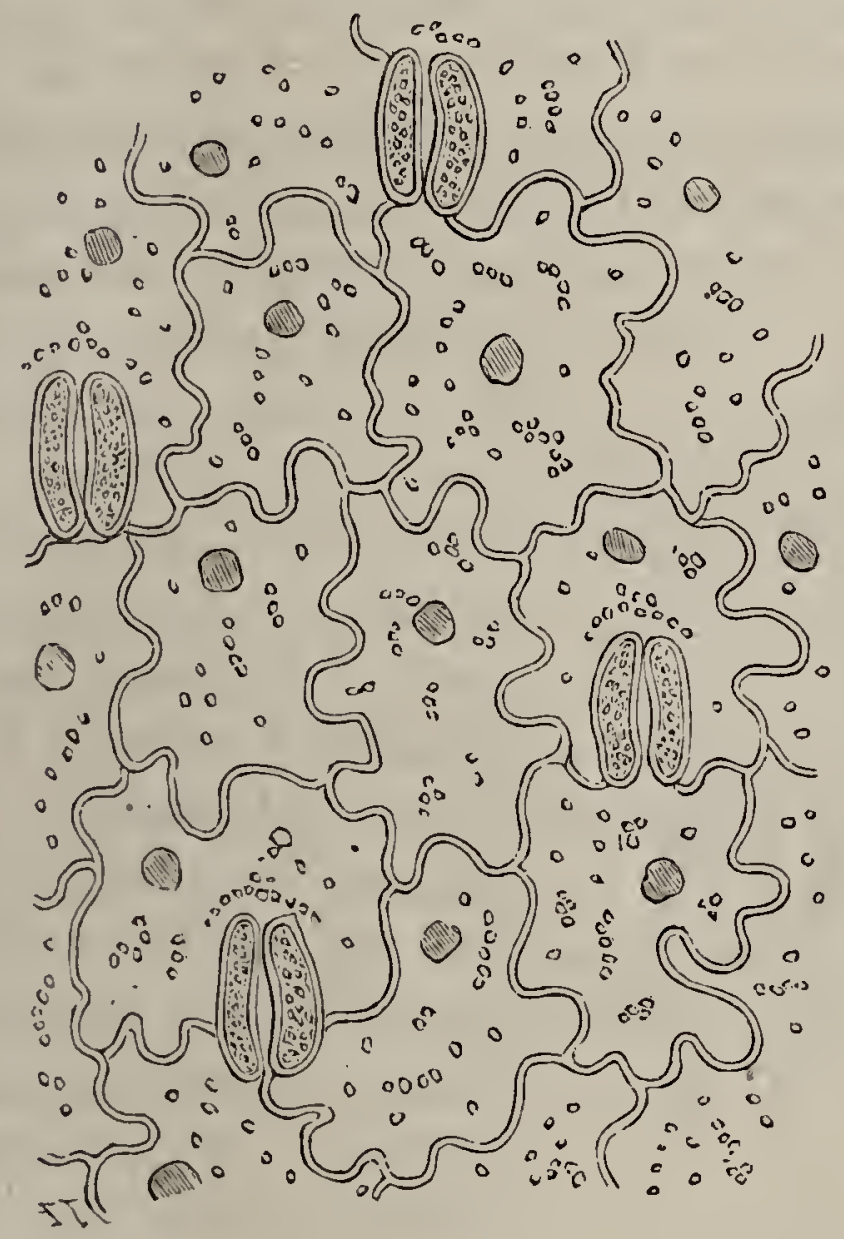

Fig. 68. - Épiderme d'une fronde de Fougère.

brane est alors formée de trois parties distinctes: $1^{\circ}$ en dehors la cuticule $; 2^{\circ}$ au-dessous, une assise très épaisse, résultat de la modification survenue dans la paroi cellulaire, et qui se divise en couches stratifiées, que l'on nomme couches cuticulaires; $3^{\circ}$ enfin plus profondément la paroi de cellulose.

Cette division de la membrane des cellules épidermiques en assises de composition différente se rencontre assez fréquemment et est facilement mise en évidence au moyen de réactifs appropriés.

Action de l'acide sulfurique. - La cuticule en effet jouit de la propriété de résister à des réactifs énergiques qui détruisent au contraire la cellulose.

Vient-on à plonger dans l'acide sulfurique des coupes de 
feuilles de Liliacées, d’Ombellifères, etc., dont les cellules épidermiques sont constituées d'une paroi de cellulose recouverte d'une cuticule; la cellulose est dissoute, et il ne reste plus que la cuticule qui se trouve ainsi complètement isolée. Si l'on fait agir le même réactif sur des cellules dont la paroi est cuticularisée dans toute son épaisseur (tiges âgées de Viscum album, feuilles aciculaires du Pinus sylvestris), on verra que les couches cuticulaires comme la cuticule résistent à l'action de cet acide. Action de la potasse. - Par contre, au moyen de la potasse

B
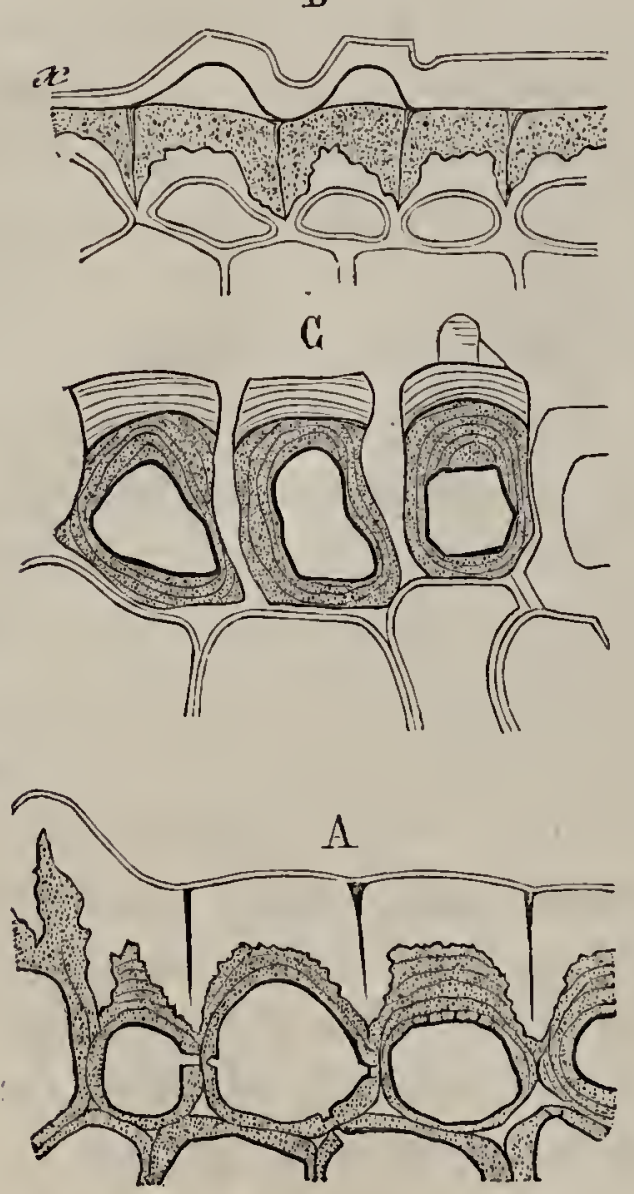

Fig. 69. - Coupe sur l'épiderme de la feuille de l'Aloe verrucosa, action des réactifs (de Bary); voir l'explication dans le texte. on arrivera facilement à distinguer la cuticule non seulement de la paroi de cellulose des cellules, mais encore de leurs couches cuticulaires. La potasse en effet dissout la cuticule, tandis qu'elle ne fait que gonfler la cellulose et les couches cuticulaires qui en même temps se dépouillent des substances qui les incrustent et présentent alors les réactions de la cellulose (chloro-iodure de zinc), réactions que l'on ne peut jamais obtenir avec la cuticule.

La figure 69, que nous reproduisons d'après M. de Bary (loc. cit.), montre les divers états par lesquels passe l'épiderme de la feuille de l'Aloe verrucosa sous l'influence d'un traitement à chaud par la potasse.

En A on voit une coupe de l'épiderme avant l'action du réactif. Les cellules épidermiques présentent sur leur face externe les trois assises que nous signalions tout à l'heure. Les parties ombrées représentent les couches de cellulose non cuticularisées. Plus en dehors se voient les couches culicularisées traversées par des traits noirs. Enfin tout à fait à la surface, le double contour représente la cuticule. 
En B, on a représenté la même coupe après traitement à chaud par la potasse. Ici les couches cuticulaires sont ombrées ; la couche de cellulose placée au-dessousn'est pas ombrée; elle est un peu gonflée. Enfin tout à fait à la surface on voit la cuticule $(x)$ qui se soulère et se sépare des couches cuticulaires.

La coupe $\mathrm{C}$ représente le même épiderme après une ébullition prolongée dans la potasse. La cuticule est complètement disparue. Les couches cellulosiques ombrées sont surmontées des couches cuticulaires dans lesquelles sont apparues de délicates stries qui les distinguent. On peut maintenant facilement déceler par les réactifs appropriés l'existence de la cellulose dans ces couches cuticulaires.

D'après ce que nous venons de dire, il ne faut donc pas confondre la cuticule avec les couches cuticulaires.

La cuticule n'est pas l'apanage exclusif des cellules épidermiques. Elle se trouve encore à la surface de beaucoup de cellules libres (spores, grains de pollen). Elle paraît au contraire manquer sur les surfaces qui ne sont pas exposées à l'air extérieur. Ainsi elle est très peu visible sur les poils des racines, tandis qu'au contraire elle atteint souvent une grande épaisseur relative sur les poils des parties qui végètent au-dessus de la terre.

Quoi qu'il en soit, où elle existe, la cuticule par suite de variations dans son épaisseur détermine le plus souvent des saillies, stries, crêtes ou gibbosités à la surface des organes qu'elle recouvre; ces proéminences, quelquefois très développées sur les spores et les grains de pollen où elles s'accompagnent de couches cuticularisées plus ou moins épaisses, sont généralement peu élevées sur les surfaces épidermiques. On les aperçoit toutefois très nettementsur les épidermes de beaucoup de pétales; celui du Pelargonium zonale que nous reproduisons (fig. 66) donne un exemple de ces stries.

$\S 10$. - dépots cireux a la surface de l'epiderme.

Les dépôts cireux sont très fréquents à la surface de l'épiderme. Ce sont eux qui donnent aux feuilles glauques leur ton 
particulier, et qui produisent sur certains fruits (prunes, raisins, etc.) le givre qui les couvre.

Ces dépôts affectent sur les épidermes trois formes principales. Tantôt étendus en croûtes ou couches homogènes, ils se présentent ailleurs sous l'aspect de bâtonnets et de granulations.

$1{ }^{\circ}$ Croûtes cireuses. - La cire se dépose en croûtes vitreuses, polies et cassantes, quelquefois mamelonnées et d'une épaisseur moyenne de $1 \mu$ environ sur un grand nombre de feuilles telles que celles de Thuya orientalis, $T$. occidentalis, Sempervivum tectorum, $S$. calcareum, sur les jeunes tiges d'Euphorbiacées charnues (E. caput Medusæ, E. ornithopus, $E$. Canariensis, etc.). Beaucoup d'épidermes lisses et luisants doivent cet aspect à une sorte de vernis formé par.de semblables couches cireuses très minces et homogènes. Tels sont les épidermes des Cereus alatus, Opuntia, et les feuilles de Fuchsia globosa, Taxus baccata, les feuilles et tiges de Portulaca oleracea. (De Bary, loc. cit.)

Ailleurs ces couches acquiérant une plus grande épaisseur déterminent à la surface de l'épiderme des stries et des cannelures. Sur les jeunes feuilles de Corypha (Copernicia) cerifera, ces couches mesurent de 13 à $19 \mu$ d'épaisseur. Cette cire, séparée des feuilles desséchées, est recueillie sous forme de granulations qui constituent la cire carnauba du Brésil.

L'épaisseur des couches cireuses atteint jusqu'à $70 \mu$ sur les branches âgées d'Euphorbia canariensis. Les Palmiers à cire, Ceroxylon et Klopstockia présentent même des couches cireuses stratifiées qui atteignent 5 millimètres d'épaisseur.

$2^{\circ}$ Bâtonnets. - Une autre forme qu'affectent encore les dépôts cireux est celle de bâtonnets, donl on trouve déjà un bon exemple sur les feuilles de Cotyledon orbiculata et sur les fruits du Benincasa (de Bary) où ils atteignent $10 \mu$ de hauteur sur 1 u d'épaisseur, mais qui prennent un développement particulièrement remarquable chez beaucoup de Scitaminées et de Graminées. Sur les nœuds et les entre-nœuds de Saccharum officinale par exemple(fig. 70, A), ces bàtonnets, très rapprochés les uns des autres, sont fixés perpendiculairement à la surface épidermique. Les plus longs d'entre eux atteignent jusqu'à 
100 et $150 \mu$ de hauteur; leur épaisseur varie entre $1 \mu$ et $4 \mu$. Leur forme est cylindrique ou rubanée. A leur extrémité libre, les plus longs se recourbent en forme de crochet ou de vrille plus ou moins contournée. Leur. substance homogène est, chez les plus développés, finement striée en long. On trouve de semblables bâtonnets cireux sur la face inférieure des feuilles d'Heliconia farinosa, de Strelitzia ovata, sur les feuilles des tiges de Canna, etc. (De Bary.)

$3^{\circ}$ Granulations cireuses. - Les dépôts de cire sous forme de couches de granulations sont beaucoup plus fréquents que
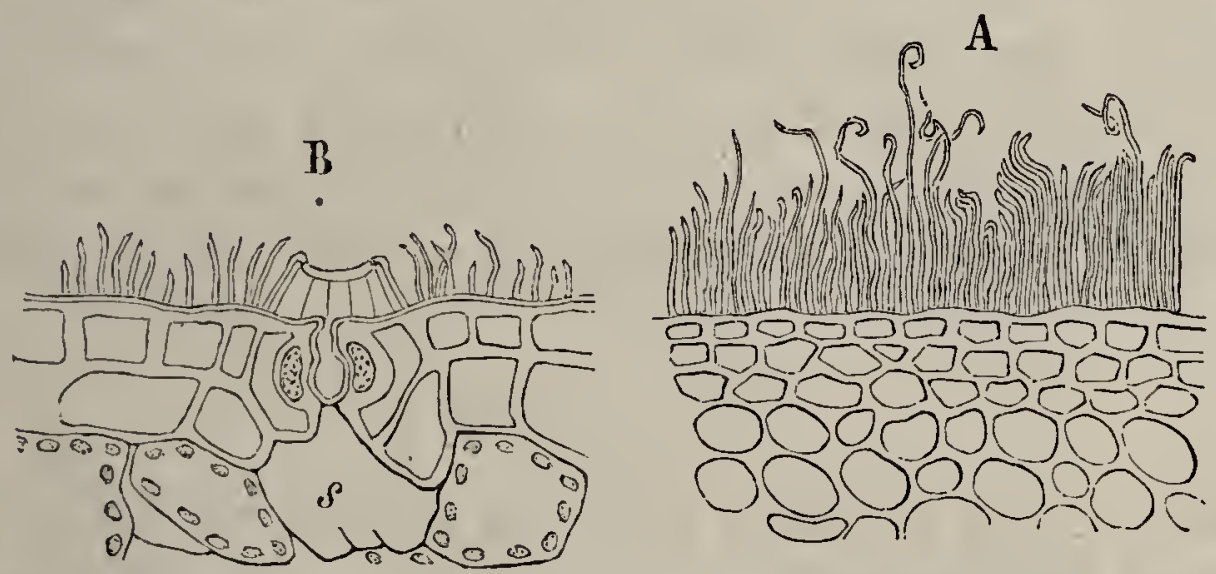

Fig. 70. - A. Coune sur un noud dela tige de Saccharum officinale (de Bary). - B. Coupe sur une feuille développée de Strelitzia svata. $-s$. Chambre respiratoire. (De Bary.)

les précédents. Ces granulations, qui mesurent environ $1 \mu$ sur les coupes transversales, sont arrondies ou en forme de bâtonnets très courts implantés perpendiculairement à la surface épidermique (Allium fistulosum, branches de l'Acer striatum). Ces granulations, assez espacées les unes des autres sur la face supérieure des feuilles de Tropæolum majus par exemple ou encore sur les feuilles de Vitis vinifera, sont ailleur's rapprochées jusqu'à se toucher, comme cela s'observe sur les feuilles des Choux rouges et blancs, sur les feuilles développées des Tulipes, des Dianthus, etc.

Enfin les surfaces très glauques ou très givrées de beaucoup de feuilles sont recouvertes de nombreuses granulations cireuses ou de petits bâtonnets entassés les uns sur les autres. Telles sont les feuilles des Eucalyptus globulus, du Ricinus communis, du Secale cereale, elc...

Pour en finir avec les dépôts cireux, signalons leurs rap- 
ports avec les stomates. Les dépôts crustacés et granuleux s'étendent en général à la surface des cellules de bordure, par conséquent jusqu'à l'ostiole des stomates. Les bâtonnets au contraire ne recouvrent généralement pas ces organes. Sur la face inférieure desfeuilles de Strelitzia ovata, par exemple, ils offrent une disposition très particulière (fig. 70, B). On peut voir sur les coupes que les bâtonnets, qui se tiennent sur les cellules annulaires qui aroisinent le stomate, penchent leurs extrémités libres vers le stomate. D'autre part, sur le bord des cellules en croissant qui forment le stomate, on voit une sorte d'anneau conique élevé, marqué à sa surface par des arêtes courbes et des fentes radiales. Cet anneau n'est autre qu'une sorte de croûte formée par l’assemblage de nombreux bâtonnets convergents. Quant à la surface même des cellules de bordure, elle est complètement libre de dépôt cireux.(De Bary.)

\section{$\S 11 .-$ stomates.}

ćtude. - Les stomates sont des organes de nature essentiellement épidermique, comme on peut s'en convaincre par l'étude de leur développement. Pour leur étude on procède donc exactement de même que pour l'épiderme; d'une part, l'examen en surface de lambeaux épidermiques fournit les notions nécessaires sur la forme générale de l’organe, sur sa répartition dans le tissu épidermique, etc. ; d'autre part, les coupes perpendiculaires au plan de l'épiderme complètent ces premières données et montrent les relations de l'organe avec les tissus sous-jacents. Nous n'avons pas besoin de dire que ces coupes doivent être très minces et faites avec le plus grand soin, si l'on veut tirer quelque profit de leur examen.

Forme des stomates. - La forme des stomates varie, et devient même très particulière dans certains cas, ainsi que nous le verrons lor'sque nous parlerons du développement de ces organes. Toutefois il existe une forme typique, si l'on peut s'exprimer ainsi, qui est celle des stomates de la plupart des plantes; nous allons en donner la description.

En général, un stomate est, comme l'indique son nom, un organe qui, examiné de face sur un lambeau d'épiderme 
(fig. 72, B), offre l'apparence d'une bouche dont les lèvres sont formées de deux cellules symétriques plus ou moins arquées, qui entourent un petit orifice que l'on nomme ostiole. Ces deux cellules ont reçu le nom de cellules de bardure ou cellules marginales. Déjà distinctes des cellules voisines de l'épiderme par leur forme, elles s'en écartent encore par leur contenu. Le plus souvent en effet les cellules de bordure des stomates renferment de nombreux grains de chlorophylle et de l'amidon.

Vu en coupe (fig. 71), le stomate se présente comme formé

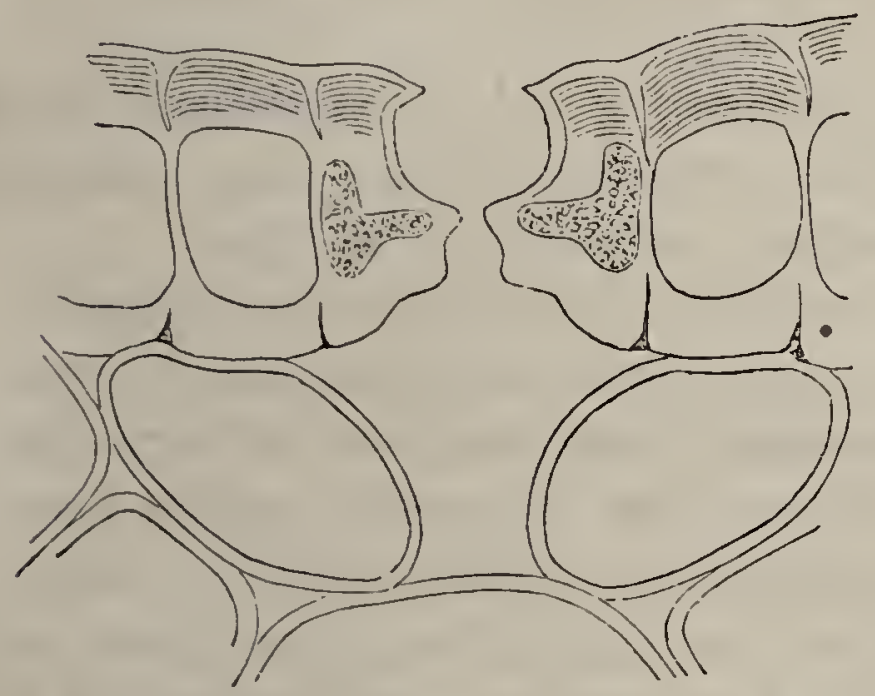

Fig. 71. - Coupe perpendiculaire d'un stomate. Épiderme fortement cuticularisé.

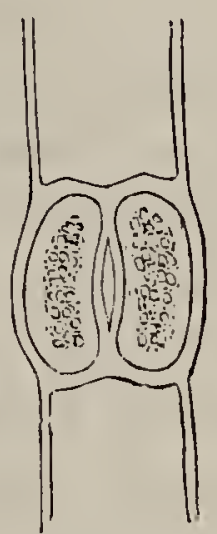

B

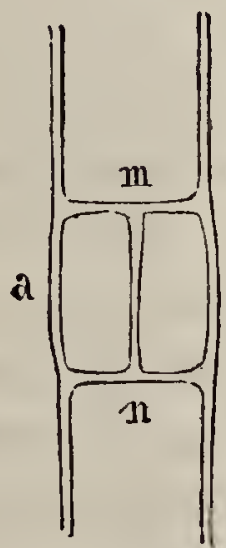

A

Fig. 72. - Formation d'un stomate. A. Division de la cellule mère.

de deux cellules séparées par un petit canal qui met en communication l'air extéricur avec une cavité plus ou moins grande creusée au milieu du tissu sous-jacent. Cette cavité a reçu le nom de chambre sous-stomatique; elle fait partie de l'appareil stomatique.

Localisation des stomates. - Les stomates n'existent pas sur toutes les parties des végétaux recouvertes d'épiderme. Les racines en sont dépourvues, et ce n'est guère que sur les parties aériennes des planles (tiges, feuilles, fleurs, etc.), qu'on les rencontre en abondance. Sur les feuilles où ces organes semblent se développer plus spécialement, ils occupent de préférence la face inférieure, et cette localisation, qui souffre cependant de nombreuses exceptions (feuilles nageantes, submergées, etc.), paraît en rapport avec la structure même du mésophylle et l'existence de nombreux méats intercellulaires 
dans la portion de ce tissu qui est en contact avec l'épiderme inférieur.

Signalons encore la dépendance qui existe entre le mode de répartition des stomates et l'arrangement des cellules épidermiques.

Sur les feuilles des Monocotylédonées, par exemple, où les cellules de l'épiderme sont allongées et disposées en séries parallèles suivant le grand axe de la feuille, les stomates affectent une disposition semblable. Une répartition des stomates en files longitudinales sobserve également sur les feuilles aciculaires des Abiétinées.

Chez les Dicotylédonées, au contraire, les stomates affectent dans leur forme et leur répartition une irrégularité en relation. d'ailleurs avec l'irrégularité des cellules épidermiques.

Dans certains cas, sur les feuilles de Saxifraga sarmentosa, par exemple, la localisation des stomates mérite d'être signalée. Si l'on enlève un lambeau d'épiderme sur cette plante, on y constate d'abord à l'œil nu de petits points blanchâtres satinés, assez régulièrement espacés. Si l'on monte alors la préparation dans l'eau ou la glycérine, on voit que ces petits points correspondent à de petites agglomérations de stomates. Ceux-ci se disposent en effet, dans le cas particulier qui nous occupe, par petits groupes espacés, tandis que tout le reste de la surface épidermique est dépourvu de ces organes.

Les stomates ne se trouvent pas toujours sur le même plan que les cellules épidermiques voisines. Tantôt ils sont enfoncés au-dessous de l'épiderme (Conifères, voir plus loin), tantôt, bien que restant au niveau de l'épiderme, ils occupent des cavités formées au milieu du mésophylle par un repli de l'épiderme. C'est ce que l'on peut voir (fig. 73) sur les feuilles du Nerium oleander. Si, en effet, on pratique des coupes sur l'épiderme de ces feuilles, on constate que de place en place l'épiderme subit une sorte d'invagination au milieu du parenchyme sous-jacent. Dans les cavités ainsi produites se développent denombreux poils, et, siles coupes sont assez délicates, on peut voir dans le fond de ces cavités les stomates développés aux dépens des cellules épidermiques, et en relation avec les méats intercellulaires du parenchyme sous-jacent. 
Développement des stomates. - Si l'on examine sur de très jeunes feuilles, ou encore à la base des feuilles des Iridées, l'épiderme qui les recouvre, on constate que cet épiderme est continu dans toute l'étendue de sa surface. Plus tard seulement, certaines de ses cellules venant à se diviser, la première ébauche des stomates apparaît. G'est d'abor'd une cloison pratiquée dans une longue ceilule épidermique qui en sépare une portion cubique ou cellule mère du stomate. Nous avons exposé plus haut (page 69 ), en Fig. 73. - Coupe de la face inférieure détail, le procédé typique de la $-s$. Stomates au fond de la cavité. formation des stomates chez l'lris

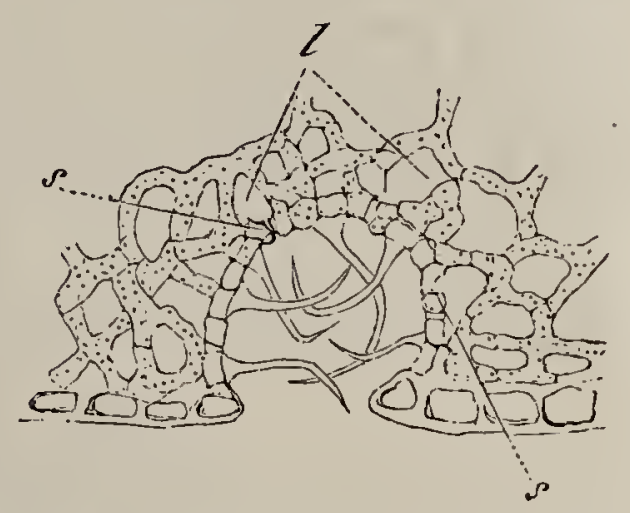
pumila; nous n'y reviendrons donc

pas ici. Nous ajouterons seulement que cette formation du stomate s'accompagne de certains phénomènes importants qui se produisent dans le tissu sous-jacent. Le parenchyme subit en effet une sorte de dislocation qui donne naissance à un méat qui va correspondre avec l'ostiole du stomate. Ge méat est la chambre aérienne ou sous-stomalique dont nous avons déjà parlé; il se trouve d'autre part en rapport avec les divers espaces intercellulaires qui abondent dans le parenchyme foliaire, disposition qui rend bien compte du rôle que doit jouer le stomate dans la vie du végétal.

La marche des phénomènes qui président à la formation des stomates subit dans certains cas des modifications intéressantes que nous allons rapidement passer en revue, et qui ont pour point de départ tantôt le mode de formation de la cloison qui donne naissance à la cellule mère, tantôt la manière dont se divise la cellule mère pour la production des cellules de bordure, tantôt enfin un travail de division qui s'opère dans les cellules épidermiques voisines du stomate.

$1^{\circ} \mathrm{Au}$ premier cas se rattache le développement des stomates d'un grand nombre de Fougères (1). La cellule mère prend nais-

(1) Oudemans, Sur l'origine des stomates de quelques espèces d'Ancimia. 
sance par une cloison en fer à cheval dont la convexité est tournée vers le centre de la cellule épidermique en division. Ghez les Aneimia, cette cloison a sa concavité tournée vers la paroi externe de la cellule épidermique dans laquelle. elle se produit. Puis, par les progrès du développement, sa convexité venant à atteindre la paroi opposée avec laquelle elle se confond, la cellule mère ainsi formée revêt définitive-

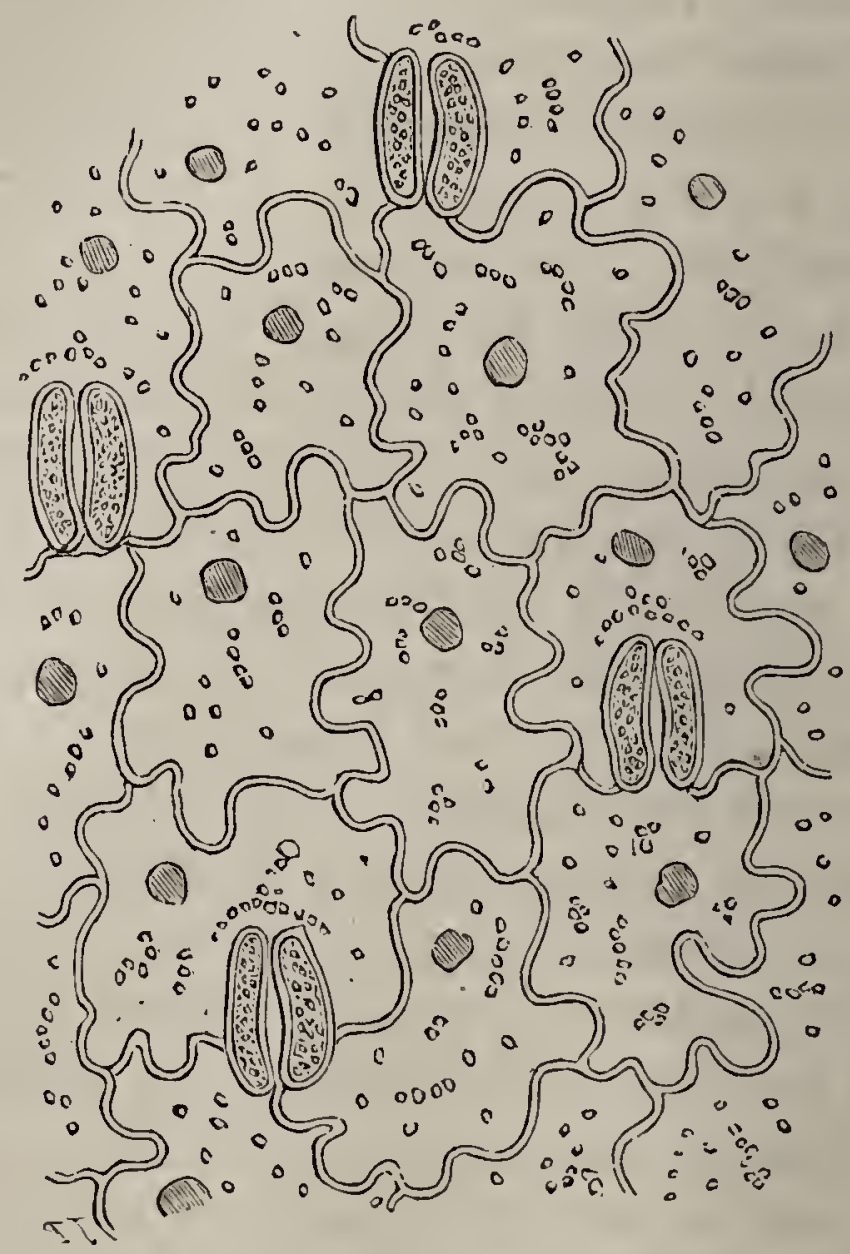

Fig. 74. - Épiderme d'une fronde de Fougère.

ment la forme d'un tronc de cône dontles bases font partie des parois inférieure et supérieure de la cellule épidermique. La cellule mère se divisant d'autre part à la manière ordinaire pour former les cellules de bordure, le stomate apparaît bientôt au milieu même de la cellule épidermique, et sans aucuno relation avec ses parois latérales.

(Congrès de botanique et d'horticulture. Amsterdam, 1865). Hildebrand, Ueber die Entwicklung der Farnkrautspaltöfnungen (Bot. Zeit. 1866, et Bull. Soc. bot., t. XV). Strasburger Jahrbuch. f. Wiss. Botanil., VII, p. 393. 
Dans beaucoup d'autres fougères, des cloisons analogues se' produisent, mais ne donnent pas lieu à la même particularité,' parce que, la cloison primitive venant au contact avec les parois latérales de la cellule épidermique, le stomate, lorsqu'il est complètement développé, se trouve au moins par un de ses points (fig. 74) adhérent à ces parois latérales. Il n'est donc plus isolé au milieu de la cellule. C'est à un mode semblạle de formation que sont dues les cellules mères des stomates d'un certain nombre d'autres plantes (OEnothérées, Silénées, Plantaginées, etc.).

$2^{\mathrm{e}}$ Cas. - Le mode de cloisonnement des cellules mères amène, avons-nous dit, des modifications importantes dans la forme de certains stomates.

On trouvera, dans les thalles de Marchantia polymorpha, un bon sujet d'étude à cet égard. Là, en effet, une cellule de l'épiderme se divise par bipartition répétée en un certain nombre de cellules qui toutes rayonnent autour d'un point vers lequel convergent leurs cloisons. En ce point les cloisons s'écartent bientôt, et il en résulte l'ostiole du stomate qui se trouve ainsi posséder un grand nombre de cellules de bordure. Alors chacune de ces cellules se subdivise elle-même en quatre ou huit cellules superposées, par des cloisonnements parallèles à la surface épidermique, si bien que le stomate devient une sorte de puits circonscrit par les nombreuses cellules marginales dont nous veno̊ns de voir le développement successif.

Dans les Prêles (Equisetum limosum), un fait de même nalure se produit. Le stomate, qui n'était d'abord formé que de deux cellules de bordure, en présente bientôt quatre par suite de cloisonnementsqui se forment dans les deux premières. Les nouvelles cellules venant à prendre ensuite un grand développement, surplombent les premières, et le stomate paraît enfoncé sous l'épiderme.

$3^{\circ}$ Cas. - Enfin, de nouvelles modifications peuvent être amenées dans la forme et la disposition générale des appareils stomatiques, par suite de la participation d'un certain nombre de cellules épidermiques voisines à cette formation.

Grâce aux divisions qui se produisent dans ces cellules, le GUIDE DE MICROGRAPIIIE. 
stomate peut se trouver entouré d'un nombre variable (deux, quatre ou davantage) de cellules qui restent en relation avec lui.

Le cas le plus simple se rencontre dans les stomates des feuilles de la plupart des Graminées, Joncées et Cypéracées (1). - L'examen en surface de l'épiderme de la feuille du Commelyna colestis, dont nous reproduisons, d'après Sachs, le développement des stomates et des cellules de voisinage, offre un bon exemple de ce cas. Sur la figure 75 : en A, nous voyons

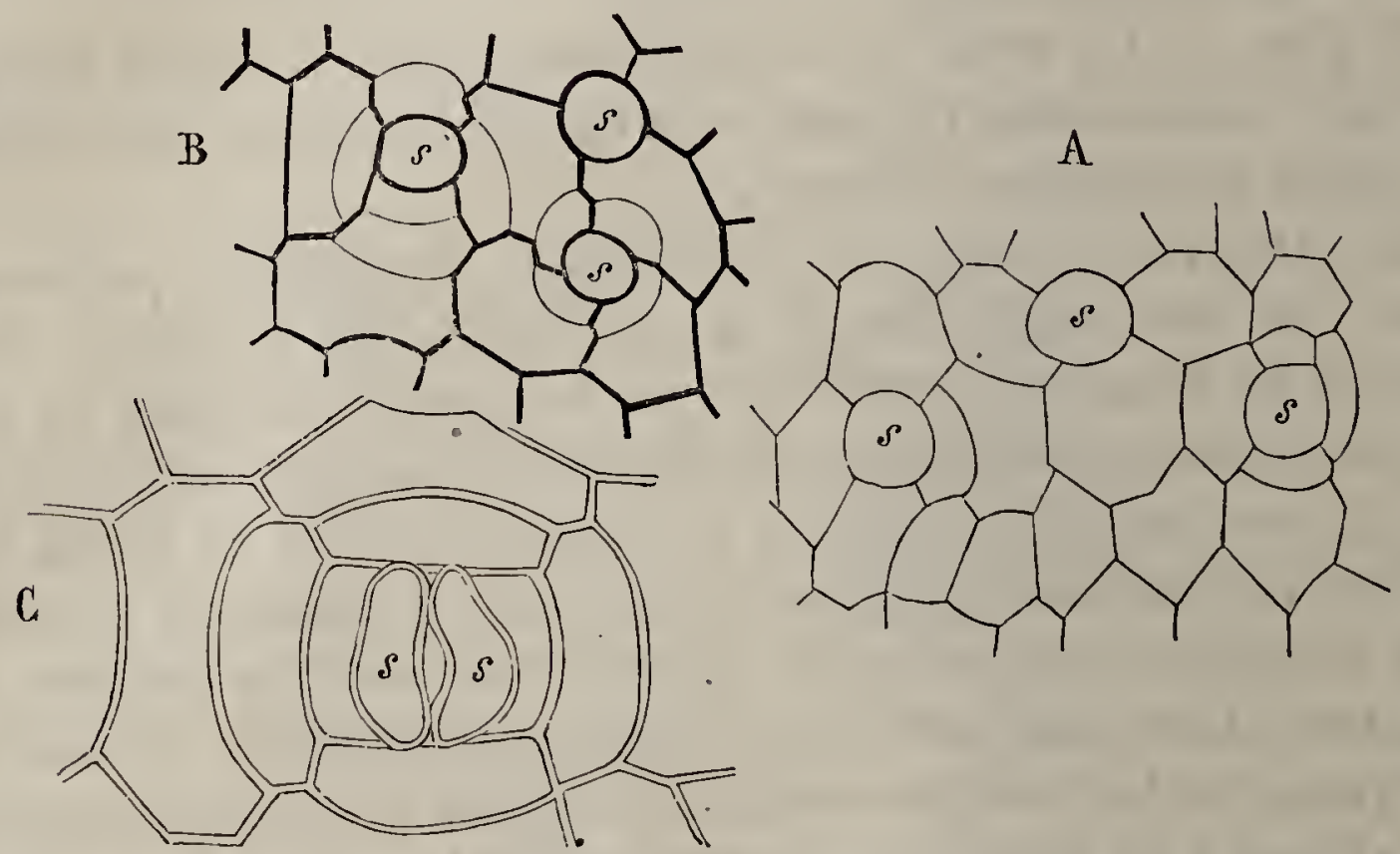

Fig. 7ö. - Développement des stomates du Commelyna cœlestis, d'après Sạchs.

les très jeunes cellules mères $(s)$ avant la formation des cellules de bordure. Déjà les cellules voisines de l'épiderme présentent quelques cloisonnements, et à droite dans la figure la cellule mère $(s)$ est presque entourée d’une bordure de jeunes cellules détachées des cellules épidermiques, par des cloisons circulaires. La figure $B$ présente un état plus avancé de ce même développement. Enfin dans la figure G, où les cellules de bordure sont définitivement spécialisées, on peut voir que le stomate est entouré de six cellules formées par les cloisonnements successifs des cellules de l'épiderme voisines du stomate. Ces cellules reçoivent quelquefois le nom de cellules accessoires.

(1) Pfitzer, Jahrb.f. Wiss. bot., VII, 1870. - Dural-Joure, Bull. Soc. bot., XVIII, 1871. 
Ailleụrs, sur les feuilles aciculaires d'un grand nombre de Conifères (Pinus pinaster, par ex.), les cellules épidermiques voisines des stomates venant à prendre un grańd développement, les stomates se trouvent surbaissés et comme enfoncés au milieu du parenchyme foliaire.

Nous n'insisterons pas davantage sur ces modifications qui présentent de nombreuses variétés, et qui semblent d'ailleurs pouvoir se grouper sous les trois chefs que nous venons d'indiquer.

\section{$\S 12$ - PAPILlEs. - POILS.}

Les papilles et les poils dérivent essentiellement de l'épiderme.

Papilles. - Étude. - Une cellule épidermique venant à saccroître par sa face libre, il en résulte, si cet accroissement est peu considérabie, une proéminence généralement de forme conique, qui a reçu le nom de papille.

Les épidermes de la plupart des corolles à aspect velouté (Pensées, Roses, etc.) sont particulièrement riches en ces sortes d'éminences cellulaires. Nous reproduisons, figure 76 ,

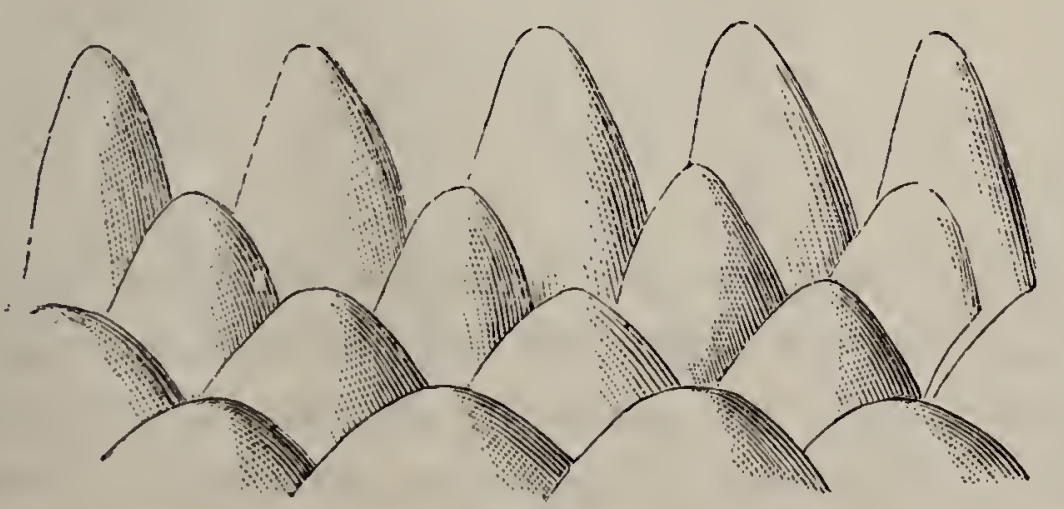

Fig. 76 .

l'aspect que présente un lambeau d'épiderme pris sur la corolle du Primula sinensis. Les papilles s'y trouvent en grand nombre sous forme de mamelons coniques, trois ou quatre fois plus hauts que larges. On trouve encore de nombreuses papilles souvent très développées sur les stigmates des fleurs.

Pour observer les papilles, il suffit de préparer des lambeaux d'épiderme, comme il a été dit plus haut, et de les examiner 
en surface. On peut encore faire des coupes perpendiculairement à la surface épidermique, et constater ainsi qu'il y a continuité entre la cavité des cellules épidermiques et celle de la portion conique qui constitue la papille.

Poils. - Leur's formes. - Si l'accroissement des cellules en dehors s'accentue davantage, les formations qui en résultent reçoivent le nom de poils.' Les papilles ne sont en réalité qu'un état intermédiaire entre les cellules épidermiques normales et les poils.

Les formes affectées par les poils sont extrêmement variées:

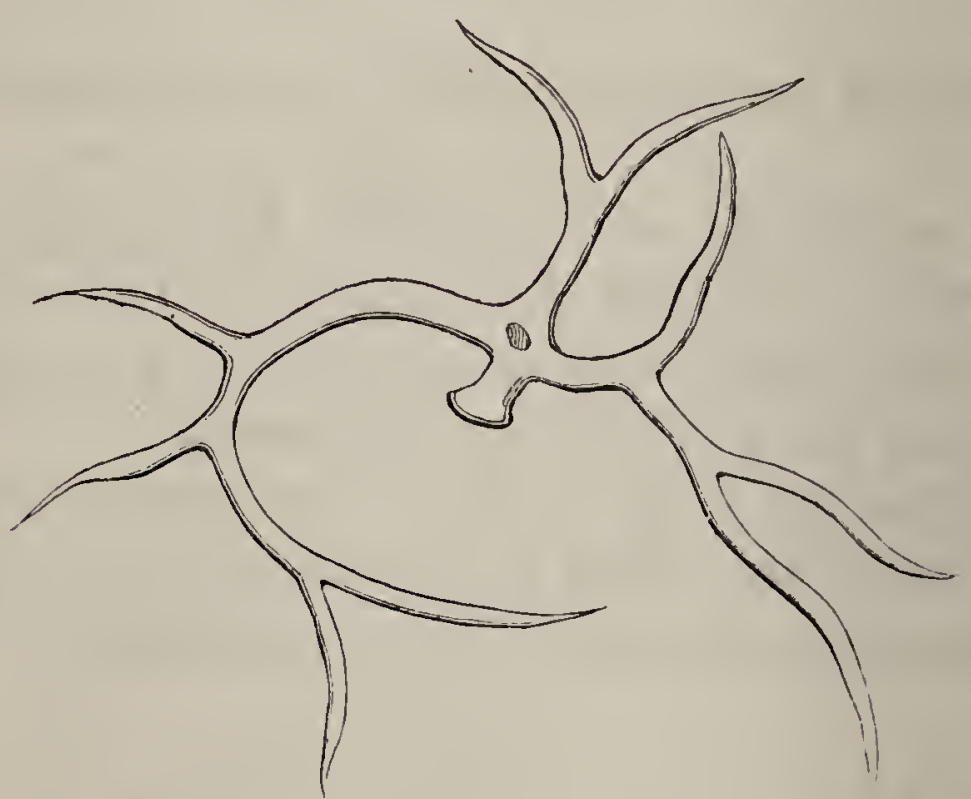

Fig. 77. - Poil rameux pris sur le Matthiola anmun.

tantòt la cellule épidermique s'allonge simplement (poils conlinus simples, , jusqu'à atteindre les dimensions remarquables qu'on observe dans les poils du coton; tantôt, en restant unicellulaire, le poil se bifurque ou se ramifie davantage et devient rameux ou étuilé (face inférieure des feuilles de l'Alyssum saxatile, feuilles de Matthiola annua, fig. 77).

Ailleurs (poils articulés) la cavité du poil devient indépendante en se séparant, par une cloison, de la cellule épidermique. Tantôt alors le poil lui-même reste encore simple, tantôt au contraire il se cloisonne transversalement (poils des $T^{\prime}(t-$ (lescantia, fig. 78, des Pelurgonium, etc.), ou dans des sens diver's de manière à produire des sortes de lames cellulaires connues sous les noms de poils en écusson (Hippophae rham- 
noïdes, Eleagnus, etc.), et de poils scarieux (poils étalés et plurisériés des Fougères).

On voit par là que les poils peuvent affecter des formes très diverses, par suite de divisions qui s'opèrent dans la cellule primitive. Le développement en épaisseur de la paroi de ces organes donne également lieu à quelques formies remarquables. Nous rappellerons à cet égard la structure singulière des poils qui recouvrent les graines du Strychnos nux vomica. Ces poils, d'après M. Planchon (loc. cit., page 404), sont formés d'une grande cellule qui, à sa base, a la forme d'une sorte d'ampoule, se rétrécissant brusquement en une partie cylindrique coudée à angle plus ou moins obtus sur la portion élargie et terminée par un sommet arrondi.

Les parois de cette cellule sont épaissies et marquées sur la partie basilaire de sortes de fentes transparentes en spirale; sur la partie rétrécie et cylindrique, les épaississements de la paroi forment des sortes de cannelures régulières, comme de petits cylindres placés parallèlement les uns aux autres dans le sens longitudinal.

Enfin, et pour terminer une description que nous abrégeons, car elle ne serait qu'une stérile énumération de faits variés à l'infini, nous rappellerons que, dans beaucoup de poils, certaines des cellules qui proviennent des divisions de la

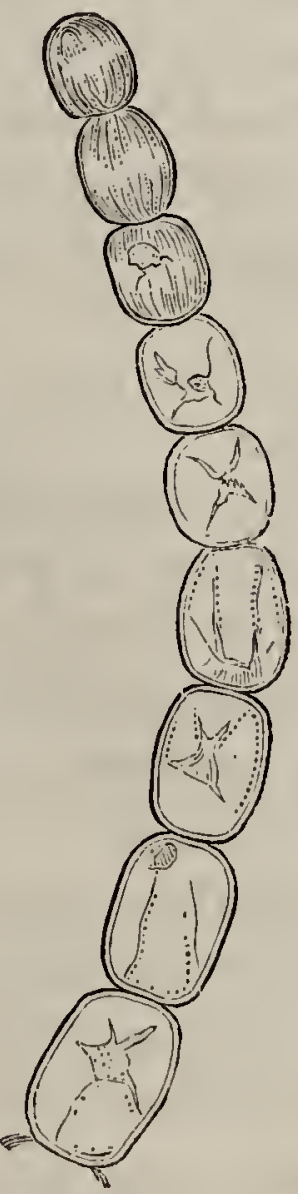

Fig. 78. - Poil de Tradescellule primitive, jouent le rôle d'organes de sécrétion. Ces poils glanduleux feront le sujet d'une étude spéciale (voir plus bas).

Etude. - L'étude des poils est fort simple, mais on ne doit pas se contenter de les arracher pour les examiner après les avoir montés dans le véhicule approprié. On pourrait, il est vrai, se rendrecompte ainsi de leur forme générale, mais, pour bien saisir les rapports qui existent entre ces formations et 
les cellules épidermiques, on doit faire des coupes sur l'épiderme.

Lorsqu'on monte des préparations de poils, on doit se mettre en garde contre les nombreuses bulles d'air que ces poils conservent toujours entre eux. Aussi ne devra-t-on jamais luter la préparation avant de s'être assaré du départ de ces bulles d'air. Le moyen le plus simple et le plus inoffensif pour s'en débarrasser consiste à porter la préparation sur la flamme d'une lampe à alcool. On chauffe doucement de manière à obtenir une ébullition modérée qui chasse tout 'air contenu dans la préparation.

Nous faisons suivre l'étude des poils, de celle des organes de sécrétion des végétaux, parimi lesquels les poils glanduleux comptent comme les plus importants, et les plus répandus.

\section{§ 13. - organes de sécrétion des végétaux.}

Les organes de sécrétion des végétaux sont de nature très diverse en apparence, mais consistent tous essentiellement en une ou plusieurs cellules actives dites sécrétantes : tantôt ces cellules sont plongées au milieu des tissus des organes (glandes intérieures), tantôt, au contraire, elles siègent à la surface de ces organes, accompagnées ou non de poils (glandes extérieures). Le produit de la sécrétion s'accumule dans un réservoir qui procède d'un développement très différent suivant les organes que l'on considère: de là, pour faciliter l'étude de ces formations, pensons-nous pouvoir les classer comme suit :

10 Il n'y a pas de réservoir spécial ; le pro- Extérieures. Toujours accompaduit sécrété se réunit sans la cavité même gnées de poils à la base. des cellules sécrétantes ou dans un es- Poils glanduleux.

pace compris entre la paroi des cellules sécrétantes et leur cuticule soulevée. Ces

glandes sont..................... Intérieures. Unicellulaires.

$2^{\circ}$ Le réservoir est un poil surmontant le Extérieur.

tissu glanduleux qui est. ........... Interrieur.

$3^{\circ}$ Le réservoir est une lacune produite au Extérieures. milieu des cellules sécrétantes par dila-

cération et résorption de celles-ci. Ces Intérieures.Glandes proprement glandes peuvent être................ dites.

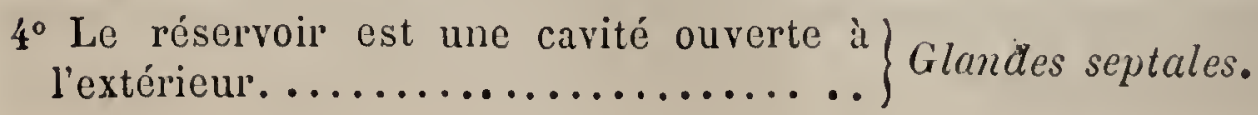


$5^{\circ}$ Le réservoir est un espace dû à l'écar-

tement des cellules sécrétantes......... Canaux résineux.

Nous avons déjà traité des canaux résineux (voir p. 15ั3), nous ne nous occuperons donc ici que des quatre premiers groupes.

$1^{\mathrm{er}}$ Groupe. - Pas de réservoir. Le produit de sćcrétion s'accumule dans la cavité même des cellules sécrétantes ou dans un espace compris entre la paroi des cellules et leur cuticule soulevée.

$1^{\circ}$ Glandes extérieures. Poils glandulifères. - Dans ce premier groupe rentrent les poils dits glandulifères, c'est-à-dire ces poils que nous avons déjà mentionnés, qui portent à leur sommet une ou plusieurs cellules sécrétantes. Ces sortes d'organes glanduleux sont très répandus dans les végétaux et en particulier chez les Labiées et les Géraniacées. Tantôt la glande est unicellulaire, tantôt, au contraire, elle est formée d'un plus ou moins grand nombre de cellules qui prennent naissance par des cloisonnements successifs soit exclusivement verticaux, soit verticaux pour une portion de la glande et horizontaux pour une autre portion. D'autre part, la longueur du poil qui supporte ces glandes peut varier dans des limites assez étendues, et le nombre des cellules ainsi que leur forme peuvent présenter des variations intéressantes dont on doit tenir compte dans l'étude de ces organes.

G'est en se basant sur ces différents faits, que M. Martinet (1), auquel nous empruntons une grande partie de ce qui va suivre, a établi la classilication que nous donnons des poils glanduleux à glande au sommet :

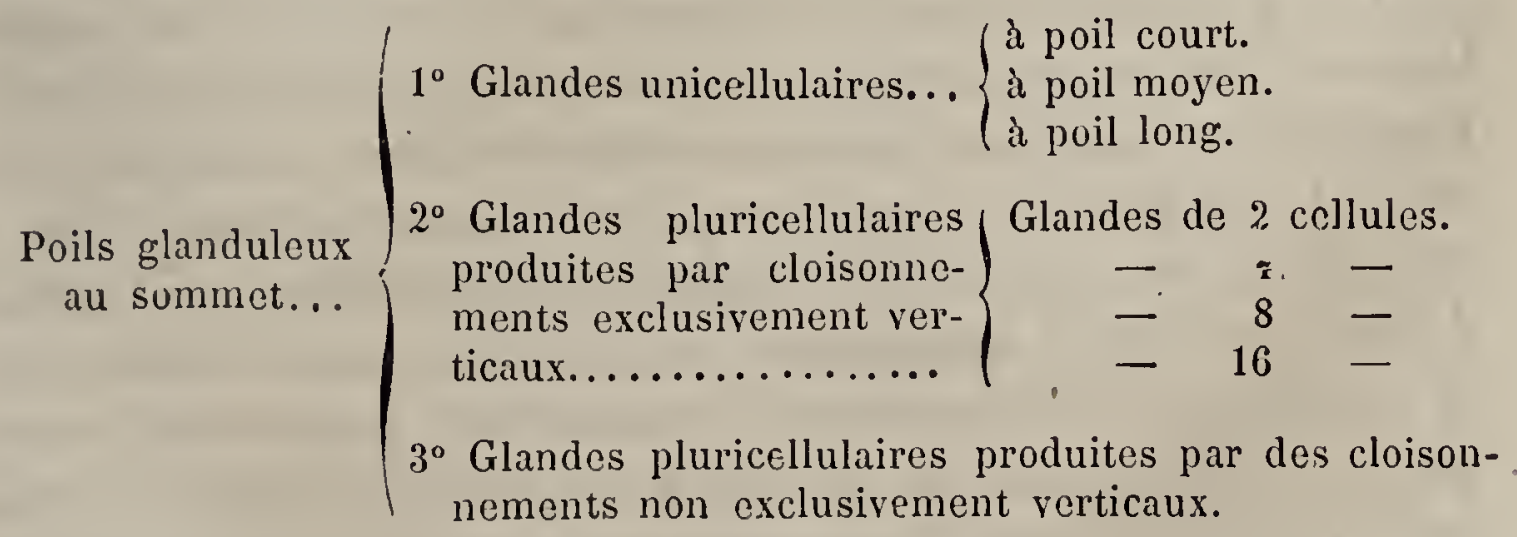

Étude. - Pour étudier ces glandes, on devra faire des

(1) Martinet, Ann. Sc. natur., 5e série, t. XIV, 1871. 
coupes normalement à la surface épidermique (tiges, feuilles) qui les supporte; ces coupes devront être assez minces pour montrer les rapports qui existent entre les glandes et les cellules épidermiques. Si l'on examine des glandes pluricellulaires, on devra faire des coupes jusqu'à ce qu'on ait obtenu des sections à travers le tissu même de la glande. Il ne suffirait pas dans ces recherches de soulever des lambeaux d'épiderme et de les monter pour les examiner, car l'appareil glandulaire ne se montrerait alors que d'une manière incomplète et impropre à une bonne étude.

A. Poils à glandes unicellulaires. - A la surface des feuilles et des parties vertes de la plupart des Labiées (Satureia montana, Mentha citrata, etc.), on trouve des glandes unicellulaires sphériques surmontant un poil court formé de une ou deux cellules superposées. De semblables glandes unicellulaires à poil rudimentaire s'observent également parmi les Rhinanthacées dans l'Euphrasia off. et les Pedicularis sceptrum, corallinum; enfin, chez les Orobanchées sur l'Epiphegus et chez les Monotropées sur l'Hypopitys vulgaris (1).

Dans tous ces cas, la vésicule glandulaire est généralement beaucoup plus volumineuse que les cellules du poil dont elle se distingue encore par sa forme arrondie. Cette cellule glandulaire affecte d'ailleurs un aspect un peu différent suivant son état au moment de l'observation. Si elle est en pleine activité de sécrétion, le produit (huile essentielle) qui la remplit la gonfle et la fait apparaître comme une grosse vésicule jaunâtre ou un peu diversement colorée; si la sécrétion est encore peu abondante, la cellule est moins distendue, et remplie de granulations grisâtres au milieu desquelles se montrent quelques goutteleltes huileuses reconnaissables à leur réfringence. Si enfin le produit de sécrétion a été éliminé, comme cela se rencontre sur les feuilles âgées ou dessécliẹes, la cellule a perdu sa forme sphérique; ses parois, comme chiffonnées et revenues sur elles-mêmes, laissent voir à leur surface des plis qu'il faut se garder de confondre avec des cloisons cellulaires. Dans ce dernier cas également, la cellule a perdu beau-

(1) A. Chatin, Anat. comp. des végétaux, pl. xxxiv, xxxvi, XLII, LIII. 
coup de son volume et paraît généralement plus petite que les cellules du pédicelle.

Tout ce que nous venons de dire s'applique également aux glandes longuement pédicellées que l'on rencontre souvent aussi chez les Labiées et en particulier dans les Lavandula lanata, Lamium longiflorum, etc.

Dans les divers exemples que nous avons cités plus haut, la cellule glandulaire est à peu près régulièrement sphérique. Ailleurs, dans le Thymus vulgaris, le Salvia glutinosa parmi les Labiées, et surtout chez les Solanées (Atropa Belladona, Hyosciamusalbus), la cellule glandulaire prend une forme allongée ou croïde.

Enfin, à côté des Labiées si riches en poils glanduleux unicellulaires, signalons encore les Géraniacées, Erodium, Gerarium, et particulièrement les Pelargonium, où elles se distinguent par un pédicelle notablement plus allongé que chez les Labiées. Ce sont encore ces mêmes glandes unicellulaires que l'on retrouve dans les Chenopodium et en particulier dans le Chenopodium vulvaria où elles sont en si grand nombre que, pour trouver place les unes à côté des autres, elles se recouvrent successivement.

La forme des cellules qui composent le poil pédicellaire mérite également de fixer l'attention. Tantôt toutes ses cellules sont semblables, mais le plus fréquemment, dans les poils de grandeur moyenne la cellule la plus inférieure ou deux ou trois cellules des plus inférieures sont grandes et de forme plus ou moins conoïde, tandis que les autres cellules, au nombre de deux ou trois beaucoup plus petites, forment une sorte de collet qui supporte la glande. On trouvera des exemples de cette disposition dans le Lophanthus sinensis et le Pelargonium tomentosum.

B. Glandes pluricellulaires par cloisons verticales. $-1^{\circ} \mathrm{La}$ glande formant une tête sphérique est composée de deux cellules séparées par une cloison verticale (fig. $79, t)$. On en trouve de nombreux exemples dans les Labiées; dans les genres Melissa, Hyssopus, Nepeta, Lophanthus, etc., la glande est portée par un pédicelle court de une ou deux cellules. Elle peut même . paraîlre sessile.

De semblables glandes à pédicelle moyen sont rares non 
seulement chez les Labiées, mais même chez les autres plantes. Le genre Stachys en offre cependant des exemples.

Enfin, dans les Ballota hirsuta et Scutellaria alpina, on rencontre des glandes 2-cellulaires à poil allongé.

$2^{\circ}$ On trouvera des glandes à quatre cellules dans beaucoup de Labiées. - On s'assurera que les précédentes ne sont pas un état premier de celles-ci, en examinant les Saugespar exemple (Salvia splendens, farinacea, etc.), où l'on ne trouvera que des glandes à quatre cellules à quelque âge que ce soit de la plante (Martinet, loc. cit.). On rencontre les mêmes glandes dans beaucoup d'autres Labiées, Lamium album, Galeopsis ladanum, etc. - Mais toutes les glandes à quatre cellules que l'on rencontre chez les Labiées sont à poil court. - Pour les glandes 4-cellulaires à poil moyen, il faut les rechercher dans les Solanées, (Solanum rubrum). Celles à poils longs sont encore plus rares (Cucumis melo).

$3^{\circ}$ Glandes à huit cellules (voir p. 187).

$4^{\circ}$ Glandes à 16-32 cellules. Elles ne se rencontrent que dans deux genres parmi les Labiées (Galeopsis et Scutellaria). Elles y sont à pédicelle long.

On en trouve de semblables à pédicelle court dans le Cannabis sativa. Pour bien étudier ces glandes, il faut absolument pratiquer des coupes dans le tissu glanduleux lui-même.

G. Glaindes pluricellulaires par cloisonnements non exclusivement verticaux. - Ces sortes de glandes se rencontrent principalement dans les Solanées (1). Dans les Nicotiana auriculata, glutinosa, etc., ainsi que dans le Cicer arietinum, ces glandes consistent en plusieurs cellules superposées, résultant de cloisonnements horizontaux, et surmontées de trois ou quatre cellules dues à la production de cloisons verticales.

Signalons enfin, dans le Schizanthus pinnatus, de pareilles glandes surmontant un poil formé de plusieurs rangées de cellules juxtaposées.

Wtude de quelques exemples de glandes dont le produit de sécrétion - s'accumule entre la paroi des céíiles et leur cuticule soulevée.

(1) On trouve même dans l'Atropa Beltadona des glandes pluricellulaires par cloisonnements uniquement horizontaux. 
Parmi les glandes que nous avons étudićes, celles des $S_{a l v i a}$ et des Cannabis, par exemple, présentent cette particularité. Nous allons étudier plus spécialement quelques glandes des Labiẻes, celles du Houblon et les glandes des bourgeons.

$1^{\circ}$ Labiées. - Dans beaucoup de Labiées on trouve des glandes pluricellulaires, que l'examen des glandes du Satureia montana, par exemple, fera parfaitement bien connaître. Si l'on enlève un lambeau d'épiderme sur une leuille de cette plante et qu'on examine la face inférieure de cet épiderme au microscope, on aperçoit à travers les cellules épidermiques une formation particulière consistant en une petite ouverture arrondie (voir fig. 79, C), d'où partent en rayonnant huit cellules allongées plus larges en dehors qu'en dedans, et qui, accolées l'une à l'autre, offrent l'aspect d'une coupe de cristal renversée. Si le même épiderme est examiné par sa face supérieure, on observe, à l'endroit correspondant à la première figure, une vésicule arrondie ou réniforme remplie d'un suc jaune, quelquefois noirâtre, ou au contraire assez limpides pour permettre d'apercevoir par transparence la même disposition qu'à la face inférieure. Si l'on pratique des coupes sur les mêmes feuilles, on reconnaît que l'on a alfaire à des glandes très brièvement pédicellées, montées sur une seule cellule, dont on avait pré-

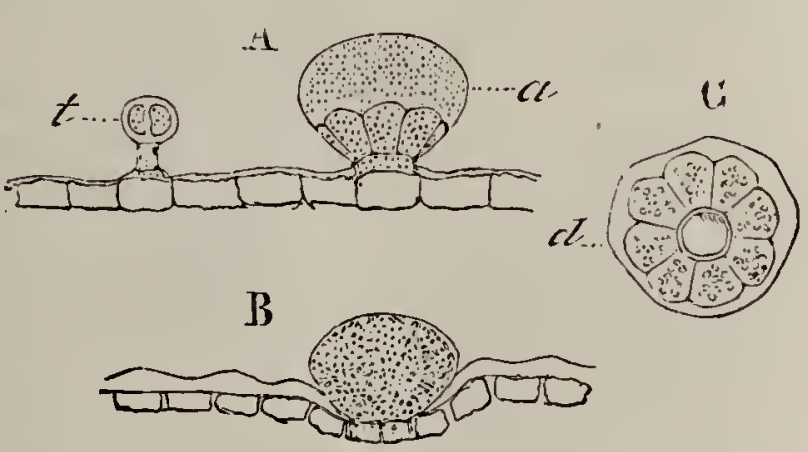

Fig. 79. - Glandes de la Ballotte noire (voir l'explication dans le texte). cédemment l'image au centre des huit cellules rayonnantes. Ces glandes en forme de cupules sont surmontées d'une sphère hyaline remplie d'huile essentielle $(a)$. La sphère est le résultat du décollement de la cuticule, le produit de sécrétion s'étant extravasé entre les cellules sécrétantes et leur cuticule qui s'est peu à peu soulevée et constitue ainsi le réservoir de la glande (fig. $79, \mathrm{~A}$ ).

En observant le développement de ces glandes, on voit que deux premiers cloisonnements verticaux déterminent dans la jeune utricule quatre cellules de dimensions égales. Puis, dans ces ceillules se produisent de nouveaux cloisonnements, mais de telle sorte que chacune d'elles se trouve alors divisée en une grande cellule et une petite (Martinet, loc. cit.). Cette irrégularité ne porte que sur la partie supérieure de la glande, de telle sorte que, vue par sa face inféricure, elle paraît formée de huit cellules égales.

Les coupes montreront encore, ce que ne pourrait faire le simple soulèvement de l'épiderme, que les glandes qui nous occupent se trouvent placées dans une fossette ou dépression de l'épiderme qui tantôt est peu profonde (Thymus vulgaris), tantôt au contraire est très marquée, à bords presque à pic (fig. 79, B) (Satureia montana, 
S. hortensis, Calamintha nepeta, Glechoma hederacea, etc.), tantôt enfin très évasée (Hyssopus officinalis).

Nous avons dit enfin que chez les Labiées ces sortes de glandes sont pour ainsi dire sessiles, tant leur pédicelle est court; dans d'autres plantes, Veronica glandulosa, Antirrhinum majus, on en trouvera pourvues d'un long pédicelle.

Glandes du Woublon. Lupulin. - Ces glandes, très semblables

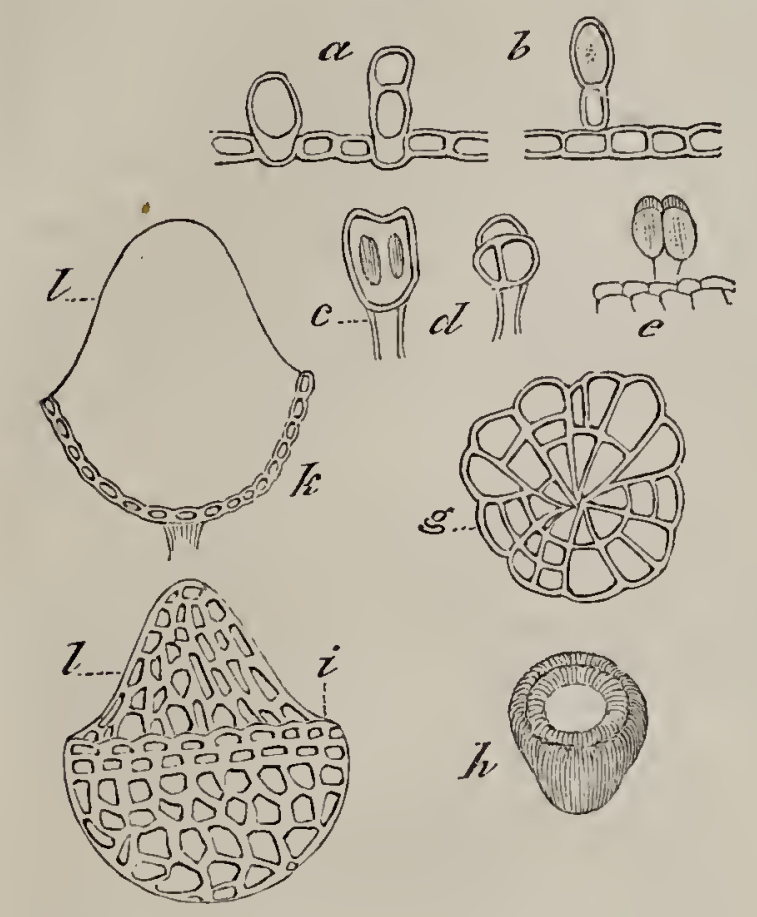

Fig. 80. - Développement des glandes du Houblon (lupulin), d'après MI. Personne. aux précédentes, s'en distinguent cependant par le mode de cloisonnement, qui n'est point exclusivement vertical. Depuis les recherches de M. Personne (1), on sait que le lupulin, qui se présente sous l'aspect d'une poussière jaune, est formé par des glandes qui affectent la forme d'un gland muni de sa cupule (fig. $80, h$ ) et qui naissent en grand nombre sur les ovaires, sur la face inféricure des bractées et sur celle des feuilles du Houblon.

Examincees à un grossissement de 200 à 300 diamètres, ces glandes paraissent formées de deux parties, l'une inférieure cupuliforme, l'autre supérieure conoïde, de structure apparente semblable.

- Elles sont constituées de cellules plus ou moins irrégulières, rangées le plus souvent en séries rayonnantes du sommet du cône et du centre de la cupule à la ligne où ces deux parties se réunissent (fig. $80, l, i$ ). Mais ce n'est là qu'une apparence. Car, au moyen de coupes et d'un examen attentif, on constate que la moitié inférieure ou cupuliforme du grain est formée d'une seule couche de cellules $(k)$, et c'est par la base de cette cupule que la glande est fixée, tandis que la moitié supérieure ou conique $(l)$ est constituée par une membrane fort mince, continue. Les cellules qui sont dessinćes à sa surface ne sont que les empreintes des cellules de la cupule.

Si l'on étudic le développement de cette glande, on assiste aux phénomènes suivants : "Elle commence comme un poil par une cellule qui se développe entre celles de l'épiderme ( saillante à l'extérieur se partage en deux par une cloison transversale, à la hauteur de la surface externe de cet épiderme. La cellule qui résulte de cette division se partage à son tour transversalement en deux cellules $(b)$ dont l'inférieure constituera le pédicelle, et la

(1) Personne, Amm. Sc. nat., Bot., 4e séric, t. I, 15.34. 
supérieure la glande par une série de cloisonnements non plus horizontaux, mais verticaux $(c, d, e)$. " (Personne, loc. cit.) Finalement on obtient un disque $(g)$ dont les bords se relèvent pour former une cupule presque sessile sur l'épiderme $(l, i)$. Alors commence la sécrétion d'un liquide jaune par cette glande. Ce liquide, à mesure qu'il se forme, s'épanche sur toute la surface interne de la cupule, entre les cellules qui le sécrètent et la cuticule qui les recouvre. Celle-ci, peu à peu soulevée sur toute l'étendue de la face interne de la cupule, est refoulée à l'extérieur et prend un aspect conoïde en même temps qu'à sa surface elle conserve l'empreinte des cellules dont elle a été détachée.

On peut provoquer artificiellement le soulèvement de cette cuticule en plaçant les cupules dans de l'eau légèrement alcalisée; on les voit alors passer peu à peu par tous les états jusqu’à la forme définitive de la glande en forme de gland. (Personne.)

Poils glanduleux des bourgeons. - Ces poils ou collétères (Hanstein) (1), qui produisent les matières visqueuses et résineuses dont sont fréquemment pourvus les bourgeons des arbres et arbrisseaux, sont très semblables aux précédentes formations. Tantôt portées par les écailles prolectrices du bourgeon (Esculus), tantôt par les stipules dont le développement précède celui des feuilles (Viola, Prunus), tantôt enfin par les jeunes feuilles elles-mêmes (Syringa, Ribes sanguineum), ces glandes affectent des formes diverses, mais dans toules la matière sécrétée (mucilagineuse ou résineuse) s'accumule entre la cuticule et les cellules de la glande (2).

$2^{\circ}$ Glandes unicellulaires intérieures. - On les rencontre dans diverses familles de plantes et en particulier dans les Laurinées, les Monimiacées et les Valérianées.

Laurinées. - Si l'on pratique des coupes sur la feuille du Laurus nobilis par exemple, on constate dans l'assise des cellules en palissade certaines cellules dépourvues de chlorophylle et remplies de goutlelettes réfringentes: ce sont là des glandes unicellulaires (fig. 81, g). On en rencontrédde même nature dans les Laurus camphora et Benzoin, où elles naissent presque indislinctement dans l'un ou l'autre des deux parenchymes de la

(1) Ueber die Organe der IIarz-und Schleimalsonderung in den Laublinuspen., Bot. Zuitung, 1868$)$.

(:) D'après 11. Hanstein, le mucilage gommeux ainsi produit n'est pas sécrété par les cellules, mais provient de la transformation d'une couche de la membrane cellublaire situce sous la cuticuled M. Hanstein nomme cette couche colligène. Notons que l'épiderme peut, dans certains cas, joner ì lui seul le même ròle. C'est de cette façon par exemple que se forme le baume verdatte qui enuiat les feuilles des bourgeons du Peuplier. 
feuille. - Les recherches de M. G. Planchon (1) ont également établi l'existence de ces cellules dans la racine du Sassafras offcinalis. Sur des coupes de cette

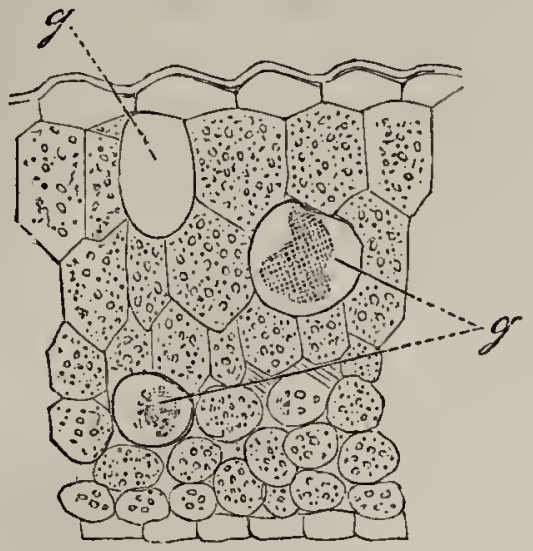

Fig. 81. - Glandes unicellulaires dans le parcuchyme de la feuille du Laurus nobilis. - g. Glandes (d'après MI. J. Chatin, loc. cit.). portion du végétal, on observe une écorce limitée intérieurement par une zone formée de cellules tabulaires; et recouvrant un parenchyme brunâtre parmi les éléments duquel on distingue des cellules généralement plus volumineuses que les utricules voisines, et remplies d'huile essentielle. Dans le bois, on retrouve çà et là de grosses cellules oléifères et également isolées.

Monimiacées. - Ce sont également des glandes unicellulaires différenciées au milieu du parenchyme herbacé et de la moelle, ou encore dans le mésophylle des feuilles, que l'on observe dans les Monimiacées (Peumus Boldo, Calycanthus occidentalis, etc.) (2).

Valérianées. - Enfin dans la famille des Valérianées, nous retrouvons des cellules isolées, diversement réparties dans la racine et la tige, et qui renferment les substances actives qu'elles ont produites (3). Ces cellules oléo-résinifères sont localisées soit dans la couche périxyle du parenchyme cortical des rhizomes (Nardostachys), soit dans cette assise et en même temps dans celle qui confine à l'épiderme (Valeriana offic., $V$. Celtica, etc.); on en trouve dans la moelle du Valeriana montana. (J. Chatin.)

$2^{\mathrm{e}}$ Gronpe. - Le réservoir est un poil surmontant le tissu glanduleux. Deux cas peuvent se présenter : ou bien la glande est extérieure, c'est-à-dire au-dessus de l'épiderme (Urticées), ou bien elle est intéricure, c'est-à-dire au-dessous de l'épiderme au

(1) Traité pratique de la détermination des drogues simples d'origine végétale, t. I, p. 588 .

(2) Cl. Verne, Etude sur le Boldo. Thèse de l'École supérieure de pharmacie de Paris, 18 i4.

(3) J. Chatin, Etudes botaniques, chimiques ct médicales sur les Valéria. nécs. Thèse de la Faculté de médecine de Paris, 1871. 
milieu du parenchyme de la feuille ou de l'organe qui porte la glande (Malpighiacées).

Urticées. - Dans l'Urtica urens on trouve, à la surface des feuilles et des tiges, des poils d'une structure toute particulière, dont on fera l'étude au moyen de coupes, les unes perpendiculaires à l'épiderme qui les porte, et les autres transversales dirigées sur les diverses parties de la glande. Ces poils sont formés d'une seule cellule qui se renfle inférieurement en une ampoule ovoïde enchâssée dans une petite colonne cylindrique (fig. $82, \mathrm{~A})$, et pleine. Celle-ci, pour le recevoir, se creuse en godet $(b)$, qui s'amincit à son bord supérieur jusqu'à n'être plus formé que de deux rangs, puis d'un seul rang de cellules, comme le montrent les coupes transversales G, B. De même, au moyen de coupes transversales, on constate que le pied qui supporte ce poil est un tissu de cellules en continuité avec le parenchyme sousjacent. Ce tissu est la portion sécrétante de l'appareil. Il est plein dans sa partie inférieure $(a)$, comme le montre la coupe transversale (D) sise à gauche du poil. Quant au liquide produit, il se réunit dans le poil.

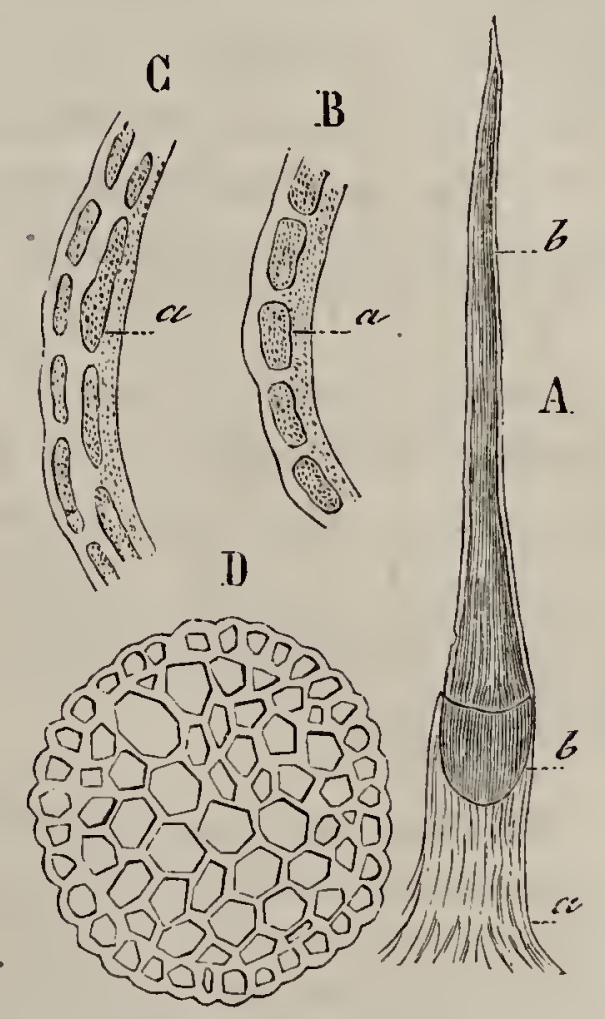

Fig. 82. - Glande et poil de l'Urtica urens (d'après M. Duchartre).

Malpighiacées. - Les longs et durs poils que l'on trouve a la face inférieure des feuilles du Malpighia urens sont à peu près de même nature. Seulement la glande, au lieu d'être placée à la surface du parenchyme foliaire, est plongée au milieu même de ce parenchyme, sous l'épiderme. Le tissu glanduleux est formé de cellules généralement petites et remplies de granulations fines de forme arrondie; cette glande est surmontée d'un poil dit en navette, c'est-à-dire constitué de deux parties: l'une, normale à l'épiderme, est formée par une cellule courte, souvent à peine plus haute que les cellules épidermiques qui l'entourent ; l'autre, très allongée et paral- 
lèle à l'épiderme, forme deux longues branches pointues provenant de la ramification de la cellule. Ces poils en navette peuvent dépasser un demi-centimètre de longueur. Leurs pointes très acérées sont formées par un épaississement de la paroi de la cellule. - Dans ces poils se trouvent de nombreux globules huileux, produit de la sécrétion de la glande sous-jacente.

La préparation de ces glandes avec leur réservoir est assez délicate, et ne s'obtient qu'à l'aide de certaines précautions. En effet, les poils sont tellement durs qu'ils se détachent de la feuille dès qu'on veut pratiquer des coupes. Ils se séparent donc de la glande et se présentent le plus souvent isolés au milieu de la préparation; on ne voit plus sur l'épiderme que la trace de la base du poil. Pour obtenir une préparation complète de la glande et du poil, il faut préalablement laisser la portion de feuille, où l'on pratiquera les coupes, se ramollir dans l'eau alcalisée. Le poil perdra alors de son élasticité et, a vec quelque soin, on arrivera à faire de bonnes coupes qui, pour être intéressantes, devront ètre dirigées suivant le grand axe du poil.

Tentacules glandulifères. - Sous ce nom nous désignons les curicux appareils de sécrétion que l'on observe à la surface des feuilles de certaines plantes de la famille des Droséracées, appareils qui au premier aspect ressemblent à des poils glanduleux, mais qui par un examen plus approfondi ne nous paraissent pouvoir supporter la comparaison. Les tentacules des Droséracées ont été successivement étudiés par MM. Groënland, Trécul, Warming, Darwin (1), etc.

Ces appareils glanduleux pris, par exemple, sur les feuilles du Drosera rotundifolia, se composent de deux parties distinctes, savoir : un pédicelle et un tissu glandulaire au sommet.

Le pédicelle n'est pas un poil ; voici en effetet, d'après Trécul (loc. cit.), quelle en est la structure :

Il se compose de trois parties:

$1^{\circ}$ Un épiderme formé de cellules allongées, teintées en rose à la partie supérieure de l'organe, et parsemé principalement à la base de petits stomates semblables à ceux du limbe de la feuille.

$2^{\circ}$ En dedans de cet épiderme, on aperçoit sur les coupes trans-

(1) Trécul, Am. des Sc. nat., Bot., , ie série, t. III.

J. Groönland, Amm. Sc. nat., Bot., 4e série, t. III. - Warming, Sur la difféerence entre les trichomes. Extr. des Amn. Soc. des Sc. nat. de Copenhague. - Darwin, Plantes insectivores. Paris, $18 i 7$. 
versales un parenchyme à cellules allongées renfermant de la chlorophylle et par places aussi de la matière colorante rose.

$3^{\circ}$ Enfin, au centre du pédicelle existe un système vasculaire composé par un faisceau de deux à trois trachées d'une grande délicatesse qui se continuent jusqu'au milieu de la glande.

Quant à la glande, elle n'est pas moins remarquable par sa structure. D'après les recherches de Warming (loc. cit.), elle est formée d'une agglomération de trachéides spiraux et réticulés au milieu desquels viennent se perdre les trachées du pédicelle. D'autre part, autour de cette masse centrale se trouvent trois couches de cellules. La plus profonde, celle qui enveloppe directement les trachéides, est formée de cellules allongées dont les plus inférieures se relèvent en dehors et atteignent la surface épidermique. Les deux autres couches sont formées de cellules polyédriques.

D'après la structure que nous venons d'exposer, on voit que ces appareils tant par le pédicelle que par la glande sont absolument distincts des poils glanduleux.

Nous n'insisterons pas davantage sur l'étude de ces intéressants organes. Ajoutons qu'on les rencontre dans les diverses espèces de Drosera, dans le Drosophyllum lusitanicum, etc.

$3^{\mathrm{e}}$ Groupe. - Le réservoir est une lacune produite par résorption des cellules sécrétantes. - Toutes ces glandes sont pluricellulaires. Comme celles du groupe précédent elles̀ peuvent être extérieures ou intérieures.

$1^{\circ}$ Glandes extérieures. - Les glandes de cette nature, exterieures, sont peu répandues. Ce sont elles qu'on observe dans le Dictaminus et le Cuphea lanceolata (Martinet, loc. cit.).

Dictamnus albus. - Si l'on fait des coupes sur les pédoncules, les bractées, le calice, la corolle ou les étamines du Dictamnus, on y trouve trois sortes de poils:

1. Des poils ordinaires;

20 Des poils glanduleux à leur sommet;

$3^{\circ}$ Enfin des poils courts formés généralement de trois, quatre ou cinq cellules peu développées. Ces derniers organes reposent sur une glande volumineuse de forme à peu près sphérique, adhérente à l'épiderme par une large surface (Martinet). La glande est formée, comme le montre une coupe menée perpendiculairementà l'épider'me, pardeux sortes de tissus bien distincts : l'un, enveloppant, n'est qu'une légère modification de l'épiderme; l'autre, enveloppé ou glandulaire, se distingue par la délicatesse des parois de ses cellules; ces dernières se 
résorbent lentement et forment bientôt une lacune où s'accumule le produit de la sécrétion.

D'après M. Rauter le développement de ces glandes prend son point de départ dans une cellule du jeune épiderme; cette cellule se divise par des cloisons d'abord perpendiculaires, puis tangentielles, de manière à former deux assises cellulaires; l'assise externe prolonge simplement l'épiderme, tandis que l'interne, en continuant à se diviser, engendre tout le tissu de la glande. Par la suite du développement, le corps tout entier de la glande est en quelque sorte expulsé de l'organe et rejeté à sa surface.

Les glandes du Cuphea lanceolata présentent une disposition à peu près semblable, sauf que le poil est constitué par toutes les cellules qui recouvrent la partie supérieure de la glande, aussi est-il formé de plusieurs rangées de cellules.

$2^{\circ}$ Glandes intérieures. - Les glandes de cette sorte sont répandues dans un certain nombre de familles de plantes, parmi lesquelles nous citerons particulièrement les Aurantiacées, les Rutacées, les Hypéricinées, les Térébinthacées et les Myrtacées.

Leur mode de développement est partout le même (J. Chatin [1]); la glande, d'abord unicellulaire, ne tarde pas à acquérir un nombre variable de cellules, dont la résorption ultérieure déterminera la formation d'un réservoir où s'accumulera le produit de sécrétion.

Aurantiacées (2). - Sur une très jeune feuille de Citrus Aurantium (J. Chatin, loc. cit.), " mesurant כ̋ millimètres de lon" gueur, on constate qu'au point où se formera la glande, une "cellule du mésophylle prend un développement spécial : "d'abord sensiblement polyédrique (fig. 83, A, g), elle s'arron" dit peu à peu et revêt une forme assez régulièrement ovoïde; " en même temps la chlorophylle en disparaît. Peu après on " voit apparaître une cloison qui divise en deux utricules la " cellule primordiale de la glande; cette division se répète de "façon à constituer un ensemble de quatre cellules à parois

(1) Siège des substances actives dans les plantes médicinales. - Thèse pour l'agrégation de l'École de médecine. Paris, 1876.

(2) Baillon, De la famille des Aurantiacées. - Thèse de la Faculté de médecine. Paris, 1855. 
" minces, à contours sinueux (fig. $83, \mathrm{~B}, g$ ); " souvent dès cette époque on voit apparaître, dans l'intérieur des cellules glandulaires, de petites gouttelettes oléagineuses. La division se poursuivant, la glande acquiert successivement huit, seize, trente-deux, etc., cellules. Puis, lorsque la sécrétion est assez avancée dans la glande, les cellules du centre de l'organe se rompent, leurs parois disparaissent, et durant un certain temps la glande n'est plus composée que de quelques assises de cel-

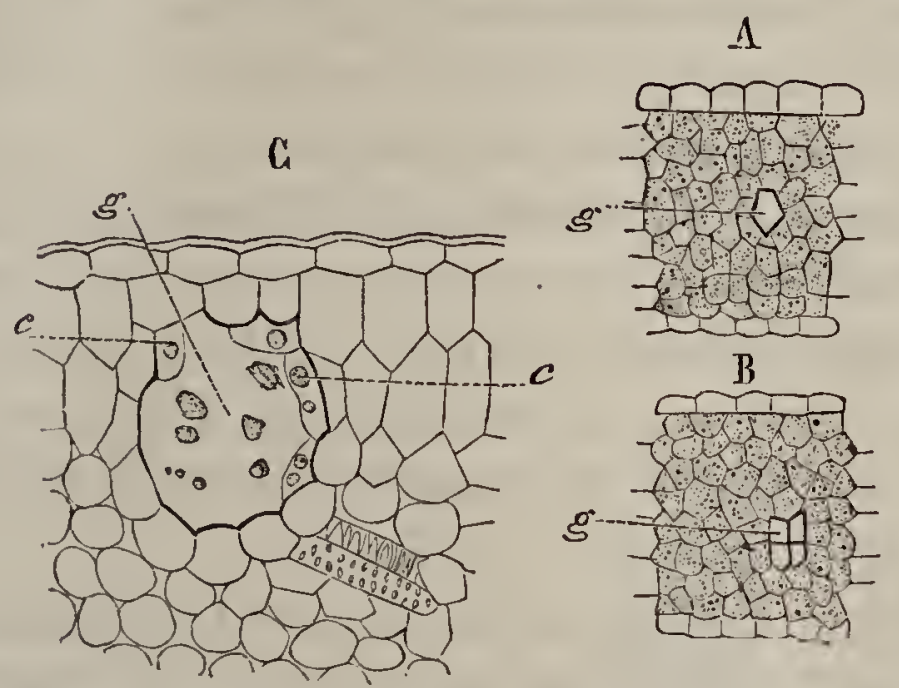

Fig. 83. - Coupes sur les feuilles du Citrus Aurantium. Développement des glandes, d'après M. J. Chatin.

lules périphériques riches en globules oléagineux (fig. 83, G), circonscrivant une cavité où se réunissent ces mêmes globules à mesure que la résorption des cellules gagne davantage vers l'extérieur. Finalement on ne trouve plus qu'une grande cavité, sorte de lacune au milieu du mésophylle, remplie du produit de sécrétion.

Pour observer ces glandes, il suffit de pratiquer des coupes fines sur les feuilles ou sur l'épicarpe des divers Citrus. Ces coupes devront être minces, et l'on tiendra compte, dans l'observation, des parties de la glande sur lesquelles aura porté la coupe. Si la coupe passe par le centre d'une glande bien développée, on n'apercevra qu'une large lacune remplie d'huile et bordée le plus souvent d'une seule assise de cellules sécrétantes; mais si la coupe passe par un plan presque tangentiel à la surface de la glande, on apercevra au milieu du mésophylle un parenchyme à cellules remplies de granulations et de globules huileux qu'il ne faudrait pas prendre pour une glande 
jeune, car cette apparence est due à ce que le plan de la coupe traverse l'assise des cellules périphériques de l'organe, laissant de côté la cavité même que l'on apercevrait sur une autre coupe. Dans ce même cas, la glande paraîtra assez profondément enfoncée dans le parenchyme de la feuille. Ce n'est là toutefois qu'une apparence due à la direction même de la coupe qui n'atteint qu'une portion de la périphérie de l'organe, car toutes les glandes des feuilles aussi bien que des fruits des Aurantiacées sont en contact avec l'épiderme. (Martinet, loc. cit.)

Ces glandes s'observent aux deux faces des feuilles des Citrus, mais elles sont plus abondantes à la face supérieure. Enfin, en faisant des coupes qui intéressent toute la largeur des jeunes feuilles, on pourra rencontrer ces glandes à divers états de développement, car elles n'apparaissent pas toutes à la même époque dans le mésophylle. Les glandes des bords de la feuille se développent en général avant celles du milieu. (J. Chatin.)

Les' glandes de l'épicarpe du fruit des Aurantiacées ont une structure et un mode de développement identiques.

Hypéricinées. - Ces glandes, très abondantes dans les feuilles des Millepertuis, offrent les mêmes caractères généraux que les précédentes. Elles ne présentent toutefois jamais un aussi grand nombre de cellules sécrétantes.

Rutacées. - Dans les Ruta et les Diosma on trouve des glandes pluricellulaires de même structure et d'un développement identique à celui des glandes des Aurantiacées. - Dans le Ruta angustifolia ces glandes existent dans les feuilles, les pétioles, les rameaux et les tiges. Contrairement toutefois à ce que l'on observe dans les Aurantiacées, ces glandes ne șont pas absolument en contact avec l'épiderme. Elles en sont à peu près constamment séparées par une assise de cellules chlorophylliennes.

Dans le Diosma alba, on rencontre également de ces glandes, mais elles n’atteignent généralement pas le degré de complication qui nous a été offert par les diverses plantes précédentes. - Le plus sourent en effet elles ne comprennent que huit cellules, el elles s'arrêtent même parfoìs à quatre cellules constitutives. 
Le Dictamnus Fraxinella présente des glandes pluricellulaires intérieures de même structure que les précédentes, mais qui méritent d'être signalées pour leur mode de développement. Elles prennent. en effet leur origine dans deux cellules, dont l'une appartient au jeune épiderme et l'autre à l'assise parenchymateuse sous-jacente (Rauter). La première forme de son côté deux assises de cellules, dont l'externe prolonge l'épiderme, tandis que l'interne contribue à la formation du tissu de la glande dont la masse principale est constituée par les divisions de la seconde des deux cellules mères primitives.

T'érébinthacées. - Les feuilles du Schinus molle par exemple (J. Chatin, loc. cit.) présentent deux sortes d'organes de sécrétion dans leur parenchyme. Ce sont, d'une part, des glandes tout à fait semblables à celles que nous avons décrites dans les Aurantiacées, et, d'autre part, des canaux oléifères, qui ne se distinguent des précédentes glandes que par les proportions dans lesquelles se fait la différenciation du parenchyme en tissu glandulaire. Si bien que, lorsqu'arrive la résorption des cellules, on obtient non pas une lacune courte, mais une lacune souvent très étendue au milieu du parenchyme.

Myrtacées. - Les glandes foliaires du Myrtus communis se développent principalement au voisinage des nervures comme

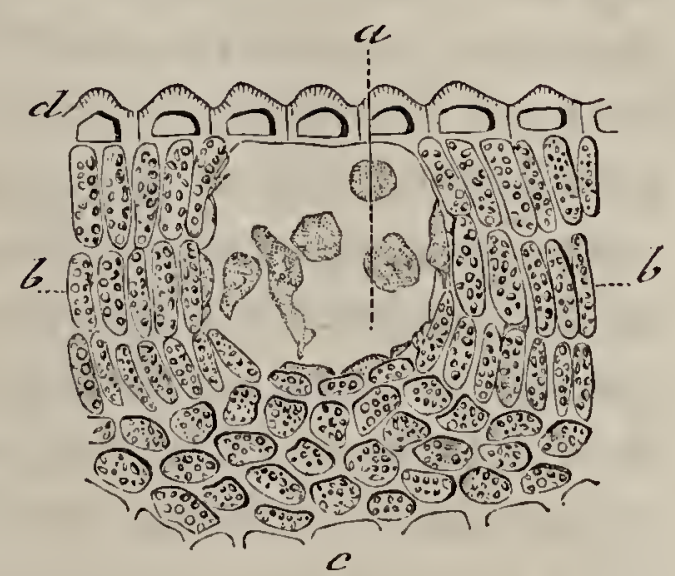

Fig. 84. - Feuille d'Eucalyptus globulus (coupe). - a. Glande. $b, b$. Trois rangées supcrposées de cellules en palissade. - $c$. Cellules du parenchyme inféricur. $-d$. Épiderme à cuticule épaisse. dans les Ruta; elles sont séparées généralement de l'épiderme par une assise de cellules chlorophylliennes. Pour le reste, structure et développement, elles ne diffèrent en rien des glandes précédemment décrites dans les Aurantiacées.

Les feuilles et les rameaux des divers Eucalyptus (fig. 84) présentent également de nombreuses glandes pluricellulaires intérieures, construites sur le type qui nous cccupe en ce moment. Ces glandes acquièrent souvent dans les rameaux 
un grand développement, et, soulevant l'épiderme, y déterminent des excroissances verruqueuses rougeatres (Eucalyptus Resdoni) que l'on pourrait à première vue confondre avec des lenticelles ou des productions analogues. Il nous paraît inutile d'insister davantage sur ces productions intéressantes.

$4^{\dot{a}}$ Groupe. - Le réservoir de la glande est ouvert à l'exterieur. Glandes florales. - Dans ce groupe rentrent les formations très diverses, connues généralement sous le nom de nectaires, c'est-à-dire les glandes florales. T'antôt le nectar sécrété se rassemble simplement dans le fond de la fleur (Nicotiana, Labiées), tantôt le nectaire affectant la forme d'une fossette (base des pétales des Ranunculus, Fritillaria imperialis, etc.), ou d'une coupe (Helleborus fotidus, Eranthis hyemalis, etc.), le produit de sécrétion se renferme dans la cavité de l'organe. D'autres fois encore, le tissu glanduleux occupe le fond d'une feuille florale développée en éperon (Aquilegia vulgaris, Violariées, etc.) et le suc nectarifère remplit peu à peu la cavité de l'éperon. Il nous est impossible d'insister davantage sur ces productions, qui relèvent le plus souvent de la botanique descriptive.

Glandes septales. - Nous croyons cependant devoir signaler encore certaines glandes, désignées sous le nom de glandes septales de l'ovaire, dont M. Brongniart (Ann. des Sc. ratur., $B o t .$, t. II, série IV) a fait une étude détaillée.

Ge sont des cavités sécrétantes bien définies, à parois formées par un tissu glanduleux propre, et possédant un conduit excréteur régulier. Ces organes se trouvent chez beaucoup de Monocotylédonées (Liliacées, Amaryllidées, Broméliacées, Cannées, Musacées, Iridées et Hæmodoracées), dans la cloison qui sépare les loges de l'ovaire; ils en occupent le milieu sur une étendue plus ou moins considérable; c'est une sorte de dédoublement qui partage la cloison en deux lamelles qui appartiennent à chacun des carpelles contigus. Le tissu qui tapisse cette cavité est plus dense que celui du reste de l'ovaire. Il est formé de cellules plus petites remplies d'une matière jaunâtre.

La cavité de ces glandes se prolonge, ver's l'extérieur, en un canal étroit qui aboutit à la surface de l'ovaire dans le fond du sillon qui indique presque toujours au dehors la ligne de 
jonction des carpelles. C'est donc au moyen de coupes longitudinales de la cloison des ovaires des plantes précitées, qu'on pourra bien étudier ces organes de sécrétion.

$\breve{\partial}^{\circ}$ Groupe. - Le réservoir est un espace interccllulaire dî̀ $\grave{a}$ l'écartement des cellules sécrétantes. - Dans ce cas les cellules de sécrétion ne disparaissent pas, et se retrouvent toujours autour du canal ou méat qu'elles limitent. Dans ce groupe rentrent les canaux sécréteurs dont nous avons parlé longuement plus haut (voir p. 153).

\section{\$14. HYPODERME.}

On réunit généralement, sous le nom d'hypoderme, des formations de nature très diverse qui n'ont d'autre caractère commun que de se trouver tout à fait à la périphérie du tissu fondamental de l'écorce, immédiatement au-dessous de l'épiderme. Les éléments qui forment l'hypoderme se réduisent quelquefois à une seule assise de cellules, ou au contraire forment une couche souvent très épaisse de plusieurs assises superposées. Leur origine semblerait devoir les faire classer parmi les éléments du tissu fondamental plutôt que parmi ceux du tissu tégumentaire. L'hypoderme, en effet, résulte de différenciations qui s'opèrent plus ou moins tardivement dans les cellules périphériques de la zone du parenchyme cortical.

Quoi qu'il en soit, ainsi que nous venons de le dire, l'hypoderme revêt des formes très variées parmi lesquelles on en peut distinguer trois principales:

a. Hypodermes à éléments prosenchymateux et à éléments scléreux;

b. Collenchyme;

c. Hypoderme parenchymateux.

a. On rencontre de nombreux exemples du premier groupe dans les différents organes des plantes, racines, tiges, feuilles, graines.

Les racines de Salsepareille, par exemple, présentent à leur périphérie deux ou plusieurs assises de cellules qui constituent sous le nom d'epiblema un hypoderme sclérenchymateux : sur 
des coupes transversales de ces racines (fig. 8丂, $h$ ), on aperçoit à la phériphérie du tissu fondamental cortical, de grosses cellules à parois très épaisses, dures, et dont la cavité très
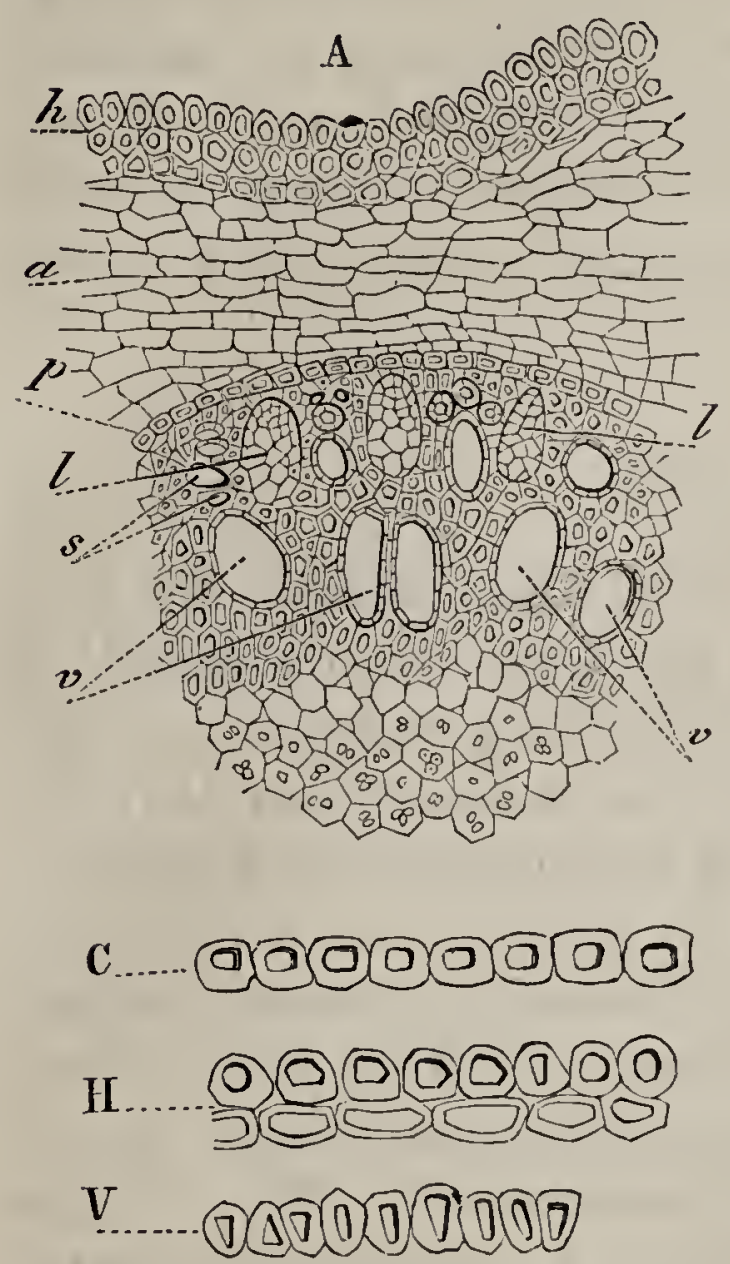

Fig. 85. - A. Coupe transiersale sur la racine de la Salsepareille caraque. h. Hypoderme. réduite paraît le plus souvent excentrique, par suite de l'épaississement plus considérable de l'une des parois de ces cellules; ce sont les éléments de l'hypoderme de ces racines.

A la périphérie des rhizomes des Fougères (Pteris aquilina, fig. 98, S), on aperçoit également un hypoderme, caractérisé par des cellules à parois durcies et généralement colorées en brun.

Les tiges des Prêles, les feuilles aciculaires de beaucoup de Conifères, en particulier du Pinus Pinaster, présentent au-dessous de l'épiderme une assise de longues fibres épaisses, qui souvent même se groupent en faisceaux, principalement le long des arêtes des feuilles en question.

Enfin beaucoup de graines présentent dans leurs enveloppes des couches d'éléments durs, sclérenchymateux, généralement allongés perpendiculairement à l'épiderme, et qui contribuent pour la plus grande part à donner à ces enveloppes leur consistance cornée ou crustacée. Les graines des Papilionacées, celles des Thymélées (Daphne Laureola, etc.) présentent ainsi au-dessous de l'épiderme de leurs téguments une assise de prismes durs, pressés les uns contre les autres.

b. On a donné le nom de collenchyme à une variété de tissu placé au-dessous de l'épiderme, à la périphérie du parenchyme cortical et qui consiste en cellules prismatiques allongées, dont l'épaississement des parois se localise aux 
arêtes, là où plusieurs cellules viennent à se toucher (fig. 86). Ce tissu revêt sur les coupes transversales un aspect très particulier, comparable un peu à un damier, dans lequel des losanges brillants et réfringents $(v)$ alternent à peu près régulièrement avec des espaces plus sombres $(d)$. Les losanges représentent la coupe des épaississements, les espaces sombres les cavités des cellules.

Le collenchyme se rencontre très fréquemment dans les tiges des Dicotylédones. Il est très développé dans les pétioles des feuilles des Begonia, dans les tiges de l'Acanthus spinosus, du Rhus coriaria, etc.

c. Enfin, plus rarement, l'hypoderme est un tissu aqueux, plein de sève et à

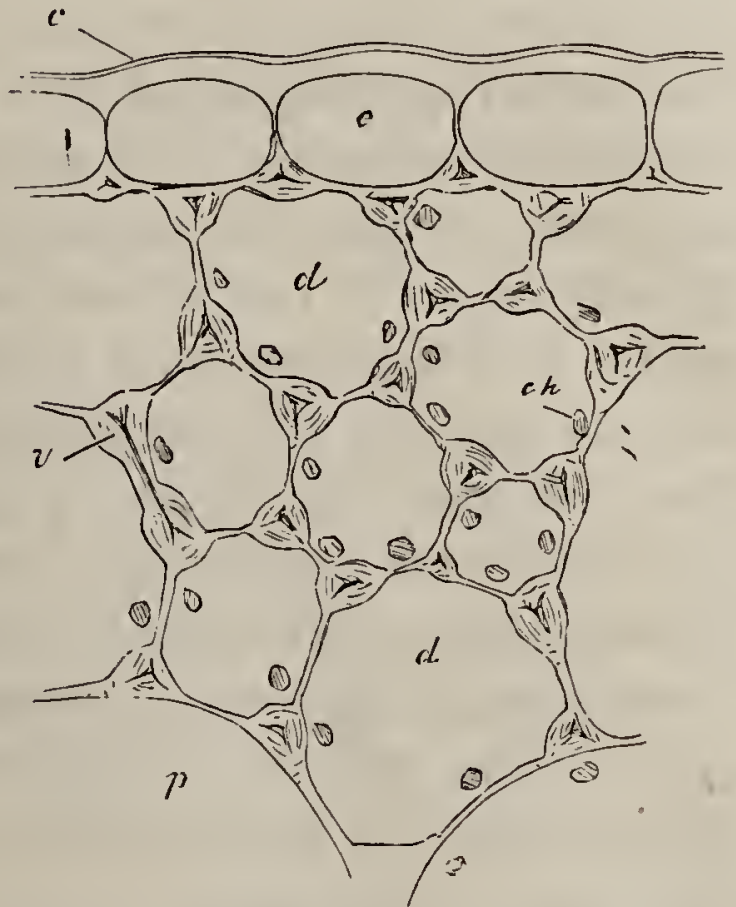

Fig. 86. - Collenchyme, d'apres Sachs. $e$. Cellules de l'épiderme. -- $c$. Cuticule. d. Cavilés des cellules du collenchyme. - v. Épaississcments. - ch. Grains de chlorophylle. parois minces. Les feuilles des Tradescantia, celles des Broméliacées en offrent des exemples.

\section{§ 15. LIÈGE. - PÉRIDERME.}

Le LIÈGE ou suber est une formation tégumentaire destinée à remplacer l'épiderme détruit accidentellement ou par suite du développement en épaisseur des organes qu'il recouvre.

C'est un lissu dense, formé de cellules dont les caractères sont parfaitement définis et qui, pressées les unes contre les autres, ne laissent entre elles aucun méat. De forme tabulaire, à parois ordinairement peu épaisses, mais comme cuticularisées, ceś cellules sont remplies d'air et dépourvues de tout contenu solide ou liquide. Le tissu qu'elles forment est donc essentiellement un tissu de protection; les modifications chimiques que subissent leurs parois leur permettent en effet de résister aux réactifs et par suite aux agents ex- 
térieurs, absolument comme les couches cuticularisées de l'épiderme.

Le suber s'observe rarement chez les Monocotylédonées et dans les tiges herbacées annuelles des Dicotylédonées. Il se développe principalement à la surface des tiges des Dicotylédonées qui acquièrent un grand développement en épaissẹr. Il constitue alors le plus souvent, sous le nom de périderme, une zone composée d'un nombre variable d'assises cellulaires qui enveloppe la tige d'une façon continue. Ailleurs, il prend un tel développement en épaisseur qu'il forme de véritables masses de liège qui augmentent chaque année en épaisseur. C'est ce que l'on observe particulièrement dans les Quercus suber, Quercus occidentalis, Aristolochia biloba, A. cymbifera, Ulmus suberosa, Evonymus europaca, etc.

Développement du périclerme (suber). - Il résulte des recherches de MM. Mohl, Hanstein, Sanio, etc. (1), que le développement du périderme ne se fait pas de la même manière dans tous les végétaux.

ćtude. A. - Dans les cas les plus rares, les cellules épidermiques elles-mêmes deviennent le point de départ de la formation du périderme. Nous reproduisons (fig. 87), d'après M. Sanio, des coupes sur le Sorbus aucuparia qui montrent clairement ce mode de développement. En A on voit que les qua. tre cellules épidermiques que comprend la figure ont subi une bipartition tangentielle qui les a divisées en deux assises. A gauche, sur la même figure, deux des cellules de l'assise inférieure sont déjà subdivisées par des cloisons tangentielles en quatre autres cellules $a, a$ et $b, b$. Les cellules $a, a$, restant susceptibles de se diviser, vont dorénavant former la couche génératrice du périderme qui se produira plus tard. Cette couche de méristème a reçu le nom de phellogène. Quant aux cellules $b, b$, elles constituent un tissu particulier qui vient s'ajouter aux éléments du parenchyme cortical sous-jacent. Elles peuvent renfermer de la chlorophylle comme ce dernier tissu dont

(1) Mohl, Untersuch. üb. d. Entwick. des Korkes. Diss. 1838.

Hanstein, Unters. üb. d. Bau und Entw. d. Buumrinde. Berlin, 1853.

Sanio, Vergl. Unters. üb. d. Bau u. d. Entw. des Korkes. Pringsheim. Iahr., II, 39. 
elles ne diffèrent que par leur origine. Ce nouveau tissu reçoit le nom de phelloderme. On peut l'observer dans un grand nombre de cas et particulièrement dans les branches de deux ou trois ans des Salix purpurea et alba, dans celles du Fagus sylvatica, etc.

Revenons à notre figure 87. Le phellogène ainsi produit aux dépens des cellules épidermiques va par des divisions successives engendrer au dehors de nouvelles couches de suber.

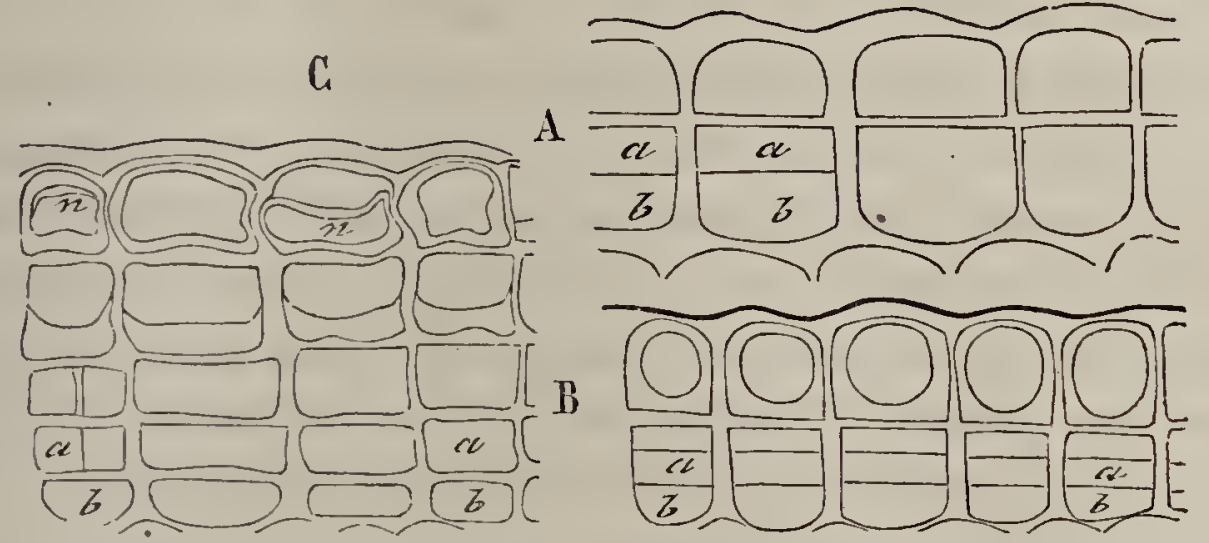

lig. 87. - Coupes transversales sur une branche de Sorbus aucuparia, d'après Sanio. Développement du périderme. (Voir l'explication dans le texte.)

Ce développement centripète du périderme se voit en $\mathrm{B}$ qui représente un état plus avancé du développement dans la même tige de Sorbus aucuparia. On y peut voir maintenant au-dessus de l'assise $a, a$ (phellogène) deux assises de cellules de liège dont les supérieures ont épaissi notablement leurs parois. - La figure G prise sur une coupe d'un rameau plus âgé montre trois assisées de cellules au périderme. Les parois des cellules des deux assises les plus extérieures sont épaissies. En $n, n$ la couche profonde de la paroi des cellules s'est séparée des enveloppes extérieures subérifiées. On peut voir également à gauche de cette figure des cloisons radiales qui se forment dans les cellules du périderme et du phellogène ; cloisons qui déterminent l'accroissement en nombre des cellules d'une même assise.

On trouvera des exemples du même mode de formation du liège aux dépens des cellules épidermiques, dans les Nerium oleander, Viburnum lantana, lantanoïdes, dans la plupart des Pomacées, le Solanum dulcamara, les diverses espèces de $S a-$ 
lix, l'Euphorbia antiquorum, le Daphne laureola, le Melastoma cymosum, etc.

B. Le mode de développement que nous venons d'exposer n'est pas, nous l'avons dit, le plus fréquent. Ordinairement en effet l'épiderme reste ètranger à la formation du périderme. L'une des assises du parenchyme sous-jacent à l'épiderme joue alors le rôle de phellogène. Tantôt c'est l'assise immédiatement au contact avec l'épiderme qui se subdivise pour former l'épiderme, tantôt c'est une assise plus ou moins profondément située dans la masse même de ce parenchyme.

Quoi qu'il en soit, le liège se forme presque toujours de dehors en dedans, c'est-à-dire que c'est à la face interne de la couche de suber déjà formée que le phellogène en produit sans cesse de nouvelles. Il y a d'ailleurs sous ce rapport des variations assez nombreuses dans le détail desquelles il ne nous est pas possible d'entrer ici. (Voir Duchartre, $2^{\circ}$ édition, p. 220, pour le résumé des recherches de M. Sanio.)

\section{§ 16. RHYTIDOME ET ÉCORCE CREVASSÉE. LENTICELLES.}

On a donné le nom de rhytidome à des masses de tissu qui se trouvent séparées des autres tissus de la tige au moyen de lamelles de liège qu'engendrent des assises de phellogène développées très profondément dans l'épaisseur de l'écorce de beaucoup de Dicotylédones et de Conifères. Ces couches de tissu, privées par cet isolement de leurs moyens de nutrition, se dessèchent bientôt, meurent et finalement se détachent de l'arbre. Le rhytidome ne pouvant suivre l'accroissement en épaisseur des tiges sur lesquelles il s'est développé, se fendille et il en résulte des crevasses (écorce crevassée) tantôt longitudinales (Quercus robur), tantôt circulaires (Prunus cerasus).

Le Platane (Platanus occidertalis) offre le type de la formation que nous venons de signaler. Chaque année le rhytidome s'en détache sous forme de larges plaques.

Pour terminer ce qui a trait aux formations subéreuses, signalons enfin les lenticelles. Ce sont de petites proéminences éparses à la surface des tiges. Arrondies sur les parties jeunes, 
elles prennent plus tard la forme de petites lignes plus ou moins allongées transversalement à la surface de l'écorce. D'après M. Stahl (1) les lenticelles peuvent se former de deux manières différentes.

A. Tantôt leur développement est intimement lié à l'existence des stomates. Et alors à chaque stomate peut correspondre une lenticelle (Sureau, Cerisier, Lilas, Troëne, etc.); ou encore les stomates se disposent par groupes qui deviennent chacun le point de départ d'une de ces formations. D'après M. d'Arbaumont (2), dans le Cissus quinquefolia, chaque groupe de stomates se compose d'un gros stomate placé au centre, entouré d'organes de même nature plus petits et développés plus tardivement. Une troisième série de stomates, qui se forment plus tard, s'arrêtent dans leur développement et ne déterminent jamais la formation de lenticelles.

Quoi qu'il en soit, sous ces stomates isolés ou groupés (par כ dans le Noyer, 9 dans le Peuplier, jusqu'à 30 dans l'Hedera Regnoriana;, on voit les cellules du parenchyme qui circonscrit la chambre sous-stomatique se modifier, perdre leur chlorophylle et combler bientôt cet espace intercellulaire (cellules comblantes). Toutefois chez le Cissus quinquefolia cette chambre stomatique ne serait jamais obstruée. (D'Arbaumont, loc. cit.) - Bientôt apparaît tout autour du tissu ainsi différencié une assise de méristème qui continuera d'engendrer des cellules qui participeront à l'accroissement de la lenticelle.

B. Dans les plantes où se forme tôt ou tard un rhytidome les choses se passent autrement. Là, en effet, les stomates disparaissant rapidement, il ne peut y avoir de relation entre ces organes et les lenticelles. Celles - ci apparaissent à la surface du périderme de formation subséquente et émanent alor's du phellogène (Berberis, Conifères, etc.).

(1) Enwwicklungsgesch. und Anatomie der Lenticellen, Bot.Zeitung, 187:, $n^{\circ}$ s $36,3 i, 38$ et 39 .

(2) D'Arbaumont, Bull. Soc. bot., t. XXIV. 
AnT. 4.

\section{Faisceaux.}

Sous le nom de faisceaux on désigne des assemblages d'éléments variés qui affectent la forme de cordons plus ou moins épais et qui concourent dans une large mesure à la structure des plantes, tiges, racines, feuilles, etc.

Étude. - On étudiera la structure des faisceaux au moyen de coupes transversales et longitudinales pratiquées sur les organes qui les renferment. Dans l'examen d'un faisceau on n'oubliera point que sa structure varie dans les différents. points de son étendue et aux diverses époques de son développement.

Également, au moyen des coupes faites à des niveaux distincts, on suivra la marche des faisceaux et leur répartition. Si l'on veut avoir des préparations d'ensemble qui montrent cette disposition, on pourra procéder à l'isolement des faisceaux des tissus qui les enveloppent de manière à réduire l'organe (tige, feuille, etc.) au squelette que lui forment ces faisceaux. Cet isolement s'opère par désagrégation et destruclion des tissus de voisinage. Pour cela à l'exemple de Hartig on peut faire cuire dans l'eau, pendant 48 ou 60 heures, la partie du végétal à préparer, on voit alors tout le parenchyme non lignifié disparaître et ne plus laisser que le squelette formé par les faisceaux. Ce procédé convient à tous les végétaux herbacés qui présentent des faisceaux lignifiés. On peut encore par la macération dans l'eau et la putréfaction ou par la putréfaclion lente et sèche, principalement chez les Fougères arborescentes, les Dracæna, Yucca, etc., obtenir de très beaux squelęttes.

Structure des faiscenux développés. - Tout faisceau développé et complet est formé de deux parties fondamentales, savoir :

$1^{\circ}$ Le liber (phloème de Nrgeli; partie cribreuse (Siebtheil) de de Bary).

$2^{\circ}$ Le bois (xylème de Nageli; partie vasculaire (Gefasstheil) de de Bary). 
Nous reviendrons plus tard sur le cambium, que nous ne considérons pas à dessein comme partie constitutive essentielle du faisceau, puisqu'il disparaît dans les faisceaux développés de beaucoup de plantes dicotylédonées et de toutes les Monocotylédonées.

Deux choses sont à considérer dans l'étude des faisceaux : d'une part, la nature et la forme des éléments qui entrent dans leur composition; d'autre part, la répartition de ces éléments et leurs rapports réciproques.

§ 17. Fonme ET RÉPartition des ÉLEMENTS CONSTitutifs des Faisceaux.

\section{A. ÉLÉMENTS DU LIBER DES FAISCEAUX.}

On trouve dans le liber trois sortes d'éléments qui sont par ordre d'importance : les tubes cribreux et les cellules grillagées, les cellules cambiformes et les fibres libériennes.

Nous avons décrit plus haut les premiers et les derniers de ces éléments; quant aux cellules cambiformes, ce sont des éléments séreux à parois minces, de forme prismatique, qui ont été signalés pour la première fois par Nægeli. Dans beaucoup de cas (Crassulacées, Cactées, Euphorbiacées succulentes, etc.) où les tubes cribreux sont peu développés et à parois minces, il devient assez difficile de distinguer entre elles ces deux formations.

Les trois espèces d'éléments que nous vẹons d'énumérer n'existent pas toujours réunies dans le liber des faisceaux. De nombreuses variations se présentent à cet égard. Ainsi par exemple, dans les faisceaux très grêles des extrémités de l'axe ou encore dans ceux des dernières nervures des feuilles, les cellules cambiformes paraissent former à elles seules la partie libérienne. Ailleurs, et les exemples en sont nombreux, le liber est uniquement formé de tubes cribreux et de cellules cambiformes. Il reçoit alors le nom de liber mou, par opposition au nom de liber dur, que l'on donne à cette partie du faisceau lorsqu'il s'y développe des fibres épaisses.

Nous reproduisons (fig. 88) un exemple de faisceau à liber mou, pris dans la tige du Cucurbita maxima. Sur cette coupe, 
on voit en $g$, en dehors des vaisseaux ponctués $v$, la section transversale de tubes cribreux au niveau de leurs cloisons transverses. Ces tubes sont entourés de cellules cambiformes à parois minces.

Une semblable association de tubes cribreux et de cellules cambiformes se retrouve chez beaucoup de Monocotylédonées

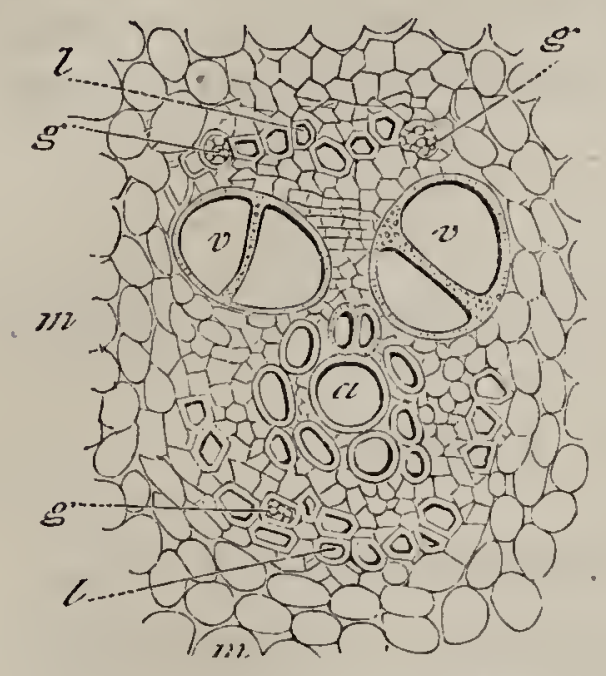

Fig. 88. - Coupe transversale d'un faisceau de Cucurbita maxima. $l$, l. Liber mou. - g. Tubes cribreux. - v. Vaisseaux ponctués. - $a$. Vaisseaux annelés. $m$. Moelle. (Graminées, par ex.), chez les Equisetum (fig. 98 S), ainsi que dans beaucoup de Dicotylédonées, Renonculacées, Ombellifères (Fœniculum, par ex.), Vitis, Aristolochia, etc.

Dans ces exemples, sur les coupes transversales, on aperçoit les éléments cribreux à grand diamètre à section polygonale, accompagnés des cellules cambiformes à section rectangulaire ou carrée. L'arrangement de ces deux espèces d'éléments est tel, que chaque tube cribreux s'accole par une de ses faces à un tube de même nature, par une autre face à une cellule cambiforme, et ainsi de suite alternativement.

Ailleurs, dans le pétiole de l'Olea Europaa, par exemple, dans la tige des Lobelia, des Crassulacées, Cactées, etc., les cellules cambiformes constiluent des groupes plus ou moins volumineux, intercalés dans les tubes cribreux.

Quant aux fibres libériennes, tantôt elles se déreloppent en grand nombre et forment presque à elles seules la partie libériennne du faisceau (tige d'Helianthus annuus, de Tilia, de Dattier, fig. 89', tantôt, au contraire, elles n'apparaissent qu'en petit nombre. Lorsqu'elles sont très développées, elles se disposent généralement dans la partie libérienne du faisceau, sous forme de masses prosenchymaleuses qui présententsur les coupes transversales l'aspect d'ares à concavité tournée vers le bois. Si, au contraire, les fibres libériennes sont mélangées en nombre restreint aux tubes cribreux et aux cellules cambiformes, comme c'est le cas dans un grand nombre de fais. 
ceaux, on rencontre dans l'arrangement réciproque de ces divers éléments de nombreuses variations.

Dansle Tilleul, le Noyer, la Vigne, par' exemple, on trouve une

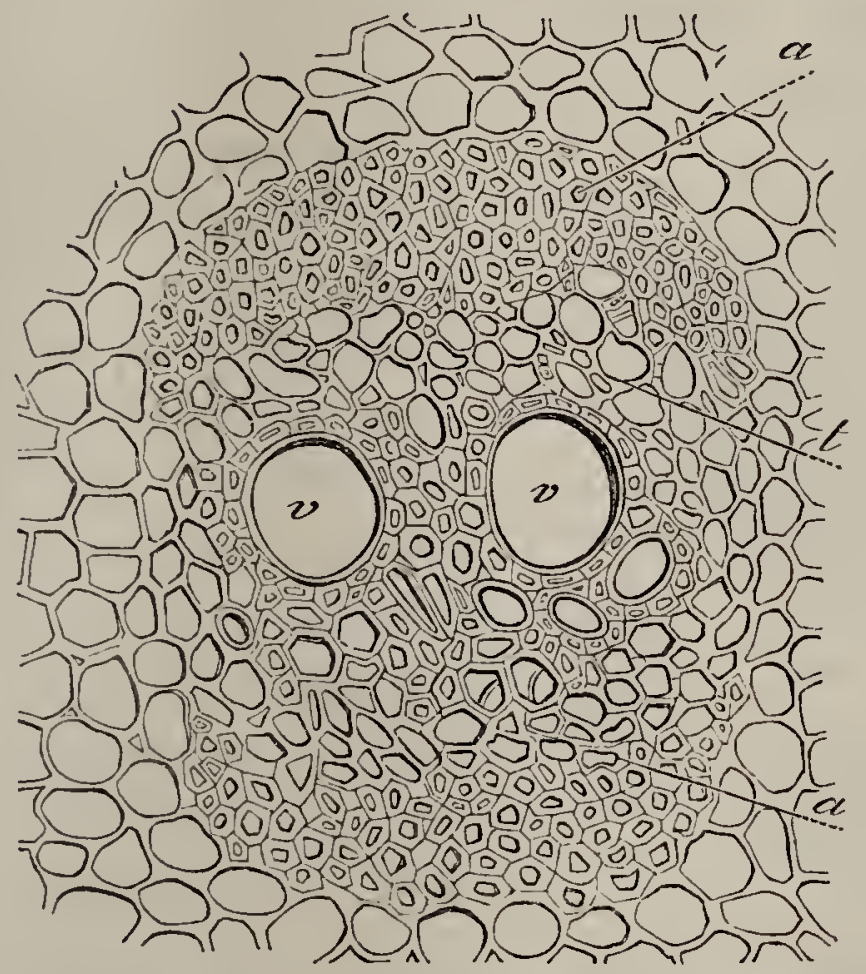

Fig. 89. - Faisceau fermé de la tige du Dattier (Coupe transversale). a. Fibres libériennes.

alternance assez régulière d'assises de liber mou avec des couches de fibres libériennes. Dans le Sureau, le liber mou et les fibres libériennes sont disposés par faisceaux qui alternent entre eux. Dans le Poirier, les cellules criblées et grillagées constituent la plus grande partie de la formation annuelle, et même, dans le Bouleau et le Hêtre, il ne se produit de fibres libériennes dures que dans le cours de la première année; les productions postérieures consistent en un mélange de

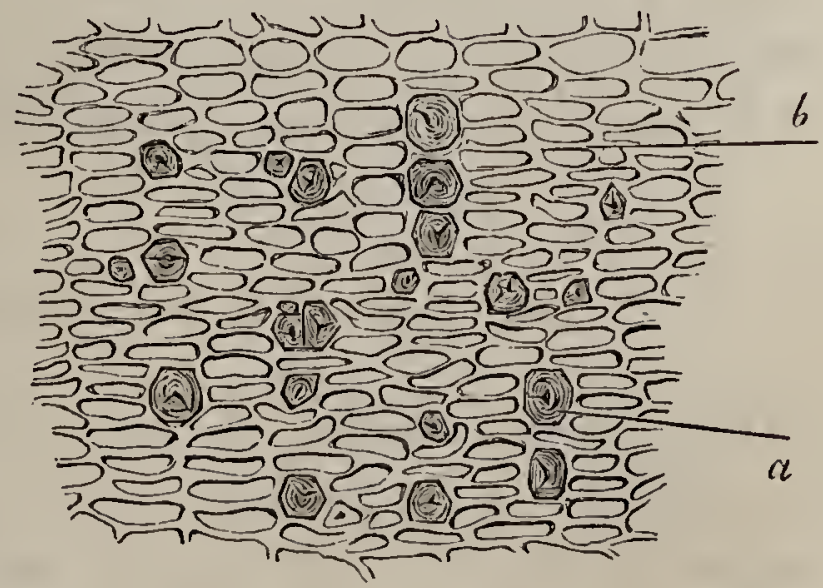

Fig. 90. - Coupe transversale de l'écorce du Quinquina Loxa. - a. Fibres libériennes. $b$. Parenchyme interposé. tubes cribreux et de cellules parenchymateuses plus ou moins allongées (Duchartre). Le mode de répartition des fibres libériennes et l'épaisseur plus GUIDE DE MICHOGHAPHIE. 
ou moins grande de leurs parois, servent dans les écorces de Quinquina à caractériser les bonnes et les mauvaises espèces.

Dans les écorces de Galisaya, qui peuvent être prises comme type des bonnes espèces (Q. Loxa, Q. Huanuco, etc.) (fig. 90), les fibres libériennes fines, courtes, peu adhérentes entre elles,

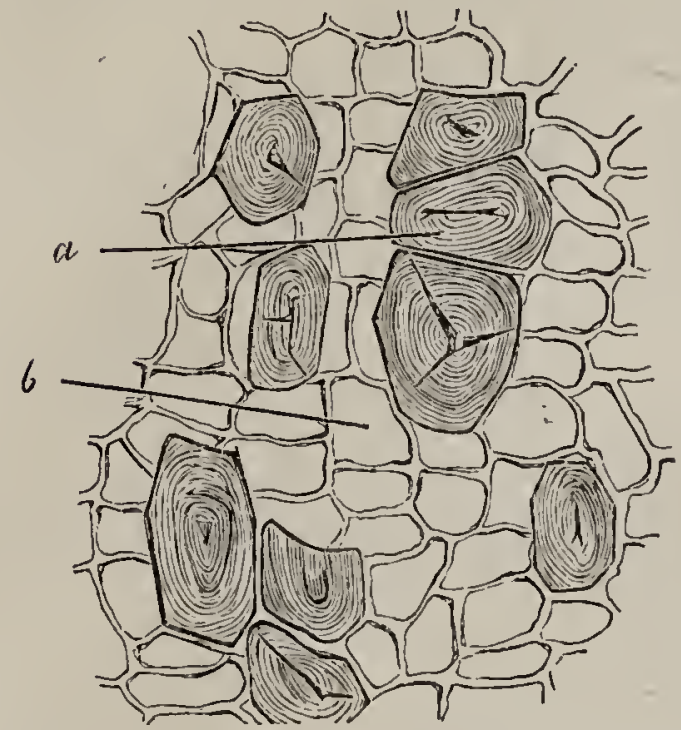

Fig. 91. - Coupe transversale sur l'écorce du Quinquina Maracaïbo. $a$. Groupe de grosses fibres libériennes. - $b$. Parenchyme. isolées pour la plupart au milieu d'un tissu parenchymateux abondant, forment des rangées radiales plus ou moins régulières. Dans le type opposé, celui des écorces de Cinchona pubescens qui caractérise les espèces inférieures (Q. Maracaïbo, Q. Huamalies, etc.) (fig. 91), les fibres présentent généralement un grand développement en épaisseur. Elles sont réunies par groupes de trois ou quatre et fortement adhérentes les unes aux autres. Un tissu parenchymateux abondant sépare ces groupes de fibres (Planchon, loc. cit.).

Dans les faisceaux primaires des Conifères et spécialement dans ceux des feuilles de ces plantes, ainsi que dans les faisceaux des feuilles de Welwits hia, le liber se fait remarquer par des éléments à parois molles et très épaisses, mélangés à de grandes cellules parenchymateuses.

\section{B. Éléments DU BoIS DES Faisceaux.}

Ges éléments sont de trois sortes qui correspondent aux trois espèces d'éléments du liber. Ce sont : les vaisseaux (et.essentiellement les trachées), les cellules ligneuses et les fibres ligneuses, que l'on peut respectivement opposer aux tubes cribreux, aux cellules cambiformes et aux fibres libériennes.

vaisseaux. - Les plus importants de ces éléments sont les trachées et les vaisseaux annelés; ce sont eux, en effet, qui forment le bois primaire; on les retroure dans tous les faisceaux, 
alors même que tout le reste du bois du faisceau est dépourvu de vaisseaux d'une autre forme (Conifères et Cycadées).

Outre les trachées, on peut rencontrer dans le bois des faisceaux toutes les autres formes vasculaires déjà décrites. Ces éléments affectent alors généralement un certain ordre dans les tiges. Les trachées occupent la face interne des faisceaux, et les gros vaisseaux réticulés et ponctués sont à l'extérieur. (fig. 92). Quoi qu'il en soit, les trachées se font remarquer par leur longueur et leur petit diamètre. Pour en bien déterminer l'existence et la situation, il faut faire des coupes longitudinales et transversales sur les faisceaux. Quant aux vaisseaux annelés, réticulés, rayés, ponctués, nous renvoyons pour leur étude à la page 133. Mentionnons encore la particularité que présente le bois des

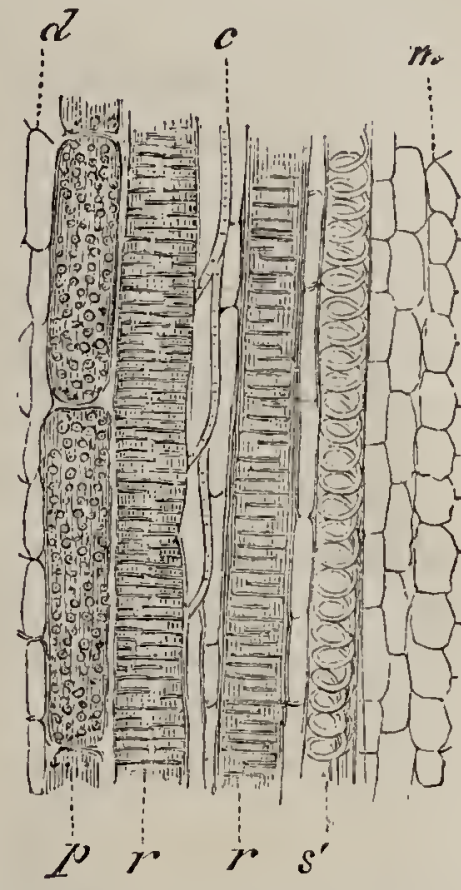

Fig. 92. - Coupe longitudinale d'un faisceau de Malva Mauritiana. - m. Moelle. $-d$. Cellules ligneuses. c. Fibres ligneuses. $p$. Vaissseaux ponctués. $r$. Vaisseaux rayés. $s$. Trachées. Gryptogames vasculaires, dans lequel, abstraction faite des trachées du bois primaire, on ne trouve généralement que des vaisseaux d'une seule forme désignés sous le nom de vaisseaux scalariformes (voir fig. 43).

Fibres ligneuses. - Dans la partie vasculaire des faisceaux, on trouve très fréquemment, à côté des vaisseaux, des éléments prosenchymateux à parois généralement épaisses, dures et lignifiées à cavité plus ou moins large suivant l'épaisseur de la paroi. Ces fibres

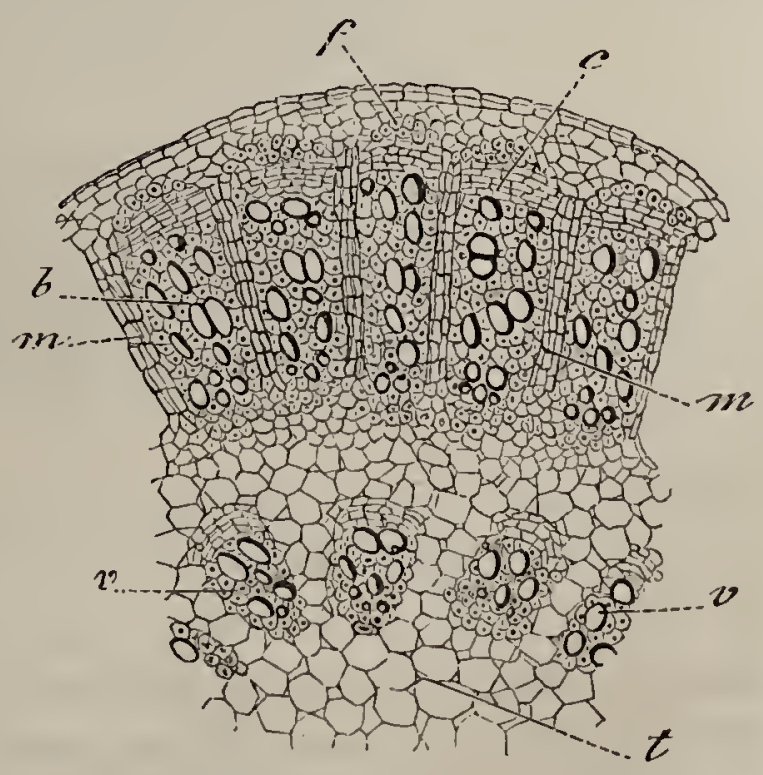
très-nombreuses dans les bois durs se répartissent de façons 
diverses autour des vais seaux. Tantôt elles forment des masses très compactes interrompues de place en place par les vaisseaux qui sur les coupes transversales se distinguent par leurs sections larges et leurs parois plus minces (fig. 93, coupe de la tige du Piper medium). Tantôt (Chênes, Figuiers, etc.) ces fibres forment des groupes répartis sans ordre appréciable et non mêlés aux vaisseaux, qui dans ces mêmes bois sont accompagnés de fibres à parois notablement plus minces.

Bois des Conifères. - Le bois des faisceaux chez les Conifères mérite une mention spéciale. En effet, à part les vaisseaux annelés et les trachées du bois primaire (étui médullaire), on ne trouve plus dans ces faisceaux aucun élément vasculaire proprement dit. Les

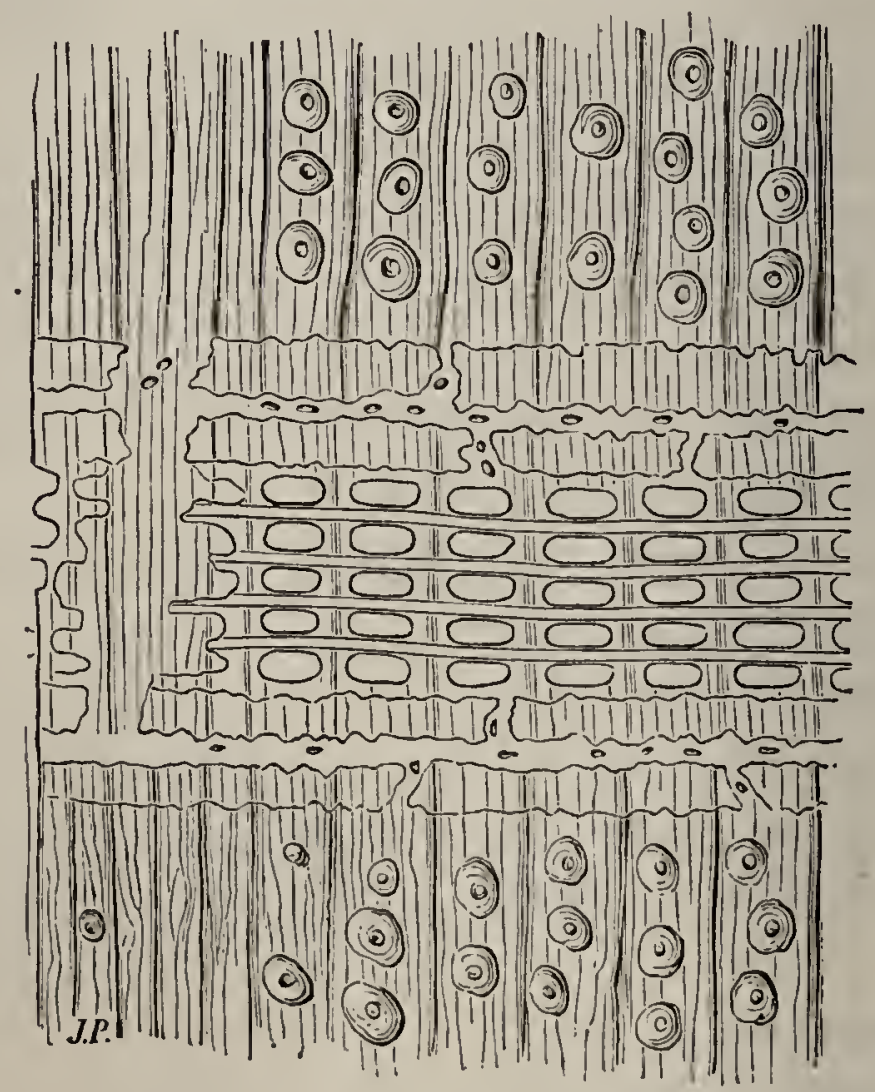

Fig. 94. - Fibres aréolées ponctuées coupées en long (Conifères). Ln rạon médullaire est compris dans la section.

coupes longitudinales et transversales ne montrent plus (fig. 94) que des fibres d'une nature particulière, pressées les unes contre les autres, et remarquables par leurs larges ponctuations aréolées, dont nous avons expliqué ailleurs le mode de formation. Ces fibres, dures bien que flexibles, présentent ordinairement une assez large cavité et des parois relativement peu épaisses. Très fréquemment, des communications directes s'établissent entre leurs cavités par l'intermédiaire des ponctuations. 
Ces fibres caractéristiques du bois des Conifères se retrouvent avec quelques modifications dans le bois des faisceaux des Cycadées (Zamia, Brongniart). Ici encore, les trachées et les vaisseaux annelés constituent les sculs éléments incontestablement vasculaires. Tout le reste du bois est formé de fibres aréolées ponctuées, dont les marques sont généralement étendues transversalement et se répartissent de manière à donner à la fibre un aspect plus ou moins comparable à celui qui distingue les vaisseaux scalariformes (rayés-aréolés). Aussi ces fibres, ainsi d'aillcurs que celles des Conifëres, sont-elles souvent considérées comme des formes vasculaires spéciales.

Cellules ligneuses. - Aux éléments vasculaires et prosenchymateux du bois, viennent s'ajouter fréquemment des cellules à parois minces, à ponctuations simples ou aréolées, quelquefois lignifiées et qui se mêlent.en proportions diverses aux autres éléments.

Ces cellules, qui forment le parenchyme ligneux, peuvent renfermer en hiver de l'amidon; souvent aussi elles contiennent de la chlorophylle, du tannin ou des cristaux d'oxalate de chaux. Leur répartition dans le bois des faisceaux est variable. Dans le Hêtre et le Ghêne, par exemple, elles forment des assises simples entourant chaque vaisseau comme d'une gaîne propre (Vigne); dans les Tilleuls, elles forment des bandes plus ou moins irrégulières qui se portent transversalement d'un bord à l'autre du faisceau.

Issues du cambium par division transversale de ses cellules avant leur épaississement, elles peuvent parfois se développer en quantité considérable et former un tissu très dense dans lequel ne se trouvent que de rares vaisseaux. Les racines charnues du Radis, de la Carotte, du Dahlia, les tubercules de la Pomme de terre, offrent de bons exemples de cette richesse du bois en tissu parenchymateux. La moelle apparente de ces organes répond en effet, en réalité, par son origine au corps ligneux d'un arbre dicotylédoné, seulement les éléments du bois, à l'exception de quelques vaisseaux, n'y sont pas lignifiés.

$\$$ 18. RAPPORTS DE POSITION ENTRE LES DIFFÉRENTES PARTIES DES FAISCEAUX.

Dans le précédent chapitre, nous avons déjà dit quelques mots de la position relative des divers éléments dans le fais- 
ceau. Cette question nous paraît avoir assez d'importance pour mériter quelques développements.

Si l'on envisage la position réciproque des parties cribreuse (liber) et vasculaire (bois) dans les faisceaux, on peut reconnaître trois manières d'être distinctes; Russow (de Bary, loc. cit.) distingue alors les faisceaux en collatéraux, concentriques et radiaires ou rayonnants.

A. Faisceaux collatéraux (Collaterale Bündel). - Ces faisceaux se composent, dans la majeure partie des cas, d'une portion libérienne (cribreuse) et d'une portion ligneuse (vasculaire), qui se touchent par une de leurs faces, le reste de leur surface confinant aux divers tissus du voisinage. Cette forme est caractéristique des faisceaux des tiges et des feuilles de la plupart des Phanérogames; on la rencontre également dans Jes tiges des Equisetum, des Ophioglossées, de l'Osmunda, etc.

Dans les cas normaux, la partie libérienne et la partie ligneuse de chaque faisceau sont alors orientées de telle sorte, que la dernière est tournée vers le milieu et la première vers la périphérie de l'organe qu'il parcourt (voir fig. 950). Les éléments de chacune des parties du

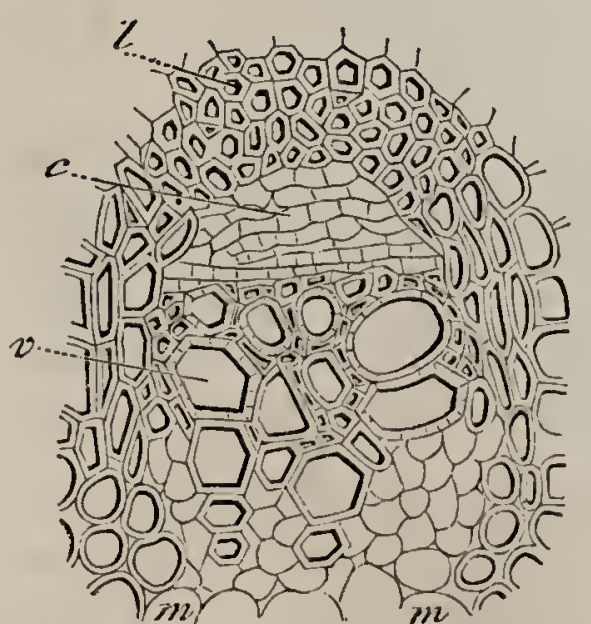

Fig. 95. - Coupe transversale d'un faisecau extérieur d'une tige d'Aralia racemosa. - $l$. Fibres libériennes. - $c$. Quelques rangées de Cambium persistent, au voisinage du bois. - $v$. Vaisseaux. - m. Hoelle.

proéminant le plus souvent à la face interne du faisceau, se reconnaissent par suite aisément sur les coupes transversales. 
Sous le nom de bicollatérale le même auteur (de Bary, loc. cit.) désigne une variété de la forme collatérale, dans laquelle la partie ligneuse de chaque faisceau est flanquée, sur deux de ses faces opposées, d'une partie libérienne. En un mot, dans cette forme il y a deux couches libériennes, l'une à la face externe, l'autre à la face interne du faisceau. Comme type de cette disposition, nous signalerons particulièrement les faisceaux foliaires des Cucurbitacées (fig. 96). Dans cet exemple, les deux parties libériennes ont une structure typique (liber mou) déjà décrite, et se distinguent encore par leur grand développement.

On trouve encore de nombreux exemples de la forme bicollatérale dans les faisceaux en séries circulaires de beaucoup de tiges de Dicotylédonées : Chicoracées, Solanées (Nicotiana), Asclépiadées, Apocynées (Nerium), Strychnées, Daphne, etc.

$B$. Faisceaux concentriques $(C$ oncentrische Bündel). - Dans ce groupe se rangent les faisceaux dont l'une des deux parties occupant le centre

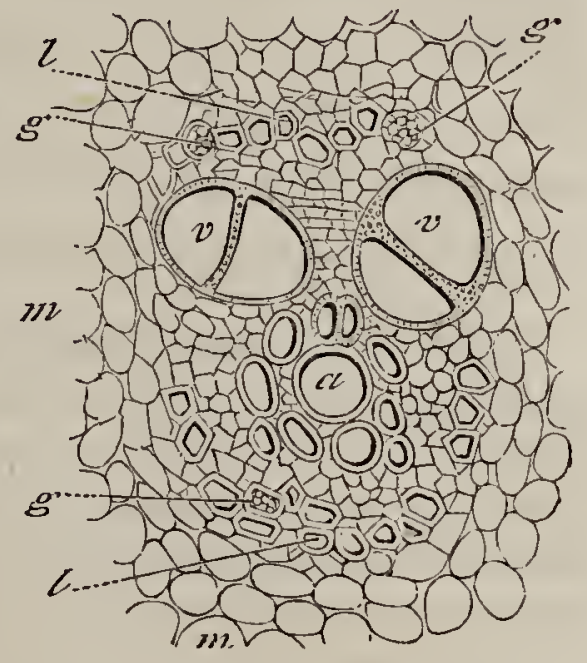

Fig. 96. - Coupe transversale d'un faisceau de Cucurbita maxima.$l, l$. Liber mou. - $g$. Tubes cribreux. - $v$. Vaisseaux ponctués.$a$. Vaisseaux annelés. - $m$. Moelle. est entourée par l'autre. Deux cas, par suite, sont à considérer, suiyant que le liber est entouré par le bois, ou, au contraire, que le bois est entouré par le liber.

Le premier cas se présente à l'extrémité des faisceaux foliaires dans les Rhizomes de beaucoup de Monocotylédonées (Iris germanica, Cyperus aureus, Carex arenaria, Acorus calamus, A.gramineus, etc.). Dans le reste de leur parcours, ces faisceaux rentrent dans la catégorie des faisceaux collatéraux. Quoi qu'il en soit, là où ils sont concentriques, leur coupe transversale montre en général une et rarement plusieurs assises de vaisseaux qui forment un cercle au milieu duquel se trouvent les cellules parenchymateuses du liber mou.

Le deuxième cas, dans lequel la portion ligneuse du faisceau étant placée au milien est entourée de toutes parts par la portion libérienne, se rencontre chez quelques Dicotylédonées 
à faisceaux anormaux, mais est surtout caractéristique du groupe des Fougères (fig. 97).

Parmi les Dicotylédonées, citons les faisceaux de la moelle des Mélastomacées. Un groupe de vaisseaux reliés par quelques cellules ligneuses prismatiques est entouré de toutes parts par un cercle de tubes cribreux et de cellules cambiformes. G'est également le cas de signaler le faisceau axile de la plupart des plantes aquatiques, Hippuris, Trapa, Callitriche, Bulliardia, Elatine, Hottonia, Myriophyllum, etc. Ce faisceau se compose ordinairement d'une portion vasculaire annulaire renfermant une quantité plus ou moins grande de parenchyme (moelle) et entourée d'un cercle de liber. Ces deux parties sont reliées entre elles par les éléments d'un parenchyme délicat.

Faisceaux des Fougères. - Nous venons de dire que les faisceaux des Fougères peuvent être pris comme types des faisceaux concentriques. Nous allons entrer dans quelques détails au sujet de la constitution souvent singulière de ces faisceaux. En règle générale, le faisceau des Fougères se compose d'une partie centrale vasculaire (fig. 97) dont les éléments sont des vaisseaux scalariformes et quel-

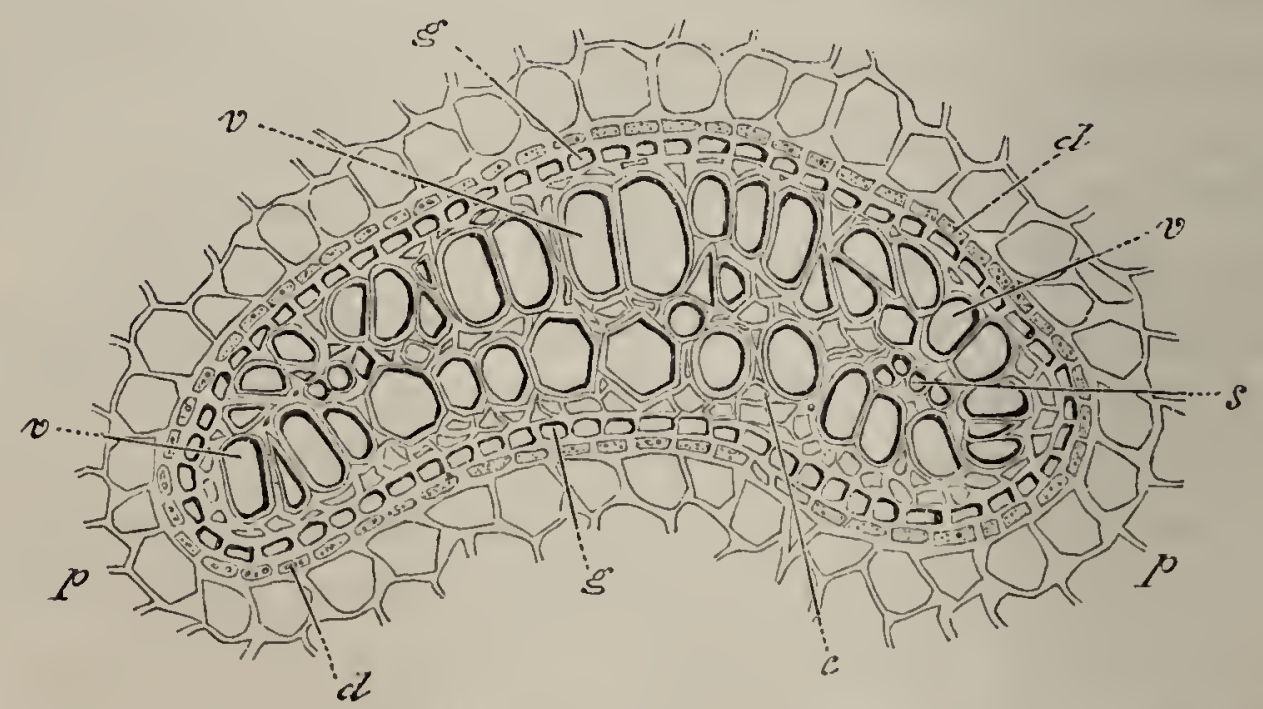

Fig. 97. - Un faiseeau grossi de Pleris Aquilina (Rhizome). - vv. Vaisseaux scalariformes. $-s$. Trachées. $-c$. Cellules criblées. - g. Fibres libériennes. - $d$. Gaîne du faisceau. $-p$. Parenchyme fondamental.

ques vaisseaux spiralés et annelés reliés entre eux par quelques cellules ligneuses. Autour de cette portion ligneuse se trouve une zone de liber qui l'enveloppe complètement et qui comprend des cellules grillagées $(c)$ et plus extérieurement une zone de fibres épaissies de nature libérienne $(g)$. Au dehors le tout est entouré d'une gaîne propre formée de cellules étroites disposées en une couche unique $(d)$.

Quant à la forme qu'affecte l'ensemble du faisceau, elle est varia- 
ble. Tantôt arrondie sur la coupe transversale, elle est le plus souvent ellipsoïde, comme le représente le faisceau de la tige du Pteris uquilina que nous figurons ici. Le plus souvent les vaisseaux qui le composent se disposent de manière à former à ses extrémités un crochet très caractéristique de beaucoup de ces plantes.

Déjà remarquables par leur forme générale, les faisceaux des Fougères le sont encore par la situation qu'y occupent les éléments vasculaires essentiels, c'est-à-dire les vaisseaux annelés et spiraux (1).

Sans vouloir entrer dans de trop longs détails, mentionnons d'abord l'absence fréquente des trachées dans les faisceaux des tiges tandis qu'on les retrouve dans les faisceaux des pétioles des mêmes plantes. Ainsi, dans les Polypodium aureum, Asplenium striatum, Adianthum tenerum, Athyrium Filix fæminea, les faisceaux des tiges ne possèdent pas de trachées, tandis qu'on en trouve dans les faisceaux pétiolaires.

D'autre part on observe, quant à la situation de ces trachées dans les faisceaux où elles existent, de notables différences. Dans le Pteris aquilina par exemple (fig. 97, s), ils occupent les foyers de l'ellipse que forme la coupe transversale du faisceau. Dans les faisceaux pétiolaires à crochets des Asplenium striatum, A dianthum tenerum, etc., ils sont enfermés dans ces crochets composés généralement de vaisseaux rayés ou ponctués toujours plus petits que les autres vaisseaux du faisceau. Dans d'autres cas, Adianthum nigrum, Ceterach off., Scolopendrium off., dans lesquels les faisceaux pétiolaires s'unissent de manière à figurer un $X$ ou un $T$, les vaisseaux spiraux et annelés occupent les extrémités des branches de ces figures.

Tous ces faits que nous ne faisons qu'indiquer rapidement prouvent assez combien la constitution des faisceaux des Fougères est variable.

C. Faisceanx radiaires (Radiale Bündel). - Ces faisceaux sont caractérisés par ce fait que la partie vasculaire forme des bandes ou rayons étendus du centre du faisceau à la périphérie, entre lesquels se trouve la partie libérienne, également disposée en bandes rayonnantes. Dans tous ces faisceaux les trachées et les tubes cribreux se développent d'abord à la périphérie du faisceau; plus tard seulement la formation alteint le centre.

C'est à cet ordre de faisceaux qu'appartient le corps ligneux central des racines (considéré alors comme un seul faisceau). Nous reviendrons sur ce sujet en traitant de la structure des racines. Le faisceau axile des tiges des Lycopodiacées rentrerait également dans ce groupe (Voir chap. V).

(1) Trécu. Annales Sc. nat. bot., $5^{\bullet}$ série, t. XI et XII. 
\$ 19. FAISCEAUX INCOMPLETS ET RUDIMENTAIRES.

Il peut arriver que les faisceaux deviennent incomplets par suite de l'atrophie de leur partie vasculaire, ou encore qu'ils restent rudimentaires par suite d'un arrêt de développement.

Faisceaux incomplets. - Au premier cas se rattachent les faisceaux des tiges des Equisetum, ceux des chaumes et des feuilles d'un grand nombre de Monocotylédonées, Hydrocharis, Butomus, Sagiltaria, Alisma, Juncacées, Cypéracées, A corus calamus, Leucoyum, Commélinées (Tradescantia albiflora, zebrina, etc.), plantes qui, pour la plupart, vivent dans l'eau ou végètent dans les marécages. A la même catégorie de faisceaux devenant incomplets par suite de résorption de la partie vasculaire, se rattachent, parmi les Dicotylédonées, ceux des Renoncules aquatiques, du Nelumbium des Nymphoea, Nuphar, Brasiana peltata (1), etc.

Dans toutes ces plantes, les vaisseaux venant à se détruire

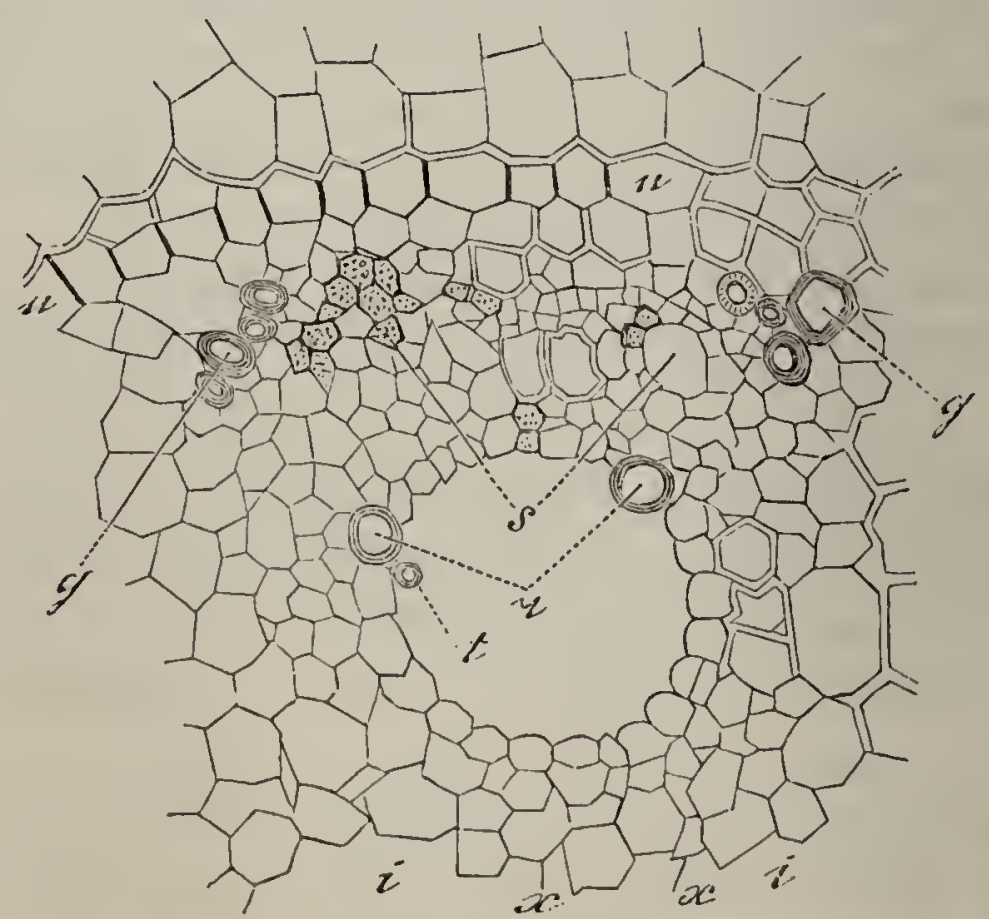

Fig. 95. - Coupe transversale d'un faisceau de la tige d'Equisetum palustre, d'après de Bary.

sont remplacés par une lacune ou canal intercellulaire renfermant de l'air. Ici outefois la résorption n'atteint pas tous les vaisseaux. Dans la figure 98, par exemple, qui représente

(1) Trćcul, Ann. Sc. nat. bot., $4^{\mathrm{e}}$ série, t. I. 
une coupe transversale d'un entre-nœud développé d'Equisetum palustre, on voit encore sur les bords du grand canal intercellulaire formé par la résorption des vaisseaux et la destruction d'une partie du parenchy me voisin, un certain nombre de vaisseaux $(r, t)$ persistants. On peut voir également que la partie cribreuse du faisceau $(s, s)$ située à la face externe du canal prend un grand développement. Dans le Nymphœa alba (fig. 61), on peut voir égallement à droite de la lacune (a) deux vaisseaux qui persistent au milieu d'un lissu çellulaire à parois minces. Autour de la lacune se produit fréquemment une prolifération cellulaire abondante.

Dans les divers exemples que nous venons de citer, tous les faisceaux ne présentent pas le même phénomène d'atrophie vasculaire. Ainsi, dans l'Acorus calamus, par exemple, on observe un très grand canal à la face interne des gros faisceaux, tandis qu'il n'y en a point dans les petits. Le même fait se reproduit pour les divers faisceaux des Renoncules susdites et du Nelumbium.

Dans une autre catégorie de faisceaux incomplets, l'alrophie, au lieu deporter sur une partie seulement des vaisseaux de chaque faisceau, atteint tous les vaisseaux. A ce type se rattachent les faisceaux foliaires des entre-nœuds du Potamogeton natans (dans les faisceaux propres à la tige et dans les nœuds, les trachées persisterit). L'atrophie vasculaire détermine alors la formation d'un canal généralement rempli d'eau. A ce type se rattachent avec quelques modifications les faisceaux des $P_{O}$ iamogeton lucens, gramineus, des Zanichellia, Cymodocea, Zostera, Althenia fliformis (1). Dans tous cescas la partie cribreuse des faisceaux persiste et même prend souvent un grand développement.

Faisceaux rudimentaires. - Quant aux faisceaux qui restent rudimentaires par suite d'une sorte de rétrogradation amenée par le séjour dans l'eau, on en trouve des exemples remarquables même parmi certaines Dicotylédonées dont les faisceaux se rapprochent par leur structure des faisceaux de beaucoup de Monocotylédonées. C'est ainsi que le faisceau

(1) Prillieux, Ann. Sc.nat. Lot., $5^{\mathrm{e}}$ série, t. II, 186 '. 
axile de l'Utricularia vulgaris (1) se présente avec une structure tout à fait rudimentaire. Il se compose en effet de cellules étroites, allongées, pleines d'un liquide granuleux, munies de cloisons transverses horizontales et dont la paroi s'épaissit notablement avec l'âge (cellules conductrices simples de Caspary). L'axe du faisceau est occupé par un unique vaisseau étroit, formé par une série de cellules superposées à cloisons transverses fortement obliques et imperforées; ces cellules sont annelées, et leurs anneaux assez espacés alternent çà et là avec quelques tours de spire (2). Ce vaisseau appartient à la classe des vaisseaux imparfaits si répandus chez les Monocotylédonées et si rares chez lès Dicotylédonées, où leur présence exclusive dans tous les organes n'a encore été signalée que dans l' $A l$ drovandia, le Monotropa, le Nelumbium et les Nymphéacées. Dans l'Utricularia vulgaris, ce vaisseau est permanent, il n'y a donc pas formation de lacune intercellulaire. C'est la seule différence d'avec la structure des faisceaux de l'Elodea canadensis et de l'Hydrilla verticillata, plantes Monocotylédonées de la tribu des Hydrillées, chez lesquelles il existe un ou deux vaisseaux incomplets semblables, mais qui disparaissent bientôt pour faire place à un canal intercellulaire.

Dans une autre Dicotylédonée, l'Aldrovandia vesiculosa(Droséracée étudiée par Caspary), la structure du faisceau ne diffère de celle des précédents faisceaux rudimentaires qu'en ce que le nombre des trachéides s'y élève jusqu'à 8 ou 9. Elles occupent le milieu du faisceau et tantôt persistent (dans les nœuds), tantôt s'atrophient et disparaissent (dans les entrenœuds) pour ne laisser qu'une lacune à leur place.

On trouve encore des faisceaux rudimentaires de structure analogue dans les feuilles des Lemma, dans les Pogostemon, le Vallisneria spiralis et les rhizomes des Epipogon et Corallorhiza (De Bary, loc. cit.).

(1) Van Thiegem, Ann. Sc. nat.bot., t. X, $5^{\mathbf{e}}$ série.

(2) L'influence du milieu liquide sur l'état rudimentaire du faisceau des tiges de l'Utriculaire se manifeste d'une façon très-intéressante, si l'on étudie la structure du faisceau du rameau florifère maintenu comme on le sait au-dessus de l'cau. Ici, en effet, le faisceau a une structure plus complexe. Formé à sa périphérie de fibres allongées, il renferme à sa face interne un grand nombre de vaisseaux annelés et spiralés (Van Thiegem, loc. cit.). 
§ 20. DÉveloppement des Faisceaux. Faisceaux ouverts. FAISCEAUX FERMÉS.

A l'origine, les faisceaux consistent en un méristème homogène formé de cellules allongées ou cubiques. Il n'y a encore aucune différenciation apparente dans ces cellules. Mais bientôt ce méristème primitif (procambium) commence à engendrer des éléments qui, dès leur apparition, donnent au faisceau naissant ses caractères essentiels de structure. Ce procambium, en effet, engendre tout d'abord à sa périphérie du prosenchyme libérien ou plus souvent encore des cellules grillagées et des tubes cribreux. D’autre part, à sa face interne apparaissent des trachées et des vaisseaux annelés. Dès lors les deux parties libérienne et ligneuse du faisceau sont différenciées.

Entre ces deux portions se trouve le cambium non transformé, actif et prêt à engendrer de nouveaux éléments.

G'est alors que va se produire dans l'organisation intime $\mathrm{du}$ faisceau un phénomène important. En effet, dans un grand nombre de cas, et particulièrement chez les Monocotylédonées (1) (fig. 89), les Cryptogames et un certain nombre de Dicotylédonées à tige herbacée (Cucurbita maxima, par exemple) (fig. 88), tout le procambium du faisceau se transforme successivement en éléments libériens et ligneux. De sorte que finalement le méristème disparaît complètement. Ces faisceaux sont dits fermés (Schleiden). Ils sont en effet fermés à tout accroissement diamétral ultérieur, puisque la zone génératrice de leurs éléments n'existe plus.

Chez le plus grand nombre des Dicotylédonées au contraire, une portion du procambium persiste toujours entre les parties libérienne et ligneuse des faisceaux. Ce .méristème définitif prend alors le nom de cambium. Il produit constamment à sa face interne de nouveaux éléments de bois qui forment le bois secondaire du faisceau par opposition au bois primaire engendré par le procambium. Ce bois secondaire comprend des

(1) Toutefois, d'après M. Van Thiegem (loc. cit.), le groupe des Aroïdées présente quelques exceptions à cette règle. La zone génératrice persiste en effet au moins sur une portion de la périphéric de la tige, chez les Monstérinées, et sur toute la périphéric dans l'Acorıs. 
vaisseaux réticulés, rayés et ponctués, des fibres et des cellules ligneuses. D'autre part le cambium produit sur son bord externe les éléments du liber secondaire (fibres, tubes cribreux, cellules cambiformes, etc.).

Ges faisceaux à cambium définitif sont dits faisceaux ouverts (Schleiden). En eff'et, par suite de l'existence de cette zone génératrice permanente, ils continueront indéfiniment à se développer en épaisseur. Chez les Conifères, le bois secondaire n’est composé que de fibres aréolées, sans vaisseaux.

ctude. - On suivra très facilement le développement des faisceaux vasculaires dans une plante en germination, en étudiant, à l'aide de coupes transversales et longitudinales, l'embryon avant la période de germination, et ensuite à différents degrés de cette période. On peut constater ainsi facilement l'apparition successive des diverses parties des faisceaux.

On peut encore étudier le développement des faisceaux dans les jeunes 'pousses, en ayant soin de commencer l'étude du bourgeon qui les renferme avant son épanouissement, et de continuer cette étude jusqu'à l'achèvement complet de l'accroissement en longueur du jeune entre-nœud. - Ceci est nécessaire si l'on veut assister au déreloppement successif de tous les éléments. Sur le Hêtre par exemple, au moment où la jeune branche sort de son bourgeon, on ne trouve dans les faisceaux vasculaires que des vaisseaux spiralés et annelés à spirales et anneaux très espacés; plus tard on voit naître des vaisseaux à spirales plus serrées, et c'esi seulement Jorsque l'allongement de la pousse est terminé qu'apparaissent les vaisseaux réticulés ou ponctués et les cellules ligneuses lignifiées.

ART. 5.

\section{Tissu fondamental}

M. Sachs, qui a introduit récemment l'expression dé tissu fondamental, définit ce tissu de la manière suirante : "Le lissu fondamental est toute la masse du lissu d'une plante et d'un 
" orgarie qui, après la formation et l'achèvement du tissu " tégumentaire et des faisceaux vasculaires, subsiste entre " eux. ")

A vrai dire, cette distinction d'un tissu fondamental n'a d'importance que dans les plantes à système vasculaire bien développé; car dans les Gryptogames cellulaires, par exemple, où il n'y a point de vaisseaux, et dans lesquelles l'épiderme lui-même est à peine différencié, les tissus parenchymateux qui seuls concourent à la structure des organes n'ont pas besoin d'une détermination spéciale.

D'après la définition du tissu fondamental que nous reproduisons plus haut, celui-ci comprend les tissus que dans beaucoup de Phanérogames et de Cryptogames vasculaires, on désigne généralement sous les noms de moelle, de parenchyme cortical et de rayons médullaires. Ces tissus forment en effet dans les organes où ils existent un ensemble de même nature qu'il est bon de pouvoir désigner d'un nom commun. Il suit également de là que le tissu dans lequel sont répartis les faisceaux dans les tiges des Monocotylédonées, aussi bien que celui qui constitue le mésophylle des feuilles, doivent tous se grouper dans la même catégorie.

Eléments du tissu fondamental. - Il ne faudrait pas croire toutefois que le tissu fondamental ne comporte que des parenchymes. Comme dans les systèmes de tissus précédents (tissu tégumentaire, faisceaux), des éléments de nature très diverse, cellules sclérenchymateuses, fibres, etc., peuvent s'y développer.

G'est ainsi que, fréquemment, à la périphérie du tissu fondamental des tiges ou des racines (fig. 85), voire même des feuilles (Conifères), en contact avec le tissu tégumentaire, on voit se différencier des éléments caractérisés par l'épaississement et la coloration de leurs parois, éléments qui se superposent souvent en plusieurs couches successives et forment cette zone particulière que nous avons déjà étudiée sous le nom d'hypoderme (voir page 199).

D'autre part, au sein même du tissu fondamental parenchymateux (parenchyme cortical, moelle), il n'est pas rare de voir se développer soit des cellules sclérenchymateuses dites pier- 
reuses, isolées, par groupes, ou par assises, soit des fibres épaisses fasciculées ou isolées, etc.

Comme exemple de cellules sclérenchymateuses isolées, nous rappellerons celles que l'on rencontre dans le mésophylle des feuilles du Camellia japonica (fig. 33). Dans le parenchyme fondamental dont le développement considérable forme la partie succulente des poires, on trouve des groupes de cellules pierreuses qui y forment comme de petits noyaux durs souvent répartis en grand nombre dans le tissu mou environnant.

Des exemples de cellules sclérenchymateuses disposées en cordons aplatis et de configuration diverse se peuvent voir dans le tissu fondamental interposé aux faisceaux des Fougères arborescentes et du Pteris aquilina (fig. 99, s, s). Ces

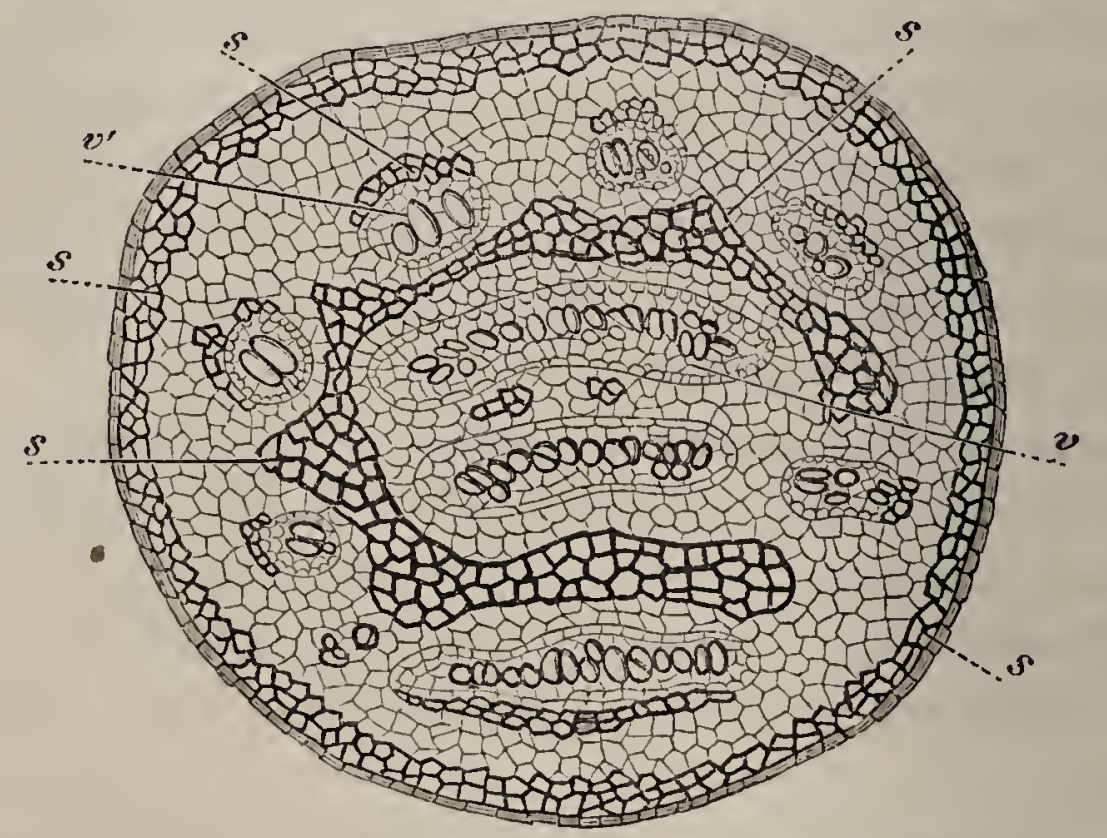

Fig. 99. - Coupe transversale sur la tige du Pteris Aquilina. - s, s. Cellules sclérenchymateuses.

cellules sclérenchymateuses, allongées parallèlement au grand axe des tiges, présentent des parois généralement colorées en brun. Leur assemblage détermine autour des faisceaux qu'elles accompagnent des dessins variés.

Signalons enfin les cellules pierreuses et les faisceaux de fibres très semblables à celles du liber que l'on rencontre dans un grand nombre d'écorces d'arbres, et dont nous rappelons ici quelques exemples. 
Écorce des cannelles. $1^{\circ}$ Cannelle de Ceylan (Cinnamomum seylanicum). - Sur les coupes transversales des écorces de cannelle de Ceylan du commerce (les couches tégumentaires faisant généralement défaut) on trouve, tout à fait à l'extérieur, plusieurs assises d'un tissu parenchymateux dans lequel sont répartis de place en place des paquets de fibres à parois épaisses, d'un petit diamètre transversal, comparativement surtout à leur longueur. En dedans de cette première zone, le parenchyme fondamental subit une nouvelle modification et se transforme en cellules pierreuses, à parois très-épaisses, canaliculées. Ces cellules disposées sur deux ou trois rangs forment une couche continue qui sépare la zone externe précédemment décrite d'une zone interne composée d'un parenchyme parsemé d'éléments fibreux isolés et de cellules gommeuses. Les ėléments de ce parenchyme renferment généralement de l'amidon.

$2^{\circ}$ Cannelle de Chine (Cinnamomum aromaticum). - Dans cette écorce, les coupes transversales font reconnaître une structure à peu près semblable, sauf que le tissu tégumentaire y est généralement représenté par quelques assises de cellules subéreuses (périderme), et que la zone des cellules pierreuses, moins régulière que dans la cannelle de Ceylan est souvent même interrompue par des bandes de tissu fondamental (Planchon, loc. cit.). Enfin l'amidon est plus abondant dans ces écorces que dans les écorces de Ceylan.

$3^{\circ}$ Cannelle giroflée (Dicypellium curyophyllatum). - Cette espèce ne renferme pas d'amidon, et, dans la généralité des cas, sa partie la plus externe est formée par une zone de cellules pierreuses disposées en deux ou quatre assises. De plus, à la face interne se montre la couche libérienne composée de faisceaux prosenchymateux denses qui proéminent dans la zone moyenne composée comme précédemment d'un parenchyme parsemé de longues fibres isolées à parois épaisses et de grosses cellules gommeuses (Planchon, loc. cit.).

$4^{\circ}$ Cannelle blanche (Cannella alba). - Dans cette écorce, des cellules pierreuses de couleur jaune-citron ou d'un jaune verdâtre occupent la périphérie du tissu fondamental. Disposées sur deux ou trois rangs, elles circonscrivent un parenchyme cortical rempli de grandes cellules à résine, qui lui-même est limité plus en dedans par les faisceaux libériens.

Écorces d'Angusture. - L'examen des écorces d'Angusture montre également bien les différenciations qui peuvent se produire dans le parenchyme fondamental. Ici encore des cellules sclérenchymateuses apparaissent en plus ou moins grande abondance, et leur répartition permet de distinguer aisément, par l'examen de la structure anatomique, entre les écorces d'Angusture vraie et de fausse Angusture.

Angusture vraie (Galipea officinalis). - Les coupes transversales de cette écorce montrent de dehors en dedans : $1^{\circ}$ une zône périder- 
mique de cellules subéreuses; $2^{\circ}$ en dedans de ces cellules un tissu parenchymateux dans lequel se voient de nombreuses cellules pierreuses à parois jaunâtres, ponctuées, qui forment des groupes allongés dans le sens tangentiel, et répartis à des distances très-inégales. $3^{\circ} \mathrm{A}$ la face interne de cette zone se trouve une couche de cellules assez minces, renfermant des groupes de cellules sclérenchymateuses semblables aux précédentes; cette zone se continue avec le liber qui se fait remarquer par ses paquets de fibres à parois très-épaisses (Planchon, loc. cit.).

Angusture fausse (Strychnos nux vomica). - La structure anatomique de cette écorce est également très-caractéristique. A la zone péridermique formée de cellules cubiques, succède ún tissu parenchymateux parsemé de quelques groupes de cellules sclérenchymateuses. Puis vient le liber; mais entre ce liber et la zone parenchymateuse on trouve une zone presque continue formée de trois à quatre assises de grosses cellules pierreuses à parois jaunes, dures, ponctuées, qui présentent sur les coupes transversales un contour ellipsoïde ou arrondi.

Les quelques exemples que nous venons d'indiquer succinctement et qu'il serait oiseux de multiplier davantage, pourront être pris comme types de ces modifications que subissent certains des éléments du parenchyme fondamental.

Les trois systèmes de tissus (tégumentaire, fasciculaire, fondamental) que nous venons d'examiner, se groupent dé manières diverses pour former les tiges, les racines, les feuilles, etc. Pour connaître la structure de ces organes, il va donc nous suffire d'étudier dans chacun d'eux les rapports réciproques de ces trois systèmes de tissus. 


\section{CHAPITRE V}

\section{STRUGTURE DES TIGES}

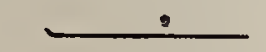

Étude. - Nous étudierons successivement la structure des tiges chez les Dicotylédonées, les Monocotylédonées et les Acotylédonées.

Pour observer les diverses particularités que nous allons signaler, on devra pratiquer des coupes transversales, longitudinales et tangentielles sur des échantillons prélevés avec soin, en tenant compte des précautions que nous avons indiquées pages 38 et suivantes.

Il est bon, lorsqu'on étudie la tige d'une plante, d'examinér d'abord les échantillons de force médiocre qui permettent d'embrasser d'un seul coup d'œil sous le microscope la disposition générale du centre à la périphérie, dans une coupe transversale; mais on n'oubliera pas que la structure de la tige varie aux diverses époques de son développement, et par suite on ne devra pas s'en tenir à ces premières coupes. Celles qu'on fera sur des portions de tige plus volumineuse seront très-difficilement obtenues complètes. On pourra avec avantage se servir des microtomes.

Quoi qu'il en soit, on doit s'attacher avant tout à obtenir des coupes minces et dirigées dans un plan régulièrement perpendiculaire ou parallèle relativement à l'axe de la tige. La détermination exacte du plan suivant lequel on fait les coupes est de la plus grande importance. Si l'on n'y prend garde, on obtient des coupes obliques par rapport à la direction des faisceaux, et l'interprétation des préparations devient difficile, souvent même impossible. Lor'squ'on a obtenu de bonnes coupes, on examine successivement les diverses parties, tissu tégumen- 
taire, faisceaux, parenchyme fondamental, on note la situation des éléments, leur forme, leurs caractères particuliers."

Pour l'étude des rayons médullaires, et des faisceaux, les coupes tangentielles seront particulièrement instructives. Les coupes transversales et longitudinales, passant par l'axe, ne pourront embrasser l'ensemble des tissus que sur les tiges d'un diamètre peu considérable. Quoi qu'il en soit, ces coupes seront d'une grande utilité.

\section{ArT. 1.}

\section{Tige des Dicotylédonées.}

\section{§1. DIGOTYLÉdONÉES A TIGE NORMALE.}

Si l'on fait une coupe transversale sur un jeune rameau ou sur une tige d'une année, on peut constater à un faible grossissement (fig. 100) que le parenchyme fondamental est divisé en

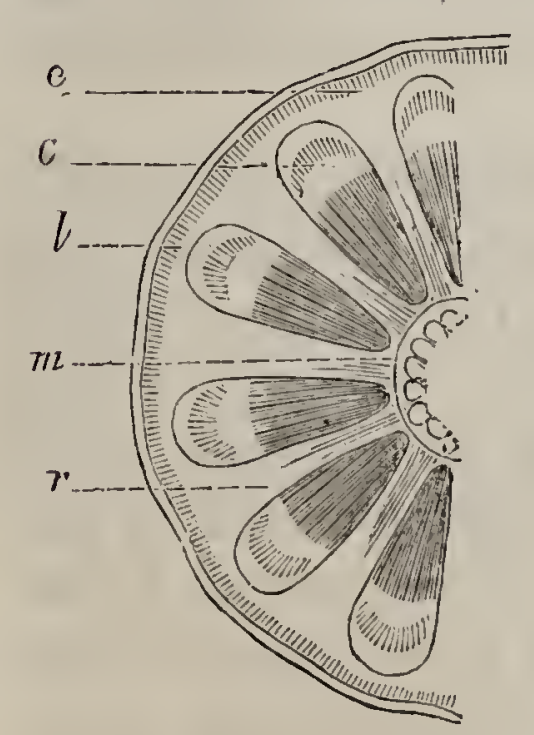

Fig. 100. - Coupe transversale d'une tige de Dicotylédonéc (schéma). $\sim e$. Ecorce. - c. Cambium du faisceau.

- $l$. Liber. $-m$. Hoclle. $r$. Rayons médullaires. trois parties distinctes, l'une centrale, la seconde périphérique, toutes deux réunies par une troisième partie composée de lames rayonnantes qui alternent d'autre part avec les faisceaux libéroligneux. Ces lames rayonnantes on treçu le nom de rayons médullaires, et l'on appelle moelle le parenchyme central qu'elles relient au parenchyme périphérique ou cortical. Si maintenant on examine cette coupe avec un plus fort grossissement, on voit, d'une part, que le parenchyme cortical est limité au dehors par une couche tégumentaire; d'autre part, que chacun des faisceaux est formé de deux parties bien distinctes, l'une externe qui est la partie libérienne, l'autre interne qui est la partie ligneuse, reconnaissables toutes deux aux caractères que nous avons indiqués plus haut.

Cela posé, on désigne généralement sous le nom d'écorce toute la partie de la tige composée : $1^{\circ}$ par le tissu tégumen- 
taire formé, lorsqu'il est complet, d'un épiderme, d'un hypoderme et d'un périderme (voir pages 163 et 199 ), $2^{\circ}$ par le tissu parenchymateux cortical, et $3^{\circ}$ par le liber des faisceaux.

On donne le nom de bois à l'ensemble des parties ligneuses des faisceaux. Enfin, la moelle et les rayons médullaires complètent l'énumération des diverses parties qui constituent la tige des Dicotylédonées.

Tels sont les rapports qu'affectent entre elles les différentes parties constitutives d'une jeune tige. Si la tige appartient à une plante herbacée, par conséquent peu durable et de faible consistance, ces rapports ne subissent que de légères modifications; le tissu fondamental acquiert en général un grand développement relativement aux faisceaux chez lesquels, le plus souvent, l'activité de la zone cambiale s'éteint de bonne heure (faisceaux fermés). Il en résulte que les rayons médullaires deviennent tellement larges, qu'il n'y a plus lieu de distinguer entre une moelle et un parenchyme cortical. Les faisceaux sont alors épars, quoique assez généralement disposés en série circulaire, dans un tissu fondamental le plus souvent homogène. Ces tiges herbacées se rapprochent, comme nous le verrons, par leur structure, des tiges des Monocotylédonées.

Dans les Dicotylédonées ligneuses, au contraire, de grandes modifications surviennent dans la suite du développement. De nouveaux faisceaux apparaissent entre les premiers, et les rayons médullaires, de plus en plus resserrés, se réduisent à deux ou trois, souvent même à une seule assise de cellules. En même temps, le cambium des faisceaux, conservant toute son activité (faisceaux ouverts), forme de nouveau bois et de nouveau liber. Les couches libériennes de l'écorce augmentent donc en épaisseur. Le bois s'accroît en proportion considérable, et la moelle, très-nettement délimitée, finit même bientôt, dans certaines tiges, par être réduite à une bande centrale de quelques cellules. Nous renvoyons pour les détails de structure de l'écorce et du bois aux détails que nous avons donnés dans les chapitres précédents.

Rayons médullaires. - Les rayons médullaires, examinés en coupe tangentielle sur les tiges ligneuses, se présentent comme des assises de cellules muriformes à parois minces, renfermant souvent 
de l'amidon. Tantôt composés d'une ou deux files verticales de cellules (Charme, Tilleul, Noisetier, Daphné, ils peuvent ailleurs être plus épais (Platane) ou varier dans la même tige, comme cela se voit dans le Chêne et le Hetre où l'on trouve mélangés des rayons épais et d'autres fort étroits. Les mêmes coupes tangentielles montrent que ces rayons médullaires sont ordinairement peu prolongés dans le sens longitudinal de la tige, bien que chez la Vigne et la Viorne (Clematis vitalba) ils s'étendent sur toute la longueur d'un entre-nœud. Enfin, au moyen des coupes transversales, on verra que dans les plantes ligneuses il existe à la fois de grands rayons ou rayons primaires s'étendant de la moelle à l'écorce, et de petits rayons ou rayons propres au bois secondaire, et qui commencent plus ou moins loin de la moelle.

Les rayons médullaires font défaut chez les Crassulacées, ainsi que chez la Clandestine (Lathræa clandestina), les Melampyrum, etc. (Duchartre, Éléments, p. 210).

Moelle. - La moelle est formée de cellules quelquefois prosenchymateuses, dont l'activité a une durée variable. Gris (1) a groupé, sous ce rapport, les cellules de ce tissu en trois catégories et les désigne sous les noms de cellules actives, cellules inertes et cellules cristallogènes. L'aclivité des premières se manifeste par l'épaississement de leurs parois qui deviennent ponctuées, et par la présence dans leur cavité d'un contenu nutritif principalement composé d'amidon. Les cellules inertes ne vivent généralement qu'une année. Leurs parois ponctuées ne s'épaississent pas. Leur cavité ne renferme pas de matière nutritive. Quant aux cellules cristallogènes, elles doivent leur nom aux cristaux qu'elles renferment.

Ces trois sortes de cellules se groupent de différentes manières dans la moelle des diverses tiges : de là, les moelles homogénes, formées essentiellement de cellules actives; les moelles hétérogénes formées d'un mélange de cellules actives et de cèllules inertes; enfin, les moelles inertes, formées de cellules inertes sans mélange de cellules actives (Sureau).

Sans vouloir insister davantage, ajoutons que dans les moelles hétérogènes il arrive souvent,que les celles inertes qui occupent le centre se détruisent au bout d'un certain temps, destruction qui donne lieu aux tiges fistuleuses dont il a été déjà question page 133 (Ombellifères, Lonicera, etc.). Dans les Noyers, l'Euphorbe des Canaries, etc., la moelle est composée de lames transversales alternativement formées les unes de cellules inertes, les autres de cellules actives. Les premières disparaissent de bonne heure, ne laissant dans le canal médullaire que des sortes de diaphragmes plus ou moins espacés, constitués par les dernières, et parfois très-minces (Duchartre, loc. cit.).

(1) Ann.Sc. nat., Bol., $5^{\text {e }}$ série, t. XIV. 
Nous nous bornerons à ces indications sommaires sur les rapports des différentes parties de la tige dans les cas normaux, pour arriver immédiatement à l'étude du mode d'accroissement de la tige.

\section{§ 2. A CCROISSEMENT DES TIGES DES DICOTYLÉDONÉES.}

$1^{\circ}$ Accroissement en longueur. Étude. - Pour étudier l'accroissement des tiges en longueur, on fera des coupes longitudinales sur le bourgeon terminal. Ges coupes devront passer très-exactement par l'axe du bourgeon. Celui-ci renferme en effet en son milieu un petit mamelon terminal généralement conique (cône ou point végétatif) que forme un tissu très-délicat. Comme il est difficile d'obtenir des coupes minces sur ce tissu, on pourra se contenter de tranches comprenant une épaisseur de trois à quatre assises de cellules, mais alor's on rendra les préparations transparentes en les traitant alternativement par la potasse et l'acide chlorhydrique et en les montant dans la glycérine. On pourrait encore placer les coupes dans un pel d'eau additionnée de chlorure de calcium sec et les chauffer jusqu'à siccité presque complète. En dissolvant le chlorure de calcium avec un peu d'eau et montant les coupes dans la glycérine on obtient au bout de peu de temps une très-grande transparence (Treub.). Sur ces coupes on pourra constater alors que le tissu (méristème primitif) qui forme le cône végétatif est déjà, par la forme et la disposition générale de ses cellules différencié, en trois zones : l'une externe, généralement formée d'une seule assise de cellules qui continuent l'épiderme de la portion de tige située au-dessous du point végéta tif, reçoit le nom de dermatogène (fig. 113,d)(Hanstein)(1). Elle est appelée à former l'épiderme du nouvel entre-nœud. Une seconde zone recouverte directement par la précédente est constituée de deux ou trois assises de cellules et a reçu le nom de périblème (fig. 113, pb). Elle se continue au-dessous du point végétatif avec l'écorce primaire du jeune rameau, elle devient le point de départ de la même formation dans le nouvel entre-nœud. Enfin, le centre du cône végétatif est rem-

(1) Hanstein, Die Scheitelzellgruppe im Vegeiationspunkt der Phanerogamen, Bonn, 1868. 
pli par un méristème désigné du nom de plérome (fig. $113, p l$ ), à la périphérie dũquel se développeront les faisceaux et dont le centre formera la moelle dans les tiges où celle-ci existe (1).

L'accroissement terminal des tiges s'opère donc par l'intermédiaire d'un méristème, qui se divise très-rapidement en couches distinctes correspondant aux diverses parties de la tige développée. Chez les Dicotylédonées, cet accroissement est généralement indéfini; il n'y a guère d'exception que pour les plantes dont l'extrémité de l'axe se termine par une fleur.

$2^{\circ}$ ccroissement transversal. - Dans un certain nombre de tiges herbacées qui n'ont qu'une durée très-limitée, l'accroissement en épaisseur s'arrête rapidement, en même temps que le cambium des faisceaux disparaît (faisceaux fermés). Il n'en est pas de même chez d'autres tiges annuelles (Brassica, etc.), et surtout chez les Dicotylédonées ligneuses où le bois et l'écorce primaires dont nous avons indiqué plus haut le mode de développement (p. 221) se trouvent bientôt renfor. cés par des formations secondaires qui, tout en augmentant la consistance de la tige, participent à son accroissement transversal. - Ce sont, d'ure part, de nouveaux éléments de bois et de liber engendrés par le cambium des faisceaux primaires, d'autre part l'apparition de nouveaux arcs cambiaux aux dépens d'une assise de cellules qui entoure le cylindre vasculaire. Ces nouveaux arcs générateurs s'intercalent aux arcs cambiaux des premiers faisceaux, et il en résulte la formation d'une zone génératrice continue qui va produire à l'extérieur des couches libériennes, et à l'intérieur des couches de bois. Ce liber secondaire est généralement formé de fibres épaisses accompagnées de cellules parenchymateuses. Quant au bois secondaire, il n'est formé que de vaisseaux ponctués ou rayés et de fibres ligneuses, mais il ne s'y produit ni vaisseaux spiralés, ni vaisseaux annelés. Le cambium produit tous ces éléments par division successive des cellules qui le composent et transformation lente en liber ou en bois. D'après les recherches de M. Sanio chez le Pinus sylvestris (2),

(1) Dans les plantes aquatiques (voir page 219) oú il n'y a pas de moelle, le plérome se transforme tout entier en un faisceau axile.

(2) Pringsheim, Jahrb., Bd. IX. 
le travail de division s'opère dans une couche spécialement active du cambium, qu'il appelle couche initiale. Le cambium se voit en $c c$ (fig. 101) sur la coupe transversale de Sambucus nigra que nous reproduisons d'après M. de Bary

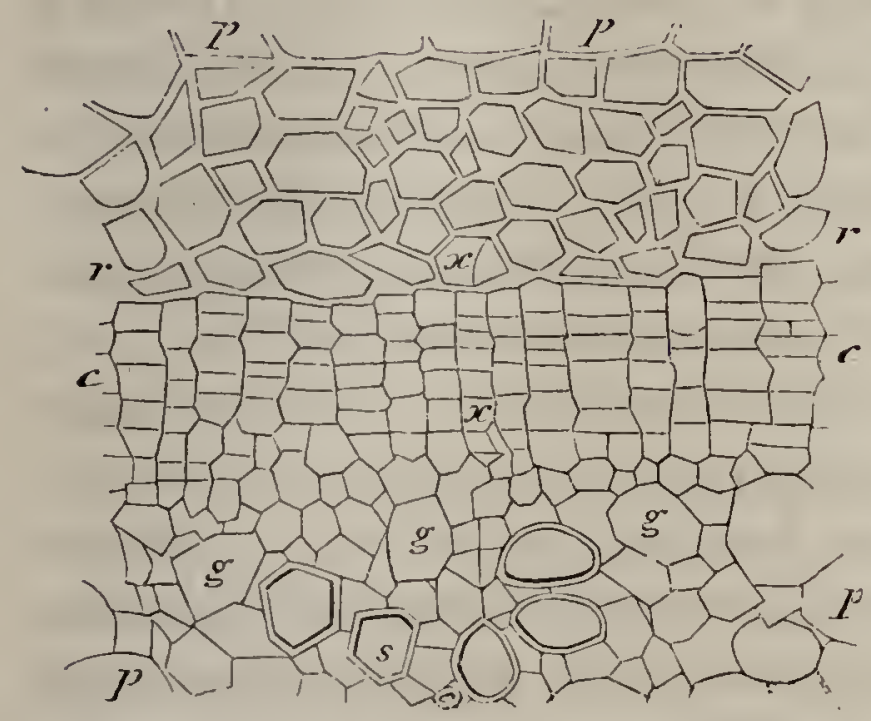

Fig. 101. - Coupe transversale d'un jeune entrcnœud de Sambucusnigra (de Bary). - cc. Cambium. - rr. Limitc de l'écorce primairc. - $g g$. Vaisscaux ponctués en formation. - $s$. Trachécs. - $p p$. Parcnchyme.

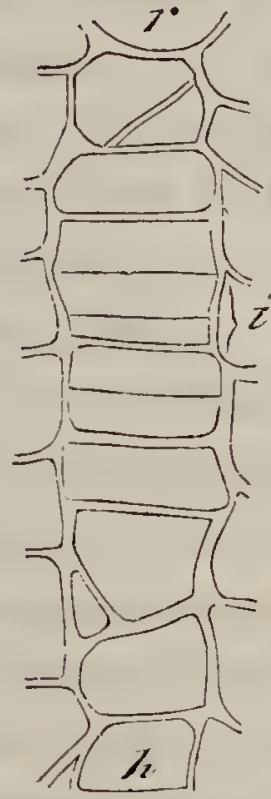

Fig. 102. - La rangée de cellules $(x x)$ dc la figure 101 , vue à un plus fort grossissement. - $h$. Côté du bois. - $r$. Côté de l'écorce.

(loc. cit.). Chaque cellule (cellule initiale) de la couche active se divise tangentiellement en deux cellules sœurs (en $i$, fig. 102) dont l'une devient initiale à son tour cet l'autre cellule mère de tissu; alors, suivant que cette dernière occupe la face interne ou la face externe de la première, elle donne lieu à des éléments du bois ou de l'écorce. En général chaque cellule mère de tissu se divise par cloison tangentielle en deux cellules qui deviennent directement des éléments propres à l'une des deux parties, corticale ou ligneuse.

Quoi qu'il en soit, lorsque, comme c'est le cas pour les tiges ligneuses de nos arbres, l'activité du cambium se suspend périodiquement pour reprendre avec vigueur au début de la nouvelle période végétative, il se produit dans le cours de chaque période d'activité une couche de bois secondaire et une couche d'écorce secondaire qui se placent, la première en dehors des couches ligneuses des années précédentes, la seconde en dedans des couches libériennes antérieurement formées. - Le même fait se reproduisant chaque année, le 
bois primaire se trouve continuellement repoussé vers le centre de la tige. Il y forme l'étui médullaire, et proémine à la face interne des nouvelles formations, déterminant dans la moelle autant de saillies qu'il existait de faisceaux primitifs dans la tige (trois dans le Nerium Oleander, quatre dans le Buxus sempervirens, cinq dans le Chêne, le Châtaignier, etc.). Quant à l'écorce primaire, elle disparaît fréquemment, par exfoliation consécutive à la formation du rhytidome. - Quelquefois cependant, ses cellules devenant le siège d'une segmentation active, elle peut suivre sans se déchirer le développement transversal de la tige (Viscum, Helianthus annuus, etc.).

La formation des couches annuelles dans le bois des tiges ligneuses se traduit fréquemment à l'œil nu, grâce à une densité plus grande des couches formées à la fin de la période végétative. D'autre part, à mesure que les couches ligneuses avancent en âge, leurs parois durcissent, se colorent en brun plus ou moins foncé, et il en résulte au voisinage de la moelle une partie ligneuse de couleur foncée et d'une grande densité, que l'on nomme duramen ou cœur du bois. Les couches plus récentes et plus extérieures forment une zone claire et moins dense qui reçoit le nom 'd'aubier. Certains de nos arbres dits à bois blanc (Saules, Peupliers, etc.) ont dans toutes leurs parties une consistance peu prononcée et une couleur pâle homogène.

L'accroissement transversal chez les Gymnospermes s'opère exactement comme chez les Angiospermes; seulement, au moins chez les Conifères et les Cycadées, le bois secondaire ne renferme jamais de vaisseaux, mais seulement les susdites fibres aréolées ponctuées (1).

Étude. - Pour étudier le développement en épaisseur des tiges, on fera des séries de coupes transversales à des hauteurs diverses sur de jeunes branches, de manière à constater

(1) Chez les Gnétacées, on observe dans la constitution du bois secondaire une sorte de passage entre les autres Gymnospermes et les Angiospermes. Dans les Ephedra, par exemple, on trouve de larges vaisseaux dont les articles sont séparés par des cloisons transverses obliques percées d'un ou plusieurs trous arrondis. Leurs parois latérales possèdent des ponctuations aréolées. Dans le bois du Welwitschia les fibres à ponctuations aréolées paraissent manquer et être remplacées par des " vaisseaux poreux » à paroi épaisse (Sachs'. 
les diverses phases que nous venons de retracer. Au voisinage du point végétatif, on apercevra dans le tissu fondamental le cercle de cambium des faisceaux qui le divise en deux zones, moelle et écorce. Un peu plus bas, on assistera à l'apparition des premiers éléments des faisceaux et à la fusion des zones cambiales fasciculaires en une seule couche, interrompue seulement par les rayons médullaires, et à la formation des éléments du bois et de l'écorce secondaires. Nous n'avons pas besoin d'ajouter que c'est au printemps et en été seulement qu'on pourra assister à ce développement du jeune bois, l'automne et l'hiver étant des périodes d'arrêt dans la végétation.

\section{§ 3. DICOTYLÉDONÉES A TIGE ANORMALE.}

De nombreuses anomalies, qui altèrent plus ou moins profondément le type de structure que nous avons décrit, se rencontrent chez les Dicotylédonées. Tantôt l'altération provient d'un développement singulier de l'écorce par rapport au bois (Bignoniacées, Aristolochiées, Malpighiacées), tantôt, de l'existence pour une même tige de plusieurs centres générateurs, de telle sorte que la tige paraît formée de faisceaux de petites tiges soudées (Sapindacées), tantôt encore, chez certaines Dicotylédonées aquatiques, d'une telle simplification de structure, que le bois n'est plus formé que par un seul faisceau qui occupe l'axe de la tige (Hippuris, Aldrovandia, C'eratophyllum, Trapa). Enfin d'intéressantes anomalies consistent dans la formation de faisceaux surnuméraires propres aux tiges, qui viennent s'ajouter aux faisceaux ordinaires communs aux feuilles et à la tige et que l'on nomme, par opposition aux précédents, faisceaux foliaires. Les faisceaux surnuméraires pouvant se placer en dehors ou en dedans des faisceaux foliaires, nous examinerons successivement ces deux cas.

$1^{\circ}$ Les faisceaux surnuméraires sont intérieurs par rapport aux faisceaux foliaires.

a. Tous les faisceaux sont isolés au milieu du tissu fondamental, la structure de la tige se rapproche de celle des Monocotylédonées. A ce groupe se rattachent les tiges des Cucurbitacées sarmenteuses(Cucurbita, C'ucumis, Bryonia), chez 
lesquelles les faisceaux forment plusieurs cercles concentriques (dans les Cucurbitacées non sarmenteuses, comme l'Ecbalium Elaterium, il n'y a qu'un seul cercle de faisceaux). Sur la figure 103, qui représente une coupe transversale de la

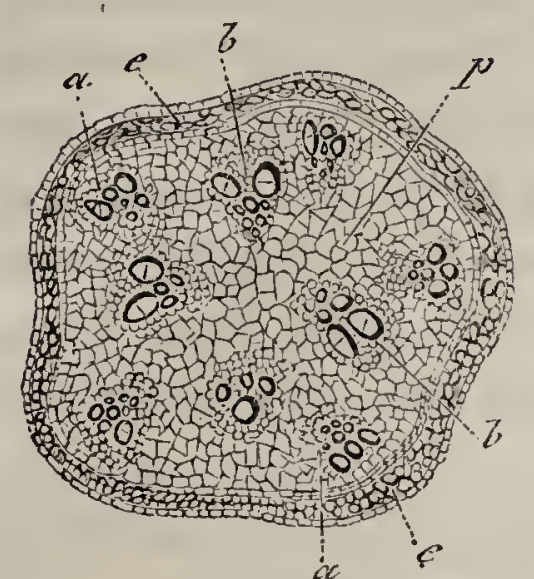

Fig. 103. - Coupe transversale d'une tige de Cucurtita maxima.

faisceaux (sur notre coupe, les faisceaux surnuméraires sont au nombre de 4, tandis qu'il y a 弓̆ faisceaux foliaires).

Les tiges des Nymphxacées rentrent dans le même groupe. $b$. Dans certains cas, les faisceaux foliaires, extérieurs, for-

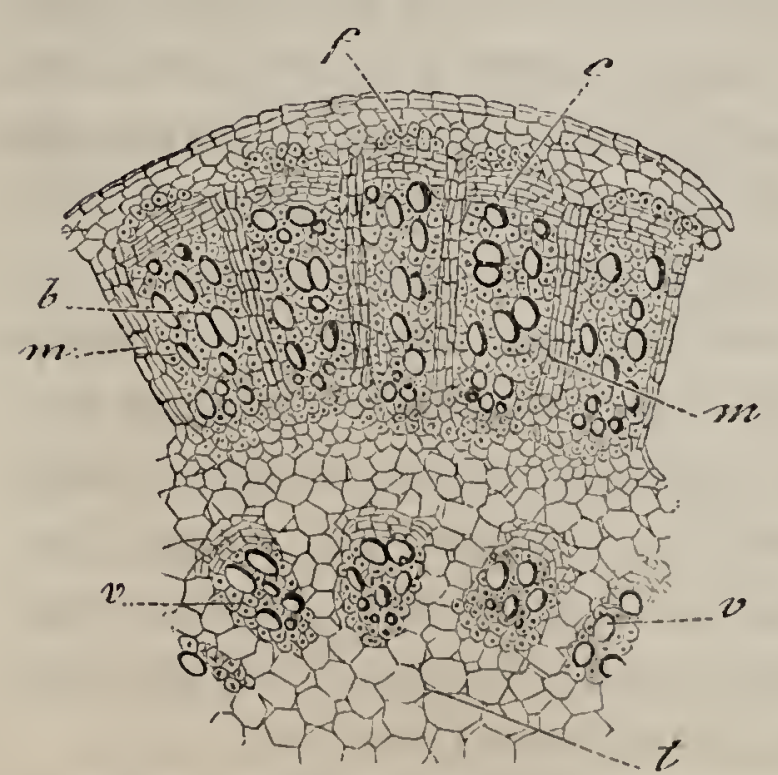

Fig. 10\%. - Coupe transversale sur une tige de Piper medium. - Bois extérieur et Faisccaux dans la moelle $t .-b, v$. Vais. seaux. - $m$. Rayons médullaires. $-c$. Cambium. - $f$. Fibres libériennes. ment un anneau fermé, tandis que les faisceaux surnuméraires sont épar's dans la moelle. Le Piper medium, dont nous donnons (fig. 104) une portion de coupe transversale de la tige, en est un exemple. Dans la région A, on voit les faisceaux foliaires réunis, comme dans les cas typiques des Dicotylédonées, en un anneau fermé interrompu seulement par les rayons médullaires $(m, m)$. Dans la région médullaire $B$, se trouvent les faisceaux surnuméraires $(v, v)$ disposés en cercle d'une façon plus ou moins régulière. A ce type de structure se rattachent diverses 
tiges parmi les Araliacées (Aralia racemosa), les Bigonniacées et un certain nombre d'Ombellifères : Silaus pratensis, Peucedanum, Opopanax chironium, Ferula communis, etc. Dans les plantes de cette dernière famille, les faisceaux surnuméraires placés en dédans des faisceaux foliaires peuvent alteindre un nombre considérable (13 dans le Silais, 20 dans l'Opopanax et jusquià 100 dans la Ferula communis). Ce nombre varie du reste dans les entre-nœuds successifs.

Gitons enfin, comme se rapportant à cette catégorie, un certain nombre d'Orobanchées à tige róbuste, telles que Orobanche elatior, rubens, caryophyllacea, etc., qui possèdent, en dedans du cercle des faisceaux foliaires, un certain nombre de petits faisceaux propres à la tige répandus dans la moelle.

$2^{\circ}$ Les faisceaux surnuméraires sont extérieurs par rapport aux faisceaux foliaires.

a. Les faisceaux surnuméraires propres à la tige constituent un anneau fermé, comme celui des Dicotylédonées anormales, et les faisceaux foliaires sont dispersés dans la moelle. C'est le cas de diverses plantes telles que Amarantus (Nægeli) Atriplex, Phytolacca, Mirabilis, etc.

b. Enfin les faisceaux foliaires sont disposés en un anneau sur la section transversale et leur accroissement s'arrête de bonne heure, le cambium ne persistant pas. Il se forme alor's en dehors, successivement, plusieurs anneaux concentriques libéro-ligneux, grâce à la formation d'un méristème qui se développe dans l'écorce primaire pour chacun de ces anneaux. L'écorce primaire, pour suffire à la formation de ces divers faisceaux, se développe à mesure. A ce cas se rattachent les lianes de la famille des Ménispermées (Cocculus, Cissampelos), dont la structure devient quelquefois encore plus anormale par suite de l'irrégularité des couches libéro-ligneuses successives ainsi formées. Les prernières, en effet, sont circulaires, mais bientôt celles qui se forment en dehors, au lieu de constituer des anneaux complets, ne forment que des moitiés d'anneaux qui s'appliquent sur l'une des faces des formations primitives; la moelle devient a'ors, sur la coupe transversale, complètement excentrique.

Les anomalies que présentent les tiges du genre Bauhinia, 
(Légumineuse) el celles de diverses Polygalées reconnaissent une origine semblable, avec cette différence que les nouveaux anneaux successifs de faisceaux surnuméraires prennent naissance dans l'écorce secondaire et non dans l'écorce primaire.

Ant. 2.

\section{Tige des Monocoțylédonées.}

On peut établir parmi les tiges des Monocotylédonées deux groupes distincts, suivant qu'elles sont ou non pourvues d'une assise de méristème capable d'engendrer de nouveaux faisceaux dans le cours de leur développement. Les Monocotylédonées chez lesquelles existe ce cercle générateur sont susceptibles d'un accroissement transversal plus ou moins considérable, et établissent le passage aux Dicotylédonées, bien que cet accroissement transvers̉al diffère essentiellement par son mécanisme de celui des Dicotylédonées. Quant à l'accroissement en longueur, il se produit comme chez ces dernières plantes.

\section{§ 4. TIǴES DÉPoUrvUes D'ANNEAU D'ÉPAISSISSEMENT .}

$1^{\circ}$ Tiges des paImiers. - Sur les coupes transversales, les différences de structure qui existent entre les tiges des Monocotylédonées et celles des Dicotylédonées n'apparaissent qu'à partir de l'époque où chez ces dernières se forment les ar'cs générateurs intrafasciculaires qui déterminent l'apparition de l'anneau libéro-ligneux et la division du tissu fondamental en moelle et écorce (1).

Chez les Palmier's, rien de semblable ne se produit, et les coupes transversales sont tout à fait caractéristiques. Dans un parenchyme homogène se voient épars, sans ordre apparent, de nombreux faisceaux qui occupent toute la surface de la section (fig. 10今). Par des coupes longitudinales on se rendra

(1) Chez quelques Monocotylédonées, particulièrement dans les gros rhyzomes, dans les tiges d'Allium. etc., le parenchyme fondamental est divisé en deux couches, lune corticale, l'autre centrale où se trouvent les faisceaux, pal une assise de cellules a parois épaisses (zone protectrice de M. Van Tieghem, Endoderme), qui d'ailleurs, à part le développement des parois cellulaires se retrouveraient dans toutes les tiges tant des Dicotylédonées que des Monocotylédonées. 
compte aisément de cette disposition. Tandis, en effet, que chez les Dicotylédonées normales tous les faisceaux, après être sortis des feuilles, viennent se ranger en un cylindre autour de la moelle et descendent parallèlement entre eux dans la tige, chez les Monocotylédonées qui nous occupent, les faisceaux ont un trajet beaucoup plus irrégulier.

Ghaque faisceau en sortant de la feuille correspondante se dirige d'abord, en décrivant une courbe à concavité inférieure, vers le centre de la tige. Puis il revient en décrivant une seconde courbe vers la périphérie, et enfin descend verticalement en

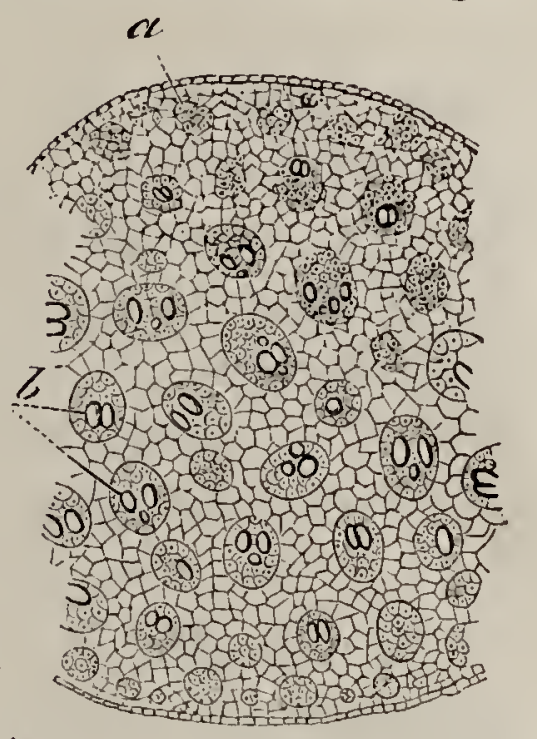

Fig. 105. - Coupe transversale d'une tige de Dattier. - a. Faisceaux de fibres. $-b$. Faisceaux libéro-ligneux.

se plaçant au dehors des faisceaux des feuilles plus âgées. Ce trajet se répétant pour chaque faisceau, il en résulte dans la partie centrale et moyenne de la tige des Palmiers un entre-croisement de faisceaux tel que sur les coupes transversales on ne peut s'attendre à trouver des anneaux vasculaires réguliers, mais bien la répartition irrégulière qui devient caractéristique (fig. 10气ั).

D'autre part, si l'on jette un coup d'œil sur la coupe, on voit que la répartition des faisceaux n'est pas la seule particularité intéressante qu'elle présente. La structure des faisceaux (faisceaux fermés) se montre, en eff'et, bien différente suivant que l'on étudie ceux du centre ou ceux de la périphérie. Plus on serapproche de l'épiderme, plus les faisceaux deviennent minces et pauvres en vaisseaux. Ceux qui sont placés tout à fait au voisinage de l'épiderme ne sont composés que de fibres épaisses

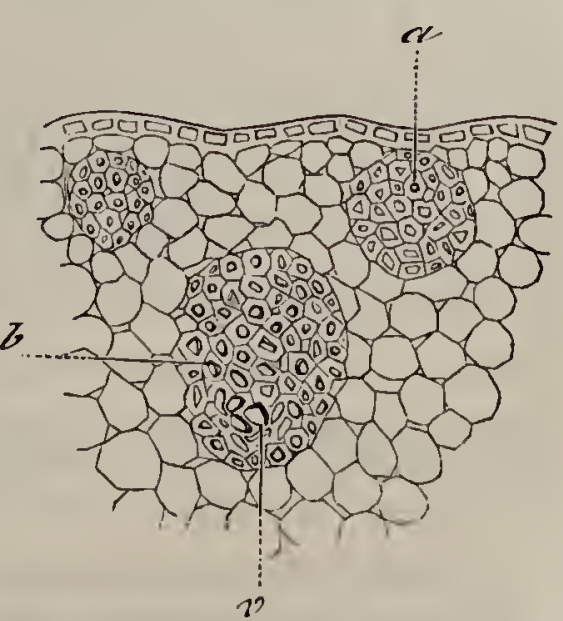

Fig. 106. - Les faisceaux fibreux du bord de la coupe précédente; vus à un plus fort grossissement. - $a$. Faisceaux de fibres. - $b$. Fibres. - $v$. Vaisseau. (fig. 106,a). Ils forment une couche fibreuse d'un développe- 
ment variable, peu dense dans les tiges des Calamus, Geonoma; Desmoncus, etc., et au contraire très dure dans celle des Phonix, Jubxa spectabilis, et surtout dans celle des Cocos, Elixs, Syagrus, etc. D'après Mohl (1), ces faisceaux fibreux représenteraient les extrémités inférieures des faisceaux fibro-vasculaires venus des feuilles, dont la structure se modifierait ainsi à mesure qu'ils s'éloignent de leur point de départ. Gette opinion est très-vraisemblable, surtout si l'on considère que les faisceaux voisins plus internes (fig. 106, b) renferment le plus souvent une ou deux trachées, et représentent en réalité, à un niveau plus élevé, les faisceaux venus des feuilles plus jeunes. On peut donc sur une seule coupe transversale observer toutes les modifications qui s'opèrent dans le parcours des faisceaux, puisque dans la partie centrale de la coupe se trouvent les sections des parties les plus élevées et en même temps les plus complètes des faisceaux foliaires.

Quoi qu'il en soit, certains des cordons fibreux de la périphérie ne seraient pas les extrémités des faisceaux libéro-ligneux, mais la continuation des faisceaux sclérenchymateux que l'on trouve sous l'épiderme des feuilles; ils seraient alors indépendants du système vasculaire de la tige.

$2^{\circ}$ Tiges des Graminées. - Dans les tiges (chaumes) à longs entre-nœuds des Graminées et de quelques Palmiers (Calamus, etc.), la marche des faisceaux n'est pas absolument identique à celle que nous venons de décrire. Dans toute la longueur des entre-nœuds, les faisceaux descendentverticalement dans la tige et parallèlement entre eux. Les courbures et les entre-croisements qu'ils forment à leur sortie des feuilles se localisent aux nœuds, et de leurs intrications résultent des plancher's ou diaphragmes (2) durs qui cloisonnent la tige souvent devenue fistuleuse par déchirement du parenchyme central.

(1) Mohl, Struchura Palmarum, Verm. Schrift., 1845.

(2) Dans les nouds du Maïs on voit même un réseau de faisceaux horizontaux qui concourent à former les diaphragmas. 
§ 3. TIGES POURVues D'Un aNNEAU d'ÉPAISISEEMENT.

Chez les Liliacées arborescentes telles que les Yucca parmi les Aloïnées, les Draccena (1) et Curdyline dans la tribu des Asparagées, on trouve, en dehors d'un corps ligneux composé, comme chez les Palmiers, de faisceaux communs aux feuilles et aux tiges, un nombre plus ou moins grand de couches concentriques de faisceaux fibro-vasculaires fermés et propres aux tiges, sortes de faisceaux surnuméraires venant, comme chez certaines Dicotylédonées anormales (page 23ă), s'ajouter au système ligneux typique. M. Millardet donne le nom de buis primordial à la partie centrale de la tige formée par les faisceaux communs à la tige et aux feuilles, et le nom de bois secondaire à la partie périphérique composée des faisceaux surnuméraires. Dans le bois primaire les faisceaux offrent dans leur répartition et leur structure la plus grande analogie avec ceux des tiges des Palmiers épars au milieu du tissu fondamental; ils sont complets dans la partie centrale, et réduits à leur portion fibreuse dans la partie périphérique.

Quant aux faisceaux surnuméraires, ils se forment au moyen d'un tissu générateur qui résulte de la transformation d'une assise du parenchyme fondamental parallèle à la surface de la tige. Ces faisceaux très grêles ne renferment pas de vaisseaux. lls s'anastomosent fréquemment entre eux et forment un réseau à mailles plus ou moins larges. La zone génératrice de ces faisceaux est permanente, de sorte qu'il en résulte un accroissement transversal souvent très considérable, quoique très lent, des tiges de ces plantes.

(1) Millardet, Sur l'anatomie et le développement du corps ligneux dans les genres Yuccaet Dracana (Mcimoires de la Soc. des sc. nat. de Cherbourg, t. XI, 186j!. 
AnT. 3.

\section{Tige des Acotylédones vasculaires.}

§ 6. TIGE DES FOUGÈRES (1).

Étude. - Connaissant la structure propre des faisceaux de ces plantes (voir page 216), deux faits nous restent à examiner dans l'étude de la structure de leurs tiges. En effet, sur les coupes transversales on constate une répartition très varia-

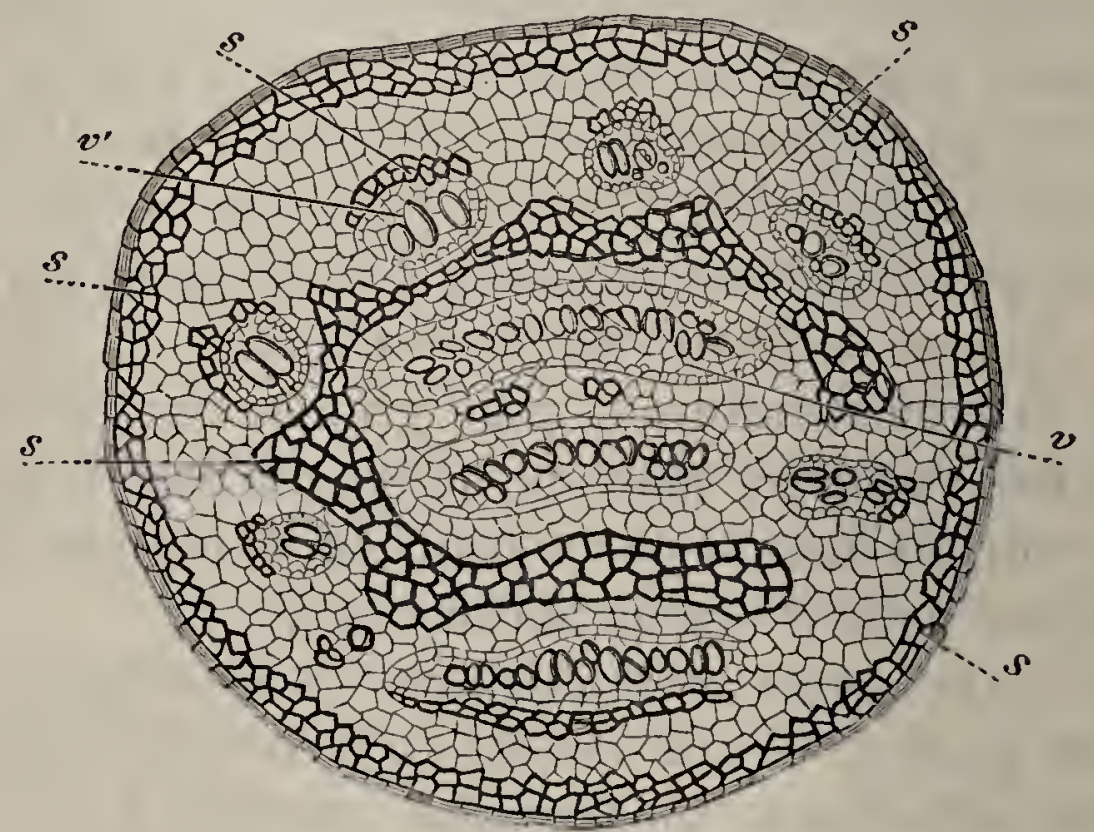

Fig. 107 - Coupe transversale de la tige du Pteris Aquilina. - s,s. Sclérenchyme.

ble, suivant les espèces, des faisceaux vasculaires, et d'autre part, des modifications dans le tissu fondamental.

Tissu fondamental. - Ces modifications consistent, d'une part, dans l'apparition d'une assise de cellules qui se différencient autour de chaque faisceau (gaîne des vaisseaux), et d'autre part, dans la formation d'éléments sclérenchymateux qui tantôt se répartissent en couches continues, comme cela se voit (fig. 107) au-dessous de l'épiderme de la tige du Pteris aquelina, tantôt se groupent en faisceaux de forme variée,

(1) Mettenius, Ueber d. Bau. und d. Wachsthum d. Farne. (Nova acta Acad. Lenpold., Ad. 28).

Mohl, Verm. Schrift.

Hofmeister, Beitr. zur Kenntniss. d. Gefasskryptogamen.

Trécul, Ann. des Sc. nat., $5^{\mathrm{c}}$ série, t. X; de Bary, loc. cit. 
comme le montre la même coupe (fig. 107, s,s), et les tiges de Gleichenia, Alsophilla, etc. Cette différenciation du tissu fondamental sous-épidermique en sclérenchyme se présente également dans les Fougères arborescentes. Ailleurs, au contraire, tout le tissu fondamental consiste en cellules à parois minces (Polypodium aureum, P. vulgare, Aspidium Filix mas, etc.).

Enfin, comme nous allons le voir, le tissu fondamental est fréquemment divisé en moelle et tissu cortical par suite de la disposition des faisceaux.

Répartition des faisceaux. - $a$. Faisceau axile et cylindre fasciculaire unique.

Dans un certain nombre de Fougères très grêles, la tige ne renferme qu'un seul faisceau qui en occupe le centre; cette disposition se rencontre particulièrement dans les $L y$ godium, parmi les Schizéacées, dans les Hymenophyllum, Gleichenia, etc.

Ailleurs le faisceau, axile dans le jeune âge, écarte bientôt ses éléments de telle sorte que, dans les grosses tiges, il forme un cylindre qui est alors remarquable par sa continuité. Il n'est interrompu que par de minces fentes linéaires au-dessous de l'insertion des feuilles, et c'est par ces fentes seulement que la moelle est mise en communication avec le parenchyme cortical. Quelques Schizéacées, le Loxosoma parmi les Hy ménophyllées, le Botrychíum lunaria parmi les Ophioglossées, présentent une semblable organisation.

Ce n'est là, du reste, qu'une variété dans l'organisation typique d'un grand nombre. de Polypodiacées, de Gyathées et en général des Fougères arborescentes. Dans ces plantes, en effet, de gros faisceaux se disposent en un cylindre qui divise le parenchyme fondamental en moelle et écorce. A chaque insertion de feuille correspond dans ce cylindre une lacune ou fente dont les bords se replient en dehors. C'est à l'existence de ces fentes qu'est due l'apparence de faisceaux semilunaires ou à cornes réfléchies vers l'extérieur que présentent les coupes transversales. Quoi qu'il en soit, le cylindre entier présente la forme d'un réseau dont les mailles sont formées par les fentes foliaires. Des bords de ces fentes $p$ artentles faisceaux foliaires qui traversent le parenchyme cortical pour 
arriver aux feuilles après un trajet plus ou moins long. Les faisceaux foliaires se retrouvent sur les coupes transversales en plus ou moins grand nombre, épars dans le tissu cortical. Ghez d'autres Fougères qui ne présentent sur la coupe transversale qu'un seul cercle de faisceaux, on remarque que deux de ces faisceaux ont un développement très considérable relativement à tous les autres. L'un de ces faisceaux occupe la face inférieure du rhizome, l'autre sa face supérieure. Ils cheminent ainsi parallèlement et s'anastomosent de place en place par des branches transversales qui s'unissent à angle plus ou moins aigu. Ces anastomoses déterminent ainsi les mailles d'un réseau, et c'est des bords de ces mailles que s'échappent de petits faisceaux foliaires qui, sur les coupes transversales, forment l'anneau vasculaire.

A cette structure, à part diverses modifications dans le nombre et le volume des faisceaux ainsi que dans la forme des fentes ou mailles, se rattachent les Asplenium obtusifolium, Acrostichum brevipes, A. simplex, Polypodium tenellum, Nephrolepis ramosa, Cespidium coriaceum, etc.

b. Faisceaux formant plusieurs cercles concentriques. Chez un certain nombre de Fougères, divers Pteris, Ceratopteris, etc., on trouve sur la coupe transversale plusieurs cercles concentriques de faisceaux semblables de configuration et d'épaisseur.

Parmi ces cercles concentriques, les plus extérieurs représentent la coupe de sortes de cônes emboîtés, dont les sommets embrassent le cylindre central. Ils sont formés, en effet, par les faisceaux foliaires émanés de ce cylindre, faisceaux qui, au lieu de pénétrer immédiatement dans les feuilles, cheminent sur une certaine longueur dans le parenchyme cortical en se rapprochant peu à peu de la périphérie.

c. Faisceaux accessoires dans la moelle ou dans le parenchyme cortical.

Enfin, chez un certain nombre de Fougères, outre le cylindre des faisceaux communs à la tige et aux feuilles, on voit se développer soit dans la moelle, soit dans le parenchyme cortical, des faisceaux accessoires.

Le Pteris Aquilina, par exemple, présente en dedans du cer- 
cle normal deux grands faisceaux $a$ (fig. 107) qui seraient propres à la tige.

On trouve des exemples de faisceaux accessoires dans un grand nombre de Cyathées.

\section{§ T. TIGE DES LYCOPODIACÉES.}

Dans les tiges des Lycopodiacées, tantôt on ne trouve qu'un seul faisceau qui en occupe l'axe (Selaginella denticulata), tantôt au contraire plusieurs faisceaux, ou bren séparés par du tissu fondamental et entourés chacun d'une gaîne spéciale (3 dans Selaginella incequalifoliu), ou bien réunis sans intermédiaire en un cylindre axile entouré d'une gaîne commune (Lycopodium). Quoi qu'il en soit, tous ces faisceaux sont caractérisés par ce fait que sur les coupes transversales leurs vaisseaux scalariformes sont disposés en séries allongées formant généralement deux rangées aux extrémités desquelles se trouvent les trachées.

D'autre part, chez les Selaginella, ces faisceaux sont généralement entourés de grandes lacunes dont les parois semblent des cordons cellulaires qui relient le faisceau au parenchyme fondamental. Ce parenchyme, à parois minces dans ces mêmes plantes, se transforme chez des Lycopodium en un sclérenchyme extrêmement dur.

Ajoutons à ce rapide exposé que les Isoètes présentent une dégradation de structure tout à fait particulière. L'axe de la tige de ces plantes est occupé par un faisceau de courtes cellules arrondies, lâchement unies entre elles et dont la paroi est munie de minces bandes d'épaississement spiralées ou réticulées. On peut à peine donner le nom de faisceau à ce tissu. (Sachs, loc. cit.)

\section{§ 8. TIGE DES ÉQUUISÉTACÉLS.}

Faisceaux. - Les faisceaux fibro-vasculaires des Équisétacées appartiennent au groupe des faisceaux incomplets dont il a été question plus haut (page 218). Disposés sur la coupe transversale en un cercle unique, ils sont situés le long des côtes 
que présente la tige annelée de ces plantes. Dans les entrenœuds développés (fig. 108), ils présentent à leur face interne une lacune produite par la résorption d'une partie des vaisseaux annelés et spiralés et la destruction des cellules du parenchyme voisin. Il y a donc sur la coupe transversale un cer-

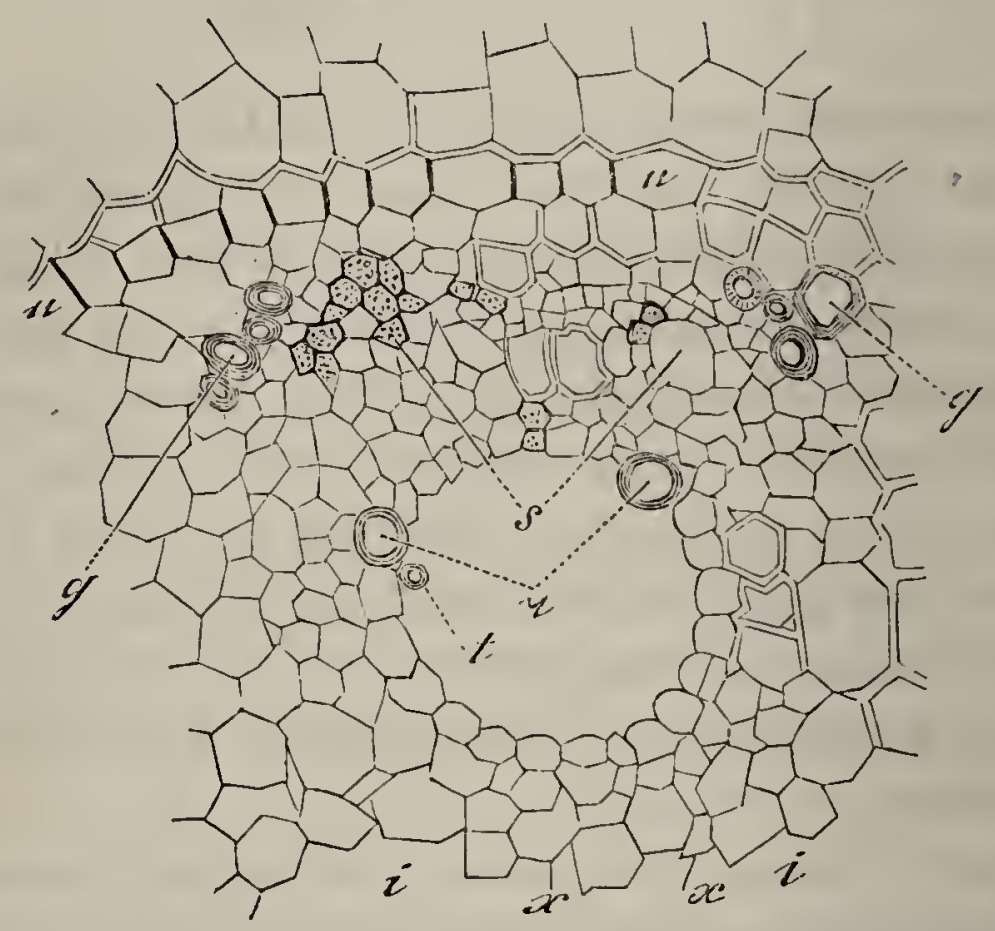

Fig. 108. Coupe transrersale d'un faisceau de la tige de l'Equisetum palustre.

cle de lacunes (lacunes carénales) en relation avec le cercle vasculaire. Dans la partie cribreuse des faisceaux existent souvent quelques vaisseaux annelés $(g, g)$ et, mêlés à de nombreuses cellules à parois minces, des tubes criblés $(s)$ qui complètent le faisceau. Enfin celui-ci est limité extérieurement par un endoderme, sorte de gaîne $(u)$ formée de cellules à parois radiales plissées, qui tantôt est propre à chaque faisceau, tantôt forme une enveloppe commune à tous les faisceaux du cylindre ligneux.

Tissu fondamental. - Épiderme. - Si l'on examine une coupe transversale générale d'un entre-nœud d'E quisetum on constate dans le tissu fondamental deux autres séries de lacunes, qui concourent à donner à ces tiges un aspect tout à fait caractéristique (fig. 109). Ce sont: d'une part, une grande lacune centrale formée par résorption et destruction du parenchyme médullaire; et d'autre part, à la périphérie, un cercle de lacunes qui alternent avec les lacunes carénales des faisceaux et se trou- 
vent par suite correspondre aux sillons de la tige (lacunes valléculaires). Comme la la cune centrale, ces lacunes valléculaires sont le résultat d'une destruction des cellules du parenchyme fondamental. Elles sont généralement limitées en dehors pardes bandes de cellules à chlorophylle, qui peuvent prendre un développement plus ou moins considérable.

Quant à l'épiderme, caractérisé par une incrustation de silice qui semble remplacer la cuticule, il est de plus pourvu de stomates d'une configuration spéciale (voir page 177) qui occupent le fond des sillons; cet épiderme est souvent renforcé intérieurement par un hypoderme qui résulte de la différenciation

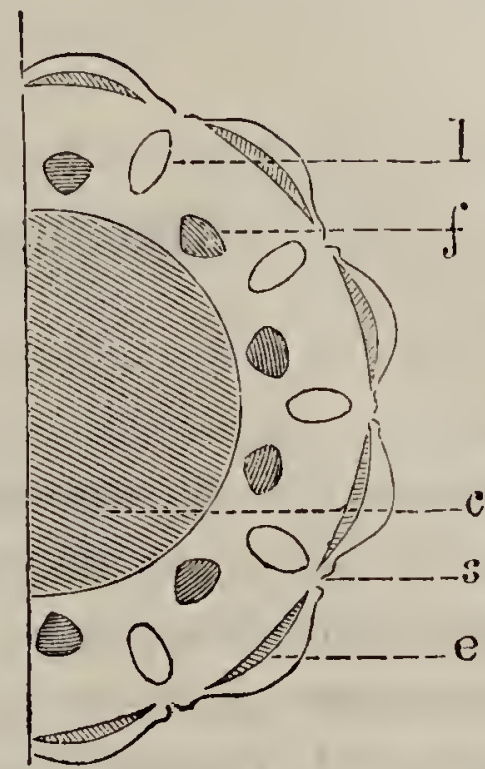

Fig. 109. - Tige d'Equisetum. c. Lacune centrale. - $l$. Lacunes valléculaires. - $f$. Faisceaux. des cellules périphériques du tissu fondamental, en éléments scléreux disposés tantôt en faisceaux, tantôt en couche continue et sur plusieurs rangs.

§ 9. aCcroissement terminal DES tiges des Gryptogames vasculaires.

Les tiges des Cryptogames vasculaires se différencient très nettement des tiges des Phanérogames par leur mode d'accroissement en longueur. Ce n'est point comme chez les Phanérogames par l'intermédiaire d'un méristème, mais au moyen d'une seule cellule terminale en forme de pyramide triangulaire (dans les Equisetum) que se fait l'allongement de la tige des Cryptogames. Des cloisonnements successifs de cette cellule, d'abord parallèles à ses faccs, donnent naissance à un premier groupe de cellules qui se cloisonnent elles-mêmes dans des sens divers et bien déterminés. Ainsi se forme un tissu qui par des différenciations ultérieures donnera lieu à l'épiderme, aux faisceaux fibro-vasculaires et au parenchyme fondamental. Nous ne saurions entrer à ce sujet dans des détails que ne comporte pas cet ouvrage. 


\section{CHAPITRE VI}

\section{STRUCTURE DE LA RAGINE}

Étude. - Ge que nous avons dit au sujet des tiges tant pour la direction des coupes que pour les différents modes de préparation s'applique également aux racines. Nous ferons remarquer toutefois qu'il est très important pour les recherches sur la racine d'avoir à sa disposition des sujets frais et non altérés. Cette dernière condition est souvent difficile à remplir, car en déterrant les racines que l'on veut étudier, on les déchire fréquemment à la surface et l'on détruit l'extrémité si l'on ne prend les plus grandes précautions. Aussi devra-t-on enlever les racines avec la terre qui les entoure, puis les placer dans l'eau jusqu'à ce qu'elles soient débarrassées de toute impureté. Pour l'étude de la pilorhize et du point végétatif, on aura même tout avantage à employer les racines que développent dans l'eau les nombreux oignons à fleur qu'il est si facile de se procurer.

\section{Arr. 1.}

Racines des Phanérogames et des Gryptogames (1).

Les racines des Phanérogames et des Cryptogames vasculaires présentent pendant la première période de leur développement la même structure générale. Ce n'est que par suite de formations secondaires ou au moyen de caractères indépendants de leur structure histologique qu'on peut les distinguer

(1) Nœgeli et Leitgeb, Entstehung u. Wachsthum d. Wurzeln München, 1867.

Van Thiegem, La racine. Recherches sur la symétrie de structure dans les plantes vasculaires (Ann. des sc.nat., $5^{\mathrm{e}}$ série, t. XIII); de Bary, loc. cit. 
plus tard. Aussi conseillons-nous d'étudier d'abord de jeunes racines prises dans ces deux groupes de plantes. C'est seulement après avoir constaté leur identité de structure à cette époque qu'on pourra mieux saisir les modifications qui leur donnent ensuite leurs caractères propres.

Période primaire. - Toute racine jeune se compose essentiellement d'un tissu fondamental recouvert d'un épiderme et traversé en son milieu par un cylindre fibro-vasculaire. A sa face profonde, au contact avec le cylindre fibro-vasculaire, le tissu fondamental se différencie en une assise de cellules à parois radiales plissées (fig. $110 p$ ) qui reçoit le nom de zone

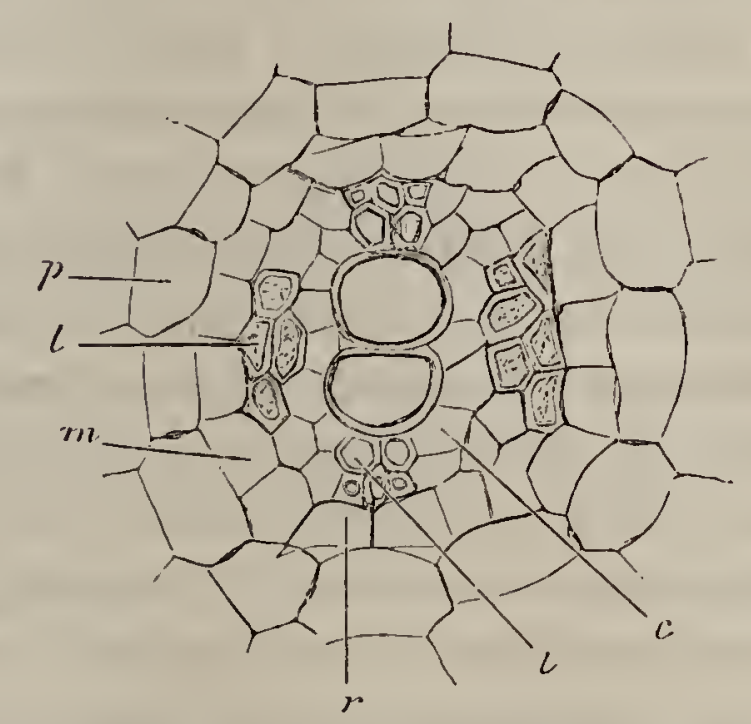

Fig. 110. - Coupe transversale d'une racinc binaire dans une Monoeotylédone (pivot del'Allium Cepa). $-c$. Tissu eonjonctif. $-p$. Membrane protcetriee. - $v$. Bandc vasculaire formée de dcux faiseeaux qui se joignent au centre. - $l$. Faisceau libérien. $m, r$. Zone rhizogrène.

motectrice ou endoderme, analogue à celle que nous avons déjà rencontrée autour des faisceaux dans la tige.

Le cylindre fibro-vasculaire central mérite une étude spéciale. Il est considéré par la plupart des botanistes français comme formé par un groupe de faisceaux qui se distinguent au premier abord de ceux de la tige en ce que leurs parties vasculaire et libérienne, au lieu d'être juxtaposées, l'une en dedans, l'autre au dehors, se trouvent placées l'une à côté de l'autre, séparées par une ou plusieurs assises de cellules. En un mot, dans la racine, le liber et le bois des faisceaux alternent l'un avec l'autre (fig. 110). Pour les botanistes allemands 
(Sachs, de Bary, etc.), le cylindre fibro-vasculaire représente un seul faisceau du groupe des faisceaux rayonnants (voir page 217) caractérisés en ce que leur partie vasculaire est disposée par bandes ou lames radiales entre lesquelles, et alternant avec elles, se trouvent en même nombre de semblables lames libériennes.

Quelle que soit l'opinion que l'on adopte, les faisceaux ou rayons vasculaires et libériens primaires de la racine se différencient encore très nettement des faisceaux de la tige, par leur mode de développement. Dans la racine, c'est par la périphérie que commence l'apparition ảes premiers éléments caractéristiques, vaisseaux spiralés d'une part et éléments cribreux de l'autre. De là, la formation gagne le centre du cylindre axile où l'on trouve alors les vaisseaux à grand diamètre. - Par suite, sur les coupes transversales des très jeunes racines, le nombre des points de développement périphériques suffit à faire connaître le nombre des faisceaux ou rayons vasculaires et libériens qui existeront plus tard. - L'orientation de ces points de développement est d'ailleurs parfaitement déterminée. Dans une racine binaire par exemple, les points de développement des deux faisceaux ou rayons vasculaires se trouvent aux deux extrémités de l'un des diamètres du cylindre axile. Ceux des parties libériennes correspondantes occupent les extrémités du diamètre en croix avec le précédent (fig. 110). Lorsqu'il y a un plus grand nombre de parties vasculaires et libériennes, celles-ci se trouvent réparties sur les coupes transversales à des distances égales les unes des autres.

Dans certaines racines, par suite de leur développement centripète, les faisceaux ou rayons vasculaires arrivent à se toucher au centre du cylindre (fig. 110); mais souvent aussi ils restent plus ou moins écartés les uns des autres. Le vide central qui en résulte est comblé par un tissu parenchymateux, sorte de moelle d'où partent des lames cellulaires qui se placent entre les faisceaux ou rayons vasculaires et libériens pour venir aboutir en dedans de l'endoderme à une assise régulière de cellules qui forment le péricambium (Nœgeli et Leitgeb) ou zone rhizogène (Van Thiegem) (fig. 110, $m, r$ ). 
Telle est la structure de la racine dans la période primaire chez toutes les plantes vasculaires. Les différences que l'on observe consistent principalement dans le nombre des faisceaux ou rayons vasculaires et libériens qui forment le cylindre axile. Au nombre de deux (racines binaires) chez un grand nombre de Dicotylédonées : Crucifères (Brassica, Raphanus), Fumaria, Caryophyllées, Vitis, Urtica, Ombellifères (Anthriscus cerefolium, Fæniculum, Petroselinum sativum, Carum carvi, Coriandrum, Daucus, Pastinaca sativa, etc. (Van Thiegem), Chenopodées (Beta atriplex, mirabilis), Centranthus et Valeriana, Tagetes erecta, on en trouve généralement quatre chez les Cucurbitacées, les Euphorbiacées (Euplıorbia, Ricinus, Mercurialis, Tropoolum majus), etc. Chez les Papilionacées leur nombre varie avec les espèces. Il y en a deux dans Lupinus varius, Trigonella; trois dans Pisum sativum; Orobus vernus, Vicia sativa, Medicago sativa, Ervum lens; quatre dans Phaseolus, Dolichos liynosus, Cicer arietinum; cinq, sept et même douze dans Vicia faba (Van Thiegem). D'après le même auteur, ce nombre est également sujet à varier pour la même espèce dans divers Pins, où on en peut trouver de trois à sept.

Le nombre de ces parties vasculaires et libériennes (de 2 à 20 et même 50) varie également chez les Monocotylédonées et les Cryptogames. Parmi ces dernières, les petites racines sont généralement binaires (Cyathea medullaris). Les grosses racines présentent 3 ou 4 lames vasculaires et même jusqu'à 15 et 20 dans les racines volumineuses de Maraltia et d'Angiopteris (Van Thiegem).

Zone rhizogène (fig. $110, m, r)$. - Les fonclions propres à la zone rhizogrène établissent un premier caractère distinctif qui sépare complétement les racines des Gryptogames de celles des Phanérogames (Van Thiegem). Chez les Phanérogames, en effet, c'est cette assise qui devient le point de départ de la formation des radicelles. Les groupes de cellules génératrices sont alors généralement placés en face des faisceaux ou rayons vasculaires (1). Chez les Cryptogames, au contraire, cette assise reste inactive ou même manque totalement (Prêles), et c'est l'endoderme qui produit les radicelles (Fougères, Marsi-

(1) M. Van Thiegem cite cependant quelques exceptions à cette règle: chez les Graminées, d'une part, la membrane rhizogène s'interrompt d'une façon régulière en face des vaisscaux, de sorte que les radicelles se produisent en face des faisceaux libériens. D'autre part, chez les Ombellifères et les Araliacées, la membrane rlizogène est creuséc en face des faisceaux vasculaires et des faisccaux libériens par des canaux sécréteurs qui empêchent la formation des radicelles. Celles-ci naissent alors entre les parties libérienne et vasculailc. Chez le Pittosporum, enfin, elles naissent en face des faisceaux libériens, la zone rlizogène étant interrompue en delor's des faisccaux vasculaires par un arc de canaux sécréteurs. 
liacées). Chez les Prêles, l'endoderme caractérisé par les parois plissées de ses cellules forme l'avant-dernière couche du parenchyme cortical, il joue uniquement un rôle de protection, et c'est une assise plus interne qui engendre les radicelles. Mais dans aucun cas, chez les Cryptogames (1), la membrane rhizogène ou péricambium n'intervient dans la formation des radicelles.

Si maintenant on examine l'orientation des faisceaux des radicelles relativement aux faisceaux de la racine principale, on trouvera une nouvelle différence caractéristique entre les Gryptogames et les Phanérogames. Chez les Cryptogames, quand la structure de la radicelle est binaire, le plan de ses faisceaux est toujours en croix avec l'axe de la racine mère. Ghez les Phanérogames, au contraire, le plan des faisceaux de la radicelle passe par l'axe de la racine mère.

Le mode d'origine et l'orientation des faisceaux des radicelles fournissent donc des caractères distinctifs très nets entre les racines des Cryptogames et celles des Phanérogames. Quant aux caractères distinctifs entre les racines des Monocotylédonées et celles des Dicotylédonées, ils sont essentiellement fournis par l'apparition de productions secondaires chez ces dernières, productions qui altèrent profondément leur structure primitive et qui déterminent souvent un accroissement considérable en épaisseur. Chez les Monocotylédonées, au contraire, la racine ne s'épaissit pas, et conserve ses premiers caractères de structure (il en est de même chez les Cryptogames). Les seules modifications consistent dans l'épaississement fréquent des parois radiales et internes des cellules de l'endoderme ou couche protectrice (fig. 112), dans la formation d'un hypoderme ou d'une couche subéreuse à la périphérie du parenchyme cortical, enfin dans des dégradations de structure qui arrivent même, dans les cas extrêmes (Vallisneria, Lemmacées), jusqu'à faire disparaître le faisceau vasculaire axile, dont la place est occupée par une grande lacune. Période secondaire dans le développement des racines des Dicotylédonées. - A la période primaire, avons-nous dit, succède

(1) Les Lycopodiacées et les Ophioglossées ne produisent pas de radicolles latérales. Elles se ramifient par dichotomic. 
cher. les Dicotylédonées une période secondaire qui les caractérise essentiellement. De nouvelles productions apparaissent, et prennent leur origine dans un cambium qui se développe à la face interne des faisceaux ou rayons libériens. Ces assises de cambium, se rejoignant bientôt au dehors des faisceaux ou rayons vasculaires au moyen d'un dédoublement des cel-

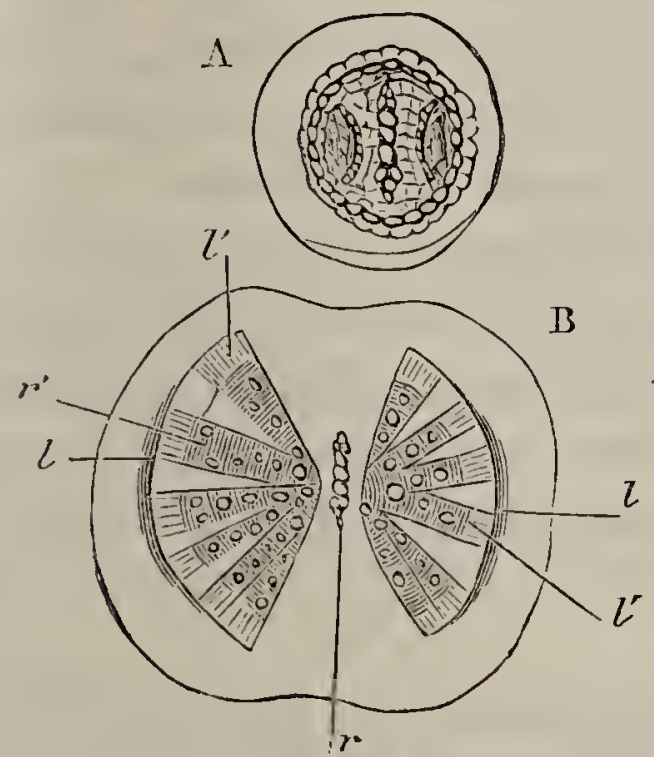

Fig. 111. - Sections transversales d'une racine adventive de Capucine (Tropoolum majus. - A. Avant l'apparition des productions secondaires. - B. Après la formation des deux faisceaux libéroligneux secondaires. (D'après Van Thiegem.)

lules de l'assise rhizogène, forment bientôt un anneau générateur continu (Van Thiegem, loc. cit.). Cette couche génératrice se comporte alors comme le cambium de la tige et développe en dedans, par formation centrifuge, des éléments ligneux, et en dehors, par formation centripète, des éléments libériens. Ces productions secondaires peuvent prendre naissance sur toute l'étendue de la zone génératrice ou se localiser aux parlies de cette zone qui correspondent aux faisceaux libériens primaires. Dans ce dernier cas, les arcs générateurs extérieurs aux faisceaux vasculaires primaires ne produisent que des cellules parenchymateuses.

Quoi qu'il en soit, par suite de ces formations, le liber primaire est repoussé au dehors (fig. $111, l$ ), tandis que le bois primaire $(r)$ reste en dedans des nouvelles couches. Les coupes que nous reproduisons d'après M. Van Thiegem montrent les changements qui se sont opérés depuis la période primaire (A), où la section transversale est comparable à la 
coupe de la racine de Monocotylédone figurée plus haut (fig. 110), jusqu'à l'entier développement de la racine du Tropoolum majus. On peut voir quel important développement prennent les formations secondaires.

En même temps que ces modifications se produisent dans le cylindre ligneux, la membrane rhizogène se transforme en zone génératrice et produit en dehors une couche subéreuse et, en dedans, du parenchyme cortical secondaire. - Il en résulte une écorce secondaire qui fréquemment persiste seule, l'écorce primaire venant à s'exfolier.

Telles sont les formations secondaires qui seules établissent une distinction entre les racines des Dicotylédonées et celles des Monocotylédonées, puisque d'autre part ces racines sont absolument comparables tant par le mode d'origine de leurs radicelles que par l'orientation des faisceaux de ces radicelles (Van Thiegem).

On pourra prendre comme exemple des différences de structure entre les racines développées des Dicotylédonées et celles des Monocotylédonées, les racines connues sous le nom d'Ipécacuantas et les racines des Salsepareilles.

Ipécacuunhas. - Dans toutes ces racines les formations secondaires produisent un corps ligneux central, qui acquiert une grande densité et que l'on nomme méditullium. Ses vaisseaux, à large ouverture dans les Ipécas ondulé et strié mineur, sont au contraire d'un calibre relativement étroit dans les lpécas annelé et strié majeur. De plus, dans ce dernier le parenchyme cortical est complètement dépourvu d'amidon, tandis qu'il en regorge dans les trois autres espèces. A la périphérie de ce parenchyme cortical se trouve ordinairement un périderme formé de plusicurs assises de cellules subéreuses.

Sulsepareilles. - Dans les racines de Salsepareille on retrouve l'organisation propre aux racines des Monocotylédonées, qui conservent, nous l'avons dit, leur structure primaire. Sur les coupes transversales, en effet, on voit (fig. 112,l) les faisceaux libériens alterner avec les faisceaux vasculaires $(v)$ qui se réunissent par deux et prennent ici, comme cela est fréquent d'ailleur's chez les Monocotylédonées, la forme d'un $\mathrm{V}$ dont l'ouverture tournée au dehors embrasse la partic libérienne.

Ces racines présentent encore à la périphérie du parenchỵme cortical un hypoderme très développé $(h)$, et à la face profonde du même parenchyme un endoderme, ou couche protectrice, sous forme d'une assise de cellules dont les parois sont considérablement épaissies (fig. 112, p). 


\section{CHAPITRE VI. - STRUGTURE DE LA RACINE.}

Les caractères distinctifs des principales sortes de Salscpareilles sont tirés de l'examen du faisceau libéro - ligneux axile très développé par rapport à la moelle dans les Salsepareille de la Vera-Cruz et Salsepareille rouge, par exemple, et au contraire ne formant qu'un mince anneau autour d'une large moelle dans les Salsepareilles Caraque (fig. 112) et du Para; ou un anneau plus épais dans la Salsepareille de Honduras. - Le nombre des assises cellulaires de l'hypoderme (epiblema), ainsi que la forme des ouvertures des cellules de la couche protectrice vues en section transversale, fournissent également de bons caractères distinctifs.

Ces cellules à ouverture carrée à peu près régulière caractériscnt la Salsepareille Caraque (rig. $112, c)$. Elles présentent des ouvertures polygonales dans la Salsepareille de Hondurus (fig. 112, H'. Enfin, leurs ouvertures sont plus ou moins régulière-
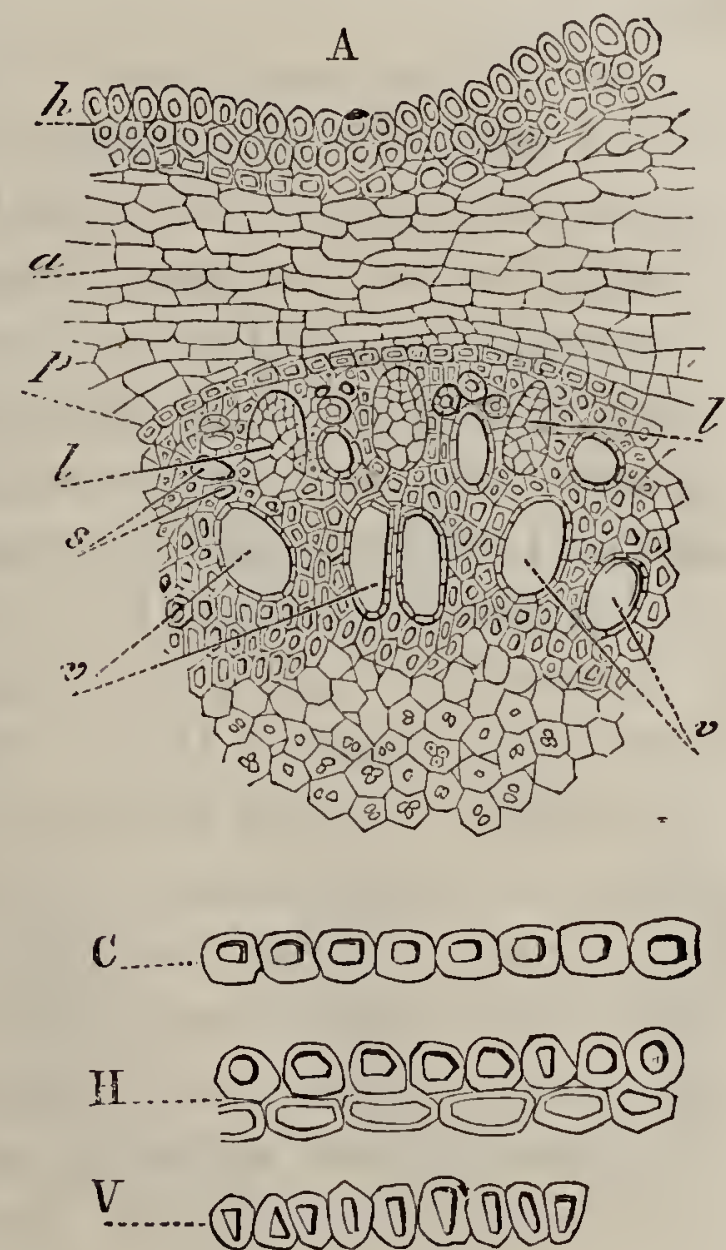

Fig. 112. - Coupe transversale sur la racine de Salseparcille earaque. - Voir l'explicatiun dans le texte. ment triangulaires dans la Salsepareille de la Vera-Cruz (fig. 112, V). (Planchon, loc. cit.)

Racines aériennes des Monocotylédonées. - Les racines aériennes de certaines Monocotylédonées épiphytes et particulièrement celles des Orchidées et Aroïdées sont remarquables par la présence d'une sorte de manteau (velamen) de cellules spiralées ou trachéides qui les recouvre et est séparé du tissu parenchymateux cortical vert par une assise de cellules sur la nature desquelles deux opinions sont en présence. Suivant MM. Schleiden et A. Chatin (1), cette assise cellulaire représente l'épiderme et $M$. Chatin la nomme membrane épidermoïdale. - Pour MM. Oudemans (2), Leit-

(1) A. Chatin, Mémoires de la Sor. de Cherbourg, vol. IV, 1856.

(2) Oudemans, Ueber den Sitz der Oberhaut bei den Luftwurzeln der Orchideen (Abhandl. d. K. Acal. z. Amsterdam, 1861. Math. phys., classe IX). 
geb (1), de Bary (loc.cit.), etc., cette couche représente l'endoderme.

Quoi qu'il en soit, d'après Treub et de Bary, le vélamen des racines aériennes des Orchidées est une production du dermatogène. Rarement il est réduit à une seule assise de cellules (Vanilla planifolia, aphylla, Sarcopodium Lobbii); le plus souvent il comporte de 2 à 18 couches de cellules, pressées les unes contre les autres et qui ne laissent aucun méat entre elles (1).

Les cellules du vélamen renferment de l'air; ordinairement à parois incolores, elles forment une couche blanche luisante. - Plongées dans l'eau, elles absorbent rapidement ce liquide et laissent voir alors par transparence la matière verte du parenchyme cortical. D'après Leitgeb, dans les vieilles racines (Vanda furva, Anselia africana), dans l'intérieur des cellules spiralées, on trouverait de très petites cellules vertes d'algues qui donnent aux racines une couleur verte.

Toutefois, quelques racines présentent une coloration brune; dans l'Eria stellata par exemple, cette coloration est due aux parois des cellules spiralées qui sont brunes; dans le Trichotosia ferox, les trachéides sont remplis d'une substance colorée en rouge brun. Enfin Leitgeb a quelquefois rencontré, voire même en grande abondance dans le Renanthera coccinea, des granulations plus ou moins grosses formées d'une substance noire brunâtre, qui occupent de préférence les couches cellulaires les plus profondes.

Chez les Aroïdées épiphytes on rencontre un vélamen semblable à celui des racines des Orchidées; il est tantôt formé de quatre à cinq assises de cellules spiralées ou réticulées ( $A n$ thurium acaule, égregium, crassinervium, intermedium), tantôt de deux assises seulement. Dans l'Homalonema cærulescens, on trouve six assises de cellules, mais celles-ci sont lisses et à parois minces. Un pareil vélamen formé de cellules à parois lisses et minces se retrouve dans l'Anthurium violaceum, le Philodendron pedatum et autres Aroïdées. Les racines aériennes de l'Hartwegia comosa et celles du Hoya carnosa présentent une organisation semblable.

(1) Leitgeb, Die Luftwurzelh.... Deutschr. d. Wiener Acarl. Math. naturw. Classe Bd 24, 1s6i.

(2) Voir encore : Fockens, Ueber die Luftwurzeln. Diss., Güttingen, 1857. 
1. ACCroissement EN LONGUeUR des RaCines. - PILORhize.

La racine possède comme la tige un cône végétatif, par lequel se fait l'accroissement en longueur. Différencié chez les Phanérogames en dermatogène, périblème et plérome (fig. 113 et 114), comme le cône végétatif de la tige, il se comporte de la même manière dans le développement des tissus. Dans les figures que nous reproduisons d'après M. Hanstein, l'assise cellulaire externe ombrée (d) représente

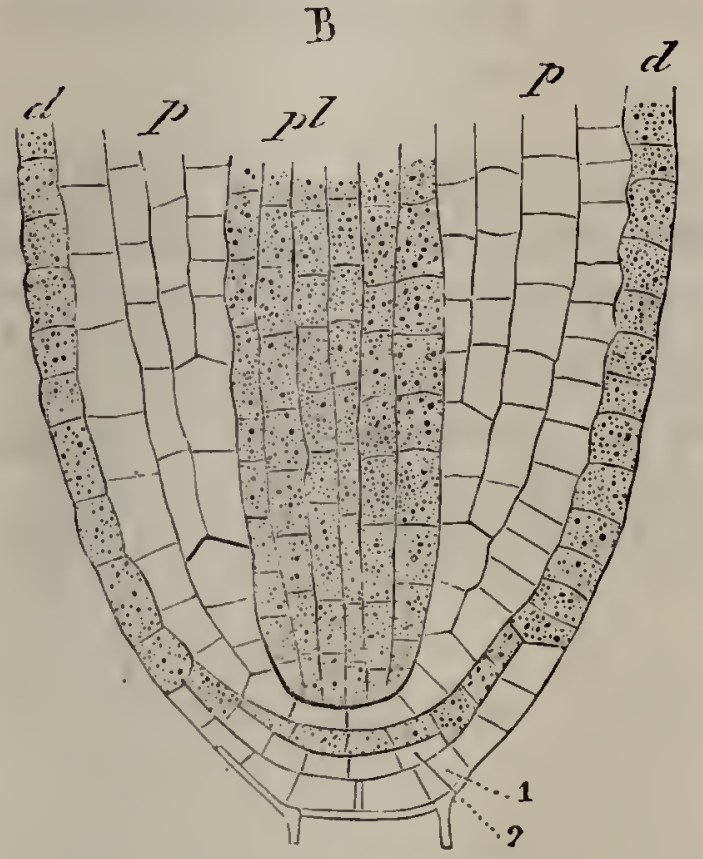

Fig. 113. - Figure théorique montrant la formation de la racine principale dans un cmbryon dicotylédoné, d'après M. Hanstein.
A

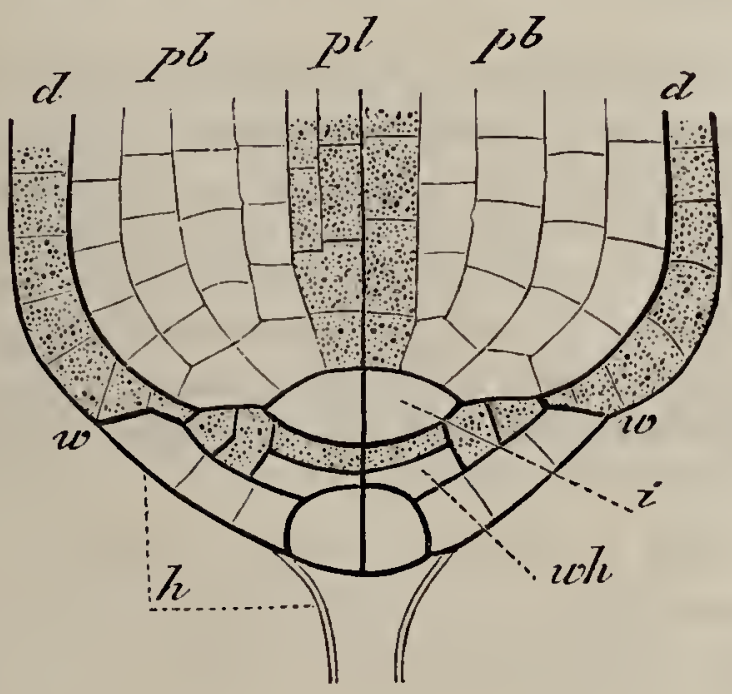

Fig. 114. - Figure théorique montrant la même formation chez les Monocotylédonées, d'après M. Hanstein. - $w, w$. Limite de la tige et de la racine. - $h$. Hypophyse.

le dermatogène. Les assises cellulaires centrales également ombrées $(p l)$ constituent le plérome. Quant aux assises $(p)$ intermédiaires, elles forment le périblème. Ghez les Cryptogames, d'autre part, le développement de la racine comme celui de la tige se fait par les cloisonnements successifs d'une cellule terminale.

Mais il est un fait qui caractérise le point végétatif des racines, c'est l'existence d'une pilorhize ou coiffe, qui recouvre leur extrémité et sert d'organe protecteur au cône végétatif.

Pilorhize. - La Pilorhize est un organe qui se développe 
soit par segmentation de la cellule terminale, chez les Cryptogames, soit par des divisions tangentielles des cellules du dermatogène chez les Phanérogames, comme le montrent les figures 113 et 114 ( 2 et $w h$ ). Plusieurs assises de cellules prennent naissance de la sorte èt forment une gaîne à l'extrémité de la racine, gaîne qui s'exfolie extérieurement en mềme temps qu'elle se reproduit intérieurement, le dermatogène se subdivisant d'une manière continue pour former de nóuvelles as sises de cellules. Cettè coiffe s'observera très facilement à l'extrémité des racines des Lemna, où elle forme une gaîne souvent très puissante semblable à un doigt de gant qui protège efficacement l'extrémité de la racine (1).

(1) Il nous est impossible d'entrer ici dans les détails relatifs à la formation de la coiffe dans l'embryon et aux différences que l'on observe dans son origine. Nous renvoyons aux recherches publićes par M. M. Reinke, Untersuchungen über Wachstumgeschichte u. Morphologie..... Bot. Abhandl., I, 1871. - Hanstein, Die Entwick. des Keimes der Monocot. u. Dicot. bot. Abhandl., 18;0. - Janczewski, Recherches sur l'accroissement terminal des racines dans les Plianérogames. Ann. sc. nat., Bot., $5^{\mathrm{e}}$ série, t. XX, 1875 . Flahaut, Bull. Soc. bot. de France, t. XXIV, 1877 et Thèse de la Sorbonne, 1878. 


\section{CHAPITRE VII}

\section{FEUILLES. BOURGEONS}

Étude (1). - Pour l'examen de la strùcture du pétiole on fera des coupes transversales et longitudinales. Cette partie de la feuille est essentiellement constituée par un ou plusieurs faisceaux provenant de la tige, rapprochés et dirigés parallèlement entre eux, de manière à former un cylindre ou plus souvent un hémicylindre qui occupe l'axe du pétiole. Sur les coupes transversales le pétiole et sa partie fibro-vasculaire affectent le plus souvent une apparence semi-lunaire, rarement circulaire. La constitution des faisceaux est d'ailleurs semblable à celle des faisceaux de la tige, et les trachées occupent la partie concave de la coupe.

- Ces faisceaux sont entourés d'un parenchyme plus ou moins riche en chlorophylle recouvert d'un épiderme ordinairement formé d'une seule assise de cellules. Dans un grand nombre de plantes aquatiques le parenchyme se creuse de canaux très larges, qui se remplissent d'air. (Voir fig. 60, pétiole de Cabla.)

Pour étudier le limbe des feuilles, on fera des coupes perpendiculaires à sa surface, dirigées, les unes transversalement, et les autres longitudinalement. Ces coupes se font très aisément sur les feuilles coriaces et épaisses. Déjà plus diffiles à pratiquer sur les feuilles charnues, elles le sont encore davantage sur les feuilles molles. On peut alors, avant de faire les coupes, replier la feuille plusieurs fois sur elle-même, de

(1) Brongniart, Recherches sur la structure et les fonctions des feuilles. Ann des sc. nat., Bot., $1^{\text {re }}$ série, t. XXI; - J. Chatin, loc. cit. 
manière à obtenir une petite masse plus dense que l'on introduit entre deux morceaux de moelle de sureau. On pratique alors en grand nombre des coupes que l'on recueille dans un baquet plein d'eau, et parmi ces coupes on choisit celles qui paraissent.plus propres à l'observation. Il ne faut pas oublier que, les tissus du limbe étant généralement gorgés de chlorophylle, les coupes doivent être très minces pour être examinées utilement. Si cependant la chlorophylle devenait un obstacle par trop gênant, on pourrait éclaircir les coupes au moyen d'acide acétique et les monter dans la glycérine. Mais ce procédé ne doit être employé qu'avec beaucoup de ménagements, car l'acide acétique peut altérer certaines substances contenues dans le tissu des feuilles (cystolithes des Urticées, etc.). - Quoi qu'il en soit, an moyen des coupes on constate l'arrangement des faisceaux fibro-vasculaires (nervures) au milieu du parenchyme. On examine la structure de ce parenchyme ainsi que les épidermes qui le limitent aux faces supérieure et inférieure du limbe. On étudie sur ces épidermes les stomates, les poils, les glandes, etc. (Voir p.179); dans le parenchyme, les glandes, les cristaux, les canaux résineux (Conifères, Ombellifères). Enfin on complète cette étude par l'examen en surface des cellules épidermiques, au moyen de lambeaux que l'on prépare comme il a été dit plus haut (p. 162).

\section{$\S 1$. STRUCTURE DU LIMBE.}

1. Nervures. - Les nervures des feuilles présentent une structure variable dans les différents points de leur parcour's. - Les grosses nervures, ou nervures principales, sont le prolongement des faisceaux du pétiole et offrent généralement. la même composition. Souvent très développées, elles proéminent plus ou moins à la face supérieure et surtout à la face inférieure du limbe (fig. 113, A) et sont généralement accompagnées d'un parenchyme incolore à éléments souvent épaissis. quelquefois même modifié en collenchyme au voisinage de l'épiderme.

Dans certaines feuilles (Phormium tenax) chacune des ner- 
vures est accompagnée d'une enveloppe de fibres très épaisses qui, s'étendant jusqu'aux épidermes, forment une sorte de cloison fibreuse longitudinale.

Dans les feuilles aciculaires de beaucoup de Conifères, le faisceau (fig. 117), axile, est entouré d'un tissu incolore à élé-
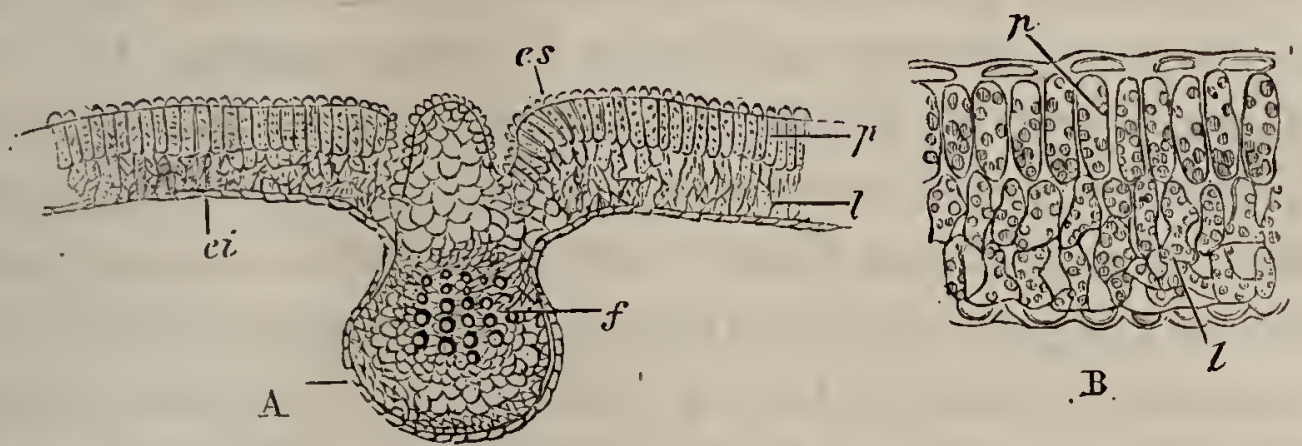

Fig. 115 et 116. - Feuille de Malva Mauritiana. - A. Coupe transversale passant par la nervure médiane. - ei. Épiderme inférieur. - es. Épiderme supérieur. - $p$. Parenchyme en palissade. $-l$. Parenchyme lacuneux. $-f$. Faisceau de la nervure médianc. - B. Une portion de la coupe précédente vue à un fort grossissement.

ments très caractéristiques, en même temps qu'un hypoderme formé de cellules ou de paquets de fibres épaisses se distingue à la périphérie du limbe.

Étudiées dans leurs dernières ramifications, les nervures ne sont plus composées que de trachées qui bientôt même cèdent la place à des cellules allongées, derniers vestiges de l'organisation vasculaire du faisceau.

Chez les Orchidées, les faisceaux disposés en trois plans présentent une structure différente suivant leur siège. Ceux du plan médian, qui souvent existent seuls, sont de beaucoup les plus volumineux et offrent les mêmes élé- Fig. 117. - Coupe transversale ments que les faisceaux des tiges.

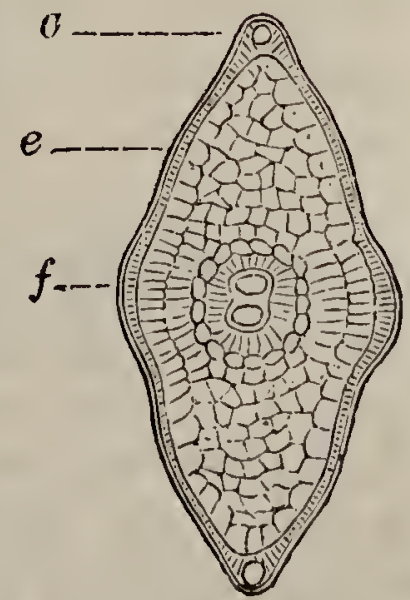
d'une feuille. Quant aux faisceaux des plans inférieur et supérieur, voisins de l'épiderme, ils sont beaucoup plus grêles et consistent uniquement en paquets de fibres épaisses et habituellement ponctuées (1).

(1) A. Chatin, Anatomic des plantes aériennes de l'ordre des Orchidées (Mémoires de la Société des sciences naturelles de Cherbourg, t. V, 1857). 
Enfin dans certaines plantes qui vivent dans l'eau, les faisceaux des nervures deviennent incomplets (voir p. 218) et se creusent de lacunes par résorption des vaisseaux. L'Ouvirandra fenestralis montre de semblables faisceaux incomplets et même, le tissu parenchymateux venant à disparaître, la feuille se réduit à peu près à ses nervures, et présente un limbe criblé de trous comme un tamis à larges mailles (1).

$2^{\circ}$ Parenchyme. - Entre les nervures existe généralement un parenchyme que limitent au dehors deux épidermes, l’un à la face supérieure et l'autre à la face inférieure du limbe. - Ce parenchyme, assez variable dans sa composition, présente toutefois chez les Dicotylédonées. un type extrêmement répandu. Il se compose alors de deux zones distinctes: l'une est en contact avecl'épiderme supérieur et est formée de cellules allongées et placées perpendiculairement à cet épiderme.

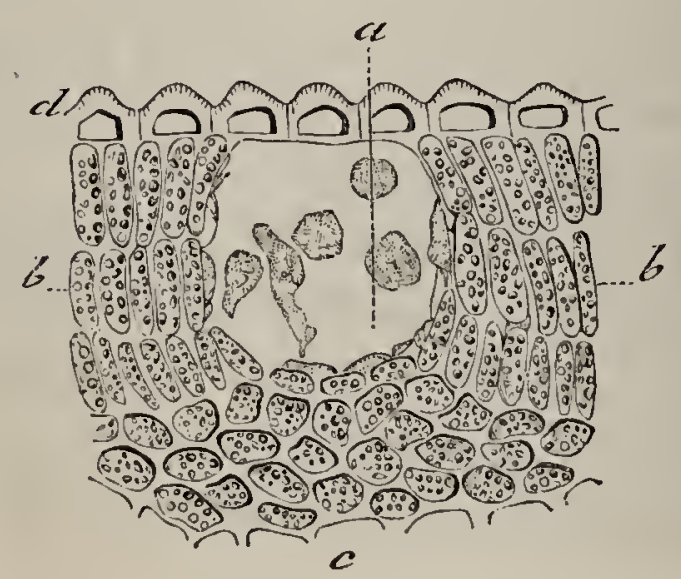

Fig. 118. - Feuille d'Eucalyptus glabulus (eoupe). - a. Glande - b. b. Trois rangées superposées de cellules en palissade. - c. Cellules du parenchyme inférieur. $d$. Épiderme à cuticule épaisse.

Très serrées les unes contre les autres (fig. 116, $p, \mathrm{~A}$ et B) et gorgées de chlorophylle, ces cellules ne laissent entre elles āucun méat. Elles forment la zone dite des cellules en palissade. - Généralemẹt constituée par une seule assise de cellules, elle peut dans certains cas en présenter deux ou trois superposées (fig. 118), comme le montre la feuille d'Eucalyptus.

D'autre part, en contact avec l'épiderme inférieur se trouve la seconde portion du parenchyme. Elle est formée de cellules irrégulières, rameuses (fig. 116) qui, laissant entre elles

(1) A. Chatin, Sur l'anatomie de l'Ouvirandra fenestralis. Bull. Soc. bot. de Franc?, t. II, 1856. 
de nombreux méats, forment un parenchyme lacuneux. Ces méats sont, par l'intermédiaire des chambres sous-stomatiques et des stomates, en relation avec l'extérieur.

Nous allons enregistrer quelques-unes des modifications que subit le type que nous venons de décrire.

$1^{\circ}$ Feuilles des Monocotylédonées. - Souvent le parenchyme est homogène ou uniforme chez les Monocotylédonées. Il est alors formé d'une seule espèce de cellules généralement arrondies et lâchement unies, pouvant même se creuser de lacunes plus ou moins larges par écartement de ces éléments. (Hyancinthus orientalis). Ailleurs, le parenchyme, dit hétérogène symétrique (A. Chatin), est composé de cellules plus serrées

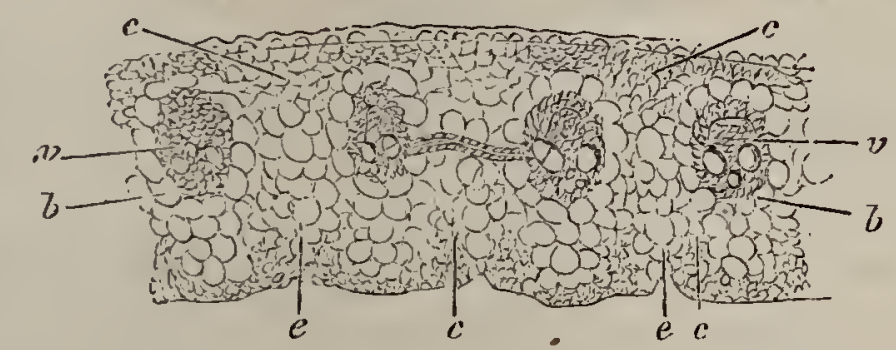

Fig. 119. - Feuille d'Arundo donax en eoupe transversale. $-c, c$. Cellules à chlorophylle. $b, b$. Gaine des faisceaux. $-e, e$. Cannelures de la feuille. $-v$. Vaisseaux.

entre elles sous l'un et l'aulre épidermes, plus lâchement unies dans la portion moyenne qui représente le parenchyme lacuneux. La figure 119 (Arundo donax) offre un exemple de cette disposition. Au voisinage des épidermes, les cellules sont très petites $(c)$, serrées et remplies de matière verte. Au contraire, dans la partie médiane de la coupe, les cellules, beaucoup plus larges et plus lâchement unies, sont en même temps complètement dépourvues de chlorophylle. La même coupe montre très nettement une disposition qui s'observe fréquemment dans le limbe des feuilles des Monocotylédonées; celte particularité consiste dans la différenciation manifeste des cellules du parenchyme voisines des faisceaux, en une gaine $(b, b)$ formée d'une assise d'éléments très développés et à parois minees.

Les feuilles des plantes grasses peuvent en général se rattacher par la disposition des éléments de leur parenchyme au type que nous venons de mentionner, et n'en diffèrent que par les grandes dimensions des cellules. Dans les feuilles d'Aloès en 
particulier, les cellules du parenchyme central prennent un énorme développement, et forment un tissu de consistance fluide. Ces mêmes feuilles d'Aloès sont encore intéressantes par l'existence de longues cellules avoisinant les faisceaux et remplies de matière brune. Ces cellules sont entourées d'éléments plus petits renfermant un liquide incolore et un corps nucléiforme jaunâtre qui pourraient bien jouer un rôle important dans la production du suc brun que renferment les premières cellules (1).

$2^{\circ}$ Feuilles à parenchyme externe incolore. - Il arrive dans certains cas que le parenchyme vert, au lieu de se trouver au voisinage de l'épiderme, s'en trouve séparé par une (Begonia zebrina), deux ou même plusieurs (Begonia sanguinea, Peperomia blanda), assises de grandes cellules à parois minces et sans chlorophylle. (Duchartre, loc. cit.)

$3^{\circ}$ Feuilles des Orchidées (2).

Dạns certaines plantes de cette famille (Pleurothallis racemiflora, spatulata, Lepanthes cochlearifolia, etc.), on trouve, d'après M. Trécul, que le parenchyme des feuilles est séparé de l'épiderme par une couche de cellules spiralées ordinairement dépourvues de chlorophylle, mais pouvant en renfermer, comme l'a montré M. A. Chatin dans les feuilles des Brassavola venosa et Lælia anceps.

Ces cellules spiralées se trouvent disposées de manières diverses, tantôt réparties au milieu du parenchyme vert (Stilis, Pleurothallis prolifera, etc.), elles forment dans le Physosiphon Loddrgesï une rangée de cellules allongées perpendiculairement à l'épiderme supérieur dont elles sont séparées par une couche de cellules incolores. Contre l'épiderme inférieur se trouvent des cellules spiralées. Diverses Broméliacées ont aussi leurs grandes cellules externes et incolores pourvues d'épaississements spiraux. (Duchartre, loc. cit.)

Fenilles des plantes submergées. - Dans beaucoup de plantes submergées, le parenchyme se réduit à deux ou trois assises de cellules, dont les plus extérieures sont considérées

(1) Baillon, art. Alors. Dict. encyclopéd. des sc. médicales, t. III, p. 363.

(2) Trécul, Bull. Soc. bot. de France, t. II, 1855. A. Chatin, loc. cit. 
comme épidermiques et recouvertes d'une cuticule. Les cellules du parenchyme sont tantôt exactement rapprochées les unes des autres (Potamogeton), tantôt au contraire s'écartent et le parenchyme se trouve creusé de lacunes (Zostera marina, Cymodocea xquarea, etc.). (Duchartre, loc. cit.)

Signalons enfin la structure très simple des feuilles des Mousses et rappelons l'organisation singulière des feuilles des Sphagnum avec leurs deux formes de cellules disposées en une seule assise. L'une de ces formes consiste en cellules incolores à parois spiralées perforées; l'autre en cellules étroites et allongées remplies de chlorophylle.

\section{$\S$ 2. BOURGEONS.}

En faisant des coupes longitudinales sur les bourgeons terminaux, on étudiera le développement des feuilles, tantôt basipèıe, tantôt, au contraire, basifuge (1). On devra dans tous les cas, pour faire ces recherches, choisir des bourgeons qui se développent d'une manière continue (Bouleau, Aune). Sur les côtés du cône végétatif; on aperçoit alors de petits mamelons, formés d'un tissu cellulaire très délicat, et de plus en plus saillants à mesure qu'on s'éloigne de l'extrémité terminale (fig. 120). Chacun de ces mamelons est une feuille.

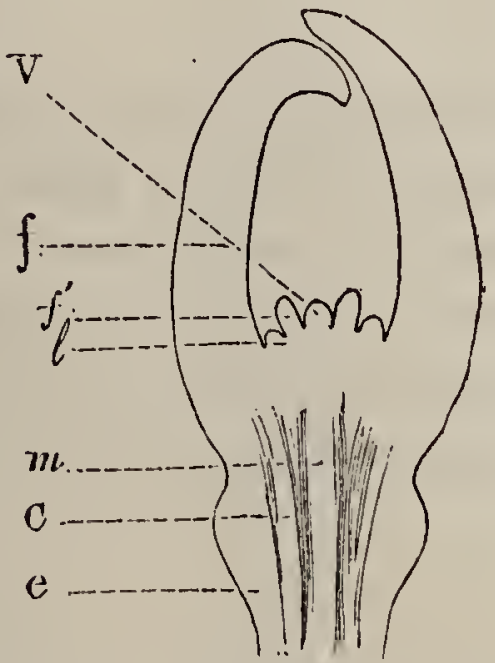

Fig. 120. - Coupe longitudinale d'un bourgeon.

Enfin au moyen des coupes transversales, sur les bourgeons plus âgés, mais pris avant leur épanouissement, on constate la disposition des jeunes feuilles autour de l'axe, disposition qui se retrouvera sur la tige. On pourra, pour les feuilles opposées, choisir le Marronnier d'Inde, le Seringat ou le Café; pour la disposition $1 / 2$ la Vigne et l'Ampelopsis; pour la disposition 1/3 l'Aune et le Bouleau, et pour le quinconce $(\mathbf{2} / \mathbf{5})$, le Chène.

(1) Trécul, Ann.sc.nat., Bot., se séric, t. XX, $185 j$. 
La disposition réciproque des feuilles dans le bourgeon ou préfoliation s'étudiera égalementau moyen de coupes transversales. Nous reproduisons (fig. 121, 122 et 123), comme exemples de ces coupes, les préfoliations imbriquée, équitante et semi.

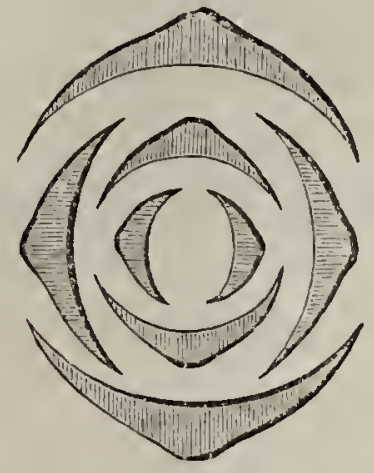

Fig. 121. - Coupe d'un bourgeon de Lilas (préfoliation imbriquée).

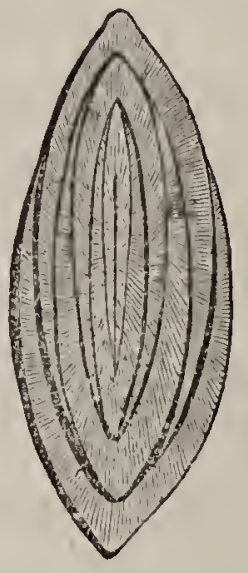

Fig. 122. - Coupe d'un bourgeon de Sauge (préfoliation semi-équitante).

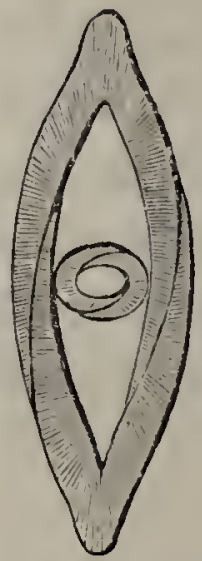

lig. 123. - Coupe d'un bourgeon d'Iris (préfoliation équitante).

équitante. On devra s'habituer à reproduire exactement ces dispositions des feuilles les unes par rapport aux autres dans les bourgeons; ce sera un bon exercice préparatoire pour l'étude des fleurs et la reproduction de leurs diagrammes. L'étude de la préfoliation étant du domaine de l'organographie, nous ne pouvons que l'indiquer en passant. 


\section{CHAPITRE VIII}

\section{ORGANES DE REPRODUGTION}

Art. 1.

\section{Gryptogames cellulaires}

\section{$\S 1$. Algues.}

Appareil végétatif. - Les Algues sont des végétaux cellulaires caractérisés par leur contenu chlorophyllien et qui offrent les formes les plus simples, mais dont la structure et les dimensions acquièrent, chez les types les plus élevés, un grand développement. Tantôt réduites à une seule cellule (Protococcus, Vaucheria, etc.), elles sont ailleurs formées de plusieurs cellules groupées en séries linéaires (Conferves (fig. 124), Spirogyra, etc.), ou en membrane (Pediustrum, V. p. 1'6).

Leurs formes les plus élevées en organisation montrent même dans leur structure une différenciation du thalle, dans laquelle on pourrait distinguer à la rigueur une partie foliacée, et une partie caulinaire (Laminaria, Fucus). Nous aurons d'ailleurs, par la suite, l'occasion de décrire quelques-unes de ces formes de l'appareil végétatif.

Reproduction. - La reproduction chez les Algues se fait au moyen de spores, que l'on désigne sous les noms de spores immobiles, zoospores ou spores motiles, zygospores ou spores résultant d'une conjugation, tétraspores, ou spores se développant par groupes de quatre, oospores ou spores résultant de la fécondation par les anthérozoïdes, auxospores ou spores dẹs Diatomées caractérisées par les dimensions considérables que pren-

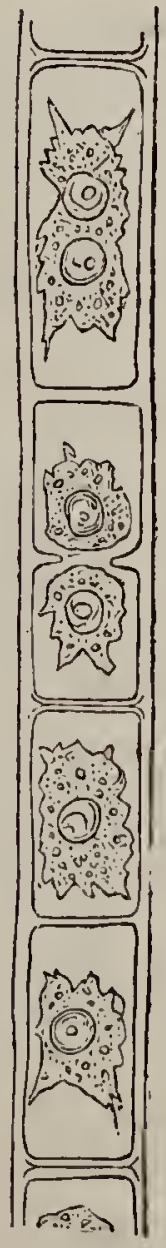

Fig. 124. nent subitement les nouveaux individus auxquels elles donnent naissance.

Ces spores prennent naissance dans des conditions variées qui permettent de distinguer une reproduction asexuce et une reproduction sexuée. Jans le premier cas, aucun acte fécondateur ne paraît 
intervenir dans la production de la spore qui jouit cependant de la propriété de germer et de reproduire un individu semblable à celui dont elle est née; dans le second cas, deux matières plasmiques distincles, qùe l'on peut considérer comme ayant chacune un sexe propre, s'unissent pour former la spore.

Dans tous les cas la cellule mère des spores reçoit le nom de sporange. Toutefois, l'expression oogone s'applique à la cellule mère dont le contenu protoplasmatique, oosphère, doit subir la fécondation au moyen des anthérozoïdes, pour devenir l'oospore.

L'appareil mâle reçoit le nom d'anthéridie, et donne naissance aux anthérozoides.

Nous examinerons quelques exemples de reproduction asexuée et de reproduction sexuée tant par fécondation que par comulation de zoospores et par conjugation. On n'oubliera pas que certaines Algues présentent à la fois les deux modes de reproduction sexuée et asexuée. Il y a alors le plus souvent alternance de générations.

Étude. - Les Algues unicellulaires ou de peu de dimen-' sions ne demandent, pour être observées, aucune préparation spéciale. Il suffit, pour l'étude de leur reproduction, de se procurer des sujets bien frais et très vivants, et, après les avoir débarrassés des impuretés qui les souillent fréquemment, de les placer sur le porte-objet. On s'attache à les examiner dans le milieu et autant que possible dans les conditions d'existence qui leur sont propres. On emploie comme véhicule l'eau douce ou l'eau salée suivant leur habitat, et, pour ne point les écraser par la compression du verre couvreur, on place entre celui-ci et le porte-objet de petites bandes de caoutchouc ou de papier d'étain. Il est bon pendant l'examen, qui dure souvent très longtemps, d'entretenir sur le porteobjet un courant d'eau comme il a été dit plus haut (p. 22).

Les Algues filamenteuses seront légèrement écartées les unes des autres au moyen des aiguilles. Pour les Algues d'une structure plus compliquée (Fucus, Laminaires, etc.), il est nécessaire de pratiquer des coupes transversales et longitudinales sur des sujets frais ou conservés dans l’alcool créosoté. Si elles sont incrustées de matières calcaires (Corallina), on les traite préalablement par l'acide acétique ou l'acide chlorhydrique étendus.

Couleur des Igues. - On examinera également la matière colorante des Algues. La chlorophylle qui se présente sou- 
vent en grains isolés, ou en amas étoilés (zygnema), spiralés (spirogyra), semble, dans certains cas, faire défaut et être remplacée par une autre matière colorante. On verra qu'elle est simplement associée à l'une de ces matières colorantes. Dans les Nostocs et les Oscillaires par exemple, une matière bleue, phycocyunine (Kützing et Cohn), isolable par l'eau froide, masque la chlorophylle. Les Algues olivâtres (Fucus, etc.) doivent leur couleur à une matière jaune (phycoxanthine)(1), qu'on isole par' la benzine et l'alcool. Ce dernier liquide se colore en jaune, et la benzine dissout la chlorophylle. Une matière rouge-brun est souvent associée aux précédentes dans les Algues brunâtres; et enfin le pigment rouge, qui masque la chlorophylle chez les Floridées, est, d'après, M. Rosanoff (2), une substance fluorescente qu'on peut extraire par l'eau froide (phycoérythrine).

Mouvements. - Certaines Algues présentent des mouvements curieux qu'il sera bon d'observer. Les Psorospermies par exemple (voir plus loin) sont animées d'un mouvement brownien rapide qui leur a fait donner le nom, chez le ver à soie, de corpuscules vibrants ou oscillants.

Parmi les Nostochinées (3) les Oscillaires, Algutues bleuâtres formées de filaments de petites cellules superposées, doivent leur nom à des mouvements d'oscillation qui se répètent à intervalles assez éloignés. Lorsque les filaments observés sont bien vivants, chaque mouvement oscillatoire se fait brusquement et transporte le filament en un point quelquefois assez éloigné du point de départ, pour le faire sortir du champ du microscope. Dans ce mouvement, l'une des extrémités du filament reste fixe. D'autres Oscillariées du genre Spirulina ont la forme de tire-bouchon et progressent par un contournement lent sans modification des courbes de la spire.

Deces Oscillaires peuvent être‘rapprochées les Bactéries, qui

(1) Millardet et Kraus, Mém. de la Soc. cles sc.nat. de Strasbourg, VI, 1868.

(2) Rosanoff, Compte rendus, LXII, 1866.

(3) Citons à propos des Oscillariées les Beggiatoa filaments très fins à mouvements oscillatoires. Leur protoplasma renferme du Soufre cristallin. Ces Algues habitent les eaux thermales sulfureuses où elles constituent des flocons qui ont été nommés glairive, barégine; elles jouent un grand rôle dans le dégagement d'hydrogène sulfuré dans les eaux thermales. 
possèdent des mouvements de deux sortes. Le premier n'est qu'un mouvement sur place (M. brownien) de balancement, de rotation ou d'inflexion; le second est un mouvement de translation fort variable ; tantôt lent, tantôt rapide, interrompu par des périodes de repos. La combinaison de ces deux sortes de mouvements, lorsqu'on examine une goutle d'eau remplie de ces petits corps, présente le plus curieux spectacle de mobilité active que l'on puisse voir. Ajoutons que la plupart des Bactéries (Spirillum volutans, Vibrio Rugula, V. Serpens, Bacterium, Bacillus, etc.) sont pourvues de cils vibratiles analogues à ceux de beaucoup de spores d'Algues.

Les cellules des Nostocs (voir plus loin) qui doivent produire de nouvelles familles, s'échappent de la gangue gélatineuse qui les enveloppe, par des mouvements de balancement ou d'oscillation très curieux.

Citons encore le Volvox globator (fig. 12כั) que l'on rencontre dans les étangs, sur les Characées, en automne. Il se présente sous la forme d'une sphère creuse limitée extérieurement par une membrane hyaline au-dessous de laquelle

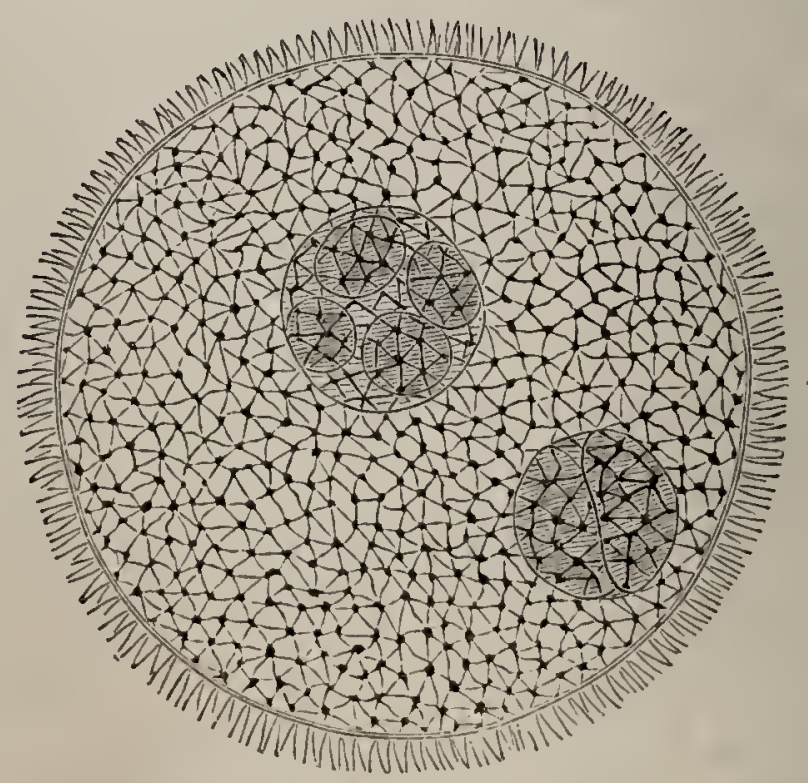

Fig. 125. - Volvox globator d'après le 1)r Peiletan. On voit dans l'intérieur de la sphère deux globes, jeunes volvocesdont l'un est encore adhérent à la paroi; son protoplasma se divise en deux masses. L'autre, dont le protoplasma est déjà divisé en 4 masses, est libre dans la cavité de la sphère.

apparaissent une multitude de petits points, souvent verts, reliés entre eux par de fines lignes vertes. De chacun des points verts partent deux longs cils qui traversent la membrane externe de la sphère et viennent s'agiter au dehors. La combi- 
naison de ces mouvements imprime à la sphère un mouvement de rotation. (Pelletan.)

Exemples de reproduction asexuée. - La reproduction asexuée s'opère, soit par spores immobiles, soit par zoospores.

$1^{\circ}$ Les spores immobiles sont le plus souvent des cellules arrondies, munies d'une paroi. On les rencontre particulièrement dans les Algues à structure simple, comme les Nostocs, les Palmella, Chroococcus, etc.

Les Nostocs sont des Algues formées de chapelets de cellules arrondies ou ovoïdes, colorées en vert. Ces chapelets sont entourés d'une sorte de gangue gélatineuse. Ils présentent de place en place des cellules plus volumineuses, à contenu incolore et à paroi épaissie, jaunâtre, qui reçoivent le nom d'hétérocystes (Thuret) (1).

La reproduction de ces Algues se fait par spores immobiles provenant d'une transformation directe des cellules comprises entre deux hétérocystes. Ces cellules s'amplifient, se gorgent de gouttelettes huileuses, et finalement se recouvrent d'une nouvelle membrane assez épaisse. (Duchartre, Élém. de Bot.) On trouve les Nostocs sur la terre humide, sur les rochers ou sur les murs humides où ils forment. des masses gélatineuses.

Les tétraspores des Floridées, qui naissent par division d'une cellule mère, rentrent dans le groupe des spores asexuées immobiles.

$2^{\circ}$ Les zonspores sont des corps protoplasmatiques dépourvus de membrane, et munis de cils vibratiles. On doit examiner leur forme et leur structure. Tantôt ovoïdes, rarement fusiformes (Ulothrix rorida), ils renferment une matière verte, et fréquemment un point rouge, point oculiforme, placé sur le côté. Les cils, répartis sur toute la surface de la zoospore dans les Vaucheria par exemple, ne forment chez les OEdogonium qu'une couronne autour de l'extrémité ou rostre qui est incolore. Ailleurs les cils vibratiles beaucoup plus longs n'existent qu'au nombre de deux ou quatre, généralement antérieur's dans les Confervacées. Ces cils vibratiles impriment aux zoospores des mouvements qui varient suivant l'espèce de plante et suivant les conditions de l'observation. D'une durée très variable également (de une demi-heure à une journée entière), ces mouvements commencentà se ralentir quelque temps avant la germination. Puis les cils disparaissent, et la zoospore

(1) Thuret, Ann. des sc. nat., Bot., $3^{\mathrm{e}}$ série, t. II; Ann. des sc. nat., Bot., Ge série, t. I, 1875. 
qui s'est généralement fixée par son rostre, s'enveloppe d'une membrane. Elle développe une sorte de crampon (rhizoïde) au point où elle s'est fixée, et par son extrémité libre s'allonge et forme un nouvel individu. D'après Pringsheim (1), on rencontre chez l'Hydrodictyon des zoospores beaucoup plus petites que les autres, et qui, une fois réduites au repos, ne se développent souvent qu'après un temps très long. Ces zoospores durables n'ont pas été trouvées encore dans les autres Algues.

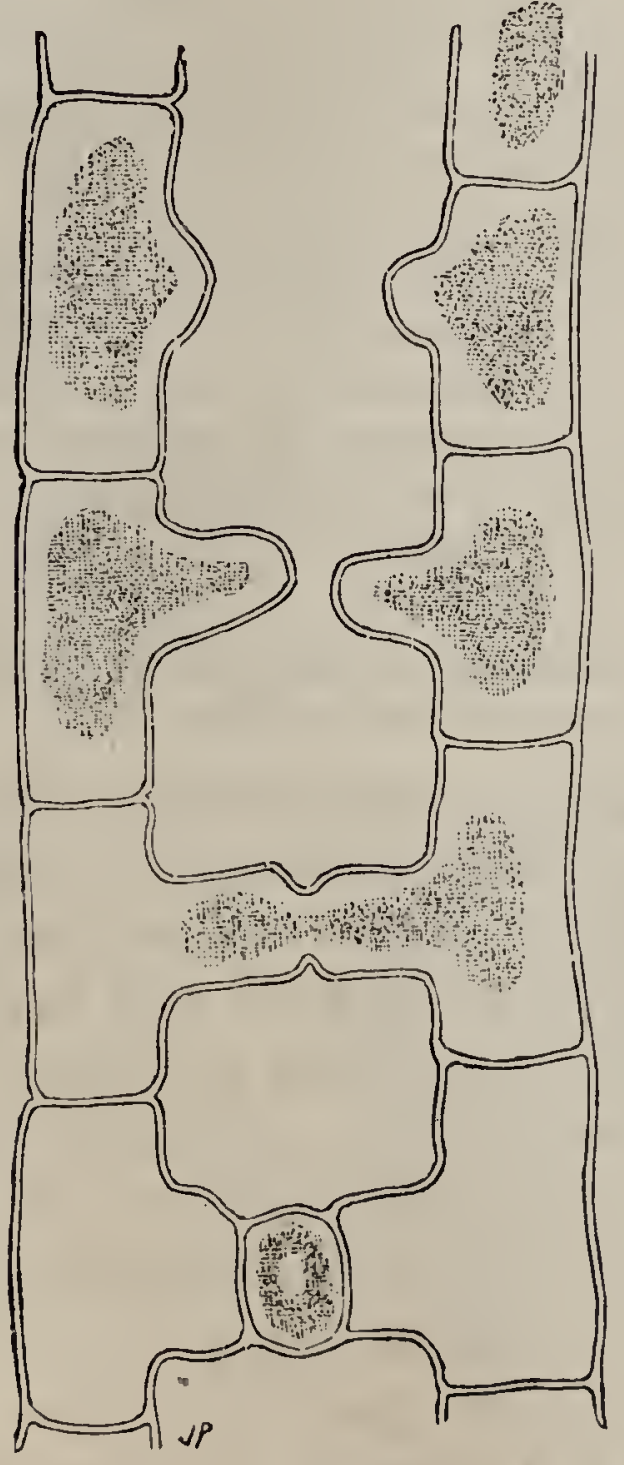

Fig. 126. - Conjugation entre deux filaments d'algue.

Comme type de la formation asexuée d'une zoospore, nous rappellerons la formation par rajeunissement des zoospores du Vaucheria Ungeri (voir page 73).

\section{Exemples de reproduction} sexuée : $-1^{\circ}$ Par conjugation. La conjugation ou conjugaison consiste dans la formation d'une spore à trois enveloppes concentriques (zygospore) au moyen de la réunion de deux masses protoplasmatiques provenant de deux cellules différentes.

Ce mode de reproduction s'ob serve dans un grand nombre d'Algues d'eau douce désignées sous le nom de Conjuguées et qui comprennent les deux groupes des Zygnémées (Spirog!pra, Zygnema, Mesocarpus, etc.), et des Desmidiées. La conjugation s'observe très fréquemment aussi chez les Diatomées.

Si l'on prend pour exemple les Spirogyra, on voit que deux cellules situées vis-à-vis l'une de l'autre et appartenant à deux filaments voisins (fig. 126), envoient chacune un prolongement d'abord en forme de mamelon. Ces deux prolonge-

(1) Pringsheim, Sur les zoospores durables de l'Hydrodictyon. Annales mensuelles de l'Académie de Berlin, 1 si1. 
ments se rencontrent bientôt, se soudent parleur surface de contact, puis, celle-ci venant à disparaître, un canal de communication est bientôt établi entre les deux cellules. Entre temps, le protoplasma s'est contracté en une sphère dans chacune des cellules. Ces sphères émettent dans le tube de communication un prolongement protoplasmatique, et bientôt, la jonction de ces prolongements avant lieu, l'union des deux masses va se terminer dans la cellule où la contraction protoplasmatique a commencé en dernier lieu. Le corps qui résulte de cette union est une zygospore dont le volume, par suite de contraction, ne dépasse pas celui de la masse protoplasmatique réceptrice au moment où l'union a commencé à se faire. La germination de cette zygospore s'opère seulement après quelques mois de repos.

Ce mode de conjugation, dit scalaire ou scaliforme, subit quelques modifications. Dans les Mesocarpus par exemple, le canal de communication établi entre deux filaments voisins se renfle en son milieu, et c'est là que viennent se confondre les deux masses protoplasma-

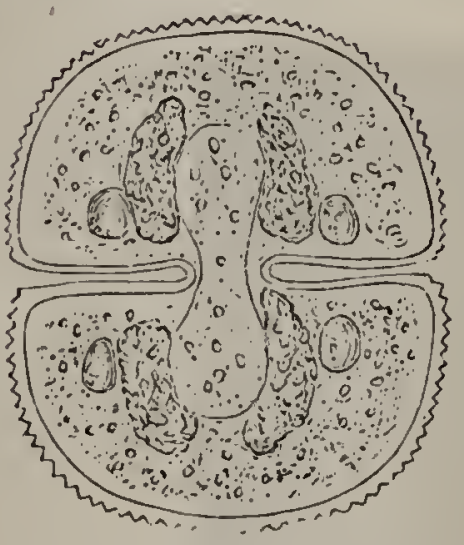

Fig. 127. - Cosmarium Botrytis.

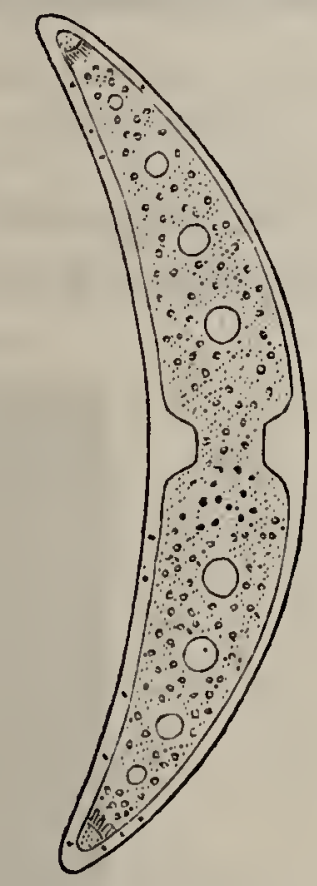

Fig. 128. - Clusterium lunula.

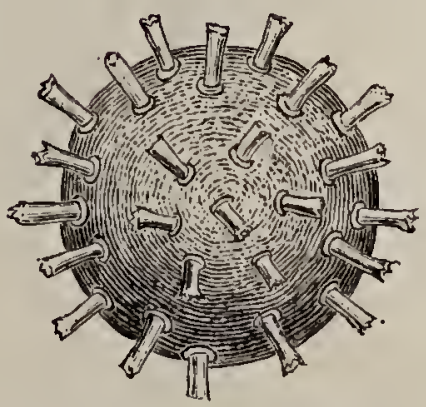

Fig. 129. - Zygospore de Cosmarium.

tiques. M. Duchartre distingue cette conjugation sous le nom de scaliforme intermédiaire.

Enfin au mode de conjugation scaliforme, on trouve souvent associe dans les Spirogyra (1) un autre mode dit de conjugation lutérale (Külzing), dans laquelle les deux cellules qui entrent en communication appartiennent au même filament et sont contiguës.

Reproduction des Desmidices. - Les Desmidiées sont des Algues qui habitent les eaux douces. On les trouve aussi en abondance dans les marais tourbeux et dans les Sphagnum. Elles sont composées

(i) P. Petit, Bull. Soc. bot. de France, 1874.

GUIDE DE Micrographie. 
d'une seule cellule ordinairement aplatie, et appelée fronde, partagée en deux moitiés symétriques (hémisomates) (fig. 127 et 128, Pell.). La reproduction de ces Algues s'opère par conjugation, et elles se

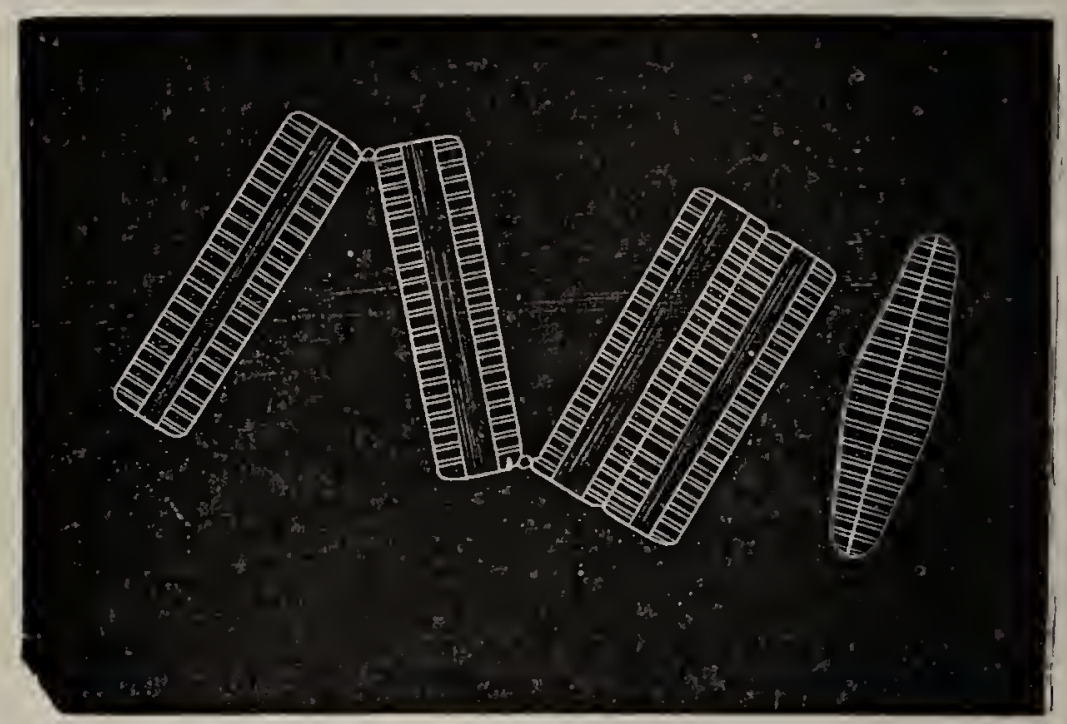

Fig. 130. - Diatoma vulgare (Pelletan). Quatre frustules réunis, de laee; - un frustule libre de profil.

multiplient par division. C'est le procédé de conjugation intermédiaire dont il a été parlé plus haut que l'on retrouve ici. La zygo-

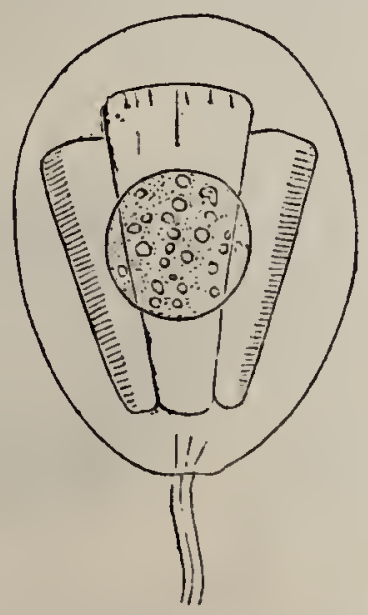

Fig. 131. - Gomphonema geminatum. Conjugaison et formation d'auxospore. Les deux cellules conjuguées, portées sur un pédieelle, se sont enveloppées d'une masse mueilagineuse à travers laquelle on ne distingue que diffcilement les stries des frustules: entre elles apparaissent l'auxospore et le frustule nouveau, anrandi qui en résulte (Pelletan).

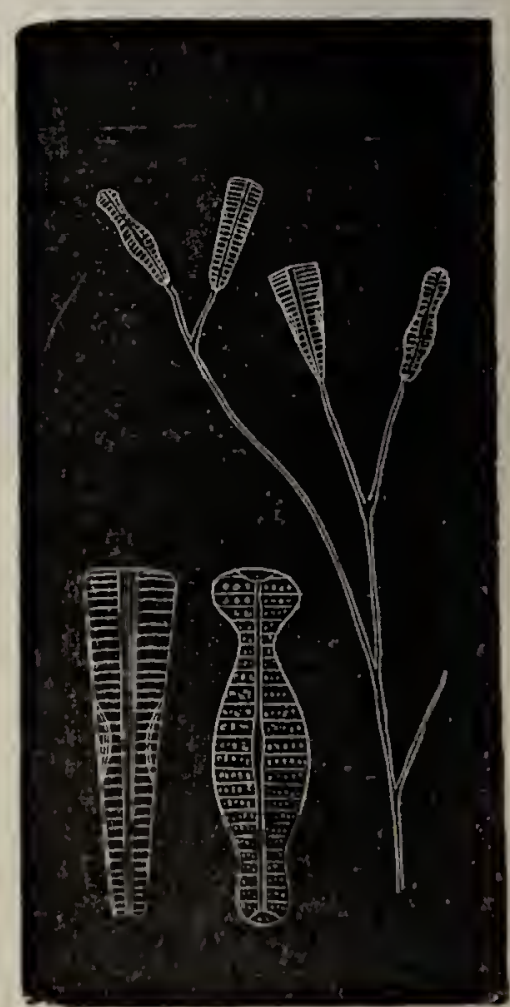

Fig. 132. - Gomplunema geminalum.

spore est formée, comme toujours, de trois membranes dont la moyenne, épaisse et brune, développe souvent des pointes plus ou moins dentées (fig. 129). 
Reproduction des Diatomées. - Les Diatomées sont des Algues microscopiques formées d'une seule cellule qu'on appelle frustule, enfermée dans une enveloppe siliceuse. Le frustule, formé de deux valves séparées par une bande dite connective (fig. 130), renferme un protoplasma coloré en vert (endochrôme) ou en brun jaunâtre.

Ces Algues se multiplient par division et se reproduisent en partie par conjugation. La conjugation s'opère entre deux frustules (fig. 131 et 132), qui se placent parallèlement et s'entourent d'une substance gélatineuse. Tantôt les deux endochròmes se confondent en une masse unique, auxospore, qui se transforme peu à peu en un frustule semblable aux parents, mais plus grand, et qui se multipliera par division. Tantôt chaque frustule émet deux tubes de communication et deux masses d'endochrôme, de telle sorte qu'il y a formation de deux auxospores qui se comportent d'ailleurs comme précédemment. (Voir Pelletan, loc. cit.)

$2^{\circ}$ Copulation de zoospores. - Dans les Pandorina (1), Ulothrix zonala (2), U. seriata (Max. Cornu) (3), on a observé une reproduction caractérisée par la fusion de deux zoospores libres qui donnent naissance à une oospore qui germe après une période de repos.

$3^{\circ}$ Fécondation. - Ce mode de reproduction sexuée consisle dans l'intervention d'un individu mâle (anthérozoïde) venant féconder une masse protoplasmatique (oosphère) renfermée dans une cellule mère (oogone). De cette fécondation résulte une oospore qui tantôt germe directement (Vaucheria), tantôt produit par division des zoospores qui vont se fixer et germer ensuite en une nouvelle plante (Bulbochcele, OEdogonium diplandrum).

On pourra prendre comme sujet d'é-
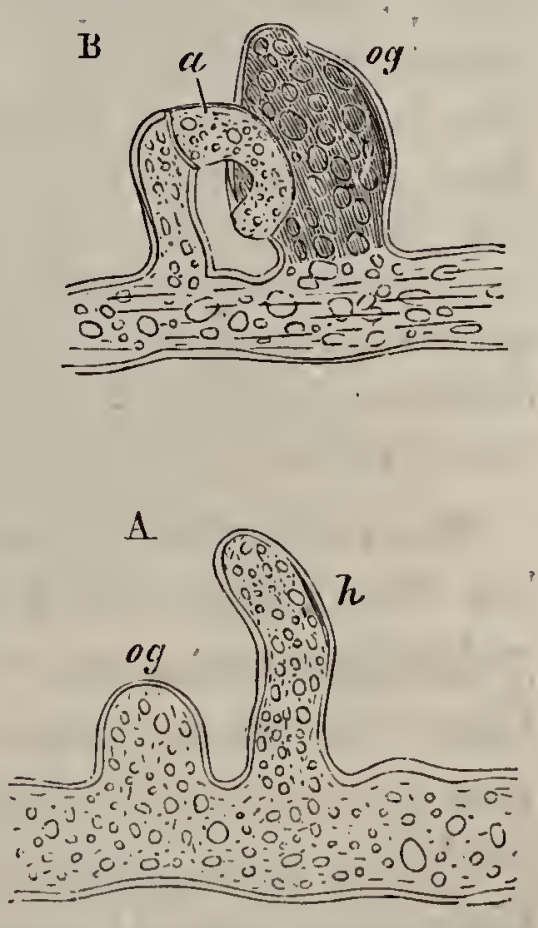

Fig. 133. - Vaucheria sessilis. - A, B. Naissance de l'anthéridic (cornicule) $a$ sur la branche $h$, et de l'oogone og. D'après Pringsheim. tude le Vaucheria sessilis (fig. 133) dans lequel l'anthéridie a (cornicule) apparaît à côté du sporange ou oogone $(\circ g)$.

Comme on le voit en A, l'anthéridie $h$ se développe sur le filament

(1) Pringsheim, Monatsbericht, 8 novembre 1869.

(2) Cramer, Bot. Zeitung, $18 i 1$.

(3) Max. Cornu, Bull. Soc. bot. de France, 1874. 
plus rapidement que l'oogone og. Ce dernier se renfle et son contenu se sépare bientôt de la cellule par une cloison transverse. Le contenu granuleux et de couleur verte se rassemble au centre de l'oogone, tandis qu'i son sommet courbé en forme de bec on ne trouve plus qu'un protoplasma incolore. En ce point la paroi, s'ouvrant bientôt, se gonfle en une sorte de gelée au moyen de laquelle les anthérozoïdes, qui s'échappent par une ouverture de l'anthéridie développée, pourront atteindre la masse protoplasmique verte ou oosphère renfermée dans la cavité de l'oegone. Aussitôt la fécondation opérée, l'oosphère se couvre d'une membrane et constitue alors une oospore.

Fucacées. - Chez les Fucus, les organes mâles et femelles apparaissent, soit à côté l'un de l'autre dans des cavités ou conceptacles qui se trouvent aux extrémités des frondes (Fucus platycarpus), soit sur des thalles différents (Fucus vesiculosus, serratus, nodosus). C'est sur ces conceptacles que devront être faites les coupes. Chaque oogone, attachée au fond du conceptacle par un pied unicellulaire, renferme un corps protoplasmatique (oosphère) qui tantôt demeure simple (Pycnophycus, Himanthalia, etc.), tantôt se divise en deux (Pelvetia), quatre (Ozothallia vulg.), ou huit oosphères (Fucus). - Les anthérozoïdes très petits, contenant un point rouge et munis de deux cils, l'un en avant, l'autre en arrière, sont réunis en grand nombre dans des cellules généralement ovoïdes (anthéridies) disposées sur des poils dont elles ne sont que des rameaux transformés. La fécondation des oosphères se produit, en dehors des conceptacles, une fois que celles-ci se sont successivement débarrassées des membranes de l'oogone. L'oosphère fécondée se couvre d'une membrane, et, devenue oospore, se fixe pour germer.

Reproduction chez les Floridées. - La reproduction chez les Floridées diffère beaucoup de celle des autres Algues. On y distingue une reproduction asexuée par tétraspores immo. biles, qu'on ne retrouve pas toutefois chez les Némaliées, et une reproduction sexuée dans laquelle les anthérozoïdes immobiles sont entraînés par l'eau et viennent se fixer à un filament hyalin (trichogyne) qui s'insère sur un corps appelé trichophore. "Ce dernier est un corps généralement pluricel" lulaire, dans lequel ou à côté duquel se font sentir les suites " de la fécondation, car c'est à côté et au-dessous de lui que " se forment des filaments celluleux ou des masses de tissu " qui constituent le fruit ou cystocarpe; c'est dans ce derniel" "que naissent plus tard les spores." (Sachs, loc. cit.)

Parmi ces Algues le Sphạrococcus crispus (Carragaheen ou mousse perlée), le Gigartina helminthocorton (mousse de Corse) et la Corallina officinalis sont utilisés en pharmacie. 
Le thalle de la première est comprimé en forme de ruban étroit, celui de la seconde est cylindrique et paraît formé, à la loupe, de tubes finement striés transversalemerit, apparence qu'ils doivent à leur structure. Ces filaments se composent en effet de cellules rangées côte à côte par étages assez réguliers, et ce sont les plans horizontaux de séparation qui forment les stries transversales de la surface.

Par des coupes dans le tissu même du thalle du Sphærococcus crispus, on constatera l'existence des tétraspores ; celles-ci se réunissent en grand nombre sous forme de petits amas ovoïdes, rosés (capsules), qu'on retrouve très facilement sur l'algue sèche après l'avoir fait détremper dans l'eau. Dans le Gigartina helminthocorton, les tétraspores se forment aux extrémités des rameaux.

Le thalle de la Coralline est,.comme le montre la figure (fig. 134)

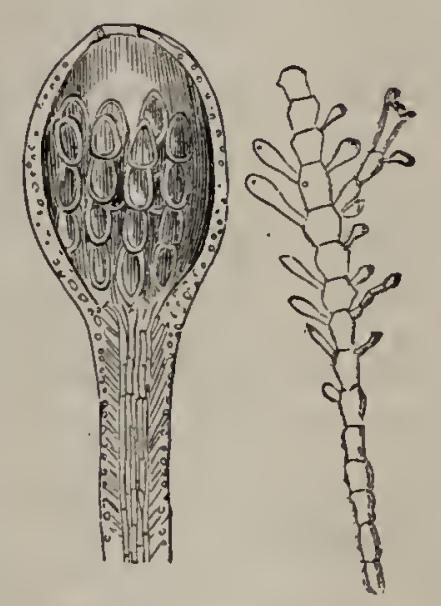

Fig. 134. - Corallina officinalis. Thalle et conceptacle d'après Guibourt.

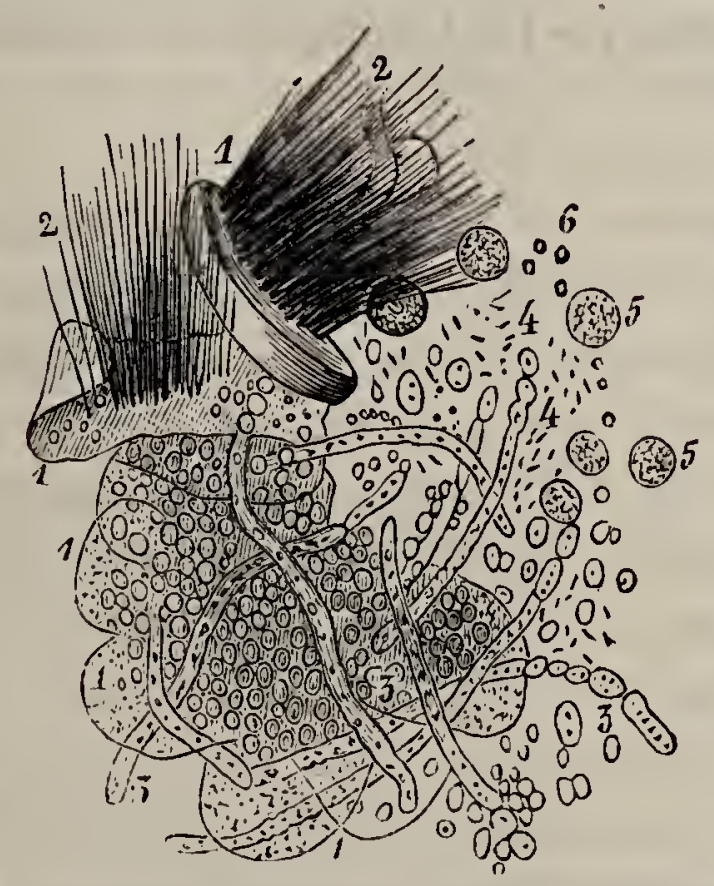

Fig. 135. - 1 et 2 Leptothrix buccalis.

composé d'articles courts et assez larges imprégnés de carbonate de chaux. Lorsqu'on l'a débarrassé de ce carbonate de „chaux, on constate que le thalle est formé d'une partie centrale constituée par une série de cellules longues et étroites juxtaposées et d'une partie corticale formée de cellules arrondies, serrées les unes contre les autres.

Les tétraspores se produisent à l'intérieur de conceptacles qui naissent à l'aisselle des articles. Ces conceptacles sont ovoïdes, pédicellés et renferment un certain nombre de tétraspores provenant chacune de la division d'une cellule mère. A leur sommet les conceptacles présentent une ouverture (fig. 134).

Algues parasites. - Les Algues parasites de l’homme sont assez peu nombreuses. 
Gitons le Leptothrix buccalis décrit par M. Robin (1).

Genre Leptothrix. - "Filaments non rameux, ni engaînés, ni co" hérents. "

Leptothrix buccalis. - "Filaments assez raides, droits ou courbés, " quelquefois coudés brusquement, à angle généralement obtus, à " bords nets, non moniliformes, extrémités non effilées, larges " de $0^{\mathrm{mm}}, 000 弓$ et longs de $0^{\mathrm{mm}}, 020$ à $0^{\mathrm{mm}}, 100$, incólores, élastiques, "réunis généralement par la base à une gangue amorphe, granuleuse, " et formant des faisceaux plus ou moins serrés, à moins qu'ils n’aient " été détachés (fig. 135, 1 et 2).

Cette Algue se trouve à la surface de la langue, parmi les matières accumulées dans les interstices des dents. Les liquides de l'estomac et de l'intestin ne semblent pas un milieu

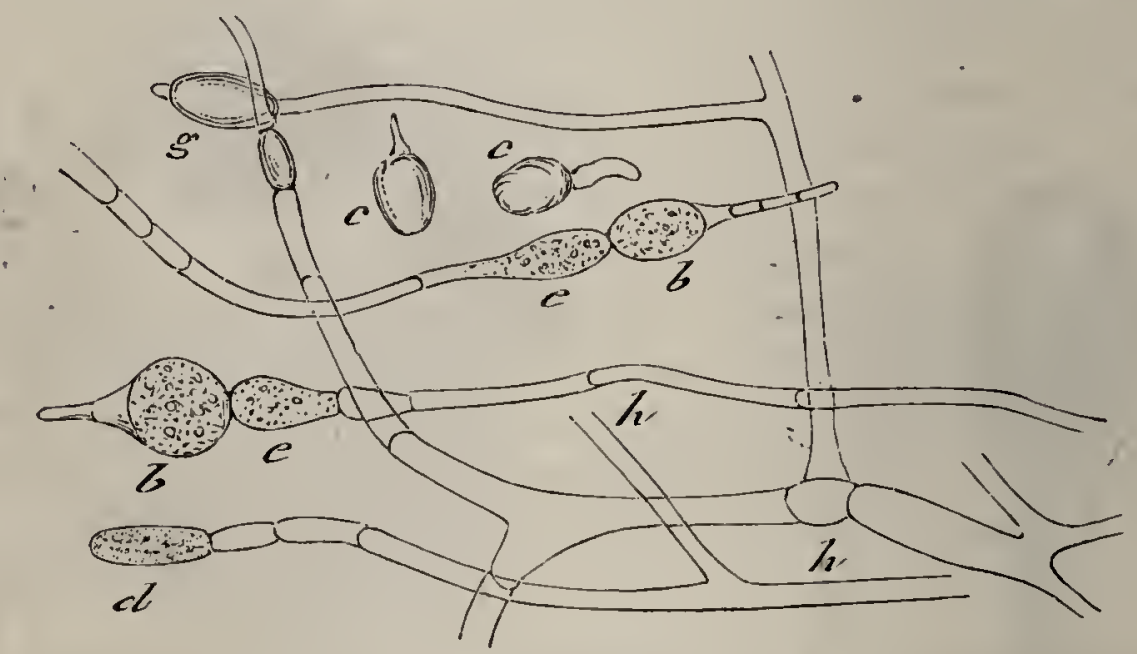

Fig. 136. - Algue de l'utérus. (Ch. Robin.)

favorable à son développement, car on n'y rencontre généralement que des filaments isolés non fasciculés, et très rarement implantés sur leur gangue.

Pour les observer on gratte fortement et aussi loin en arrière qué possible le dos de la langue avec une spatule. On trouve en même temps les produits de la desquamation buccale (voir plus loin).

Enfin, sous le nom de Leptomitus, on désigne des Algues (?) dont nous empruntons la caractéristique à M. Robin.

Leptomitus. "Trichoma articulatum, in apicem attenuatum, ramo"sum; articuli cavi, vaginati. Spermatia (sporidia) lateralia, raro " interstitialia, epispermio pellucido cincta."

(1) Ch. Robin, Histoire naturelle des végétaux parasites qui croissent sur. l'homme et sur les animaux vivants. Paris, 1853. 
Nous reproduisons (fig. 136) le Leptomitus de l'utérus rencontré par M. Lebert dans le mucus de l'utérus. Il se compose : $1^{\circ}$ de tubes pâles, ramifiés, non cloisonnés; $2^{\circ}$ de tubes un peu plus larges $(h, h)$, articulés (réceptacles), cloisonnés, terminés par des spores $(b, d, g)$ à divers degrés de développement. Les spores libres sont ovoïdes et terminées par un petit prolongement séparé d'elles par une cloison $(c, c)$.

M. Gubler, observant une main blessée soumise à l'irrigation continue, y a découvert un parasite auquel jl a donné le nom de Leptomitus epidermidis. On cite encore le Leptomitus urophilus, composé de filaments hyalins très rameux, dont les articles sont quelquefois aussi larges que longs. M. Rayer l'a trouvé mêlé à des poils dans une urine malade (Ch. Robin).

Psorospermies (1). Pébrine. - On désigne sous le nom de Psorospermies de petits organismes végétaux que l'on rencontre fréquemment chez les poissons, les reptiles et les insectes. Ce sont eux qui constituent chez le Bomby $x$ mor $i$, les corpuscules de Cornalia caractéristiques de la maladie appelée $P$ ébrine.

Chez les poissons, entre la membrane interne et la membrane externe de la vessie natatoire (Tanche, Carpe, Cyprin), où on les observe le plus facilement, les psorospermies apparaissent comme des cellules ovales, formées d'une enveloppe résistante divisée en deux valves réunies par une bande connective annulaire. "Cette bande annulaire est composée elle" même de deux anneaux accolés, dont chacun appartient à la " valve qu'il borde et semble s'unir à l'anneau de l'autre valve " par l'intermédiaire de petits filaments très difficiles à aper" cevoir, mais qui prennent un grand accroissement lorsque " les valves s'entr'ouvrent au moment de la conjugaison de la " cellule avec une autre."

La psorospermie renferme un protoplasma et deux corpuscules brillants. Le protoplasma peut, à un moment donné, s'échapper de la cellude et constituer une cellule où se forment de nouveaux individus. Quant aux corpuscules brillants, ce sont deux cellules contenant chacune un long filament enroulé en spirale.

(1) Nous empruntons les dérails qui suivent au Dr Pelletan (loc. cit.). 
Les psorospermies se reproduisent aussi par auxospores qui succèdent à la conjugation de deux cellules voisines.

Pour observer les psorospermies du ver à soie, il suffit de broyer l'insecte avec un peu d'eau. Alors, au milieu des débris de l'animal, on trouve des corpuscules vibrants, animés d'un mouvement brownien rapide, qui sont des psorospermies à divers états de développement.

Dans la figure 137, on voit en $a$ des corpuscules ovoïdes à contours nets et brillants, mesurant $0^{\mathrm{mm}}, 0030$ de long sur $0^{\mathrm{mm}}, 002$ د̆

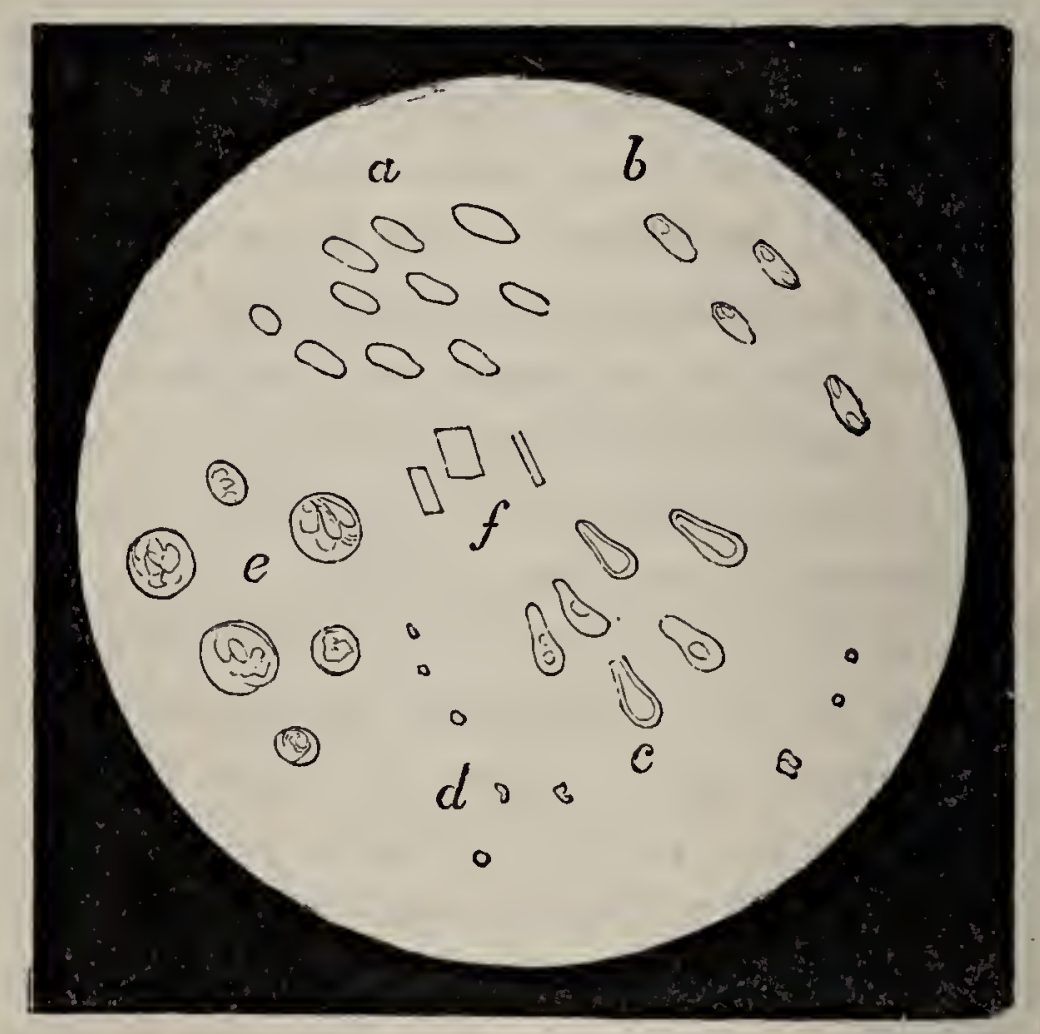

Fig. 137. - Psorospermies du ver à soie à différents états (6r0 diam.) (Pelletan).

de large. Ces corpuscules sont considérés par M. Pasteur comme des organismes vieillis et incapables de reproduction.

En $b$, se voient des corpuscules plus pâles, d'apparence gélatineuse, contenant un ou deux globules. En $c$, ce sont des corpuscules pyriformes pâles, à double contour, et qui parfois renferment un ou deux globules semblables à ceux que l'on rencontre libres en $d$, et qui sont des agents de reproduction. Enfin en $e$ on voit des cellules-mères de psorospermies. Ces derniers éléments sont quelquefois tellement nombreux qu'ils forment au milieu des tissus de l'insecte une sorte de gangue épaisse. 
On trouvera encore des psorospermies chez les Reptiles (Couleuvres) et les Crustacés (Ecrevisses) où elles sont très volumineuses. Parmi les Insectes, les Pyrales en offrent de très grosses.

\section{$\S$ 2. Champignons.}

Les Champignons sont très bien caractérisés par leur mode de végétation spécial, et l'absence absolue de chlorophylle dans leurs tissus et par suite d'amidon. On ne s'étonnera point dès lors de leur trouver une composition chimique toute particulière. La cellulose y est remplacée par une substance appelée fungine, et l'analyse révèle l'existence de matières azotées telles que la gélatine et l'osmazome associées à des principes carbonés (sucre, mannite, matières grasses, gomme, etc.). Ghez les espèces vénéneuses on trouve un alcaloïde mal défini, appelé amanitine ou bulbosine (Boudier). Enfin les Champignons sont particulièrement intéressants par leur polymorphisme dont nous aurons à faire connaître quelques exemples.

Appareil végétatif. - Thalle, Mycelium, Sclérote. - Tantôt le thalle est très simple, et reçoit le nom de filament (Thalle filamenteux ou floconneux). Il consiste alors en une seule cellule plus ou moins ramifiée (Mucorinées). Ailleurs, par cloisonnement et union de plusieurs filaments, on voit se former une sorte de feutrage (Mycélium membraneux), variable dans sa forme et sa consistance, qui a reçu le nom de Mycélium. Lne forme particulièrement dense, tuberculeuse, reçoit le nom de Sclérote. Les sclérotes naissent en général sur le mycélium membraneux par agglomération de filaments en masses compactes.

Appareils de reproduction. - A l'appareil végétatif se joint chez les Champignons un appareil plus ou moins développé, et qui reçoit le nom de réceptacle fructifère. Ce réceptacle naît du mycélium et affecte des formes variées. Tantôt très simple, il est réduit à un filament ramifié ou non, qui porte les spores; tantôt il est composé de filaments ou cellules allongées qui se groupent pour former une masse solide souvent très considérable (Ghampignons à chapeau). Ce réceptacle fructifère supporte un lissu spécial (hyménium) d'où émanent les spores. Cet hyménium est tantôt à la surface du réceptacle (réceptacle gymnocarpe: Hyménomycètes, par 
exemple), tantôt à l'intérieur (réceptacle angrocarpe : Truffe). Dans tous les cas il ne produit jamais que des cellules reproductrices asexuées.

Reproduction sexuée. - On trouve, comme chez les Algues, divers modes de reproduction sexuée, mais ici les exemples qu'on en connaît sont relativement rares.

Conjugation. - Chez les Mucorinées (Syzygites megalocarpus, Rhizopus nigricans) par exemple, outre une reproduction asexuée par spores, on observe une conjugation qui s'opère entre deux filaments du mycélium. La zygospore qui en résulte développe directement chez le Syzygites un filament dressé qui porte un système de sporanges à spores asexuées. Celles-ci produisent un mycélium qui développe des zygospores. Il y a là une véritable alternance de générations qu'on pourra prendre pour exemple.

Fécondation. - Ailleurs, chez les Saprolégniées (Champignons filamenteux que l'on trouve souvent sur les mouches mortes), ainsi que chez certains Champignons entophytes (Peronospora, Cystopus candidus), on observe une fécondation qui s'opère de la manière suivante : un filament naît sur le mycélium et se renfle à son extrémité en une sphère femelle ou oogone. D'autre part, un filament mâle à extrémité conformée en petite ampoule ovoïde et considérée comme une anthéridie, vient pénétrer l'oogone ou s'appliquer à sa surface, et du contact résulte une oospore qui en germant devient un grand zoosporange dont le contenu se divise en zoospores qui se fixent et germent; chez certaines Saprolégniées (Monoblepharis), l'appareil mâle est constitué par une anthéridie qui développe des anthérozoïdes munis d'un long cil, et qui fécondent l'oosphère (1) (Cornu).

IBeproduction asexuée. Etude. - Elle a lieu, ici comme chez les Algues, au moyen de spores ou cellules reproductrices qui sont le plus souvent immobiles. On distingue deux sortes principales de spores: les unes, dites T'hécaspores ou Ascospores, se développent en général par formation libre (voir page 63), dans l'intérieur de cellules-mères spéciales, vrais sporanges, appelées Thèques ou Asques. Les autres au contraire ont un développement exogène et se développent à la surface de cellules-mères que l'on nomme Basides, où elles sont portées par de petits filaments nommés Stérigmates ou Spicules. Ces spores sont appelées Basidiospores. Pour examiner les spores on doit faire des coupes à travers les réceptacles fructifères lorsque ceux-ci possèdent un certain volume, et

(1) Max. Cornu, Amm. sc. nat., 5e série, t. XV, $18 i 2$. 
si l'on étudie les basidiospores, ces coupes devront être dirigées perpendiculairement à la surface hyméniale dont la situation varie, comme nous l'avons dit plus haut, avec les espèces.

Exemples de Thécaspores. - Ces exemples sont nombreux,

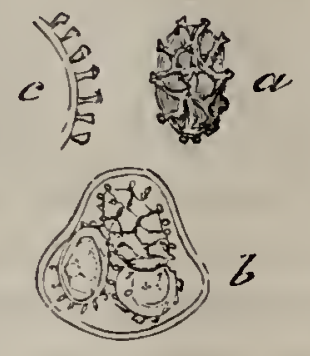

B

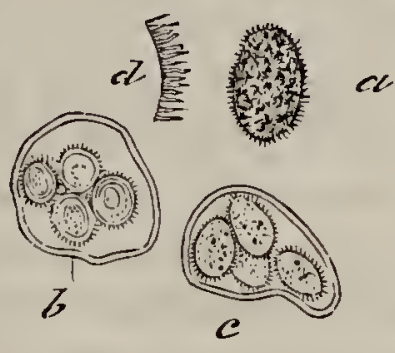

A.

Fig. 139. - A. Spores du Tuber melanosporum. - $a$. Spore grossie. - $b$. Spores eoupćes transversalement et vues daus leur thèque. - $c$ Spores entières dans leur thèque. d. Purtion de paroi d'une spore fortement grossie, avee ses pointes. - B. Spores du Tuber mesentericum. - $a$. Spore isolée grossie. - $b$. Spoles dans leur thèque. c. Paroi grossie avec ornements.

car on en trouve chez les Champignons les plus simples (ferments) comme chez ceux qui atteignent un haut degré d'organisation (Tubéracées, Morille, Pézizes, Claviceps, etc.).

Truffe. - Si par exemple on pratique des coupes minces sur le réceptacle fructifère angiocarpe de la Truffe, on constate d'une part que ces coupes présentent à l'œil une apparence marbrée dont on se rend aisément compte par l'examen microscopique. 'Tout à fait à la périphérie on trouve un feutrage épais, de couleur brune, de cellules allongées, qui forme le peridium et enveloppe un tissu moins dense de cellules entre lesquelles existe de l'air qui donne à ce tissu un aspect blanchâtre. Des espaces vides remplis d'un suc particulier apparaissent avec une teinte noire. Enfin le tissu hyménial est lui-même de couleur grisâtre. L'ensemble de ces bandes blanches de tissu et de l'hyménium forme la gleba. Sur les mêmes coupes examinées, et même à un faible grossissement, on aperçoit de nombreuses spores ovoïdes groupées par quatre ou huit dans l'intérieur de cellules (thèques) à parois minces incolores.

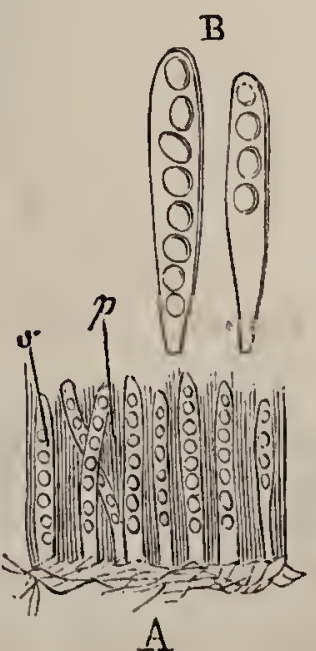

Fig. 139. - Pézize. A. Coupe sur l'hyméniuin. - $p$. Paraphyses. - $s$. Thèques et spores. - B. Deux thèques grossies avec les spores.

L'exospore (1) ou membrane externe des spores est colorée en brun plus ou moins foncé et ornée de manières diverses (fig. 138). Dans le

(1) A. Chatin, la Truffe. 
Tuber melanosporum par exemple, A, l'exospore est couverte de petites pointes fines, que nous avons représentées à un fort grossissement (600 fois) en $d$; dans le Tuber mesentericum, l'exospore est ornée d'une sorte de réseau relevé de saillies dont l'extrémité libre se termine $(c)$ en forme de tête de clou.

$2^{\circ}$ Les Discomycètes (Morille, Pézize), etc., seront également d'excellents exemples à étudier. La couche hyméniale occupe la surface extérieure du réceptacle tantôt plissé (Morille), tantôt en forme de coupe plus ou moins profonde (Pézizes). Sur cet hyménium, au moyen de coupes, on reconnaît l'existence de thèques allongées (fig. 139, B) entremêlées (A) de paraphyses ou poils souvent colorés (Peziza auran. tiaca) brillamment. Dans les thèques se développent par formation libre des spores ovoïdes généralement au nombre de huit.

Exemples de Basidiospores. - Tantôt chez les Basidiosporées le réceptacle est angiocarpe et formé comme chez la Truffe d’un péridiurn enveloppant une gleba (Lycoperdon). L'hyménium alors porte des basides surmontées par des spores.

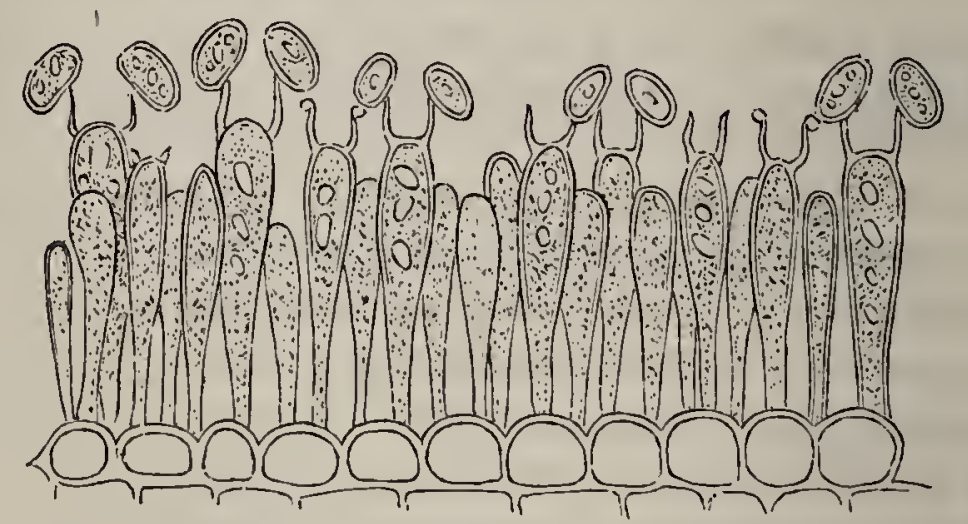

Fig. 140. - Coupe menée perpendiculairement à l'hyménium de l'Agaricus edulis.

Ailleurs (Hyménomycètes) l'hyménium revêt les prolongements de la surface inférieure du réceptacle fructifère. Dans les Agarics, ces prolongements forment des lamelles disposées radialement. Ces lamelles sont concentriques dans les Cyclomyces, anastomosées en réseau dans les Polypores; elles forment des tubes étroits, perpendiculaires à la surface et serrés côte à côte dans les Bolets. Enfin, dans les Hydnum, la face inférieure du réceptacle fructifère est garnie de pointes molles qui pendent comme des stalactites et sur lesquelles s'étale l'hyménium.

Agaric. - On pourra, pour l'étude, faire des coupes sur l'A garicus edulis qu'il est facile de se procurer à peu près à tous les états de 
développement. Toutefois, pour voir des spores bien développées, il sera bon de pratiquer des coupes sur des échantillons assez avancés en âge. Sur ces coupes (fig. 140) on trouvera de longues cellules renflées à l'extrémité, dont l'ensemble constitue l'hyménium et qui reposent sur une couche de cellules assez courtes appartenant au tissu du réceptacle fructifère. Parmi les longues cellules hyméniales, on en trouve un grand nombre (basides) qui développent à leur extrémité deux à quatre stérigmates portant chacun une spore. Ces spores développées se détachent, tombent et germent pour reproduire un mycélium.

Modifications des spores. - $1^{\circ}$ Conidies. - On a donné ce nom à de petits corps reproducteurs susceptibles de germer qui se produisent principalement chez les Champignons filamenteux (Phycomycètes), à l'extrémité des filaments fertiles. Ces

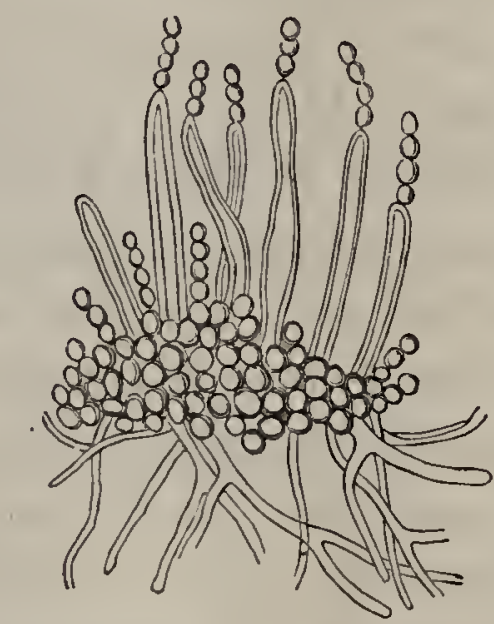

Fig. 141. - Torula sacchari. D’après Payer.

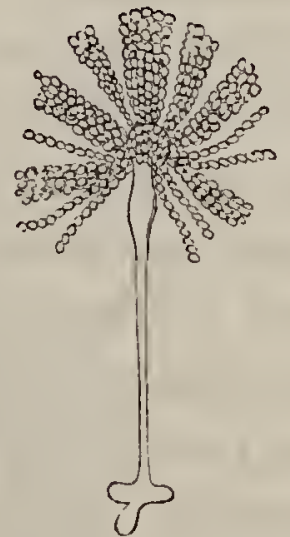

Fig. 142. - Aspergillus glaucus.

Conidies naissent successivement, souvent en grand nombre, à l'extrémité de ces filaments dont la cellule terminale joue le rôle de baside, et ils se disposent en chapelet, la spore la plus ancienne étant à l'extrémité. Nous reproduisons comme exemples de cette disposition en chapelet le Torula sacchari et l'Aspergillus Glaucus. On peut voir que dans le Torula (fig. 141) les chapelets de spores s'insèrent directement sur le mycélium filamenteux dont quelques filaments deviennent fertiles. Dans l'Aspergillus glaucus (fig. 142), ces chapelets de spores ne s'insèrent pas directement sur le mycélium, mais surdes filaments intermédiaires.

$2^{\circ}$ Stylospores et Pycnides. - Dans certains Champignons $(C e-$ 
nangium frangulx) on voit se développer des conceptacles appelés Pycnides qui s'ouvrent à leur sommet pour laisser échapper des spores appelées Stylospores parce qu'elles sont séparées de leur baside par un étranglement ou stérigmate.

$3^{\circ}$ Spermaties et spermogonies. - On trouve sur les Ascomycètes des conceptacles (spermogonies) tapissés de corps très grêles en forme de bâtonnets (spermaties) développés en grand nombre à l'extrémité de filaments cellulaires et qui répondraient aux conidies, car M. Max. Cornu (1) a pu obtenir leur germination chez certaines espèces.

$44^{\circ}$ Chlamydospores. - On a donné ce nom à des spores propres aux Mucorinées et qui diffèrent des spores ordinaires que possèdent ces mêmes plantes en ce qu'elles naissent isolément et dans le filament même du champignon.

Polymorphisme. - Comme nous l'avons déjà dit, beaucoup de champignons sont remarquables par les formes variées que prend une espèce à certaines époques de son développement. A ce polymorphisme vient s'ajouter pour certains d'entre eux une intéressante particularité. En effet, si les uns (monoxènes) subissent leurs diverses transformations sans changer de place (Claviceps purpurea), les autres (hétéroxènes) ne peuvent revêtir les diverses formes qui constituent le cycle le plus complet de leur développement, qu'à la condition de trouver pour chacune de ces formes un siége déterminé (OEcidium berberidis et Puccinia graminis). Nous allons citer quelques exemples de ces deux cas.

$1^{\circ}$ Champignons monoxènes. - Exemple : Claviceps purpurea. Ce champignon, qui vit en parasite sur le seigle, commence par développer un mycélium filamenteux blanc qui envahit l'ovaire de cette plante, le pénètre et y développe des conidies. Ce premier état, considéré longtemps comme une espèce autonome, avait reçu le nom de sphacélie. Mais bientôt les filaments de ces champignons développent un sclérote, qui, envahissant l'ovaire, soulève la sphacélie gui se dessèche et meurt. Ce sclérote, qui n'est même pas un état du champignon, reçut le nom de Sclerotium clavus. Mais si l'on observe la suite du développement, on voit bientôt naître à la surface de ce sclérote (2)

(1) Max. Cornu, Comptes rendus, t. LXXXII, 1876.

(2) Il suffit pour développer l'appareil fructifère, de piquer dans le sable des sclérotes que l'on arrose de temps en temps. On recouvre le tout d'une cloche et on l'abandonne à une température de 15 degrés environ. 
des appareils fructifères (fig. 143) en forme de tête sphérique pédiculée. Une coupe dans la partie sphérique montre un stroma cellulaire renfermant à sa périphérie de nombreux conceptacles (fig. 144) rem-

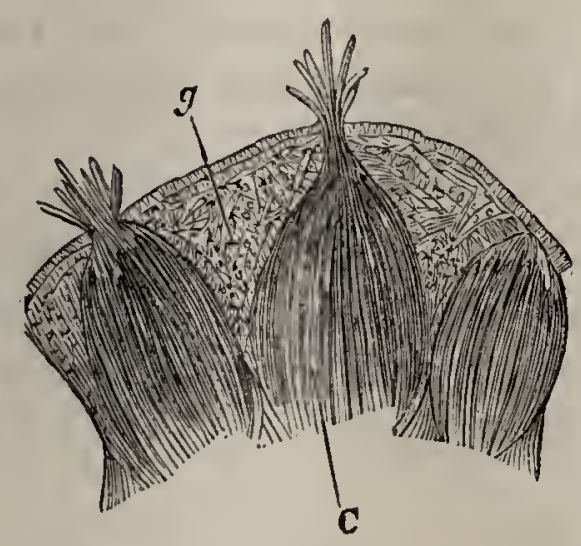

Fig. 143. - Coupe sur le réeeptacle du Claviceps purpurea. - C. Coneeptacle. Les thèques font saillie au dehors. g. Tissu eellulaire au milieu duquel sont ereusés les coneeptaeles.

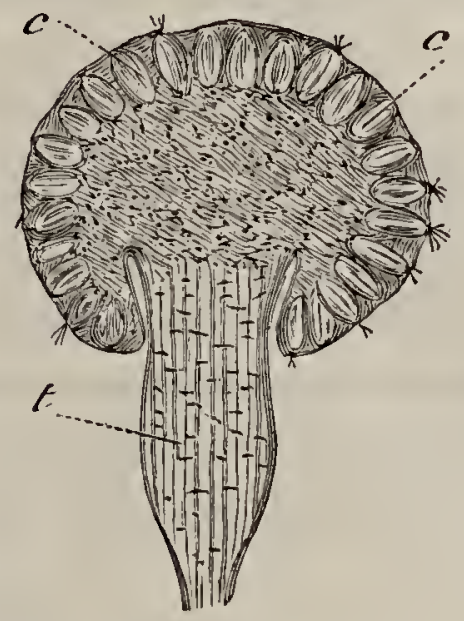

Fig. 144. - Coupe d'ensemble du Claviceps purpurea. - c, c. Coneeptaeles. $-t$. Pied qui supporte l'appareil fruetifere.

plis de longues thèques contenant chacune plusieurs thécaspores grêles et filiformes.

On terminerait le cycle du développement en semant ces spores

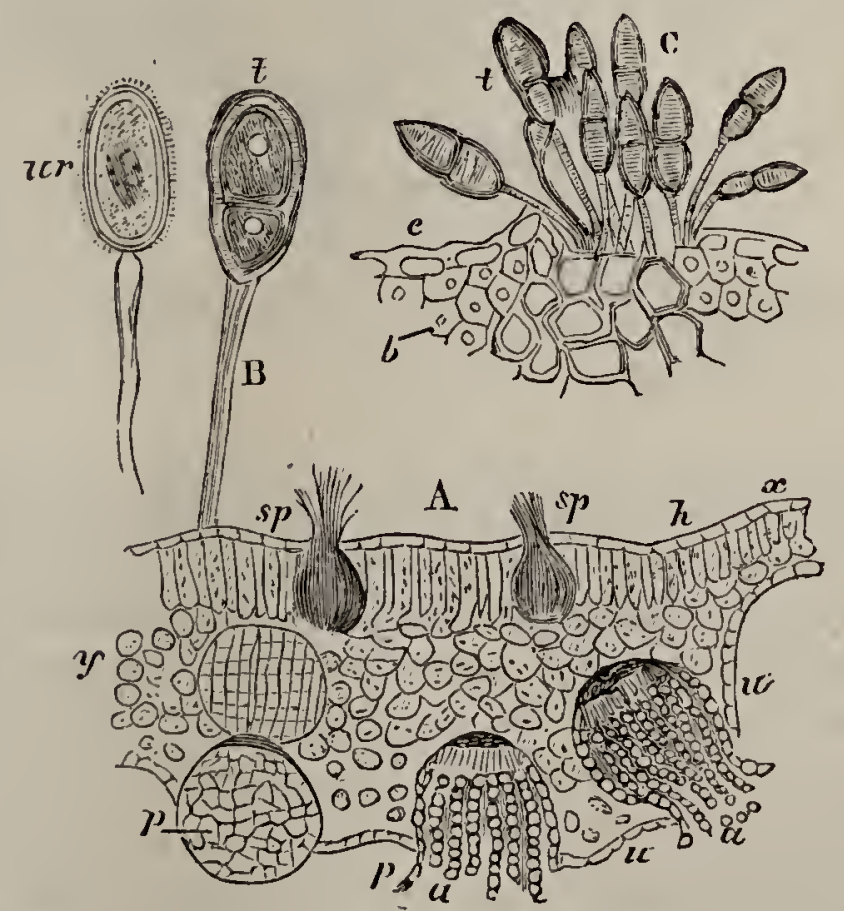

Fig. 145. - Puccinia graminis. - A. Seetion transversale de la feuille du Berberis vulg. avee spermogonies $s p$ et œeidiums $a$ (d'après Saehs). - $p$. Le péridium de l'œeidium. Entre $u$ et $y$. la feuille s'est anormalement épaissie. - En $x$ elle a eonservé son épaisseur naturelle. - B et C. Un amas de Téleutospores sur une feuille de chiendent. - c. Épiderme déehiré. - b. Fibres sous-épidermiques. - $t$. Téleutospore. - ur. Urédospore.

sur des fleurs de seigle, elles détermineraient bientôt la formation d'une sphacélie. 
$3^{0}$ Champignons hétéroxè nes. - Exemple : OEcidium berberidis et Puccinia graminis. - L'OEcidium berberidis est une Urédinée qu'on trouve au printemps sur les feuilles du Berberis vulg., où elle forme des taches jaunes, renflées par suite d'une sorte d'hypertrophie du parenchỵme de la feuille. Une coupe sur ces taches montre d'une part des conceptacles (spermogonies) en forme d'outre (fig. 145, sp), qui renferment des filaments longs qui passent par l'ouverture des conceptacles, en même temps que des spermaties.

D'autre part on trouve, dans le parenchyme inféricur de la feuille (fig. 14̈̈, a), des conceptacles en forme de coupes lorsqu'ils sont complètement développés, et qui renferment des chapelets de conidies. lls forment un premier état du champignon, que l'on nommait OEcidium. Ces conidies (spores) ne reproduisent cependant pas des

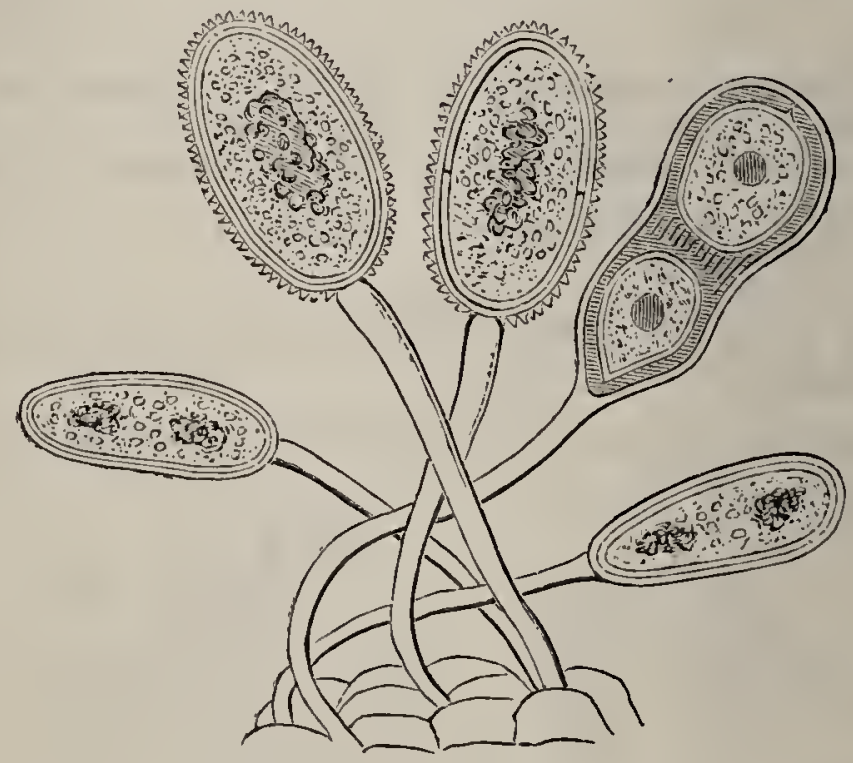

Fig. 146. - Urédospores et Téleutospores très grossies du Puccinia graminis.

OEcidium. Pour germer, elles doivent changer de siège, et c'est sur les Graminées (tiges, feuilles) qu'elles se transportent pour donner naissance à ce que l'on considérail autrefois comme un champignon autonome (Ured('), mais en réalité à une seconde forme reproductrice que l'on nomme l'Uredo du Puccinia graminis qui forme des bourrelets rouges (rouille des blés) sous l'épiderme des feuilles et des tiges des Graminées. Des coupes sur ces bourrelets montrent un mycélium dont certains filaments portent à leur extrémité une spore très grosse (fig. $14 \partial ̈, b$ et $c$, et fig. 146) renfermant des granules rouges (Urédospores), qui en tombant sur les feuilles des Graminées germe et reproduit de nouveaux urédos. Mais bientôt les urédos les plus îgés cessent de produire des urédosporeset donnent naissance à d'autres spores bicellulaires (fig. $143, b$ ), appelées Téleutospores, qui germent au printemps sur les chaumes de lia gramince, en donnant naissance à de petits filaments grêles qui portent à leur extrémité de petites spores que l'on nomme 
sporidies. Mais ces sporidies ne pourront germer que sur les feuilles de Perberis. Perforant l'épiderme de ces feuilles elles produisent un mycélium qui engendre ensuite les spermogonies et les ocidiums. Ainsi se termine le cycle du développement de ce champignon hétéroxène.

Champiginons parasites. - Leur nombre est très considérable. Les uns vivent sur les végétaux et peuvent être alors entophytes (Peronospora infestans, Cystopus candidus, etc.) ou épiphytes (Erysiphe Tuckeri) ; les autres vivent sur les animaux.

$1^{\circ}$ Entophytes. - Nous reproduisons en A (fig. 147) les branches fertiles qui naissent du mycélium unicellulaire du $C y s-$

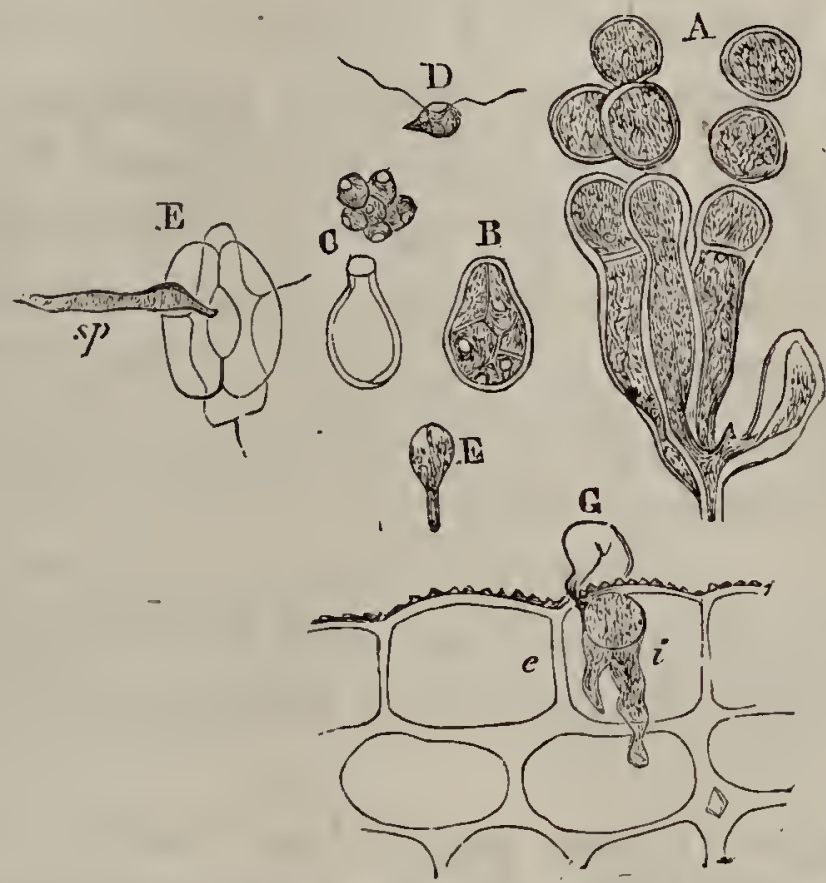

Fig. 147. - A à F. Cystopus candidus. - G. Peronospora infestans d'après de Bary. A. Branche sporifère du Iycélium du Cystopus. - B, C, D. Formation de zoospores par les spores. - F. Zoospore germant. - E. Zoospore germant sur un stomate et introduisant dans l'ostiole la pointe de son filament. - G. Peronospora germant șur l'épiderme d'une tige de pomme de terre et perçant cet épiderme $(i)$.

topus candidus (rouille blanche des Crucifères), mycélium qui vit dans l'intérieur du tissu de ces plantes. Les spores qui naissent aux extrémités de ces filaments développent chez le Cystopus candidus, comme chez le Peronospora infestans (parasile de la Pomme de terre), des zoospores (C, D, E, F). Ces zoospores, chez le Peronospora infestans, viennent s'établir sur la cuticule (fig. 147) de la plante nourricière, s'y fixent, s'entourent d'une membrane, et perçant la paroi de la cellule épi- 
dermique arrivent jusque dans les méats intercellulaires où ils développent le mycélium.

Les zoospores du Cystopus candidus germent au voisinage des stomates, et c'est par leur ouverture que les filaments germinatifs pénètrent dans le tissu. Le développement du mycélium n'a lieu toutefois que si l'ensemencement est opéré sur les cotylédons verts de la plante nourricière (Lepidium sativum, Capsella) (Sachs).

Il s'opère d'autre part dans les deux exemples que nous venons de citer une fécondation dans la profondeur des tissus de la plante nourricière. Comme exemples de champignons Entophytes nous rappellerons les formes si nombreuses de la famille des Ustilaginées. Les spores de ces champignons produisent en germant un premier mycélium qui porte des Sporidies. Celles-ci en germant envahissent les plantes dans lesquelles elles se développent, et le mycélium qu'elles forment vient fructifier dans des organes déterminés variant avec les espèces et les détruisent. Ainsi, le Tilletia caries détruit l'ovule des graminées sans altérer l'ovaire (carie des céréales). Les Ustilago Flosculorum et Antherarum attaquent les Étamines des Composées et des Caryophyllées. Les $U$. Carbo, $U$. destruens détruisent la fleur tout entière et provoquent la maladie des céréales appelée le charbon (Van Thiegem, loc. cit.).

$2^{\circ}$ Epiphytes. - Gitons parmi les champignons Épiphytes l'Erysiphe Tuckeri (Ö̈dium T'uckeri) qui produit la maladie de la vigne. On n'en connaît encore que l'état conidifère.

$3^{\circ}$ Champignons parasites des animaux $(\mathbf{1})$. - Tous ces champignons appartiennent aux formes les plus inférieures. Nous décrirons d'abord chez l'homme ceux qui produisent les teignes.

Teignes. $1^{\circ}$ Teigne faveuse. - Cette teigne présente à examiner, d'une part, un champignon caractéristique (Achorion Schœnleinii, fig. 148); d'autre part et accessoirement, et surtout dans les petites squames fines (Ardsten), un parasite très différent, le Puccinia favi. Achorion Schœnleinii. - Caractères (fig. 148). "Mycelium molle,

(1) Voir Ch. Robin, loc. cit., et L. Marchand, article du Nouveau Dict. de méd. et de chir. pratiques de Jaccoud. 
pellucidum, floccosum, floccis tenuissimis, non articulatis, ramosissimis, in stromate granuloso plerumque affinis. Receptaculum floccis crassioribus e cellulis elongatis formatum, subramosis, dis-

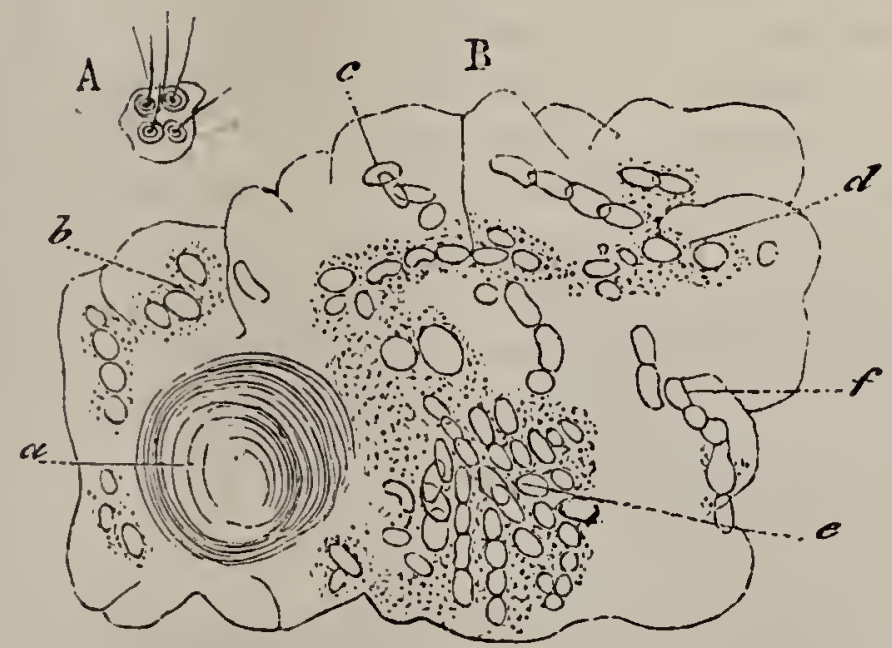

Fig. 14S. - A. Godets ou Favi de la teigne. - B. Portion d'une croûte épidermique prise dans le voisinage d'un favus. - $a$. Orifice épidermique d'une glande sébacée ou du follicule d'un poil. - $b, c, d, e, f$. Groupes de spores entourées de granulations moléculaires. - W'après M. Robin.

tincte articulatis, articulis inæqualibus, irregularibus, in sporidio abeuntibus. Sporidia rotunda, ovalia vel irregularia, in uno vel pluribus lateribus germinantia. Oidio affinis. " (Robin, loc. cit.) Ce

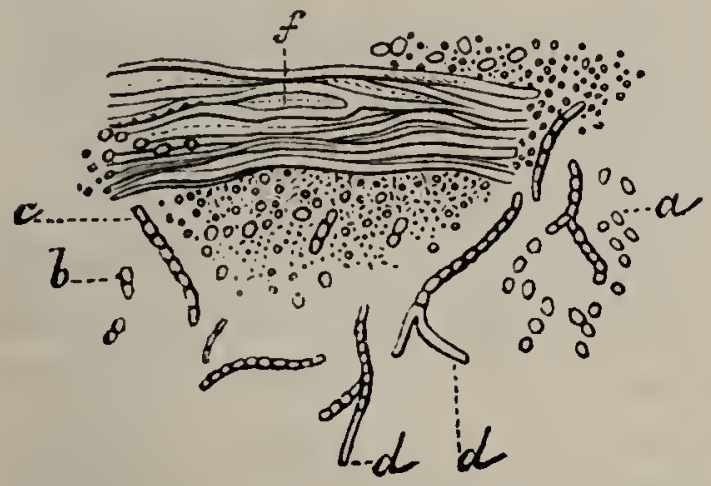

Fig. 149. - Parcelles de Favus (Bazin). $a$. Sporules isolées. - $b$. Sporules réunies. - c. Chaine de sporules. - $d$. Tubes vides. - $f$. Filaments tubuleux réunis ct granules.

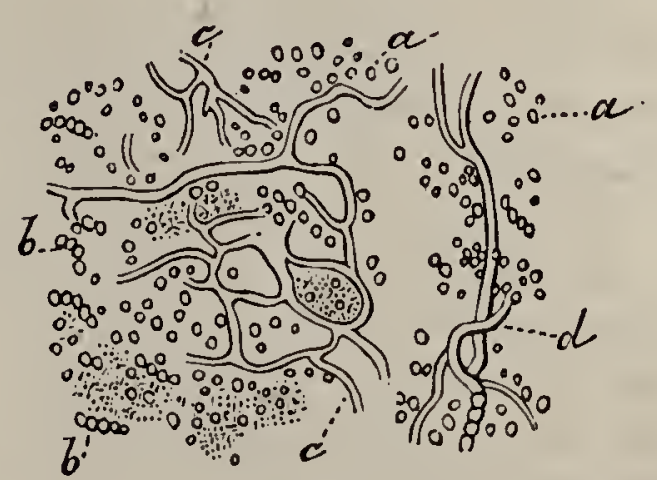

Fig. 150. - Poussière blanche qui revèt les cheveux brisés de l'herpès tonsurant (Bazin). a. Sporules isolées. - b. Sporules réunies. - $c$. tubes vides. $-d$. Tubes sporulaires.

champignon siège principalement sur la peau de la tête de l'homme; on le trouve dans la profondeur du follicule pileux contre le poil. On ne trouve alors que des spores (fig. 148, e) qui forment autour du poil des amas volumineux.

Dans les dépressions de la surface de la peau, on trouve des amas (godets ou favi) où l'on rencontre toutes les parties constituantes du végétal, mycélium, réceptacles, spores (fig. 149).

La couleur des favi est d'un jaune soufré pâle. 
Puccinia favi. - Ce parasite, que l'on rencontre également dans la teigne faveuse, est composé de réritables Téleutospores, colorées en brun rouge. Ce sont généralement deux cellules disposées comme dans la fig. 146 et supportées par un filament cylindrique.

$2^{\circ}$ Teigne tonsurante (Trichophyton tonsurans) (1), (fig. 13̈0).

Caracteres. - Spores rondes ou ovales, transparentes, incolores, à surface lisse; diamètre variant entre $0^{\mathrm{mm}}, 003$ et $0^{\mathrm{mm}}, 006$. Ces spores donnent naissance à des filaments articulés constitués par des spores enchaînées en filaments moniliformes.

Le cuir chevelu est le siège de prédilection de ce champignon. L'affection (2) débute par l'altération des poils qui changent de couleur, deviennent secs et cassants. Les spores existent dans l'intérieur même de la racine des poils. Bientôt elles se développent en grand

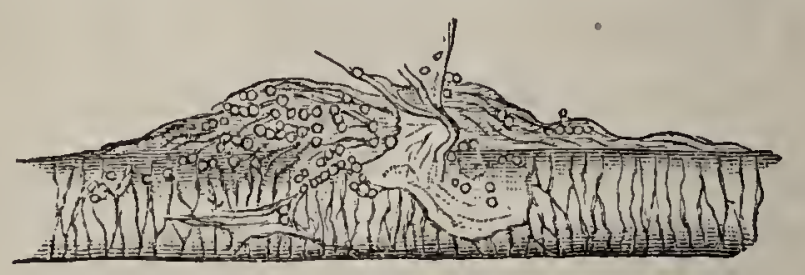

Fig. 13̆1. - Chereu dans un cas de pelade décalvante à marche rapide (Malassez).

nombre, et se logent dans les intervalles qu'elles déterminent par l'écartement des fibres de ceux-ci.

$3^{\circ}$ Teigne pelade, due au Microsporon Audouini (fig. 151).

Caractères. - Spores rondes, $0^{\mathrm{mm}}, 001$ à $0^{\mathrm{mm}}, 005$; spores ovales, $0^{\mathrm{mm}}, 002$ à $0^{\mathrm{mm}}, 008$, se gonflant dansl'eau; filaments et leurs branches courts. Il diffère du Trechophyton tonsurans par des branches nombreuses, courbées, des spores plus petites. (Robin, loc. cit.)

C'est un épiphyte que l'on retrouve assez difficilement.

M. Malassez (3) donne le procédé d'examen suivant : "On recueille non seulement les cheveux de la périphérie des plaques, mais aussi les pellicules que l'on obtient en raclant le cuir chevelu au niveau de ces plaques : ces pellicules dissociées soit dans l'éther, soit dans de l'alcool absolu pour être débarrassées de la graisse qui les souille, sont montées dans une solution d'acide phénique au centième. Le champignon occupe les parties les plus superficielles de la couche cornée de l'épiderme. "

$4^{\circ}$ Microsporon mentagrophytes (Ch. Robin). Diffère du précédent par des spores plus volumineuses et des filaments et ramifications plus

(1) Diverses espèces de Trichophyton ont encore été trouvées sur le corps humain: le Trichophyton ulcerum (Robin) a été trouvé par Lebert dans les croùtes d'un ulcère atonique de la jambe. Ce champignon formait des taclies jaunes composées de spores de 5 à 10 millièmes de millimètre, rondes ou ellipsoides.

(2) Bazin, Lcçons théoriques et cliniques sur les affections cutanées parasitaircs. Paris, 1862.

(3) Malassez, Archiv. de physiologie, 1874. 
grands. Il en diffère aussi par le siège. Il est, en effet, situé dans la profondeur du follicule pileux jusqu'ì la racine du.poil, entre lui et la paroi du follicule, et non pas dans l'épaisseur de la substance de la portion de poil placée dans le follicule, comme le Trichophyton tonsurnans, ni autour de la partie aérienne du cheveu, près du derme, comme l'est constamment le Microsporon Audouini.

Pytiriasis versicolor. - On nomme ainsi une affection parasitaire de la peau qui siège particulièrement à la poitrine et au ventre. Elle est produite par le Microsporon furfur. Le champignon est situé superficiellement: mélangé à de nombreux débris épidermiques, il passerait souvent inaperçu si l'on n'avait la précaution de traiter la préparation par de l'ammoniaque; on se débarrasse ainsi de l'épiderme (Robin), (fig. 1วั2).

Caractères. - Cellules allongées et ramifićes, spores réunies en groupes ou amas ayant seulement quelques centièmes de millimètre de diamètre. Les spores réfractent fortement la lumière et paraissent avec un contour bilinéaire.

Muguet (fig.1 303 ) . - Le muguet est une affection qui se développe à la surface de l'épithélium de la muqueuse buccale, ainsi que dans le pharynx, l'œsophage et même l'estomac et les intestins. Il forme des plaques blanches caractérisées par la présence d'un champignon spécial, l'Oïdium albicans

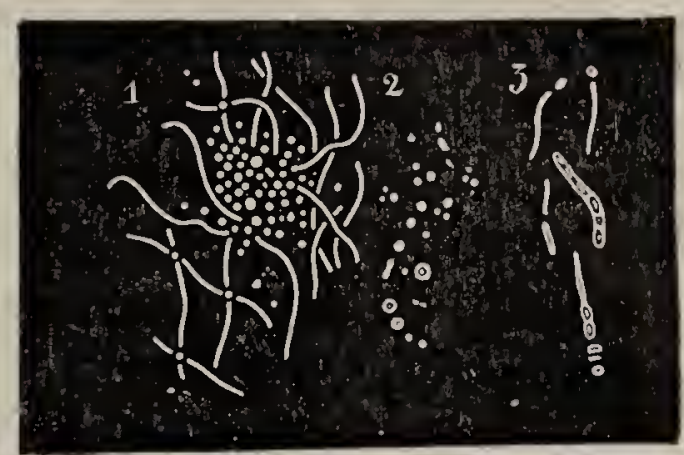

Fig. 152. - Microsparan furfur (MoquinTandon). 1. Mycélium et Sporules. 2. Spores. - 3. Spores en voie de développement.

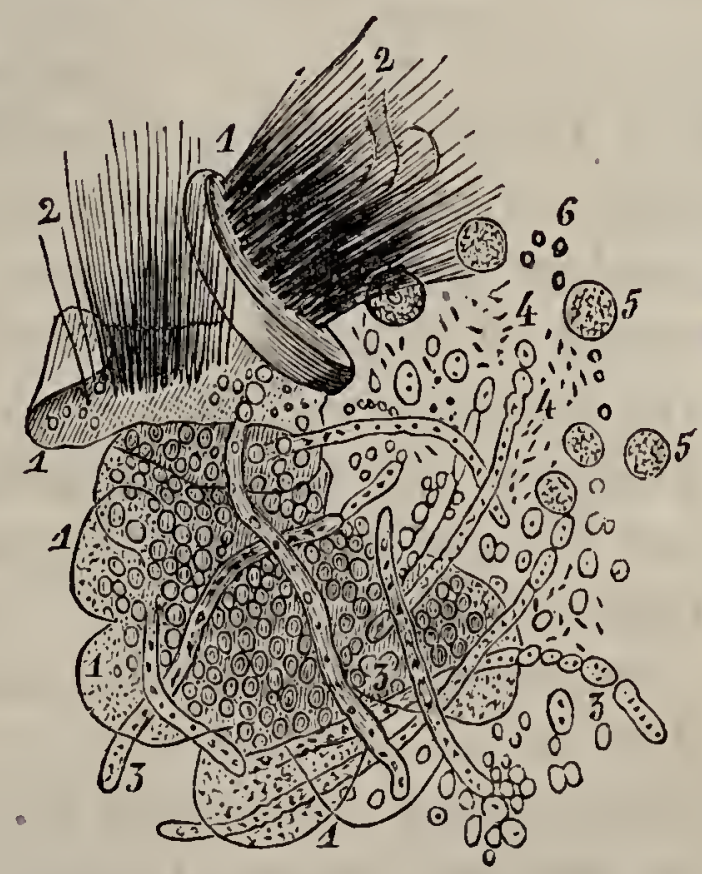

Fi.r. 153. - 1-2. Filaments du Leptothix buccalis sur leur gangue. - 3. Spores et filaments réeeptaeulaires de l'Oidium albicans. - 4. Vibrioniens. - 5. Glo bules de pus. - 6. Granulations graisseuses.

(1) (Gh. Robin).

(1) Rappelons au sujet de l'Oidium Albicans, l'existence de deux autres espèces décrites par M. Robin, sous les noms d'Ö̈dium pulmoneum (Ben- 
Caractères. - L'Oidium albicans est composé de filaments et de spores (fig. 153). Les filaments tubuleux sont cylindriques, allongés, larges de $3 \mu$ à $4 \mu$ sur $0^{\mathrm{mm}}, 0$ ว à $0^{\mathrm{mm}}, 050$ de long et plus. Les bords sontfoncés, nettement limités. L'intérieur du tube est transparent. Ces filaments sont formés de cellules allongées articulées bout à bout. Ils sont ramifiés une ou plusieurs fois. Les cellules renferment quelques granulations de teinte foncée. Les spores sont sphériques, à bords nets et foncés. Elles contiennent une fine poussière douée du mouvement brownien. Elles se mettent rarement en chapelet (Ch. Robin.)

Sarcine. - Parmi les champignons parasites de l'homme, nous devons encore citer une forme que l'on rencontre fré-

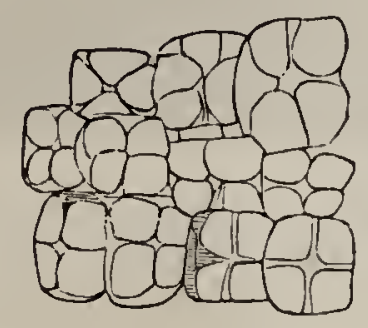

Fig. 154. - Sarcine. D'après Ni. Robin. quemment dans les vomissements, dans les fèces, ainsi que dans la vessie et l'urine. Ce champignon Sarcine, Goods (Merismopedia ventriculi, Ch. Robin) est composé de plaques quadrangulaires plus ou moins aplaties (fig. 15̆4) sous forme de masses cubiques dont chaque face est divisée en quatre saillies par deux lignes transparentes perpendiculaires l'une à l'autre. Ces cellules renferment un noyau jaunâtre. Elles sont accolées les unes aux autres de manière à former des amas de 8 à 16 éléments. La Sarcine peut être considérée comme une Bactérie (voir plus loin) dans laquelle le sectionnement a lieu par 2 cloisons perpendiculaires. La Sarcine, très voisine des Merismopedia, n'en diffère que par l'absence de la chlorophylle (Magnin, loc. cit.).

Muscardine. - Parmi les nombreux parasites des animaux, il en est un qui présente un intérêt tout particulier, c'est le champignon du Bombyx Mori (ver à soie) qui a reçu le nom de Botrytis Bassiana. Lorsqu'il se développe sur l'animal vivant, il détermine l'affection mortelle appelée Muscardine.

nett) et de Champignon de la morve. Le premier est formé de tubes articulés et rameux qui portent ì leur extrémité des spores nombreuses, rondes ou ovales et superposées en chapelet. Il a été trouvé dans les cavernes et dans les crachats d'un liomme atteint de pneumothorax. Le second, rencontré dans l'écoulement du nez d'un cheral morveux, était constitué par des filaments transparents, à divisions dichotomes, et par des spores brunâtres réunies en chapelet. 
Botrytis Bassiana (ìg. 155).-Caractères. - Mycélium à filaments cylindriques, flexibles, transparents, incolores et brunissant par la teinture d'iode. Chacun d'eux est formé par une seule cellule allongée, non cloisonnée. Granulations dans l'intérieur des filaments allongés.

Du mycélium partent des filaments réceptaculaires composés de cellules placées bout à bout. A ces filaments, sont adhérentes des spores sphériques à contenu homogène dépourvu de granulations. Tantôt isolées an sommet de leurs branches, ailleurs, elles se groupent par trois, puis quatre, cinq ou six ou même davantage (fig. $155, b, b$ ). Ce sont ces spores qui en s'introduisant dans le corps de l'insecte y germent rapidement et déterminent la mort. Vingt-quatre heures après la mort l'insecte devient dur et prend une teinte rosée, puis après un laps de temps à peu près égal il commence à blanchir par suite de la sortie des rameaux du Botrytis qui se couvrent d'une quantité considérable de spores. Ces spores se détachent au moindre attouchement, le corps de l'insecte blanchit alors les doigts comme le ferait un morceau de craie.

Moisissures. - On donne ce nom à des champignons très divers. - Pour n'en donner que quelques exemples, nous citerons : $1^{\circ}$ l'Eurotium Aspergillus glaucus, dont nous avons donné figure 14.0 l'état conidifère, mais qui par le développement
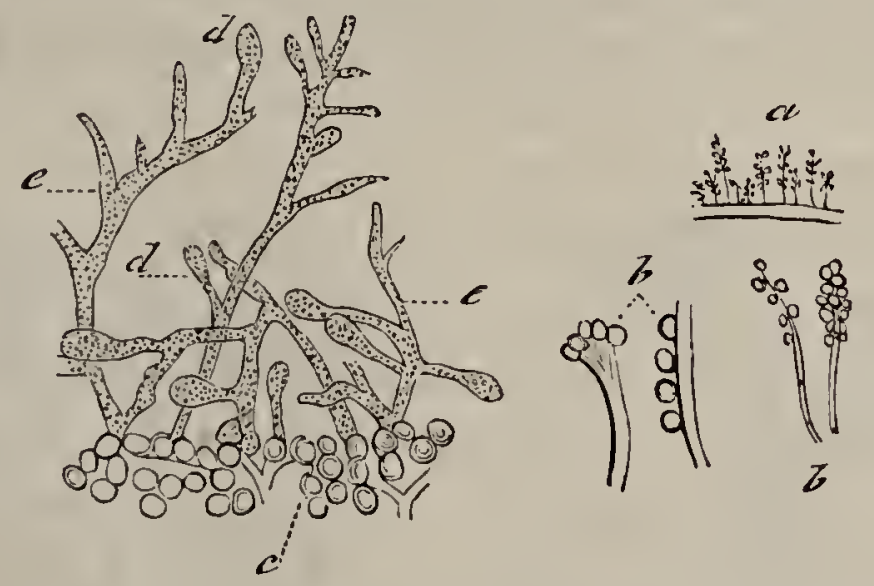

Fig. 153̈. - Botrytis Bassiana. Champignon de la Museardine d'après M. Ch. Robin. $a$. Filaments sporifères. $-b, b$. Tigelles grossies pour montrer l'insertion des spores, soit latéralcment, soit à l'extrémité. $-c$. Spores inoculées. $-d, e$. Myeélium qui en nait.

d'asques résultant d'une fécondation est un Pyrénomycète. Ce champignon croît sur beaucoup de corps organiques morts ou en voie de décomposition et particulièrement sur les fruits cuits.

$2^{\circ}$ Le Penicillium glaucum, qui sous une de ses formes se montre couvert de conidies en chapelet disposées en pinceaux élégants, assez semblables à celles d’e l'Aspergillus. Cette 
moisissure, extrêmement commune, peut se développer sur les objets les plus divers.

$3^{\circ}$ Les Mucors, Phycomycètes chez lesquels l'asque occupe l'extrémité de filaments allongés, et se

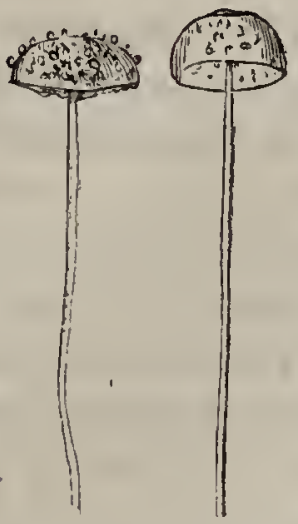
remplit de spores souvent verdâtres ou même noires (Ascophora mucedo, fig. 156). Nous reproduisons deux de ces Sporanges situés à l'extrémité d'un filament. Ces Sporanges, au lieu d'être globuleux, sont quelquefois très étroits et ne renferment qu'une rangée de spores en chapelet ( $P$ istocephalis); tantôt la cloison qui sépare le Fig. 1306. - Ascophora sporange du filament qu'il termine est mucedo, d'après Payer. plane, tantôt elle se voûte plus ou moins fortement en dedans, formant ce qu'on appelle la columelle. Rappelons enfin que les Mucorinées, outre les Spores, possèdent des chlamydospores, qui naissent dans l'intérieur même du filament par transformation du protoplasma.

Une espèce de moisissure décrite par Robin sous le nom d'Aspergillus auricularis a été trouvée par Pacini et Mayer dans le

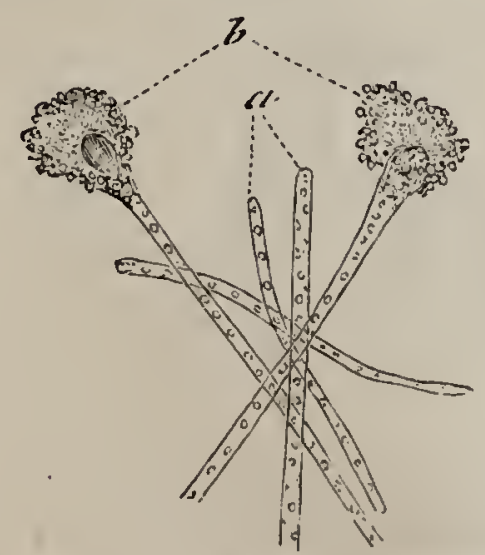

Fig. 157. - Filaments, moisissures trouvées dans le conduit auditif externe. - $a$. Filaments simples. - $b$. Champignons complets à extrémité capitée couverte de spores. - D'apres M. Ch. Robin.

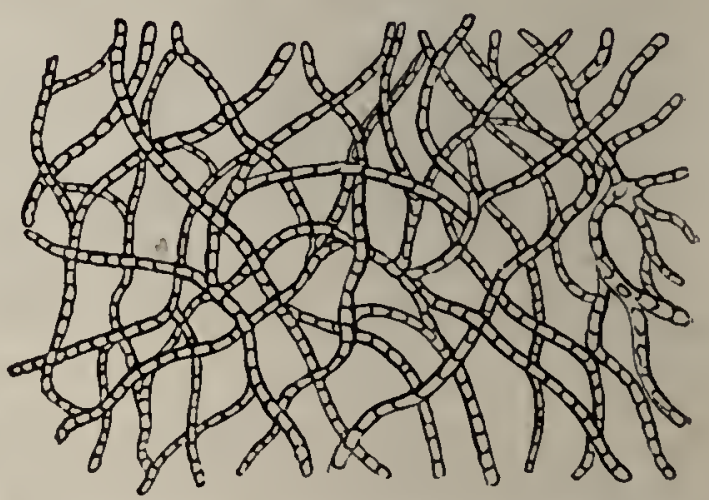

Fig. 158. - Aspergillus, lubes du Mycélium (L. Beale).

conduit auditif externe (fig. 157). Nous reproduisons également (fig.15̈8) le mycélium d'un Aspergillus rencontré par de nombreux observateurs dans le conduit auditif externe, sous forme de plaques noirâtres. Les Mucors forment des touffes ordinairement. 
verdâtres sur toutes les substances susceptibles de fermenter.

$4^{\circ}$ Signalons encore l'Hygrocrocis arsenicus qui se développe sous forme de filaments de cellules allongées, dans l'intérieur des solutions arsenicales (1).

Ferments (2). - On donne ce nom à divers organismes végétaux qui, par le fait même de leur végétation au sein de certains liquides, déterminent le dédoublement et la décomposition de principes particuliers contenus dans ces liquides. Il semble résulter des recherches les plus récentes que la plupart des végétaux microscopiques (Mucors, Aspergillus, Penicillium, etc.) peuvent, lorsqu'on les place dans des conditions convenables, jouer le rôle de ferments. Toutefois, parmi les agents les plus actifs et les plus répandus, nous considérerons spécialement les Saccharomyces et les Bactéries.

$1^{\circ}$ Les Saccharomyces déterminent la fermentation alcoolique des sucs végétaux sucrés (moût de raisin, moût de pommes et de poires) ou d'extraits sucrés (moût de bière).

Ces champignons sont formés de petites cellules arrondies ou ellipsoïdales qui produisent par bourgeonnement, dans des conditions convenables (matières sucrées et albuminoïdes), de nouvelles cellules semblables à elles. Toutefois, lorsque la nourriture est précaire, les cellules de levûre s'accroissent et leur contenu protoplasmatique produit par formation libre 1, 4, 5 spores qui, reportées en un liquide sucré fermentescible, bourgeonnent et forment de nouvelles cellules de levûre. Le Saccharomyces cerevisice ou levûre de bière présente deux variétés : la levûre basse qui fonctionne entre 4 et 10 degrés, et la levûre haute qui agit à une température plus élevée. La première reste au fond des vases où se fait la fermentation, et on l'y trouve sous forme de cellules un peu moins grosses et un peu plus oblongues que celles de la levûre haute. De plus les cellules de la levûre basse sont disjointes, tandis que celles de la levûre haute, qui se tiennent à la surface du liquide, sont disposées en groupes rameux. Cette forme rameuse tient à ce que les cellules-filles issues d'une cellule-mère se mettent

(1) Léon Marchand, Comptes rendus, novembre 1878.

(2) Nous faisons abstraction des ferments solubles pour ne nous occuper ici que des ferments organisés. 
elles-mêmes à bourgeonner sans s'en détacher (1). M. Pasteur distingue encore une autre sorte de levûre qu'il appelle caséeuse, formée de cellules oblongues, pyriformes ou même cylindriques, que l'on rencontre fréquemment dans le dépôt des bouteilles de pale-ale.

La fermentation des jus de raisin, de pommes et de poires est produite par les $S$. ellipsoïdeus, conglomeratus, Pastorianus, etc. Gette dernière espèce est remarquable par sa forme rameuse.

IBactériens (2). - On désigne aujourd'hui sous le nom de Bactériens ou Schizomycètes (Nrgeli) des organismes végétaux très-inférieurs et qui paraissent jouer un rôle considérable dans certaines fermentations et décompositions (putréfaction). Il ne nous est pas possible d'entrer dans de grands détails a u sujet de ces petits êtres, nous nous bornerons donc à indiquer succinctement leurs formes principales. On peut sous ce rapport les diviser en deux groupes. Les uns sont globuleux, ce sont les Monades (Monas crepusculum, Micrococcus, etc.), qui ne sont probablement que des spores de Bactéries plus élevées. Les autres sont filiformes, on les nomme Bactéries proprement dites, et ils peuvent être :

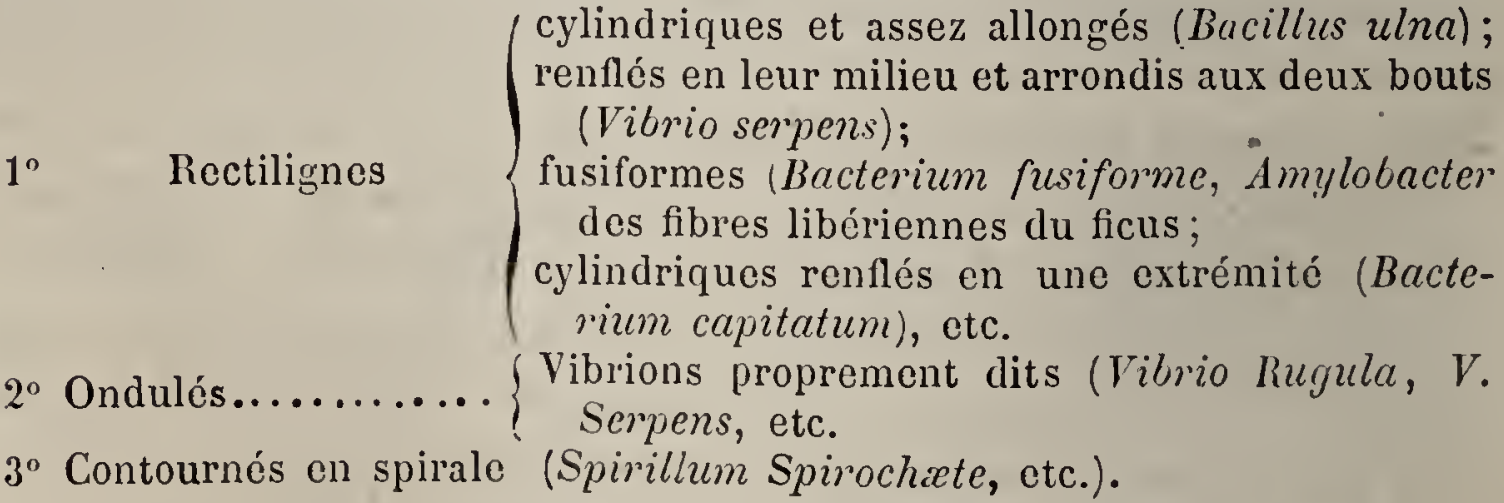

Tous ces Bactériens, de dimensions très petites, variant entre $2 /{ }_{10}$ de millimètre (Spirillum), et 3 à $4 \mu$ (Monas vinosa) de longueur (3), peuvent exister en nombre tellement consi-

(1) Duclaux, Art. Fenmentations du Diction. Encyclop. des sc. médic. de Dechambre.

(2) Magnin (Thèse d'agrégation de l'École de médecine, Paris, 18is).

(3) Monas vinosa, $0,5 \mu$ de diam. à $1 \mu$ sur 3 à $4 \mu$ de largeur.

Bacterium termo, 0,6 ì $0,8 \mu$ de larg. sur 2 ì $3 \mu$. longueur. Vibrio lineola, 0,5 à $1 \mu$ de larg. sur 3 à $8 \mu$ longueur.

Bacillus ulna, 0,7 i $1 \mu$

5 i $8 \mu$

Bacillus Anthrais, 1 ì $2 \mu \quad-\quad 10$ à $50 \mu$

Spirillum volutans, $7 \mathrm{~s} \quad$ - 10 à $40 \mu$ 
dérable dans certains liquides, qu'ils y déterminent un trouble facilement apparent, voire même une pellicule à la surface ou des dépôts relativement considérables sur les parois des vases.

Leur organisation est semblable à celle de toutes les cellules. Une paroi, dont on admet généralement l'existence, renferme un protoplasma quelquefois coloré. Des cils qui ont été découverts chez les Spirillum volutans, Vibrio serpens, Bacillus, Bacterium, etc., participent sans doute à la production des mouvements dont nous avons parlé plus haut. Quoi qu'il en soit, les Bactéries ne vivent pas toujours isolées, très-fréquemment elles se groupent et forment alors :

$1^{\circ}$ Des chaînettes, constituant la forme Torula lorsque les articles sont globuleux, et la forme Leptothrix lorsque les articles sont cylindriques;

$2^{\circ}$ Des amas (forme Zooglœa), constitués par des Bactéries englobées sans mouvement dans une sorte de mucilage produit par la gélification des parois des Bactéries en voie de multiplication;

$3^{\circ}$ Des membranes (forme Mycoderme) dans lesquelles les Bactéries sont sans mouvement bien que non enveloppées de mucilage;

\section{$4^{\circ}$ Des dépôts pulvérulents.}

Ajoutons que les Bactéries se reproduisent par scissiparité et par formation de spores endogènes.

$2^{\circ}$ Fermentation acétique. - La transformation du vin en vinaigre s'opère au moyen d'une Microbactérie (Mycoderma aceti, Pasteur), formée d'articles courts, deux à trois plus longs que larges (long. $=1, \check{\check{a}} \mu$ ). Elle forme des membranes (mycoderme) unies puis plissées à la surface du vin, et son développement est favorisé par une légère acidité du liquide destiné à la nourrir.On doit se garder de la confondre avec

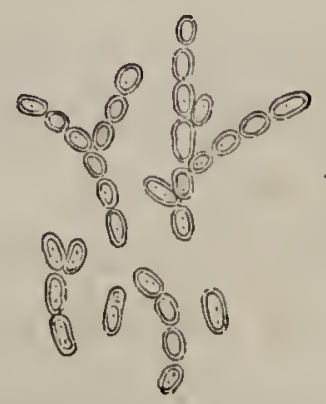

Fig. 159. - Mycoderma un saccharomycète, le Mycoderma vini (fig. 15̆9) formé de globules ovales, semblables en volume à ceux de la levûre de bière, tantôt isolés, tantôt en chapelets, - c'est ce dernier qui 
forme les fleurs du vin observées dans les bouteilles de vin en vidange; il transforme directement l'alcool en eau et acide carbonique, sans le faire passer par l'état intermédiaire d'acide acétique. Il agit de même sur l'acide acétique, aussi doit-on s'opposer à son développement lors de la fabrication du vinaigre.

$3^{\circ}$ Fermentation lactique. - Cette fermentation paraît se produire sous l'influence d'une Bactérie (ferment ou vibrion lactique de Pasteur) qui transforme le glucose et les substances susceptibles d'en fournir (mannite, acide malique, etc.), en acide lactique. - Le ferment est formé d'articles presque globuleux, très courts, un peu renflés aux extrémités : longueur d'un article $=1,6 \mu$; d'une série $=50 \mu$.

Les ferments acétique et lactique sont donc des Microbactéries, groupe qui ne renferme que le genre Bacterium, et paraissent se rapporter aux $B$. termo et $B$. catenula, espèces intéressantes, qui avec les $B$. linola et punctum, se trouvent dans les infusions de matières végétales ou animales; elles prennent ici la forme $Z$ ooglcea ou la forme Torula, et paraissent présider aux putréfactions.

$4^{\circ}$ Fermentation butyrique. - Cette fermentation est accompagnée de la présence d'une Bactérie filiforme allongée (Desmobactérie) de $6 \mu$ de longueur; tantôt isolés, les filaments peuvent s'unir en très grand nombre (forme Leptothrix). 1ls paraissent se rapprocher du Bacillus subtilis que l'on trouve dans les eaux stagnantes.

Citons comme espèce très voisine, le Bacillus anthracis qui se développe dans les affections charbonneuses, chez l'homme (pustule maligne), le mouton (sang de rate), le bœuf (maladie de sang), etc.: on le trouve surtout dans les vaisseaux capillaires; c'est au même groupe également qu'appartient le $B a$ cillus amylobacter (van Thiegem) qui se développe dans les tissus végétaux en putréfaction et ne se distingue du Bacillus subtilis que par l'apparition de l'amidon dans son protoplasma à la fin de la période de multiplication.

$5^{\circ}$ Fermentation ammoniacale. - La transformation de l'urée en carbonate d'ammoniaque dans l'urine expulsée de l'organisme, ainsi que le dédoublement de l'acide hippurique en 
acide benzoïque et glycolammine dans l'urine des herbivores, sont des phénomènes corrélatifs de la vie et du développement d'un champignon en chapelets de très petits grains sphériques atteignant à peine $0^{\mathrm{mm}}, 015$ (sphérobactérie).

Cette Bactérie globulaire (Micrococcus Urex, Cohn), revêtant la forme Torula, se retrouve à peu près semblable dans le vin filant.

Rapprochons de cette espèce les nombreuses Bactéries globulaires pathogènes, en chapelets ou en amas: $\boldsymbol{M}$. vaccinx, dans le vaccin récent et le pus des pustules varioliques; $\boldsymbol{M}$. diphthericus, septicus, $\boldsymbol{M}$. de la rougeole, de la diarrhée épidéinique, du Typhus exanthématique intestinal, etc.

Parmi les Sphérobactéries, beaucoup végètent sous la forme Zooglea à la surface des substances dont elles se nourrissent. Telles sont: le Micrococcus prodigiosus (Cohn; Palmella prodigiosa, Mont.), qui forme des masses rouges sur les substances alimentaires cuites. On a observé ce Micrococcus dans le lait rouge attribué à tort à des lésions des mamelles (Cohn). Au même genre Micrococcus se rapportent les petites Bactéries arrondies trouvées par Eberth dans les sueurs bleues, jaunes, rouges, et par Chalvet dans le pus des bords de certaines plaies, mais qu'il ne faut pas confondre avec la coloration bleue du pus, produite par le Bacterium xruginosum, espèce très voisine du vibrion lactique ( $B$. termo).

$6^{\circ}$ Fermentation gallique. - Enfin, d'après M. Van Thiegem (2), certains Pyrénomycètes, tels que l'Eurotium nigrum (Aspergillus niger) et le Penicillium glaucum, déterminent dans le cours du développement de leur mycélium la fermentation gallique ou dédoublement du tannin, à la température ordinaire, en acide gallique et en glucose.

\section{§ 3. Myxomycètes.}

On nomme ainsi des corps dont la place dans la classification n'est pas bien déterminée. Ils se composent d'un appareil végétatif gélatineux (Plasmodie) sur lequel, à un moment

(1) Annales scient. de l'Ecole normale, $1^{\text {re }}$ série, 1864.

(2) Ann. sc. nat., 5e série, VIII, 1868. 
déterminé, se produisent des sporanges qui se remplissent de spores.

On pourra étudier l'Athalium septicum qui prend naissance dans le tan. On procédera comme il a été dit page š3.

\section{$\S 4$. Lichens.}

Malgré quelques contestations, on s'accorde assez généralement aujourd'hui pour considérer les Lichens comme formés par la réunion du Champignon Ascomycètes et d'Algues, les premiers vivant en parasites sur les secondes. L'ensemble des filaments mycéliens du champignon et des cellules (gonidies) de l'algue forme l'appareil végétatif ou thalle du lichen.

Appareil végétatif. - Structure. - Le thalle se présente sur les coupes comme formé de deux parties : l'une, composée de cellules arrondies, à chlorophylle (Gonidies) et qui représentent l'algue; l'autre, composée de cellules allongées, filamenteuses, comme celles des champignons, et qui représentent le mycélium du champignon parasite. Lorsque ces deux parties constituantes du thalle sont mélangées en proportions à peu près égales, le lichen est dit homoomère (Collema, Leptogium). On l'appelle hétéromère lorsque les gonidies forment des couches distinctes de celles que constitue le mycélium du champignon.

Le plus souvent, les filaments de ce dernier forment a la périphérie du thalle un feutrage assez dense disposé en une couche corticale.

La forme extérieure des thalles les fait distinguer en :

10 Thalles crustacés. Ils forment alors des croûtes pulvérulentes, farineuses (Lecidea, Beomyces) ;

$2^{\circ}$ Thalles foliacés, expansions aplaties, membraneuses (Peltigera, Sticta);

$3^{\circ}$ Thalles fruticuleux, qui présentent des expansions en forme d'entonnoir (Cenomyce pixidata);

$4^{0}$ Thalles gélatineux (Collema).

Appareils reproducteurs. - Les appareils reproducteurs les plus constants sont les Apothécies et les Sorédies.

Les Apothécies ne sont autre chose que des sortes de conceptacles, en forme de coupes plus ou moins étalées, semblables à celles des Pézizes, à la surface desquelles se montrent des asques entremêlées de paraphyses, et renfermant en général chacune huit spores. Cies asques procèdent d'une couche hy- 
méniale qui tapisse le fond de l'apothécie. Cet hyménium est tantôt libre à la surface de l'apothécie (Parmelia, Cetraria, etc.), tantôt il est renfermé dans l'apothécie, qui est creusée de conceptacles semblablement à ce que nous avons décrit pour le périthèce du Claviceps purpuren.

Sorédies. - Sur beaucoup de lichens on trouve de petits amas formés d'une réunion de gonidies et de filaments entrelacés qui sont capables de donner un nouveau thalle de lichen lorsqu'ils sont expulsés au dehors. On a donné à ces sortes de propagules le nom de sorédies.

Enfin, on trouve sur beaucoup de lichens (Parmelia, Cetraria islandica, etc.) des Spermogonies développant des Spermaties, des Pycnides renfermant des Stylospores, corps reproducteurs que nous avons déjà décrits chez les champignons.

Cetraria Islandica. - Les apothécies du Cetraria sont grandes, arrondies, marginales, de couleur brune; elles sont entourées d'un bourrelet, et les thèques allongées fournissent chacune huit spores elliptiques. On fera des coupes sur ces apothécies comme sur les réceptacles fructifères des champignons.

On trouve à l'extrémité des cils durs qui bordent les lobes du thalle des spermogonies isolées ou groupées, et qui portent des spermaties cylindriques.

Roccella tinctoria. - Ici les apothécies sont éparses sur les branches du thalle, et ne sont jamais terminales. Elles sont arrondies, peu saillantes et de couleur gris foncé ou noires. Chaque thèque renferme huit spores, triseptées.

Les spermogonies apparaissent souvent à l'œil nu comme de petites taches noires disséminées à la surface du thalle. Elles renferment des spermaties linéaires souvent arquées.

\section{§ 5. Characées.}

Les Characées s'observent comme les Algues. Ge sont, en effet, des plantes d'eau douce, qui comprennent deux genres: les Chara et les Nitella.

Appareil végétatif. - Il résulte de la superposition d'entrenœuds qui atteignent jusqu'à 5 et 6 centimètres de longueur et que rattachent l'un à l'autre des nœuds formés chacun d'une seule assise de cellules en général plus larges que hautes, rangées en cercle autour de deux cellules centrales. De ce verticille de cellules qui forment le nœud, naissent les feuilles, longues, pointues, et à l'aisselle de la 
feuille apparue la première, se forment deux rameaux secondaires chez les Nitella, un seul chez les Chara.

Chaque entre-nœud de la tige est formé chez les Nitella par une seule cellule développée en cylindre long et peu épais; aussi pourra$\mathrm{t}$-on très bien suivre à travers ce cylindre les mouvements du protoplasma. Il n'en est plus de mêne dans les Chara. Chez ces dernières plantes, en effet, la cellule cylindrique axile est recouverte d'un sys-

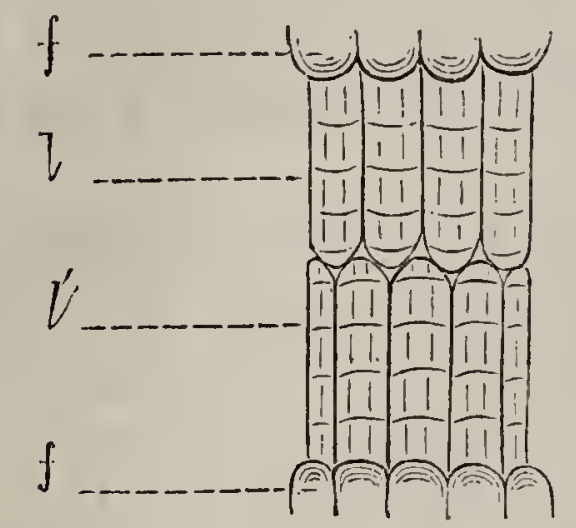

Fig. 160. - Système cortical du Chara fragilis. $l$. Tubes descendant du verticille supérieur $f$, et allant à la rencontre des tubes, $l^{\prime}$, montant du verticille inférieur, $f^{\prime}$.

tème cortical formé de tubes émanés, dans la moitié inférieure de l'entre-nœud, du verticille foliaire qui limite en bas l'entre-nœud, et dans la moitié supérieure, du verticille qui limite en haut ce même entre-nœud. Ces deux séries de tubes se rencontrent au milieu de l'entre-nœud (fig. 160). De plus, ces tubes ne sont pas simples; chacun d'eux, en effet, comporte quatre séries de cellules dont une interne (fig. 161), en contact avec la paroi de la tige (tube central), et trois périphériques. On fera des coupes transversales afin de se rendre compte de celte intéressante disposition que nous représentons ci-contre.

Organes reproducteurs. - La reproduction sexuée s'opère chez les Characées au moyen d'Anthéridies et d'organes femelles appelés Oogemmes ou Sporogemmes. Ordinairement situés l'un près de l'autre, les deux sexes sont au contraire séparés chez les Nitella.

L'Anthéridie (fig. 162) est globuleuse. Sa paroi se compose de huit cellules ou écussons, triangulaires et trapézoïdes, à bords dentés, à paroi interne colorée en rouge à la maturité. Du centre de cette paroi (fig. 163, A) part une cellule cylindrique (manubrie) qui porte à son extrémité une petile cellule ou léle qui, 
à son tour, en supporte six autres plus petites, de chacune desquelles (fig. 163 et 164, A), partent quatre longs filaments hyalins, composés de cellules courtes superposées en file unique et dans chacune desquelles se produit un anthérozoïde. A la maturité, les écussons s'isolent et bientôt les anthérozoïdes, soūs forme d'un fil très grêle enroulé en spirale (fig. 164, C), sortent de leurs cellules. Avant l'isolement des Écussons, ceux-ci sont tous rattachés par l'intermédiaire de leur tête à la cellule qui
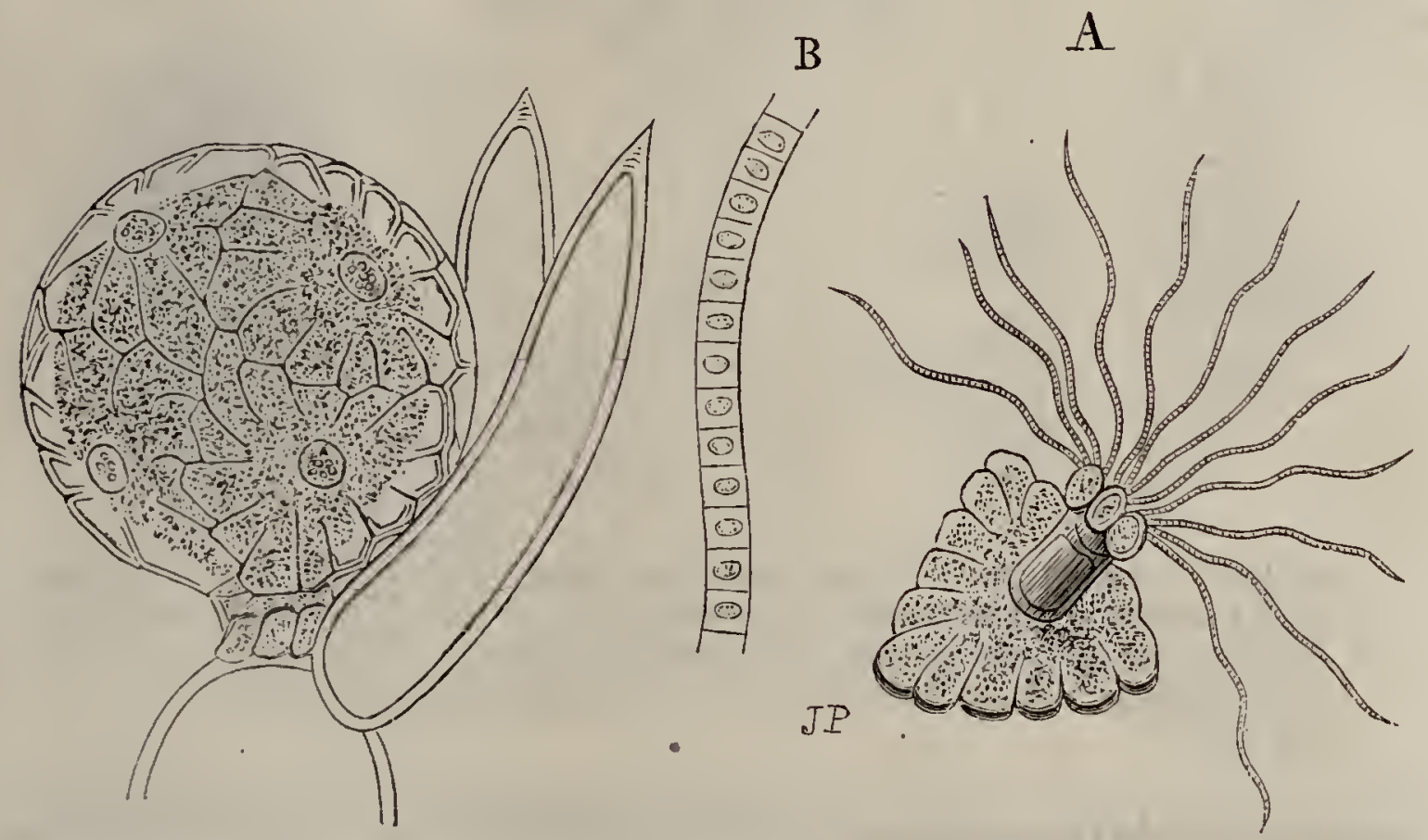

Fig. 162. - Anthéridie du Chara fragilis.
Figg. 163. - A. Un écusson séparé de l'Anthéridie du Chara fragilis, avec 3 cellules à filaments. - B. Fragment d'un filament avant maturité des Anthérozoïdes.

porte l'anthéridie elle-même (fig. 164, s). Les Anthérozoïdes développés $(c)$ ont la forme de filaments spiralés portant à leur extrémité antérieure amincie, deux longs cils vibratiles.

L'organe femelle (Sporocarpe, Oogemme) se compose d'une série axile de cellules autour de laquelle s'enroulent cinq tubes en spirale et que surmonte la couronne formée par des processus émanant des tubes en spirale (fig. 165). Cette série axile est formée de trois cellules; l'une à la base répond au nœud de la pousse latérale métamorphosée en oogemme, au-dessus de celle-ci s'en trouve une seconde qui apparaît de bonne heure dans les Chara et qui est remplacée chez les Nitella par un groupe discoïde de cellules. Enfin une cellule terminale ovoïde 
beaucoup plus volumineuse occupe l'axe de l'organe. Dans cette dernière cellule se trouvent du protoplasma, des gouttes d'huile et des grains d'amidon, sauf dans la région terminale (papille) qui ne contient qu'un protoplasma hyalin. Au moment

B

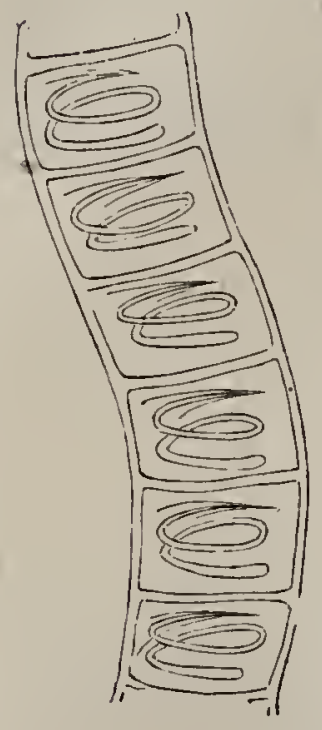

A

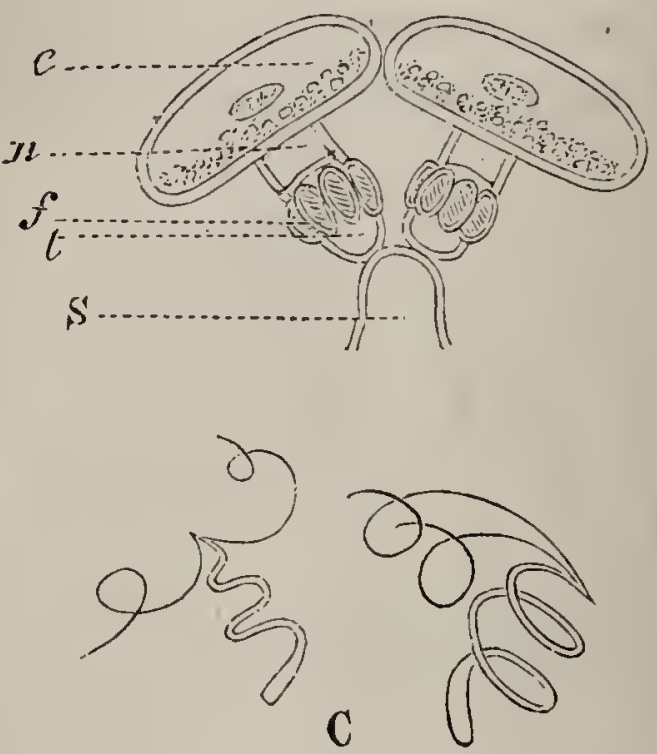

C

Fig. 164. - Anthéridie du Chara fragilis non mùre. A. 2 écussons. $-n$. Manubries. $-t$. Tètes. $-f$. Ccllules d'où naissent les" filaments. - $s$. Cellule de support. - B. Filament avec Anthérozoïdes. - C. Anthérozoides libres.

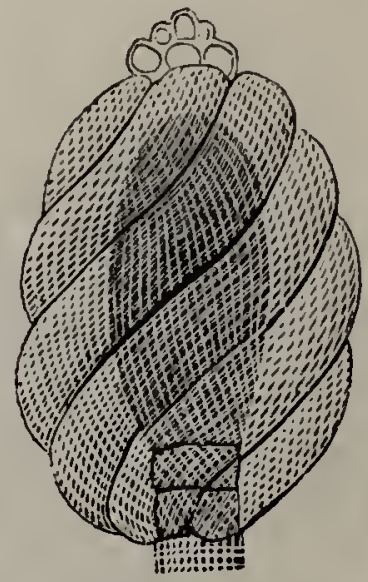

Figr. 160̈. - Organe femelle de Nitella flexilis.

de la fécondation, les cinq tubes spiralés s'écartent au-dessous de la couronne, et par les fentes ainsi produites, les Anthérozoïdes arrivent jusqu'à la papille de la cellule terminale ou Oosphère. La fécondation opérée, la paroi des tubes en contact avec l'oosphère s'épaissit et se colore en noir.

\section{§ 6. Muscinées.}

Nous traitons des Muscinées dans l'article suivant.

ArT. 2.

\section{Muscinées et Gryptogames vasculaires.}

Appareil végétatif. - Chez les Muscinées (Mousses, Hépatiques), l'appareil végélatif est encore uniquement composé de cellules. Toutefois, on peut reconnaîlre déjà, dans la structure des tissus qui le composent, une différenciation des cellules sinon en vaisseaux, du 
moins en cellules allongées, qui forment un cylindre central dans la tige et dans la nervure des feuilles de certaines mousses. Chez les Cryptogames vasculaires, la structure de l'appareil végétatif devient très complexe, les tiges et les racines possèdent un ou plusieurs faisceaux fibro-vasculaires, dont nous avons déjà donné la description. (Voir p. 242 et suiv.)

Appareils de reproduction. - Chez les Muscinées comme chez les Cryptogames vasculaires, il y a alternance de géné-

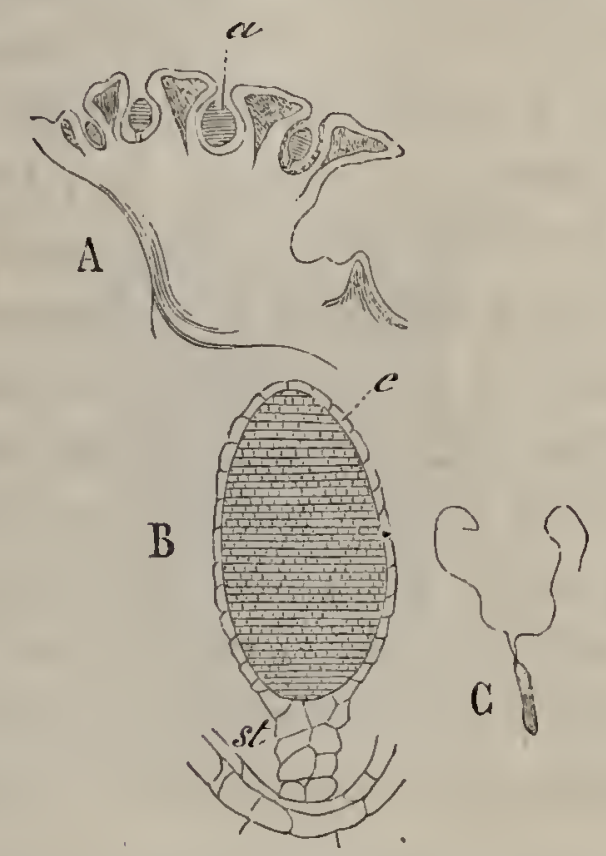

Fig. 166.-A. Seetion longitudinale perpendieulaire à travers un chapeau mâle de Marchantia polymorpha. Les anthéridies $a$ en voie de développement. Elles sont enfoncées dans des eavités du chapeau. - B. Une anthéridie presque mûre; st, son pédicelle; e, sa paroi. - C. Anthérozuïde, grossi 800 fois. (D'après Sachs.)

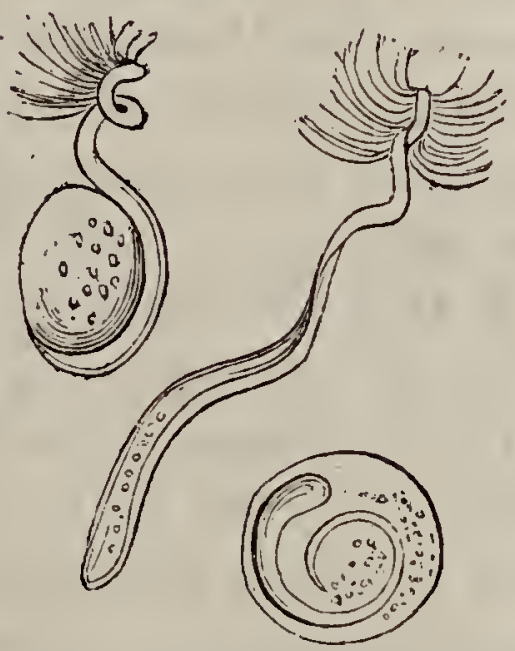

Fig. 167. - Anthérozoïdes d'Equisetum à divers degrés de développement.

rations au moyen d'organes sexués, mâles (Anthéridies) et femelles (Archégones), et au moyen d'organes reproducteurs asexués (spores).

$1^{\circ}$ Anthéridies, Anthérozoirdes. - Les appareils mâles où Anthéridies sont essentiellement des sacs dont la paroi est formée par une assise de cellules, et qui renferment un nombre plus ou moins considérable de cellules-mères d'Anthérozoïdes. Ces sacs sont tantôt pédicellés (Muscinées, fig. 166), tantôt ils font saillie à la surface de l'appareil végétatif (Fougères, Equisétacées, fig. 169), ou bien encore sont enfoncés dans la substance du thalle (Ophioglossées). Ils sont arrondis ou fusiformes (fig. 168, a). Chez les Rhizocarpées et chez les Selagi- 
nella, parmi les Lycopodiacées, l'anthéridie devient très simple et se trouve représentée par deux ou plusieurs cellules d'un prothalle plus ou moins rudimentaire, cellules qui, par des subdivisions successives, forment huit (Salvinia) à trente-deux (Pilularia, Marsilia) cellules-mères d'Anthérozoïdes.

A maturité, les Anthéridies se déchirent et laissent échapper les Anthérozoïdes.

Ceux-ci sont de très petits corps allongés, généralement enroulés en spirale, et qui portent des cils vibratiles dont la répartition varie avec les plantes. Les cils sont au nombre de deux à l'extrémité antérieure amincie du corps de l'Anthérozoïde des Muscinées (fig. 166,c). Chez les Gryptogames vasculaires, au contraire, les cils sont nombreux et occupent les premiers tours de la spire. De plus, à l'extrémité postérieure de celle-ci, se trouve une petite sphère protoplasmatique (fig. 167) qui semble être formée par la partie du protoplasma de la cellule-mère non utilisée dans la formation de la spire.

Les mouvements des Anthérozoïdes sont extrêmement rapides, et les cils sont alors difficiles à apercevoir. On y arrivera plus aisément en colorant faiblement par le carmin le liquide dans lequel on les observe.

Étude. - Pour avoir des Anthérozoïdes bien vivants, il faut pratiquer des coupes sur les Anthéridies fraîches et bien développées. Les parties du thalle sur lesquelles doivent porter les coupes varient suivant les plantes :

$1^{\circ}$ Parmi les Hépatiques, chez le Marchantia polymorpha, les Anthéridies (fig. 166) sont séparées des Archégones et portées, en nombre plus ou moins considérable, sur une sorte de réceptacle pédicellé (chapeau), en forme de bouclier, festonné sur les bords. Chez les espèces dont le thalle se différencie en tige et feuilles, les Anthéridies se développent à l'aisselle des feuilles, tantôt isolées (Radula), tantôt groupées;

$2^{\circ}$ Chez les Mousses, les Anthéridies, allongées et entremêlées de paraphyses (poils colorés ou non [fig. 168, p]), sont groupées à l'extrémité de petites tiges feuillées qui forment le thalle. C'est ce qu'on appelle souvent une fleur mâle. Il peut, du reste, dans certaines mousses se trouver des fleurs hermaphrodites; enfin, lorsqu'elles sont unisexuées, elles peuvent 
être monö̈ques ou diö̈ues (Funaria hygrometrica, Dicranum undulatum, etc.).

Les Anthéridies de la plupart des Mousses sont enveloppées par un involucre de feuilles nommé Périgone, lorsque ces Anthéridies ne sont point accompagnées d'organes femelles (fig. 168), et Périgame lorsqu'il embrasse une fleur hermaphrodite ;

$3^{\circ}$ Chez les Fougères et les Equisétacées, les Anthéridies sont portées sur un prothalle qui, contrairement à ce qui a lieu

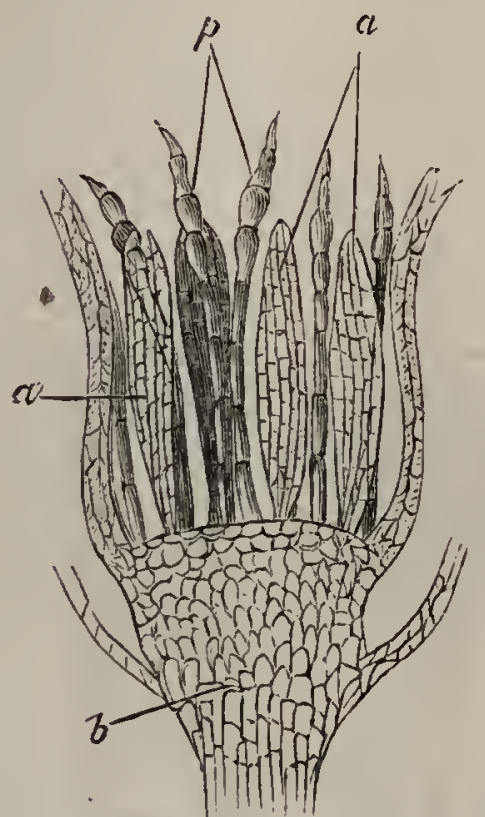

Fig. 108. - Coupe longitudinale de la fleur mâle du Bryum hornum. - $a$. Anthéridies. - $p$. Paraphyses. - $b$. Extrémité terminale du pied fertile. Extérieurement aux paraphyses et aux anthéridies; on aperçoit la coupe des fenilles du périgone.

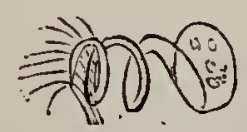

B

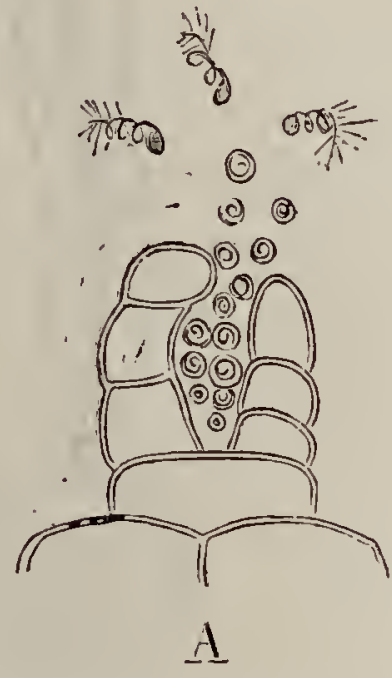

Fig. 169. - Anthéridie de Fougère. A. Anthéridie ouverte laissant échapper les anthérozoïdes. - B. Anthérozoïde et sa vésicule à l'extrémité postérieure.

chez les Muscinées, prend un développement très peu considérable relativement à la génération asexuée.

Ce prothalle tantôt porte les deux organes sexués (Anthéridies et Archégones), tantôt, au contraire, est dioïque (toutes les Equisétacées et quelques Fougères). Les Anthéridies se trouvent à la face inférieure du prothalle membraneux des Fougères (fig. 169), et au sommet ou au bord des lobes de celui des Prêles. Ces prothalles peuvent être obtenus à tous les degrés de développement en semant sur la terre humide des spores de Fougères ou de Prêles. On recouvre d'une cloche et on abandonne le tout pendant trois ou quatre semaines en un lieu frais (Polypodiacées, Aneimia, Osmuinda). 
On assiste sur les très jeunes prothalles, et sans avoir besoin de faire des coupes, à l'apparition des Anthéridies.

Sur les prothalles plus âgés, ou encore sur les thalles des Mousses et des Hépatiques, on doit faire des coupes fines pour examiner la structure des Anthéridies (fig. 168). Si les Anthéridies sonc mûres, on trouvera dans les coupes de nombreux Anthérozoïdes qui s'échappent par les déchirures faites

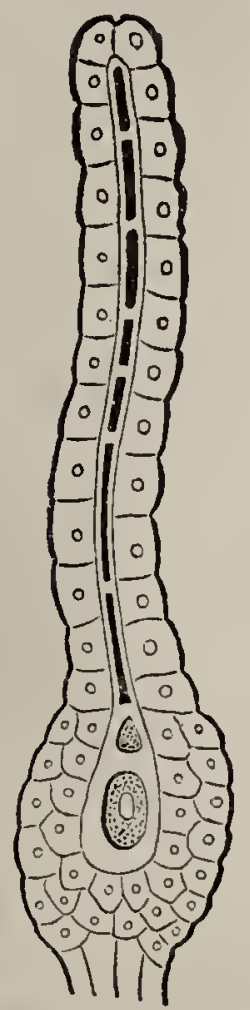

Fig. 170. - Archégone de Funaria liygrometrica.

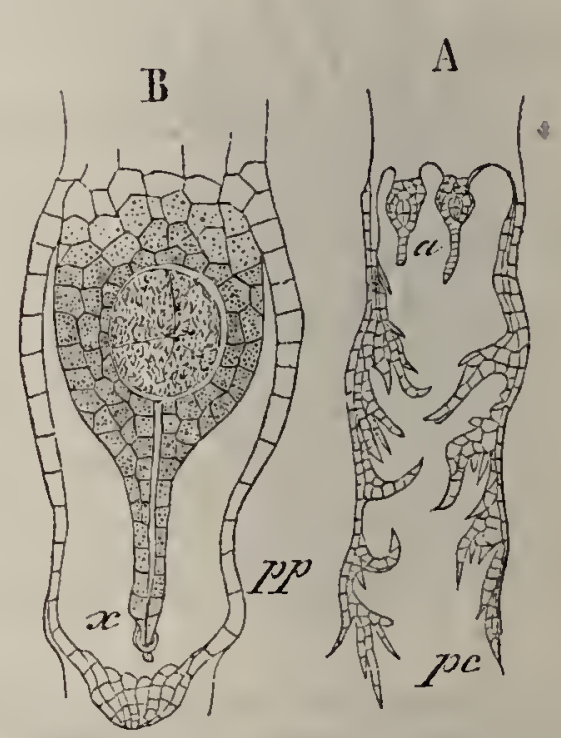

Fig. 171. - A. Coupe tangentielle perpendiculaire à travers le chapeau femelle du Marchantia polymorpha (Sachs). - $a$. Deux archégones. - pc. Enveloppe commune des archégones ou périchèze. - B. Archégone après la fécondation. Les cellules $x$ qui bordent l'ouverture du col sont flétries; l'oospore commence à se diviser. - $p p$. Périanthe en voie de développement.

par le rasoir sur les Anthéridies. Il vaut mieux, au moyen d'une bonne loupe, enlever les Anthéridies avec une pointe en les détachant par leur base, lorsqu'elles sont pédiculées, et les monter dans l'eau en ayant soin de ne pas les comprimer. $\mathrm{Au}$ bout de dix à quinze minutes, si elles sont bien développées, on les voit éclater et un nuage de spermatozoïdes actifs sort par l'ouverture.

A rchégones. - Les Archégones ou organes femelles sont, lorsqu'on les considère au moment de la fécondation, des 
corps en forme de bouteille à col plus ou moins allongé, et à panse (fig. 170) renflée, tantôt courtement pédicellée (Muscinées), tantôt plongée au milieu du tissu du prothalle (Gryptogames vasculaires). Le col de l'Archégone est rempli par une rangée axile de cellules qui se gélifient avant la fécondation et livrent passage aux Anthérozoïdes. Ceux-ci peuvent ainsi arriver jusqu'à la partie renflée ou ventre de l'Archégone, qui est occupé par une masse protoplasmatique (oosphère).

L'étude des Archégones se fera au moyen de coupes, comme
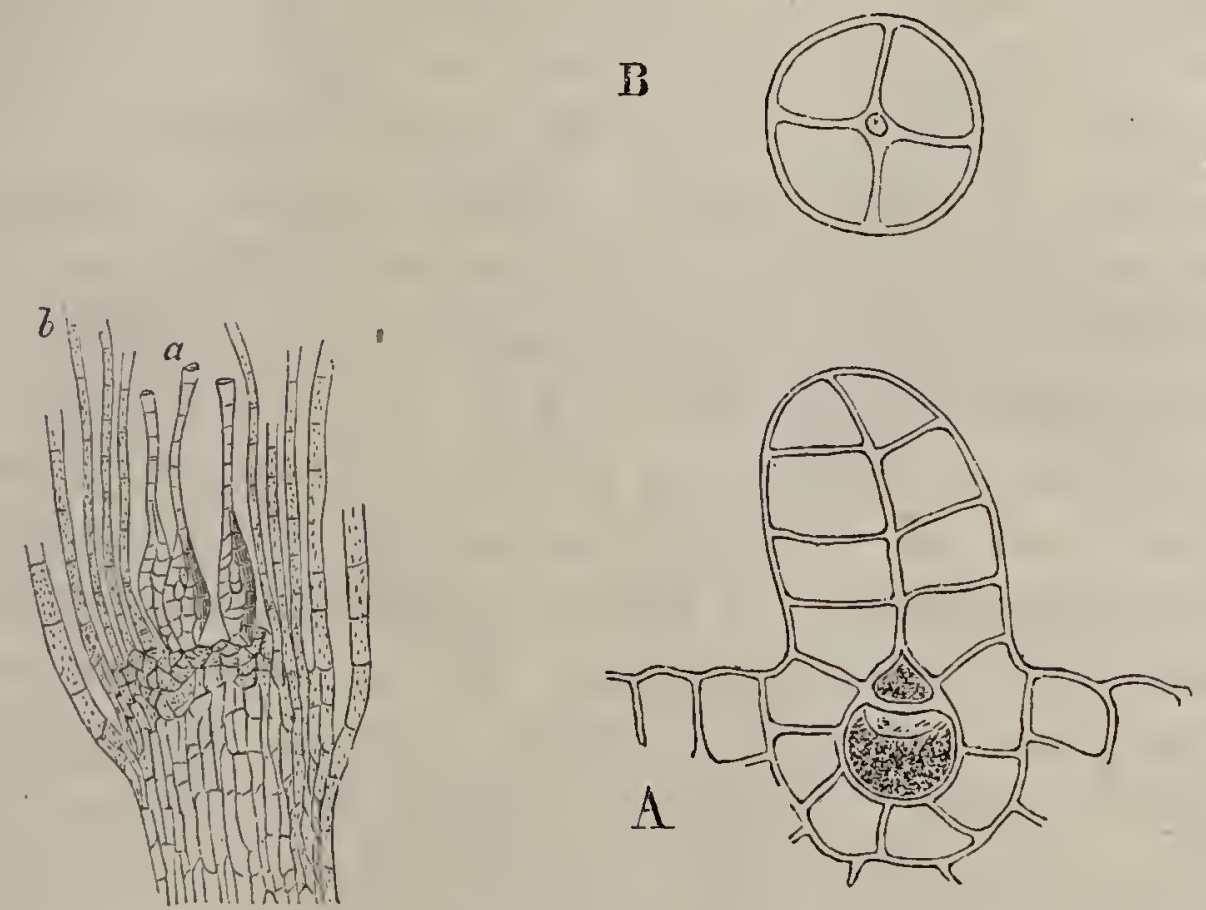

Fig. 172. - Coupe longitudinale du sommet d'un Fig. 173. - Archégone de Fougère. pied femcllc de Funaria hygrometrica. - a. Archézoncs. - b. Feuilles.

A. Archégone montrant l'oosphère et la cellule qui s'introduit dans le col. - B. Coupe transversale du col.

celle des Anthéridies. Ce que nous avons dit de la situation des Anthéridies dans les diverses plantes s'applique en général aux Archégones. Toutefois, dans le Marchantia polymorpha, les Archégones sont situés sur des supports particuliers (chapeau femelle) à bords très profondément divisés en lobes distincts. C'est à la face inférieure de ces lobes qu'on trouvera les Archégones (fig. 171) enveloppés par des expansions foliacées qui leur forment un involucre appelé périchèze (pc).

$2^{\circ}$ Chez les Mousses, les Archégones forment des fleurs femelles (fig. 172), ou des fleurs hermaphrodites en se joignant à des Anthéridies, dans le même périchèze:. 
$3^{\circ}$ Enfin, chez les Fougères (fig. 173i, les Archégones naissent, comme les Anthéridies, sur la face inférieure du prothalle, mais en avant de celles-ci, et chez les Equisétacées elles apparaissent sur le bord antérieur du lobe charnu du prothalle femelle. On procédera à l'examen des Archégones comme nous l'avons indiqué pour les Anthéridies.

Génération asexuée. - Sporogone. Sporange. Spores. - La fécondation qui résulte de l'action des Anthérozoïdes sur l'oosphère donne lieu à une oospore qui produit la seconde génération asexuée. Or, suivant que l'on étudie les Muscinées ou les Cryptogames vasculaires, on observe une différence importante dans le résultat de cette fécondation. Chez les Muscinées, en effet, l'organe asexué qui doit engendrer les spores naît pour ainsi dire directement de l'oospore fécondée et, restant toujours en intime relation avec l'appareil végétatif sexué, semble n'être que le fruit de cette plante. Chez les Cryptogames vasculaires, au contraire, l'oospore provenant de la fécondation de l'oosphère donne lieu à un appareil végétatif très développé, sur lequel apparaîtront, plus tard, les organes producteurs des spores. En un mot, chez les Muscinées, la génération asexuée reste très peu développée, et la génération sexuée constitue la plante dite Mousse, ou Marchantia, par exemple, tandis que chez les Cryptogames vasculaires la génération sexuée prend un très faible accroissement relativement à la génération asexuée qui forme les appareils végétatifs que l’on appelle des Fougères, des Prêles, etc.

Sporogone des Muscinées. - Capsule. - $1^{0}$ Mousses. L'Oospore ou Oosphère fécondée croît rapidement chez les Mousses et, par des divisions successives, forme bientôt un corps pluricellulaire (sporogone) dont la base, s'allongeant rapidement, devient le pédicule ou soie. Les parois de l'Archégone ne pouvant suivre le développement du Sporogone qu'elles renferment, se déchirent transversalement, et le jeune fruit porté par son pédicule reste pendant un temps plus ou moins long recouvert par la portion supérieure de l'Archégone qu'il a soulevée avec lui. Cette sorte de capuchon a reçu le nom de Coiffe (fig. 174). On donne ordinairement le nom de Capsule ou d'Urne (Sporange) à la partie du Sporogone rue 
supporte la soie. Gette capsule est fort intéressante à étudier et présente des variations très grandes, suivant les espèces. Formée d'ụne paroi de plusieurs assises de cellules, recouverte d'un épiderme souvent stomatifère, elle est remplie à l'état jeune par un tissu qui donnera naissance aux spores, ses cellules engendrant chacune 4 spores par une double bi-

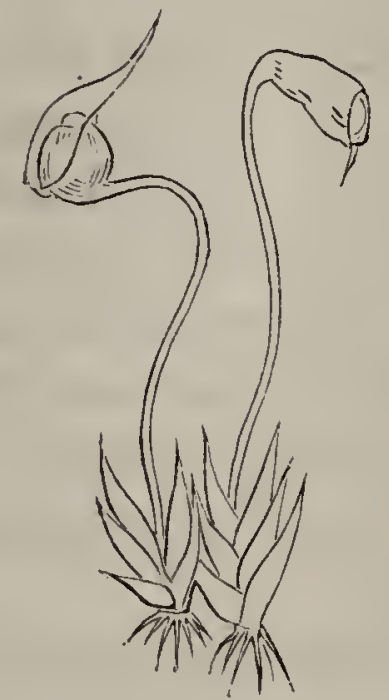

Eig. 174. - Deux pieds de Funaria liygrometrica. L'urne est recouverte par la coiffe.

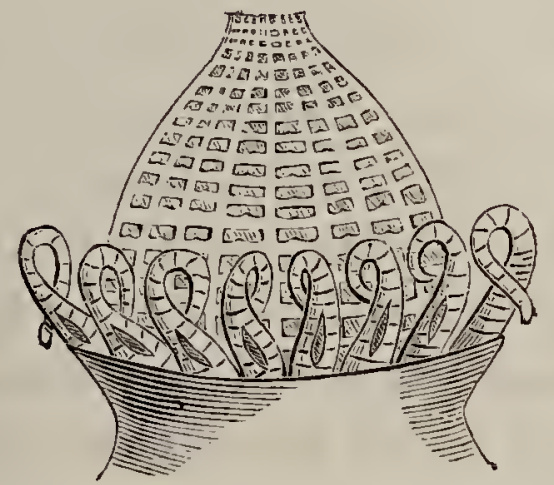

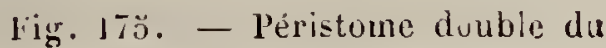
Fontinalis antipyretica.

partition. Toutefois, ce tissu est rarement employé out entier à la formation des spores. Le plus souvent une portion centrale persiste à l'état de tissu appelé Columelle. Ajoutons que le sommet de la capsule se différencie en une sorte de couvercle (opercule) qui tombe à l'époque de la maturité de la capsule, et offre une structure variable. L'union de l'opercule aux'bords de l'urne présente un ou deux cercles de dents qui forment le Péristome. Ces dents sont en nombre variable. Il y en a 4 dans les Tetraphis, 8 dans les Splanchnum, 16 dans les Grimmia; 32 dans les Torula, 32 ou 64 dans les Polytrichum, etc.

Les dents du Péristome consistent en portions de membranes épaissies et durcies ayant appartenu à une assise cellulaire séparée, par quelques rangées de cellules à parois minces, de l'épiderme caduc qui constitue l'opercule. Pendant que ces rangées de cellules et les places minces de lạ première année se déchirent et sont écartées, les fragments épaissis subsistent et constituent le péristome. Lorsque le péristome comporte 
deux rangées de dents, les plus internes (endostome) prennent généralement le nom de cils. Des modifications diverses peuvent se présenter. Nous figurons (fig. 175), le péristome double du Fontinalis, dont l'endostome, au lieu de cils est constitué par un réseau de bandes longitudinales et transversales.

Sans insister davantage sur ces détails, ajoutons que la fécondation de l'Oosphère chez les Hépatiques donne également lieu à un Sporogone, mais celui-ci reste beaucoup plus longtemps enfermé dans l'Archégone. De plus, son organisation intérieure est différente de celle de la capsule des Mousses. Il ne renferme généralement pas de Columelle et, outre les Sporanges, développe en général un grand nombre d'organes de dissémination nommés Elatères, qui consistent chacun en une longue cellule fusiforme dont la paroi s'épaissit fortement suivant 1-3 lignes spirales parallèles et se résorbe finalement entre ces épaississements.

Les spores des Muscinées naissent quatre par quatre dans l'intérieur des cellules-mères, elles sont tétraédriques ou globuleuses, souvent fort grosses et colorées de teintes diverses. Leurs parois sont formées d'une membrane (Endospore) recouverte d'une cuticule (Exospore), qui détermine à leur surface la production d'ornements variés. Elles renferment, outre un proloplasma incolore, de la chlorophylle, de l'amidon et de l'huile grasse.

Sporanges et Spores des Cryptogames vasculaires. - L'appareil végétatif (voir plus haut), qui résulte du développement de l'oosphère fécondée, développe dans le cours d'une vie autonome des organes ou Sporanges, qui produisent tantôt des spores d'une seule espèce (Fougères, Equisétacées), tantôt deux sortes de spores (Rhizocarpées et Lycopodiacées) nommées Macrospores, spores femelles qui, en germant, donneront. des prothalles femelles, et Microspores, spores qui, par germination, donnent un prothalle mâle.

Les sporanges des Fougères et des Equisétacées s'éludient facilement au moyen de coupes sur les frondes des premières et sur les scutelles groupées au sommet des pieds fertiles des secondes.

$1^{\circ}$ Chez les Fougères, les Sporanges (fig. 176) groupés en amas 
(Sores) de formes variées sont tantôt recouverts d'un repli de l'épiderme (Indusie), tantôt nus. Ces sporanges doivent être examinés au point de vue de leur forme, de leur

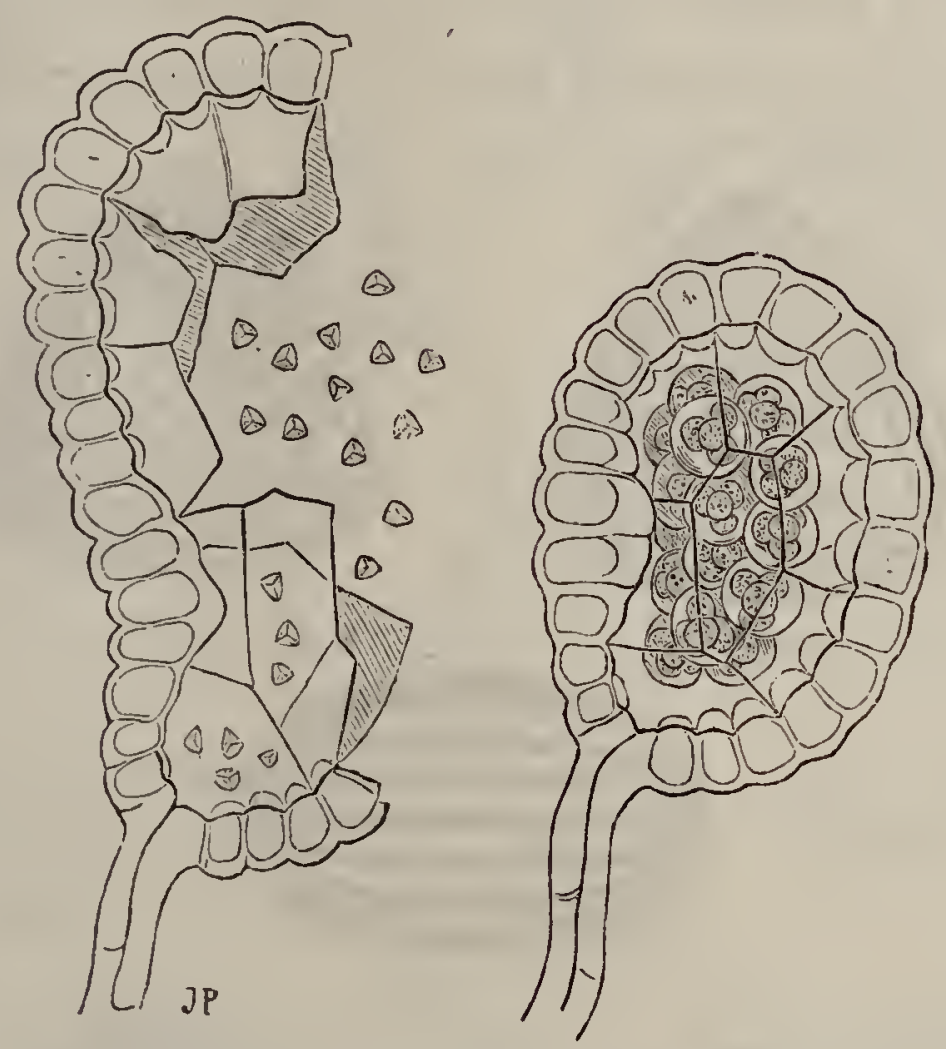

Fig. 176. - Sporanges de Fougère. - Sporange avant la maturité. - Sporange mûr ouvert, émettant les spores.

structure et de leur mode de déhiscence. Leur paroi, formée d'une assise de cellules, est munie sur une étendue variable d'une bande de cellules à parois épaissies et colorées qui forment l'anneau ou connecticule (fig. 176), production en rapport avec la déhiscence des Sporanges. Cet anneau complet est transversal chez les Gleichéniacées. Il est terminal chez les Schizæacées (Schizæa, Aneimia), et forme une sorte de calotte au sommet du Sporange. Il est oblique chez les Cyathéacées (Alsoplita, Cibotium). L'anneau est incomplet et longitudinal chez les Polypodiacées. En plaçant des Sporanges mûrs dans une goutte d'eau, on les voit bientôt éclater, et l'on peut constater que la déhiscence se fait suivant un plan perpendiculaire au plan de l'anneau ; longitudinalement, par exemple, si l'anneau est transversal.

Les spores des Fougères se produisent généralement en grand nombre dans l'intérieur des Sporanges. Leur forme est variable. Elles sont généralement colorées en brun à maturité, 
et leur paroi se compose d'une endospore et d'une exospore ou cuticule pourvue de bandes d'épaississement (fig. 177).

$2^{\circ}$ On étudiera les Sporanges des Equisétacées au moyen de coupes sur les écussons disposés au sommet des tiges fertiles. Les spores qui se forment dans ces Sporanges méritent une

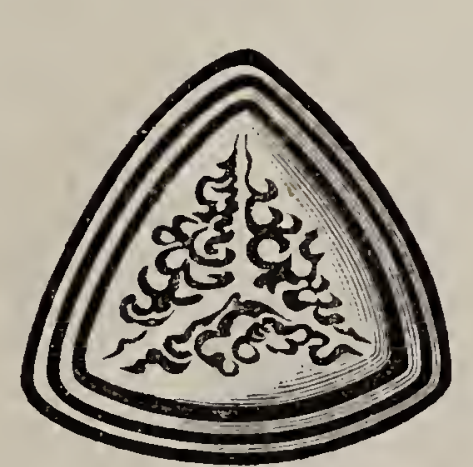

A
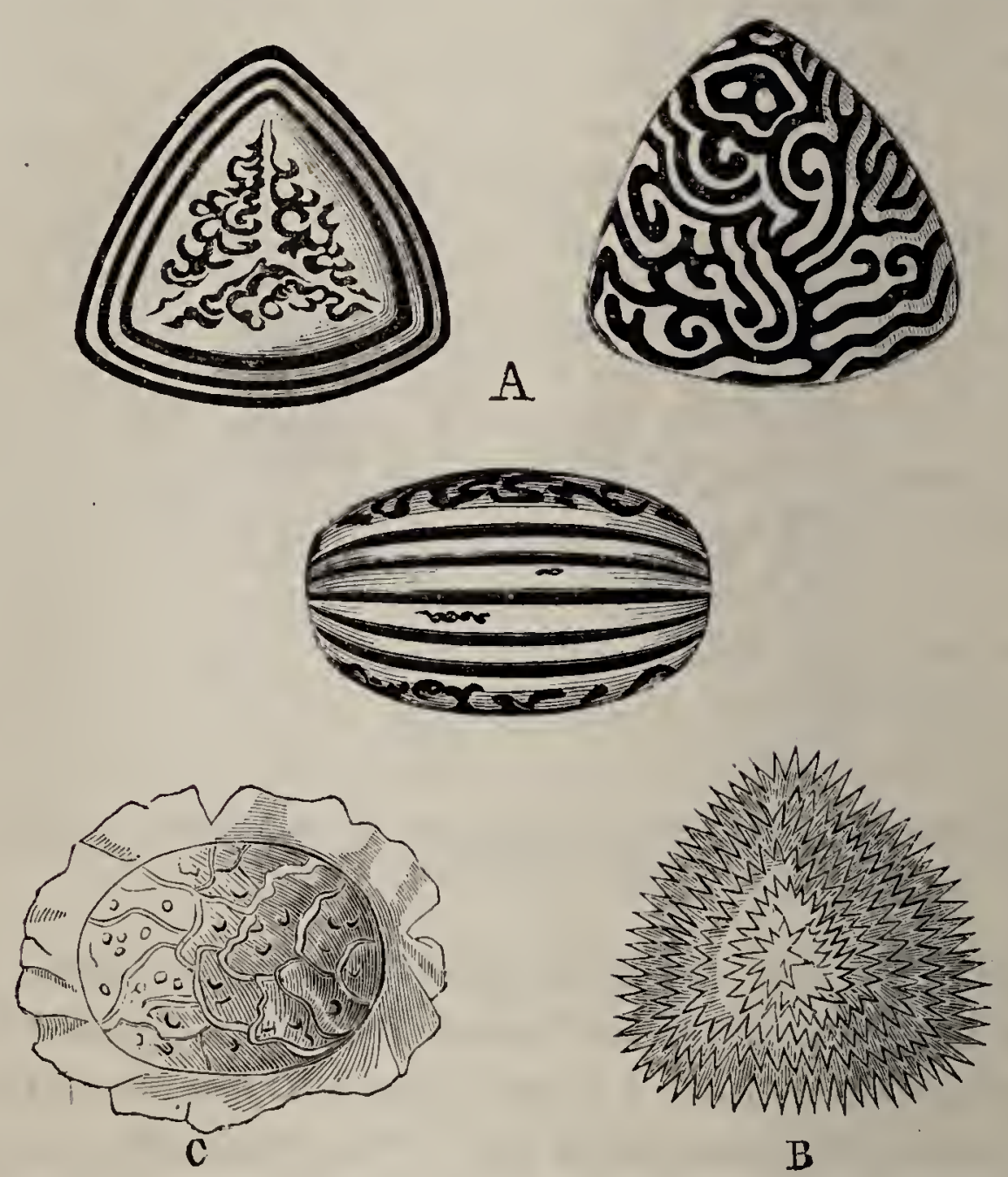

Fig. 177. - Spores de Fougères. - A. Gymnogramma calomelanos. - B. Allosurus. - C. Aspidium.

attention spéciale à cause de la formation d'élatères aux dépens d'une membrane externe non cuticularisée, qui se déchire à maturité en deux rubans spiralés (fig. 178).

La germination des spores des Fougères et des Équisétacées donne naissance au prothalle, qui portera les organes sexués. Ainsi se termine le cycle du développement.

$3^{\circ}$ Chez les Rhizocarpées, les Sporanges naissent dans des capsules ou conceptacles creux, dits fruits sporifères, qui présentent de notables différences de structure suivant les genres. Dans le Salvinia, le fruit uniloculaire présente en son centre ın renflement sphérique pédicellé qui se courre de sporanges, 
(lonnant tantôt des macrospores (fruit femelle), tantôt des microspores (fruit mâle).

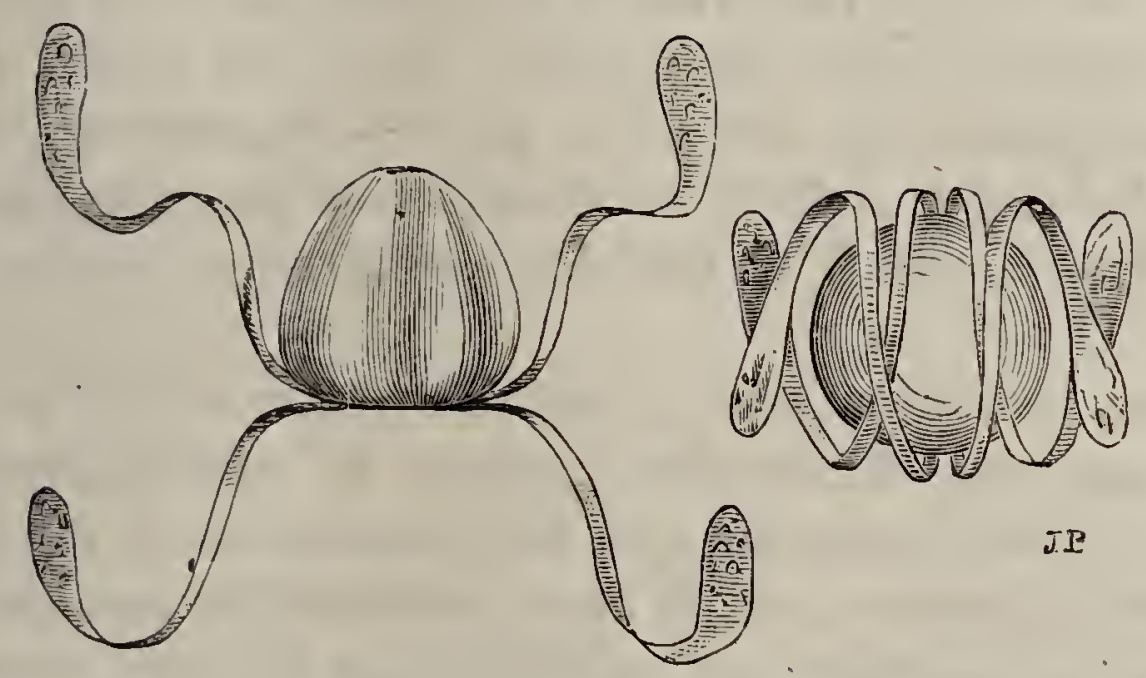

Fig. 178. - Spores d'Equisetum. Élatères développées et enroulées.

Le fruit du Pilularia, 2-4 loculaire, porte une sorte de placenta longitudinal pariétal, sur lequel s'insèrent de nombreux sporanges dont les inférieurs forment des macrospores (fig. 179), les supérieurs des microspores (Sachs).

Enfin, dans les Marsilia, l'intérieur du fruit est divisé en deux loges par une cloison longitudinale, et chacune de ces loges est subdivisée en huit ou neuf logettes superposées, par des cloisons transversales. Dans chaque logette un placenta porte une rangée de macrosporanges entre deux rangées de mi-

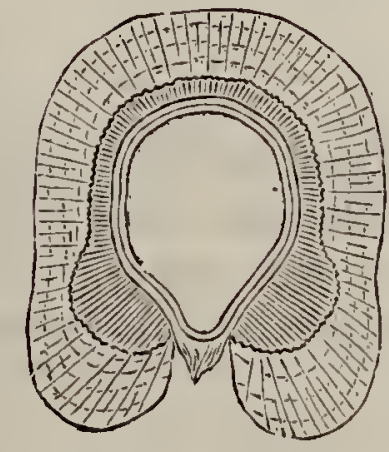

Fig. 179. - Macrospore de Pilularia. crosporanges.

Comme nous l'avons dit, les Macrosporanges donnent des macrospores qui, en germant, produisent autant de prothalles femelles, qui ne se séparent jamais d'elles et qui développent chacun un ou plusieurs Archégones. Les microsporanges donnent naissance aux microspores qui produisent les Anthérozoïdes (1).

Enfin, chez les Lycopodiacées, les Sporanges se développent solitaires à l'aisselle des feuilles. Ces Sporanges sont

(1) Voir Duchartre, loc. cit.; Saclis, loc. cat. 
de deux sortes dans les Isoeles et Selaginella, savoir : des Macrosporanges, renfermant quatre grosses macrospores, et des Microsporanges renfermant un grand nombre de Microspores formées quatre par quatre. Dans les genres Lycopodium et Psilotum, on ne connaît que des Microspores (fig. 192). Le prothalle, qui naît de la germination des microspores de Lycopodium, porte à la fois des Archégones et des Anthéridies.

Comme précédemment, toutes ces observations se feront par coupes aux différentes époques du développement, et l'étude ne sera complète que lorsqu'après avoir constaté la formation des spores, on en aura déterminé la germination et étudié sur le prothalle qui en résulte, les organes sexués, anthéridies ou archégones.

ART. 3.

\section{Phanérogames}

\section{$\S 1$. ÉTUDE DE LA FLEUR.}

Pour étudier une fleur, on commence par examiner le nombre des pièces des verticilles et la position de ces pièces les unes par rapport aux autres. Celte étude se fera particulièrement au moyen de coupes transversales sur des fleurs non épanouies;-on obtiendra
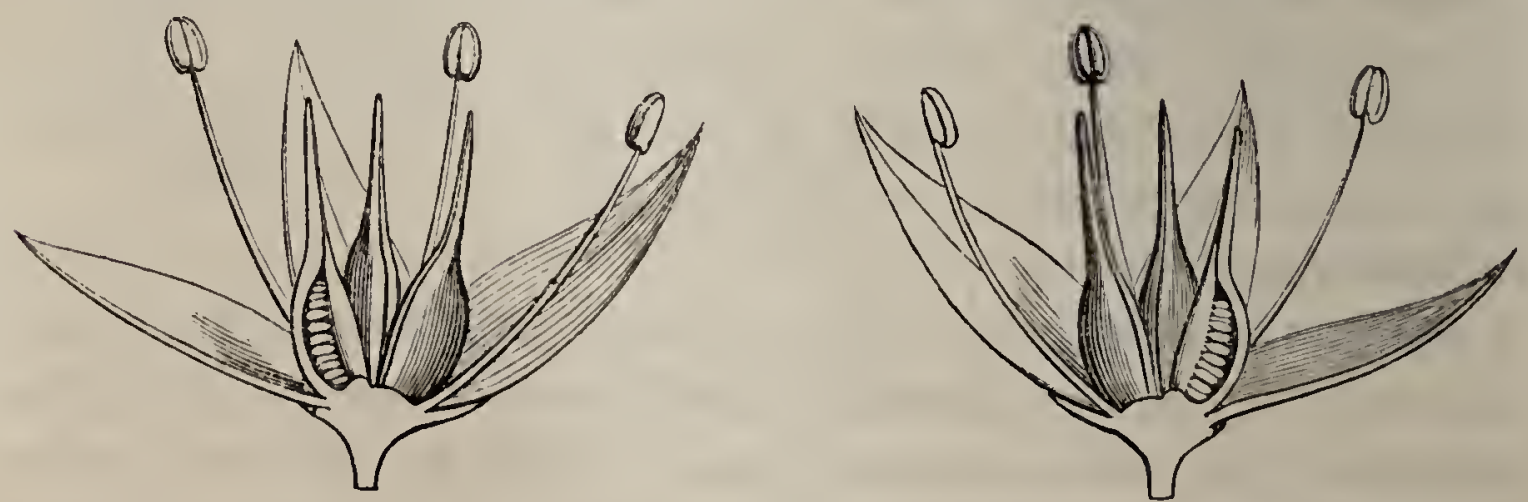

Fig. 180. - Coupe d'une fleur de Crnssula lactea pour montrer comment doivent être faites les coupes longitudinales.

alors, en examinant ces coupes à un faible grossissement et en les reproduisant par le dessin, une sorte de figure semblable à un diagramme (projection horizontale d'une fleur), sauf que sur une seule coupe on ne rencontrera pas toujours tous les éléments composant les verticilles, tandis que les diagrammes les comportent tous. II 
sera donc nécessaire de faire des coupes transversales et longitudinales à diverses hauteurs sur le bouton. Les coupes longitudinales domnent des notions importantes que les premières ne peuvent in-

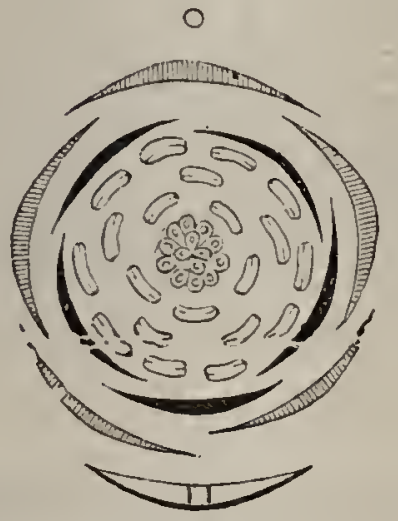

Fig. 181. - Diagramme de Fraisier. (Payer.)

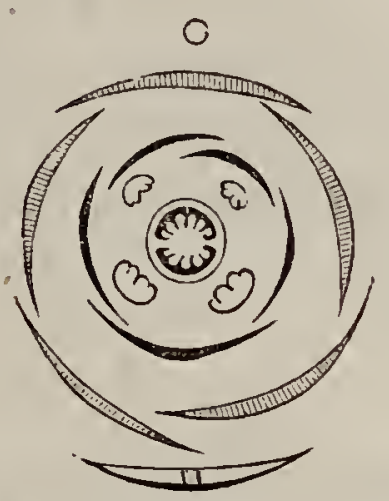

Fig. 182. - Diagramme de Pedicularis. (Payer.)

diquer, telles que le mode d'insertion des pièces du verticille sur le torus (fig. 180), elc. C'est encore au moyen de coupes transversales et longitudinales, ou par dissection avec les aiguilles sous la loupe

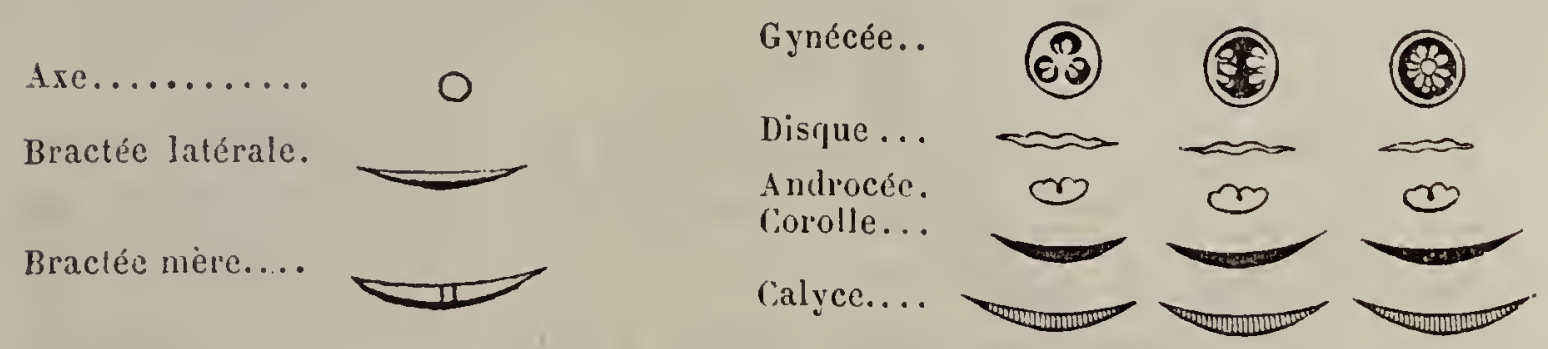

Firg. 1\$3. - Légrende d'un diagramme.

montée, que l'on fera l'étude organogénique des fleurs. On examinera l'ordre d'apparition des divers verticilles et de leurs pièces composantes, les rapports de nombre et de situation entre ces verticilles, etc.

Nous reproduisons ci-contre quelques diagrammes pour montrer comment on peut représenter sur un même plan toutes les parties d'une fleur et indiquer avec leur forme leurs rapports de nombre, de siluation, d'orientation par rapport à l'axe qui les porte, etc. (voir fig. 181, 182 et 183 ).

\section{§ 2. StRUCTURE DU PÉrianthe.}

La structure des pièces qui forment le calyce et la corolle se rapproche beaucoup de la structure des feuilles, dont les sépales et les pétales ne sont que des modifications. Au mo̊yen des coupes, on examinera le parenchyme généralement uni- 
forme, parcouru par des nervures disposées comme dans les feuilles, et réduites généralement à quelques trachées, principalement aux extrémités de ces organes. On étudiera les épidermes, comme il a été dit page 163, et l'on y trouvera, principalement sur les corolles veloutées, de nombreuses cellules relevées en papilles coniques proéminentes. Les corolles seront d'excellents sujets pour l'étude des matières colorantes.

\section{\$ 3. Structure des ÉtaMines.}

L'étude des Étamines doit porter sur le filet, l'Anthère et les grains de Pollen. C'est au moyen de coupes minces que l'on fera cette étude.

$1^{\circ}$ Le filet montre en général, sur les sections transversales, un faisceau fibro-vasculaire axile entouré d'un parenchyme, enveloppé par un épiderme. Le faisceau fibro-vasculaire du filet se prolonge entre les anthères dans le connectif, où on le relrouve sur les coupes (fig. 185, a).

$2^{\circ}$ Anthères. - Au moyen des coupes sur les Anthères, on l'econnaît que leurs parois sont formées de trois couches, distinctes dans les très jeunes individus, mais qui se réduisent en général chez les Anthères plus âgées à deux couches, par suite de la résorption de l'une d'elles. Ces trois couches ont été nommées Exothèque, Mésothèque et Endothèque, d'après leur situation. L'Exothèque est l'assise épidermique externe. II peut arriver qu'elle disparaisse complètement vers l'époque. de la maturation (Calendula, Laurus nolilis, Mahonia, Vilis, Ficaria, Nepenthes, Squamrria); quelquefois sa destruction n'a lieu que sur la ligne de déhiscence (Schaueria, etc.) (A. Chatin). Les cellules de l'Exothèque sont ordinairement relevées en papilles, ou même allongées en poils (Lycopersicon). Très épaisses et scléreuses (Zamia, Siphocampylos), elles renferment, quoique assez tardivement, des matières colorantes diverses. L'Endothèque est la couche la plus interne, transitoire; le Mésothèque est le tissu compris entre les deux précédentes formations.

La structure du Mésothèque présente un intérêt tout particulier. Dans un grand nombre de cas, en effet, toutes ses 
cellules se font remarquer par des épaississements en bandes spiralées ou réticulées, qui leur ont fait donner le nom de cellules fibreuses (Purkinje, fig. 185). M. A. Chatin (1) a montré d'autre part, que ces cellules dans un grand nombre d'Anthères se localisent d'une manière spéciale, ordinairement en rapport avec le mode de déhiscence de ces Anthères.

Ainsi, dans les Anthères à déhiscence longitudinale, ces cellules forment tantôt une bande de chaque côté de la ligne de déhiscence (Lathrca, Melampyrum, Orobanche) ou, au con-

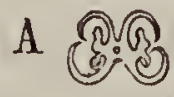

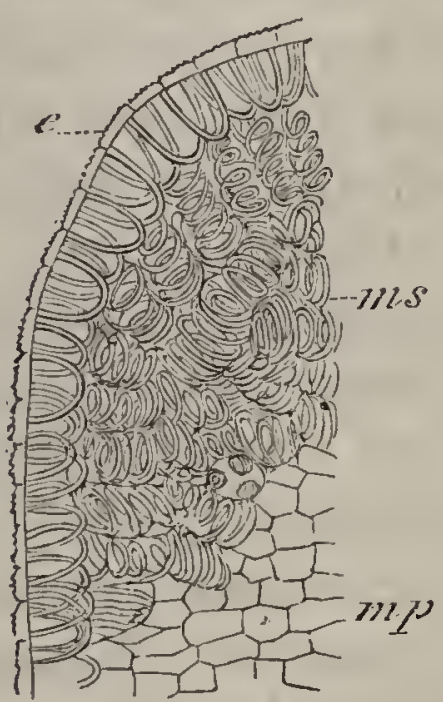

Fig. 184. - Localisátion des cellules fibreuses. Coupe longitudinale sur le sommet fibreux de l'anthère du Solanum sisymbrium. - e. Épiderme. $m s$. Cellules fibreuses. - $m p$. Le tissu situé plus bas u'est pas modifié en cellules fibreuses. D’après M. A. Chatin.
Fig. 18ว. - A. Coupe générale. - B. Portion de coupe transversale grossie de la portion médiane d'une anthère de Solanum sisymbrium. Les placentoïdes $\left(p, p^{\prime}\right)$ encore très développés. - $c$. Faisceau du connectif. l. Lacunes par écartement développées dans l'épaisseur des tissus du IIésothèque. D'après M. Chatin.

traire, elles ne se montrent que le long de l'attache des parois au connectif (Chlora, Halesia, Chironia), ou encore elles n'existent que sur l'une des deux valves que sépare la ligne de déhiscence (Witheringia) (A. Ghatin).

Dans les Anthères des Laurinées à déhiscence valvulaire, ces cellules sont limitées à l'épaisseur de ces valvules. Chez les Berbéridées, toutefois, on les observe encore sur le reste

(1) A. Chatin, De l'Anthère. Recherches sur le développement, la structure et les fonctions de ses tissus. Paris, 1870.

GUIDE DE MICROGRAPHIE. 
des parois. Enfin elles manquent chez les Anthères à déhiscence poricide (Ericacées, Pyrolacées, Mélastomacées, etc.), sauf, toutefois, dans le genre Solanum dont l'ouverture apicilaire est munie de cellules fibreuses (fig. 184), le reste du tissu en étant dépourvu; il peut être creusé de lacunes par écartement.

La coupe transversale de l'Anthère montre ordinairement, en son milieu, la section du connectif où l'on reconnaît l'existence d'un faisceau vasculaire axile, entouré d'un tissu parenchymateux dont les éléments se transforment quelquefois en cellules fibreuses. Cette transformation n'est que partielle dans les Telima, Saxifraga, Sedum, etc. Elle est totale chez les Crássula, Lonicera, Allium, Tulipa, Iris, etc. Ailleurs, les cellules du parenchyme qui entoure le faisceau du connectif épaississent fortement leurs parois (Vinca). Enfin dans les Nuphar il se creuse de lacunes (A. Chatin).

Dans les Anthères des Dicotylédones gamopétales on trouve une saillie longitudinale qui s'avance dans chaque logette et y proémine plus ou moins. M. Chatin, qui a appelé l'attention sur ce fait, donne au processus parenchymateux ainsi formé le nom de Placentoide, tout en faisant remarquer que cette dénomination n'entraîne aucune comparaison avec le Placenta des Ovaires (1). Nous reproduisons (fig. 18ə, B) un Placentoïde dans l'Anthère du Solanum Sisymbrium.

\section{\$. POLLEN.}

Le Pollen est ordinairement sous forme d'une poussière composée de cellules ou grains de Pollen. - Un grain de Pol-

(1) Ces placentoïdes que l'on observe particulièrement bien sur les Anthères non mûres, alor's que la cloison des logettes persiste encore, partent de cette cloison et s'arancent plus ou moins loin jusqu'aux parois opposées des logettes (voir fig. 185, A et B). Leur structure est simplement parencliymateuse. M. Ghatin n'y a point rencontré de cellules fibreuses. D'ailleurs leur présence semble coïncider avec l'existence de cloisons dépourvues de ces éléments. C'est, comme nous l'avons dit, dans les Corolliflores qu'on rencontre les placentoïdes; cliez les Solanées, par exemple dans les genres Solanum, Atropa, Datura, Hyoscyamus, etc.; chez les Scropliulariées dans les Verbascum, Pedicularis, mais non pas dans les Veronica ni les Chelone; cliez les Labiées dans les Salvia, Rosmarinus, Lamium, Leonurus, Marmubium; clıez les Orobanchées dans les Clandestina et Squamaria, non dans les Orobanche. 
len se compose en général de deux enveloppes renfermant un contenu granuleux (fovilla) qui consiste en protoplasma, riche en substances amylacées et huileuses; l'enveloppe intérieure ou intine présente les caractères de la cellulose, comme on peut le reconnaître au moyen des réactifs; l'extérieure ou exine est de nature cuticulaire, ordinairement résistante, épaisse et présentant des saillies mamelonnées, réticulées ou pointues (fig. 186).

L'exine manque dans quelques cas (Zostera, Naias, Ruppia). Ailleurs, au contraire, elle se dédouble en deux lames (Clarkia, Mirabilis, Convolvulus). Rarement lisse à la surface (Clarkia elegans), elle présente, avons-nous dit, des ornements variés. Dans le Passiflora, ce sont des bandes réticulées; dans les Malvacées, ce sont des pointes aiguës; dans les Viscum, Alpinia, des éminences mamelonnées. Mais les productions les plus intéressantes

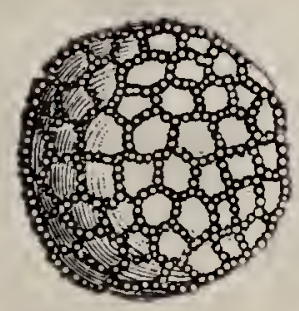

Fig. 186. - Grain de Pollen de Lis blanc. de l'exine sont les pores et les plis. Les pores sont des espaces clairs dans lesquels l'exine ferait complètement défaut (Schacht). Ils livrent passage au boyau pollinique, comme on peut s'en convaincre en montant dans l'eau des grains frais de Pollen. Au bout de peu de temps, on voit l'intine traverser l'exine par les pores, sous forme de tubes allongés. Ces pores sont généralement au nombre de trois chez les Dicotylédonées (Onagrariées, Protéacées, Gupulifères, Géraniacées, Composées). Rarement, au nombre de deux (Ficus, Beloperone), ou de quatre ou six (Impatiens, Ulmus, Carpinus), on les trouve plus souvent nombreux (Nyctaginées, Convolvulacées, Malvacées, Alsinées, Silénées, etc.).

Les pores des Cucurbita, ceux des Stellaria et des Passiflores sont fermés par des opercules qui se soulèvent au moment de l'émission du boyau pollinique.

Plis. - Ce sont des enfoncements qui divisent la surface du grain de Pollen en saillies variables en nombre. Chez la plupart des Dicotylédonées, on trouve trois plis, tandis que le grain de pollen des Monocotylé.donées n'en offre généralement qu'un seul longitudinal, et c'est à ce pli que corres- 
pond le point de sortie du boyau pollinique (Gladiolus, Lilium, Yucca, etc.).

Grains simples et composés. - Nous avons parlé jusqu'ici de grains de Pollen formés de cellules isolées ou Pollens simpies

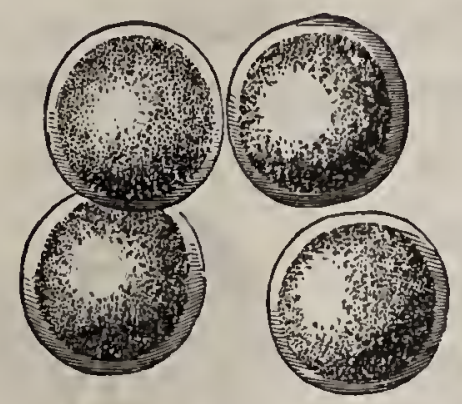

Fig. 187. - Pollen simple de Ranunculus repens.

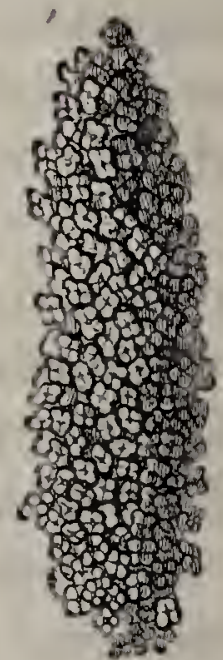

Fig. 188. - Nlasse pollinique de Neottia nidus avis.

(pulvérulents [fig. 187]). Mais il arrive fréquemment que ces grains se présentent dans les Anthères, groupés par quatre ( $T e ́-$ trades) ou en plus grand nombre. Chẹ les OrcuidéEs par exemple, on rencontre tous les degrés, depuis les grains isolés (CY-

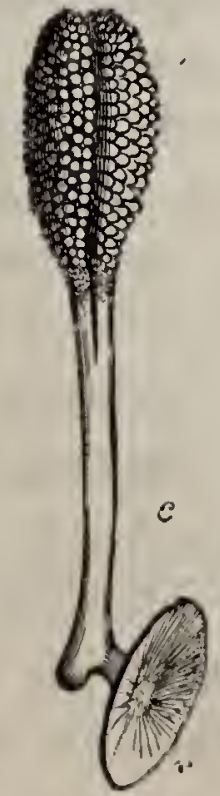

Fig. 189. - Ilasse pollinique de Platanthera Chlorantha.

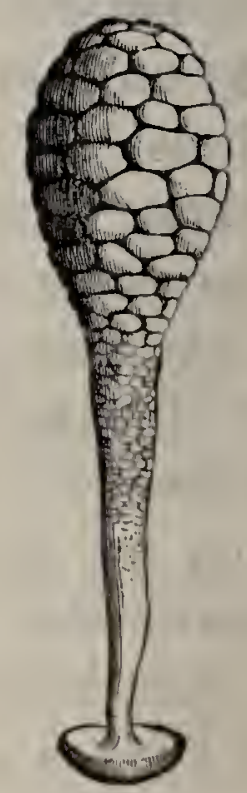

Fig. 190. - Masse pollinique d'Orchis maculata.

PRIPÉbiées) en passant par les Tétrades des Néottiées (fig. 188), jusqu'aux OpInydées où tous les grains issus d'une même cellule-mère demeurent réunis et forment à l'intérieur de chaque loge d'anthère un grand nombre de petites masses polliniques, 
et aux Céroranidées enfin où tous les grains de Pollen sont réunis en une pollinie munie d'un prolongement ou caudicule (fig. 189,c) qui, au contact du stigmate, se termine en une petite glande pluricellulaire appelée rétinacle (fig. 189 et 190,r).

Les Ascléptadées présentent également des masses polliniques (fig. 191).

Les Typha (fig. 192, B) et les Ericacées (Rhododendron) ont leurs grains de Pollen groupés par quatre. Enfin, chez les Légumineuses, les genres Acacia et Mimosa présentent des grains composés à des degrés très variables, depuis quatre (Mimosa pudica,

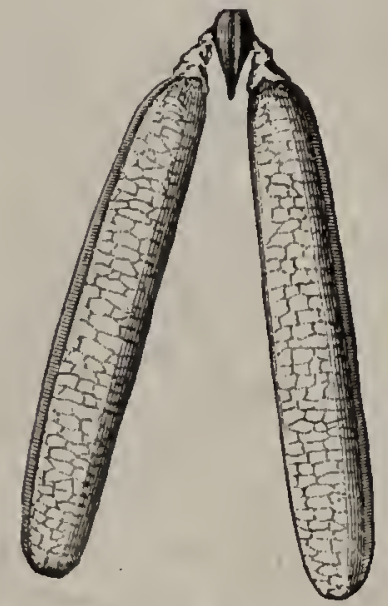

Fig. 191. - Masse pollinique d'Asclepias floribunda.
A

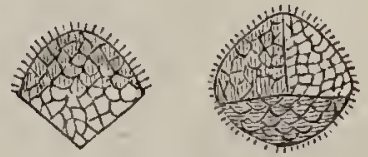

B

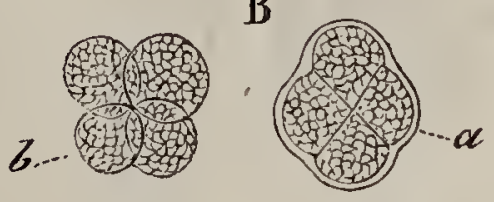

C

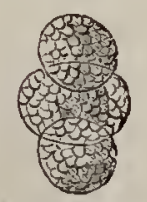

Fig. 192. - A. Microspores du Lycopodium clavatum. - B. Pollen de Typha. - a. Les grains sont renfermés dans leur cellulemère (Tétrade). - $b$. Grains débarrassés de la eellule-mère. - C. Pollen du pin.

M. casta) jusqu'à huit (Acacia undulata, A. cordifolia, A. paradoxa, etc.), et seize (Acacia Julibrissin, A. Lophantha). On en trouve même composés de trente̊-deux à trente-six cellules dans l'Inga spectabilis.

Pollen des Coniferes. - Dans les Gupressinées et les Taxinées, la forme extérieure des grains n'offre rien de particulier, mais la formation du boyau pollinique se fait tout autrement que dans les autres Phanérogames., Ce n'est pas l'intine, d'après Schacht, qui produit le boyau pollinique, mais son contenu, qui se divise en deux cellules inégales, dont la plus grosse se transforme en tube pollinique (fig. 193).

Chez les Abiétinées, la forme du grain de Pollen est très particulière. Chaque grain semble produit par la réunion de trois 
cellules, dont l'une médiane, transparente et incolore, et les deux autres latérales, réticulées à leur surface et opaques (fig. 192, G). Ces deux formations latérales sont le résultat d'un soulèvement de l'exine, et la cellule centrale représente seule le grain de Pollen. La formation du boyau pollinique serait également ici, d'après Schacht, le résultat d'une formation cellulaire dans l'intérieur du grain de Pollen. La plus grande

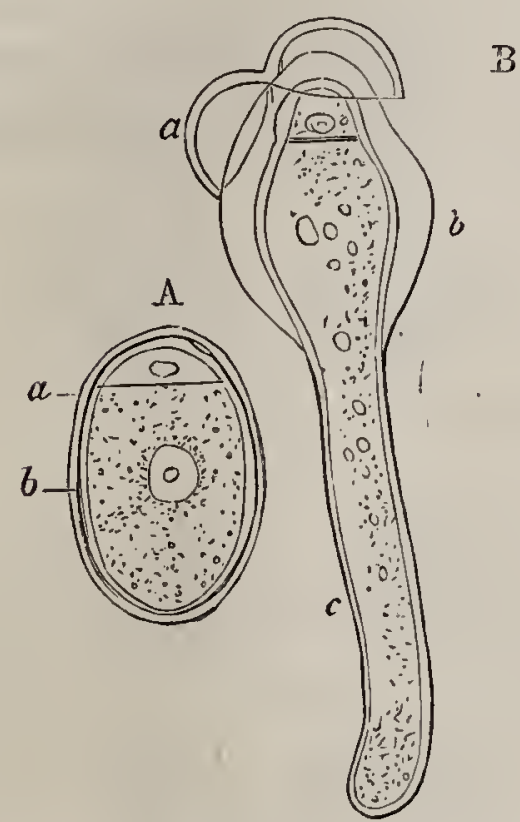

Fig. 193. - Pollen du Cupressus sempervirens (Schacht.) - A. Un grain dc pollen avee ses deux eellules. $-a$. L'enveloppe externe; $b$, l'enveloppe interne. - B. Un autre grain qui a formé le tube pollinique avec la plus grosse de ses cellules, et rejeté son enveloppe externe $a$.

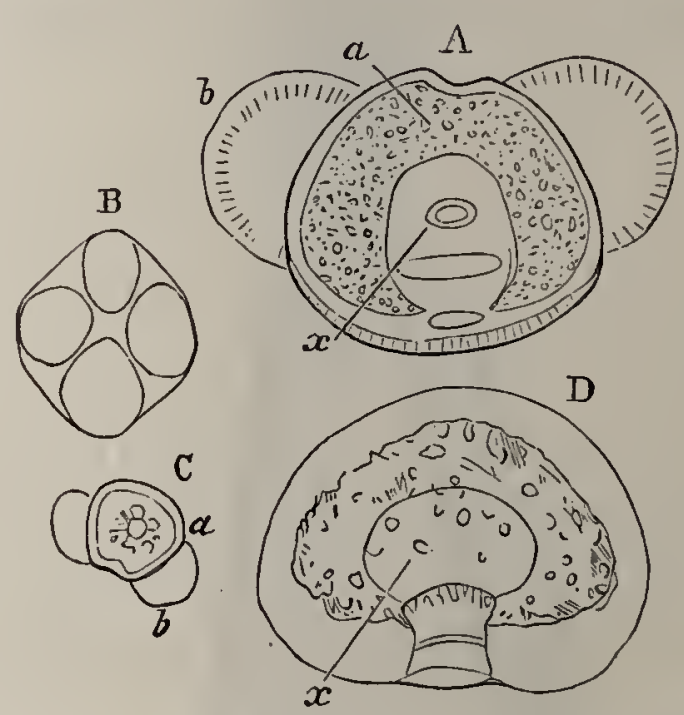

Fig. 194. - Pollen du Picea vulgaris, d'après Schacht. - B. La cellule-mère. - C. Un de ees grains de pollen déjà pourvu d'une partie eentralc $a$ et dc deux appendiees latéraux (b). - A. Un grain de pollen mùr : $x$ le corps cellulaire dont la cellule terminale devicndra plus tard le tube pollinique. - D. L'enveloppe pollinique interne qui a été séparée de l'enveloppe extérieure par l'emploi de l'acide azutique. - (B et C. grussis 200 fois. $-\mathbf{A}$. D. 400 fois.)

des cellules ainsi produites (fig. 194) deviendrait le boyau pollinique. Les recherches de Strasbürger ne sembleraient pas confirmer cette explication.

Développement des grains de Pollen. - On étudiera le développement des grains de Pollen au moyen de coupes sur les jeunes Anthères. On trouve alors au milieu de celles-ci un tissu de cellules à parois épaisses, riches en protoplasma, qui forment dans les logettes une couche parallèle à l'épiderrne, et ne sont autres que les cellules-mères des grains de Pollen. En effet, bientôt le noyau de ces cellules disparaît, et on en roit 
se former deux nouveaux qui, ou bien sont immédiatement suivis de la bi-partition de la cellule-mère ou bien se dissolvent de nouveau, et à leur place apparaissent quatre nouveaux noyaux suivis de la quadri-partition simultanée (voir page i1) de la cellule-mère. C'est là le cas le plus fréquent chez les Liliacées (Schacht, loc. crt.). Ghez les Dicotylédonées, aussitôt après la dissolution du noyau de la cellule-mère et simulta-

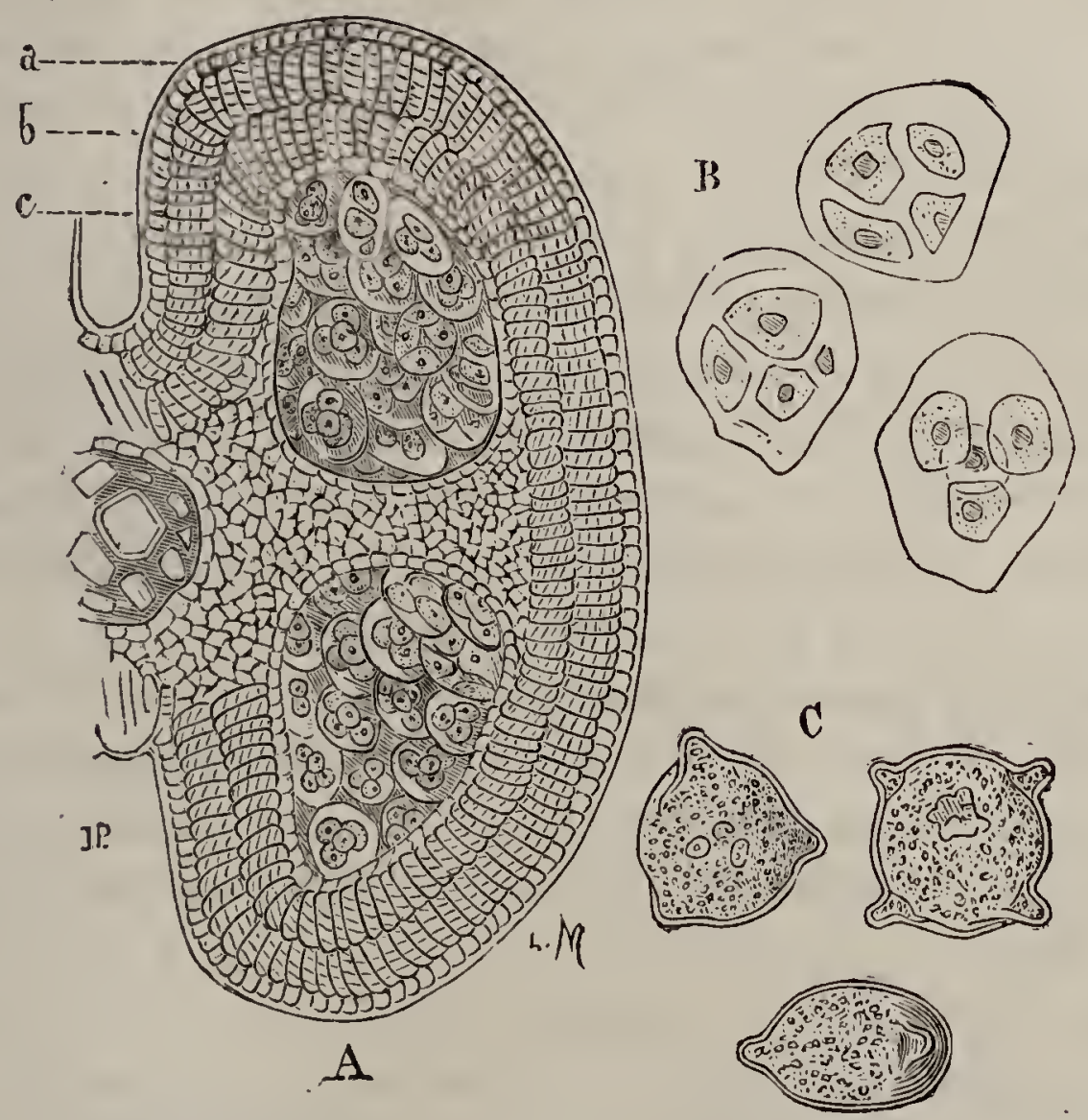

Fig. 195. - Anthère de Fuchsia. - A. Coupe transversale d'une demi-anthère montrant les deux loges pleines de cellules-mères. - B. Cellules-mères isolées montrant des grains de pollen en voie de formation. - C. Jeunes grains de pollen.

nément, apparaissent quatre nouveaux noyaux, après quoi le corps protoplasmatique s'étrangle en quatre lobes. En même temps des lames rentrantes, partant de la paroi de la cellulemère, pénètrent dans les sillons qui divisent le corps protoplasmatique (fig. 195).

L'enveloppe de la cellule-mère persistant, on a ainsi une tétrade, comme nous en avons signalé des exemples (voir plus haut). Mais, ordinairement, celle-ci disparaît et les grains de Pollen deviennent complètement libres.

L'adhérence de toutos les cellules-mères des grains de 
Pollen d'une même loge d'Anthère donne lieu aux masses polliniques dont il a été question plus haut.

Forme des grains de Pollen (1). - Tantôt arrondis (Canna, Musa, etc.), cubiques (Basella rubra), prismatiques'à six pans dans les Arundinaria, Lagurus, etc., les grains de pollen sont trigones chez les Papilionacées, les Hydrophyllées, les Asparaginées, etc. Des espèces d'un même genre peuvent d'ailleurs présenter des formes polliniques différentes. Ainsi, dans le genre Viola, le Viola tricolor a un pollen pentagonal avec cinq bandes, tandis que les $V$. odorata et cornuta ne présentent que de petits sillons.

Ailleurs, la forme des grains de Pollen devient tout à fait particulière. Ainsi, le pollen du Tropceolum tricolor, celui des Limnanthes alba et pulchella représentent un croissant; celui des Borraginées, un haltère; celui du $Z e a$ maïs a la forme même du grain de maïs comprimé dans l'épi; celui de l'Iris est allongé, fendu comme un pain et orné, comme celui du Lis, d'un réseau à larges mailles carrées.

ćtude des grains de Pollen. - Pour étudier la forme des grains de Pollen, on ne doit pas employer l'eau qui les gonfle, fait disparaître les plis et les amène tous à la forme sphérique. La glycérine a l'inconvénient de les contracter. L'huile d'olive, d'après M. Edgeworth, aurait l'avantage de ne déformer ni gonfler les grains; cependant elle fait quelquefois disparaître les pointes qui hérissent leur surface. Ajoutons enfin que dans l'examen de la forme des grains il est nécessaire de tenir comple de leur âge.

Les jeunes grains sont toujours plus ou moins régulièrement prismatiques en raison même de leur formation dans la cellule-mère; ce n'est que plus tard, lorsqu'ils sont devenus libres, qu'ils s'accroissent librement et prennent leur forme définitive.

Pour étudier le boyau pollinique, on devra prendre des grains frais et bien développés, et on les montera dans l'eau pure ou mieux dans une solution de gomme, afin que les

(1) Packenham Edgewortli, Londres, 1877 (Analyse in Journal de Micro. graphio de Pelletan, $\mathrm{n}^{\circ} 6$, octobre 1877). 
phénomènes d'osmose se produisent plus lentement et ne fassent pas éclater le grain. Il sèrait encore préférable de semer des grains de pollen sur les stigmates des fleurs, et d'observer le développement du boyau pollinique au moyen de coupes sur ces stigmates.

Lorsqu'on veut pratiquer des coupes sur les grains de pollen, on opère comme il a été dit plus haut (page 41).

\section{$\S 5$. PISTIL.}

$1^{\circ}$ Style et stigmate. - Au moyen de coupes transversales et longitudinales, on reconnaitra que le style est généralement creusé en son centre d'un canal. Le style est formé d'un tissu cellulaire parcouru par un ou plusieurs faisceaux fibrovasculaires déliés, et recouvert par un épiderme. La cavité centrale est souvent obstruée par un tissu de cellules à parois délicates, lâchement unies, et que l'on nomme tissu conducteur.

A son extrémité supérieure, le style se termine généralement par une petite masse de tissu recouvert d'un épiderme dont les cellules se relèvent en papilles volumineuses ou en poils. Le tissu même du style sécrète en abondance une hu-

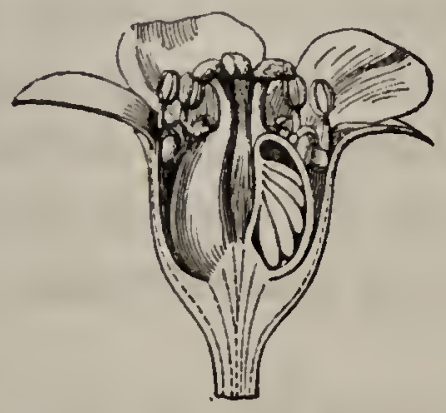

Fig. 196. - Oraire supère (Coupe d'une fleur de Spirée).

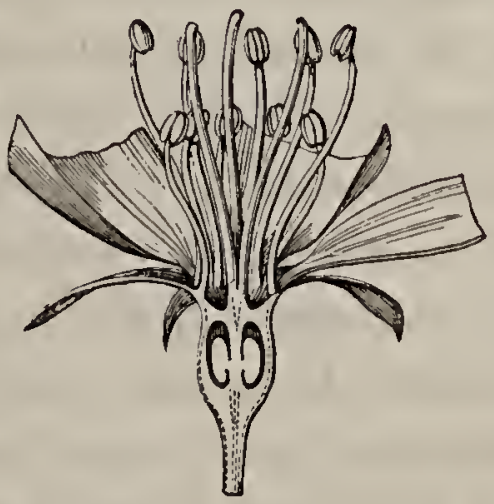

Fig. 197. - Ovaire infère (Coupe d'une fleur de Pommier).

meur visqueuse, appelée à jouer un rôle important dans la fécondation, en déterminant la formation du boyau pollinique.

Les papilles stigmatiques sont tantôt coniques, tantôt cylindriques ou de formes variées. 
$2^{\circ}$ Ovaire. - L'étude de l'ovaire se fait au moyen de coupes transversales menées à différentes hauteurs et de coupes longitudinales. La structure de l'ovaire variant à l'infini, il ne nous est possible de donner que des indications générales.

On examinera les parois de l'ovaire généralement formées de trois enveloppes : l'interne et l'externe, correspondant aux deux épidermes des feuilles; la moyenne, formée générale-

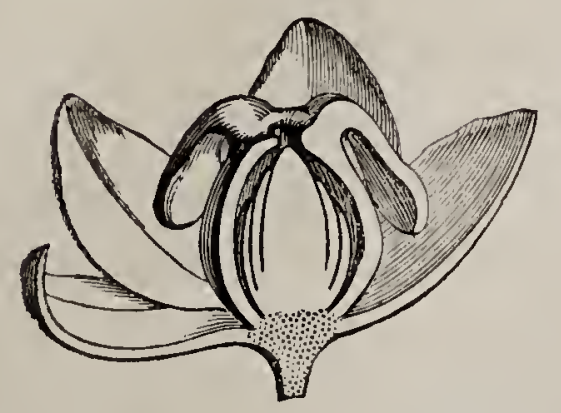

Fig. 198. - Coupe longitudinale du pistil de Rhubarbe (Ovule orthotrope). ment de plusieurs couches de cellules, est analogue au mésophylle des feuilles et est parcourue par les faisceaux fibro-vasculaires.

On examinera le nombre des loges, les cloisons quiles limitent, la disposition des placentas et le passage des faisceaux fibro-vasculaires dans ceux-ci. Au moyen des coupes longitudinales menées suivant la direction des placentas, on observera le mode d'insertion des ovules (fig. 196, 197 et 198).

$3^{\circ}$ Ovules. - Les Ovules sont de petits corps formés d'un parenchyme central (nucelle, qui a la valeur du macrosporange des Cryptogames vasculaires), généralement entouré de deux enveloppes (primine et secondine), ouvertes ( $m$, fig. 200) au sommet du nucelle (micropyle), et formées d'une ou plusieurs assises de cellules limitées par un épiderme interne et un épiderme externe. Ces corps sont supportés par un pédicelle plus ou moins développé (Funicule), traversé par un faisceau fibro-vasculaire qui prend fin à la base du nucelle en s'épanouissant dans une petite masse de tissu ordinairement assez distincte et qui forme la Chalaze.

En étudiant l'Ovule au moyen de coupes ou par la dissection avec l'aiguille, en s'aidant de la loupe montée, on constate d'importantes modifications dans sa structure et dans l'orientation de ses diverses parties.

Tantôt, en effet, les téguments de l'ovule se réduisent à un seul, notamment chez les Dicotylédonées monopétales et quelques polypétales (Ombellifères). Ailleurs, même, ceux-ci disparaissent complètement et le nucelle est nu (Santalacées). 
D'ailleurs ces modifications sont très-fréquentes et peuvent. même se présenter dans les genres d'une même famille. Ainsi M. Scheiden a signalé les Renonculacées comme pourvues d'ovules à deux téguments dans les genres Clematis, Adonis, Aquilegia, Aconitum, Pıonia, dans plusieurs espèces de Delphinium (D. Consolida, Ajacıs, etc.), et à un seul tégument dans les Thalictrum, Anemone, Hepatica, Ranunculus.

Au sujet de la forme des ovules, on peut considérer trois types principaux reliés entre eux par des états intermédiaires.

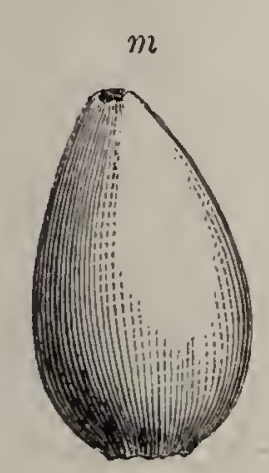

$h$

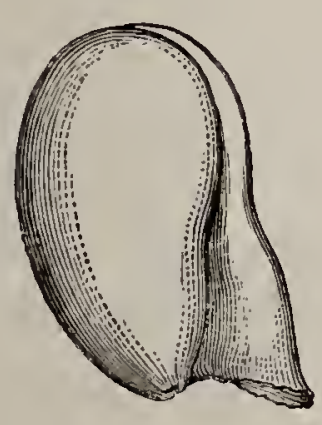

$m h$

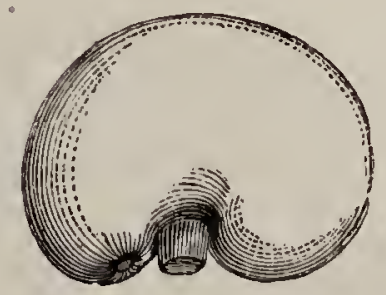

$m h$

Fig. 199. - Ovule orthotrope Fig. 200. - Ovule anatrope Fig. 201. - Ovule campylodc Rhubarbe. $h$, hile; $m$, d'Hellébore fétide. micropyle. trope de Haricot.

Ces trois formes qui font désigner les ovules sous les noms d'O. Orthotrope, O. Campylotrope, O. Anatrope (fig. 199, 200 et 201) s'observent soit directement en examinant les ovules à la loupe, soit au moyen de coupes longitudinales lorsque leur grosseur le permet. Les Ovules Orthotropes chez lesquels le micropyle est directement opposé au point d'attache se rencontrent chez les Polygonum, Hydrocharis, Urticées, Juglandées, Pipéracées, etc. (fig. 199). Les Ovules Anatropes où le micro- • pyle est voisin du hile et où le faisceau vasculaire du funicule longe un côté de l'ovule s'observent chez les Cucurbitacées, Iridées, Liliacées, Impatiens, Viola, etc. (fig. 200). Enfin, les Ovules Campylotropes dans lesquels le microphyle et la chalaze sont voisins, vu le développement unilatéral de l'ovule, s'observent chez les Crucifères, Chénopodées, Caryophyllées, Solanées, etc. (fig. 201). Il ne nous appartient pas d'insister davantage sur ces formes variées. 
§ 6. DÉveloppenent de L'ovaire. - Péricarpe.

L'Ovaire, en se développant, constitue le péricarpe qui est formé, par suite, de trois enveloppes, dont les noms sont de dehors en dedans: Epicarpe, Mésocarpe, Endocarpe.

Par les coupes sur ces fruits, on constate des modifications dans la structure de l'ovaire, qui ont été amenées par le développement. Dans les fruits charnus en particulier, le Mésocarpe, qui représente le parenchyme médian de la paroi ovarienne, présente de grandes cellules à parois minces, parcourues par des faisceaux fibro-vasculaires réduits aux trachées. Dans les fruits à noyau, le noyau est formé par l'endocarpe lignifié, et dans les Aurantiacées, où l'endocarpe reste très mince,. il porte des poils glanduleux qui se remplissent d'un liquide sucré, qui les gonfle. On voit par là combien sont variées les modifications subies par la paroi ovarienne dans le cours de son développement. Nous rappellerons encore à ce sujet les fruits des Ombellifères qui se distinguent par l'apparition dans le fond des sillons qui marquent leur surface, de canaux résineux, souvent très nombreux, et qui ont été décrits sous le non de bandelettes (voir page 157).

\section{§ 7. DÉveloppenent DE l'ovule. - SaC embryonnaire. — graine.}

Pour étudier le développement des Ovules, on doit faire des coupes longitudinales, ou même les observer directement si leur transparence le permet (Monotropa, Pyrola, Orchidées). Lor'squ'ils sont trop petits pour être coupés, et que leur transparence ne permet pas de les observer à loisir, on peut les traiter par une dissolution de potasse. Mais, en général, le mieux est de faire des coupes minces, qui passent par le centre de l'ovule. Schacht indique le procédé suivant:

"Après avoir détaché l'ovule, on le place sur l'index et, avec un rasoir bien aiguisé, on fait une coupe longitudinale très mince, passant par le centre; on réussira très bien dans cette préparation en enlevant d'abord un des côtés de l'ovule, puis le retournant avec un pinceau très fin et enlevant ensuite l'autre côté. On porte alor's sous le microscope la coupe que l'on a obtenue. On peut l'améliorer encore en la taillant 
une troisième et une quatrième fois. C'est ainsi que doivent être examinés les phénomènés du développement chez les Ovules des Labiées, Borraginées, Crucifères, Conifères, etc. "

Sac embryonnaire. - L'étude du sac embryonnaire présente un intérêt tout particulier. - On pourra l'examiner au moyen de coupes pratiquées comme nous venons de l'indiquer. Toutefois les commençants feront bien de prendre comme sujets d'étude des plantes telles que les Gladiolus, Crocus, Zea, Euphrasia,Cheiranthus, chez lesquelles la paroi du sac embryonnaire est, même avant la fécondation, assez solide pour qu'on puisse l'isoler avec l'aiguille. — On aperçoit alors dans le sac embryonnaire deux formations:

$1^{\circ}$ L'une, placée dans le voisinage du micropyle, consiste en đeux vésicules protoplasmatiques ovoïdes ou globuleuses ordinairement dépourvues de membrane d'enveloppe, celle-ci n'apparaissant que comme phénomène consécutif à la fécondation (fig. 202) (sauf toutefois, d'après M. Hofmeister, dans quelques plantes, Nuphar, Tropæolum, Cheiranthus, Rosa, etc.). - Ces deux vésicules ont reçu le nom de vésicules embryonnaires; dans les Crocus. Gladiolus, Phormium tenax, d'après Schacht, la moitié supérieure de chacune des vésicules est coiffée d'une masse brillante, cellulosique, d'apparence filamenteuse, qu'il nomme appareil filigère et que l'on met bien en évidence en plongeant dans l'alcool les fleurs avant d'observer le sac embryonnaire. Le même appareil s'obsęrve

A

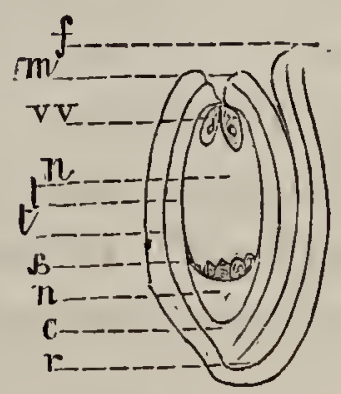

Fig. 202. - Coupe longitudinale d'un ovule anatrope après le développement des vésicules embryonnaires. $a$. Cellules antipodes. $m$. Micropyle. - c. Chalaze. - r. Raphé. $-n, n$. Nucelle. encore, quoique plus difficilement, dans l'Iris (Hofmeister), le Fuchsia gloriosa, le Campanula medium, l'Euphrasia odontites, etc. (Schacht, loc. cit.).

$2^{\circ} \mathrm{La}$ seconde formation que présente le sac embryonnaire consiste en deux vésicules à parois très délicates, pourvues d'un noyau brillant, et qui occupent l'extrémité du sac opposé au micropyle, d'où le nom de vésicules antipodes qui leur a été donné; ces corps sont transiloires. 
On examinera encore le développement de l'albumen dans le sac embryonnaire. Les cellules qui le forment se produisent, suivant les espèces, par formation libre ou par division. - Nous renvoyons pour cette étude à la page 63 où nous sommes entrés dans d'assez longs détails à ce sujet.

Développement de l'embryon. - Pour étudier le développement de l'embryon, on aura tout avantage à provoquer soimême la fécondation, en saupoudrant les fleurs avec le pollen. - On n'oubliera pas que certaines plantes, et en particulier les Conifères, mettent un long temps à mûrir leurs graines. Ainsi les graines des Pinus et Juniperus demandent deux ou - trois années : leurs ovules se développent au printemps, alors a lieu la pollinisation; c'est au printemps suivant seulement que se forme l'endosperme et qu'apparaissent les corpuscules ; enfin, vers le milieu de ce deuxième été (juin), la fructification commence, et à l'automne l'embryon est formé, la graine mûrit (dans le Pinus Pinea et le Juniperus, ce dernier phénomène s'accomplit seulement à l'automne de la troisième année). L'A bies, le Picea, le Laryx, le Thuya, le Taxus, l'Araucaria, n'emploient au contraire qu'une année pour développer leurs graines (Schacht, loc. cit.).

Quoi qu'il en soit, après la fécondation, les deux vésicules embryonnaires se recouvrent d'une membrane. La supérieure

A

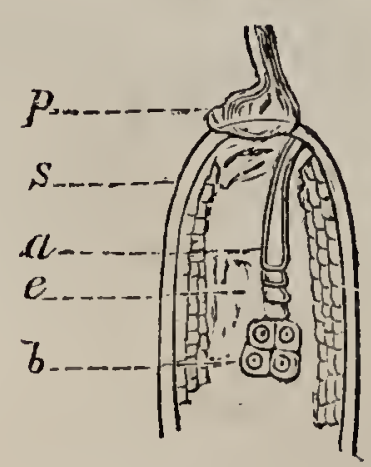

Fig. 203. - Vésicule cmbryonnaire fécondéc d'un Arabis. $p$. Extrémité du tube pollinique. - $s$. Paroi du sac embryounaire. - e. Endosperme. - a. Vésicule embryonnaire . suspenseur. - b. Embryon.

va par des divisions successives former le suspenseur, l'inférieure constituera l'embryon (fig. 203). Pour cela, cette cellule se divise un grand nombre de fois, et donne lieu à une masse compacte ou méristème qui bientôt se différencie en une couche périphérique d'une seule assise (dermatogène), en même temps que par des cloisonnements principalement longitudinaux la masse du tissu central se sépare en un faisceau axile qui constitue le plérome (fig. 113 et 114). Le périblème ou tissu interposé entre les deux précédentes couches s'accroît par des divisions principalement 
transversales. Avant que ces divisions se soient opérées, il s'est produit entre le suspenseur et le corps embryonnaire une cellule ( $h$, fig. 11つ) que M. Hanstein nomme hypophyse, dont procédera la racine. - Les divisions dans cette cellule commencent après la différenciation des trois couches susdites, dans le corps embryonnaire.

Si l'on examine un état de développement un peu plus avancé, on voit, chez les Dicotylédonées, se produire à l'extré-

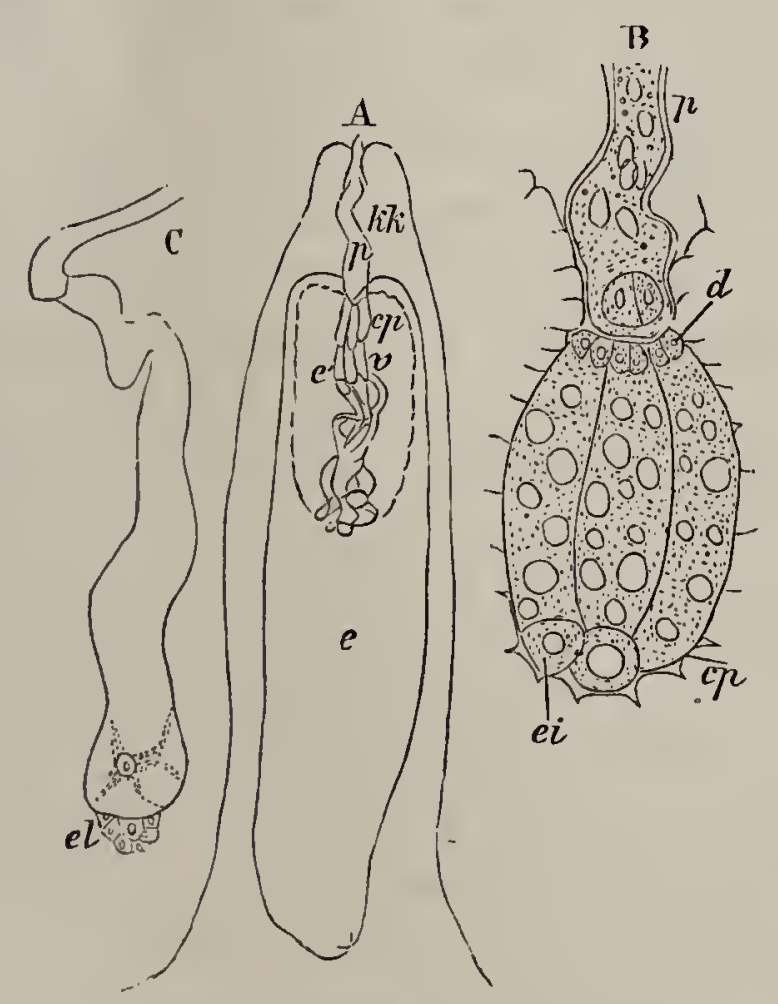

Fig. 204. - Juniperus communis d'après M. IIofmeister. - A. Section longitudina'e du nucelle $k k ; e$, l'cndosperme; $e^{\prime}$, région ramollic de l'cndosperme; $p$, tubc pollinique; $c p$, les corpusculcs; $v$, les proembryons. Commencement d'août. - B. Trois corpusculcs rapprochés. Dans deux, l'oosphèrc fécondéc ei occupe l'extrémité inféricure. - $d$. Cellules operculaires formant le col de l'archégone. $-p$. Tube polliniquc. 28 juillet. C. Extrémité inférieure d'une des séries longitudinales des cellules du proembryon, avec lc début d'embryon, el.

mité du corps embryonnaire la plus éloignée du suspenseur deux mamelons qui sont le premier indice des cotylédons. Il ne s'en forme qu'un seul chez les Monocotylédonées.

Embryon des coniféres. - Ghez les Conifères (fig. 20') plusieurs corpuscules peuvent être fécondés à la fois et se développer, bien qu'en général un seul d'entre eux arrive à maturité complète. Ces corpuscules des conifères sont d'après les recherches de Strasbürger (loc. cit.) tout à fait comparables aux archégones des Cryptogames vasculaires. Ils proviennent 
de cellules-mères spéciales qui naissent par formation libre dans le sac embryonnaire. Chacune de ces cellules, après avoir grandi notablement, se divise au voisinage du sommet en une petite cellule (fig. 205, B, $d$ ) qui occupe ce sommet et, par division, formera le col de l'archégone, qui se composera alors de quatre à huit cellules. - La cellule inférieure est la cellule centrale de l'archégone; son protoplasma est rempli de vacuoles (Strasbürger) (1) avant la fécondation; après l'action de la matière fécondante, une cellule $(e i)$ se sépare à la partie inférieure de la grande cellule centrale. - C'est l'oospore, qui par des divisions forme un corps ou proembryon, composé de trois à quatre étages de cellules superposées. Les cellules de l'étage supérieur (Taxus, Juniperus) ou de l'étage moyen (Abiétinées) venant à s'allonger considérablement, le fond de la cellule centrale se déchire, et ces cellules se développent en longs tubes (fig. 204, $\mathrm{A}, v$ ) qui pénètrent dans la partie ramollie de l'endosperme.

Ghez les Abiétinées et les Cupressinées, chacun de ces tubes produit à son extrémité un commencement d'embryon (fig. 20亏, G, el); chez les Taxus, ces tubes demeurent réunis et ne forment à leur sommet qu'un seul embryon. Ainsi donc dans la généralité des Gymnospermes, chaque corpuscule peut à lui seul développer plusieurs embryons.

Graine. Les enveloppes de la Graine (Testa et Tegmen) sont de structure très diverse et sembleraient d'après de récents travaux (2) ne pouvoir être considérées en général comme parties correspondantes aux enveloppes (primine et secondine) de l'ovule. Quoi qu'il en soit, l'enveloppe externe de la Graine se fait souvent remarquer par des épaississements dans ses cellules, qui deviennent même quelquefois très allongées perpendiculairement à la surface de la graine.

L'albumen offre également un sujet d'étude intéressant, et présente des variations nombreuses. Tantôt très volumineux, ses cellules sont remplies d'amidon, d'huile, d'aleurone, etc.

(1) Strasbürger, die Befruchtung bei den Coniferen, Iéna, 1869, et die Coniferen und die Gnetaceen, Iéna, 1872.

(2) Bertrand, Comptes rendus. - Poisson, Bull. Snc. Bot. 1878. - Baillon, Revue internationale des sciences dirigée par J. L. de Lanessan. No 2. 187 s. 
Ailleurs, il devient corné, par suite de l'épaississement souvent considérable des parois de ses cellules (Ombellifères, Phytelephas macrocarpa, etc.). Lorsqu'on nè retrouve aucune trace d'albumen dans la graine mûre (Orchidées nombreuses, Légu-

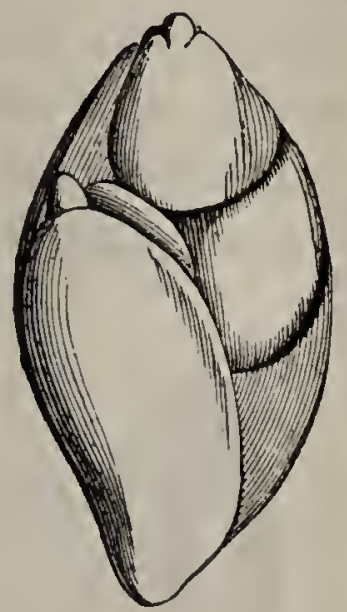

Fig. 205.

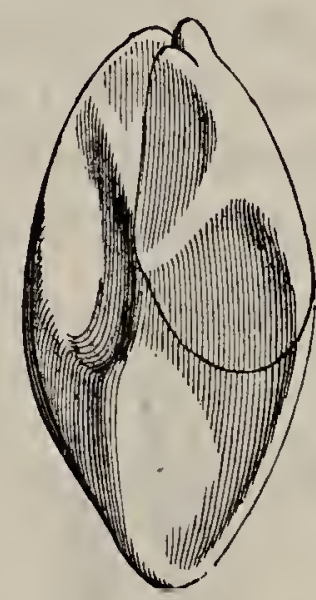

Fig. 206.

Graine d'Oranger divisée en 2 parties pour montrer qu'il y a plusieurs embryons.

mineuses, etc.), c'est qu'il a été absorbé tout entier par l'embryon en développement. D'autres plantes au contraire présentent deux albumens concentriques. L'extérieur provient alors d'une portion persistante du nucelle (albumen nucellaire) qui devient le siège d'un accroissement spécial et

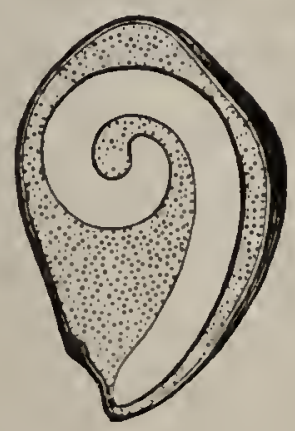

Fig. 207. - Coupe d'une graine d'oignon. Fig. 208. - Graine de Nielle des blés coupée en long pour montrer l'embryon entourant l'albumen.

d’un dépôt de matières amylacées ou oléagineuses. On trouvera des exemples de ce double albumen chez les Nymphéacées, les Zingibéracées et les Pipéracées.

Quant à l'embryon, il est bon de le séparer de la graine pour l'étudier. Dans certaines graines (Aurantiacées, fig. 205 et 206), on trouvera plusieurs embryons développés dans GUIDE DE/MICROGRAPHIE. 
chaque graine. La présence ou l'absence (Cuscutes, Monotropa, Hydnora, Rafflesia, Orchidées, etc.) des cotylédons, leur nombre, leur arrangement réciproque; la situation de l'embryon dans l'albumen. (intraire) ou au dehors (extraire) (fig. 207 et 208), seront autant de questions à étudier.

La forme de l'embryon offre de nombreuses variations: tantôt droit, tantôt courbé en arc, ou encore enroulé en spirale (Cuscute), il peut être plié en deux de telle sorte que la tigelle vient s'appliquer parallèlement aux cotylédons, soit
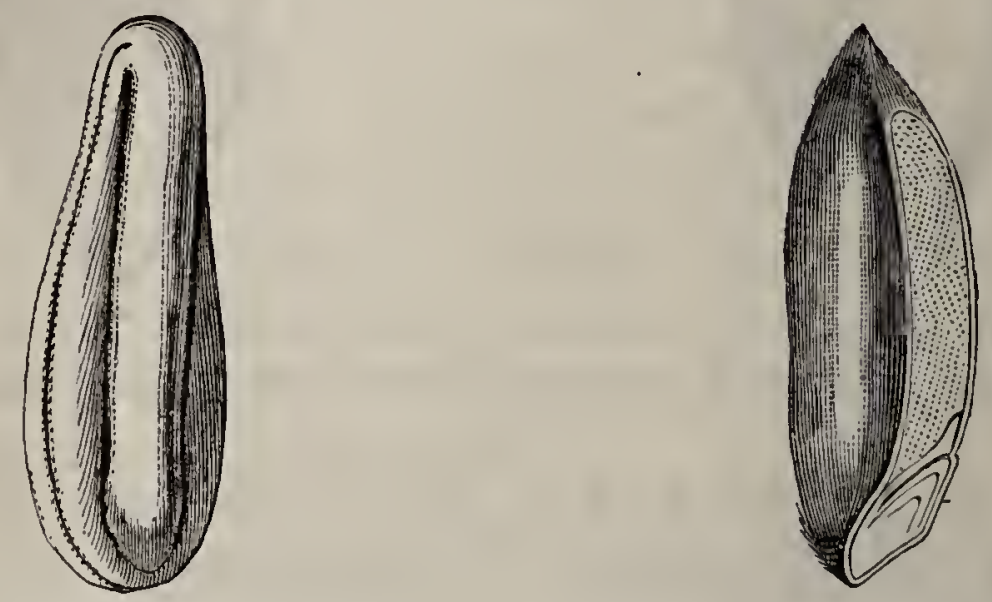

Fig. 209. - Embryon du Pastel des teintu- Fig. 210. - Coupe de la caryopse du blé. riers. Les cotylédons sont incombants. Embryon extraire.

sur le dos de l'un d'eux (cotylédons incombants, fig. 209), soit sur leur commissure (cotylédons accombants). Nous ne pouvons que signaler ces diverses questions, qui ne rentrent pas dans le plan général de notre ouvrage. 


\section{HISTOLOGIE ANIMALE}

\section{CHAPITRE IX}

\section{DU SANG AU POINT DE VUE MIGROSGOPIQUE}

Les instruments d'investigation et d'analyse se perfectionnent de jour en jour et, grâce à eux, le médecin, le chimiste peuvent procéder aux recherches les plus délicates. L'importance de l'examen du sang au point vue clinique et physiologique n'échappe à personne; de récents travaux, dont nous donnerons ci-après l'analyse, en ont fourni des preuves aussi nombreuses qu'éloquentes : si la clinique, si la physiologie, ont retiré de l'analyse microscopique du sang, des résultats fécorids, on peut dire, que le rôle joué dans les recherches médico-légales par le microscope, n'est pas moins prépondérant. On trouve, dans les annales judiciaires, des affaires même très récentes, dans lesquelles, la constatation microscopique des éléments du sang, soit sur un vêtement, soit sur un objet quelconque, a pour ainsi dire constitué la seule preuve invoquée contre l'accusé. Si l'on songe qu'en pareils cas, la condamnation dépend des résultats fournis par l'expertise, on sentira l'urgente obligation de se familiariser au laboratoire, avec ces recherches si délicates, qui demandent à la fois un œil expérimenté et un esprit rompu aux méthodes scientifiques. Le médecin et le pharmacien, peuvent, à un moment donné, être moralement obligés d'assumer la lourde responsabilité d'un pareil examen, et s'ils ne sont pas depuis longtemps habitués à la pratique de ces recherches, ils s'exposeront à commettre des erreurs, dont les conséquences 
peuvent être irremédiables pour un innocent et quelquefois aussi pour l'expert.

Lorsque le sang coule dans nos vaisseaux, on peut le considérer, d'une façon théorique, comme formé de deux parties distinctes, l'une comprenant tous les éléments figurés solides, l'autre constituée par le sérum tenant en dissolution les matières alluminoïdes, les sels, etc.

Dans ces conditions purement théoriques, nous le répétons, seule, la première classe d'éléments serait justiciable du microscope. Mais dans la pratique il n'en est pas ainsi. En effet, peu de temps après être sorti des vaisseaux, le sang, d'abord liquide, ne tarde pas à se prendre en masse, par la coagulation de la fibrine. Ce corps a des caractères physiques qui permettent de le reconnaître au microscope.

De plus, le sang ne contient pas toujours que des éléments normaux. En effet, dans certaines maladies soit d'origine infectieuse, soit de toute autre nature, le sang peut renfermer des vibrioniens ou d'autres éléments anormaux, dont la constatation éclaire le diagnostic.

G'est en nous conformant à cet ordre d'idées, que nous étudierons le sang, en le considérant d'abord au point de vue normal, puis au point de vue pathologique.

\section{§. SANG NORMAL.}

Le moyen le plus pratique de se procurer du sang, c'est de faire une légère piqûre avec une épingle et d'interrompre ensuite la circulation, dans l'extrémité d'un doigt. La petite quantité de sang qui s'échappe suffit amplement pour pratiquer l'examen au microscope (1).

(1) MI. Hayem est d'avis que, par cette méthode, on n'obtient pas un sang véritablement physiologique, et que par des numérations successives faites chez la même persomme, on ne trouve pas de résultats corıcordants. On évite, d'après l'auteur, cette cause d'erreur, en faisant à l'aide de la pointe d'une lancette, sur le doigt libre, une petite plaie suffisante pour laisser échapper quelques gouttes de sang, dès qu'on exerce la plus légère pression sur la pulpe. Des recherches comparatives ont démontrè à M. Hayem l'importance de cette manière d'opérer. L'exactitude des résultats dépend de la rapidité avec laquelle on agit et de la quantité de sang qui s'écoule; celle-ci doit être assez abondante. Il faut également éviter l'évaporation, qui aurait pour effet 
CHAP. IX. - DU SANG AU POINT DE VUE MICROSGOPIQUE. 341

Il est très importaut de prendre quelques précautions dans cet examen. On ne doit mettre sur le porte-objet qu'une quantité très faible de sang, afin de ne pas avoir une superposition des globules. De plus, comme, sous l'influence de l'air, les globules s'altèrent rapidement, il faut immédiatement placer la lamelle sur la préparation. Par surcroît de précaution, on peut même fermer complètement la préparation, par l'un des moyens usités en pareil cas (baume de Judée, paraffine, etc.).

L'œil est tout d'abord maîtrisé, par un grand nombre de corpuscules d'un jaune pâle, qui sont les globules rouges du sang. Au milieu de l'énorme quantité de globules rouges, l'observateur ne tarde pas à distinguer d'autres corpuscules sphériques plus gros, bien moins nombreux que les globules rouges. Ce sont les globules blancs. Avec plus d'attention on découvrira encore. des globules réfringents (granulations découvertes par Donné et connues sous le nom de corpuscules élémentaires de Zimmermann).

Quand une préparation de sang vient d'être faite, il y a généralement des courants qui s'établissent, et que le moindre mouvement communiqué à la préparation peut faire renaître, quand ils se sont éteints. Les globules de sang sont entraînés par ces courants, et, grâce à la rapidité de leur course, ils se présentent à l'observateur sous des aspects différents. Les globules rouges sont biconcaves; de sorte que, vus de face, ils ont une forme circulaire ; leur couleur est plus accentuée sur les bords qu'au centre. En effet, si l'on examine un globule sanguin vu de champ, on constate qu'il est plus mince au centre, qu'aux extrémités. MM. Duval et Leréboullet comparent le globule sanguin vu ainsi, à un biscuil rétréci dans sa partie médiane. C'est ce qui explique que, vu de face, le globule rouge paraisse décoloré au centre, puisque sous une épaisseur plus faible, il contient nécessairement moins de matière colorante et donne ainsi plus facilement passage à.la lumière.

d'augmenter le nombre des globules, par la concentration du plasma. La petite plaic faite par la lancette est, d'ailleurs, lout aussi inoffensive que la piqûre d'une aiguille. 
D'après M. Hayem le sang normal contient constamment des globules de dimensions diverses. On peut distinguer, à ce point de vue, trois variétés de globules: les grands, les moyens et les petits. Les grands ont un diamètre moyen de $8 \mu, 5$; les plus grands atteignent $8 \mu, 8$ (en chiffre rond $9 \mu$ ) ; les moyens ont $7 \mu, 5$ de diamètre ; les petits $6 \mu$, 5 , et les plus petits du sang normal $6 \mu$.

A l'état normal, les globules sanguins ne contiennent pas de noyaux. Les globules rouges, lorsqu'ils ne sont pas altérés dans leur forme, ont une tendance à s'empiler, comme des pièces de monnaie ; quelquefois, comme le contact ne s'effectue que par un point plus ou moins étendu de leur surface, la pile de globules paraît renversée. Quelques auteurs attachent une certaine importance, à la plus ou moins grande facilité avec laquelle les globules se mettent en pile, et en déduisent un état d'altération plus ou moins avancé, de ces éléments.

Dans la figure 211, on a représenté des globules crénelés

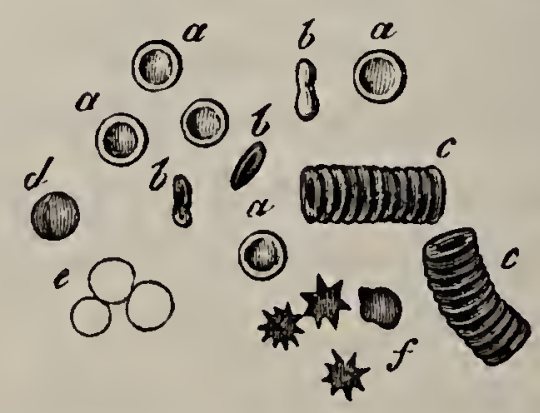

Fig. 211. - Globules sanquins. - $a$. Vus de face. - b. Vus de profil. - c. Globules empilés. - $d$. Globule devenu sphérique sous l'influence de l'eau. $-e$. Globules décolorés par l'eau. - $f$. Giobules altérés par l'évaporation. (350 D.)

ou mûriformes. C'est une des altérations les plus fréquentes du globule sanguin. Elle est attribuée par certains auteurs à la suppression d'une partie de l'eau de constitution du globule.

Ge n'est pas la seule altération que puisse éprouver le globule sanguin; quand nous étudierons le sang pathologique, ainsi que l'influence des réactifs sur le sang, nous verrons de quelle façon se comportent les globules sous l'influence de ces différents agents.

Avant de passer à l'étude des globules blancs, il nous a paru u tile de faire connaître, d'après les recherches de M.Hayem, 
CHAP. IX. - DU SANG AU POINT DE VUE MIGROSCOPIQUE. 343

les caractères anatomiques du sang chez le nouveau-né pendant les premiers jours de la vie. (Comptes rendus 21 mai 1877.) $\mathrm{Au}$ point de vue de leurs dimensions, les globules rouges sont beaucoup plus inégaux que chez l'adulte; il y en a qui dépassent en grandeur les plus gros globules de l'adulte, tandis qu'un certain nombre sont extrêmement petits. Voici les mensurations données par M. Hayem.

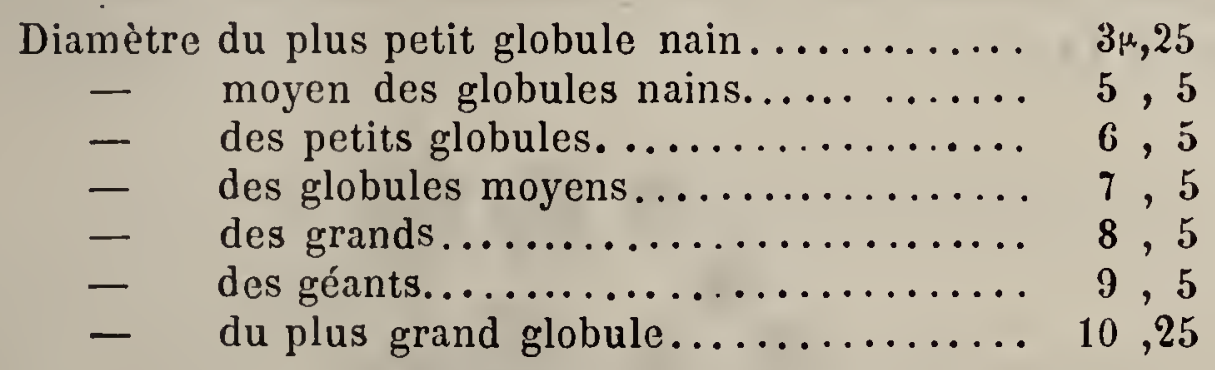

Ces globules de dimensions diverses sont mélangés dans des proportions irrégulières, qui, en se modifiant sensiblement d'un jour à l'autre, rendent impossible la détermination précise de la moyenne générale des dimensions globulaires.

M. Hayem á remarqué de plus, que les globules sanguins de l'enfant différaient de ceux de l'adulte, par leur constitution. Ils s'altèrent plus vite, résistent moins à l'action des réactifs; ils s'endosmosent avec la plus grande facilité.

Les globules du sang du fœtus se distinguent de ceux de l'adulte, par l'existence d'un noyau. D'après Robin, ce serait vers le quatrième mois de la vie embryonnaire que le noyau disparaîtrait; d'après Kœlliker au contraire, cette disparition n'aurait lieu qu'au cinquième mois. Ces globules sont plus volumineux que ceux de l'adulte, ils sont plus altérables. Quand ils sont extravasés, ils présentent des prolongements sarcodiques (Robin).

D'après MM. Mathias Duval et Lereboullet, lorsque les globules sanguins du nouveau-né présentent un noyau, c'est l'indice d'un état pathologique. 
$\S$ 2. GLOBULES BLANCS.

Corpuscules lymphatiques ou chyleux du sang.

Les globules blancs ont des caractères si nets et si tranchés, qu'il n'est pas possible de les confondre avec les globules rouges. Ils sont sphériques, et leur grosseur dépasse d'un tiers environ celle des globules rouges. Leur diamètre est égal à $11 \mu$.

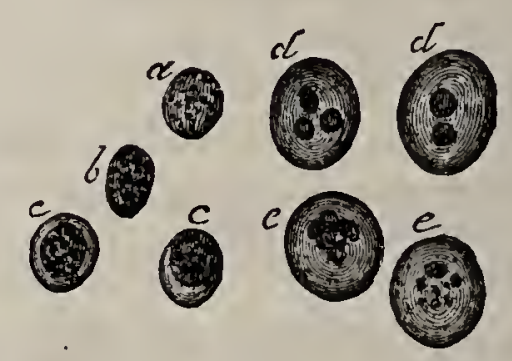

Fig. 212. - Globules blancs ou lymphatiques du sang. - $a, b$. Petites cellules, telles qu'on les rencontre dans le canal thoracique. $-a$. Cellule vue de face. $-b$. Cellule vue de profil. $-c, c$. Cellule avec noyau apparent. $-d, d$. Grosses cellules, possédant plusieurs noyaux. - e,e,e. Les mêmes traitées par l'acide acétique et dont le.noyau est en voie de destruction ou détruit (Kœlliker).

Leurs contours ne sont pas très nets et présentent souvent des irrégularités; leur aspect est granuleux; leur coloration est blanche. Les uns ont un noyau, les autres en ont deux. D'après M. Ranvier (histologie technique), la présence de deux noyaux ou d'un noyau étranglé, indique que le globule serait sur le point de se multiplier par segmentation, comme cela se voit dans certains végétaux unicellulaires.

Les globules blancs, quand ils sont virants, présentent des mouvements amiboïdes, c'est-à-dire qu'on les voit se déformer et pousser des prolongements. La même particularité s'observe dans certaines cellules végétales, mais les mouvements sont moins rapides.

Quand on examine les globules blancs d'un mammifère, il faut tenir la préparation à une température voisine de celle du corps de l'animal; avec la grenouille, sur laquelle ce phénomène s'observe très bien, une telle précaution est inutile.

Si les globules rouges sont toujours caractéristiques de la présence du sang, il n'en est pas de même des globules blancs. 
CHAP. IX. - DU SANG AU POINT DE VUE MIGROSGOPIQUE. 345

Ceux-ci en effet se retrouvent dans le pus, comme nous le verrons plus loin.

A côté des globules blancs proprement dits il y a de très petits globules blancs ou globulins. On rencontre encore des granulations incolores très petites. D'après Kœlliker, tous ces élóments, excepté ceux qui sont extrêmement petits, participeraient à ces mouvements que nous avons décrits pour les globules blancs proprement dits et que l'auteur compare à des mouvements de reptation.

\section{§ 3. ACTION EXERCÉE PAR DIFFÉRENTS RÉACTIFS.}

10 Sur les globules rouges du sang:

$E a u$. - L'eau agit rapidement et énergiquement sur les globules rouges, en les gonflant et en dissolvant leur matière colorante. Il en résulte que d'une part, en 'même témps que le diamètre transversal du globule diminue, son épaisseur augmente; il se décolore, et l'eau ambiante se colore en jaune. Les globules se transforment en vésicules incolores, qu'il est souvent très difficile d'apercevoir. Le liquide ambiant se colorant par la dissolution de l'hémoglobine, les globules blancs se teignent également. Pour rendre de nouveau visibles les hématies, on peut les recolorer avec un peu de teinture d'iode. Certains sels, tels que le chlorure de sodium, l'azotate de potasse; certains acides, tels que l'acide gallique et l'acide chromique, en les contractant, leur donnent des contours plus faciles à percevoir.

Éther. - L'éther ne dissout pas complètement les globules comme on l'a prétendu, mais il les convertit instantanément, comme l'eau, en cercles à peine visibles, au milieu du coagulum finement granulé qui se produit en même temps.

Chloroforme. - D'après Kœlliker, le chloroforme agırait de la même façon, mais plus lentement.

Acide acétique. - Suivant son degré de concentration, l'acide acétique agit plus ou moins énergiquement sur les globules. Ceux-ci pâlissent avec une rapidité variable, mais ils ne disparaissent complètement que dans l'acide cristallisable. 
Alcool. - D'après M. Ranvier, l'alcool au $1 / 3$ rendrait les globules sphériques comme l'eau, mais ceux-ci revêtiraient un double contour très net. L'alcool à $36^{\circ}$ Gartier conserverait aux globules leur forme normale.

Potasse. --Les solutions étendues de potasse dissolvent les globules sanguins, après en avoir préalablement altéré la forme. Inversement une solution très concentrée de potasse ne détruit pas les globules; elle les contracte. Si on ajoute ensuite de l'eau, les globules acquièrent alors un volume très considérable, qui peut aller jusqu'à $13 \mu$ de diamètre. Ils se dissolvent ensuite, comme dans les solutions étendues de potasse (Kœiliker).

Soude, ammoniaque. - La soude et l'ammoniaque en solution exercent sur les globules une action moins énergique que les solutions au même degré de concentration de potasse. Toutefois, en solution concentrée, la soude a une action comparable à celle de la potasse.

Sels. - D'après Kühne (Virch. Arch., t. XIV, p. 333), le glycocholate, le cholate de soude, détruisent les globules sanguins. La bile agit de la même façon. Cette observation a été le fondement de théories pathologiques, dont le bien fondé n'a pas encore été complètement démontré.

Action de la température. - La chaleur, la congélation, détruisent les globules sanguins, mais respectent les enveloppes (1). Sous l'influence de la chaleur, la substance du glo-

(1) J. A. Pouchet (Expériences sur la congélation des animaux, Rouen, 1865), formule ainsi le résultat de ses reclıerclies sur l'action du froid sur le sang.

$1^{\circ}$ L'un des premiers plénomènes produits par le froid est la contraction des vaisseaux capillaires : le microscope la fait immédiatement découvrir. Celle-ci est telle, qu'aucun globule du sang ne peut plus y être admis; aussi ces vaisseaux restent-ils absolument vides; de là, la pâleur des organes réfrigérés.

$2^{\circ}$ Le second phénomène est l'altération des globules du sang par la congélation.

Par l'effet de celle-ci, ces globules subissent trois sortes d'altérations : tantôt leur nucléus sort de son enveloppe et nage en liberté dans le plasma. Les nucléus libres ont l'apparence granuleuse et sont plus opaques que dans l'état normal. Les enveloppes énucléées sont flasques et déchirées, ou elles ont été dissoutes et ne se discernent plus. Tantôt aussi on aperçoit le nucléus déjà altéré et cependant encore contenu dans son enveloppe, où il est opaque 
CHAP. IX. - DU SANG AU POINT DE VUE MICROSCOPIQUE. 347

bule semble se fondre et avoir la consistance de l'huile; à $70^{\circ} \mathrm{C}$. les globules et les gouttes de globules se décolorent et se transforment. en petites sphères transparentes, d'un volume très inégal (Ranvier).

$2^{\circ}$ Sur les globules blancs.

$E a u$. - D'une façon générale les globules blancs résistent mieux que les globules rouges. Par l'action de l'eau ils ne tardent pas à devenir granuleux. On voit apparaître un ou plusieurs noyaux; ceux-ci sont rendus beaucoup plus nets par l'addition d'acide acétique.

\section{§ 4. NUMÉRATION DES GLOBULES DU SANG.}

L'étude de cette question a reçu depuis peu d'années, en France, une vive impulsion de deux savants, MM. Malassez et Hayem. C'est M. Malassez qui, le premier, a fait entrer la numération des globules du sang, dans une voie pratique, par la création d'un instrument dont nous donnons la description. Nous emprunterons à ces deux auteurs les renseignements qui vont suivre.

Depuis longtemps déjà on s'était préoccupé du dosage des globules à l'état sain et à l'état pathologique. Les travaux d'Andral et Gavarret et de Becquerel et Rodier sont le témoignage des nombreuses et fécondes recherches faites dans cette direction. La chimie ne pouvant donner qu'une appréciation pondérale, il appartenait au microscope de montrer que, outre la diminution des globules, il y avait des modifications morphologiques qui avaient un véritable intérêt. Jongtemps on

et plus ou moins excentriquement situé. Tantôt enfin les globules sanguins sont simplement plus ou moins crénelés sur leurs bords et plus foncés de couleur.

Ce sont surtout les globules des reptiles qui expulsent leur nucléus, les globules des mammifères offrent des crénelures.

Le nombre des globules, ainsi altérés et rentrés dans la circulation, est proportionnel à l'étendue de la congélation. Si la congélation n'a envalii que les membres, $\frac{1}{16}$ ou $\frac{1}{20}$ seulement est altéré. Si l'animal a étć totalement envalii par la glace, presque tous les globules sont désorganisés; il n’en reste pas $1 \%$ d'inaltérés.

M. Pouchet a tiré de ces faits des déductions physiologiques très importantes (loc. cit., p. 14). 
a cherché un moyen pratique de réaliser ce desideratum. On comprend sans peine, combien il aurait été difficile, pour un observateur, de dénombrer l'immense quantité de globules contenus dans une goutte de sang. Tous les histologistes ont été d'accord, pour reconnaître la nécessité de diluer le sang, c'est-à-dire d'augmenter la quantité de sérum, pour diminuer ainsi le nombre des globules, dans un volume déterminé de sang.

Il est nécessaire que le mélange soit parfaitement fait, et que les globules soient uniformément répartis.

C'est Vierordt qui le premier (Arch. für plıysiologische Heilkunde, Bd. XI, 1852, et Bd. XIII, 1854) donna le moyen de faire la numération des globules du sang. Voici en quoi consiste son procédé. Le sang, étant recueilli à l'aide d'un tube capillaire bien calibré, est étendu dans une quantité de sérum artificiel toujours la même (679,9 fois celle du sang). Au mélange ainsi obtenu, on ajoute un dixième de solution gommeuse, et on le reprend avec une pipette, pour l'étendre sur un porte-objet, en lignes étroites et régulières. On le laisse sécher à l'air libre, puis on place la préparation sous le microscope, et l'on compte les globules, en s'aidant d'une lame micrométrique placée sur le sang desséché. Comme le fait observer M. Hayem (1), auquel nous empruntons ces détails, ce procédé, demandant cinq ou six heures, avait peu de chances pour entrer dans la pratique.

Welcker (Arch. der Vereins f. gemein Arbeitcn zu Göttingen, 1854, t. I, p. 161 et 19 ă; Viertelj f. prakt. Heilkunde. Prag., $18 \check{4}$, t. XLIV, p. 11), apporta quelques modifications à celte méthode, mais sans la rendre plus prompte et plus pratique. En 186ã, Mantegazza imagina un procédé différent, mais très imparfait; il était fondé également sur un calcul de surface.

Cramer (Neder. Lancet) réalisa un très grand progrès, en mettant en pratique l'usage des dilutions sanguines en 1850 . L'appareil de Gramer, très ingénieux, comme on va le voir, ne fut pas vulgarisé. Il se compose d'une lame porte-objet, sur les bords de laquelle, sont collées deux bandes de verre très minces

(1) Voir : Thèse inaugurale de Malassez et Hayem, leçon faite à la Charité en $18: 5$. 
et parlout d'égale épaisseur. Sur ces lamelles, est placée une autre lame, semblable à la première. On a ainsi un espace capillaire, de section rectangulaire, ayant pour hauteur, l'épaisseur des lamelles. Après avoir déterminé, par une mensuration faite au microscope, le volume de ce capillaire artificiel, Cramer faisait une dissolution de sang, à l'aide d'eau salée à $\mathbf{1} / 200$, et en se servant de tubes très bien calibrés. Il faisait ensuite pénétrer par aspiration une partie du mélange dans le capillaire, et en s'aidant d'un oculaire, dans lequel était une glace quadrillée, il comptail les globules dans un espace d'une étendue déterminée et arrivait, à l'aide d'une formule calculée d'avance, à connaître le nombre des globules contenus dans un millimètre de sang (Hayem, loc. cit.).

En 1867, notre excellent maître, M. Potain, fit connaître un appareil qui porie dans la science le nom de mélangeur Potain; cet appareil sera décrit avec celui de M. Malassez.

Ainsi que nous l'avons dit, l'opération préliminaire consiste à étendre le sang avec du sérum artificiel, et à obtenir un mélange parfaitement homogène. Voici quelle est la formule adoptée par MM. Potain et Malassez. On fait une solution de gomme arabique, ayant au pèse-urine, une densité de 1,020, et on en prend 1 volume; on fait ensuite des solutions de sulfate de soude, de chlorure de sodium, ayant chacune, une densité de 1,020 , et on prend partie égale, de chacune de ces solutions pour constituer 3 volumes. M. Malassez fait au sujet de ce sérum une remarque fort imporlante. Le sérum artificiel ne se comporte pas toujours de la même façon vis-àvis de tous les globules, et s'il en conserve un certain nombre, pendant le temps nécessaire à l'examen, il en ratatine et parfois, en gonfle rapidement d'autres, cela varie suivant le sang qu'on examine, de sorte qu'il est à peu près impossible d'avoir un sérum qui s’appliạue également bien à tous les cas (1).

Si l'on ne tient pas, dit M. Malassez, à conserver aux globules leur forme, il convient d'ajouter au sérum un peu de carbonate de potasse ou de soude; une goutte de solution à 50 p. 100

(1) Du reste, M. Malassez se sert maintenant d'une solution du sulfate de soude marquant 1,1/20 au densimètre; la raison de ce choix est dans la facile altération du sérum dont nous avons donné plus haut la formule. 
dans 15 grammes de sérum environ. Avec cette modification

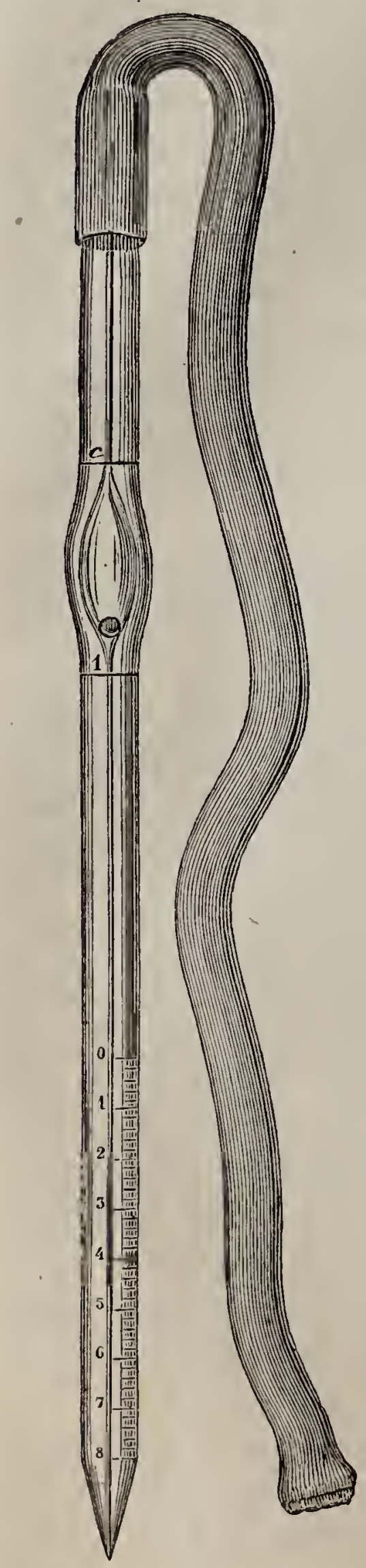

tous les globules deviennent sphériques, mais ils se répartissent plus régulièrement; la numération devient alors plus facile.

Comme généralement, dans les essais cliniques, on ne dispose que d'une faible quantité de liquide, il est nécessaire de faire usage du mélangeur Potain (fig. 214). Cet appareil se compose d'un tube capillaire effilé à l'une des extrémités et divisé en deux parties inégales, par une ampoule. Cette ampoule renferme une petite boule de verre. Le tube capillaire qui termine l'appareil, à sa partie supérieure, a une section un peu plus large, que le tube capillaire soudé à l'autre extrémité de l'ampoule. On adapte un tube en caoutchouc à l'extrémité de l'appareil.

La longue portion du tube capillaire est construite de telle façon, que sa capacité soit très exactement égale au centième de celle de la dilatation ampullaire. La capacité de l'ampoule est fixée par deux traits situés, l'un à sa partie supérieure, l'autre à sa partie inférieure.

D'autre part, la longue portion du tube capillaire est divisée en deux parties d'égale capacité. Voici quelle marche on doit suivre, quand on reut obtenir un mélange de sang à $1 / 100$. On plonge la pointe effilée du tube Fìg. :13. - Mélangeur Potain. dans le sang à examiner et l'on aspire doucement par le tube en caoutchouc, adapté à la courte portion du tube capillaire, jusqu'à ce que 
CHAP. IX. - DU SANG AU.POINT DE VUE MICROSCOPIQUE. 351

le sang arrive au trait, qui sépare la longue portion du tube capillaire, de la partie inférieure de l'ampoule. Si, par une aspiration trop énergique, le liquide sanguin a dépassé le trait, il suffit de refouler le liquide, en soufflant légèrement dans le tube en caoutchouc, en même temps que l'on essuie le sang qui sort par la pointe de l'instrument. Cette opération doit être faite assez rapidement, lorsque l'on a à examiner un sang se coagulant facilement, comme celui du chien par exemple.

Geci fait, on essuie exactement la pointe de l'appareil, que l'on plonge dans le serum artificiel, et l'on aspire doucement, à l'aide du tube en caoutchouc, en imprimant à l'appareil, avec les doigts, de petits mouvements de rotation, grâce auxquels, le mélange de sang et de sérum commence à s'opérer.

L'aspiration est maintenue, jusqu'à ce que le mélange de sang et de sérum arrive au trait qui forme le poini de séparation, entre l'extrémité supérieure de l'ampoule et la courte portion du tube capillaire.

On a alor's, dans l'ampoule, un mélange de sér'um et de sang à 1/100. Cette ampoule contient, ainsi que nous l'avons dit, une petite boule de verre. En agitant l'appareil dans des sens divers, on fait voyager la petite boule de verre qui, traversant dans toutes les directions la masse liquide, rend le mélange aussi homogène que possible.

Quand on veut faire une prise de ce mélange, on souffle par le tube en caoutchouc, de façon à expulser la partie du liquide sanguin qui est contenue dans la longue partie du tube capillaire.

Il y a des cas où l'on ne doit faire le mélange de sang et de serum artificiel, qu'à $\frac{1}{200}$, lorsque, par exemple, on a à examiner un sang normal ou très riche en globules. En se reportant à ce que nous avons dit plus haut, il suffira de n'aspirer le sang, que jusqu'au trait, marquant la moitié de la capacité de la longue portion de l'appareil. On finit par reconnaître à la couleur du sang, quand on doit recourir à cet artifice opératoire, suivant M. Malassez.

Il nous reste maintenant à décrire l'appareil proprement dit de M. Malassez, appareil auquel l'auteur a donné le nom 
de capillaire artificiel. On sait en effet que, si l'on examine au microscope, la membrane interdigitale d'une grenouille, on voit le sang circuler dans les capillaires, qui tapissent cette membrane. Le capillaire artificiel de M. Malassez, se présente sous la forme d'une petite bande de verre, ayant environ 2 à 3

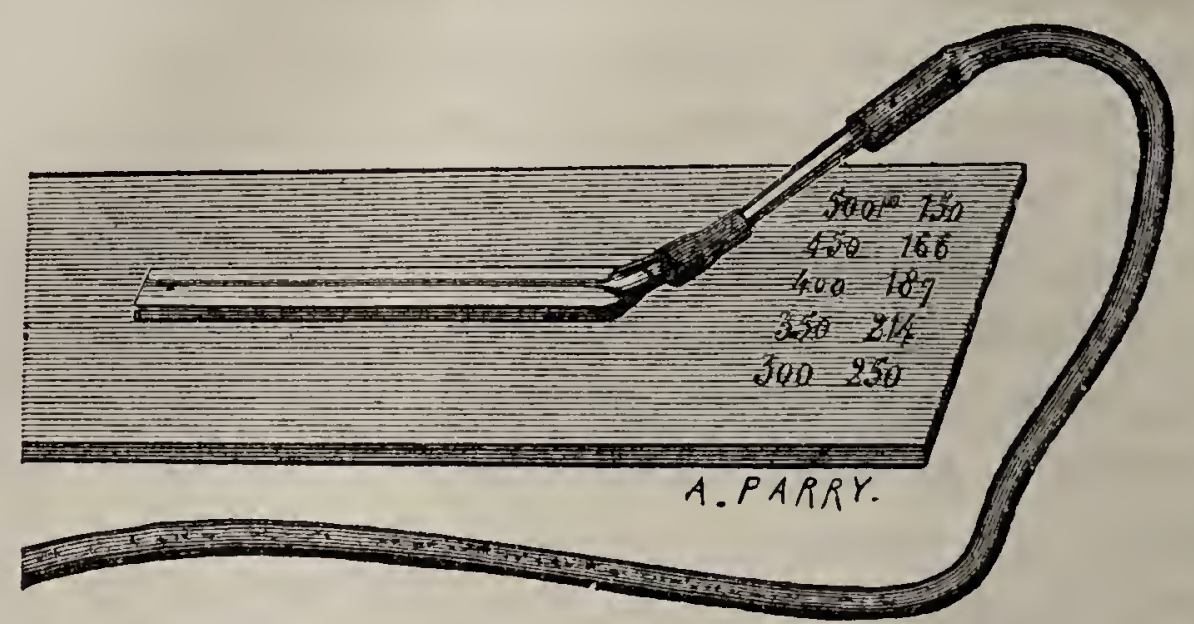

Fig. 214. - Capillaire artificiel de Malassez.

centimètres de lonğueur sur 4 à 5 millimètres de largeur et 1 millimètre d'épaisseur ; elle est fixée sur une glace porte-objet. Dans cette petite bande de verre, très près de sa face supérieure, a été ménagé un canal, qu'on ne peut bien voir à l'œil nu, que sous un certain jour; ce canal est aplati de haut en bas; à la coupe, il a la forme d'une ellipse dont le grand axe aurait environ $250 \mu$ et le petil $70 \mu$. L'une de ses extrémités est libre, l'autre relevée en forme de crochet, communique avec un tube en caoutchouc très fin. La capacité de ce capillaire artificiel a été exactement mesurée (1). Les chiffres qui sont gravés sur la lame porte-objet, indiquent quelle est sa capacité pour un certain nombre de longueurs. Dans la première colonne sont inscrites les longueurs; dans la seconde sont portées les capacités correspondantes. Les longueurs sont exprimées en millièmes de millimètre, et les capacités en millièmes de millimètre cube. Le capillaire représenté ici a par exemple pour une longueur de כ̋0u une capacité égale à la $150^{\mathrm{e}}$ partie d'un millimètre cube.

(1) C'est lì, nous devons l'avouer, ce qui rend la construction de l'appareil de M. Malassez si délicate. 
CHAP. IX. - DU SANG AU POINT DE VUE MICROSCOPIQUE. 3ə̋3

Pour faire pénétrer le sang dans le capillaire artificiel, il suffit de déposer à son extrémité libre, sur la lamelle, une goutte du mélange sanguin. Ce dernier pénètre dans l'appareil par l'effet de la capillarité.

Toutefois, d'après M. Hayem, comme les liquides pénètrent plus facilement que les solides dans le tube capillaire, il pourrait arriver que, si l'ascension du liquide se faisait lentement, il y ait un certain nombre de globules éliminés. Pour éviter cet inconvénient, M. Malassez conseille d'agiter la goutte du mélange sanguin, afin de faciliter une égale répartition des globules et de s'opposer à ce qu'ils gagnent les parties inférieures, en vertu de leur densité. Pour plus d'exactitude, l'auteur conseille même de vider le capillaire en soufflant par le tube en caoutchouc, l'appareil ayant été mouillé une première fois, l'ascension du liquide sanguin se fera plus facilement (1). Quand celui-ci est arrivé à l'autre extrémité du tube, on étanche avec un peu de papier buvard, ou un linge quelconque, le liquide déposé sur la lamelle et désormais inutile, afin que, continuant à pénétrer dans le capillaire, il ne mette pas les globules en mouvement, ce qui rendrait leur numération impossible. On porte alors le capillaire sous le microscope, et à l'aide d'une lentille convenable et d'un oculaire quadrillé, on obtient une image analogue à celle figurée p. 3 วั4.

Le tube rentrant du microscope doit au préalable avoir été placé dans une situation déterminée une fois pour toutes de façon que la partie quadrillée du champ microscopique recouvre une longueur voulue du capillaire dont la capacité a été mesurée à l'avance.

Pour compter les globulès, il faut comprendre toute la partie du capillaire recouverte par le quadrillage, entre la dernière ligne de droite et la dernière ligne de gauche. Il est nécessaire de compter carré par carré. Il arrive quelquefois que des globules sont placés à cheval sur un trait, il est prudent,

(1) Le lavage préalable du capillaire avec le mélange sanguin, dont on veut appréciel la richesse, a encore pour avantage d'empécher la dilution qui se produirait, s'il était resté un peu d'eau dans l'appareil, dans un lavage précédent. 
afin de ne pas commettre d'oubli, de les compter immédiatement. Afin d'obtenir un degré plus grand d'exactitude, M. Malassez conseille de faire deux ou trois numérations sur différents points du capillaire artificiel et de prendre une moyenne.

Le nombre ainsi obtenu sera multiplié : $1^{\circ}$ par le chiffre qui

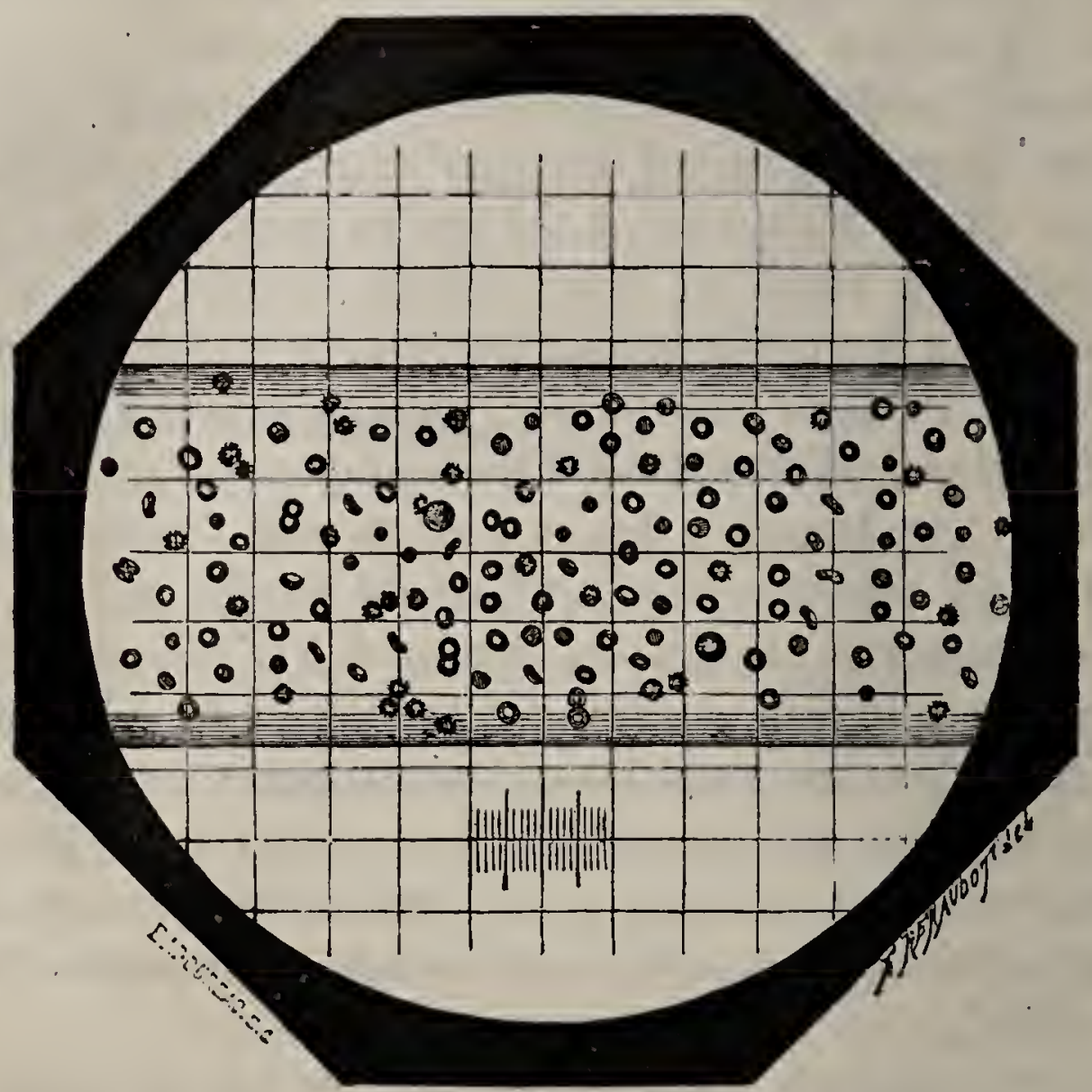

fig. 215. - Capillaire recourert par le quadrillag e .

se trouve sur la lame porte-objet, en regard de la longueur suivant laquelle les globules auront été comptés; $2^{\circ}$ par le titre du mélange.

Le produit donnera le nombre des globules par millimètre cube du sang.

Supposons par exemple que le chilfre 118 soit le nombre des globules trouvés dans une longueur de $500 \mu$; supposons que nous nous soyons servi du capillaire artificiel représenté (fig. 215), dans lequel le volume du canal est égal à la $150^{\circ}$ parlie d'un millimètre cube pour une longueur de $500 \mu$; supposons enfin que le mélange sanguin soit à $\frac{1}{200}$. Le nombre 
CHAP. IX. - DU SANG AU POINT DE VUE MIGROSCOPIQUE. 3ă des globules par millimètre cube de sang sera évidemment égal à

$$
118+150+? 00=3,540000
$$

Il reste maintenant à prendre un soin tout particulier des appareils; ces soins sont de la plus haute importance, et c'est avec raison que $M$. Malassez insiste sur ces précautions.

Pour nettoyer le capillaire, on souflle d'abord par le petit tube en caoutchouc de façon à en chasser le liquide sanguin qui y est contenu. On recueille ce liquide avec du papier buvard, puis on place à l'extrémité libre du capillaire une goutte d'eau distillée qui y pénètre par l'effet de la capillarité; on chasse cette eau à l'aide du tube en caoutchouc, et l'on répète plusieurs fois celte manœurre.

Le mélangeur doit être soumis au même traitement. On ajuste le tube en caoutchouc sur la longue portion du capillaire, et l'on chasse le liquide sanguin que l'appareil renferme; ceci fait, on replace le tube en caoutchouc sur la courte portion du capillaire, et on y fait passer de l'eau distillée en ayart soin d'imprimer à l'appareil des mouvements de rotation, de façon à faire mouvoir rapidement la petite boule contenue dans l'ampoule. Puis on chasse l'eau.

Si, en dépit de ces précautions, l'appareil venait à s'encrasser, il faudrait, suivant le conseil de M. Malassez, faire passer dans le capillaire et dans le mélangeur une solution de potasse ou de soude à 25 p. 100, puis les laver à l'eau distillée.

La méthode de M. Malassez, telle que nous venons de l'exposer, est également applicable à la numération des globules blancs. Dans son travail, cet histologiste critique avec une grande compétence les méthodes employées antérieurement. Nous ne pouvons le suivre dans ces développements intéressants ; toutefois, il y a une observation de la plus haute importance et d'un intérêt pratique considérable, que nous devons consigner ici.

On fait une préparation de sang pur et l'on compte le nombre des globules blancs. On répète cette opération de nouveau avec le même sang étendu de trois ou quatre fois son volume 
de sérum artificiel, et l'on constate par la numération que dans ce second cas on trouve plus de globules blancs que dans la première opération. Comme il n'est pas possible d'admettre que ce soit le sérum artificiel qui ait augmenté le nombre des globules, il est nécessaire de chercher une autre explication. Voici celle qui est donnée par M. Malassez : Les globules blancs vivants se fixent aux corps avec lesquels ils sont en contact et s'aplatissent contre eux; on sait que ce phénomène se produit avec le verre dans des préparations fraîches de sang pur, ce qui rend les globules blancs moins visibles. N'est-il pas vraisemblable d'ádmettre, dit M. Malassez, que si le sang est riche en globules blancs, et que les espaces laissés entre les piles de globules rouges soient peu considérables, une partie des globules blancs sera masquée par les globules rouges; tandis que, lorsque le sang est étendu de sérum, les globules blancs devenant sous l'influence de ce liquide à la fois sphériques et plus réfringents, ne peuvent plus échapper à l'observation, au milieu des globules rouges moins nombreux et plus régulièrement disséminés.

Application de la méthode Malassez. - Les globules blancs étant infiniment moins nombreux que les globules rouges, il en résulte que, pour en faire la numération, il faut employer un liquide sanguin plus concentré, que lorsqu'il s'agit de compter les globules rouges, et, de plus, qu'il faut faire cette numération sur une plus large surface, c'est-à-dire sur une plus grande longueur du capillaire artificiel. M. Malassez fait un mélange au cinquantième de sang et de sérum artificiel à l'aide du mélangeur Potain, toutefois il enseigne l'artifice suivant. Le mélangeur ordinaire n'est qu'au centième; il suffira donc de remplir deux fois la longue portion de l'appareil, et l'on aura ainsi un mélange à $\frac{1}{50}$. Pour faire cette opération, il faut, après avoir rempli une fois sa longue portion, aspirer un peu d'air dans la longue portion du mélangeur, de façon à produire un index, et à remplir de nouveau le tube capillaire en se guidant sur l'ascension de l'index. Ceci fait, on remplit l'ampoule comme il a été indiqué plus haut avec du sérum artificiel, puis on brasse le mélange que l'on peut introduire dans le capillaire artificiel par le mode opératoire exposé. 
Il ne faut pas se contenter de compter les globules dans un ou plusieurs champs microscopiques, mais bien dans dix et vingt champs microscopiques contigus; de telle sorte que, si le champ microscopique recouvre une longueur de tube de un demi-millimètre par exemple, on aura compté les globules dans une longueur de tube de un demi à 1 centimètre. Supposons, dit M. Malassez, que dans vingt champs microscopiques nous ayons trouvé 32 globules blancs; le nombre de globules blancs par champ microscopique sera de $\frac{32}{20}=1,6$. Supposons encore que le champ microscopique recouvre une longueur de capillaire de un demi-rnillimètre, et que dans ce capillaire cette longueur corresponde, comme capacité, à la centième partie d'un millimètre cube, le nombre de globules blancs par millimètre cube du mélange, sera cent fois plus considérable. $1,6, \times 100=160$. Or, le mélange étant au cinquantième, il en résulte que la quantité de globules blancs contenus dans le sang pur, sera cinquante fois plus fort, d'où $160 \times 50=8,000$.

Telle serait la richesse réelle du sang en globules blancs.

Si l'on voulait avoir la richesse du sang en globules blancs relativement au nombre des globules rouges, il faudrait calculer le nombre de globules rouges contenus dans un millimètre cube, et diviser le chiffre trouvé par la quantité de globules blancs contenus dans la même capacité. Supposons que, dans un millimètre cube de sang, on ait trouvé un nombre de globules rouges égal à 4,400,000 globules; la quantité de globules blancs contenus dans la même capacité étant égale à 8,000 , la richesse relative sera donnée par l'équation suivante :

$$
\begin{aligned}
& \frac{8000}{4.400000}=\frac{1}{x} \text { d'où } \\
& x=\frac{4.400000}{8000}=550 .
\end{aligned}
$$

Ce qui revient à dire que pour 550 globules rouges, il y a 1 globule blanc, ou encore que les globules rouges sont 550 fois plus nombreux que les globules blancs.

M. Hayem, a fait à l'appareil de M. Malassez quelques critiques que nous devons signaler. Ces critiques portent toutes, sur' le rôle important que joue la capillarité dans l'appareil que nous venons de décrire. Le mélange sanguin étant consti- 
tué par une partie solide et par une partie liquide, il en résulte qu'il doit pénétrer inégalement dans le tube capillaire, le sérum ayant une ascension plus rapide que les globules, l'homogénéité du liquide est ainsi détruite. De plus, dit M. Hayem, les parois elles-mêmes de l'espace capillaire, repoussent les globules du sang, de sorte qu'il se forme une zone claire analogue à celle qui se produit dans les capillaires naturels. L'expérience a démontré que, en raison de la dilution du sérum et du petit nombre des globules, l'inconvénient signalé par M. Hayem n'existe pas ou du moins est plus théorique que pratique. Quant à la répulsion qu'exerceraient les parois du tube capillaire, elle tient tout simplement à la forme elliptique du canal, en vertu de laquelle les globules ont une tendance à gagner les parties déclives. Pour nous, ce que l'on peut reprocher à cet appareil, c'est sa perfection même ainsi que la délicatesse des manœurres, qui nécessitent un certain temps d'apprentissage.

MM. Hayem et Nachet ont imaginé un appareil basé sur le même principe que celui de M. Malassez, mais reposant sur une méthode différente ; sans repousser le mélangeur Potain, M. Hayem conseille de faire le mélange de sang et de sérum par la méthode suivante: il se sert de deux pipettes graduées, une pour le sang, une autre pour le sérum; la pipette destinée au sérum porte des divisions permettant de prendre de 100 à 500 millimètres cubes. Le sérum dont on se sert ne doit pas avoir une composition quelconque pour conserver aux globules leur aspect physiologique et faciliter leur dissémination régulière. M. Hayem donne la préférence aux sérums naturels, physiologiques ou pathologiques. Cet auteur dit avoir retiré de grands avantages du liquide obtenu par une ponction chez un malade atteint d'hydropneumothorax. C'était un liquide très riche en albumine et ne contenant que des traces de fibrine; sa densilé était égale à 1019. La sérosité de l'ascite, que tout médecin peut, dit M. Hayem, se procurer facilement, fournirait également un excellent véhicule. Nous ne pensons pas que l'usage des sérosités naturelles puisse se généraliser, attendu que ces liquides n'ont pas tous la même densité ni la même composition, et que de plus, en supposant que ces 
liquides remplissent parfaitement les indications nécessaires, on n'en a pas toujours à sa disposition (1). Suivant M. Hayem, le sérum iodé de M. Schultz, préparé avec du liquide amniotique de vache, permet de faire un mélange très homogène; toutefois il rétracterait les globules, et par conséquent ne saurait servir à la mensuration de ces éléments. Ce dernier véhicule ne nous paraît pas non plus très pratique, et en attendant que l'on trouve un sérum artificiel qui ne déforme pas les globules, nous conseillons l'emploi de celui dont M. Grancher, professeur agrégé à la Faculté de médecine, a donné la formule, qui est la suivante :

Sulfate de soude cristallisé........... 1 gramme.

Eau distillée..................... 40 -

Ce sérum gonfle les globules et les rend sphériques, mais il ne les décolore pas; de plus, grâce au peu de densité du liquide, les globules gagnent rapidement le fond de la préparation.

Quelque sérum que l'on choisisse, voici comment il faut opérer. On prend par exemple 500 millimètres cubes de sérum à l'aide d'une pipette qui a été graduée de façon à tenir compte du mouillage du verre; ce sérum est déposé avec soin dans une petite éprouvetle. C'est alors que l'on prend le sang par la méthode que nous avons indiquée précédemment. L'aspiration. d'une quantité déterminée du sang se fail à l'aide d'une pipette parfaitement calibrée et graduée qui ressemble à celle de $\mathrm{M}$. Potain. Les divisions que porte le tube permettent de prendre 2 millimètres cubes, $2^{\mathrm{mm}}, 5$ ou 5 millimètres

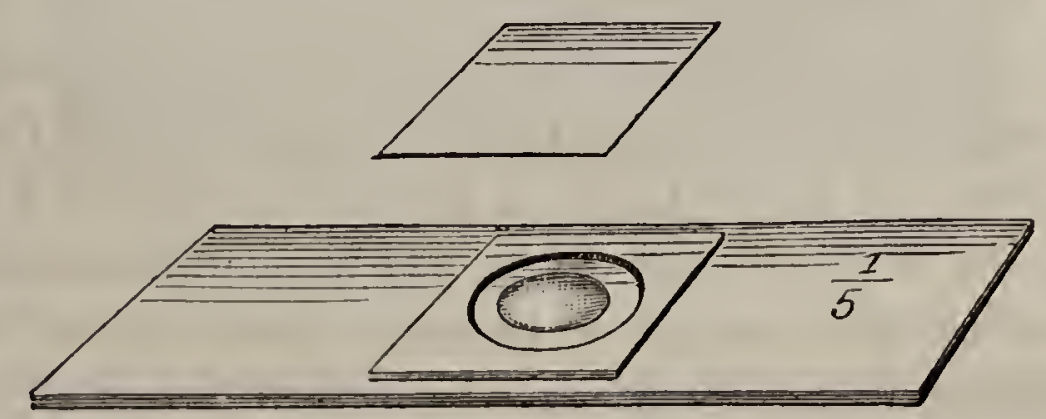

Fig. 216. - Cellule de MII. Nachet et Hayem.

cubes de sang. Supposons, dit M. Hayem, qu'on en prenne

(1) La présence fréquente des globules blancs et même des globules rouges dans ces liquides pathologiques peut encore modifier le résultat obtenu. 
2 millimètres cubes. En les portant dans la petite éprouvette, qui contient 500 millimètres cubes de sérum, on aura un mélange au $251^{\circ}$. On comprend qu'il est facile d'obtenir de même des mélanges au $201^{\circ}$ ou au $102^{\circ}$, soit en faisant varier la quan-

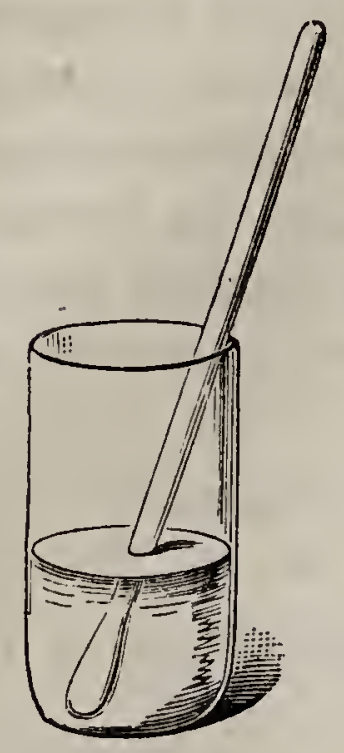

Fig. 217. tité de sérum, soit en prenant une quantité plus grande de sang. Il suffit de souffler dans le tube en caoutchouc que porte la pipette pour faire tomber le sang au fond de l'éprouvette. En aspirant deux ou trois fois de suite un peu de sérum qu'on repousse aussitôt, on vide facilement tout le tube capillaire. On introduit alors dans la petite éprouvette contenant le sérum et le sang un agitateur terminé par une petite palette à l'aide duquel on fait un mélange aussi intime que possible.

L'appareil de MM. Nachet et Hayem se compose d'une petite cellule formée par une lamelle de verre mince perforée à son centre de manière à former une ouverture d'environ 1 centimètre de diamètre et fixée sur une lame de verre porte-objet parfaitement plane. L'épaisseur a été diminuée d'une quantité déterminée à l'aide du sphéromètre, et on a ainsi une cavité dont l'épaisseur est mathématiquement connue. En déposant au centre de la cellule une goutte du liquide sanguin, et en la recouvrant immédiatement par une lamelle de verre très plane qui vient reposer sur les bords de la cellule, on obtient ainsi une couche de liquide, à surfaces parallèles, dont l'épaisseur est égale à un cinquième de millimètre. Si l'on a soin, dit M. Hayem, de bien placer la goutte de liquide à examiner au milieu de la cellule, et de ne pas la prendre assez volumineuse pour qu'elle remplisse la cavité tout entière, on n'aura pas à craindre le soulèvement de la petite lamelle par le liquide, phénomène qui se produit facilement lorsque la cellule contient une quantité surabondante de liquide.

Il ne reste plus maintenant qu'à recouvrir la cellule à l'aide de la petite lamelle. Pour empêcher celle-ci de glisser et pour s'opposer en même temps à l'évaporation du liquide san. 
CHAP. IX. - DU SANG AU POINT DE VUE MICROSCOPIQUE. 361 guin, M. Hayem conseille d'humecter les bords de la lamelle avec de la salive.

On n'a plus alors qu'à compter les globules. Cette numération se fait par un procédé analogue à celui de M. Malassez. Dans l'oculaire, on a placé une glace sur laquelle est disposé un carré, et le tube rentrant du microscope est enfoncé dans sa monture, jusqu'à un trait calculé de façon que, le côté du carré ait, avec l'objectif dont on se sert, ( $n^{\circ} 2$ Nachet), une valeur d'un cinquième de millimètre, soit celle de la hauteur de la cellule. On a ainsi sous les yeux la projection d'un cube d'un cinquième de millimètre de côté. De plus, ce carré de l'oculaire est divisé en seize carrés égaux, dans lesquels on a placé des lignes réciproquement perpendiculaires qui n'arrivent pas jusqu'aux bords des petits carrés et qui sont desti-

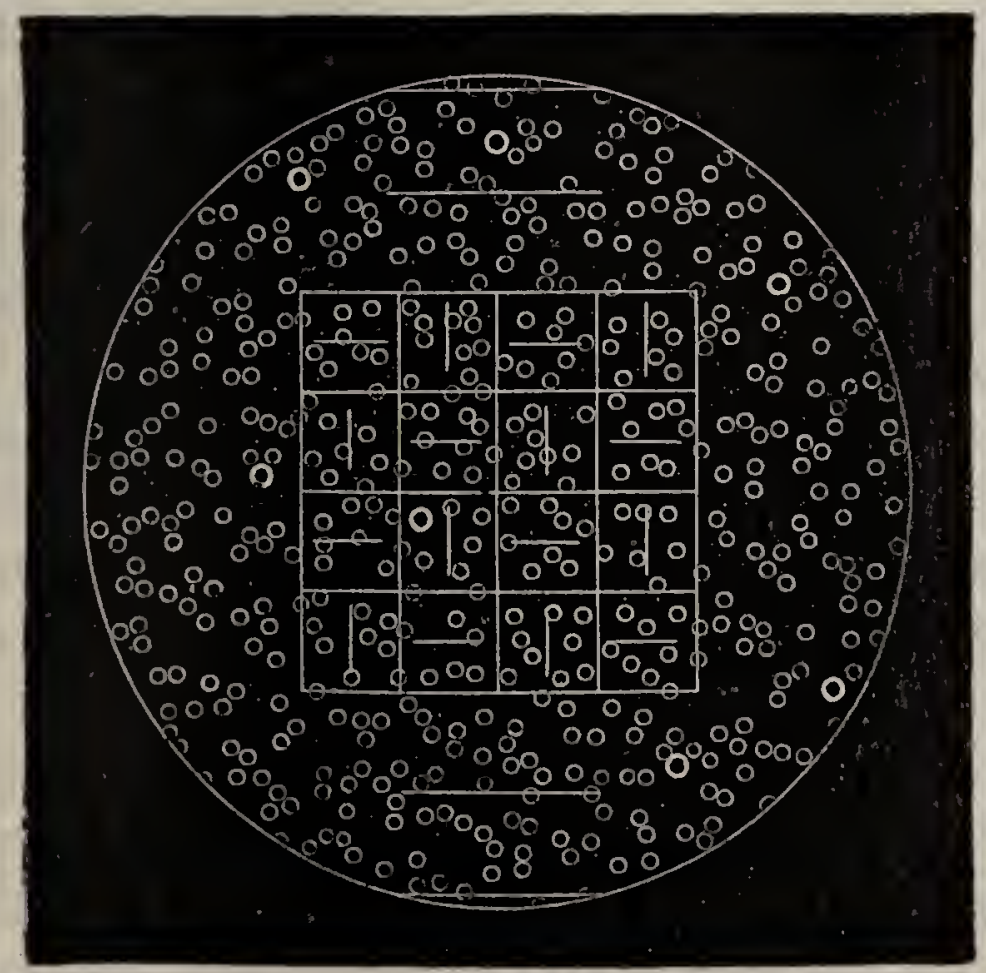

Fig. 218. - Appareil de MM. Nachet et Hayem.

nées à faciliter la numération,(fig.218).Au bout de quelques minutes, les globules sont tombés par leur propre poids au fond de la cellule. En comptant ceux qui sont compris dans les seize petits carrés; on a très exactement le chiffre des globules contenus dans un cube d'un cinquième de millimètre de côté. Il suffira donc, de multiplier ce chiffre par 123 pour savoir ce que 
renferme 1 millimètre cube de mélange, et, pour connaître la valeur d'un millimètre cube de sang, de multiplier le dernier chiffre trouvé par le titre de ce mélange (Hayem). Dans l'exemple choisi par l'auteur, c'est-à-dire, avec un mélange au $251^{\circ}$, soit $x$, le nombre de globules comptés dans les seize carrés, il faudra multiplier $x$ par 125 , puis par 251 , soit $125 \times 251=31,375$. Si le mélange avait été fait au $201^{\mathrm{e}}$, on aurait à multiplier $x$ par $: 125 \times 201=25,125$; avec un mélange au $101^{\circ}$ par 120 × $\times 101=12,625$.

Pour obtenir un résultat plus rapproché, M. Hayem, comme M. Malassez, conseille de faire la numération plusieurs fois de suite (1).

Quand on veut faire la numération des globules blancs, il faut faire usage d'un mélange sanguin au $101^{\mathrm{e}}$. On comprend que dans ce cas les globules rouges sont si nombreux qu'il devient difficile de les compter, on fait alors un second mélange au $21^{\mathrm{e}}$ à l'aide duquel on compte les globules rouges.

Nous ne voulons pas donner ici les résultats qui ont été obtenus par les différents expérimentateurs qui se sont servi de ces deux méthodes. Les chiffres ne concordent pas toujours, il est sage d'attendre que des expériences plus nombreuses aient été faites. En général les chiffres donnés par la méthode de M. Hayem sont supérieurs à ceux obtenus par le procédé de M. Malassez. On a supposé que l'addition d'un peu de salive pour faire adhérer la lamelle de recouvrement, en soulevant la plaque, augmentait la hauteur du cylindre et la rendait supérieure à $\frac{1}{5}$ de millimètre : pour cette raison on aurait une augmentation dans le nombre des globules. Une objection plus sérieuse a été faite par M. le $\mathrm{D}^{\mathrm{r}}$ Esbach, chef du laboratoire de clinique médicale à l'hôpital Necker. M. Esbach a bien voulu nous communiquer le résultat de ses recher-

(1) Nous trouvons dans un travail de M. le $\mathrm{D}^{r}$ Albin Meunier, intitulé : "Etude parallèle des globules rouges et blancs du sang et des principaux óléments de l'urine, dans quelques maladies aiguës ", unc observation touchant l'appareil d'Hayem. Elle nous a paru avoir un intérêt pratique. Pour rendre cet appareil plus parfait, dit l'auteur, il conviendrait dajouter an microscope un petit niveau d'eau qui permettrait d'avoir l'instrument toujours dans un plan horizontal; s'il dévie de ce plan, on a, par exemple, 150 globules dans un champ et 200 dans un autre. Il y a donc nécessité d'établir l'lorizontalité. 
CHaP. IX. - DU SANG aU PoINT DE vUE Microscopique. 363

ches encore inédites. Lorsqu'après avoir agité le mélange sanguin, avec la petite spatule, on transporte à l'extrémité de celle-ci une goutte de liquide dans la cellule, il arrive que les globules suivant la densité du sérum gagnent plus ou moins rapidement l'extrémité de la goutte du liquide sanguin. En effet, dit.M. Esbach, prenez du sérum constitué par une solution de sulfate de soude d'une densité de 1008, les globules se déposent très rapidement, dès qu'on a cessé d'agiter le mélange, ils gagnent les parties inférieures du liquide. Un phénomène identique a lieu dans la goutte du sérum sanguin. Or, comme on dépose précisément dans la cellule la partie la plus inférieure de la goutelette, il se trouve qu'on $y$ introduit en même temps, une quantité anormale de globules.

Si maintenant on prend un sérum de composition analogue, mais de densité plus élevée, et se rapprochant davantage de la densité du sérum du sang, le phénomène est bien moins accentué, et la numération subséquente donne un chiffre notablement moindre de globules. Enfin si l'on emploie un sérum visqueux, comme celui de M. Potain, par exemple, mais sans addition de carbonate de soude, les variations seront encore moindres, parce que la répartition des globules sera plus égale.

Ainsi donc, avec la méthode de M. Hayem, moins le sérum est dense, plus l'errèur est grande et plus on est exposé à compter un trop grand nombre de globules.

Voici par quel moyen le $\mathrm{D}^{\mathrm{r}}$ Esbach propose de se mettre à l'abri de cette cause d'erreur. Le mélange étant opéré, on y plonge la pipette capillaire que l'on emploie pour le sang, on aspire et on repousse plusieurs fois le liquide.

Enfin on pratique l'aspiration une dernière fois, et l'on emporte l'instrument chargé du mélange. L'extrémité est essuyée avec soin, et on laisse écouler la première goutte hors de la cellule, puis, touchant le fond de la cellule avec la pointe de la pipette, on y laisse tomber une quantité suffisante de liquide que l'on recouvre immédiatement avec la lamelle. M. Esbach conseille l'emploi d'un sérum dont la densité varie entre 1020 et 1024 . 
Avec cet esprit à la fois si ingénieux et si pratique qui le caractérise, M. Esbach a apporté un notable perfectionnement aux méthodes de MM. Malassez et Hayem. Nous devons également à l'obligeance de l'auteur, la communication de cette importante modification, à laquelle il a donné le nom de numération à la chambre claire. Au lieu d'un oculaire quadrillé on se sert d'une chambre claire, munie dans son intérieur d'une glace quadrillée. On règle le tirage du microscope comme d'habitude. Sur une surface plane, un morceau de marbre par exemple, on pose une feuille de papier, puis sur celle-ci le microscope qui, par son poids, en assurera la stabilité.

Si l'instrument, étant au point, on regarde dans la chambre claire, on aperçoit la préparation comme si elle était sur le papier luj-même; de plus on voit très bien une plume ou un crayon à l'aide duquel on trace des lignes ou des points. A mesure que M. Esbach compte un globule, il le marque d'un trait à la plume. Arrivé au bas de chaque colonne de petits carrés, il inscrit le nombre des globules, et il fait de même pour chaque colonne. On voit que, grâce à cette méthode, on compte facilemeut les globules et qu'on ne risque pas de compter deux fois le même ni d'en oublier un seul qui, n'étant point marqué d'un point, s'offrirait de lui-même à la vue.

Pour rendre cette numération plus rapide encore, M. Esbach remplace la feuille de papier par une plaque de zinc; celle-ci est mise en rapport par un fil avec une pile au bichromate, à laquelle est également reliée la plume de l'opérateur, par un fil souple. Sur le trajet de l'un des fils, est interposé un petit compteur électrique,dont la construction est des plus simples, puisqu'il consiste en un disque de bronze, portant 300 petites dents numérotées, de telle sorte qu'à chaque globule marqué, le compteur avance d'une unité. La seule préoccupation de l'opérateur consiste donc à faire des barres sur les globules, sans avoir à compter et sans erreur possible. Il y a de plus, une grande économie de temps quand il s'agit de compter 300 ou 400 globules. 
§ ว̈. SUR LES GLOBUi.JNS, MICROCYTES OU PETITS GLOBUL.eS.

Les petits globules du sang ont une forme sphérique et mesurent de 3 à $6 \mu$. Leur coloration est variable; les plus petits sont à la fois plus réfringents et d'une coloration plus foncée que les autres globules; d'autres sont au contraire plus pâles et comme en voie de dissolution (1). Sous ces apparences, dit M. Hayem, différents observateurs, entre autres Masius et Vanlair, ont pris ces hématies pour des éléments particuliers, qu'ils ont décrits sous le nom de microcytes. D’après le même auteur, ces prétendus microcytes ne préexisteraient pas dans le sang, ils ne seraient que le produit des réactions causées par les agents extérieurs. Leur nombre varie dans une préparation suivant la façon dont elle a été faite.

Outre ces éléments on en trouve dans le sang qui, bien que d'une extrême ténuité, n'en présentent pas moins les caractères propres à l'hématie, c'est-à-dire qu'ils sont à la fois discoïdes et biconcaves. Bien qu'ils ne mesurent que $2 \mu$, ils ont la même forme que les globules normaux. Outre ces globules extrêmement petits, il y en a en revanche qui sont extrêmement développés et qui mesurent jusqu'à 12 et $14 \mu$. Entre ces derniers et ceux qui ne mesurent que $2 \mu$ on peut trouver une foule d'intermédiaires étant tous à la fois, discoïdes et biconcaves. D'après M. Hayem, les globules en boule et fortement colorés, dont nous parlions plus haut, seraient dans une sorte d'état tétanique. C'est ainsi que certains réactifs leur rendraient, en les tuant, leur forme normale, c'est-à-dire biconcave.

Quant aux globules pâles en voie de dissolution, ce seraient des éléments très vulnérables ayant subi plus facilement que les autres l'action des agents extérieurs.

Nous énumérons ci-après quelques-unes des conditions dans lesquelles ces globules nains ont été observés:

Le sang de l'enfant nouveau-né en contient beaucoup ; ils sont rares chez l'adulte bien portant; pendant la période

(1) G. Hayem, Comptes rendus de l'Académie des sciences, du 28 mai 1877. 
menstruelle on en trouve un cerlain nombre chez la femme.

A l'état pathologique, voici quelques-unes des maladies dans lesquelles on rencontre à la fois et des globules nains, et des petits globules sphériques : à la suite d'hémorrhagies, d'accouchement, d'épistaxis, d'hémoptysie, d'hématémèses, de méthrorrhagie, etc., les globules rouges, d'abord moins nombreux, commencent à se multiplier, on voit apparaître des globules nains et des globules sphériques. Le même fait se représente à la fin de certaines maladies, telles que la fièvre typhoïde, la variole, le rhumatisme, etc. Il en est de même dans les anémies chroniques.

De ses nombreuses observations cliniques, M. Hayem conclut, que les petits globules rouges de sang, aussi bien à l'état pathologique qu'à l'état normal, se montrent toutes les fois qu'il se fait une production active de nouveaux éléments. Ils caractérisent un sang en voie d'évolution ou de réparation; ce sont des globules jeunes et incomplètement développés. Ils ne diffèrent des glohules adultes que par leur exiguïté et la facilité avec laquelle certains d'entre eux deviennent sphériques lorsqu'ils sont sortis des vaisseaux.

§6. vésicules ÉLÉMENTAIRES DE DONNÉ ET DE ZIMMERMANN.

hématoblastes (Hayem). - Formation de la filrine; ses propriétés, ses caractères différentiels. - M. Hayem examinant le sang de certains vertébrés ovipares (V. Comptes rendus de l'Académie des Sciences, 12 novembre 1877), constata la présence, d'une manière constante, de cellules incolores différant essentiellement des globules blancs. Ces éléments, en se développant progressivement, deviendraient des globules rouges parfaits, et pour ceite raison M. Hayem les a désignés sous le nom d'hématoblastes. Cet observateur a constaté leur présence chez tous les vertébrés ovipares examinés par lui (divers oiseaux, tortue, lézard, couleuvre, grenouille, crapaud, triton, axolotl et divers poissons).

Dans leurs transformations successives, les hématoblastes passent par deux phases principales. A un premier degré de développement, ils sont constitués par des éléments pâles et 
délicats qu'il est dificile de distinguer des globules blancs. Ils en diffèrent, dans le sang pur, par la transparence et la faible réfringence de leur protoplasma ; par la viscosité de ce protoplasma, propriété qui les fait adhérer entre eux et former des amas considérables, auxquels viennent s'accrocher des globules rouges en dessinant une sorte de rosace. En outre, ils ont une forme plus ou moins allongée, tantôt anguleuse; leur noyau est toujours unique et plus net que le corps de l'élément, ce qui est l'inverse de ce qu'on observe dans les globules blancs. La forme du noyau des hématoblastes varie avec l'espèce animale, mais, dans une même espèce, il est toujours semblable à celui du globule rouge adulte; quelquefois cependant il est un peu plus gros et un peu plus allongé.

Dans la seconde phase du développement, la plaque protoplasmique prend de plus en plus nettement l'apparence d'un petit dișque ; les éléments perdent leur viscosité ; ils se présentent avec des caractères peu différents d'un animal à l'autre. Le disque poursuit son développement, en se rapprochant graduellement, dans la plupart des cas, de la forme du globule rouge adulte.

M. Hayem a également recherché la présence de ces éléments dans le sang de l'homme, et chez les vivipares. Leur diamètre est très petit et oscille entre $1 \mu, 5$ à $3 \mu$; pour le voir d'une façon nette, il est nécessaire d'employer des grossissements assez forts. Ils sont très altérables. Immédiatement après leur sortie des vaisseaux ils deviennent épineux, se plissent et ont de la tendance à se grouper. Cette tendance est moins prononcée chez l'hómme que chez certains animaux.

Pour étudier ces éléments, M. Hayem conseille l'emploi de liquide amniotique iodé, dont on laisse préalablement évaporer l'excès d'iode. Sous l'influence de ce réactif, ils deviennent d'abord épineux, puis ils reprennent leur forme normale qui est déjà le plus souvent discoïde et biconcave. Parmi les hématoblastes les plus développés, il y en a qui sont déjà nettement colorés par l'hémoglobine, de sorte qu'ils constituent un état intermédiaire entre l'hématoblaste et le globule rouge à l'état parfait. Avant d'aroir acquis leur entier développement, il y a des 
hématoblastes qui ont tous les caractères du globule rouge, ce sont ces hématies extrêmement petites que nous avons appelées plus haut d'après M. Hayem, globules nains.

Dans la séance de la Société de biologie, du 2 février 1878, M. G. Pouchet a fait une communication sur ce même sujet. Après avoir établi que les corpuscules décrits par M. Hayem sous le nom d'hématoblastes avaient été entrevus par Donné en 1840, qui les confondit avec les granulations du chyle, et parfaitement décrits en 1846, parZimmermann, qui les appelle corpuscules élémentaires, et plus tard par'M. Robin, sous le nomłde globulins, M. G. Pouchet a donné une nouvelle description de ces corps. D'après ce savant anatomiste, leurs dimensions seraient très variables; les plus petits que l'on aperçoive nettement, sont allongés et mesurent $2 \mu$ de long environ, sur $1 \mu$ au plus, de large. Ils sont nettement atténués aux extrémités, riziformes et ont dès cette époque, une très grande tendance à s'agglutiner, soit entre eux, soit aux hématies ou aux leucocytes, contre lesquels ils se montrent souvent fixés par le travers ou par une de leurs extrémités. A côté de ces corps on en trouve d'autres nettement reconnaissables pour le même élément anatomique, mais ayant atteint des dimensions plus grandes. Ils sont aplatis, ovoïdes, mesurant 3 à $4 \mu$ de long sur 2 à $3 \mu$ de large. Leurs bords sont nets, leur substance peu réfrangible, sans granulations visibles, bien qu'elle ne présente pas la même transparence que celle des hématies. On ne voit aucune trace de noyau ou de nucléole. Ces éléments commencent à offrir une très faible réaction hématique; ils fixent en même temp̀s, très légèrement, le carmin et deviennent un peu rosés, sans jamais se teinter à l'unisson des noyaux des leucocytes. Le développement de ces éléments anatomiques paraît se faire rapidement, et ils gardent leur forme ovoïde aplatie. Bientôt leur grand axe dépasse celui des hématies normales, ils constituent alor's une variété constante d'hématies qui ne semble pas avoir fixé l'attention des anatomistes. C'est seulement alor's que l'élément commence à se bourreler sensiblement, en même temps qu'un retrait, se produisant dans le sens de son grand axe, tend à lui faire prendre la figure discoïde définitive de l'hématie. Les éléments se trou- 
vent à l'état normal dans le sang de l'homme, et on peut les faire apparaître en grand nombre dans le sang des animaux, en les soumettant à des hémorrhagies soutenues jusqu'à la syncope (G. Pouchet).

Poussant plus loin ses recherches, M. G. Pouchet a essayé de déterminer l'origine de ces corps élémentaires (Socièté de Biologie, mars 1878). Pour cet observateur les corpuscules appelés à devenir des hématies dériveraient pent-être du corps des leucocytes et en seraient des émanations devenues libres. Un premier fait à noter, c'est que ces corpuscules présentent, au début, exactement toutes les réactions de la substance du corps des leucocytes, avec les matières colorantes. D'autre part la substance du corps des leucocytes apparaîl chez tous les vertébrés comme apte par excellence à fixer l'hémoglobine aux dépens du sérum ambiant. M. Pouchet se demande si les leucocytes ne seraient pas des émanations et comme des rejets du corps des leucocytes, se faisant alors par un mécanisme cellulaire intime, analogue à celui qui a pour résultat l'expulsion des globules polaires par le vitellus.

La vérification de cette hypothèse par l'expérience était d'ailleurs difficile. En effet, la condition même de l'évolution normale des leucocytes est leur circulation, qui ne nous permet pas de les garder attachés sous nos yeux; dès qu'un leucocyte est immobilisé, il n'est plus dans des conditions normales. Mais d'autre part, en comprimant légèrement une veine mésentérique d'un lapin, jusqu'à ce que la nappe de sérum n'entraîne plus qu'un petit nombre d'éléments figurés, M. G. Pouchet a pu voir des leucocytes se fixer aux éléments des parois vasculaires, en groupes plus ou moins nombreux. Ces groupes sont communément accompagnés d'un amas plus ou moins considérable de corpuscules élémentaires. On rencontre également souvent dans le sang, des leucocytes auxquels semblent adhérer des corpuscules élémentaires. Toutefois, M. Pouchet, ne donne son hypothèse qu'à titre provisoire pour expliquer l'origine de corps, que nous ne voyons pas dériver directement de cellules.

L'état intermédiaire des hématoblastes se retrouve fréGUIDE DE MICROGIAPHE. 
quemment dans le sang des anémiques. Mème quand ils sont parvenus à l'état adulte, ils conservent certaines particularités de forme, qui ont été décrites par M. Hayem dans l'anémie.

Si nous avons insisté un peu longuement sur les hématoblastes, c'est parce que, outre leur rôle physiologique, ils auraient, d'après M. Hayem, dans la formation de la fibrine, une influence prépondérante.

En faisant passer, à l'exemple de M. Ranvier, à travers une préparation de sang coagulé, de grenouille, un courant de sérum iodé, on voit, d'après M. Hayem, que les hématies disposées en rosaces autour des amas d'hématoblastes, sont fixées dans cette situalion par des filaments fins partant du centre des rosaces. Cette sorte de lavage entraîne un certain nombre d'éléments et il devient facile de constater, que les hématoblastes se sont transformés en corpuscules irréguliers, anguleux, étoilés, et que de la surface de ces éléments et de leurs prolongements, partent des fibrilles extrêmement fines et délicates, qui se divisent et s'entrecroisent, en formant un réseau, dont les derniers filaments, extrêment tenus, ne se voient bien que lorsqu'ils ont été colorés par l'iode. Les fibrilles principales et les plus épaisses, relient entre eux les hématoblastes qui occupent le centre des rosaces; la plupart des autres, rattachent les hématies autour de ce même centre, à l'aide de fibrilles qui les déforment de diverses manières. Les hématoblastes d'où émane le réseau de fibrilles, sont faciles à reconnaître, malgré les altérations qu'ils ont subies; on en distingue souvent encore, le noyau unique et volumineux. Avec le sang de l'homme, les choses se passent à peu chose près, comme chez la grenouille. Les hypothèses faites pour expliquer ces faits, les déductions qu'on en a tirées ne nous paraissent pas encore suffisamment établies (1).

(1) On sait (V. Cornil et Ranvier) que des globules rouges du sang ajoutés à certains exsudats liquides, celui de la pleur'ésie par exemple, y déterminent la formation de la fibrine. Peut-être la coagulation se produit-elle par l'action ci-dessus décrite des liémastoblastes?

M. Ranvier, dans son Traité techique d'histologic, avait appelé l'attention sur le rôle des vésicules élémentaires de Zimmermann. Il en avait distingué deux espèces: les premières, sphériques comme de petites gouttelet- 
Quand on examine de la fibrine au microscope, deux cas peuvent se présenter. Ou la fibrine s'est formée, après que les globules ont gagné en vertu de leur poids, la partie inférieure du vase, ou de la cavité, qui les renferment, ou elie s'est coagulée, en entraînant dans ses mailles, une ceriaine quantité des globules rouges. Dans le premier cas la fibrine est isolée et presque à l'état de pureté, dans le second, on a une dis-

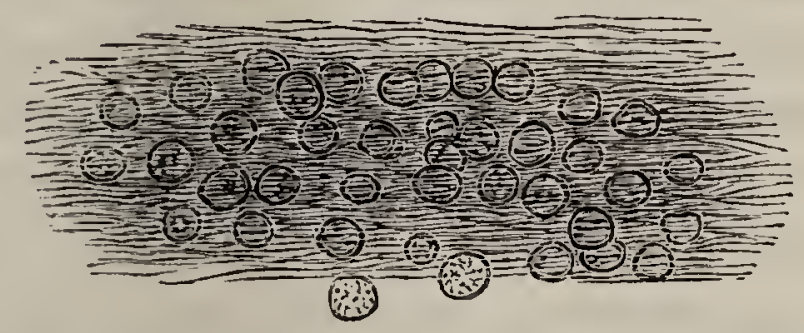

Fig. 219. - Fibrine ayant emprisonné des globules blancs.

position analogue à celle représentée dans la figure ci-dessus. (Quand la fibrine est isolée et qu'on l'examine avec un grossissement de 20 diamètres, elle apparaît sous la forme d'un fin lacis de fibrilles diversement anastomosées et entremêlées. La

tes de graisse; les autres, anguleuses ou de forme variée et paraissant, au premier abord, être des débris de globules blancs, dont elles diffèrent, en ce que l'eau ne les altère pas. Elles sont colorées par l'iode, mais elles demeurent incolores, dans les solutions carminées, ce qui, d'après Ranvier, tenderait à les rapproclier de la fibrine..

Ayant fait par un procédé spécial (loc. cit., p. 215) une préparation de sang humain, M. Ranvier attendit que la coagulation fùt accomplie, puis il arrosa la préparation avec une pipette et de l'eau distillée, jusqu'à ce que la lame ne représentât plus de coloration du tout. Ayant ensuite examiné sa préparation à un grossissement de 400 à $540 \mathrm{D}$., le réticum fibrineux apparut d'une façon nette avec une disposition très particulière et représentée dans l'ouvrage de M. Ranvier. Cet observateur avait vu que des fibrilles d'une extrêne minceur partaient de granulations angulıuses ayant de $1 \mu$ à $5 \mu$ de $\mathrm{D}$.

Pour M. Ranvier, et c'est en cela que son opinion diffère de celle de M. Hayem, ces granulations auraient les mêmes propriétés micro-chimiques, que les fibrilles; elles ne sont ni gonflées, ni amoindries par l'eau; ce réactif n'y détermine pas de vacuoles; les granulations sont colorées par l'iode et par le rouge d'aniline, de même que les fibrilles qui s'en détachent, et-leur coloration paraît même plus intense, parce qu'elles sont plus épaisses que les fibrilles. En résumé, M. le professeur Ranvier a observé, le premier, le ròle de.ces granulations anguleuses, dans la formation du coagulum fibrineux; pour lui, ces granulations ne seraient que de la fibrine, et elles agiraient de la même façon qu'un cristal de sulfate de soude, plongé dans une solution saturée du même sel. Toutefois, M. Ranvier admet que ces corpuscules sont probablement des éléments normaux du sang. Nous avons exposé plus haut l'opinion de M. Hayem. 
forme et la dimension de ces fibrilles n'est pas régulière. Quelquefois, la fibrine peut se présenter sous forme de caillots d'apparence variable et de texture homogène: mais sous l'influence de différentes préparations, qu'on lui fait ordinairement subir, en vue d'un examen microscopique, les fibrilles ne tardent pas à apparaître. D'après MM. Cornil et Ranvier, pour bien voi: le réticulum fibrineux, il faut faire durcir le caillot dans l'alcool et pratiquer des coupes très minces qui, après macération dans l'eau, sont nettoyées au pinceau. Lorsqu'on fait agir de l'eau sur un petit fragment du caillot, pour dissoudre les globules rouges, sans attaquer la fibrine, celle-ci apparaît sous forme de lames irrégulières, anostomosées.

Rappeions, que c'est à la rétraction du réticulum fibrineux, qu'est due la diminution de volume des caillots sanguins; il se fait une sorte d'expression, en vertu de laquelle, la partie liquide est chassée du caillot.

Le réactif par excellence de la fibrine, est l'acide acétique. Ce réactif gonfle la fibrine, lui donne un aspect homogène et gélatineux et finit par la disșoudre complètement. Par l'emploi de l'acide acétique, il est facile de différencier la fibrine du mucus, qui ne se dissout pas dans ce réactif; le mucus se dis. sout de plus, dans les alcalis.

Comme nous l'avons vu plus haut les filaments de fibrine sont colorés par l'iode ; ils résistent à l'action du picrocarminate d'ammoniaque (1).

Lorsqu'on examine le sang d'un animal qui vient de faire un très copieux repas, on voit, surtout quand les matières grasses ont été ingérées en abondance, un nombre plus ou moins considérable de corpuscules sphériques, très réfringents et légèrement jaunâtres; ce sont des globules de graisse. lls viennent en grande partie des vaisseaux chylifères. Quelquefois, ils sont en nombre si considérable, que le sérum prend un aspect laiteux. La propriété caractéristique de ces éléments, c’est d'être solubles dans l'éther. .

(1) Il est très important de savoir caractériser la fibrine cn raison de la forme particulière qu'elle peut prendre. C'est ainsi qu'on la rencontre souvent dans l'urine, où elle a un aspect vermiforme, qui préoccupe à tort les malades, cn les trompant sur la véritable nature de ces flaments fibrineux. 


\section{$\S$ 7. Sang a l’état PathologiQue.}

On peut dire qu'actuellement, l'histoire du sang traverse une période de rénovation. Des observateurs très distingués, se sont mis à l'œuvre et chaque jour des travaux considérables viennent éclairer la question. Ces recherches ne conduisent pas toujours leurs auteurs à des résultats concordants, aussi serons-nous forcés de donner souvent des opinions différentes sur un même sujet.

Nous avons vu que les globules sanguins, s'altéraient avec la plus grande facilité, sous les influences diverses que nous avons énoncées, il faudra donc bien se mettre à l'abri des causes d'erreur et ne pas prendre pour des altérations pathologiques, de simples accidents de préparation.

Les globules du sang peuvent être modifiés :

$1^{\circ}$ Dans leur nombre;

$2^{\circ}$ Dans leur forme et dans leurs dimensions;

$3^{\circ}$ Dans leur constitution chimique.

L'état pathologique dans lequel ces altérations ont été le mieux étudiées est l'anémie. C'est en particulier aux travaux de M. Hayem que nous empruntons ce qui va suivre:

$1^{\circ}$ Nous ne parlons pás des modifications dans le nombre.

$2^{\circ}$ En général, dit cet auteur, en raison d'un défaut de consistance probable, les globules éprouvent des déformations variables, qui portent surtout sur les globules moyens et petits. Lorsque ces déformations sont peu accentuées, les globules, au lieu d'être parfaitement circulaires, prennent une forme ovalaire'allongée. Quand, au contraire, elles sont très prononcées, elles donnent aux hématies, des apparences très variables qui sont comparables aux formes d'un bâtonnet, d'une raquette, d'un corps ovalaire étiré en pointe, à l'une de ses extrémités ou aux deux.

Le sang des anémiques, dit M. Hayem, contient presque toujours un certain nombre de globules plus petits, que les plus petits globules du sang normal. Le diamètre de ces petits éléments, varie de $2 y, 2$ à $6 \mu$; les petits globules ne mesurant que $2 \cdot,, 2$ à $2 ., ., 3$, sont rares et toujours peu nombreux, tandis 
qu'il est fréquent d'en trouver un grand nombre mesurant $3 \mu, 3 ; 3 \mu, 8 ; 4 \mu ; 5 \mu$. Les plus communs sont ceux qui mesurent de $4 \mu, \breve{s}$ à $6 \mu$.

A côté de ces globules, il y en a d'autres, qui ont reçu le nom de globules géants en raison de leurs dimensions anormales. C'est ainsi, que M. Hayem en a rencontré qui avaient jusqu'à 14u; mais en moyenne, ils n'atteignent que 10 à $12 \mu$. Leur forme est régulièrement discoïde, comme celle des globules sanguins normaux, mais en revanche, ils sont moins nettement aplatis au centre et beaucoup moins épais que les globules sanguins, à l'état normal.

M. Hayem a résumé de la façon suivante, les altérations observées dans les dimensions des globules, sous l'influence de l'anémie chronique: dans tous les cas d'anémie chronique, d'une certaine intensité, la moyenne des dimensions globulaires, est toujour's supérieure à la normale. M. Malassez a publié des observations dans les Archives de physiologie qui démontrent qu'il n'en est pas toujours ainsi.

Manassein, d'après Duval et Lereboullet, aurait constaté que la diminution dans les dimensions du globule sanguin est en corrélation, avec une suractivité pathologique de ses échanges, (fièvre) ou bien encore avec une moindre absorption d'oxygène, due à une réduction notable de l'activité respiratoire.

M. Gubler a constaté l'augmentation de volume des globules rouges, dans un cas de maladie d'Addison; M.Vulpian a retrouvé la même particularité dans un cas de cyanose cardiaque (loc. cit., p. 47), et M. Malassez dans le sang des saturnins.On a décrit un grand nombre de variétés de déformation des globules sanguins, dans différentes maladies infectieuses. Nous sommes loin de nier ces déformations, mais en considérant que dans ces cas particuliers, les globules sont en général beaucoup plus altérables, qu'à l'état normal, nous préférons ne pas insister sur les descriptions données par les auteurs (1). Sous l'influence de certains agents toxiques, on a observé la diffluence des globules sanguins. Il est très important de noter que lorsqu'il y a accumulation des acides biliaires dans le sang par le

(1) Coze et Feltz, Recherehes sur les maladies infertieuses. Par'is, 1 Si2. 
CHAP. IX. - DU SANG AU POINT DE VUE MICROSCOPIQUE. 373

fait d'ictère grave, par exemple, il y a pour ainsi dire dissolution des globules sanguins, et formation très rapide d'après Duval et Lereboullet, de cristaux d'hémoglobine.

Le globule sanguin peut encore subir des modifications, dans sa composition chimique, par la fixation de certains gaz toxiques, tels que l'acide cyanhydrique; on reconnaît ces altérarations par la spectroscopie.

$3^{\circ}$ Certains de ces globules sont également altérés, dans leur constitution chimique; c'est ainsi que les globules rouges des anémiques, sont souvent décolorés (1). Chose importante à noter, cette décoloration porte de préférence sur les globules dont les dimensions sont normales. Nous avons vu que les globules géants perdaient en épaisseur ce qu'ils avaient gagné en étendue; au point de vue de la coloration, ils sont également très inférieur's aux globules normaux. Quelquefois, dans des cas d'anémie très profonde, la décoloration porte indistinctement sur tous les globules. Ces observations ont conduit les auteurs à étudier le pouvoir colorant dı sang, c'est-à-dire la richesse du globule en hémoglobine. Ces recherches ont été faites à l'aide d'instruments spéciaux appelés Colorimètres, dont la description ne rentre pas dans notre sujet.

\section{§ 8. DE LA MÉLANÉMIE.}

On désigne généralement sous ce nom, un état particulier du sang, contenant soit des granulations pigmentaires libres, soit des globules blancs, renfermant des particules pigmentaires, ce qui est le cas le plus général.

Un grand nombre d'observateurs, font dériver les globules rouges des globules blancs, qui ne seraient pour ainsi dire que des globules rouges en voie de formation. Le professeur Rouget a observé(2), que chez la grenouille, par exemple, la matière colorante des globules, se dépose à l'état de granulations fixes, dans les globules blanes, lorsque ceux-ci vont se transformer en globules rouges. Cette matière colorante se dissolverait ensuite et colorerait uniformément le globule rouge. Cel état

(1) Donné, en 1844 , avait fait une remarque semblable.

(2) Duval et Lereboullet, p. 5i. 
intermédiaire du globule blanc, ne se rencontre ordinairement pas chez l'homme à l'état normal, et il faut que la nutrition soit troublée, par une cause quelconque, pour qu'on l'obserre dans le sang. MM. Cornil et Ranvier ont observé cette particularité, à Paris, chez des sujets atteints de fièvre pernicieuse, d'origine palustre; Virchow a fait la même observation. BrownSéquard a de nouveau retrouvé ces globules pigmentaires, dans un cas de maladie d'Addison. Kelsch, 22 fois sur 24, a trouvé ces globules pigmentés dans le sang de malades atteints de fièvre paludéenne.

Voici, d'après MM. Duval et Lereboullet, le procédé à suivre pour mettre ces globules nettement en évidence. Après avoir recueilli une goutte de sang, il faut la délayer dans une faible quantité de sérum artificiel, afin de bien isoler les globules rouges et d'éviter ainsi les amas qui masquent les globules mélanifères.

Ces particules pigmentaires, d'après Cornil et Ranvier, sunt arrondies ou anguleuses, d'un noir intense, d'un diamètre variant depuis une extrême petitesse, jusqu'à 8 ou $9 \mu$. Les auteurs ne parlent ici que des particules seules et ne comprennent pas dans leur mensuration, le globule blanc, qui les renferme. Ces globules, le plus souvent sphériques, mesurent de 7 à $15 \%$, renfermant de trois à six granules arrondis de $1 \mu$. (Duval et Lereboullet). On comprend que ces mensurations n'ont rien d'absolu et qu'elles subissent une foule d'exceptions.

Le globule blanc se comporte vis-à-ris du pigment pathologique, comme en général il le fait en présence d'une matière colorante pulvérulente et inorganique. C'est ainsi que si l'on injecte dans le sang d'un animal, du vermillon en poudre impalpable, suspendu dans l'eau, les globules. blancs s'emparent de ces fines granulations et les transpor. tent dans les organes.

\section{§ 9. altélation DES giobleEs blancs.}

Nous ne pouvons comprendre sous ce nom, les nombreuses variations numériques des globules blancs, dans divers états pathologiques, dont le plus typique est la leucocythémie. Dans 
cette affection, le nombre des globules blancs est consiaérablement augmenté, et le sang peut prendre un aspect.presque laiteux. Dans un cas observé par MM. Cornil et Ranvier, le nombre des globules blancs, dépassait celui des globules rouges. Quand on examine une préparation de sang leucémique, sans y ajouter d'eau, on voit les globules blancs, sous la forme de corpuscules granuleux, dont la dimension varie entre 7 et $12 \mu$; après addition d'eau, ces globules se gonflent, deviennent plus transparents, et l'on distingue dans les uns tantôt un seul noyau, tantôt deux, quelquefois plus (Cornil et Ranvier).

La seule altération proprement dite, qui ait été observée dans les globules blancs est la dégénérescence graisseuse (Iœderholm). MM. Charcot et Vulpian ont également observé dans un cas de leucocythose, que les globules blancs étaient infiltrés de granulations, à bords réfringents, ne se dissolvant pas dans l'acide acétique (Duval et Lereboullet) (1).

\section{$\S 10$. CRistaUX DE CHOLestérine dans te SANG.}

Voy. Cholestérine.

(1) “ Le Journal de médecine et de chirurgie pratiques, de novembre 1878 , rapporte, d'après le New-Orleans medical Journal, les constatations faites par le $\mathrm{D}^{\mathrm{r}}$ J. Jones, au sujet de taches de sang. Il s'agissait d'un meurtre commis sur un vieillard, au moyen d'un instrument contondant, qui avait amené une fracture du crâne, avec perte de sang considérable. Le coupable supposé fut arrêté, portant sur ses vêtements des taches qu'il prétendait être produites par de la peinture. Les pièces du vêtement furent envoyées au $D^{r}$ Jones, qui les examina au microscope et constata tout d'abord, que ces taches étaient bien constituées par du sang humiain; mais, de plus, il crut devoir préciser et annoncer, que le sang provenait d'un sujet qui avait eu récemment, ou qui avait encore au moment du meurtre, des atteintes de malaria. Il se fondait pour cela surtout, sur la grande quantité de globules blancs qu'on y rencontrait. Le Dr Jones, appelé devant la cour, donna une démonstration évidente de ce qu'il annonçait. Or l'enquête prouva, par de nombreux témoignages, que le vieillard assassiné, avait ì l'époque du meurtre, des accès de fièrre intermittente. Aussi la conviction des juges fut-elle complète. L'accusé dont les vêtements portaient des taclıes de sang, convaincu de son crime, fut condamné à la peine capitale. "

Cette opinion est évidemment exagérée, car le vieillard en question aurait pu avoir, dans son système sanguin, une grande quantité de globules blancs, sous l'influence de divers états pathologiques complètement différents. 


\section{$\S$ 11. INFUSOIRES CONTENUS DANS LE SANG.}

Dans certaines maladies infectieuses, spontanées ou provoquées, et même dans certains empoisonnements, on a constaté depuis longtemps la présence d’infusoires filiformes (1).

Le rôle joué par les infusoires dans ces affections, n'a pas encore été très bien déterminé et l'on a beaucoup agité la question de savoir, si ces éléments sont la cause ou l'effet de la maladie, el s'ils peuvent reproduire par introduction dans un organisme vivant, un milieu septicémique, semblable à celui dans lequel ils se sont développés.

Pour certains auteurs, les Bactéries ne seraient que des témoins d'un état putride, sans pouvoir servir à le caractériser.

Cependant quelques observations prouvent que ces infusoires, lorsqu'ils apparaissent, produisent en raison de l'exercice de leurs fonctions vitales, des troubles considérables dans l'hématose. M. Pasteur a fait sur ces différents points de la science des recherches très approfondies, dont les résultats n'ont pas encore jusqu'ici force de loi.

Pour faire avec succès l'examen de ces infusoires, il faut se servir d'un grossissement assez considérable, ऽ00 D. envil'on ; souvent même, il est nécessaire de se servir d'objectifs à immersion (Duval et Lereboullet) et l'on est forcé de recourir à l'emploi de divers réactifs pour les caractériser.

D’après M. Davaine, (Art. Bactérie, Dict. Dechambre) il est nécessaire pour distinguer les vibrioniens, de corps filamenteux ou de cristaux en aiguilles, de les soumettre à certains réactifs. L'acide sulfurique el la potasse caustique ne délruisent pas immédiatement les vibrioniens; ces filaments pâlissent, mais ils résistent longtemps, quelquefois indéfiniment, à leur action. L'iode les jaunil el les rend plus apparents. Leur mort déterminée par un changement de milieu, par une température élevée, amène en peu de temps leur destruction. Suivan ́ le conseil donné par MM. Duval et Lereboullet, on peut pour rendre l'observation plus facile, additionner le liquide d'une goutte de carmin ou de fuschine. Il faut bien se garder de confondre les

(1) Dans l'empoisonnement par la cyclamine on trouve dans le sang une grande quantité de vibrions. 
CHaP. IX. - DU SANG AU POINT DE VUE Microscopique. 379 vibrioniens avec des granulations élémentaires, que l'on rencontre parfois dans le sang, et qui ne sont que le résultat de la destruction plus ou moins complète soit des éléments du sang, soit de certains tissus (Duval et Lereboullel).

Classification des Vibrioniens. - Voici d'après M. Davaine la classification des Vibrioniens (1):

Filaments droits ou infléchis, $\left\{\begin{array}{l}\text { se tournant } \\ \text { spontanément }\end{array}\left\{\begin{array}{l}\text { rigides.... } \\ \text { flexués.... }\end{array}\right.\right.$ mais non tournés en hélice immobiles............. Bacteridium

Filaments tournés en lı́licc................. Spirillum

I. Genre Bactérie. - Corps filiforme raide, devenant plus ou moins distinctement articulé, par suite d'une division spontanée imparfaite; mouvement vacillant non ondulatoire (Dujardin).

$B$. termo, apparaît au bout de fort peu de temps dans les matières régétales ou animales en putréfaction. D'après M. Pasteur, ce vibrionien vivrait en absorbant l'oxygène des substances avec lesquelles il est en contact.

B. Cutenula, B. chaînette, ainsi nommé, parce que les filaments filiformes et cylindriques qui le forment, sont souvent assemblés par trois, quatre ou cinq. On le trouve chez les malades atteints de la fièvre typhoïde et dans certaines infusions fétides.

B. Putredinis. B. de la pourriture (Davaine), se présentent sous trois états différents. Les bactéries de la pourriture peuvent être desséchées sans périr, elles gardent alors leur vitalité pendant plusieurs mois. M. Davaine a fait, au sujet de cette bactérie, des observations fort curieuses que nous allons rap. porter : elles déterminent dans les plantes une pourriture ordinairement plus humide que celle qui est causée par le mycelium du champignon; quelquefois ce sont des ulcérations sèches.

La pourriture débute généralement par la racine et envahit ensuite toute la plante. M. Davaine l'a observée dans des végétaux à parenchyme très tendre, comme la balsamine et dans les plantes grasses trop fortement arrosées. Elle peut se trans-

(1) Voir sur le même sujet les renseignements donnés p. $29 S$ et suivantes (Première partie!. 
mettre par inoculation, aux tiges et aux feuilles d'un grand nombre de ces plantes. Gette pourriture est arrêtée par l'exposition du végétal envahi, à une température de $52^{\circ}$ cent. à วัฐ cent. (beaucoup de plantes grasses peuvent, suivant

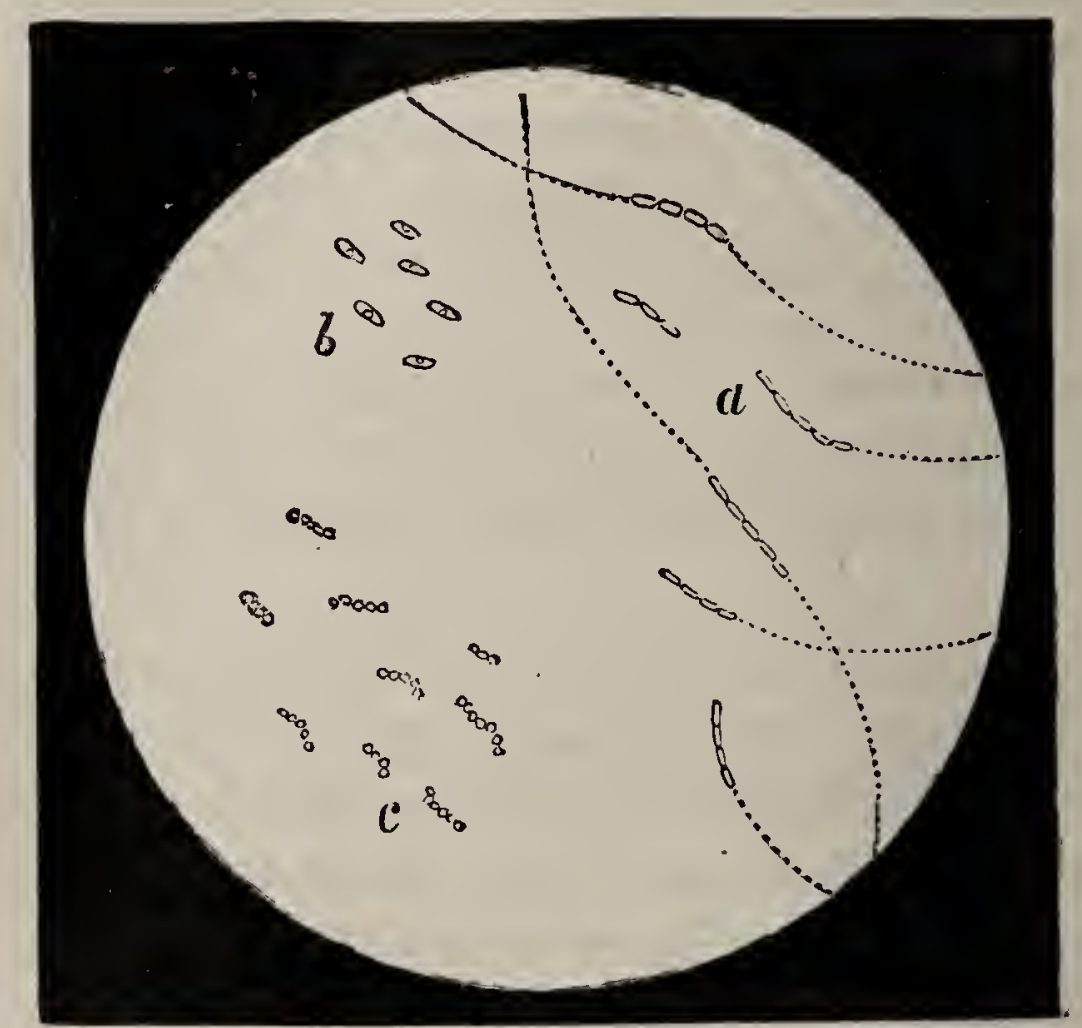

Fig. 220. - Bactéries et Vibrions. - a. Vibrio mula. - b. Bacterium putredinis. Les lignes ponctuées indiquent le chemín parcouru par les Vibrions (800 D, - P).

M. Davaine, supporter cette température sans en être altérées). Le Bacterium putredinis change de forme suivant le végétal sur lequel il s'est développé.

II. Genre Vibrion. - Corps filiforme plus ou moins distinctement articulé, par suite d'une division spontanée imparfaite, susceptible d'un mouvement ondulatoire comme un serpent (Dujardin).

Vibrio lineola. - Vibrion linéole (Müller), corps cylindri. ques, un peu renflés au milieu, deux ou trois fois plus longs que larges, assemblés par deux ou trois, en une ligne très mince, un peu flexueuse et présentant seulement deux ou trois inflexions. On les a rencontrés dans des infusions régétales, ainsi que dans le pus des chancres de la verge et de la rulve (Donné).

Vibrio Rugula (Müller). - Vibrion Rugule. Corps diaphanes, 
CHAP. IX. - DU SANG AU POINT DE VUE MICROSCOPIQUE. 381

en fils alternativement ủroits ou flexueux de cinq à huit inflexions se mouvant avec vivacité en ondulant ou en serpentant; a été trouvé dans les matières intestinales de l'homme (Leeuwenhoeck) et dans les déjections des cholériques (Pouchet).

On trouve le Vibrion baguette (Vibrio bacillus) dans la matière blanche qui s'amasse autour des. dents (Leeuwenhoeck), ainsi que dans les intestins de différents mammifères (Davaine).

Le Vibrion lactique (1) (Pasteur), en raison de son importance sera décrit à l'article Lait. Si nous avons donné ici la description très succincle, de quelques vibrions autres que ceux que l'on rencontre dans le sang, c'est dans le but de conserver à ce chapitre si spécial des vibrioniens, plus d'homogénéité.

III. Cenre Bactéridie (Davaine) Bacteridium - Corps filiforme, droit ou infléchi, plus ou moins distinctement articulé, par suite d'une division spontanée imparfaite, toujours immo. bile.

I. Bactéridie charbonneuse (Davaine). - Filaments droits, roides, cylindriques, quelquefois composés de deux, trois et très rarement quatre segments, offrant alors des inflexions à

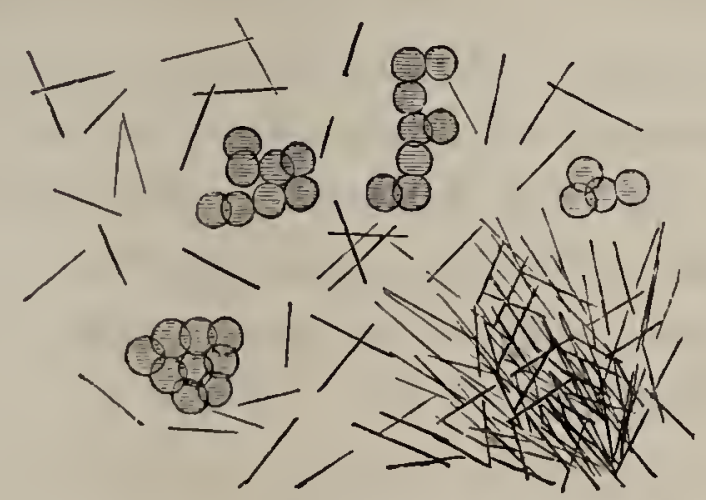

Fig. 221. - Sang charbouneux.

angles obtus, en rapport avec les articles; très minces relativement à la longueur. Dans la pustule maligne, les filaments simples ont jusqu'a $0^{\mathrm{mm}}, 01$ de longueur, dans le sang des gros vaisseaux; ils sont ordinairement courts et atteignent leurs plus grandes dimensions dans la rate.

On peut distinguer les Bactéridiés, des cristaux en aiguilles

(1) V. p. 300. Première partic. 
par leur résistance à l'aclion de la potasse caustique et de l'acide sulfurique; on les distingue des vibrioniens qui se forment-dans le sang putréfié, à ce que ceux-ci sont doués de mouvements spontanés; en outre, les Bactéridies charbonneuses se détruisent par la putréfaction. Les Bactéridies existent principalement dans les vaisseaux capillaires, surtout dans ceux du foie et de la rate. Elles semblent quelquefois rares dans le sang du cœur, mais on les trouve alors en grande quantité, dans des concrétions fibrineuses placées le plus souvent entre les colonnes charnues ou dans les oreillettes. Elles se déreloppent aussi dans le corps muqueux de la peau de l'homme, constituant la pustule maligne (1).

M. Davaine a également décrit les Bacté:idies intestinales (V. Matières fécales).

IV. Genre spirillum (Ehrenberg). - Corps filiforme contourné en hélice non extensible, quoique contractile (Dujardin).

L'article de M. Davaine contient sur.ce genre des délails fort intéressants; nous y renvoyons le lecteur qui voudrait de plus amples développements sur ce sujet.

Nous ne voulons pas davantage entrer dans l'examen du rôle physiologique des Vibrioniens : ce serait d'abord sortir du cadre de cet ouvrage, et de plus on peut dire que cette question est encơre à l'étude. Des conclusions différentes sont chaque jour fournies par des hommes éminents, et il nous paraît sage d'attendre que l'accord se fasse sur ces questions si difficiles et si importantes.

\section{$\S 12$. hématozoaires de L'HOMMe.}

Tout ce qui suit a été emprunté au bel ouvrage de M. Davaine, qu'il faut toujours consulter chaque fois que l'on veut déterminer les parasites de l'homme ou ceux des animaux (2).

On ne connaît pas en Europe d'entozoaire qui fasse son sé-

(1) Voir Bulletin de l'Académie de médecine, Communications de MI. Pasteur et Colin. Séance du 30 avril 1878.

(2) Traité des entozoaires et des maladies vermineuses de ihomme et res animaux domestiques, par C. Davaine. Paris, 187 . 
jour normal dans le sang de l'homme, mais en Égypte on a très souvent constaté, 117 fois sur 363 autopsies, la présence d'un ver du genre distome que l'on rencontre fréquemment dans les vaisseaux des organes abdominaux.

Nous devons faire ici une remarque générale, à propos des hématozoaires, nous parlerons souvent de leur présence et de l'apparition de leurs œufs dans l'urine. Il nous a semblé plus naturel de signaler au moins ces faits dans ce chapitre plutôt que de les reporter à l'article Urine. C'est ainsi que les œufs du distome hcematobie, se rencontrent souvent dans l'urine des sujets qui portent ce parasite (V.la description dans Davaine, p. 319, et chapitre des Parasites). Ce n'est pas impunément, que la ressie peut renfermer de ces œufs. On les a vus, en effet, constituer le noyau de graviers ou de pierres, dont les couches extérieures sont formées d'acide urique. Ces graviers se rencontrent dans les reins, dans l'uretère et dans la vessie. Lorsqu'on se trouvera en présence d'une hématurie, ou de symptômes du côté des reins et de la vessie dont on n'aura pas l'explication, il sera prudent de rechercher la présence des ovules du distome hæmatobie, soit dans les urines, soit dans les matières fécales (1).

Le distome hépatique, ainsi que cela a été démontré par quelques observations concluantes, peut être rencontré accidentellement dans les vaisseaux sanguins de l'homme. Quelquefois, ces distomes, comme l'a observé M. Davaine, entraînés par le torrent circulatoire, sont arrêtés dans les capillaires. soit à la tête, soit aux pieds. Leur présence détermine l'apparition d'une petite tumeur, formée selon toute apparence, par l'animal lui-même gorgé de sang, ou par des caillots sanguins (V. Parasites).

Les états intermédiaires de ces parasites peuvent également se rencontrer dans les divers liquides de l'économie.

On a également constaté la présence dans l’Inde, d'Hématozoaires nématoïdes, existant soit dans le sang, soit dans l'urine, a dilférents états de développement. Ces parasites produisent

(1) Outre l'hématurie simple, accompagnée ou non de gravelle urique, le distome hæmatobie donne lieu également à l'urine chyleuse ou albuminograis seuse. 
des désordres plus ou moins graves. Le $\mathrm{D}^{\mathrm{r}}$ Lewis qui les a découverts leur a imposé le nom de Filaria sanguinis hominis (fig. 222); mais, d'après M. Davaine (loc. cit., p. 949), aucun des caractères de ces helminthes, ne prouve qu'ils appartiennent aux

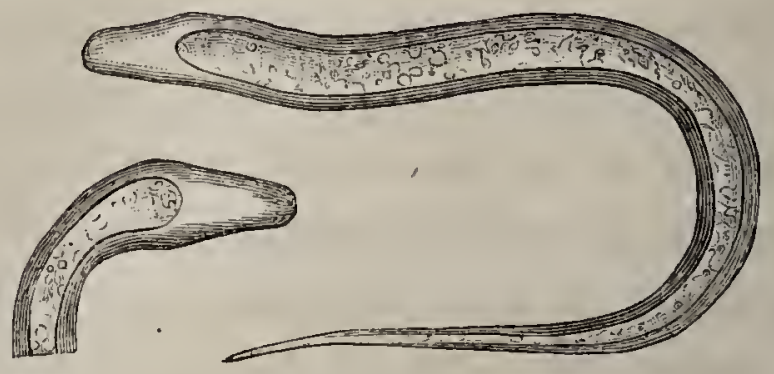

Fig. 229. - Filaria sanguinis hominis.

Filariens. Ces entozoaires, d'après Lewis, ont la forme de petits serpents, qui s'agitent vivement sans avancer, parmi les corpuscules sanguins. Leur corps est cylindrique, très long et très aminci à l'extrémité postérieure.

Particularité digne de remarque, ces vers sont enveloppés dans un tube très délicat, fermé aux deux bouts, dans l'inténieur duquel ils peuvent s'allonger et se rétracter, même jusqu'à la moitié de leur longueur. Ce tube, parfaitement transparent, dépourvu de structure apparente, ne se distingue du liquide ambiant que par sa réfringence.

Ces,parasites sont très communs chez les animaux dómestiques. Nous renvoyons à l'ouvrage de M. Davaine, qui en a fait une étude complète.

\section{\$ 13. DES GLOBULES DANS DIFFÉRENTES ESPÈCES ANIMALI:S.}

Les notions qui vont suivre ont une grande utilité, au point de vue de la détermination de l'origine des globules sanguins. En médecine légale, il est de la plus haute importance de savoir, si, par exemple, une tache de sang provient d'un mammilère ou d'un oiseau. Ce n'est pas que les globules du sang che\% les mammifères ne présentent pas des caractères distinctifs, faciles à constater à l'état frais, mais il faudrait bien se garder de se contenter de la mensuration des globules pour conclure, parce que, ainsi que nous l'avons vu, sous des influences di- 
CllaP. IX. - DU SANG AU POINT DE VUE MICROSCOPIQUE. 385 verses, les globules sanguins peuvent affecter des formes différentes. Leur facile altérabilité au contact des liquides, de l'air, doit rendre l'observateur très circonspect.

Chez presque tous les mammifères, les globules sanguins sont circulaires; les chameaux et les lamas font exception a cette règle, car leurs globules sanguins sont elliptiques. Leurs dimensions sont très variables. Chez quelques animaux, tels que le chien et le lapin, il y a peu de différence avec les glo-

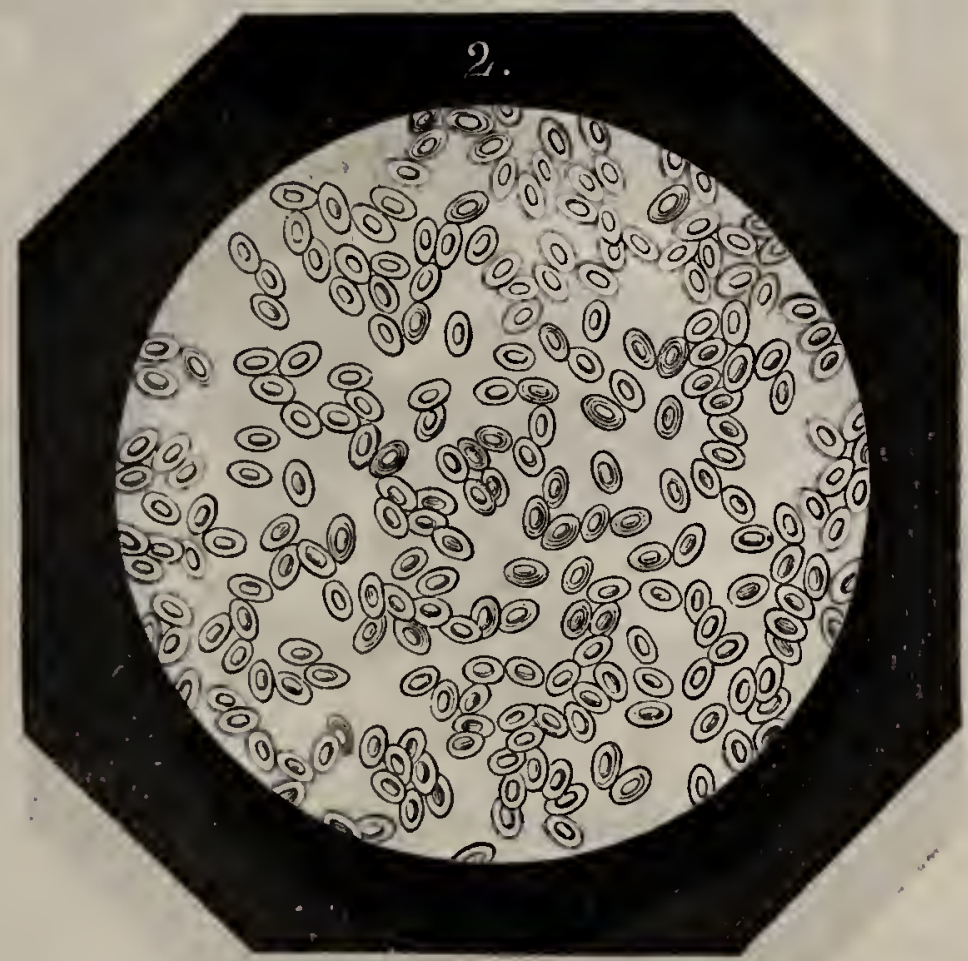

Fig. 223. - Globules sanguins des oiseaux.

bules rouges de l'homme, et leur diamètre est égal environ $\grave{a} \frac{1}{124}$ de millimètre; chez la chèvre, ils n'ont plus qu'un $\frac{1}{250}$ de millimètre; enfin chez le chevrotain ils n'atteignent plus qu'environ $\frac{1}{480}$ de millimètre (Milne-Edwards). Voici d'après Koelliker, le chilfre exact de quelques mensurations.

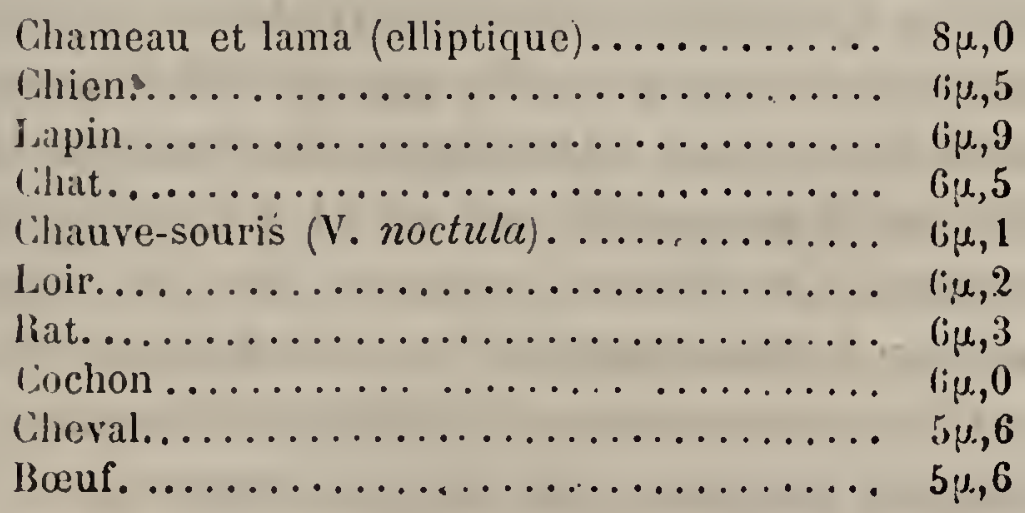




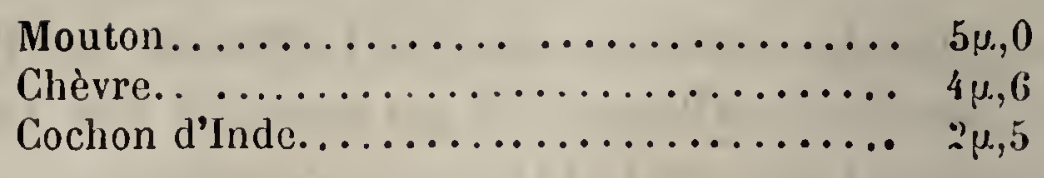

Rarement les corpuscules sanguins sont plus gros que ceux de l'homme, cépendant, ceux de l'éléphant mesurent $9 \mu, 4$.

Les globules sanguins des oiseaux sont elliptiques, et munis d'un noyau arrondi. Ils ont de 12 à $14 \mu$ de longueur; 6,5 à $8 \varkappa$ de largeur (fig. 224).

Les globules sanguins des poissons sont également ellipti-

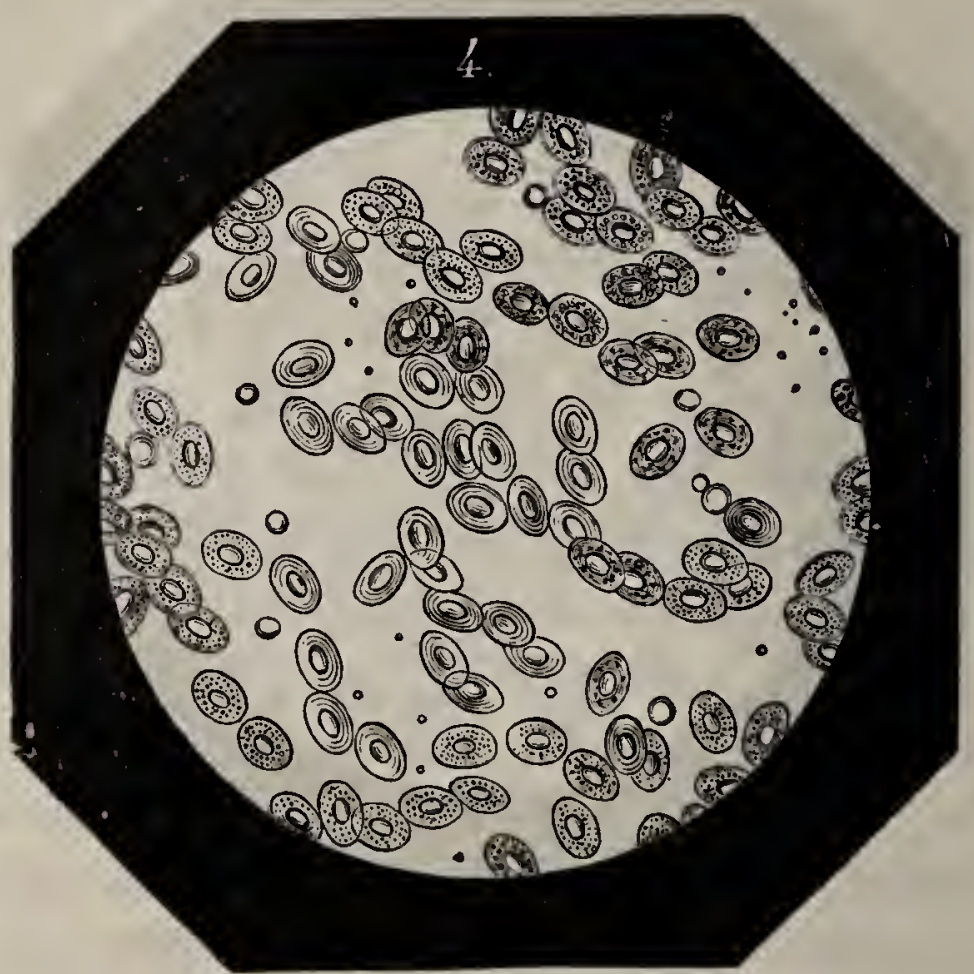

Fig. 2ュ4. - Globules sangruins des poissons.

ques et ont un noyau (fig. 224). Ils sont plus volumineux que

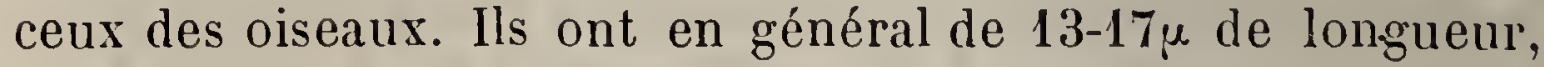
ceux des Plagiostomes, mesurent de 22 à $33 \mu$; ceux des Lépidoriens ont $41 \mu$ en longueur et 29 en largeur.

C'est chez les Amphibies nus et les reptiles, que l'on rencontre les globules les plus gros. Ils ont de 15 à $58 \mu$ en longueur et renferment des noyaux sphériques et elliptiques (Kœlliker). Les globules de la grenouille ont de 21 à $22 \mu$ de longueur sur 亏ั5 $\mu$ de largeur. Le Triton cristatus $29 \mu$ de longueur sur $19 \mu$ de largeur; Salamandre $37 \mu$ de longueur sur $23 \mu, 8$ de largeur. Le Proteus anguineus a des globules énormes, puisqu'ils mesurent $58 \mu$ de longueur, sur $35 \% \mu$ de largeur. 
CHAP. IX. - DU SANG AU POINT DE, VUE MIGROSCOPIQUE. 387

Les globules sanguins des invertébrés ressemblent aux glo-

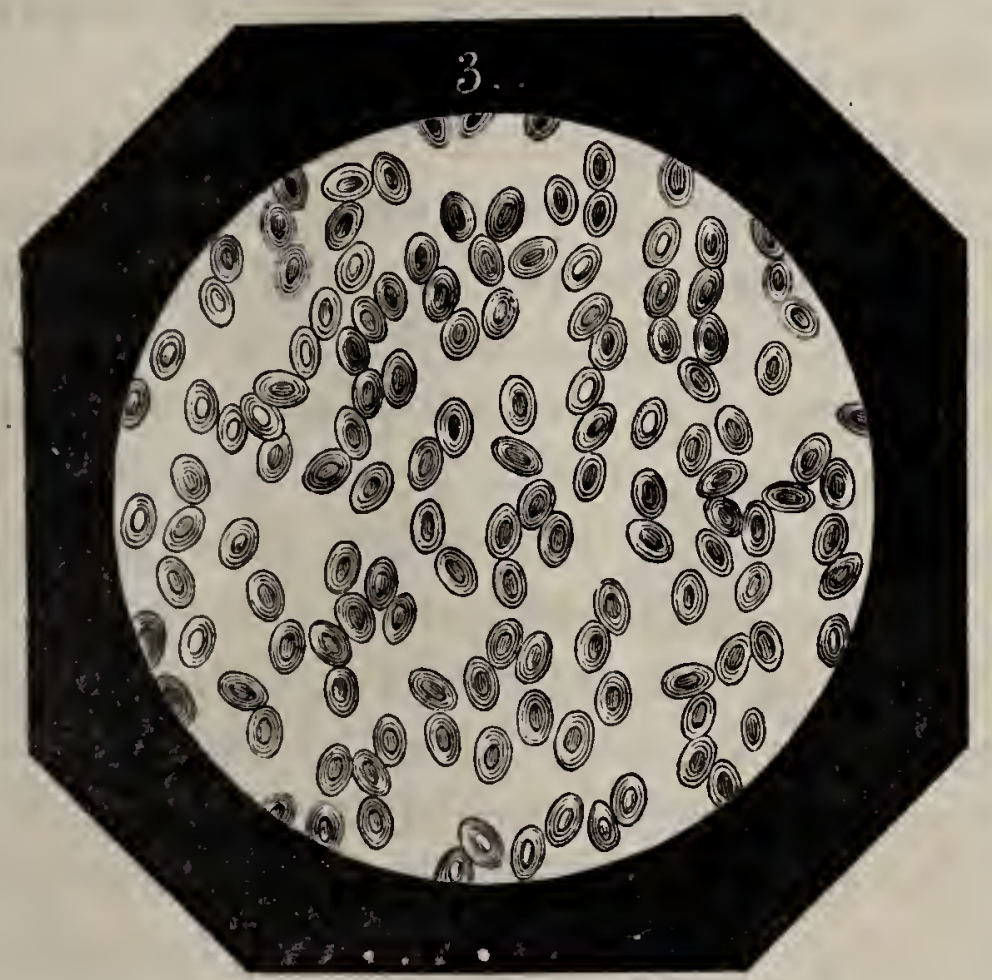

Fig. 225. - Globules sanguins des reptiles et des amphibies.

bules blancs des animaux supérieurs et sont presque toujours incolores.

\section{S 14. DU SANG EXTRAVASÉ.}

Lor'sque le sang, par une cause quelconque, a été rejeté en dehors de la circulation, ses principaux éléments subissent des modifications, plus ou moins profondes, suivant que le sang chassé des vaisseaux, est resté emprisonné dans les organes et soustrait à l'action de l'air, ou suivant qu'il a été répandu au dehors. Nous plaçant dans la première hypothèse, nous allons rapidement étudier les altérations que l'on rencontre le plus souvent. Nous avons vu que la plasmine se dédoublait et qu'il $y$ avait formation d'un caillot. Suivant que cette coagulation s'est accomplie avec lenteur ou avec rapidité, le caillot présente un aspect. différent. Dans le premier cas, en vertu de leur poids spécifique, les globules du sang ont gagné la partie la plus déclive de la cavité qui les renferme, et la fibrine, en se rétractant, n'en a retenu que peu ou point. $\mathrm{Si}$, au contraire, celte coagulation s'est effectuée rapidement, la fibrine a emprisonné les globules. 
Comme le fait observer M. Robin, le caillot, ferme dans le premier cas, est mou dans le second ; parce qu'alors il y a plus de globules que de fibrine.

Nous avons vu quels étaient les caractères présentés par la fibrine dans les caillots, mais lorsque le coagulum sanguin s'est formé au contact des parois d'une veine enflammée, la fibrine ne présente plus l'état fibrillaire, elle prend alors l'aspect grenu, et tend à se ramollir plus rapidement que lorsqu'elle est à l'état strié (Robin). Cette grande facilité de ramollissement, a pu faire croire à la présence du pus dans les caillots. L'examen microscopique démontrera que l'on a sous les yeux de la fibrine réduite à l'élat de granulations moléculaires, en suspension dans le liquide. C'est ce que M. Robin appelle le pseudo-pus fibrineux. Quand on trouve des leucocytes dans ces conditions, c'est qu'ils préexistaient dans la veine, dans le cas de phébite par exemple, et qu'ils ont été emprisonnés par la fibrine.

Nous avons vu que, dans le cas de formation lente du caillot, la fibrine n'emprisonnait pas les globules, et qu'on avait alors des caillots incolores; toutefois, il est important de savoir qu'un coagulum formé dans des conditions différentes pourrait à la longue devenir également incolore, par la résorption lente des hématies (Robin).

Quand le sang a séjourné dans une cavité close, il ne tarde pas à prendre une coloration rouge-groseille (Robin). Les hématies se sont ramollies, et leur oxygène a été remplacé par de l'acide carbonique. Elles ont perdu la forme de disque et ont pris l'aspect sphérique. Le caillot tend alors à revêtir une coloration se rapprochant de la couleur de la rouille, et ensuite une coloration jaunâtre, analogue à celle de l'ocre. Les changements de coloration, dit M. Robin, sont la conséquence d'un commencement de séparation de l'hématosine des globules (V. plus loin les détails que nous donnons sur la composition chimique de la matière colorante du sang); on trouve même des granules d'hématosine, arrondis ou ovoïdes, qui sont épars entre les fibrilles du caillot, et pénètrent même dans les éléments des tissus ambiants.

La fibrine persiste plus ou moins longtemps, suivant le 
CHAP. IX. - DU SANG AU POINT DE VUE MICROSCOPIQUE. : \&9

milieu qui la renferme. C'est ainsi que la fibrine et les hématies disparaissent rapidement dans le tissu de l'ovaire, tandis

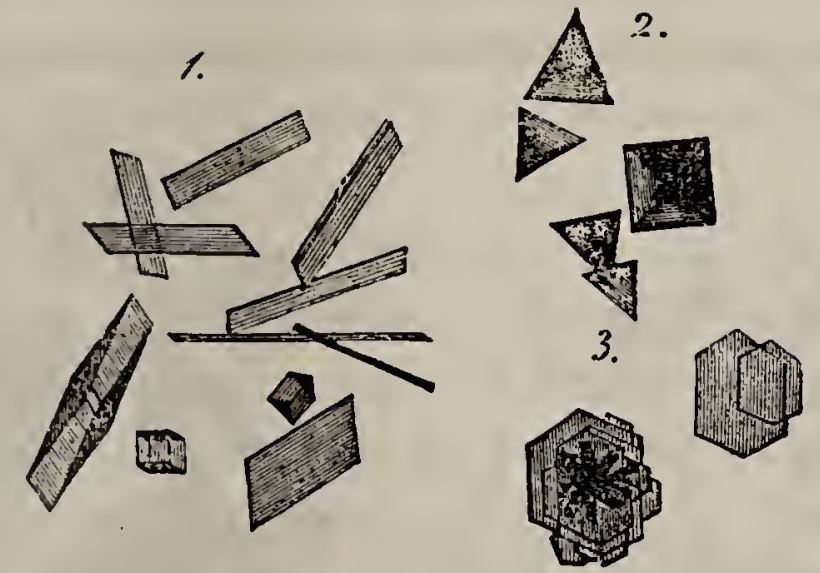

Fig. 226. - Cristaux extraits du sang frais (d'apres Funkc). - 1. Cristal prismatique de l’honme. - $\%$. Télraèdre du cuchon d'Inde. - 3. Plaques hexaédriques de l’écureuil.

que dans le cerveau, les hématies s'étant rapidement résorbées, la fibrine peut conserver pendant dix-huit mois au moins, son aspect fibrillaire.

Avant d'étudier maintenant comment on pourra reconnaître la présence du sang épanché hors de l'économie et adhé-

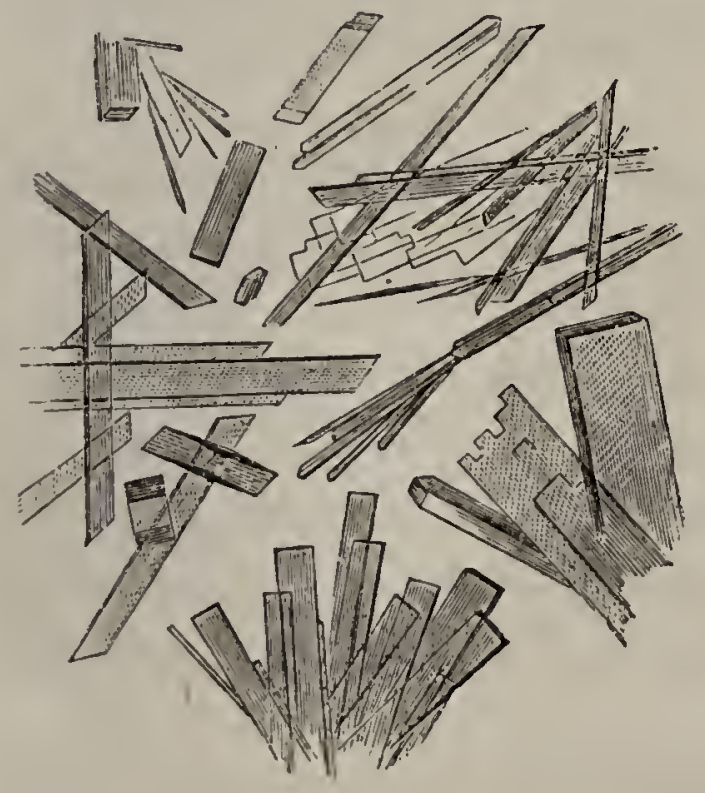

Fiğ. 227. - Hématocristalline (homme).

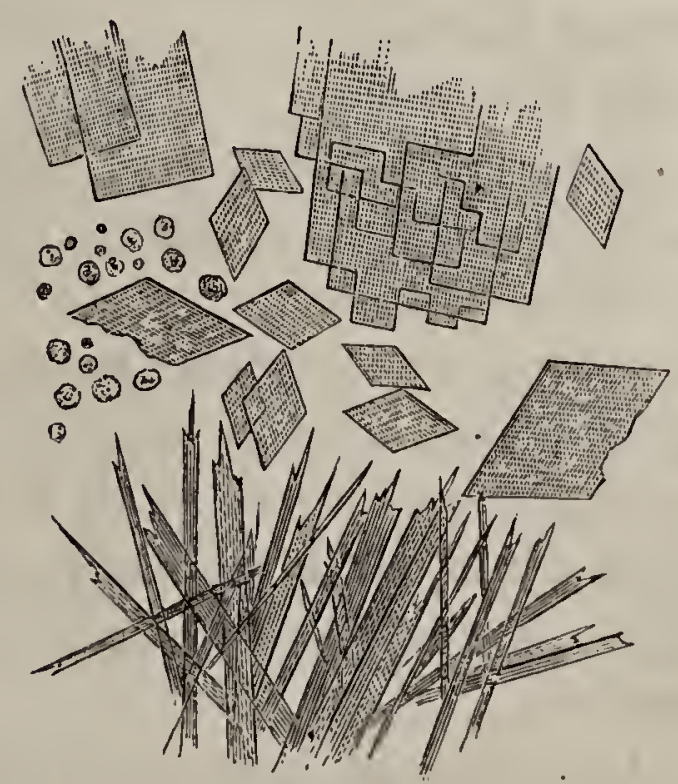

Fig. 228. - Hématocristalline (homme). Cristaux prismatiques.

rant soit à des vêtements, soit à tout autre objet, nous devons rappeler en peu de mots quelle est la constitution chimique du globule sanguin.

L'hémoglobine ou hématocristalline constitue la matièrc colorante du globule sanguin; suivant que ce corps a été retirć du sang d'espèces animales différentes, il présente des variétés 
dans la forme cristalline. Par sa composition, l'hémoglobine se rapproche des matières albuminoïdes, mais elle s'en écarte par le fer qu'elle contient et par la facilité avec laquelle elle cristallise. Lorsque, placée dans les conditions que nous avons

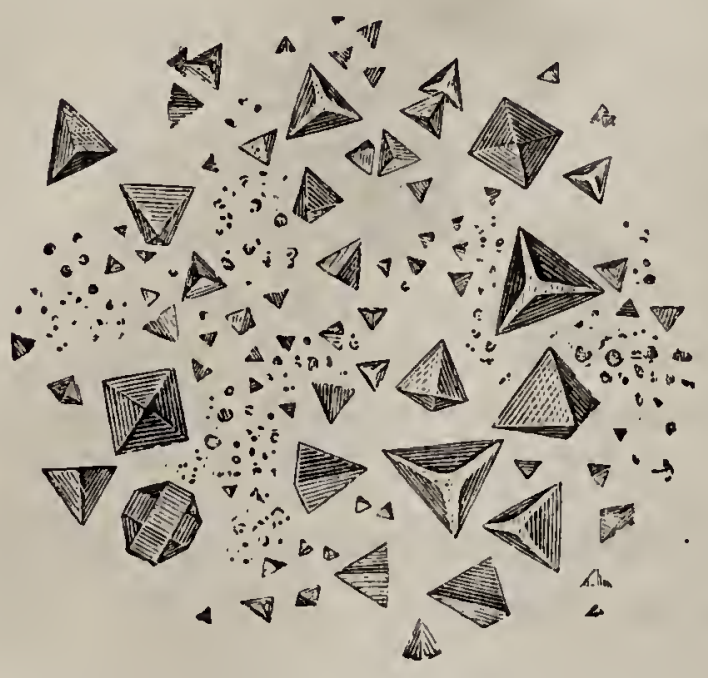

Fig. 229. - Hématocristalline (cochon d'Inde). Tétraèdres.

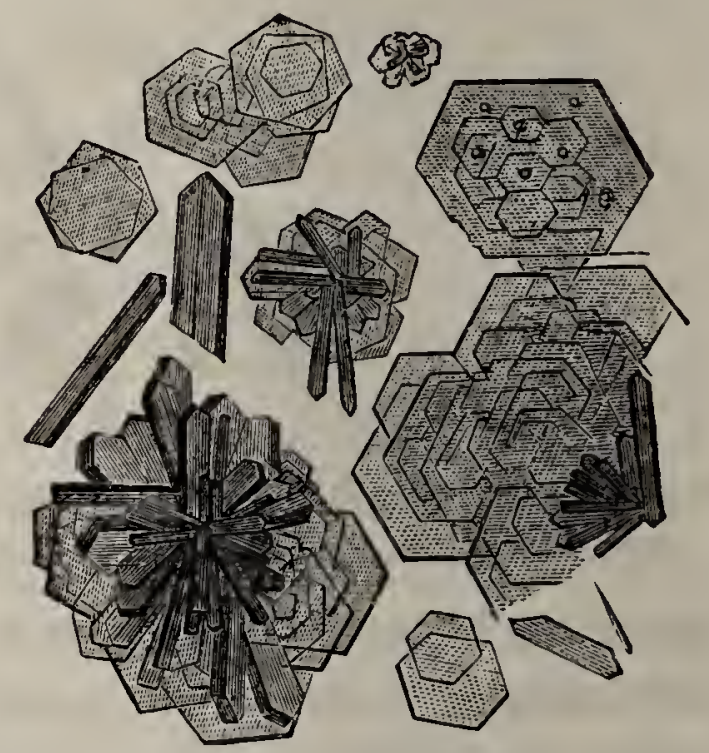

Fig. 230. - Hématocristalline (écureuil). Plaques hexaédriques.

cxaminées précédemment, l'hémoglobine se décompose, elle donne naissance à une substance albuminoïde que l'on appelle hématine.

Les cristaux d'hémoglobine sont colorés en rouge et appartiennent au système rhombique. Il $\mathbf{y}$ a une exception pour les cristaux provenant du sang de l'écureuil, qui appartiennent au système hexagonal (Gorup-Besanez). L'hémoglobine est soluble dans l'eau, mais sa solubilité varie suivant les espèces de sang dont elle a été extraite. Les cristaux d'hémoglobine, provenant du sang humain, sont parmi les plus solubles; ceux extraits du sang du cobaye le sont fort peu.

Les solutions aqueuses d'hémogglobine, se décomposent très facilement au-dessus de $0^{\circ}$.

L'hémoglobine est soluble dans les alcalis et dans les carbonates alcalins très étendus. L'ammoniaque en solution très étendue la dissout également. D'après le traducteur de Gorup-Besanez, le docteur L. Gautier, les cristaux d'hémoglobine sont solubles dans l'urine normale, dans les solutions albumineuses très étendues, dans les liquides séreux, dans la bile, dans la glycérine aqueuse et dans certains sels neutres; 
CHAP. IX. - DU SANG AU POINT DE VUE MICROSCOPIQUE. 391

ils sont insolubles dans l'alcool, l'éther, la benzine, les huiles grasses, dans le chloroforme, dans l'alcool amylique et dans le sulfure de carbone. Ils peuvent se conserver longtemps dans l'alcool absolu, sans changer notablement de forme ; mais perdent leur couleur, leur éclat et leur pouvoir bi-réfringent (L. Gautier).

D'après Preyer' (V. Gorup-Besanez, p. 106), pour obtenir rapidement des cristaux d'hémoglobine, afin de les soumettre à l'examen microscopique, on mélange quelques centimètres cubes de sang défibriné, avec une quantité d'eau suffisante, pour que le mélange donne une solution limpide, souvent une goutte de celle-ci, recouverte par le couvre-objet, fournit immédiatement, en l'évaporant à froid, des cristaux d'hémoglobine. Dans le cas contraire, on ajoute à la dissolution environ $1 / 4$ de son volume d'alcool, et l'on place le mélange dans une capsule de platine ou d'argent, contenant un mélange réfrigérant.

Ce serait sortir de notre cadre que de parler des propriétés optiques de l'hémoglobine. Nos lecteurs savent quel parti on a tiré pour la détermination du sang, de la propriété que possède l'hémoglobine de fixer l'oxygène, et de donner ainsi un spectre particulier. Nous renvoyons aux traités dẻ physique et de chimie biologique, pour tout ce qui concerne cette question.

On a trouvé des cristaux d'hémoglobine dans le tube intestinal de certains animaux qui se nourrissent de sang, et en particulier dans celui de la sangsue (Rouget). On en avaiı déduit, en ce qui regarde la sangsue, que, d’après les caractères différents, revêtus par les cristaux d'hémoglobine, on pourrait reconnaître l'espèce animale sur laquelle la sangsue avait vécu. Mais, d'après M. Vaillant, celte détermination serait plus que problémalique, en raison du temps considérable que les sangsues mettent à éliminer le sang qu'elles ont absorbé.

L'hématine est un produit de décomposition de l'hémoglobine, dont elle diffère par l'absence de globuline. Elle est considérée comme la matière colorante propre du sang. L'hématine diffère encore de l'hémoglobine par ses qualités optiques, et l'on a mis cette précieuse propriété à profit, pour déterminer 
l'existence de petites quantités de sang, altéré ou ancien. L'hématine se forme spontanément dans le sang épanché accidentellement dans les tissus. On en trouve également dans les matières fécales, lorsque du sang a traversé le tube digestif.

Lorsque le sang a longtemps séjourné dans un vase, on y trouve également des granulations d'hématine. Ce corps n'est pas cristallisé. Voici, d'après M. Robin, ses principaux caractères: "Il se présente sous forme de granulations amorphes, d'un rouge foncé. presque noir, insolubles dans l'eau, la glycérine, l'alcool, l'éther, la soude, la potasse, l'ammoniaque, les acides acétique, azotique, chlorhydrique. L'acide sulfurique, placé directement et sans addition d'eau sur ces globules, les dissout en colorant en rouge jaunâtre le réactif et le tissu examiné; cette action met de quinze à vingt minutes à se produire; puis, au bout de quelques heures, la coloration disparaît en passant au violet bleuâtre, puis verdâtre plus ou moins foncé (Ch. Robin). " Ces propriétés négatives seraient insuffisantes pour caractériser microscopiquement l'hématine, aussi a-t-on recours à un artifice qui consiste à la convertir en chlorhydrate d'hématine, qu'or appelle improprement hémine.

Le procédé le plus certain, pour obtenir ces cristaux de chlorhydrate d'hémaline, consiste à dessécher du sang ou un liquide, qui est supposé en contenir et à le chauffer avec de l'acide acétique cristallisable et une trace de chlorure de sodium. Lorsque l'évaporation est complète, on aperçoit des cristaux, appelés d'abord cristaux de Teichmann, dn nom de l'auteur qui a découvert cette réaction. On peut également obtenir ces cristaux par d'autres méthodes, par exemple, en traitant le sang par de l'éther alcoolisé, contenant de l'acide acétique ou de l'acide oxalique (V. Gorup-Besanez, p. 111). Ces cristaux se présentent sous forme de lamelles rhombiques, ordinairement très petites; elles sont d'un brun noir ou rouge-brun; quelquefois, elles ont aussi la forme d'aiguilles rhombiques apla. ties et fréquemment croisées.

Voici les principales réactions des cristaux d'hémine :

Ils sont insolubles dans l'eau, l'alcool et l'éther, ainsi que dans le chloroforme. 
CIIAP. IX. - DU SANG AU POINT DE VUE MICROSCOPIQUE. 393

L'acide chlorhydrique, l'acide acétique, n'exercent à froid aucune action sur les cristaux; à chaud, ils les dissolvent en partie. L'acide azotique ne les attaque pas à la température ordinaire, tandis qu'au-dessus de $\mathbf{1 0 0}$ degrés, ces cristaux son complètement décomposés. L'acide sulfurique étendu est

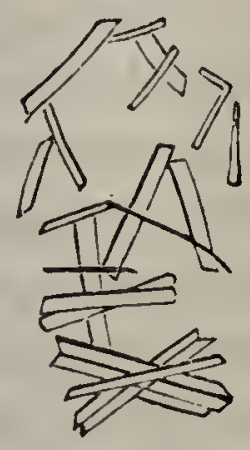

Fig. 231. - Cristaux d'hémine provevenant d'une tache de sang frais.

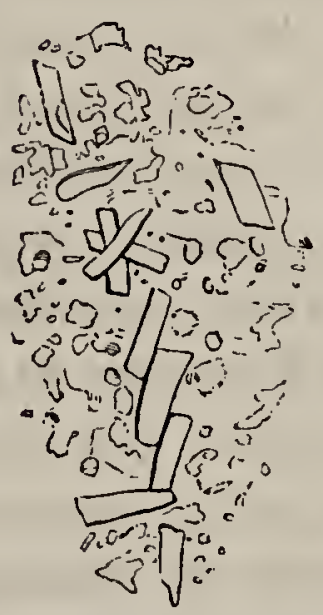

Fig. 232. - Cristaux d'hémine provenant d'une tache de sang ancien.

sans actión sur eux, l'acide sulfurique concentré les dissoul, au contraire, à la température ordinaire et la solution prend une coloration rouge-violet.

Le carbonate de soude en solution aqueuse et étendue est sans action sur l'hémine, qui est dissoute, au contraire, par les alcalis caustiques. L'ammoniaque dissout ces cristaux sans les décomposer.

Desséchés, ou suspendus dans un liquide incolore, ils se présentent sous forme d'une masse bleu noirâtre, chatoyante, à éclat métallique, paraissant brune par transparence. Lorsqu'on frotte ces cristaux sur de la porcelaine, ils laissent sur celle-ci une empreinte brune. Les réactions qui précèdent sont empruntées à l'ourrage de Gorup-Besanez.

Nous avons fait pressentir tout à l'heure l'importance des réactions de l'hématine envisagée au point de vue de la médecine légale, nous allons donner maintenant la marche à suivre pour mener à bien ces délicates recherches.

M. le $\mathrm{D}^{\mathrm{r}} \mathrm{P}$. Cazeneuve, dans son remarquable travail sur l'hématine (1), a étudié avec beaucoup de soin tous les détails

(1) Recherches de chimie médicale sur l'hẻmatine. Paris, G. Masson. 1876. 
de cette opération. Nous allons résumer ses indications. Étant donnée une tache, dit M. Cazeneuve, que l'on soupçonne être du sang, l'expert découpera le tissu sur lequel elle se trouve et raclera avec précaution la surface de l'objet que l'on suppose avoir été taché de sang. Ces parcelles ont un aspect variable suivant leur origine; on les dépose dans un. petit tube, dont la partie inférieure a été effilée à la lampe et fermée. On introduit de l'eau dans ce tube un peu audessus de la partie effilée. Au contact de l'eau, lorsque les particules recueillies proviennent réellement d'une tache de sang, la matière colorante, la matière albumineuse, et un petit flocon fibrineux se détachent. On caractérisera la fibrine par ses réactions, et l'on pourra rechercher la présence de l'hémoglobine, par le spectroscope. Nous laissons ce point de côté.

Pour mettre en évidence les cristaux de chlorhydrate d'hématine, on opère de la façon suivante : on prend un tube que l'on effile à la lampe, sur une longueur d'un centimètre, de telle façon que la partie rétrécie du tube retienne l'eau par l'effet de la capillarité. On verse de l'eau distillée dans le tube, en s'arrêtant un peu au-dessus de la partie renflée de celui-ci. Le fragment de tissu supportant la tache, ou les particules recueillies à la surface d'un objet quelconque, sont mis dans le tube, en contact avec l'eau distillée. Après quelques instants de macération, on voit se détacher de la surface du liquide, des stries de matière colorante qui le teintent en se diffusant. Soufflant alors par la grosse extrémité du tube, on dépose une goutte de ce liquide sur la lame porte-objet, puis on y ajoute une goutte de solution de chlorure de sodium à $1 / 1000^{\circ}$. Ceci fait, on évapore doucement presque à siccité. Il faut éviter de chauffer trop, afin que le liquide ne se trouble pas par la coagulation de l'albumine qui entraverait la formation des cristaux. On recouvre la faible quantité de liquide restée sur la lamelle de verre, par une plaque couvre-objet et on fait pénétrer, entre les deux lamelles, une goutte d'acide acétique cristallisable. On chauffe arec précaution jusqu'à ćbullition, et l'on regarde au microscope. Si l'on ne voit pas de cristaux, on répète le traitement par l'acide acétique et, grầce à cette précaution, les cristaux caractéristiques d'hémine, 
ou de chlorhydrate d'hématine apparaissent, quand la tache traitée était réellement formée par du sang. Dans le cas où les cristaux ne se formeraient pas, M. Gazeneuve conseille de répéter une troisième fois le traitement par l'acide acétique, comme il a été dit plus haut.

Voici quelles sont 'les conditions préalables pour que cette réaction réussisse; il faut éviter d'employer un excès de chlorure de sodium, dont la cristallisation en masse englobel'ait la matière colorante. L'acide acétique doit être monohydraté, de telle sorte que la décomposition du chlorure de sodium soit plus rapide. L'emploi d'un acide trop dilué peut faire complètement échouer l'opération. Avant de faire pérée trer l'acide acétique entre les deux lamelles, il faut préalablement avoir fait évaporer l'eau, au moins en partie, afin qu'au contact d'un excès d'eau, l'acideacétique ne s'hydrate pas trop.

Si le sang, en raison d'un commencement de putréfaction, était très alcalin, il faudrait saturer cet excès d'alcalinité par de l'acide acétique, avant de faire évaporer le liquide sur la lamelle porte-objet.

Lorsque le sang a été coagulé antérieurement à la recherche, il faut immédiatement traiter la tache par l'acide acétique et la chaleur, de manière à dissoudre la matière albuminoïde. On ajoute ensuite une goutte de solution de sel marin à $1 / 1000^{e}$, et l'on évapore comme précédemment, jusqu'à siccité. On recouvre de la lamelle et l'on fait intervenir l'acide acétique cristallisable.

Les cristaux une fois obtenus, on les déterminera par leur forme, et leurs principales réactions.

Lorsqu'on n'a à sa disposition qu'une très pelite tache de sang, on supprime l'artifice du tube eflilé, et l'on agit directement sur la tache portée sur la lamelle porte-objet. Quand le tissu a abandonné la matière colorante, on ajoute une très faible quantité de la solution titrée de chlorure de sodium, et l'on poursuit la série d'opérations comme il a été dit.

On doit se servir pour cette recherche d'un grossissement de trois cents diamètres environ, parce que ces cristaux sont quelquefois très petits.

Aucune autre substance que l'hématine ne peut donner 
des crislaux semblables à ceux que nous venons de décrire. Des tissus teints avec de l'indigo, traités par de l'acide acétique, donment également des cristaux, mais ceux-ci sont colorés en bleu, et leur forme est tout à fait différente (GorupBesanez, p. 416).

Lorsque le sang est épanché en dehors des vaisseaux et qu'il séjourne dans un espace clos, l'hématine subit une modification dans sa composition et dans sa forme, et l'on a alors l'hématoïdine. Ce corps diffère de l'hématine, en ce qu'il renferme un équivalent d'eau en plus, et un équivalent de fer en moins.

D'après MM. Duval et Lereboullet, l'hématoïdine se pré-

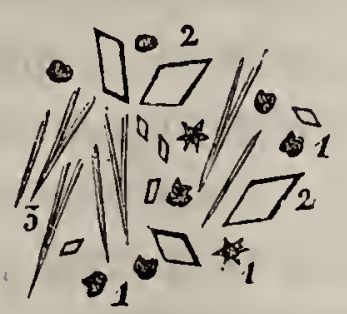

Fig. 233. Ciristaux d'hématoïdine. -1 . Globules rouges granuleux. - 2. Prismes rhomboédriques d'hématödine. - 3. Aiguilles cristillines. sente sous forme de cristaux trè̀s petits, prismes rhomboïdaux obliques, ou parfois de fines aiguilles, de couleur très pure, jaune rougeâtre, ou rouge de rubis, quand ces cristaux sont ou plus volumineux ou superposés; ils sont insolubles dans l'eau, l'alcool, l'éther, la glycérine, l'acide acétique; solubles dans l'ammoniaque. Les acides azotique ou chlorhydrique concentrés, dissolvent ces cristaux; étendus d'eau, ils n'ont plus d'action sur eux. La potasse et la soude ne les dissolvent pas; ils se fendillent sous l'action de ces deux réactifs.

Il est de la plus haute importance de noter que les réactions précédentes, quand elles fournissent un résultat favorable entre les mains de l'opérateur, ne leur donnent qu'un seul ordre de preures, c'est-à-dire, témoignent uniquement de l'existence du sang. Quant à l'origine de ce sang, elle ne peut ètre définitivement établie que par la présence des globules, et encore, ne faudrait-il se prononcer qu'avec la plus extrême réserve, et en tenant compte des altérations que la dessiccation et le contact de l'air font subir aux globules. Parfois, des circonstances secondaires pourront mettre sur la voie; c'est ainsi que le sang provenant de l'écoulement menstruel pourra, dans quelques cas, être déterminé par la présence de débris d'épithélium de l'utérus et du vagin. 


\section{CHAPITRE $X$}

\section{DU PUS}

La difficulté de définir ce produit pathologique a frappé tous les auteurs; toutefois, cette difficulté devient moins grande, lorsqu'on envisage le pus au point de vue purement descriptif,comme nous le faisons: Aussi, à l'exemple de M. Robin, définirons-nous le pus, comme le résultat de la double production accidentelle, et dans des régions où l'on n'en trouve pas habituellement, de globules blancs et d'une sérosité plus ou moins abondante.

Suivant que le pus s'est formé au contact de tel ou tel tissu, il peut présenter des caractères différents, mais dont l'importance, au point de vue de la détermination de ce produit accidentel, est médiocre.

Comme nous l'avons dit plus haut, le pus renfermé deux parties bien distinctes : une partie liquide, qui est le sérum, et une partie solide, principalement constituée par les globules blancs. Nous verrons en effet que, sous certaines influences, le pus peut renfermer d'autres éléments solides que les globules blancs. Bien que ces derniers soient moins denses que les hématies, ils gagnent cependant la partie inférieure du liquide qui les renferme. Aussi, quand on veut rechercher la présence du pus, dans une sécrélion normale ou pathologique, est-il nécessaire de permettre aux globules blancs de se déposer.

Le sérum du pus ne présente rien de particulier à noter lorsqu'il est soumis à l'examen microscopique.

\section{§ 1. GLOBULES BLANCS.}

Suivant leur plus ou moins grande abondance dans le sérum, les globules blancs communiquent au pus l'aspect dit crémeux ou sćreux.

Les globules blancs du pus, lorsqu'ils sont examinés peu de 
temps après leur production, ne diffèrent pas des globules blancs du sang. Comme ceux-ci, ils peuvent présenter encore des expansions sarcodiques et n'avoir pas de noyaux. Si, au contraire, le pus est resté un certain nombre d'heures, en contact avec. les tissus, les globules blancs seront d'autant plus profondément altérés, que ce contact aura eu une durée plus considérable. Les leucocytes sont gonflés : ils présentent un ou plusieurs noyaux; leur contenu est granuleux; ce sont des éléments anatomiques morts. L'eau agit sur les globules blancs en les gonflant et en y faisant apparaître un ou plusieurs noyaux. Ces noyaux sont rendus plus visibles encore par l'action de l'acide acétique.

On a donné le nom de globules pyoïdes à une variété de globules, chez lesquels l'acide acétique ne provoque pas l'apparition des noyaux.

Outre les leucocytes, on trouvẽ encore des glolulins, considérés par certains histologistes, comme les noyaux libres des globules de pus, et par d'autres, comme des débris de globules blancs, dont l'enveloppe aurait été détruite.

Le pus des abcès profonds et interstitiels de la cornée, est presque uniquement formé par des leucocytes (1). C'est un pus concret. Ces globules blancs sont souvent hypertrophiés et remplis de granulations graisseuses; ils offrent toutes les réactions propres à ces éléments. Cependant, on rencontre quelques leucocytes de la variété pyoïde.

Quand le pus a séjourné longtemps dans les os, on voit qu'il a perdu son sérum, et on le retrouve à l'état de masse pulpeuse, friable et demi-solide. Les leucocytes sont devenus irréguliers, polyédriques. L'acide acétique leur rend leur forme sphérique et y fait apparaître deux ou trois noyaux.

\section{§ 2. granulations graisseuses.}

Le pus renferme fréquemment des granulations graisseuses de volume variable, provenant du tissu cellulo-adipeux. Ces

(1) Le sérum est remplacé par une substance anorphe interposée, remplie de granulations grisâtres et jaunâtres qui sont attaquées par l'acide acétique (Robin). 
globules réfractent fortement la lumière, ils ont des contours très nets et l'éther les dissout très facilement. Outre ces granulations graisseuses, le pus peut encore, dans certaines conditions, contenir des corpuscules graisseux, provenant de la dégénérescence même du globule blanc. A l'état physiologique, ces matières grasses sont dissimulées dans les élém ents qui constituent le globule. Dès que celui-ci est soustrait à son milieu normal, il se produit, dans l'intimité des substances qui le composent, une sorte de dissociation, en vertu de laquelle les granulations graisseuses sont mises en liberté. D'après MM. Duval et Lereboullet, cette dégénérescence se produit très vite, lorsque les globules de pus sont nombreux, pressés et tassés dans l'épaisseur d'un tissu. La même particularité peut encore être observée dans le pus des phlegmons et dans le liquide des pleurésies purulentes. G'est en se fondant sur l'état granuleux que présentent alors les leucocytes, que certains histologistes avaient cru pouvoir établir une différence entre les globules blancs du pus et les globules blancs du sang.

M. Ranvier a donné la détermination expérimentale de la série d'altérations successives par lesquelles passe le globule blanc: "De la moelle de sureau est placée dans le tissu cellulaire ou dans le péritoine d'un animal(1); elle y détermine une suppuration, et des globules de pus pénètrent dans les cellules de la moelle, à travers leurs canaux poreux. Au bout de quatre jours, on trouve les globules de pus, dans quatre ou cinq rangẻes de cellules : les uns, superficiels, présentent des mouvements a miboïdes et n'ont pas de granulations graisseuses dans leur intérieur; d'autres, situés plus profondément, conservent leur forme sphérique et montrent des granulations graisseuses. Enfin, à côté d'eux, on trouve des amas de granulations graisseuses, noyées dans une masse protéique. On voit par là que des globules de pus soustraits aux conditions de leur nutrition subissent très rapidement la destruction graisseuse. "

Dans le pus des abcès de la mamelle, il n'est pas rare de trouver du lail, caractérisé par ses globules de matières grasses (V. LAIT).

(1) Le sac lymphatique dorsal de la grenouille, se prête bien à cette expćrience. 
Il est très commun de trouver dans le pus des os, des gouttes d'huile qui viennent du tissu adipeux ou même de la moelle des os. D'après Robin, il y a des cas où le pus provenant de la moelle des os contient un grand nombre de cellules petites, arrondies et contenant un noyau qui caractérise, d'après cet auteur, la moelle des os (médullocèles). La présence de ces médullocèles pourrait faire croire à un

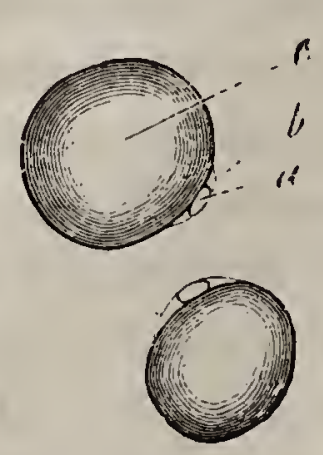

Fig. 234. - Deux ecllules adipeuses de la moelle du fémur de l'homme. $a$. Noyau. - b. Membrane de la eellule. c. Graisse. Gross., 350 . (Kœlliker). pus très riche en globules blancs. En effet, au premier abord, ces deux éléments sont faciles à confondre. On les distingue cejendant, en ce que les leucocytes à l'état frais ne laissent voir un noyau qu'après l'action de l'eau; de plus, alors que le noyau des leucocytes se fragmente par l'action de l'acide acétique, celui des médullocèles demeure intact (Cih. Robin).

Le pus provenant du foie est également riche en globules de graisse.

Hématies. Globules rouges. - Il n'est pas rare de trouver des globules rouges mélangés accidentellement au pus et ayant subi des altérations plus ou moins profondes. Ces globules rovges peuvent avoir été introduits directement dans le pus, soil par l'incision de l'abcès, ou bien par l'ouverture dans le foyer, d'un ou de plusieurs capillaires. Quelquefois même, ces globules rouges altérés sont si abondants, qu'ils peuventcommunıquer au sang, unecoloration rouge-chocolat, dont l'origine est révélée par l'examen microscopique.

Débris de tissus. - Suivant que le pus examiné provient de tel ou tel organe, on peut trouver au milieu des éléments anatomiques, les débris de différents tissus; des cellules épithéliales, pavimenteuses, nucléaires, sphériques ùu ovoïdes.

On rencontre souvent dans le pus des plaies, de petits filaments de couleur ocracée qui, d'après MM. Robin et Zeis, sont uniquement formés d'éléments anatomiques, fibres musculaires, fibres élastiques, éléments du tissu adipeux; quelquefois tous ces éléments sont réunis ensemble. On y rencontre de plus, des hématies en voie d'altération, et la couleur rouge ocracée est due à la présence d'une grande quantité d'héma- 
tine et de cristaux d'hématoïdine, provenant des globules rouges (Gh. Robin).

Vibrions, leptothrix, bactéries.-Quand on regarde du pus à l'aide d'un fort grossissement, on voit qu'il renferme un très grand nombre de vibrions (voy. p. 379). On avait pensé que la présence de ces microzoaires dans le pus communiquait à celui-ci un plus ou moins grand degré de virulence, mais cette assertion est combattue par les faits. Du pus frais contient également des vibrions. Il est même difficile d'invoquer, pour expliquer leur présence, l'influence de l'air, car on a constaté l'existence de ces vibrions, même dans du pus provenant d'abcès développés hors du contact de l'atmosphère. On peut donc considérer la présence des microzoaires dans le pus, comme un fait normal. C'est surtout dans le pus des ulcères variqueux, ou non variqueux, des vieillards; des tumeurs épithéliales, des cancroïdes, des ulcères phagédéniques et des chancres, que se montrent surtout les vibrions. Ils trouvent là, en effet, toutes les conditions nécessaires à leur développement. En revanche, les globules blancs sont peu abondants.

Algues (pus bleu). - Nous n'avons pas à parler ici de la coloration verdâtre que le pus doit, dans certains cas, à la présence de la biliverdine. Nous nous occuperons seulement de ces organismes microscopiques, qui se développent dans certains hôpitaux, sur les linges à pansement..D'après M. Robin, ce seraient des algues, voisines des protococcus, section des Palmellées, qui donneraient au pus la coloration bleu verdatre, dont l'origine a souvent préoccupé les auteurs. Ces algues unicellulaires, dit M. Robin, ont des spores de $0^{\mathrm{mm}}, 005$ à $0^{\mathrm{mm}}, 006$ de large et quielques granulations dans leur intérieur; elles sont colorées en bleu verdâtre et faciles à reconnaître au microscope. D'après Billroth, ce seraient, au contraire, des vibrions, qui donneraient au pus cette coloration spéciale. L'un de nous a fait, avec M. Broca, des expériences tendant à prouver que l'on peut facilement cultiver ces algues microscopiques et en obtenir de grandes quantités. Pour cela, il suffit de laver avec soin, avec de l'eau ammoniacale, puis avec de l'eau distillée, soit de la charpie, soit de la toile à pan- 
sement, et de placer le linge ou la charpie dans une étuve à température constante, chauffée entre $36^{\circ}$ ou $37^{\circ}$, en ayant soin que le linge ou la charpie soient exposés, sous la plus grande surface possible, à l'action d'un courant d'air. Préalablement, la charpie a été imbibée d'une solution d'eau albumineuse étendue. Il suffit de placer à la surface un fragment de charpie ou de linge coloré en bleu, pour voir cette coloration s'étendre à la surface du linge et de la charpie. L'accès de l'air est indispensable é les algues ne se développent pas dans l'intérieur de la charpie; aussi doit-on donner la préférence aux bandes de toile, employées pour les pansements. Ces algues, ne se trouvant plus en présence de matières étrangères pouvant altérer leur couleur, sont franchement bleues.

Ces faits permettent d'expliquer comment on a pu observer, dans des salles de chirurgie, de véritables épidémies de pus bleu. Il suffit, en effet, que la même pince ait été employée aux pansements de plusieurs malades, pour que les algues, trouvant des conditions favorables à leur développement, matière albuminoïde, température et air, apparaissent rapidement. Il n'est pas rare également de voir ces végétaux inférieurs se développer sur la peau saine, même à une certaine distance de la plaie, pourvu qu'ils trouvent des conditions favorables de température et d'humidité.

L'apparition de ces algues ne paraît, du reste, avoir aucune influence sur la marche de la cicatrisation.

Des cristaux contenus dans le pus. - Lorsque le pus a séjourné très longtemps dans des cavités closes, il n'est pas rare d'y trouver des cristaux d'acides gras et surtout de cholestérine. Ce dernier corps est surtout abondant dans le pus des abcès du bassin, de l'ovaire, du testicule; il en est de même dans les abcès profonds du pli de l'aine, et dans les abcès du psoas. (Robin.) Ces deux substances seront étudiées à part. Elles sont, du reste, faciles à reconnaître. Lorsque le pus est très altéré et que ses éléments sont pour ainsi dire presque complètement détruits, on y trouve des concrétions calcaires, de volume variable, qui font effervescence avec l'acide sulfurique et donnent des cristaux de sulfate de chaux. Dans le pus séreux, il n'est pas rare de trouver à la fois des cristaux irréguliers de phos- 
phate de chaux (voy. ce mot) et des cristaux de cholestérine. Lorsque le pus a été desséché, on peut y rencontrer des cristaux de phosphate ammoniaco-magnésien (voy. ce mot). Le pus des abcès froids, outre des cristaux de phosphate de chaux, peut encore contenir des cristaux de carbonate de -chaux irréguliers.

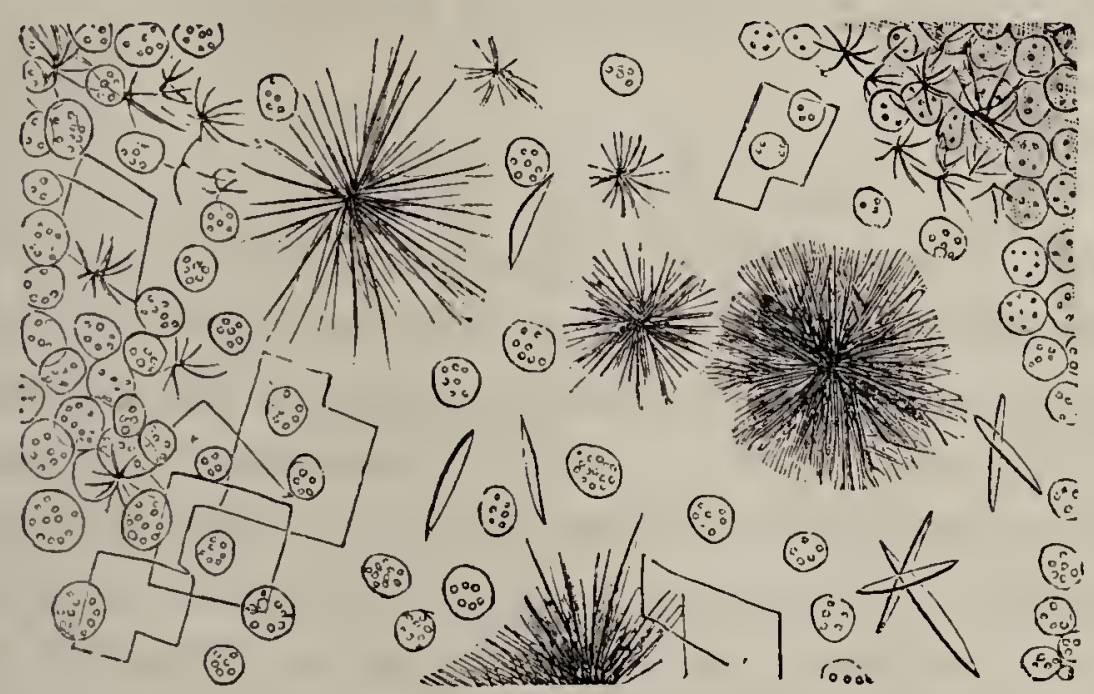

Fig. 235. - Pus altéré montrant des leucorytes granuleux, des cristaux aiguillés d'acides gras et des tables de cholestérine.

Concrétions cristalloïdes du pus. - Sous ce nom, M. Robin a décrit des corps particuliers qu'il a trouvés dans le pus d'abcès profonds et anciens. Ce sont des grains mous, jaunâtres, atteignant un diamètre de $1 / 10^{\circ}$ de millimètre, entourés d'une sorte d'atmosphère, ou couche mince, visqueuse, finement grenue, retenant des leucocytes du pus. Ces grains étaient formés par des corpuscules longs de 2 à 6 centièmes de millimètre, renflés d'un côté, amincis du côté opposé, placés en série, à la suite les uns des autres, de manières diverses, et ces séries étaient groupées, les unes contre les autres, sous forme de rayon autour d'un centre, formé de matière grenue pour composer ces grains. Bien que réfractant fortement la lumière, ayant un centre brillant, un contour net et foncé, les corpuscules étaient dissous, ou du moins fort pâlis, par l'acide acétique et insolubles dans l'ammoniaque et dans l'éther. (Ch. Robin.)

Colorations anormales du pus. - D'après" Gh. Robin, le pus provenant du foie peut présenter des colorations différentes: tantôt il est verdâtre ou jaunâtre, quand il est coloré par la 
bile; tantôt il offre une coloration rouge lie-de-vin ou brunchocolat, à cause de son mélange avec du sang et avec le détritus de la substance du foie.

Dans la carie des os, l'altération des hématies qui sont mélangées au pus va si loin, que celui-ci peut prendre une coloration noirâtre. D'après $M$. Robin, cette coloration serait attribuable à l'action du sulfhydrate d'ammoniaque.

\section{\$3. - MUCO-PUS.}

Lorsque, sous l'influence d'une hypersécrétion, les sécrétions normales des muqueuses sont exagérées, elles peuvent contenir un nombre anormal de globules blancs, et alors on donne à ces sécrétions le nom de muco-pus. Cette dénomination est impropre, car rien ne prouve, comme le dit Robin, que ces leucocytes soient accompagnés de la partie liquide du pus; ils sont seulement en plus grand nombre. C'est ce qu'on peut observer dans les sécrétions des muqueuses, de la trachée, des bronches, des fosses nasales, de l'urèthre, etc.

D'une façon générale, il ne faut jamais se contenter d'un simple examen à l'œil nu, pour décider si un liquide contient du pus, parce que des cellules épithéliales réunies en grand nombre peuvent donner à un liquide l'aspect puriforme (1).

On peut trouver du pus dans un grand nombre de liquides de l'économie, dans le liquide lacrymal, dans la salive, dans les matières fécales, dans l'urine, dans le lait, etc., etc.

Nous aurons l'occasion de revenir sur ces différents points, mais dès maintenant il sera facile, par la description qui précède, de reconnaître la présence du pus dans les circonstances les plus diverses.

(1) Il en serait de même pour d'autres éléments anatomiques. 


\section{CHAPITRE XI}

\section{DES SÉDIMENTS DE L'URINE.}

Le temps n'est pas éloigné où l'usage du microscope n'était familier qu'à certains savants privilégiés; aussi, l'étude des sédiments de l'urine était-elle fort peu avancée; les médecins les plus habiles étaient impuissants à distinguer un dépôt de pus d'un dépôt de matière saline, et laissaient passer complètement inaperçus des éléments qui, par leur petit nombre et leur volume, n'étaient pas appréciables à l'œil nu. Aussi la pathologie générale, et la pathologie spéciale des organes génitaux, ont-elles pris un grand essor, depuis que le microscope peut rapidement mettre en évidence tel ou tel élément figurant anormalement dans l'urine. La chimie et la science du microscope, comme toutes les branches de nos connaissances, se prêtent mutuellement un appui fécond, mais il est des cas nombreux, où le secours de la chimie ne saurait être invoqué, en raison de la minime proportion de la matière à examiner ou de sa nature même, lorsqu'il s'agit, par exemple, de quelques globules sanguins, de rares globules de pus, ou de spermatozoïdes. Un simple examen microscopique permettra à un observateur exercé de différencier du phosphate ammoniaco-magnésien, par exemple, d'acide urique ou d'urates. N'oublions pas non plus que la chimie nous prêtera un puissant secours, par l'emploi de réactifs appropriés à chaque substance; le microscope nous permet de suivre l'action chimique, au moment même où elle s'effectue, et d'en observer les effets ultérieurs, lorsqu'elle doit donner naissance à des corps nouveaux, ou simplement différents par la forme.

Nous avons divisé en deux grandes classes les sédiments de l'urine. Nous étudierons d'abord les sédimen ts formés par des éléments anatomiques organisés, et ensuite les sédiments 
formés par des éléments non organisés, et ayant une forme cristalline.

\section{Sèdiments formés par des éléments anatomiques organisés.}

$\S 1$. - Les éléments organisés les plus simples, que l'on rencontre dans les dépôts abandonnés par l'urine, sont des cellules épithéliales. Ces cellules peuvent provenir soit des reins, soit des uretères, soit de la vessie, ou bien encore du canal de
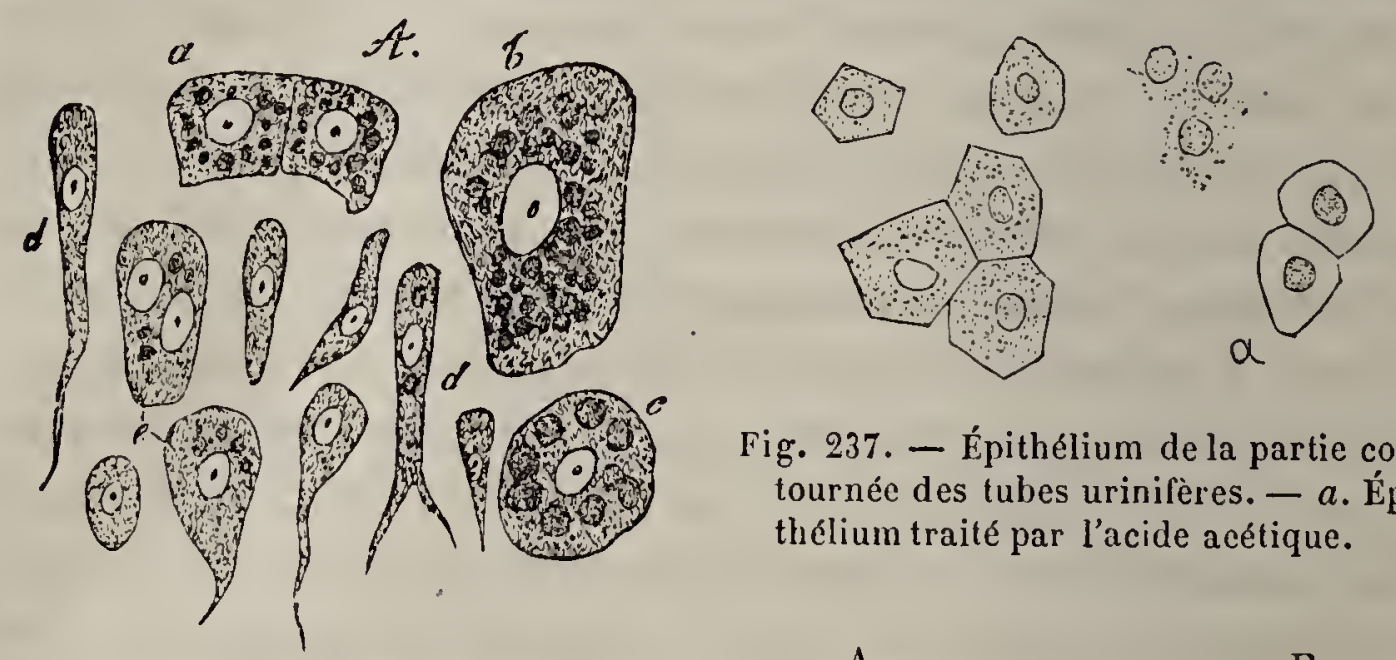

Fig. 237. - Épithélium de la partie contournée des tubes urinifères. - $a$. Épithélium traité par l'acide acétique.

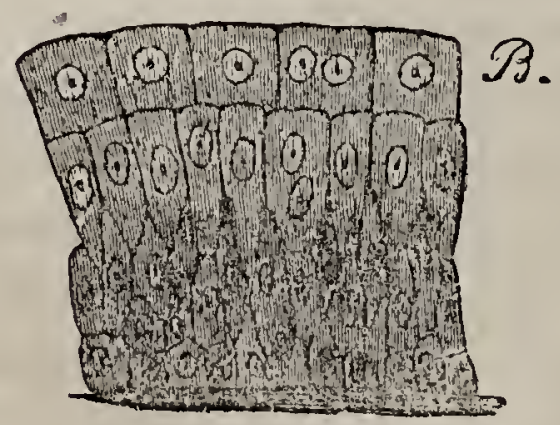

Fig. $236(\star)$
A

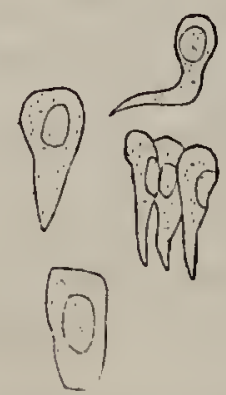

Fig. 238. - Épithélium de l'uretère.

\section{B}

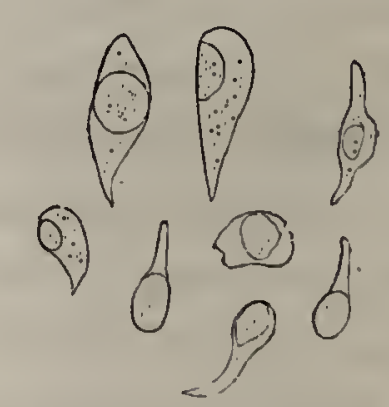

Fig. 239. - Épithélium de l'urèthre.

l'urèthre ou du vagin. Elles ont une forme différente, quelquefois difficile à apprécier, mais il n'en est pas moins très utile, dans certains cas, de les caractériser.

D’après Kölliker (p. 6ə̈9), l'épithélium de la muqueuse qui tapisse le bassinet (fig. 236), les calices et l'uretère (fig. 238), a

(“) Épithélium du bassinet de l’homme. Grossiss. 350 D. - A. Cellules épithéliales isolées. B. Épithélium en place; $a$, petites cellules pavimenteuses; $b$, grosses cellules pavimenteuses; $c$, les mêmes avec corpuscules en forme de noyau dans leur intéricur; $d$, cellules cylindriques et coniques des couches profondes; $e$, formes intermédiaires (Köllike. 
de 45 à $90 \mu$; il est stratifié et se distingue par les variétés que présentent la forme et le volume de ses éléments, dont les plus profonds sont petits et arrondis, ceux des couches moyennes, cylindriques ou coniques, et mesurant de 22 à $40 ّ$ de longueur, tandis que ceux de la surface sont polygonaux ou arrondis, de 13 à $22 \mu$ de diamètre, ou aplatis en forme de lamelles, qui ont jusqu'à $43 \mu$ de diamètre. Ces cellules ont cela de remarquable, qu'on y rencontre souvent deux noyaux; on y trouve aussi des grains arrondis, transparents, à contour's médiocrement fon-

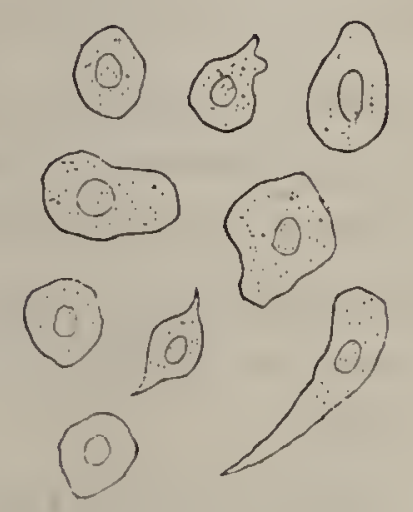

Fig. 240. - Epithélium résical.

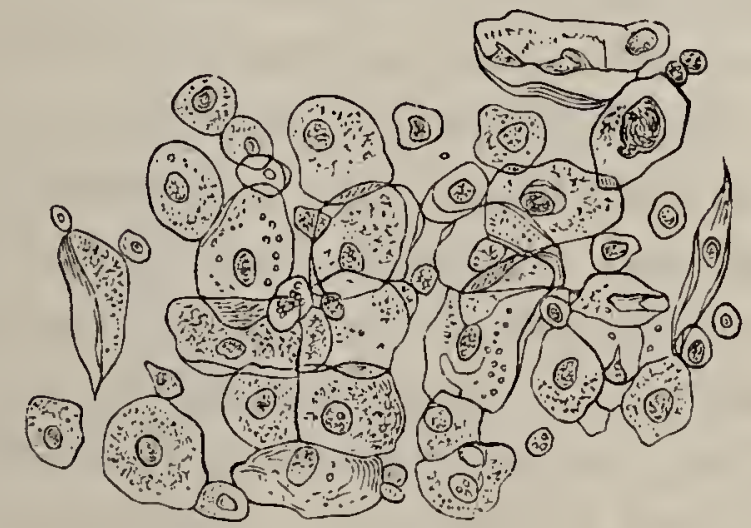

Fig. 24.1. - Épithélium vaginal à tous les degrés de développement dans la leucorrhée épithéliale et vaginale. Gross. 220 D. (D'après Tyler-Smith.)

cés, de 2 à $4, \breve{\jmath} \mu$ de largeur, qui prennent quelquefois l'aspect de noyaux (Kölliker).

L'épithélium de la muqueuse vésicale (fig. 240) est stratifié, et a de 60 à $100 \mu$ d’épaisseur ; les éléments les plus profonds de l'épithélium sont en général fusiformes, coniques ou cylindriques; ceux qui les recouvrent sont arrondis, polygonaux ou aplatis. Ces éléments sont aussi irréguliers que ceux du bassinet, ce qui dépend surtout des nombreuses dépressions que présente la face inférieure de la couche épithéliale superfi cielle, dépressions qui servent à loger les extrémités des cellules allongées, situées plus profondément, d'où résultent des formes étoilées ou dentelées. (Kölliker.)

L'épithélium de l'urèthre (fig. 239) est surtout cylindrique, devenant écailleux vers l'orifice. Ges cellules sont pâles et ont $26 \mu$ de longueur.

L'épithélium du vagin (fig. 241) consiste en grandes cellules de la variété pavimenteuse.

Dans certaines affections rénales, les cellules épithéliales qui 
tapissent les tubuli subissent des altérations qu'il est très important de connaîlre. Nous v'avons pas à les étudier sur place, mais comme à la suite de ces altérations il se fait une sécrélion d'une substance protéique hyaline, vitreuse, à l'intérieur des tubes urinifères, cette substance englobe, ou montre àısa surface, des éléments cellulaires plus ou moins altérés. Nous prendrons pour guide, dans cette étude, le Manuel d'histologie pathologique de MM. Cornil et Ranvier; ces auteurs ont traité avec une haute compétence tout ce qui a trait à la question qui nous occupe.

Nous venons de voir que la substance protéique est sćcrétée à la suite d'altérations cellulaires; elle revêt la forme cylindrique, de telle sorte qu'on a donné à ces coagulations le nom de cylindres. Ceux-ci sont emportés par l'urine dans laquelle on les retrouve et ils ont une grande importance, au point de vue pathologique, parce qu'ils jettent une vive lumière sur la nature des désordres dont le rein est le siège.

On peut trouver dans les urines des cellules épithéliales granuleuses, contenant des granulations transparentes et colloïdes. Ces cellules sont unies par une matière homogène et

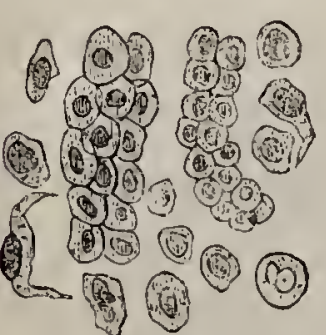

Fig. 242. - Épithélium rénal et gaine des tubes urinifères. Gross. $290 \mathrm{D}$. légèrement granuleuse, difficile à constater, mais dont la présence, suivant MM. Cornil et Ranvier, est indiscutable; ce sont les cylindres épithéliaux ou gaines épilhéliales (MM. Duval et Lereboullet). Ces gaines épithéliales sont formées par des cellules polyédriques très régulièrement disposées les unes à côté des autres, renfermant ou non des granulations amorphes. Le noyau de ces cellules devient très apparent par l'action de l'acide acétique. D'après MM. Duval, Lereboullet et Golding-Bird, ces cylindres épithéliaux se trouvent dans l'urine, non seulement dans les cas de néphrite, mais encore chaque fois qu'il y a fièrre intense. G'est ainsi que ces auteurs ont pu constater leur présence dans la scarlatine, et même dans l'érysipèle.

Sous le nom de cylindres muqueux, MM. Cornil et Ranvier ont décrit des cylindres très pàles, étroits, formés d'une matière amorphe finement granuleuse, molle, dont los bords ne 
sọt pas limités par une ligne sombre. Ils ont souvent à leur surface des cellules rénales ou des corpuscules lymphatiques. Ces cylindres généralement très longs, formés d'une matière protéique analogue à la mucine, sont fréquemment difficiles à reconnaître à cause de leur transparence. Leur présence dans l'urine n'a pas une signification grave; elle est souvent le résultat d'une congestion simple du rein ou d'un catarrhe léger des tubuli.

Les cylindres hyalins, que l'on rencontre dans la plupart des affections des reins, amenant l'albuminurie, sont formés par

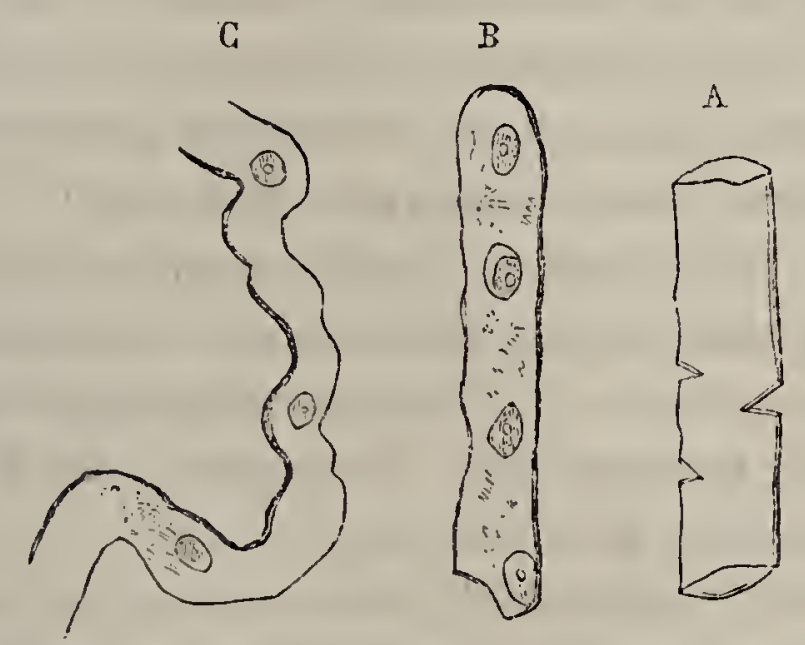

Fig. 243. - A. Cylindre hyalin arec eassures sur ses bords. - B. Cylindre hyalin ayant entrainé à sa surface des fragments de cellules. - C. Cylindre contourné. (D'après Cornil et Ranvier.)

une matière homogène hyaline, colloïde, sans granulations dans leur intérieur. Leurs bords sont bien accentués et ombrés; ils ne s'aplatissent pas entre deux lames de verre et conservent la forme cylindrique. Les extrémités sont formées par une surface circulaire. Ils varient comme forme, comme longueur et comme diamètre; le plus souvent, ils n'ont pas plus de 50 à $100 \mu$, mais ils peuvent atteindre 1 millimètre de longueur; ils sont quelquefois en tire-bouchon, comme les tubes contournés où ils ont pris naissance. Il en est de très étroits, d'autres sont très gros. Leur largeur varie entre $\check{3}$ et 40 u et quelques'uns portent des fentes vitreuses et des fêlures transversales. Quand ils sont nombreux, disent MM. Cornil et Ranvier, ils indiquent loujours une maladie de Bright grave; s'ils sont durs et à bords ombrés, ils sont l'indice que l'affection remonte à une époque ancienne. 
L'acide acétique est sans action sur eux; ils se colorent facilement par toutes les matières colorantes, par le carmin, par la matière colorante du sang, de telle sorte que lorsque le sang est mélangé à l'urine, dans la maladie de Bright, ils sont colorés en jaune-brun. La solution d'iode dans l'iodure de potassium les colore, mais la coloration ne persiste pas.

Dans le cas de dégénérescence granulo-graisseuse, des cellules épithéliales grenues se fixent à la surface du cylindre et constituent comme une sorte de revêtement cortical complet.

Accidentellement, ces cylindres peuvent présenter, à leur surface ou dans leur intérieur, des granulations d'urate de soude ou des cristaux de phosphate tribasique, d'oxalate de chaux ou d'acide urique. Chacun de ces corps présente des caractères spéciaux que nous étudierons ci-après.

Dans l'ictère, les cylindres hyalins sont colorés en jaune et recouverts de granulations jaunes; on rencontre également dans l'urine des cellules épithéliales contenant du pigment biliaire, et même, suivant une observation de MM. Cornil et Ranvier, des cristaux de liliverdine.

Dans un certain nombre d'intoxications, les reins subissent des altérations profondes, caractérisées par la dégénérescence

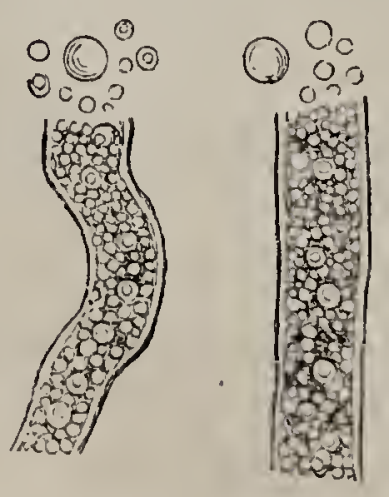

Fig. 244. - Stéatose pure. Tubes du reju; substance corticale. granulo-graisseuse (fig. 24วั et 246): C'est le phosphore qui produit les désordres les plus graves et les plus rapides, mais ces désordres se retrouvent également, dans l'empoisonnement par l'arsenic et par l'antimoine. Les cylindres que l'on rencontre dans l'urine sont composés par une masse grenue, contenant des molécules graisseuses; ils sont pleins.

Lorsque sous l'influence de l'élimination de certains poisons, ou de toute autre cause, il se produit dans le rein une congestion intense, il se fait des hémorrhagies à l'intérieur des tubes urinifères ; la fibrine s'y coagule et prend la forme des tubes. On a alors de véritables cylindres fibrineux. Les caractères de la fibrine s'y retrouvent, en effet, tels que nous les avons indiqués; elle a l'aspect fibrillaire et se gonfle sous l'influence de l'acide 
acétique. Entre les mailles, on peut même distinguer des globules blancs et des globules rouges. Quelquefois la fibrine peut se présenter sous la forme de petites masses, contenant également des hématies altérées par leur séjour au contact de l'urine.

Mode opératoire pour la recherche des cylindres (Cornil et Ranvier). - Pour pratiquer avec succès la recherche des cylindres, il faut, après avoir laissé reposer l'urine dans un verre à expérience, prendre avec une pipette une goutte du

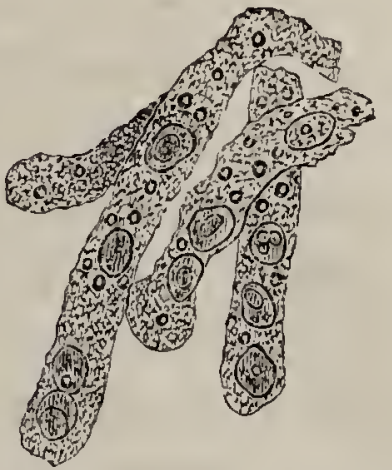

Fig. 245. - Cylindres granuleux trouvés dans l'urine albumineuse. dépôt, la mettre sur une lame de verre et l'examiner à un faible grossissement (100 à 150 diam.), en ayant soin de ne pas la recouvirir par un verre mince. Si on opérait autrement, les cylindres pourraient être chassés par la compression des lamelles, en dehors de la préparation.

Nous renvoyons ceux de nos lecteurs qui voudraient faire une étude plus complète de ces altérations au livre de MM. Cornil et Ranvier, dans lequel cette question est traitée d'une manière très remarquable.

\section{§ 2. - DU PUS DANS L'URINE.}

On rencontre fréquemment du pus dans l'urine pathologique. Les caractères des globules blancs ne diffèrent pas sensiblement de ceux que nous avons donnés; toutefois, lorsque l'urine est ammoniacale, les globules de pus sont profondément altérés et se transforment en une masse muco-gélatineuse, adhérant assez fortement au vase. L'examen microscopique permet néanmoins de retrouver dans cette masse des globules de pus parfaitement caractéristiques. Si l'urine n'est que légèrement ammoniacale, les leucocytes sont gonflés, pâles et montrant leurs noyaux. Souvent ils sont augmentés de volume. Ce gonflement peut être tel, dit M. Robin, que les granulations sont douées d'un mouvement brownien, dans le leucocyte où se sont formés un ou deux éléments nucléiformes; sur d'autres globules la surface de l'élément est seule 
gonflée en une vésicule hyaline, entourant la masse granuleuse que constitue l'ensemble de ce dernier.

Dans l'urine, les leucocytes sont généralement privés de mouvements amibiformes. Quand ces leucocytes proviennent de la vessie, ils sont généralement accompagnés de cristaux d'urate et de phosphate ammoniaco-magnésien.

Lorsque l'urine renferme une quantité notable de pus, celui-ci gagne les parties inférieures du vase; toutefois ce dépôt se fait d'autant plus lentement, que la proportion du pus est moindre. Pour faciliter le dépôt des globules du pus, M. Méhu conseille d'ajouter à l'urine du sulfate de soude pur.

La présence du pus dans l'urine est toujours un symptôme important à signaler. Il ne faut pas oublier, cependant, que le pus peut provenir chez la femme du vagin, et chez l'homme du canal de l'urèthre.

Dans les cas douteux, il sera nécessaire de recourir à l'action des réactifs chimiques sur le liquide urinaire.

\section{$\S 3$. - DU SANG DANS L URINE.}

Nous connaissons maintenant les altérations que subissent les globules sanguins, guand ils sont sortis des vaisseaux. Au contact de l'urine, les globules rouges subissent des modifications d'autant plus profondes, qu'ils y ont séjourné plus longtemps, soit dans la vessie, soit dans le vase où elle a été recueillie. La réaction de l'urine a une certaine influence sur la rapidité de l'altération des globules sanguins. Lorsqu'elle est acide, ces derniers se conservent à peu près intacts pendant un temps assez long; ils sont dentelés et gonflés et se rapprochent de la forme sphérique. Leur couleur est plus claire qu'à l'état normal; en outre, ils ont toujours des contours plus nets, mais ils ne sont plus placés les uns sur les autres, de manière à s'empiler comme des pièces de monnaie.

Le moyen le plus simple de recueillir les globules sanguins est. de laisser déposer l'urine dans un tube effilé, ou dans un vase conique.

Quand les globules de sang ne sont pas détruits et qu'ils se sont déposés, l'urine n'offre pas de coloration particulière. Si, 
au contraire, la matière colorante du sang s'est dissoute dans le liquide urinaire, celui-ci peut prendre des colorations variant du brun au rouge-orangé.

Quelquefois on trouve du pus en grande abondance mélangé aux globules rouges et, dans ces cas, il n'est pas rare de trouver dans le dépôt urinaire, des fragments de calculs qui ont pu donner lieu à une inflammation des bassinets ou produire des déchirures, en passant par les uretères.

Lorsque les globules rouges sont complètement détruits, l'urine renferme en dissolution la matière colorante du sang; c'est alors qu'il faut recourir au spectroscope, pour mettre en évidence la présence du sang dans l’urine.

L'existence du sang dans l'urine a des significations diverses, suivant que ce dernier provient des reins, de la vessie, du canal de l'urèthre. G'est un symptôme dont la gravité varie suivant une foule de considérations, qui relèvent de la pathologie.

§ 4. - DE I.A FIBRINE DANS L'URINE.

Lorsque nous avons étudié la fibrine du sang, nous avons donné les caractères de cette substance. Nous n'aurons donc que peu de chose à ajouter. Si la quantité de sang contenue dans l'urine est abondante, on peut rencontrer des caillots fibrineux affectant des formes diverses, ainsi que des volumes variables, et présentant les caractères sur lesquels nous avons insisté.

Parfois la fibrine affecte l'aspect filiforme, ou se présente sous l'apparence de très petites particules.

Quand on veut examiner un de ces caillots fibrineux, on le saisit avec une pince et on le porte sur la lamelle, où il est dissocié avec des aiguilles, sans y ajouter d'autres liquides que l'urine elle-même.

$\S 3 ̈ .-$ DES SPERyatozoÏdes daNS L'URINE.

Nous renvoyons au chapitre spécial que nous consacrons aux spermatozoïdes, pour leur description. Il nous suffira de dire que pour faire la recherche des spermatozoïdes dans l'u- 
rine, il faut la laisser déposer dans un verre conique, et examiner les couches inférieures du liquide à un grossissement d'au moins 300 diamètres. On se trouve bien de recueillir les dépôts abandonnés par l'urine à l'aide d'une pipette effilée, dont le maniement est connu de tous.

Généralement les spermatozoïdes sont privés de mouvement; tantôt ils sont rectilignes, tantôt au contraire la partie inférieure est recourbée sur elle-même, ou sur la partie antérieure.

Dans cerlains cas, on a pu observer dans l'urine (Clémens) des cellules spermatiques renfermant des spermatozoïdes, ou seulement des granulations.

On trouve des spermatozoïdes dans l'urine, après des pollutions volontaires ou involontaires; l'examen de cette sécrétion

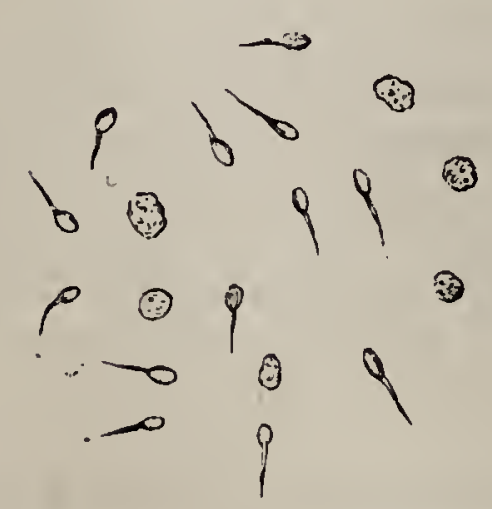

Fig. 246. - Spermatozoïdes.
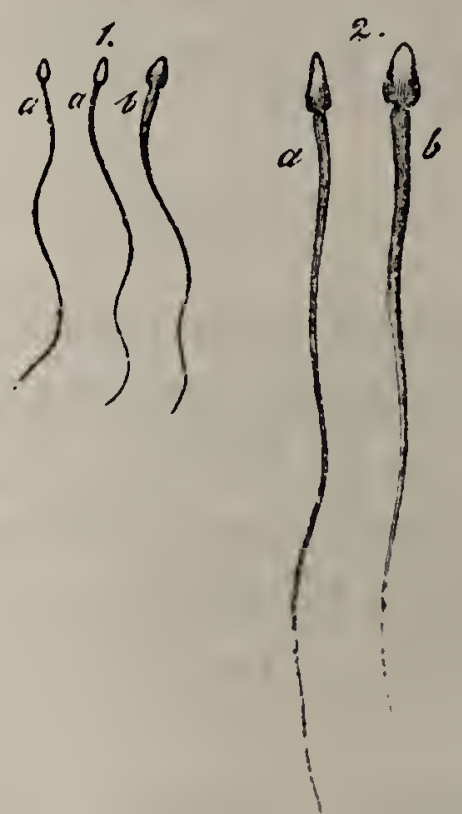

Fig. 247. - Spermatozoïdes de l'homme. -1. Grossissement de 350 D. - 2. Grossis. de $800 \mathrm{D}$; $a$, vu de profil; $b$, vu de face.

peut donc devenir très important, lorsqu'il s'agit de déterminer l'existence d'une spermatorrhée ou de l'onanisme.

L'existence des spermatozoïdes a été constatée dans l'urine de la femme, après le coït.

Souvent, outre les spermatozoïdes, on peut rencontrer des cristaux d'oxalate de chaux, des leucocytes, des cellules d'épithélium vésical, ainsi que des filaments de mucus. D'après M. Robin, dans le cas où l'on aurait à examiner une urine con- 
tenant à la fois des spermatozoïdes et des globules sanguins, c'est au-dessous du dépôt sanguin qu'il faudrait aller chercher les spermatozoïdes.

M. Rouvière conseille de suivre la méthode suivante, pour la recherche des spermatozoïdes dans l'urine. On raisse déposer l'urine suspecte, après avoir ajouté à sa surface, lorsqu'on est en été, une couche de benzine qui s'oppose à la putréfaction. On décante au bout de 10 à 12 heures, puis on agite le dépôt avec de l'éther. On recueille le liquide éthéré et on le place dans un verre conique, et on y ajoute quelques gouttes d'eau distillée. Par ce moyen, dit l’auteur de cette méthode, on concentre les spermatozoaires sous un petit volume, avec les matières grasses et le mucus ; ce liquide, examiné au microscope, laisse voir les spermatozoaires, en si petit nombre qu'ils soient. M. Rouvière signale l'existence de spermatozoaires d'un plus petit volume que ceux que l'on rencontre normalement.

A l'article Sperme, au sujet de la spermatorrhée, nous donnons de plus amples détails sur cette question.

\section{§6. — vÉGÉTATIONS FongoïdES DANS L'URINE SUCRÉE.}

La première partie de ce manuel renfermant de nombreux renseignements sur les végétaux inférieurs, nous serons sobres de détails sur les végétations du genre Saccharomyces que l'on rencontre dans les urines sucrées, ainsi que sur les bactériens constituant les torules. C'est d'abord à la surface de l'urine que se développent ces végétations, où elles forment une couche mince et blanchatre. Ce sont de petits corps ovales dans lesquels on voit apparaître, en même temps qu'ils augmentent de volume, de fines granulations. Ge développement continue, la vésicule se dilate et d'ovale devient tubuleuse. Les granulations internes deviennent plus volumineuses, plus transparentes et se détachent de l'extérieur de la vésicule mère, comme des hourgeons. La masse ressemble alors à une végétation confervoïde, qui plus tard se scinde par portions. En même temps des vésicules ovales ou spores tombent au fond du vase (Golding Bird). Les différentes phases de ce dévelop- 
pement n'exigent que quelques heures pour se succéder. Les spores, placées dans un milieu de végétation favorable, c'està-dire dans un liquide sucré, donneront naissance à leur tour à de nouvelles cellules.

Ces figures, que nous empruntons à Golding Bird, représentent l'accroissement des saccharomyces, d'après Lionel Beale (Work on the microscope) et le docteur Otto Funke (Atlas); aa montrent la forme vésiculaire primitive; $b$, la germination; et $b$ (fig. 250 ), le développement au bout du huitième jour.

Outre les végétations caractéristiques qui apparaissent dans

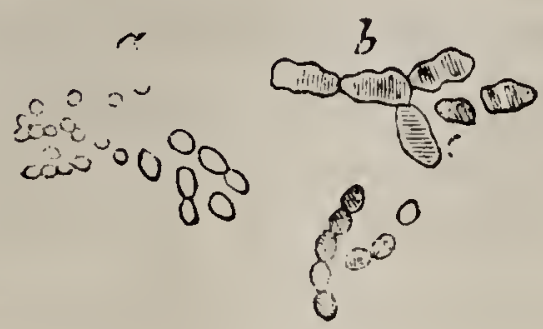

Fig. 248. - Saccharomyces.

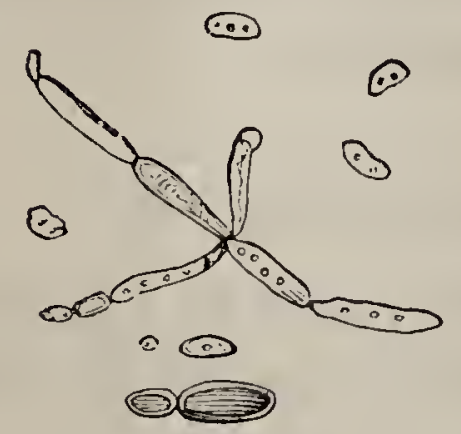

Fig. 249.-Saccharomyces cerevisix.

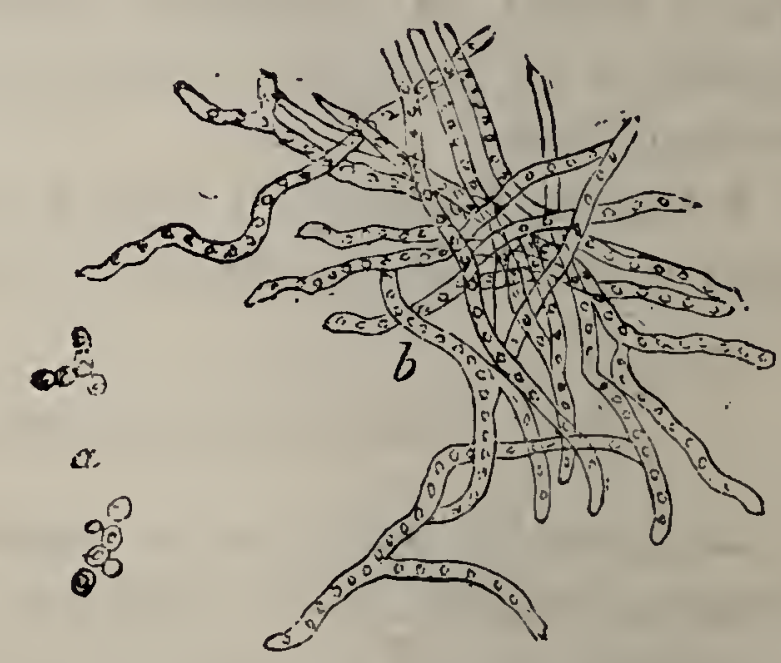

Fig. 250. - Saccharomyces à différents degrés de développement.

l'urine glycosurique, on a trouvé des champignons ayant vé-

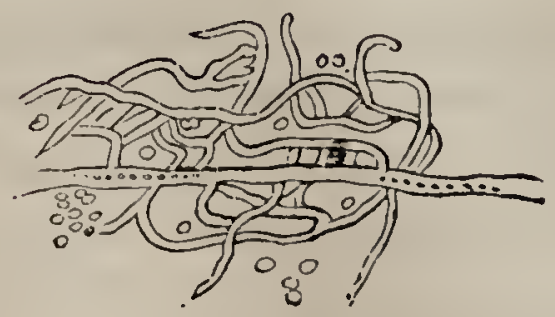

Fig. 231. - Penicillium glaucum.

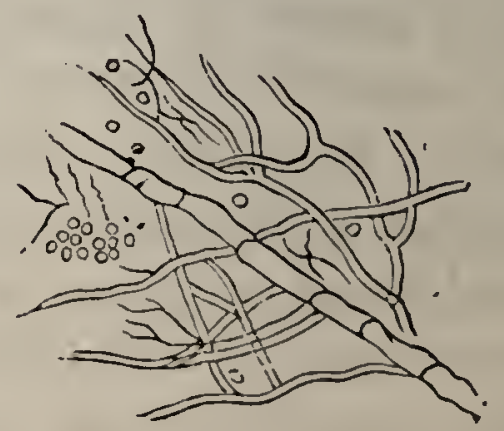

Fig. 252. - Penicillium glaucum.

gété dans des urines ne contenant pas de sucre. Le docteur Hassal a décrit des champignons développés dans une urine 
acide et albumineuse, qu'il a reconnus être identiques au $P e-$ nicillium glaucum.

Heller el Basham auraient découvert, l'un en 1848, l'autre en

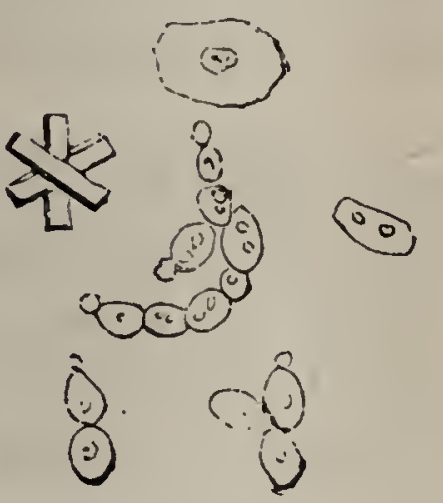

Fig. 253. - Conferves.

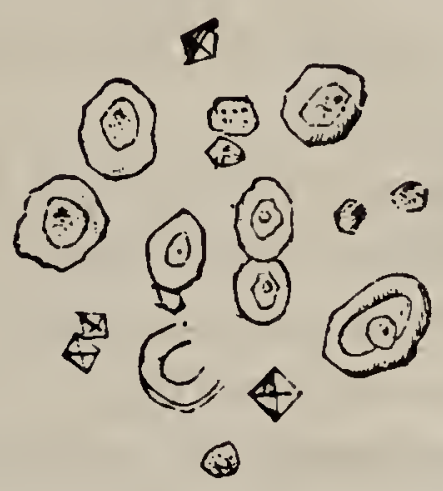

Figr. 2034. - Productions organiques et oxalate de chaux.

1849, dans l'urine de malades atteints de fièvre typhoïde et dans celle d'individus dyspeptiques, des productions (fig. 2ə3) se rapprochant à la fois de la forme torula et du penicillium. D'après Golding Bird, Basham rencontra ces corps dans l'urine en même temps que des cristaux d'acide urique en étoiles. Ils consistaiente $n$ cellules ovales, arrangées en forme de grains de chapelets, avec de petites cellules naissant des parois des cellules mères.

Basham a également rencontré, dans l'urine d'un malade atteint d'oxalurie, une conferve mélangée à l'oxalate de chaux (fig. 2ð̈4). Cette conferve étail constituée par de nombreuses cellules annulaires nucléées, quelques-unes elliptiques et en fer à cheval. Leur apparence annulaire indiquait évidemment une plus grande épaisseur vers les bords qu'au centre, comme cela existe dans l'uredo et dans la puccinia (1).

\section{§7. - infusoines et bactériens dans L'URine.}

Il est très commun de rencontrer des infusoires dans l'urine, surtout quand celle-ci est alcaline, mais cette condition

(1) Dans une communication faite à la Société de Biologie, le 15 mars 1879, sur les urines bleues, M. A. Robin a appelé l'attention sur certaines urines qui ne bleuissent qu’à a surface. Ayant examiné au microscope la pellicule bleuâtre, il y a l'econnu la présence d'organismes inférieurs, qu'il n'a pas déterminés, mais qui, à notre avis, semblent beaucoup se rapprocher par leurs réactions chimiques de ceux que l'on rencontre dans le pus bleu 
n'est pas indispensable. L'apparition de ces vibrioniens suit souvent de très près l'émission de l'urine; ils ont la forme linéaire et une longueur variant entre sั $\mu$ et $8 \mu$. Ils se meuvent avec une rapidité extrême; souvent ils prennent naissance dans la vessie et on peut constater leur présence dans l'urine fraîche.

Neubauer et Vogel (p. 1533) décrivent comme des infusoires, des monades punctiformes, qui se grouperaient sous forme de chapelet ou de ramification. Quand l'urine commence à s'altérer, ils seraient en petit nombre; plus tard ils deviennent plus nombreux, se rassemblent à la surface du liquide où ils forment, avec le triple phosphate et les champignons, une pellicule qui se fendille et tombe plus tard au fond du vase. Ils se forment surtout abondamment dans les urines.

Hassal a trouvé dans l'urine une deuxième espèce d'infusoire, le Bodo urinarius; les individus qui sont vivants et qui se meuvent sont ovales ou ronds et ont un diamètre variant entre $1 / 60^{\circ}$ et $1 / 100^{\circ}$ de millimètre; ils sont granulés et sembla bles à des cellules muqueuses. Souvent ils sont plus larges à une extrémité et en différentes parties; ils sont pourvus de un, deux ou trois cils. Ils se multiplient par division. D'après Hassal, ils ont la plus grande analogie avec le Bodointestinalis d'Eremberg. On les rencontre fréquemment dans l'urine albumineuse, à côté des infusoires (Neubauer et Vogel, loc. cit.).

La fermentation ammoniacale serait due, d'après Pasteur et Van Tieghem(1), au développement dans l'urine d'une torulacée, constituée par des cellules globuleuses, réunies sous forme de chapelets; ces cellules ont $0,0010 ั$ millimètres de diamètre. Elles ne renferment pas de granulations; leur enveloppe et leur contenu ne présentent aucune différence. Ce ferment paraît se multiplier par bourgeonnement et il ne se développe jamais à la surface du liquide, mais dans ses parties moyennes ou dans ses parties inférieures. Quelquefois même, ce ferment constitue avec les sels un dépôt au fond du vase.

Parmi les végétaux unicellulaires qui peuvent se développer

(1) Kecherches sur la fermentation de l'urée, de l'acide hippurique. Paris, 1864 . 
dans l'urine se trouvent les sarcines, qui sont caractérisées par des cellules cubiques très petites, juxtaposées en groupes, ou fragments cuboïdes, ou prismatiques, pouvant être parfois assez gros pour être visibles à l'œil nu (Robin). La présence de sarcines dans l'urine a été constatée par différents auteurs, en particulier par Ph. Munk, par Virchow, par Welker. La réaction de l'urine paraît être sans in- Fig. 253. - Sarcines. fluence sur le déreloppement de ces végétaux inférieurs (voy. Neubauer et Vogel, p. 15ั3). On trouve également des sarcines dans l'estomac et le tube intestinal (voy. Sarcine, p. 294, $1^{\mathrm{re}}$ partie). .

\section{§ 8. - DE LA KYESTÉINE.}

On a décrit sous ce nom une sorte de pellicule, qui se forme fréquemment à la surface de l'urine émise par les femmes enceintes. Certains auteurs avaient même cru voir dans cette pellicule un élément sérieux pour diagnostiquer la grossesse. Le nom que porte cette pellicule lui a été donné par Nauche. Un grand nombre d'opinions diverses ont été formulées sur la nature de la kyestéine, nous allons résumer les principales. D'après Golding Bird, si on examine la pellicule au microscope, on y découvre un très grand nombre de cristaux de phosphate ammoniaco-magnésien, entrelacés dans une masse de matière granuleuse, parsemée çà et là de globules graisseux. Lorsque l'urine est conservée un certain temps, la pellicule se brise et tombe sous forme de dépôt au fond du vase. Si l'on recueille le dépôt sur une lame de rerre, il présente la même apparence que la pellicule, mais les cristaux sont plus nombreux, et la matière animale se montre sous la forme de granules amorphes. L'àcide acétique semble coaguler cette matière amorphe; elle est au contraire dissoute par l'ammoniaque. Outre ces éléments, la kyestéine renferme encore de la matière grasse, que le docteur Ress a pu caractériser microscopiquement, et que Lehman avait pu recueillir, en traitant la kyestéine par l'éther. On a proposé de 
donner à la substance albuminoïde de la kyestéine le nom de gravidine (Starck), mais, comme le fait observer Golding Bird, ce nom ne peut être accepté, attendu quill préjuge une question et qu'il ne la résout pas.

Hoffle et Veit sont d'avis que la kyestéine est formée surtout par des infusoires, auxquels se mêlent des algues et des conferves, ainsi que des cristaux de phosphate ammoniaco-magnésien. Lehman a formulé une opinion à peu près semblable. Da'près Robin, cette pellicule ou kyestéine se formerait d'au : tant plus vite, que l'urine est mélangée à une plus grande quantité de substances organiques coagulables, telles que du mucus ou de l'albumine.

M. Béchamp (Recherchessur la nature de la kyestéine, Montpellier médical, 1870, p. 209) s'est occupé également de cette question, qu'il a traitée au point de vue d'idées spéciales qu'il professe, mais qui jusqu'ici ne comptent qu'un nombre restreint de partisans. Pour lui, cette matière albuminoïde, qui se rapprocherait de la caséine d'après Golding Bird, du mucus d'après Lehman et de la mucosine altérée d'après, Robin, ne serait que la néphrozymase, qui servirait à nourrir les nombreux infusoires (vibrions, bactéries), seuls agents qui, d'après M. Béchamp, peuvent donner naissance à la kyestéine.

\section{§ 9. - DE La matière grasse dans L'Urine.}

Nous avons déjà eu l'occasion de parler des urines chyleuses à propos des hématozoaires du sang (voy . p. 382). Souvent les urines chyleuses ou lactescentes sont en même temps hématuriques. Les globules sanguins gagnent la partie inférieure du vase, tandis que les globules chyleux ou graisseux gagnent les couches supérieures du liquide. Il est nécessaire d'examiner ces globules graisseux à un. grossissement considérable, car ils sont souvent tellement fins, qu'ils échapperaient facilement à la vue. Ils sont animés du mouvement brownien et l'éther les dissout facilement. M. Robin conseille d'employer le procédé suivant, pour faciliter l'agglomération de ces corpuscules graisseux. Ce procédé consiste à chauffer la préparation sur la lampe à alcool, ou mieux, à chauffer 
préalablement une certaine quantité de liquide, dans un verre de montre ou dans une capsule, à moins que, l'urine se trouvant albumineuse, on provoque ainsi la formation de caillots albumineux. En raison même de l'origine supposée de ces urines chyleuses, il faudra toujours rechercher si le dépôt formé au fond du verre renfermant le réactif contient soit des tubes rénaux, des épithéliums, des hématozoaires, des œufs de parasites, etc. Dans ce cas, il sera prudent d'examiner le sang, afin d'y rechercher des parasites.

11 y a au sujet des urines renfermant des globules graisseux plusieurs observations importantes à faire. S'il n'est pas très rare de rencontrer des globules de matière grasse dans l'urine, il faudrait cependant se bien garder de leur attribuer une origine pathologique, surtout quand l'urine a été extraite à l'aide d'une sonde. On sait, en effet, que les sondes sont toujours imprégnées d'un corps gras; huile, cérat, beurre, etc. Le corps gras employé peut se retrouver dans l'urine, même un certain temps après que le malade a été sondé.

Dans quelques auteurs, il est fait mention d'urines laiteuses, c'est-à-dire contenant des globules de matière grasse du lait. Chaque fois que les malades dont provenaient ces urines pseudo-pathologiques étaient soumis à une étroite surveillance, on ne tardait pas à découvrir une supercherie. A ce propos, nous dirons, d'une façon générale, que chaque fois que l'on trouvera dans un liquide physiologique un élément tout à fait en dehors de cẹux qu'on a l'habitude d'y rencontrer, il faudra se tenir sur la plus grande réserve et soumettre le malade à une surveillance attentive. Si quelquefois les malades peuvent tromper le médecin sans le vouloir, il en est un certain nombre, surtout parmi les femmes, hystériques ou non, qui mettent tout en œurre pour induire le médecin en erreur. Dans tous les cas, le volume des globules du lait dépasse de beaucoup celui des globules gras des urines chyleuses.

Une urine riche en globules de pus peut parfois donner à l'œil l'aspect d'une urine chyleuse ou laiteuse. Un simple examen microscopique tranchera la question.

Beale est d'avis que les urines véritablement chyleuses, doivent cette particularité à une séparation du chyle par les reins. 
Le même auteur, dans le cas de dégénérescence graisseuse du rein, aurait trouvé des cellules adipeuses dans l'urine. Dans le

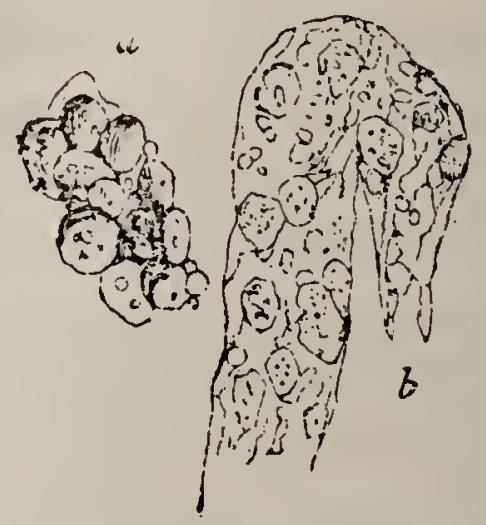

Fig. 256. - $a$. Cellules épithéliales remplies de globules graisseux. - $b$. Moules tubuleux, contenant des cellules épithéliales présentant la mème altération.

cas de dégénérescence graisseuse du rein, il se forme de la graisse dans les cellules épithéliales des tubuli. Ces cellules épithéliales se rencontrent dans l'urine, remplies de globules graisseux; il en est quelquefois de même des tubes qui les contiennent. Claude Bernard a vu, et-souvent nous avons pu le constater également, que lorsqu'on fait entrer dans l'alimentation d'un chien une grande quantité de matières grasses, on en retrouve par le microscope dans l'urine ; il ne serait pas impossible que, chez certaines personnes absorbant une grande quantité de matières grasses, ou d'huile de foie de morue, on pût également retrouver dans l'urine des globules graisseux.

Golding Bird décrit, d'après le docteur Florian Heller, une matière grasse particulière trouvée par ce dernier dans l'urine d'un malade. Ce patient, qui présentait tous les symptômes de la pierre, rendait de petites concrétions qui, à l'examen, se montrèrent composées d'une substance grasse spéciale. Ces concrétions, à l'état récent, étaient lisses, devenant par la dessiccation dures, jaunes, cireuses, amorphes; présentant à la lumière transmise une couleur jaune sale. Cette substance fond à la chaleur, se boursoufle et s'enflamme, émettant une odeur particulière de gomme laque, de benjoin, en laissant une cendre volumineuse. On lui a donné le nom d'uro-stéalithe.

\section{§ 10. mucus de l'urine. - Énéorème (Donné, Robin).}

Lorsque l'on verse de l'urine normale, peu de temps après 
son émission, dans un vase conique, on voit se former, après le refroidissement, un léger nuage qui gagne lenternent et peu à peu le fond du vase. On a donné à ce dépôt léger le nom impropre de mucus, qui implique une simplicité de constitution qu'il n'a pas. M. Robin conserve à ce dépôt le nom d'énéorème. On recueille cet énéorème à l'aide d'une pipette, en prenant la précaution d'attendre qu'il ait gagné la partie la plus effilée $\mathrm{du}$ tube, et alors on laisse tomber sur le porte-objet une goutte d'urine. M. Robin conseille d'examiner ce dépôt à un grossissement de 400 à 500 diamètres, en raison de sa ténuité. Le même auteur donne un moyen pratique de faciliter le dépôt des énéorèmes, par l'addition à l'urine d'un ou deux dixièmes de son volume d'alcool. Suivant M. Robin, cette proportion d'alcool n'altère pas les épithéliums, les spermatozoïdes, les filaments de mucus, ni même les hématies. Les leucocytes seuls deviennent un peu irréguliers. Comme on le voit, la composition des énéorèmes est très complexe; on y trouve quelques rares cellules épithéliales, souvent difficiles à rencontrer. Ces cellules épithéliales proviennent presque toujours de la vessie, nous avons donné les principaux.caractères de ces cellules.

Quelquefois ces cellules épithéliales sont couvertes de fines granulations, qui sont considérées, dit M. Robin, comme des Micrococcus. Outre ces éléments, ces dépôts comprennent encore souvent des leucocytes appelés aussi, par quelques auteurs, globules muqueux (voy. Pus).

Donné a décrit dans son Cours de microscopie (p. 260) des filaments blancs parfaitement distincts, que l'on rencontre dans l'urine normale, au moment où elle vient d'être rendue. La présence de ces filaments, peut inquiéter vivement des personnes ayant eu déjà des affections des voies urinaires. Ils peuvent avoir 1, ou 2, ou 3 centimètres de long, et de 1 à 3 dixièmes de millimètre d'épaisseur. Ils sont constitués par des filaments muqueux, se gonflant peu à peu dans l'urine et quelquefois striés. Lorsque ces stries n'existent pas, on peut les faire apparaître par l'action de l'acide acétique. Ces filaments peuvent contenir des leucocytes, des cellules épithéliales, et quelquefois des zoospermes morts, ou même 
vivants, quand l'urine est fraîche. Ces éléments, ainsi que le fait observer avec raison M. Robin, sont plus nombreux chez les individus qui ont eu récemment la blennorrhagie; c'est même souvent pour eux une cause d'inquiétude. Donné avait émis l'idée que ces filaments provenaient des canaux prostatiques, mais cet organe ne produisant pas de mucus, M. Robin les fait venir des plis du golfe de l'urèthre ou de Lecat, à la jonction des parties membraneuse et bulbaire du canal; c'est en ce point, d'après cet auteur, qu'ils se chargeraient de quelques spermatozoïdes, qui se trouvent souvent dans le canal des personnes continentes. Les leucocytes et les cellules épithéliales qui les accompagnent viennent également du canal de l'urèthre.

Ainsi que nous l'avons dit, dans le cours de la blennorrhagie, ou peu de temps après sa guérison, on trouve dans l'urine une quantité assez considérable de ces filaments, chargés d'un grand nombre de leucocytes et de cellules épithéliales, venant de l'urèthre. Outre ces éléments, le dépôt dont nous venons d'étudier les parties constituantes contient encore parfois des urates et des cristaux d'oxalate.

L'urine de la femme contient souvent des cellules épithéliales et du mucus, provenant du vagin.

Dans un article publié le 30 août 1876 dans le Bulletin de thérapeutique, M. Méhu a nié l'existence, dans l'urine, du mucus vésical. Cet auteur s'appuie sur ce fait, qu'une urine filtrée et récente ne se trouble pas par l'acide acétique, et par conséquent ne contient pas de mucine (voy. art. Mucus).

Lorsque l'urine, même acide, donne un trouble par l'acide acétique, on est en droit d'y rechercher la présence des leucocytes. Cette présomption devient une certitude, si l'urine se trouble par la chaleur seule.

Pour M. Méhu, l'expression mucus de la vessie a pour signification pus dans la vessie.

Dans le cas de cystite et de catarrhe vésical, l'urine laisse déposer un dépôt muqueux et très filant. Pour le recucillir, on est obligé de décanter l'urine et d'en saisir avec des pinces une portion, que l'on porte sur le champ du microscope. Il faut employer pour l'examen un grossissement de 400 diamè- 
tres. On constate la présence, dans ce mucus, de cellules épithéliales pavimenteuses de la vessie, polyédriques, sphéroïdales, granuleuses ou non, et enfin une grande quantité de leucocytes généralement granuleux. Lorsque l'urine est ammoniacale, le mucus devient glaireux et partiellement miscible à l'urine, qui est rendue filante. Dans ce cas, on trouve également un grand nombre d'infusoires.

\section{$\S$ 11. - DES POUSSIÈres ET DES CORPS ÉTRaNgers QUE L'ON PEUT RENCONTRER DaNS L'URINE.}

Nous n'avons pas la prétention de passer en revue tous les corps étrangers qui peuvent être introduits volontairement, ou involontairement, dans.l'urine; ce serait une tâche audessus de nos forces. L'air ambiant, les vases employés, les instruments dont l'observateur se sert, l'opérateur lui-même, sont autant de véhicules aptes à introduire dans les préparations les corpuscules ou les objets les plus divers. Il résulte du nombre considérable de ces chances d'erreurs, ou de fausses interprétations, que l'opérateur doit mettre tout son soin à placer les objets destinés à être étudiés au microscope, à l'abri des substances qui peuvent être apportées par les différentes roies auxquelles nous faisions tout à l'heure allusion.

Nous ne parlerons pas des stries ou des bulles d'air, qui peuvent se trouver sur la surface même du porte-objet, et qu'un observateur inexpérimenté peut chercher vainement à caractériser; cet inconvénient est propre à toutes les préparations. microscopiques faites dans de mauvaises conditions. Il est facile de se mettre à l'abri d'un tel inconvénient, par le choix des plaques et par les précautions prescrites pour leur nettoyage et leur conservation (voy. p. 47 et 49 ).

Le meilleur moyen, dit M. Robin, de se familiariser avec l'étude des poussières que peut contenir un laboratoire, c'est de laisser exposée à l'air libre une lamelle de verre et d'examiner ensuite au microscope, à l'aide d'une goutte de glycérine, les corpuscules qui s'y sont déposés. A côté de granulations calcaires ou șiliceuses de volumes variables, de forme 
généralement polyédrique, mais plus souvent irrégulière, on trouve des cellules d'origine végétale, des fragments de fibres ligneuses ou libériennes, des poils de plantes (voy. leur description), des cellules filamenteuses provenant des aigrettes de certains fruits; toutes les variétés de grains de pollen, de fécules, de thèques ou sporanges diverses, de spores de cryptogames; du noir de fumée et des fragments de charbon.
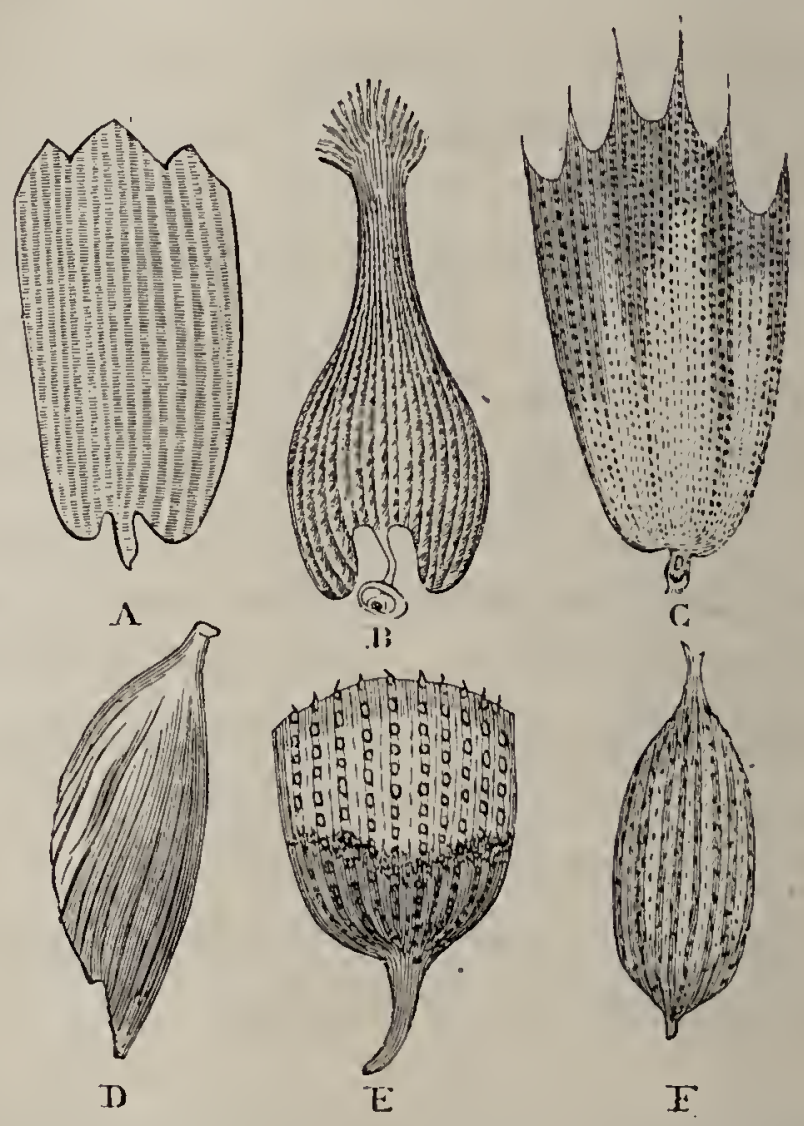

Fig. 257. - A. Écaille de papillon blanc (Satyrus janira) rue dans l'eau et grossie 150 fois. - B. Écaille en cœur du Pieris rapæ, rue à sec; grossie 200 fois. - C. Écaille de papillon blane (Pieris napi) provenant de la taehe noire de l'aile supérieure, vue dans l'eau gommée; grossie 160 fois. - D. Écaille d'inseete eolénptère (Callichroma alpina); grossie 250 fois. - E. Écaille de papillon (Polyommate argiolus); grossie 400 fois. - F. Écaille d'inscete (Dermeste des fourrures, Attagenus pellio); grossie 200 fuis.

On peut encore y rencontrer des éléments anatomiques entiers, ou brisés, ainsi que des fragments de tissus animaux, tels que: écailles de papillon, d'insectes divers (fig. 257 et 258 ); cellules épithéliales desséchées; poils, ou fragments de poils, des insectes (fig. 2j̋8) et des vertébrés; barbes et barbules de plume; fragments d'animaux articulés, de très petit volume, tels que les acariens (fig. 260), squelettes d'infusoires siliceux et autres, surtout dans les temps de grands vents; corpuscules indéterminés de nature azotée, de formes variées, parmi les- 
CHAPITRE XI. - DES SÉDIMENTS DE L'URINE.

quels il en est d'arrondis, offrant les caractères d'infusoires entiers et desséchés, etc. Nous avons emprunté cette longue énumération à M. Robin.

On comprend que, suivant que les poussières examinées
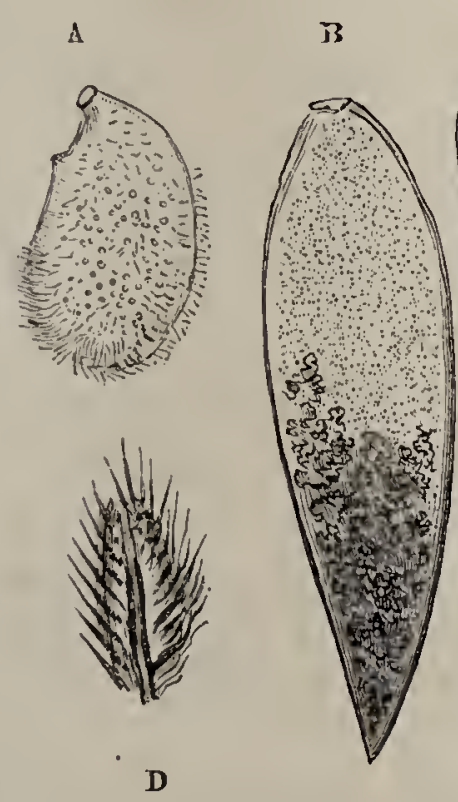

C

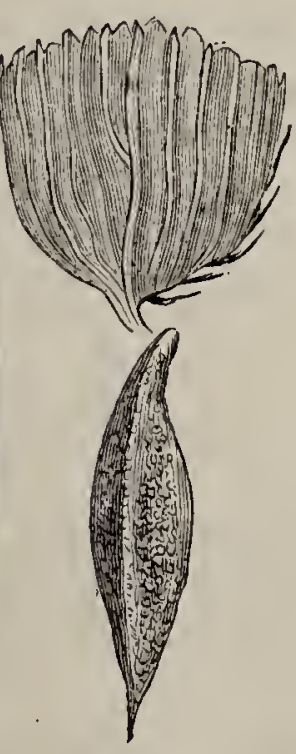

E

Fig. 258. - A. Éeaille d'insecte coléoptère (Hoplia squamosa ou argentea); grossie 200 fois. - B. Écaille d'insecte coléoptère (Curculionite exotique); grossie 200 'fois (écaille de la tache noire). - C. Écaille d'insecte coléoptère (Cryptorynchus lapathi); grossie 150 fois. - D. Écaille laciniée d'insecte coléoptère (Hylesimus varius); grossie 3j0 fois. - E. Écaille d'inseete coléoptère (Clytus arcuatus); grossie 300 fois.

proviendront d'un milieu différent, elles pourront présenter une composition essentiellement variable. Dans une pharma-

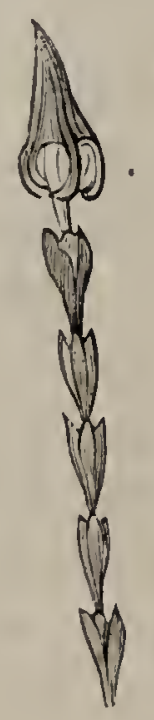

A

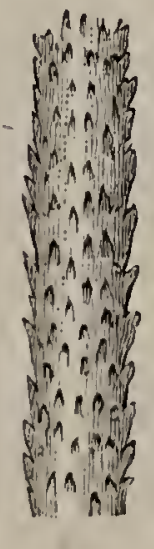

$B$

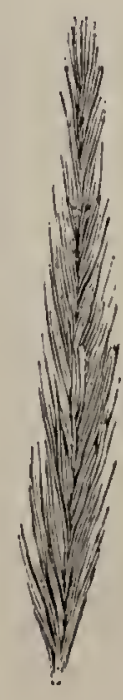

C

Fig. 259. - A. Poil artieulé et sagitté de la larve, d’anthrène; grossi 300 fois. - B. Poil hispide, portion d'un poil volumineux a vec aspérités de la surface (larve d'anthrène). - C. Poil lispide de la larve d’anthrène; grussi 300 fois, poil entièrement velu. 
cie, dans un atelier industriel, on aura des poussières différant complètement.

Les poussières qui se détachent des vêtements, dit M. Robin, sont de formes diverses et se présentent sous l'apparence de

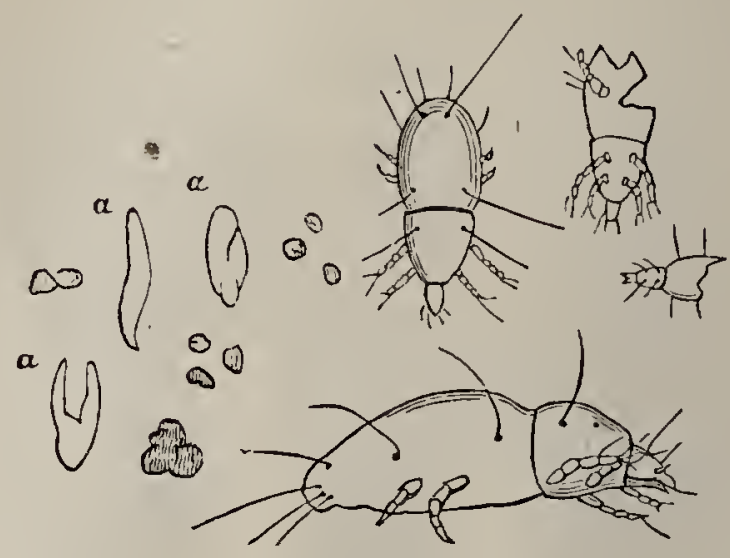

Figr. 2́60. - Poussières contenant des enveloppes de Tyroglyphus entomophagus. $-a$. Ovules de l'acarien, qui est représenté de dos et de côté. Enveloppes provenant de la mue de l'acarien. Fèces globuleuses (d'après A. Laboulbène et Ch. Robin).

granulations sans coloration particulière. L'eau est sans action sur eux, l'acide acétique les attaque faiblement, en dégageant quelques bulles de gaz, tandis que l'acide chlorhydrique les dissout complètement, en produisant un dégagement de gaz plus abondant. Ces réactions permettent de supposer que ces granulations sont formées par un carbonate.

Nous avons dit que l'on trouvait également dans les poussières une grande quantité de sporanges ou de spores, provenant d'espèces diverses, parmi lesquelles M. Robin signale les suivantes, dont on trouvera les caractères dans la première partie de ce livre : Puccinie, Phragmidium, Uredo, AEcidium, Oidium. On a également donné les caractères des différents. pollens, ainsi que ceux des fécules.

Il est très important de se familiariser également avec l'aspect des fragments de liège, qui tombent fréquemment dans. les vases à la fermeture desquels il a été employé.

Nous ne saurions trop le répéter, il faut se mettre en garde contre les simulateurs. M. Robin signale quelques-unes de ces fraudes. Des malades introduisent dans le canal de l'urèthre de la laine de matelas, des cheveux, qui sont entraînés. ensuite par l'urine. Nous consacrons un chapitre spécial à 
l'étude des poils de différents animaux, le lecteur y trouvera leurs principaux caractères. Au sujet des cheveux que l'on peut trouver dans l'urine, il est utile de savoir que, dans des cas très rares, la pilimiction (Robin) peut se produire. Il arrive quelquefois que des kystes pileux peuvent s'ouvrir dans la vessie; les cheveux, séjournant au contact de l'urine, peuvent se charger d'urates ou d'acide urique. Outre les cheveux, on peut trouver encore dans l'urine des filaments de coton, de chanvre, de soie, de laine, etc. Chacune de ces substances a été ou sera étudiée, nous n'y reviendrons pas.

Il est très important de se familiariser avec l'étude des plumes d'oiseaux et du duvet.

La présence de l'amidon dans l'urine est' très fréquente, surtout dans celle des femmes. Il est à peine nécessaire d'ajonter que l'existence de l'amidon dans l'urine est purement accidentelle. La détermination de la nature de ces grains d'amidon n'est pas toujours exempte de difficultés, en raison de l'altération qu'ils subissent au contact de l'urine. Mais, grâce à la réaction de l'iode, on parvient toujours à les caractériser. Nous ne saurions trop appeler l'attention sur ce point.

\section{\$12. - des parasites que l'on peut rencontrer dans l'urine.}

A propos des hématozoaires, nous avons parlé déjà des parasites et des œufs; que l'on peut rencontrer dans l'urine. M. le docteur Méhu (1) a eu la rare bonne fortune d'observer, dans l'urine d'un Français venant du Caire, des œufs de Billıarzia hæmatobia (Distoma hæmatobium) (Bilharz). Nous donnons la figure de l'ouvrage du docteur Méhu (p. 430). L'urine conlenait en même temps des globules blancs et des hématies.

Lionel Beale, dans son livre intituié : The Microscope in medicine, rapporte des observations analogues et donne des figures qui ne diffèrent pas essentiellement de celle'de M. Méhu, mais qui lui sont inférieures au point de vue de la netteté. Il rapporte que le docteur John Harley, ay ant appelé l'attention sur l'existence de l'hématurie endémique, dans

(1) Traité de chimie médicale, 18i8, p. 541. 
certaines parties du cap de Bonne-Espérance et dans Natal, démontra que cette affection était produite par une espèce de Bilharzia. Après l'avoir comparée avec beaucoup de soin

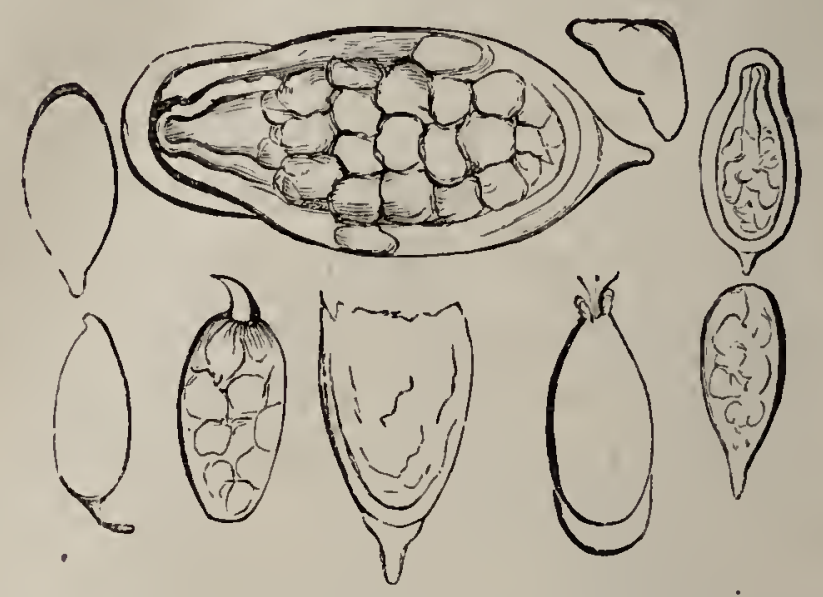

Fig. 261. - OEufs du Bilharzia hæmatobia provenant de l'urine.

aux figures que Griesinger donne du Bilharzia hæmalobia, cet observateur crut devoir la rapporter à une autre espèce, à laquelle il donna le nom de $B$. capensis. Toutefois, d'un examen ultérieur, il résulta que cette espèce était identique avec le Bilharzia hæmatobia.

Le docteur Harley a trouvé, dans l'urine de trois patients, des œufs ét des embryons ciliés de ce parasite, et aussi une portion de ses intestins; il y avait également une partie de ses téguments ciliés. Ce parasite est un ver trématode non hermaphrodite. Il a deux suçoirs et, dans le corps du mâle, est un canal particulier, "canal gynécophorique », qui reçoit la femelle pendant la copulation. On trouve principalement le parasite dans les veines vésicales mésentériques et dans les veines portes; sa présence dans les petites branches donne lieu à des lésions de la membrane muqueuse des intestins, de la vessie, des uretères et des bassinets des reins. Les principaux symptômes sont dela diarrhée, de l'hématurie, accompagnées d'une grande anémie et de la prostration des forces. Au bout d'un certain temps, les œufs et les embryons des parasites se trouvent dans l'urine. Le docteur John Harley pense que les œufs deviennentsouvent, après la disparition totale de l'hématurie, le noyau de calculs rénaux.

Outre le Bilharzia heematobia, M. J. Grevaux a trouvé un nou- 
veau parasite dans les urines de l'hématurie chyleuse des pays chauds, qu'il décrit en ces termes: (Journal de l'anatomie et de la physiologie, 1875) :

"Cet animal, long de $0^{\mathrm{mm}}, 26$, est mince comme un fil ; une extrémité obtuse paraît correspondre à la tête, qui porte près de sa terminaison un petit point, ressemblant plutôt à un amas de granulations qu'à un orifice; agilité remarquable, vitalité très grande. Depuis l'époque où nous avons découvert ce parasite, dit M. Grevaux, nous avons, pendant une période de quatre années, examiné les urines du même malade, et chaque fois nous avons retrouvé le même helminthe. " MM. Balbiani et Davaine, consultés sur l'origine de ces parasites, les ont considérés comme des embryons d'un nématoöde, ayant quelques traits de ressemblance avec les embryons du Strongle géant.

D'après L. Beale, des échinocoques, provenant des kystes hydatiques des reins, ont traversé le kyste et ont pu passer dans l'urine. Leurs crochets sont caractéristiques et on en a trouvé dans les dépôts urinaires. L. Beale mentionne un cas, d'après Simon, dans lequel de petits kystes ont été rejetés en entier.

Le docteur A. Farre a décrit, sous le nom de Diplosoma crenata, un helmin the dont il a également étudié les œufs. Il s'agissait d'une femme de vingt-quatre ans qui, dans l'espace de deux ou trois mois, rendit de 800 à 1000 ver's. Un examen attentif montra que ces vers n'appartenaient pas à la même espèce : les uns, d'une longueur de $0^{\mathrm{m}}, 10$ à $0^{\mathrm{m}}, 15$, furent éliminés en grande quantité; les autres étaient plus petits et avaient une longueur variant entre $0^{\mathrm{m}}, 01$ et $0^{\mathrm{m}}, 02$ et demi. Ces derniers furent rejetés en une seule fois et vécurent dans l'urine pendant trois jours; leurs mouvements étaient très actifs. On a reconnu qu'ils appartenaient au genre Spiroptère, et Rudolphi leur a donné le nom de Spiroptera hominis. Les helminthes de la plus grande espèce ontété reconnus être des Diplosoma crenata (L. Beale, p. 432).

Un autre parasite, le Dactylius aculeatus, a été trouvé dans l'urine d'une petite fille de cinq ans par Drake (voy. L. Beale, loc. cit.). La femelle a environ $0^{\mathrm{m}}, 024$ de long et le mâle $0^{\mathrm{m}}, 012$ 
seulement. Ces vers étaient doués de mouvements très actifs et pouvaient vivre dans l'urine deux ou trois jours ; leur tégument était garni d'épines réunies en faisceaux.

Le Strongle géant, assez commun dans le rein de certains animaux et en particulier dans celui du chien, aurait été observé dans le rein de l'homme, d'après L. Beale. Le fait a été révoqué en doute par Küchenmeister.

\section{Sédiments de l'urine formès par des éléments non organisés et affectant la forme cristalline.}

\section{§ 1. 一 URÉE.}

En raison de sa grande solubilité, l'urée ne peut être considérée comme devant être placée au nombre des sédiments urinaires. Toutefois, comme ce corps est très important à connaître et que, de plus, il se combine à certains acides, pour donner des produits cristallisés, nous avons tenu

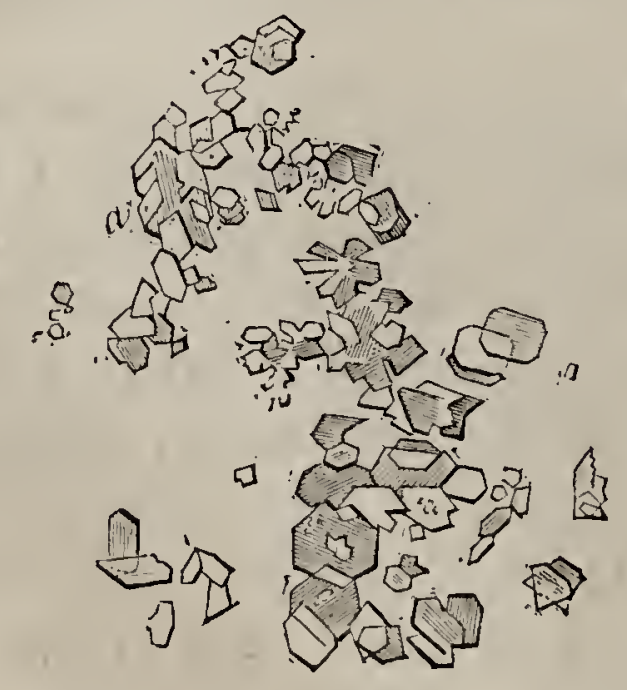

Fig. 262. - Nitrate d'urée.

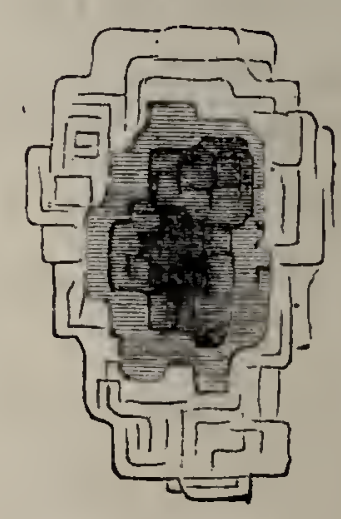

Fig. 263. - Nitrate d'urée.

a donner différentes figures qui pourront être utiles à nos lecteurs.

L'azotate d'urée (fig. 262, 263, 264) s'obtient avec la plus grande fiıcilité. Si l'on opère sur de l'urine humaine, il suffit d'en évaporer une partie afin de la concentrer et d'y ajouter son volume d'acide nitrique; après quelques instants, il se 
fait un dépôt de plaques brillantes d'azotate d’urée. L'évaporation préalable n'est pas nécessaire avec l'urine de chien, qui

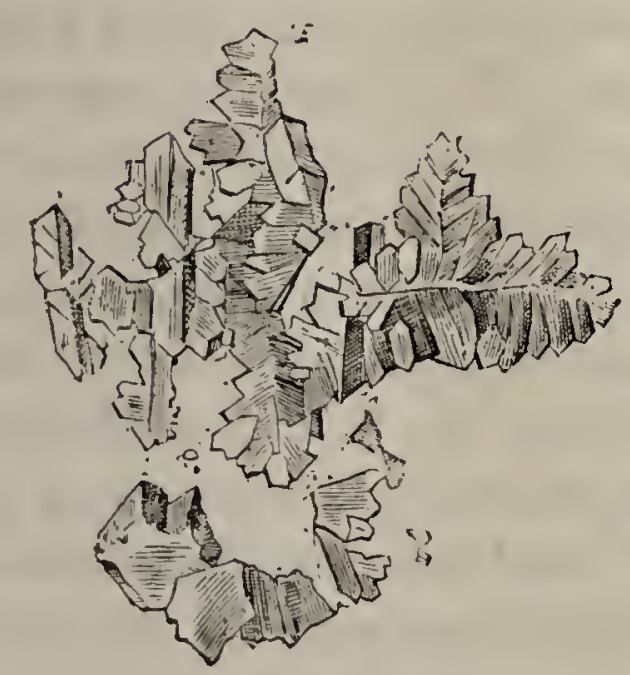

Fig. 264. - Nitrate d'urée.

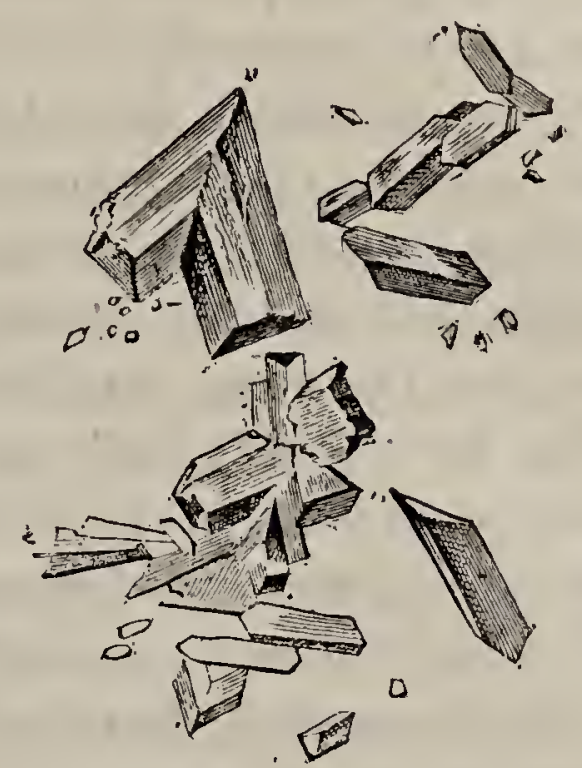

Fig. 265. - Oxalate d'urée.

ordinairement est très riche en urée. On a également employé l'acide oxalique pour isoler l'urée à l'état d'oxalate d'urée. La figure 265 donne la forme de l'oxalate d'urée.

L'urée peut être obtenue de son nitrate, par un traitement chimique fort simple, que nous n'avons pas à indiquer ici.

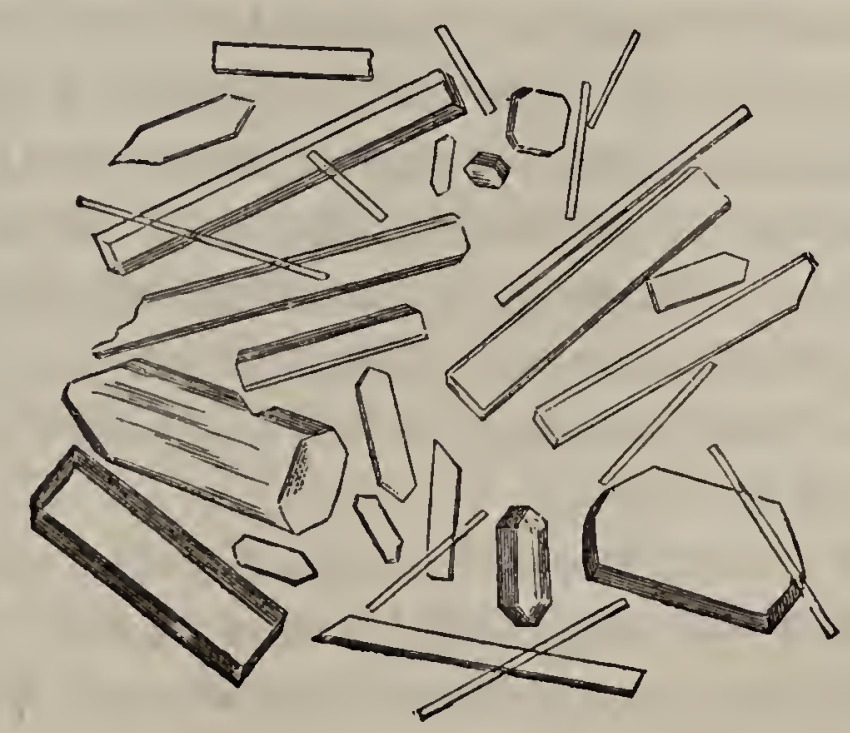

Fig. 266. - Urée.

Après évaporation du liquide qui tenait l'urée en solution, on obtient des cristaux figurés ci-dessus. Les cristaux d'urée appartiennent au système du prisme droit à base carrée; ce GUIDE DE MICROGRAPHIE. 
sont des prismes à quatre pans, terminés à leur ęxtrémité par une ou deux facettes obliques (Méhu).

On peut provoquer la formation des composés cristallisés de l'urée sur le porte-objet, en opérant de la façon suivante: on place, sur la goutte dans laquelle on veut rechercher l'urée, l'extrémité d'un petit morceau de fil retors, puis on couvre la goutte et la moitié du fil avec une plaque de verre. Ceci fait, l'extrémité libre du fil est mise en contact avec, de l'acide azotique pur. Les deux liquides se mêlent peu à peu et la production des cristaux s'effectue avec une grande régularité, sous la lamelle de verre et à l'extrémité du fil. Si l'on observe les cristaux pendant leur formation, on trouvera d'abord, à côté de plusieurs formes compliquées, des tables rhomboïdales ou des prismes courts, dont les angles aigus ont $82^{\circ}$. Par suite du remplacement des angles obtus par des faces, les formes sont changées en tab́les hexagonales ou en prismes à six pans. Cependant, ce développement régulier n'a lieu que lorsque les cristaux se forment lentement, tandis que si leur formation est plus rapide, il se dépose promptement une grande quantité de tables hexagonales imbriquées les unes sur les autres. Fréquemment aussi, au premier contacl des deux liquides, il se forme des octaèdres rhomboédriques obtus, qui durent très peu et dont les angles aigus mesurent $82^{\circ}$, mais auxquels s'ajoutent rapidement de nouvelles particules salines, de telle sorte que loctaèdre primitif prend la forme des tables rhomboïdales ou hexagonales nommées plus haut. Enfin, on observe encore de doubles cristaux très caractéristiques, qui par suite d’un arrangément particulier, difficile à décrire, donnent lieu à des formes cristallines tout à fait semblables à celles du gypse (Neubauer et Vogel).

On provoque la formation d'oxalate d'urée d'une façon analogue. L’oxalate d'urée se précipite sous la forme de lamelles minces ou allongées, ou sous forme de prismes. Si on laisse la formation des cristaux seffectuer sous le microscope, ils se présentent ordinairement avec l'apparence d'azotate d'urée, c'est-à-dire en tables hexagonales, mais quelquefois aussi en prismes à quatre faces (Neubauer et Vogel). 


\section{§ 2. - acide urique. - URATES.}

L'acide urique est un produit normal d'excrétion ; tantôt il est libre, tantôt il est combiné soit à l'ammoniaque, soit à d'autres alcalis. On connaît mal encore les conditions qui font varier la quantité d'acide urique rendue chaque jour; la moyenne oscille entre 0,50 et 0,60 centig. On voit donc que, pour une quantité d’urine déterminée, la proportion d'acide urique est très variable et qu'il est absolument nécessaire de doser l'acidè urique sur la quantité d'urine émise en vingtquatre heures.

Il n'estpas rare de voir des personnes présentant l'apparence d une bonne santé, émettre chaque jour une quantité très appréciable de cristaux d'acide urique pur; cependant, ces personnes sont fréquemment sous l'imminence de certains accidents, sur lesquels nous n'avons pas à insister ici. Les rhumatisants, les goutteux, les fiévreux, quelle que soit l'origine de la fièvre, rendent un excès d'acide urique; toutefois, comme la proportion d'urine émise peut être diminuée, il ne faut pas exagérer l’importance de ce symptôme.

La forme des cristaux d'acide urique est très variable; néanmoins, il y a un certain nombre de formes cristallines fondamentales, types auxquels se ramènent aisément les formes rares. Disons tout de suite que l'on peut toujours obtenir l'une des formes connues, en dissolvant les cristaux dans une solution alcaline de soude ou de potasse et en les précipitant de cette solution par l'acide acétique. Dans les cas douteux, il faudra recourir à une réaction chimique, et en particulier à l'action successive de l'acide azotique et de l'ammoniaque, donnant la murexide de Liebig, ou le purpurate d'ammoniaque de Prout.

Le volume des cristaux d'acide urique est très variable; tantôt ces cristaux sont si volumineux, que l'on peut déterminer leur forme à l'aide d'une simple loupe; tantôt, au contraire, ils sont d'un volume si petit, qu'on a besoin d'un grossissement assez fort pour les caractériser. Généralement ces cristaux sont colorés; ils sont ambrés et ont des reflets dorés; tantôt, vus en masse, ils sont rougeâtres ou rouge-orangé. 
Lorsqu'une urine contient à la fois des urates et de l'acide urique, on conseille d'en chauffer une certaine quantité dans un verre de montre; les urates se redissolvent el l'acide urique se dépose.

Si, dans la plupart des cas, l'acide urique ne se dépose que par refroidissement de l'urine, il est cependant. des circonstances en vertu desquelles l'acide urique se dépose dans la vessie. C'est ainsi que l'agitation de l'urine pendant un voyage faciliterait, dit M. Méhu, le dépôt de l'acide urique dans la vessie.

Les formes cristallines de l'acide urique si variables, comme nous l'avons dit, peuvent être rapportées à des modifications de prisme rhombique.

On peut obtenir artificiellement des variétés cristallines par l'addition d'acide chlorhydrique à une solution d'urates alcalins; les cristaux qu'on obtient alors se présentent soit sous la forme de rhomboïdes parfaits, soit sous la forme de tables carrées, généralement excavées sur leurs côtés et prenant imparfaitement l'apparence de sabliers ou d'haltères.

Lorsque l'on veut examiner des cristaux d'acide urique, on peut sans inconvénient les laver dans de l'eau, ou ajouter ce liquide à la préparation microscopique.

Souvent, les cristaux sont.si volumineux, qu'il faut employer

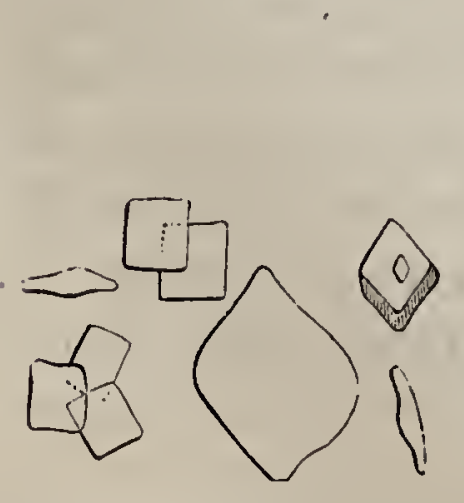

Figr. 267. - Acide urique.

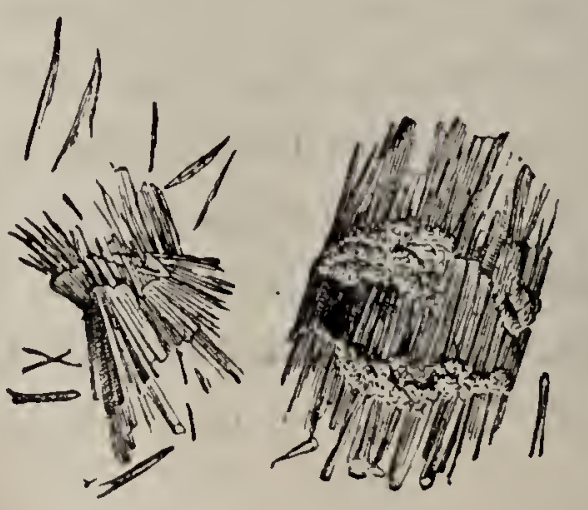

Fig. 268. - Acide urique.

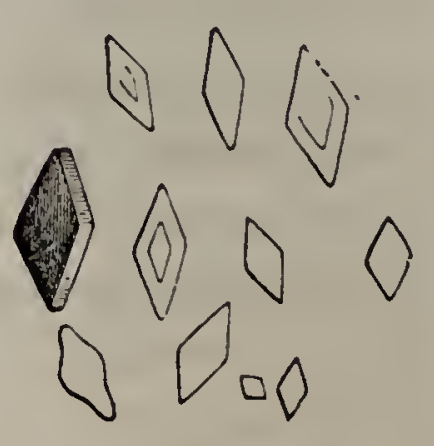

Fig. 269. - Acide urique.

un très faible grossissement pour les voir dans leur ensemble.

Nous donnons. un certain nombre de formes cristallines d'acide urique.

La figure 269 représente les cristaux rhomboïdes ordinaires de l'acide urique; quelquefois ces cristaux sont si minces qu'ils 
ressemblent à des lames losangiques peu colorées. Golding Bird signale un fait très fréquent : il arrive que ces cristaux présentent à leur intérieur des lignes géométriques qui sembleraient indiquer qu'il y a eu un cristal plus petit emprisonné dans le cristal principal.

Parfois les angles des cristaux sont aigus, parfois, au contraire, ils sont obtus ou arrondis, le cristal devient alors elliptique. On rencontre fréquemment ce spécimen, dit Golding Bird, dans le dépôt jaune de l'urine des jeunes enfants, tandis qu'au contraire on ne le trouverait pas dans les dépôts d'acide urique obtenu artificiellement.

Les angles des cristaux peuvent se modifier si profondément, que dans certains cas d'affection calculeuse le rhombe peut être remplacé par un carré (Golding Bird). Le dépôt est alor's très coloré et les cristaux beaucoup plus épais que dans la première variété. Ces cristaux peuvent présenter également la même particularité que celle obserrée dans la forme précédente; on observe dans le cristal des lignes parallèles à celles qui délimitent ses contours.

'Parmi les variétés accidentelles d'acide urique, on remarque les suivantes, qui sont susceptibles d'éprouver de nombreuses modifications. Les angles obtus du losange se sont arrondis,
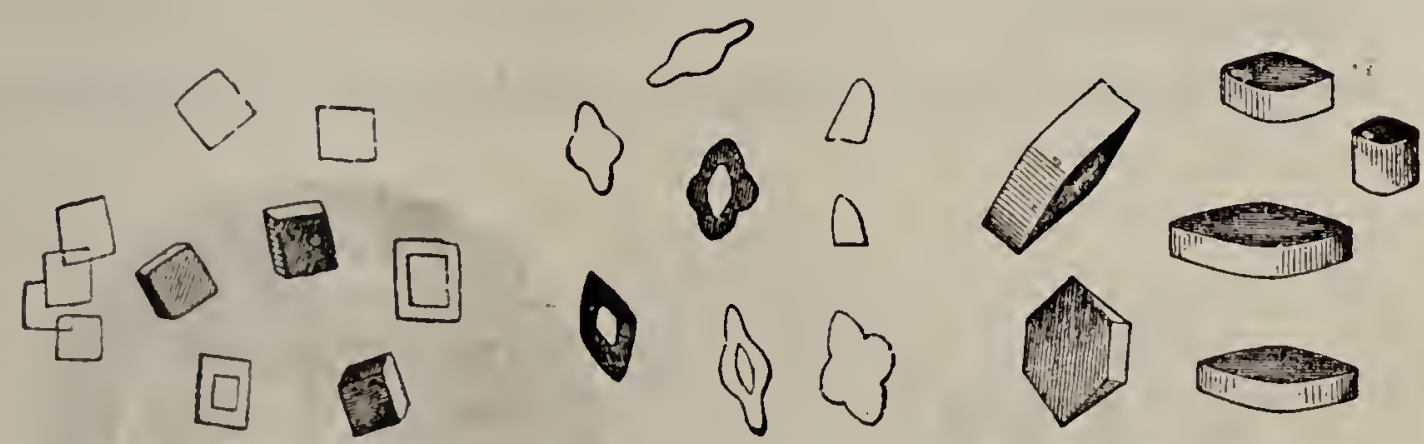

Fig. 270. - Acide urique. Fig. 271. - Acide urique. Fig. 272. - Acide urique.

et la ligne qui joint cet angle obtus à l'angle aigu qui termine le losange, s'étant excavée plus ou moins, il en résulte des cristaux ir'réguliers qui ne présentent plus que des lignes courbes (fig. 2 21 ).

La forme losangique avec quelques modifications est certainement la plus commune. Pour bien observer ces cristaux, il faut les déplacer, en ajoutant du liquide à la préparation, de façon à les voir sous toutes leurs faces. Leur épaisseur 
varie, mais généralement elle est assez considérable. Cette variété, dit Golding Bird, se rencontre fréquemment avec des urates et des cristaux d'oxalate de chaux (fig. 272).

Une forme rare de cristaux d'acide urique, figurée dans l'Atlas de Robin et ${ }_{d}$ Verdeil et dans Golding Bird, est la suivante: les cristaux se présentent sous la forme de tables, généralement plus longues que larges et dont les arètes sont nettement limitées.

Les extrémités, au contraire, sont finement dentées et la surface des cristaux offre des stries parallèles quelquefois continues, d'autres fois interrompues. Il semblerait que ces stries soient formées par des aiguilles très fines et très rapprochées. Robin et Verdeil, Golding Bird, ont figuré et décrit sur la surface de ces cristaux deux lignes sombres, peu distantes l'une de l'autre et affectant la forme de deux croissants (fig. 273).

Différentes théories ont été données sur le mode de formation de ces cristaux. D'une façon générale, il paraît démontré que la plus ou moins grande rapidité avec laquelle se forment les cristaux a une grande influence sur la variété de forme cristalline qu'ils affectent; lorsque l'on traite à chaud une solution d'urates par de l'acide acétique, suivant que la solution se refroidit plus ou moins vite, on a des cristaux de forme différente.

Les cristaux d'acide urique ne sont pas toujours isolés; au

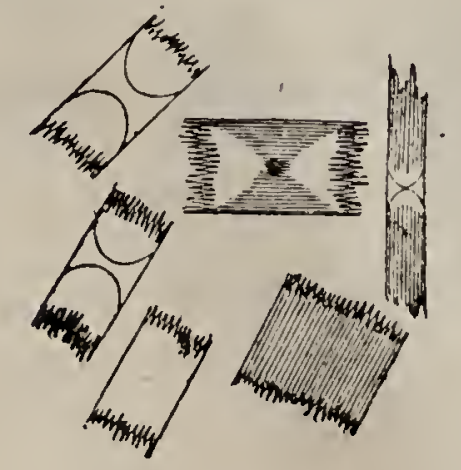

Fig. 273. - Acide urique.

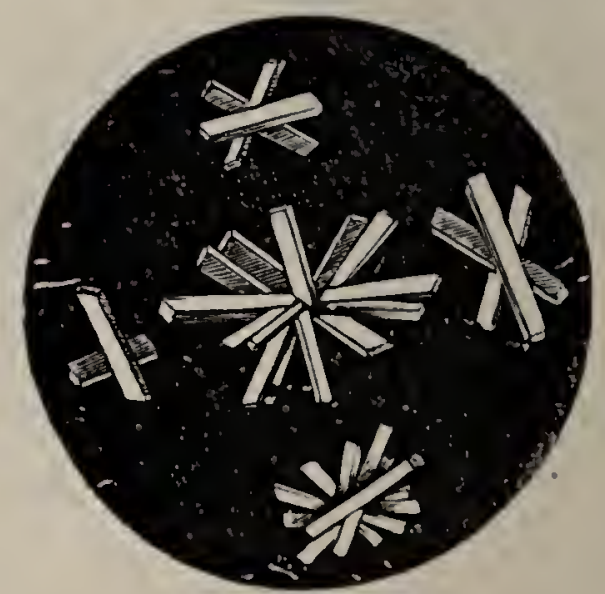

Fig. 274. - Acide urique.

contraire, ils sont très fréquemment soudés entre eux et forment ainsi des agglomérations de formes très variées. Golding Bird a observé deux variétés de cristaux, l'une formée de pris- 
mes rhomboïdaux soudés entre eux (fig. 274), et l'autre formée par des losanges en masses épineuses (fig. 275). Cet auteur a remarqué que ce dernier mode de cristallisation se produisait surtout quand il y avait une tendance à la formation de calculs d'acide urique. Il arrive fréquemment, ainsi qu'on en voit un exemple sur la figure $27 \%$, que ces cristaux se groupent le

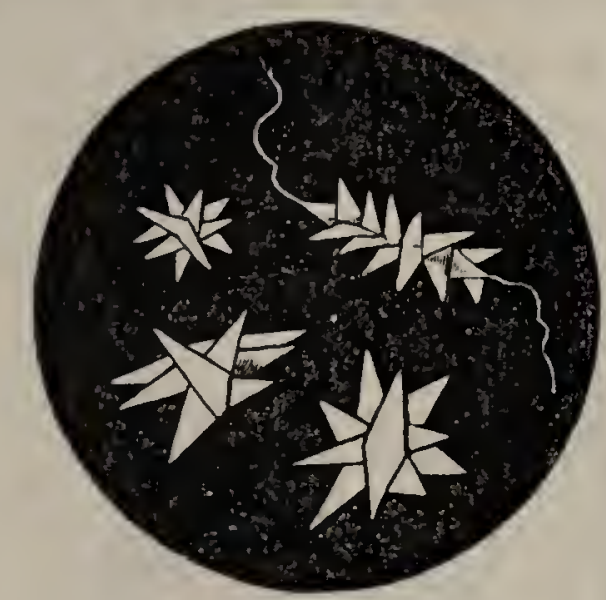

Fig. 275. - Acide urique.

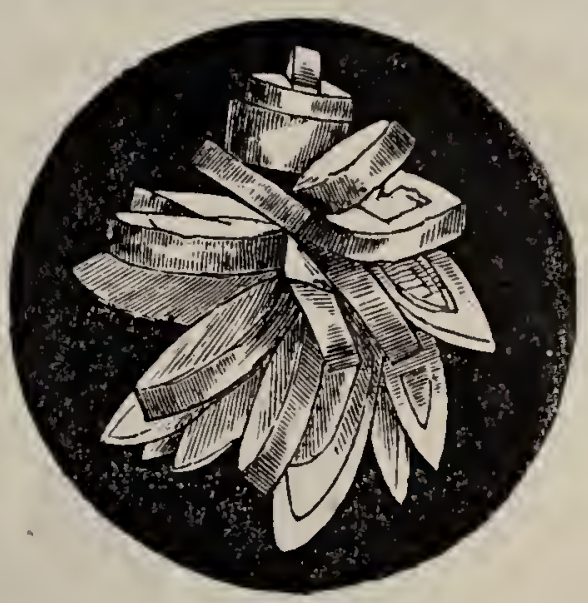

Fig. 976. - Acide urique.

long d'un fil ou d'un cheveu. On a assez rarement l'occasion d'observer cette dernière forme de cristaux.

Bien que Golding Bird considère la forme suivante (fig. 276), constituée par l'agglomération en masses volumineuses de losanges, comme assez rare, on l'observe cependant assez fréquemment dans les urines qui laissent déposer une grande quantité de cristaux d'acide urique. Sous le nom de concrétions

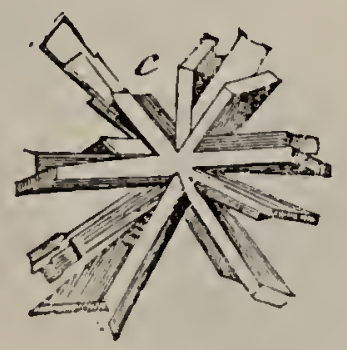

Fig. 277. - Acide urique.

pisiformes, Golding Bird a décrit de petites masses sphériques, de grosseur variable et constituées par de l'acide urique, que l'on trouve souvent en masse considérable, dans l'urine des goutteux. Au premier abord, ces petits calculs n'ont pas l'apparence cristalline; mais si on les traite par de l'acide nitrique faible, leur structure cristalline devient évidente et présente 
l'apparence de nombreux rhomboïdes déliés, partant d'un centre commun.

\section{§ 3. - FORMES RARES D'ACIDE URIQUE.}

Il nous suffira d'appeler l'attention sur les figures suivantes pour montrer combien sont singulières les formes que peut affecter l'acide urique (fig. 278) : $a$, cristal en haltères; $b$, cris-

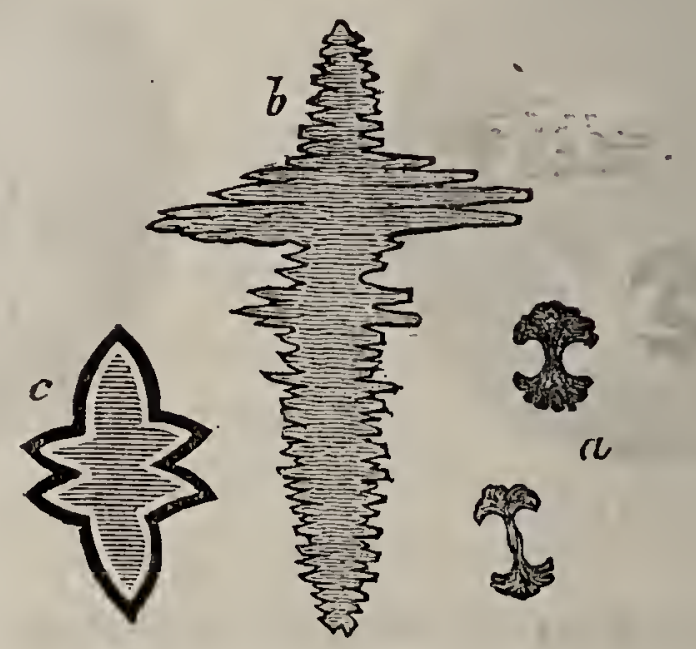

Fig. 278. - Acide urique.

tal fusiforme ; $c$, cette dernière forme est si particulière, qu'elle ne peut guère servir de terme à une comparaison.

Comme nous l'avons dit plus haut, il arrive fréquemment

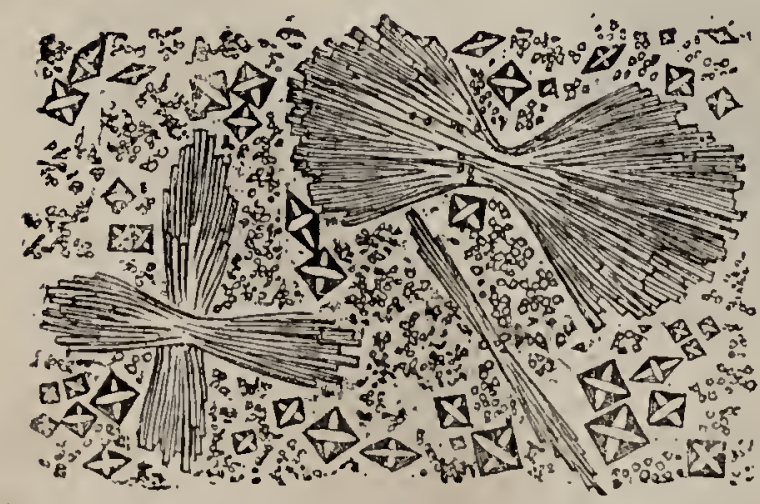

Fig. 279. - Acide urique uni à l'urate de soude et à l'oxalate de chaux.

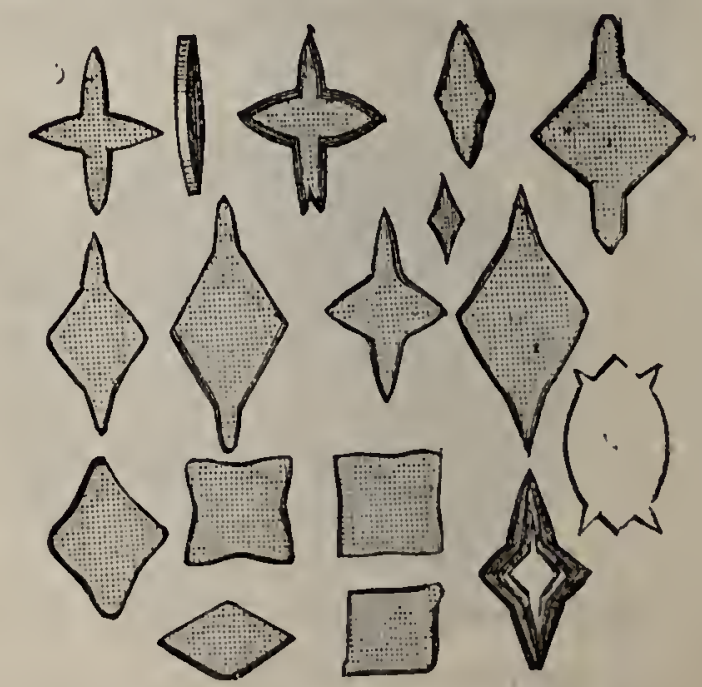

Fig. 280. - Acide urique (Iéhu).

que les cristaux d'acide urique sont mélangés à des urates et à des cristaux d'oxalate de chaux. La figure 279 montre 
de l'acide urique cristallin ayant pris la forme de faux haltères. (Golding Bird).

M. Méhu a figuré dans son Traité de chimie médicale. différentes formes d’acide urique qu'il a observées. La figure 280 donne la forme des cristaux d'acide urique que l'on trouve dans les urines chargées de pigment biliaire, ou pigment rouge hépatique. Ce sont ces urines que l'on a appelées. à tort hémaphérques. Le nom qui leur a été imposé par M. Méhu doit suivant nous être adopté. G'est également dans ces urines, riches en pigment rouge hépatique, que ce même observateur a observé les formes bizarres figurées par

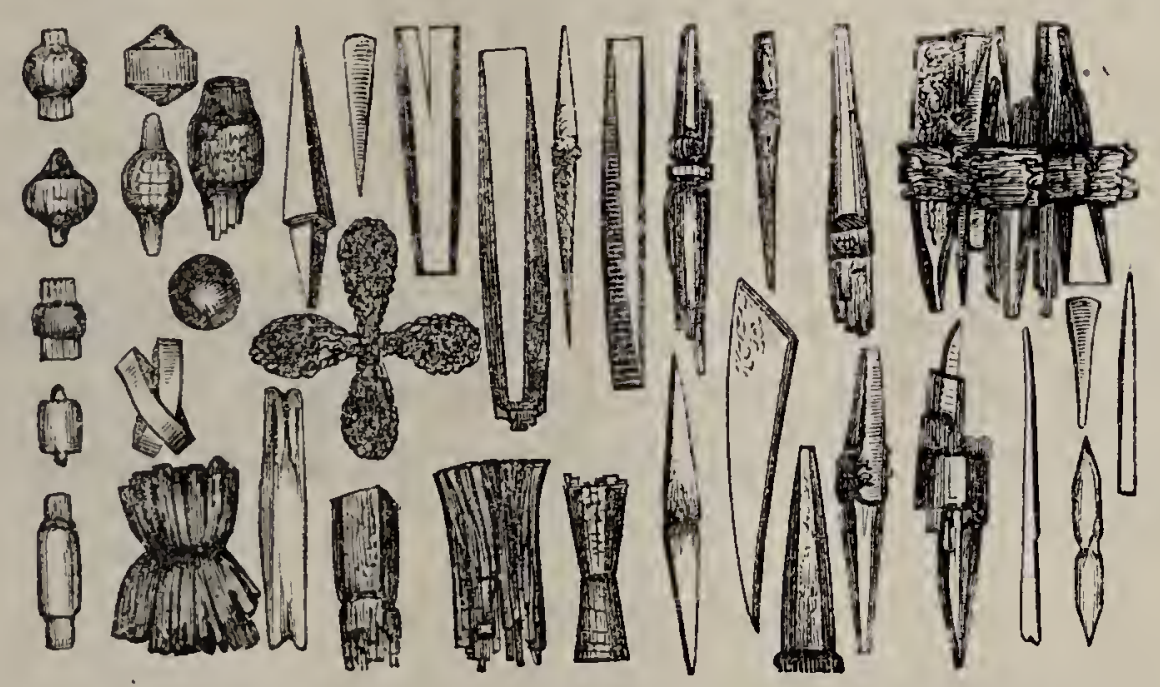

Fig. 281. - Acide urique dans les urines très colorées (Méhu).

lui ci-dessus. M. Méhu compare ces cristaux à des lames d'épées, de poignards, de baïonneltes, à des pierres à aiguiser, à des gerbes, à des rosaces, etc., et il insiste avec raison sur la coloration plus ou moins jaune-orangée, qui ne leur fait jamais défaut.

Nous avons vu plus haut que Golding Bird avait cru voir une certaine coincidence entre l'apparition dans l'urine de cristaux losangiques d'acide urique groupés en masses épineuses (fig. 27oั), et la formation de calculs d'acide urique. M. Méhu a fait des observations analogues, seulement la forme cristalline qu'il décrit est tout à fait particulière et diffère essentiellement de celle donnée par Golding Bird. Quoi qu'il en soit, ces deux observations sont d'une grande importance, il est à souhaiter que de nouvelles recherches con- 
firment celles qui ont déjà été faites. Les cristaux reproduits par M. Méhu (fig. 282) ont la forme de clous, de stalactites, d'épines, etc. Cet auteur a rencontré ces cristaux dans des urines contenant des globules ronges, des globules blancs et une minime quantité d'albumine. Pour M. Méhu, cette forme si

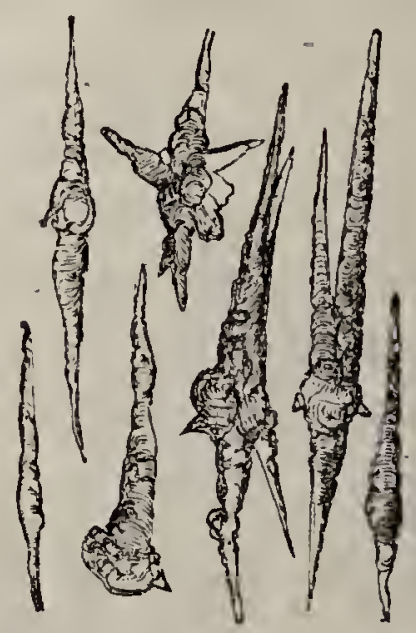

Fig. 2S2. - Acide urique (Méhu).

spéciale de cristaux serait l'indice de la présence, dans le rein, d'un calcul ou d'un gravier d'acide urique. Il y aurait là un élément important de diagnostic sur lequel nous appelons l'attention.

\section{$\S 4 .-$ DES URATES.}

Les urates se déposent lorsque l'urine est refroidie, et il suffit d'élever la température de celle-ci pour les dissoudre. Ils sont très différents comme couleur et varient du blanc-jaunâtre au rouge-brique, en passant par tous les degrés du rose. Cette dernière coloration est très fréquente dans l'urine des fiévreux. Les urines qui contiennent une grande quantité d'urates prennent parfois un aspect trouble dâns toute leur masse, et le dépôt qu'elles abandonnent pourrait être pris, à un simple examen, pour un dépôt purulent. Lorsque l'on place une goutte d'une telle urine sur le champ du microscope, on voit qu'elle est formée d'une foule de granulations très fines, soit isolées, soiten groupes irréguliers. Il arrive très fréquemment que ces granulations d'urates sont mélangées à un grand nombre de cristaux d'acide urique, de volumes variables, de formes différentes, groupés ou isolés. Nous avons fréquemment observé des urines dans lesquelles 
l'abondance d'un tel dépôt était véritablement remarquable.

Lorsque le dépôt se compose uniquement d'urates, il suffit de faire pénétrer dans la préparation quelques gouttes d'acide acétique et d'attendre un certain temps. On voit apparaître des cristaux d'acide urique ayant la forme classique.

\section{§ כ. - urate acide d'ammoniaque.}

L’urate d'ammoniaque se présente quelquefois en fines aiguilles, groupées en étoiles. Toutefois, cette forme est rare, et des observateurs sérieux ne l'ont jamais rencontrée. Le docteur Bence Jones a démontré que la présence d'une matière saline, ou de la matière colorante de l'urine, modifiait la cristallisation en aiguilles de l'urate d'ammoniaque, et le transformait en globules extrêmement petits.

Une forme assez fréquente d'urate d'ammoniaque est la suivante (fig. 283) : elle se rencontre dans les urines putréfiées. Les masses sphériques hérissées de pointes sont plus souvent observées que ces masses en forme de haltères, qui les accompagnent quelquefois.

Il n'est pas rare d'observer, en même temps que l'urateacide d'ammoniaque, des cristaux de phosphate ammoniaco-

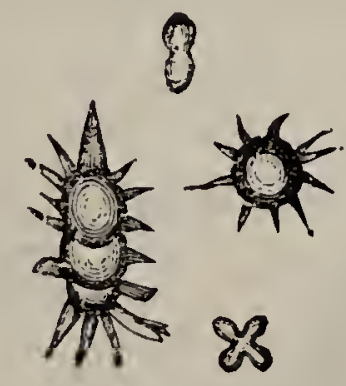

Fig. 283. - Urate de soude.

magnésien, du phosphate de chaux amorphe et des globules de pus.

M. Méhu (loc. cit.) donne le moyen suivant pour distinguer l'urate d'ammoniaque des urates de soude et de potasse. On traite l'urate par une goutte d'acide chlorhydrique sur une plaque de verre et on laisse la cristallisation s'effectuer. lentement. On observe alors des cristaux d'acide urique, des cubes 
de chlorure de potassium ou de sodium ou des arborisations de chlorhydrate d'ammoniaque.

En préparant artificiellement de l'urate d'ammoniaque, on obtient des cristaux très réguliers qui rappellent assez fidèlement ceux qui se forment spontanément dans l'urine.

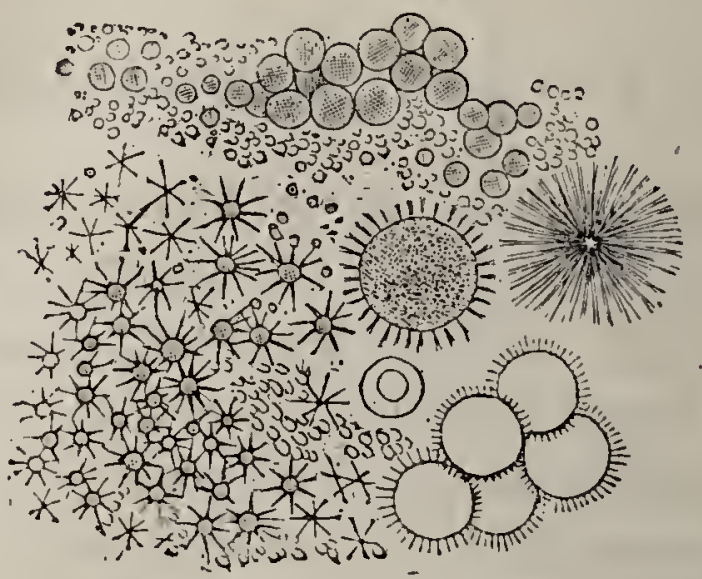

Fig. 284. - Urate d'ammoniaque.

L'urine des oiseaux et celle des reptiles renferment une grande quantité d'urate d'ammoniaque, n'ayant que rarement l'aspect cristallin aiguillé et se présentant plus fréquemment sous la forme de corpuscules arrondis ou ovales.

\section{\$ 6. - URATE ACIDE DE SOUdE.}

Ce sel forme fréquemment un dépôt distinct. Il se présente

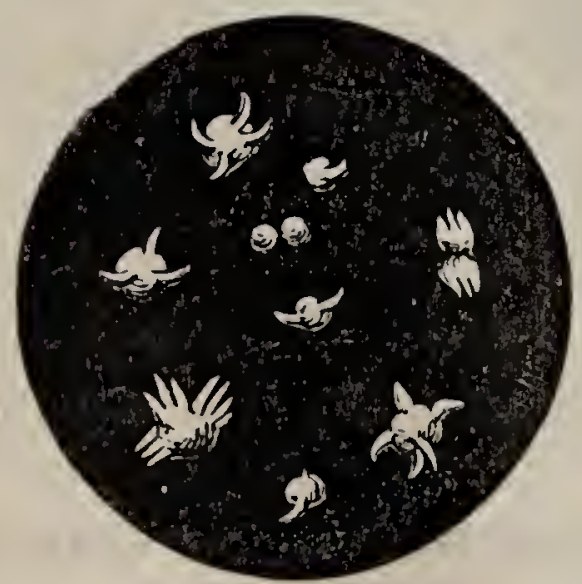

Fig. 285. - Urate de soude.

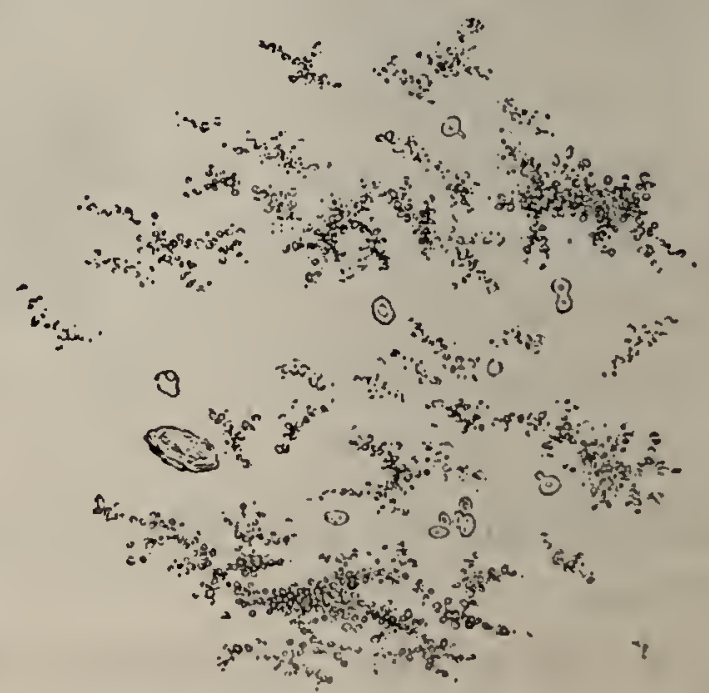

Fig. 286. - Urate de soude.

communément sous la forme de fines granulations arrondies. Golding Bird l'a rencontré sous forme de masses arrondies, 
jaunâtres ou blanches, éparses, munies de prolongements saillants, ordinairement courbés.

Cet urate se rencontre dans les articulations des goutteux sous forme de concrétions.

Par la préparation artificielle de l'urate de soude, on l'ob-

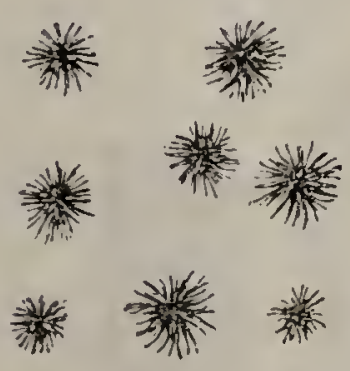

Fig. 287. - Urate de soude.

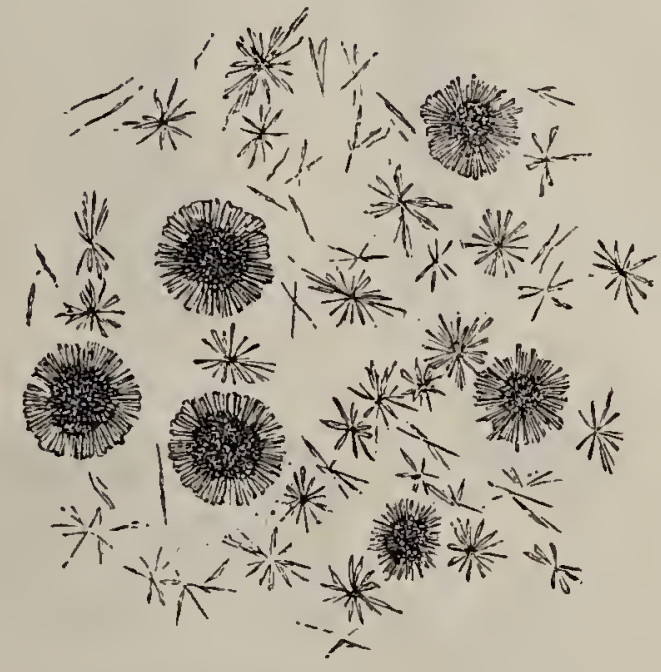

Fig. 288. - Urate de soude.

tient en aiguilles et en masses cristallines, formées par des aiguilles partant d'un centre commun.

\section{§7. - URATES DE MaGNÉSIE.}

L'urate de magnésie ordinaire se rencontre fréquemment dans les calculs. Il est facilement soluble dans l'eau bouillante, qui le laisse précipiter par le refroidissement. Examiné au microscope, il présente deux variétés de formes : tantôt il constitue des amas amorphes, tantôt au contraire il cristallise en prismes taillés ou non en biseau, et réunis le plus souvent en grand nombre, pour former des amas sphéroïdaux. Ces prismes peuvent être isolés, et dans ce cas ils sont plats, demi-transparents; ils ont environ $0^{\mathrm{mm}}, 10$ de largeur et une longueur variable. Parfois les sphérules déterminées par l'agglomération régulière des prismes surnagent sur le liquide. Ces sphérules sont d'un blanc nacré, d'une texture soyeuse. Les cristaux peuvent atteindre 1 millimètre de largeur (Gh. Robin). Le bi-urate hydraté de magnésie (Bigelow) est très rare. Il cristallise sous la forme 
de prismes à quatre faces, à angles réguliers. Ils ressemblent beaucoup à des prismes d'acide hippurique. Les cristaux d'acide hippurique sont très solubles dans l'eau, tandis que les

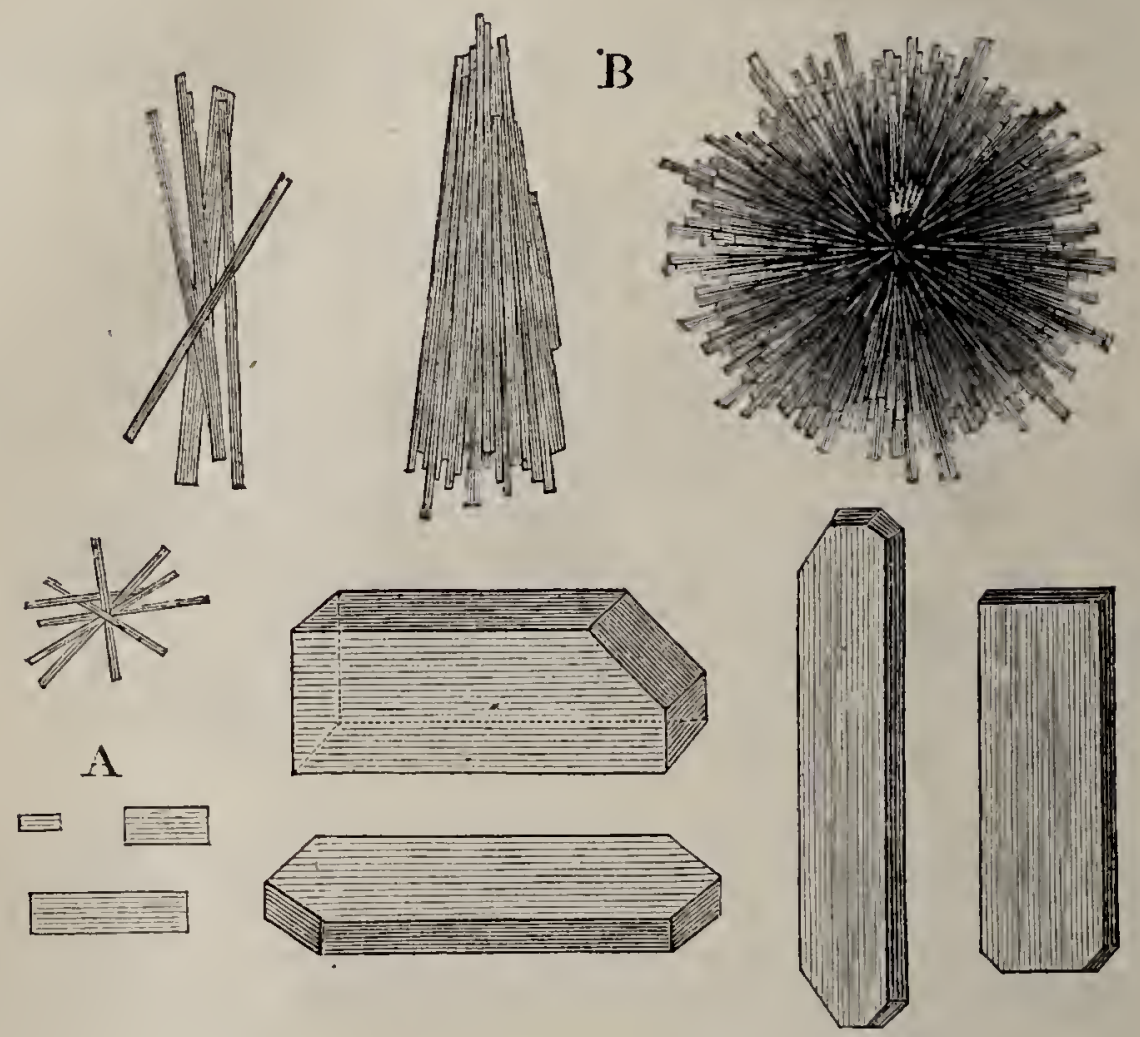

Fig. 289. - Urate de magnésie des calculs urinaires, d’après Ch..Robin.

A, prismes isolés. - B, prismes réunis et formant des amas sphéroidıux.

cristaux de cet urate de magnésie y sont insolubles. Le biurate hydraté de magnésie résiste à l'action de l'acide acétique (Gh. Robin).

§ 8. - recherche de liagide urique dans le sang. - urate de soude.

Dans certaines affections, rhumatisme ou goutte, mais surtout dan's cette dernière, il arrive fréquemment qu'il se forme un excès d'urate de soude ou d'acide urique libre, même dans le sang. Il y a alors pour le clinicien un grand intérêt à constater ce fait. Deux procédés sont employés pour cette recherche, ils sont dus tous les deux au docteur Garrod. On peut mettre en évidence l'urate de soude, par le procédé suivant: on évapore au bain-marie du sérum du sang, que l'on débarrasse de la matière grasse par la digestion dans l'alcool. Le résidu insoluble est épuisé par l'eau bouillante; la 
solution aqueuse, concentrée par évaporation lente, se couvre d'une pellicule de cristaux d'urate de soude.

Généralement on se contente d'isoler l'acide urique. Le sérum du sang est évaporé à siccité, au bain-marie, puis pul-

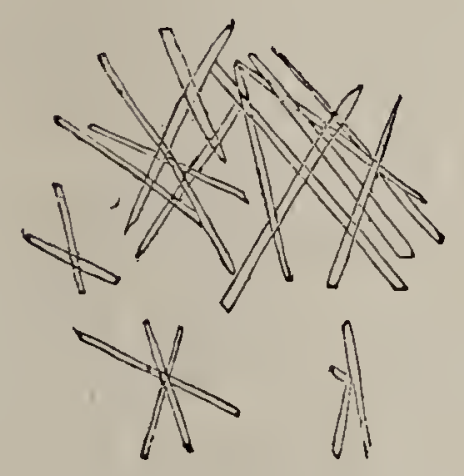

Fig. 290. - Urate de soude dans le sang des goutteux.

vérisé et épuisé par digestion avec l'eau à $100^{\circ}$, pendant une heure. On ajoute ensuite à la solution aqueuse quelques gouttes d'acide acétique, et quelques fibrilles de chanvre ou de lin. Au bout d'un certain temps, l'acide urique cristallise le long de ces fils. On a simplifié le mode opératoire primitif de Garrod par le suivant: on recueille dans une capsule de verre $\mathbf{5}$ grammes

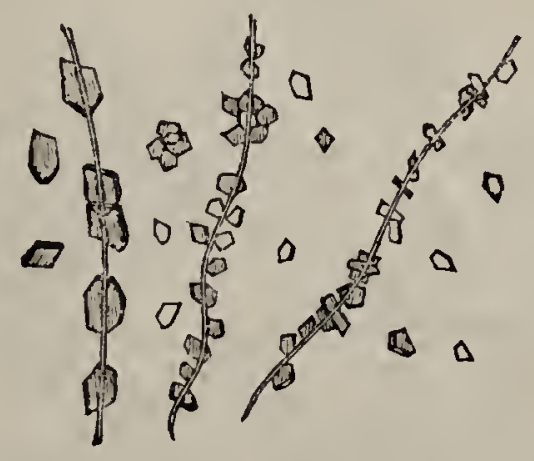

Fig. 291. - Cristaux d'acide urique obtenus par le procédé du fil (d'après Garrod).

environ de sérum, on y ajoute quelques gouttes d’acide acétique et on y laisse tomber un fil. Au bout de 36 à.48 heures, des cristaux d'acide urique se sont déposés le long du fil. Le sérum doit être frais, sans cela il pourrait donner, par fermentation, de l'acide oxalique, de l'urée et de l'allantoïne. Si l'évaporation est poussée trop loin, on pourrait obtenir des cristaux de phosphate ammoniaco-magnésien. 


\section{§ 9. - ACIDE hippuriQue.}

Normalement, l'acide hippurique n'existe qu'en petite quantité dans l'urine humaine, tandis qu'au contraire il est très abondant dans l'urine des herbivores. M. Méhu estime que la quantité d'acide hippurique, rendue dans les vingt-quatre heures, ne dépasse pas 3 à 4 décigrammes. Sous l'influence d'une alimentation spéciale, ou de l'introduction dans l'économie d'acide benzoïque, l'acide hippurique apparaît dans l'urine en proportion plus considérable. D'après Heller, une alimentation composée de pain de froment ou de seigle, ou mieux encore de pain de seigle seul, fait apparaître dans l'urine une quantité notable d'acide hippurique, et l'acide urique disparaît presque complètement; si l'on fait intervenir la viande dans l'alimentation, la relation est renversée, l'acide hippurique disparaît, tandis que la proportion normale d'acide urique reparait. Suivant Lawson, l'urine des habitants de la Jamaïque serait riche en acide hippurique. Sous l'influence des pommes vertes, des prunes, des baies de myrtille, on constate la présence de

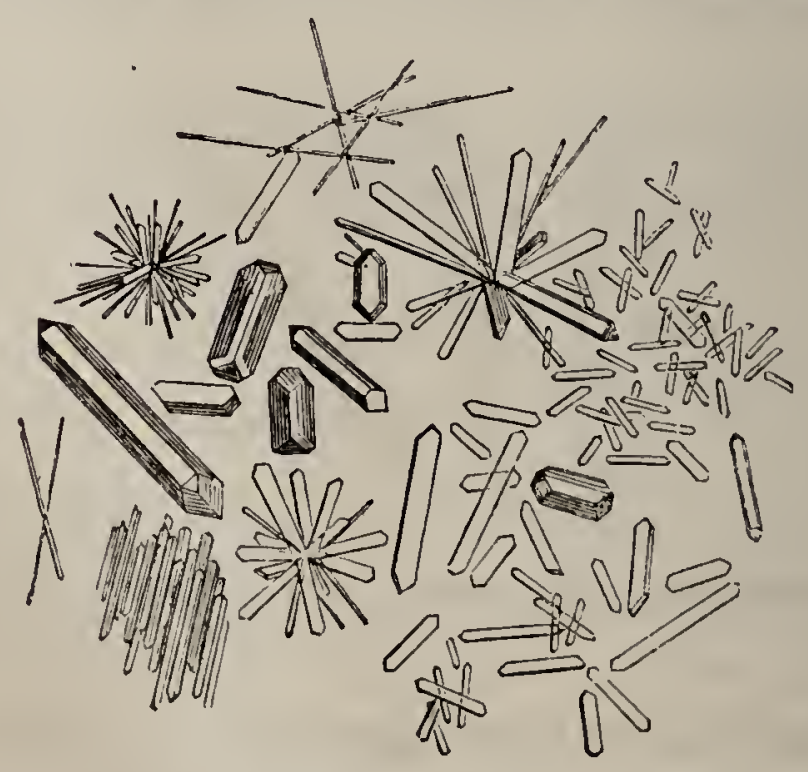

Fig. 292. - Acide hippurique.

l’acide hippurique dans l'urine. Certains médicaments, tels que l'acide benzoïque, l'acide cinnamique, l'essence d'amandes amères, provoquent également la formation de l'acide hippurique. D'après M. Bouchardat, sous l'influence du régime lacté, 
la proportion de l'acide hippurique s'élèverait à la dose de 2 gr. 23 par kilogramme d'urine (Méhu).

L'acide hippurique, lorsqu'il n'a pas été purifié, est souillé par des matières colorantes, dont on peut aisément le débarrasser; il apparaît alors sous la forme de cristaux aiguillés longs et déliés, à quatre pans, prismes rhombiques, exigeant au moins 600 fois leur poids d'eau froide pour se dissoudre (Golding Bird).

Lorsqu'on a obtenu l'acide hippurique, par addition d'acide chlorhydrique à l'urine de cheval, il se présente fréquemment sous la forme de figures linéaires, délicates, se ramifiant dans le liquide comme des algues, ou en faisceaux de baguettes surmontées de feuilles (Golding Bird). On a également comparé cette cristallisation à un éventail ou à une queue de pigeon.

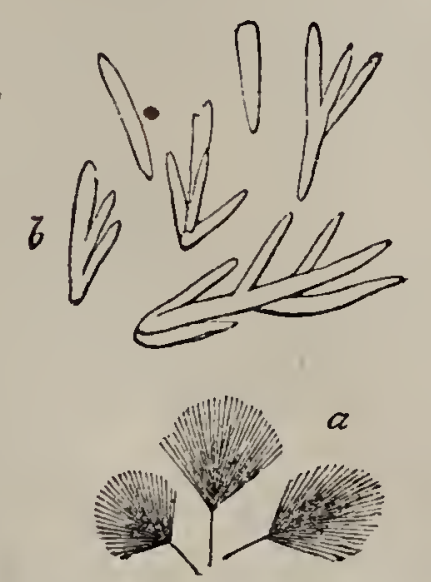

Fig. 293. - Acide hippurique.

Quelquefois, l'acide hippurique et l'acide urique figurent en même temps dans les sédiments urinaires et l'on a alors de gros cristaux d'acide urique hérissés de cristaux d'acide hippurique. Dans ce cas, on opère la séparation par l'alcool bouillant, qui ne dissout que l'acide hippurique.

Dans l'urine de cheval, l'acide hippurique se trouve à l'état de combinaison avec la chaux.

Si l'on était tenté de confondre des cristaux d'acide hippurique, soit avec du phosphate ammoniaco-magnésien, soit avec de l'acide urique, la distinction serait facilement faite à l'aide des réactifs chimiques. Les cristaux d'acide urique ne disparaissent pas par l'addition d'un acide, comme les cristaux de phosphate ammoniaco-magnésien, et de plus, ćes derniers ne 
donnent pas la réaction de la murexide, comme l'acide urique, en présence de l'acide azotique et de l'ammoniaque.

\section{$\S 10$. C CHLORURE DE SODIUM.}

Le sel marin se rencontre dans tous les liquides del'économie, et à ce titre il ne devrait pas figurer au nombre des sédiments de l'urine, d'autant plus que, s'il est renfermé dans ce liquide, en quantité très notable, en raison de sa solubilité, - n ne l'y rencontre pas à l'état cristallin. Mais, comme ce composé salin apparaît chaque fois que l'on évapore une urine, au point de vue d'une recherche quelconque, il nous a paru utile de donner ici ses caractères généraux, qui pourront servir dans toutes les circonstances.

Le chlorure de sodium affecte des formes différentes, suivant qu'ilęristallise ou non, en présence des matières organiques.

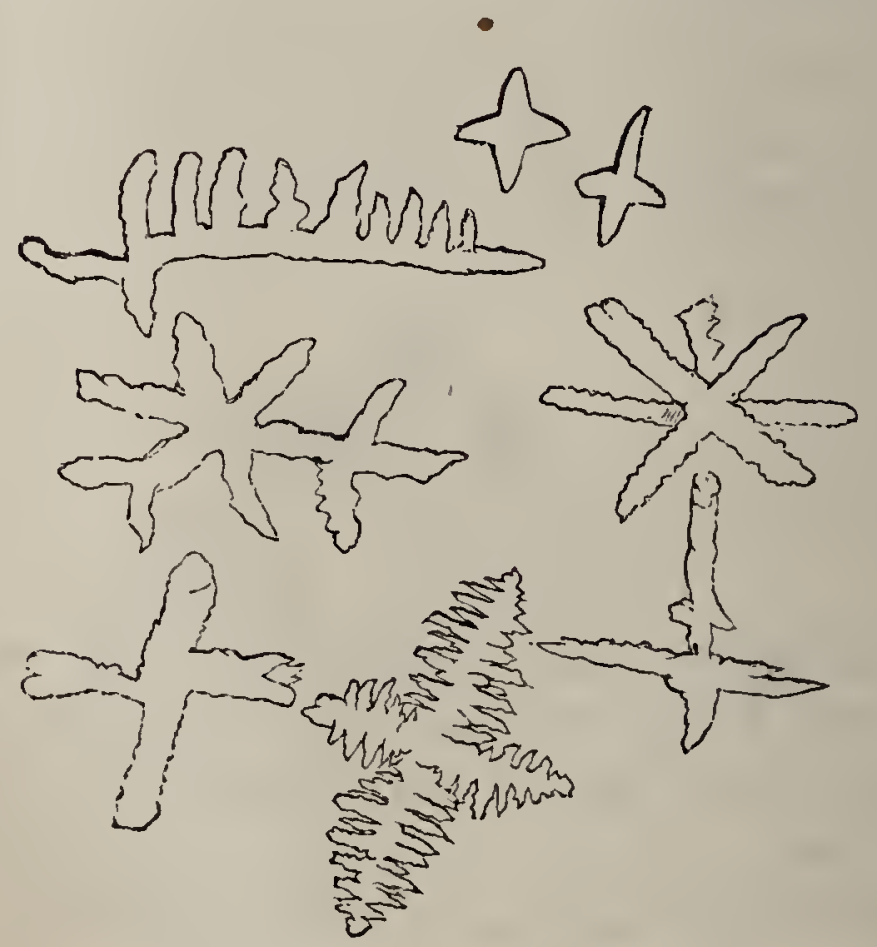

rig. 294. - Chlorure de sodium.

Lorsqu'on fait évaporer quelques gouttes d'urine sur un verre plat, le chlorure de sodium cristallise sous la forme de croix ou de glaives différemment modifiés (fig. 294). Souvent il est mélangé avec des cristaux de phosphate de soude dont la forme est différente (fig. 295). Les cristaux marqués a sont du chlorure de sodium; ceux de phosphate de soude ont été 
obtenus par le traitement des cendres provenant de la calcination de l'urine.

Le sel marin cristallise ordinairement en cubes, mais en présence de l'urée, des acides biliaires, il cristallise en octaèdres ainsi qu'en tétraèdres. Parfois, la forme cristalline du chlorure de sodium pourrait le faire confondre avec la cystine, mais sa solubilité dans l'eau l'en fera différencier faci-

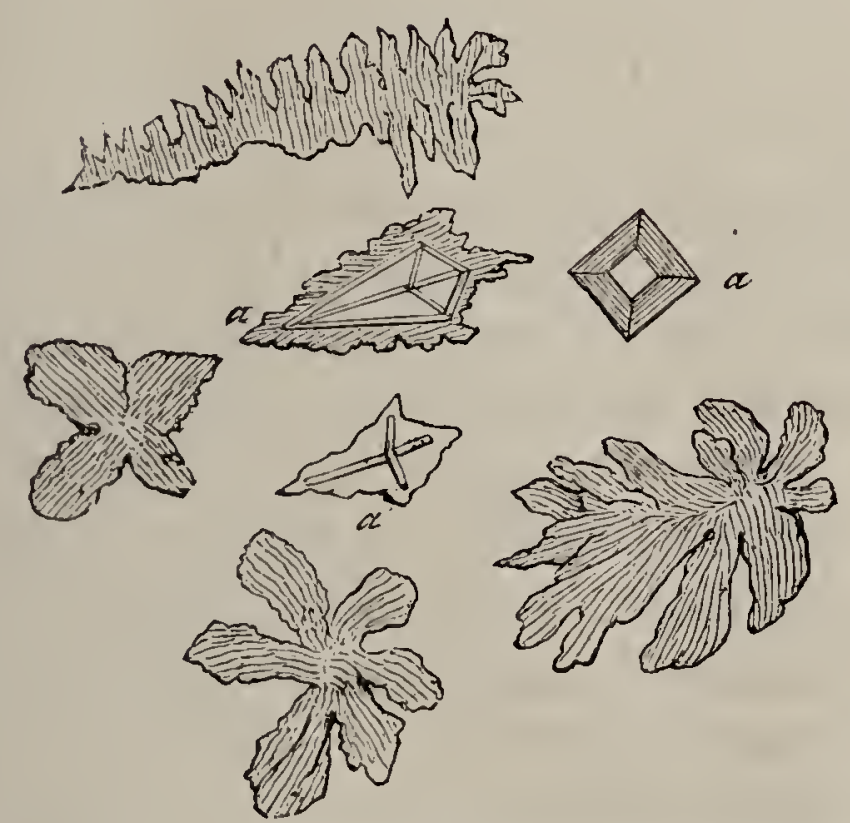

Hig. 293. - Phosphate de soude tribasique ressemblant à du chlorhydrate d'ammoniaque.

lement. Quand l'urine est évaporée rapidement, on a alors des cristaux en forme de glaives déjà décrits. Ce dernier mode de cristallisation se rencontrerait surtout fréquemment, d'après

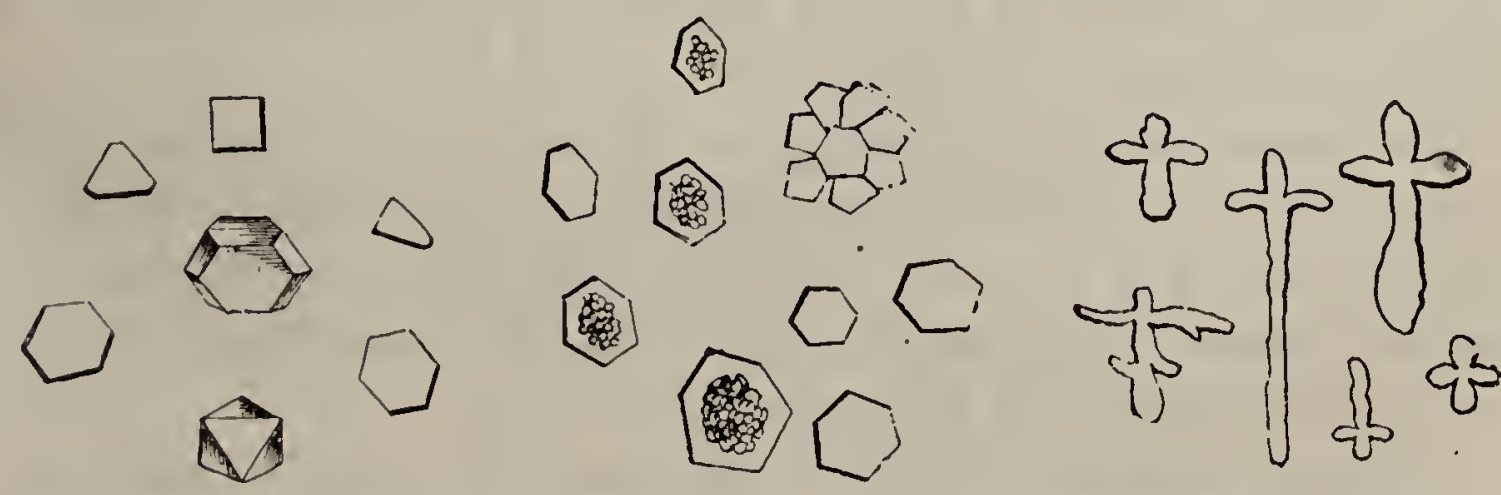

liig. 996. - Chlorure de
sodium.

Fig. 297. - Cystine.

Fig. 298. - Chlorure de sodium.

Golding Bird, lorsque le chlorure de sodium cristallise en présence de l'urée.

Quelquefois on pourrait être tenté de confondre le chlo- 
rure de sodium avec l'oxalate de chaux; mais la solubilité du chlorure de sodium établit eṇtre les deux composés cristallins une différence bien tranchée ; outre les formes cristallines que nous venons d'examiner, on observe encore, quand on traite par l'eau des cendres provenant soit du sang, soit de l'urine, soit du liquide de l'ascite, etc., que les cristaux de chlorure de sodium se groupent en trémie ou en escalier.

\section{$\S 11 .-$ DES PHOSPhates.}

Les phosphates jouent un rôle prépondérant dans l'organisme; on sait qu'ils forment la trame solide du squelette; on les rencontre non seulement dans les os, mais encore dans les dents, dans des calculs d'origine différente. Les cendres des différents liquides normaux, ou pathologiques, de l'économie, en renferment également dans des proportions considérables. L'urine normale contient à la fois des phosphates alcalins solubles dans l'eau, et des phosphates insolubles dans ce liquide, tels que le phosphate de chaux et le phosphate de magnésie, rendus solubles, grâce à la réaction acide de cette sécrétion. Aussi, lorsque l’urine, par une cause quelconque, devient alcaline, soit à l'air libre, soit dans la vessie, ces phosphates se déposent, sous la forme de phosphate de chaux, ou de phosphate ammoniaco-magnésien. Chaque fois que l'urine, en vertu d'un état pathologique, séjourne dans la vessie et que cet organe n'est pas à l'état normal, il se fait sur place un dépôt de phosphate terreux.

La proportion des phosphates contenus dans l'urine varie avec l'alimentation. Lorsque certains végétaux riches en phosphates, tels que les pois, le maïs, les haricots, le froment, dominent dans l'alimentation, il y a dans les cendres de l'urine une forte proportion de phosphates.

D’après certains auteurs, les phosphates solubles l'emporteraient en quantité sur les phosphates insolubles : les premiers provenant directement de l'alimentation et des phénomènes d'oxydation qui se passent dans les tissus ; les seconds tirés du lait et de certains végétaux qui contiennent des phosphates de chaux et de magnésíe. Toutefois, il est important de noter 
que la viande, la farine, le froment, les graines de légumineuses, contiennent des phosphates alcalins basiques.

Lorsqu'on introduit dans l'économie, sous forme de médicament, une certaine quantité de phospbates, on en retrouve une proportion variable dans l'urine ; une grande partie s'élimine également par l'intestin. C'est ainsi que, dit Golding Bird, si l'on abandonne au repos des matières fécales liquides provenant d'une personne faisant usage de farineux (diarrhée chronique traitée par les farineux), on trouve au fond du vase de gros cristaux de phosphate ammoniaco-magnésien.

Les phosphates se trouvent parfois à la surface de l'urine, (voy. Kyestéine) ; tantôt, au contraire, ils se déposent au fond du vase qui la renferme. Lorsqu'il n'y a qu'une très petite quantité de phosphates, les cristaux peuvent rester suspendus au milieu du liquide. Quandils sont à la surface de l'urine, les cristaux prennent des reflets variés; parfois ils peuvent donner à l'urine l'apparence purulente, surtout quand celle-ci est à la fois très alcaline et de consistance épaisse. L'examen microscopique tranche facilement la question. Les phosphates sont accompagnés quelquefois par les urates; ceux-ci sont peu colorés. D’une façon générale, les urines riches en phos-

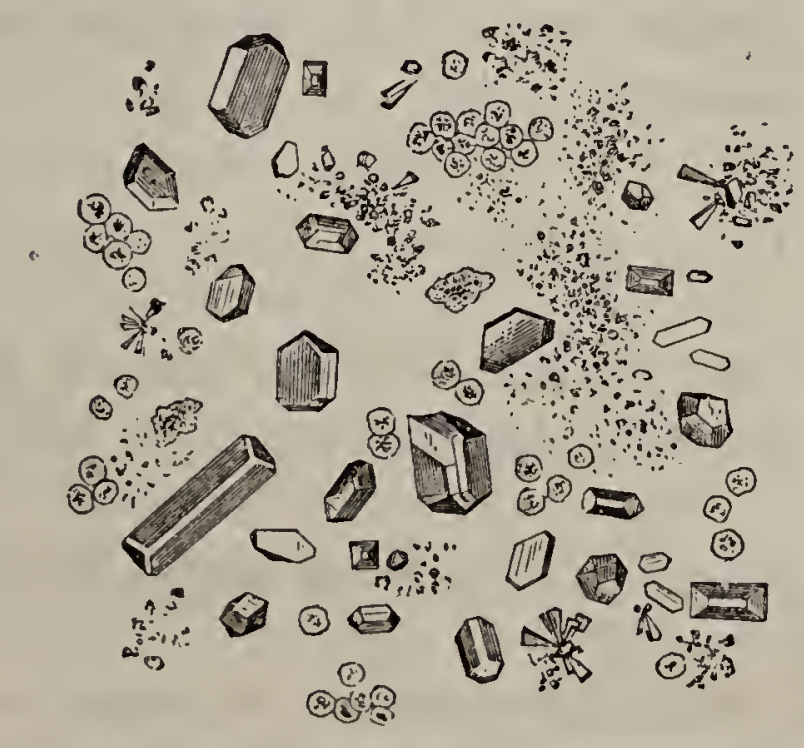

Fig. 299. - Phosphate ammoniaco-magnésien.

phates sont peu colorées, et il en est de même des dépôts concomitants.

En se groupant autour des cristaux d'urates ou d'oxala- 
tes, les phosphates peuvent constituer des calculs dits calculs phosphatiques.

Les phosphates sont abondants dans l'urine de malades atteints d'une affection médullaire ou d'une lésion cérébrale.

\section{$\S$ 12. - phosphate neutre de soude (2NaO,Ho, Ph( $\left.0^{5}+24 \mathrm{Aq}\right)$.}

Très commun dans les liquides de l'organisme, existe dans l'urine normale en solution ; soluble dans l'eau ; s'obtient par
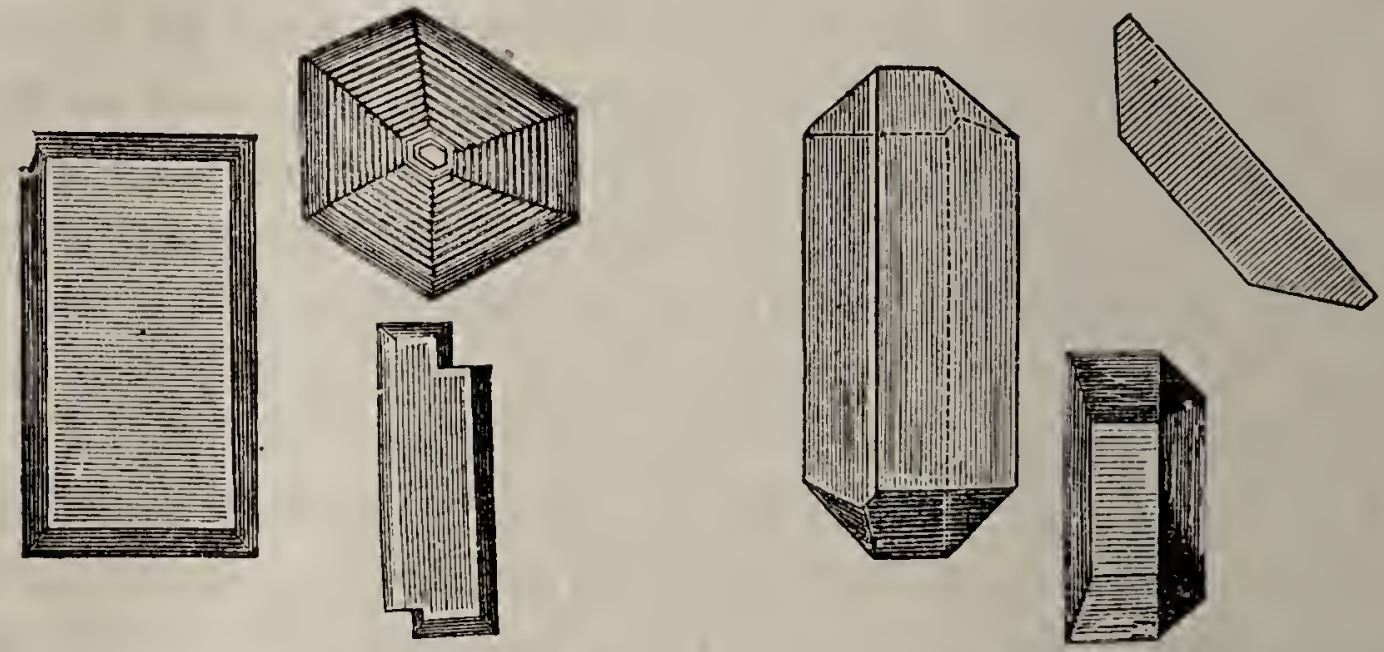

Fig. 300. - Phosphate neutre de soude.

Fig. 301. - Phosphate acide de soude.

l'évaporation de l'urine, souvent à l'état de mélange avec d'autres phosphates alcalins.

\section{§ 13. - Phosphate ACIDE DE soude.}

C'est à ce'sel que l'urine doit, suivant un grand nombre d'auteurs, sa réaction acide.

$\S 14$. - phosphate amyoniaco-Magnésien $2 \mathrm{MgO}, \mathrm{AzH}^{3} \mathrm{HO}, \mathrm{PhO}^{5}+12 \mathrm{Aq}$.

On rencontre ordinairement ce sel dans les urines ammoniacales. Il a toujours, ou du moins dans l'immense majorité des cas, des formes cristallines parfaitement définies; il se présente sous la forme de prismes volumineux, dérivant d'un prisme droit à base rhomboïdale; ces cristaux sont insolubles dans l'eau, surtout dans de l'eau ammoniacale; ils sont très 
solubles même dans les acides faibles. On compare généralement ces cristaux à des catafalques. Le plus ordinairement ils sont transparents ; cependant, dans certains cas, ils sont opaques comme de l'émail et ne peuvent être vus que par la

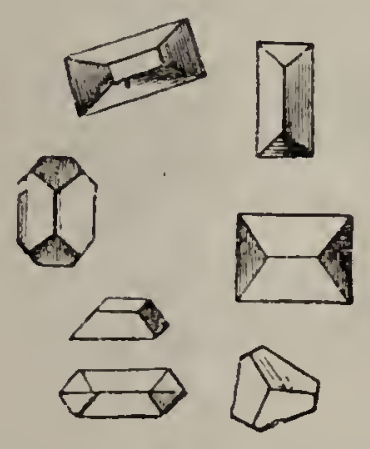

Fig. 302. - Prismes de phosphate ammoniaco-magnésien.

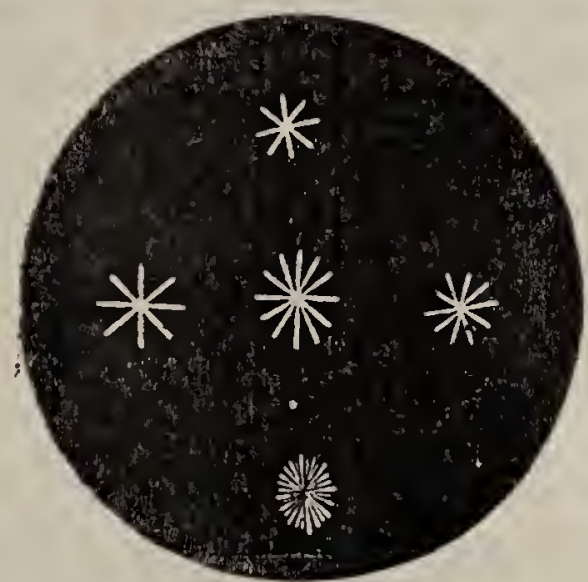

Fig. 303. - Étoiles simples du sel neutre.

lumière directe. Lorsqu'ils sont conservés dans le baume, ils polarisent la lumière, montrant de magnifiques séries de teintes, lorsque les axes des tourmalines ou du spath calcaire sont croisés dans le microscope polarisant (Golding Bird).

Le même auteur a donné la description de petits calculs de phosphate ammoniaco-magnésien présentant des cristaux de forme particulière. Les concrétions très petites sont généralement composées de prismes aiguillés, groupés régulièrement autour d'un centre commun, de façon à figurer une étoile (fig. 303).

Parfois très simple, l'étoile, grâce au nombre considérable de ses rayons, peut prendre l'apparence sphérique; Golding Bird a également noté que quelquefois les cristaux de phosphate ammoniaco-magnésien se groupaient à la façon de l'acide urique, le long des filaments de fibrine, provenant soit du rein, soit de la vessie. La forme étoilée ne s'observe guère que si le dépôt s'est effectué très rapidement.

Ce même auteur dit avoir quelquefois observé une variété rare de cristaux de phosphate ammoniaco-magnésien à laquelle il a donné le nom de penniforme. Ces cristaux n'auraient été observés que dans l'urine fraîche, c'est-à-dire acide, ce qui est en contradiction avec l'observation quotidienne; d'autre 
part, Hassal (Lancet, avril 18ø3) aurait reconnu que ces cristaux ne seraient que du phosphate de chaux et ne se rencontreraient pas dạns l'urine fraîche. En présence de ces opinions opposées et de la rareté de cette forme cristalline, il nous paraît sage de n'admettre qu'arec la plus grande réserve la cristallisation penniforme du phosphate ammoniaco-magnésien.

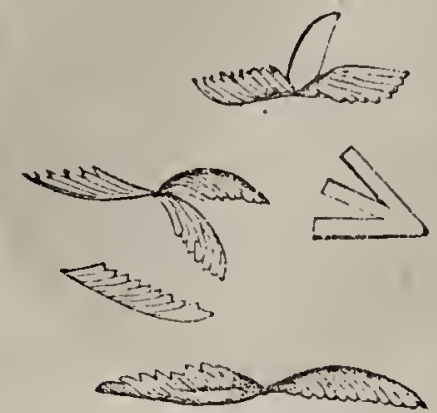

Fig. 304. - Cristaux penniformes de sel neutre.

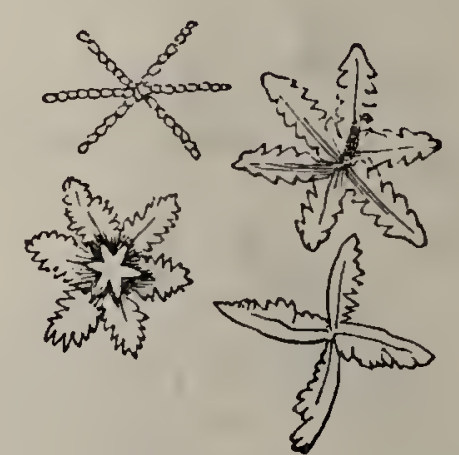

Fig. 305. - Cristaux étoilés de phosphate ammoniaco-magnésien.

D'après Golding Bird, l'urine des femmes enceintes laisserait voir à sa surface (voy. Kyestéine) des cristaux étoilés et foliacés de phosphate ammoniaco-magnésien. Ces cristaux sont souvent très minces et très fins et échappent facilement à l'examen. Par l'action de la lumière polarisée, ils apparaissent revêtus de brillantes couleurs (fig. 305 ).

Il est très fréquent de rencontrer le phosphate ammoniacomagnésien dans l'urine des personnes atteintes d'une affection soit de la vessie (cystite), soit du canal de l'urèthre (hypertrophie de la prostate, ou rétrécissement du canal). Dans ces cas, l'urine est souvent très riche en globules blancs.

Le phosphate ammoniaco-magnésien se rencontre dans l'urine des diabétiques. Seul, ou accompagné d'urates et de carbonates, le phosphate ammoniaco-magnésien se rencontre dans les incrustations de la muqueuse vésicale et des sondes laissées à demeure dans la vessie; les cristaux prennent des aspects variés, suivant qu'ils sont colorés par du pus ou du sang.

\section{\$1̆. - Phosphate de ChaUX.}

C'est généralement le phosphate bibasique que l'on rencontre dans les dépôts urinaires; dans la plupart des cas il 
est amorphe, ou sous forme de granulations arrondies, accolées aux cristaux de phosphate ammoniaco-magnésien. D'après certains auteur's, le phosphate amorphe serait le phosphate tribasique, et le phosphate cristallisé serait le bibasique. Robin et Verdeil représentent dans leur atlas du phosphate de chaux basique cristallisé, provenant du pus d'un os carié. Robin admet l'existence, dans certains cas, du phosphate acide de chaux dans l'urine. Ce phosphate bibasique se rencontre, d'après M. Méhu, dans les urines des personnes qui absorbent une des différentes préparations phosphatées, en usage dans la thérapeutique.

Lorsque le dépôt s'est fait très lentement, les granulations du phosphate de chaux réfractent fortement la lumière, en lui donnant une teinte brunatre ou jaune au centre et noire à la périphérie. Leur surface peut être lisse, grenue ou finement hérissée, surtout quand ils se sont produits dans une urine riche en phosphates qu'on a laissée évaporer. Avec eux, et en plus grand nombre parfois, sont des amas en forme de sablier, pourant atteindre un volume de 1 à 2 centièmes de millimètre. Il est des cas dans lesquels ils sont accompagnés de cristaux en lamelles étroites, allongées, ou en aiguilles isolées ou groupées de diverses manières. Des cristaux analogues, ayant les mêmes réactions, se voient parfois dans les urines acides, avec de l'oxalate de chaux, et semblent, d'après la réaction du liquide, être plutôt du phosphate acide de chaux que du phosphate tribasique (Robin).

Ce savant observateur, faisant réagir différents acides sur les granulations de phosphate de chaux, a vu qu'ils abandonnaient une sorte de gangue organique incolore.

Si l'on était tenté de confondre des grains de carbonate de chaux avec ceux de phosphate, le dégagement de bulles d'acide carbonique, sous l'influence de l'acide, lèverait tous les doutes.

Le carbonate de chaux se rencontre fréquemment dans le sédiment abandonné par l'urine des enfants et dans les urines alcalines. Ce sédiment se rapproche beaucoup par ses caractères optiques du phosphate de chaux.

Le phosphate bibasique de chaux cristallise. Nous donnons, 
d'après l'ouvrage de M. Méhu, quelques-unes des formes cristallines de phosphate bi-calcique provenant soit de l'urine (B), soit du sperme (A). Pour ne pas scinder ce qui a trait au phos-
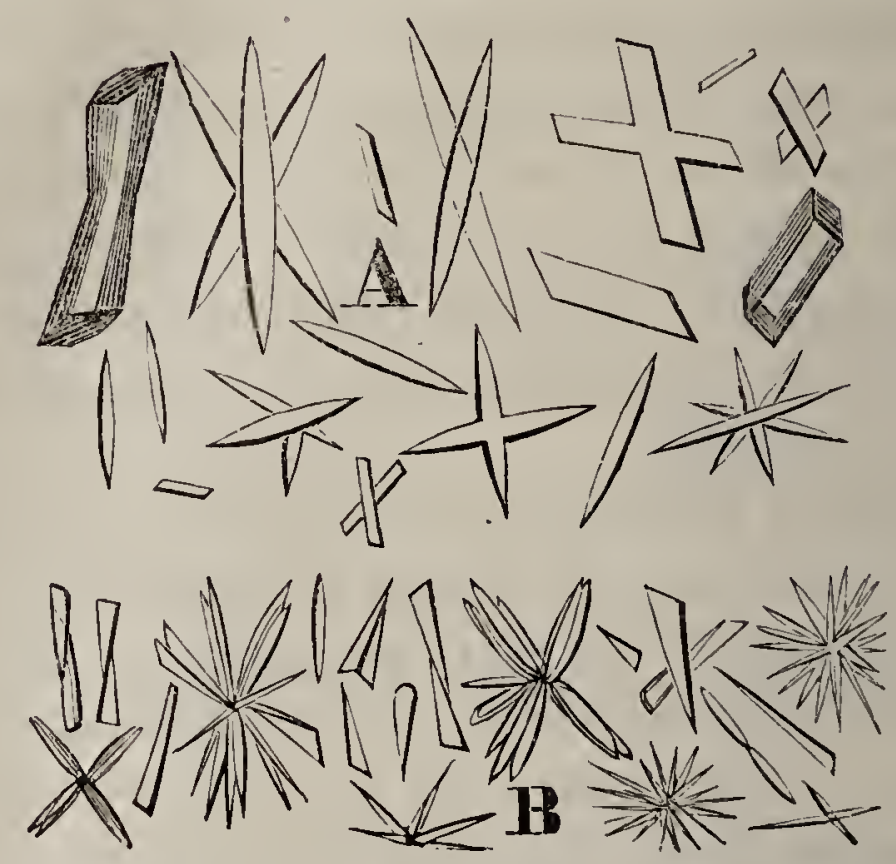

Fig. 306. - Phosphate bibasique de chaux (Iéhu). - A, du sperme; B, de l'urine.

phate de chaux, nous dirons tout de suite, d'après M. Mébu, que les cristaux de phosphate de chaux du sperme sont facilement solubles dans l'acide acétique, et qu'ils sont réellement constitués par du phosphate de chaux et non par du phosphate de magnésie.

D'après Neubauer et Vogel, voici quels seraient les caractères du phosphate de chaux cristallisé : "Ces cristaux sont tantôt isolés, tantôt agrégés le plus fréquemment, et se présentent sous forme de globules et de rosaces. Quelquefois ils sont minces et en forme d'aiguilles et alors, en se croisant à angle droit et se plaçant les uns sur les autres, ils forment souvent des amas de cristaux globuleux; parfois ils sont minces et à surface parfaitement unie; leurs extrémités se terminent par des pointes aiguës; très fréquemment aussi, les cristaux sont épais, plus ou moins cunéiformes et adhèrent ensemble par leurs extrémités pointues, de maniẹre à décrire une portion de cercle plus ou moins considérable. L'extrémité libre et large est ordinairement un peu oblique et les cristaux complètement formés se présentent avec six faces. " 


\section{§ 16. - Phosphate de magnésie.}

Accompagne souvent le phosphate de chaux; généralement amorphe. M. Méhu a observé des calculs constitués uniquement par du phosphate de magnésie; ils provenaient d'un enfant de deux ans. Ce phosphate de magnésie aurait cependant été observé à l'état cristallisé par Birkett et Hassal, chez deux malades auxquels on faisait prendre de l'hyposul-

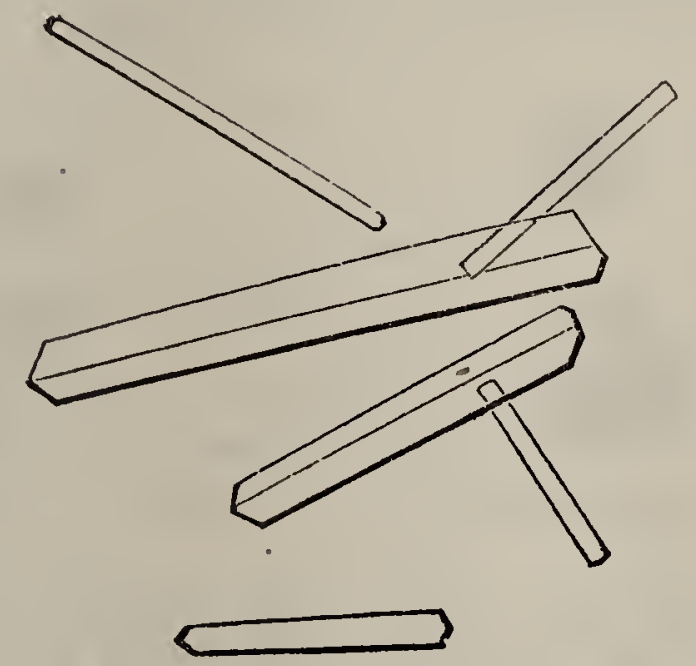

Fig. 307. - Phosphate de magnésje.

fite de soude, contre les sarcince ventriculi. Ce sont des cristaux longs et déliés, pointus à leurs extrémités, fréquemment divisés en cristaux secondaires et plus ou moins agrégés en fais. ceaux.

Dans un autre cas, ces cristaux se présentaient sous la forme de prismes à six pans, aux extrémités pointues, avec des facettes inégales, parfois tronqués et obliques. Le phosphate acide de magnésie se rencontre à l'état cristallisé dans l'urine du lapin. Robin et Verdeil ont figuré des cristaux de phosphate de magnésie provenant du pus.

\section{$\S 17$. - Carbonate de chaux.}

Ainsi que nous l'avons déjà dit, le carbonate de chaux se rencontre dans les urines alcalines ou très faiblement acides et encore dans l'urine desjeunes enfants. Dans les urines alcalines, le carbonate de chaux se formerait, d'après Golding 
Bird, par l'action di carbonate d'ammoniaque, provenanl de la décomposition de l'urée, sur le phosphate de chaux.

Lorsque l'on veut faire la détermination du carbonate de chaux par l'action d'un acide, il faut avoir soin de laver les granulations à l'aide d'un peu d'eau, car le carbonate d'arnmoniaque, qui baigne les granulations examinées, pourrait donner le change, en laissant dégager des bulles d'acide carbonique.

Il est rare de rencontrer le carbonate de chaux à l'état cristallisé; on l'observe dans les urines à peine alcalines ou même

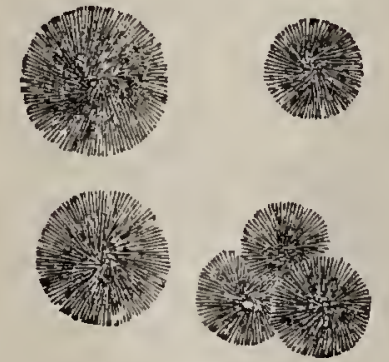

Fig. 308. - Carbonate de chaux.

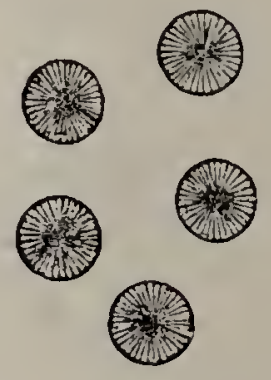

Fig. 309. - Carbonate de chaux.

faiblement acides (fig. 308). Ces masses cristallines ont la forme sphérique et sont constituées par des cristaux partant du centre et allant à la périphérie.

Dans l'urine des herbivores, on trouve toujours du carbonate de chaux (urines jumenteuses). Lorsqu'on examine au microscope les sphères cristallines que l'on trouve dans l'urine du cheval, après avoir pris le soin de les laver, on voit que ces sphères, qui réfractent vivement la lumière, sont constituées par un grand nombre d'aiguilles partant d'un centre commun. Ces corps ont été comparés par Golding Bird à de véritables petites perles, analogues à celles des huîtres perlières (fig. 309).

Le carbonate de chaux se présente également sous la forme de hallères.

\section{\$18. - DE L'oXalate DE ChaUX.}

- L'oxalate de chaux se rencontre à la fois dans les sédiments de l'urine, et dans certains calculs provenant soit des reins, soit de la vessie, dont il forme ou la totalité ou simplement le noyau. Dans les sédiments de l'urine, il est nette- 
ment cristallisé; dans les calculs, il est presque toujours amorphe. On a beaucoup discuté d'abord sur l'existence de ce sédiment, et ensuite sur la valeur du symptôme qu'il constituait. Bien qu'il y ail encore des recherches à faire sur ce point, on peut dire que, le plus fréquemment, c'est avec nos aliments (cresson, tomate, oseille) que l'oxalate de chaux pénètre dans l'économie. Il suffit de manger de l'oseille ou de prendre de la rhubarbe, pour trouver des cristaux d'oxalate de chaux, en grande quantité, dans l'urine. Aussi, chaque fois que l'on trouvera des cristaux d'oxalate de chaux dans une urine, il faudra s'enquérir avec soin des circonstances qui ont pu faire pénétrer ce corps dans l'économie. Toutefois, on considère comme démontré que, dans certaines formes de dyspepsie, il y a production d'oxalate de chaux; le même symptôme se produit lorsque l'hématose, soit en raison de lésions d'organes, ou d'insuffisance du milieu respirable, se fait d'une façon incomplète. Le trouble (irritabilité fonctionnelle) des fonclions nerveuses ou des facultés mentales, le catarrhe intestinal, prédisposent à la production d'oxalate de chaux.

La maladie spéciale à laquelle on a donné le nom d'oxalurie paraît ne pas exister, comme espèce morbide caractérisée.

Le $\mathrm{D}^{\mathrm{r}}$ Harley a observé, chez un malade atteint de rétention d'urine, que la peau s'était recouverte d'une croûte de cristaux d'oxalate de chaux.

Il n'est pas rare, lorsqu'on examine le dépôt abandonné par une urine, de n'apercevoir d'autre élément cristallisé que l'oxalate de chaux. Il-se présente sous la forme d'octaèdres
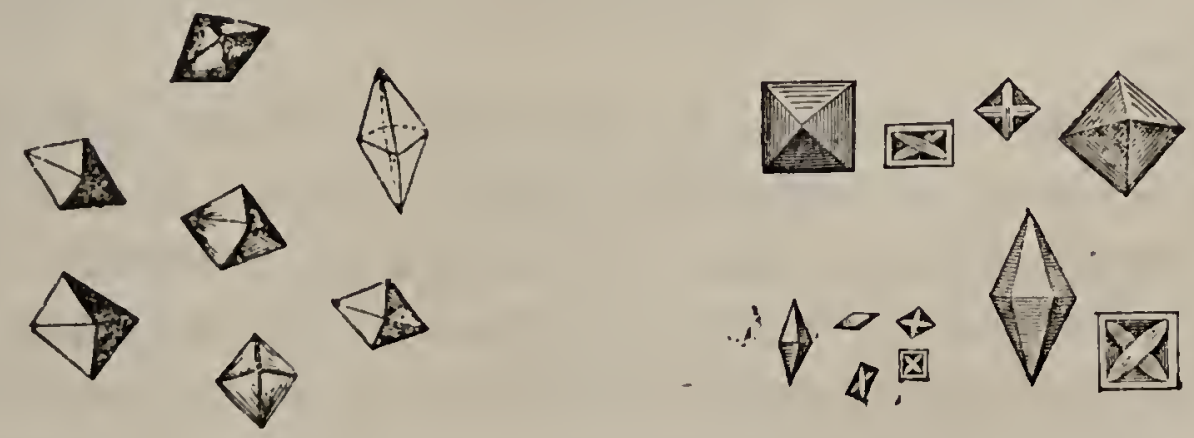

Fig. $310 .-$ Oxalate de chaux.

Fig. 311. - Oxalate de chaux.

transparents, parfaitement définis et d'une grande pureté de formes (fig. 310 et 311 ). Lorsque la lumière est très vive, ces 
cristaux ressemblent à des cubes traversés par une croix, le point d'intersection des deux bras correspondant à un des sommets de l'octaèdre (Golding Bird) (fig. 312); quelquefois ces cristaux sont si petits qu'ils se groupent les uns contre les autres et qu'on a quelque 'peine à les distinguer. Il est nécessaire d'employer un fort grossissement.

Golding Bird décrit une forme assez rare de cristaux d'oxa-

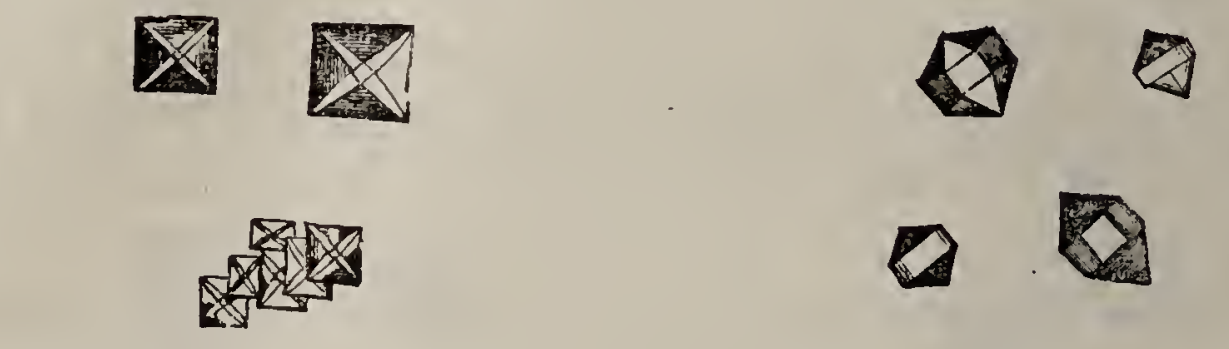

Fig. 312. - Oxalate de chaux.

Fig. 313. - Oxalate de chaux.

late de chaux; ces cristaux sont constitués par un prisme carré, terminé par une pyramide à quatre pans, à chaque extrémité (fig. 314).

D'une façon générale, on compare la forme la plus commune des cristaux d'oxalate de chaux à celle d'une enveloppe de lettre, vue du côté où elle se ferme.

Pour bien observer les cristaux d'oxalate de chaux, il faut employer un grossissement de 400 à 600 diamètres.

Caractères différentiels. - Les cristaux d'oxalate de chaux sont insolubles dans l'eau; les alcalis ne les dissolvent pas non plus; il en est de même de l'acide acétique, qui reste sans action sur eux. Les acides forts, comme l'acide azotique et l'acide chlorhydrique, les dissolvent facilement et sans effervescence.

Golding-Bird signale la particularité suivante, qui est intéressante. Lorsqu'un sédiment urinaire, contenant de l'oxalate, a été abandonné sur une lamelle et s'est desséché, chaque cristal offre une apparence curieuse. Il présente une partie transparente et une partie obscure; la partie transparente semble être constituée par un cube transparent ayant ses angles et ses côtés opposés aux angles et aux côtés du plus grand cube. Ce dernier est obscur et semble aussi encadrer le plus petit (fig. 314). 
ChapITRE XI. - DES SÉdinENTS DE L'URINE.

Parmi les sédiments qui accompagnent le plus fréquemment l'oxalate de chaux, nous pouvons signaler l'acide urique et
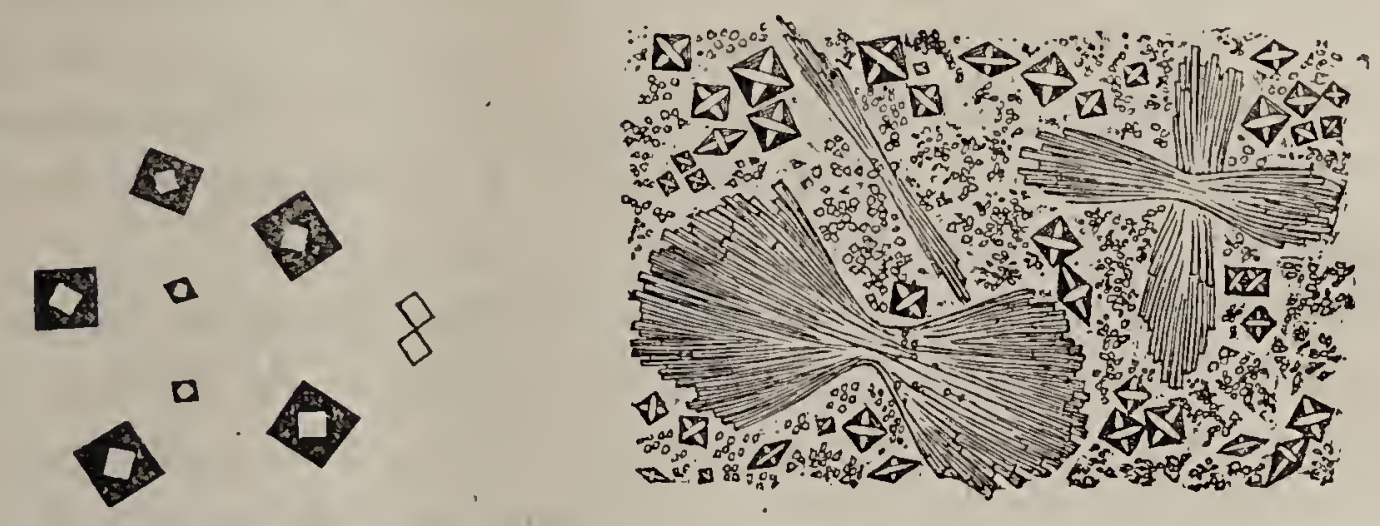

Fig. 314. - Oxalate de chaux. Fig. 315. - Acide urique uni à l'azotate de soude et à l'oxalate de chaux.

les urates. L'action des réactifs, à défaut de la forme microscopique, servirait à les reconnaître facilement (fig. 316).

L'oxalate de chaux accompagne quelquefois le phosphate ammoniaco-magnésien, la cystine, la xanthine, le pus, le sucre, le sang.

Fréquemment, des cellules épithéliales provenant des reins

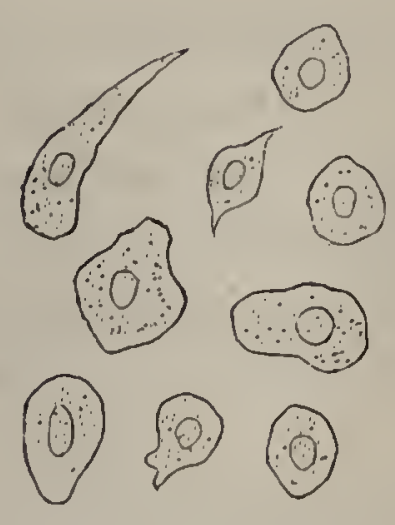

liig. $31_{6}$. - Epithélium de la vessie.

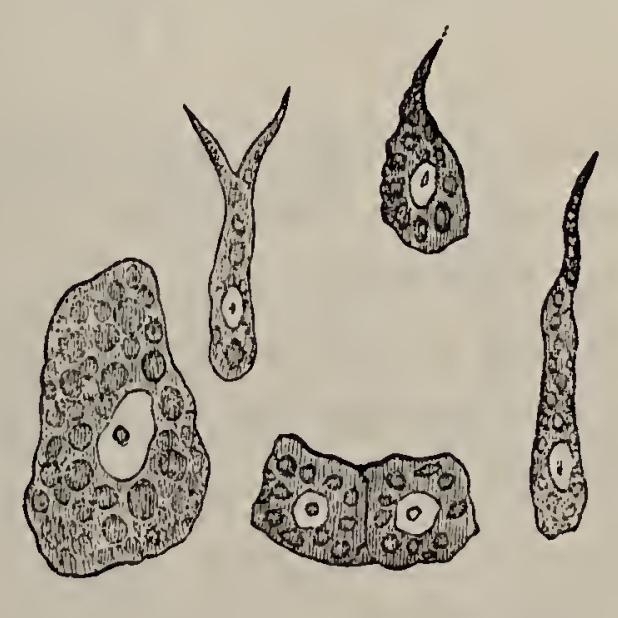

Fig. 317. - Epithélium venant du rein.

el de la vessie sont observées en même temps que des cristaux d'oxalate de chaux.

D'une façon générale, on trouve plus d'oxalate de chaux dans l'urine du soir que dans celle du matin.

Golding Bird insiste particulièrement sur la fréquence des cellules épithéliales dans les dépôts où l'oxalate de chaux domine. Quelquefois même, de l'abondance de ces cellules épi- 
théliales, il concluait à la présence de cristaux d'oxalate de chaux.

Les cristaux d'oxalate de chaux peuvent accompagner les prismes de phosphate ammoniaco-magnésien; il n'est pas rare non plus, le fait se rencontre même très fréquemment, de voir un dépôt urinaire constitué à la fois par de l'acide urique ou un urate et de l'oxalate de chaux.

D'après M. Robin, lorsque les cristaux d'oxalate de chaux sont assez abondants, comme dans l'épilepsie, la chorée, certaines paraplégies, il n'est pas rare de voir, à côté de cristaux présentant la forme classique, des agglómérations cristallines d'oxalate de chaux, ovoïdes ou sphériques, soit même en forme de sablier. Ces masses sont formées par des aiguilles peu distinctes. Lorsqu'on dissout ces agglomérations cristallines, il reste une légère gangue organique, qui reproduit la forme de l'amas. D'après le même auteur, on peut trouver ces agglomérats en sablier, jusque dans les tubes du rein et dans leurs moules.

\section{§ 19. - DE L'INosite.}

On ne rencontre pas l'inosite dans les sédiments urinaires en raison de sa solubilité. Pour lisoler, il faut recourir à certaines méthodes, exposées en détail dans les ouvrages spéciaux. On trouve linosite dans la chair musculaire du cœur, dans les muscles striés du cheval, du bœuf, dans le liquide des hydatides, dans le foie, les poumons, le cerveau, la rate, les reins.

A l'état normal l'urine n'en contient pas; dans l'albuminurie, dans l'urémie, on l'y trouve. Dans certaines formes de diabète on la rencontre dans l'urine, où, suivant certains auteur's, elle remplacerait le sucre. Les tumeurs du cerveau en contiennent également; les muscles des alcooliques en renfermeraient une assez forte proportion.

D'après Gorup-Besanez, l'inosite se présente sous forme de cristaux appartenant au système clinorhombique, généralement groupés en forme de choux-fleurs, mais quelquefois aussi isolés et offrant ainsi une longueur de 6 à 8 millimètres. 
La forme fondamentale serait un prisme clinorectangulaire. Ces cristaux sont assez solubles dans l'eau, peu solubles dans

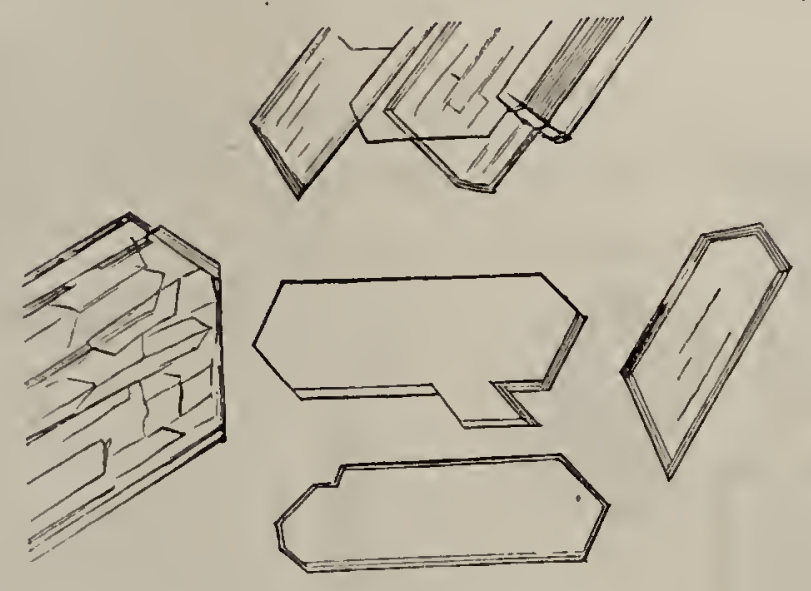

Fig. 318. - Inosite.

l'alcool concentré, insolubles dans l'alcool absolu et dans l'éther.

Dissoute dans l'alcool bouillant, l'inosite se dépose par le refroidissement de la solution, sous forme de petites lamelles brillantes, semblables à de la cholestérine et à éclat nacré (Gorup-Besanez).

\section{§ 20. - CRÉatine et CRÉAtinine.}

Découverte par Chevreul dans le jus de viande, la créatine n'est pas un des éléments constants de l'urine, mais comme la créatinine se transforme facilement en créatine, il en résulte que l'on trouve parfois dans l'urine une plus forte proportion de créatine que de créatinine (Méhu). La créatine ne figure pas parmi les sédiments urinaires; Harley prétend cependant que le fait peut se présenter. On en trouve une quantité assez considérable dans les préparations vendues sous le nom d'extrait de viande.

La créaline cristallise en prismes incolores qui appartiennent au système klinorhombique (fig. 319 et 320 ). Ces cristaux sont à la fois très brillants et très volumineux. La créatine est peu soluble dans l'eau $(\mathbf{7 4 , 4 )}$; plus soluble dans l'eau bouillante. Insoluble dans l'éther, elle se dissout dans un peu moins de 100 parties d'alcool absolu. . 
La créatinine (fig. 321 et 322) ne diffère de la créatine, que par deux équivalents deau en moins. Elle cristallise sous forme de

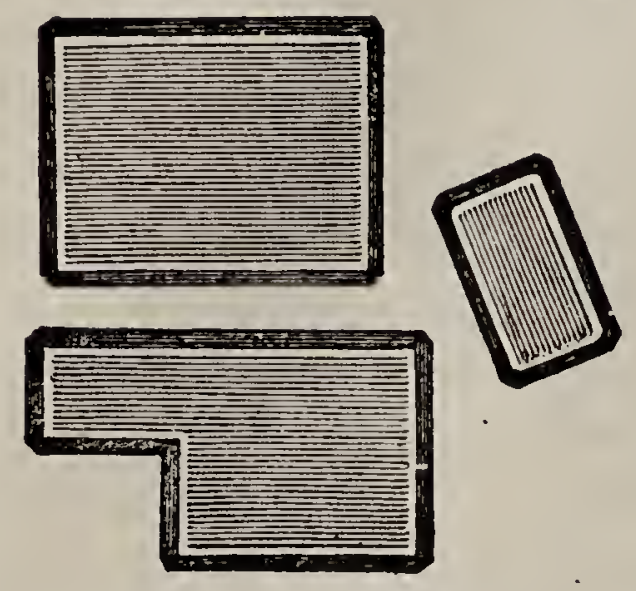

Fig. 319. - Créatine.

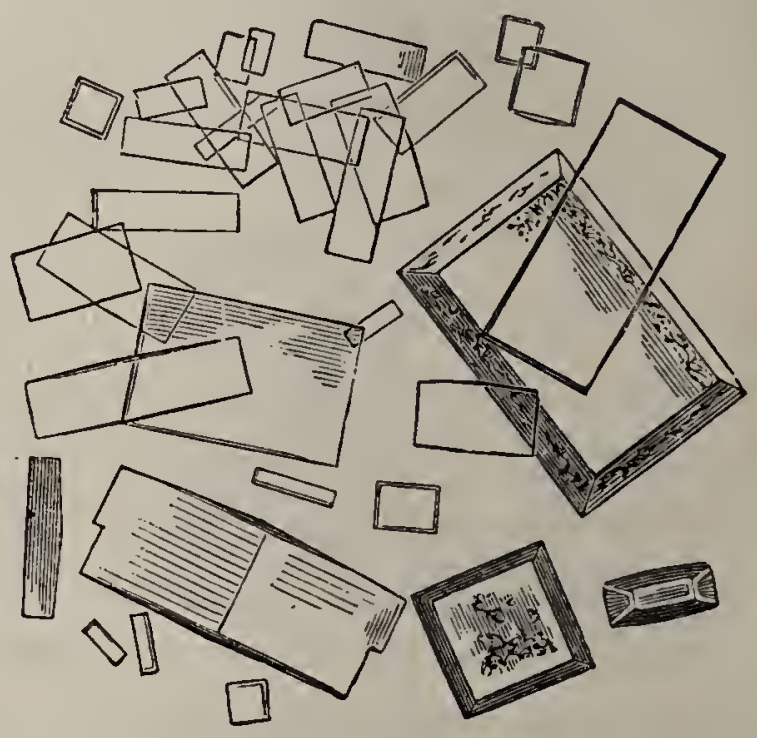

Fig. 320. - Créatine.

prismes incolores volumineux, et est plus soluble dans l'eau que la créatine $(11,5)$.

La créatinine jouit des propriétés des alcalis, elle donne des combinaisons cristallines avec les acides (sulfate et chlorhydrate).

Il y a un caractère différentiel important entre la créatine

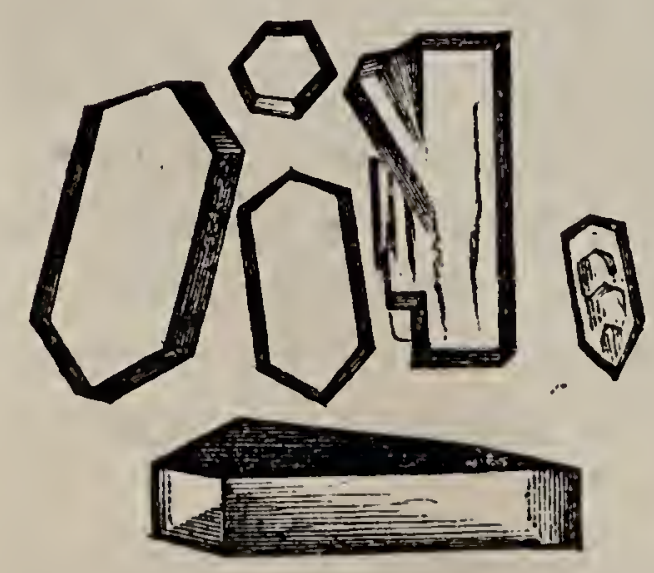

Fig. 3:1. - Créatinine.

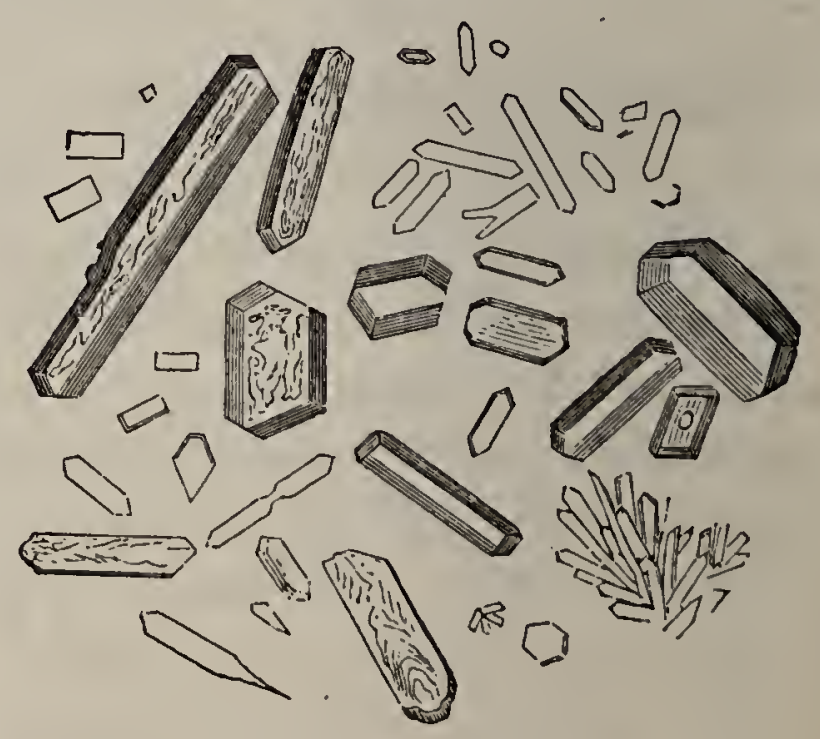

Fig. 322. - Créatinine.

et la créatinine. Si l'on verse une solution concentrée de chlorure de zinc dans une solution concentrée de créatinine, il se dépose un précipité cristallisé, résultant de la combinaison, à équivalents égaux, de chlorure de zinc et de créatinine. 
Lorsque le dépôt des cristaux s'est effectué lentement, ceux-ci se groupent autour d'un centre commun et forment des masses étoilées ou sphériques, présentant parfois l'aspect de houppes ou d'aigrettes.

Le chlorure de zinc ne précipite pas la créatine.

L'urine normale contient de la créatinine en des proportions qui varient entre 6 et 16 décigrammes par vingt-quatre heures (Neubauer, Munk, Méhu). Une alimentation végétale diminue la quantité de créatine excrétée, un régime animal l'augmente au contraire. Le jeûne, certaines affections fébriles, comme la pneumonie, les pyrexies en général, augmentent la proportion de créatinine; le malade vivant de lui-même est dans les mêmes conditions que s'il était soumis à un régime carnivore. C'est Pettenkofer qui a découvert l'existence de la créatine et de la créatinine dans l'urine.

Liebig a démontré l'identité de ces corps avec ceux qui ont été trouvés par Ghevreul dans le suc de la viande.

L'action de la chaleur, l'alcalinité de l'urine favorisent la transformation de la créatinine en créatine (Méhu).

\section{§ 21. - DE LA Cholestérine.}

La cholestérine est une matière blanche cristalline. Bien que cette substance ait porté longtemps le nom de principe gras de la bile, ce n'est pas un corps gras. Elle est considérée comme un des éléments normaux de l'économie; on la rencontre en proportion considérable dans la bile, où elle serait dissoute, à la faveur des acides glycocholique et taurocholique; c'est surtout dans les calculs biliaires, ainsi que nous le verrons plus tard, qu'on la rencontre en abondance; parfois même, mais cette circonstance est rare, ces calculs sont uniquement formés de cholestérine, sans mélange de matières colorantes de la bile, de sorte qu'ils sont transpacents. Nous reviendrons sur ce sujet. On trouve encore la cholestérine dans le liquide des kystes ovariques, des hydrocèles, des kystes hydatiques, dans les liquides séro-sanguins, accumulés dans les tissus à la suite d'un traumatisme.

On la rencontre également dans le contenu complexe des 
kystes sébacés ou des loupes. Généralement lestumeurs à contenu demi-solide et de formation ancienne contiennent de la cholestérine.

Lehmann a trouvé des cristaux de cholestérine dans le

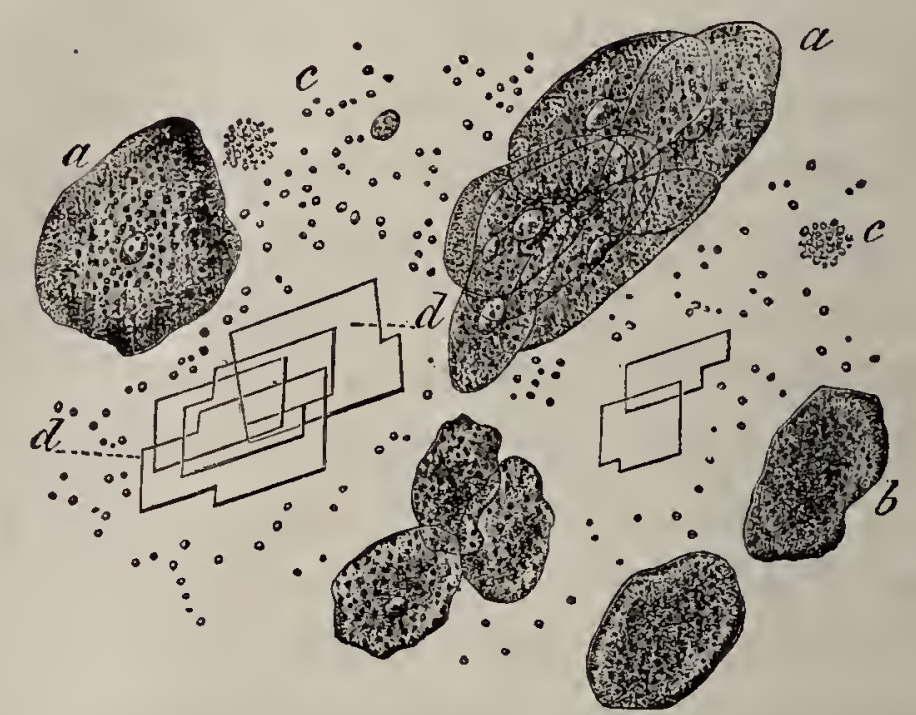

Fig. 323. - Éléments microscopiques du contenu d'une loupe. - $a a$, cellules épidermiques arec gouttelettes graisseuses; $b b$, cellules à noyaux effacés; $c c$, granulations graisseuses isolées; $d$, cholestérine (Follin).

plexus choroïde du cerveau et dáns les crachats de la phthisie pulmonaire, à sa dernière période. On rencontre encore la cholestérine dans les tubercules crétacés et les échinocoques, dans le sang, dans le pus, dans le méconium, dans le cerveau, la moelle, le foie. La cholestérine existerait également dans certains végétaux, dans le blé, le seigle (Ritthausen), dans l'orge (Lintner), dans les fèves, dans les pois (Beneke) et dans un grand nombre de graines (Méhu).

La présence de la cholestérine dạns l'urine a été longtemps méconnue. Muller a le premier signalé l'existence de ce produit, dans la kyestéine (voy. ce mot) de l'urine des femmes enceintes. Gmelin a rencontré également la cholestérine dans une urine biliaire; depuis lors, des observations analogues avaient été faites par différents auteurs. G'est le $\mathrm{D}^{\mathrm{r}}$ Beale qui a le mieux étudié la question; il a signalé à plusieurs reprises l'existence de la cholestérine dans l'urine, à la suite de dégénérescence graisseuse du rein. Cet auteur a signalé un fait que, pour notre part, nous n'avons pas eu l'occasion de vérifier. D'après ses propres observations, les globules huileux que l'on trouve 
au fond du vase, en cas de maladies des reins, ne sont point formés de matières grasses, mais de cholestérine. Pour le prouver, le $\mathrm{D}^{\mathrm{r}}$ Beale fait dissoudre ces globules dans l'alcool, puis il abandonne le liquide qui cristallise spontanément, en fournissant des cristaux caractéristiques. Il a constaté, de plus, qu'en raison de sa densité supérieure à celle des matières grasses, la cholestérine était plus lourde que l'eau et gagnait ainsi la partie inférieure des matières grasses. M. Méhu a également appelé l'attention sur ce point; il a fixé la densité de la cholestérine au nombre suivant: 1,047. Si l'on voit presque toujours les cristaux de cholestérine scintiller à la surface des liquides, c'est parce que des bulles de gaz adhèrent soit à la partie inférieure des cristaux, soit même entre les lamelles cristallines, et diminuent ainsi leur densité.

La cholestérine se transforme dans l'intestin en stercorine ou séroline de Boudet.

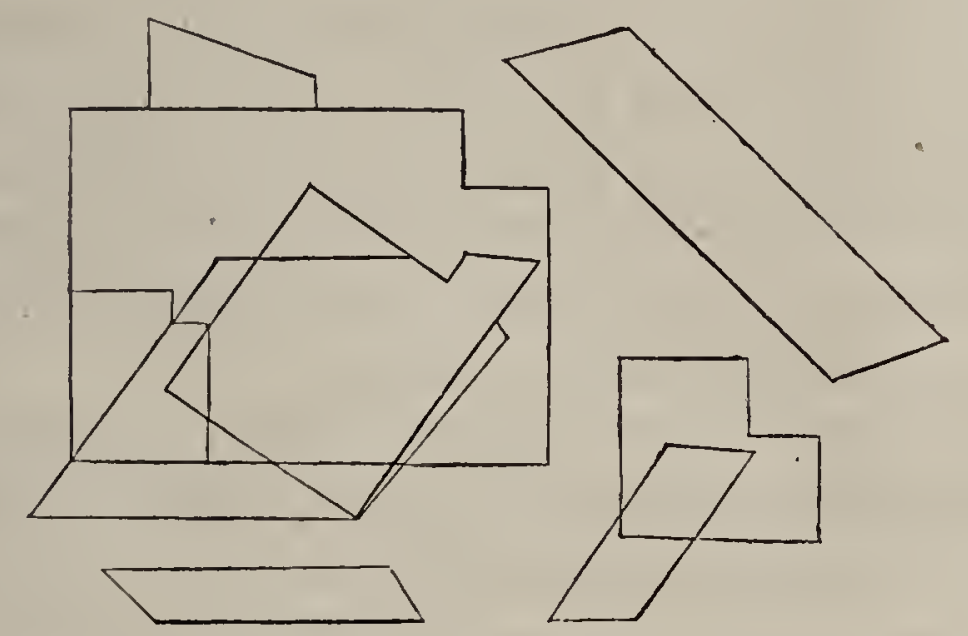

Fig. 324. - Cristaux de cholestérine.

Dans une affection particulière à laquelle on a donné le nom de cholestérémie, il y a accumulation de cholestérine dans le sang, qui peut en fournir 1,85 pour 1,000 (Méhu). - M. Picot. de Tours (1), dans un cas d'hépatite intestinale à forme atrophique suraiguë, prétend avoir trouvé dans le sang un grand nombre de cristaux de cholestérine. Outre la présence de ces cristaux, M. Picot dit avoir constaté une diminution très notable

(1) Journal de l'Anatomie, mai 1872. 
dans le nombre des globules rouges, ainsi que des modifications de forme.

La cholestérine, soit qu'elle ait cristallisé dans l'économie, soit qu'on l'ait fait cristalliser artificiellement, se présente sous la forme de grandes tables rhomboïdales, à côtés parallèles et à angles aigus. Les cristaux sont souvent très grands et quelquefois superposés. Grâce à la transparence de la cholestérine, la superposition des cristaux n'est pas un obstacle à la détermination de leur forme.

La cholestérine est soluble dans l'alcool chaud et dans un mélange à parties égales d'alcool et d'éther; le chloroforme en dissout environ le quart de son poids; elle est également soluble dans la benzine et le sulfure de carbone.

Lorsque la cholestérine est très sèche et qu'on la traite par l'acide sulfurique concentré, on obtient une magnifique série de couleurs, passant par les diverses nuances de l'orangé, du rouge, du pourpre et du vert (Harley, Zwenger).

Les solutions alcalines n'attaquent pas la cholestérine. Au contact d'un peu d'iode et d'acide sulfurique concentré, la cholestérine se colore en violet, en bleu et en rouge (Méhu). En présence du chlorure de zinc et de l'iode, la cholestérine se colore en vert-bleu ou violet. Ces réactions peuvent être répétées sur le champ du microscope.

Parfois les tables de cholestérine sont si minces, que pour apercevoir nettement leurs contours, il faut adapter au microscope un diaphragme latéral ou central.

D'une façon générale on peut dire que la recherche de la cholestérine est très facile en raison de la netteté et du volume de ses cristaux.

\section{$\S 22 .-$ CYSTINe.}

Cette substance a été découverte dans un calcul et décrite pour la première fois par Wollaston. La cystine n'existe pas dans l'urine normale, et elle a élé rarement observée dans les sédiments urinaires. Lorsqu'elle se présente dans l’urine, cette substance forme un dépôt pulvérulent presque blanc; tantôt, au contraire, elle reste suspendue dans le li- 
quide. Au moment de l'émission, l'urine serait trouble et précipiterait, plus ou moins abondamment.

Lorsqu'elle fait partie d'un sédiment urinaire, la cystine se présente sous forme de cristaux, dont le type est un he-

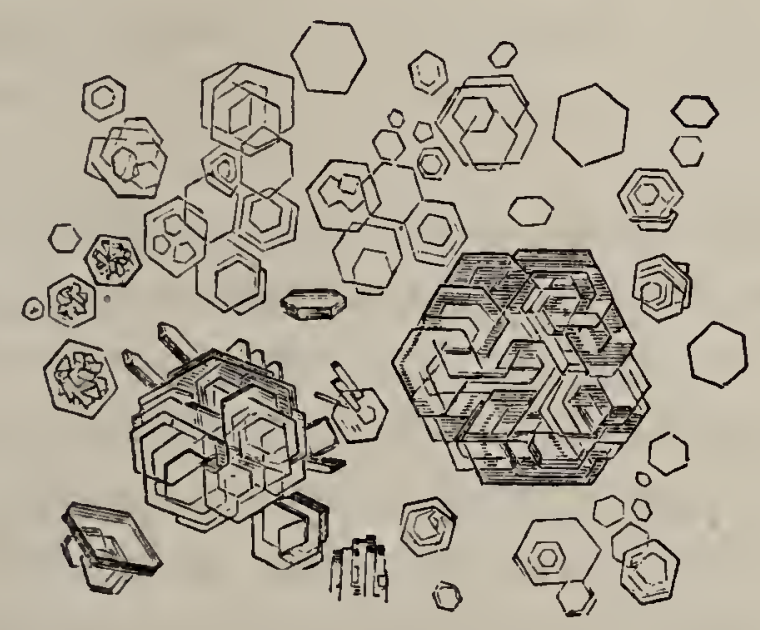

Fig. 325. - Cystine.

xagone régulier. Ces lames hexagonales ne sont pas toujours ni régulières ni isolées; le plus souvent même, les cristaux de cystine sont groupés et superposés, de telle façon que l'on n'aperçoit que par transparence les arètes des lames hexagonales. La réunion de ces cristaux forme des sortes de rosaces, plus foncées au centre qu'à la circonférence.

Les cristaux de cystine se dissolvent bien dans les acides minéraux et dans l'acide oxalique, mais surtout dans l'acide chlorhydrique. L'acide acétique, non plus que l'acide tartrique, ne dissolvent la cystine.

Les alcalis fixes ainsi que leurs carbonates dissolvent la cystine; l'ammoniaque jouit au plus haut point de cette propriété. Le carbonate d'ammoniaque ne dissout pas la cystine.

Lorsqu'une solution ammoniacale de cystine est abandonnée à l'évaporation spontanée, on observe des cristaux isolés. Si l'évaporation a été poussée vite, la cristallisation se fait d'une façon confuse.

La cystine, en raisón de l'alcalinité que présente souvent l'urine qui la laisse déposer, est fréquemment mêlée à du phosphate de chaux; l'action de l'acide acétique, qui dissout 
les cristaux de phosphate et laisse intacts ceux de cystine, servira à les différencier facilement.

Si parfois on était tenté de confondre la cystine avec des urates incolores, l'action de la chaleur lèverait tous les doutes, puisque les urates se redissolveraient.

Du reste, l'action dissolvante de l'ammoniaque devra toujours être essayée; - c’est le réactif par excellence de la cystine.

L'urine contenant de la cystine est généralement pâle et huileuse comme l'urine des diabétiques. L'odeur d'une telle urine, disent les auteurs, est variable; suivant les uns, cette odeur rappellerait le parfum de la rose sauvage, plus ou moins accentué; moins fréquemment (Golding Bird), l'odeur de l'urine rappelle celle de l'acide sulfhydrique ou de choux pourris. Cette odeur caractéristique peut servir, dit M. Roberts, à faire soupçonner la présence de la cystine, $\left(\mathrm{C}^{6} \mathrm{H}^{6} \mathrm{AzS}^{2} \mathrm{O}^{4}\right)$ dans une urine qui contient du soufre et peut ainsi, par sa décomposition partielle, donner naissance à des produits sulfurés; on a également essayé d'expliquer par une raison analogue (Golding Bird) la coloration verdâtre que prennent, à la longue, les calculs de cystine quand ils sont exposés à la lumière.

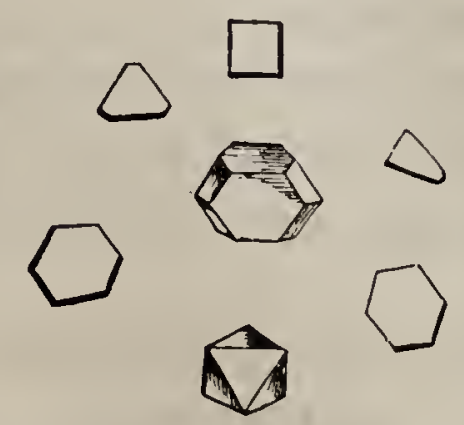

Fig. 326. - Chlorure de sodium.

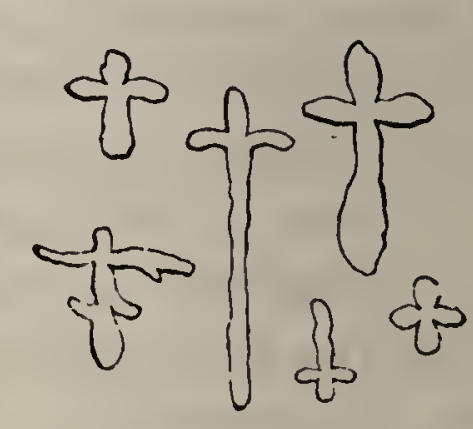

Fig. 327. - Chlorure de sodium.

Lorsque l'on fait évaporer lentement de l'urine, il arrive que le chlorure de sodium prend des formes cristallines, se rapprochant beaucoup de celles de la cystine. Leur solubilité dans l'eau écartera toute chance derreur. $\mathrm{Si}$, au contraire, l'évaporation de l’urine a été très rapide, le chlorure de sodium affecte la forme de glaives ou de croix, et alors aucun doute ne peut subsister. 
L'urine de certaines femmes chlorotiques contiendrait, d’après Schearman, de la cystine, dont on provoquerait le dépôt par l'addition de carbonate d'ammoniaque.

\section{$\S 23 .-$ Xanthine.}

Nous dirons peu de chose de ce corps, en raison de son extrême rareté et du peu de précision de ses caractères microscopiques. Il a été trouvé dans des calculs urinaires, qu'il forme presque exclusivement; quelquefois le noyau est constitué par de l'acide urique. Ces calculs sont rares. C'est Marcet, qui a le premier signalé l'existence de la xanthine. Depuis, d'autres calculs ont été observés par Laugier en France, par Langenbeck, de Hanovre, par Wœhler et Liebig, etc., etc. On rencontre encore la xanthine dans l'urine humaine, surtout chez les leucémiques, dans le cerveau, la rate, le foie, le pancréas du bœuf, le thymus du veau, dans les foies atteints de cirrhose et dans certaines tumeurs de la rate (Méhu).

A l'état de pureté, la xanthine est amorphe, blanche, mais elle donne avec les acides des produits cristallisés. Elle prend sous la pression de l'ongle, ou de tout autre corps poli, un état cireux; presque insoluble dans l'eau froide, elle est à peine soluble dans l'eau bouillante. La xanthine est insoluble dans l'alcool et dans l'éther, mais se dissout facilement dans les alcalis et dans l'ammoniaque. Les acides précipitent la xanthine de ses solutions alcalines.

On peut la dissoudre dans l'acide azotique ainsi que dans l'acide sulfurique; elle est précipitée par les alcalis de la solution acide. L'azotate et le chlorhydrate de xanthine peuvent cristalliser et donner des cristaux très fins.

Le chlorhydrate de xanthine cristallise en tables hexagonales, ou en masses globuleuses, constituées par des cristaux confus.

L'azolate double d'argent et de xanthine cristallise en fines aiguilles, formant des amas sphériques, analogues à ceux donnés par les acides gras, et à la wavellite (alumine phosphatée).

Au premier abord, on peut être tenté de confondre un 
calcul de xanthine avec un calcul d’acide urique. La différenciation se fera par les réactions chimiques. La cassure des calculs de xanthine présente une couleur de cannelle ou de miel jaune (Golding Bird).

La forme cristalline de la cystine ne permettra pas de la confondre avec la xanthine.

D’après John Davy, on rencontrerait la xanthine dans les excréments des arachnides; chez les insectes, c'est de l'acide urique que l'on trouve.

\section{§ 24. - TAURINE.}

Ce corps est extrêmement riche en soufre, ainsi que l'a démontré Redtenbacher qui en a dosé près de 35 p. 100; il dérive de l’acide choléique.

On trouverait parfois de la taurine dans l'urine, sous l'influence de certaines affections du foie. Elle existerait normalement dans les muscles de certains poissons, de certains mollusques.

La taurine se rencontre dans les excréments de l'homme.

Ge corps se présente sous la forme de prismes à quatre ou à six côtés, terminés par des pyramides ou pointements obli-

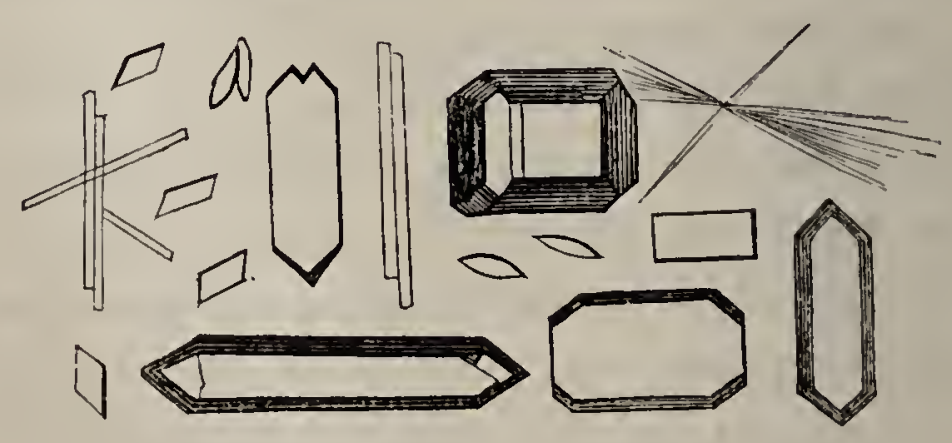

Fig. 328. - Taurine:

ques, à quatre ou six faces. La forme fondamentale est un prisme oblique droit.

Les cristaux sont neutres au tournesol, solubles dans 15 parties d'eau à $12^{\circ}$ et plus solubles dans l'eau chaude ; à peu près insolubles dans l'alcool et dans l'éther froid.

Les cristaux ne sont pas altérés par les alcalis peu concentrés, ni par les acides à froid, ni par le contact de l’air. 
La potasse en solution concentrée peut dissoudre les cristaux de taurine.

\section{$\S 25$. - LEUCINE.}

Dans le ramollissement du foie, dans le typhus et la variole, on trouve de la leucine dans l'urine.

Ge corps existe normalement dans le suc pancréatique, la

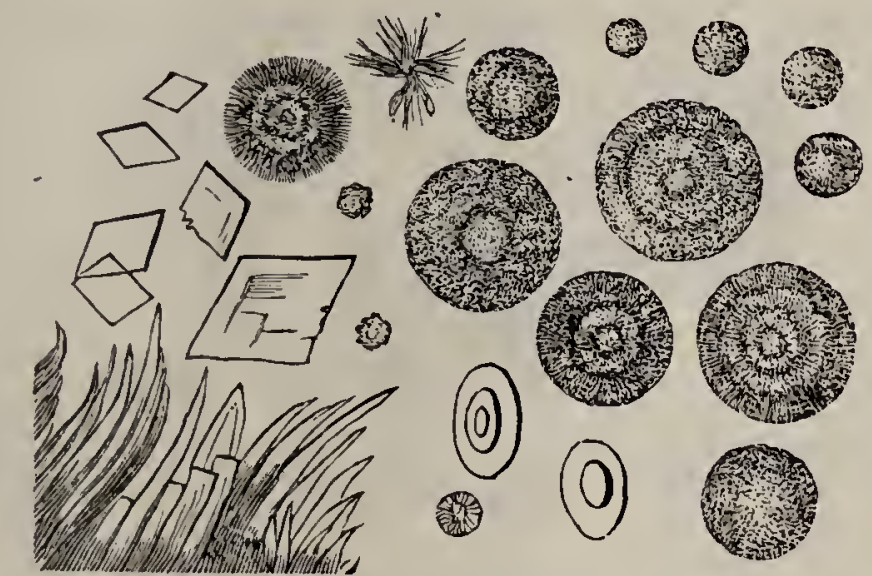

Fig. 329. - Formes variées sous lesquelles se présente la leucine.

rate, le thymus, le foie, le rein, les glandes salivaires, la salive, le cerveau, le poumon, les ganglions lymphatiques; il est un produit constant de la putréfactión des matières albuminoïdes, de l’épiderme, de la corne, de la sueur (Méhu). Ia leucine accompagne presque toujours la tyrosine.

La leucine cristallise en paillettes analogues à celles de la cholestérine (Méhu). Ce corps se présente également sous la forme de masses sphériques huileuses, ayant une grande légèreté spécifique et nageant à la surface de l'urine. Leur insolubilité dans l’éther, les distingue des matières grasses. Elles nont pas l'aspect nettement cristallin, mais sont parfois bordées çà et là de pointes fines (fig. 329).

Les cristaux sont peu solubles dans l'eau froide, très solubles dans l'eau bouillante, peu solubles dans l'alcool, insolubles dans l'éther.

Parfois, dit Harley, la leucine se présente avec une structure lamelleuse, semblable à celle de l'amidon de pommes de terre, et, par cela même, serait susceptible d'être confondue avec des cristaux microscopiques de carbonate de chaux. Les cris- 
taux calcaires vont au fond de l'eau, tandis que la plupart des globules de leucine surnagent, comme nous venons de le dire.

Dans le cas d'ictère, la leucine est colorée en jaune.

Un pharmacien distingué de Paris, M. Tréhyou, a bien voulu nous remettre, pour l'examinèr, un dépôt urinaire très curieux. Ce dépôt était constitué par de la leucine; nous en donnons ci-contre la figure (fig. $33(0)$.

Les sphérules de leucine étaient groupées ou isolées; au fur et à mesure que l'urine devenait ammoniacale, ces petites

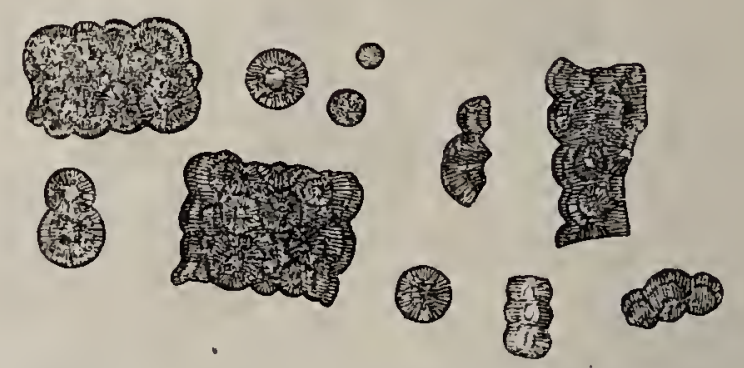

Fig. 330. - Sphérules de leucine, trouvées dans un dépôt urinaire.

sphères se fendillaient dans tous les sens. Le travail de désorganisation s'accentuant davantage, elles perdaient leur transparence et leur aspect cristallin. La dissociation devenant plus profonde, la leucine s'est transformée en amas de très fines granulations, qu'il eût été presque impossible de caractériser, si l'on n'avait pas suivi ce travail de transformation.

Ces sphérules de leucine constituaient un dépôt blanchâtre pulvérulent, peu abondant. Il nous fut impossible d'avoir des renseignements sur le malade qui avait fourni cette urine.

Dans ce cas particulier, la leucine était accompagnée de nombreuses cellules épithéliales, de leucocytes, d'un nombre considérable de cristaux d'oxalate de chaux et damas d'une matière bleue, offrant en certains points une apparence cristalline assez nette.

Le dépôt qui nous fut remis était si peu abondant, que nous avons pu à peine en faire quelques préparations microscopiques, conservées jusqu'ici d'une façon assez satisfaisante.

$$
\S 26 .- \text { tYrosine. }
$$

La tyrosine accompagne fréquemment la leucine, dans l'urine rendue pendant les maladies signalées plus haut; on la 
rencontre aussi dans les écailles cutanées des pellagreux.

La tyrosine cristallise en fines aiguilles, soyeuses et blanches, souvent groupées en étoiles.

Les cristaux de tyrosine sont peu solubles dans l'eau froide, plus solubles dans l'eau bouillante; ils sont insolubles dans l'alcool concentré et dans l'éther.

La tyrosine est très soluble dans l'ammoniaque; par éva-

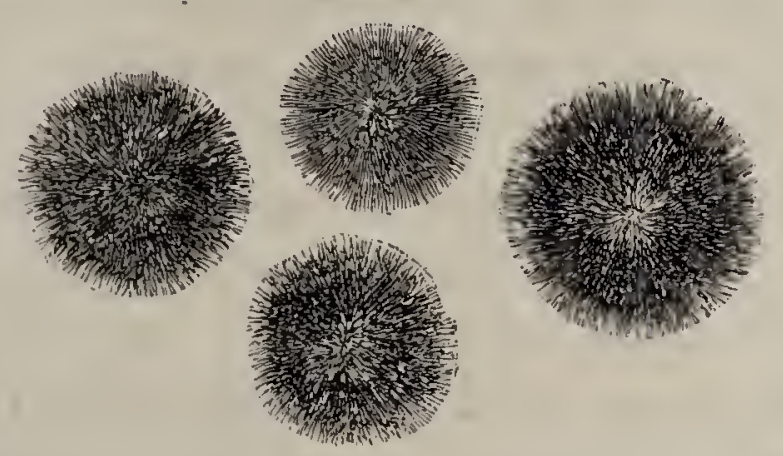

Fig. 331. - Sphères de tyrosine hérissées de pointes et provenant de l'urine dans un cas d'atrophie aiguë du foie.

poration on obtient de petites sphères constituées par de fines. aiguilles partant d'un centre commun.

La tyrosine se dissout dans les acides minéraux sans s'y altérer. Elle est soluble dans les alcalis. Les acides la précipitent de sa solution alcaline.

$$
\text { § 27. - GLUCOSE. }
$$

La présence du sucre dans l'urine a été découverte en 1674 par un médecin anglais, Thomas Willis. En 181 , notre compa-

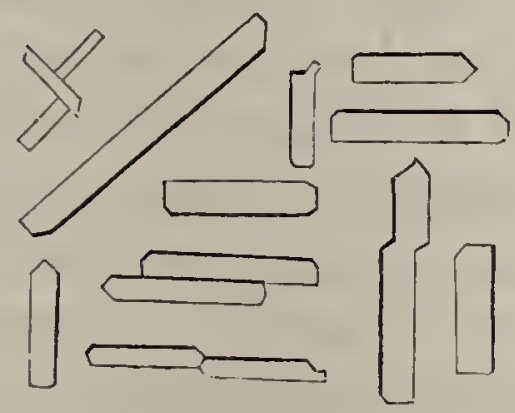

Fig. 332. - Cristaus de glucose et de chlorure de sodium s'étant déposés spontanément, dans une urine concentrée.

triote M. Chevreul démontra que le sucre de l'urine différait du sucre de canne, et se rapprochait beaucoup du sucre de raisin. 
Le sucre ne peut être considéré comme un sédiment de l'urine, mais quand on fait évaporer quelques gouttes d'une urine sucrée, ou que celle-ci s'évapore spontanément, on trouve des cristaux de glucose. Le sucre ne cristallise bien que dans le cas où l'urine est très riche en sucre et ne contient que peu d'urée, ou d'autres sels.

La forme cristalline la plus caractéristique est le prisme rhomboïdal; parfois les cristaux sont disposés en touffes rameuses (Harley). Ce même auteur est d'avis que le sucre du diabète ne cristallise avec autant de régularité qu'à la condition d'être combiné avec le chlorure de sodium.

Quand l'urine contient une plus forte proportion de sels, le sucre cristallise en petites masses circulaires, offrant des saillies formées de cristaux microscopiques. Ces masses semblent être constituées par une aggrégation de petites tables de sucre. Examinées sur un fond sombre, elles ressemblent à des fragments de sucre d'orge (Gibb, d'après Harley).

Nous rappellerons que, dans les urines sucrées, se développent des végétaux inférieurs, sur lesquels nous avons antérieurement insisté (voy. p. 415).

28. - matière colorante bleue de L'URine. - indigotine (Schunck, Méhu). - unoglocine (Heller!.

On observe que, dans certaines maladies, l'urine prend une coloration bleuâtre ou violacée, soit à sa surface qui est irisée, soit à sa partie inférieure qui contient un dépôt coloré. Cette matière colorante est toujours en quantité très faible; elle a été étudiée par M. Méhu (Bull. de thérapeut., 1871). D’après cet auteur, la matière colorante violette est formée par un mélange, en des proportions variables, d'une matière co. lorante bleue et d'une matière colorante rouge.

La matière colorante bleue jouit des propriétés de l'indigotine et a été obtenue cristallisée par M. Méhu (fig. 333).

Elle tend à se déposer la première avec le sédiment, et comme elle apparaît surtout dans les urines putrides, c'est avec les phosphates terreux qu'on la rencontre sur le filtre. Le sulfbydrate d'ammoniaque tend à détruire la matière co- 
lorante violette, mais celle-ci se reproduit lorsque l'urine est agitée en présence de l'air. L'oxygène paraît donc être-nécessaire au développement de la matière colorante bleue.

La matière colorante rouge existe en dissolution; son pouvoir colorant est très intense ; elle n'a pas été obtenue à l'état cristallisé.

La matière colorante bleue cristallisée affecte la forme de prismes droits, dont les extrémités sont assez fréquemment taillées en biseau; leurs arêtes sont quelquefois remplacées par des facettes. Tantôt ils sont isolés, tantôt groupés en masses irrégulières, ou bien ce sont de longues aiguilles prismatiques disposées en rayon (Méhu, Chim. médic., p. 325).

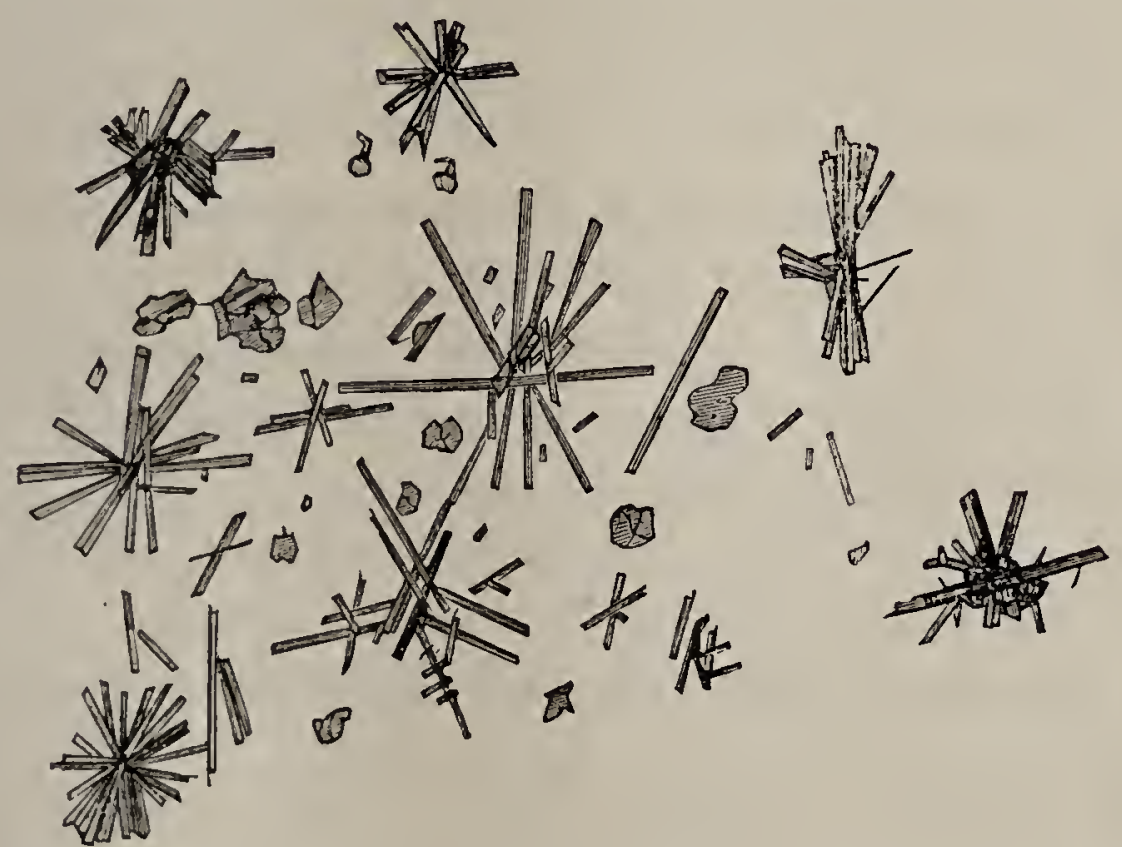

Fig. 333. - Pigment bleu de l'urine cristallisé dans l'alcool (Méhu).

Ces cristaux sont bleus, presque noirs, s'ils sont un peu épais. La matière colorante bleue est à peine soluble dans l'alcool concentré, qu'elle colore nettement en bleu; l'éther, le chloroforme, n'en dissolvent que des traces.

La matière colorante rouge (indirubine) est au contraire très soluble dans ces véhicules (Méhu).

Ces matières colorantes bleue et rouge de l'urine dériveraient, d'après Schunck, de l'indicane, qui se dédoublerait sous l'influence de la putréfaction en indigotine et en indirubine.

L'indigotine se rencontre rarement dans les sédiments urinaires à l'état de cristaux s'étant spontanément formés. D'a- 
près M. Méhu, les formes cristallines, quoique différentes de celles de l'indigotine cristallisée artificiellement, peuvent néanmoins se rapporter toutes au même système cristallin. Parfois aussi, dit cet auteur, l'indigotine se trouve dans le sédiment urinaire, à l'état de granulations amorphes, transparentes, d'un beau bleu, mélangées çà et là à des masses. d'une teinte rouge ou orangée.

Celles-ci contiennent la matière colorante rouge (indirubine) et souvent aussi le pigment urinaire normal.

M. Méhu fait une remarque très importante sur certaines plaques de formes irrégulières, de couleur bleue, tantôt claire, tantôt foncée, qui semblent être des détritus épithéliaux teints. par de l'indigotine. Ces plaques ne paraissent désigner aucun état morbide; elles ne sont jamais en assez grand nombre pour qu'il soit possible d'en faire une étude chimique. Ces fragments d'indigotine ou de matière organique colorées par de l'indigotine se voient également dans les urines des individus en bonne santé, comme aussi chez les malades (loc. cit., p. 330). Nous pensons que l'origine épithéliale de ces débris organiques colorés en bleu est l'exception.

D’après Golding Bird, lorsqu'on administre de l'indigo par les voies digestives, on en retrouve dans l'urine.

On a également signalé (Julia de Fontenelle) la présence du bleu de Prusse dans l'urine. Dans chacun de ces cas, du fer avait été absorbé volontairement ou involontairement. Les. auteurs ont émis cette hypothèse, que le cyanogène proviendrait de la décomposition de l'urée.

Des urines diversement colorées peuvent être rencontrées, mais la détermination du principe colorant est plutôt du ressort de la chimie que de la microscopie.

Il résulte d'une communication faite pàr le $\mathrm{D}^{\mathrm{r}}$ Albert Robin, à la Société de biologie, en mars 1879, qu'il y a trois espèces d'urines bleues, dont nous décrivons simplement les sédiments au point de vue de la matière colorante qui les caractérise.

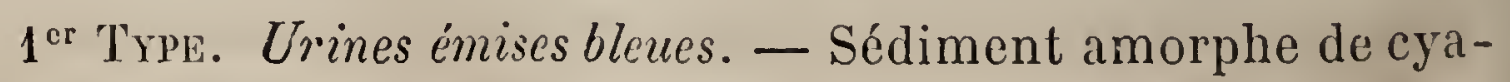
nourine (Braconnot et Alb. Robin) qui rougit par l'acide chlorhydrique et redevient bleue par l'ammoniaque. - Très rare. 
$2^{\mathrm{c}}$ TrPE. Urines devenant bleues spontanément, quelques heures après leur émission. - Sédiment amorphe ou cristallisé en aiguilles et en prismes isolés, ou réunis en amas étoilés ; ces aiguilles et ces prismes ne sont pas de l'indigotine, comme on l'a prétendu, mais bien de l'indigose. Ces cristaux résistent à l'action de l'acide chlorhydrique et sont assez solubles dans le chloroforme. Ces urines se rencontrent dans la fièvre typhoïde surtout. (A. Robin.)

$3^{\circ}$ TYPE. Urines devenant bleues plusieurs jours après leur émission et seulement à la surface. - On trouve, à la superficie du liquide, des sporules plus ou moins teintées de bleu; il est urgent de s'assurer que ces urines ne renferment pas d'indigose, qui, comme on le sait, vient quelquefois former des irisations à la surface du liquide, et pourrait teinter en bleu des spores indifférentes, comme celles du l'enicillium glaucum.

\section{§ 29. - DEs calculs urinaires.}

Le microscope ne peut que très rarement donner des renseignements précis, sur la composition des calculs. Les substances qui les constituent sont généralement à l'état amorphe, et, de plus, les calculs sont fréquernment formés de couches concentriques, de composition différente. C'est donc surtout à l'analyse chimique qu'il faut recourir; cependant, comme on peut avoir à étudier un faux calcul, l'examen microscopique pourra mettre sur la voie de l'erreur ou de la fraude.

Nous étudierons dans un chapitre spécial les calculs intestinaux.

\section{§ 30. - calcul d’oxalate de chaux cristalliś.}

Notre savant collègue et ami, M. le docteur Reliquet, a bien voulu nous confier un calcul, très curieux par sa forme cristalline et sa transparence, rendu spontanément par un malade après de vives douleurs.

Ce calcul avait un peu moins d'un centimètre de long sur cinq ou six millimètres de large ; il a été représenté ci-dessus considérablement grossi. Il était d'un blanc jaunatre; il pré- 
sentait des angles très aigus et une partie presque plane, que nous appellerons sa base. Cette base était transparente et formée de couches superposées et parallèles. Le calcul, placé sur sa base, montrait des groupes de cristaux brillants et relativement très volumineux, d'une forme très pure; ces cristaux paraissaient être constitués, par des prismes terminés par des pyramides à quatre pans, ou par des octaèdres.

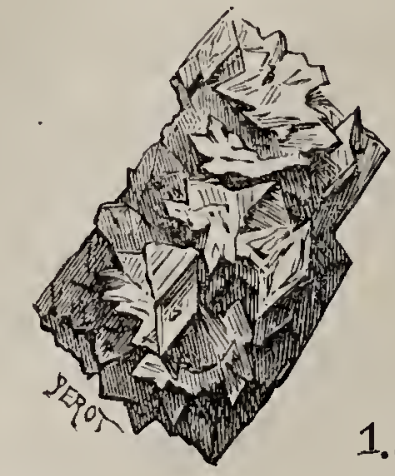

1.2 .3

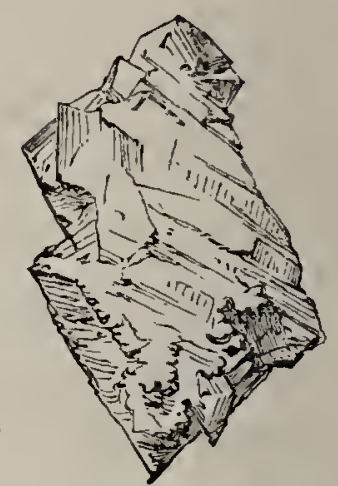

Fig. 334. - Calcul d'oxalate de chaux cristallisé.

L'analyse chimique a confirmé les prévisions tirées uniquement de l'examen des cristaux. Cette forme de calcul d'oxalate de chaux est très rare, et n'a pas encore été signalée, au moins à notre connaissance.

\section{$\S 31 .-$ Calculs biliatres.}

Ges calculs se rencontrent dans la vésicule biliaire ou dans le contenu de l'intestin. Parfois la vésicule est distendue par un grand nombre de ces cristaux, qui, par l'action du frottement, prennent des formes géométriques régulières; parfois, au contraire, un seul calcul peut remplir et distendre la vésicule biliaire. Si nous en parlons ici, c'est que fréquemment ils sont constitués par de la cholestérine associée à des matières colorantes de la bile, à du mucus et à quelques sels. A l'œil nu, lor'squ'on observe un de ces calculs, presque uniquement formé par de la cholestérine, on voit qu'il est constitué soit par des aiguilles orientées diversement, tantôt dirigées horizontalement, tantôt partant d'un centre commun, comme les rayons d'une sphère. Lorsque la cholestérine est emprisonnée dans une gangue, formée par des produits bi- 
liaires, celle-ci brille sur un fond sombre et affecte sa forme cristalline ordinaire. Voici quel serait, d'après M. Robin, la structure des calculs biliaires. La surface des calculs striés présente l'aspect d'aiguilles pyramidales, ou de lamelles brillantes, dont la forme générale est triangulaire, le sommet part d'un centre ou noyau, et la base correspond à la périphérie; dans les calculs composés de cholestérine pure, les stries sont radiées et brillantes ; dans ceux qui sont tout à fait transparents, il n'existe pas de noyau. Quand les calculs sont formés de cholestérine pure ou presque pure, celle-ci se présente sous la forme de paillettes, quelquefois larges de 2 à 3 millimètres et disposées en rayonnant autour du centre de la masse, mais généralement microscopiques, losangiques et souvent encore très régulières et imbriquées. Suivant le plus ou moins grand nombre de granules microscopiques colorés, interposés aux lames de cholestérine, la teinte des cristaux lamelleux passe du blanc nacré au blanc jaunâtre.

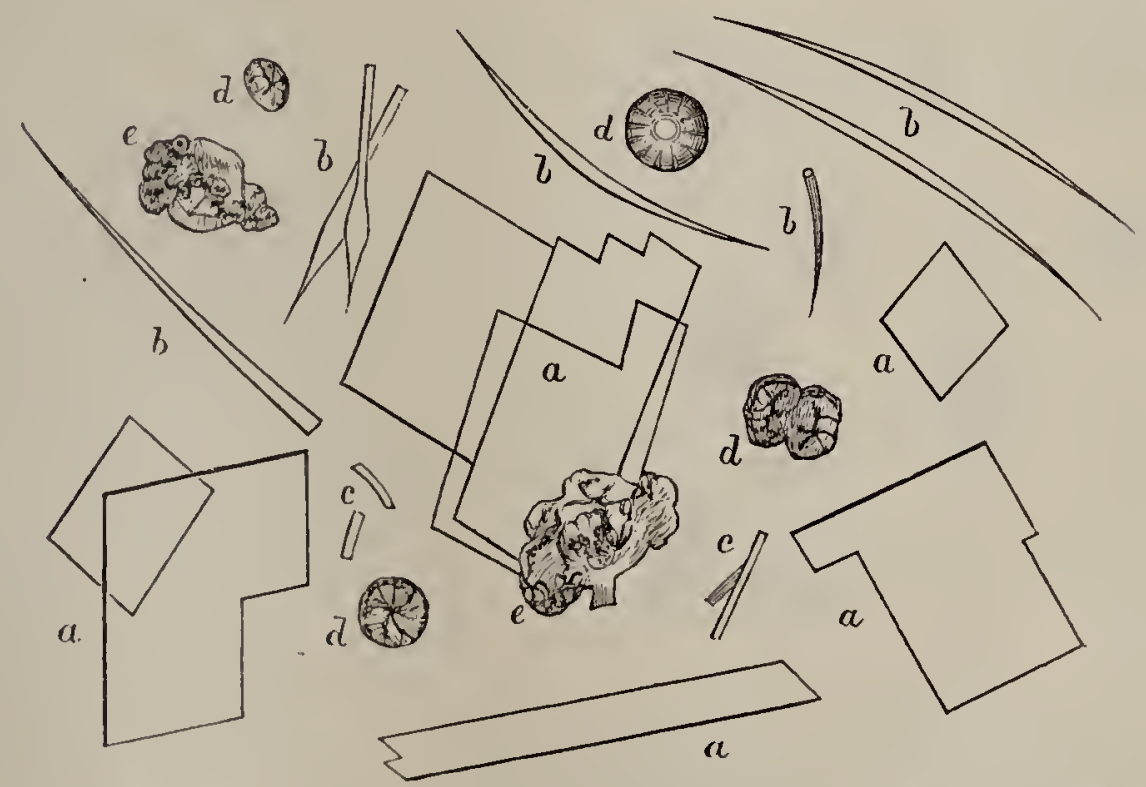

rig. 335. - Éléments entrant dans la composition des calculs biliaires.

Les calculs biliaires, dans lesquels dominent les matières colorantes biliaires (biliverdine, biliphéine, cholépyrrhine). offrent des colorations très variables. Ils sont solubles dans l'éther, ainsi que dans la potasse et la soude; avec l'acide nitrique, ils fournissent les réactions des matières colorantes biliaires et passent par les teintes verte, bleue, violette, rouge et jaune. La matière colorante vue au microscope forme 
des granules ou des fragments jaune orangé ou verdâtres. Nous donnons, d'après le magistral ouvrage du professeur Laboulbène, l'analyse d'un calcul biliaire par dissolution alcoolique : $a, a, a$, cristaux de cholestérine $; b, b, b$, cristaux aciculés de cholate de chaux; $c, c, c$, cristaux bacillaires de la même substance; $d, d, d$, matière grasse cristalline ; $e, e, e$, substance amorphe colorée en vert. 


\section{CHAPITRE XII}

\section{DU LAIT AU POINT DE VUE MIGROSGOPIQUE.}

Ainsi que le sang, le liquide produit par les glandes mammaires est, d'une façon générale, composé de deux parties, une partie liquide, une partie solide. L'analogie se poursuit encore, et de même que la fibrine, dissoute dans le sang, se coagule sous l'influence de causes diverses, nous verrons également que la caséine, dissoute dans le sérum du lait, peut

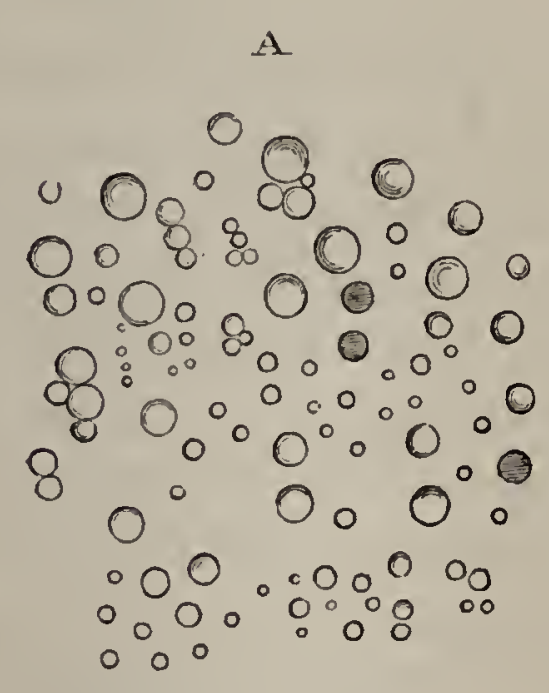

lig. 336. - Lait normal.

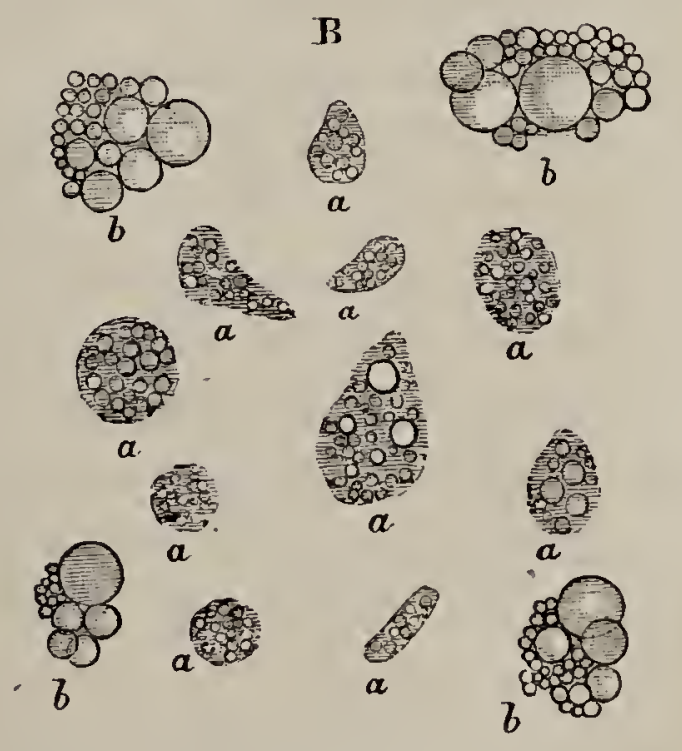

Fig. 337. - Éléments du colostrum. A, corps granulcux. - B, globules agglomérées.

aussi apparaître dans le champ du microscope. Les éléments solides du lait sont constitués par un très grand nombre de petites granulations graisseuses, animées d'un mouvement brownien, et par des globules d'un volume plus considérable, mais variable, et, à une certaine période de la lactation, par des corps granuleux (Donné). Outre ces éléments, le lait renferme encore quelques rares globules blancs, des cellules épithéliales d'origine diverse, etc. 
$\S 1$. Du colostrum. - Dès qu'une femme devient enceinte, il se passe, du côté des glandes mammaires, une série de phénomènes préparatoires, qui semblent marcher parallèlement au développement de l'utérus. Le sein augmente d'abord de volume, et, à une époque variable suivant les femmes, la glande sécrète un liquide tantôt séreux, ne contenant que quelques globules de graisse, tantôt, au contraire, un liquide jaunâtre épais, visqueux, qui est le colostrum. Nous tenons à insister sur ce point, c'est qu'il n'y a pas de règle précise pour l'apparition du colostrum ; tantôt, on pourra le faire sourdre à la simple pression de la glande mammaire d'une femme enceinte de deux mois, tantôt, au contraire, une femme arrivera jusqu'au terme de sa grossesse, sans que la sécrétion lactée se soit éveillée. Les grossesses antérieures ne nous ont pas paru exercer une influence marquée sur le développement de la sécrétion lactée. Par conséquent, il n'y a pas de déduction véritablement scientifique à tirer de l'époque de l'apparition du colostrum.

Lorsqu'on examine du colostrum au microscope, on voit un nombre plus ou moins considérable de globules laiteux, tantôt régulièrement sphériques, tantôt irréguliers; les uns sont très gros, les autres extrêmement fins. D'après Donné (1), ces gouttelettes oléagineuses seraient de la substance butyreuse mal élaborée, qui monterait très facilement à la partie supérieure du colostrum. La plupart des autres globules gras, ajoute Donné, sont très petils et forment comme une poussière; ces globules, au lieu de se déplacer librement dans le sérum, comme cela se voit dans le lait complètement élaboré, sont pour la plupart liés entre eux par une matière visqueuse, de manière qu'en les faisant circuler sur la lame de verre, ils se déplacent par petites masses agglomérées, au lieu de monter les uns sur les autres et sans adhérence, comme dans le lait pur. C'est à Donné que revient l'honneur d'avoir décrit le premier ces corps si caractéristiques, auxquels il a

(1) Du lait et en particulier de celui des nourrices, etc. Paris, 1837. Donné est mort récemment presque oublié ; il a rendu de nombreux services à la science; nous tenons à lui rendre cet hommage. 
imposé le nom de corps granuleux, nom qui leur est justement resté. C'est à tort que Simon (Die Frauenmilch, p. 53) a nié l'existence de ces corps granuleux qu'on voit avec la plus grande facilité. "Ces corps particuliers n'ont pas toujours la forme globulaire, ni même une forme constante, ils présentent à cet égard toutes les variétés possibles; il en est de petits, ayant moins d'un centième de millimètre, et d'autres très gros, ayant plusieurs fois ce diamètre; ils sont peu transparents, d'une couleur un peu jaunâtre et comme granuleux, c'est-à-dire, qu'ils semblent composés d'une multitude de petits grains, liés entre eux, ou renfermés dans une enveloppe transparente; très souvent il existe, au centre ou dans tout autre point de ces petites masses, un globule qui ne paraît être autre chose qu'żn véritable globule laiteux emprisonné dans cette matière. " Donné n'avait pas déterminé la nature de ces corps particuliers, mais il avait reconnu qüils ne se dissolvent pas dans les alcalis ; toutefois, de même que les globules laiteux véritables, ils disparaissaient dans l'éther; après l'évaporation de ce dissolvant, il restait sur le verre des petits amas d'aiguilles cristallines, constitués par des cristaux de margarine. Depuis on a déterminé l'origine des corps granuleux. D'après G. Pouchet et Tourneux, ces corps seraient les cellules de la glande mammaire chargées de graisse. Pour les observer, disent ces auteurs, le colostrum est laissé pendant vingtquatre heures avec huit ou dix fois son volume d'éther. On recueille le dépôt au fond du verre, avec une pipette, et on colore avec le picrocarminate.

La présence de ces corps granuleux ne persiste pas ordinairement dans le lait; chaque jour ils diminuent de nombre; les globules laiteux prennent une forme régulière, ils deviennent parfaitement sphériques et d'une grosseur sinon égale, ce qui n'existe jamais dans le lait, mais au moins n'offrant pas cette énorme disproportion que nous avons signalée plus haut. Le temps nécessaire à l'accomplissement de ces modifications est extrêmement variable; vingt jours après l'accouchement, on peut encore trouver des corps granuleux dans le lait d'une bonne nourrice.

Donné, à la suite de nombreuses recherches, a fait le ta- 
bleau suivant des diverses modifications que subit le lait depuis l'accouchement jusqu'à l'état parfait : "Le premier jour, colostrum jaunâtre, visqueux, demi-transparent, alcalin; il se compose de globules laiteux, la plupart agglomérés, très disproportionnés entre eux, pour la grosseur, mêlés de corps granuleux nombreux, de forme variée et de gouttes oléagineuses; ce liquide, traité par l'ammoniaque, se prend tout entier en une masse visqueuse et filante.

"Le troisième jour l'enfant a déjà tété plusieurs fois, les seins commencent à se gonfler, le lait est jaune, il présente à peu près les mêmes caractères que le premier jour, sauf qu'il contient déjà moins de corps granuleux.

"Le sixième jour, l'état de la mère et celui de l'enfant ne laissent rien à désirer, les seins sont gonflés et l'enfant tète sans difficulté; cependant il faut une certaine pression pour faire sortir le lait. Celui-ci est très jaune et bleuit fortement le papier rouge de tournesol; les globules laiteux sont généralement gros, mais mieux proportionnés entre eux; il existe encore un certain nombre de gouttes oléagineuses, mais on ne voit pas cette espèce de poussière de petits globules que l'on remarque dans certains laits pauvres. Les masses de globules agglomérés (1) n'ont pas disparu, mais les corps granuleux deviennent assez rares; du reste les globules laiteux sont. nombreux et serrés.

"Le septième jour, la couleur du lait est toujours très jaune et la consistance assez grande; on voit encore quelques gros globules huileux, mais le plus grand nombre est bien net, bien circonscrit et bien proportionné; les masses agglomérées disparaissent peu à peu, les corps granuleux deviennent rares.

"Le dixième jour le lait est abondant, les seins sont très gonflés et très durs, le lait est assez épais, légèrement jaunâtre ; il présente au microscope des globules très nombreux et très serrés, dont quelques-uns sont très gros et n'ont pas moins de 2 à 3 centièmes de millimètre en diamètre; mais le plus grand nombre sont d'une moyenne grosseur et n'ont pas plus de

(1) Il ne faut pas les confondre avec les corps granuleux. 
$1 / 150$ à 1/200 de millimètre; il y en a de beaucoup plus petits, mais il sont peu nombreux, relativement aux autres; il existe encore quelques petites agglomérations et quelques corps granuleux très rares.

"Le quinzième jour, le lait est d'un beau blanc mat, avec une légère teinte de jaune; on aperçoit dêtemps en temps un corps granuleux et quelques petites agglomérations ; l'ammoniaque, lui communique encore un peu de viscosité; enfin, le vingt-quatrième jour, le lait est tout à fait blanc, riche en globules et ne contient plus aucun corps étranger; il reste tout à fait limpide, quand on le mêle avec de l'ammoniaque; depuis cette époque, le lait ne présente plus decaractères particuliers, et il paraît avoir acquis ses qualités normales. D (Donné, loc. cit.)

Ainsi que le dit fort bien Donné, dans son mémoire, ce sont là des moyennes qui peuvent subir de nombreuses exceptions; aussi faudrait-il bien se garder de croire que, dans l'observation directe des faits, les choses se passent avec une régularité mathématique. G'est ainsi que, d'après les recherches de l'auteur lui-même, on peut trouver des laits parfaitement bons en apparence et des nourrices très saines et bien portantes, offrant ce mélange des éléments du colostrum, longtemps après qu'il ne devait plus en exister de trace. Le lait peut renfermer des corps granuleux pendant plusieurs mois. Dans ces cas, Donné a cru remarquer que les enfants étaient chétifs, comme s'ils ne recevaient qu'un lait mal élaboré et peu nourrissant. Gette remarque mérite d'être confirmée. En un mot, pour Donné, la persistance du colostrum dans le lait serait le signe d'un état d'imperfection de ce liquide.

Henle, après Donné et quelques autres auteurs, a étudié également les corps granuleux du colostrum; ces globules consisteraient, d'après cet observateur, en des agglomérations de très petits globules, unis entre eux par une substance grise, qui se dissout dans l'acide acétique, et laisse ainsi en liberté les globules qu'elle réunissait. Nous avons dit plus haut quelle était la véritable origine des corps granuleux. L'iode les colore en brun (Hassal, Filhol); ces auteurs disent que l'éther les dissout entièrement; nous avons vu qu'il n'en était rien. D'après 
Arthur Hill, Hassal, les corpuscules granuleux paraissent être très rares dans le colostrum de la vache, de la chèvre et de l'ânesse. Antérieurement à ces auteurs, Donné avait fait la même remarque ; sauf ce point parliculier, il résulte des recherches de cet auteur, que le lait subit les mêmes modifications chez les animaux que chez la femme, mais ces modifications sont moins accentuées.

C'est avec intention, que nous avons fait tout à l'heure de grandes réserves pour ce qui concerne la détermination de l'âge du lait, par la présence, dans celui-ci, des corps granuleux en plus ou moins grande quantité. On sait combien en médecine légale il faut se défier des opinions toutes faites et des affirmations catégoriques, aussi ne croyons-nous pas que l'on puisse appliquer les résultats fournis par Donné, à la solution de certains problèmes de médecine légale, comme le conseillent des auteurs estimés. Dans un cas d'avortement, ou d'accouchement clandestin, il ne faudrait pas croire que, par un examen du lait, on puisse avec quelque certitude déterminer l'époque à laquelle remonte le part. Que dans la majorité des cas, ainsi que l'ont prétendu Bœker, Morel et Tourdes, le lait, chez les femmes qui n'ont pas allaité, reste plus longtemps à l'état imparfait, cela est possible, mais ce n'est pas un fait constant. C'est ainsi que nous pouvons actuellement observer une jeune femme accouchée récemment et n'ayant pas allaité, dont le lait ne présente ni globules agglomérés ni corps granuleux. Aussi les conclusions suivantes de Morel et Tourdes ne doivent pas être acceptées sans les plus expresses réserves: $1^{\circ}$ le lait reste imparfait chez les femmes qui n'allaitent pas; il continue à être caractérisé par l'inégalité des globules et par la présence des globules de colostrum; $2^{\circ}$ la diminution et la pauvreté croissantes de la sécrétion ne fournissent que de simples indices; $3^{\circ}$ la rareté ou l'absence de la poussière globuleuse annonce un lait plus ancien. Un signe d'âge semble résulter de l'atrophie des corpuscules du colostrum. Nous ne voulons pas quitter ce sujet sans parler de l'examen des taches de lait appliqué à la médecine légale. Nous empruntons les renseignements qui suivent, à la monographie du docteur J. Gosse, sur les taches. On trouve particulièrement ces taches 
GHAP. XII. - DU LAIT AU POINT DE VUE MICROSCOPIQUE. 491

sur la chemise au-devant des seins. Quand le lait est encore à l'état de colostrum, leur coloration tranche d'une façon nette sur le tissu blanc; elle est plus foncée que lorsqu'il s'agit de lait arrivé à l'état parfait. Ces taches empèsent fortement le linge, qui devient rude au toucher. Elles sont visibles des deux côtés, sur les tissus de chanvre et de coton. Leur aspect varie suivant l'âge du colostrum et suivant qu'il est plus ou moins séreux. Dix taches de colostrum d'un jour ont présenté au docteur Gosse les caractères suivants : coloration jaunâtre uniforme, le linge empesé plus fortement encore que pour du colostrum des jours suivants, taches plus petites et un peu sinueuses. Les taches du colostrum de deux à trois jours au plus ont un aspect caractéristique : le centre de la tache (la partie tachée primitivement par le colostrum) jaunâtre est entouré par une portion beaucoup plus claire, grise. Cette portion, qui constitue le bord de la tache, est beaucoup moins foncée vers le centre que vers le bord, qui offre une sorte de liséré gris, très marqué. Les bords présentent plutôt des dentelures que des sinuosités. Sur les toiles de chanvre colorées, (en bleu par exemple) on ne voit pas la coloration jaune, mais une teinte bleu foncé, très tranchée. Sur les tissus de laine noire, on voit, du côté de la tache, une coloration blanc grisâtre, un peu brillante, ayant des analogies avec l'aspect que présentent les taches spermatiques. M. le docteur Gosse a revivifié des taches de deux mois, par l'eau distillée, après les avoir fait macérer pendant quinze minutes, et a examiné au microscope l'eau de macération, très faiblement opaline. Au grossissement de כొว̆0 diamètres, il a vu distinctement les corps granuleux, ainsi que quelques rares globules graisseux. Ceux-ci sont libres, très peu déformés. L'ammoniaque rend l'eau de macération très faiblement glutineuse, cependant assez pour que l'on puisse le constater. Par l'addition d'acide acétique et d'éther, les globules graisseux disparaissent en grande partie, mais non complètement; la majorité de ceux que l'on retrouve sont déformés et présentent quelquefois une forme analogue à celle des larmes bataviques. Quelques corps granuleux persistent également. (Gosse, loc. cit., p. 70.) 
Les taches produites par le lait acquièrent une raideur qui diminue un peu par la chaleur, laquelle du reste ne les fait pas changer de couleur. Bayard, d'après le docteur Gosse, attribuerait à ces taches une coloration jaunâtre. Cette coloration existe, en effet, pour certains laits et surtout pour le lait des deuxième et troisième mois ; mais, passé ce temps, les taches deviennent plutôt d'un gris assez pâle. Leur teinte est uniforme, seulement quelquefois elles présentent un liséré d'un gris un peu foncé. Sur de la toile de couleur, elles se manifestent par une coloration un pell foncée de la partie tachée. Sur des étoffes de laine, elles sont à peine visibles, même sur les étoffes noires. En général elles sont assez grandes, arrondies et n'offrent pas de relief; sur de la toile ou des cotonnades, elles sont visibles de deux côtés. Ces mêmes étoffes, regardées par transparence, présentent une moins grande opacité, dans la partie tachée. Si l'on fait macérer les taches dans de l'eau légèrement acidulée, on retrouve par l'examen microscopique, les globules du lait dans l'eau de macération. Ceux-ci sont un peu contractés, libres et suspendus dan's le liquide. L'ammoniaque ne rend pas le liquide glutineux. L'éther dissout une grande partie des globules, non la totalité, même lorsqu'on y a ajouté quelques gouttes d'acide acétique (Gosse, loc. cit., p. 74). M. le docteur Tourdes (Dict. encyclop., $2^{\mathrm{e}}$ série, t. I, p. 43) dit qu'en 1857 , dans un cas de suspicion d'infanticide il a constalé avec le docteur Kœberlé, que du lait provenant d'une femme dont l'accouchement datait de sept jours, conservé sur une plaque de verre et examiné dix-neuf jours après, offrait encore tous les caractères essentiels du lait et contenait des corpuscules irréguliers, análogues à ceux du colostrum. Les expériences comparatives, faites sur des laits d'âges différents, ont montré aux auteur's, qu'on pouvait retrouver sur ces taches, en les délayant dans une gouttelette d'eau sucrée, les indices des différentes périodes, mais que les corpuscules de colostrum étaient l'élément qui s'altérait le plus facilement.

Donné a recherché s'il y avait un rapport entre la sécrétion du colostrum et la sécrétion lactée, après l'accouchement, en d'autres termes, s'il était possible de reconnaître d'avance, 
CHAP. XII. - DU LAIT AU POINT DE VUE MIGROSCOPIQUE. :93

si une femme aura du lait, en suffisante quantilé, pour nourrir son enfant. L'auteur que nous venons de citer a tranché la question avec beaucoup de précision, au moins dans la règle qu'il a établie: "La sécrétion de la glande mammaire est, après l'accouchement, dans un rapport constant avec l'état qu'elle présente pendant la gestation, de telle sorte qu'il est possible de prévoir, par l'observation de ces caractères, pendant la grossesse, ce qu'elle sera, lorsqu'elle aura acquis toute son activité après le part. »

Donné a résumé de la façon suivante les caractères que présente le colostrum :

$1^{\circ}$ Sécrétion presque nulle et liquide visqueux, contenant à peine quelques globules laiteux, mêlés de corps granuleux rares;

$2^{\circ}$ Colostrum plus ou moins abondant, mais pauvre en globules laiteux, qui sont petits, mal formés et souvent entremêiés, outre les corps granuleux, de globules muqueux.

$3^{\circ}$ Enfin, colostrum riche en globules laiteux réguliers et d'une bonne grosseur, n'étant mélangés d'aucune autre substance que des corps granuleux particuliers au coløstrum.

Voici mainlenant les indicalions que l'on peut tirer d'après l'auteur de ces divers états de la sécrétion lactée, vers les derniers temps de la gestation.

$1^{\circ}$ Le premier état appartient aux femmes chez lesquelles la sécrétion du lait est pour ainsi dire nulle après l'accouchement, ou bien chez lesquelles elle ne produit qu'un liquide séreux, pauvre en éléments nutritifs et incapable de suffire à l'allaitement d'un enfant.

$2^{\circ}$ Chez les femmes de la deuxième catégorie, le lait, après l'accouchement, peut être en petite quanlité ou très abondant; mais il est toujours pauvre et séreux.

$3^{\circ}$ Enfin, le colostrum riche en globules laiteux et pur de loute substance étrangère à la composition du lait, autre que les corps granuleux, indique toujours un lait également riche, abondant et de bonne qualité. - (Donné).

Nous pouvons ajouter que notre expérience personnelle vient confirmer, d'une façon générale, les résultats obtenus par Donné. 
§ II. Du lait. - Lorsqu'on examine du lait à l'état parfait, on voit qu’il est formé d'un liquide, dans lequel sont suspendus un nombre extrêmement considérable de globules butyreux, nettement sphériques, réfractant fortement la lumière, et de volume variable. Cette inégalité de volume avait frappé les premiers micrographes, qui avaient cru pouvoir en déduire, que ces globules divers avaient une composition différente. Leew enhoeck, le grand observateur au microscope, rapporte en ces termes l'impression produite sur lui, par l'examen du lait au microscope. "Vidi multos globulos, similes sextce parti globuli sanguinei et etiam alios, quorum bini, terni aut quaterni se invicem modo attingebant, fundum versus descendere et multos variæ magnitudinis globulos in superficie fluitantes, inter quos posteriores adipem sive butyrum esse judicabam."

Pendant longtemps, on a cru qu'il y avait dans le lait des globules de caséine et des globules de beurre. Hodgkin, Lyster (Annales des sciences naturelles, t. XII, p. 69), ont émis les premiers l'opinion que les globules du lait étaient tous identiques. Mais, à celte époque, on considérait les plus petits globules comme formés de caséine. Raspail était d'avis que, parmi ces globules, il y en avait d'albumineux et d'oléagineux. Donné a démontré que ces globules, quel que fût leur volume, étaient. tous solubles dans l'éther. La démonstration ne laissait rien à désirer; le même auteur a également remarqué que toute la matière grasse du lait n'y existait pas sous forme de globules graisseux; et que, si l'on agitait le sérum avec de l'éther et qu'on l'additionnât d'eau ensuite, il se séparait une certaine quantité d'huile, qui était hor's de proportion avec les globules butyreux que pourait encore contenir le sérum.

L’identité des globules du lait ayant élé établie, une longue discussion s'élera parmi les observateur's sur ce point: les globules du lait ont-ils, ou non, une enveloppe de nature différente? Raspail, dans sa chimie organique, dit que l'on voit les globules enveloppés par une membrane transparente et albumineuse, diaphane et nullement granuleuse par elle-même. Donné et Dujardin s'élevèrent contre cette opinion, soutenue par Mandl, Turpin, Henle, Dumas, etc. MM. Filhol et Joly ont démontré que ce qui avait pu donner naissance à cette fausse 
CIIAP. XII. - DU LAIT AU POINT DE VUE MICROSCOPIQUE. 495 interprétation, c'était la coagulation de la caséine autour des globules butyreux, un certain temps après que le lait a été retiré de la mamelle, ou qu'il a subi l'influence de certains réactifs, tels que l'alcool, l'éther ou un acide faible. M. de Sinety s'est occupé récemment de cette question; l'autorité légitime qui s'attache aux travaux de cet observateur distingué nous fait un devoir de citer ses belles recherches. Il n'est pas besoin de substances étrangères, dit M. de Sinety, pour amener des coagulations dans le lait; au bout de peu de temps, il se forme dans ce liquide des coagulations très faciles à constater au microscope, tandis qu'à l'œil nu, au goût et à l'odeur, on ne pourrait encore saisir aucune transformation. Si on examine immédiatement le lait, au sortir de la mamelle, en ayant soin de ne pas l'agiter, on ne trouve aucune trace de membrane, autour des globules gras, ni aucune substance coagulée, dans la préparation soumise à l'examen. Si le lait n'est pas agité, les coagulations se montrent plus tardivement. M. de Sinety en a toujours trouvé au bout d'une heure, et parmi les globules gras; un grand nombre sont alors entourés d'une substance membraneuse, facile à reconnaître aux plis qu'elle forme en certains points. Ainsi que le fait justement observer M. de Sinety, ces observations montrent que, comme tous les liquides de l'organisme, le lait est soumis dans la mamelle à des échanges continuels et incessants, qui constituent la vie. Personne n'aurait l'idée de considérer comme normal, le sang, quand il a été extrait des vaisseaux. Le phénomène de la formation du caillot a nécessairement frappé les premiers qui l'ont vu. Pour le lait, il en est de même que pour le sang, et pour être moins faciles à observer et nécessiter l'emploi du microscope, les transformations morphologiques que subit ce liquide, hor's de la mamelle, n'y sont pas moins évidentes. Dans l'organisme vivant, le lait ne se compose que d'un liquide amorphe, tenant en suspension des corpuscules sphériques de dimensions différentes, formés de matières grasses. Ces petits corps, poursuit M. de Sinety, ne sont pas même entourés de cette fine membrane, qui se forme au contact des substances grasses et albuminoïdes, et qu'Ascherson avait très bien étudiée et décrite sous le nom de membrane haptogène. 
M. de Sinety a repris l'expérience d'Ascherson, et il a vu comme lui, que, si l'on agite de l'huile avec de l'albumine de l'œuf, par exemple, il se forme, autour de chaque gouttelette d'huile, une enveloppe membraneuse, que l'addition d'une goutte de rouge d’aniline rend encore plus évidente, mais qu'on peut très bien observer, sans l'aide d'aucun réactif. Le lait vivant est, à ce point de vue, une émulsion toute spéciale et différente de celle que nous obtenons dans nos laboratoires. Dès qu'il a quitté la mamelle, il devient semblable alors, en certains points, au liquide soumis à nos expériences. Il paraît parfaitement fluide à l'œil nu, mais le microscope nous montre qu'il contient bientôt des substances coagulées, de véritables petits caillots. Alors aussi ces globules s'entourent d'une membrane comme les gouttelettes d'huile, quand on agite celle-ci avec l'albumine. On voit, par ce qui précède, que M. de Sinety a donné l'appui de son autorité scientifique à l'opinion précédemment émise par MM. Filhol et Joly. En résumé, les globules du lait vivant ne sont pas entourés d'une membrane, mais lorsqu'il s'est fait dans ce liquide des coagulations spontanées, ou provoquées par des réactifs, les globules du lait sont revêtus d'une membrane enveloppante.

La grosseur des globules du lait est excessivement variable dans un même lait, et, à plus forte raison, d'une femme à une autre. Nous avons vu que, dans le colostrum, il y avait des globules butyreux, d'une grosseur considérable et de forme irrégulière, mais, à mesure que le lait devient plus parfait, les globules tendent à s'égaliser. Néanmoins, la variation des globules entre eux est dans le rapport de $\mathbf{1}$ à 5 .

Il résulterait des recherches de Donné, qu'abstraction faite de ces globules volumineux, que l'on trouve dans les laits jeunes, les globules du lait tendraient à augmenter de volume, depuis l'accouchement jusqu'à une certaine époque de l'allaitement; c'est ainsi que les petits globules, très nombreux après l'accouchement, tendraient à se rapprocher du type de $1 / 100^{\circ}$ de millimètre.

Des recherches de Donné et Duvergier, il résulterait que le lait à gros globules est plus fort et plus propre à acquérir de la richesse par l'allaitement, mais tous les enfants ne 
peuvent le supporter. Cette condition du lait coïnciderait le plus fréquemment avec le tempérament lymphatique. Le lait à petits globules paraîtrait se rattacher de préférence aux tempéraments sanguins; il est généralement plus pauvre et moins capable d'acquérir de la richesse. Le lait à globules moyens est la condition la plus communément observée. Il arrive quelquefois que les globules diffèrent dans chaque sein, ce qui s'observe surtout, quand on examine un sein plutôt que l'autre (Donné et Duvergier).

Eu égard à l'importance du rôle joué par les matières grasses dans l'alimentation des enfants, les observateurs ont cherché un moyen pratique d'évaluer la richesse du lait en globules. Une question incidente de la plus haute gravité se posait en même temps: les divers éléments qui entrent dans la composition du lait, sucre de lait (lactine), caséine, etc., varientils dans le même sens que la matière grasse? En un mot, quand un lait est riche en matières grasses, contient-il également une proportion aussi considérable des autres éléments nutritifs? MM. Péligot et Payen avaient résolu la question par l'affirmative. M. Péligot, dans son travail sur le lait d'ânesse, fait voir, que le plus souvent, la quantité de caséum et de sucre augmente, en même temps que la proportion de beurre et diminue avec elle. Les observations directes de Donné l'ont conduit à admettre la réalité du rapport établi par Péligot et Payen. D'après M. Husson, la diminution d'un principe amènerait, au contraire, presque nécessairement l'augmentation de l'autre. C'est surtout entre le sucre de lait et la caséine, que cette corrélation existerait. De sorte que, si l'analyse chimique démontre une diminution notable du sucre de lait, accompagnée d'une augmentation de caséine, ou d'apparition d'albumine, on peut conclure que l'altération est due à un certain état pathologique, ou à l'influence d'une alimentation mauvaise (Husson). Antérieurement, Simon, Filhol et Jolly s'étaient inscrits contre le rapport établi par Péligot, Payen et Donné. De leur côté, MM. Vernois et Becquerel affirment aussi que : comme dans le sang, comme dans l'urine, les éléments du lait ne sont pas solidaires entre eux. Chaque élément semble avoir une existence à part, que modifient tour à tour des in- 
fluences spéciales. Il n'existe pas de proportions régulières et constantes dans leur développement, et jusqu'ici, ni par l'étude de la densité, ni par celle du beurre, ou de tout autre élément pris à part, on ne peut donner aucune idée précise de ce qu'on appelle la richesse, ou la bonté du lait. Il faut de toute nécessité recourir à l'analyse complète. Quoi qu'il en soit, M. le docteur Bouchut a présenté à l'Académie des sciences, 17 octobre 1877, un procédé d'analyse du lait, reposantsurla numération des globules gras. Les globules du lait de femme, dit M. Bouchut, ont un diamètre qui varie entre $1 / 300$ de millimètre et $3 / 300$. Nous pensons que l'écart est souvent plus considérable, et c'est là, le point critiquable de la méthode. Faisant lui-même cette critique, M. Bouchut dit: "Si tous les globules de lait étaient d'égal volume, il est évident qu'ils auraient même poids, et que de leur nombre dans 1 millimètre cube, on pourrait arriver d'une façon précise à leur poids et au poids du beurre par litre. Mais il n'en est pas ainsi. Il y a des globules et des globulins. Les gros globules du lait ont $3 / 300$ de diamètre, et les petits varient entre $2 / 300$ et $1 / 300$. Il en résulte qu'avec ce volume inégal, leur poids de beurre est un peu variable, et cette différence se traduit dans le poids du beurre, calculé d'après le nombre des globules contenus dans un litre."

Quoi qu'il en soit, M. Bouchut a pensé que la mumération des globules du lait pouvait être employée comme moyen sérieux d’appréciation des qualités du lait, et il a appliqué à cette numération, en le modifiant, le procédé donné par M. Hayem pour la numération des globules du sang (V. Sang). M. Bouchut emploie une cuvette de $1 / 10$ de millimètre, afin de rendre plus rapide l'ascension des globules du lait, à la surface du liquide. On prend une goutte de lait de femme, mesurée avec le compte-gouttes gradué de Limousin, on l'introduit dans 100 gouttes d'eau distillée pure, ou mieux, salée au centième, cette addition a pour but d'avoir un liquide à 1,030 de densité, facilitant l'élévation des globules du lait. Cette ascension est plus lente dans l'eau distillée. Alor's, une goutte de ce mélange au centième étant placée sous un microscope, dont l'oculaire renferme un quadrillage ayant $1 / 5$ de millimètre de côté, 
CHAP. XII. - DU LAIT AU POINT DE VUE MICROSCopiQUE. 499

comme celui qui sert aux numérations des globules sanguins, on compte ce qui se trouve compris dans le carré. Supposons, dit M. Bouchut, qu'on y trouve une première fois 94 globules de lait, gros ou petits, il faut changer la préparation de place et compter de nouveau. On doit faire ainsi trois calculs successifs, sur des points différents et prendre la moyenne de l'addition des trois numérotages. Cette moyenne doit être divisée par 4, puisque, ayant compté dans un quadrillage de $1 / 5$ de millimètre de côté et renfermant quatre côtés et quatre carrés de $1 / 10$, il faut prendre le quart du nombre des globules trouvés, qui représente les globules d'un des quatre carrés, compris dans le quadrillage complet. Quand cette opération est achevée, on multiplie le total par 1,000 qui est le cube de 10. Cela est nécessaire parce que la cellule est au dixième. On multiplie ensuite par 100, puisque le titre du liquide est au centième. Supposons, avec M. Bouchut, 292, le nombre des globules trouvés, dans trois calculs différents, faits sur le quadrillé au-dessous duquel, se trouve la solution de lait à $1 / 100$, on a : $292: 3=97,030: 4=24,270 \times$ $1000=24270 \times 100=2,427,000$. D'après ces calculs, on voit donc qu'il y a dans cet échantillon de lait, deux millions quatre cent. vingt-sept mille globules, dans 1 millimètre cube.

Pour déduire du nombre des globules, la densité du lait et le poids du beurre, $M$. Bouchut, a fait parallèlement sur un certain nombre de laits de vache $: 1^{\circ}$ la numération exacte des globules, sur le lait préparé pour le microscope $; 2^{\circ}$ la détermination de la densité correspondante du lait; $3^{\circ}$ la détermination chimique, par l'analyse, de la quantité en poids du beurre, contenue dans le lait soumis à l'analyse. C'est en s'appuyant sur ces calculs, que M. Bouchut donne un tableau qui permet, étant donné le nombre des globules gras du lait, de déterminer approximativement, la densité du lait et sa richesse en beurre par litre. Ainsi, un lait de vache renfermant 2,402,500 globules et globulins par millimètre cube, donne 300/1000 de beurre pour ce millimètre, et se rapporte à un lait qui, par litre, donnerait 36 grammes de beurre et marquerait 1032 au densimètre.

Dans le lait de femme qui renferme 1 ou 2 millions de glo- 
bules par millimètre cube, il y aurait 2 ou $300 / 1000$ de beurre dans ce millimètre, chiffre obtenu par le calcul et sans qu'il soit fait d'analyse (Bouchut). Voici, toutes réserves faites, le tableau des résultats obtenus par l'auteur, en comparant le nombre des globules de lait de vache, à la densité de ce liquide et au poids de beurre qu'il contient par 1,000.

\begin{tabular}{|c|c|c|c|c|}
\hline \multicolumn{2}{|c|}{$\begin{array}{c}\text { GLOBULES } \\
\text { par millimètre cube. }\end{array}$} & DENSITÉ. & \multicolumn{2}{|c|}{$\begin{array}{c}\text { BEURRE } \\
\text { par litre. }\end{array}$} \\
\hline & 1.102 .500 & 1,022 & $2 \dot{z}$ & gran \\
\hline & 1.182 .000 & 1,021 & 21 & - \\
\hline & 1.925 .500 & 1,030 & 26 & - \\
\hline & 2.105 .000 & 1,028 & 29 & - \\
\hline & 2.205 .0010 & 1,032 & 37 & - \\
\hline & 2.305 .000 & 1,030 & 35 & - \\
\hline & 2.400 .000 & 1,030 & 37 & - \\
\hline & $2.407 .00 !$ & 1,033 & $3 i$ & - \\
\hline & 2.692 .000 & 1,030 & 29 & - \\
\hline $10^{\circ}$ & 3.700 .000 & $1,0: 30$ & 34 & - \\
\hline
\end{tabular}

D’après M. Bouchut, si le nombre des globules diminue dans une proportion considérable, la densité s'abaisse dans la même proportion et la quantité de beurre diminue également. Mais il faut pour cela que la variation du chiffre des globules soit assez forle. De petites différences ne se traduisent pas par des modifications très profondes de la densité et du poids du beurre. On ne peut compter qu'à un ou deux degrés de différence pour la densité, et autant pour la quantité de beurre.

La méthode de M. Bouchut, ainsi qu'il le répète lui-même en différents endroits de son mémoire, n’est qu’approximative. 
Avant de quitter ce sujet, nous tenons à relater une observation de Donné, qui peut être utilisée en pratique. Il est des circonstances dans lesquelles le lait est trop riche en corps gras; l'enfant souffre, il digère mal et l'on est tenté de croire que la nourrice est insuffisante et que, par conséquent, il est nécessaire de la remplacer. Dans une circonstance analogue, Donné ayant examiné le lait au microscope, il fut frappé de la prodigieuse quantité des globules; ils étaient tellement serrés, qu'à peine voyait-on quelques espaces libres éntre eux, et partout, sans confusion ni agglomération. M. Donné engagea la mère à continuer de nourrir son enfant, en prenant seulement le soin d'éloigner les heures de l'allaitement, afin de laisser aux digestions le temps de se faire et pour diminuer un peu la consistance du lait par son séjour dans les mamelles; cette simple précaution suffit et remplit le but.

Nous sommes d'avis que le lait n'a pas de qualité occulte, et qu'un bon lait peut convenir à tout enfant, si le contraire paraît être observé, c'est parce que l'accommodation entre certains principes du lait et certains estomacs se fait difficilement, il appartient au médecin d'espacer ou de rapprocher l'heure des têtées, d'augmenter ou de diminuer la quantité de lait que prend l'enfant, car les nouveau-nés font des indigestions aussi bien que les adultes, parce qu'ils prennent trop de nourriture, de là des accidents intestinaux souvent fort graves.

Ces idées ne sont pas partagées par tous les médecins. M. le $\mathrm{D}^{\mathrm{r}} \mathrm{J}$. Grangé a publié sur ce sujet, un remarquable article dans le journal des Connaissances médicales pratiques et de pharmacologie, 1879, intitulé : la Réglementation des têtées.

$\S$ iit. - des altérations du lait.

Il est un certain nombre de circonstances dans lesquelles les éléments constitutifs du lait peuvent diminuer en quantité. Contrairement à ce que l'on pouvait penser, lorsque le lait séjourne dans la mamelle, ce n'est pas l'élément liquide qui se résorbe, ce sont les éléments solides. Un lait sera d'au- 
tant plus pauvre en globules, qu'il y aura eu plus d'espace entre deux têtées. C'est à $M$. Péligot que l'on doit cette importante remarque.

Des observations nombreuses ont été faites sur les animaux et sur la femme. Donné ayant observé le lait d'une chèvre qui n'avait pas donné à têter depuis seize heures, trouva que les globules étaient en masses agglomérées et confuses; le cinquième jour, il y avait dans le lait du trayon gauche, une telle confusion dans les globules, ils étaient, pour ainsi dire, tellement amalgamés ensemble, que l'on pouvait à peine les distinguer. Une ânesse fut soumise à la même expérience; au bout de douze heures de sevrage, il n'y avait que quelques rares agglomérations, les globules étaient généralement réguliers. Au bout de quatre jours de sevrage, la mamelle était engor gée; les globules étaient, pour la plupart, réunis en masses agglomérées et compactes, leurs contours étaient irréguliers ; il y avait une si grande quantité de petits globules qu'ils formaient comme une poussière, par laquelle la transparence du liquide était troublée.

Il peut survenir, chez la femme, des circonstances pathologiques, qui réalisentles conditions expérimentales nécessaires à l'altération du lait, par la station prolongée dans la mamelle. En effet, il n'est pas rare, sous des influences diverses, de voir la mamelle s'engorger, devenir dure et tuméfiée. Dans ces conditions, Donné a observé que, si, au début, les globules étaient encore réguliers, il y avail cependant quelques agglomérations; traité par l'ammoniaque, le lait ne devenait pas visqueux. Au fur et à mesure que l'inflammation augmentait, les agglomérations de globules se trouvaient en plus grand nombre. Le lait prenait l'aspect légèrement filant avec l'ammoniaque. Chose digne de remarque, Donné a vu reparaître sous l'influence de l'engorgement du sein, ces corps granuleux, dont nous connaissons maintenant l'origine. Ainsi donc, lorsque l'on observe, dans du lait, l'agglomération des globules laiteux et la présence des corps granuleux, c'est que le lait ou n'est pas de bonne nature, ou n'est pas complètement formé. Cette modification a lieu sous l'influence d'une lésion de la glande, ou par suite d'une altération de la sécrétion 
CHAP. XII. - DU LAIT AU POINT DE VUE MIGROSGOPIQUE. 303

lactée, pouvant dépendre d'un état général mauvais, tel qu'une métro-péritonite, par exemple.

Dans le cas d'inflammation de la glande mammaire, les altérations du lait ne se bornent pas à l'apparition des corps granuleux et à l'agglomération des globules, les leucocytes s'y montrent également, en grande quan tité; on a alors du lait purulent.

Le pus sort en même ternps que le lait par l'orifice des canaux galactophores; seul, l'examen microscopique peut déceler sa présence d'une façon certaine. Il y a cependant un grand intérêt à reconnaître cette altération du lait, car les hommes les plus familiarisés avec l'hygiène infantile, comme P. Dubois, Depaul, ont reconnu depuis longtemps qu'un lait purulent était préjudiciable aux enfants. Cette remarque est d'autant plus importante, qu'on a l'habitude, comme le dit fort bien Donné, de faire têter le plus possible à l'enfant, le sein de la nourrice, quand il y a menace d'inflammation de la glande mammaire.

Il n'y a pas de difficulté à reconnaître au microscope la présence du pus dans le lait. Nous avons donné avec détail l'aspect du globule blanc; ce dernier est insoluble dans l'éther, tandis que les globules du lait s'y dissolvent facilement. Si l'on traite, au contraire, le lait par la sonde ou la potasse, en solution, les globules blancs disparaîtront, tandis que les globules de lait resteront intacts.

Non seulement, le pus peut apparaître dans le lait, quand un abcès s'étant formé dans la glande mammaire, il a été ouvert par le bistouri du chirurgien, mais on peut encore constater sa présence dans cette sécrétion, avant même qu'il y ait de la fluctuation. La démonstration de celte importante proposition a été faite par Donné; depuis, dans un certain nombre de cas, nous avons pu vérifier son exactitude.

Les choses se passent de la même façon dans le lait des animaux; sous l'influence d'un abcès ou d'une inflammation de la glande mammaire. On peut donc trouver du pus dans du lait de vache, comme on en trouve dans du lait de femme et on le reconnaîtra, aux mêmes caractères que ceux exposés plus haut. Le lait, sous l'influence de l'ammoniaque, se prend en une gelée tenace et visqueuse. 
D'une façon générale, on peut dire que chaque fois qu'une nourrice souffre physiquement, son lait subit des altérations plus ou moins profondes, altérations que le seul examen microscopique est souvent impuissant à déceler.

Sous des influences diverses, dont la plus commune est l'existence de crevasses du mamelon, le sang peut apparaître dans le lait, même en quantité considérable. Lorsqu'on abandonne au repos, un lait ainsi altéré dans sa composition, les globules sanguins gagnent la partie la plus inférieure du vase. Nous ne reviendrons pas sur les caractères que nous avons donnés du globule sanguin, mais il est fort important d'être familiarisé avec leur recherche. Ainsi que nous l'a appris $M$. le professeur Depaul, un médecin peut être appelé près d'un enfant qui vient de vomir du lait contenant du sang. L'inquiétude des parents est grande et l'on pourrait être tenté de croire à une ulcération, siégeant dans les premières portions du tube digestif. Lorsque l'on aura constaté la présence réelle du sang dans les matières vomies, il faudra examiner avec le plus grand soin les mamelons de la nourrice et presque toujours, on y trouvera des crevasses, qui, sous l'influence des efforts énergiques de succion de l'enfant, s'ouvrent et laissent échapper du sang.

L'enfant peut parfaitement ne pas vomir du lait mélangé à du sang, mais les matières fécales prennent alors une colaration toute spéciale; elles sont noirâtres et de nature à inquiéter vivement les personnes qui entourent le nouveau-né. Și l'on examine ces matières fécales au microscope, on y apercevra des globules sanguins plus ou moins altérés, qui ont résisté à l'action de la digestion. On peut également, dans la plupart des cas, remonter à l'origine de ce sang, qui provient du sein de la nourrice.

Lorsque le lait a été abandonné au contact de l'air et qu'il s'y est altéré, il peut se développer à sa surface, un certain nombre de végétaux inférieur's, parmi lesquels nous citerons le Penicillium glaucum.

Influence du baraltage et de l'écrémage sur le lait. - Quand le lait a été soumis au barattage, même le plus parfait, il reste encore des globules butyreux dans le petit lait. L'analyse chi- 
CHAP. XII. - DU LAIT AU POINT DE VUE MICROSCOPIQUE. כ̋0̈

mique ainsi que l'examen microscopique le prouvent surabondamment. Dans le lait non baratté, les globules se touchent, il n'y a pour ainsi dire pas d'espaces vides, tandis que dans. le lait baratté, les globules sont moins nombreux.

D’après M. Boussingault, ils sont disposés en groupes isolés, un peu plus volumineux, probablement, par ce que des globules se sont soudés par l'effet de l'agitation: mais dans l'état où ils sont, ils résistent à l'agglomération et demeurent en quelque sorte insaisissables. C'est à ces globules butyreux, ajoute le même auteur, que les fromages maigres doivent de renfermer une certaine proportion de matière grasse, bien qu'ils soient préparés avec du lait ayant passé par la baratte, ou avec du lait écrémé.

Lait écrémé. - Lorsque le lait est laissé au repos pendant vingt-quatre heures à une température de $12^{\circ}$ à $15^{\circ}$, la crème monte à sa surface. Plus lente a été l'ascension de la crème, plus l'écrémage est complet, et moins il reste de globules butyreux dans la couche de liquide sous-jacent. Vu au microscope, le lait écrémé ne présente plus qu'une faible quantité de globules butyreux, et se montre d'autant plus appauvri, que l'écrémage a été plus parfait.

Lait de beurre. - Lorsqu'on a séparé le beurre de la crème par le barattage, il reste un liquide, dit M. Boussingault, qui a l'apparence du lait normal bien qu'il ne contienne que peu de matière grasse. Au microscope le lait de beurre a de nombreux et de très petits globules; l'image est confuse, parce que ce lait est assez opaque, à cause de petites particules disséminées dans le liquide et ressemblant à du caséum coagulé. Il serait impossible de confondre l'aspect du lait de beurre avec le lait; au microscope, on reconnaîtrait si du lait de beurre a été mélangé à du lait écrémé, fraude que l’on a pratiquée quelquefois pour communiquer au lait écrémé, et surtout au lait baratté, l'apparence du lait normal (Boussingault, Journal de l'Agriculture, 12 octobre 1872).

\$ 1V. - du lait en dehons de La gestation et de L'allaiteanent.

Si, dans la majorité des cas, la présence du lait dans les seins d'une femme ou d'une jeune fille, est l'indice d'un état de 
grossesse, plus ou moins avancée, ou même d'un accouchement à terme ou non, spontané ou provoqué, plus ou moins récent, il faudrait bien se garder, dans une expertise médico-légale, de conclure, par la seule existence du lait dans les seins. Ce serait commettre une grave imprudence ainsi que cela ressort des faits qui suivent.

La glande mammaire, qui existe chez les deux sexes à un état de développement variable, peut entrer en fonctionnement sous les influences les plus diverses. C'est ainsi que chez l'enfant nouveau-né, garçon ou fille, on peut, à un certain moment, faire sourdre de la mamelle du lait jouissant de toutes les propriétés physiques et chimiques de ce liquide. On peut même, dit M. de Sinety, entretenir cette lactation en miniature, en excitant la petite mamelle par une traite répétée. Nous avons eu l'occasion d'observer, dans le service de M. Depaul, des abcès de la mamelle chez des enfants nouveau-nés. Si une petite fille de quelques jours peut avoir du lait dans les mamelles, il est encore des exemples avérés, qui montrent que la sécrétion lactée peut s'établir chez une vierge, dans toute l'acceplion du mot. Nous empruntons les renseignements qui suivent, au mémoire de MM. Filhol et Joly. Cardan cite un cas d'infanticide (le véritable auteur est inconnu), dans lequel une jeune fille fut condamnée au dernier supplice, uniquement parce qu'elle avait du lait dans ses mamelles. En revanche, Baudeloque cite le cas d'une petite fille de huit ans, qui ayant appliqué à son sein la bouche d'un très jeune enfant, allaité par sa mère, aurait eu bientôt assez de lait pour le nourrir elle-même, pendant un mois. Des jeunes filles, ayant présenté leur sein, dans des conditions analogues, à de jeunes enfants, ont vu la sécrétion lactée s'établir. Ce fait, parait donc être en dehors de loute contestation. Non seulement la glande mammaire peut fonctionner chez des enfants nouveau-nés, chez des vierges, mais la sécrétion lactée peut être rappelée, dans des mamelles depuis longternps taries. Sous l'influence d'excitants locaux, de fomentations aromatiques ou excitantes, pratiquées dans l'une des îles du Cap-Ver't, par exemple, avec les feuilles du Jatropha Curcas, on pent, en s’aidant de succions réitérées, rétablir la sécrétion lactée. 
CHAP. XII. - DU LAIT AU POINT UE VUE MICROSCOPIQUE. 507

MM. Filhol et Joly citent l'exemple d'une femme de soixantequinze ans, qui serait parvenue à allaiter l'enfant de sa fille morte, grâce aux efforts de succion de l'enfant.

Des faits analogues ont été observés chez les animaux. Haller parle, d'après Kerkingius, d'une chienne qui ayant été têtée par un chat, finit par donner du lait en abondance. Buffon, Filhol et Joly ont vu des chiennes, qui n'avaient jamais subi les approches du mâle, avoir assez de lait pour allaiter plusieurs petits.

Ghez l'homme, la sécrétion lactée peut également s'établir, suivant M. de Sinety, à l'époque de la puberlé; à cet àge où les seins se développent chez la jeune fille, on observe aussi chez les garçons, un gonflement de la mamelle. Les sujets accusent une sensation de tension et de picotements dans cette région. Quelquefois même, il se fait un écoulement séro-lactescent par les mamelles. Il peut se produire de véritables mammites. Dans une foule d'ouvrages anciens et modernes, on trouve des exemples de sécrétion lactée existant chez des hommes. M. Filhol et M. Joly, dans leur mémoire, donnent un certain nombre d'indications bibliographiqués; parmi les auteurs modernes nous citerons: MM. de Humboldt, Schmetzer de Heilbronn, qui eurent l'occa sion d'observer, à plusieurs reprises, la sécrétion lactée dans les mamelles d'un jeune soldat de vingt-deux ans. L'analyse chimique de ce lait a été faite. Hall a observé, en 1837, un homme de couleur, âgé de quarante-cinq ans, qui avait une sécrétion lactée abondante. En 184. Auzias-Turenne a observé à Paris, un Arabe, étudiant en médecine, nommé Zuchari-Effendi, qui avait des seins très-volumineux, dont on pouvait faire jaillir par la pression un lait très abondant. Les hommes observés avaient des organes génitaux bien développés.

Des faits semblables peuvent être observés chez les animaux, c'est ainsi que depuis Aristote jusqu'à nos jours, on a vu des bones donner du lait en quantité variable. En 1844, Schlonberger a fait l'analyse d'un lait fourni par un bouc. En 1815, il y avait au jardin des plantes de Paris, un bouc qui fournissait également du lait. Ce bouc a nourri sa propre 
fille. On cite aussi des béliers et des taureaux, des chiens et des chats qui ont donné du lait (Filhol et Joly).

De la présence du lait dans le sang des jeunes animaux soumis $\dot{a}$ l'allaitement. - A propos de l'injection intra-reineuse de lait dans les cas d'hémorrhagie grave, on a soulevé incidemment la question de savoir si, chez les jeunes animaux allaités, une certaine quantité de globules de lait passait directement dans le sang et pouvait y être constatée microscopiquement, l'affirmative a été soutenue à la Société de Biologie (février 1879) par M. le docteur Laborde. Cet expérimentateur habile a exposé devant la Société les faits qu'il croyait devoir confirmer son opinion. M. Laborde avait été frappé de voir, que chez des animaux allaités, les globules rouges avaient une apparence finement murilorme, qu'ils perdaient, lorsqu'on venait à ajouter à la préparation une certaine quantité d'éther et il en avait conclu à la fixation directe des globules butyreux par les globules rouges. Outre la précision des observations, ce qui contribuait à rendre plus acceptable l'opinion de M. Laborde, c'est que dans le sérum on voyait nettement de petits corps sphériques réfringents, qu'il considérait comme de fìns globules de lait nageant librement dans le liquide. M. le professeur Ranvier avait déjà émis des doutes touchant l'interprétation des phénomènes observés par M. Laborde ; l'observation directe des faits, nous a également conduits à une explication différente. En effet, nous considérons l'aspect particulier des globules rouges, si bien décrit par M. Laborde, comme une altération du globule; cet élat finiment et régulièrement muriforme, s'observe assez fréquemment, et il suffit, pour le faire disparaître, d'ajouter à la préparation un liquide quelconque, de l'éther ou de l'eau. Quant aux granulations réfringentes, nous les considérons comme étant des corpuscules élémentaires de Zimmermann, que nous avons décrits à l'arlicle Sang. Les observations de M. Laborde ont élé faites sur de jeunes chiens; ces observations sont très exactes, mais, comme nous venons de le dire, nous différons d'opinion avec cet observateúr au point de vue de leur interprétation.

Nous avons examiné le sang d'un grand nombre d'enfants exclusivement allaités et à des époques plus ou moins éloignées 
CHAP. XII. - DU LAIT AU POINT DE VUE MIGROSCOPIQUE. 309 de la têtée; il ne nous a pas été possible de caractériser, par le microscope, et par l'acide osmique, la présence de globules de lait. Les globules réfringents que l'on trouve dans le sang des enfants nouveau-nés, sont des corpuscules de Zimmermann.

Lorsqu'on examine au microscope du sang de chats nouveau-nés, âgés d'un jour, par exemple, on est surpris d'y trouver des myriades de corpuscules brillants et fins, animés de mouvement brownien. Plusieurs auteurs ont cru voir, dans ces petits corps, la preuve du passage du lait dans le sang. Nous ne partageons pas cette opinion, attendu que ces corpuscules infiniment petits, diminuent singulièrement de nom. bre, au fur et à mesure que les petits chats avancent en âge et, comme la quantité de lait absorbée par ces jeunes animaux, augmente chaque jour, il devrait en résulter une augmentation parallèle de ces corpuscules, ce qui n'est pas. On n'est du reste pas encore fixé sur la nature de ces corpuscules (1).

§ v. - DU LIgUIDE DES TUBERCULES DE. MONTGOMÉRY.

Ces glandes sébacées se trouvent dans le derme de l'aréole mammaire, en assez grand nombre. Sous l'influence de la grossesse, elles prennent un volume assez considérable. Chez les femmes dont la sécrétion lactée devient très abondante, ces tubercules sécrètent, on du moins laissent échapper, du lait.

\section{$\S$ VI. — DU LAIT CHEZ LeS aNIMAUX.}

Jusqu'ici nous ne connaissons pas de caractères microscopiques qui puissent permettre de différencier le lait des animaux. Les globules sont plus ou moins réguliers, mais cela est très variable.

\section{$\S$ VII. - DES COLORATIONS ACCIDENTEi.LES DU LAIT.}

MM. Filhol et Joly donnent les détails suivants, sur ces colorations anormales. La coloration bleue du lait est la plus fréquente. Des faits de ce genre ont été observés en Allemagne

(1) M. Hayem a publié une note sur le sang du cliat nouveau-né, Comptes rendus de la Sociéte de Biologie, 13 aviil 1878. 
par Bremer, Hermstaedt, et plus récemment, en France, par M. Bailleul. Le lait ne paraît nullement altéré dans ses qualités. Klaproth l'a soumis à l'action des réactifs et il a vu que la matière colorante se comportait absolument comme l'indigo. Bremer, d'après ses observations, est d'avis que celte coloration est due, non pas à un état pathologique, mais à l'influence de l'alimentation. C'est ainsi que, d'après MM. Filhol et Joly, l'on aurait vu des vaches nourries exclusivement à l'étable avec du sainfoin (Hedysarum onobrychis) donner du lait bleu, au bout de deux jours et n'en plus fournir, dès que l'on modifiait leur alimentation. Mais, comme le font observer ces auteurs, il est difficile d'expliquer pourquoi, dans un seul troupeau, où toutes les vaches sont soumises à la même alimentation, il n'y en a qu'un certain nombre qui fournissent du lait bleu. L'Hedysarum onobrychis ne serait pas la seule plante qui puisse donner cette teinte au lait, l'Anchusa offičnalis, et même l'Equisetum arvense, jouiraient, d'après Hermstaedt, de la même propriété (Filh. et Joly). Une observation, qui tendrait à démontrer, que dans la plupart des cas, la coloration bleue serait due à la présence de l'indigo, c'est que le lait n'est pas bleu au sortir de la mamelle. Abandonné au repos, il ne tarde pas à se couvrir à la surface de petites taches qui, en s'agrandissant peu à peu, finissent par former une couche continue, dont la teinte bleue foncée se communique plus tard à la masse. Examiné au microscope, un lait ainsi coloré ne présenterait point de trace de moisissure, d'après M. Bremer, tandis que, suivant M. Bailleul, ces mêmes taches, seraient dues à une sorte de byssus, dont on pourrait même empêcher la naissance, en domnant aux vaches du sel marin. Il est presque certain, que ces deux causes de coloration existent.

D'après Fuchs, la coloration bleue du lait serait due à un infusoire qu'il nomme vibrio cyanogenus; la coloration jaune qu'on observe quelquefois chez la vache, serait produite par le vibrio xanthogenus. Le premier de ces animacules serait incolore, mais ferait bleuir toute espèce de lait avec lequel il serail. en contact. Le vibrio xanthogenus se comporte comme le précédent, on le trouve quelquefois dans le lait bleu (Fil. et Joly). 
GHAP. XII. - DU LAIT AU POINT DE VUE MIGROSCOPIQUE. 511

D'après MM. Filhol et Joly, il ne faudrait pas croire que l'influence de l'alimentation sur le lait soit absolue. C'est ainsi que Parmentier et Deyeux n'ont pu colorer en bleu, ou en jaune, le lait des vaches qu'ils nourrissaient avec du pastel, (Isatis tinctoria), ou de la gaude (Reseda luteola) et même du safran. D'autre part, Landerer a observé la coloration en bleu du lait d'une dame, qui prenait de l'indigo, contre des attaques d'éclampsie. De son côté, Hermstaedt a vu le lait des vaches et des brebis, devenir bleu, surtout, lorsqu'elles paissaient le chaume. Les plantes qui, suivant lui, donnent cette couleur au lait sont: l'Hedysarum onobrychis (die Esparcette), l'Anchusa officinalis (das Krant der gemeinen Ochsenzunge), la Mercurialis annua (das jahrige Bingelkrant), la Mercurialis perennis (dar perenairende Bingelkrant), le Polygonum aviculare (der Vogelknotrig) et le Polygonum fagopyrum (der Buchwaiszenknotrig). Toutes ces plantes contiennent, en effet, de l'indigo ou une substance qui lui ressemble, dit Hermstaedt, et il ajoute : Comme pour l'indigo, la coloration en bleu de cette substance, paraît due à sa seule oxydation, au moyen de l'air contenu dans le lait sorti des mamelles. "Du reste, Hermstaedt a observé, comme Bremer, que le beurre que l'on fabrique avec la crème du lait bleu, n'est pas bleu lui-même, mais le lait de beurre a cette couleur: il la perd si on le filtre. Le fromage lui-même est plus ou moins coloré. Hermstaedt assure aussi, que le lait des vaches est teint en rouge, si on leur donne à mangẹ de la garance (Rubia tinctorum), du Galium rubioides et même du Galium verum. Quelquefois, dans ce cas, la couleur rouge se communique au beurre ; cette couleur rouge persiste dans le lait, sept ou huit jours après qu'on a supprimé la garance (Filhol et Joly, loc. cit., p. 88).

\section{S VHI. - EXAMEN MICROSCOPIQUE DE LA CASÉINe.}

La caséine liquide, disent MM. Filhol et Joly (p. 96, loc. cit.), lorsqu'elle est parfaitement dissoute dans le serum filtré, présente au microscope, l'aspect d'un liquide homogène et limpide. Mais, dès que la coagulation commence, sous l'influence de la présure, de l'alcool, de l'éther, ou d'un acide 
très affaibli, on voit se former instantanément, sur le porteobjet du microscope, une innombrable quantité de granules excessivement fins et mesurant à peine $1 / 100$ de millimètre. Ces granules d'abord isolés et libres, ne tardent pas à se grouper, de manière à donner naissance à des membranes également granulées et comme finement ponctuées, à leur surface. Ces membranes pointillées finissent bientôt par se réunir et de cette réunion, résulte une membrane totale, plus on moins mince, légèrement jaunâtre et plus ou moins transparente, suivant la quantité de serum filtré que l'on a employé. Il arrive quelquefois, que des globules butyreux ont passé à travers le filtre, avec le serum chargé de caséine : alors on voit ces globules, d'abord mobiles, dans lé liquide, devenir complètement immobiles dans la masse, dès qu'elle s'est coagulée.

On retrouverait quelquefois dans les matières fécales des enfants, de la caséine qui aurait résisté à l'action de la digestion.

$\S$ IX. - CORPS Étrangers du Lait.

Lorsqu'on recueille directement le lait à la mamelle on peut
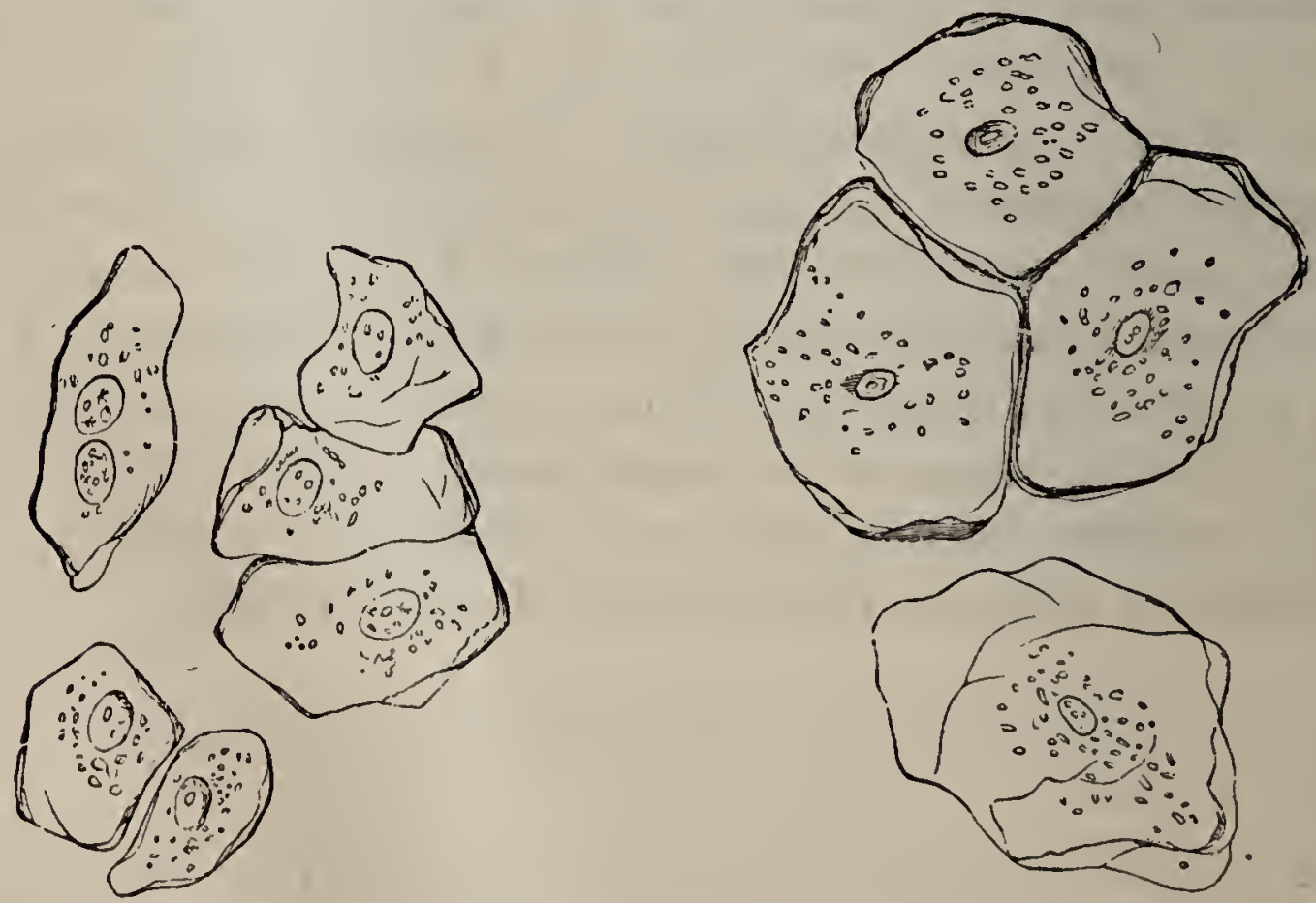

Fig. 338. - Cellules épithéliales de la cavitẻ buccale de l'homme, grossissement 350 D. (Kölliker.)

y trouver une foule de corps étrangers, surtout chez les femmes qui ne prennent pas de soins fréquents de propreté. 
CHAP. XII. - DU LAIT AU POINT DE VUE MICROSGOPIQUE. ä13

A la fin de la grossesse, le lait coule en plus ou moins grande abondance, se dessèche à la surface du mamelon, et subit sur place une sorte de fermentation. Grâce aux conditions favorables de chaleur et d'humidité, il se'produit à la surface du mamelon des végétations qui peuvent se trouver mêlées accidentellement au lảit.

Lorsqu'une nourrice donne à teter à un enfant atteint de muguet, il reste sur le mamelon des frảments du parasite végétal, et dans les services hospitaliers, où une même nourrice allaite piusieur's enfants, le mamelon sert de moyen de propagation à la maladie.

On trouve fréquemment, dans le lait des nourrices, des cellules épithéliales provenant de la bouche des enfants. Ces cellules se détachent facilement pendant les efforts de succion. Lorsque la mamelle est engorgée, on rencontre également des groupes de cellules, provenant des canaux galactophores.

$$
\$ x .- \text { du vibrion lactique (Pasteur) (V. p. 300). }
$$

Nous empruntons les détails qui suivent à l'article Bactérie fait par M. Davaine dans le Dictionnaire encyclopédique des sciences médicales. "Articles globuleux très courts, un peu renflés aux extrémités; longueur d’un seul article; $0^{\mathrm{mm}}, 0016$; d'une série $0^{\mathrm{mm}}, 0 亏 1$ environ. Le vibrion lactique pourrait ètre rapproché, pour la forme, du Bacterium termo ou du Bacterium catenula. Ses mouvements ressemblent aux mouvements browniens. M. Davaine les a vus continuer, après le contact d'une solution aqueuse d'iode, ce qui indiquerait qu'ils ne sont point spontanés. Le vibrion lactique se forme dans les liquides sucrés, déterminant la formation de l'acide lactique, et dans le lait, dont il coagule la caséine. Il apparaît d'abord par amas dispersés dans toute la hauteur du liquide, son apparition précède la coagulation. Du. lait porté vingt jours de suite, pendant une minute, à une température voisine de 100 degrés centigrades, avait conservé ses qualités physiques ordinaires, le vibrion lactique ne s'y était pas développé. L'ayant laissé cinc jour's sans le chauffer, M. Davaine GUIDE DF, MICROGRAPHIF. 
y vit apparaître des amas de ces vibrions et le lendemain la caséine fut coagulée.

$$
\text { S XI. - SLCRE DE LAIT. }
$$

Nous nous bornerons à donner la forme cristalline, renvoyant aux traités spéciaux de chimie pour ses principales propriétés. Il cristallise sous la forme de prismes à quatre pans,

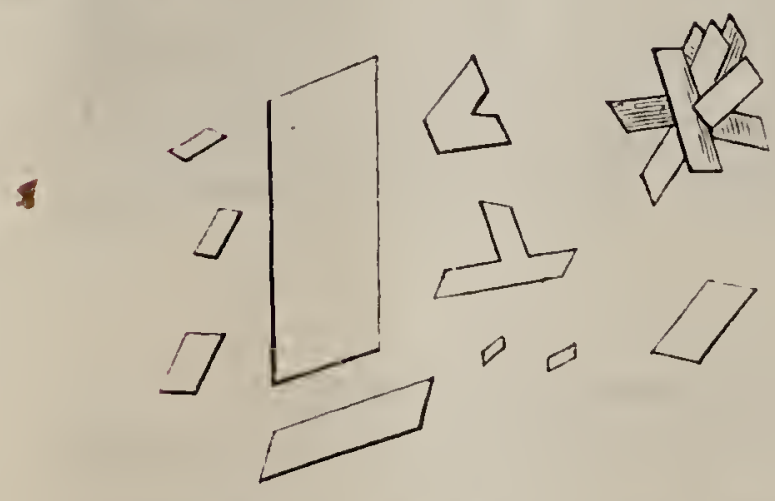

Fig. 339. - Sucre de lait.

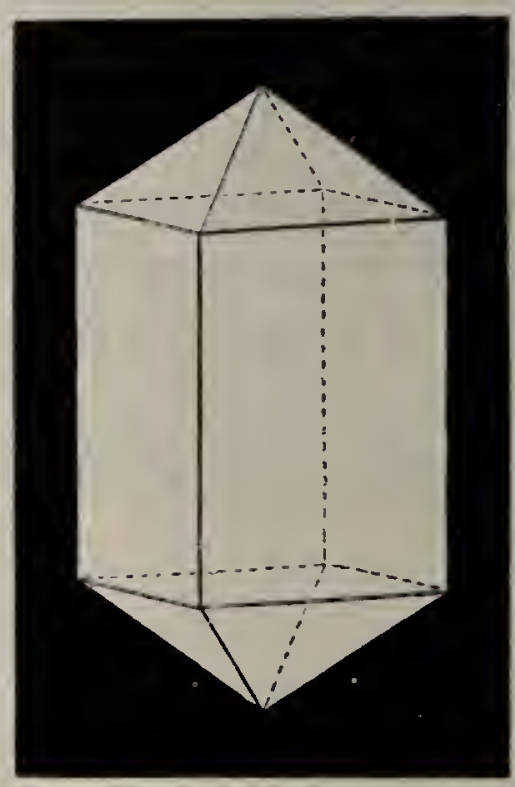

Fig. 340. - sucre de lait.

et plus fréquemment, sous l'aspect de prismes rhomboïdaux droits, terminés par des sommets à quatre faces. Ces cristaux sont assez peu solubles dans l'eau froide et insolubles dans l'alcool et dans l'éther.

\section{$\S$ XII. - DU BeURRE ET DE SES falsifications.}

Le beurre est le résultat du barattage du lait, qui a pour effet de rapprocher les globules butyreux et de permettre leur séparation des autres éléments. Dans le cours de cette étude nous emprunterons plus d'un renseignement à la monographie de M. Husson (1). Parmi les substances que l'on peut introduire frauduleusement dans le beurre, nous citerons la caséine. Nous savons par ce qui précède, que le beurre doit

(1) Le lait, la creme of le beurre, Paris, chez Asselin. 
CHAP. XII. - DU LAIT AU POINT DE VUE MICROSCOPIQUE. 引̆

toujours contenir une faible proportion de caséine, puisque celle-ci se coagule autour des globules gras; mais on peut ajouter frauduleusement jusqu'à 20 p. 100 (Husson) de caséine dans le beurre. Il suffit de faire chauffer le beurre au bain-marie, la caséine se dépose. S'il restait des doutes, l'examen microscopique les lèverait immédiatement.

Il est des falsifications plus rares, mais qui ont été signalées. On a parfois ajouté au beurre des fécules diverses. Une simple préparation microscopique permettra d'apercevoir cette fraude grossière, et grâce à la forme, maintenant bien connue de nous (V.p. 120), des diver's genres de fécule, il sera possible de déterminer l'origine même de l'élément frauduleux. On a introduit dans le beurre du plâtre, de la craie, de la céruse, ou du sulfate de baryte. L'examen microscopique seul serait impuissant à faire reconnaître cette fraude, mais, grâce aux réactifs, on pourra déterminer la nature de ces corpuscules inorganiques. Pour déterminer la séparation de ces différents éléments, il suffira, comme le conseille M. Husson, de faire fondre le beurre, au bain-marie, avec dix fois son poids d'eau.

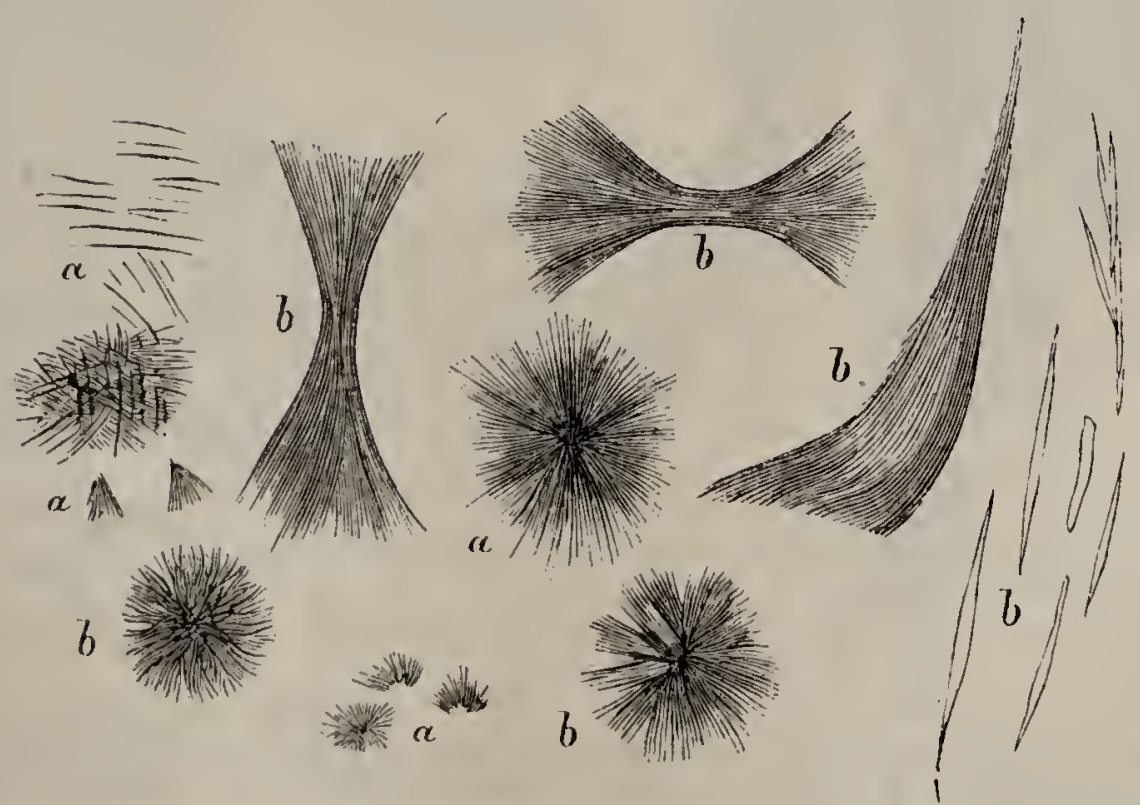

Fig. 341. - Stéarine. - $a, a, a$. Aiguilles isolées ou groupées, retirées de la graisse humaine. - $b, b, b$. Aiguilles isolées ou groupées, extraites de la graisse de mouton.

Une fraude beaucoup plus répandue, consiste dans l'addition au beurre, de corps gras provenant de différents's animaux.

De nombreux procédés ont été donnés pour rechercher cette fraude qui est très usitée. La plupart de ces méthodes ren- 
trant dans le domaine de la chimie, nous ne pouvons que renvoyer aux traités spéciaux, pour les faire connaître. Nous nous bornerons à donner les procédés de recherche, dans lesquels le microscope joue le principal rôle. Depuis un certain nombre d'années, les élèves du laboratoire de micrographie de l'École de pharmacie, ont été familiarisés avec ces différentes

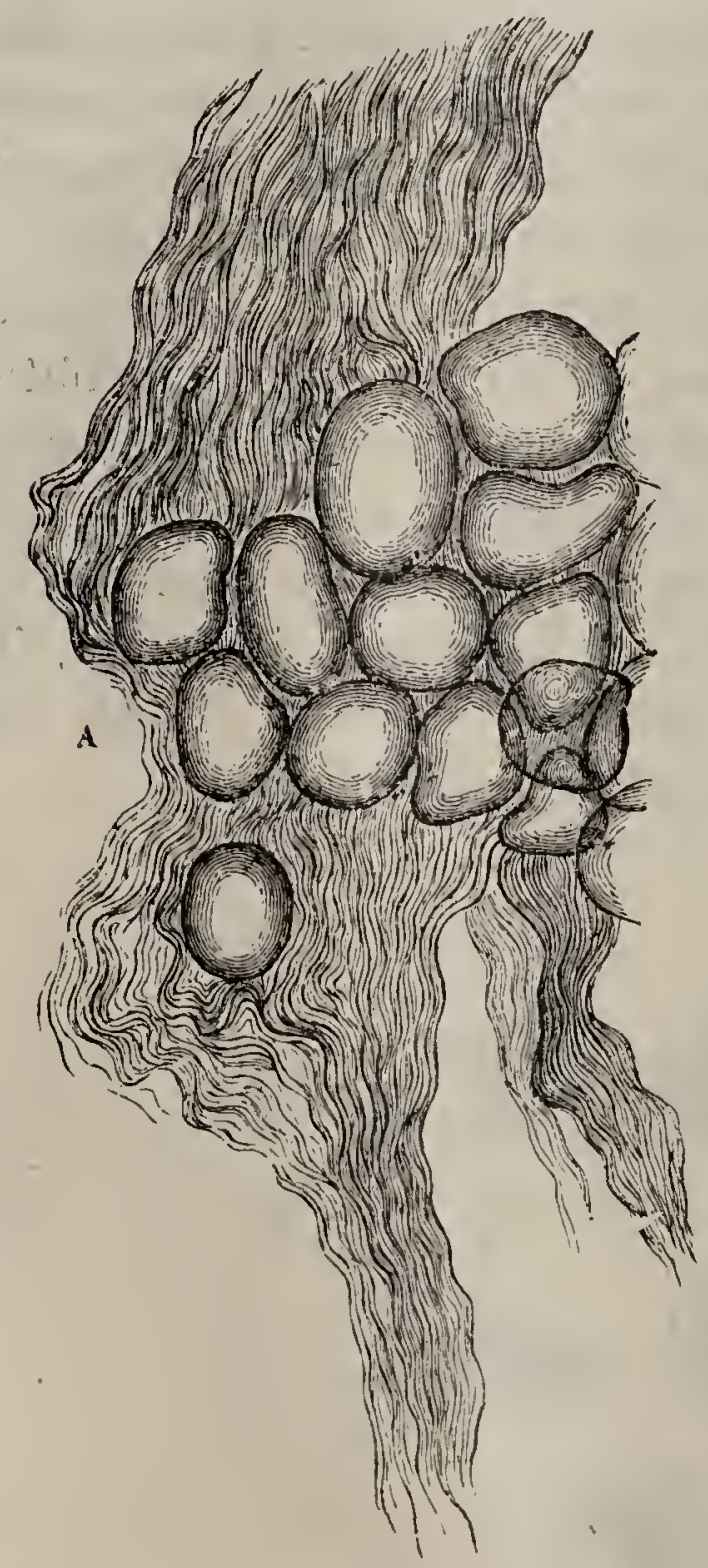

lig. 312. - Tissu conjonctif làche de l'homme renfermant des cellules arlipeuses. Grossissement de 850 diamètres (Kölliker).

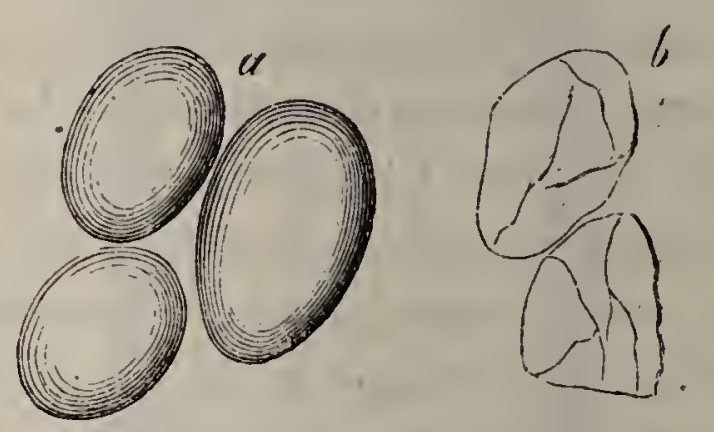

Kig. 343. - Cellules adipeuses normales de la mamelle (grossies 350 fois). - $a$. Sans réactifs. - $b$. Traitées par l'éther qui a enlevé la graisse et laissé seulement l'enveloppe mince et plissée.

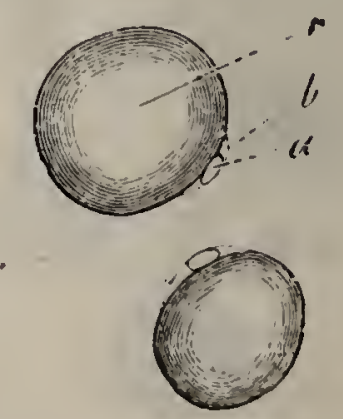

Fig. 344. - Deux cellules adipeuses tirées de la inoelle du fémur de l'homme. - a. Noyau. b. Nembrane de la cellule. $-c$. Goutte de graisse (grossissement de 350 diamètres).

manipulations. Lorsqu'on examine du beurre frais au microscope, on ne voit que des globules gras; il n'y a ni cristaux ni tissu conjonclif. Toutefois; il est important de faire une remarque, c'est quẻ le beurre, même exempt de toute adulté- 
CHAP. XII. - DU LAIT AU POINT DE VUE MICROSCOPIQUE. כ̆

ration, peut avoir été fondu accidentellement, en tout ou en partie; dans ce cas, on pourra voir des cristaux de margarine, mais ceux-ci ont une forme spéciale.

Dans le cas où le beurre a été adultéré par l'addition de suif fondu, on trouve des cristaux de stéarine parfaitement déterminés; de plus, si on dissout le beurre dans de l'éther ou du sulfure de carbone, le dépôt examiné au microscope, laissera voir des débris de tissu conjonctif et de vésicules adipeuses vides, ou encore à moitié remplies. Avec le suif de veau (Husson), les cristaux aiguillés de stéarine n'ont pas la même netteté. De plus, on observe quelques cristaux de margarine sous forme de petits plumasseaux isolés ou pris dans les globules gras.

Il est très important de se familiariser avec les formes cristallines de la stéarine que l'on peut préparer, en traitant par l'éther, de la graisse humaine, ou de la graisse de mouton. Nous en dirons autant pour les débris de vésicules adipeuses, que l'on peut étudier en examinant au microscope du tissu cellulo-adipeux de mouton, de veau, ou de l'homme.

Le beurre préparé d'une façon normale ne doit pas contenir de cristaux de stéarine. Le beurre frais qui a subi la fusion, montre de longues aiguilles flexucuses et fines de margarine, réunies en faisceaux. Si le beurre a subi l'action d'une température assez élevée, les cristaux de margarine ne sont plus courts et groupés autour d'un point central.

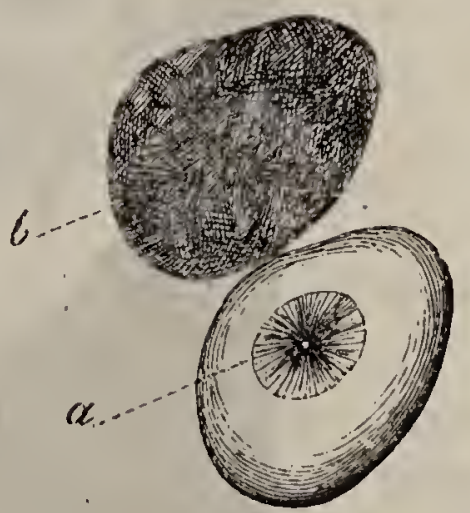

lig. 34วั. - Cellules graisseuses renfermant des cristaux de margarine (grossies $3 \ddot{0} 0$ fois). - a. CelJule qui contient une étoile formée d'aiguilles eristallisées, eomme on en trouve quelquefois dans la graisse normale. - $b$. Cellule entièrement remplie de cristaux, prise dans un lobule graisseux blanc, d’un individu émacié.

Le beurre artificiel de Mouriès, ou margarine Mouriès, est, comme on le pense bien, très riche en cristaux de margarine. Mais ces cristaux sont coupés et souvent englobés dans de la matière grasse. On voit de nombreux globules gras ovoïdes, qui semblent fendillés à leur surface, par des aiguilles cristallines. La stéarine a été séparée de la margarine, pendant 
les divers traitements que l'on a fait subir à la graisse de bœuf, qui sert à la préparation de ce produit alimentaire. La méthode de séparation est basée sur la différence des points de fusion de la stéarine et de la margarine.

Voici les caractères donnés par M. Husson, pour ce qui regarde les fragments de tissus végétaux et animaux, ainsi que les débris de matière colorante que l'on peut reconnaître au microscope: "Le curcuma se présente sous forme de petites masses finement granulées, souvent ovoïdes et ayant

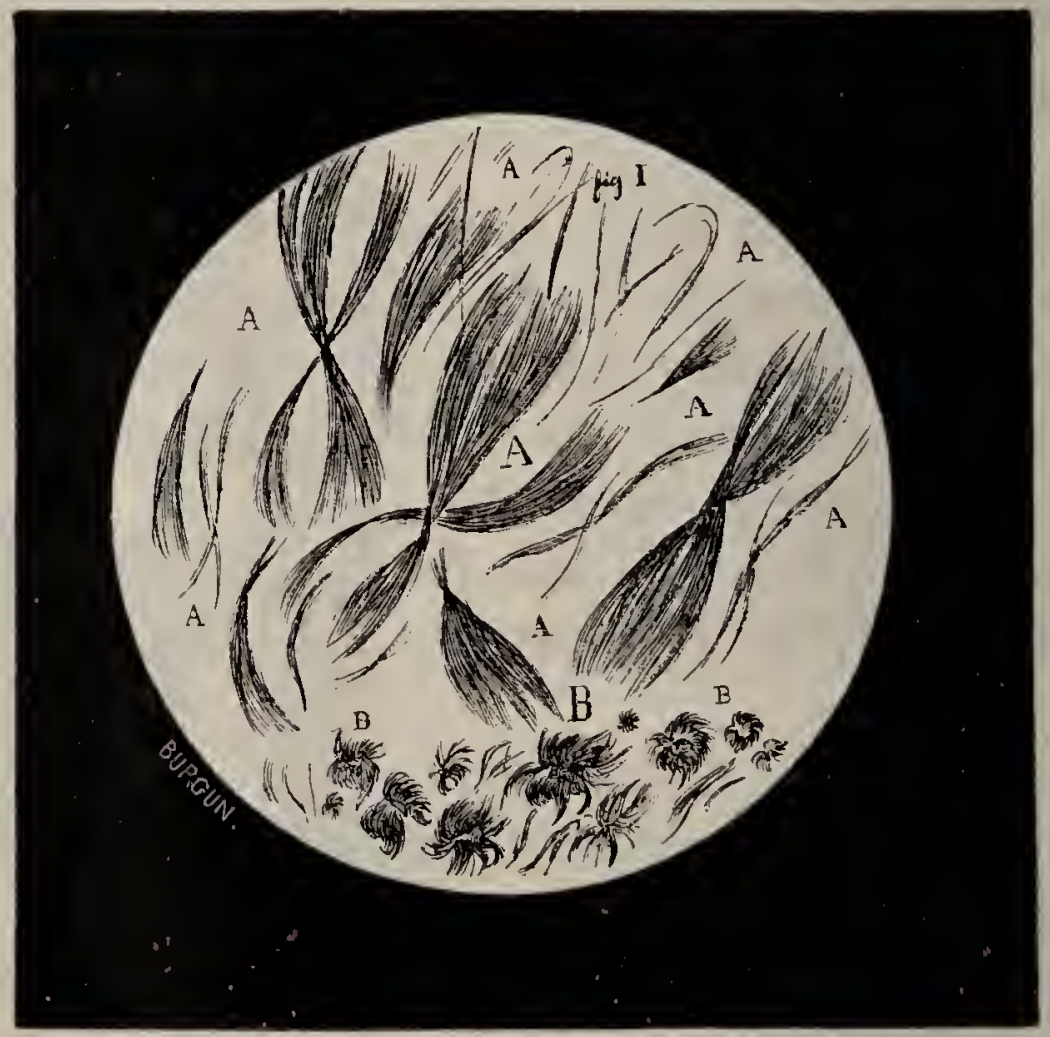

Fig. 346. - Cristaux de margarine du heurre frais, d’après Husson (1).

une teinte d'un jaune roux. Cette couleur se fonce et brunit en présence d'un peu d'alcool. Les débris de safran se montrent sous l'aspect de fibres et de cellules végétales, toutes teintes en jaune, couleur que l'on voit passer au bleu et au violet, sous l'influence, de l'acide sulfurique. Le rocon apparaît sous forme de plaques d'un jaune roux, remplies de sortes de rognons ou noyaux plus foncés (Husson). L'emploi du jus de carotte laisse des traces caractéristiques : outre les

(1) Lorsque le beurre a subi la fusion i une chaleur assez forte, les aiguilles de margarine diminuent de longueur et se présentent ave la formo liguréc en B fig. 346. 

cellules végétales, on remarque une masse de fragments ayant l'aspect d'aiguilles brisées d'un rouge carotte.

Dans le cas où l'on serait chargé d'une expertise, il ne faudrait pas se contenter d'un simple examen microscopique, bien que la présence, constatée d'une façon certaine, de débris de cellules adipeuses, ou de cellules entières, soit l'indice d'une adultération du beurre, il faudra recourir aux procédés chimiques. On trouvera le détail de ces procédés dans les

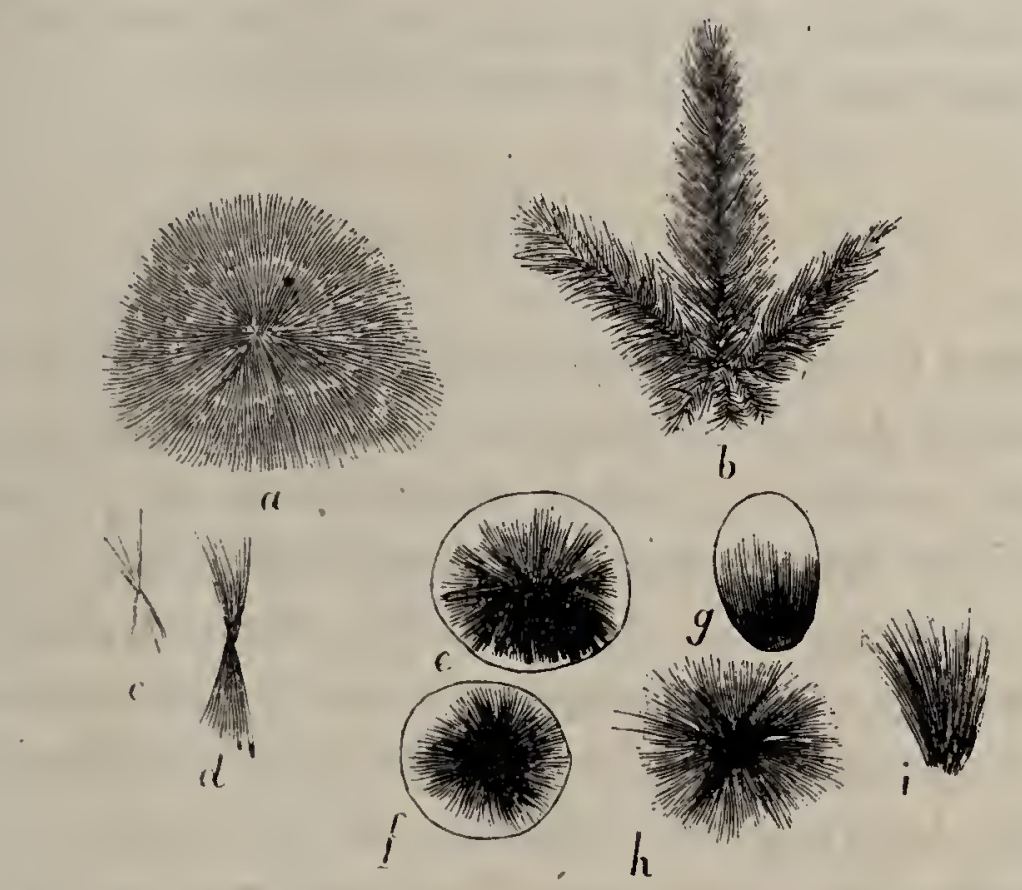

Fig. 347. - Margarine. - $a, b$. Margarine pure. $-c, d, h, i$. Cristaux isolés. $f, e, g$. Cristaux contenus dans des vésicules adipeuses.

traités spéciaux et en particulier dans celui de M. Husson. Cet auteur résume ainsi la marche qu'il conseille de suivre: On prend un poids déterminé de beurre, que l'on traite par un mélange à parties égales d'éther à 66 et d'alcool à 90 , dans les proportions de $10 \mathrm{p} .100$. On opère la dissolution en plaçant le mélange dans un bain-marie, à la température de $35^{\circ}$ à $40^{\circ}$, puis on laisse refroidir jusqu'à 18. Au bout de 24 heures, le beurre naturel doit laisser un dépôt de margarine pure, qui desséché, ne devra pas être supérieur à 40 p. 100, ni inférieur à 3ّ̋. Une augmentation dans ces chiffres, serait un indice certain de falsification, à l'aide de suif de bouf, de veau ou de mouton; une diminution au contraire, indiquerait un mélange de margarine Mouriès, d'axonge ou de graisse d'oie. L'observation microscopique indiquera quelle est la matière grasse employée pour cette fraude (Husson, p. 214, loc. cit.). 
D'après M. Husson, dans ces conditions, l'axonge abandonnerait des cellules polyédriques, globules gras à demi figéş et comprimés, ce qui leur donne l'aspect de paillettes, au.milieu desquelles on remarque qúelques cristaux très petits de margarine. Quand le saindoux a été mal préparé, on voit des débris de cèllules adipeuses.

La graisse d'oie offrirait des caractères à"peu près analogues. G'est ainsi que l'on observerait des plaques carrées ou rectangulaires très petites et brillantes, au milieu desquelles on voit de petits faisceaux de margarine cristallisée.

\section{§ XIII. - ADULtÉration bes FROMAGES.}

Nous serons très concis sur ce sujet; on sait que les fromages, dont les modes de fabrication sont très variés, sont constitués, d'une façon générale, par la coagulațion de la caséine du lait. Celle-ci entraîne les principes albuminoïdes, les matières grasses, de la lactose et des sels. On trouvera dans l'ouvrage de. M. Husson des renseignements très intéressants sur la fabrication des fromages. Quelquefois, on introduit dans le fromage blanc, dans un but de fraude, de la fécule. Il suffit, pour découvrir cette tromperie, de délayer le fromage dans un peu d'eau et d'examiner le dépôt au microscope. On trouvera des grains d'ạnidon plus ou moins altérés, mais gràce à la teinture d'iode, on sera bientôt fixé sur leur véritable nature. A la surface des fromages qui ont subi la férmentation, on constate souvent, d'après M. Robin, la présence de mycélium et parfois de spores des genres Penicillium et Mucor. Ceux qui sont envahis par les moisissures qui les colorent en vert, présentent en outre des réceptacles et un grand nombre de spores. Dans le fromage de Roquefort, ce sont celles du Penicillium glaucum. La réaction des fromages ainsi envahis, est alcaline.

".A la surface el parfois dans l'intérieur des fromages secs, on peut trouver, d'après les observations de M. Robin, une quantité plus ou moins grande de Tyroglyphus ciro et longior, seuls ou réunis, qui en réduisent la croûte en poussière. On retrouve dans cette poussière, les excréments, les oufs et les 
CHAP. XII. - DU LaIT AU POINT DE VUE MicRoscopique. 52I enveloppes, ainsi que des acariens à différents états de développement.

$\S$ xiv. - taches formées par du fromage blanc (V. Gosse, loc. cit., ainsi que Briand et Chaudé).

Les taches formées par du fromage blanc, ont des caractères faciles à reconnaître. Elles varient de couleur suivant leur ancienneté; généralement, elles sont d'un blanc sale, mais elles peuvent être, surtout sur les bords, colorées en gris jaunâtre. Elle ne donnent pas de résistance aux tissus. Par l'influence de la chaleur, elles se ramollissent et laissent plus facilement pasșer les rayons lumineux. Si on examine de semblables taches, on ne tardera pas à y constater la présence de globules de lait, agglomérés et déformés; ils peuvent avoir perdu leur forme sphérique; ils sont ternes et contiennent parfois de petits cristaux dans leur intérieur. Ils sont emprisonnés dans des masses de caséum de volume variable, demi-transparentes et irrégulièrement granuleuses.

L'éther dissoudra facilement les globules de lait.

Les algues se développent avec la plus grande facilité à la surface des taches formées par le fromage blanc. Elles seront dẹterminées à l'aide des caractères donnés dans la première partie de ce manuel. 


\title{
CHAPITRE XII
}

\section{DU SPERME}

\author{
$\S \mathrm{I}^{\mathrm{er}}$.
}

Le sperme éjaculé est un liquide complexe, dont les éléments constituants ont une origine différente; il est opalin, blanchâtre et visqueux, il a une odeur spéciale; produit par l'organe mâle, il a pour but la fécondation de l'ovule.

Le testicule ne fournit pas le sperme tel que nous le connaissons; il donne seulement naissance au spermatozoïde qui sera étudié ci-après. Observé dans le testicule même, le sperme est épais et concret, d'un blanc mat. Cette matière est constituée, au moins pour les neuf dixièmes, par des spermatozoïdes (Robin); parmi ceux-ci, on en voil qui sont encore contenus dans les cellules embryonnaires mâles, ou qui en sont incomplètement sortis. Chez un certain nombre d'animaux, le sperme est porté sans mélange d'autre liquide, dans l'organe femelle.

Au produit du testicule s'ajoutent des liquides, dans lesquels vivent les spermatozoïdes. Près des vésicules séminales, au bas du canal déférent, le sperme reçoit le liquide fourni par les follicules. Ce liquide brunâtre ou gris jaunâtre, plus ou moins foncé, contient d'après M. Robin : $1^{\circ}$ un sérum; $2^{\circ}$ des cellules épithéliales prismatiques et des épithéliums nucléaires ovoïdes; $3^{\circ}$ des granulations arrondies ou polyédriques irrégulières, réfractant fortement la lumière, à centre brillant et à contour brunâtre foncé. Dès le moment-où celte liqueur est mêlée aux spermatozoïdes, le sperme perd sa coloration crémeuse et devient gris brunattre; on trouve parfois dans le sperme des cellules épithéliales cylindriques, munies de très longs cils vibratiles; elles proviennent de l'épididyme. 
Dans les vésicules séminales, s'ajoute au sperme un nouveau liquide produit par les parois des vésicules séminales. Cette humeur, dit M. Ch. Robin, relativenent abondante, est d'une couleur légèrement grisâtre, mais sans coloration brune. Elle

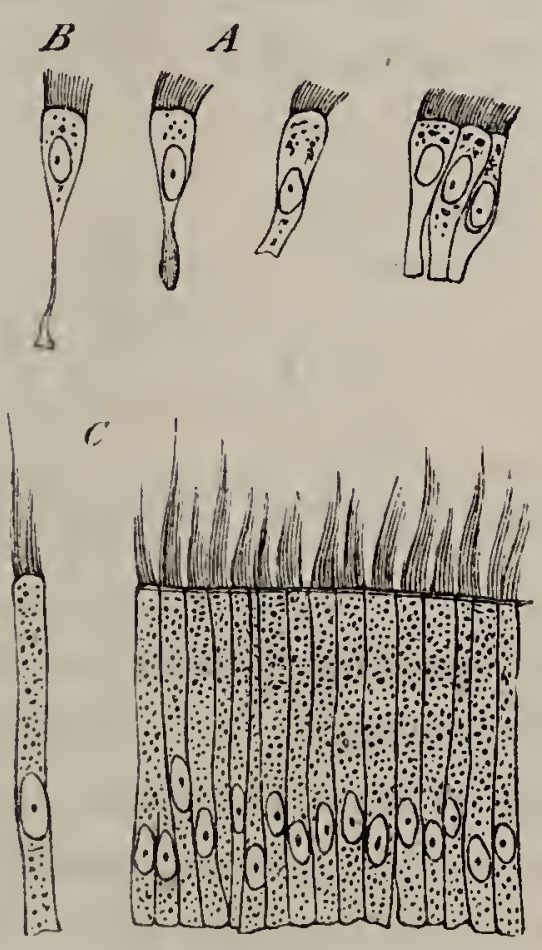

Fign. 34s. - Cellules épithélıales vihratiles de l'épididyme d'un suieidé (gross. de 100 diamètres). - A. Des raisseaux efférents. - B. Des ềnes séminifères. - C. De l'épididyme proprement dit. (Kuelliker.)

constitue presque uniquement le produit de l'éjaculation dans les coïts très rapprochés, avec le liquide prostatique. Le liquide des vésicules séminales renferme des cellules épithéliales prismatiques et des épithéliums nucléaires en petite quantité (Ch. Robin). Lorsque le sperme a séjourné pendant plusieurs jour's dans les vésicules spermatiques, il s'y forme de petites concrétions particulières auxquelles M. Robin a donné le nom de sympexions. Ces concrétions sont formées par des matières azotées, et jaunissent par la teinture d'iode ; elles englobent dans leur épaisseur, les spermatozoïdes qui restent immobiles, à peu près comme dans de la glace (Robin).

L'acide acétique gonfle et rend transparents les sympexions. Il met en liberté les spermatozoïdes, les globules blancs et les globules graisseux, qu'ils tiennent emprisonnés. Dans un cas cité par Reliquet (Gazette des hôpilaux, 1874), il s'était développé un si grand nombre de sympexions dans les vésicules 
séminales, qu'ils avaient déterminé une oblitération des canaux éjaculateurs.

Lorsqu'il n'y a pas eu d'éjaculation depuis longtemps, les sympexions peuvent devenir brunâtres ou rosés; dans les mêmes circonstances, le sperme peut également prendre une coloration rosée. Cela tient, dit M. Robin, à ce que sous l'in-

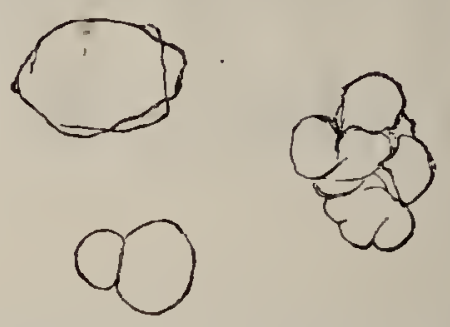

Fig. 349. - Sympexions provenant du liquide des vésicules séminales. Gross. de 203 diamètres. (G. Pouchet.)

fluence du séjour prolongé du sperme dans les vésicules séminales, de petites hémorrhagies ont lieu dans celles-ci. Donc, lorsqu'on trouve des globules rouges dans le sperme, il ne faut pas toujours en tirer de conséquence alarmante. On rencontre quelquefois dans le sperme de l'hématoïdine en grains amorphes. Les hématies seraient surtout fréquentes dans le sperme des vieillards. Il se forme également dans les vésicules séminales, de petites concrétions formées de phosphate, de carbonate de chaux et de matière animale.

Lors de l'éjaculation, le sperme reçoit encore d'autres humeurs; tel est le liquide prostatique, fourni en grande quantité au moment de l'éjaculation. Le liquide produit par la prostate est alcalin, d'un blạnc crémeux, un peu jaunâtre, plus ou moins foncé, suivant les sujets. C'est lui qui restitue au sperme, au moment de l'éjaculation, sa coloration blanche, lactescente, opaline, qu'il n'avait plus dans les vésicules séminales (Robin). Le liquide prostatique ne renferme pas de leucocytes; il contient des granules moléculares, de fines granulations grisâtres: c'est à ces éléments qu'il doit sa coloration blanche. Les canaux excréteur's de la prostate sont revêtus d'un épithélium à cils vibratiles; ces cellules sont quelquefois expulsées avec le sperme. Il se forme fréquemment dans la prostate de petits calculs, sur lesquels nous insisterons peu, parce qu'ils n'ont jamais élé observés dans le sperme. 
M. Robin en a donné une description très détaillée. La forme de ces petits calculs est extrêmement variable; leur coloration est jaune d'ambre plus ou moins foncé. Quelquefois ils sont tellement colorés, qu'on les a comparés soit à des grains de tabac, soit à des fragments de café torréfié et moulu. Observés au microscope, ils ont une coloration rougeatre, ce qui autorise à croire qu'ils dérivent des matières colorantes du sang. Ces concrétions ont une structure tout à fait spéciale; elles sont formées de couches concentriques légulièrement disposées, tantôt minces, tantôt épaisses, alternées ; généralement, les plus minces sont les plus extérieures. Traitées par l'acide acétique ou par l'acide chlorhydrique, elles ne font que devenir un peu plus pâles, sans qu'il y ait dégagement de gaz. Ce dernier acide les gonfle et les ramollit. Quand elles sont devenues opaques, ces acides dégagent des bulles gazeuses. La teinture d'iode les colore en brun rougeâtre ou brun jaunâtre. Elles brûlent sans laisser de résidu appréciable (Ch. Robin).

Un peu avant l'éjaculation, les glandes de Méry ou de Cooper fournissent également une liqueur qui se mélange au sperme. Ce liquide est sécrété pendant l'érection ; il est hyalin, filant et visqueux et communique les mêmes caractères au sperme. Il ne renferme aucun élément anatomique. Ce fait, sur lequel insiste justement M. Robin, doit être retenu, parce que le liquide des glandes bulbo-uréthrales, peut être pris pour du sperme, soit par des malades, surtout par des hypocondriaques, soit même par le médecin. L'examen microscopi que du liquide permettra de rassurer les malades. Le mucus du canal de l'urèthre. ou des glandes de Littre, est également entraîné par le sperme, au moment de l'éjaculation; il renferme quelques cellules épithéliales pavimenteuses ou polyédriques, provenant du canal de l'urèthre. Il se rencontre parfois, dans le sperme éjaculé, sous forme de filaments finement striés, se gonflant lentement dans l'eau sans s'y dissoudre. Ces flocons ou filaments de mucosine, ont été quelquefois considérés à tort comme de la fibrine (Ch. Robin).

Maintenant que nous avons énuméré les éléments secondaires, qui constituent le liquide spermatique, nous allons revenir arec détails sur l'élément le plus important, celui sans 
lequel il n'y a pas de sperme, dans le sens physiologique du mot, c'est-à-dire le spermatozoïde.

La découvertè des spermatozoïdes est due à Leeuwenhoek (1). Mais, ce n'est que depuis une quarantaine d'années, que leur existence dans le sperme a été généralement admise. G'est ainsi qu'en 1833, de Blainville. dans son cours de physiologie professé au Muséum, niait énergiquement l'existence des spermatozoïdes. DeBlainville admettait bien, dansle liquide spermatique, l'existence de petites masses gélatiniformes, plus ou moins arrondies, ovales, et ayant une partie prolongée en forme de queue, "semblables en un mol aux dessins que Buffon et d'autres observateurs nous onl donnés des prétendus animalcules spermatiques, " mais pour lui, la forme ovalaire des petites masses, dépendait de la manière dont elles étaient éclairées. Quant à la queue, elle était formée par la matière glutineuse et visqueuse du sperme, adhérant fortement à Ia petite masse arrondie, cherchant en un mot à la relenir. L'appendice caudal du spermatozoïde résultait donc uniquement du contact de deux matières de densité différente. De Blainville termine sa démonstration en disant : "Mais, c'est assez nous arrêter à une illusion d'optique, qui a malheureusement séduit un grand nombre de personnes, depuis Leeuwenhoek, l'un de ses premiers fauteurs, jusqu'à MM. Prévost et Dumas, qui, dans ces derniers temps encore, ont soutenu l'existence des animalcules spermatiques. "

Cet exemple montre bien que si les observations positives ont parfois grand mal à faire leur chemin, elles finissent toujours par s'imposer, en dépit des obstacles.

Les spermatozoïdes sont des éléments anatomiques doués de mouvements ondulatoires; ils sont libres, dépourvus de noyaux, incapables de se reproduire, triple caraclère qu'ils partagent avec les hématies ( $\mathrm{u}$. Pouchet). On a l'habitude de considérer les spermatozoïdes de l'homme comme constitués

(1) D'après le $\mathrm{D}^{\mathrm{r}}$ Gosse les spermato\%oïdes auraient été découverts en 1677, par Louis Hammon, étudiant de Dantzig, et dans la même aunée, ainsi que dans l'année suivante, décrits par Leeuwenhoek. Baudrimont dans sa thèse de concours p. 19, dit que c'est à Hartoker que l'on devrait cette découverte qu'il aurait faitn $\in$ n 1655 . L'auteur n'a pas pu vérifier le fait. 
par deux parties distincles: une tète ou disque, un appendice filiforme ou queue. Leur longueur totale est de $50 \mu$, la tête seule mesure environ, $\breve{b} \mu \operatorname{sur} 4 \mu$ de large, elle a de 1 à $2 \mu$ d'épaisseur. D'après M. G. Pouchet, auquel nous empruntons cette description et la figure ci-contre, la tête du spermatozoïde serait légèrement déprimée. C'est ainsi que, vue de profil, elle offre l'aspect qui est représenté sur' la figure et semble être aplatie verticalement. Les spermatozoïdes, dit M. Pouchet, ont une symétrie bilatérale manifeste; une des faces est un peu bombée, l'autre est excavée, mais seulement en avant; pour la mẹme raison, le spermatozoïde vu en dessus, est transparent à la partie antérieure et un peu plus foncé en arrière (Précis d'histologie humaine, p. 727). L'appendice filiforme ne serait pas d'avantage exactement implanté sur le bord de la tête; son point d'attache est légèrement reporté vers la face excavée du disque "un peu à la manière du manche d'une cuiller. " Il semblerait de plus, dit M. Pouchet, qu'on distinguerait une sorte d'articulation qui unirail les deux parties du spermatozoïde, au delà de laquelle, Fig. 350. - Spermatozoides de la queue se renfle un peu. Les con-

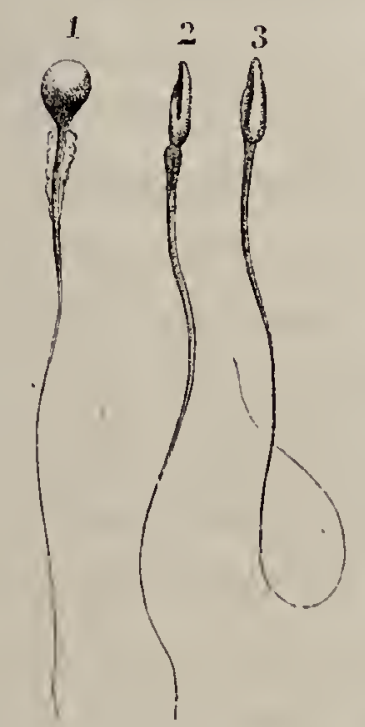
tours de celle-ci ne sont pas toujours aussi nets vers son origine, qu'à son extrémilé effilée; elle est souvent environnée, au voisinage de la tête, d'une sorte de frange irrégulière (V. fig. 3̋ั0) qui paraît être un débris du corps cellulaire, aux dépens duquel s'est formé le spermatozoïde.

La queue mesure à l'origine moins de $1 \mu$ de diamètre, el va en s'amincissant progressivement jusqu'à son extrémité : c'est assurément, dit M. G. Pouchet, de toutes les parties de l'organisme humain, même de tout le monde microscopique, un des objets les plus ténus qu'il soit donné à l'homme de contempler.

Godard, qui a examinéle sperıne d'un grand nombre d'individus, a observé dans quelques cas, des spermatozoïdes très 
petits, parfaitement formés et doués de mouvements très vifs et rapides; la vitalité de ces spermatozoïdes paraissait être plus énergique et d'une plus longue durée.

Leś spermatozoïdes sont animés d'un mouvement de progression assez rapide, qui est le résultat d'une ondulation totale, dans laquelle la tête se déjette alternativement à droite puis à gauche. La rapidité du mouvement de translation des spermatozoïdes a été évaluée à $60 \mu$ par seconde, c'est-à-dire qu'en une seconde, ils parcourent une partie de l'espace à peu près égale à leur propre longueur. Ce mouvement de propulsion est suffisamment énergique pour faire cheminer le spermatozoïde à travers un liquide visqueux et pour lui permettre d'écarter de sa route, des cristaux beaucoup plus volumineux que lui, qui se sont déposés par suite de la concenIration du sperme, par évaporation.

M. G. Pouchet (loc. cit.) a fait à propos des spermatozoïdes une remarque d'un grand intérêt. Laissant de côté loutes les théories qui ont été émises sur la nature du spermatozoïde; théories qui, à l'heure actuelle, n'ont pas un fondement scientifique bien solide, ce savant anatomiste appelle l'attention sur la symétrie bilatérale du spermatozoïde, caractère qui ne se retrouve pas dans les autres éléments anatomiques, lesquels sont tous, si on les suppose ramenés' à leur forme normale, des solides de révolution. Les spermatozoïdes seuls font exception à cette règle, aussi bien ceux de l'homme que ceux des autres mammifères, tels que les rongeurs, où la forme symétrique de chaque côté d'un plan médian est encore plus accusée (G. Pouchel, loc. cit., p. 729).

Nous serons brel's sur le développement des spermatozoïdes, que nous ne pouvons passer sous silence, en raison des débris de cellules qu'ils emportent parfois. Différentes théories ont été données sur le mode de développement des spermatozoïdes. Les explications de Kölliker ne sont plus généralement admises, les renseignements qui suivent sont empruntés à l'ouvrage de G. Pouchet et Tourneux. L'étude du développement des spermatozoïdes est difficile à faire chez l'homme, parce qu'on peut dilficilement se procurer des testicules frais, aussi les auteurs ont-ils fait porter leurs recherches sur le testicule du rat, qui présente des avantages particuliers. Lil longueur du spermatozoïde chez cet animal est de 14rk $\mu$ (Neumann). Les 
iléments anatomiques qui doninent naissance aux spermatozoïdes ont reçu le nom de spermatoblastes. On les rencontre dans les canalicules spermatiques, avec les cellules testiculaires. "Les spermatoblastes sont des éléments allongés, dans leur forme générale, reposant directement sur la paroi propre des canalicules. L'ensemble des bases de ces cellules vues à travers la paroi du canalicule figure une

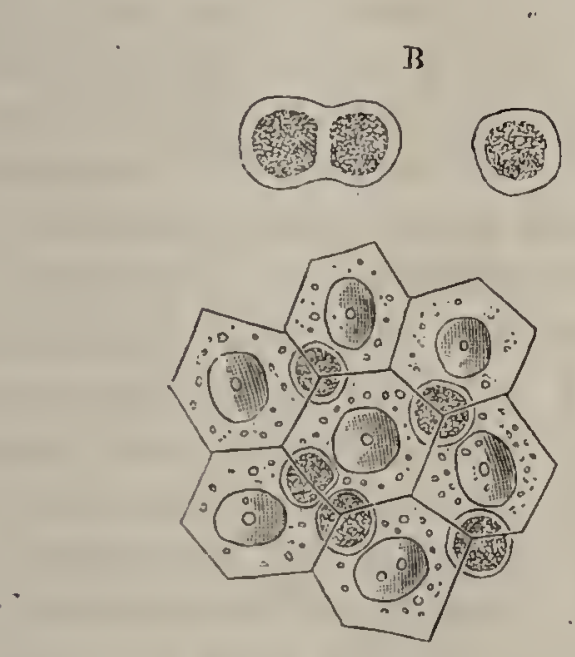

A.

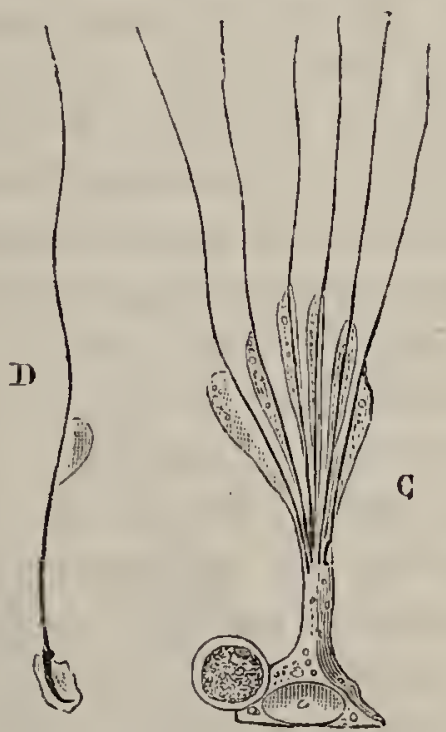

Fig. 351. - Giléments cles canalicules séminiferes du rat après macération dims la liqueur le Müller. - A. Mosaïque formée par la base des spermatoblastes (Gross. 250/1). B. Cellules lestieulaires, une d'elles a deux noyaux. - C. Spermatoblaste, présentant contre sà base une cellule testieulaire. - 1). Spermatozoïde réeemment détaché (à uı grossissement plus fort), avec un fragment du corps du spermatoblaste adhérent à la tète.

sorte de mosaïque régulière composée de pièces polygonales à cinq ou six faces. Chaque spermatoblaste offre dans cette base un noyau ovoïde, clair, nucléolé, mesurant de 13 à 18 \% de diamètre. Au-dessus de la base, le corps de la cellule se rétrécit subitement, il présente à sa surface des dépressions séparées par des crêtes et qui répondent aux cellules testiculaires, au milieu desquelles est enchìssé le spermatoblaste; puis il se termine par une extrémité plus ou moins irrégulièrement découpée et rameuse, tournée vers l'axe du canalicule. "

Les cellules tesíiculaires présentent moins d'intérêt. pour nous, parce qu'on n'est pas encore bien fixé sur les rapports de ces cellules avec les spermatoblastes. Ce sont des éléments sphériques ou légèrement polyédriques; ils entourent les spermatoblastes et leurs prolongements, qu'ils dépassent parfois du côté de la cavité du conduit. lls se logent dans les excavations de la partie moyenne des spermatoblastes, et possèdent de un i deux noyaux. Il ne faut pas confondre ces cellules, avec les cellules volumineuses que l'on peut trouver a la surface du revetement cellulaire des canalicules spermatiques, et qui renferment de huit à vingt petites vésicules claires, décrites sous le nom d'ovules mâles par Ch. Rohin, de cellules mères par 
quelques auteurs; leur rôle physiologique est encore obscur (G. Pouchet et Tourneux).

Revenons aux spermatoblastes : à un certain moment l'extrémité rameuse du spermatoblaste qui, nous l'avons vu plus haut, est tournée vers l'axe du canalicule spermatique, se renfle; chacun de ses prolongements prend une forme ovoïde et devient le centre de formation d'un spermatozoïde. Bientôt on distingue, appliquée contre chacun de ces prolongements, la queue d'un spermatozoïde qui en dépasse l'extrémité el flotte dans la cavité centrale du canalicule spermatique. La tête est encore indistincte, elle se forme dans l'intérieur même du spermatoblaste, au niveau de l'étranglement qui sépare la base du spermatoblaste de ses prolongements. A mesure que le spermatozoïde, toujours adhérent par la région qui répondra à sa tête, se développe, il entraîne avec lui le bourgeon dont il procède; puis la tête se détache à son tour du spermatoblaste et le spermatozoïde devient libre, emportant ce qui reste encore du bourgeon aux dépens duquel il s'est développé. C'est ce résidu qui adhère à la queue du spermatozoïde et qui a été représenté sur la figure empruntée à l'ouvrage de MM. Pouchet et Tourneux (fig. 33̈1). Ce reste de bourgeon finit par disparaître. On peut le considérer, comme le dit d'une façon si originale M. Pouchet, comme un viatique, que le spermatozoïde emporte avec lui et qu'il absorbe progressivement dans les premiers temps de sa vie indépendante. Ce résidu est toujours limité par un trait aussi nettement accentué que le spermatozoïde lui-même; au contraire, les fragments du spermatoblaste qui peuvent rester adhérents soit à la tête, soit à l'extrémité de la queue du spermatozoïde, se présentent sous l'aspect d'un léger voile granuleux.

Il peut arriver que les prolongements du spermatoblaste ou bourgeon, ne produisent pas de spermatozoïdes; alors ils se développent d'une façon considérable, se renflent à leur extrémité, prennent un aspect pyriforme et finalement se détachent des spermatoblastes. lls sont formés d'une substance hyaline qui est colorée uniformément dans toutes ses parties par le carmin (Pouchet et Tourneux, loc. cit., p. 730) (1).

(1) En portant ses observations sur la glande sexuelle des mollusques gastéropodes, Mathias Duval a pu observer avec une grande netteté la formation des spermatozoildes, car cliez ces animaux les éléments spermatiques sont relativement très longs, et en suivant attentivement l'état de la glande pendant l'hiver, le printemps et l'été, on a successivement sous les yeux les diverses formes de l'évolution spermatique : quand on observe seulement pendant la saison chaude, toutes ces formes se trouvent côte ì côte, et il est alors difficile d'établir avec certitude le véritable ordre de passage de l'une il l'autre. - Dans les circonstances sus-indiquées, on voit que les cellules épithéliales des culs-de-sac glandulaires, grossissent et sont le siège d'une formation endogène de nnyaux; ceux-ci se portent å la périphérie et deviennent le centre d'autant de bourgeons, auxquels l'auteur réserve le nom de 
Les détails qui précèdent étaient absolument nécessaires pour faire bien comprendre les particularités de forme que peuvent présenter les spermatozoïdes, quand on les observe encore adhérents au bourgeon du spermatoblaste, ou ayant entraîné un ou plusieurs fragments de cette cellule (1).

Quand on examine du sperme éjaculé depuis un certain temps, on observe qu'il renferme des cristaux de teinte ambrée, prismes obliques à base rhomboïdale, soit isolés, soit réunis en croix, en étoile; à base bien déterminée ou remplacée par des biseaux allongés, donnant au cristal la forme d'un fuseau. Ces cristaux sont des dérivés du prisme oblique à base rhom-

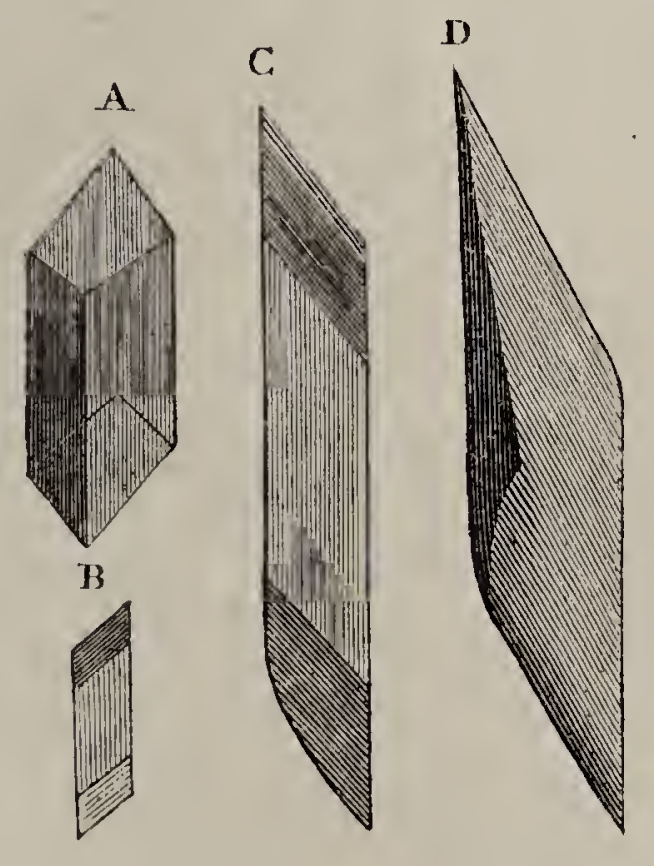

Fig. 352. - Phosphate de magnésie.

boïdale. Quelquefois, il y a de vrais prismes rhomboïdaux obliques avec des bords très nettement dessinés. Ils peuvent être d'un volume très considérable et se brisent avec facilité.

spermatoblastes; ces spermatoblastes forment ainsi de véritables grappes, qui se transforment en faisceaux de spermatozoìdes, chaque spermatoblaste donnant naissance à un spermatozoïde par le procédé suivant : dans le voisinage du noyau propre du spermatoblaste, apparaît une nouvelle formation nucléaire, le corpuscule céphalique, qui sera la tête du spermatozoïde : en même temps, se montre à l'une des extrémités de ce corpuscule céphalique, un filament qui naît par différenciation dans le protoplasma du spermatoblaste et s'accroît ì ses dépens : ce protoplasma disparaît donc peu à pcu, ainsi que le noyau propre qui s'atrophie, et il ne reste en définitif que le spermatozoïde avec sa portion céphalique et son filament caudal.

(1) Donné avait vu des spermatozoides présentant cette particularité dont il n'avait pas saisi la signification. 
Leur présence même dans les taches de sperme est assez fréquente (Ch. Robin). Ces cristaux, d'après cet auteur, seraient du phosphate de magnésic.

Dans son Traité de chimie médicale, p. 484, M. Méhu a décrit les caractères du phosphate bicalcique qui existe également dans le sperme, ces cristaux se dissolvent rapidement dans l'acide acétique. M. Robin a également signalé dans le sperme la présếnce de cristaux de phosphate ammoniaco-ma-

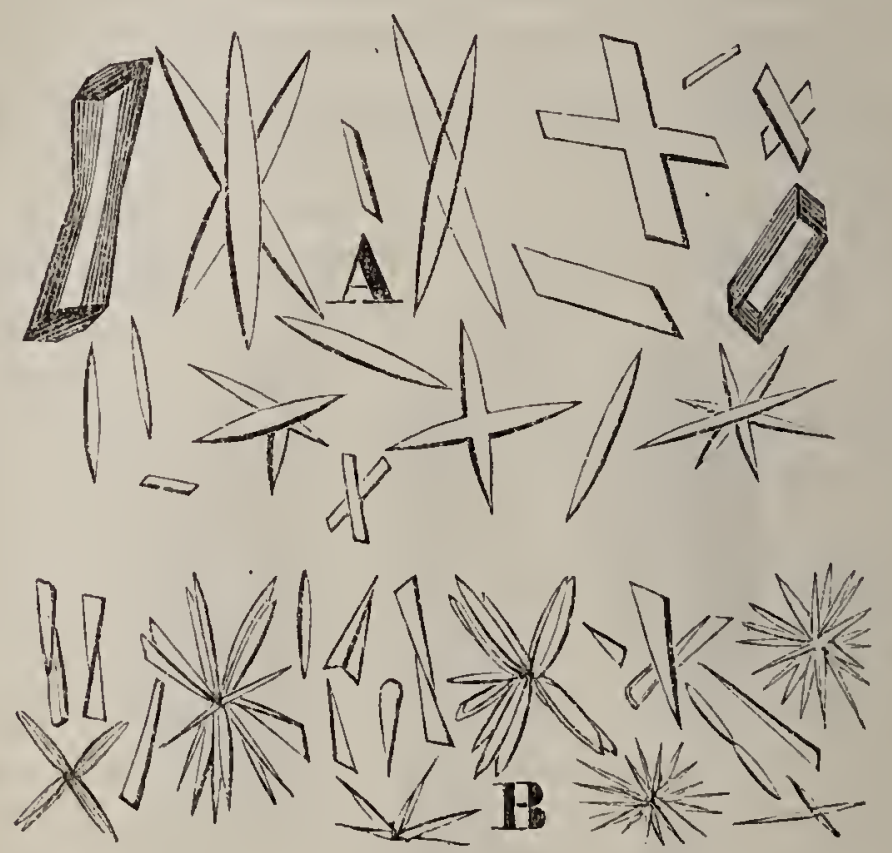

Fig. 3̋̈3. - 'Phosphate bibasique de chaux (IIéhu). - A. Du sperme. - B. De l'urine.

gnésien; mais ce fait se présente rarement, à moins que le sperme ne se soit solidifié. Bien que l'oxalate de chaux existe fréquemment dans les urines qui renferment des spermatozoïdes, la présence de l'oxalate n'a pas été signalée dans le sperme.

On peut encore rencontrer des globules blancs dans le sperme éjaculé, chez des individus qui ont eu des blennorrhagies, avec ou sans épididymite; quelquefois même, ces globules blancs conservent dans le sperme assez de vitalité, pour que l'on puisse observer les mouvements expansifs que nous avons décrits. M. Gh. Robin a signalé la présence dans le sperme, de gouttes visqueuses sphériques ou non, se déformant facilement, hyalines, incolores, légèrement rusées ou jaunâtres. Ces gouttes, dont le volume rarie beaucoup, se retrouvent plus ou moins abondamment dans le sperme éjaculé, d'un sujet à l'autre, tantôt dans le sperme normal, tantôl dans 
le sperme d'individus n'ayant plus de spermatozoïdes, à la suite d'épididymites doubles. La substance qu'ils constituent est susceptible de s'étirer en forme de larmes, de fuseaux plus ou moins effilés, de filaments cylindroïdes subdivisés ou non, avec ou sans anastomoses réticulées ou fasciculées, offrant les aspects les plus variés. Elle n'est pas attaquée par l'eau. L'acide acetique pâlit cette substance, y fait apparaître les leucocytes ou les spermatozoïdes qu'elle englobe, puis la dissout on la liquéfie; elle se liquéfie spontanément avant le début de la putréfaction (Ch. Robin, Traité du microscope, p. 489).

Pour bien examiner le sperme, il faut se servir d'un grossissement d'au moins 400 diamètres. L'examen du sperme fraîchement éjaculé, n’exige généralement pas l'ad̉dition d'un liquide quelconque pour le diluer; si au début l'examen des spermatozoïdes peut être rendu difficile par la rapidité de leur's mouvements, par suite de l'évaporation, le sperme se concentre, et les mouvements des spermatozoïdes deviennent plus lents. Dans la majorité des cas, il suffit de placer une goutte de sperme entre deux lamelles de verre. Quand on veut observer les mouvements des spermatozoïdes, pendant un certain temps, il est nécessaire de maintenir la préparation à une température de $30^{\circ}$ à $33^{\circ}$ environ.

Dans certains cas, on peut avoir à examiner du sperme pour se prononcer sur l'existence ou la non-existence des spermatozoïdes. Ce contrôle est souvent demandé par les personnes qui, après plusieur's années de ménage, n’ont pas d'enfants. L'examen microscopique tranche généralement la question; lorsque cel examen a été pratiqué à plusieurs reprises, el que les résultats qu'il a fournis ont toujours été négatifs, en ce qui concerne la présence des spermatozoïdes, on peut en déduire que l’impuissance est le fait du mari. Cette déduction sera encore corroborée, si la personne a eu autrefois une épididymite double, d'où est résultée l'oblitération des canaux épididymaires. (Quand on s'est formé une opinion basée sur plusieur's examens microscopiques, pratiqués à des époques successives, il peut être quelquefois sage de ne pas dévoiler au malade la vérité exacle et de laisser une porte ouverte à l'espérance d'une guérison, ou d'ajonter, par la pensée, quelques sper- 
matozoïdes rares et incomplets, àla liqueur spermatique. Outre qu'en agissant ainsi, on ne risque pas d'assombrir la vie d'un homme, et de la condamner presque fatalement à l'hypocon-. drie, on se met à l'abri de certaines surprises qui peuvent sur-

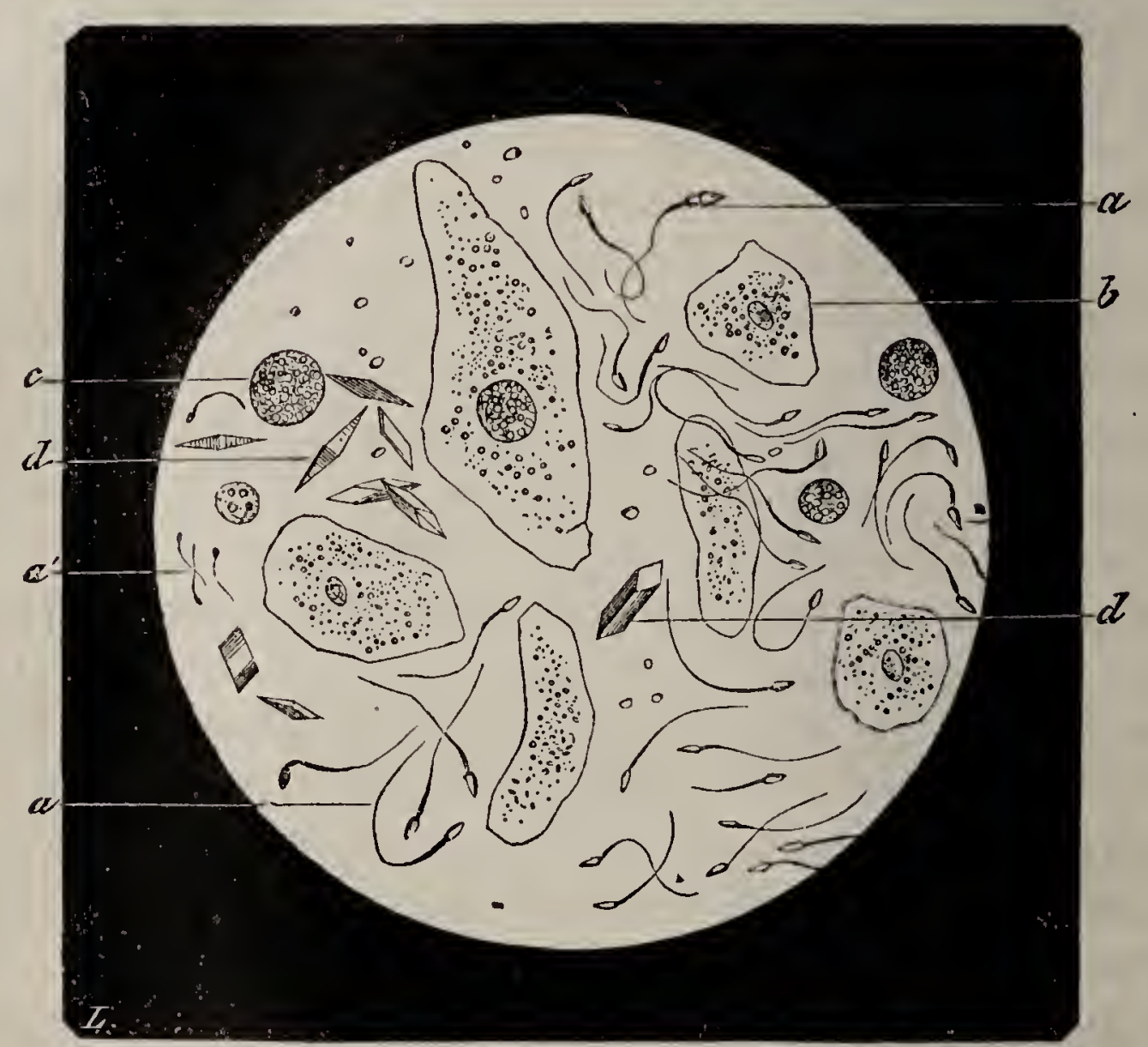

Fig. 354. - Sperme de l'homme (Liégeois) - aa. Spermatozoïdes normaux, à spermatuzoỉdes a petites têtes que l'on trouve ehez certains sujets. - $b$. Cellule épithéliale pavimenteuse. - c. Leucoeyte, fines granulations de l'humeur prostatique éparses. - $d$. Cristaux de phosphate de magnésie.

venir, comme l'apparition d'une grossesse, par exemple, grossesse qu'il serait peut être difficile d'expliquer si on n'avait pas fait à l'avance quelques réserves.

§ Ir. - ACTLON DE DIFFÉhENTS RÉACTIFS SUR LES SPERMATOZOÏDES.

L'eau arrête généralement les mouvements des spermatozoïdes; il en est de même des dissolutions minérales très étendues. Les spermatozoïdes se replient sur eux-mêmes en forme de boucle. Ce serait une erreur de croire qu'ils sont morts.

II suffit, en effet, d'ajouter au liquide une solution concen- 
trée d'un sel alcalin, de sucre ou d'albumine, pour voir réapparaître ces mouvements, souvent même d'une façon intense.

Chez quelques espèces animales, les spermatozoïdes vivent très bien soit dans l'eau de mer, soit dans l'eau douce.

Les alcalis semblent exciter l'énergie des mouvements des spermatozoïdes, puis ils meurent rapidement; de plus, dans une solution assez fortement alcaline, les spermatozoïdes ne se conservent pas.

Les acides, même les acides faibles, tuent les spermatozoïdes; c'est en raison de cette sensibilité à l'action des acides, que les spermatozoïdes sont tués par l'urine normale. L'acide acétique qui tue les spermatozoïdes, conserve longtemps l'intégrité de leur forme; il en est de même de l'urine acide, mais à un moindre degré, puisque Donné prétend que l'on peut conserver des spermatozoïdes pendant plusieurs années, dans l'acide acétique. L'acide sulfurique pâlit les spermatozoïdes, mais il ne les dissout pas immédiatement.

La teinture d'iode, l'eau iodée colorent les spermatozoïdes en jaune; la partie intermédiaire à la tête et à la queue, paraît se colorer plus fortement.

Le violet de méthylaniline colore les spermatozoïdes (G. Pouchet).

Donné a étudié l'action exercée par différentes humeurs de l'économie sur les spermatozoïdes.

Le sang n'exerce aucune action nocive sur les zoospermes; ce fait ne doit pas nous surprendre, puisque nous avons vu qu'à la suite d'une longue continence, il se faisait de petites hérnorrhagies dans les vésicules séminales, ce qui ne nuisait en rien à la vitalité des spermatozoïdes. Donné ayant mis des spermatozoïdes de l'homme dans du sang de grenouille, a vu qu'ils y vivaient très bien, et qu'ils repoussaient sans difficulté des globules de sang beaucoup plus gros qu'eux. Quand les spermatozoïdes meurent, ils restent étendus, tantôt la tête directement allongée, tantôt fléchie à droite ou à gauche et formant un demi-cercle.

Le lait, particulièrement le lait de femme, paraît agir sur les spermatozoïdes comme le sang.

L'action de la salive, bien que ce liquide soit généralement 
alcalin, n'est pas favorable à la conservation de la vie des spermatozoïdes; la salive les tue rapidement et lorsqu'ils sont morts, leur corps se contourne toujours sur lui-même, de manière que le filament caudal forme une espèce de nœud, ou d'œillet (Donné).

Nous avons vu que l'urine normale en raison de la réaction acide, tuait rapidement les spermatozoïdes. Leur corps reste toujours allongé en ligne droite; la queue ne forme aucun angle avec la tête (Donné).

Le pus, en raison de son alcalinité, ne paraît pas exercer d'action nocive sur les spermatozoïdes quelle que soit l'origine du pus; ils ne paraissent pas vivre moins longtemps dans ce milieu, que dans la liqueur séminale elle-même. La même observation a été faite pour la matière muco-purulente du catarrhe utérin.

Donné a étudié avec beaucoup de soin l'action exercée sur les spermatozoïdes par le mucus sécrété soil par l'utérus, soit par le vagin. Ces recherches ont, au point de vue de la pathologie, une grande importance. Bien que le mucus vaginal soit légèrement acide, les spermatozö̈des peuvent y vivre un certain nombre d'heures ; dans le mucus cervical, au contraire, ils peuvent vivre beaucoup plus longtemps, quarante heures par exemple. Le mucus vaginal purulent n'exerce pas, nous l'avons vu, d'action délétère sur les spermatozoïdes.

Dans l'état normal, le mucus vaginal, légèrement acide, est visqueux, d'apparence crémeuse, en raison des nombreuses cellules épithèliales qu'il contient. Examiné au microscope, il montre généralement de larges cellules épithéliales pavimenteuses, contournées ou roulées sur elles-mèmes; elles ont un noyau et sont finement granulées. Il est des circonstances dans lesquelles l'acidité du mucus vaginal devient très considérable, par exemple dans le cas de grossesse, où il y a une congestion vive de la muqueuse vaginale, ou bien quand cet organe est vivement irrilé par une cause quelconque. Donné aýant étudié l'action exercée sur les spermatozoïdes par de. tels mucus, vit qu'ils les tuaient rapidement. Il a fait des observations analogues en ce qui concerne le mucus vaginal des femmes enceintes. L'extrême acidilé du mucus vaginal peut donc être considérée comme une calise de stérilité.

Au mucus vaginal viennent se joindre le mucus sécrété par le col utérin et par le corps de l'utérus. Ces deux mucus ont une propriété commune c'est l'alcalinité. Il est assez difficile de se procurer ce mucus complexe, dans l'état normal, mais il devient plus abondant 
lans ces affections utérines si fréquentes et aussi, pendant la période congestive que précède la menstruation. Tyler Smith (1), qui a étudié les caractères microscopiques du mncus utérin, a reconnu que le mucus du col était très tenace, ce qui est d'une observation journalière, gluant, demi-solide, transparent, ne tenant en suspension aucun élément anatomique; sauf quelques cellules prismatiques granuleuses et souvent un assez grand. nombre de lẻucocytes. Le mucus du corps est, au contraire, très visqueux, demi-liquide, grisâtre; il tient en suspension de nombreuses cellules épithéliales prismatiques ou cylindriques, munies ou non de cils vibratiles, des amas de grosses cellules sans enveloppes, mais à noyau volumineux et à protoplasma granuleux, enfin, même dans les conditions physiologiques, un assez grand nombre de globules graisseux.

En raison de son alcalinité, le mucus utérin a, sur les spermatozoïdes, une action toute spéciale; ils peuvent vivre à son contact pendant fort longtemps. Donné avait remarqué que le mucus utérin permettait aux spermatozoïdes de se mouvoir avec autant de facilité que dans la liqueur séminale même; plus récemment, Marion Sims, cité par MM. Duval et Lereboullet, et le docteur Percy, de New-York, ont cherché combien de terups les spermatozoïdes pouvaient vivre dans l'utérus. Le docteur Percy a retrouvé quelques spermalozoïles vivants, dans le col utérin, huit jours et demi, après le dernier rapprochement sexuel. Pour Marion Sims, les spermatozoïdes ne vivraient pas plus de douze heures dans le mucus vaginal et on pourrait en trouver dans le mucus utérin, plus de quarante heures après le dernier coït,

Comme nous le verrons ci-après, il peut devenir nécessaire, afin de rechercher la cause de la stérilité chez une femme, d'examiner les caractères physiques et chimiques du mucus vaginal et utérin, ct de rechercher même, l'action exercée par ce mucus complexe sur. la vitalité des spermatozoïdes. Voici comment Marion Sims conseille d'opérer (2): "Supposons que nous devions examiner le múcus vaginal aussitôt après le coüt, c'est-à-dire dans l'espace d'une heure : on recommande à la femme de vider la vessie avant l'acte, et de rester tranquillement couchée sur le dos, jusqu'au moment de l'exploration. Pour recueillir quelques gouttes du liquide contenu dans le vagin, il faut y introduire l'index, opérer une pression en bas et en arrière, sur la paroi postérieure, précisément audessous du col ulérin. La semence s'amasse nécessairement dans la poclie formée par cette pression; on l'aspire alors au moyen d'une seringue. Il importe, avant de procéder à cette manipulation, de débarrasser le vagin de tout le mucus qu'il peut contenir, afin

(1) The pathology and the treatment of leucomhixa, citc par Courty; Trailé de maladies de l'utérus et par Duval et Lereboullet; Manuel du Mieroscope. 1. $37 \%$.

(2) Cité par Duval è Lerehoullet, p. зіт: 
que la seringue ne puisse en recueillir une portion qui viendrait se mêler à celui du col et nuire par conséquent à la précision de l'observation. Pour recueillir le mucus sur un point plus élevé, vers la cavité utérine, on doit enfoncer la seringue d'un pouce dans le canal cervical, et conduire l'opération avec beaucoup de délicatesse; il est bon que le bout de la seringue présente une forme bulbeuse : ce renflement, qui remplit l'orifice et le canal du col, empêche l'air d'entrer dans cet instrument, ainsi que M. Marion Sims l'a vu, quand l'extrémité de la seringue était allongée et terminée en pointe.

Antérieurement à ces recherches, Donné, auquel on ne rend pas suffisamment justice, avait étudié directement l'action du mucus utérin des femmes stériles, sur les spermatozoïdes. Au premier abord, ce mucus ne présentait rien de particulier, mis au contact des spermatozoïdes, il les tuait rapidement. Tous ces mucus étaient alcalins, dit Donné ; tantôt ils étaient purs et transparents, tantôt ils étaient opaques et purulents. Il était difficile d'assigner une cause à l'action de ces mucus, sur la vitalité des spermatozoïdes; Donné a pensé trouver une explication dans l'excès d'alcalinité du mucus utérin; d'après cet observateur distingué, chaque fois qu'à l'aide d'un papier de tournesol, il prenait la réaction des mucus qui tuaient les spermatozoïdes, il trouvait que dans la plupart des cas, le papier rouge était ramené très rapidement au bleu foncé. Cette explication est-elle la vraie ? Cela est possible, mais nous faisons quelques réserves, car il nous paraît difficile qu'un simple excès d'alcalinité puisse tuer les spermatozoïdes, alors que nous savons très bien, qu'un milieu alcalin est pour eux un milieı normal, et que même une solution alcaline concentrée, ne les tue pas immédiatement. Marion Sims, qui a fait des observations analogues, ne se prononce pas sur la nature de l'élément qui agirait d'une façon si énergique sur le spermatozoïde. Un léger degré d'inflammation du col semble, dans certains cas, produire dans la sécrétion du mucus, des principes nuisibles aux spermatozoïdes.

Il faut rendre cette justice à Donné, c'est que le premier il a bien étudié cette question, et qu'il a démontré en outre, contrairement à ce que l'on croyait à soll époque, que la plupart des femmes affectées de cet écoulement complexe, compris sous le nom générique de flueurs blanches, pouvaient néanmoins être très fécondes, tandis qu'il en est un certain nombre d'autres, dont le mucus tue les spermatozoïdes.

§ III. - DU SPERME CHEZ DIFFÉRENTES ESPÈCES ANIMALES.

Il peut se présenter différents cas de médecine légale dans lesquels il peut être utile de connaître la forme des spermatozoïdes des animaux qui nous entourent. La figure $30 ّ 5$ due à 
M. Liégeois, donne l'aspect d'un certain nombre de spermatozoïdes. Il-faut reconnaître toutefois que la distinction entre les spermatozoïdes des différents animaux, peut parfois être très difficile. Il est utile d'examiner au microscope du sperme

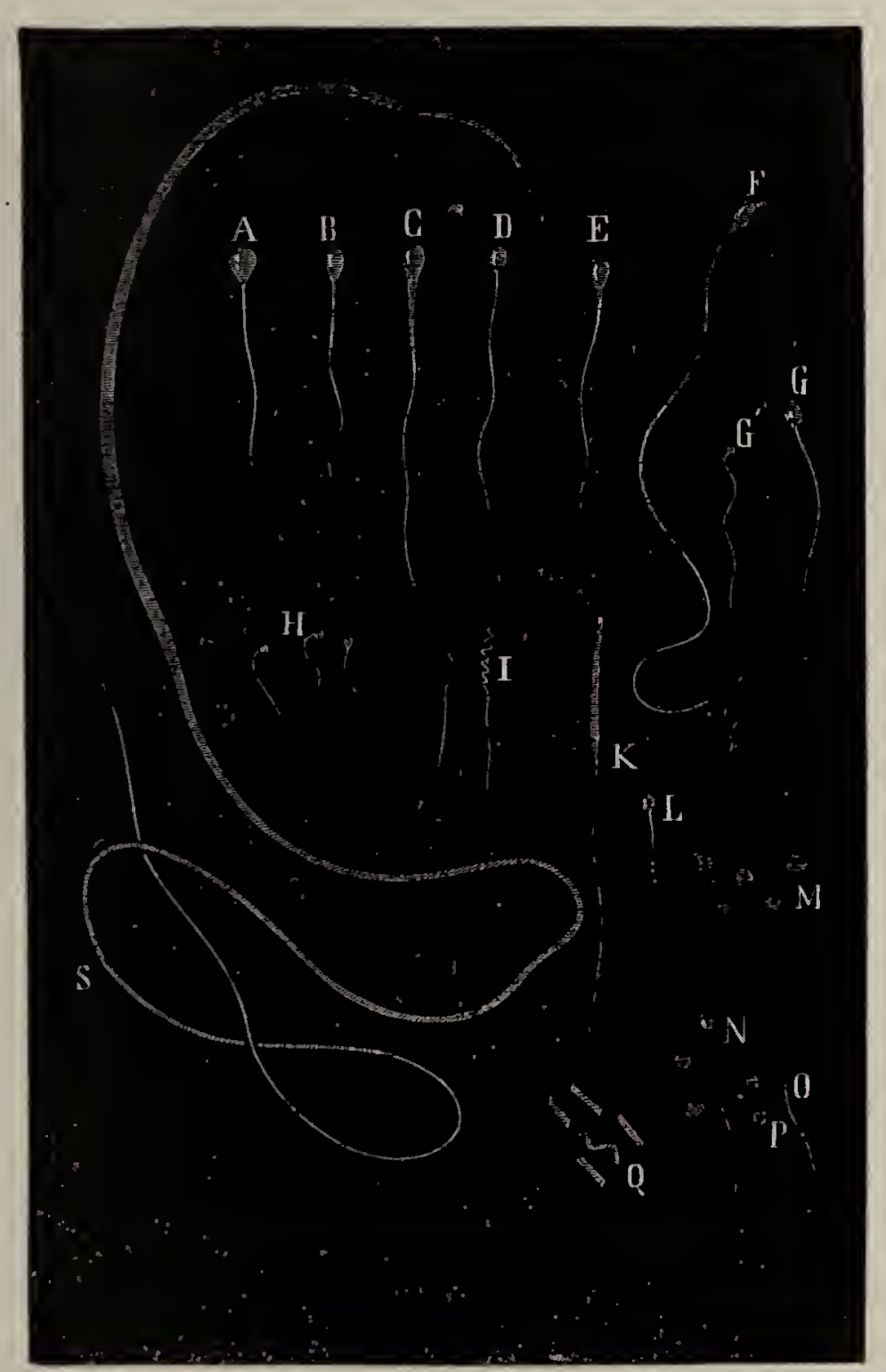

Vig. 355. - Spermatozoïdes de divers animaux. - A. Cochon d'Inde. - B. Taureau. C. Mouton. - D. Cheral. - E. Lapin. - F. Rat. - G. G'. Homme. - H. Coq. I. Moineau. - K. Pigeon. - L. Perche. - MI. Brochet. - N. 0. Grenouille (en hiver). P. Granulations mobiles du sperme chez le mème animal. - Q. Grenouille (en été). S. Mérobranche (Liégeois).

de taureau, d'âne, de chien, de cheval. Chez ces espèces, d'après Donné, le sperme serait plus fluide que chez l'homme, et d'autre part, les mouvements des spermatozoïdes seraient plus lents. Les zoospermes ont, du reste, chez ces animaux domestiques, ainsi que chez le lapin, à très peu de chose près, 
la même forme et les mêmes apparences que chez l'homme (Donné).

\section{§ IV. - DU SPERME DANS LA CRYPTORCHIDIE.}

Nous nous étenderons peu sur ce sujet. Chez un grand nombre d'animaux, les testicules restent normalement dans la cavité abdominale, ce qui ne les empêche pas d'être féconds et d'avoir par conséquent des spermatozoïdes. Chez l'homme, il n'en est pas de même, et quand les testicules sont arrêtés dans l'un des points du trajet, qu'ils devaient parcourir, pour arriver dans les bourses, l'individu qui est porteur de cette anomalie, peut être puissant au point de vue du coït, mais il ne peut se reproduire, parce que son sperme ne renferme pas de spermatozoïdes. Quand il n'y a qu'un testicule arrêté dans sa migration, et que celui qui est descendu dans le scrotum est sain, l'homme est apte à procréer des enfants des deux sexes; si, au contraire, le testicule descendu est à l'état pathologique, le sperme ne contient pas de spermatozoïdes et l'homme ne peut procréer.

\section{$\S$ v. - oblitíration des voles spernatiques.}

M. Gosselin a démontré qu'à la suite d'orchite double, ou bi-latérale, ou d'autre maladie du testicule, le canal déférent et la queue de l'épididyme s'oblitéraient quelquefois, d'une manière définitive, ou temporairement. Dans ce cas, il ne se produirait plus de spermatozoïdes; les autres caractères du sperme restent les mêmes. C'est le microscope qui, comme précédemment, tranchera la question, si une personne atteinte d'une des affections auxquelles nous venons de faire allusion, voulait être fixée, d'une façon positive, sur ses facultés procréatrices. M. Robin a signalé dans le pseudo-sperme éjaculé par les personnes atteintes soit de cryptorchídie, soit d'oblitération des conduits épididymaires, l'existence d'un très grand nombre de petits noyaux sphériques, que l'on ne rencontre qu'en petit nombre; dans le véritable sperme. Leur origine n'est pas absolument connue. "Ces noyaux ont de $0^{\mathrm{mm}}, 00 \%$ à 


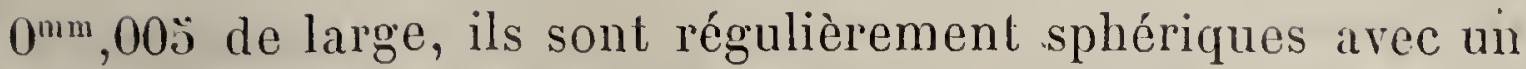
contour net; leur substance est translucide, et, pour bien les étudier, il faut se servir d'un grossissement de כั00 à รัวั0 diamètres, parce quavec un plus faible grossissement, ils ressemblent à de petits anneaux, tellement ils sont pâles et translucides. Ils sont presque toujours pourvus de granulations grisâtres, très pâles elles-mêmes, principalement disposées vers la périphérie de ces éléments anatomiques; mais ils ne renferment ni nucléole, ni granulations graisseuses à l'intérieur. " (Ch. Robin.)

Le liquide dépourvu de spermatozoïdes contient des sympexions, comme le liquide spermatique normal, toutes les fois qu'il y a eu un certain laps de temps entre les éjaculations. Par refroidissement, il s'y produit également de ces cristaux que nous avons décrits. Il peut se conserver plusieurs jours, sans entrer en putréfaction. Un liquide de cette sorte examiné par nous, avait une odeur très désagréable, même peı de temps après avoir été éjaculé. Ajoutons pour terminer, que chez les individus affectés de l'une des infirmités que nous venons de signaler, la sécrétion de la liqueur pseudo-spermatique se fait avec autant d'abondance, que si c'était du sperme véritable. Les malades ne sont nullement avertis qu'il se passe quelque chose d'anormal dans la production de leur liqueur séminale, dont l'aspect extérieur ne diffère pas de celui du sperme physiologique.

\section{§ V. - DU LIQUIDE DES KYSTES SPERMATIQUES.}

Les travaux de M. Gosselin ont singulièrement éclairé la pathogénie de ces kystes au point de vue chirurgical; nous nous occuperons seulement de l'examen du liquide au microscope. Le liquide des liystes spermatiques se présente ordinairement avec l'aspect trouble et opalin; quelquefois même, il est presque laiteux et un peu filant. Si on examine un tel liquide avant de l'aroir filtré, on voit qu'il renferme un grand nombre de spermatozoïdes immobiles, ou bien, doués de mouvements plus on moins rapides; le liquide filtré est transparent comme de l'eau et il ne contient plus 
de spermatozoïdes. D'après Ch. Robin, il n'y aurait pas un rapport absolu entre la présence des spermatozoïdes dans le liquide des kystes spermatiques et l'opalinité de ce liquide. Cet éminent micrographe dit avoir plusieurs fois observé des liquides opalins, provenant de kystes spermatiques, qui ne contenaient aucun spermatozoïde. "Sauf plus de fluidité et un peu plus de transparence, ces liquides étaient à ceux d'origine analogue, pourvus de spermatozoïdes, ce que l'hurneur stérile éjaculée après une double oblitération épididymaire, est au sperme proprement dit. "(Robin.) Les liquides lactescents ne contenant pas de spermatozoïdes devaient cette apparence à de fins granules graisseux et à de nombreux noyaux sphériques très petits. La.présence de ces petits noyaux dans les liquides dits spermatiques, prouve que ces liquides proviennent de l'épididyme. M. Robin avait déjà signalé l'existence de ces noyaux, dans les liquides stériles éjaculés par des individus ayant déjà eu une épididymite double avec oblitération.

§ vir. - De la spermatorrhée. (Pertes blanches. Pertes séminales.)

Il serait superflu d'insister sur l'importance qu'il y a à diagnostiquer la spermatorrhée vraie ou supposée ; les conséquences qu'elle entraîne au point de vue physique et moral, sont très graves; le micrographe peut donc rendre un grand service en constatant la présence des spermatozoïdes, dans des taches ou dans l'urine. L'examen des taches sera traité ultérieurement et nous nous occuperons seulement de la recherche des spermatozoïdes dans l'urine (V. Sédiments urinaires, p. 413). Hippocrate connaissait et a magistralement décrit la spermatorrhée. Wickmann, Sainte-Marie, Lallemand se sont beaucoup occupés de cette question, qui n'est véritablement entrée dans une voie scientifique, que par l'application du microscope à la recherche des spermatozoïdes. On comprend combien devait être grand l'embarras des observateurs, pour décider si oui ou non, il y avait du sperme dans l'urine, alors que le microscope n'avait pas encore été appliqué à l'étude des sédiments urinaires. Les caractères cliniques de l'urine spermatique étaient 
bien vagues et pouvaient être facilement confondus avec ceux d'urines complètement différentes. Quelquefois le diagnostic est rendu plus facile, lorsque les malades, par exemple, perdent du sperme en allant à la selle, au lit, à la moindre érection, en faisant de l'équitation, en marchant, etc. Certaines personnes sont sujettes à avoir de la spermatorrhée pour ainsi dire normale; il suffit qu'elles restent quatre ou cinq semaines, sans avoir de rapprochement sexuel ou de pollution spontanée ou provoquée, pour voir apparaître du sperme, soit pendant la défécation, soit au commencement, soit à la fin de la miction. Il est d'autres cas, dans lesquels les malades ont des pollutions nocturnes très fréquentes, qui sont pour eux la cause d'une débilité très grande et d'accidents variés; chez quelques personnes, ces pertes séminales peuvent se produire sans entraîner aucune espèce de sensation, ces malades ne s'en aperçoivent même pas. Il faut une circonstance particulière, dit Donné, une sorte de hasard, pour découvrir ce qui se passe; ce n'est que lorsque le malade se réveille après l'écoulement du sperme, qu'il se sent humide et qu'il reconnaît ce qui vient de lui arriver. Lorsque le médecin soupçonne qu'il peut se produire des pertes séminales, il est nécessaire qu'il examine, avec le plus grand soin, les taches que l'on peut rencontrer sur le linge du malade.

Dans le cas où la spermatorrhée n'est que la conséquence d'une trop grande réplétion des vésicules séminales, on trouve dans l'urine de ces filaments décrits dans les sédiments urinaires, et qui sont formés aux dépens du mucus uréthral. Ces filaments contiennent ordinairement des spermatozoïdes qui sont, pour ainsi dire, englobés dans le mucus, au fur et à mesure qu'ils sortent des vésicules séminales. D'autres fois, l'expulsion du sperme ne se fait qu'à la fin de la miction, et les dernières gouttes d'urine sont comme troublées ou grisâtres. Sous l'influence de ces pertes séminales, qui ne sont que l'effet de la continence et dont la gravité est pour ainsi dire nulle, on voit des individus devenir hypocondriaques, s'affecter outre mesure et tomber réellement malades. Il appartient au médecin de bien établir, s'il se trouve en présence d'une spermatorrhée pour ainsi dire normale, ou bien, au contraire, si c'est une 
spermatorhée proprement dite, le mode de traitement variant considérablement d'un cas à l'autre.

Avant d'entrer dans l'étude de la spermatorrhée vraie, il est nécessaire d'établir ce fait, c'est que l'urine normale en dehors des conditions que nous venons d'énoncer, ou, lorsqu'elle est émise peu de temps après une émission de sperme, spontanée ou autre, ne contient jamais de spermatozoïdes.

Les caractères cliniques d'une urine renfermant des spelmatozoïdes, sont assez confus; lorsque la quantité de sperme est considérable, il y a un dépôt blanchâtre, plus ou moins nuageux, à la partie inférieure du vase; mais si, au contraire, la proportion des spermatozoïdes est peu considérable, l'urine peut parfaitement ne présenter à l'œil nu, aucun caractère appréciable. C'est donc au microscope qu'il faut recourir, si l'on veut être fixé d'une façon certaine, sur la présence des spermatozoïdes.

La pesanteur spécifique des zoospermes étant plus grande que celle de.l'urine, ils tombent naturellement au fond des vases par le repos, dit Donné; il suffira donc, d'après le conseil de cet observateur, d'abandonner l'urine au repos dans des éprouveltes longues et étroites; quand le dépôt est entièrement formé, on le sépare soit à l'aide d'une pipette, soit par décantation et l'on cherche, à l'aide du microscope, s'il contient des spermatozoïdes. Donné dit qu'une seule goutte de sperme, prise au bout d'une baguetle de verre et mise dans plus d'un demi-litre d'urine, permet de retrouver au microscope des quantités considérables d'auimalcules. Beaucoup d'autres procédés ont été donnés, nous en avons indiqué quelques-uns, mais dans la plupart des cas, le procédé de Donné est sulfisant. Cet auteur a fait une remarque intéressante, que nous devonssignaler, parce qu'elle est, pour ainsi dire, le corollaire du procédé qu'il a décrit. Lorsque les urines contiennent une grande quantité de produits susceptibles de cristalliser et de se déposer par le refroidissement et le repos, il arrive que les zoospermes se recouvrent d'une multitude de petits cristaux; ils se perdent et se confondent au milieu du dépôt, et l'on a quelquefois de la peine à reconnaître leurs formes altérées en apparence; mais, pour leur restituer leur aspect 
normal, il suffit de traiter le dépôt par une quantité d'eau capable de dissoudre les sels, et, si l'on n'y parvient pas par ce moyen, de faire chauffer, pour débarrasser les animalcules des cristaux attachés à leur corps; on les voit alors reparaître in tacts et sans aucune altération de leurs formes (Donné). Grâce à la résistance qu'ils offrent à l'action des différents milieux dans lesquels ils se trouvent plongés, les spermatozoïdes conservent leur forme, même après ces traitements variés; on peut retrouver des spermatozoïdes dans l'urine, plusieurs jours après l'émission. Nous devons également à Donné, une autre observation intéressante, elle a trait à la présence très fréquente de cristaux d'oxalate de chaux, dans les urines contenant du sperme; cette remarque n'a pas de caractère absolu. Nous savons en effet qu'il est assez fréquent de rencontrer dans l'urine des cristaux d'oxalate de chaux, sans que pour cela il y ait des spermatozoïdes; néanmoins la coïncidence de la présence simultanée de l'oxalate de chaux et des spermatozoïdes, a été fréquemment vérifiée. Outre les spermatozoïdes, on peut encore rencontrer soit des leucocytes, soit des cellules épithéliales, soit encore des granules d'urate de soude, des cristaux d'acide urique, ou de phosphate ammoniaco-magnésien (Ch. Robin).

M. Robin a étudié les caractères des différentes humeurs, qui pourraient être prises pour du sperme, à la suite d'une observation superficielle. Il est de la plus haute importance d'être parfaitement fixé sur les caractères différentiels de ces humeurs, pour ne pas diagnostiquer d'abord de spermatorrhée, où elle n'existe pas, et ensuite, pour pouvoir rassurer les malades, en leur faisant, pour ainsi dire, toucher du doigt, les propriétés du liquide qu'ils émettent. Le liquide bulbo-uréthral est celui qui vient mouiller l'orifice du canal de l'urèthre, à la suite d'érection violente et prolongée; il est visqueux, collant, hyalin et transparent. Ce liquide n'a pas l'odeur du sperme; examiné au microscope, il ne présente pas d'éléments anatomiques, sauf quelques cellules épithéliales pavimenteuses (Ch. Robin). A la suite de blennorrhagies, les glandes bulbo-uréthrales peuvent, dans quelques circonstances, émettre une certaine quantité de liquide. Cette émission s'accompagne, d'après 
M. Robin, d'une sensalion plus ou moins vive de piqûre; dans ce cas particulier, le liquide contient une grande quantité de globules blancs.

On peut encore prendre pour du sperme, dit M. Robin, le liquide fourni par les glandes de la muqueuse uréthrale ou glandes de Littre, lorsque celles-ci ont une suractivité fonctionnelle, à la suite d'une blennorrhagie, d'excès de coït ou d'abus de boissons alcooliques. Get écoulement ne serait pas contagieux.

Ge liquide se distingue du sperme, d'abord parce qu'il ne renferme pas de spermatozoïdes, et ensuite, parce qu'il n'est pas tenace ni filant entre les doigts, ni visqueux, comme le liquide des glandes bulbo-uréthrales. Il renferme, en outre, une assez grande quantité de cellules épithéliales, en général petites, qui viennent du canal'de l'urèthre, ainsi qu'un assez grand nombre de leucocytes.

Nous avons.vu qu'il y avait des spermatozoïdes plus petits que les autres, mais ayant la même forme et jouissant même d'une vitalité plus énergique, mais il n'y a pas de spermatozoïdes mal développés ou incomplets, comme l'ont cru différents auteurs, Lallemand en particulier. La queue ou cil du spermatozoïde, peut être brisée accidentellement, et cela s'observe surtout, quand on examine des taches sur le linge, mais même dans ce cas, on aperçoit la tête et le prolongement caudal. Par conséquent, il ne faudrait pas, dans une expertise médico-légale, se prononcer sur de simples apparences; les spermatozoïdes existent ou n'existent pas, et, s'ils existent, ils ont des formes assez nettes pour qu'on puisse les reconnaître. Dans le doute, l'abstention est une règle absolue. Le micrographe, comme tout autre expert, n'a à tenir aucun compte des preuves dites morales. C'est pourquoi il faut se familiariser de longue main, avec la recherche des spermatozoïdes, dans les liquides, dans les taches'; ce n'est qu'au prix d'une séric d'expériences, que l'on pourra devenir assez sûr de soi, pour se prononcer avec quelque certitude sur la présence des spermatozoïdes. L'écueil le plus redoutable consiste à prendre pour un spermatozoïde, plus ou moins incomplet, un de ces milliers de corps étrangers, que l'on trouve dans les liquides, 
CHAPITRE XIII. - DU SPERME.

dans les taches. Le meilleur prócédé ne met pas, comme l'expérience longuement acquise, à l'abri d'une erreur de ce genre.

$\S$ ViII. - examen des taches de Sperme.

Nous savons maintenant par les remarquables expériences de Donné, combien est grande la résistance des spermatozoïdes, à l'action des différents réactifs que l'on fait agir sur eux. C'est grâce à cette résistance que l'on peut retrouver les spermatozoïdes sur le linge taché de sperme, ainsi que sur les porte-objets qui ont servi à les examiner, et où ils se sont desséchés. Les contours de la tête n'offrent plus la même netteté; mais la queue, entre les deux ménisques de matière accumulée contre elle, par l'évaporation, dévie fortement la lumière, et il devient facile ainsi, d'apprécier la véritable longueur mesurée par une ligne obscure, reconnaissable à l'observation la plus superficielle (Pouchet). L'écueil le plus difficile à éviter, surtout pour les personnes encore inexpérimentées, c'est de ne pas prendre pour un spermatozoïde, dont la tête aurait été séparée de la queue, une de ces nombreuses granulations que l'on peut rencontrer dans le linge; en un mot, le difficile n'est pas de reconnaître un spermatozoïde, quand il y en a un grand nombre, c'est d'en voir là où il n’y en a pas. Les meilleurs procédés, et ceux qui ont été donnés sont nombreux, ne mettront jamais complètement à l'abri de cette erreur, une personne qui ne serait pas très familiarisée avec ce genre de recherches. Les taches de sperme ne présentent pas à l'œil nu des caractères si précis, qu'il ne soit pas possible de les confondre avec des taches d'une origine différente. La recherche des spermatozoïdes dans les taches, est bascée sur la propriété qu'elles présentent de pouvoir se réhumecter, se gonfler et reprendre, pour ainsi dire, leur aspect primitif; les taches spermatiques peuvent conserver cette propriété pendant plusieurs années. Il faut néanmoins être prévenu, que la consistance mucilagineuse du sperme s'est perdue par la dessiccation, et qu'après révivification apparente du sperme, celui-ci n’est plus mucilagineux. Le procédé classique pour la recherche du sperme est le suivant: on trempe dans 
l'eau, un des fragments de linge sur lequel se trouve la tache; le liquide s'élève lentement dans le tissu et vient imbiber la tache qui se gonfle. On recueille cette matière avec soin et on l'examine au microscope (Ch. Robin).

Ce procédé a subi de nombreuses modifications de la part des auteur's et des médecins légistes. Ratier en mars 1837, ayant pris des linges tachés de sperme, les fit macérer dans des verres de montre; ayant soumis le liquide à l'examen microscopique, il indiqua le premier des caractères propres à faire reconnaître les taches de sperme; il élait parvenu à déterminer la présence des spermatozoïdes. C'est le docteur Bayard qui, sans connaître les travaux de Ratier, a vulgarisé les méthodes propres à exécuter cette recherche; cependant, même de son temps, ce n'était pas encore chose facile à répéter, puisque Orfila et Donné s'y étaient vainement essayés.

Les taches de sperme présentent des caractères objectifs différents, selon les tissus qui les supportent. Sur un linge blanc elles sont généralement grisâtres, quelquefois presque blanches et d'un jaune citron (Gosse); sur'les tissus colorés elles paraissent blanchâtres; elles sont même un peu transparentes, de telle sorte, que l'on est forcé quelquefois, pour les reconnaître, de mettre la tache entre l'œil et la lumière. Sur des étoffes de laine, elles présentent un reflet un peu brillant. Si on froisse le linge entre les doigts, on éprouve la sensation de raideur, analogue à celle que produirait une tache produite par de l'amidon ou par du sirop. M. le docteur Gosse dit dans son remarquable travail sur les taches, que bien que les taches de sperme ne soient pas odorantes quand elles sont sèches, elles reprennent facilement leur odeur caractéristique quand elles sont imbibées d'eau, et même, que si l'on emploie de l'eau chaude, ou de la vapeur d'eau, l'odeur se rapproche assez de celle de la lessive. Nous pensons que les taches de sperme perdent facilement, au bout d'un certain temps, l'odeur spécifique du liquide séminal : c'est là du reste un caractère d'un ordre secondaire. Le contour irrégulier, en carte de géographie, des taches de sperme est connu de tout le monde. Quand le tissu est épais, le sperme peut ne pas pénétrer jusqu’à la face opposée du tissu. D’une façon générale, les taches de sperme 
varient d'aspect, suivant que la liqueur spermatique a été émise après une longue continence, ou au contraire, après des éjaculations répétées, par un homme jeune ou par un vieillard.

Les médecins légistes ont indiqué en quels endroits l'on rencontrait le plus fréquemment les taches de sperme, mais ces règles n'ont absolument rien de précis ; on comprend, sans que nous y insistions, que les circonstances dans lesquelles ces taches se produisent, peuvent varier à l'infini. Néanmoins, d'après M. Devergie (Médecine légale, t. I, p. 360), dans les caśs de viol, on trouve les taches plutôt sur le devant, que sur le derrière de la chemise de la femme. Tardieu,'dans son ouvrage sur les attentats, admet que leur siège est excessivement variable. Sur le linge d'un homme les taches occupent ordinairement la partie antérieure; celles que l'on trouverait sur le pantalon peuvent exister plus particulièrement à l'intérieur, mais quelquefois, à l'extérieur, à la hauteur de la partie supérieure des cuisses (Gosse, loc. cit., p. 15 et suiv.). Dans les rapports juridiques, on devra aussi soigneusement relater la position et la dispersion des taches sur les draps du lit. La disposition de ces taches peut, dans certains cas, fournir des données, relitivement aux circonstances du crime, à la résistance de la victime et au nombre des tentatives (1).

La composition de ces taches peut être complexe; elles peuvent contenir du sang, des corps gras et d'autres substances; sur la peau humaine les taches de sperme ont l'aspect d'écailles de poisson ou plutôt de collodion desséché (Gosse).

Nous ne parlerons pas du procédé de Bayard, qui était très compliqué et dont l'usage a été abandonné. Le procédé de Koblanck, recommandé par Casper, consistait à faire une sorte de macération de la tache dans de l'eau froide, et à examiner cette eau au microscope; au bout d'un certain temps, on devait y trouver des spermatozoïdes. Le procédé de Carl Schmidt (Schmidt, p. 47) est le suivant: on recherche de quel côté du tissu se toruve la tache de sperme; ce côté trouvé, on plie le morceau de tissu en forme de cône el on met la face tachée

(1) Clı. Robin dans Manue! Briand et Chaulé, p. 72:2, cité par Gosse. 
dans un verre de montre, à moitié rempli d'eau, de manière à la tenir suspendue au-dessous du niveau du liquide. En agissant ainsi, la tache seule est mouillée ; le contact est prolongé pendant trois ou quatre heures et la tache est ramollie. On chauffe légèrement l'eau du verre de montre, après y avoir ajouté quelques gouttes de solution ammoniacale, on remue le linge et on le presse de haut en bas entre l'index et le pouce. La tache a disparu du linge, l'eau est devenue trouble et un peu muqueuse. I'on examine ce liquide et on y trouve des spermatozoïdes qui sont quelquefois brisés. Ces deux procédés, dit le docteur Gosse, ont l'inconvénient soit de séparer les parties de la tache qui vont adhérer à la soucoupe, soit d'avoir une dissolution trop étendue, et alors on n'en apporte qu'une faible partie sous le champ du microscope (loc. cit., p. 20). Nous avons donné plus haut le procédé de M. Robin; le temps pendant lequel on laisse la tache en contact avec l'eau est variable ; il peut aller, suivant l'ancieņneté de la tache, de vingt minutes à deux heures; on se sert généralement de la pointe d'un scalpel pour enlever le sperme adhérent au tissu. Il est absolument nécessaire d'agir dans toutes les manipulations avec la plus grande délicatesse. M. Robin conseille de se servir d'eau distillée, ou d'eau faiblement alcaline, pour pratiquer cette recherche : d'après cet observateur, il serait bon d'ajouter quelques gouttes d'acide acétique faible à la préparation, pour dissoudre le mucus et rendre les spermatozoïdes plus nettement perceptibles.

Nous savons que les spermatozoïdes peuvent être entiers ou brisés. S'íls sont brisés, ils peuvent l'être soit près de la tête, soit au milieu de la queue; aussi peut-on voir des fragments de queue disséminés dans la préparation. On peut constater également la présence de granulations graisseuses, à centre jaunatre, de globules blancs, de sympexions, de cristaux de phosphates.

Quelquefois on trouve dans le sperme des éléments étrangers à ce produit. C'est ainsi que la présence de cellules épilhéliales pavimenteuses est assez fréquente; plus rarement on y rencontre de très petites cellules prismatiques, provenant, comme les premières, du canal de l'urèthre. 
Nous ne parlerons que pour mémoire des filaments de tissu, soie, laine, coton, qui ont leur structure et leur coloration particulière.

Si le linge a été sali ou exposé à la poussière, on trouve de petits grains irréguliers, très divers, de volume, de forme, de coloration plus ou moins brillants, à contours épais et noirâtres. Ils présentent les caractères chimiques propres soit des poussières inorganiques (par l'acide acétique, dégagement de bulles de gaz; dissolution par l'acide chlorhydrique avec dégagement de gaz): on peut aussi rencontrer dans ces taches, de la poussière de rouille, ayant une coloralion caractéristique. Ces poussières sont attaquées à la longue par l'acide acétique; l'acide chlorhydrique les dissout facilement (Dr Gosse).

M. Robin a signalé également la présence de grains d'amidon altér'és dans leur forme, gonflés, ou éclatés. Ces grains d'amidon proviennent de l'empesage du tissu.

Le docteur Gosse est'd'avis que, si après un examen attentif, on ne trouvait pas de spermatozoïdes, il ne faudrait pas en conclure d'une manière absolue que ce ne sont pas des taches de sperme que l'on a examinées. Cet auteur s'appuie sur l'opinion de Casper (Ueber Nothzucht., p. ๖0), que le sperme de certains individus, particulièrement des vieillards (1), ne renfermerait pas de spermatozoïdes, que ceux-ci pouvaient varier de quantité et même disparaître passagèrement, sous l'influence de diverses causes, par exemple d'une longue maladie ou d'excès vénériens. Casper conclut en ces termes: “Nos observations suffisent pour la pratique, car elles prouvent que les taches proviennent certainement du sperme, lorsque le microscope montre qu'elles contiennent des spermatozoaires; mais que l'absence de spermatozoaires ne peut pas prouver que ces taches ne proviennent pas du sperme. D'après ce qui précède, le médecin légiste pourra, dans le premier cas, poser une conclusion certaine; dans le second cas, juger avec plus ou moins de vraisemblance les circonstances du cas particulier. "Sauf les cas que nous avons examinés, cas dans lesquels le sperme

(1) Le sperme des vicillards contient généralement des spermatozoïdes. 
ne renferme pas de spermatozoïdes, on peut dire que les spermatozoïdes ne disparaissent pas avec la facilité dont parle Casper, même à la suite de maladie grave; il se peut à la rigueur, qu'ils diminuent de nombre, mais il en restera toujour's assez, pour qu'avec une recherche attentive, on puisse mettre leur existence hors de toute contestation. Bien que le sperme stérile contienne quelques éléments anatomiques propres à le faire reconnaître, nous pensons avec M. Robin, que pour conclure à l'existence du sperme dans une tache, il faut absolument trouver des spermatozoïdes.

Le docteurLonguet a communiqué dernièrement à la Société de médecine légale, un procédé pour la recherche des spermatozoïdes; ce procédé, sur lequel l'expérience n'a pas encore exercé son contrôle, aurait donné de bons résultats entre les mains de l'auteur. Il y a, dit M. Longuet, une manipulation préalable qui s'impose à l'expert, quelle que soit d'ailleurs la méthode qu'il compte suivre ensuite, pour isoler les éléments figurés; elle consiste à mettre en contact avec de l'eau distillée; une partie de l'étoffe tachée, de façon à gonfler par imbibition le tissu lui-même et la matière dont il est imprégné. Cela fait, on le porte sur une plaque de verre propre et sèche, et, à l'aide d'aiguilles on l'effile, on le dissocie avec ménagement, pour ne pas briser les spermatozoïdes, s'ils existent. Les fils séparés sont eux-mêmes étalés, fibrille par fibrille, à ce point que tous les éléments dont ils sont formés, puissent être isolés, l'un après l'autre, dans le champ du microscope et soumis à un examen minutieux. Pour les rendre plus visibles et en mieux délimiter les contours, on a l'habitude de les teinter avec une solution faible d'iode; quelque précaution que l'on prenne, on s'expose à créer des spermatozoïdes artificiels, que l'on pourrait confondre avec des spermatozoïdes vrais. Certaines fibrilles végétales, et en particulier celles du chanvie, contiennent dans leur intérieur des granulations ovoïdes, légèrement aplaties suivant leur plus grand diamètre, par pression réciproque, très réfringentes, absolument semblables en un mot, à ce qu'on appelle la tête des spermatozoïdes, dont elles possèdent souvent les dimensions, l'aspect el même la forme; ces granulations deviennent libres, dès que les cellules sont 
brisées et se dispersent dans le liquide au milieu duquel nagent les débris de l'étoffe. M. Longuet a cherché une matière colorante qui, par son action élective, permît de distinguer les spermatozoaires des débris végétaux et, après de nombreux essais, il s'est arrêté au carmin ammoniacal, tel qu'on l'emploie en histologie.

Les spermatozoïdes se comportent diversement avec le carmin, suivant qu'ịls sont frais ou desséchés depuis longtemps: très peu modifiés, quand ils sont récents, ils fixent la couleur avec intensité, quand ils sont anciens, mais particulièrement dans la partie renflée, la queue restant incolore. Cette propriété singulière suffit, d'après M. Longuet, à les faire reconnaître immédiatement au milieu des éléments étrangers qui affectent des formes analogues. Voici comment l'auteur conseille de procéder : $\mathbf{1}^{\circ}$ prendre un petit carré de l'étoffe qu'on suppose être tachée de sperme, le plus près possible du centre de la tache; $2^{\circ}$ plonger ce petit carré d'étoffe dans une petite quantité d'eau distillée colorée par quelques gouttes, ว̀ à 6 pour š grammes d'eau, d'une solution ammoniacale de carmin; $3^{\circ}$ laisser macérer pendant trente-six à quarantehuit heures, et même plus, car il n'en résulte aucun inconvénient; $4^{\circ}$ dissocier l'étoffe avec de grands ménagements, en l'effilant brin à brin; $\check{\partial}^{\circ}$ dissocier chacun de ces brins un à un et séparément $; 6^{\circ}$ examiner séparément aussi au microscope, avec un grossissement de כ̌00 diamètres, chaque brindilie dissociée dans une goutte de glycérine ordinaire. Dans une préparation faite selon les règles, on verra, autour des fibrilles végétales non colorées et parfaitement réfringentes, des grappes de spermatozoïdes, la plupart complètes, dont la tête sera colorée en rouge vif, tandis que la queue ne sera pas teintée. L'avanlage du procédé de $\mathrm{M}$. le $\mathrm{D}^{\mathrm{r}}$ Longuet consisterait surlout en ceci, qu'il donnerait des résultats d'autant plus nets, que la tache serait plus ancienne, c'est-à-dire, dans les circonstances les plus mauvaises; car rien n'est facile comme d'isoler et de reconnaître les spermatozoïdes, quand la tache est récente.

Le mucus vaginal laisse parfois sur le linge des laches qui par leur' aspect extérieur rappellent assez fidèlement celles for- 
mées de sperme. Nous avons eu l'occasion d'examiner de telles taches, qui étaient considérées comme du spermē; après les avoir traitées par le procédé de M. Robin, nous avons constaté l'absence de spermatozoïdes, et la présence de larges cellules qui nous ont présenté tous les caractères habituels de l'épithélium vaginal.

§ IX. - DU SPERME DANS DIFFÉRENTS PRODIUTS DE L'ÉCONOMIE : MATIL̀RES FÉCALES, MUCUS.

Il est souvent nécessaire de rechercher la présence de spermatozoïdes dans les matières fécales, lorsque des actes de pédérasíie ont précédé un crime, ou en ont été le motif. Il est des cas de médecine légale, dans lesquels une telle recherche a produit des résultats importants. M. Ch. Robin est d'avis que l'on doit procéder à cet examen chaque fois qu'il y a soupçon de pédérastie.

Lor'sque les matières fécales contenues dans le rectum sont liquides, cet examen n'offre pas de difficulté, en ce sens qu'ilsuffit d'examiner directement ce liquide, pour y faire la recher'che des spermatozoïdes. Si au contraire, les matières sont demisolides, nous conseillons de les délayer dans l'eau et de laisser déposer, dans un vase conique; les spermatozoïdes, en raison de leur densité, gagnent les parties inférieures du vase. Si l'on opère sur le rectum d'un cadavre, la recherche est bien plus facile, en ce sens que l'on peut examiner le rectum et son contenu, en variant, autant qu'il est besoin, les procédés de recherche.

Lorsque nous avons parlé des taches de sperme, nous arons indiqué que ces taches pouvaient être complexes; nous devons à l'obligeance de M. le docteur Brouardel, professeur de médecine légale à la Faculté, et maître des conférences à la Morgue, un exemple de la difficulté qu'il y a parfois à faire une détermination exacte, pouvant être, comme on le verra, d'une importance capitale. M. Brouardel, grâce à son habileté opératoire et à ses connaissances spéciales, est parvenu à déterminer la composition de taches qui, tout d'abord, avaient été considérées, après un premier examen praliqué par un autre expert, 
comme formées de sperme et de pus blennorrhagique. Partant de cette idée, le juge d'instruction avait commis $\mathbf{M}$. le docteur Brouardel à l'effet de constater : $1^{\circ}$ si les taches spermatiques mélangées de mucus blennorrhagique, constatées sur la serviette, peuvent provenir du même individu que les taches spermatiques, simplement spermatiques, remarquées sur les draps.

Pour procéder à ces recherches, M. Brouardel a découpé, à l'aide de ciseaux propres, une petile languette de tissu correspondant à chaque tache. Chacune de ces petites languettes a été mise dans un verre de montre, en contact avec quelques gouttes d'eau fraîchement distillée. Après les quelques heures suffisantes pour l'imbibition du tissu, le savant expert a procédé avec beaucoup de soin, à l'aide de deux stylets de verre, à l'effilochage de chaque fil. Cette opération terminće et chaque fil légèrement comprimé avec le bord arrondi d'un petit stylet de verre, on a recouvert la goutte de liquide obtenue avec une lamelle propre et on l'a portée sous le champ du microscope. M. Brouardel s'est d'abord servi d'un grossissement de 300 diamètres, puis d'un grossissement de 600. Voici maintenant quels étaient les caractères extérieurs des taches : $1^{\circ}$ Serviette. M. Brouardel a constaté l'existence sur cette serviette de larges et nombreuses taches de forme circulaire, diversement colorées et d'apparence empesée : les unes légèrement grisâtres; les autres comme superposées aux premières, de couleur jaunâtre el présentant par places de petits noyaux desséchés, plus foncés en couleur que le reste de la tache. Sur quelques-uns de ces noyaux, on voyait de petits corpuscules noirâtres qui s'y trouvaient comme incrustés.

Sur l'autre face de la servieité, M. Brouardel a trouvé aussi une ou deux taches analogues, comme aspect, aux précédentes; il a vu aussi une petite tache d'environ un centimetre et demi de longueur, sur un demi-centimètre de largeur, ayant l'aspect d'une traînée de mucosité grisâtre, desséchée et piquetée de petits points noirs.

Sur le bord opposé de la serviette, il a remarqué une tache rougeâtre de forme ovale.

Après avoir examiné successivement au microscope les gouttes de liquide provenant de l'imbibition de huit échantillons de ces diverses taches, M. Brouardel a nettement vu dans les liquides examinés :

$1^{\circ}$ Des débris de spermatozoïdes, têtes et queues séparées;

$2^{\circ}$ Des spermatozoïdes complets;

$3^{\circ}$ Un grand nombre de petits noyaux sphériques de mucus;

$4^{\circ}$ Des cellules d'épithélium pavimenteux simple;

$5^{\circ}$ Des cellules d'épithélium cylindro-conique, avec un noyau el des cils vibratiles ;

$6^{\circ}$ Un assez graud nombre de leucocyles accompagnés de petites granulations graisseuses; 
70 Des corpuscules noirâtres incrustés dans quelques-unes des taches, présentant les caractères microscopiques, comme forme et comme couleur, de fins grains de tabac à priser (plusieurs contreépreuves faites avec des grains de tabac à priser, mélangés à du mucus, ne laissent aucun doute sur leur identité).

Examen du premier drap. - Sur ce drap M. Brouardel a constaté la présence d'un certain nombre de taches grisâtres d'apparence empesée, irrégulièrement disséminées et deux ou trois taches jaunâtres, à surface écailleuse, ayant l'aspect de mucosité desséchée ct piquetée de points noirs.

M. Brouardel a soumis à l'examen microscopique les liquides pro-

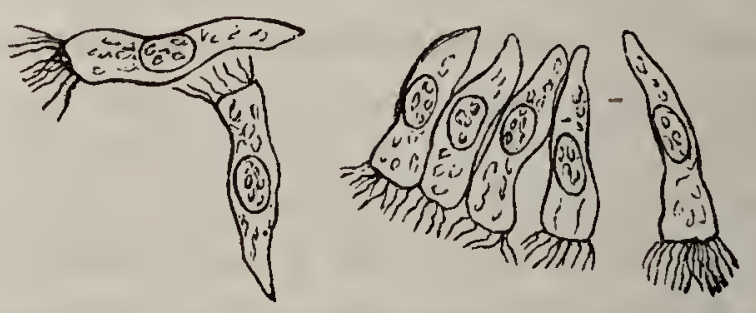

Fig. 356. - Cellules vibratiles des très fines bronches. Gross. 350 diamètres. (Kölliker.)

venant de l'imbibition de neuf échantillons de ces diverses taches; et il a nettement vu dans le plus grand nombre :

-10 Des débris de spermatozoïdes, têtes et queues séparées ;

$2^{\circ}$ Des spermatozoïdes complets;

$3^{\circ}$ Quelques leucocytes accompagnés de granulations et de cellules d'épithélium simple;

Dans les liquides provenant de l'imbibition des taches colorées en jaune, à surface écailleuse et piquetée de points noirs, l'expert a seulement vu :

$1^{\circ}$ Des cellules d'épithélium pavimenteux;

$2^{\circ}$ Quelques cellules d'épithélium à cils vibratiles;

$3^{\circ}$ Un grand nombre de leucocytes;

$4^{\circ}$ Des grains noirâtres analogues comme forme et comme couleur à de fins grains de tabac à priser.

Examen du deuxième drap. - M. Brouardel a vu sur ce drap un certain nombre de taches grisâtres d'apparence empesée, ayant quelques-unes la forme de petites gouttelettes groupées en traînée.

Ayant soumis à l'examen microscopique, les liquides provenant de l'imbibition de dix échantillons de ces diverses taches, il y a nettement vu :

10 Des débris de spermatozoïdes, têtes et queues séparées;

$2^{\circ}$ Des spermatozoïdes complets ;

$3^{\circ}$ Quelques rares cellules d'épithélium simple;

$4^{\circ}$ Quelques petites granulations et quelques rares leucocytes.

Conclusions. $-1^{\circ}$ La serviette et les draps présentent tous les trois des taches de sperme; 
$2^{\circ}$ Les taches du deuxième drap sont constituées par du sperme seul;

$3^{\circ}$ Le premier drap (1) présente des taches de deux ordres nettement séparés : $1^{\circ}$ des taches de sperme; $2^{\circ}$ des taches formées par des mucosités de crachats. Ces dernières contiennent des cellules d'épithélium cylindro-conique à noyaux, à cils vibratiles, qui ne peuvent provenir que de l'arrière-gorge et de l'arrière-cavité des fosses nasales, bronches. La présence de ces éléments anatomiques et des grains de tabac, indique que telle est bien leur origine;

$4^{\circ}$ Sur la serviette, on trouve des taches constituées par différents éléments, mais cette fois ils sont intimement mélangés; ce sont des
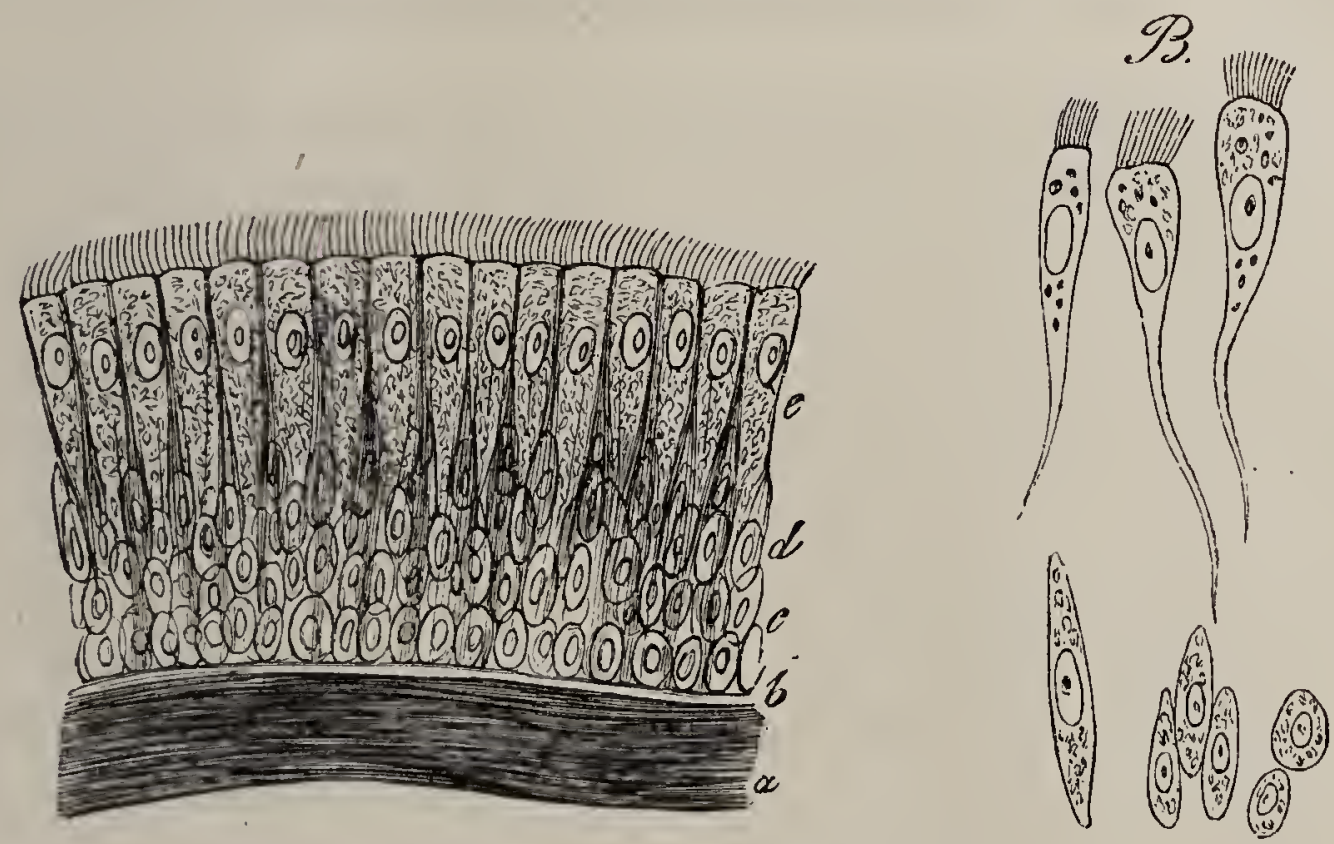

Fig. 357. - Épithélium vibratile de la trachée humaine. Gross. de 350 diamètres. A. Epithélium in situ. - $a$. Portion interne des fibres élastiques longitudinales. $-b$. Couche superfieielle homogène de la muqueuse. $-c$. Collules les plus profondes, qui sont arrondies. $-d$. Cellules moyennes, un peu allongées. $-e$. Cellules extérieures garnies de cils vibratiles. - B. Cellules isolées des diverses couches.

spermatozoïdes entiers et brisés, des cellules d'épithélium à cils vibratiles (provenant de l'arrière-gorge, du nez ou des bronches) et des grains de tabac: ces taches ont été faites par expuition simultanée de tous ces éléments réunis au préalable dans la bouche.

$5^{\circ}$ Les caractères microscopiques de ces taches, leur forme à l'œil nu, ne permettent pas de croire qu'aucune d'elles résulte d'une souillure par pus blennorrhagique.

Ces recherches ont été faites à l'occasion de l'assassinat de la veuve Crem.... par deux jeunes gens.

On voit de quelle importance a étć pour la justice, la découverte dans les taches, de cellules d'épithélium à cils vibratiles, ainsi que

(1) Désigné dans lo rapport, ainsi que lo précédent et la serviette, par ic numéro des scellés. 
de grains de tabac. Ces éléments ont permis de reconstituer la scène qui a dù précéder le crime. Sans le microscope, et il faut le dire également, sans la précision que M. Brouardel a apportée dans ces délicates recherches, une partie de la vérité serait restée dans l'ombre.

$\S$ x. - végétaux ressemblant a deEs spermatozoïdes.

L.-S. Beale, dans son ouvrage $S u r$ l'urine, dit avoir rencontré une fois, dans ce liquide, un végétal qui présentait quelques points de ressemblance avec les spermatozoïdes. 


\section{CHAPITRE XIV}

\section{DES PRODUITS DES ORGANES GÉNITAUX DE LA FEMIME}

Nous allons compléter les renseignements donnés plus haut sur le mucus vaginal el sur le mucus utérin. Nous n'ajouterons que peu de chose à ce que nous avons dit sur la sécrétion du mucus utérin. Ce produit complexe fourni par le corps et par le col de l'utérus, subit à l'époque de la menstruation, certaines modifications qu'il peut être utile de connaittre. C'est ainsi qu'il prend une odeur caractéristique, que l'on retrouve, dit M. Robin, dans les organes génitaux des femelles de mammifères en rut; de plus, le mucus utérin change de coloration, il devient brun rougeâtre, communique cette couleur au mucus vaginal, et tache le linge. La durée de ce phénomène est ordinairement d'un ou deux jours. D'après M. Robin, le mucus pourrait redevenir complètement normal avant l'apparition du sang, laquelle se ferait d'une façon brusque. On couçoit qu'à ce moment, le mucus utéro-vaginal présente des caractères spéciaux : il contient un plus grand nombre de leucocytes, et quelques globules rouges, provenant des capillaires rompus ì la surface de la muqueuse utérine et de cellules épithéliales pavimenteuses, en assez grand nombre, venant de la surface du vagin et de la vulve (Robin).

D'après ce même auteur, lorsque l'hémorrhagie utérine s'est établie, le mucus utéro-vaginal sécrété en plus grande abondance, renferme un très grand nombre de globules rouges normaux, quelques leucocytes, des cellules d'épithélium pavimenteux, surtout du vagin, des cellules prismatiques, des épithéliums nucléaires de l'utérus. Quand les règles cessent, ces éléments diminuent graduellement et le mucus utéro-va- 
ginal repasse par les phases du début de la menstruation. Après l'écoulement sanguin, dit M. Robin, on voit quelquefois revenir un mucus blanchâtre un peu purulent. Comme nous l'avons vu à l'article Sang, le sang menstruel ne constitue pas une variété du fluide sanguin. Le caractère qui permettra de distinguer le sang menstruel, du sang ordinaire, c'est la présence des cellules épithéliales, surtout de cellules cylindriques à cils vibratiles, et des épithéliums nucléaires (Robin, Ann. d'hyg., t. V, p. 421).

Nous savons déjà qu'il peut être très difficile dans certains cas, de faire une distinction entre des taches produites par du sperme, et des taches abandonnées par du mucus vaginal, ou utéro-vaginal. Cette distinction, qu'il est souvent fort important d'établir, ne peut être faite qu'à l'aide du microscope, en employant l'un des procédés que nous avons décrits pour la préparation des taches de sperme. Il est bien rare, quand il y a leucorrhée, que cet écoulement soit uniquement vaginal. Voici quels sont les caractères qui ont été attribués à ce liquide : il contient un grand nombre de cellules pavimenteuses du vagin, mêlées à des globules de pus granuleux, des globules de graisse, des parasites (vibrions, leptothrix, trichomonas. Voy. plus loin). Quand il y a de la blennorrhagie le mucus

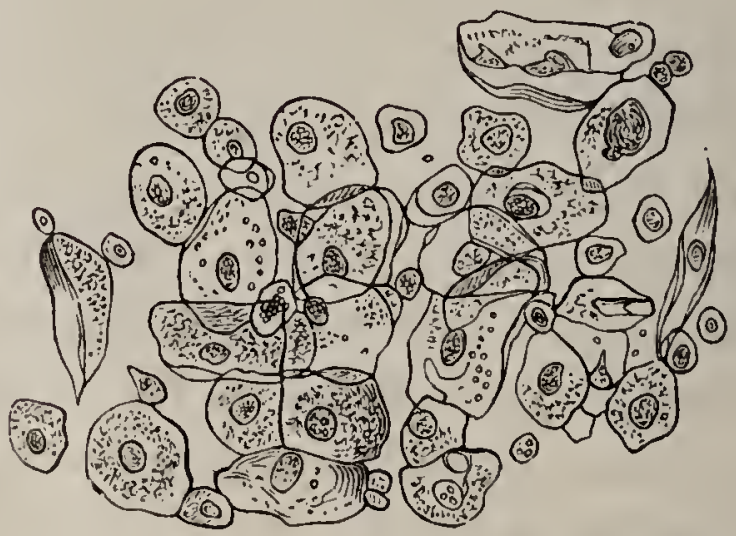

Fig. 358. - Épithélium vaginal à tous les degrés de développement dans la leucorrhée épithéliale ou vaginale. Gross. de 350 diamètres. (D’après Tyler-Smith.)

vaginal change d'aspect, il devient jaunâtre et puriforme et colore le linge en jaune verdâtre; son odeur est très fétide, surtout quand le col utérin participe à l'inflammation, tandis que l'odeur de la leucorrhée vaginale simple, est plutôt une odeur de fermentation (Courty, cité par Duval et Lereboul- 
CH. XIY. - PRODUITS DES ORGANES GENITAUX DE LA FEMME. 561

let). Nous donnons, d'après Tyler-Smith, une figure représentant l'épithélium vaginal à tous les degrés de développement dans la leucorrhée épithéliale et vaginale : cette figure est empruntée à l'ouvrage de MM. Duval et Lereboullet.

Lorsque l'utérus participe à l'inflammation générale, on rencontre dans le mucus utéro-vaginal, des éléments provenant de l'utérus, de sorte qu'il est difficile d'assigner à ces écoulements des caractères d'une précision parfaite. D'après Tyler-

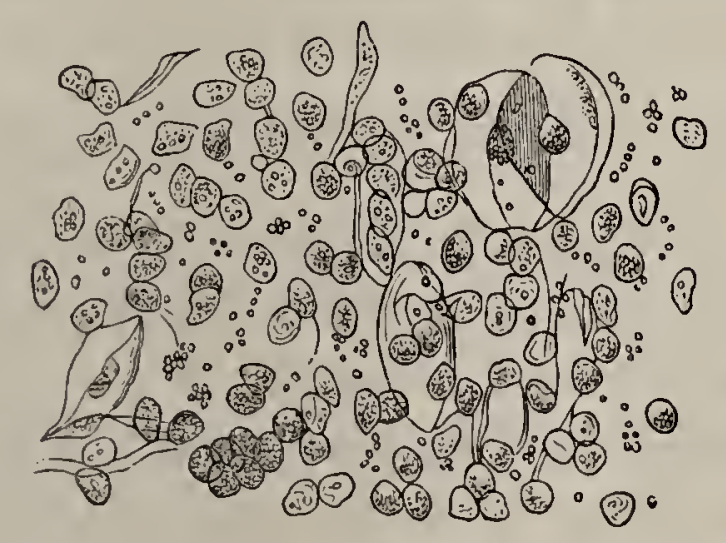

Fig. 339. - Quelques cellules épithéliales; leucocytes et gouttelettes huileuses dans la leucorrhée muqueuse et cervicale. Gross. de 220 diamètres. (D’après Tyler-Smith.)

Smith, il y aurait néanmoins deux leucorrhées, la leucorrhée vaginale ou épithéliale, la leucorrhée utérine ou muqueuse. "La leucorrhée vaginale ou épithéliale est constituée par de la lymphe, ou du plasma acide, de l'épithélium pavimenteux, des corpuscules de pus, des globules de sang, de la matière grasse. La leucorrhée cervico-utérine ou muqueuse, est constituée par du mucus alcalin, des corpuscules muqueux, de l'épithélium cylindrique altéré, des corpuscules de pus, des globules de sang et des particules grasses. Les premiers de ces éléments sont constants et caractéristiques, les autres (pus, sang, particules grasses) sont accidentels et dépendent souvent de l'inflammation des muqueuses ou des complications de la leucorrhée " (Courty, cité par MM. Duval et Lereboullet). Comme le font justement observer ces auteurs, après Stoltz, en pratique, cette distinction devient très difficile à cause du mélange des éléments provenant à la fois de l'utérus et du ragin $(1)$.

(1) Le Dr Hottenier a communiqué à la Société de Biologie un mémoire sut certaines modifications qu'éprouve la constitution histologique, du pus GUIDE DE MICROGRAPHIE. 
Il peut arriver que les taches, qu'un expert est chargé d'examiner, soient constituées à la fois pardu sperme et du mucus vaginal ou utéro-vaginal. Ces taches sont grisâtres, empesées el circonscrites, comme les taches de sperme (Robin). On y retrouve les spermatozoaires, par les procédés que nous avons donnés. D'après Gosse, l'acide nitrique donne un précipité dans l'eau, où ont macéré ces taches. Lorsque celles-ci sont uniquement formées par du mucus vaginal, elles sont ordinairement beaucoup plus grandes et plus nombreuses que des taches spermatiques. Il suffit d'avoir vu le lit même d'une toute petite fille, atteinte de leucorrhée, pour en être convaincu.

Quand il y a de la vaginite ou de la blennorrhagie, les taches sont verdâtres ou jaune verdâtre. Elles empèsent les tissus, qu'elles rendent durs au toucher; le plus souvent, elles ont une certaine épaisseur et ne traversent pas les tissus. D'après le docteur Gosse, elles ne deviennent pas jaunes près du feu. Mouillées pendant quelques heures dans l'eau, elles perdent leur couleur et prennent une odeur caractéristique tout à fait différente de celle du sperme. Leur dissolution aqueuse portée à l'ébullition, produit un coagulum albumineux blanc; à froid, l'acide nitrique y produit également un précipité. Le résidu insoluble, opaque, du mucus, présente des éléments de l'épi-

en général et du muco-pus utérin en particulier, suivant les diverses périodes de la maladie. Voici le résumé et les conclusions de ce travail.

$1^{\circ}$ Les hématies sont susceptibles de s'altérer pathologiquement et expérimentalement, leur hémoglobine se changeant d'abord en hématine, puis l'hématine disparaissant progressivement.

$2^{\circ}$ Il y a lieu de distinguer deux espèces d'éléments blancs dans le pus: l'un, corps discoïde, lenticulaire, irrégulier, crevassé, sans noyaux, évolution ultime de l'hématie, morte pendant le phénomène inflammatoire, et réduite à l'état de caillot élémentaire décoloré; l'autre, corps sphéroïde, à noyaux discoïdes, véritable cellule lymphatique du pus louable, état embryonnaire des éléments épithéliaux en voie de formation.

3o Relativement à l'ordre de succession de ces faits histologiques, la clinique et l'histologie pathologique démontrent parallèlement : que.le début de la suppuration, ou période inflammatoire, est caractérisé par la sortic, hors des vaisseaux sanguins, des éléments rouges, incolores et blancs du sang, plus ou moins altérés, et que la période terminale de la suppuration, coincidant avec une réparation organique, est caractérisée par une exsudation migratrice presque exclusivement lymphatique, qui permet de considérer la lymphe comme un liquide embryonnaire rénovateur des tissus. 
thélium, et des globules de pus. La teinture d'iode agit sur ces derniers, ainsi que sur les nucléoles et coagule le mucus intercellulaire en longs filaments (Gosse et Schmidt). L'ammoniaque rend le résidu visqueux.

Il est très important, en médecine légale, de pouvoir reconnaître les taches produites par les liquides qui s'échappent de l'utérus et du vagin, à la suite de l'accouchement normal ou provoqué, à terme ou avant terme.

\section{§ I. - DES LOCHIES.}

Lorsqu'une femme vient d'être délivrée, même en dehor's de toute hémorrbagie, elle continue à perdre du sang en quantité variable, par le fait de la rétraction de l'utérus. Ce sang présente des caractères particuliers, en ce sens, qu'il est très riche en globules blancs, dont on trouve de un à cing, pour cent globules rouges; quelquefois même, dit M. Robin. cette proportion est doublée.

A compter de la fin du premier jour, le liquide qui s'écoule par le vagin, ne contient plus qu'un tiers environ de globules rouges ou hématies, à côté des autres éléments en suspension dans le fluide séro-muqueux des lochies; à côté des hématies on voit un grand nombre de globules blancs, tantôt isolés, tantôt réunis, et enfin des cellules épithéliales pavimenteuses du vagin. Parmi ces cellules « il en est qui sont sphéroïdales ou à peine polyédriques par pression réciproque, réunies en groupes, rarement isolées, semblables à celles de la profondeur de l'épithélium du vagin, ou des lèvres du col de l'utérus. Ces dernières, bien plus étroites que les autres et plus épaisśes, renferment un noyau sphérique, parfois nucléolé, large de 7 à 8 millièmes de millimètre. Les autres ont un noyau ovoïde sans nucléole, et quelques-unes d'entre elles manquent de noyau. " (Robin.)

Quand les femmes n'ont pas de fièvre et qu'elles étaient antéricurement bien portantes, le liquide n'a pas d'odeur désagréable; outre les éléments signalés plus haut, le liquide qui s'écoule du vagin contient encore un certain nombre de granules graisseux.

A partir du deuxiène jour, on voit les globules blancs l'emporter en nombre sur les globules rouges; les lochies changent de couleur, de rouges qu'elles étaient, elles deviennent brunâtres, et au fur et à mesure qu'on s'éloigne de l'époque de l'accouchement, cette teinte pîlit de plus en plus, les lochies deviennent roussâtres, puis jaunìtres, puis grisâtres vers le cinquième jour, quand les choses se pas- 
sent absolument d'une façon normale. Cependant, il ne faut pas oublier que ces phénomènes ne sc succèdent pas toujours avec cette précision; il y a des femmes dont les lochies restent sanguinolentes. plus longtemps; il en est d'autres qui, à l'époque de la montée du lait, généralement vers le troisième jour, ont une petite perte sanguine, qui ne se renouvelle pas. A partir du cinquième jour, il n'y a généralement plus de globules rouges, ou bien, ils sont très rares; les globules blancs, au contraire, dominent; ils deviennent même très volumineux et se remplissent de granules de graisse, en un mot, ils deviennent granuleux (Robin).

Les ccllules pavimenteuses du vagin diminuent ćgalement de nombre : ces cellules, dit M. Robin, sont généralement réuries par imbrication en lamelles plus ou moins larges, auxquelles adherent souvent des leucocytes, et l'on trouve de plus, des cellules polyédriques ou presque sphéroïdales, semblables à celles des couches profondes de l'épithélium vaginal ou du col de l'utérus. Les granulations moléculaires grisâtres, en suspension dans le liquide, devenu plus visqueux, sont beaucoup plus abondantes qu'aux époques antérieures, et les granules graisseux ont diminué de quantité.

D'après le $\mathrm{D}^{\mathrm{r}}$ Gosse, les lochies forment des taches jaune grisâtre ou un peu rougeâtres. Les tissus qu'elles empèsent sont rudes au toucher. Elles sont souvent plus claires à la périphérie qu'au centre. Lorsqu'on les approche du feu, elles ne changent pas de couleur. Traitées à froid par l'eau distillée, elles se détachent et le linge alors est coloré et non empesé. Si on filtre leur dissolution aqueuse et qu'on la fasse évaporer, elle devient semblable à de la colle à bouche (Gosse) et se colore en jaune-brun; le liquide aqueux donne un précipité par la chaleur et par l'acide azotique. Ces taches examinées au microscope, laissent voir des globules rouges en plus ou moins. graud nombre, des cellules épithéliales à cils vibratiles, des cellules épithéliales cylindriques imbriquées, des glóbules de pus, des granulations graisseuses. Quand les lochies sont devenues presque incolores, c'est-à-dire laiteuses, les épithéliums et les cellules de pus deviennent plus rares, à mesure que l'on s'éloigne de l'époque de l'accouchement (Gosse).

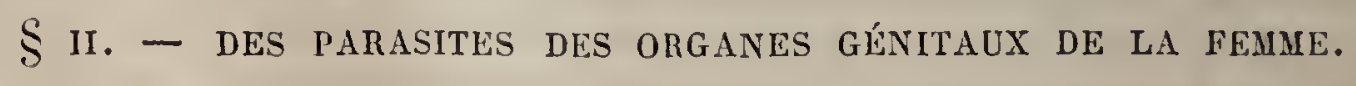

Parmi les parasites les uns sont visibles à l'œil nu, les autres au contraire sont microscopiques, le plus grand nombre d'entre 
CII. XIV. - PRODUITS DES ORGANES GÉNITAUX DE LA FEMME. ว̈6ว̆

eux, appartiennent aux végétaux inférieurs, il en est néanmoins qui font partie du règne animal.Nous ne ferons qu'indiquer ceux qui sont de nature végétale, renvoyant pour leur étude complète, à la première partie de ce livre. Il y a longtemps que les parasites non microscopiques des organes génitaux de la femme sont connus; différents auteurs anciens en ont fait mention. Hippocrate et Aristote mentionnent la présence d'ascarides lombricoïdes, dans les organes génitaux de la femme; la môle hydatiforme fut longtemps considérée comme un produit parasitaire. La présence du muguet dans les organes génitaux, le caractère épidémique que peut prendre cette affection dans les agglomérations de femmes ou de jeunes filles, sont depuis longtemps connus.

Bergmann a démontré l'existence de larves de mouches (Musca vomitoria) dans le vagin. M. Robin a décrit une algue
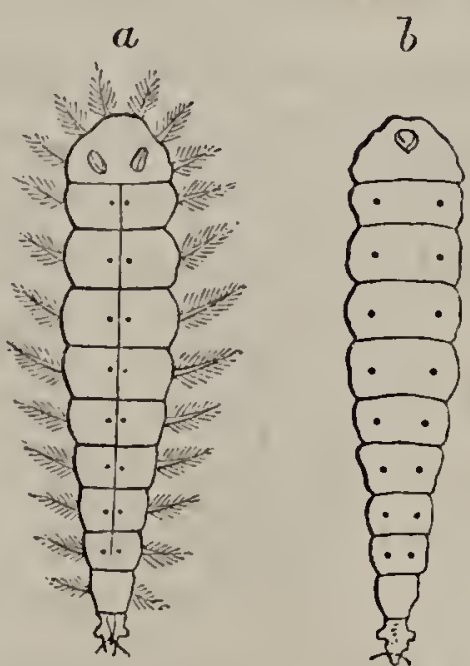

liig. 360. - Larves de museides du genre Anthomya, trouvées dans les déjections alvines. - a. Larve pourvue d'appendices latéraux. - b. Larres sans appendiees. - La tête est dirigée en has, le dernier segment placé en haut de la figure porte les stigmates. (b'après Laboulbène.)

trouvée sur les granulations du col utérin qu'il a décrite sous le nom de Leptomitus uteri (V. p. 278). En 18כ34, Stich a signalé l'existence de cysticerques dans le tissu utérin. Leuckart n'admet pas l'opinion de Vix, non plus que celle de Benedetti, qui prétend aroir trouvé ces parasites entre le placenta et la paroi utérine. Non seulement on peut trouver dans le vagin des ascarides complètement développés, mais Vix a signalé la présence dans le mucus vaginal, aussi bien que dans le mucus utérin, des œufs d'oxyure, mêlés à un certain nombre 
d'embryons en? roie de développement. Cet auteur en conclut que les oxyures et probablement aussi les vers intestinaux peuvent se développer dans les organes génitaux de la femme. Dans un certain nombre de cas dans lesquels la présence d'ascarides lombricoïdes dans le vagin a été signalée, il y avait une fistule faisant communiquer le vagin et le rectum, Dans son ouvrage sur les entozoaires, M. Davaine rapporte également un grand nombre d'observations d'oxyures et de trichomonas trouvés dans les organes génitaux. Cet auteur n’admet pas l'expulsion d'échinocoques par le vagin, ne connaissant pas, dit-il, d'exemple de kyste hydatique ouvert spontanément dans la cavité du péritoine, ou du vagin, ni dans celle de l'utérus.

Avant de passer à l'étude de quelques-uns de ces parasites, nous donnerons d'après le $\mathrm{D}^{\mathrm{r}}$ Gasser le moyen de les recueillir. Il faut éviter, dit cet auteur, l'introduction du spéculum, les. injections et toutes les recherches qui pourraient détacher ou détruire les champignons. On écarte avec le pouce et l'index, les grandes et les petites lèvres, et avec un verre de montre, tenu de la main droite, on recueille le mucus qui tapisse leur face interne, ainsi que l'entrée du vagin. Si l'hymen existe encore, on se sert d'une curette, qu'on introduit à plusieurs reprises dans le vagin, afin de réunir une quantité de mucus suffisante pour l'examen microscopique. Ces précautions ont leur raison d'être, parce. que les parasites végétaux des organes génitaux de la femme ne forment jamais des couches aussi épaisses que celles qu'on observe, sur les surfaces exposées à l'air, généralement; même ils n'atteignent pas le développement de ceux qu'on rencontre dans la bouche. Quelquefois on est obligé de faire un certain nombre de préparations avant de découvrir quelques mycéliums (Gasser, loc. cit., p. 18) (1).

Le Pediculus pubis ou $P$. pudendi (vulgo morpion), ne peut guère être considéré comme un véritable parasite des organes génitaux de la femme; on le rencontre tout aussi

(1) Nous avons puisé de nombreux renseignements dans le trarail du Dr Gasser. - Paris, 1874, Sur les parasites_des organes ginitaux de la femme. 


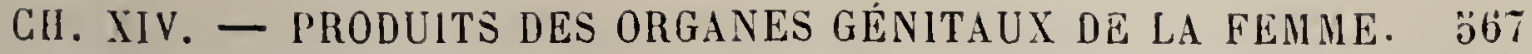

fréquemment chez l'homme. Une bonne loupe suffit pour rendre compte des détails de sa structure générale. La forme du corps est triangulaire, le thorax n'est pas distinct de l'abdomen; le milieu du dos est d'un brun rougeâtre ; les pattes sont longues, fortes, munies de grosses pinces, de couleur rougeâtre, particulièrement les deux paires inférieures. L'abdomen a huit segments et porte sur les côtés de petits tubercules garnis de poils rudes. La disposition et la force de ses pinces, font qu'on ne détache le morpion de la peau, qu'avec une extrême difficulté. Il produit des démangeaisons plus forles que les autres espèces de poux; il pique même si fort, qu'il détermine la sortie de petites gouttes de sang. Les œufs ont la forme générale de ceux des poux, ils sont attachés aux poils de la région habitée (Gasser).

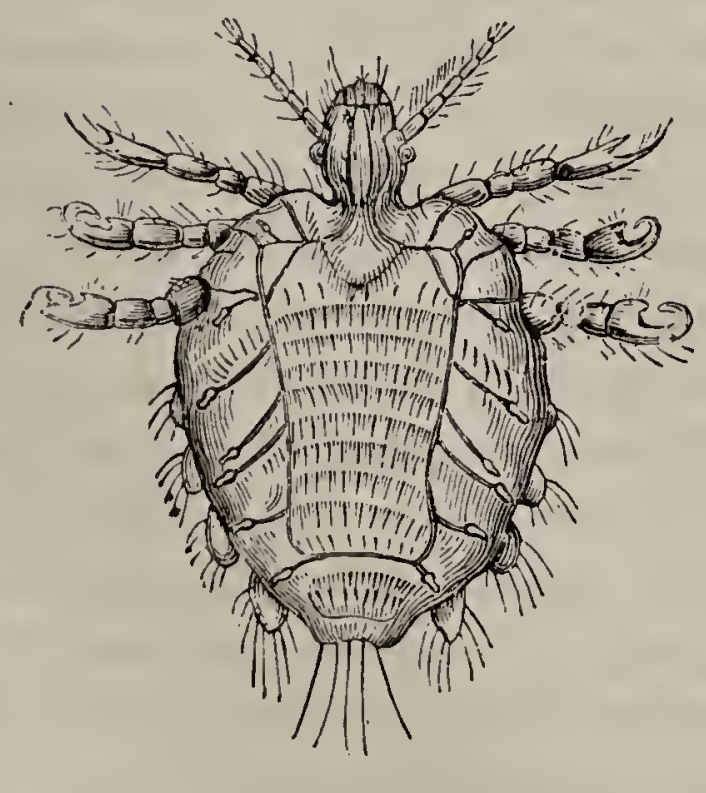

Fig. 361.-Pediculus pubis.

Des parasites végétaux ou animaux, peuvent être introduits dans les organes génitaux, à la suite d'injections, de lotions, d'applications de pièces de pansement, de substances médicamenteuses, d'instruments, etc. Les attouchements, l'onanisme, peuvent également favoriser l'introduction des parasites. Chez les personnes qui manient le blé ou la farine, dit le $\mathrm{D}^{\mathrm{r}}$ Gasser, on trouve quelquefois sur les doigts des acariens, qui peuvent ainsi être introduits dans les organes génitaux. Le coïl est aussi un mode d'introduction des parasites. Haussmann raconte qu'il a trouvé des acares dans le vagin d'une 
femme qui ne présentait aucun symptôme de gale; malgré les recherches les plus minutieuses, il ne put découvrir sur le reste du corps le plus léger sillon, ni un seul acarus. Il est donc probable, que ceux trouvés dans le vagin, y avaient été introduits par son amant, qui avait la gale. Le pénis est en effet un organe de prédilection pour l'acarus.

Un certain nombre des parasites qui peuvent se trouver accidentellement dans l'urine, tels que le Distoma hrmatobium, peuvent pénétrer dans le vagin. Griesinger en a retrouvé dans le mucus vaginal d'Égyptiennes.

Ainsi que nous l'avons vu, un certain nombre de parasites habitant l'intestin, peuvent pénétrer accidentellement dans le vagin. Les oxyures, dit le $\mathrm{D}^{\mathrm{r}}$ Gasser, peuvent arriver dans le vagin par un mouvement de reptation, en contournant le périnée; d'autres fois, les parasites y pénètrent avec les matières fécales. Aussi, chez les personnes malpropres atteintes d'un catarrhe intestinal, il n'est pas rare de voir des parasites introduits dans les organes génitaux avec les matières fécales. D'autres fois, ces parasites y pénètrent par une fistule. On admetenfin, que les oxyures peuvent être transportés directement par la malade dans le vagin. On sait en effet que ces vers occasionnent des démangeaisons très vives, qui poussent les malades à se gratter, de sorte qu'il n'est pas impossible que quelques-uns restent attachés aux doigts et soient ainsi introduits dans les organes génitaux. On a vu souvent des ascarides lombricoïdes pénétrer dans le vagin par une fistule recto-vaginale; mais les parasites qui arrivent le plus souvent dans cet organe, par cette voie, sont des œufs de tænia solium, d'ascarides lombricoïdes, le leptothrix buccalis, des spores, etc. On y rencontre rarement des œufs d'oxyures vermiculaires.

On sait combien il est frécquent de voir des petites filles atteintes de vulvite. D'après Guersant, cette affection serait fréquemment causée par des oxyures vermiculaires qui passeraient du rectum dans le vagin. M. Bouchut partage cette opinion.

Donné a découvert dans le mucus vaginal un infusoire particulier auquel il a donné le nom de Trichomonas vaginale. 
CII XIV. - PRODUITS DES ORGANES GENITAUX DE LA FEMME. 369

Cet animalcule ne se rencontrerait pas dans le mucus vaginal des femmes saines et propres, mais au contraire, il serait fréquent, chez celles qui négligent tout soin de propreté et qui sont affectées d'écoulement suspect. Grâce à la coïncidence de l'existence du trichomonas et des globules de pus, il est assez difficile de retrouver le parasite microscopique qui présente avec ceux-ci, plusieurs points de ressemblance. Ordinairement, il se déplace très peu et n'exécute que de faibles mouvements. Parfois, plusieurs individus se réunissent et formentun groupe, que l'on pourrait prendre pour une agglomération de globules de pus. Donné a fourni ce caractère, qui permet, suivant lui, de diagnostiquer pour ainsi dire, la présence des trichomonades vaginales: quand cet animalcule existe, le mucus vaginal renfermerait des bulles d'air qui lui donnent un aspect écumeux, tandis que dans l'état normal, la matière qui le compose est homogène et n'est pas mélangée de bulles gazeuses. Ce caractère serait constant. En regardant du mucus vaginal à un grossissement de 300 ou 400 diamètres, au milieu des globules de pus et des cellules épithéliales, on voit de petits corps qui, à première vue, peuvent être confondus avec des globules de pus. Ils s'en distinguent bientôt par des mouvements propres, indépendants des mouvements de courant et de totalité, que la capillarité et l'évaporation déterminent. Le doute cesse, quand on voit que ces mouvements volontaires sont produits par l'agitation de petits cils ou filaments, dont l'animal se sert, soit pour se déplacer, soit pour appréhender sa nouruiture (Donné). Ce parasite, de couleur grisâtre, a une forme ovale ou pyriforme, il porte à son extrémité antérieure, un filament double ou bifurqué, son extrémité caudale est, ou bien arrondie, ou terrninée par un filament rigide, de longueur variable, en moyenne de $0^{\mathrm{mm}}, 00$ วั. Près de l'extrémité antérieure de l'animal et sur l'un des côtés, on voit des sillons, correspondant probablement, à l'ouverture buccale et un certain nombre de cils vibratiles courts, animés d'un mouvement vacillant très rapide, dont il est impossible de déterminer la fréquence dans un temps donné, chez un animal parfaitement sain. Dans l'intérieur de la substance contractile homogène, on trouve 
chez la plupart de ces parasites, quelques noyaux, tantôt très fins, tantôt très gros, mais pas de vésicule contractile; même à un grossissement considérable, on n'aperçoit pas à leur surface de stratifications. La longueur de ces animaux varie entre $0^{\mathrm{mm}}, 008$ et $0^{\mathrm{mm}}, 018$; au contact de l'eau, cette longueur diminue, le parasite se pelotonnant sur lui-même. Dans son

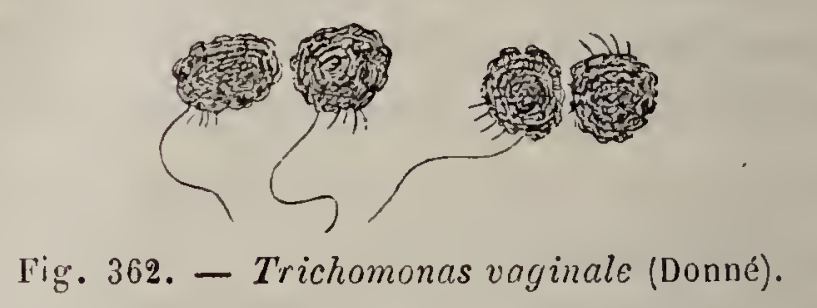

intérieur apparaissent des vacuoles; les mouvements en général, et ceux des cils en particulier, s'affaiblissent et disparaissent enfin complètement (Gasser, p. 33.) (1).

Haussmann a décrit des parasites qu'il a rencontrés dans le mucus vaginal : ces parasites sont arrondis, d'une dimension beaucoup plus faible que les trichomonas. Ils ont l'aspect de deux animaux d'inégale grandeur, accolés l'un à l'autre sur une de leurs faces, se confondant cependant manifestement par leurs deux extrémités, en un seul animal et qui n'étaient munis que d'un seul appendice.

Parlois encore, ajoute le docteur Gasser, on remarque sur un des côtés de l'enveloppe du trichomonas, une cavité cupuliforme. Outre ces parasites, on en rencontre encore de complètement recouverts de cils fins et courts, se dirigeant tous vers l'extrémité caudale et se distinguant par une absence totale de mouvements, des cils qui entourent l'ouverture buccale des filaments ciliaires qui les recouvrent. Ces parasites d'un diamètre de $0^{\mathrm{mm}}$,, 033 , se distinguent des autres infusoires par leur complète immobilité. Salisbury en a fait une nouvelle espèce sous le nom de Ciliaris bicaudalis. Cependant, à part les cils dont ils sont entièrement recouverts, leurs appendices ne diffèrent pas de ceux qui ont été décrits dans les formes précédentes (Gasser).

(1) Voir les recherches microscopiques sur la nature des mucus et la matière des divers écoulcments des organes génitaux urinaires, ctc., etc., parle $\mathrm{D}^{\mathrm{r}}$ A. Donnć. Pal'is, 1837. Leeuwenhoeck (in- ${ }^{\circ}, 1$ 1222), p. 153, avait examiné le mucus vaginal et en avait décrit les cellules épithéliales (squamula). 
CII. XIV. - PRODUITS DES ORGANES GÉNITAUX DE LA FEMME. כ̃ II

D'après cet auteur, les mouvements des trichomonas s'observent non seulement à la température nòrmale du vagin, mais persistent encore assez longtemps, à une température inférieure à $20^{\circ}$ centigrades; au sein d'une masse abondante de mucus qui les protège contre l'évaporation, les mouvements s'observent bien plus longtemps; mais au contact de l'eau, d'une solution de tannin, d'acide chromique, de sublimé, etc., les mouvements s'arrêtent et le parasite devient rigide. C'est ce qui explique pourquoi on trouve des trichomonas immobiles, chez les femmes qui ont recours aux injections. Le travail de l'accouchement leur est aussi préjudiciable que les injections, ou tout autre traitement local; car de même que les parasites accidentellement déposés dans les organes génitaux, ils sont ou détruits ou expulsés. Au sixième ou au septième jour de la puerpéralité, ils peuvent cependant reparaître aussi bien dans les lochies, que dans le canal vaginal (Gasser).

Haussmann (voir Gasser, p. 34, loc. cit.), sur 200 femmes grosses, a trouvé 7 fois des trichomonas, ce qui donne la proportion de 37 p. 100 , et sur 100 femmes malades, mais non enceintes, la proportion s'est élevée à 40 p. 100.

Hennig prétend n'avoir jamais trouvé de trichomonas avant la puberté, ni après 40 ans; sous ce rapport il serait en contradiction, d'après le docteur Gasser, avec les autres observateur's, qui l'ont rencontré chez les petites filles de six à sept ans et chez des femmes ayant dépassé l'âge de la ménopause. On s'explique du reste pourquoi Hennig n'a pas trouvé de trichomonas chez les femmes àgées, c'est qu'à cette période de l'existence, la muqueuse vaginale ne présente plus des condilions aussi favorables à son développement ( $D^{r}$ Gasser). Ce serait dans le catarrhe virulent des organes génitaux, accompagné d'une sécrétion muco-purulente abondante, à réaction fortement acide, qu'on en trouverait le plus; dans ce cas, le dixième environ de ce muco-pus se compose de parasites vivants, accolés les uns aux autres.

Le Bacterium termo (V. Vibrioniens, art. Sang, p. 379) a été rencontré dans les liquides des organes génitaux; d'autres vibrioniens y auraient été également trouvés.

Les parasites des organes génilaux appartiemnent surtout au 
règne végétal; ce sont principalement des champignons et des algues microscopiques.

S iII. - Des taches laissíes par le liquide amniotique.

Avant la naissance, l'enfant est contenu dans une sorte de sac sans ouverture, constitué par plusieurs enveloppes, dont la plus interne est l'amnios; le fœetus baigne dans un liquide fourni par l'amnios et que l'on appelle liquide amniotique. On peut dans certains cas être chargé de déterminer si des taches trouvées sur du linge ont été produites par du liquide amniotique. Quand la poche des eaux se crève brusquement, le liquide est quelquefois projeté assez loin entre les jambes de la parturiente, et alors, il peut laisser des taches formées presque exclusivement de liquide amniotique. Si, au contraire, le liquide amniotique s'écoule petit à petit pendant le travail et en assez grande quantité, au moment de l'expulsion de l'enfant, on a alors un liquide mélangé à du sang et aux produits de la sécrétion vaginale, si abondante pendant l'accouchement. Dans le premier cas, la détermination de la nature des taches est chose délicate; dans le second, la complexité des éléments qui entrent dans la constitution de la tache, peut mettre sur la voie, en ce sens que l'on pourra trouver des éléments anatomiques facilement déterminables, mais qui masqueront complètement les caractères déjà si confus du liquide amniotique.

Le liquide amniotique est généralement très fluide, tantôt d'une couleur un peu jaunâtre ou citrine, tantôt d'une couleur légèrement verdâtre. Lorsque l'enfant a souffert dans la cavité amniotique et qu'il y a rendu son méconium (Voy. ce mot), le liquide amniotique devient vert et laisse des taches assez facilement reconnaissables. Quand on laisse déposer du liquide amniotique, il abandonne parfois, dit M. Robin, un dépôt grisâtre composé de cellulẻs épithéliales cutanées, et même du rein ou de la vessie. Il contient de plus quelques leucocytes, avec de petits flocons de mucosine. On y trouve également des noyaux des cellules épidermiques fœetales, hypertrophiés et détachés. Suivant l'observation de M. Robin, les cellules les plus superficielles de l'épiderme fœlal, ont un 
CH. XIV. - PRODUITS DES ORGANES GÉNITAUX DE LA FEMME. כั73

gros noyau qui disparaît à la fin du deuxième mois ou au commencement du troisième. Ce noyau s'hypertrophie et fait une saillie pyriforme à la surface du corps, devient mamelonné ; puis son point d'union avec la cellule se rétrécit en forme de pédicule. Celui-ci finit par se rompre, le noyau tombe dans le liquide amniotique, et la cellule reste alors sans noyau jusqu'à

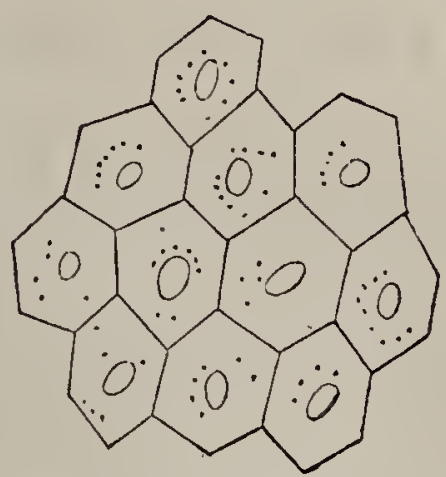

Fig. 363. - Epithéljum d'un embryon de deux mois. Gross. de 350 diamètres (Kölliker).

l'époque de sa desquamation (Ch. Robin, Journal de la Physiologie de l'homme et des animaux. Paris, 1861).

L'acide acétique donne un précipité dans le liquide amniotique; l'acide azotique y révèle quelquefois la présence de traces d'albumine. Le liquide amniotique a une odeur spéciale bien connue des accoucheurs et qui rappelle celle du sperme; lorsque le fotus est mis au monde mort et macéré, le liquide amniolique a parfois une odeur désagréable, mais en général il conserve bien les fœtus.

Voici quels sont les caractères assignés aux taches produites par le liquide amniotique. Ces taches ont une coloration variable, comme celle du liquide amniotique. D'après M. Tardieu, elles sont en général d'un gris jaunâtre et bordées par un liséré grisâtre très marqué. La dimension de ces taches peut être très considérable, puisqu'il peut sortir d'un seul coup, au moins un demi-litre de liquide amniotique. Ces taches empèsent un peu le linge, mais elles ne forment pas de croûtes à sa surface. Quand on examine au microscope l'eau dans laquelle on a fait macérer des taches de liquide amniotique, on voit quelquefois des cellules épithéliales parimenteuses, présentant un noyau fréquemment granuleux et des poils de duvet provenant du fœtus (Robin et Tardieu. - V. 
article Poils). On peut également y retrouver des noyaux de cellules décrits par M. Robin. Nous le répétons, le liquide amniotique seul laisse des taches difficiles à déterminer; il est du reste assez rare qu'il ne contienne pas des éléments étrangers pouvant permettre à l'observateur de remonter à l'origine des taches.

\section{$\S$ IV. - DES SMEGMA.}

On donne ce nom à des produits blanchâtres, d'une consistance crémeuse, d'aspect gras, que l'on trouve dans les plis des petites lèvres, ou entre le gland et le prépuce. Cies smegma ont une composition différente. Celui que l'on trouve dans les plis des petites lèvres est formé par un résidu épithélial et quelques gouttes huileuses, venant de la sécrétion des glandes sébacées de ces replis cutanés. Le smegma du prépuce a une origine différente, aucune glande ne concourt à sa formation. Il se présente, dit M. Ch. Robin, sous l'aspect d'une matière blanchâtre, demi-liquide, pâteuse, ou de consistance de savon mouillé, qui s'accumule au fond du repli balano-préputial chez l'homme, ainsi qu'entre les petites lèvres et le clitoris chez la femme. Le smegma se compose $1^{\circ}$ de cellules épithéliales pavimenteuses, minces, finement granuleuses, plissées; un peu irrégulières, ordinairement pourvues de noyaux, mais sans granulations graisseuses; $2^{\circ}$ de beaucoup de fines granulations moléculaires grisâtres, libres ou adhérentes aux cellules, quelquefois réunies en masses amorphes; $3^{\circ}$ quelquefois, surtout chez les cnfants, de globes épidermiques; $4^{\circ}$ presque constamment, on y trouve quelques rares cristaux offrant les caractères de ceux de l'acide stéarique, bien que la réaction du smegma soit alcaline (Ch. Robin).

Le smegma préputial n'est pas le produit de glandes sébacées, il ne renferme pas de granulations graisseuses, ni de ces cellules épithéliales de même caractère que celles que l'on rencontre dans la malière sébacée. Il est le résultat de l'accumulation de l'épithélium balano-préputial, humecté par le liquide qui exsude à la surface de toutes les muqueuses (Ch. Robin). 
CH. XIV, - PRODUITS DES ORGANES GÉNITAUX DE LA FEMME. כ7כ

Ces smegma sont parfois considérés comme des produits pathologiques; il n'en est rien. Nous ne pensons pas que des taches formées par des smegma aient jamais été examinées à un point de vue médico-légal; il n'en est pas de même des taches produites par le smegma ou enduit fœtal.

$$
\S \text { v. - DU sMegma ou ENduit fetal (Vernix caseasa). }
$$

Quand un enfant vient au monde, il n'est pas rare de le voir plus ou moins complètement recouvert par un enduit blanchâtre et gras, plus abondant dans certaines parties du corps que dans d'autres. G'est pour débarrasser les enfants de ce vernis, qu'on a l'habitude de les enduire d'un corps gras, huile ou cérat, qui permet de l'enlever plus facilement. Néanmoins par simple friction, avec un linge ordinaire, on peut en

A

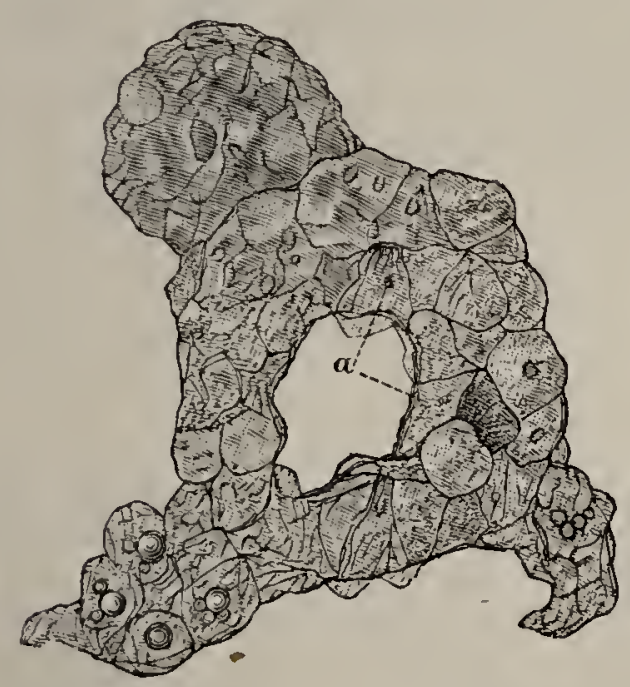

B

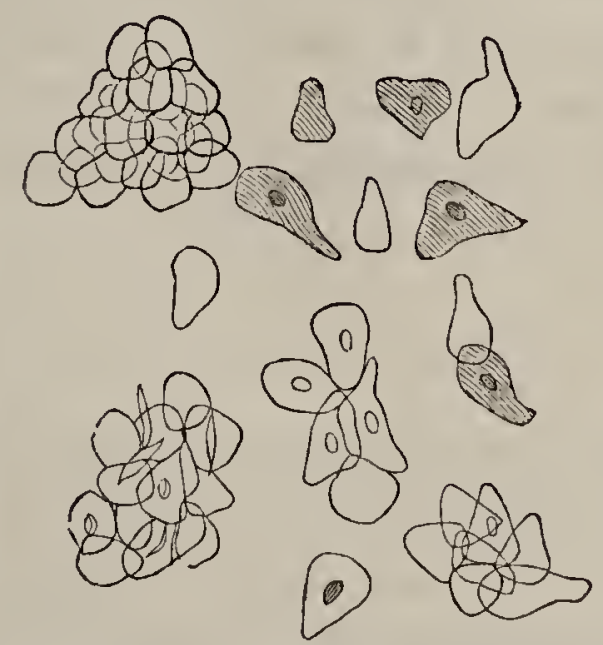

Fig. 364. - A. Lambeau d'enduit fœtal. - a. Corpuscules qui seront décrits à l'article Méconium. - B. Enduit fotal traité par l'éther, cellules groupées ou isolées.

enlever la majeure partie. Cet enduit n'est pas constitué, à proprement parler, par de la matière sébacée, mais bien, comme le dit M. Robin, par le résidu de cette sécrétion, c'està-dire par des cellules épithéliales, expulsées des glandes et agglutinées entre elles par la matière huileuse. Ce smegma fœtal est en quantité plus ou moins considérable, suivant les cas, mais il existe toujours. L'enduit sébacé est constitué par deux sortes d'éléments visibles au microscope $: 1^{\circ}$ des cellules 
épithéliales; $2^{\circ}$ des granulations graisseuses en très-petit nombre. Voici la description que donne M. Robin de ces'cellules épithéliales : Elles sont pavimenteuses, plutôt polyédriques, quand elles sont libres, qu'aplaties, si ce n'est quand elles sont pressées les unes contre les autres. Leur diamètre est de 2 à 3 centièmes de millimètre et rarement de 3 ă millièmes. Leurs angles sont ordinairement mousses, peu réguliers. Leurs bords n'ont pas également sur toutes, la netteté qu'ils offrent dans beaucoup de cellules épithéliales. Elles sont transparentes, incolores, très souvent plissées, ou marquées de très fines lignes, pales, irrégulières ou rectilignes, se joignant les unes avec les autres sous des angles variés. Ces cellules manquent complètement de noyau (1), elles ne sont pas granuleuses ou à peine. Grâce au liquide de nature graisseuse qui les imprègne, des bulles d'air restent adhérentes à leur surface, et l'eau les humecte difficilement, ce qui en rend l'examen plus difficile. - L'acide acétique et la glycérine pâlissent ces cellules; la glycérine les gonfle, en arrondit les bords et les rend plus nets. Les rares granulations graisseuses que l'on rencontre dans l'enduit fœtal, sont adhérentes aux cellules épithéliales.

\section{$\S$ vi. — épiderme fetal.}

On a vu, par une des figures qui précèdent, quels étaient les caractères de l'épiderme d'un fœtus de deux ou trois mois. Les cellules de l'épiderme d'un fœetus à terme sont un peu plus larges que celles du smegma cutané. Elles ont (Robin) de 4 à š centièmes de millimètre en général, elles sont plus transparentes, très minces, aplaties, imbriquées, plus régulièrement polygonales, souvent contiguës par leurs bords et juxtaposées en mosaïque; aucune n'offre l'aspect vésiculiforme et la forme sphéroïdale, comme certaines des précédentes. Leurs bords sont pâles, nets, leurs angles généralement bien déterminés, non arrondis. A la surface de

(1) On peut voir, par la figure 364 , qu'un certain nombre de ces cellules ont un noyau parfaitement visible. 
l'épiderme, elles sont à peine granuleuses, quelquefois marquées de fines et pâles stries, à leur superficie, dépourvues de noyaux et presque tout à fait sans granulations; plus profondément, on en trouve quelques-unes qui offrent parfois un assez grand nombre de granulations grisâtres. Ces cellules sont rarement isolées; le plus souvent elles sont imbriquées en lamelles plus ou moins grandes. L'adhérence de ces lamelles épithéliales se fait par l'intermédiaire d'une substance intercellulaire, demi-liquide, que le nitrate d'argent colore en noir. Suivant la disposition de ces lambeaux d'épithélium, on voit les cellules de face, ou de côté, ou par leurs bords. On peut alor's se rendre compte de leur épaisseur et de leur mode de superposition. Quand les lambeaux d'épiderme sont un peu grands, on peut voir les orifices des glandes sudoripares et ceux des follicules pileux (V. Robin, T'raité des humeurs).

La connaissance de ce qui précède est très importante, au point de vue de la détermination des taches, dans des cas d'infanticide. C'est à MM. Robin et Tardieu que l'on doit les notions qui suivent. Ces taches sont généralement d'une dimension qui rappelle celle d'un fœtus tout entier, dont elles offrent quelquefois même l'empreinte. Aussi n'en trouve-t-on souvent qu'une seule. Cette tache est d'un blanc grisâtre; sur un tissu coloré, elle paraît beaucoup plus blanche. Elle est plus prononcée sur la face qui a été en contact direct avec l'enfant, que sur l'autre et présente dans plusieurs de ses parties une certaine épaisseur, due au dépôt d'une matière desséchée, compacte, graissant légèrement le tissu, s'enlevant sous forme de lamelles et qui n'est autre chose que de l'enduit fotal desséché.

Quelques parties présentent fréquemment une teinte rougeâtre, due à du sang; dans ce cas, la face externe du linge, surtout s'il est formé de chanvre ou de coton, peut être par place d'une couleur brun rouge, le sang ayant pénétré le premier dans le tissu et ayant été recouvert par l'enduit, ou ayant imbibé l'étoffe par capillarité. A la surface de la tache peurent se voir des pellicules grisâtres, minces comme des pelures d'oignon, larges de 1 à 2 centimètres et à surface brillante. Enfin, ces taches sont quelquefois verdâtres, cette colo- 
ralion se manifeste lorsque l'enfant a rendu le méconium, pendant le travail ( $\mathrm{D}^{\mathrm{r}}$ Gosse, loc. cit., p. 6כ̋). Voici quel est le mode opératoire conseillé par MM. Robin et Tardieu, dont l'efficacité a été reconnue par le $\mathrm{D}^{\mathrm{r}}$ Gosse. Après avoir fait imbiber les taches, d'après le procédé ordinaire, en ajoutant seulement un peu de glycérinè dans l'eau, et après avoir laissé tremper pendant quelques heures les pellicules dans un verre de montre contenant ce liquide, on voit, avec un grossissement de 500 diamètres, que ces pellicules sont formées de cellules épithéliales pavimenteuses, régulièrement imbriquées, qui proviennent de l'épiderme. On y aperçoit l'orifice des glandes, ou des follicules pileux (voy. Poils), puis un petit nombre de poils de duvet, qu'on trouve sur le corps du fœtus et qui est parfaitement reconnaissable. Ces poils, souvent détachés de leurs follicules et libres, sont pâles, incolores, légèrement striés en long, sans matière colorante dans leur épaisseur, larges de $0^{\mathrm{mm}}, 03$, sans canal médullaire, à extrémités pointues, un peu irréguliers, à racine petite et effilée. On ne peut les confondre avec les poils de l'homme adulte, qui présentent les caractères suivants: diamètre variant de $0^{\mathrm{mm}}, 06$ à $0^{\mathrm{mm}}, 08$, extrémité libre un peu aplatie, substance pourvue de matière colorante, centre creusé d'un canal médullaire continu, ou interrompu et plein d'une moelle graisseuse, plus ou moins opaque. Sur les plus épais de ces lambeaux épidermiques, formés de cellules superposées, on pourra remarquer que les plus profondes d'entre elles sont plus petites que les autres et pourvues d'un noyau. Ge sont là des caractères qui appartiennent à l'épiderme encore mince du fœtus, quandil est enlevé par un frottement un peu rude, ou en raclant, caractères qu'on ne retrouve pas sur les lamelles épidermiques, détachées naturellement de la surface du corps de l'homme (D'Gosse). Quand on peut détacher l'enduit fotal sans le secours d'aucun liquide, il est préférable de l'examiner directement, sans addition d'eau, parce qu'en raison de l'enduit gras qui recouvre les éléments, l'eau ne les mouille pas; l'emploi de la glycérine est de beaucoup préférable.

Nous donnons ci-après le résultat d'une expertise faite par M. Ch. Robin (Briand et Chaudé, Duval et Lereboullet). 
"Ayant saisi avec des pinces de petits lambeaux de pellicules qui adhéraient à la toile de la paillasse, nous les avons laissé tremper, pendant quelques heures, dans des verres de montre contenant de l'eau. lls y sont devenus plus mous, plus transparents, faciles à dilacérer. Portés sous le microscope, entre deux lames de verre et examinés à un grossissement de 500 diamètres, tous se sont montrés formés de cellules épithéliales, pavimenteuses, semblables à celles de l'épiderme superficiel du corps des fœtus à terme. Toutes ces cellules étaient imbriquées régulièrement; çà et là on voyait des orifices glandulaires, ou des follicules pileux, reconnaissables par l'imbrication concentrique des cellules épithéliales et par les lignes qui les circonscrivent. Nous y avons même vu un petit nombre de poils de duvet, qu'on trouve sur le corps des fœtus, et parfaitement reconnaissables à leur forme et à leur structure propre. Les cellules épithéliales élaient minces, aplaties, polygonales, à cinq ou six pans, larges en moyenne de 4 à 5 centièmes de millimètre.

"Leurs bords étaient minces, réguliers; - la plupart étaient peu granuleuses ou, du moins, ne renfermaient que des granulations moléculaires fines, grisâtres. Quelques-unes pourtant étaient plus foncées, par suite de la présence d'un plus grand nombre de granulations et du plus grand volume de celles-ci. Aucune ne contenait de noyau. L’acide acétique et la glycérine rendaient ces cellules plus pâles, plus transparentes, sans cependant les dissoudre, et en même temps permettaient de les dissocier plus facilement. Nous avons en outre rencontré à la surface des lambeaux d'épiderme des granulations microscopiques, de forme et d'aspect divers, que leurs caractères extérieurs et leurs réactions chimiques nous ont fait reconnaître pour des grains de poussière. Dans l'examen des taches mêmes qui entourent les pellicules épidermiques, que nous venons de décrire, nous rencontrons quelques cellules épithéliales un peu plus petites que celles de l'épiderme proprement dit, et se rapprochant beaucoup des caractères offerts par celles du smegma cutané. " 


\section{CHAPITRE XV}

\section{DES MATIÈRES FÉGALES. EXGRÉMENTS, OU F ĖGES}

Les matières fécales sont composées par des débris de substances alimentaires non digérées, mélangés aux résidus des humeurs ver'sées dans le tube digestif.

En tenant compte de cette définition nous ne devrions pas commencer ce chapitre en parlant du Méconium, qui n'est pas à proprement parler un excrément, puisqu'il ne renferme aucune particule de matière alimentaire, étant fréquemment expulsé avant, pendant, ou immédiatement après la naissance. Si nous rapprochons l'étude de ce produit de celle des matières fécales, c'est parce que, peu de temps après la naissance, il est mélangé avec les parties non digérées du lait, et aussi parce qu'il est expulsé par le même organe que les matières fécales proprement dites.

\section{§ I. - DU MÉconiuM.}

On a donné ce nom à la matière rejetée par les enfants, en raison des analogies de consistance et de couleur qu'elle présente avec le suc de pavols. Les principes de la bile n'entrent que pour un tiers dans sa composition, le reste paraît être fourni par l'intestin lui-même.

Nous ne nous occuperons que du méconium du fœtus, depuis l'âge moyen de sept mois jusqu'à terme. En effet, ì partir du septième mois de la grossesse, quelquefois plus tôt, le mé- 
conium présente à peu près les mêmes caractères que ceux qu'il aura au moment de la naissance (Ch. Robin).

Le méconium est brun, ou brun verdâtre, d'une consistance visqueuse. Il renferme surtout un mucus spécial, qui tient reliés ensemble tous les éléments anatomiques qui le composent. "Par lui-même, dit M. Robin, ce mucus ne présente rien de bien particulier. Il est transparent, ses stries sont parallèles entre elles, rectilignes ou onduleuses, rapprochées les unes des autres en certains points, s'écartant ensuite et finissant par disparaître. Cette particularité est détruite par la dessiccation. Dans ce mucus on voit beaucoup de granulations moléculaires, grisâtres et très petites, ainsi que quelques granulations graisseuses. Elles ont une coloration jaunâtre, un centre brillant et un contour foncé.. On rencontre, en outre, soit des

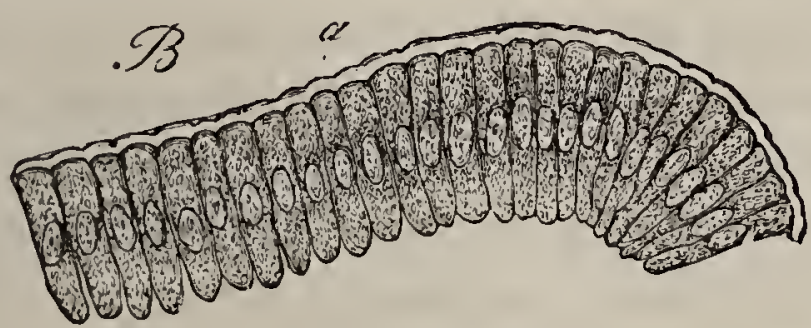

Fig. 365. - Cẹllules épithéliales de.l'jntestin grêle, encore adhérentes les unes avec les autres (gross. 300 d.). - $a$. Membrane gonflée par l'eau (Kölliker).

cellules isolées, soit surtout des gaînes encore tout entières, reproduisant la forme des villosités dont elles sont détachées, ou bien encore des lambeaux de l'épithélium qui tapisse l'estomac et le gros intestin." (Gh. Robin.)

"A l'époque de la naissance, les cellules prismatiques qu'on $\mathrm{y}$ trouve sont tantôt isolées, tantôt juxtaposées en nombre plus ou moins grand. Elles sont généralement peu régulières, à bords moins nets, que ceux des cellules prises à la surface même de la muqueuse; elles sont en même temps plus granuleuses, et peu laissent encore voir leur noyau ovoïde. On distingue pourtant leur extrémité adhérente, ou la plus étroite, de l'extrémité libre, un peu plus large, qui était tournée vers la cavité de l'intestin. La plupart sont teintées en jaune verdâtre foncé, par la matière colorante de.la bile. Il est facile de reconnaître la nature de ces cellules, lorsqu'on a déjà vu les cel- 
lules semblables qu'on observe dans la bile prise dans la vésicule du fiel. " (Robin, Traité des humeurs.)

On trouve fréquemment de la cholestérine cristallisée dans le méconium. Les éléments qui le caractérisent surtout, ce sont des grains, ou grumeaux de matière colorante verte de la bile (biliverdine). Pendant la vie extra-utérine, cette matière colorante, au lieu d'être en grains isolés, comme dans le méconium, est intimement mêlée au sérum biliaire. D'après M. Robin, ces granules affectent des formes différentes: tantôt ils sont globuleux ou ovoïdes, tantôt ils sont polyédriques et à angles arrondis. Cette dernière forme est même la plus fréquente. Le diamètre de ces grains est très variable (de s̆ à $40 \mu$ ); la plupart ont de 10 à 20 millièmes de millimètre. Ce caractère suffit pour empêcher qu'on les confonde avec des grains de chlorophylle.

L'acide nitrique produit sur ces grains la série de colora. tions que l'on observe, quand on le fait réagir sur les matières colorantes de la bile; cependant, la coloration violette est la seule nettement visible au microscope. Lorsque les enfants ont tété, le méconium conserve encore sa viscosité, mais il est devenu vert-jaunâtre. On y trouve encore des cristaux de cholestérine, mais les granules de biliverdine sont devenus rares. Cette couleur est due principalement, dit M. Robin, à la présence de cellules épithéliales pavimenteuses, pâles, la plupart sans noyaux, quelquefois plus foncées, par suite de la présence d'un grand nombre de granulations jaunâtres. Ces cellules sont généralement étalées,' quelques-unes plissées; rarement elles sont imbriquées; suivant M. Robin, elles proviendraient de l'œsophage et seraient entraînées par les premiers mouvements de déglutilion.

Nous avons représenté en $a$ (fig. 366) les granules de matière colorante verte, dont le volume est très variable, ainsi que nous l'avons dit, et qui passent par des colorations diverses sous l'influence de l'acide azotique. Les cellules épithéliales figurées en $b$ sont, les unes incolores, les autres colorées en jaune, et beaucoup d'entre elles contiennent, dans leur intérieur, des corps très petits, tantôt isolés, tantôt groupés, de couleur jaune orangé, affectant soit la forme losangique, arec des 
GHAPITRE XV. - DES MATIĖRES FÉCALES.

arêtes très pures, soit la forme figurée en $b$ à la figure 367 . Disons tout de suite que nous avons également rencontré ces

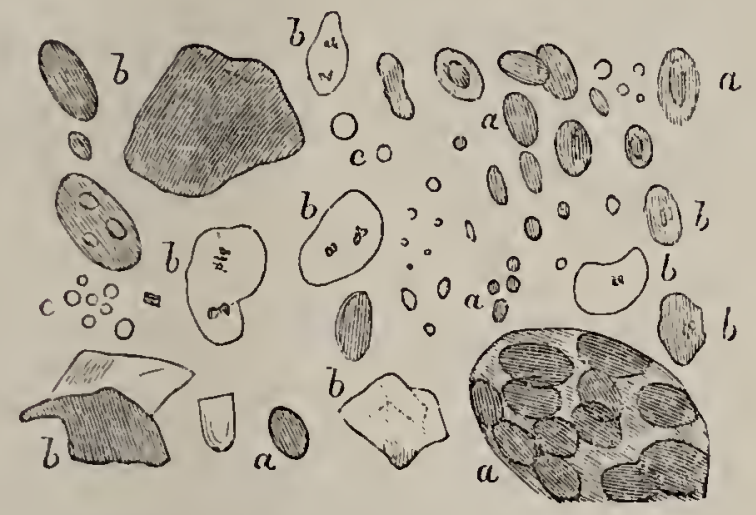

Fig. 366. - Éléments du méconium.

petits corps dans l'enduit fœtal (1). Enfin, en $c$ nous avons figuré les corpuscules réfringents, dont quelques-uns sont extrêmement fins.

Dans la figure 367 nous avons représenté, en $a$, des cellules épithéliales groupées et contenant de ces petits corps jaune orangé, dont nous venons de parler, qui sont représentés en $b$,

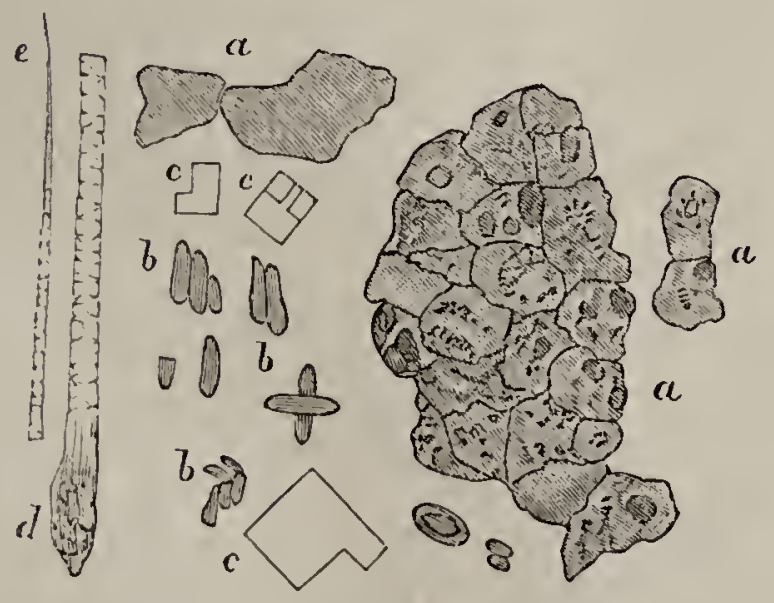

Fig. 367. - liléments du méconium.

à un fort grossissement. En $c$, on voit des cristaux de cholestérine; enfin en $d$ et en $e$ la racine et la pointe de l'un de ces poils de duvet, que l'on rencontre si fréquemment dans le méconium.

Nous avons eu l'occasion d'observer un méconium peu coloré (fig. 368) dont l'aspect différait du méconium normal. Outre

(1) V. la figure 364. Ces corps ont des dimensions très variables. 
des cellules épithéliales représentées en $b$ et contenant de ces petits corps losangiques déjà décrits, il y avait des masses, probablement formées de matière grasse, groupées ou isolées, ainsi que de fines granulations réfringentes. En $d$ on voit une agglomération de granulations jaune-orangé, granulations différant des corps losangiques, dont il a été parlé plus

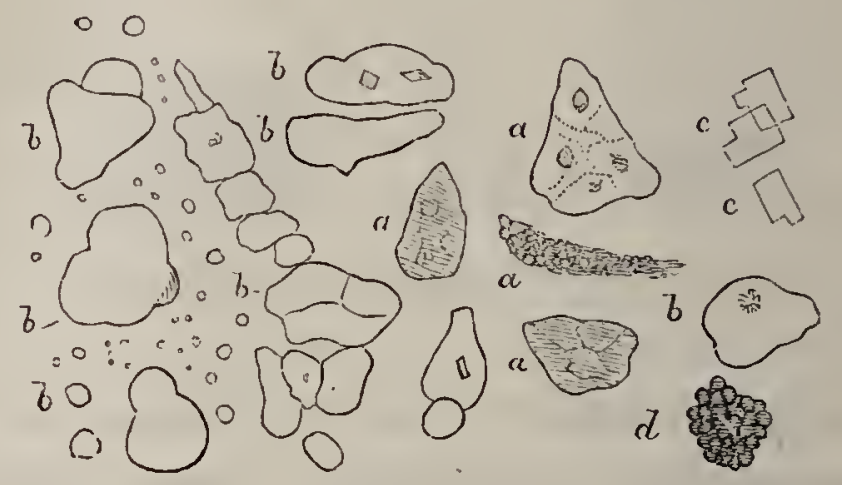

Fig. 368. - Méconium anormal.

haut. Il y avait, en outre, des poils de duvet assez fortement pigmentés.

Tous ces éléments étaient invisqués dans le mucus intestinal.

Le méconium peut se conserver très longtemps, desséché sur un linge, ou dans un morceau de papier, sans exhaler aucune odeur. Au toucher il donne la sensation d'un corps gras; sa coloration n'est pas altérée : il peut se putréfier cependant, s'il ne se dessèche pas.

Les linges qui ont reçu du méconium sont colorés en jaune verdâtre, ou en brun verdâtre, suivant l'épaisseur de la couche de méconium, qui a été déposée à leur surface. Les taches sont rudes au toucher; en raison de sa viscosité, le méconium traverse rarement les tissus. Quand une couche de méconium assez épaisse s'est desséchée entre les plis d'un linge, il n'est pas rare qu'il s'en détache de larges écailles portant imprimées, sur chacune des faces en contact avec le linge, les reliefs du tissu; d'autres fois, il suffit de soulever légèrement l'un des bords relevés, de la couche desséchée du méconium, pour la détacher complètement du linge. Quand on examine au microscope, à un grossissement ade $500 \mathrm{D}$., du méconium ainsi recueilli; on voit qu'il est formé, comme il a été dil plus haut, d'un mélange de granulations, de cellules, de cristaux et de 
grumeaux, tenus en suspension dans le mucus. Nous avons vu quels étaient les caractères du mucus. Les granulations moléculaires ont un diamètre de $0^{\mathrm{mm}}, 025$ à $0^{\mathrm{mm}}, 075$, elles constituent la partie principale du méconium. Elles se dissolvent dans l'eau et dans l'alcool et paraissent être des granulations de mucus. Elles sont grisâtres et éparses d'une façon uniforme $\left(D^{r}\right.$ Gosse). Nous conmaissons les réactions des granulations graisseuses; quant aux éléments anatomiques, ils ont été décrits plus haut.

En raison de la facile conservation du méconium, les éléments qui le constituent sont assez facilement déterminables. Il y aurait un grand intérêt à fixer le caractère différentiel du méconium humain et du méconium des animaux.

§ II. - Matil̀res FÉCALES DES ENFANTS NoURRis EXCLUSIVEMENT DE LAIT.

Dès que l'enfant a introduit dans son tube digestif une certaine quantité de liquide ou de lait, le méconium change d'aspect: de vert qu'il était il devient vert-grisâtre, ou vertjaunâtre. Bientôt les matières fécales de l'enfant sont striées de jaune. Celte couleur tend à préd ominer chaque jour davantage, le méconium n'apparaît plus qu'en quelques points, sous la forme de granulations verdâtres. Vers le cinquième ou le sixième jour $\left(\mathrm{D}^{\mathrm{r}}\right.$ Gosse, loc. cit., p. 83 et suiv.), plus tôt, suivant nos observations, elles sont vert jaunâtre et offrent presque constamment des grumeaux blanchâtres, de dimensions très variables, depuis celle de la tête d'une épingle jusqu'à celle d'un gros pois. Le septième jour, quelquefois même le troisième, les matières fécales prennent une couleur jaune vif, qui a la plus grande analogie avec celle de l'omelette. C'est la coloration qu'elles garderont durant tout l'allaitement, si l'enfant est bien portant. Elles continuent à présenter des grumeaux blanchâtres, qui vont en diminuant dans les jours suivants, pour reparaître de temps en temps pendant toute la durée de l'alimentation lactée. Cela a lieu; lors même que l'enfant est bien portant, et dépend d'une alimentation un peu trop abondante ( $D^{r}$ Gosse, loc. cit.). Les matières fécales d'un enfant i la mamelle ont toujours une odeur de lait aigri. 
Dès qu'un enfant commence à souffrir, que son alimentation est mauvaise, ou insuffisante, ses excréments changent d'aspect. On les voit devenir verdâtres, les grumeaux sont plus volumineux et plus abondants. La couleur verdâtre s'accentue de plus en plus, quand l'enfant a une véritable diarrhée.

Quand on examine les matières fécales d'un enfant tout à fait bien portant, à côté de globules de lait, plus ou moins abondants, ayant échappé à l'action des sucs digestifs, on voit un grand nombre de fines aiguilles cristallines isolées, ou formant des masses, ou étoiles épineuses, et constituées par de la matière grasse. Parfois l'abondance de ces cristaux et de ces masses cristallines est considérable. A côté de ces cristaux, on voit des globules de lait déformés, opaques, paraissant s'être soudés et constituant quelquefois des masses assez volumineuses. Ces masses opalines contiennent fréquemment des cristaux, dans leur intérieur. Quand le lait de la mère est pauvre, les matières fécales de l'enfant semblent ne pas renfermer de cristaux de matière grasse. Des cellules épithéliales, en plus ou moins grand nombre, figurent également dans ces matières fécales. Des granulations jaunes, de formes diverses, les unes très fines, les autres groupées et paraissant être une transformation des masses verdâtres du méconium, donnent aux matières fécales du nouveau-né leur coloration jaune caractéristique (1). Outre ces éléments, il y a un très grand nombre de bactéries. Le mucus intestinal est très abondant, et, comme dans le méconium, il retient unis les éléments anatomiques qui constituent les matières fécales. Lorsque l'on met les matières fécales dans de l'éther, elles se prennent en une sorte de gelée, formée par le mucus intestinal, reconnaissable à ses stries parallèles et à l'action exercée sur lui par l'acide acétique. Les globules de lait sont emprisonnés et échappent en partie à l'action de l'éther.

Les matières fécales des nouveau-nés subissent des modifications pathologiques plus ou moins profondes et généralement peu connues.

Sous des influences légères, on voit apparaître dans les ma-

(1) Sous l'influence de l'acide azotique, ces granulations passent successivement par une série de colorations, verte, bleue et rose violacé. 
tières fécales de petits îlots bleu-verdâtre, qui semblent coïncider avec un trouble des fonctions digestives. Ces îlots, qui tranchent par leur coloration si spéciale sur la couleur jaune de l'ensemble, ne paraissent pas renfermer d'éléments spéciaux et sont seulement différemment colorés, probablement par des matières colorantes biliaires. Lorsque la nourrice a des crevasses sur le mamelon, alors même que le sang ne passe pas dans les organes digestifs de l'enfant, il est fréquent de trouvèr, outre ces îlots de matières bleu-verdâtre, de très nombreux leucocytes, provenant, suivant toute apparence, de la suppuration des crevasses du mamelon. L'enfant souffre évidemment d'un tel état de choses; il y a dans les matières fécales un grand nombre de globules de lait inaltérés et pas de cristaux de matière grasse, dont la présence nous paraît coïncider généralement avec un état de santé florissante (1).

Il nous a semblé, en effet, qu'il y avait une sorte de balancement entre la présence dans les matières fécales de globules de lait et de cristaux de matière grasse. Quand les globules sont très abondants, il y a peu ou point de cristaux; quand ces derniers dominent, il y a, au contraire, peu de globules inaltérés.

Nous avons examiné les matières fécales d'un enfant syphilitique, atteint d'ictère grave et athrepsique, qui a succombé peu de temps après cet examen. Cet enfant avait tété sa mère et avait bu du lait de vache. Les matières fécales étaient granuleuses et d'un blanc jaunatre. Le microscope permit de voir qu'elles étaient presque exclusivement formées par des globules de lait inaltérés, au moins en apparence, et possédant leur pouvoir réfringent ordinaire. Les plus gros étaient cependant légèrement déformés.

On voyait également quelques cellules épithéliales, colorées en jaune, et de ces granulations jaunes, représentant probablement les vestiges du colostrum. Ces éléments étaient invisqués dans le mucus intestinal, laissant voir un grand nombre de fines granulations.

(1) Les matières fécales peuvent ne renfermer ni globules de lait, ni cristaux; il est probable qu'il y a alor's digestion complète. Ce fait se rencontre assez rarement. 
Qu'était devenue la caséine dans ce cas particulier? Nous avouons qu'il n'est pas facile d'en démontrer l'existence dans les matières fécales des enfants nouveau-nés, au moins quand ils sont exclusivement nourris au sein. Les réactions de la caséine ne sont pas nettes et se confondent avec celles du mucus intestinal, si abondant dans les matières fécales des nouveau-nés. Nous verrons, un peu plus loin, que le $\mathrm{D}^{\mathrm{r}}$ Gosse compare ces grumeaux blancs à du fromage ; pour l'aspect, c'est possible, mais pour la constitution la preuve n'est pas faite.

Il y a dans cette voie de nouvelles recherches à poursuivre; nous espérons pouvoir, plus tard, combler quelques-uns de ces desiderata.

Les taches produites par les excréments d'enfants à la mamelle ont un aspect différent, suivant que ceux-ci sont bien portants ou malades. S'ils sont bien portants, si les matières fécales ont cette couleur d'omelette, qui est le signe d'une bonne santé, les taches qu'elles produiront deviendront un peu plus foncées par la dessiccation. Ces taches forment un relief plus ou moins considérable, généralement grenu, suivant l'épaisseur de la couche restée adhérente au linge. Celui-ci, au niveau des taches, est un peu rude au toucher. Si les matières fécales étaient émises seules, elles traverseraient rarement le linge, mais l'urine peut les délayer et, pénétrant le tissu, lui donner une coloration toute spéciate.

Le $\mathrm{D}^{\mathrm{r}}$ Gosse appelle tout particulièrementl'attention sur les points suivants. Il a vu que ces grains de biliverdine, dont nous avons signalé la présence dans le méconium, persistaient constamment jusqu'au cinquième jour et, dans des cas exceptionnels, jusqu'au douzième jour et peut-être au delà. En second lieu, à partir du cinquième ou du sixième jour, les grumeaux blancs que l'on y découvre, sont formés exclusivement de caséum, renfermant des globules de lait irrégulièrement granuleux, demi-transparents et groupés les uns contre les autres; c'est un véritable fromage.

Sur cinquante-neuf échantillons de matières fécales examinés par le $\mathrm{D}^{\mathrm{r}}$ Gosse, provenant d'enfants âgés de cinq à douze jours, cet observateur a tonjours constaté la présence 
de ces grumeaux, qui sont pour ainsi dire les résidus de l'alimentation lactée. C'est donc principalement à ce caractère que l'on reconnaîtra des matières fécales d'enfants nourris avec le lait.

\section{§ III. - DEs Matières fÉCALes.}

La couleur des matières fécales est extrêmement' variable, suivant le genre d'alimentation, et aussi suivant l'état des fonctions digestives; cette coloration varie également sous l'influence d'inflammations de'voisinage, telles que les péritonites, d'abcès ou de tumeurs; dans les affections générales, que la muqueuse intestinale soit saine ou ulcérée, la coloration et l'odeur sont également modifiées. La couleur des matières fécales est généralement d'un brun plus ou moins foncé, quelquefois verdâtre, ou vert foncé, avec des traînées de mucus concret, ou demimconcret, à la surface. Cette teinte brun verdâtre peut parfois s'accuser davantage et aller presque jusqu'au noir; d'autres fois, au contraire, cette couleur est jaune ou jaune roussâtre. D'une façon générale, les matières fécales, abandonnées à l'air libre, prennent une teinte très foncée, allant presque jusqu'au noir. La matière colorante verte des matières fécales est la biliverdine.

Quand on examine des déjections au microscope, on y rencontre des éléments de deux ordres: les uns provenant des aliments incomplètement digérés, les autres constitués par les résidus des humeurs versées dans le tube digestif (Ch. Robin, Traité des humeur's). C'est ainsi que l'on peut trouver des graines entières, ayant échappé, grâce à leur enveloppe, à l'action' des sucs digestifs ; d'après M. Robin, ces graines n'auraient pas perdu toujours la faculté de germer. Nous en avons de nombreux exemples dans les observations qui ont été recueillies, de plantes issues de graines apportées dans certains pays par des oiseaux parcourant rapidement de grands espaces. Si les graines ont été écrasées, leur enveloppe échappe généralement à la digestion, parfois même une partie de leur contenu est retrouvé intact, au milieu des excréments; on voit encore des cellules contenant de l'amidon, des débris de cellules, des trachées à moitié déroulées, des grains d'amidon, des frag- 
ments de carolle, facilement reconnaissables à leur coloration. De tous les aliments; ce sont les légumes que l'on retrouve le plus souvent intacts, au milieu des matières fécales. Il est de la plus haute importance de se familiariser avec l'aspect de ces débris végétaux, ayant subi plus ou moins complètement l'action de la digestion. Dans les expertises médico-légales, il $\mathrm{y}$ a souvent un grand intérêt à savoir quelles substances ont figuré dans le dernier repas d'une personne morte dans des conditions anormales.

Il est très fréquent de trouver des fibres musculaires striées, au milieu des matières fécales; il y a même des cas, où la digestion ne se faisant pour ainsi dire pas, on retrouve dans les excréments la viande à peine altérée. Certains tissus, tels que les ligaments jaunes (Robin), les tuniques des artérioles, résistent souvent à l'action des sucs digestifs et sont rendus à peine modifiés. Dans les matières fécales du chien, il est fréquent de rencontrer de petits fragments d'os. Si au contraire on examine des matières fécales d'herbivores, on y trouvera une foule de résidus cellulaires ou ligneux.

Lor'sque les matières grasses entrent pour une très forte proportion dans l'alimentation, il y en a presque toujours un excès qui passe inaltéré et que l'on retrouve avec leurs caractères bien connus.

Il est très commun également de rencontrer des grains d'amidon, tantôt intacts, tantôt altérés par la digestion, gonflés ou éclatés.

Une autre partie des excréments est formée par le reliquat des humeurs versées dans le tube digestif; c'est pour cette raison que les personnes qui ne prennent pas du tout d'aliments peuvent néanmoins rejeter des excréments; c'est également en vertu de la même loi, que des matières s'amoncellent peu à peu dans le côlon et dans le rectum des animaux soumis à la torpeur hibernale.

Lorsque nous avons étudié le méconium, nous avons vu qu'il était presque constant d'y rencontrer des cristaux lamellaires de cholestérine. Dans les matières fécales, on ne retrouve pas ce corps, qui suivant les auteurs (Flint) s'est transformé par le travail digestif en stercorine. 
Le phosphate ammoniaco-magnésien, au contraire, existe constamment, même dans les déjections normales, comme il est facile de le vérifier. C'est surtout dans les selles diarrhéiques qu'il est commun de rencontrer ces cristaux. M. Ch. Robin dil que chez des sujets soumis à un mauvais régime, dont les végétaux sont la partie dominante, il a trouvé le phosphate ammoniacomagnésien, à l'état de gros cristaux, ou de groupes de cristaux, en quantité telle-

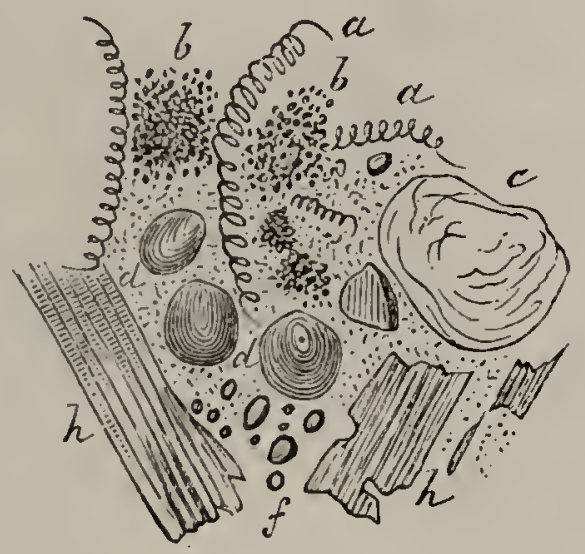

Fign. 369. - Débris d'aliments incomplètement digérés. - $a$, trachée. $-b$, amas granulcux de chlorophylle. $-c$, cellule végétale ayant perdu scs grains d'amidon. $-f$, globules gras. $-h$, débris de fibres musculaires.

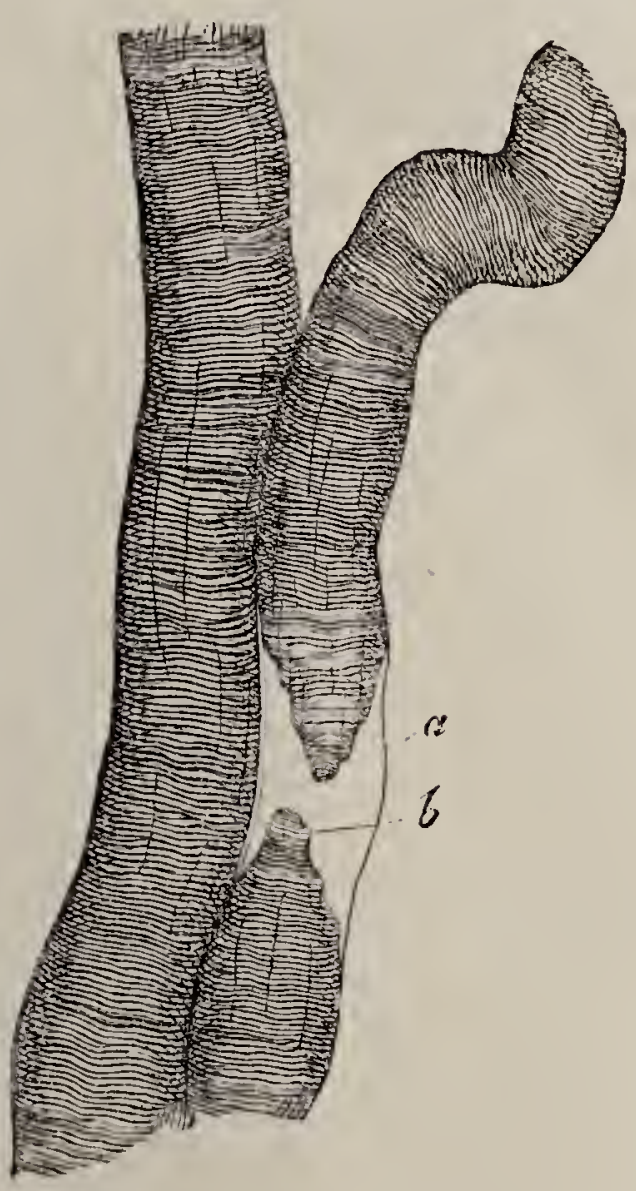

Fig. 370. - Fibres musculaires striées. Dans unc d'elies, la substance contractile (b) s'est rompue et laissc voir le sarcolemme (a) sous formc d'un tube vide. (Gr. $350 \mathrm{~d}$.).

ment considérable, qu'il évalue à un gramme la quantité de cristaux rendus à chaque défécation.

Quand on veut examiner des matières fécales au microscope, si celles-ci sont solides, il est nécessaire de diminuer leur cohésion, en y ajoutant une certaine quantité d'eau. Voici, d'après M. Ch. Robin, les différents éléments que l'on rencontre généralement $: 1^{\circ}$ un nombre considérable de fines granulations moléculaires, douées de mouvement brownien. les unes grisâtres, azotées, solubles dans l'acide acétique; les autres jaunâtres, réfractant la lumière à la manière des corps gras, et d'autres enfin, souvent très abondantes, qui sont irrégulières, 
plus grosses que les précédentes et dont la nature n'a pas été déterminée ;

$2^{\circ}$ Des gouttes graisseuses généralement peu abondantes, en dehors du régime lacté, ou autres régimes dans lesquels les corps gras entrent pour une forte proportion;

$3^{\circ}$ De nombreuses aiguilles jaunâtres de nature graisseuse

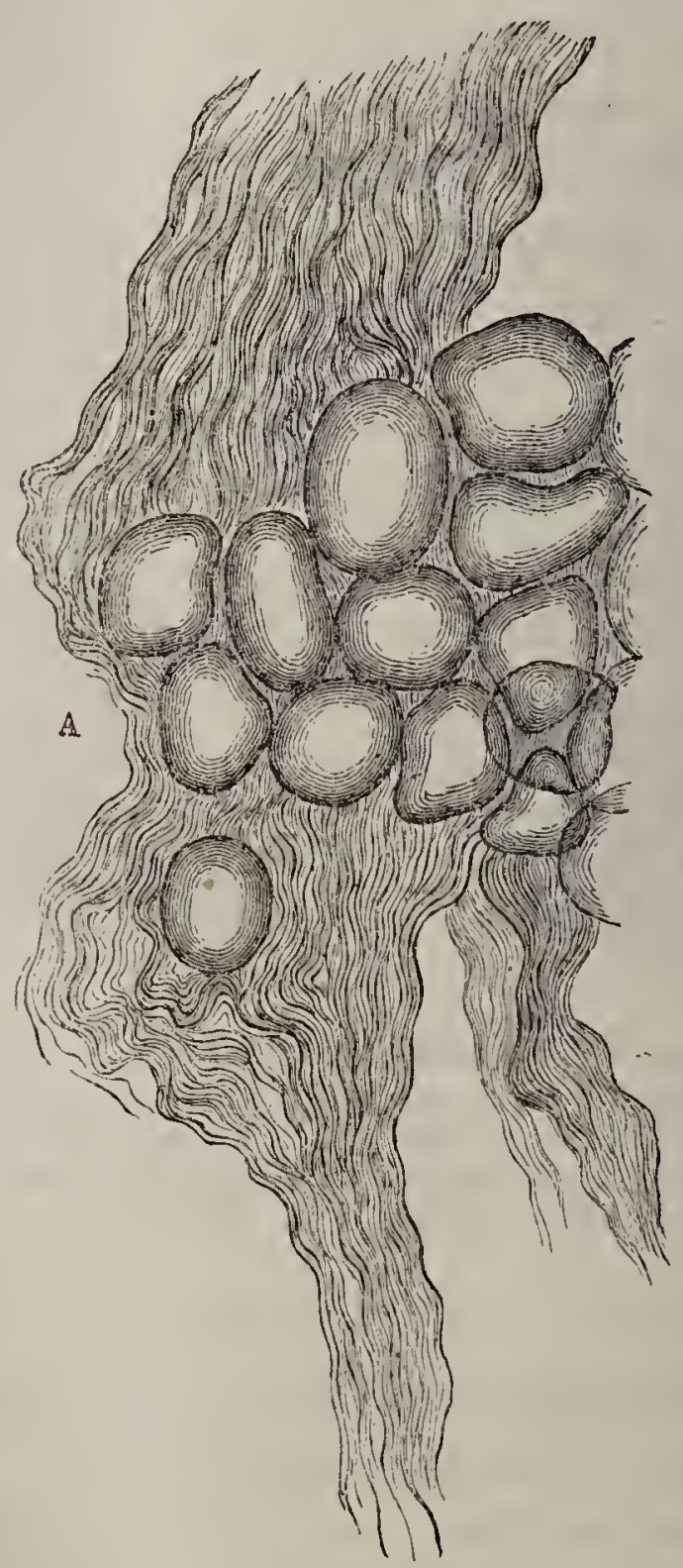

Eig. 371. - Tissu conjonctif làche de l'homne, renfermant des cellules adipeuses. (Gross. 350 d.).

qui sont des fragments de cristaux aciculaires de stéarine, de margarine, d'acide stéarique ou margarique, ou des stéarates ou margarates;

$4^{\circ}$ Des granulations de matière colorante de la bile, plus ou moins modifiées par l'acte digestif et d'autant plus nombreuses que les matières sont plus colorées. L'acide azotique n'agit pas 
sur ces granulations biliaires, avec autant de netteté que dans le méconium par exemple: la réaction est fugitive, cependant la teinte rougeâtre par laquelle se termine la réaction azotique apparaît au bout d'un temps variable.

$\breve{\partial}^{\circ}$ Comme nous l'avons dit, on trouve fréquemment des débris de tissu musculaire, soit parce que la digestion se fait mal, ou bien parce que la quantité de viande ingérée a été trop considérable, ce qui est le cas le plus fréquent. On a également observé que plus la viande élait cuite, plus elle résistait à l'action des sucs digestifs, d'où l'indication de manger la viande peu cuite, afin de ne pas condamner l'économie à ac-

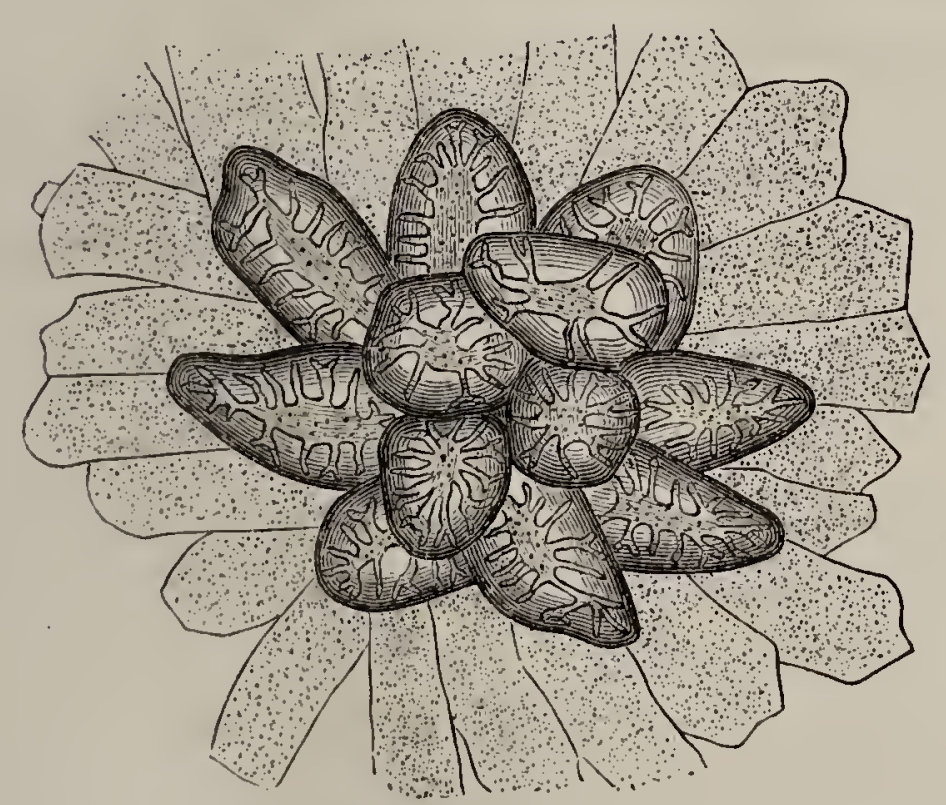

Fig. 372. - Cellules dites pierreuses de la poire.

complir une besogne inutile. Généralement, il est facile de voir la striation des faisceaux musculaires: ces débris sont colorés en jaune brunâtre, par suite de l'action tinctoriale de la biliverdine. La forme et le volume de ces fragments de tissu musculaire sont, comme on le comprend, très variables.

$6^{\circ} \mathrm{M}$. Robin appelle encore l'atlention sur les fibres élastiques ou tissu lamineux des ligaments ou des membranes jaunes élastiques. Généralement, ces tissus ayant résisté seuls à l'àction de la digestion, sont complètement débarrassés des autres. Des fragments d'artères ont élé pris parfois pour des vers intestinaux (Ch. Robin).

$7^{\circ}$ Nous avons signalé l'existence dans les matières fécales GUIDE DE MICHOGंHAPHIE. 
de cellules végétales et même de débris entiers de végétaux. Les cellules pierreuses provenant de l'ingestion de fruits, on de médicaments (cannelle, etc.), se retrouvent dans les malières fécales. Nous n'insistons pas davantage sur ce point, en raison des détails donnés dans la première partie de cel ouvrage, sur la structure des régétaux.

On peut trouver également des spores de champignons que l'on rencontre dans les selles; leurs caractères anatomiques peuvent, dans un cas d'empoisonnement, servir à diagnostiquer à quelle espèce, comestible ou toxique, on a eu affaire. On consultera sur ce point le travail de Boudier (de Montmorency) sur les champignons, au point de vue de leurs caractères usuels, chimiques et toxicologiques.

$8^{\circ}$ Bien qu'il soit fréquent de rencontrer des œufs de vers intestinaux chez des personnes, surtout chez des enfants, d'une bonne santé apparente, nous reportons cette étude aux développements que nous nous proposons de consacrer aux parasites de l'intestin.

Siv. - des Modifications produttes par les maladies sur les déJeGtions iNTESTINaLES. - Matières fÉGates pathologiques.

Nous savons déjà que, sous l'influence de diverses affections du tube digestif, groupées sous le nom de dyspepsie, les malières alimentaires, la vian de même, peuvent traverser l'intestin sans être profondément modifiées parl'action des sucs digestifs. S'il y a une lésion du parcréas, les matières grasses passent pour ainsi dire inaltérées et se retrouvent sous forme huileuse, ou de suif, à la surface des excréments. En même temps, dit M. Ch. Robin, les faisceaux primitifs ou striés des muscles passent presque intarls, et souvent même sans être dissociés, c'est-à-dire sans être plus isolés les uns des autres, qu'ils ne le sont dans le chyme, au sortir de l'estomac.

On voit encore, suivant le même auteur, des lobules de tissu adipeux, sphériques, ou lenticulaires, flottant çà et là, ou adhérant aux flocons, formés par les masses musculaires incomplètement dissociées. M. Robin attribue la coloration jaunâtre de ces globules el l'opalescence plus ou moins complète 
qu'ils présentent, à un commencement de saponification produite par les sucs digestifs.

Les déjections des cholériques ont été étudiées avec beaucoup de soin, par MM. Gh. Robin, Legros, Goujon et Papillon. Dans un certaiin nombre decas, les déjections des cholériques sont formées uniquement d'un liquide qui n'est nullement visqueux, n'abandonnant quelquefois rien, quand on le laisse au repos.

Quand, au contraire, il se forme un léger dépôt, celui-ci est constilué, d'après M. Robin, des éléments suivauts: $1^{\circ}$ des cellules épilhéliales, isolées ou sous forme de lambeaux, réunies parfois en petils amas visibles à l'œil nu; ce sont ces cellules épithéliales, dit M. Robin, qui forment avec quelques leucocytes cetle matière blanche loute particulière, assez semblable à une décoction de riz mal cuit, qui constitue presque à elle seule, chez certains cholériques, la totalité des déjections;

$2^{\circ}$ De petits cristaux aciculaires d'acides gras (stéarique ou margarique), isolés ou groupés;

$3^{\circ}$ Quelquefois de pelits grains blancs, de consistance páteuse, formés d'une masse centrale, tantôl grasse, tantôt huileuse, se divisant facilement en petits fragments, réfractant assez fortement la lumière et parsemés de petits cristaux d'acide stéarique; les grains sont souvent entourés d'une couche de cristaux aciculaires, d'acide stéarique ou margarique, comme feutrés ensemble;

4. Souvent des débris de tissus végétaux, ou de tissus animaux, ainsi que des goulles libres d'huile;

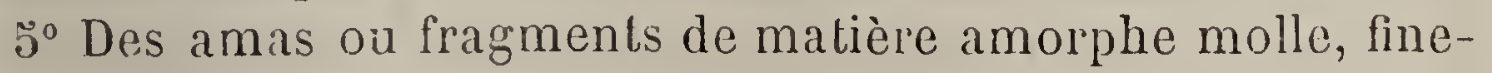
ment et uniformément granuleuse, comme le sont cerlains mucus concrets;

$6^{\circ}$ Rarrement des leucocyles;

$7^{\circ}$ Des globules de ferments;

$8^{\circ}$ La plupart des éléments qui viennent d'êlre signalés son! fréqueminent englobés dans des flocons de mucus intestinal;

$9^{\circ}$ Quelquefois des œufs d'entozoaires.

Des évacuations nivines sanguinolentes et puriformes (Ch. Robin, Traité des Humeur's). - A l'état normal, le mucus 
fourni par le gros intestin est grisâtre, demi-transparent et filant; le mucus renferme des flocons qui paraissent finement striés au microscope. Entre les stries se trouvent des granulations graisseuses, des leucocytes en petite quantité et des cellules épithéliales desquamées, dont les agglomérations sont disposées en séries, ou en traînées (Ch. Robin). Dans la dyssenterie, ce mucus est rejeté à l'état de flocons plus ou moins volumineux; l'acide acélique rend ces stries plus visibles. Ces flocons tiennent emprisonnés des leucocyles et des cellules épithéliales. Les déjections devenant rapidement sanguinolentes, on y trouve un grand nombre d'hématies, qui ne présentent pas l'état crénelé ou frangé, ni la désagrégation en granules, qu'ils subissent dans l'intestin grêle. Les leucocytes sont parfois tellement abondants, qu'ils donnent une apparence puriforme au liquide. On y voit aussi des cellules épithéliales prismatiques, généralement devenues ovoïdes, et des noyaux libres d’épithélium. Ces cellules, ajoute M. Ch. Robin, sont souvent chargées de granulations graisseuses, parfois ce sont des gaînes épithéliales entières, des villosités de l'intestin grêle, à cellules plus ou moins granulcuses, qui sont mêlées à ces divers éléments, avec des cristaux de phosphate ammo. niaco-magnésien et des vibrions. Le tout nage dans un mucus glaireux, homogène ou en flocons striés (Ch. Robin, loc. cit.).

Lorsqu'il y a des ulcérations chroniques dans l'intestin, le nombre des globules blancs l'emporte sur celui des globules rouges; les selles peuvent prendre un aspect puriforme. Dans des cas assez nombreux, des abcès provenant de divers points de la cavité abdominale, du rein, des annexes de l'utérus, peuvent s'ouvrir dans l'intestin. Quand le foyer purulent qui s'est ouvert est considérable, on peut avoir des déjections presque uniquement formées de pus, présentant'une coloration gris. verdatre particulic̀re, plus ou moins fétide.

Le plus souvent, les leucocyles sont accompagnés d'hématies et de mucus intestinal. Parfois, à la suite de la rupture ou de l'ouverture spontanée de l'abcès, il se forme dans le foyer de petites hémorrhagies, à la suite desquelles il apparaît dans les déjections, du sang en quantité plus ou moins considérable, quelquefois même de véritables caillots fibrineux. 


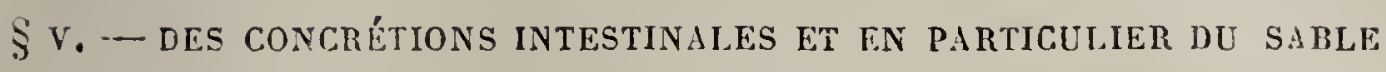
INTESTINAL.

Dans un chapitre précédent nous avons parlé des calculs biliaires. Nous ne mentionnerons que pour mémoire les corps étrangers volumineux, qui se forment dans les voies digestives des grandes espèces d’animaux ruminants, ou soli èdes, et connues sous le nom de bézoards ou d'égagropiles. Les détails qui suivent sont empruntés à une communication faite ¿ l'Académie de médecine le 18 novembre 1873, par notre maître le professeur Laboulbène, si versé dans les questions d'histoire naturelle et d'anatomie pathologique. On a observé dans l'intestin de l'homme des concrétions d'un assez gros volume. L'une de ces concrélions, décrite avec détails par M. Laboulbène, préserte, au point de vue microscopique, cette particularité intéressante, qu elle élait composée de fragments végétaux provenant de cariopses d'avoine et d'éléments minéraux organiques. Les plus fréquents des corps étrangers intestinaux sont, les noyaux, les graines de fruits alimentaires, les débris d'os, d'arêtes, sans compter tous les objets qui peuvent être introduits accidentellement dans les voies digestives, ou les calculs venus du foie. 11 . Làboulbène rappelle, avec, raison, combien sont graves les accidents que peuvent produire ces corps étrangers, quand ils s'arrêtent dans une portion de l'intestin et surtout quand ils s'engagent dans l'appendice iléo-cœcal. L’inflammation des parois intestinales, la perforation de l'appendice sont possibles et sont suivies de péritonite, ou de phlegmon iliaque.

A côté de ces concrétions d'un volume relativement considérable, il se produit, dans l'intestin, du sable ou du gravier' intestinal. M. le professcur Laboulbène a fail connaître six observations d'expulsion de sable intestinal; nous renvoyons à sa communication pour les détails clini fues des observations, ne conservant que ce qui a surtout trait à nos études.

$1^{\circ} \mathrm{A}$ l’œil nu, la malière sableuse était formée de pelits grains brunatres, séparés, fins, ayant en moyenne un dem:-millimètre de diamètre, mais un certain nombre n'araient que deux 
ou trois dixièmes de millimètre. Avec une forte loupe, on constatait que les plus gros grains, foncés en couleur, sont inégaux à leur surface, ceux de moindre volume sont un peu moins colorés; et placés sur une lame de ver'e, beaucoup offrent un aspect hyalin, ou un peu transparent. Après macération dans une eau légèrement acidulée, soit par l'acide acétique, soit par l'acide chlorhydrique, la plupart des granula-

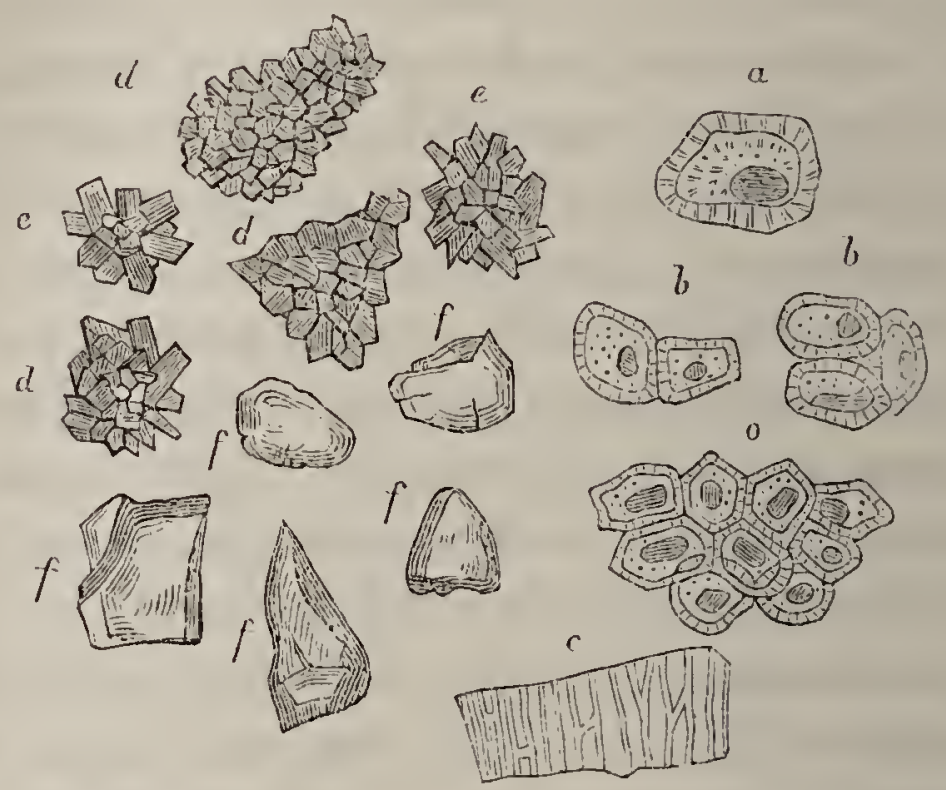

Fig. 373. - Sable intestinal (Labonlbène). $-d, d, d, e, e$. IIasses d'apparence cristalline composées de petits corps agglomérés; $e, e$, sont plus petites et plus anguleuses. $f, f, f, f$. Grains siliceux, à cassure nette et régulière. $-b, b$, $a$. Cellules à parois épáissies et à nuyau foncé, pireilles aux cellules végétales qui proviennent des grains dits pierreux des poires. - ". L'une de ces cellules plus grossic, montrant sur sa paroi les canaux qui vont de- l'intéricur à l'extérieur. - $c$. Fragrment d'un tissu végétal, parcouru par des tubes trachéens, trouvé dans le tube intestinal.

lions brunâtres laissent voir qu'elles sont revêtues et comme empâtées d'une matière organique et leur surface paraît hérissée de cristallisations irrégulières. Il y a donc une partie centrale cristalline et une portion enveloppante organique, nettement isolée par une solution de potasse caustique. Les grains, petits et un peu plus transparents au premier abord, étaient formés par des cellules tantôt séparées, tantôt réunies en groupes, rarement arrondies, plus ordinairement polyédriques, à parois épaisses, à contenu ovoïde ou irrégulier, et d'un brun rougeâtre, placé dans la cavité de chaque cellule. Les parois étaient traversées par des canaux fort nombreux, régulièrement espacés, venant de l’intérieur et, allant à la périphérie. Il résulte de cet examen de M. Laboulbène, que 
ce n'est pas à du sable ordinaire que ressemble celte matière sableuse, car elle est enveloppée d'une substance organique ou enrobée, pour ainsi dire, dans une gangue particulière. La malade par conséquent n'a pas simplement déposé le sable dans ses déjections. Soumis à l'analyse chimique, ce sable s'est montré composé de carbonate de chaux, de silice, de traces de fer et de matière organique. - La malade ne prenait ni magnésie calcinée, ni craie préparée.

$2^{\circ}$ Che\% un autre malade, M. Laboulbène a également recueilli du sable intestinal, dont il donne la description suivante: Les granulations sont jaunàtres, assez semblables entre elles, ayant $1 / 3$ à $1 / 2$ millimètre de diamètre, les moindres seule ment 2 à 3 dixièmes de millimètre. La loupe fait voir tout de suite qu'elles sont irrégulières sur leur surface. Au microscope, on trouve que presque toutes ces granulations sont hérissées de petits points cristallins. D'autres sont, au contraire, formées par des cellules végétales à paroi épaisse et à noyau volumineux. Il y a enfin des granulations constituées par des fragments, à cassure nette, semblables à du verre brisé. Ces fragments sont identiques aux débris siliceux qui forment le sable ordimaire. L'analyse chimique a démontré que ces calculs étaient formés de silice, de phosphate de chaux et de magnésie et d'une faible quantité de matière organique.

$3^{\circ}$ Dans une troisième observation, les granulations remises au $\mathrm{D}^{\mathrm{r}}$ Laboulbène étaient plus grosses que dans le second cas; elles étaient roussâtres, la plupart avaient un demi-millimètre de diamètre. Leur surface, à la loupe et au microscope, était revêtue de prolongements prismatiques, sous la forme de cristaux irréguliers. M. Laboulbène a nettement constaté la présence de cellules végétales et même de petits grains orbiculaires, ayant un sommet pointu et recourbé et pleins de tissu végétal. L'analyse chimique a montré que ces granulations avaient une composition analogue au sable de la deuxième observation.

Dans ces cas, comme dans les précédents, les malades avaient une alimentation très riche en matières végétales; dans plusieurs autres cas observés par M. Laboulbène, la composition des grains de sable a été trouvée la même par M. Méhu. 
En résumé, dit M. Laboulbène, on peut dire que la matière sableuse intestinale, différente de la gravelle biliaire et des concrétions stercorales, reconnaît pour origine les matières siliceuses ou organiques végétales venues du dehors. Sur ces noyaux, comme autour d'un centre, des couches de matières azotées et du phosphate ammoniaco-magnésien se déposent, comme sur un corps étranger quelconque, séjournan! dans le gros intestin. Les granulations du sable intestinal ne sont donc pas analogues aux calculs rénaux, mais au contraire aux calculs vésicaux, ayant pour centre ou noyau, un corps venu dans la vessie et encroûté de substances calcaires.

$$
\text { § VI. - TACHES DE Matières fÉCALES. }
$$

Nous n'insisterons pas sur les éléments que l'on peut rencontrer dans les matières fécales, puisque nous venons d'énumérer les principaux. On comprend combien sont nombreuses les variélés de couleur, d'épaisseur, que peuvent présenter de semblables taches. D'après B. Ritter, cité par le $\mathrm{D}^{\mathrm{r}}$ Gosse, l'hygroscopicité naturelle de la matière sur laquelle une iache excrémentitielle s'est produite exerce une grande influence sur son extension, l’intensité de sa cọloration, sa dessiccation et la conservation de sa forme. Plus la matière a de tendance à absorber l'eau des matières fécales, et plus est grande la périphérie sur laquelle se ré-. pandent les produits qui ont été entraînés, ou qui y sont dissous, et plus l'extension de la tache est rapide, aux dépens de son intensité. Leur dimension changera aussi ( $V$. Gosse, loc. cit.) d'après la plus ou moins grande consistance des excréments. Enfin, leur forme variera suivant qu'elles ont été produites, par le simple écoulement des matières fécales, ou qu'elles ont été obtenues par le frottement Dans ce dernier cas, elles ne donneront que peu ou point de croûtes, et de plus elles présenteront des lraînées irrégulières qui se réunissent. Les bords seront dentelés, comme ceux des empreintes laissćes sur un linge plissé par une substance colorée (Robin el Tardieu, cités par le $\mathrm{D}^{\mathrm{r}}$ Gosse). Plus la tacheoccupe une large surface, plus sa dessiccation s'opère rapidement, plus les restes desali- 
ments qui ont échappé à la digestion et qui se trouvent mêlés aux excréments s'épaissiront. Ces taches présenteront, en outre, une grande tendance à s'exfolier et à se séparer des tissus. C'est généralement sur la face postérieure de la chemise que l'on trouve les taches de matières fécales: quant aux taches que l'on peut rencontrer sur les draps, sur du linge, leur disposition est extrimement variable. Dans les taches par frottement, on peut ne pas rencontrer les éléments qui caractérisent ordinairement les matières fécales. La détermination est alors plus délicate. Il est difficile de différencier les matières fécales de certains animaux, ayant une alimentation à peu près sernblable à celle de l'homme. G'est une question à étudier. Quant aux animaux qui sont exclusivement herbivores, leurs matières fécales offrent des caractères qui ne permettent pas de les confondre avec celles de l'homme.

M. Ch. Robin (Traité du microscope) donne les conseils suirants, pour la préparation des matières fécales el du contenu des intestins. Quand ce contenu est liquide, les préparations se font comme pour les autres fluides. Le contenu de l'intestin est généralement à l'état pultacé, ou de pâte plus ou moins ferme: les préparations se font donc le plus souvent par simple dissociation, sur le porte-objet, des parcelles que l'on veut examiner, et que l'on place préalablement dans une goutte d'eau ou de sérosité incolore. Pour bien se rendre compte de l'étal, des fragments de tissus végétaux, ayant incomplètement subi l'action de la digestion, on pourra étudier avec fruit les excréments des chenilles, des insectes parfaits, des mollusques et d'autres animaux herbivores. Chez les espèces ovipares, on trouve, à la surface des excréments, des grains d'urate de soude provenant de l'urine, qui a une consistance demi-pâteuse. Laddition d'un acide permet à lacide urique de se déposer avec ses caraclères habiluels.

§ VII. - Dl:S ANIMACULES QUI SE FORHENT DANS L'INTESTIN.

Grâce aux conditions favorables d'humidité ct de température qui existent dans l'intestin, il s'y déreloppe pendant la digestion un grand nombre d'animalcules. Les animaux, comme 
l'homme, ont des animalcules dans leur tube intestinal : Leuret et Lassaigne ont constaté l'existence des monades dans l'intestin des grenouilles; d'après Gruby et Delafond, les ruminants auraient quatre espèces d'animalcules vivants, dans les deux premiers estomacs; mais dans le troisième et le quatrième, ainsi que dans les matières excrémentitielles, on ne trouve plus que les carapaces de ces infusoires. Suivant ces auteur's, l'aliment végétal passerait à l'état d'animalcules qui entreraient ensuite dans la circulation, non sans avoir subi l'action de la digestion.

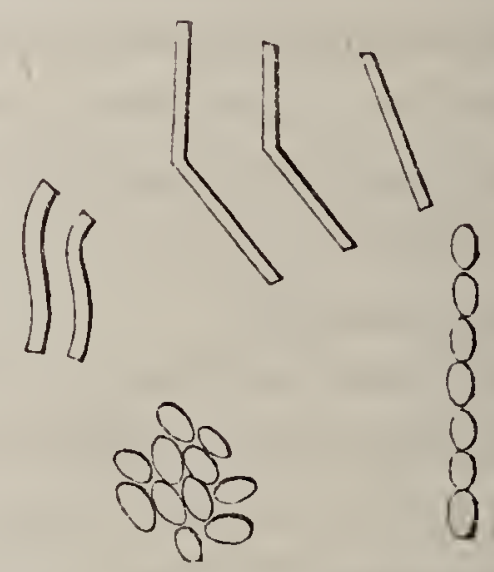

Fig. 374. - Alicrophytes vibrioniens. - Leurs diverses formes dans les selles dyssentériques (Dounon).

Cette théorie aurait besoin d'être confirmée; les carapaces dont parlent Gruby et Delafond proviennent très probablement des acariens si nombreux dans les foins.

Dans les matières fécales normales et fraîches, on ne trouve que rarement des vibrions (Ch. Robin), cependant les Leptothrix n'y seraient pas rares.

Pouchet, en 1849, a trouvé des vibrions dans les déjections des cholériques, peu de temps après leur cxpulsion. Quelques heures après la mort, et avant toute trace de putréfaction, Rainey, cité par M. Robin, a trouvé des vibrions dans toute la longueur de l'intestin, jusqu'au duodénum. Ces vibrions ont également été rencontrés dans d'autres maladies.

En 18ว̌, M. Davaine a trouvé un assez grand nombre de Cercomonas ( $C$. hominis, Davaine) dans les matières fécales de malades attcints de choléra ou de fièvre typhoïde. Les Cer'comonas sont des monadiens pourvus d'un grand cil locomoteur' et d'une queue, on d'un seul cil, qui se rencontrent dans bear- 
coup d'infusions, dans les sérosités, ou le mucus en voie d'altération. On en compte plusieurs espèces (Ch. Robin).

Malmsten de Stockholm a observé des Paramécies (Paramecium coli, Malmsten) dans les déjections liquides et purulentes de malades alteints de diarrhée chronique, avec ulcérations intestinales. Le froid tue ces animalcules, que l'on peut faire vivre en les maintenant à la température du corps humain. - Le Paramecium coli de Malmsten est décrit par M. Ch. Robin

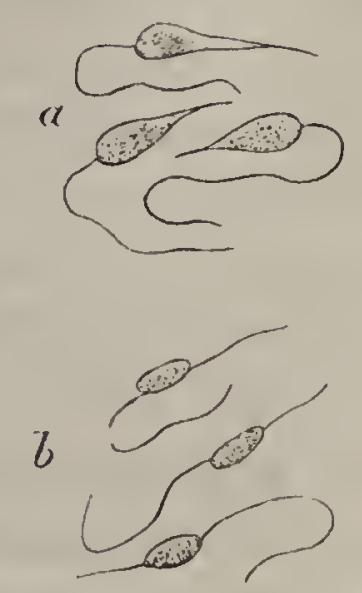

Fig. 37ว̆. - Cercomonas. a. IIunis d'un seul cil. - b. Munis d'un cil locomoteur et d'une queue.

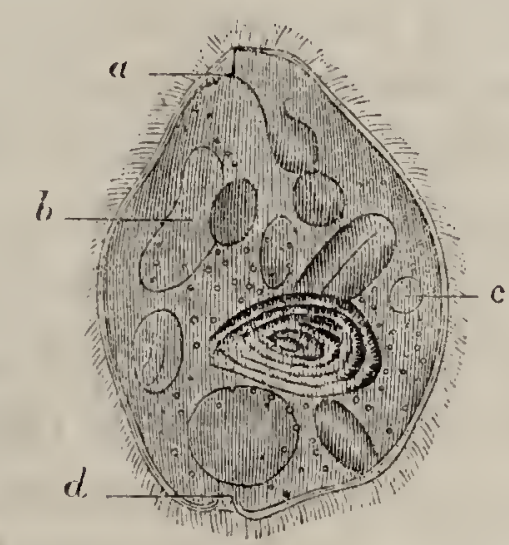

Fig. 3:6. - Plagiotoma coliou Paramecium coli (Malmsten). - $a$. Bouche. - b. Nuclcus. $-c$. Yésicule contractile. $-d$. Anus.

sous le nom de Plagiotoma coli. - Les Plagiotoma sont des bursariens à corps comprimé, plus ou moins circulaire ou ovalaire, avec des cirres buccaux dans un sillon spiral. Il en est qui vivent dans l'eau, mais la plupart se trouvent dans le mucus intestinal.

M. Dounon, dans ses remarquables recherches sur la diarrhée parasitaire de la Cochinchine, a trouvé des monades, ainsi que des vibrions, dans les déjections des malades soumis à ses soins. La première forme sous laquelle le vibrion apparaît dans le mucus est celle de granules excessivement fins, visibles seulement aux plus forts grossissements, réguliers, doués d'un mouvement brownien très vif, qui permet de les reconnaître dans le milieu qui les contient. Ces granules se réunissent ensuite en séries linéaires, commençant par deux, trois, quatre granules. Arrivés à ce chiffre, il en est qui présentent déjà des mouvements. Mais quand ils ont acquis $0^{\mathrm{mm}} ; 004$ de longueur, $0^{\mathrm{mm}}, 003$ de largeur, ces mouvements sont 
bien plus prononcés, ils représentent alors des bàtonnets allongés, terminés par deux extrémités carrées, à peine arrondies et parfaitement semblables. Ils se trouvent en quantité telle, en certains cas, que le champ du microscope en est plein. Ces vibrions linéaires ne s'arrêtent pas à cet état; ils s'accroissent en longueur et, arrivés à $0^{\mathrm{mm}}, 02$ et même à $0^{\mathrm{mm}}, 01$, à une epaisseur de $0^{\mathrm{mm}}, 002$, ils perdent leurs mouvements. Ils sont alors transformés en bâtonnets de Leptuthrix. Ceux-ci sont droits ou coudés à angles plus ou moins obtus. Ils sont sourent isolés, mais parfois on les rencontre formant, par leur association, des touffes plus ou moins étendues ou réuniessur un point central, formant une véritable boule épineuse.

On trouve aussi des spores d'oïlium et des séries linéaires de ces spores (Dounon, Description des parasiles de la diarrhée de Cochinchine et des affertions parasicaires du tube digestif).

Des parasites que l'on trouve dans les dédections des diarrhéiques, qui ont contracté leur maladie en Cochinchine, en frique, ete. - On sait combien est redoutable cette affection, à laquelle succombent, même après leur retour en Europe, un grand nombre de malades. Nous renroyons, pour l'étude des caractères cliniques de la maladie, aux travaux publiés sur celte affection, sur son traitement, par les médecins de la marine, MM. Normand, Dounon, Leroy de Méricourt, etc.

Lorsque le $\mathrm{D}^{\mathrm{r}}$ Normand découvrit dans les déjections des malades atteints de la diarrhée de Cochinchine, en 1876, un certain nombre de petits vers nématoïdes, sa découverte produisit une vive sensation. Jusqu'alors, cette maladie arait été attribuée à des causes diverses, lïgnorance de l'étiologie avait eu pour conséquence une thérapeutique un peu vague et purement empirique. Le caractère pararitaire de cette maladie étant bien établi, les médecins ont pu diriger l'action des médicaments vers un but bien défini. C'est en s'inspirant des travaux de ses devanciers et de ses propres découvertes, que le $\mathrm{D}^{\mathrm{r}}$ Doumon, médecin de la marine, est parvenu à guérir asse\% rapidement un grand nombre de ses malades.

Il est singulier que la découverte de ces nématoïdes se soit fait si longtemps attendre, si l on considère qu'ils ont près de 1 millimètre de longueur et qu'ils se trourent en nombre pro- 
digieux dans les matières expulsées. On estime qu'il peut en être rendu depuis 100,000 jusqu'à 1 million en vingt-quatre heures. Il a donc suffi d'examiner les déjections au microscope, pour y trourer ces parasites. - L'honneur d'avoir fait cette découverte revient, nous le répétons, au $\mathrm{D}^{\mathbf{r}}$ Normand. On trouve ces vers à toutes les périodes de développement. dans les déjections. Si on se propose de les rechercher dans une autopsie, on les trouve dans le tube digestif depuis le cardia jusqu'au rectum, dans le canal pancréatique, dans les conduits biliaires et la vésicule du foie. lls exisient principalement dans une couche de matière épaisse, formée par des produits de sécrétion intestinale, mêlés à des débris alimentaires, couche qui se trouve en contact avec la membrane muqueuse, depuis le pylore jusqu'à l'S iliaque du côlon.

G'est le Dr Bavay, professeur d'histoire naturelle à l'Ecole de médecine de Toulon, qui a donné la description de ces parasites (voy. Davaine, p. 968 et suiv.):

A l'état adulte l'animal est long environ de 1 millimètre et large de $0^{\mathrm{mm}}, 04$. Le corps est cylindrique, lisse, un peu aminci en avant, beaucoup plus effilé en arrière. La bouche est formée de trois lèvres peu distinctes, dont une impaire trilobée. L'œsophage musculeux, triquétre, occupe environ la cinquième partie du corps ; il est divisé en trois portions : une antérieure allongée, plus étroite en avant, brusquement rétrécie en arrière, en une sorte de détroit, qui conslitue la partie moyenne: celle-ci allongée et précédant une partie postérieure dilatée en un gésier ovoïde. On distingue vers le milieu de celui ci une tache en forme d'y, qui indique une valvule cartilagineuse oir armature stomacale. L'intesin, renflé antérieurement en un ventricule, fait suite à l'appareil osophagien et vient aboutir à un anus latéral, près de la base de la queue; il a ses parois peu visibles, mais une paire de glandes d'un jaune brun, le limite de chaque côté dans toute sa longueur. Cette glande est disposée habituellement par masses symétriques. L'ensemble de ces organes est loujours, dans la femelle plus ou moins déplacé par la masse des œufs.

La vulve est siluée au côté droil du corps, un peu au-dessous du milieu. Elle donne accès dans un utérus étendu en avant et en ar-

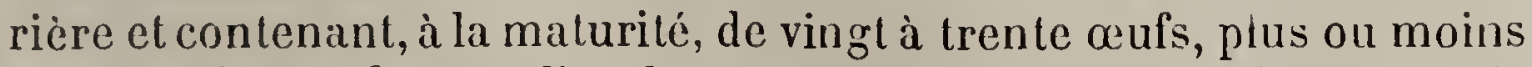
empilés; les œufs sont d'un brun corné. puis jaunes et laissant voir l'embryon. Ils éclosent parfois dans l'utėrus. La femelle ne présente le long du corps ni ailes, ni plis, ni tubercules. Le mâle, plus petit que la femelle d'un cinquième environ, a un testicule entourant la 
masse de l'intestin et les glandes annexes, qui vient aboutir à uu appareil situé à la naissance de la queue à droite, très près de l'anus. Cet appareil pénial est constitué par deux petits spicules cornés, recourbés, renflés à leur base, amincis au sommet et insérés sur un même plan transversal de l'animal. Une pièce cornée très mince; située un peu en arrière, plus courte, plus large que les spicules, se recourbe en forme d'ombilic autour de leur base. La queue est plus courte que chez la femelle et toujours contournée à droite, comme les spicules.

Ces caractères sont ceux de l'âge adulte.

A la sortic de l'œuf, les organes digestifs du jeune ver sont a

A

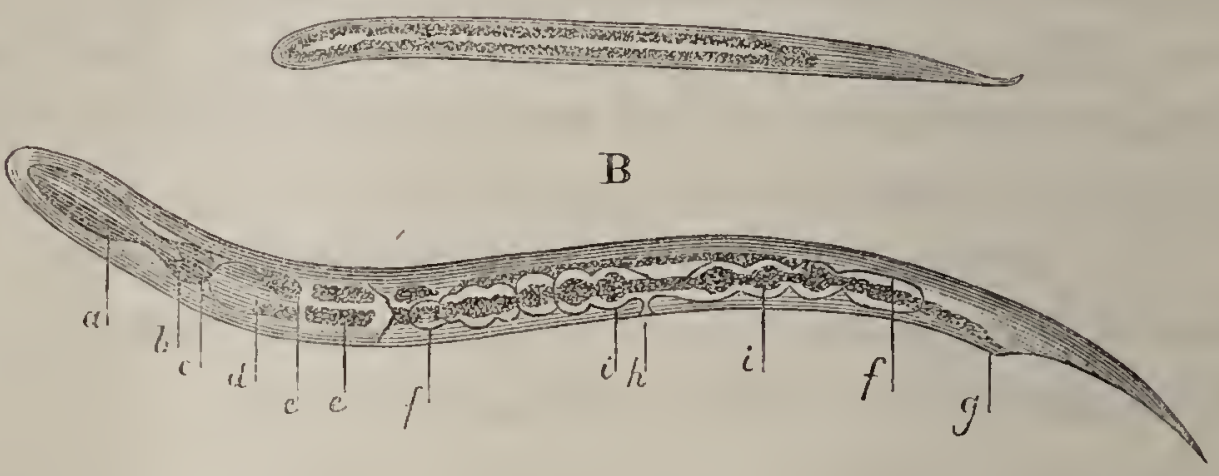

$\mathrm{C}$

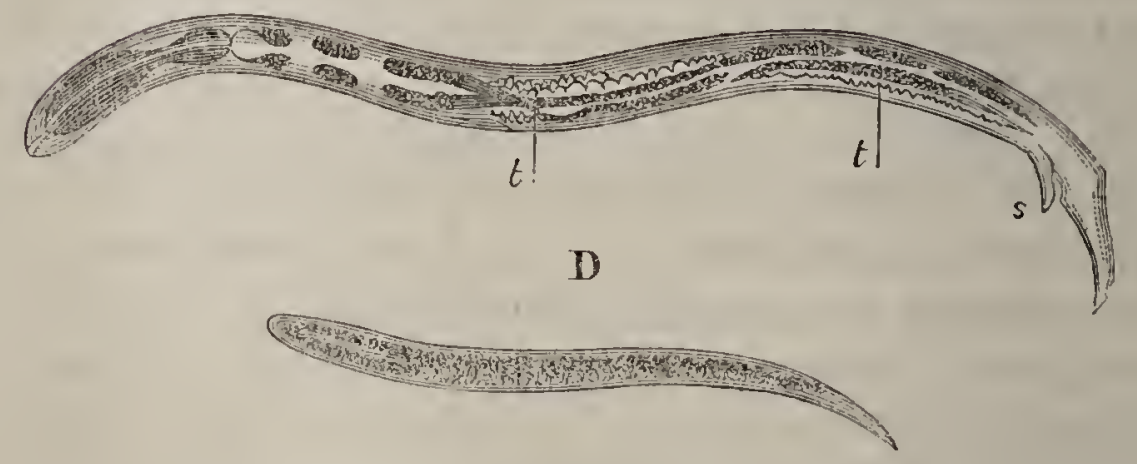

lig. 377. - Anguiilula stercorolis. - A. Premier àge. - B. Femelle adulte. - C. Milk adulte. - D. Embryon. - $a, b$. Premier et deuxième renflements osophagicns. - $c$. Valvule. - $d$. Estomac (?). - e. Foie (?). - $f$. Ovaire. - $g$. Auus (?). - $h$. Vulve. $-i$. OEufs. - t. Testicule. - s. Spicule.

peine apparents : l'intestin est moins long, relativement à l'œsophage, et l'utérus est invisible. C'est à l'âge moyen que ces vers se rencontrent le plus souvent, et c'est à cette période de leur développement que le médecin doit surtout les connaître. A ce moment leurs dimensions sont en longueur (1)m, 33 , en larşur $0^{\mathrm{mm}}, 022$. L'œsophage laisse assez bien voir sa forme carartéristique, analogue ì celle d'un pilon à deux têtes, l'une cylindrique, l'autre sphérique. L'intestin contient des globules gras provenant sans doute du lait, qui constilue le régime du malade. L'utérus n’apparaît que sous la forme d'une vésicule au côté droit de l'animal, la vulve n'est pas 
encore ouverie. Cinq jours suffisent pour que le Rhabditis stercoralis atteigne son complet développement dans des circonstances favorables; de là son extrême aboudance dans l'intestin des malades (Baray).

Les embryons éclosent parfois avant la ponte: souvent les cul: sont pondus, contenant déjà un embryon distinct et mobile; bearcoup plus rarement, ils sont expulsés avantleur développement complet. Les anguillules peuvent être conservées vivantes, pendant cinq à six jours, dans les matières intestinales où elles continuent à se développer. Quand l'embryon sort de l'œuf, il a environ $0^{\mathrm{mm}}, 10$ de longueur; l'oesophage occupe les deux cinquièmes antérieurs du corps, le reste du tube digestif est peu distinct. L'embryon acquiert bientôt $0^{\mathrm{mm}}, 24$ de longueur et devient alors très agile, mais on ne distingue pas de nouveaux organes. Lorsqu'il atteint une longueur' de (mm, 33 , apparaît au côté droit la vésicule qui est le premier indice de l'intestin. Le passage de la période embryonnaire à cette seconde période, qui est celle de la larve, est marqué par une mue.

Avant de passer au deuxieme âge, le ver prend sur ses bords un aspect dentelé, qui lui donne un peu l'apparence d'une scie à chaîne, puis on le retrouve comme engaîné dans un tube, un peu plus long et un peu plus large que lui, dans lequel il se meut d'abord obscurément, pais il s'agite assez vivement, mais sans pouvoir progresser. La gaine dont il cherche à sortir est extrêmement transparente, et, quand elle est bien débarrassée des corpuscules qui lui adhèrent et dont elle est d'abord comme hérissée, on voit à travers elle le ver et ses organes intérieurs caractéristiques. Un examen prolongé permeltra d'assister à la sorlie du ver qui commence ses évolutions dans les liquides environnants, tandis que sa gaîne restera sur place, surtout apparente par ses contours et quelques plicatures (Normand).

Le $D^{r}$ Bavay a proposé de donner au ver de la diarrhée de Cochinchine le nom d'Anguillula sterroralis; ce parasite se rapprocherait beaucoup du Rhabditis terricula de Dujardin, genre Leptodera de Schneider.

L'Anguillula stercoralis se rencontre loujours dans les déjections des malades atteints de la diarrhée de Cochinchine; il est un autre parasite, également décrit par M. Baıay, qu'on y trouve fréquemment, mais pas d'une façon constante. M. Bavay, ayant étudié un ver nématoïde trouvé dans des déjections où il accompagnait l'Anguilluia stercor'alis, n'a pu le faire entrer dans aucune des classificalions modernes; ce savant naturaliste propose de l'appeler provisoirement anguilla inrestinalis. Voici la description qu'en donne M. Bavay: 
Longueur de l'adulte $2^{\mathrm{mm}}, 20$, largeur moyenne $0^{\mathrm{mm}}, 034$. Le corps, un peu aminci en avant, se termine assez subitement en arrière, par une queue conique, dont la pointe est très sensiblement arrondie et même un peu dilatée, à l'extrémité. Avec un grossissement suffisant, la surface paraît très finement, mais très régulièrement striée el travers, dans toute sa longueur. La bouche ne présente aucune armature cornée, mais seulement trois lèvres fort petites. Elle donne accès à un œsophage à peu près cỵlindrique qui occupe environ un quart de la longueur de l'animal, sans présenter ni renflements ni stries et qui est suivi d'un intestin, avec lequel on le confondrait facilement, saus un brusque changement de teinte. Cet intestin s'é. tendjusque vers l'extrémité postéricure du corps ; mais il cesse pres que d'être visible dans la partie moyenne occupée par un ovaire très allongé. La vulve est située au tiers postérieur de l'animal. et, dans son voisinage, l'utérus contient cinq à neuf oufs assez allongés, isolés les uns des autres et devenant un peu confus, à mesure qu'ils s'éloignent de la vulve.

L'anus, en fente transversale, est situé ver's la base de la queue. Les œufs et les viscères sont d'un jaune verdâtre, assez opaques et semblent très finement granuleux. Tous les individus observés étaient des femelles ovigères, ou bien ils ne présentaient aucun organe sexuel mâle ou femelle, quoique leur taille fût assez grande... Dans les matières oủ l'on rencontre le ver, on trouve assez souvent des tronçons contenant des œufs; parfois on aperçoit ces œufs isolés et reconnaissables à leurforme allongée; dans quelques-uns, l'embryou est en voic de formation et présente alors une rangée de cellules dorsales très remarquables; dans d'autres, l'embryon est plus avancé et fait même deux tours complets. (Pour plus de détails, voy. Da. vaine, loc. cil.)

En raison de son caractère parasitaire, la diarrhée de Cochinchine n'est pas contagieuse: comme nous le verrons ciaprès, on contracterait cette maladie en buvant des eaux non filtrées et non bouillies.

L'Ankylostome duodénal se rencontre dans les déjections de certains malades. Il a été observé d'abord à Milan el à Vienne. Il est surtout fréquent en Égypte et plus encore dans certaines contrées de l'Amérique du Sud. Pour les détails cliniques, on consultera l'ouvrage de M. Davaine, p. 933, auquel nous empruntons la description suivante:

Les vers appartenant au genre Ankylostomum (Dubini) sont des vers cendrés à corps cylindrique; tête un peu amincie; bouche en forme de ventouse subcorıée, dont l'ouverture est ample, circulaire. 
tournée vers la face dorsale; dents situées dans la bouche, en dedans de la marge inférieure, au nombre de quatre; le pharynx est infundibuliforme, à parois résistantes; œsophage musculeux, s'élargissant en arrière : tégument strić en travers; deux éminences coniques ou papilles opposées, situées à la limite du premier sixième de la longueur totale du corps; anus latéral, un peu en avant de l'extrémité de la queue. - Mále pourvu d'une bourse caudale terminale, entière, excisée en dessous, multiradiée, ex-appendiculée, pénis double et très long. Femelle à queue obtuse; vulve située en arrière. Vivipare.

Ankiylostome duodénal (Dubini). - Tète arrondie au sommet;

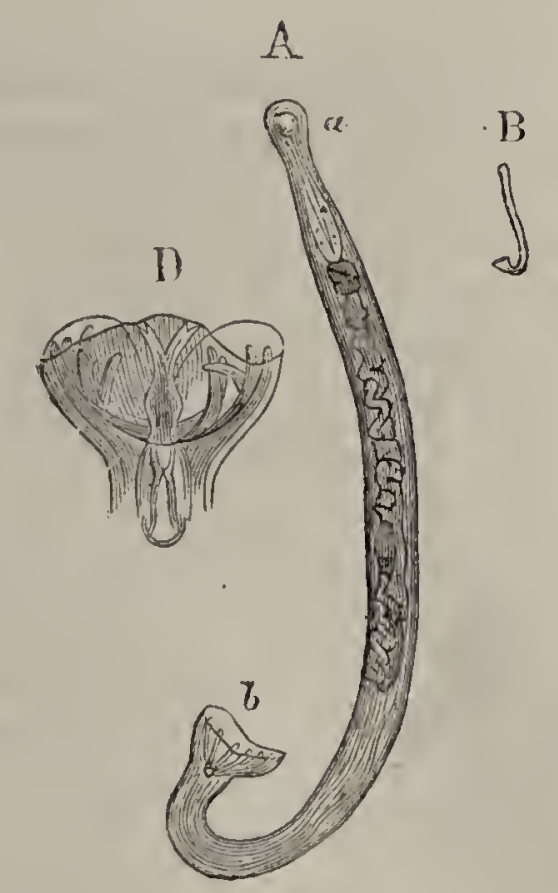

Fig. 378. - Anchilostomum duodenale, unâle. - B. De grandeur naturelte. 1. Le mème grossi: $a$, Extrémité céphalíue. - b. Eitıèmité caudale. - 1). Extréuité candale fortement grossic, pour montrer la disposition de la bourse et des wayous qui la soutiennent. (1)avaine.)

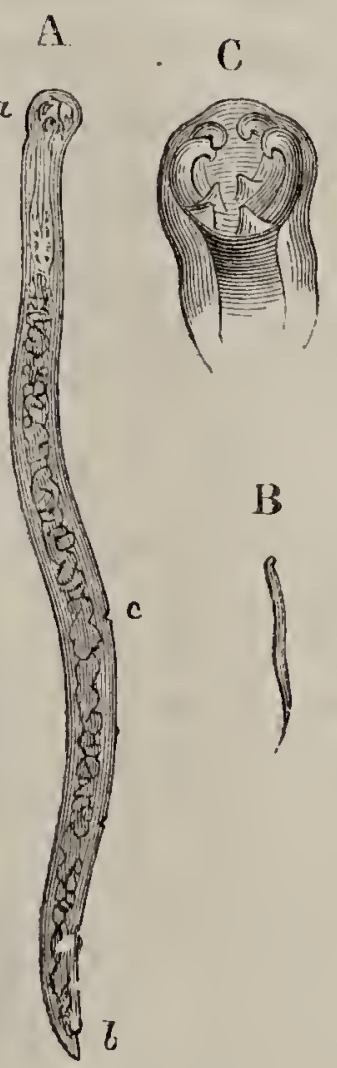

Fig. 379. - Anchilostomum dundsnale, femelle. - B. Grandeur naturelle. - A. Là mème, glossie : a. Extrémité céphalique. - $b$ Extrémité eaulale. - c. Orifice vulvaire. - C. Extıémité eéphalique fortement grossie ponl montrer la disposi tion de l'armature buecale.

limbe de la bouche muni de papilles coniques inégales, deux plus petites; crochets terminant les papilles, convergeant par leur sommet ; corps droit ou légèrement courbé, transparent en avant ; ventricule globuleux noirâtre, visible par transparence ; partie postérieure jaune rougeâtre. Mâle aminci en avant, long de six à huit millimètres; extrémité caudale infléchie, bourse cyathiforme, formant deux lobes à cinq rayons, disposés par quatre de chaque còté et trois au milieu; tous les rayons simples, excepté le médian qui 
est bifurqué au sommet. Femelle, longueur 8 à 10 millimètres ; épaisseur $0^{\mathrm{mm}}, 27$; extrémité poslérieure terminée en pointe conique; vulve située vers le quart postérieur.

Le mâle et la femelle se trouvent dans la proportion de 1 à 3 (Dubini). Dav. Synop. CXIX.

Outre les anguillules qui se trouvent dans les déjections des malades atteints de la diarrhée de la Cochinchine, il en est d'autres sur lesquelles M. le $\mathrm{D}^{\mathrm{r}}$ Dounon, médecin de première classe de la marine, a appelé récemment l'altention. Cet observateur distingué a découvert un nouvel ankylostome, auquel il a donné le nom d'ankylostome dyssentérique (Dounon) (1). L'espèce découverte par le $\mathrm{D}^{\mathrm{r}}$ Dounon ne présente pas réunis, tous les caractères du genre ankylostome.

Le corps de cet animal a $0^{\mathrm{mm}}, 2 \ddot{\partial}$ de l'orifice buccal au bord du pavillon génital. Quand les appendices rameux qui en partent sont

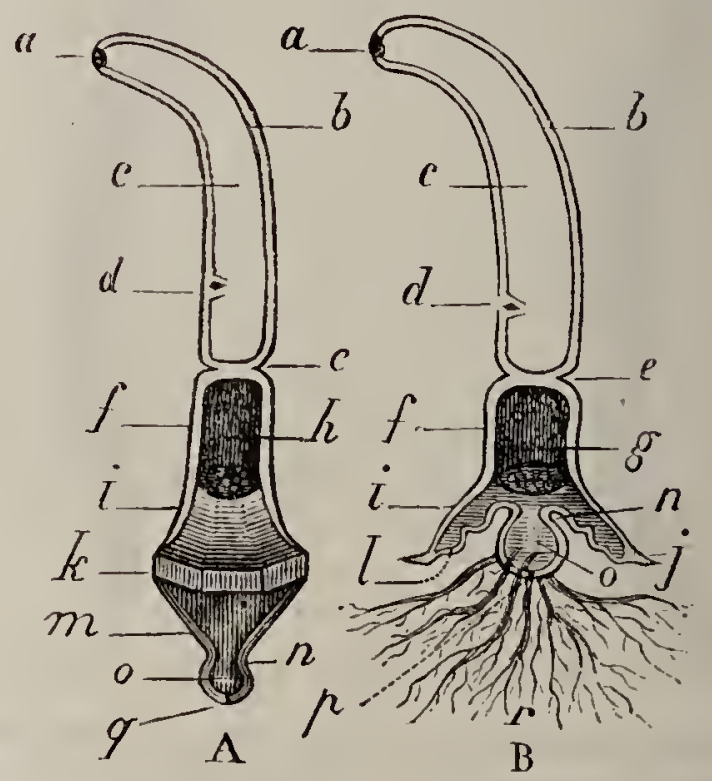

Eig. 380. - Ankỵlostome dyssentérique. - A. Femellc. - B. Nlàle. - $a$, a. Orifice buccal. - $l, b$. Paroi du tube digestif. $-c, c$. Cavité de ce tubc. $-d, d$. Anus. $e, e$. Cloison qui sépare les portions digestive et génitale. $-g$. Testicule. - h. Ovaire. - $i$, $i$. Paroi de la partic évasée de la portion génitale. $-j$. Rebord liexagunal de l'entonnoir génital, horizontal ou en plateau chez le mâle. $-k$. liebord licxagunal de la portion génitale, verícal ehez la femelle. - $l$. Membrane du génitophore dı mâle (elle est ici à l’é at inclus). - $m$. Nembranc du génitophore de la femelle (elle est ici à l'état déployé). - $n, n$. Etranglement qui séłare la nembrane plissée du génitophore. $o, o$. Génitophore. $-p$. l'énis. $-q$. Vulve. $-r$. llameaux arborescents du mâle.

complètement renversés à l'extérieur, il a $0^{\mathrm{mm}}, 4$ de longueur. Sa largeur au niveau du tube digestif est de $0^{\text {m } \mathrm{m}}, 02$, au niveau du pavillon clle est de $0^{\mathrm{mm}}, 0$; ; il est naturellement divise en deux portions qui dif-

(1) Description des Parasites, étiologie et pa'hogénie de la dinrrhe de Cochinchine et des affections parasitaires du lube digestif. Toulon, 1877. 
fërent non sculement par la forme, mais par la couleur: une antéricure, allongée, portion digestive ; la postérieure renflée, portion génitale ; la première est blanche, transparente ; la deuxième jaune opaque; ces deux portions sont séparées par une cloison transrersale. La portion antérieure figure un cylindre qui s'atténue insensiblement depuis la cloison jusquà l'orifice buccal. Cet orifice est orbiculaire; il est généralement très difficile à voir, parce qu'il ne se met jamais de champ sous le microscope, à cause de la direction du corps. Il apparaît comme une tache ronde, dans laquelle on ne découvre ni dents, ni armature. La direction de ce cylindre est d'abord à peu près rectiligne, mais du côté de l'extrémité libre il s'incurve peu à peu, puis à la fin il affecte chez beaucoup de sujets, une courbure brusque analogue à celle d'un hamecon. Le cylindre est creux; vu de travers, il présente de chaque côté ine paroi relativement très épaisse, transparente, d'aspect corné, dont les contours résistent à une dessiccation prolongée ; son épaisseur est de ()$^{\mathrm{mm}} ; 006$. Le double contour de cette paroi est très réringent et apparaît comme une ligne noire très prononcée... La cavilé du tube digestil se termine, en avant, par une portion atlénuée qui correspond à la bouche; en arrière, par un cul-de-sac arrondi, très régulier: à ce niveau, la paroi qui le constitue se continue sans ligne de démarcation, avec la paroi correspondante de la portion génitale; au niveau de l'adossement des deux parois, se voit, sur la paroi extérieure, une rigole circulaire de forme triangulaire. Un peu en avant du cul-de-sac, on voit une saillie en forme de triangle, à sommet tronqué. Les bords de ce triangle s'accusent par une ligne très réfringente, le sommet est incolore et ne se dislingue pas; les deux còtés se prolongent jusqu'à la face interne de la paroi du tube. Au centre, on voit manifestement une cavité un peu renflée en ampoule, qui part du sommet et va, à la base du triangle, s'ouvrir en dehors, en un point où il existe une perte de substance manifeste. Il n'est pas douteux que le canal central représente le rectum, et l'orifice situé sur la paroi, l'ouverture anale.

La portion génitale n'est pas cylindrique, comme la portion digestive, elle a exactement la forme d'un entonnoir dont le tube serait légèrement renflé du côté de la cloison, et dont le pavillon serait très évasé. Comme dans l'entonnoir, on trouve à y considérer une extrémité antérieure rétrécie, qui correspond à la cloison, et une extrémite postéricure évasée ; unc face interne et une face externe.

L'extrémité antéricure confine au tube digestif; elle a la forme d'un cul-de-sac arrondi, adossé à celui de la portion digestive. Les deux culs-de-sac adossés constituent une cloison assez épaisse. L'extrémité postéricure évasée a, dans les deux sens, la forme d'un hexagone regulier; clle se continue chez la femelle avec une membrane conique, plissée dans la cavité de l'entonnoir ; chez le mâle, avec 
une sorte de plateau placé de champ, qui sera décrit plus loin; elle constitue l'ouverture évasée de l'entonnoir. La face interne, cavité de l'entonnoir, correspond, dans la portion tubulaire, à l'ovaire et au teslicule. qui lui sont intimement appliqués; dans la portion évasée, elle correspond à la membrane plissée qui s'applique sur elle dans loute son étendue, au moins chez la femelle.

La face externe est conique, lisse; chez le mâle, la régularité du cône continue jusqu'au rebord de la cavité de l'entonnoir ; chez la femelle, au contraire, elle présente, avant d'arriver à ce rebord, une bande large de $0^{\mathrm{m} ı}, n 02$, tout à fait semblable à la bande métallique qui couronne la partie supérieure de l'entonnoir ; comme dans cet objet, cette bande est parallèle à la direction de l'axe, mais au lieù d'être circulaire elle est diviscee en six reclangles allongés et égaux.

La paroi comprise entre ces deux faces est épaisse, réfringente, d'une teinte nacrée, blanchâtre, tout à fait semblable à celle du tube digestif ; elle a une apparence cornée ; elle résiste à la dessiccation ; elle part du cul-de-sac dont elle forme le fond, puis elle remonte le long de la portion tubulaire; elle est conique dans le pavillon et contient des organes qui seront décrits plus tard.

A partir du bord qui limite la face externe du pavillon, si on regarde dans sa cavité, on voit chez le mâle un plateau de couleur claire, placé de champ, transversalement, par rapport à l'axe du corps. Ce plateau présente une face interne, qui ne se voit pas du dehor's, siluće du côlé de la cavité de l'entonnoir; une face externe lisse jaune, en forme de bande circulaire ; un contour exlérieur hexagonal, formé de six côtés égaux ; chacun de ces côtés présente une légère concavité en dedans et s'unit à celui qui le touche en formant un angle saillant de 20 degrés, dont le sommet représente une arête conique mousse.

Le contour intérieur représente très exactement une circonférence incluse dans l'hexagone précédent, située à $0^{\mathrm{mm}}, 001$ de la portion moyenne des côtés de l'hexagone; il est très régulier; il limite une cavilé arrondie, conique, obscure, et se continue à angle droit avec une membrane que M. Dounon appelle plissée. Chez la femelle ce plateau n'existe pas; à partir du rebord du pavillon, on voit la membrane plissée qui se continue avec lui se réfléchir en dedans, redescendre le long de la face interne hexagonale sur laquelle elle est appliquée; puis, dans les deux sexes, elle s'étale au fond de la cavité di pavillon de l'entonnoir, où elle présente trois plis circulaires, inclus les uns dans les autres, décroissant, par conséquent, de dehors en dedans. Dans l'intérieur du pli le plus interne, on voit dans les deux sexes un corps arrondi hémisphérique, mamelonné, et au centre de celui-ci, un orifice arrondi, plus grand chez la femelle, où il est obscur, et manifestement vide, c est la vulve; plus petil chez le mâle, on $\mathrm{y}$ distingue un organe de forme conique, de couleur jaune, paraissant libre d'adhérences, c'est le pénis. La membrane plissée que 
l'on aperçoit à l'intérieur du pavillon est un véritable feuillet à paroi assez épaisse, de forme conique, dont la base est insérée sur le rebord du pavillon et dont le sommet se continue avec le corps hémisphérique, que nous avons vu exister, dans son pli le plus interne. Ce corps n'a cette apparence que parce qu'il est enfuncé dans le fond du cône creux qu'elle forme; en réalité, il est parfaitement

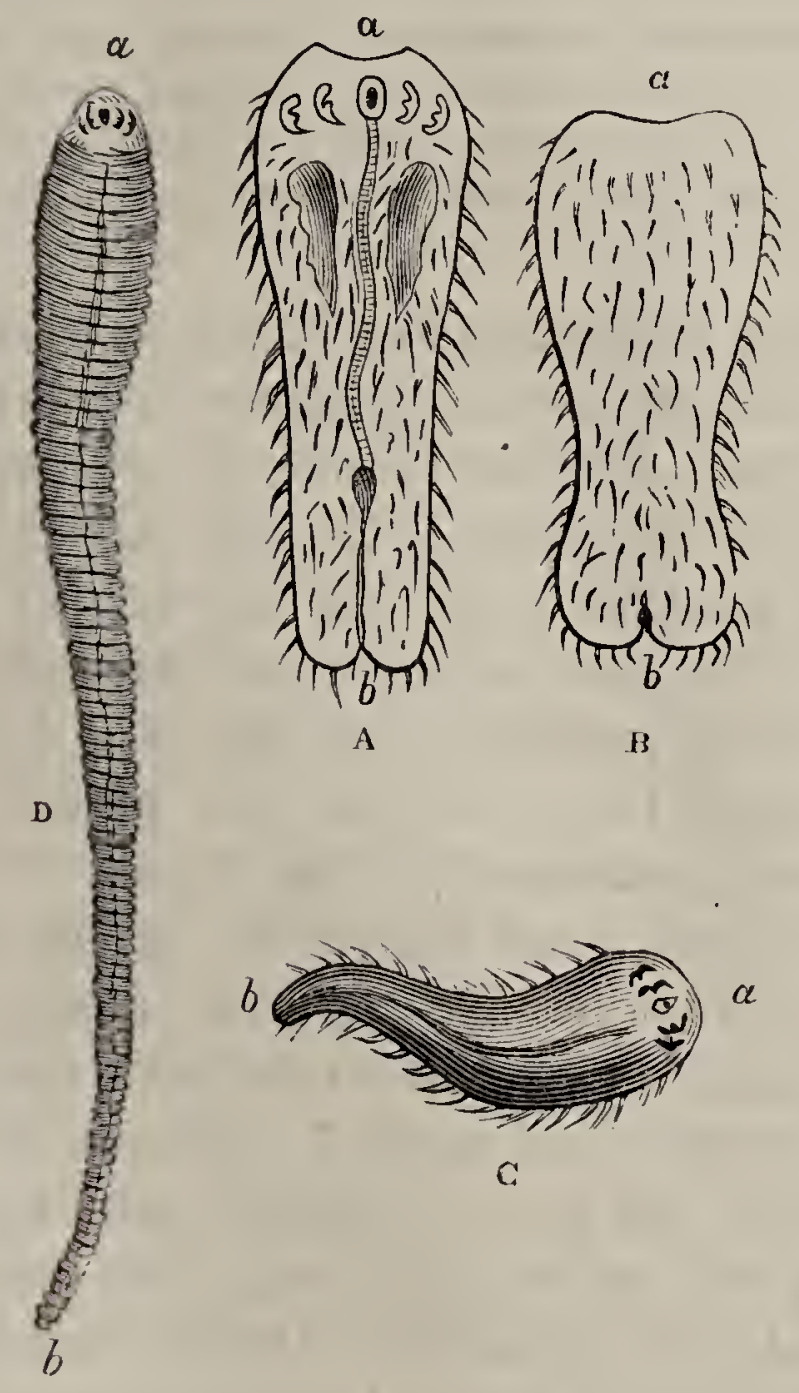

Yig. 381. - A. Linguatule, larve (face ventrale) raecourcie par la contraction. - B. Linguatule, Jarve faee dorsale). - D. Linguatule màle. - C. Linguatule jeune.asexué. - a. Extrémité antérieure. - $b$. Extrémité postérieure (correspondant à l'anus dans les fïures C, D et à la vulve dans les figures A et B). Ces parasites se rencontrent dans les matières féeales des personues atteintes de la diarrlée de Cochinchine. (Dounon.)

sphérique; II. Dounon l'appelle génitophore à cause des fouctions qu'il remplit dans la copulation. Il présente une cavité arrondic en communication avec l'extérieur par l'orifice vulvaire chez la femelle, pénien chez le mâle ; avec la cavité de la membrane plissée, par un canal qui se trouve au centre du pédicule; sa paroi est aussi épaisse que celle de la membrane plissée, avec laquelle elle se continue au niveau de l'étranglement qui les sépare. I.a surface extérieure du génitophore chez la femelle est mue et présente seulement quelques 
saillies mamelonnées. Chez le mâle, au contraire,il donne insertion, par sa circonférence équatoriale, à des expansions rameuses très remarquables; les rameaux, au nombre de six, naissent par un tronc unique qui émerge perpendiculairement de la surface externe du génitophore. Le tronc qui conslitue l'axe du rameau se présente jusqu'à l'extrémité opposée; il émet des ramifications par un seul de ses côtés. L'axe et les ramifications qui en émergent sont arrondis, jaunâtres et paraissent résistants ; ils vont diminuant progressivement de volume; leurs dernières divisions, tout en conservant la même couleur, paraissent être molles et comme gélatineuses. On n'y distingue aux plus iorts grossissements aucune trace de structure.

Les vaisseaux présentent une direction et des contours très variables: tantôt on les voit épanouis horizontalement, rigides jusque dans leurs derniers ramuscules et formant comme un éventail; tantôt au contraire ils sont repliés en arrière de la couronne du pavillon et comme couchés le long du corps; dans la figure ils sont encore épanouis, mais moins rigides; leur axe central présente des contours qui sont plus ou moins prononcés. Ces rameaux sont parfois réunis et rapprochés comme les baguettes d'un fuseau.

M. le $\mathrm{D}^{\mathrm{r}}$ Dounon a fait suivre ces détails anatomiques de considérations très remarquables, sur la physiologie des organes décrits; nous renvoyons au mémoire original de l'auteur ceux de nos lecteurs qui seraient désireux de les connaître. Néanmoins nous ne pouvons passer sous silence les détails qui suivent, parce qu'ils montrent d'une façon précise comment agissent ces parasites. "On les voit réunis en grand nombre sur un même point; les mâles paraissent plus rares que les femelles. Ils sont fixés sur la muqueuse par leur bouche, tandis que le reste du corps est couché plus ou moins obliquement. Leur fixation est très intime, on les voit rarement détachés, sans qu'ils entraînent à leur bouche un fragment qui appartient certainement à la muqueuse. On ne peut pas y reconnaître des éléments de celle-ci, jarce qu'ils sont obscurcis tant par le sang qui y est infiltré et dont on retrouve les globules plus ou moins altérés, que par de nombreuses granulations pigmentaires. Ciet animal a le pouvoir, comme tous les parasites qui vivent dans l'intestin, d'exercer une aspiration énergique; le vide qu'elle produit a une puissance assez grande 
pour attirer le sang et déterminer la formation d'une véritable ecchymose. Les ankylostomes ne présentent généralement aucun mouvement dans les selles où on les trouve éliminés. Ils ont cela de commun avec tous les parasites; leur élimination n'a lieu, en dehor's de quelques circonstances accidentelles, que par leur mort. "

\section{Parasite de la diarrhée d'Afrique. - Strongylus sanguisuga}

(Dounon, loc. cit., p. 15े). Ce parasite, dit le $D^{r}$ Dounon, se place par ses caractères anatomiques entre le genre ankylostome et le genre strongle proprement dit. Il se rapproche du premier par la ventouse cornée qu'il présente à la partie antérieure du corps, par sa couleur jaunâtre; du second, par sa forme arrondie, ses bords réfringents et par l'opacité de son parenchyme. Comme les ankylostomes, il se fixe sur la paroi de l'intestin et en pompe le sang. De ces deux noms, M. Dounon préfère celui de strongle, parce qu'aujourd'hui ce nom est plutôt une appellation générale, qu'un terme șervant à désignel un genre bien déterminé.

Le corps de cet animal présente une icinte jaunâtre, il est manifestement arrondi ; il a une longueur de $0^{\mathrm{mm}}, 25$, et une largeur de $0^{\mathrm{mm}}, 023$, au milieu

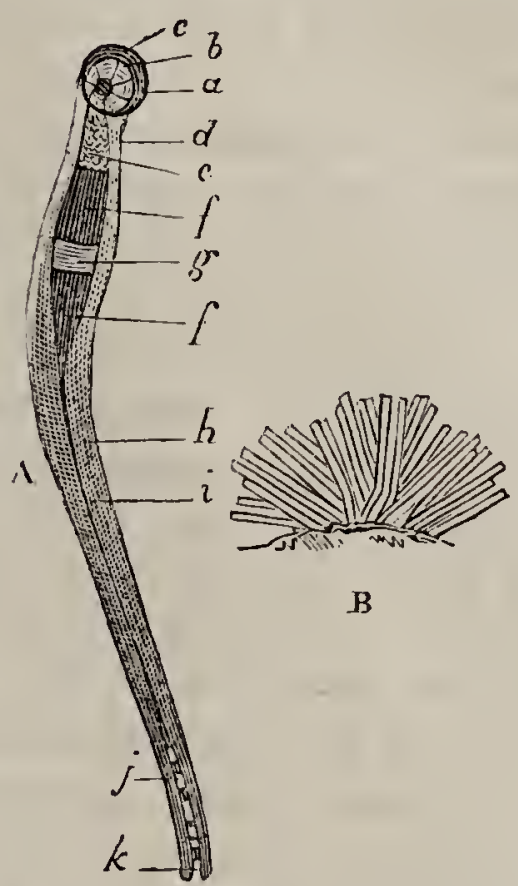
du corps, au point oủ elle est le plus considérable. De ce point, il va s'alténuant, surtout en arrière, du côté de l'extrémité caudale, oủ il s'effile peu ì peu, de façon à n'avoir plus que $0^{\mathrm{mm}}, 00 \ddot{\mathrm{de}} \mathrm{de}$ largeur. En avant, il s'atténue, mais beaucoup moins qu'en arrière; au niveau de la bouche, il a encore $0^{\mathrm{mm}}, 012$; au niveau de la cupule, il se renfle un peu jusqu'au bord antérieur de celle-ci. Le tube digestif est représenté par un canal complet qui va de la cupule à l'estrémité caudile el présente les particularités sui- 
vantes: la bouche est parfaitement sphérique; elle est ouverte et ne présente ni dents ni aucune armature; son bord parfaitement net fait un angle obtus avec la face interne de la cupule; elle se trouve au sommet du cône que forme celle-ci, sa couleur foncée tranche nettement sur les parties environnantes (fig. 3 2). La bouche se continue direclement avec l'estomac. Il n'y a pas d'osophage. Cet estomac a la forme d'une ellipse très allongée, tronquée à son extrémité antérieure, très pointue à son extrémité postérieure; sa longueur est de $0^{\mathrm{mm}}, 08$, c'est-à-dire le tiers de la longueur du corps. Il part de la bouche sous la forme d'un tube, plus foncé que les parties voisines, d'abord du même diamètre que l'orifice buccal, qui vä ensuite s'élargissant successivement, il arrive alors a avoir $0^{\mathrm{mm}}, 013$ d'épaisseur; il conserve ce calibre sur une longueur de $0^{\mathrm{mm}}, 04$. puis en arrière de ce point il s'effile successivement et d'une facon régulière, jusqu'à n'avoir plus que $0^{\mathrm{mm}}, \mathrm{l}^{\prime} 01$.

Les parois, si elles existent, sont complètement invisibles; elles paraissent être uniquement constituées par le tissu du corps de l'animal qui, à ce niveau, ne présente ni épaississement ni aucune différence de texture. Ce tissu qui est, au niveau de la partie moyenne du corps, jaunâtre et opaque, est à la partie antérieure du corps, autour de l'estomac, transparent et blanchâtre; il accompagne ce viscère et lui forme une enveloppe de $0^{\mathrm{mm}}, 002$. $0 \mathrm{n}^{4} \mathrm{n}^{\prime} \mathrm{y}$ distingue, avec les plus forts grossissements, aucune trace de structure.

Le tube digestif se continue manifestement au milieu du corps et va d'une extrémité à l'autre; mais on le perd de vue à peu près vers la partie moyenne, où il est masqué par la substance opaque qui l'environne. On le retrouve dans le sixième postérieur du corps, sous la forme d'un canal arrondi, transparent, renfermant toujours des amas irréguliers de matières pigmentaires. Il se termine par un anus circulaire qui vient s'ouvrir entre deux mamelons laléraux arrondis, dans l'angle à sommet tronqué qu'ils laissent entre eux. A sa partie antérieure, se troure une cupule qui couronne en quelque sorte le corps de cet animal et dont M. Dounon donne la description avec détails.

Sur aucun de ces animaux, cet observateur n'a pu découvrir les organes génitaux. Cet animal ne présente jamais de mouvements dans les selles, comme la plupart des autres parasites, et ne s'élimine de la surface de la muqueuse que quand il est mort; le $\mathrm{D}^{\mathrm{r}}$ Dounon a étudié les mœurs de ce parasite et les a exposées avec détails. L’animal se fixe sur la muqueuse intestinale, fait le vide dans sa cupule, y atlire la muqueuse, et aspire le sang que l'on retrouve dans son tube digeslif, dans différents états d'altération. Cette soustraclion de sang, par 
cet animal, reproduite sur un grand nombre de points, rend: compte de l'épuisement, de l'anémie et de la faiblesse, qui sont hors de proportion arec la durée de la maladie ne datant que d'un mois. Le $\mathrm{D}^{\mathrm{r}}$ Dounon, à la monographie duquel tous ces détails sont empruntés, a donné à ce parasite le nom de. Strongylus sanguisuga.

La diarrhée peut être également produite par d'autres parasites, tels que les oxyures, les ténias et les ascarides, qui seront décrits dans un chapitre spécial.

Diarrhée proluite par les larves du Carpocapsus Pomomana. - M. le $\mathrm{D}^{\mathrm{r}}$ Dounon, dans un travail publié sur le traitement de la diarrhée en Cochinchine et sur les affections. parasitaires, a signalé un cas de diarrhée produite par les larves des chenilles d'un lépidoptère appelé le Carpocapsus Pomomana. Le malade était un soldat qui mangeait des quantités considérables de fruits, poires ou pommes, de mauvaise qualité; la plupart étaient gâtés et piqués par les vers, ce qui n'empêchait pas ce soldat de les manger gloutonnement, sans prendre aucune des précautions d'usage. Le $\mathrm{D}^{\mathrm{r}}$ Dounon trouva la cause de la maladie dans les déjections du malade. Voici la description de l'animal appelé chenille rase, à cause de la rareté de ses poils. "La mâchoire supérieure en forme d'U, ouvert en arrière, est constituée par une substance excessivement dure, chilineuse, qui résiste aux instruments les plus acérés; elle a tout à fait la forme de l'arcade alvéolaire supérieure de l'homme. La mâchoire inférieure est formée par une languette, qui vient s'appliquer exactement sur la courbe alvéolaire supérieure: elle est munie à son sommet de trois appendices, qui portent des couronnes de piquants très aigus. A côté de la bouche, on trouve des appendices semblables, dont les piquants sont beaucoup plus longs. La bouche s'ouvre, comme celle des mammifires, par abaissement de la mâchoire inférieure. L'animal l'ouvre dès qu'on l'irrite, et on voit apparaître une bouche énorme, qui se continue par une cavité pharyngienne, oblique en arrière, dont la paroi postérieure est manifestement cornée. Cet animal est très rorace. La présence de cette triple couronne de piquants qui se trouve appliquéc contre l'arcade alvéolaire et des deux couronnes 
qui sont placées à côté de la bouche, rend parfaitement compte du pincement de la muqueuse, que l'animal saisit, pour ne pas être éliminé de l'intestin. Il s'aiđe aussi, pour se fixer, de ses pattes moyennes et postérieures, qui présentent à leur extrémité libre une surface concave, sur le bord de laquelle on voit une très belle couronne de piquants, dirigés de façon à attirer en dedans et à fixer le corps mou quelconque, dans lequel ils sont implantés."

Ces larves, dit M. Dounon, ont pénétré avec les fruits dans la cavité digestive; elles ont franchi l'œsophage et l'estomac sans s'y arrêter, puis, arrivées dans l'intestin, elles se sont fixées;
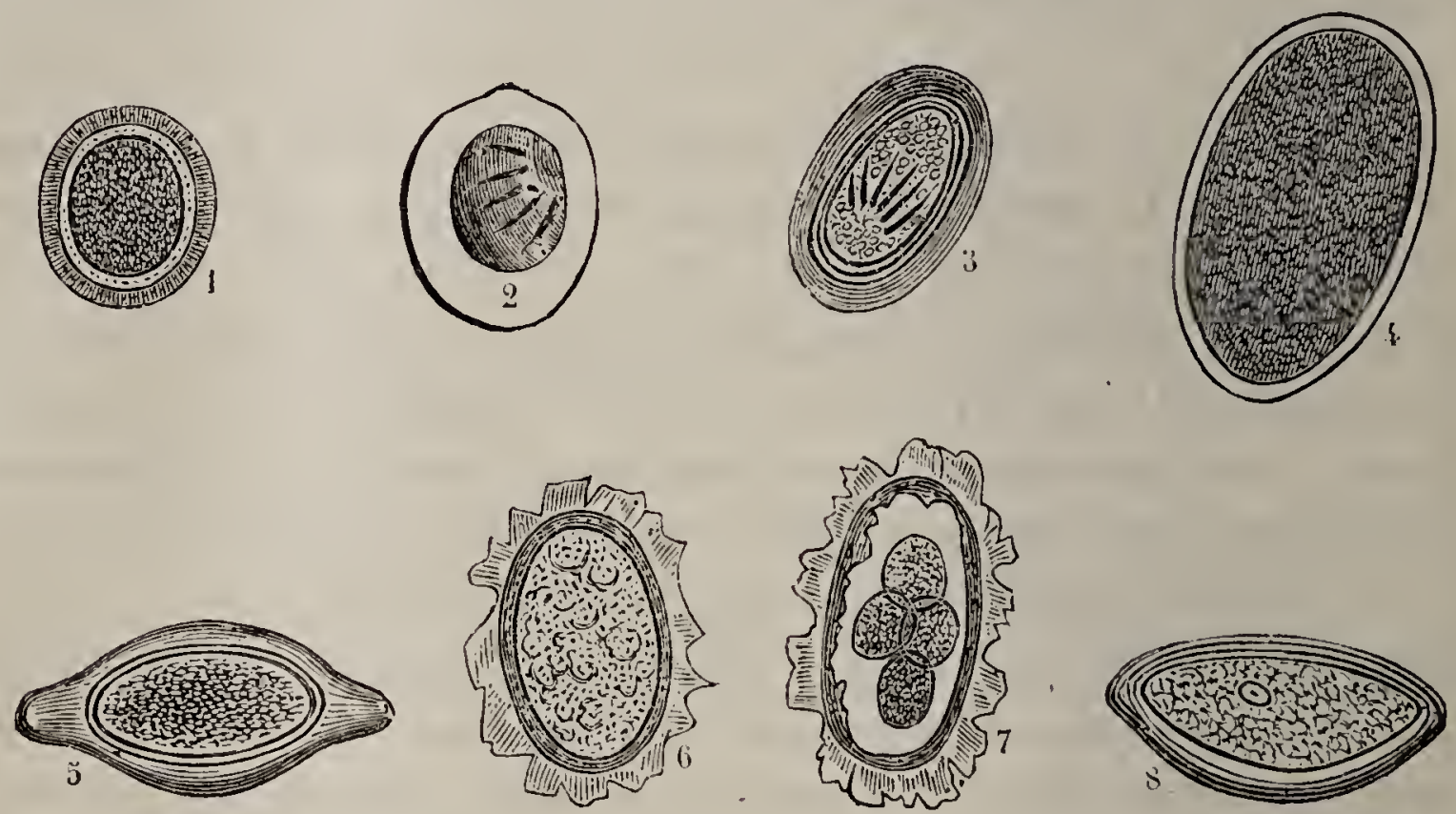

Fig. 383. - Eufs d'entozoaires. (Davaine.) - 1. Ténia solium armé (gr. 340). - 9. Ténii proglottidien, renfermant un embryon dont on aperçoit les crochets (gross. 350). 3. Ténia inerme (gross. 340). - 4. Botryocéphale (gross. 340). - 5. Tricocéphale (gross. 350). - 6. Ascaride lombricoïde (non fractionné, gross. 250). - 7. Le mème, plus développé, renfermant des cellules embryonnaires. - 8. Oxyure verniculaire (gross. 400).

leurs morsures ont déterminé une inflammation de la muqueuse, d'où il est résulté une dyssenterie légère, suivie de diarrhée chronique. Quand la mastication est incomplète, ces animaux peuvent arriver intacts de l'estomac; ils échappent à l'action des sucs digestifs et se fixent dans l'intestin.

Il nous resterait maintenant à parler des parasites qui produisent également de la diarrhée, tels que le ténia, l’oxyure, les lombrics, etc. Parmi ces parasites, il en est dont à chaque état on retrouve la trace, soil dans les tissus, soit dans les dé- 
jections; il nous a donc paru plus naturel d'étudier rapidement chacun de ces parasites, en indiquant les moyens de reconnaître leur présence. Pour toutes les questions cliniques, pathologiques et physiologiques, ainsi que pour certains développements d'un ordre purement zoologique, nous renvoyons le lecteur aux œuvres de Van Beneden, de Davaine, de Laboulbène, etc., etc. Nous donnons ci-cóntre, d'après M. Davaine, une figure des œufs des parasites les plus fréquemment rencontrés dans les matières fécales. La connaissance de ces différentes formes est absolument nécessaire (fig. 383). 


\section{GH A P I T R E X V I}

DES PARASITES

Notre intention est de ne parler que des parasites que l'or rencontre le plus fréquemment et qu'il est absolument nécessaire de connaître. Le but que nous nous proposons est des. signaler leur existence, d'indiquer les moyens de les reconnaitre, renvoyant pour de plus amples détails aux traités spéciaux. Nous réunirons dans ce chapitre des individus appartenant à des espèces complètement différentes, mais que nous. groupons sous la dénomination générale de parasites.

$1^{0}$ Des Helminthes. - Une grande partie des renseignements qui suivent ont été pris aux conférences faites à la Sorbonne, par le $\mathrm{D}^{\mathrm{r}} \mathrm{J}$. Chatin, qui a bien voulu nous autoriser a en faire usage. Nous sommes doublement heureux de pouvoir remercier M. J. Chatin des nombreux conseils pratiques. qu'il nous a si gracieusement prodigués et du désintéressement. avec lequel il nous permet de publier les résultats que lui on! donnés de longues et de patientes recherches.

Nous diviserons les Helminthes comme il suit :

$1^{\circ}$ Les Cestoïdes, qui à l'état parfait se montrent sous l'aspect. de longs rubans segmentés transversalement;

$2^{\circ}$ Les Trématodes, vers plats en forme de cour ou de feuilles;

$3^{\circ}$ Les Nématoïdes, vers cylindriques.

Dans la majorité des cas, un simple coup d'œil suffit porr différencier ces parasites. Mais si l'on veut pousser plus loin l'analyse, et appuyer son diagnostic par des caractères anatomiques irrécusables, on ne tarde pas à s'apercevoir que. 
gour établir dans quel genre, dans quelle espèce on doit ranzer le parasite, il faut recourir à l'observation microscopique. Pour mener à bien une recherche généralement délicate, il faut suivre certaines méthodes, dont la connaissance est indispensable, pour obtenir rapidement des résultats positifs. Nous avons appliqué la plupart de ces méthodes dans le Jahoratoire du $\mathrm{D}^{\mathrm{r}} \mathrm{J}$. Chatin, et avec son bienveillant concours. Les résultats obtenus ont toujours été très satisfaisants.

\section{$1^{\circ}$ Cestoïnes. - teNia Solium.}

10 État cystique. - L'étude du tænia solium à cet état est de la plus haute importance parce que le cysticerque ladrique se rencontre dans la viande du porc (cysticerque de la cellulosite, ladrerie du porc), et que ie cysticerque peut également se rencontrer chez l'homme, où il produit des troubles très graves, surtout quand il occupe le cerveau. Avant d'étudier ces cas particuliers, nous allons donner la description du cysticerque.

Le cysticerque ladrique se présente sous l'aspect d'une vésicule oblongue ou elliptique, rarement sphérique, limitée par une membrane mince et élastique, d'un blanc jaunâtre. D'après Laboulbène, l'enveloppe serait double: l'une extérieure, kyste adventif et indépendant de l'animal; l'autre gui n'est autre que l'animal lui-même, à l'état vésiculaire, replié ou invaginé, c'est à-dire rentré ou renversé sur luimême. Les enveloppes présentent une ouverture, une sorte de hile ou de pertuis, entouré d'un cercle blanchâtre, par où sort l'animal, quand il projetle sa tête ou son cou, sous forme d'un très petit tubercule blanc. L'incision de cette vésicule donne issue à une petite quantité de liquide et met à nu le scolex qui s'y trouve invaginé et représente la tête du tænia parfait.

Le scolex doit être extrait avec soin, débarrassé des débris de la vésicule, puis examiné d'abord dans le liquide cystique, si celui-ci est en quantité suffisante, soit dans du sérum. On n'exercera d'abord qu'une légère compression, puis on 
pourra placer le cysticerque dans la glycérine et le traiter par l'acide acétique, qui attaquera les corpuscules calcaires, déjà nombreux à cette période de développement. On verra alors, au sommet du scolex ou tête, une double couronne de trente-deux crochets longs de 0,17 millimètres (grands crochets) et de 0,12 millimètres (petits crochets), et au-dessous, quatre ventouses symétriquement disposées.

Tels sont les caractères du cysticerque normal, mais l'âge peut le modifier considérablement, en y apportant des changements notables : les points pigmentaires, souvent à peine

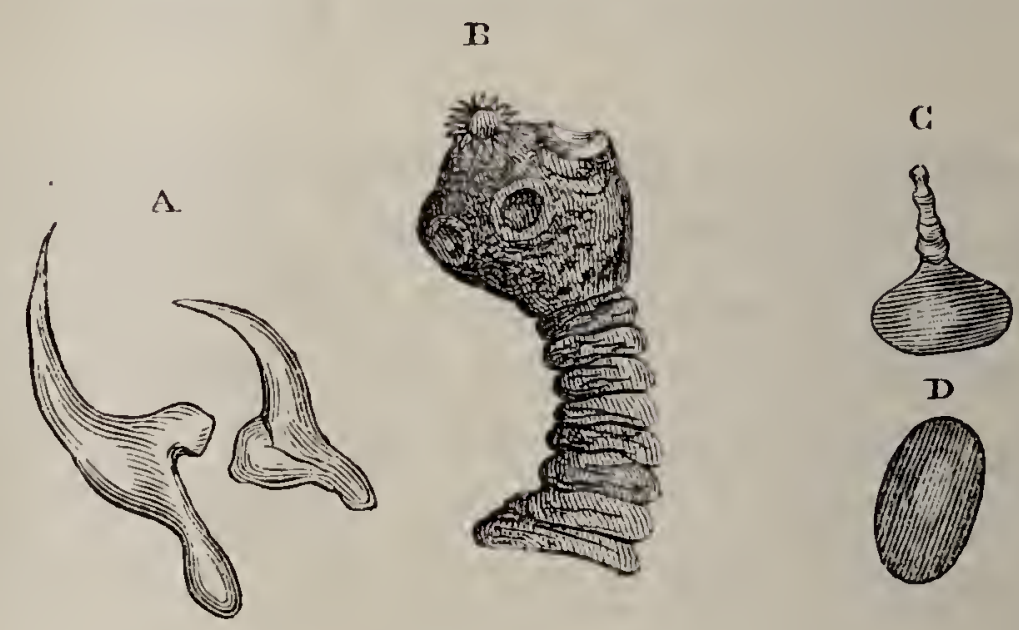

Fig. 384. - Cysticerque ladrique. - De grandeur naturelle en C, en D; en B, l'animal cst considérablement grossi et montre la tète avec les quatre ventouses, la double couronne de crochets et suivie du cou ridé. En A, deux crochets, un de chaque rangée, considérablement grossis.

indiqués dans le jeune scolex, finissent quelquefois par l'envahir complètement et lui donner un aspect noirâtre; mais cette prolifération de la matière pigmentaire n'est rien, auprès de l'abondance avec laquelle les concrétions calcaires se montrent dans ces vieux cysticerques; ils subissent une véritable transformation crétacée.

D'autre part, la vésicule elle-même peut présenter un épaississement plus ou moins considérable des parois, offrir des plicatures ou devenir muriforme, etc. Un examen attentif, l'emploi de solutions acides, la recherche des crochets (parfois masqués par les grains pigmentaires, ou les corpuscules calcaires), permettent de reconnaître la nature de ces productions. Dans la viande de porc, il est rare d'avoir à reconnaître des cysticerques altérés de la sorte, mais chez l'homme (cerveau, muscles), c'est surtout à cet état qu'on les 
rencontre. Ces différences s'expliquent parfaitement par les conditions dans lesquelles se font ces observations et par le mode de développement des Téniadés.

Quand on trouve chez le porc, dit M. Laboulbène (Des Helminthes cestoïdes de l'homme), vers la base de la langue et de chaque côté du frein de cet organe, des élevures opalines, demi-transparentes, globuleuses, ovoïdes, soulevant la

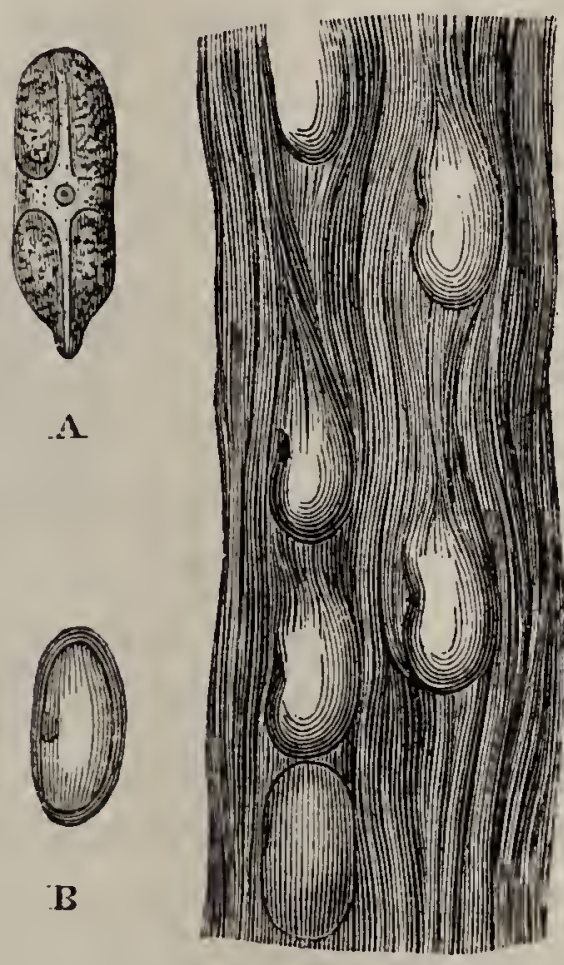

G

Fig. 383. - Fibres musculaires (C) renfermant les vésieules du Cysticerque, ou Cysticercus cellulosae. - A, B. Vésiculcs oblongues ou isolées du kyste adventif; elles sont pourvues d'une ouverturc par oủ l'anmal portc au dehors la tète ct le cou. (D'après Laboulbène.)

muqueuse et faisant saillie sous le doigt, on peut affirmer que le porc est ladre, c'est-à-dire qu'il porte des cysticerques vésiculeux, pouvant donner naissance au ténia armé ou tenia solium. Ces vésicules ladriques, se trouvant sous la langue du porc, ou encore sous la conjonctive, sont pathognomoniques et il en existe sûrement d'autres dans les fibres musculaires de l'animal. Le siège de prédilection des cysticerques est dans la langue, le cou, les épaules, le cœur, dans !es muscles intercostaux, les psoas, les masses musculaires de la cuisse, celles de la région vertébrale postérieure, etc.

Les masses musculaires de porc ladre, sectionnées, coupées 
et renfermant un grand nombre de cysticerques, offrent sur la tranche des séries de loges ou d'alvéoles de cysticerques, tantôt déchirées, tantôt pleines de liquide. Quand les parasites sont altérés ou morts, la vésicule se déforme, le pertuis s'oblitère, les crochets du rostre se détachent (Laboulbène). On consultera pour de plus amples détails les figures de M. Davaine sur les cysticerques ladriques (Synopsis XLI, édit. de 1877).

Le tissu conjonctif profond offre aussi, à la face externe des muscles, les vésicules ladriques; on peut les voir sous la plèvre, par transparence, attachées aux muscles intercostaux, et dans le cœur sous le feuillet viscéral du péricarde. Il est tout à fait exceptionnel de trouver des cysticerques dans les muscles du porc sans qu'il en. existe sous la langue (1). La graisse n'offre pas de cysticerques, quoi qu'on en ait dit: dans le tissu graisseux, où passent des fibres de muscles peauciers, les vers vésiculaires sont altachés aux fibrilles de ces muscles. Les fibres musculaires et leur tissu conjonctif surajouté sont donc le liéu d'élection des cysticerques ladriques; plus rarement les cysticerques se trouvent dans le tissu lamineux ou cellulaire des organes, sous la conjonctive, dans le larynx, dans les plis de la muqueuse anale, dans le foie, la rate, les poumons, le cerveau et ses enveloppes, dans les replis da péritoine, à la face profonde du périoste, dans la chambre antérieure de l'œil et dans le corps vitré (Laboulbène, loc. cit., p. 21).

M. Mégnin, vélérinaire de notre armée, savant de premier ordre, auquel on doit de très importants travaux, a fait à la Société de médecine publique une communication très intéressante, sur une épidémie de tania solium, provoquée dans son régiment par l'usage de porc ladrique salé. Les cysticerques résistent donc parfaitement à l'action du sel. Voici ce que dit M. Mégnin à ce sujet: “Les caractères spéciaux de la

(1) Cette règle n'est pas sans exception, dit M. Mégnin (communication ì la Socićté de médecine publique); on a pu voir deruièrement en pleine Société centrale vétérinaire, où $\mathbf{M}$. Bouley l'avait apportée, une langu' provenant d'un porc ladre, farcie de cýsticerques à l'intérieur et dont la face inféricure n’en présentait aucune trace. 
viande qui contient des germes de ténia, c'est-à-dire des cysticerques, sont si peu apparents, surtout quand la viande a été salée, qu'il est impossible au consommateur vulgaire d'éviter le danger qu'elle offre. En effet, les faisceaux de fibres musculaires et les couches graisseuses interposées entre ces faisceaux ont tout à fait l'aspect, la consistance et la couleur qu'ils présentent dans la viande la plus saine; le spécialiste seul saura reconnaître dans les interstices musculaires le cysticerque qui, dans la viande fraîche, se présente sous la forme d'un petit kyste demi-transparent, avec une petite tache

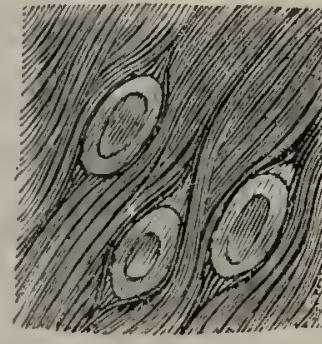

1

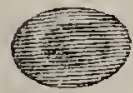

B

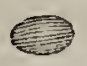

c.

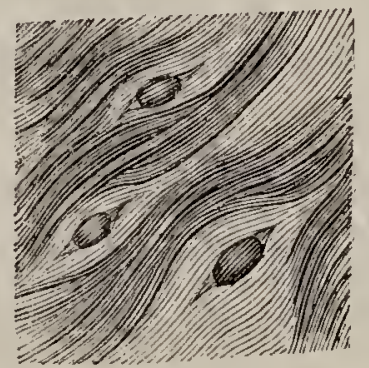

D)

Mip. 386. - A. Morceau de viande fraiche de porc-farci de cysticerques ladriques. B. Cysticerque ladrique frais isolé. - D. Morceau de viande salée et séchée (porc) larci de cysticerques ladriques. - C. Un de ces cysticerques isolé.

opaque sur un de ses côtés. Quand la viande est salée et desséchée, le liquide du kyste a disparu et le cysticerque est réduit au volume d'un grain de millet, de consistance ferme et de couleur rosée, et sous cette forme, dans laquelle il est aussi dangereux que la première, il est facile de le confondre avec un granule graisseux (Mégnin) (1). »

Il a été démontré, par des expériences très nombreuses et très probantes, que le cysticerque du porc ladre donne à l'homme le ténia solium, ou armé, et que les cucurbitins, proglottis, ou anneaux mûrs de ce dernier, produisent la ladrerie du porc. La filiation du cysticerque ladrique et du ténia armé est évidente, dit M. Laboulbène (loc. cit.). L̇e porc, en engloutissant les cucurbitins de ténia, au milieu de ma-

(i) Pour étudier complètement cette question, consultez : Delpech, De la ladrerie du pore au point de vue de l'hygiène privée c't publique, Paris, 1864; et Guardia, Ladrerie du pore dans l'anliquité (Ann. d'hyg., 1865, t. XXIII, p. 420). 
tières fécales déposées au dehors dans la campagne, arrive à être farci de cysticerques, et de plus, comme les porcs avalent les excréments les uns des autres, les œufs ingérés par un premier animal, et qui.n'ont pas eu le temps de se développer dans son intestin, sont repris par un autre porc. G'est encore en buvant dans les mares, où les cucurbitins et surtout les œufs de ténia ont été entraînés par la pluie, que les porcs contractent la ladrerie; la résistance des œufs, protégés par une coque épaisse, est considérable et leur développement peut avoir lieu au bout d'un temps fort long.

L'homme n'échappe pas à la ladrerie, et il n'est pas très rare de rencontrer des malades ladriques, présentant des phénomènes cérébraux ou des accidents épileptiformes, quand des cysticerques se sont développés dans le cerveau. Davaine, Koberlé, Lancereaux, Boyron (thèse, 1876), ont réuni des exemples de ce fait. Nous avons pu observer à l'hôpital des Gliniques un homme ladrique. C'était un ancien cocher qui autrefois avait été atteint du lénia. Au moment où nous l'avons observé, ses muscles étaient pour ainsi dire criblés de pelites tumeurs, siégeant principalement dans les muscles du bras et dans les grands pectoraux. Elles contenaient toutes des cysticerques. M. Broca détruisit toutes celles qu'il put atteindre, en y pratiquant des ponctions simples. Comme il est probable, certain même, en raison des accidents cérébraux, qu'il y en avait dans d'autres organes, l'avenir du malade n'en reste pas moins sombre.

Par quel mécanisme l'homme peut-il devenir ladrique? Il faut admettre, soit l'ingestion directe des œufs de tanic solium, ou ténia armé, en buvant l'eau d'une mare, ou d'un endroit infecté ; soit la présence d'un anneau, ou cucurbitin remonté, puis digéré dans l'estomac; ou enfin, d'un ténia fenêtré, dont les œufs devenus libres dans l'intestin auront pu s'y développer, en donnant naissance à des embryons, qui auraient perforé les parois intestinales et de là, ayant pénétré dans un vaisseau, auraient pénétré, gâầ à la circulation sanguine, dans différents organes.

M. Mégnin vient de faire récemment de nouvelles observations sur le développement et les métamorphoses des ténias. 
Il y a trente ans à peine que l'on sait que les vers vésiculaires sont des larves de ténias. Le fait a été établi par les expériences de Van Beneden, de Siebold, Leuckart, Kuchenmeister, etc., dans lesquelles ces expérimentateurs, faisant avaler à des carnassiers des ver's vésiculaires, ont vu ces vers se transformer en ténias adultes dans les intestins de ces quadrupèdes. De ces expériences, ces auteurs ont conclu non seulement que les vers vésiculaires étaient des formes imparfaites de ténias, et non des vers égarés, hydropiques et malades, comme on le croyait avant eux, mais encore qu'il était indispensable que ces vers vésiculaires fussent ingérés par un carnassier, un omnivore, un animal étranger enfin, pour pouvoir arriver à l'état parfait, c'est-à-dire à la forme rubannaire.

Cette dernière hypothèse rendait compte de l'origine des ténias des carnassiers (ténias à crochets); mais elle était impuissante à expliquer l'origine des ténias des herbivores (ténias inermes). En effet, le cheval, le bœuf. le mouton, le lapin, présentent souvent des ténias adultes (sans crochets), et cependant ils n'ingèrent aucune chair et par suite aucun ver vésiculaire.

Plusieurs autopsies de chevaux et celles de nombreux lapins de garenne viennent, dit M. Mégnin, de donner le mot de l'énigme. Chez ces animaux, les vers vésiculaires, quand ils se développent dans des cavités adventives en communication immédiate avec lïntérieur de l'intestin, cavités résultant de l'agrandissement de follicules ou de glandules, dans lesquels les embryons hexacanthes se sont introduits, ou même quand ils se développent dans la cavité du péritoine (chez le lapin sauvage), continuent leurs métamorphoses et arrivent à l'état adulte, c'est-ìdire rubannaire, sans quitter l'organisme dans lequel ils ont pénétré, à l'état d'œufs microscopiques, ayant $0^{\mathrm{mm}}, 030$ à $0^{\mathrm{mm}}, 070$ de diamètre, soit avec l'eau des boissons, soit avec des aliments herbacés; seulement, dans ce cas, ils donnent un ténia inerme, tandis que si le même ver vésiculaire est ingurgité par un carnassier ou un omnivore, il devient, dans les intestins de ce dernier, ténia armé, c'est-ì-dire qu'il conserve les crochets du scolex dont il provient. Les ténias inermes et les ténias armés sont donc deux formes adultes et paral- 
lèles du même ver, et les différences souvent très grandes qu'ils présentent sont dues exclusivement à la différence des terrains, des habitations dans lesquels ils se sont développés.

Il y a néanmoins plusieurs espèces de vers, mais chaque ténia inerme a son congénère parmi les ténias armés, et celuici est toujours un émigrant (malgré lui), au moins chez les mammifères, et le premier toujours un sédentaire (1).

On voit, par ce qui précède, combien l'inspection de la viande de porc est importante pour la santé publique. Nous examinerons plus loin si cette inspection est faite d'une façon très sérieuse et nous indiquerons les réformes à apporter aux règlements actuels. Il faut aussi se garder de boire de l'eau des mares où vont les animaux domestiques. Agir autrement, c'est s'exposer à des accidents redoutables contre lesquels la thérapeutique reste trop souvent impuissante.

$2^{\circ}$ Ĺtat parfait. - On connaît maintenant quelles conditions doivent être remplies pour que le tcenia solium alteigne cet état proglottidien, on sait qu'il se trouve alors dans l'intestin grêle de l'homme. Il faut recourir à l'observation microscopique pour le distinguer.du tcenia inermis, ou mediocanellata. Ce parasite, à l'état adulte, vit dans les mêmes conditions que le tæria solium et tend, comme nous le verrons ci-après, à devenir assez commun. La tête, les anneaux, les œufs, offrent des caractères distinctifs dont la connaissance permet de séparer aisément ces deux types.

La tête ou scolex du tænia solium, ou ténia armé, est caractéristique. On dirait un chapiteau irrégulier sur le haut d'une colonne : elle est avancée au milieu en forme de rostre, rostellum, ou proboscide fermé et entouré de crochets, formant une double couronne (Laboulbène). La tête est large de $0^{\mathrm{mm}}$,ŏ à $0^{\mathrm{mm}}, 6$; elle porte quatre ventouses el deux couronnes de crochets (fig. 387). Les dimensions de ces derniers ont été représentées par des chiffres assez variables, suivant les auteurs; ainsi Kuchenmeister indique comme longueur des grands crochets $0^{\mathrm{mm}}, 18$ et comme longueur des petits $0^{\mathrm{mm}}, 12$; I.euckart

(1) Journal des connaissances médicales pratiques et de pharmacologie. Lire le Mémoire de M. Mégnin paru dans le journal l'Anatomie, no de mai 1879 . 
donne $0^{\mathrm{mm}}, 167$ et $0^{\mathrm{mm}}, 11$. Des mensurations pratiquées par le $\mathrm{D}^{\mathrm{r}} \mathrm{J}$. Chatin, sur vingt-cinq exemplaires, il résulte que la longueur moyenne des grands crochets est $0^{\mathrm{mm}}, 17$ o et celle des petits $0^{\mathrm{mm}}, 117$. Comme le fait observer avec raison le $\mathrm{D}^{\mathrm{r}} \mathrm{J}$. Chatin, elles n'ont qu'une faible importance; ce qui importe, c'est de constater la présence des crochets, ceux-ci faisant défaut dans le ténia inerme.

Ajoutons que, s'il est facile de constater la présence des crochets quand l'animal vient d'être rendu, cette constatation devient plus délicate quand l’animal a été conservé, parce que les crochets sont tombés en majeure partie. Néanmoins, avec de l'attention on peut, même dans ce cas, apercevoir la place occupée par les crochets, comme l'a montré

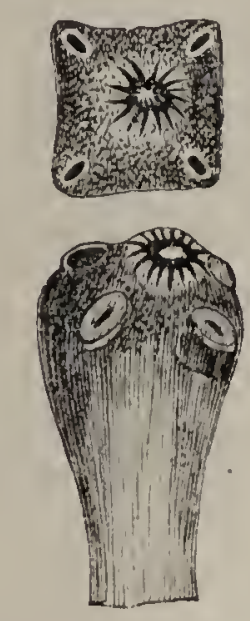

rig. 387. - Tête du ténia armé de l'homme (grossi 12 fois). (Davaine.)

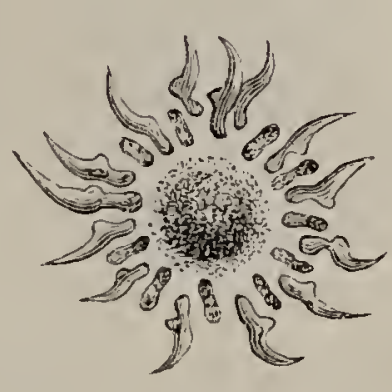

A

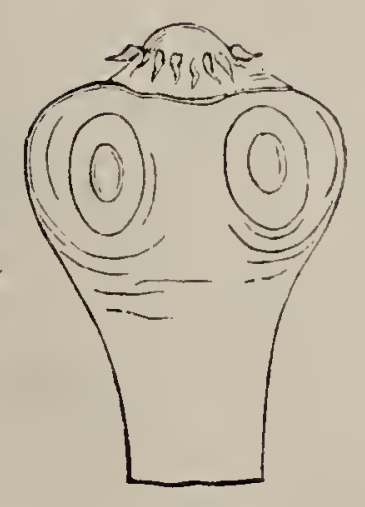

I3

Fiğ. 388. - A. IIilieu de la tête du ténia armé, très grossie, vue de face par le haut et montrant la double couroune de crochets; plusieurs de ees eroehcts sont tombés sur la partie supérieure, ou couronne interue, leur plaee est indiquée par du pigment. - B. Tête grossie du ténia armé, avec le rostellum on proboscide avancé, et une double eouronne de erochets.

M. Laboulbène (Voir la figure 388). Le nombre des crochets n'est pas toujour's le même; M. Laboulbène en a figuré douze pour chaque couronne, Leuckart en a compté vingt-six en tout, et, daprès Davaine, il y en aurait de vingt-deux à trente-deux.

Au delà du scolex, se développe le strolile, longue suite d'anneaux se continuant sur une étendue de 6 à 9 mètres, et possédant des caractères qu'il faut bien connaître, car si le scolex offre les particularités les plus importantes et les plus caractéristiques, elles peurent souvent.faire défaut, 
parce que fréquemment la tête reste fixée sur la muqueuse intestinale, lorsque le strobile se sépare en fragments plus ou moins longs. Son expulsion est toujours difficile à obtenir, même avec les meilleurs anthelminthiques.

- Lorsqu'on veut déterminer l'espèce de Cestoïde qui a été rendue par le malade, il convient d'abord de rechercher si la tête a été expulsée. Cette constatation est généralement facile, puisque l'on sait que celle-ci termine toujours l'extrémité la plus mince du ténia; on étend donc celui-ci sur une lame de verre, on sort l'extrémité la plus effilée jusqu'à sa

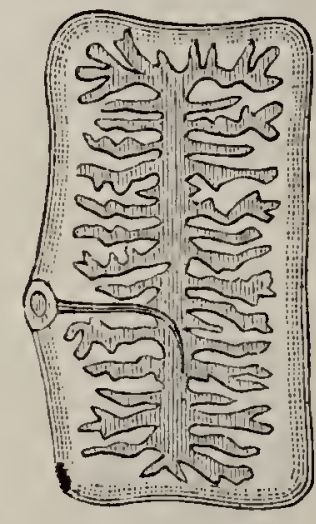

A

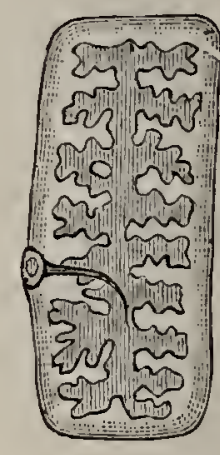

B

Fię. 389. - A. Cucurbitin grossi du ténia inerme. - B. Cucurbitin grossi du ténia solium ou ténia armé.

terminaison et, soit à l'œil nu, soit avec une faible loupe, on cherche si le renflement céphalique s'y trouve; dans le cas positif, on l'examine à un grossissement de $\frac{80}{1}$ et l'on cherche à découvrir la présence des crochets. Dans le cas contraire, qui est de beaucoup le plus fréquent, la tête étant absente, on examine soigneusement les anneaux et lon y observe les caractères suivants : dès qu'on atteint la région moyenne, ou postérieure, de la colonne strobilaire (et c'est généralement sur cette région que porte l'examen), on voit les anneaux allongés et quadrangulaires, à pores génitaux très irrégulièrement alternes et à utérus médian, présentant une dizaine de branches ramifiées et contenant des ovules, sur lesquels nous allons revenir. Enfin, sur les bords de l'article ou cucurbitin, cheminent des canaux excréteurs qui s'envoient des anastomoses parallèles aux deux bords antérieur et postérieur de 
l'anneau (1). Tous ces délails peuvent être aisément constatés. Si le cestoïde a été récemment rendu, on le traite par la glycérine additionnée d'une trace d'acide acétique; s'il a été conservé depuis un certain temps, on le place dans le mélange suivant :

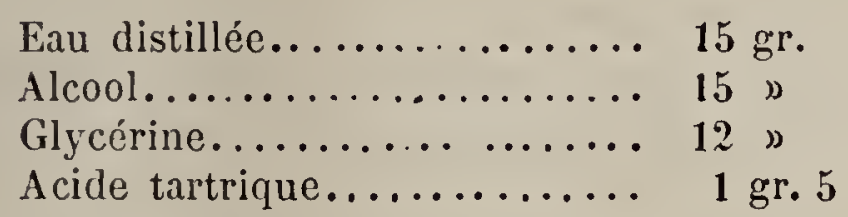

Après un séjour de dix à quinze minutes dans cette liqueur, on observe à un grossissement de $\frac{100}{1}$, puis de $\frac{180}{1} \grave{a} \frac{200}{1}$, et l'on découvre les principales dispositions des organes sexuels et des canaux excréteurs. Cependant, pour bien voir ces derniers, pour les suivre dans les divers anneaux, et remonter même jusqu'à leur origine dans le scolex, où ils débutent par un lacis assez compliqué et entourant les ventouses, il convient de traiter la pièce par l'acide carbonique, en procédant de la manière suivante : on prépare d'abord une solution concentrée de bi-carbonate de potasse et ensuite une solution également concentrée d'acide citrique. On étend le fragment de strobile sur une lame porte-objet, puis avec un pinceau fin on l'imbibe de la solution alcaline; lorsque l'imprégnation semble complète, on passe sur la pièce un second pinceau trempé dans la liqueur acide, on laisse l'effervescence se calmer, on ajoute quelques gouttes d'eau additionnée d'une faible trace de glycérine, puis on recouvre la préparation et l'on peut alors y suivre, non seulement les moindres méandres des vaisseaux, mais aussi et très nettement l'utérus, le vagin, les spermigènes, les canaux déférents, la poche du cirrhe, le pénis, etc. (2). M. le $\mathrm{D}^{\mathrm{r}} \mathrm{J}$. Chatin, si compétent dans toutes ces questions, a suivi cette technique, dans ses

(1) La dimension de ces anneaux est inférieure à celle des segments du ténia inerme.

(2) Le pénis est très court, à peine exsertile, il se voit rarement en dehors de la gaîne; celle-ci débouche avec le vagin, dont l'ouverture est située en arrière, dans une cavité commune ou cloaque. Le vagin est un canal long, très étroit et dont le diamètre, étant de moitić moindre que celui des ceufs mûrs, ne permet pas ì ces petits corps de sortir par une ponte (Davaine). 
démonstrations, soit au Muséum, soit à la Sorbonne, et toujours elle lui a donné d'excellents résultats.

Si de semblables études sont fort intéressantes au point: de vue de l'anatomie zoologique, il convient de faire observer que l'examen des cucurbitins peut fournir sous le rapport de l'observation pratique un seul caractère important: l’utérus ne comptant guère plus de dix branches irrégulièrement ramifiées, ce qui le distingue du tcenia inerme ou mediocanellata.

Cette observation exige une certaine habitude; aussi lorsque l'on veut sûrement distinguer le tania solium du tania mediocancllata ou inerme, par la seule inspection des anneaux, faut-il s'attacher moins à ceux-ci qu'aux ovules que renferment leurs cœcums utérins. Dans le ténia inerme, ces œufs seront elliptiques, comme nous le verrons bientôt; dans le cas présent, au contraire, ils seront sphériques et mesureront $0^{\mathrm{mm}}, 034$ de diamètre. On devra se familiariser avec

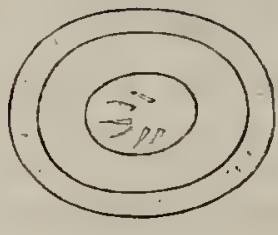

A.

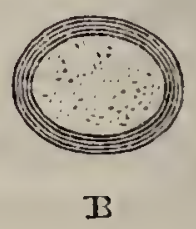

B

Fig. 390. - A. OEuf de ténia armé grossi 350 fois et traité par une solution de potasse.

- B. OEuf de ténia armé, ru sous le même grossissement dans la glycérine.

leur aspect; il conviendra de les traiter par de la potasse caustique, pour voir leurs enveloppes, l'embryon qu'ils renferment, ainsi que les crochets. En effet, lorsqu'on doit se prononcer sur la détermination d'un cestoïde, il arrive presque toujours que celui-ci se montre dépourvu de sa partie céphalique, soit qu'il ait été plus ou moins longtemps en contact avec les matières fécales, ou qu'il ait été conservé dans l'eau, dans l'alcool, l'huile, liquides qui l'altèrent au point de rendre méconnaissables les détails anatomiques des cucurbitins; les ovules, au contraire, demeurent intacts et leur examen suffil pour reconnaître aisément et sûrement l'espèce que l'orr a sous les yeux.

Lorsqu'un ténia solium vient d'être expulsé, il peut, dans. 
des conditions favorables de température, conserver certains mourements. Nous donnons ci-contre une figure dans laquelle M. Davaine a représenté les formes successives que peut prendre un cucurbitin de tcenia solium. Ces mouvements sont moins vifs que chez le ténia inerme.

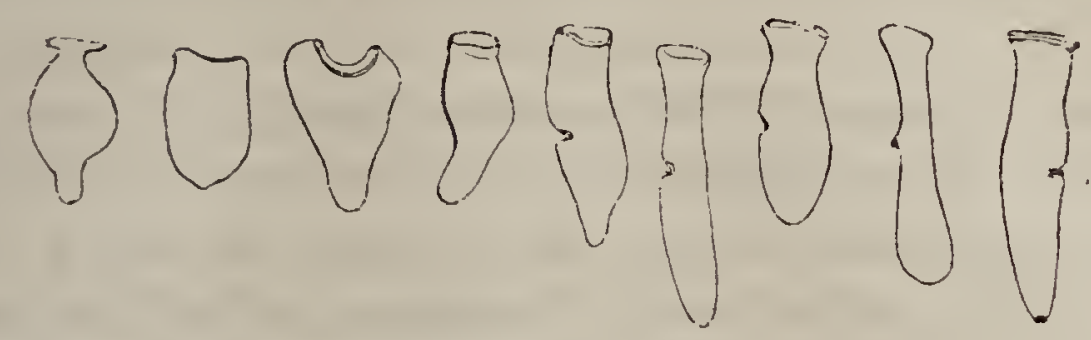

Fig. 391. - Gucurbitin du ténia solium; formes successives en quelques minutes.

Trenia mediocanellata. - Taenia inermis. - Cette espèce a certainement été connue des observateurs du dix-huitième siècle (trnia grandis, etc.); elle a été étudiée par Kuchenmeister, qui l’a pour ainsi dire tirée de l'oubli, en montrant qu'elle était distincte de tænia solium. Cet auteur insistait justement sur sa fréquence; en même temps, Von Breder, Leuckart, Cobbolt, Oliver faisaient connaître son mode de propagation par la viande des Bovidés, où elle passe sa période larvaire, aussi son étude s'impose-t-elle aujourd'hui à tous les praticiens. Laboulbène a signalé son existence à Paris et J. Chatin l'a retrouvé dans le midi de la France.

Il est aujourd'hui bien plus commun que le ténia solium, mais il s'en distingue facilement sous ces deux élats :

$1^{\circ}$ État cystique. - A cet état le tania inerme ou mediocanellata se rencontre dans les muscles du bœuf, du veau, etc., et peut s'y découvrir aussi facilement que le cysticerque du tenia solium chez le porc. Malheureusement, tandis que, depuis des siècles, la vente de la viande de celui-ci est soumise à un contrôle plus ou moins minutieux, on est encore à prendre quelques mesures contre la ladrerie du bœuf, qui devient plus fréquente de jour en jour, et qui contamine les populations d'un parasite plus difficile à chasser que le tania solium. M. Mégnin, dans un travail lu à la Société de médecine publi que, semble ne pas admettre la ladrerie du bœuf. Inspecteur par quartier de l'abattoir militaire de Vincennes, M. Mégnin 
a pu faire des recherches sur une vaste échelle, puisqu'il examine par jour environ 10 à 12 bœufs. Pendant les trois années 1874-75-76, il a vu passer sous ses yeux les spécimens de toutes les races françaises; sur aucun d'eux, il n'a constaté la présence de cysticerques. L'année dernière, en raison de l'abondance des fourrages, le bétail français ayant augmenté de prix, les fournisseurs durent se rabattre sur des animaux étrangers. C'est ainsi qu'à partir du mois d'avril, jusqu'à la fin de septembre, ce sont les bœufs de Sardaigne, de l'Italie centrale et surtout de l'Afrique, ainsi que les moutons de l'Herzégovine, de la Valachie, de la Bessarabie et même de la Perse, qui ont alimenté exclusivement la garnison de Paris, et un grand nombre de garnisons du centre et de l'est. Pendant ce temps, rien qu'à l'abattoir "de Vincennes, il a été sacrifié 250 bœufs de l'Italie centrale, 300 bœufs de Sardaigne et 500 bœufs d'Afrique. Sur aucun, malgré les recherches les plus minutieuses, et poussé par un ardent désir de faire connaissance avec la ladrerie du bœuf, M. Mégnin n'a pu trouver la trace d'un seul cysticerque. Pour contrôler cette étude, M. Mégnin fit une enquête dans les hôpitaux militaires et il ne put recueillir qu'une seule observation de ténia inerme, et encore cette observation unique n'est-elle pas probante. La grande fréquence du ténia inerme dans nos hôpitaux civils n'est certainement pas en rapport avec la rareté, pour ne pas dire l'absence du cysticerque chez le boeuf. M. Mégnin conclut de ses recherches que la ladrerie est extrêmement rare chez le bœuf et que la viande de cet animal n'est peut-être pas la principale voie que prend le ténia inerme, pour arriver dans nos intestins.

Cette question est donc encore à l'étude. Néanmoins, il n'en reste pas moins établi qu'il faut surveiller de près la viande de bœuf. MM. Cauvet et J. Arnould ont recueilli sur le bœuf; le cysticerque du ténia incrme par contre, Leuckart, Röll, Saint-Gyr, Nasse et Fourquier, Laboulbène, ont provoqué la ladrerie du veau, en faisant ingérer à cet animal des proglottis de ténia inerme, éliminés par l'homme.

L'examen de la viande suspecte se fera comme pour l'espèce porcine; les cysticerques s'y reconnaîtront aux carac- 
tères suivants : la vésicule arrondie mesure environ 3 millimètres de diamètre; le scolex qu'elle renferme est bien différent de celui qui était contenu dans le cysticerque du porc. En effet, il est carré ou tétragonal, porte quatre ventouses rondes, symétriques, presque apicales; il n'y a aucun crochet. Ce caractère que nous allons naturellement retrouver dans le ténia parfait suffit à différencier ce cysticerque. Le pigment y est peu abondant, sinon absent; mais les corpuscules calcaires sont nombreux et la crétification est très rapide. Cobbold l'a vue survenir toujours avant un an: Saint-Cyr après sept mois et demi. Les expériences du $\mathrm{D}^{\mathrm{r}} \mathrm{J}$. Chatin lui ont donné les résultats suivants :

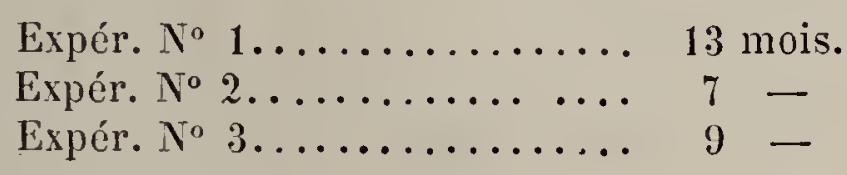

On roit que ces chiffres diffèrent peu des précédents, et mème, au point de vue pratique, il convient d'en tenir compte; en effel, si l'expert ne décourre dans le cœur, ou dans la langue, etc., aucune trace de cysticerque, mais que

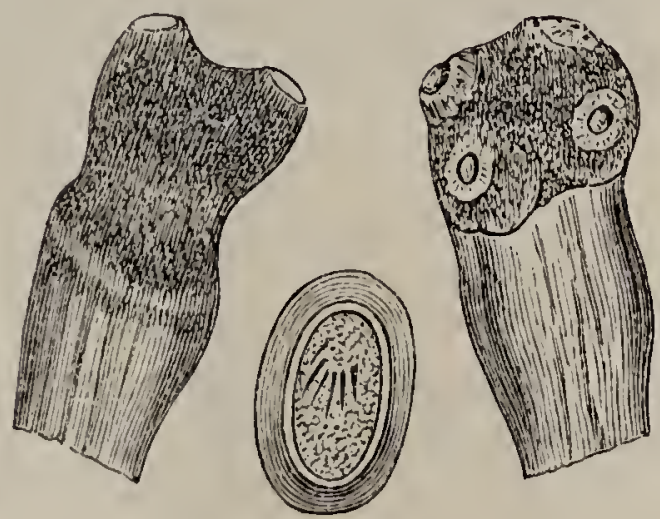

Fig. 392. - Tête du ténia inerme de l’homme (gross. 5 fois); ovule du même ténia (gross. 349 fois). (Davaine.)

son scalpel rencontre de petites granulations calcaires, que la viande "crie " sous le couteau, l'attention devra être éveillée, il pourra considérer ces formations comme les derniers vestiges de l'infection parasitaire, et, scrutant soigneusement les tissus des extrémités, les épaisses masses chárnues de la jambe, etc., y pratiquant des coupes en divers sens, il pourra y rencontrer des vésicules intactes, arec un scolex 
normal et établir ainsi, par des pièces indiscutables, l’infection de la viande.

$2^{\circ}$ '́tat parfait. - G'est sous cette forme que le tcria mediocanellata ou trnia inermis se rencontre chez l'homme où il habite l'intestin grêle comme l'espèce précédente. Les dimensions, plus considérables en longueur et en largeur, de son strobile pourraient déjà permettre de l'en distinguer.

Les fragments de ténia peuvent varier d'aspect, suivant qu'ils ont été conservés dans un liquide alcoolique, ou dans de l'eau, par les malades qui viennent les soumettre à l'examen. Dans le premier cas, ils sont contractés, isolés, séparés un à un, de forme allongée, aplatie, non cylindrique, quoique parfois un peu contournés ou repliés. La coloration est jaunâtre, et il faut une attention assez marquée, pour trouver sur un des bords longitudinaux l'ouverture génitale; si, au contraire, ces fragments ont été mis dans l'eau pure, leur forme est caractéristique, ils sont en carré allongé, rectangulaires, à bords parallèles, d'un blanc d'albumine cuite, ou à peine jaunâtre. Sur un des côtés, vers la partie médiane, on aperçoit, nettement un léger bourrelet, entourant une dépression qui est l'orifice, le pore, ou, en d'autres termes, l'ouverture commune génitale (Laboulbène).

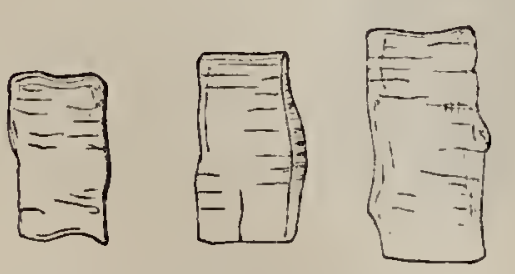

Fig. 393. - Fragments de ténia conservés dans l'alcool.
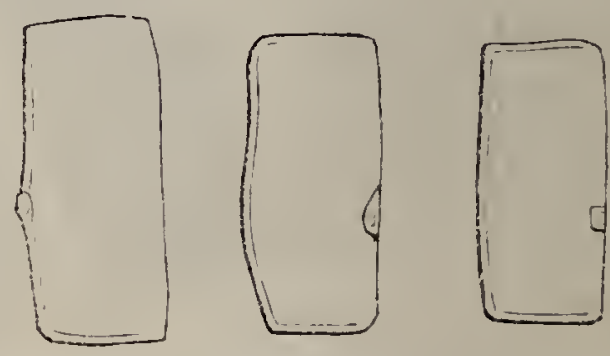

Fig. 394. - Fragments de ténia conservés daus l'eau.

T'outefois, l'appréciation de ces caractères demande une grande expérience et ne peut conduire qu'à des résultats. fort incertains; il est donc indispensable de procéder à l'examen microscopique du scolex, des proglottis et des œufs.

Le scolex est très facile à distinguer de celui du tania solium en raison de sa forme et de sa constitution; son contour n'est pas globuleux, mais tétragone, et il semble tronqué antérieure- 
ment; il est large de $2^{\mathrm{m} m}$, ă à 2 millimètres. Sa constitution se résume en quelques vaisseaux sécréteurs (qui se continuent dans les proglottis) et en quatre ventouses. La coloration de la tête du ténia inerme est due à des grains de pigment. Celui-ci existe en quantité plus ou moins grande ; de là cette apparence des ténias inermes, à têtes noires et blanches, dont a parlé M. Gonstantin Paul. Les ventouses sont fortement colorées ; de plus, la teinte noire n'occupe pas le rostre ou proboscide tronqué du ténia inerme, mais elle est répartie en lignes ou en séries de points autour du cou et entre les ventouses. Celles-ci sont protractiles et rétractiles (Laboulbène, loc. cit., p. 5̆). Comme nous l'avons dit, on n'y découvre aucune trace de crochets, caractère qui a valu à ce ténia le nom de $T$. inerme, beaucoup plus significatif que celui de T. mediocanellata. Ce caractère suffirait à le différencier nettement du $T$. solium .

Les anneaux ou proglottis, beaucoup plus vivaces que ceux du $T$. solium, s'échappent souvent par l'orifice anal, en dépit
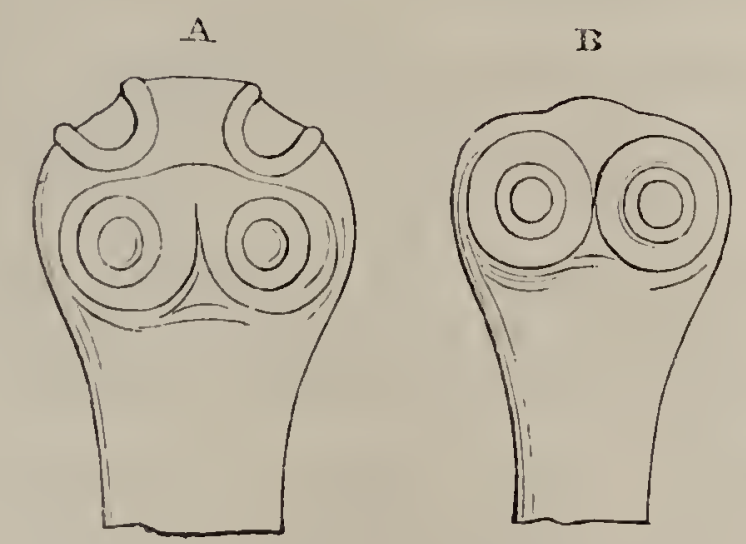

Fig. 395. - Tète grossie du ténia inerme en $A$, vue un peu penchée en arant et montrant la disposition des quatre ventouses; en $B$, la tête est vue de profil.

même de la volonté du malade et dans l'intervalle des garderobes. Ce caractère est d'une grande importance clinique. Les anneaux, qui commencent à être appréciables à une courte distance de la tête, par des rides légères, sont variables de forme et de grandeur (1). Ceux qui suivent la tête vers le tiers antérieur sont plus larges que longs; les médians à peu près carrés; les derniers, depuis le tiers postérieur, sont plus longs que

(1) Laboulbène, loc. cit. - C. Giacomini, Communication ì l'Académic de Turin, 24 juillet $18 \%$, et Tribune médicale, 1876. 
larges, Leur structure est entièrement différente, suivant la région qu’ils occupent, soit à la partie antérieure, soit sur le milieu, soit enfin à l'extrémité du long ruban formé par le ténia. Les anneaux médians renferment à la fois les ovaires et l'organe mâle; ce dernier s'est atrophié et a disparu dans les anneaux de l'extrémité postérieure du cucurbițin. Ils mesurent jusqu'à 18 millimètres de largeur; les pores génitaux sont très irrégulièrement alternes ; la matrice compte jusqu'à trente ou quarante divisions de chaque côté, mais elles sont parallèles el se ramifient dichotomiquement, régularité qui, jointe à leur plus grand nombre, peut servir à distinguer le $T$. mediocanellata ou $T$. inerme (fig. 389). Ces détails anatomiques sont quelquefois difficiles à analyser, et lorsqu'on ne possède que des anneaux sans scolex, il vaut mieux s'en tenir à l'observation plus aisée et plus sûre des ovules.

Ces œufs sont elliptiques, mesurent $0^{\mathrm{mm}}, 037$ suivant leur grand diamètre, $0^{\mathrm{mm}}, 027$ suivant leur petit diamètre ; il est donc très facile de les distinguer de ceux du $T$. solium. Comme nous le disions plus haut, l'examen des ovules constitue certainement l'élément le plus précieux pour déterminer l'espèce. Pour les obtenir, dit M. Laboulbène, il suffit de presser entre deux lames de verre un anneau de la partie postérieure du corps pour voir sortir par le pore génital une matière blanchâtre qui, examinée au microscope, est constituée par des œufs. Le nombre des œưs du ténia inerme est immense, il est même incalculable, car les œufs existent par milliers dans chaque anneau, et ceux-ci forment un strobile de plusieurs mètres, dont la moilié au moins est fertile. De plus, les cucurbitins se produisent pendant un temps indéterminé. On pourrait être étonné, sinon effrayé, de la multiplication du ténia inerme, si a plupart des œufs n'étaient forcément perdus, sans pouroir se développer et se transformer. La fécondité vraiment prodigieuse du lénia est indispensable, pour résister aux causes de destruction du ver pendant ses premiers élats. Les œufs ne se trouvent pas ordinairement dans les matières alvines, excepté lorsque les cucurbitins se sont rompus dans leur milieu et sont devenus fenêtrés; le ténia inerme ne pond pas à la manière du bothriocéphale large. En retirant par pression les. œufs de 
l'utérus, sur un anneau mûr, on troure la plupart de ceux-ci enveloppés d'une matière muqueuse ressemblant à une enreloppe albuminoïde avec quelques granulations (1). (Laboulbène, loc. cit., p. 8 et 9.)

T. Ehinococeus. - $1^{\circ}$ État cystique. - C'est seulement sous cette forme que le $T$. echinococcus s'imposeà l'observation du médecin, car c'est seulement à cette période de son développenent qu'on le rencontre chez l'homme. On sait que le proscolex, dilaté en unc vésicule souvent rolumineuse, et depuis longtemps connue sous le nom d'hydatide, donne naissance à un grand nombre de scolex (Echinococcus) qui se détachent bientôt de la paroi hydatique et tombent dans la cavité de la vésicule mère.

La détermination de ces cysticerques n'offre généralement aucune difficulté, etle médecin remonte facilement à l'origine des tumeurs ou des kystes qu'ils produisent.

Cependant le microscope peut faire distinguer la structure

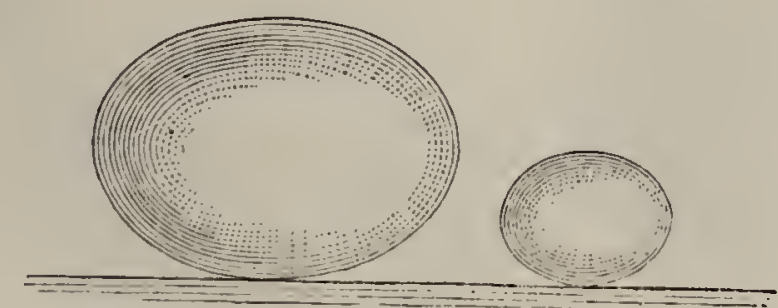

Fig. 390. - Hydatides ou hystes hydatiques ordinaires (Laboulbène).

feuilletée de la membrane hydatique et permet surtout de reconnaître dans ces forma tions, ainsi que dans le liquide obtenu par le ponctionnement des kystes, la présence de crochets insérés sur le rostre des scolex. Ces crochets fournissent le plus sûr élément de diagnostic et peuvent être aisément reconnus. Chaque scolex en porte 44; ils sont longs de $0 \mathrm{~mm}, 02$ à 0 mm, 024 et présentent nettement les trois parties caractéristiques (manche, garde, lame). En général un grossissement de 200 à 300 diamètres suffit pour les observer complètement. Le carmin, le picrocarminate d'ammoniaque, la solution d'aniline et de rosaniline, facilitent singulièrement leur examen. Les vési-

(1) P. Gervais et P.-J. Van Beneden (Zoologie midicale, t. II, p. 242, fig. 164, 1859). 
cules hydatiques sont arrondies ou ovoüdes ; elles sont constituées par une simple enveloppe ayant, d'après Laboulbène, la consistance de l'albumine peu cuite; elles sont remplies d'un liquide transparent et semblable à de l'eau distillée. Autour des hydatides volumineuses des viscères, celles du foie, par exemple, sè trouve une couche fibreuse résistante, et qui est un véritable kyste adventif, pourvu souvent d'un réseau vasculaire, tandis que les vésicules hydatiques n’ont aucun vais seau. Parfois les hydatides renferment, outre le liquide, un certain nombre d'autres hydatides absolument semblables. Dans ce cas, l'hydatide est dite hydatide mère, et celles qu'elle renferme ont été appelées hydatides filles. Il n'y a là qu'une question de
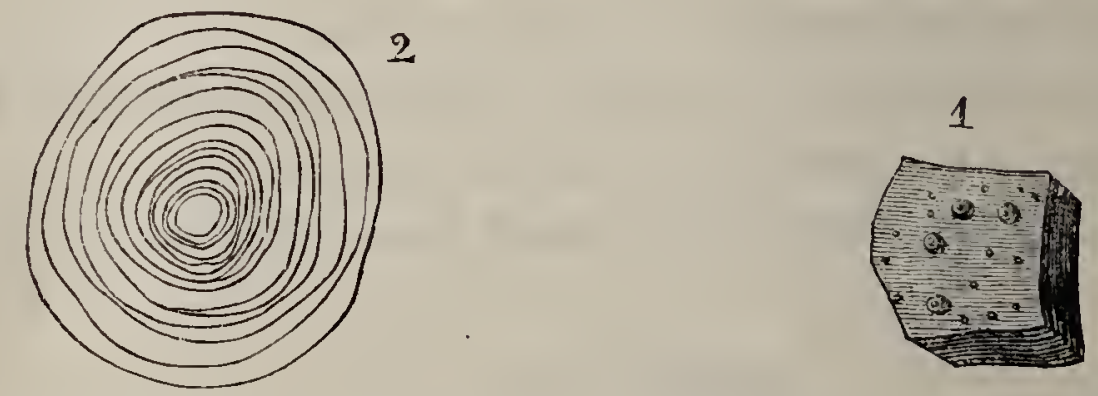

Fig. 397. - Iydatide de l'homme (Davaine). - 1. Fragment dont la tranehe montre les fiuillets dont le tissu se eompose; à la surface extérieure existent des bourgeons hydatiques. - 2. Bourgeon comprimé et grossi 40 fois.

contenant et de contenu, mais non une différence de structure des hydatides.

En examinant avec attention le liquide de plusieurs vésicules, on trouve que tantôt il est tout à fait liquide, mais que souvent il laisse déposer de petits grains blanchâtres, visibles à l'œil nu, comme une très fine semoule (Laboulbène). Ces granulations, qui nagent dans le liquide hydatique et dont plusieurs restent attachées à la partie interne des vésicules, sont les Echinocoques. Le moindre morceau de vésicule hydatique est tout à fait caractéristique. Lorsqu'on examine au microscope, à divers grossissements, un fragment obtenu en coupant ou en hachant la vésicule et placé sur la tranche, on voit, comme nous l'avons déjà indiqué, une disposition lamelliforme toute spéciale. Qu'on se représente, dit M. Laboulbène, auquel nous empruntons ces détails, un livre, ou mieux un album à feuillets 
d'inégale épaisseur, on aura une idée nette de cette disposition des lamelles emboîtées. A la partie interne de la membrane hydatique, on trouve une couche grenue des plus remarquables, découverte par le professeur Ch. Robin. Celte couche est une véritable membrane germinale, donnant naissance aux échinocoques et suivant que l'hydatide est pourvue, ou non, de cette membrane, elle est fertile ou non fertile, ainsi que Davaine l'a démontré. Les termes d'hydatide mère ou fille n'expriment que le fait de vésicules renfermant, ou ne renfermant pas d'autres vésicules; la membrane germinale seule rend l'hydatide fertile, ou apte à produire des échinocoques. Dépourvue de membrane germinale, l'hydatide mère, remplie,de vésicules semblables à elle, est réellement stérile par rapport aux échinocoques, dont la production est alors impossible.

Les hydatides mères et filles sont aussi appelées $t$ ndogènes et exogènes; ces dernières sont rares chez l'homme. M. Mégnin

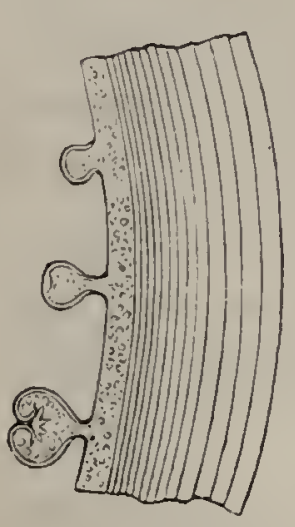

A

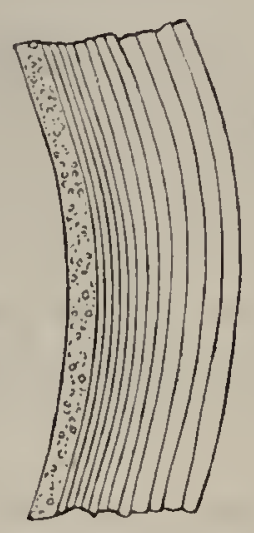

$\mathbf{B}$

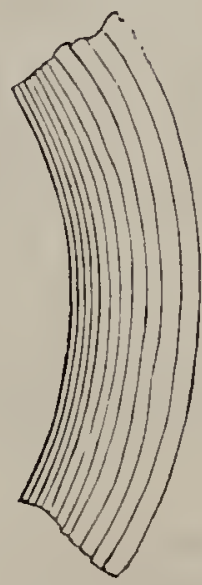

C

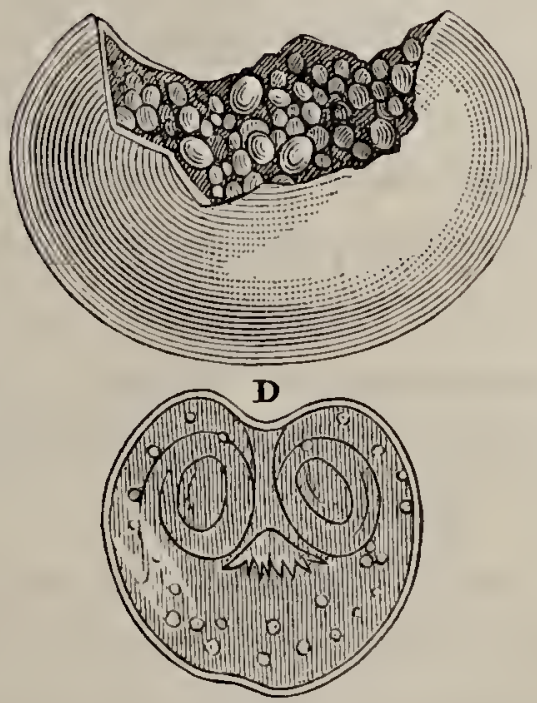

E

Fig. 398. - A. Fragment d'hydatide revètu de la membrane germinle et montrant de haut en bas le développement de l'échinocoque. - B. C. Fragments hachés de membrane hydatique, vus par la tranche, ils offrent une disposition lamelliforme; en $B$, on voit á la face interne la couche germinale granuleuse. - D. Hydatide ouverte, renfermant des hydatides plus petites. - E. Échinocoque avec la partie antérieure rentrée en dedans du corps ou invaginée; on voit la disposition des crochets des ventouses; le corps renferme des corpuscules calcaires (d'après Laboulbène).

(France médicale, juin 187ö) en a publié et figuré un remarquable exemple chez le cheval. En examinant l'intérieur d'une hydatide mère, dépourvue de membrane germinale, on peut trouver des bourgeons qui se développent ultérieurement, en 
vésicules ; ces bourgeons détachés, comprimés et examinés au microscope, offrent exactement la même disposition que les enveloppes hydatiques, constituant les grandes vésicules. Si les bourgeons sont placés sur la face externe, l'hydatide produira des vésicules exogènes (v. Davaine)., Les kystes alvéolaires à échinocoques, du foie et du poumon, appelés aussi tumeurs à échinocoques multiloculaires, se rapprochent des hydatides exogènes. Leur contenu gélatiniforme est en réalité formé de membranes hydatiques repliées et renfermant des échinocoques (Laboulbène, loc. cit., p. 27 et 28).

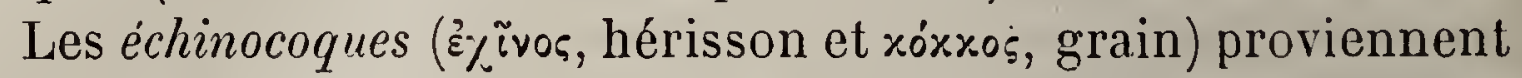
par bourgeonnement de la membrane germinale, des hydatides fertiles. D'abord ils sont constitués par une granulation blanchâtre, à peine visible à l'œil nu, qui se montre à la suriace, qui grossit, se pédiculise et qui enfin, se détache pour nager librement, dans le liquide hydatique. Le corps des échinocoques est formé par unè vésicule arrondie ou ovoïde, quand l'animal se contracte. Sur la partie postérieure, on trouve parfois les traces du pédicule, par lequel l'animal tenait à la membrane germinale. La partie antérieure, ordinairement invaginée, offre quatre ventouses et une double couronne de crochets. Le corps est parsemé de granulations formées de carbonate de chaux et de phosphate de chaux, unis à une substance organique (Laboulbène, Mémoires de la Société de biologie, 1872).

Les hydatides, ou poches hydatiques, bien développées dans nos organes, peuvent ultérieurement subir des altérations importantes. La membrane s'épaissit en plusieurs points, elle devient cartilaginiforme; la surface interne est rude, inégale, enduite de sels calcaires. L'hydatide n'est plus arrondie, mais bombée avec des enfoncements et des diverticules. La paroi cède sur quelques points, la poche peut communiquer avec les vaisseaux ou les cavités voisines. D'autres fois, quoique bien plus rarement qu'on ne l'a dit, l'intérieur est rempli d'un liquide purulent. M. Laboulbène en a observé deux cas.

Dans un degré extrême, les échinocoques périssent, le liquide se résorbe, il ne reste qu'un magma granulo-graisseux, parfois semblable à du mastic, où l'on trouve encore les cro- 
chets des échinocoques. La membrane hydatique, pressée, ridée, chiffonnée, ressemble à un petit paquel de taffetas gommé, entouré ou non d'une membrane fibreuse. Mais le diagnostic est encore possible, et dans un fait de ce genre, M. Laboulbène a pu établir l'existence d'un kyste très ancien, chez un sujet ayant succombé à une autre affection et, à force de recherches, montrer à Béhier, des crochets d'échinocoque (loc. cit., p. 30). Quand un de ces kystes hydatiques vient à se rompre dans les voies digestives, aucun ténia, soit inerme, soit armé, ne s'y développe. L'hydatide ou l'acéphalocyste sont rendus en nature, peu altérés, reconnaissables et non changés ; l'échinocoque périt dans l'intestin humain et ne s'y transforme point. M. Laboulbène a fait suivre ces développements de considérations très intéressantes sur l'étiologie comparée du T'ænia ccenurus (qui produit le tournis du mouton) (fig. 399). Nous

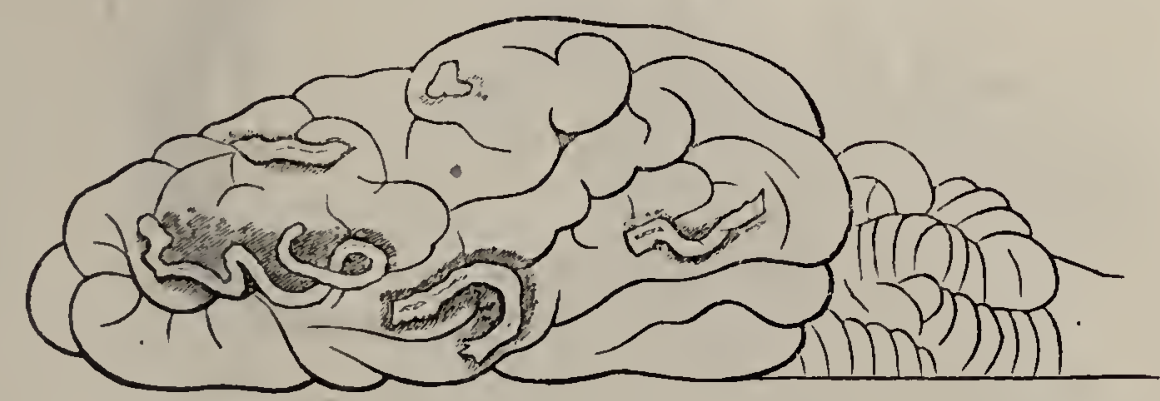

Fig. 399. - Cerveau d'un mouton ayant avalé des œufs de Tania cœnurus depuis trois semaines, et qui a été abattu après avoir donué les symptômes du tournis; la surface offre des galeries parcourues par les jeunes vésicules du cœnure (d'après Gervais et Vau Beneden).

renvoyons le lecteur au remarquable travail de M. Laboulbène, publié en mai et en juin 1877 dans le Bulletin de Therapeutique, chez O. Doin.

Se fondant sur les expériences qui ont été faites pour démontrer que le cœnure du mouton est produit par l'œuf d'un ténia du chien ou du loup, s'appuyant également sur des expériences directes, M. Laboulbène conclut que les vésicules hydatides, pourvues d'échinocoques et constituant la ladrerie hydatique, ne sont qu'une phase du développement du Tania echinococcus, ou ténia échinocoque du chien. La grandeur du ténia échinocoque est peu considérable, puisqu'elle varie entre 2 ou 3 millimètres. Le scolex possède une double rangée de 
crochets comme ceux des échinocoques. M. Laboulbène signale avec raison l'énorme disproportion qui existe entre ce minuscule ténia et le développement considérable de l'hydatide (1).

Bothriocephalus latus. Bothriocéphale large. - Ce parasite est assez rare dans nos pays; il est, au contraire, fréquent en Suisse, surtout à Genève où, suivant Odier, le quart des

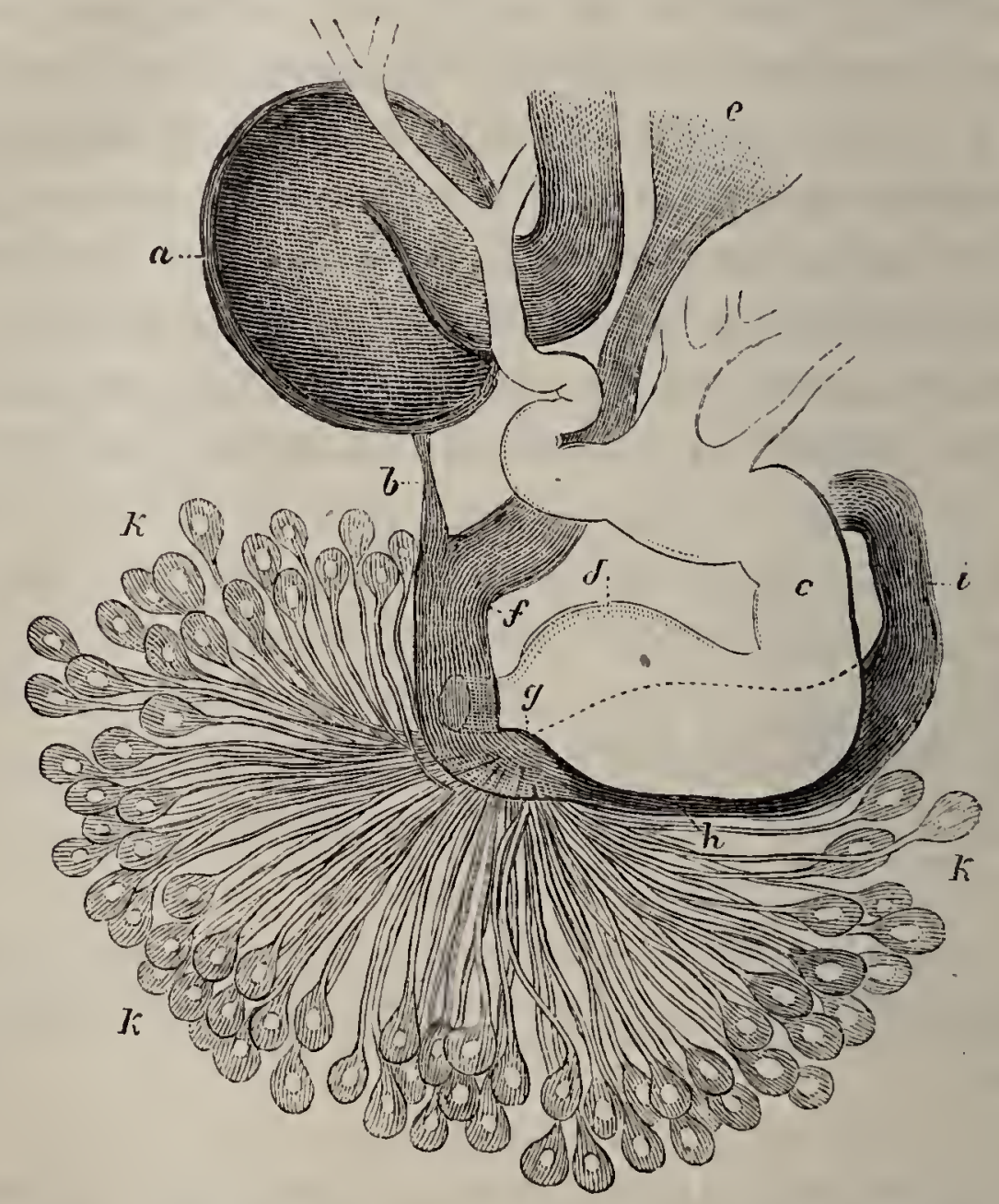

Fig. 400. - Bothriocephalus latus. Centre où se réunissent les eonduits des organes de la génération, d'après MM. Sommer et Langlois. - a. Extrémité postérieure renflée du vagin. $-b$. Petit canal de décharge au germiducte. $-c$. Vitelloducte. $-d$. Élargissement ampullaire du vitelloducte. $-\epsilon, f$. Germiducte. $-g, i$. Commencement fusiforme de la matrice. $-k, k$. Glandes unicellulaires formant la eoque; leurs eonduits se rendent en $g$, au eommencement de la matrice.

habitants en serait atteint, en Russie, en Suède, en Pologne, dans la Prusse occidentale, plus rarement en Hollande et en Belgique.

(1) D'après les observations de M. Mégnin, l'Echinocoque du cheval se transforme daus les diverticulums de l'intestin de cet animal, en un ténia incrme, qui n'est autre que le tania perfoliata des helminthologistes (loc. cit.). 
Le Bothriocéphale présente une particularité sur laquelle nous voulons insister dès maintenant: ce ténia pond ses coufs dans l'intestin, tandis que les cucurbitins des autres ténias de l'homme, s'échappent généralement en entier et sans être altérés.

Examiné dans son ensemble, le Bothriocéphale ressemble à un gros ténia inerme, dont les anneaux seraient moins allongés et plus rapprochés entre eux. Le strobile est long de 7 à 8 mètres. La couleur grisâtre et terne, ou même brunâtre, de l'animal conservé dans l'alcool, devient blanchâtre et se rapproche beaucoup de celle de nos ténias, quand le ver récemment rendu, a été placé dans l'eau. L'extrémité antérieure est terminée par la tête ou scolex. Celle-ci présente un ovoïde allongé, long de $2^{\mathrm{mm}}, 5$, large de 1 millimètre, terminé par un cou étroit et ridé en travers, à partir de 2 centimètres environ. La tête est

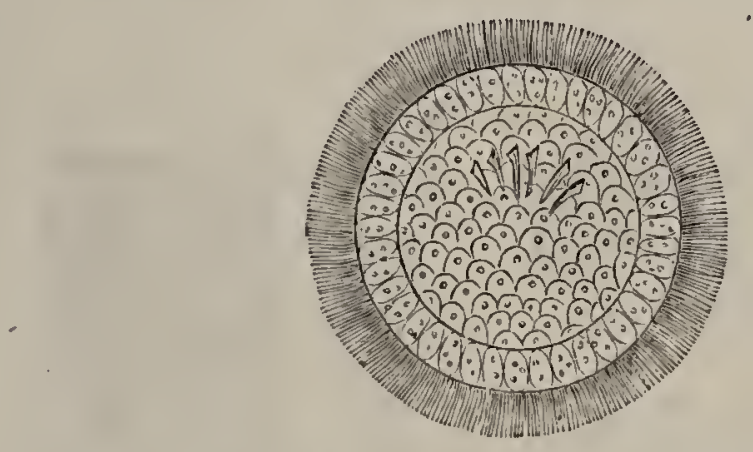

Fig. 101 . - Embryon libre du Bothriocephalus latus.

munie de deux ventouses allongées, creusées latéralement(d'où le nom générique du ver: $\beta_{0} 0$ piov, fossette, et $x \varepsilon \varphi x \lambda \eta_{n}$, tête), et elle est dépourvue de rostres et de crochets. Cette tête, en raison de sa contraclilité, prend des formes variées. Les anneaux qui composent le corps ou strobile, sont surtout élargis à leur partie médiane et plus colorés en ce point, où se trouvent les organes génitaux. Cette disposition est alsolument caractéristique.

Le corps ou strobile, examiné à l'œil nu, paraît avoir trois bandes longitudinales, une médiane plus épaisse et deux latérales plus minces. Ces trois bandes sont en rapport avec une disposition spéciale des organes génitaux. Ces organes génitaux sont constitués : $1^{\circ}$ par un pore génital médian, appelé aussi cloaque ou sinus génital, dont les bords sont garnis de papilles. Au fond, sont deux ourertures : la supérieure donne issue au pénis, l'inférieure est l'orifice du vagin. En arrière et distincte 
du pore génital, est une ouverture indépendante, où aboutissent les cornes ou ramifications réunies de la matrice et par où se fait la ponte des œufs. Les anneaux du Bothriocéphale n'ont pas, comme ceux duténia, une organisation absolument indépendante et une partie des organes génitaux passe de l'un à l'autre dans la partie centrale du champ médian; aussi les segments ne se divisent-ils pas pour former des cucurbitins.

Généralement, quand les segments après leur maturité ont laissé tomber leurs œufs dans l'intestin, ils se ratatinent et reviennent sur eux-mêmes sans abandonner le strobile. (Pour plus de détails sur la constitution des organes génitaux du Bothriocéphale large, consulter l'article Cestoïdes de Davaine, dans le Dictionnaire encyclopédique, chez V. Masson.)

Les œufs du Bothriocéphale (fig. 402) sont brunatres, par-
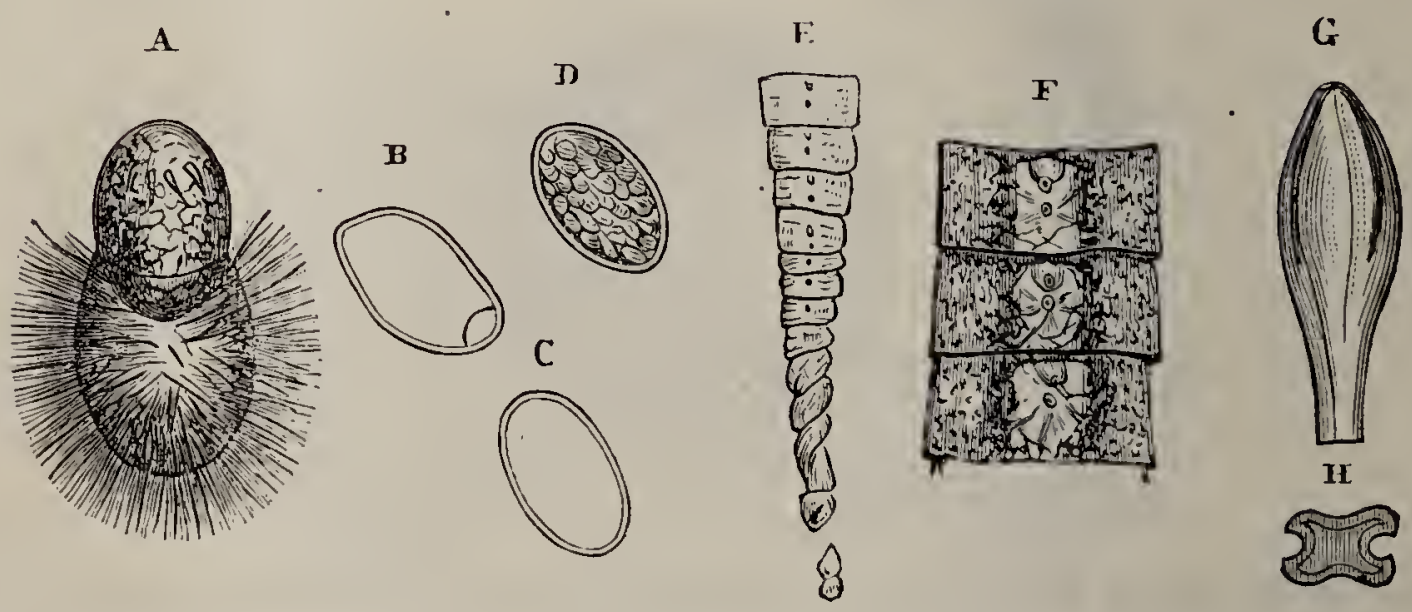

Fig. 402. - A. Embryon du“Bothriocéphale large sortant de son enveloppe ciliée. B. D. Deux sufs grossis du Bothriocéphale large. - D, après son traitement par la glyeéririe. - B, après son traitement par l'acide sulfurique; la forme est un peu modifiée; en $\mathrm{B}$, on voit l'opercule. - C. OEuf elliptique du B. L. examiné dans les déjections alvines. - E. Fragment terminal du Bothriocéphale large, composé d'anneaux réunis bout à bout et dont les pores génitaux sont situés sur la ligne médiane du corps. Les derniers auneaux sont flétris et ridés. - Trois segments du corps d'un Bothriocéphale montrant le ehamp médian et les champs latéraux. Le long de la ligne médiane, on voit les pores génitaux, avec le pénis saillant sur le segment le plus inférieur. Au-dessous est l'orifice utérin ou de la ponte. - G. Tête grossie du Bothriocéphale large aree les deux fossettes allongées. Au-dessous H, coupe montrant la disposition de ces fossettes latérales (d'après Laboulbène).

faitement elliptiques, lorsqu'ils sont vus dans les matières alvines, longs de $0^{\mathrm{mm}}, 068$ à $0^{\mathrm{mm}}, 070$ et larges de $0^{\mathrm{mm}}, 044^{\prime}$ à $0^{\mathrm{mm}}, 043 \mathrm{~s} ;$ leur coque est peu épaisse, simple. Sur l'un des pôles, on trouve un opercule ou une calotte, qui devient visible après l'action endosmotique de la glycérine, ou de l'acide sulfu- 
rique (Davaine). Le nombre des œufs du Bothriocéphale est considérable; il serait au moins de $\mathbf{1 0}$ millions, suivant Escricht.

Le Bothriocéphale est très difficile à expulser; il peut vivre dans l'intestin, concurremment à un autre ténia, et présente fréquemment des anomalies de structure. Différentes opinions ont été émises sur le développement de l'œuf du Bothriocéphale, et il règne quelque incertitude à ce sujet. Pour accomplir son entier développement, l'œuf du Bothriocéphale doit rester six ou huit mois dans de l'eau courante, ou fréquemment renouvelée. Au bout d'un mois, le vitellus se divise en cellules, bientôt après apparaît une tache embryonnaire qui s'étend lentement aux dépens du vitellus, tandis que celui-ci se rétracte, laissant entre lui et la coque, un espace de plus en plus grand. A six mois, apparaissent les six crochets de l'embryon, chez lequel se manifestent déjà quelques mouvements contractiles. Enfin, après sept à huit mois, il se détache de la coque une calotte ou opercule, livrant passage à l'embryon (Bertolin). Entre le moment de la formation embryonnaire et l'éclosion, il peut s'écouler beaucoup de temps. Leuckart a vu des embryons développés avant l'hiver, n'effectuer leur sortie qu'au mois d'avril suivant.

L'embryon est transparent, formé de deux vésicules sphériques, emboîtées l'une dans l'autre et séparées par un liquide. La vésicule extérieure est revêtue de cils vibratiles qui servent à la locomotion. L'embryon, après avoir nagé dans l'eau, en tournoyant comme un volvox, sort de son enveloppe pourru de longs cils vibratiles et on l'a vu vivre quelque temps après s'être dépouillé de son revêtement cilié. On avait longtemps cru que cet embryon pénétrait dans certains animaux aquatiques et en particulier, à Genève, dans l'organisme de la Fera. espèce de Salmonide. Il résulte des recherches du professeur C. Vogt, de Genève, que les poissons de la famille des Salmonés doivent être relevés de cette accusation, de sorte que l'hypothèse de Knoch et Leuckart paraît la plus acceptable. D’après ces auteurs, l'embryon placé dans l'eau arrive dans le tube digestiff, sans l'intermédiaire d'une nouvelle métamorphose, et il s'y développe directement en scolex, puis en strobile du Bothriocephalus latus. 
On trouve encore chez l'homme deux autres Bothriocéphales dont nous nous contenterons de donner la figure. Le Bothrio$\therefore$
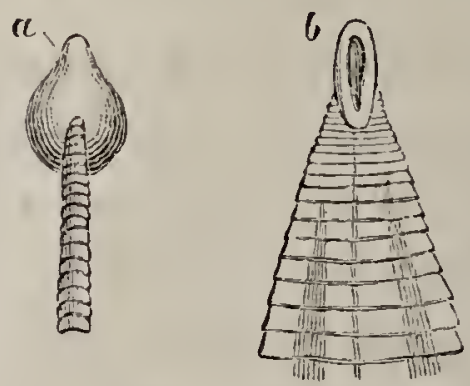

Fig. 403. - Scolex du Bothriocephalus cordatus (d'après Leukart).

cephalus cordatus (fig. 403) est long de 1 mètre, il a la tête en
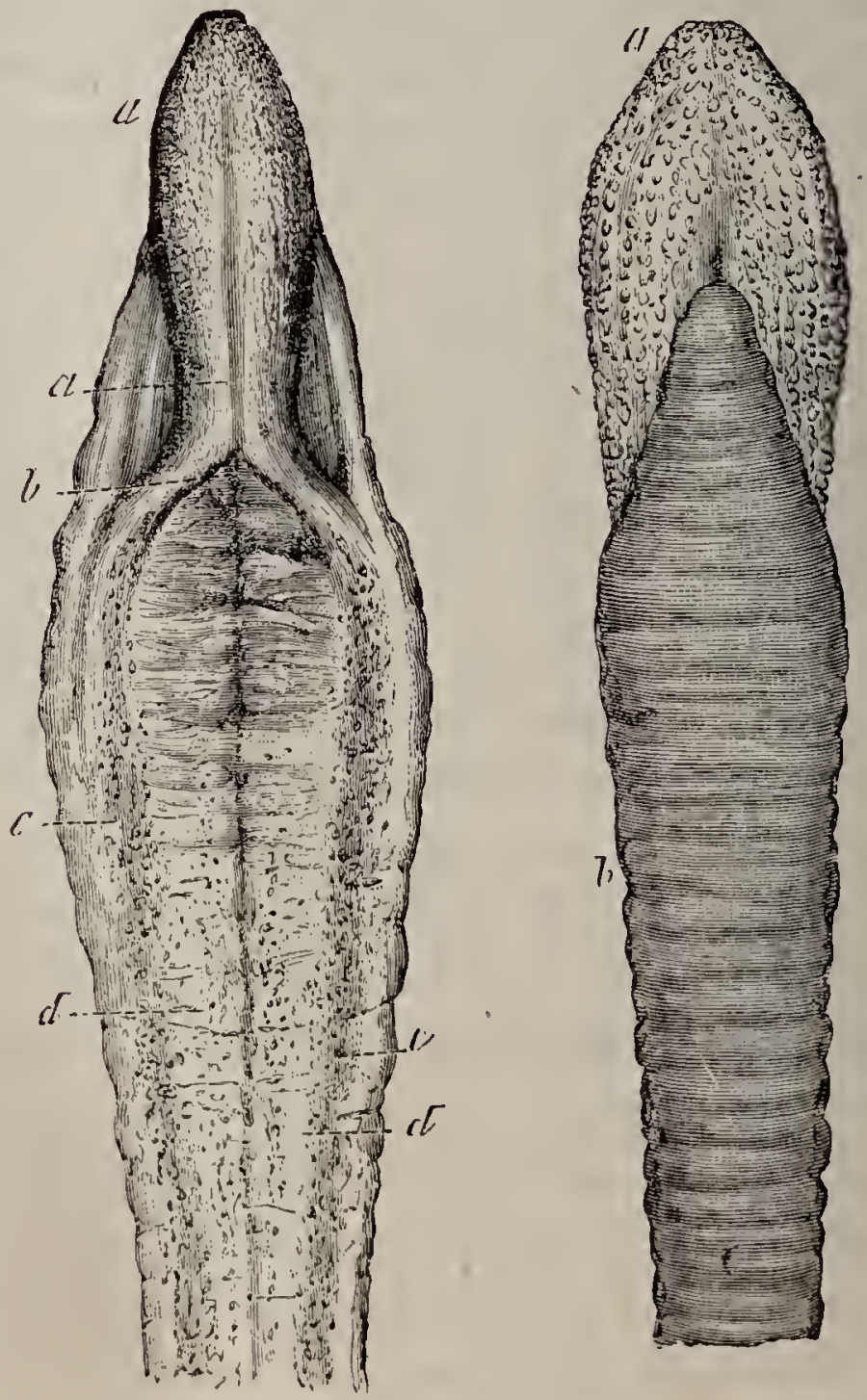

Fig. 404. - Scolex du Bothriocephalus cristatus vu sur la face et sur le còté. - a, a. Crête médiane. $-b$. Sun prolongement en arrière. $-c, c$. Trainée externe de corpuscules calcaires. $-d, d$. Traînée interne.

forme de cœur de carte à jouer et habite le Groënland ; l'autre est le Bothriocephalus cristatus (fig. 40'), décrit par M. Davaine. 
Ce savant helminthologiste lui a donné ce nom en raison de ses lèvres saillantes. Les spécimens de ce ver, observés par M. Davaine, ont été rendus par des Français qui n'avaient jamais quitté leur pays, où d'ordinaire on ne rencontre que le Bothriocéphale large (D’après Laboulbène, loc. cit., p. 36 et suivantes).

\section{$2^{\circ}$ TRÉMATODES.}

Les Trématodes qui peuvent s'observer chez l'homme sont facilement reconnaissables à leur corps aplati, déprimé en
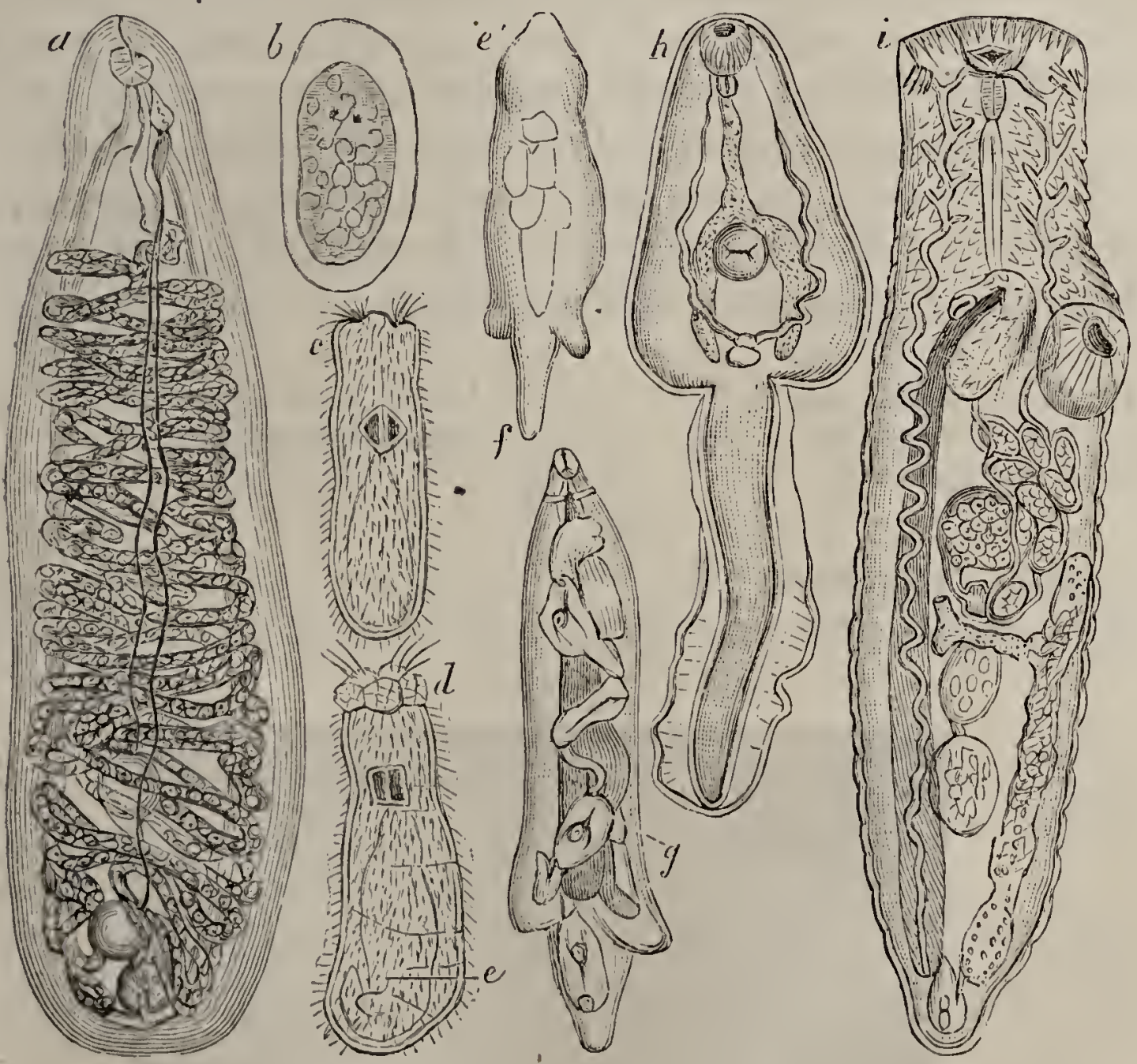

Fig. 403̈. - Générations alternantes des Distomaires, vues au microscope. - $a$. Un monostome à l'état parfait (vit dans le foie du canard ct de quelques autres oiseaux aquatiques). - -6 . Un des œufs du mème. $-c$. Proscolex sorti de l'œuf. $-d$. Le même renfermant un seolex $(e)$ en voie de développement. $-e^{\prime}$. Scolcx libre. $-f$. Scoler de distomc contenant des cercaircs $(g)$ en roic de développemcut. - $h$. Un de ces cercaires libre. $i$. Le même après sa transfurmation en distome parfait.

forme de feuille ou de fer de lance, ainsi qu'à la disposition de ¿leur appareil digestif, essentiellement composé d'une 
bouche, d'un pharynx, d'un œsophage et de deux longs cœcums qui descendent vers la région postérieure du corps et peuvent fournir des branches latérales. La bouche s'ouvre au centre d'une ventouse, qui en reçoit le nom de ventouse orale et se trouve accompagnée (dans les distomes) par un second organe d'adhérence, situé à une distance plus ou moins considérable, et représentant une ventouse abdominale. Ces animaux sont hermaphrodites (sauf le Distomum hæmato. hium) et possèdent un appareil sexuel très compliqué, surtout en ce qui concerne l'organe femelle. Nous n'insistons pas davantage sur sa description, non plus que sur celle de l'intestin, parce que les replis de l'oviducte, gorgé d'œufs, en rendent l'étude fort difficile et ne permettent d'en tirer aucun secours, pour l'examen pratique, ou la détermination des espèces.

Les Distomes ou, pour employer le nom sous lequel on les désigne le plus fréquemment, les Douves qui ont été rencontrées chez l'homme sont les.suivantes :

$1^{\circ}$ Douve hépatique.

$2^{\circ}$ Douve lancéolée.

$3^{\circ}$ Douve épaissie. $4^{\circ}$ Douve hétérophye.

$5^{\circ}$ Douve opthalmobie.

6 Douve hématobie.

Douve hépatique (Distomum hepaticum, Ab.). - Sa taille peut varier de 1 à 4 centimètres en longueur, de 3 à 15 milli-

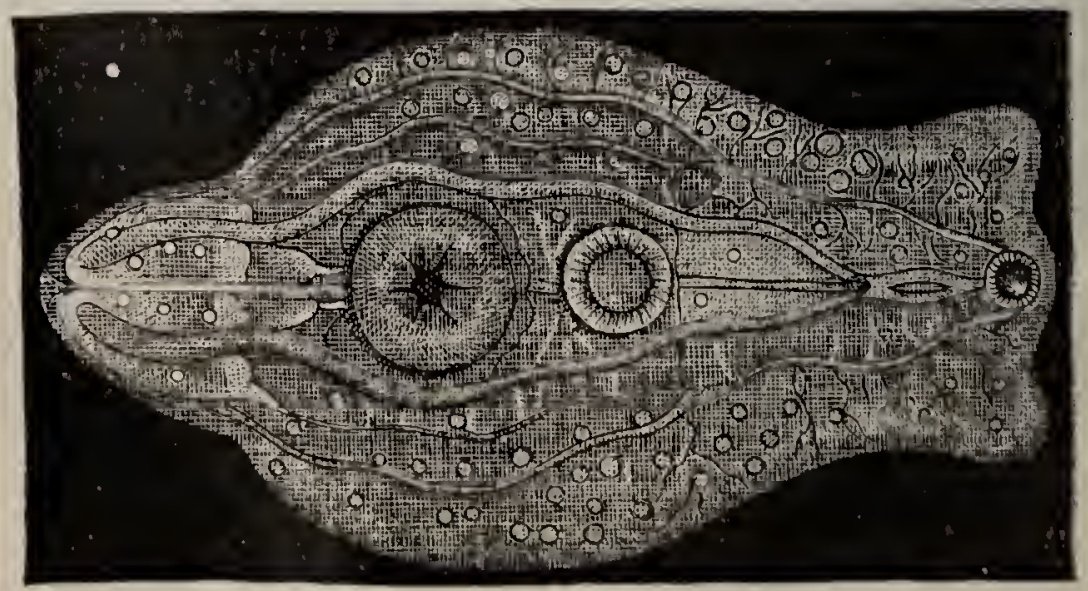

Fig. 406. - Douve hépatique.

mètres de largeur, suivant l'âge où on l'examine. De forme oblongue, elle est élargie en avant, rétrécie en arrière; sa cuticule porte de nombreuses petites épines. La ventouse orale 
est exactement terminale et portée sur une sorte de cou, la ventouse abdominale est peu éloignée de la précédente el triangulaire, tandis que celle-ci est arrondie. Dans l'intervalle de ces deux ventouses, un grossissement faible, $\frac{50}{1}$, permet de distinguer un pénis et un orifice sexuel, intimementrapprochés l'un de l'autre.

L'intestin est ramifié, c'est-à-dire que ses deux branches principales donnent naissance à de nombreux cæcums latéraux, qui peuvent se subdiviser et dessiner d'élégantes arborisations, que leur contenu brunâtre fait aisément distinguer. L'examen de cet appareil digestif présente une grande valeur, puisqu'il suffit à caractériser la Douve hépatique et permet de la distinguer de la Douve lancéolée, avec laquelle on la rencontre ordinairement. L'oviducte, très flexueux, renferme des œufs jaunâtres, ovoïdes, munis d'un opercule mesurant de $0^{\mathrm{mm}}, 12$ à $0^{\mathrm{mm}}, 14$, suivant leur grand axe et de $0^{\mathrm{mm}}, 06$ à $0^{\mathrm{mm}}, 09$, suivant leur petit axe (fig. 407). De ces œufs naît un embryon

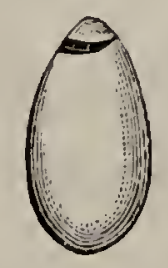

Fig. 407. - Ovule du distome hépatique grossi 107 fuis et traité par la potasse caustique pour séparer l'opercule.

cilié (proscolex), mais nous ignorons encore où se développent le scolex et le proglottis de cette espèce et des divers parasites de l'homme.

La Douve hépatique, facile à reconnaître à l'aide des caractères précédents, peut être déterminée, soit à l'œil nu, soit à l'aide d'une simple loupe. Cependant l'étude de l'intestin el des œufs exige l'emploi du microscope. Un grossissement de $\frac{1}{60}$ suffit dans le premier cas, un grossissement de 180 diamètres est nécessaire dans le second. L'examen des œufs est d'ailleurs fort aisé, le seul réactif nécessaire est la potasse, qui permet de séparer leur opercule. Les dimensions et la couleur de ces ovules doivent être notées avec soin, surtout si on les observe dans les fèces, dans une tumeur, etc., où ils 
peuvent être mélangés d'œufs appartenant au $D$. lanceolatum. La douve hépalique habite des hôtes très différents (hommes, quadrumanes, carnivores, rongeurs, ruminants, solipèdes, pachydermes, marsupiaux, etc.) On l'observe presque constamment chez le mouton, dans l'organisme duquel elle détermine une grave maladie, se généralisant souvent, et causant de redoutables épizooties (cachexie aqueuse). Chez l'homme on l'a observée dans les conduits et dans la vésicule biliaire, dans l'intestin, la veine porte, la veine cave, les veines sous-hépatiques, elc. On s'explique comment ces helminthes pénétrant dans les vaisseaux et entraînés avec le sang dans les diverses parties de l'économie, ont pu s'arrêter dans les capillaires de telle ou telle région (Voy. Sang), et y causer des tumeurs semblables à celles qui ont été observées sur divers points du corps (parois thoraciques, région occipitale, face plantaire du pied, etc.)

Le distome hépatique s'introduirait dans l'organisme sous forme de cercaires, qui se développeraient surtout dans certains mollusques, et en général, chez quelques animaux inférieurs. Ce serait donc sous cette forme et à l'aide des boissons que les cercaires pénétreraient dans l'intestin, et de là, dans les canaux biliaires.

Ces cercaires peuvent également s'introduire par le tégument externe, de là, ces tumeurs siégeant, conıme on l'a vu plus haut, en différents points du corps, sans que le foie présente la moindre altération.

Les cercaires ont été rencontrés à l'état de liberté dans l'eau de mer et dans les eaux douces (fig. 40ว̈).

Il sera facile de distinguer les distomes observés dans de semblables conditions, sans les confondre avec des lambeaux de tissu cellulaire, des vaisseaux, des nerfs, etc.; en effet, lorsque les doures se montrent dans ces habitats noureaux, leur intestin gorgé de sang est rouge et non plus brun, comme lorsqu'on observe le trématode dans le foie, où la bile distend les branches de son appareil digestif et leur communique sa couleur propre. Cette modification jointe à la couleur caractéristique du ver doit toujours rendre sa détermination facile. 
Douve lancéolée $($ D. lanceolatum $)$. - Plus petite que la précédente, car elle ne mesure que 4 millimètres à 1 centimètre de longueur et 2 à 3 millimètres de largeur. Cette espèce est effilée, atténuée en avant, élargie en arrière, ce qui est le contraire de ce que l'on observait chez la douve hépatique. Les deux ventouses sont arrondies, l'intestin est formé de deux cœcums simples, ne fournissant aucune branche latérale; l'oviducte décrit des sinuosités encore plus nombreuses que

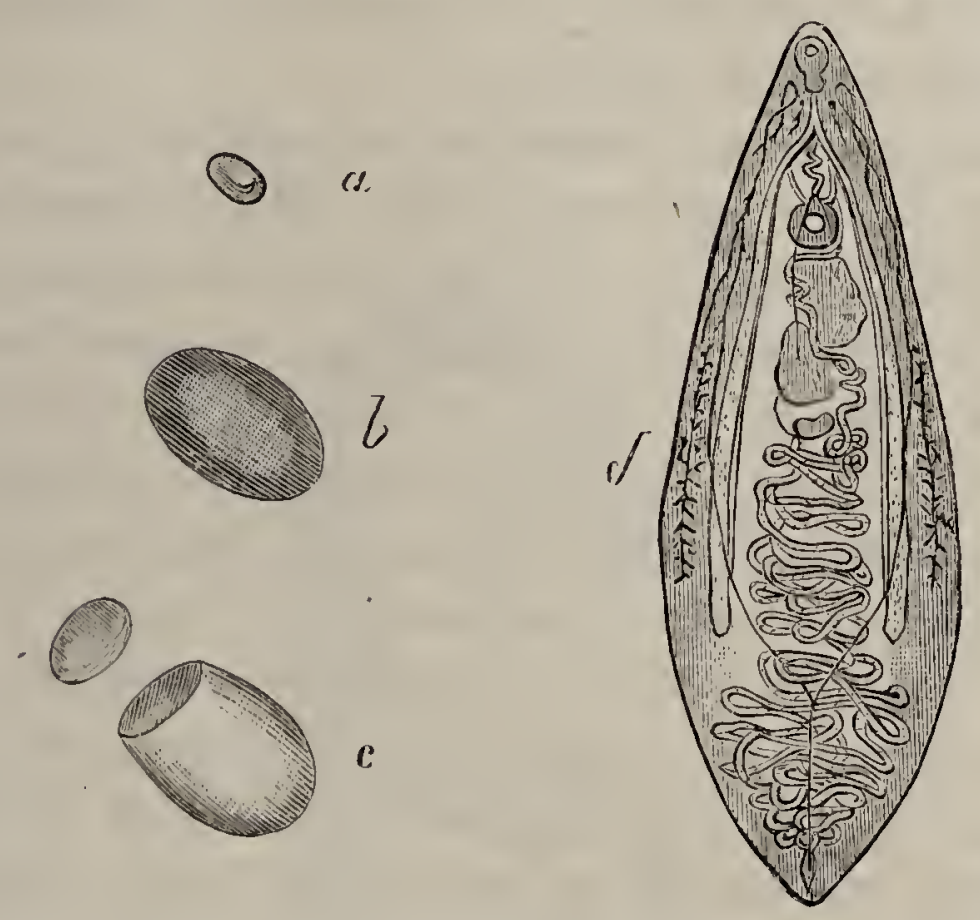

Fig. 408. - Douve lancéolée. - $a$. OEuf grossi 100 fois. - b. OEuf grossi 340 fois $-c$. OEuf traité par la potasse pour détacher l'opercule. $-d$. D. lanceolatum, grossi 10 fois.

dans le D. hepaticum et se montre comme gorgé d'œufs brunâtres, quelquefois presque noir's, longs de $0^{\mathrm{mn}}, 03$ à $0^{\mathrm{mm}}, 04$, pourvus d'un grand opercule. Leur éclosion est plus lente que dans la première espèce et donne naissance à un proscolex légèrement différent. On n'a pu suivre encore les migrations ni les générations qui lui succèdent. Cette douve se rencontre dans les mêmes conditions que la douve hépatique dont elle se distingue aisément par sa forme, sa taille, la disposilion de son tube digestif, le volume et la couleur de ses œufs. Pour observer ceux-ci, il convient de faire usage d'un grossissement de $\frac{350}{1}$.

Douve épaisse (D. crassum). - Tandis que les deux espèces précédentes ont été observées sous toutes les latitudes, la 
douve épaisse n'a encore été rencontrée qu'aux Indes et en Chine. Les cas très rares, où elle a été observée en Europe, ont toujours été fournis par des matelots ou des soldats ayant habité ces pays. C'est le géant des douves que l'on peut rencontrer chez l'homme; cette espèce mesure, en effet, de כ̀ à 8 centimètres de longueur et 2 centimètres de largeur en moyenne. Elle est très épaisse, effilée antérieurement, élargie postérieurement; les ventouses sont arrondies, distantes de $1^{\mathrm{mm}}, 8$ à $3^{\mathrm{mm}}, 2$. A un œsophage très court succèdent deux longs cœcums intestinaux non ramifiés.

Gette espèce est donc nettement caractérisée, et quand on observe des distomes, chez des malades placés dans des conditions semblables à celles qui ont été rappelées précédemment, on devra les déterminer soigneusement, comparer leurs caractères avec ceux des $D$. hepaticum et lanceolatum, puis chercher s'il n'y aurait pas lieu de les rapprocher du D. crassum.

Douve hétérophye $(D$. heterophyum). - Cette espèce, la plus petite de celles qui nous intéressent, est longue de 1 millimètre, large de $0^{\mathrm{mm}}, 4$; elle n'a été observée que deux fois, en Égypte, chez un enfant; d'apparence pyriforme, elle est atténuée en avant, arrondie en arrière; la ventouse abdominale, très développée, est située au milieu du corps; l'intestin est formé de deux longs cœcums simples; les œufs sont rouges.

Dou ve ophthalmobie $($ D. ophthalmobium. $)$ - Longue de $0^{\mathrm{mm}}, \breve{s}$, large de $0^{\mathrm{mm}}, 14$, ce distome n'a été observé qu'une seule fois par Diesing dans l'œil d'un enfant atteint de cataracte congénitale.

Douve hématobie (D. hæmatobium). - Bilharz (V. Davaine, Synopsis LXXVII.)

Distorme à sexes séparés sur deux individus. - Mâle, corps mou, blanchâtre, filiforme; partie antérieure distincte, formant le huitième ou le neuvième de la longueur totale du corps, déprimée, lancéolée, plane ou concave en dessous, légèrement convexe en dessus, lisse. Partie postérieure : cylindrique, six à sept fois plus longue que l'antérieure, en arrière de la ventouse ventrale, la marge inlléchie de chaque côté, sur la marge ventrale, forme de cette manière un canal longitudinal (canalis gynæcophorus), extrémité postérieure amincie; sur- 
face externe, couverte de papilles filifères; surface intérieure (du canal) lisse sur la partie moyenne et couverte d'épines très petites sur les côtés; ventouse buccale, située à la face inférieure terminale, triangulaire; ventouse ventrale, située près de la limite des deux parties distinctes du corps (tronc et queue), orbiculaire, de la même dimension que la buccale ; surface de chaque ventouse courerte de granules serrés et très petits; tube digestif cépourvu d'un pharynx musculaire, divisé, en avant de la ventouse ventrale, en deux parties, qui sont réunies de nouveau en arrière en un canal unique et terminé en cœcum; pore génital situé entre la ventouse ventrale et l'origine du canal longitudinal (gynœcophore); longueur totale

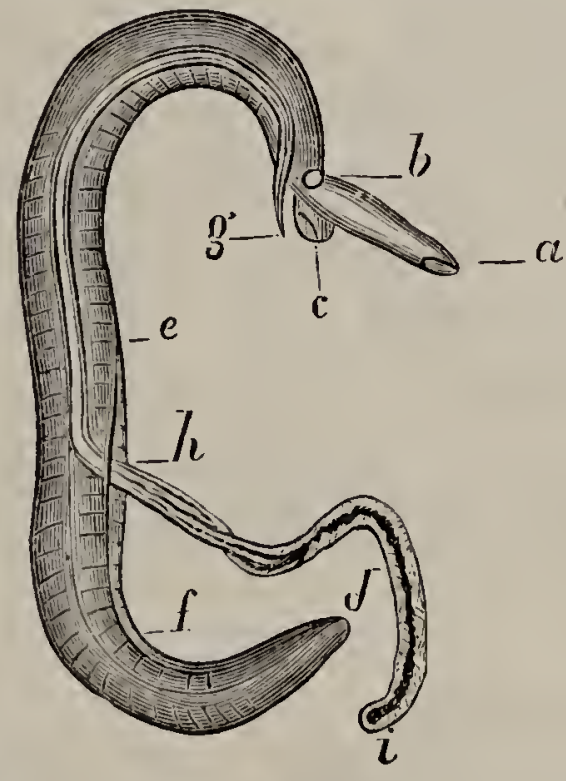

Fig. 409. - Douve hématobic. $-a, b$. Màle. $-g, i$. Femelle. $-a$. Ventouse buccale. $-a, b$. Tronc. $-c$. Ventouse ventrale. $-d, b$. Queue. $-e, f$. Ouverture ventrale constituant le canal gynécophore. $-g, h$. Portion de la femelle incluse dans le gynécophure. $-h, i$. Portion de la femelle retirée du gynécophore.

de 7 à 9 millimètres, pouvant aller jusqu'à 11 millimètr'es (Sonsino).

Femelle. - Différant_du mâle par la forme, très mince et grêle; corps rubané, lisse, transparent, très aminci en avant, dépourvu d'un canal longitudinal; ventouses et tube digestif comme chez le mâle. Pore génital réuni avec la marge postérieure de la ventouse ventrale; œufs ovales, prolongés en pointe d'un côté, longueur totale jusqu'à 15 millimètres.

Le mâle, surpassant de beaucoup la femelle en grosseur, porte celle-ci placée longitudinalement dans le canal gynæco 
phore, réalisant ainsi, en quelque sorte, l'hermaphrodisme du genre distome, auquel ce ver déroge exceptionnellement.

L'embryon encore contenu dans l'œuf est couvert de cils vibratils; devenu libre, sa forme est celle d'un cylindre allongé, plus large en avant et terminé en arrière obliquement en un coin; il est pourvu, en avant, d'une éminence du rostre qui porte une empreinte de ventouse; à l'intérieur du corps existent deux corpuscules piriformes (gemmes de sporocyste?) réunis, situés en avant. L'embryon nage au moyen de ses cils vibratils (Davaine).

\section{$3^{\circ}$ NÉMATODES.}

On connaît les nombreuses espèces de cet ordre qui se rencontrent à l'état parasitaire chez l'homme et dont la détermination exige presque constamment l'emploi du microscope, bien que la forme, les dimensions, l'habitat, permettent parfois de les distinguer à l'œil nu.

A scaris lombricö̈les. - Par sa taille (mâle long de 14 à 18 centimètres; - femelle, de 20 à 27 centimètres), par sa localisation dans l'intestin grêle, cet helminthe, l'un des plus fré-

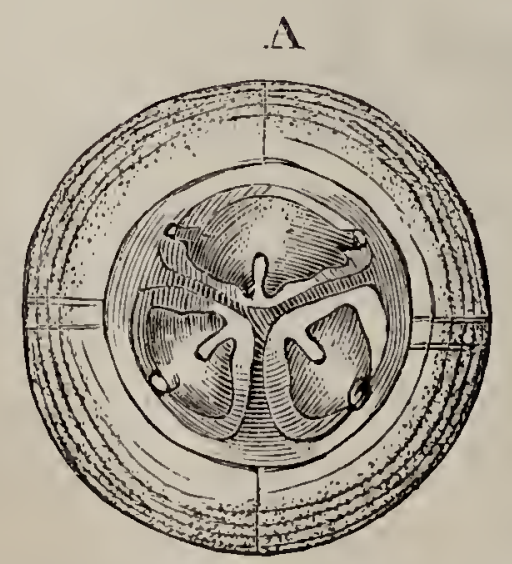

$\mathbf{B}$

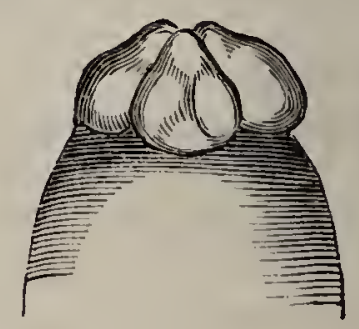

Fig. 410. - A. Ascaris lombricoïdes (bouche vue de face). - B. Extrémité antérieuse.

quents dans l'espèce humaine, peut aisément se reconnaitre; toutefois le microscope permet de distinguer les trois valves. articulées qui entourent la bouche et surtout d'étudier les œufs elliptiques $\left(0^{\mathrm{mm}}, 077\right.$ sur $\left.0^{\mathrm{mm}}, 059\right)$ dont on peut être souvent appelé à constater la présence dans les fèces (fig. 383 ).

Ces œufs sont ovoïdes, revêtus de deux enveloppes : l'interne 
ou enveloppe propre, est lisse et solide; l'externe est faite d'une substance albumineuse, inégalement répartie, ce qui lui donne un aspect bosselé; elle est teintée par les matières intestinales; cette deuxième enveloppe n'existe pas avant la ponte, les œufs sont alors blancs (Davaine).

Dxyuris vermicularis (Bremser).-L'oxyure vermiculaire qui habite surtout la portion terminale de l'intestin, mais qui peut également se trouver dans le duodénum, l'iléon, le cœcum ou le côlon, suivant la période où on l'observe, se reconnaît aux

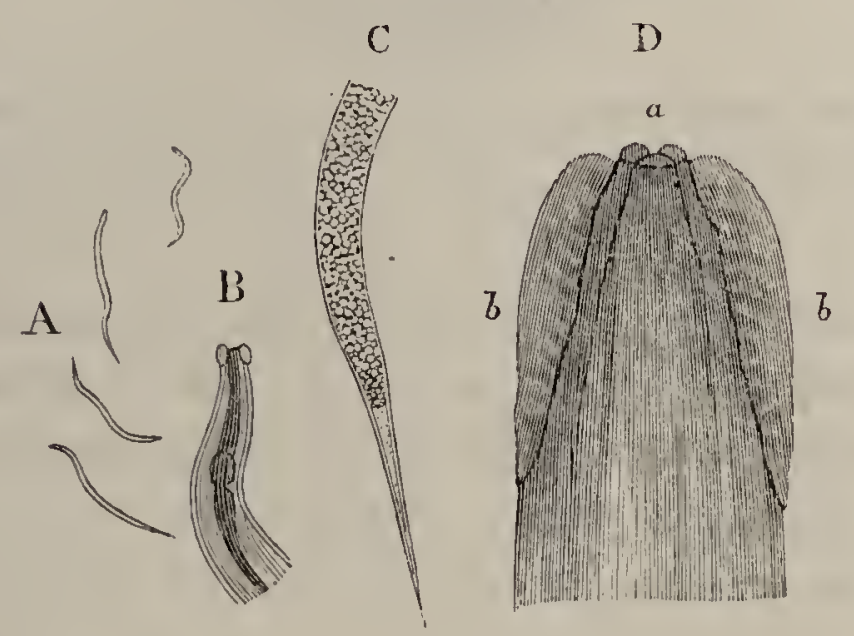

Vig. 411. - Oryure vermiculaire. - A. Individus de grandeur naturelle. - B. Extré mité céphalique grossie; l'œesophage et l'estomae sont apparents. - C. Extrémité caudale grossie. - D. Tête fortement grossie. - $a$. Bouche munie de trois lèvres. $b, b$. Renflements latéraux du derme (d'après Davaine).

deux renflements céphaliques, dont sa tête est bordée et qu'un grossissement de $\frac{60}{1}$ permei de distinguer aisément. Les œufs sont elliptiques et mesurent $0^{\mathrm{mm}}, 53$ sur $0^{\mathrm{mm}}, 18$. Pour cette espèce, comme pour les autres nématodes de petite taille, on retire les plus grand š avantages de l'emploi des réactifs colorés.

Tricocephalus dispar (Rudolphi). - Tous les traités d'helminthologie indiquent la bizarre apparence du tricocéphale, qu'un grossissement de $\frac{30}{1}$ permet d'étudier dans ses traits. principaux. Quant aux œufs, il suffit de les avoir observés une seule fois, pour pouvoir toujours les reconnaître. Les deux pôles se prolongent, en effet, sous forme de pointes mousses et fournissent un excellent caractère. L'acide acétique débarrassant les ovules, des corps gras qui les reguide de micrographie. 
couvrent très souvent, parmet de les distinguer aisément.
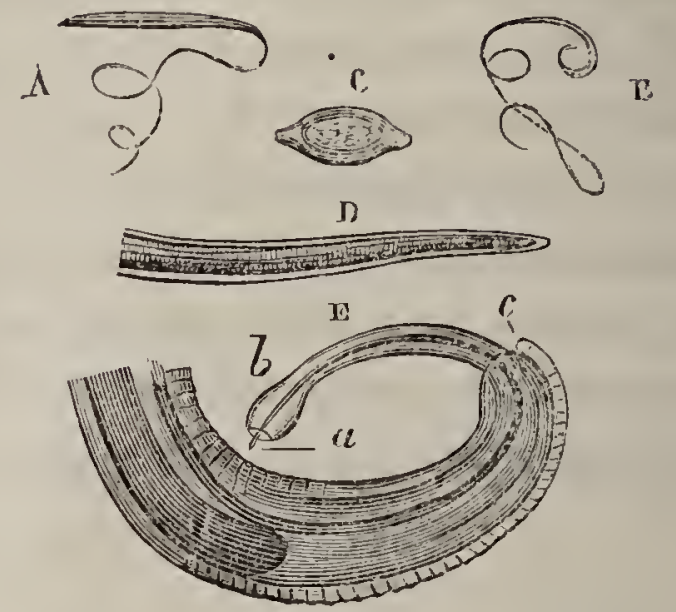

Fìr. 412. - Tricocéphale dispar. - A. Femelle. - B. Màle, de grandeur naturelle. C. OEur, à un grossissement de 130 (d.). - D. Extrémité antérieure grossie. - E. Extrémité postérieure grussie. - $a$. Spieule. $-b$. Sa gaine. $-c$. Anus.

Trichina spiralis. - Ce nématode, célèbre entre tous, par la panique qu'il cansa il y a une quinzaine d'années, lorsque plusieurs autopsies en révélèrent la fréquence en Allemagne, peut, on le sait, s'observer à deux états : $1^{\circ}$ agame et enkysté dans les muscles; $2^{\circ}$ sexué et libre dans le mucus intestinal.

Le microscope permet de le reconnaître aisément sous ces deux états et de ne pas tomber dans l'erreur qui avait fait confondre à Leuckart, la trichine et le tricocéphale.

A l'état adulte le mâle mesure un millimètre en longueur, la femelle de 3 à 4 millimètres; le corps est effilé en avant: les trois portions, initiale, moyenne et terminale, du tube digestif se reconnaissent aisément. La femelle présente l'orifice vulvaire, au point d'union du cinquième antérieur, avec les quatre cinquièmes postérieurs ; l'extrémité anale du mâle porte deux petits appendices conoïdes (fig. 4.15).

La femelle est vivipare, de sorle que l'embryon se trouve, dès qu'il est expulsé, en contact avec la muqueuse intestinale ; il s'engage immédiatement dans cette membrane, d'après les recherches de $\mathbf{H}$. Davaine (loc. cit., p. 746). On peut se faire une idée de la prolification inouïe de la Trichine par l'exemple suivant: on en a trouvé depuis 200 jusqu'à 1,000 dans l'organisme de la femelle. Si l'on songe que celle-ci pond pendant sept ou huit semaines, ainsi que cela a été observé en Allema- 
gne, on comprendra que l'organisme se trouve bientôt infecté de Trichines. Quoique ces embryons soient très nombreux, il est rare d'en rencontrer dans le mucus intestinal, où habitent leurs parents. Pour se frayer un chemin à travers les parois intestinales, et de là se rendre dans toutes les parties du corps, l'embryon n'est armé ni de slylet, ni de crochet; c'est grâce seulement à son extrême petitesse (il n'a que $0^{\mathrm{mm}}, 003$ d'épaisseurj qu'il voyage à travers les tissus. D'après M. Davaine, cette migration se ferait par le lissu musculaire, mais Zenker ainsi que quelques autres observateurs ont quelquefois trouvé des embryons dans le sang de l'homme, où ils avaient probablement été entraînés. I'embryon de la 'Trichine n'est constitué que par un simple tégument, sans organisation appréciable et par une substance granuleuse incluse, qui ne semble pas différer du vitellus, dont l'embryon s'est formé. Parvenu dans une fibre musculaire, l'embryon granditrapidement, tous ses organes, sauf ceux de la génération, se développent. Au bout de dix-neuf jours, la trichine est à l'état de larve; elle reste dans cet état, indéfiniment ou temporairement, soit qu'elle subisse une des altérations que nous indiquerons, ou que, plus favorisée, elle arrive dans l'intestin d'un mammifère, où elle se développera.

Durant sa période larvaire, longtemps seule connue, la Trichine se présente sous l'aspect d'un petit' nématode long de $1^{\mathrm{mm}}, 3$ à $0^{\mathrm{mm}}, 8$, enroulé sur lui-même dans un kyste à parois épaisses, souvent séparables en deux tuniques; il est rare que le même kyste renferme deux ou trois Trichines.

D'après les docteurs Bristowe et Rainey (V. Davaine, p. 735), le kyste serait produit par la Trichine; les parois du kyste tout en étant laminées, ne présentent pas d'une façon aussi nette que dans les membranes hydatiques, la disposition en couches concentriques et superposées. Le kyste est sujet à subir certaines altérations qui en altèrent l'aspect. Ordinairement formée par une substance transparente, la paroi du kyste réfracte fortement la lumière, on y aperçoit des granules de substance minérale, plus abondants dans les couches superficielles, et suivant d'autres, dans les couches profondes du kysle. Ces granules donnent à la capsule une consistance 
rigide qui la fait crier par' le grattage du scalpel. D'après MM. Bristowe et Rainey, ces granules se dissolveraient rapidement dans l'acide chlorhydrique, sans effervescence, ce qui indiquerait qu'ils sont formés de phosphate de chaux. Pour Küchenmeister, ces granulations seraient formées de carbonate de chaux, uni à une substance organique, mais, fait observer M. Davaine, ce carbonate pourrait provenir non des parois, mais du carbonate calcaire, qui se trouve libre dans la cavité des kystes. L'absence d'effervescence ne serait pas, d'après M., Davaine, un caractère absolu de la non-existence des carbonates; lorsque le carbonate de chaux est en très petite quantité, l'acide carbonique se dissout dans le liquide ambiant à mesure qu'il est libre. L'altération du kyste est d'autant plus prononcée, que celui-ci est de formation plus ancienne; la conséquence de cette altération est la mort de la Trichine; celle-ci est quelquefois complètement incrustée de matière terreuse.La dégénérescence crétacée commence par les pôles et n'envahitles parties centrales que plus tard. Les muscles envahis par la trichine sont parsemés de petites taches blanches dont la disposition est variable. Ces taches blanches constituent les kystes qui contiennent le ver enroulé. Ces vésicules peuvent être disposées par groupes, tantôt en séries linéaires; parfois ils sont isolés (Davaine). Le plus souvent (Owen) ils sont én contact. Le grand diamètre des kystes est toujours dirigé dans le sens des faisceaux musculaires. Les kystes sont souvent entourés d'une sorte d'atmosphère de vésicules graisseuses, qui refoulent simplement les fibres musculaires entre lesquelles ils sont logés; ils adhèrent au tissu cellulaire ambiant. Souvent les vésicules graisseuses forment. une enveloppe complète entourant le kysle.

Ces collections graisseuses ne présentent pas de caractères particuliers; les cellules sont polyédriques par pression réciproque et contiennent un liquide transparent soluble dans l'éthér; quand la paroi se rompt, il s'écoule en globules huileux. Quelques-unes de ces vésicules contiennent parfois des cristaux, très probablement de stéarine. Les vésicules graisseuses pénètrent également dans l'intérieur du liyste, et le ver succombe à une sorte d'envahissement graisseux. 
La Trichine se rencontre dans tous les muscles striés, excepté dans le cœur; les muscles superficiels sont ordinairement plus gravement atteints que les muscles profonds;
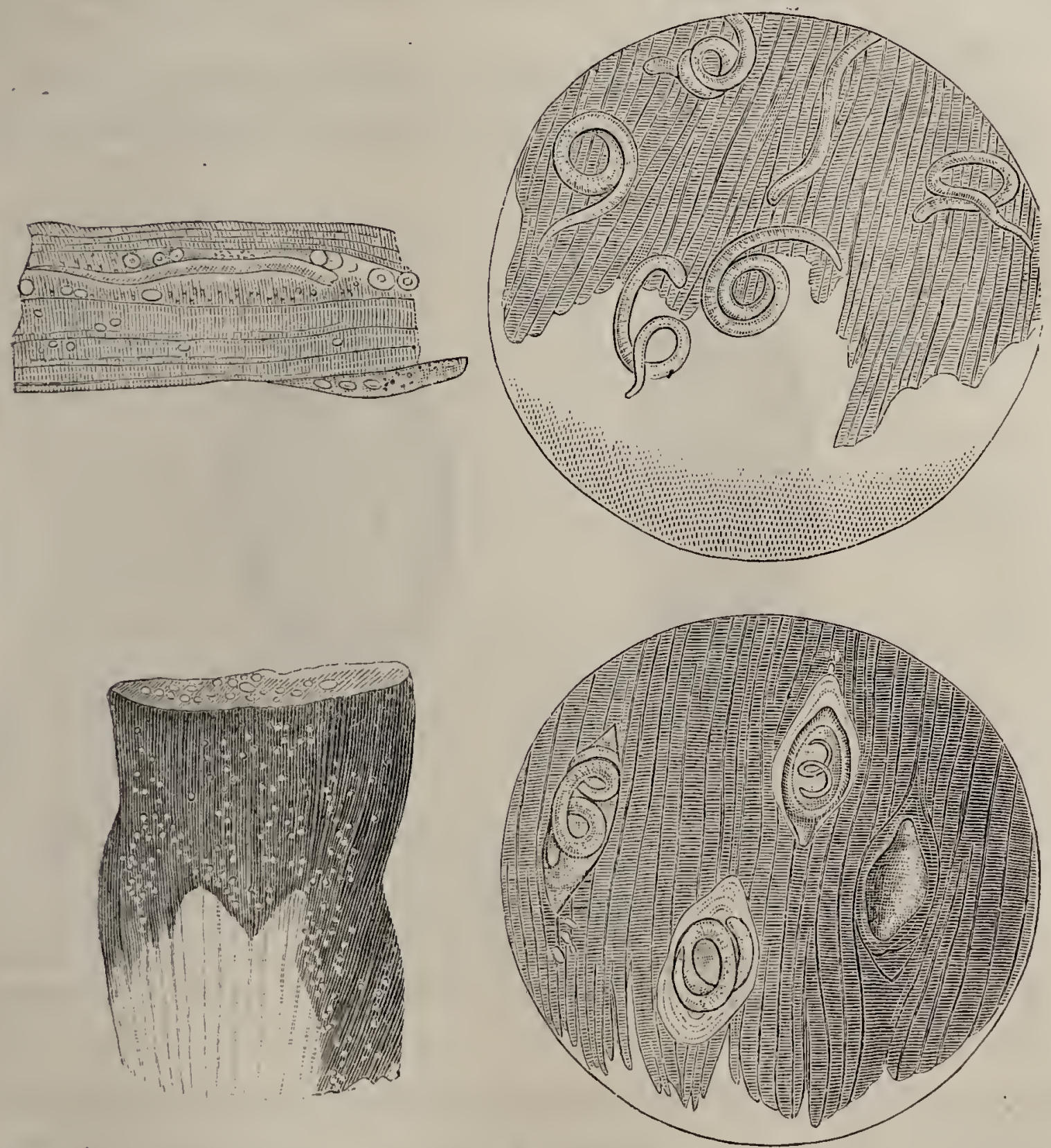

Figr. 413. - 10 Trichine à l'état de larve, paryenue dans les fibrilles musculaires; 2o pareellc de muselc triehiné vue au microscope; $3^{\circ}$ portion de musele remplie de trichines culýstées (les kystes sont représentés ici crétifićs et de grandeur naturelle); 40 kystes vus au microscope (Pennetier).

le grand pectoral et le grand dorsal surtout en sọt plus atteints que les autres (Davaine).

On trouve dans tous les traités spéciaux la liste des animanx susceptibles d'être trichinés, mais on voit, en la parcourant, que le porc est, d'après le régime de l'hoinme, le seul de 
ces animaux qui puisse lui transmettre ce parasite. En recherchant dans la viande des porcinés, la présence des cysticerques, on devra donc également examiner si elle ne contient pas de kystes à nématodes, semblables à ceux qui viennent d'être décrits.

La résistance vitale des Trichines est très considérable; elles continuent à vivre même dans les tissus pathologiques (cancer).

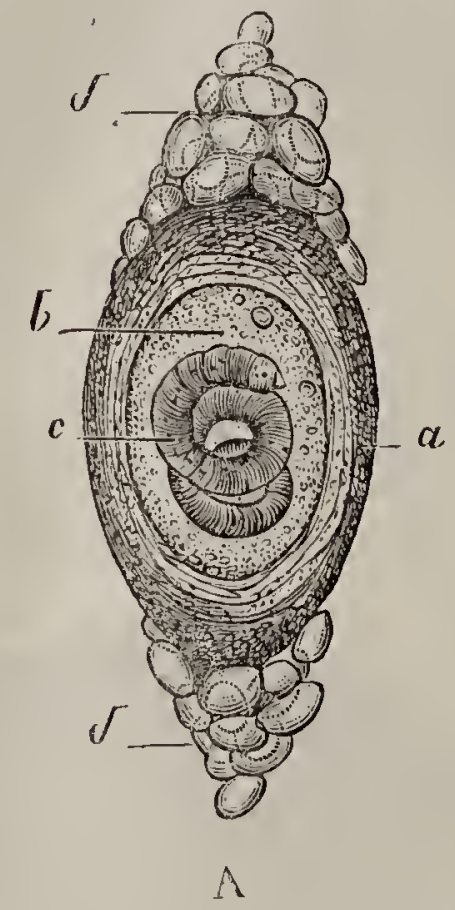

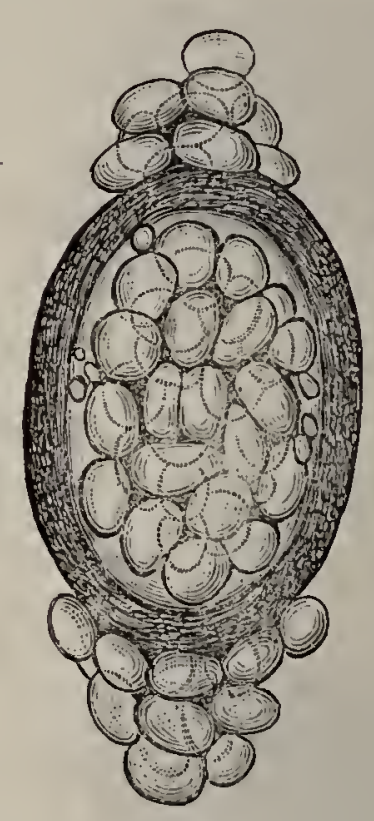

B

Fig. 414. - A. Kyste et trichine ayant subi un eommeneement d'altération. - a. Paroi du kyste, marquée de stries concentriques irrégulières, indiquant la structure lamellaire et parsemée de uranulations terreuses. - b. Cavité du kyste envahie par une matière ealcaire. - c. Ver ayaut subi un eommeneement d'altération. - dd. Fraisse qui s'arecumule aux pôles des kystes en voie de destruction. - B. liyste de la trichine envahi par des vésieules graisseuses intérieurement et extérieurentent. - Le ver a disparu (d'après Bristowe et Rainey).

Renfermées dans leur sarcolème, les Trichines sont d'une extrême résistance aux agents physiques. Plongées dans un mélange à $-20^{\circ}$, on les a retrouvées vivantes au bout de 72 heures. Protégées par leur kyste, il faut une température de $70^{\circ}$ à $75^{\circ}$ centigrades, pour leur donner la mort. Ghauffées à $60^{\circ}$ dans une masse musculaire, on les retrouve vivantes. Dépourvues de leur enveloppe protectrice el soumises à une tempéralure de $67^{\circ}$, on les roit exécuter encore quelques mouvements. D'où l'indication pratique de soumettre ìa viande suspecte à une cuisson complète. On a enterré des fragments de viande trichinée; au bout de cinq jours la putré- 
faction étail complète et les Trichines étaient vivantes. La Trichine est protégée par son kyste; dès que cel agent protecteur vient à lui faire défaul, il suffit de la toucher avec de la glycérine ou de l'eau sucrée pour la voir mourir immédiatement (Laboulbène).

En France la trichinose a toujours élé fort rare et réellement exceptionnelle: on a constaté sa présence trois fois seulement et chez le cadavre. Il y a quelques mois, la trichinose a élé observée en province, à Crépy-en-Valois (Oise), dans la clientèle d'un médecin distingué, le $\mathrm{D}^{\mathrm{r}}$ Jolivet, ancien interne des hôpilaux de Paris. Vingt personnes ayant mangé de la riande de porc salé, toutes devinrent plus ou moins malades el présentèrent des symptômes tout à fait différents de ceux que l'on observe dans nos pays. M. le Dr Jolivet fil examiner la viande par M. Laboulbène, qui y trouva de nombreuses Trichines. Celle observation sera publiée en entier, nous l'espérons.

En Allemagne, d’après les dernières statistiques (1870), la trichinose aurait diminué dans une notable proportion depuis que l'examen microscopique a élé instilué. Sur 1,728, כ̆9̋ pores examinés, on a trouvé 800 animaux trichineux appartenant à $30 ̈ 8$ communes. En Suède, au contrairc, celte affection semble beaucoup plus commune, ainsi à Lienköping, on tronve un pore trichineux sur 63 animaux, tandis qu'à Copenhague on en troure seulement 1 sur 4630 , a Schwerin 1 sur šb̆0, à Halle 1 sur 3,000. En Amérique, la trichinose semble également être assez fréquente, et ii serait indispensable d'élablir dans les ports; etprincipalement à Hambourg, un service d'inspection sćrère, sur les nombreux jambons qui nous viennent d'Amérique. A Chicago, sur 400 porcs cxaminés, on en trouva 28 infectés, c'est-à-dire $1 / 30$; sur 200 jambons jmportés d'Amérique en Suède, il $\mathrm{y}$ en avait 20 trichinés, c'est-àdire $1 / 10$ (Nocart et Bouley).

Ainsi que nous arons pu nous en assurer, les jambons d'origine allemande proprement dite, arrivent en France avec un certificat, accompagnant la lettre de voiture, et constatant que le porc n'élait pas malade et qưil n'y a pas d'épizootie dans le pays. Ces certificats, dont nous possédons un certain 


\section{nombre d'exemplaires, sont signés par l'inspecteur assermenté pour la recherche de la Trichine (1).}

(1) La trichine en Amérique. - Il y a quelques mois on découvrit en Allemagne l'existence des trichines dans un grand nombre de jambons et de porcs sur pied, venant des États-Unis d'Amérique. Quand cette nouvelle arriva en Amérique, elle produisit un certain étonnement, et quelques journaux contestèrent même l'existence de la trichine aux Etats-Unis; ils avaient oublié qu'en $187 t$ on avait signalé dans ce pays plusieurs épidémies de trichinose lıumaine et que même l'Académie des sciences de Chicago avait chargé une commission de faire une enquête sur cette maladie, chez le porc. Ces préoccupations et ces faits avaient été oubliés ou étaient restés ignorés en Europe, et l'on ne se méfiait pas assez des jambons d'Amérique; les examens microscopiques institués en Allemagne par l'autorité sanitaire ont montré que les jambons de provenance américaine étaient encore plus fréquemment infectés que les jambons allemands. Il est important de connaître ces faits, car dans certains pays et particulièrement dans le Yorkshire et le Lancashire, les colons peu aisés font un usage très commun de la viande de porc crue (The Lancet et Rev. d'hyg.).

Le docteur W. T. Belfield, répétiteur de pliysinlogie à Rush Collège, et M. H.-F. Atwood, vice-président de la société microscopique de l'État, ont pendant plusieurs semaines examiné de la viande de porc, en vue des trihines. Cet examen fut entrepris, à la demande du Conseil de santé de Chicago. Les échantillons furent fournis par un officier de santé, qui se les élait procurés dans les différents dépôts de la ville, indistinctement. Les reclierches portèrent sur une centaine de porcs, et dans liuit on trouva des trichines. Le nombre approximatif de ces helminthes varia de 35 a 13 , par pouce cubique de muscle strié. (Il faut dire que les viscères : foie, reins, cerveau, graisse, lard gras, n'en renferment jamais. Le cœur fait exception à cette règle à cause de ses fibres striées.) Un grand nombre d'expériences furent faites sur des rats, en vue de la lapidité de propagation de ces vers et de leurs effets, et ont fait roir que ces animaux peuvent être nourris de temps à autre de triclines, sans que leur santé en soit altérée. Pendant six semaines un rat ne reçut, tous les deux ou trois jours, quo de la viande de porc altérée : il n'en résulta ąucun trouble dans sa santé. Après l'avoir tué, on constata que son corps fourmillait de trichineş vivants. Les expérimentateur's affirment qu'il n'y avait pas moins de 100,000 vers. Ainsi les trichines pullulent en nombro considérable avant que la santé s'en ressente; mais au bout d'un certain temps des symptômes myotiques se manifestent, le plus souvent sous forme de douleur's rongeantes, térébrantes, prétendues rlıumatismales. Rien de plus fréquent à la campagine où, l'hiver, l'alimentation de nos campagnards consiste surtout en viande de porc moisie; car on se donne à peine le soin de la fumer ou de la faire bouillir, ce qui écarterait en grande partie le danger.

D’où le porc contracte-t-il des trichines - car on sait que ces vers ne lui appartiennent pas en propre? Il paraîtrait que cela provient de son mode de chercher sa nourriture dans la terre, où il ne troure pas toujours des truffes. Langenbeck prétend qu'il existe des trichines dans le ver de terre ou lombric; et on est disposé à le croire ì cause de si texture cliarnue. Les souris, les rats, en renferment également, de la la transmission 


\section{Dans tous ces pays, l'inspection microscopique est très exactement et très rigoureusement pratiquée; une prime}

des trichines au cliat et le dépérissement que ce dernier subit souvent, pour avoir trop mangé de son gibier favori.

Pour en revenir alix expériences de Chicago, les auteurs cités plus liaut ont trouvé qu'il suffit d'une petite quantité d'acide sulfurique mélangée à la saumure, dans laquelle sont conservés les quartiers de porc, pour tuer instantanément les trichines.

La trichine en Itrlie. - $\Lambda$ mois de janviel 1878, une quantité considérable de jambons cxpédiés par une puissante maison de Cincinnati, à des communautés de Milan et de Turin, furent préalablement soumis à l'examen microscopique, avant d'ètre livrés au commerce, et l'on reconnut que ces jambons étaient trichinés dans la proportion de 3 sur 40 .

La Gazette de Turin du 4 mars 1829 , rapporte également que le $1^{\text {er }} \mathrm{du}$ même mois, un charcutier de Turin avait reçu 190 kilogrammes de jambons provenant de l'Amérique du Nord; les experts appelés à les examiner au microscope, les trouvèrent trichinés, ce qui causa une vive émotion.

A Milan (Gazette de Turin, 5 mars), l’autorité s'est émue de ces faits. Le syndic a publić une ordomnance en vertu de laquelle toutes les viandes de porc renant de l'étranger devront être soumises à un examell microscopique avant d'être livrées au commerce : les viandes trichinées seront détruites. La commission sanitaire municipale a été chargée, dans l'intérêt public, de réglementer la vente de ces viandes.

Les viandes trichinćes peuvent être mangées relativement sans danger, lorsqu'elles ont été soumises à une cuisson prolongée (J. d'Hygiène).

Sur les porcs examinés en prusse en 1877, "u point de vu" de la trichinose cie la ladrerie, par le docteur Eulenberg. (Viertel juhrschr f. gericht/. méd $u$. offentl. Sanitatiswesen, Bd. XXX, I, I, p. 175, 1579 et Rev. d'Hyg.)

En Prusse l'examen de la viande de porc par les médecins officiels (Kreispllysicz), au point de vue de la trichinose, est obligatoire: en 1876 , on a trouvé un porc malade sur 2, 1100 , en 187\%, un sur 2,800. Le docteur Eulenberg, fait ressortir la nécessité de vérifier les instruments employés par les médecins, tous les trois ans au moins; ì côté d'un grand nombre de remarques, concernant surtout le choix des instruments, le grossissement. etc., nous velèverons celle-ci : que le point de la plus grande concentration des trichines se trouve dans les piliers du diaplipagme. L'examen des cochons au point de vue de la ladrerid est également obligatoire; depuis que cet examen est institué, le nombre des cochons ladres connus a augmenté dans des proportions énormes, de !)00 d'une année à l’autre (18i6, 187T.)

La triclizine en Espayne. - En mars 1879 , la présence de la trichine a été constatéc à Barcelone, et ce n'est pas sans de grandes peines et de nombreuses démarches, que MI. Darder, vétérinaire obtint un microscope de ladninistration. Il y a quelques années, un pliarmacien de Villar de l'Archevêque Province de Valence) réunit vingt luuit personnes à sa table, pour manger de la viande de porc. Tout les convives furent atteints d'une maladie qui se manifesta par les mêmes symptòmes et six succombèrent. On finit par décourrir qüil s'agissait de trichinose. En présence des transactions commerciales inportantes qui se font entre la France et l'Espagne, il convient d'exercer lí plus grande surveillance sur la viande de porc, qui vient de ce pays.

On a également constaté la présence de la trichine à Séville. Le Dr Ra- 
de 15 à 30 marcs est attribuée à chaque inspecteur signalant un cas de trichinose, et ces fonctions sont généralement con-

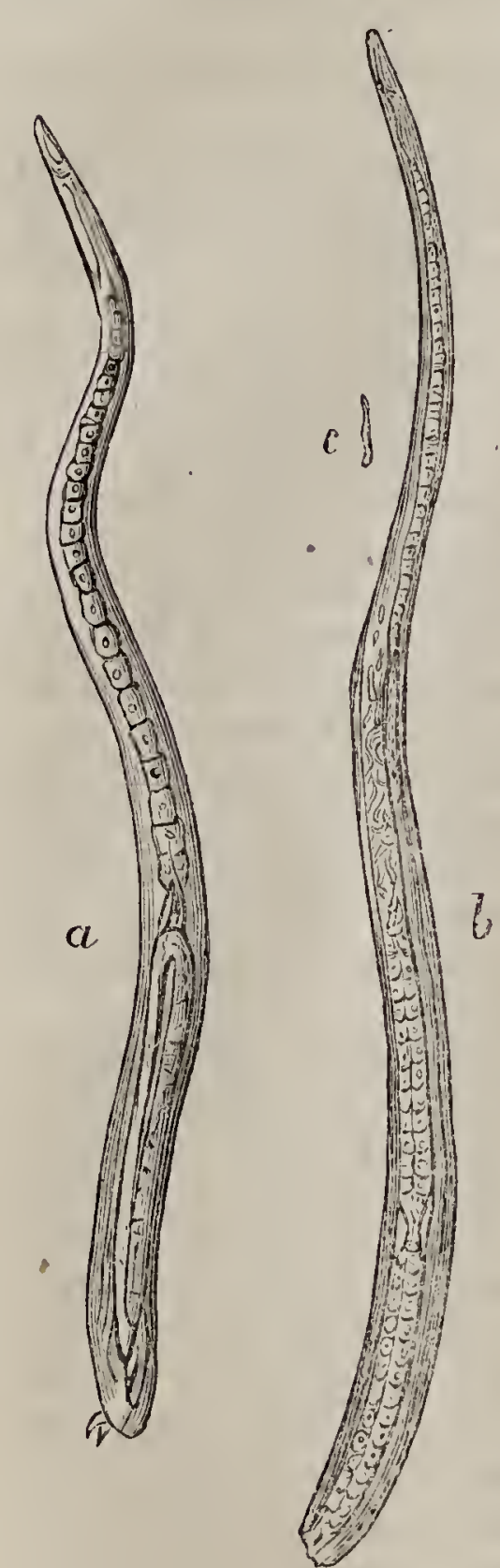

Fig. 415. - Trichines intestinales. - $a$. Mâle. $-b$. Femelle. $-c$. Embryon grossi. fiées à des femmes. Dans tous les cas douteux, elles doivent adresser les préparations à des médecins ou à des pharmaciens, désignés par le gouvernement, et qui ont sourent eu à rectifier certaines erreurs : ainsi l'on a quelquefois confondu des sporospermies, des anguillules du vinaigre, etc., avec des trichines, méprises auxquelles on ne sera pas exposé si l'on se reporte aux caractères donnés plus haut.

Voici quelle marche conseillent de suivre MM. Bouley et Nocart, dans le rapport qu'ils ont présenté au Congrès international d'hygiène. "Un grossissement de 20 à 50 diamètres est ce qu'il y a de plus commode pour ces recherches. It faut examiner des fragments

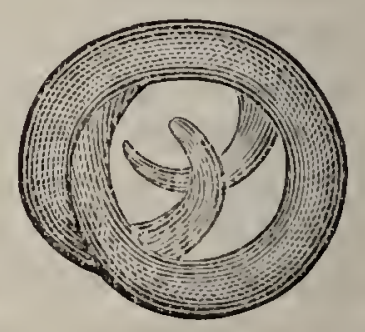

Figr. 4.16. - Trichine dégagée de son liyste et enrouléc sur elle-mème.

des muscles qui en sont le plus fréquemment le siège, c'est-ìdire du diaphragme, du masséter, des muscles laryngés, des

mon Codina Langlin a publió un mémoire sur les moyens de reconnaitre la présence de la trichine et de s'opposer à son développement.

La trichine en Syrie, en Égypte. - Une circulaire du ministre de l'intérieur d'Italic, en date du l'́ férrier 1879, informe officiellement le pays de l'existence de la trichine dans les porcs de Syrie et d'Égypte. Un décret du même jour prophibe l'importation en Italie des porcs sur pied ou de leurs viandes, en provenance de l'empire ottonan y compris l'ḱgypte. 
intercostaux, des muscles de l'avant-bras et de la jambe; on y fait, à l'aide de ciseaux fins, de minces coupes dans le sens des fibrilles et le plus près possible de leur terminaison. Ces coupes sont étalées sur une même plaque de verre, au centre d'une goutte d'eau, dilacérées à l'aide d'aiguilles imbibées d'acide acétique et de glycérine, recouvertes d'une lamelle et mises au point. En promenant la préparation sous lobjectif, de façon à en parcourir toute l'étendue, on aperçoit bientôt quelque Trichine, qui se présente sous forme de dilatation pâle, ovoïde, située entre les faisceaux primitifs, qu'elle écarte et refoule, en les incurvant'autour d'elle; c'est le liyste à l'intérieur duquel on distingue le ver, enroulé en spirale, qui peut aroir m tour et demi, deux tours ou deux tours et demi; à chaque pôle de ce kyste, se trouve un prolongement blanchâtre, opalin, en forme de cône tronqué qui, plus tard, s'infiltre de tissu adipeux et en dernier lieu, se calcifie. Si la maladie èst très avạncée, on rencontre bientôt quelques Trichines, dans l'une ou l'autre des préparations; mais lorsqu’elle est peu accusée, lorsque surtout, il s'agit de déterminer si un porc est trichiné ou non, alor's, il faut multiplier les préparations et les examiner minutieusement, avant de pouvoir porter un jugement consciencieux.

Dans ces derniers temps, un savant russe, M. Tikhomiroff, a décrit une méthode de dissociation des fibres musculaires destinée à faciliter la recherche des Trichines : La viande suspecte est coupée en petits fragments, puis mise à digérer pendant une demi-heure, dans un mélange de une partie d'acide azotique, pour une partie de chlorate de potasse; il suffit ensuite de porter les fragments du muscle dans un flacon rempli d'eau distillée et d'agiter avec force; les muscles se dissocient en fibrilles très minces, dont quelques-unes présentent, sur leur longueur, des renflements fusiformes assez facilement perceptibles, même à l'œil nu, et qui ne sont autre chose que des Trichines enkystées, ainsi que permet de s'en assurer le plus simple examen microscopique. " Comme le fon' $i$ observer LM. Bouley et Nocart, ce dernier procédé, excellent en lui-même, est trop compliqué pour entrer définitivement dans la pratique de l'inspection de la viande de boucherie. 
Altérations de la viamde provomuces par des larves d'insectes. - Pour compléter ce qui a trait aux viandes de boucherie, nous emprunterons les renseignements qui suivent au remarquable rapport de MM. Bouley et Nocart, dont nous avons parlé plus haut. Les larves de mouches, déposées pendant les chaleurs de l'été, à la surface de viandes, hâtent leur décomposition. "Un médecin anglais a constaté que, lorsque ces larves existent en grand nombre dans la viande et qu'elles sont introduites vivantes dans le tube digestif de l'homme, elles peuvent y déterminer des accidents qu’il a décrits sous le nom de myasi:." Une telle viande, à moins qu'elle ne soit dans un élat de putréfaction déjà avancé, peut parfaitement servir à la consommation, à la condition d'enlever la couche superficielle dans laquelle vivent les larves. On se met facilement it l'abri de la production de ces larves de mouche, en courrant la viande avec une gaze, ou une toile métallique. "Les mouches les plus redoutables, par ordre de grạité, sont : $1^{\circ}$ la mouche bleue, ou mouche à viande (Musca vomitoria), remarquable par sa fécondité; c’est la mère des asticots; $2^{\circ}$ la mouche grise ou mouche carnassière (Musca carnaria), encore plus grande et plus féconde que la première, mais moins fréquente; $3^{\circ}$ la mouche ordinaire (Musca domestica), redoutable par sa domesticité; $4^{\circ}$ enfin la mouche dorée (Musca cæsar), qui recherche plutôt les viandes putréfiées que les viandes frâiches. "

Viandes charbonneuses. - Nous en avons dit quelques mots à l'article Sanq. - On sait que les affections appelées charbon, fièvre charbonneuse, sang de rate, mal de montagne, etc., constituent une seule et même affection virulente, causée par le développement dans les tissus etdans le sang, d'un organisme inférienr, la bactéridic (Davaine) ou le bacillus anthracis (Colin). Un animal mort du charbon, subit rapidement la putréfaction; des débris d'animaux charbonneux, disent MM. Bouley et. Nocart, acquièrent des propriétés septiques, de sorte que linoculation d'une parcelle de sang délermine en quelques heures, non plus le charbon, mais une septicémie presque foudroyante. On peut reconnaître la viande charbonneuse aux caraclères suivants : sa couleur est rouge foncé ; lavée, elle a une consistance molle; elle est friable comme de la viande 
cuite. On peut encore la reconnaître au sang noir, épais, boueux, que l'on voit sourdre à la surface, lorsqu'on presse le morceau entre les doigts; dans les interstices musculaires, le tissu conjonctif est infiltré, ecchymosé; les débris de vaisseaux que l'on peut y rencontrer, montrent la couleur violacée de leur tunique interne; enfin, l'examen microscopique fera reconnaître, dans une gouttelette de sang, un grand nombre de bactéridies flottant dans le sérum. Si la viande est fraîche, sans mauvaise odeur, la présence de ces bâtonnets immobiles est. le signe caractéristique du charbon et permet d'affirmer l'existence de la maladie. Si la viande était putréfiée, le diagnostic serait plus délicat à cause de la présence des bactéridies de la putréfaction; mais, dans les deux cas, la viande deviait être rejetée (Bouley et Nocart, loc. cit.).

Dans la figure donnée par nous, page 381, du sang charbonneux, on n'a pas représenté l'état d'agglutination des globules sanguins qui est si particulier et si caractéristique.

Viandes septicémiques (Rapport de MM. Bouley et Nocart). - On sait, depuis les belles expériences de M. Davaine, que le sang septicémique est peut-être le poison le plus redoutable, qu'il soit donné à l'homme de manier. Une dilution à 1/10000 de ce sang injectée à un animal le tue avec une grande rapidité. M. Pasteur a démontré que cet état particulier du sang est dû à la multiplication d'un parasite microscopique, auquel il a donné le nom de Vibrion septique. Tandis que la bactéridie charbonneuse a besoin d'oxygène pour vivre, le vibrion septique serait tué par cet élément; la bactéridie charbonneuse est aérobie; le vibrion septique, au contraire, est anaérobie. La septicémie est souvent la conséquence de la mortification d'un organe, ou bien encore, l'effet du développement de ces ribrions à la surface d'une plaie. C'est ainsi que se développe la gangrène traumalique, la pourriture d'hôpital (1). La viande

(1) Sur la phosphorescence de la viande. - Ce phénomène a donnó lieu à de nonbreux travaux parmi lesquels on peut citer ceux de MM. Mateucci, Quoy, Gaymard, Becquerel, Beccaria, Nuesch, Bancel et C. Husson, etc. Parmi ces travaux, les uns ont un caractère purement chimique, nous ne nous y arrêterons pas. Tandis que Matcucci attribue ì un travail d'oxydation lente, et à la production de deux électricités se reconstituant à mesure, la phosphorescence de la viande de poisson, M. Nuesch croit avoir reconnu que 
d'un animal atteint de septicémie est molle, noirâtre, avec des reflets jaune verdâtre irisés; elle est très friable et exhale une odeur particulièrement fétide (sulfhydrate d'ammoniaque). La graisse est molle, rougeâtre; le tissu conjonctif infiltré. Le sang, comme dans le charbon, est noir, boueux et se coagule difficilement.

Les viandes charbonneuses et les viandes septicémiques doivent être écartées de la consommation. Certainement, si elles étaient parfaitement cuites, on pourrait peut-être impunément les consommer ; mais, comme il a été observé que les bactéridies charbonneuses conservaient leur action spéciale dans la viande, dite saignante, c'est-à-dire imparfaitement cuite, et qu’inoculées elles donnent le charbon, on voit à quel danger on peut s'exposer. Le suc gastrique, comme l'a démontré M. Colin, détruit la bactéridie charbonneuse, aussi cette voie d'introduction peut être considérée comme le plus souvent exempte de danger; mais il ne faut pas oublier, comme le disent fort bien MM. Bouley et Nocart, qu'avant d'être servie pour le repas, la viande doit subir des manipulations, des préparations plus ou moins longues et compliquées, au cours desquelles, le boucher, la maîtresse de maison ou la cuisinière

la phosphorescence des poissons provient de la respiration d'animaicules, comme la phosphorescence des caux de la mer, attribuće par Mateucci, à la présence d'une multitude d'animalcules méduses, ceroés, etc. Ayant observé au microscope de la viande phosphorescente, ce savant a vu une masse de petites bactéries à côté de chapelets de globules et de nagnifiques octaèdres (J. de ph. et de chim., décembre 1878).

Dans un cas de phosphorescence de viande de homard obscrvé par MM. Bancel et C. Husson, la viande était belle et saine et sans odeur putride. M. Nuesch a pu propager les éléments producteurs de la phosphorescence à de la viande de porc. MM. Bancel et Husson ont été moins heureux. Ils ont procédé à l'examen microscopique de cette viande. A un grossissement de 500 diamètres, ils ont observé de petites bactéries et des petites cellules d'un jaune roux, qui ont une certaine analogie, arec celles qui ont été signalces dans la neige rouge (protococcus nivalis). Ces cellules avaicnt pour caractère commun de pouroir vive et se développer i une température relativement basse. M. Nuesch qui a observé ce phénomène sur la viande de boucherie, considère que la phosphorescence ne communique pas de caractères nuisibles à la viande, et il sc base sur ce fait d'observation, que la putıéfaction détruit la pliosphorescence.

MM. Bancel et Husson ne partagent pas cette opinion sans apporter toutefois de preuves bien positives à l'appui de leui's réserves. 
peurent être victimes d'inoculations accidentelles, souvent fort graves et quelquefois mortelles. Le danger est d'autant plus grand que l'acheteur ignore toujours l'origine de la viande, le danger qu'il court et, par conséquent, ne prend aucune précaution pour s'en préserver.

L'importance de ces questions nous a engagé à insister sur les conséquences naturelles qu'elles entraînent. Il n'est plus permis actuellement de mettre en doute l'urgente nécessité de soumettre les viandes de boucherie à un contrôle sévère. Cette inspection est d'autant plus nécessaire que dans bon nombre de pays, dès qu'un animal de boucherie est malade, dans la crainte qu'il ne guérisse pas ou que les médicaments qui lui seront administrés, communiquent un mauvais goût à la viande, on s'empresse de l'abattre et de l'expédier sur une grande ville. Dans les centres importants, il y a un service d inspection plus ou moins bien organisé, tandis que dans les campagnes il n'y a aucune surveillance, les bouchers ét les charcutiers livrent à leurs clients, des viandes dont ils connaissent seuls l'origine. Si un grand nombre sont retenus par un sentiment de probité et aussi par la crainte de voir leur clientèle les abandonner, il peut y en avoir qui pêchent ou par ignorance, ou par excès de cupidité. Donc l'inspection est nécessaire. Jusqu'ici, dans les grands centres, les fonctions d'inspecteur ont été rerr plies par des hommes sans instruction, dont les décisions, pour être souveraines, n'en sont pas moins souvent entachées d'erreur, comme l'a encore démontré M. Bouley dans une des séances de l'Académie de médecine (septembre 1878).

Ainsi que le disent fort bien MM. Bouley et Nocart, tout est à faire dans cette grave question. Ces deux hygiénistes voudraient voir un abaltoir dans chaque canton; l'inspection des riandes derrait être faite par des hommes compétents. Il est certain que les vétérinaires, par leurs études spéciales, seraient parfaitement disposés à remplir le rôle d'inspecteur, mais leur nombre est restreint et leurs occupations nombreuses les tiennent presque constamment en voyage. Il nous semble que le pharmacien, dont la profession fait un homme très sédentaire, pourrait rendre les plus grands services, au moins, au 
point de vue de la recherche des parasites, qui demande plus de temps, que l'inspection des viandes provenant d'animaux malades. Quoi qu'il en soit, M.M. Bouley et Nocart proposent l'organisation suivante $: 1^{\circ}$ des inspecteurs communaux; $2^{\circ}$ un inspecteur cantonal.

Les inspecteurs communaux seraient choisis parl'inspecteur cantonal parmi des personnes sédentaires ayant l'habilude des animaux.

L'inspecteur cantonal serait exclusivement choisi parmi les vétérinaires.

Des services analogues existent dans presque toute l'Europe et fonctionnent à la satisfaction générale (1).

Mesures préventives prises dans quelques contrées de 1'Europe. - Dans les pays où les viandes trichinées ont fait depuis longlemps leur apparition, les détenteurs et les vendeurs de cette nourriture malsaine ont fondé une association d'assurances mutuelles, dont le but principal consiste à s'indemniser réciproquement pour les personnes éprouvées par suite de la destruction des chairs malades.

A Rirliemsen, les charcutiers ont pris des leçons d'analyse microscopigue, auprès du docteur Kitring; ils ont, en outre, adopté des statuts réglementaires, par lesquels chaque membre de l'association s'engage à posséder un bon microscope, à concourir au paiement d'une prime, à celui qui trouvera un porc trichineux.

A Brunswick, où l'examen microscopique de chaque pore est obligatoire, les bouchers ont également formé entre eux une compagnie d'assurances contre les pertes.

A Berlin, sur l'invitation de la corporation des bouchers et. avec l'assistance de son chef, un comité de médecins et de vétérinaires s'est réuni pour résoudre toutes les questions qui se raltachent à l'origine des trichines, aux moyens de les reconnaître chez le porc et de combattre les effets pernicieux qu'elles produisent chez l'homme.

Pour donner une idée des ravages que causerait à la santé publique l'introduction des viandes trichinées dans les gran-

(1) Pour plus de détails, voir le Rapport de MM. Bouley et Nocart. 
CIIAPITRE XVI. - DES PARASITES.

des villes, M. le $\mathrm{D}^{\mathrm{r}}$ Bonjean rappelle (Journal d'hygiène), qu'à Paris il y a près de 900 charcutiers, occupant 1,0000 ouvriers. La population parisienne consomme annuellement 23 millions de kilogrammes de charcuterie, qui représentent une valeur. de 35 millions de francs.

A Magdebourg, toutes les ordonnances relatives à la Trichine se trouvent représentées par l'article suivant : "Quiconque tue ou fait tuer un porc est tenu de le faire examiner microscopiquement, par un expert nommé par les autorités, à cet effet; et ce ne sera qu'en présence du certificat donné par l'expert, après vérification faite, que le porc ne contenait pas de Trichine, que la viande de celui-ci pourra être vendue ou préparée, pour la nourriture de l'homme. Celui qui contrevient à cette ordonnance encourt une amende de $\breve{~ a ̀ ~} 10$ thalers (18 fr. 75 à $37 \mathrm{fr} .50)$.

A Berlin, les bouchers font en général examiner la viande des porcs qu'ils tuent, mais un grand nombre débitent la viande de porc sans l'avoir soumise à aucun expert. Quant à la police sanitaire, elle n'intervient que dans le cas de trichinose chez l'homme; on recherche alors l'origine de l'infection, que généralement on ne réussit pas à découvrir.

En 1878, on a trouvé cinq porcs trichineux chez les quatre bouchers qui avaient fait examiner les porcs qu'ils tuaient. Beaucoup plus grand a été le nombre des jambons importés d'A mérique, et trouvés trichineux, malgré le certificat d'examen qui leur avait été délivré à Hambourg.

76 cas ont été dénoncés à la préfecture de police, ce qui suppose un nombre beaucoup plus considérable de jambons . trichineux non dénoncés.

Dans un magasin, on a trouvé 2 jambons trichineux sur $\mathbf{1 0}$ examinés, et dans un autre magasin sur 1,500 jambons examinés, 12 contenaient des trichines.

Aussi le nombre des cas de trichine chez l'homme a-t-il augmenté d'une manière alärmante à Berlin. Tandis qu'en 1876 on n'avait constaté que trois cas d'infection trichineuse, affectant deux fois, deux personnes seulement, et la troisième fois, quatre personnes, tandis qu'en 1873̆, on n'avait observé que quatre cas, attaquant deux fois une seule personne, et les 
deux autres fois, deux personnes; en 1878, il y a eu quinze fois des infections de trichine, attaquant un total de cent deux personnes, dont huit ont succombé à la maladie.

Un seul de ces foyers, infecté par la même source, comprenait trente-six personnes; un autre seize, un troisième douze. Une seule fois on a pu retrouver de la viande trichineuse chez le marchand qui avait causé l'infection de ses chalands.

Pour remédier à un tel état de choses, la police de Berlin a jugé nécessaire de rendre obligatoire l'examen des porcs tués dans la ville, ainsi que les viandes salées, venant du dehors. Il est probable que cette année la préfecture de police publierá un nouveau règlement sur la vente de la viande de porc. ( $\mathrm{D}^{\mathrm{r}}$ Sentinon, Journal d'hygiène, 1879.)

Filaria. - Dès que l'on rencontrera un Nématode très allongé, blanc jaunâtre, grisâtre ou rougeâtre, on devira songer à le placer dans ce genre ; généralement un examen, même rapide, suffira à confirmer cette première diagnose : la situation tout à fait antérieure de la vulve, la constitution de la bouche,

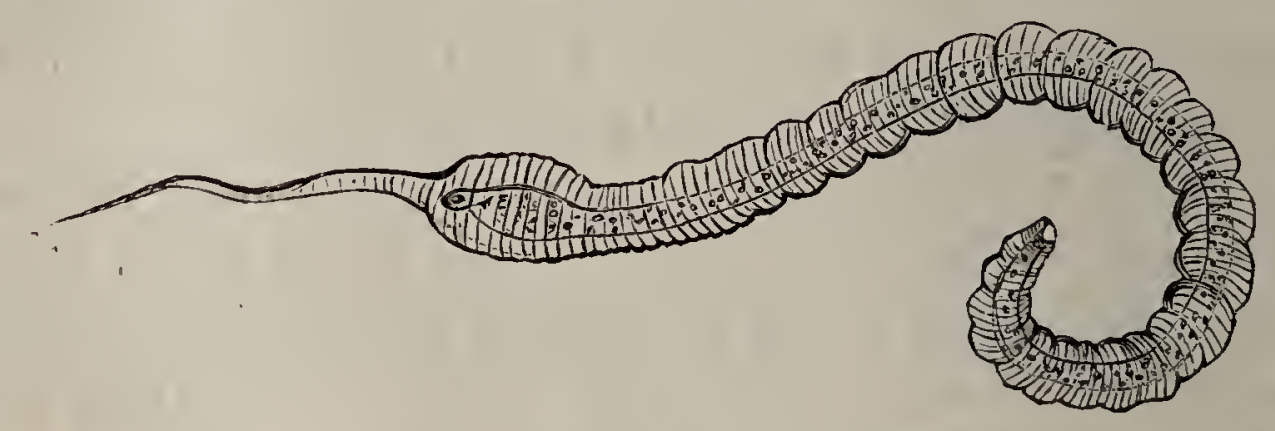

Figr. 417. - Filaria medinensis jeune (d'après Cubbold).

relevée de papilles saillantes, permeltent de reconnaître aisément les Filaires. Plusieurs espèces ont été rencontrées dans les milieux de l'œil, le sang, etc. (v. Sang). La plus célèbre est la.Filaire de Médine ( $f$. Medinensis), qui ne s'observe que chez les habitants des contrées intertropicales ou chez les voyageurs, les soldats ou les marins, etc. ayant récemment habité ces régions. On la rencontre sous les téguments de la tête; du thorax, des membres, etc.; sa situation sous-cutanée, sa taille (de 50 centimètres à $\mathbf{2}$ mètres) permettront de la distingueer facilement. Létude des embryons toujoụrs très nombreux et longs de $0^{\mathrm{mm}}, 6$ ou $0^{\mathrm{mm}}, 8$ qu'elle contient, achèveront d'établir 
le diagnostic. Pour examiner les embryons, il faudra dilacérer le corps de la Filaire et observer son contenu sous un grossissement de 160/1 et dans la glycérine additionnée d'acide acétique.

D’après M. Davaine, les embryons pénétreraient dans la peau, non par perforation, mais en s'introduisant dans le conduit excréteur d'une glande sudoripare, dont le calibre est égal à l'épaisseur de l'embryon, ou dans la gaîne des poils, et arriverait ainsi dans le derme.

Strongylus grigas. - On sait que le Strongle géant, habituellement localisé dans les reins du chien ou du bœuf, aurait
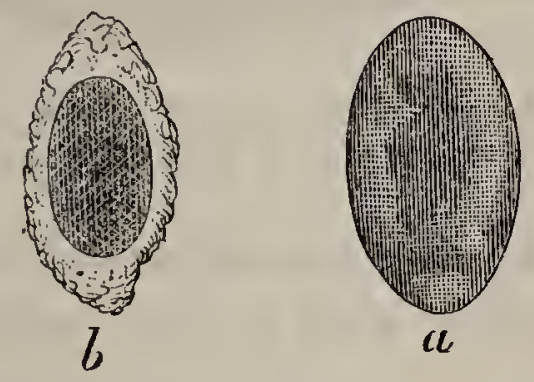

Fig. 418. - Ovule du Strongle géant (du chien). - a. Observé directement. - b. Traité par l'acide sulfurique concentré qui rend le vitellus apparent.

été observé chez l'homme. Ses grandes dimensions, sa teinte rouge, ses six papilles buccales permettront toujours de le reconnaître sûrement dans cet habitat; mais l'observation qui
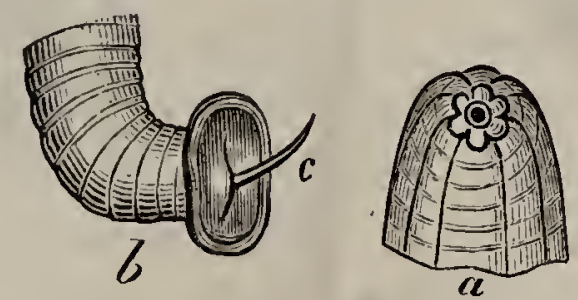

Hig. 419. - Sitrongylus gigas (mâle). - a. Extrémité céphalique montrant les six nodules qui entourent la buche. - b. Extrénité caudale avec la cupule copulatrice, du centre de laquelle sort le pénis, $c$.

permet seule de diagnostiquer sa présence, exige le concours $\mathrm{du}$ microscope, car elle repose sur l'examen de ses ovules. Ceux-ci sont bruns, elliptiques ; ils mesurent $0^{\mathrm{mm}}, 07$ suivantleur grand diamètre et $0^{\mathrm{mm}}, 04$ suivant.leur petit diamètre. Il convient de rechercher ces ovules dans l'urine (v. Sédiments urinaires) chaque fuis qu'une affection rénale grave est soupçon- 
née. Leurs grandes dimensions permettront de les observer avec un grossissement de $200 / 1$; une trace d'acide sulfurique

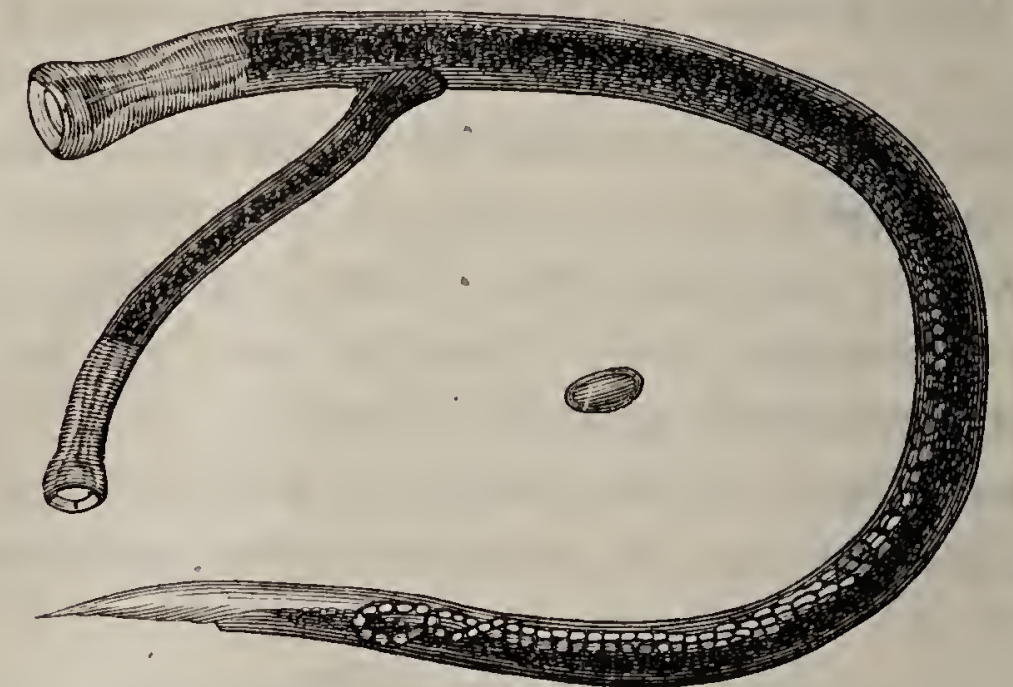

Fig. 420. - Syngamus trachealis; mâle et femelle accouplés; au centre de la figure on a représenté un ouf (Mégnin).

ou de potasse suffira pour donner toute la rigueur possible à un diagnostic, dont on ne doit pas se dissimuler la gravité.

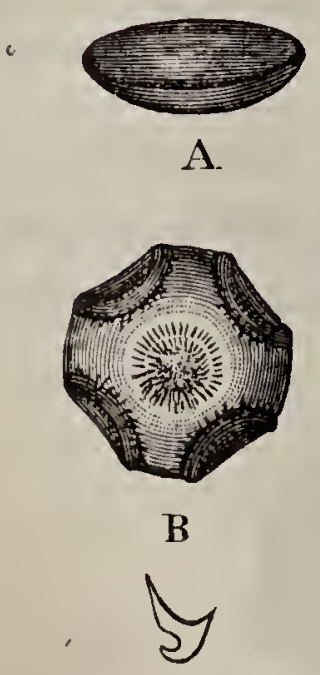

C
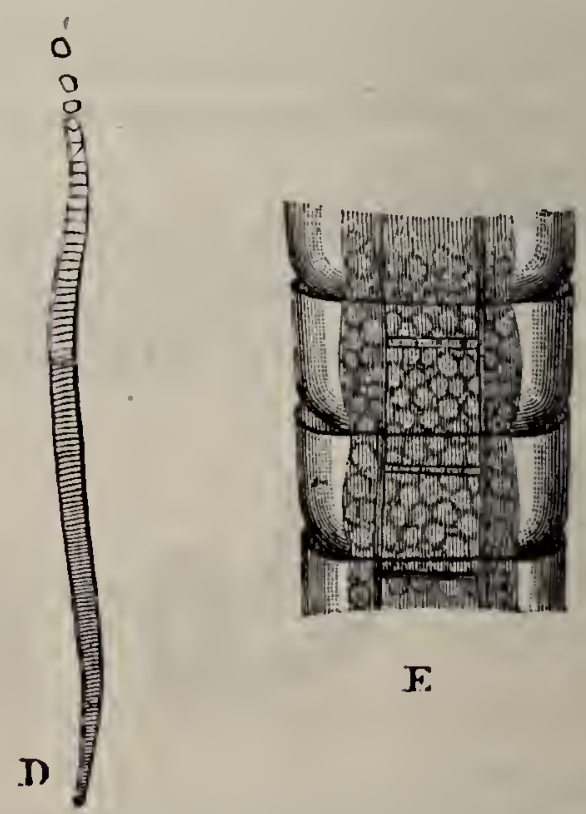

F.

Fig. 421. - Tænia infundibuliformis, varietas phasianorum. - A. Un des premiers anneaux. - B. Tête vue de face. - C. Crochet. - D. Ténia de grandeur naturelle. E. Anneaux considérablement grossis (Mégnin).

Les indications précédentes devront suffire à toutes les préparations relatives aux Nématodes parasites de l'homme ou des animaux domestiques et dont on trouvera les caractères dans les traités d'helminthologie: le Syngamus trachealis doit être signalé en raison de sa fréquence chez les gallinacées; actuellement ce parasite exerce les plus grands ravages sur les faisans 
qu'il fait mourir par milliers (Mégnin). Le Syngamus témoigne d'une évidente parenté zoologique avec le Sclérostome; on trouve ce ver presque toujours accouplé; le mâle, beaucoup plus petit que la femelle, forme avec elle un angle presque droit, ce qui a fait donner à ce parasite le nom de ver crochu. Le développement et le mode de transmission ne sont pas connus. D’après Davaine, on a trouvé ce ver dans la trachée ou dans les bronches, chez le coq domestique, le dindon, la pie, le martinet, l'étourneau, le pic-vert, le faisan, la perdrix, la cigogne noire. " M. Leidy l'indique comme très commun chez les poules en Amérique. Le $\mathrm{D}^{\mathrm{r}}$ Crisp estime à un demi-million le nombre des poulets que ce ver détruit actuellement en Angleterre, sans compter les faisans(1) et les perdrix, de sorte qu'il serait d'un intérêt véritablement national, dit-il, de trouver le moyen de prévenir l'invasion de ce ver ou de le tuer (Davaine) " (2).

Parasites des voies respiratoires. - Un ver nématoïde, le Sirongylus longevaginatus (Diesing) a été rencontré dans les voies respiratoires de l'homme. Ce cas se présente rarement; jusqu'ici, il n’a été rencontré qu'une fois. (P. la descript., voy. Davaine, Synopsis, p. GXVII.) M. Rainey, d'après Davaine, aurait également observé des vers nématoïdes à l'état de larves dont l'espèce n'aurait pu être déterminée, dans le larynx et la trachée d'un individu. Ayant examiné ces vers au microscope, M. Rainey a vu que ceux-ci étaient plus effilés à une extrémité qu’à l'autre et que l'extrémité la plus grosse se mettait toujours en mouvement, avant la plus petite. Quand les mouvements cessent, le ver reste enroulé et ressemble à

(1) Les faisans sont également atteints d'un ténia particulier, dont nous donnons ci-contre la figure. (V.fig. 421.)

Les Syngamus exercent de terribles ravages dans les faisanderies, et s'attaquent aux genres exotiques (Lopliopliores, etc.). Au Muséum la plupart des oiseaux s'en trouvent atteints, et on les rencontre aussi bien dans les Canards et les Spatules, que chez les Marabous et les Pélicans. (J. Chatin.)

(2) M. Mégnin a indiqué un moyen de détruire ce ver qu'il tient d'un faisandier de la forêt de Fontainebleau : c'est de mêler de l'ail pilé à la pâtée destinée aux faisans; le susdit faisandier a ainsi débarrassé ses parquets de ce terrible parasite (Bulletin de la Société centrale vétérinaire 1878).

Parmi les parasites des animaux domestiques nous citerons encore, le Sclérostome du cheval, Sclerostomum armatum. (V. Davaine, Synopsis, CXIII). 
une trichine renfermée dans son kyste. Ce nématoïde est long de $0^{\mathrm{mm}}, 75$, large de $0^{\mathrm{mm}}, 016$, obtus en avant, graduellement aminci en arrière. L'œsophage occupe plus du tiers de la longueur" du corps, l'intestin est droit; l'anus semble exister un peu en avant de l'extrémité postérieure; il n'y a pas d'organes génitaux internes ou externes (Davaine, p. 22).

A la suite d'une communication faite à l'Académie des sciences par M. le $\mathrm{D}^{\mathrm{r}}$ Nicati (de Marseille), sur la concomitance d'une épidémie de diphthérie ayant régné à la fois sur les basses-cours et sur les habitants de Marseille, une certaine émotion s'était manifestée et on s'était demandé si la diphthérie des oiseaux ne pouvait pas se communiquer à l'homme.
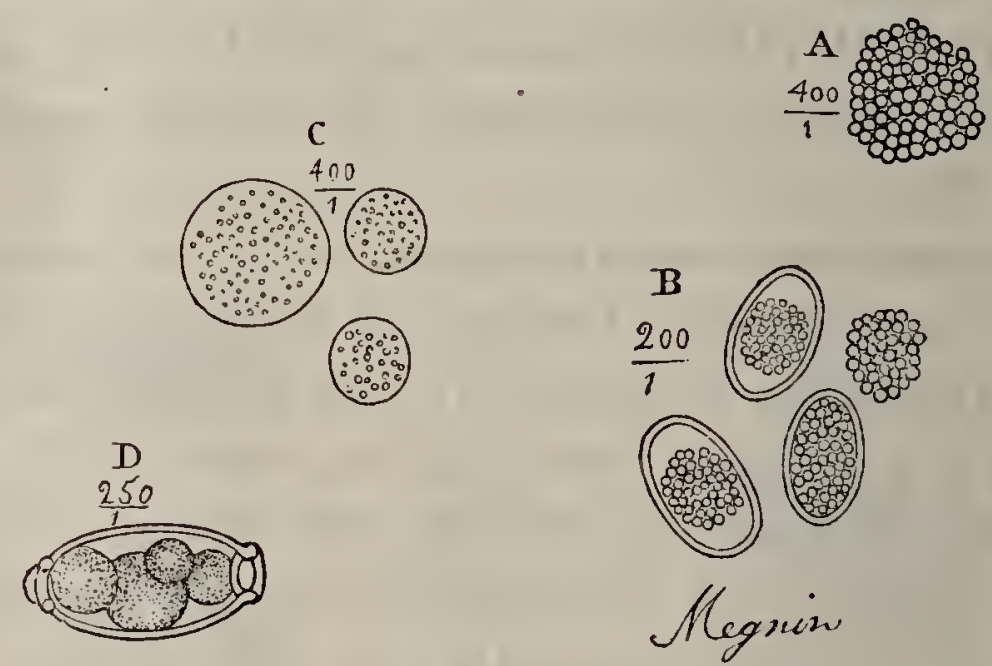

Fig. 422. - Proto-organismes de la diphthérie ou phthisie des oiseaux et des lapins. A. Jeunes psorospermies du mesentère d'une poule. - B. Jeunes psorospermies du foie chez un lapin. - C. Jeunes psorospermies du poumon de la poule. - D. Psorospermie adulte en voie de segmentation, eneore nommée grégarine (Mégnin).

M. Mégnin, ainsi que d'autres observateurs, ont démontré, soit par l'observation clinique, soit par l'anatomie pathologique, que les craintes de M. Nicati étaient exagérées. Voici le résumé des recherches de M. Mégnin sur ce point:

Gette maladie est connue des éleveurs sous le nom de muguet jaune, de chancre, d'esquinancie, et se présente sous deux formes principales, ordinairement combinées chez plusieurs malades, à savoir : $1^{\circ}$ une forme pseudo-membraneuse, caractérisée par des fausses membranes, d'un blanc jaunâtre plus ou moins foncé, que l'on rencontre tapissant un ou plusieurs des organes suivants : langue, pharynx, cavités nasales, larynx, 
jabot, intestins, réservoirs aériens; $2^{\circ}$ une forme tuberculeuse, caractérisée par des productions sphériques, caséo-granuleuses, jaunes, qui se développent dans les organes parenchymateux, dans le tissu cellulaire, dans l'épaisseur des tuniques intestinales, dans les orbites, ou sur la peau; tubercules qui ont exactement la même structure que les fausses membranes, c'est ce qui a engagé M. Mégnin à nommer cette affection tuberculo-diphthéritique.

Cette affection est très contagieuse entre oiseaux.

L'anatomie pathologique de cette maladie a été faite très soigneusement en Italie et en France, et on a toujours trouvé, comme cause déterminante, un proto-organisme qui se ren contre sous la fausse membrane, ou à la périphérie des tubercules. Ces proto-organismes ont été rangés parmi les psorospermies. Ces parasites n'ont jamais été rencontrés dans les fausses membranes de l'homme, et de plus, pas un seul cas de contagion de l'oiseau à l'homme n'a été parfaitement constaté.

On peut manger impunément des. volailles atteintes de diphthérie.

Gertains entozoaires peuvent pénétrer accidentellement dans le larynx, la trachée et les bronches (Ascarides, Hydatides).

Pseudhelminthes. - Il ne suffit pas de retracer les caractères distinctifs des principaux Helminthes, d'indiquer les procédés capables de faciliter leur étude, il faut encore signaler les erreurs qui peuvent être commises à leur sujet, et mettre les observateurs en garde, contre des déterminations trop hâlives et des rapprochements trop difficiles à justifier. Les observations de pseudhelminthes sont nombreuses et doivent être rapportées à des corps d'origine très différente. Les larves de Diptères, les larves de Teichiomyza fusca, ou mouches des latrines, ont été souvent décrites, comme des Nématodes (Oxyures nouveaux, etc.), il en a été parfois de même pour les larves d'OEstrides, mais le nombre. des anneaux, la présence d'un appareil trachéen, permettent d'éviter aisément une semblable confusion.

Souvent, des aliments incomplètement digérés (fragments de tendons de muscles, etc.) ont été considérés comme des Entozoaires, et le même rapprochement a été quelquefois admis 
pour de simples débris végétaux (pétioles, fragments de tiges, cellules endocarpiennes des Citrus, etc.) (1). Dans d'autres cas enfin, des corps d'origine différente, fortuitement rapprochés, ont pu causer de semblables méprises. C'est ainsi qu'il y a quelques années, on adressa au $\mathrm{D}^{\mathrm{r}} \mathrm{J}$. Chatin, de prétendus œufs d'Entozoaires, qui n'étaient que de simples cristaux d'urates, réunis par des masses floconneuses de mucus.

Il est certain que, si les causes d'erreur sont nombreuses, elles diminueront infailliblement, par l'application du microscope, combinée avec les connaissances d'histoire naturelle, que tout médecin ou pharmacien doit posséder aujourd'hui. Il ne faut jamais perdre l'occasion d'observer des types, d'en déterminer tous les caractères anatomiques; en suivant ces indications, on donnera à l'observation la rigueur et la méthode, sans lesquelles elle peut devenir un instrument dangereux, quand elle est dirigée par un esprit mal discipliné.

Des Acariens (Arachnides).

Presque tous les Acariens, dit M. Mégnin ont une grande tendance à la vie parasitaire et passent au moins une partie de leur vie sur d'autres animaux : les uns s'y attachent simplement pour se faire transporter ailleurs, comme les hypopes des Tyroglyphes et les nymphes de Gamases; les autres, pour y vivre des humeurs exhalées à la surface de la peau, pour y sucer le sang qui sert à leur développement et à celui de leur progéniture, comme les larves des Trombidions, des Ixodes, des Argas, des Dermanysses, des Ptéroptes, et ne causent d'autre dommage, qu'une piqûre sans conséquences graves, qui disparaît spontanément, au bout de peu de temps; d'autres enfin se logent sous l'épiderme, ou entre les débris de cette membrane qu'il ont déchirée, et déterminent par leurs morsures répétées et venimeuses, l'éruption eczémateuse et prurigineuse qui constitue la gale. (Mégnin, Précis des maladies de. la peau du cheval.)

Le mode d'action des Acariens n'est pas d'ordre purement physique; ils blessent en effet, mais la plaie qu'ils font n'est pas simple, parce qu'ils ont une salive venimeuse, comme la

(1) Observation publiée par les docteurs Bochefontaine et Galippe, dans les Comptes rendus de la Société de biologie, 1875. 
plupart des Arachnides. M. Mégnin a fait la démonstration de ce fait de la façon suivante : il a recueilli un certain nombre des Prosoptes, qui sont les plus gros des Acariens psoriques, et qui abondent dans le rouvieux du cheval, en les écrasant, on obtient une gouttelette de liquide qui, inoculée avec une aiguille très fine, détermine l'apparition d'une vésicule eczémateuse, avec démangeaison, absolument comme la piquure du Prosopte lui-même (loc. cil.).

L'ordre des Acariens renferme des espèces innombrables, réparties en douze familles. Dans la famille des Sarcoptidés se trouve une tribu composée uniquement d'Acariens psoriques, au nombre de sept espèces, subdivisibles elles-mêmes, chacune en un certain nombre de variétés. Ces sept espèces sont réparties en trois genres, de la manière suivante :

Genre Sarcoptes (Latr.)..... $\begin{cases}\text { Sarcoptes scabiei.... } & \text { (Latr.) } \\ \text { Sarcoptes notoedres.. } & \text { (Bourg et Delafond). } \\ \text { Sarcoptes nutans.... } & \text { (Ch. Robin et Lanq.) }\end{cases}$

Genre Psoroptes (Gervais).

$\left.\begin{array}{r}\text { Synon. Dermatodectes (Ger- } \\ \text { lach)............. } \\ \text { Dermatokoptes (Furs- } \\ \text { temb)............. }\end{array}\right\}$ Psoroptes longirostris (Mégnin)

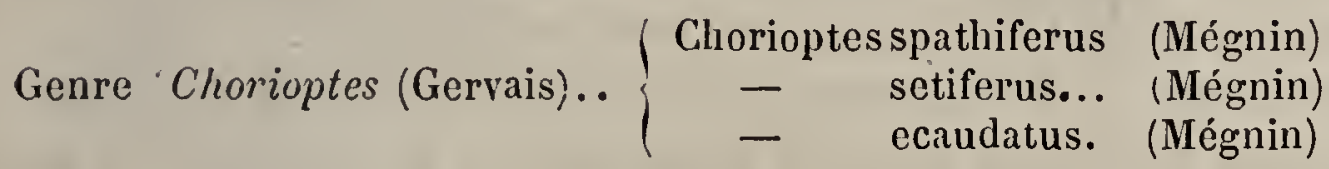

Les détails qui vont suivre seront empruntés aux différentes. monographies de M. Mégnin. Les travaux de ce savant naturaliste ont jeté une vive lumière sur l'histoire des Acariens, nous ne pouvons prendre un guide plus compétent.

Comme le fait remarquer M. Mégnin, aucune de ces espèces parasites n'est particulière à une espèce animale, ainsi qu'on l'admet généralement aujourd'hui. La première espèce de sarcoptes a été rencontrée sur dix espèces animales différentes, mais elle présente des variétés. C'est ainsi qu'elle pourrait présenter une taille plus grande, des détails anatomiques plus accentués et même une salive venimeuse plus active. M. Mégnin (1) admet six variétés de l'espèce Sarcoptes scabiei.

(1) Des condilions de la contagion de la gale des animuux à l'lomme. Paris, 1876. 
1. Sarcoptes suis. Qui cause la gale sarcoptique du porc et du sanglier. -

A près de trois fois les dimensions du Sarcopte de l'homme.

$2^{\circ}$ Sarcoptes lupi. Un peu inférieure à la précédente, comme dimension, vit sur les grands carnassiers, comme le lion, l'hyène, le loup.

\section{$3^{\circ}$ Sarcoptes equi.}

$4^{\circ}$ Sarcoptes cameli.

$5^{\circ}$ Sarcoptes capræ.

$6^{\circ}$ Sarcoptes hominis
Appartient au clieval et aux autres équidés.

A été rencontré sur le dromadaire, le lama, et la girafe.

Cause la gale sarcoptique de la chèvre, du mouton, du mouflon et de la gazelle.

Diffère peu de la précédente et est presque aussi petite qu'elle.

Le Sarcoptes notoedres offre trois variétés, de tailles très différentes, qui ont été rencontrées sur le rat, sur le coati, sur le chat et sur le lapin;

Le Sarcoptes nutans n'a été rencontré que sur les gallinacés;

Le Psoroptes longirostris a été rencontré sur quatre espèces animales différentes: le cheval, le mouton, le bœuf et le lapin. Comme les tentatives d'acclimatation de ce Psoroptes, de l'un à l'autre des animaux sur lesquels on l'a rencontré, n'a jamais réussi, on peut conclure qu'il forme quatre variétés: une variété equi, une variété bovis, une variété ovis, et une variété cuniculotis. Cette dernière variété habite exclusivement, dans l'intérieur de la conque de l'oreille du lapin.

Comme nous le montrerons par quelques exemples, la gale de différents animaux peut se transmettre à l'homme; il est donc important de se mettre à l'abri de.cette contagion. La détermination du parasite servira surtout à éclairer les intéressés, sur le danger qu'ils courent.

On sait que l' carus scabiei ou Sarcoptes hominis, est la cause directe de l'affection cutanée, contagieuse, que l'on appelle gale. Pendant longtemps, on avait ignoré,la nature exclusivement parasitaire de cette affection, bien que dès 1619 et 1620 , grâce à l'invention du microscope, des figures plus ou moins grossières du Sarcopte, aient été dessinées par Hauptmann, Michael, Etmuller, Cestoni.

Cette notion était restée dans la science, mais les médecins n'avaient pas vu l'étroite relation qui existait entre l'Acare et la gale. En 1812, un pharmacien de l'hôpital Saint-Louis attira de nouveau l'attention sur le parasite de la gale; il 
rencontra une vive opposition de la part de Raspail. En 1834, un étudiant, nommé Renuci, montra de nouveau, d'une façon incontestable, la présence d'un parasite dans les sillons. Depuis, de nombreux travaux ont mis cette découverte à l'abri de toute contestation. Le sillon est le signe le plus caractéristique de la gale, il sert d'habitation au Sarcopte, il est donc important de savoir le reconnaître ; nous emprunterons sa description au travail de M. le $\mathrm{D}^{\mathrm{r}}$ Mailhetard (Paris, 1875̈). "Il se

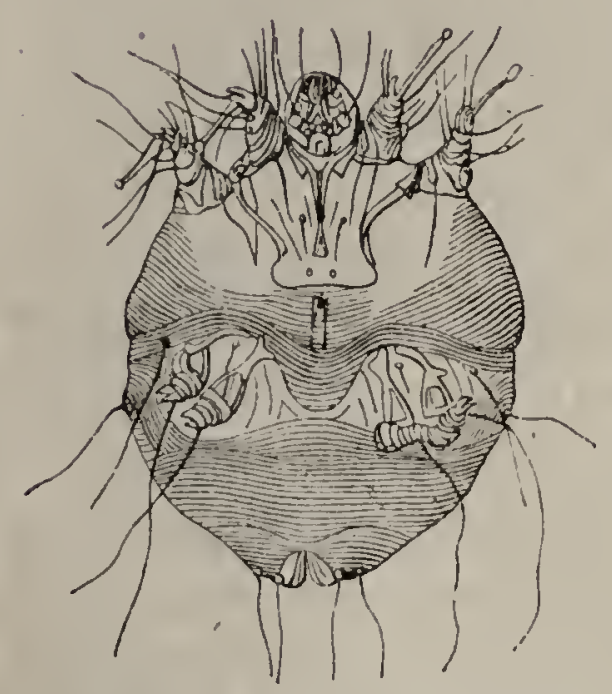

Fig. 423. - Acarus de la gale. Mâle, vu eu dessous.

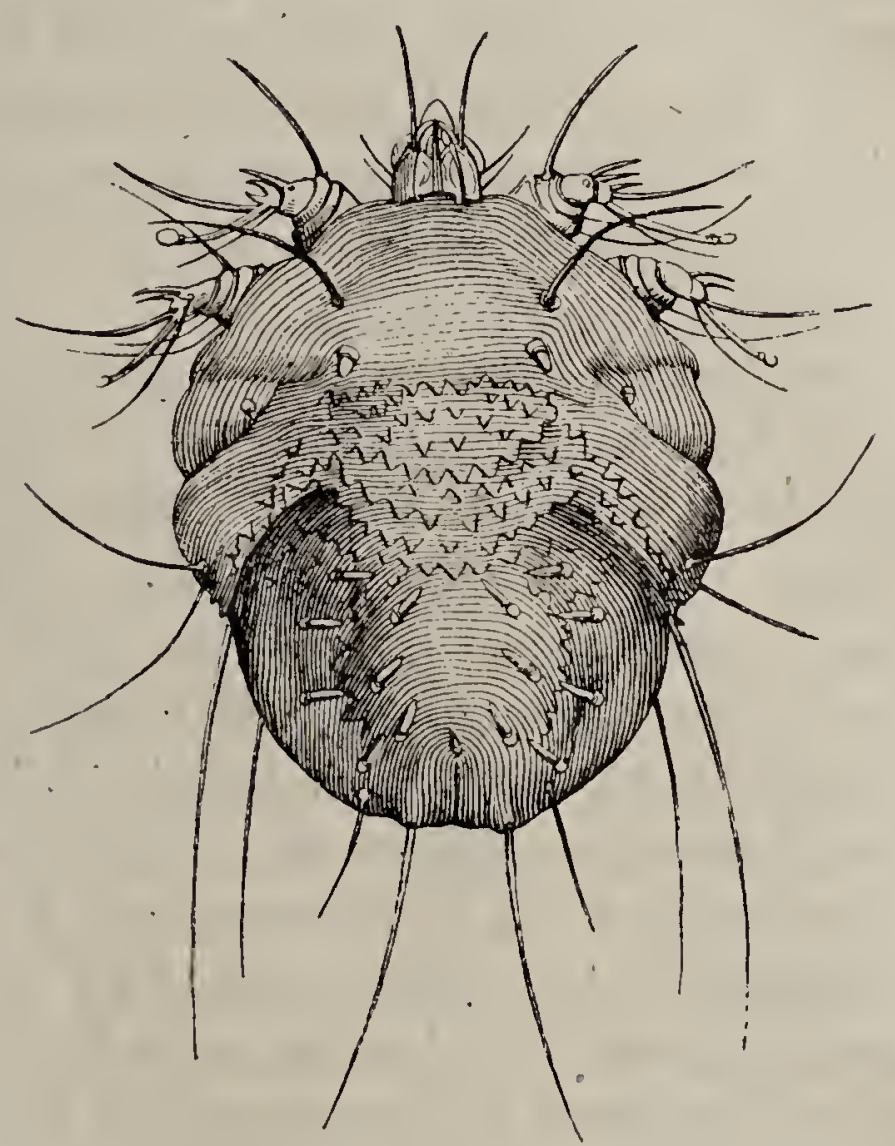

Fig. 424. - La femelle du même, vue par sa face dorsale, tous deux fortement grossis.

rencontre le plus souvent aux mains, dans les espaces interdigitaux, sur les faces latérales des doigts, sur les poignets, sur la verge, le scrotum chez l'homme, et sur le mamelon chez la femme. Il représente une petite ligne ordinairement courbe et de dimensions variables, dimensions qui peuvent atteindre de 3 millimètres à 3 centimètres, rarement plus. C'est une traînée, indiquant que quelque chose a passé par là, et qui ressemble parfaitement à la lésion qui résulterait d'un trait irrégulier fait sur l'épiderme, avec la pointe d'une épingle. Sa cou- 
leur est variable, généralement noire chez les personnes malpropres, elle est grise chez celles qui ont l'habitude de se laver souvent les mains. La courbure décrite par le sillon ressemble le plus ordinairement à un $e$ ou à une cédille; mais, lorsqu'il est un peu long, il est sinueux et représente des lignes courtes, réunies entre elles, de façon à simuler plus ou moins grossièrement la lettre $S$; il est rarement droit. Le sillon présente deux extrémités, l'une plus large est ouverte, c'est la porte d'entrée de l'Acare, l'autre plus étroite est fermée et terminée par un point blanc, c'est à ce bout que se tient l'Acare..."

Le sillon trouvé, il reste une manœuvre délicate à accomplir, c'est de déloger l'Acare saus le tuer et sans altérer ses formes. On a proposé plusieurs méthodes pour y arriver; voici les plus employées:

On déchire l'épiderme avec précaution à une petite distance de la papule, ou de la vésicule, sur le bord de laquelle on aperçoit l'éminence punctiforme, déterminée par la présence du parasite. Poussée avec précaution, l'aiguille passe sous l'Acare qui s'y cramponne et reste immobile. On peut alors l'examiner à un grossissement de 50 à 100 diamètres. On a proposé de sectionner la vésicule, mais d'après M. Mailhetard, cette méthode serait mauvaise, parce que le sillon ne communique pas avec la vésicule et n'a le plus souvent, avec elle, qu'un rapport de voisinage. "Il en est de même de la pustule. La vésicule et la pustule sont des lésions sous-épidermiques, tandis que le sillon est intra-épidermique; ce qui explique pourquoi l'on voit le sillon ramper sur la vésicule ou la pustule. " Le $\mathrm{D}^{\mathrm{r}}$ Mailhetard conseille de raser le sillon avec la pointe d'une épingle depuis la porte d'entrée de celui-ci jusqu'à son extrémité. Le mème sillon peut renfermer outre un Acare, plusieurs œufs, ainsi que des excréments, qui donneraient aux écailles épidermiques, soulevées pour former la galerie, leur couleur noire ou grise.

Dans le cas où la gale se complique d'eczéma, on conseille de faire bouillir les croûtes qui existent à la surface de la peau, dans une solution de soude caustique. On détruit ainsi les corpuscules de pus et les parcelles épidermiques, les Acares restent intacts. On réussira souvent à isoler les Acariens après avoir laissé tremper les croûtes pendant quelque temps, 
dans un mélange d'eau, d'acide acétique et d'alcool. (Robin, Duval et Lereboullet.)

Le Sarcopte est ovale. Sa longueur est égale à 3 ou 4 dixièmes de millimètre. Le Sarcopte mâle est moitié plus petit que celui de la femelle origère; il a la forme d'une tortue, les bords latéraux sont dentelés; le dos est recouvert de petits appendices coniques, ressemblant assez bien à des écailles munies de soie; la peau est sillonnée de replis, de duplicatures diverses; la tête a quatre paires de mâchoires et de même longueur. Les pattes sont au nombre de quatre paires; elles sont grosses et courtes; elle sont munies de ventouses ou du moins les deux paires antérieures et la dernière paire postérienre. Les mâles sont peu nombreux, ils sont vagabonds, dit Mí. Lailler, ils parcourent la surface du corps sans se fixer sur un point; ils ne creusent pas de sillons dans l'épiderme; on ne les trouve que sous les croûtes ou dans les rainures de l'épiderme où ils se réfugient. Au contraire, la femelle ovigère est très commune. Elle a un corps ovalaire, quatre paires de pattes; les pattes antérieures sont pourvues d'ambulacres à ventouses; les pattes postérieures présentent des soies d'égale longueur. L'oviducte est en forme de fente transversale, légèrement arquée, située en arrière de l'apodème sternal. La femelle pubère est plus petite que la précédente; les soies de ses pattes postérieures sont plus courtes, elle n'a pas d'oviductes. La nymphe est de même taille que le mâle; son corps ressembleà celui de la femelle pubère, mais il est plus petit, la deuxième paire de pattes postérieures est beaucoup plus petite que la première ; elle est terminée par une soie moitié plus courte et plus grêle.

La larve est de moitié plus petite que la précédente dont elle se distingue par l'absence de la deuxième paire de pattes postérieures, elle est donc hexapode. Quant à l'œuf, il est allongé, de la dimension de la larve dépourvue de la quatrième paire de pattes (Lallier). Chez tous les acariens, les femelles adultes ont une vulve spéciale pour la ponte, située sous le thorax et qui n'existe pas encore chez les jeunes femelles nubiles; chez celle-ci l'accouplement se fait par l'anus qui est, à cette période seulement, une large ouverture vulvo-anale. (Mégnin.) 
Dermatoses du cheval causées par des Aciriens (Mégnin, loc. cit., p. 28 et suiv.). - Le cheval peut nourrir trois Acariens psoriques différents, déterminant chacun une forme de gale particulière. Ils appartiennent tous les trois à la famille des Sarcoptidés, et aux genres Sarcoptes, Psoroptes et Chorioptes. sarcoptes seabiei (Latreille), variété equi.-Ge Sarcopte a été 'découvert en 1846 sur le cheval par Eichtdæt en Allemagne, et par Delafond en 18506 en France, sur des chevaux destinés à la

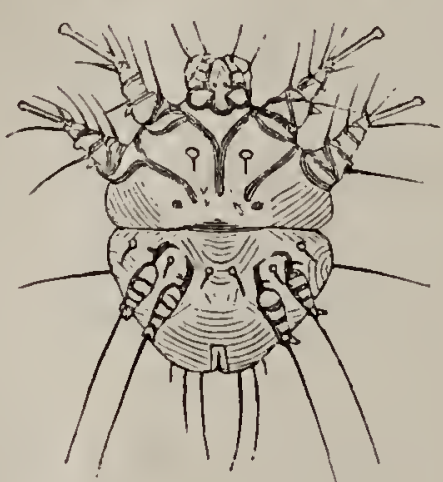

A

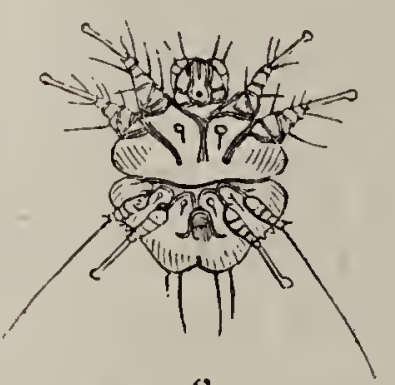

c:

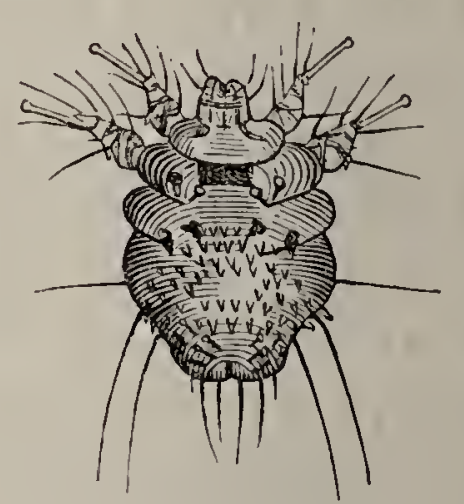

B

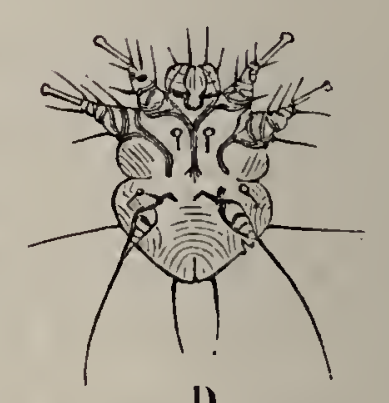

D)

Fig. 425. - Sarcoptes scabiei, var. equi. - A. Femclle ovigère (face rentrale). - B. Femelle ovigère (face dorsale). - C. Jàle (face veutrale). - D. Larve (face ventrale) (Mégnin).

dissection. Jusqu'à ces derniers temps, ce Sarcopte avait été considéré comme identique à celui de l'homme, mais il en diffère par une plus grande taille et par certains détails anatomiques plus accentués, et surtout par des crochets aux membres et des épines dorsales plus aiguës et plus développées.

- Voici, d’après M. Mégnin, les caractères de ce Sarcopte : "rostre peu caché par l'épistome, dépassé par deux paires de soies, des palpes presque aussi longues que lui (fig. 423̈), joues étroites ; céphalo-thorax à quatre segments, très distincts les uns des autres et de l'abdomen, sur les côtés et sur le dos; deux aiguillons ou spinules sur le bord de l'épistome; trois paires d'aiguillons gros et courts, en triangle, sur les trois segments thoraciques; de nombreuses saillies cutanées coniques-aiguës, interrompant les stries du corps el 
existant jusque sur les côtés du corps el entre deux rangées de sept paires de spinules sur le nologastre; une paire de longues soies sur les côtés du corps et une sous le ventre au même niveau; près de l'anus, qui est rétro-dorsal, deux paires de longues soies dont les plus grandes sont en dedans; épimère céphalo-thoracique médicn, descendant aussi bas que ceux de la deuxième paire ; plastron chitineux, grenu, quadrangulaire sur le céphalo-thorax; crochet aigu à la face inférieure du deuxième article des pattes antérieures, à deux crochets aigus inégaux, dont le terminal très fort, à l'extrémilé des tarses des mêmes patles, presque égaux aux tarses postérieurs; soies et cirres des articles des pattes comme dans la figure.

Femelle ovigère (A et $\mathrm{B}$ ). - Longue de $0^{\mathrm{mm}}, 40 \mathrm{à} 0^{\mathrm{mm}}, 50$, large de $0^{\mathrm{mm}}, 30$ à $0^{\mathrm{mm}}, 3 \ddot{3}$, grisâtre ou légèrement rosée ; oviducte sur le milieu de la face inférieure du troisième anneau céphalo-thoracique, accompagné d'une paire de pièces chilineuses brunes, en forme de feuilles de trèfle el d'un double épimérile longitudinal médian ; plastron céphalo-lhoracique dor'sal rectangulaire, transversal, sur le milieu du deuxième anneau, présentant à son bord antérieur la trace de deux stigmates contigus; les deux paires de pattes postérieures articulćes sur des épimères libres, portant chacune, au lieu de ventouse, une longue soie tarsienne de même longueur et de mème force dans chaque membre (fig. $42 \%$ ).

Femelle pubère. - Longue de $0^{\mathrm{mm}}, 33$ à $0^{\mathrm{mm}}, 40$, large de $0^{\mathrm{mm}}, 25$ à $0^{\mathrm{man}}, 31$, ne se distingue de la précédente que par l'absence d'oviducte et par une plus petite taille.

Mále (C). - Longueur $0^{\mathrm{mm}}, 2 \partial \ddot{a}$ à $0^{\mathrm{mm}}, 28$, large de $0^{\mathrm{mm}}, 18$ à $0^{\mathrm{mm}}, 20$, gris roussâtre; organe génital complexe, formé par une pièce médiane à deux branches, s'articulant toujours complètement avec les épimères des quatre paltes postéricures, réunies par paires de chaque côté; tarse de la quatrième paire de pattes pourvu d'une venlouse pédiculée au lieu d'une soie ; saillies cutanées moins nombreuses; large plastron occupant les parties médianes et supérieures du deuxième et troisième anneau céphalo-thoracique, une paire de petits plastrons en forme de disques grenus, roussâtres sur le notogastre de chaque côté de la ligne médiane.

Nymphe. - Longue de $0^{\mathrm{mm}}, 30$, large de $0^{\mathrm{mm}}, 20$, en tout semblable à la jeune femelle pubère, dont elle ne se distingue, outre sa taille plus petite, que par la quatrième paire de pattes beaucoup plus petite et portant une soie plus grêle et plus courte de moitié, que celle de la troisième paire.

Larve (D). - Longue de $0^{\mathrm{mm}}, 16$, à $0^{\mathrm{rm}}, 10$ à $0^{\mathrm{mm}}, 25$, large de $0^{\mathrm{mm}}, 17$, se distingue de la nymphe en ce qu'elle est hexapode par l'absence. de la quatrième paire de pattes, et en ce qu'elle ne porte qu'une seule paire de soies anales représentées par la plus interne.

On rencontre ce parasile sur le cheval el sur quelques autres grands quadrupèdes, sur la peau desquels il habite, caché sous les 
couches épidermiques, à des profondeurs variables suivant l'âge ; ce sont les femelles ovigères et les femelles fécondées, qui se logent le plus profondément et probablement, au fond des terriers, ou des sillons, comme chez l'homme, sillons ou terriers, qu'il est impossible de voir, chez les animaux couverts de poils et à peau colorée en noir, par un pigment abondant. Les nymphes elles-mêmes vivent plus superficiellement, afin de pouvoir se rencontrer pour s'accoupler; les larves aussi vivent à la superficie de la peau. Cette manière de vivre dans les couches épidermiques, dit M. Mégnin, explique pourquoi, la récolte des Sarcoptes est si difficile; il faut racler jusqu'au sang, pour obtenir surtout les femelles adultes, qui sont les plus nombreuses; les mâles sont relativement très rares. Si l'on se contente de recueillir seulement les croûtes qui se détachent facilement, on n'obtiendra jamais rien. La présence du parasite est absolument indispensable pour distinguer la dermatose parasitaire, de la dartre sèche, ou chronique, du cheval.

Psoroptes longirostris. - Découvert en 1813 par Gohier, à
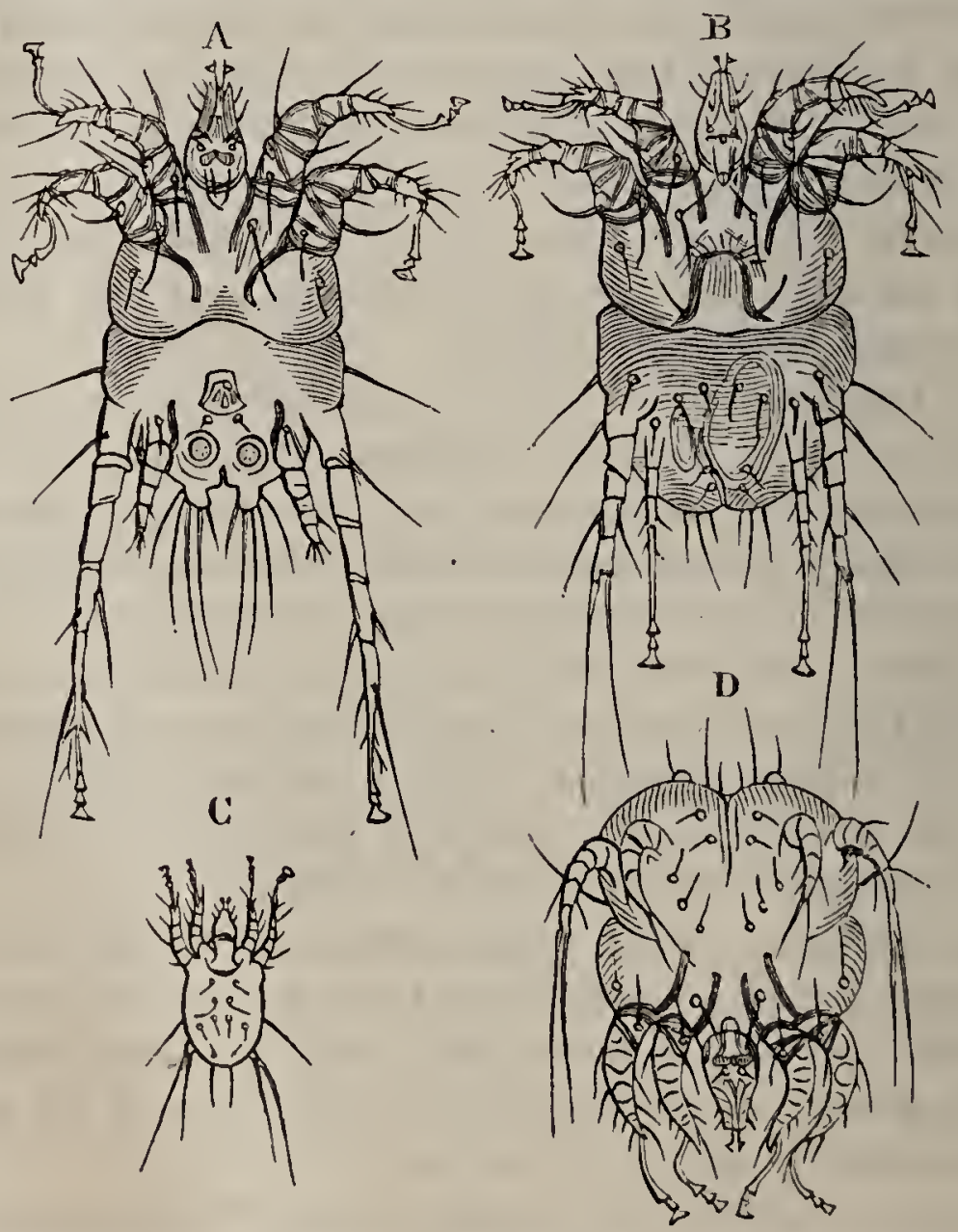

Fig. 426. - Psoroptes longirostris, var. equi (gross. de 50 D.). - A. Mâle (face inférieure. - B. Femelle ovigère (face inférieure). - C. Larve (face dorsale). - D. Jeune femelle pubère ( $2^{\circ}$ forme), face inférieure, renversée la tète en bas et inclinée de manière à montrer la partie rétro-dorsale (IIégnin).

Lyon. Synonymes: Psoroptes equi (V. Gervais), Dermatodectes 
equi (Gerlach), Dermatodectes communis (Bourg. et Delaf.), Dermatocoptes communis (Furstenberg).

Description. - Psoropte à rostre bien détaché et saillant, à soie des palpes courtes (fig. 426), céphalo-thorax à segments peu distincts, portant, sur la face supérieure, une plaque grenue jaunâtre, courte et étroite, occupant la partie médiane du premier segment. Cinq paires de poils dorsaux, dont une de plus grande dimension, insérée, sur une large papille non percée, placée près des angles postérieurs de la plaque grenue céphalo-thoracique. Deux paires de poils latéraux près des hanches, des deuxième et troisième paires de pattes; quatre paires de poils sous-thoraciques et ventraux, entre les épimères des pattes.

Femelle ovigère (B). - Longueur $0^{\mathrm{mm}}, 60$ à $0^{\mathrm{mm}}, 80$, sans les pattes ; largeur $0^{\mathrm{mm}}, 30$ à $0^{\mathrm{mm}}, 50$; couleur générale blanc nacré, avec les pièces du squelette de couleur rouille; oviducte en forme de courte fente transversale, vers le troisième anneau thoracique, à lèvres fortement plissées ; la lèvre inférieure munie d'une paire d'épimérites en forme de deux branches de lyre renversées. La troisième paire de pattes terminée par deux longues soies, la quatriéme par une ventouse pédiculée.

Jeune femelle putbère (première forme). — Longue de $0^{\mathrm{mm}}, 40$, large de $0^{\mathrm{mm}}, 25$ à $0^{\mathrm{mm}}, 30$; fente vulvo-anale grande, longitudinale, sousabdominale, à lèvres chitineuses, portant de chaque côté de la commissure postérieure de celte fente, mais sur lá face dorsale, deux tubercules hémisphériques saillants, chitineux, servant à l'accouplement. Absence complète d'oviducte sous-thoracique. Pour le reste de la conformation et pour les pattes, ressemblance complète avec la femelle ovigère, sauf la ventouse de la quatrième paire de pattes qui est comme arrêtée dans son développement.

Jeune femelle pubère (deuxième forme). - Longue de $0^{\mathrm{mm}}, 40 \mathrm{à} 0^{\mathrm{mm}}, 50$, large de $0^{\mathrm{mm}}, 30 \mathrm{à} 0^{\mathrm{mm}}, 40$, ressemble tout à fait à la précédente, si ce n'est la quatrième paire de pattes qui est imparfaite et terminée par deux poils grêles, au milieu d'une ventouse pédiculée (D).

Mále $(\Lambda)$. - Longueur $0^{\mathrm{mm}}, \ddot{0} 0$, largeur $0^{\mathrm{mm}}, 30$; gris roussâtre; organe génital complexe entre les pattes postérieures, accompagné d'une paire de ventouses copulatrices, en forme de gobelets; trois paires de paties complètes, la quatrième rudimentaire. Lobes abdominaux triangulaires, arrondis, portant chacun cinq poils simples, les trois de l'extrémité très grands et forts. Notogastre recouvert d'un large plastron trapézoïdal, en chitine grenue et rousse.

Nymphe. 一 Longue de $0^{\mathrm{mm}}, 40 \mathrm{à} 0^{\mathrm{mm}}, 50$, large de $0^{\mathrm{mm}}, 30 \mathrm{à} 0^{\mathrm{mm}}, 40$; ressemble tout à fait à la jeune femelle pubè̀re, deuxième forme, sauf les tubercules copulateurs qui sont absents et la fente vulvoanale moins grande.

Larve hexapode $(\mathrm{C})$. - Longue de $0^{\mathrm{mm}}, 20$ à $0^{\mathrm{mm}}, 40$, large de $0^{\mathrm{mm}}, 12$ GUIDE DE MICROGRAPHE. 
à $0^{\mathrm{mm}}, 25$, n'ayant qu'une paire de pattes postérieures, terminée par deux longs poils; c'est la quatrième qui manque. Entre les tailles extrêmes que nous indiquons, M. Mégnin a constaté au moins trois tailles différentes intermédiaires, ce qui indiquerait au moins trois mues pendant cette période.

OEuf. - Long de $0^{\mathrm{mm}}, 20$, large de $0^{\mathrm{mm}}, 12$, couleur blanche, opaline. On rencontre souvent des œufs à des degrés divers d'incubation, depuis celui où l'embryon est à peine indiqué par des bosselures, jusqu'à celui où il est tout formé et prêt à sortir.

Habitat. - Les psoroptes se rencontrent sur le cheval en sociétés nombreuses qui ne se déplacent qu'en rayonnant et en suivant une progression régulière; c'est ce qui explique la forme et l'aspect particulier de la gale psoroptique, laquelle se présente par larges plaques d'impétigo, à grosses croûtes humides, loujours nettement séparées par des parties saines; c'est au milieu des croûtes qu'habitent les psoroptes, aussi est-il facile, avec un peu d'attention, de les voir grouiller au milieu et à la simple vue. On peut même voir les psoroptes accouplés, le mâle traînant la femelle qui est comme inerte. Ils ne ponctionnent la peau qu'au fur et à mesure de leurs besoins et ne se cachent jamais sous l'épiderme; aussi est-il très façile de se rendre compte de leur présence et d'en récolter. Ils sont assez volumineux pour que, à la simple loupe, l'observateur puisse les reconnaître spécifiquement.

Chorioptes spathiferus. - Chorioptes spathiferus. Syn. Sarcoptes bovis (Hering); Symbiotes bovis (Gerlach), Sarco-dermatodecte communis (Bourg et Delaf.).

Diagnose. - Choriopte à rostre à moitié caché par l'épistome, à soies des palpes très courtes, céphalo-thorax à segments peu distincts, portant sur sa face supérieure et sur la ligne médiane une bande chilineuse, grenue, s'élargissant en arrière, et s'étendant jusque près de la ligne de démarcation du quatrième segment ; deux petites lignes de même substance à la naissance des pattes. Au sommet du triangle formé de chaque côté par le troisième anneau, large papille chitineuse circulaire, percée d'une ouverture en demi-lune, au pied du long poil qu'elle porte à son centre; quatre autres poils dorsaux très petits; une autre paire de poils sur les côtés du corps, à la naissance de la troisième paire de pattes, trois paires de petits poils sous le thorax, entre les épimères des pattes, et une paire de poils accompagnés de très fins stylets, de chaque côté de l'anus, épimères des pattes antérieures libres.

Femelle ovigère (fig. 427, B). - Longue de quatre dixièmes de millimètre, large de deux à trois; couleur générale blanc nacré, avec les pièces en chitine de couleur rousse; vulve ou oviducte en forme de courte fente transversale, à lèvres fortement plissées, sous le 
troisième anneau céphalo-thoracique, chaque lèvre accompagnée de deux épimérites en chitine, formant par leur ensemble deux figures concentriques en forme de lyre renversée ; troisième paire de pattes terminée par deux longues soies ; quatrième paire par une ventouse énorme, à pédicule court, comme celle des pattes antérieures.

Male (fig. $427, \mathrm{~A}^{\prime}$. - Long de $0^{\mathrm{mm}}, 28$, large de $0^{\mathrm{mm}}, 18$, gris roussâtre; organe génital complexe, entre les pattes postérieures, accompagné d'une paire de ventouses copulatrices, en forme de gobelets; quatre
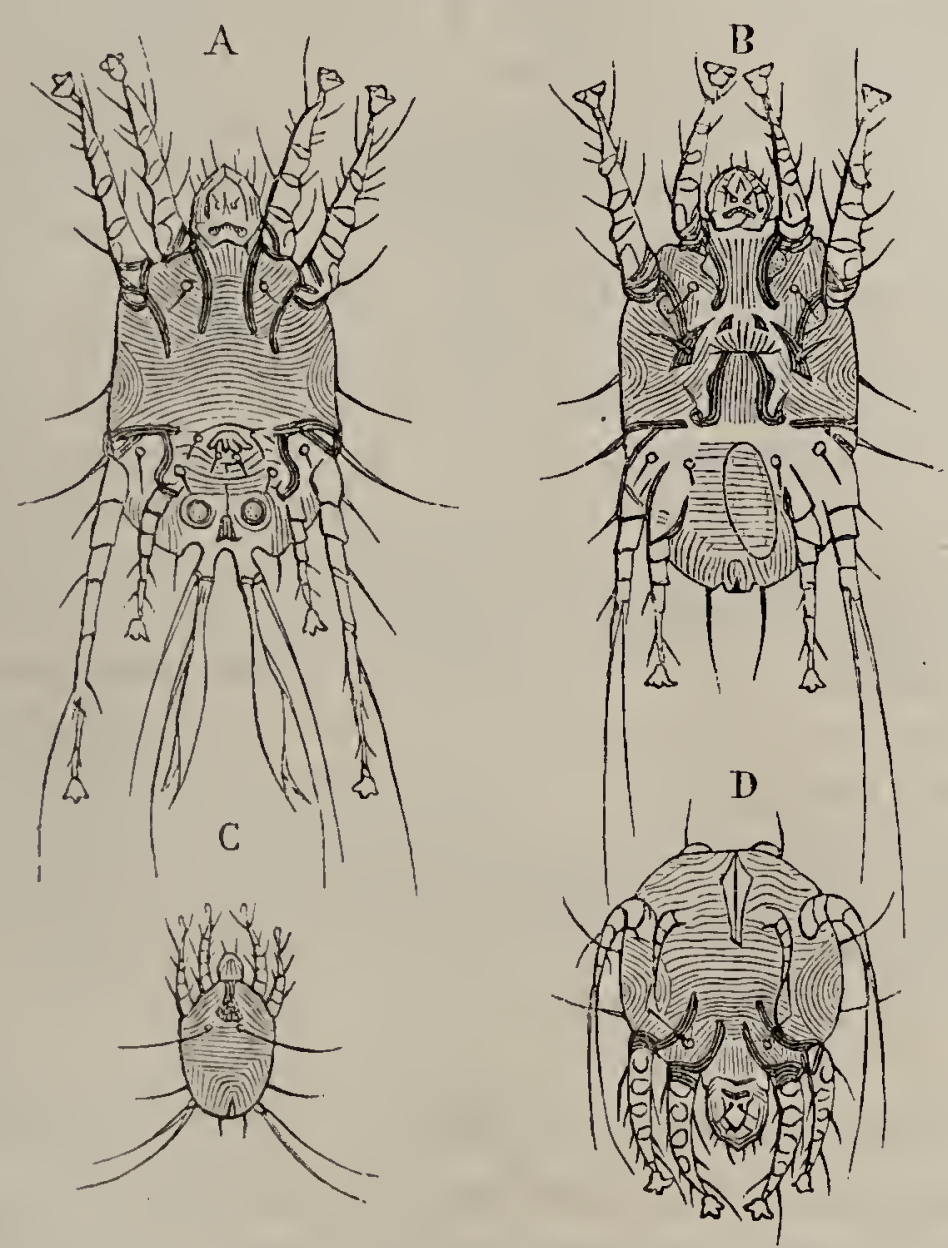

Fig. 427. - Chorioptes spathiferus (gross. de 50 D.). - A. Màle. - B. Femelle ovigère (face ventrale). - C. Larve (face dorsale). - D. Jeune femelle pubère, face ventrale inclinée, tête en bas, montrant l'extrémité rétro-dorsale.

paires de paltes complètes, c'est-à-dire toutes munies de ventouses; les première, deuxième et troisième paires longues, la quatrième rudimentaire. Lobes abdominaux rectangulaires, portant à leur extrémité, outre un poil ordinaire gros et long, un faisceau de trois poils, collés à leur base, composé d'un poil ordinaire et de deux autres poils superposés, élargis en mince membrane et spathiformes. Notogastre recouvert par un large plastron trapézoïdal en chitine grenue.

Jeune femelle pubère (fig. $427, \mathrm{D})$. - Longue de $0^{\mathrm{mm}}, 27$, large de $0^{\mathrm{mm}}, 16$. Absence complète de vulve sous-thoracique. Anus très grand,

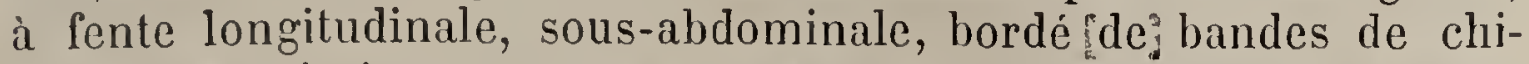
tine, ce qui n'existe pas aux autres âges, ni à l'autre sexe. De chaque côté de l'anus, mais sur la face dorsale, deux tubercules hémisphéri- 
ques saillants, servant à l'accouplement. l.es quatre pattes postérieures sont toutes incomplètes et terminées chacune par deux soies.

Nymphe. - Octopode, semblable à la jeune femelle pubère, dont elle ne diffère que par l'absence de tubercules copulateurs et par une plus pelite taille.

Larve (fig. $427, \mathrm{C}$ ). - Hexapode, longue de $0^{\mathrm{mm}}, 20$ environ, ayant. comme celle des Psoroptes l'unique paire de pattes postérieures, terminée par deux soies simples et inégales.

OEuf. - Long de $0^{\mathrm{mm}}, 1 \ddot{3}$, large de $0^{\mathrm{mm}}, 9$; ovoïde, gris-perle, présentant souvent un embryon plus ou moins développé.

IIabitat. - Ce parasite ne se cache pas sous l'épiderme, mais au milieu des croûtes dont il provoque l'apparition par ses morsures. Des trois acariens que nous venons de décrire, c'est le moins dangereux.

M. Mégnin signale, dans l'ouvrage auquel nous empruntons tout ce qui a trait aux dermatoses du cheval, des causes d'erreur qui peuvent se présenter, dans l'exạmen des croûtes d'un cheval galeux. Dans tous les détritus épidermiques de la peau du cheval, dit cet auteur, aussi bien en bonne santé que malade, on trouve des cadavres d'Acariens, provenant des fourrages; ce sont des Glyciphages (fig. 428 B), des Tyroglyphes, des Cheylites, des Gamases, etc.; on pourrait les prendre pour des restes d'Acariens psoriques et conclure à tort, sur cette base, à l'existence de la gale; les trouverait-on vivants, ce qui est très rare, qu'il en serait de même, attendu qu'ils sont parfaitement inoffensifs. Les nymphes hypopiales des Tyroglyphes (fig. 428, C) que l'on rencontre vivantes et quelquefois en très grand nombre sur les animaux, peuvent être prises avec plus d'apparence encore pour des Acariens psoriques (loc. cit., p. 41).

Fausses gales acariennes (Mégnin, loc. cit., p. כ̌ ).

I. Gale dermanyssique. - Les Dermanysses (fig. 428, A) ressemblent beaucoup aux Gamases, à la famille desquels ils appartiennent; ils en diffèrent par des téguments plus mous, plus transparents. Ils habitent, en colonies nombreuses, les poulaillers, les pigeonniers et les nids d'oiseaux; les perchoirs. creux des oiseaux en sont quelquefois remplis; ils y restent tapis pendant le jour, mais la nuit ils circulent avec une agilité extrême, se répandent au loin et vont sucer le sang des oiseaux endormis, ou des animaux qui se trouvent à leur portée; rentrés le matin dans leurs cachettes, on les trouve, surtout les grandes femelles fécondées, gonflés d'un liquide rouge, qui n'est autre que le sang dont ils se sont repus pendant la nuit. Malgré leur petitesse (1/2 mill. de long), mais en raison de leur nombre, ils finissent par épuiser leurs victimes, 
surtout quand elles sont petites et faibles. Les piqûres de Dermanysses ne sont pas venimeuses, elles guérissent spontanément, sans être suivies de symptômes inflammatoires.

Quand ils sont très nombreux dans un poulailler, ils se répan-

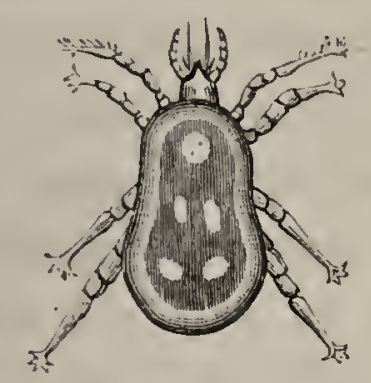

A
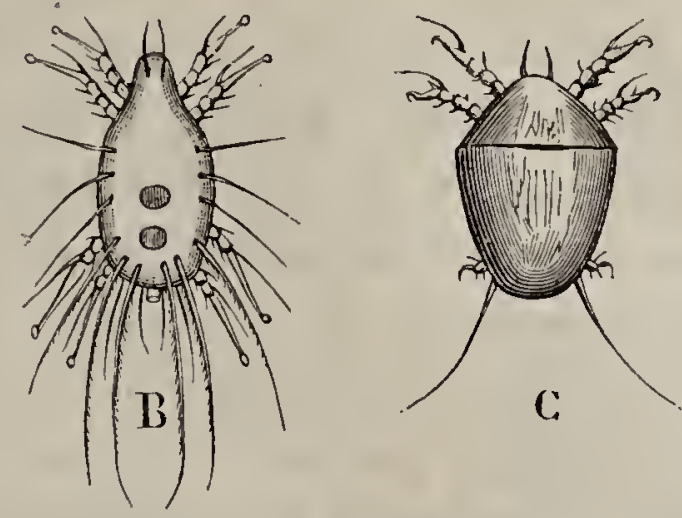

Fig. 428. - A. Dermanysse, $\frac{30}{1} \cdot$ - B. Glyciphagus cursor, $\frac{25}{1} \cdot$ - C. Hypope, $\frac{50}{1}$.

dent souvent, soit sur les personnes qui passent, soit sur les grands animaux, et surtout sur les chevaux, quand l'écurie est voisine du poulailler.

II. Exode pénétrant (Mégnin). - Les grands Ixodes, qui ont 4 à 5 millimètres à peine, n'attaquent guère que les chiens et quelquefois les chasseurs. Ils introduisent seulement leur rostre, à dents rétrogrades, dans les téguments, et tout leur corps reste en dehor's, où il apparaît quelquefois gonflé, livide et de la grosseur d'une olive, ou tout au moins d'une graine de ricin.

M. Mégnin a découvert un petit Ixode qui n'a guère que 1 à 2 millimètres de long et dont les habitudes sont différentes (1). Il se loge entièrement sous les téguments, s'y cache et provoque bientôt, par sa présence, l'apparition de grosses pustules, de vrais petits furoncles qui s'accompagnent de démangeaisons très vives. M. Mégnin a observé des furoncles ixodiques sur des chiens, des lièvres et sur le cheval. C'est l'Ixode pénétrant; ce parasite vit dans les herbes des forêts sablonneuses et c'est là qu'il s’attache aux animaux qui passent à sa portée.

Parasite accidentel de l'homme. - M. Robin a signalé, en 1867, un acarien qui s'était multiplié en quantité innombrable, dans des tas de blé nouvellement égrené, et qui avait

(1) M. Mégnin a reconnu plus tard que c'était une nymphe de l'Ixode reduve. 
déterminé un prurit d'une assez longue durée chez des indivi. dus qui maniaient le grain, ou vivaient dans le voisinage de ces amas. M. Robin a reconnu une nymphe, ressemblant aux nymphes des Oribates. Les Oribates se distinguent des Sarcoptes par la dureté de leur enveloppe extérieure (bouclier et cuirasse) et leurs palpes à cinq articles velus et par leurs trachées. (V. pour la fig., Robin, Traité du Microscope, p. 701.)

Transmission de la gale des animaux à l'homme. Contagion d'un animal à un autre. - Il y a dans la science d'assez. nombreux exemples de contagion de la gale du cheval à l'homme. M. Mégnin en rapporte un assez grand nombre. Nous ne mentionnerons pas ces différents exemples, il nous suffit d'en établir l'existence. Non seulement la gale du cheval peut se transmettre à l'homme, mais elle peut encore êlre communiquée à d'autres animaux. C'est ainsi que Grognier a publié, en 1827, l'observation d'un cheval qui avait donné la gale à deux vaches placées près de lui dans une étable, ainsi qu'à plusieurs personnes qui l'avaient pansé.

La gale du chat peut se transmettre à l'homme, ainsi qu'aux animaux. Hertwig rapporte le fait d'une gale générale, communiquée à une servante qui faisait coucher un chat galeux

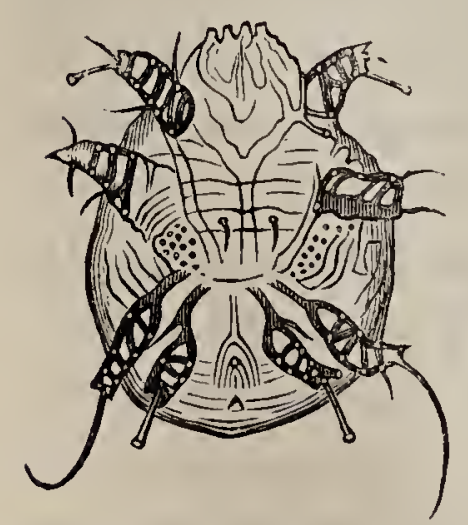

Fig. 429. - Acarus du chat. dans son lit. Dans la même année (1838) un autre auteur allemand racontait le fait d'une jeune fille, qui avait contracté une éruption à la poitrine, pour y avoir fait reposer un chat galeux. Rademacher a vu la gale du chat se transmettre à une vache, sur laquelle un chat galeux avait l'habitude de se coucher, puis à une ser. vante qui soignait la vache, et enfin à toute la famille du propriétaire de l'animal (Mégnin, loc. cit., p. 11).

M. Gervais a observé, en 1843, qu'un dromadaire galeux, du Jardin des plantes de Paris, avait communiqué la gale aux gardiens de la ménagerie. Cette gale présente un caractère d'acuité tout particulier.

La gale de la chèvre peut être communiquée aux cheraux.

Le Sarcoptes scabiei, variété lupi, s'étant propagé dans une 
ménagerie, sur des lions, des hyènes et un ours, les employés de la ménagerie contractèrent la gale.

Le Sarcoptes scabiei, variété suis, qui caractérise la gale du porc et du sanglier, peut se transmettre à l'homme, d'après Delafond. M. Mégnin cite plusieur's autres auteur's qui ont fait des observations analogues.

La gale de la poule, produite par le Sarcoptes nutans (Ch. Robin), peut se transmettre au cheval, à l'âne, au mulet, aux grands et aux petits ruminants.

En 1863, MM. Delafond et Bourguignon communiquèrént à la Société de biologie un cas de transmission de la gale du chien à l'homme.

Dans beaucoup de cas, la preuve de la contagion de la gale des animaux à l'homme a été faite expérimentalement. M. Mégnin a pu communiquer la gale du chat, Sarcoptes notoedres, variélé cati,

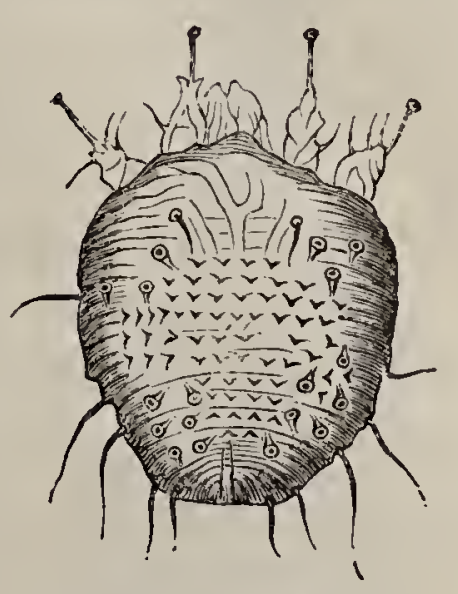

Fig. 430. - Acarus du chien. au cheval. Le Sarcopte notoédre a été retrouvé chez le rat d'égouts de Paris (Mus decumanus de Pallas), on l'a découvert également chez le lapin. Suivant les espèces animales sur lesquelles il vit, le Sarcople varie de dimensions. M. Mégnin est d'avis que c'est le rat qui est, pour ainsi dire, la patrie d'origine de ce sar'copte, soit qu'il devienne la proie du chat, soit qu'il le communique au lapin, avec lequel il cohabite.

Il était important, au point de vue de la contagion, de savoir quel est le degré de résistance des Sarcoples, quand ils sont en dehor's de leur habitat. M. Mégnin dit qu'au milieu descroûtes et à une température convenable, se rapprochant de celle du corps, il n'a pu conserver des Sarcoptes plus de vingt-quatre à soixante-douze heures, tandis qu'il a vu vivre, dans les mêmes conditions, des Psoroples une quinzaine de jours, et les Chorioptes un mois et plus; les œufs de Sarcople, au contraire, ont éclos encore au bout de trois mois de conservation dans un lieu sec et ils s'y conservent probablement encore davantage, avec toute leur vitalilé ; c'est ainsi qu'un auteur allemand aurait vu la gale sarcoptique se développer sur un cheval, à la suite de 
l'usage d'une couverture mise au rebut pendant quatre ans, après avoir servi à des chevaux galeux (Mégn., loc. cit., p. 22).

Les conclusions de M. Mégnin serviront à l'élude précédente :

"1 ${ }^{\circ}$ Les acariens psoriques du genre Chorioptes, qui sont particuliers aux jeunes animaux domestiques et à quelques espèces sauvages, émigrent difficilement des régions qu'ils occupent, ne s'acclimatent pas sur les animaux âgés de la même espèce, non plus que sur des animaux d'espèces différentes, ni sur l'homme, c'est-à-dire que la gale chorioptique ne se transmet pas des jeunes animaux aux animaux âgés, ou d'espèces différentes, ni à l'homme.

" $2^{\circ}$ Les acariens psoriques du genre Psoroptes s'acclimatent facilement et rapidement sur des animaux de la même espèce, quel que soit leur âge, mais ne s'acclimatent pas sur des animaux d'espèces différentes, ni sur l'homme, c'est-à-dire que la gale psoroptique des animaux n'est contagieuse ni aux animaux d'espèces différentes de celle dont elle provient, ni à l'homme.

" $3^{\circ}$ Les acariens psoriques du genre Sarcoptes s'acclimatent avec une grande facilité sur des animaux de la même espèce, quel que suit leur âge; quelques variétés des espèces de ce genre s'acclimatent avec autant de rapidité sur des animaux d'espèces différentes, en prenant à la longue les caractères des variétés propres à ces dernières : tel est le Sarcoptes scabię, variété lupi, qui s'acclimate facilement sur le cheval et sur l'homme; telle est la variété ovis de la même espèce qui s'acclimate facilement sur le mouton, le mouflon et les autres ruminants, et peut-être aussi sur l'homme; tel est enfin le Sarcoptes notoedres du rat qui s'acclimate sur le chat, le coati, le lapin et le cheval.

“ $4^{\circ}$ Enfin, il n'est qu'un moyen certain de reconnaître, sur l'homme ou l'animal galeux, si l'affection qu'ils portent est bien celle qui est proprè à leur espèce, ou si elle leur a été transmise par une espèce différente : c'est la détermination exacte des caraclères zoologiques, spécifiques et de variétés de l'acarien psorique qu'ils nourrissent. ")

Parmi les acariens qui vivent sur l'homme et sur les ani- 
maux, nous devons citer le Demodex (Demodex follicularis (Owen), Simonea folliculorum (P. Gervais), Acarus folliculorum (Henle, puis Simon). Ce parasite ne semble pas déterminer de troubles pathologiques, bien qu'il vive dans les glandes sébacées de la peau. Pour le recueillir, il suffit de presser les ailes du nez, dont l'appareil glandulaire est ordinairement très riche, ou de les racler avec une spatule. On examine au microscope le produit obtenu, à l'aide d'un peu de glycérine; un grossissement de 300 à 400 diamètres suffit.

Voici, d'après Duval et L.ereboullet, la description de ce parasite. Il a de $83 \ddot{\mu}$. à $125 \mu$ de longueur et environ $23 \mu$. de largeur; la tête est pourvue de deux palpes latéraux et bifides et d'un proboscide long et tuberculeux, sur lequel on trouve un organe triangulaire, composé de deux pointes, ou défenses fines. La tête tient immédiatement au thorax, qui compose environ le quart de la longueur de tout l'animal.

De chaque côté du thorax, il y a quatre pattes très courtes, coniques, consistant en trois segments et portant trois griffes étroites, à leurs extrémités libres. De la base de chaque patte, une arête s'étend transversalement à travers le thorax, et ces bandes transversales sont reliées les unes aux autres par une crête longitudinale, placée sur la ligne médiane. L'abdomen est environ trois fois aussi long que la poitrine. Les téguments présentent un grand nombre de constrictions, qui ont l'air de lignes transverses placées en juxtaposition et donnent à ses rebords latéraux l'aspect d'une lime. Une autre variété de cet animal est caractérisée par

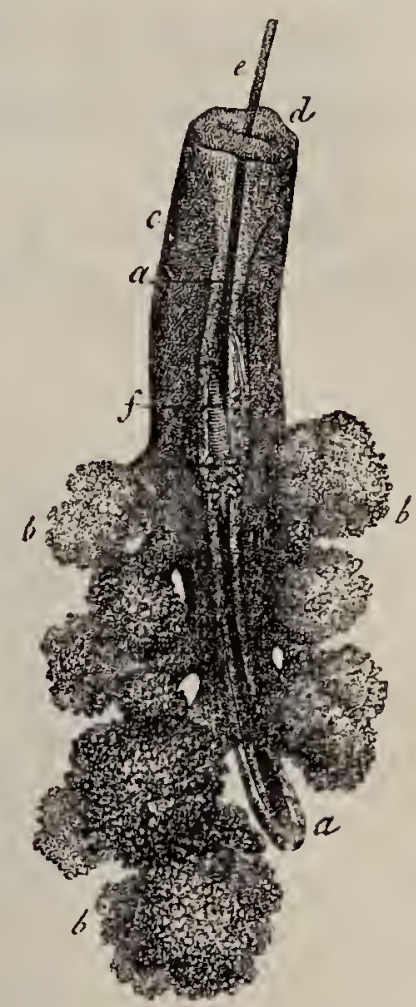

Fig. 431. - Premier degré de l'hypertrophie d'une glande sébacée (Comédon). - $a a$. Poil et bulbe pileux. - $b$. Cellules hypertrophiées de la glande sébacée. - $c$. Canal commun au follicule pileux et à la glande sébacée, distendu par l'épithélium qui fait saillie en $d$. $-i$. Poil qui traverse cet amas d'épithélium. - $f$. Demodex folliculorum. (Follin.) la brièveté de l'abdomen qui peut ne pas être plus long que le thorax et qui, de toute façon, ne dépasse pas cette région de plus d'une demi-longueur. Dans une troisième variété, les pattes sont au nombre de trois seulement et l'abdomen est complètement lisse; enfin une quatrième variété présente une forme cordée. Peut-être ces diverses apparences correspondent-elles à divers degrés du développement du parasite. 
Nous ne pouvons quitter ce sujet sans parler également du Demodex du chien, bien que l'affection qu'il cause chez celui-ci ne paraisse pas jusqu'à présent être transmissible à l'homme. Chez le chien le Demodex produit la gale folliculaire. C'est une maladie très grave et très fréquente. Après la ragee, dit M. Mégnin, dans l'ordre d'importance, c'est certainement l'affection la plus redoutable.

Voici, d'après M. Mégnin, les caractères du Demodex folliculorum du chien. La femelle adulte a 2: centièmes de millimètre : le mâle en a
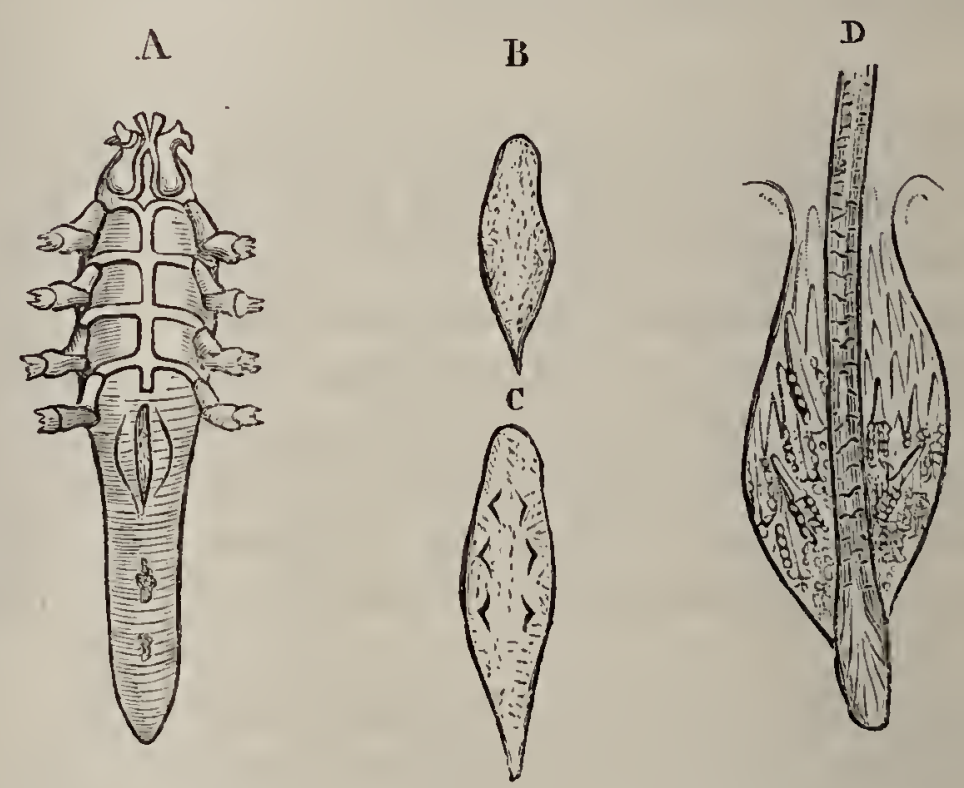

Fig. 432. - Demodex folliculorım (du chien). - A. Femelle adulte. - B. Larve sous forme de petite sole. - C. Larve avant acquis trois paires de tubercules de reptation qui tiennent lieu de pattes. - D. Demodex oceupant le follieule dilaté d'un poil.

23. Ce parasite donne naissance à de petites larves sans pattes sous forme de petiles soles (fig. 432, B) qui grandissent, acquièrent trois paires de petits tubercules de reptation (C), qui tiennent lieu de pattes, et finissent, après avoir grandi encore et mué une dernìre fois, par prendre la forme adulte. Le mouton et le chien ont également un Demodex; l'espèce qui vit sur le chien est la plus dangereuse.

Nous n'insisterons pas davantage et nous renvoyons le lecteur, pour tout ce qui a trait aux affections parasitaires du chien, au livre si remarquable de M. Mégnin (1).

Des acariens qui vivent dans la poudre de cantharides (Laboulbène, Fumouze et Robin). - Dans les vieux fourrages, dans un

(1) Le Chien, histoire, hygiène, médecine. P. Mégnin, Paris, chez Deyrolle. 
certain nombre de poudres pharmaceutiques, on rencontre des acariens. Nous n'arons à nous occuper ici que des espèces qui peuvent intéresser le médecin et le pharmacien. M. Fumouze a porté son attention sur les espèces qui vivent dans les Cantharides, mais il serait intéressant d'étudier les acariens qui vivent au milieu des poudres pharmaceutiques. Parmi les acariens déterminés par M. Fumouze, les uns appartiennent au genre Tyroglyphe, les autres au genre Glyciphage et au genre Cheyletus.

A. $1^{\circ}$ Le Tyroglypluus longior (Gervais) possède les caractères suivants (fig. $433, \mathrm{~A})$ :

Corps arrondi sur les flancs et en arrière, rétréci au devant du sillon circulaire, d'un gris blanchâtre ; lisse et présentant des taches
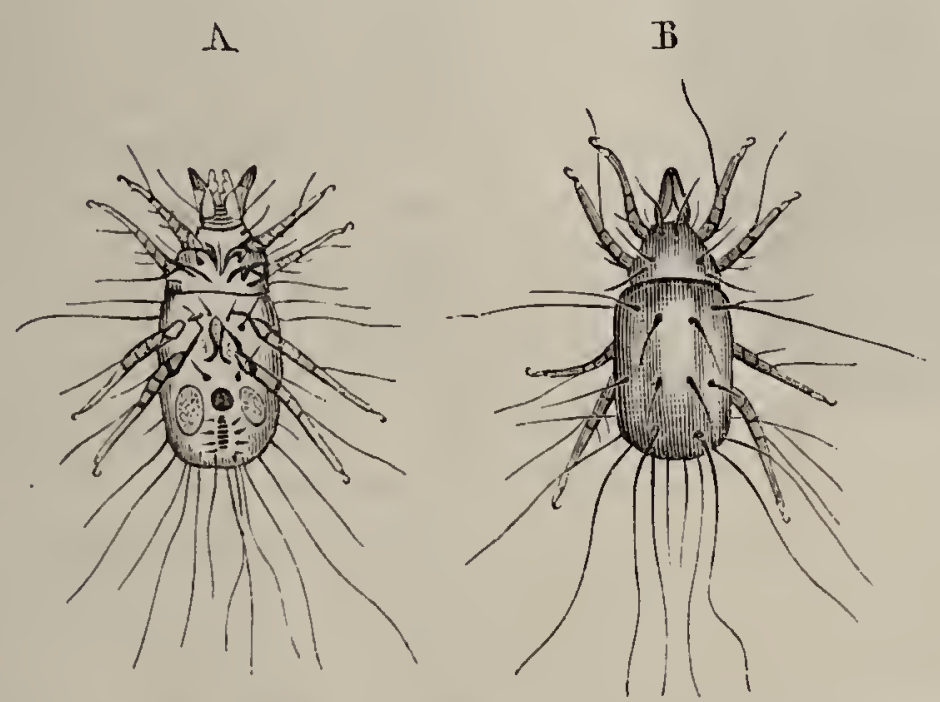

Fig. 433. - A. Tyroglyphus longior. - B. Tyroglyphus siculus.

brillantes; pattes à tarse long, effilé, le rostre et les pattes sont très peu colorés, les poils sont plus longs que le corps. Le mâle, toujours plus petit que la femelle, présente deux ventouses aux pattes de la quatrième paire.

Ces petits animaux, d'après M. Fumouze, vivraient en société, et auraient une résistance vitale très énergique.

$2^{\circ}$ Le Tyroglyphus siculus (Ch. Robin et A. Fumouze) (fig. 433, B).

Ce tyroglyphe a reçu ce nom parce qu'il a été trouvé dans la Cantharide de Sicile (V. Fumouze, Sur la Cantharide officinale, p. 47). 
Nous devons signaler le $T$. farinx qui a été signalé dans la farine de blé par différents auteurs, et en particulier par M. Mégnin (fig. 434).

B. $1^{\circ}$ Glyciphagus cursor (Gervais) (fig. 428, B). Caractères:

Corps grisâtre, mat, très atténué en avant, allant en s'élargissant jusqu'à l'espace compris entre la deuxième et la troisième paire de pattes et présentant, à cet endroit, un sillon circulaire très prononcé,

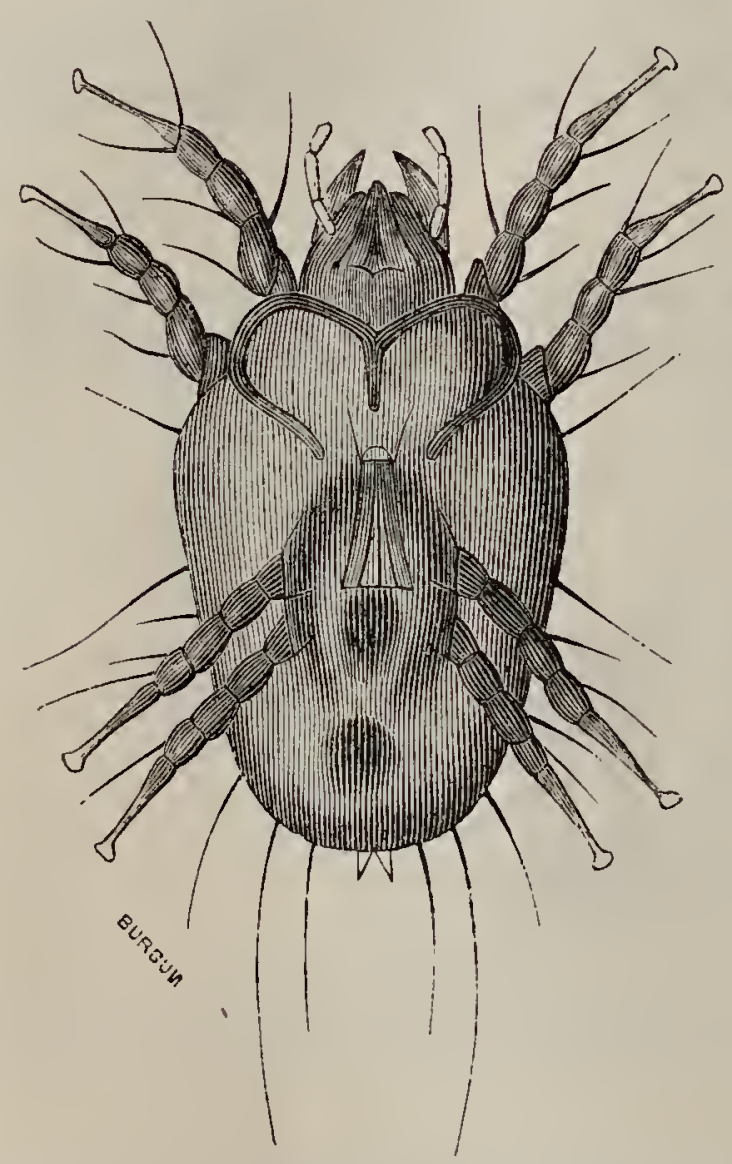

Fig. 434. - Tyroglyphus farinæ (Mégnin). sur les flancs surtout, et détachant bien l'abdomen du céphalothorax; abdomen assez gros et long, un peu resserré, arrondi, mousse en arrière, appendice médian assez long, d'aspect tubuleux, nettement tronqué, nul chez le mâle. Rostre incliné légèrement, un peu coloré, d'une teinte pelure d'oignon. Pattes semblables dans les deux sexes, effilées, grêles, très longues, les tarses surtout, mesurant chacune en longueur plus que la largeur du corps; tarses lisses, offrant quelques poils piquants, assez rigides, hérissés; les postérieurs ne dépassant pas, mais pouvant atteindre la longueur du corps. Chez le mâle, l'organe sexuel est placé au milieu du premier article de la troisième paire de paties, qu'il dépasse un peu en avant. Chez la femelle, la vulve est située entre la troisième et la deuxième paire de pattes.

OEuf régulièrement ovoïde, long de $0^{\mathrm{mm}}, 10$ à $0^{\mathrm{mm}}, 13$, large de $0^{\mathrm{mm}}, 6$ à $0^{\mathrm{mm}}, 8$.

Cette espèce a été rencontrée dans un échantillon de cantharides de France.

\section{$2^{\circ}$ Glyciphagus spinipes.}

Cette espèce a été trouvée dans différents échantillons de cantharides de France (Voir Fumouze, p. 50).

C. Genre Cheyletus. - M. Fumouze a étudié plusieurs individus appartenant à ce genre, mais il ne les a pas déterminés. 
M. Mégnin, auquel nous devons de si beaux travaux sur les Acariens, a publié dernièrement un Mémoire fort curieux sur les Cheylétides parasites, dont nous allons donner quelques courts extraits. M. Fumouze, dans la monographie que nous avons citée, avait bien remarqué que les Gheylétides avaient des mœurs tout à fait spéciales, et qu'ils ne se faisaient pas faute de saisir leurs ennemis à l'aide de leur palpe maxillaire, mais il n'avait tiré de cette observation aucune déduction. Rappelant à grands traits la division des parasites créée par Van Beneden, M. Mégnin montre qu'il y a encore place pour une quatrième classe. Van Beneden divise en effet les parasites en trois classes; il nomme commensaux ceux qui s'attachent à un animal, non pas pour vivre à ses dépens, mais pour profiter des restes de sa table; il appelle mutualistes ceux qui, vivant exclusivement des excrétions naturelles des animaux, jouent sur leur peau, ou sur leurs muqueuses, le même rôle que les chiens de Constantinople jouent dans les rues de cette ville, c'est-à-dire qu'ils exécutent un véritable travail de voirie; enfin, l'auteur fait une troisième classe avec les parasites proprement dits, c'est-à-dire avec ceux qui ont besoin, pour vivre, des humeurs qui entretiennent la propre vie de leur hôte. M. Mégnin propose de les diviser en deux sous-classes: les parasites inoffensifs et les parasites dangereux. Les Acariens ont des représentants dans chacune de ces classes. M. Mégnin a créé une quatrième division pour des parasites qu'il a appelés parasites auxiliaires. Étudiant un jour des Listrophores (acarien mutualiste qui foisonne dans les poils du lapin, en compagnie d'Ixodes, de Gamases, etc.) qu'il avait placés dans une cage de verre, M. Mégnin fut surpris de voir que deux Cheylètes qu'il y avait introduits involontairement tuaient les Listrophores, qu'ils poignardaient avecleurs petites mandibules en stylets aigus, après les avoir saisis avec leurs terribles palpes. Ils tuaient leurs victimes pour les sucer, exactement comme font les araignées des mouches, avec cette différence que les Cheylètes sont à peu près du même volume que leur proie, qu'ils ne leur tendent pas de piège et qu'ils les chassent littéralement à courre, au fond des poils du lapin, comme sous le couvert d'une épaisse forêt (Mégnin). 
On voit donc que le Cheylète est pour le lapin un véritable parasite auxiliaire, c'est-à-dire utile, puisqu'il le débarrasse des vrais parasites nuisibles. M. Mégnin a observé le même fait chez des oiseaux.

Jusqu'à ce jour, le Cheyletus eruditus avait constitué à lui seul le genre Cheyletus, mais M. Mégnin en a découvert d'au-

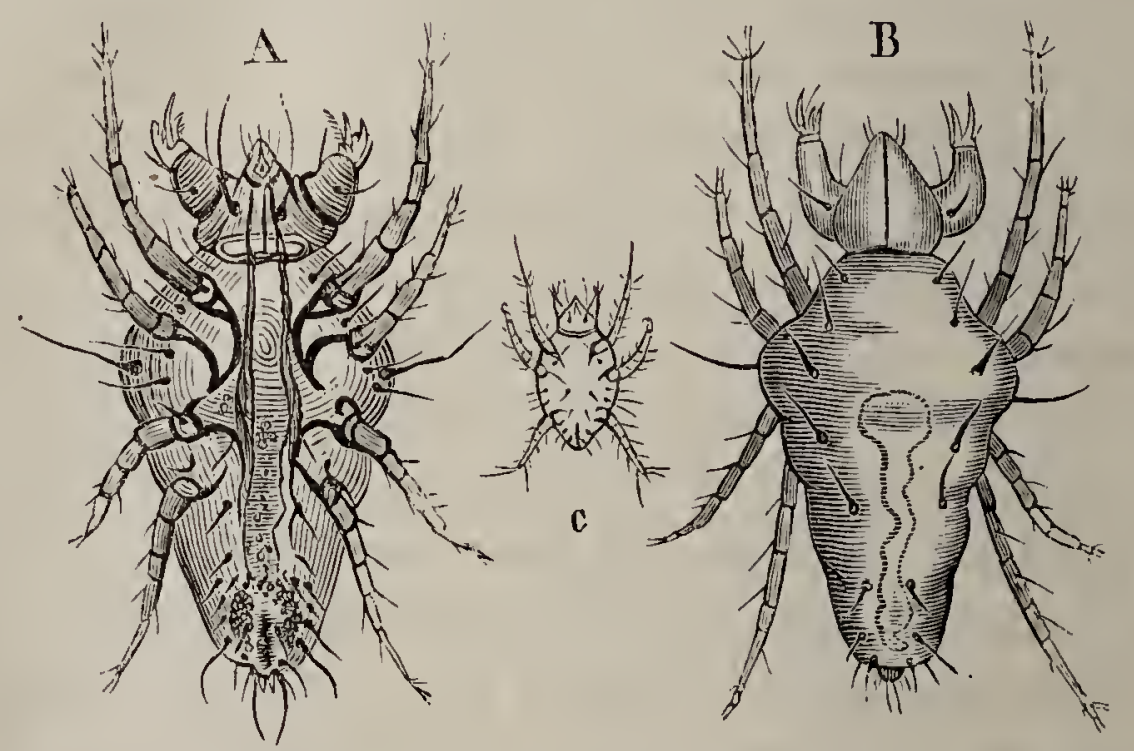

Fig. 435. - Cheyletus eruditus. - A. Vu par sa face ventrale. - B. Vu par sa face dorsale. - C. Larve hexapode du Cheyletus, vue par sa face ventrale.

tres espèces. Le Cheyletus eruditus a été ainsi nommé parce qu'on le trouve habituellement dans les vieux livres, les vieux linges, la vieille charpie, les vieilles étoupes, les fourrages altérés et moisis, la poussière des grenier's. C'est très probablement cet acarien que M. Le Roy de Méricourt avait trouvé dans le pus qui s'écoulait de l'oreille d'un marin, et auquel M. Laboulbène avait donné tout d'abord le nom de Tyroglyphus Mericourti. M. Mégnin pense qu'il y avait été introduit avec de la charpie. Jusqu'ici, l'histoire complète de cet acarien n'a pas été faite; MM. Fumouze et Robin, qui en ont fait une très bonne étude, n'ont vu que la forme octopode asexuée ou la nymphe et la larve hexapode.

M. Mégnin a fréquemment rencontré le Cheyletus eruditus, accompagné d'une nouvelle espèce à laquelle il a donné le nom de Cheyletus longipes. Parmi les Cheylètes décrits par M. Mégnin, nous signalerons les suivanls : 
$2^{\circ}$ Dans le genre Harpirhyncus:

Cheyletus parasitivorax.

- heteropalpus..

Har.irhyncus nidulans....... (Mégnin.)

macronycus...

(Pour plus de détails, lire le mémoire de M. Mégnin.)

Du Phylloxera vastatrix. - Get insecte a pris une telle importance dans ces dernières années à cause des ravages qu'il

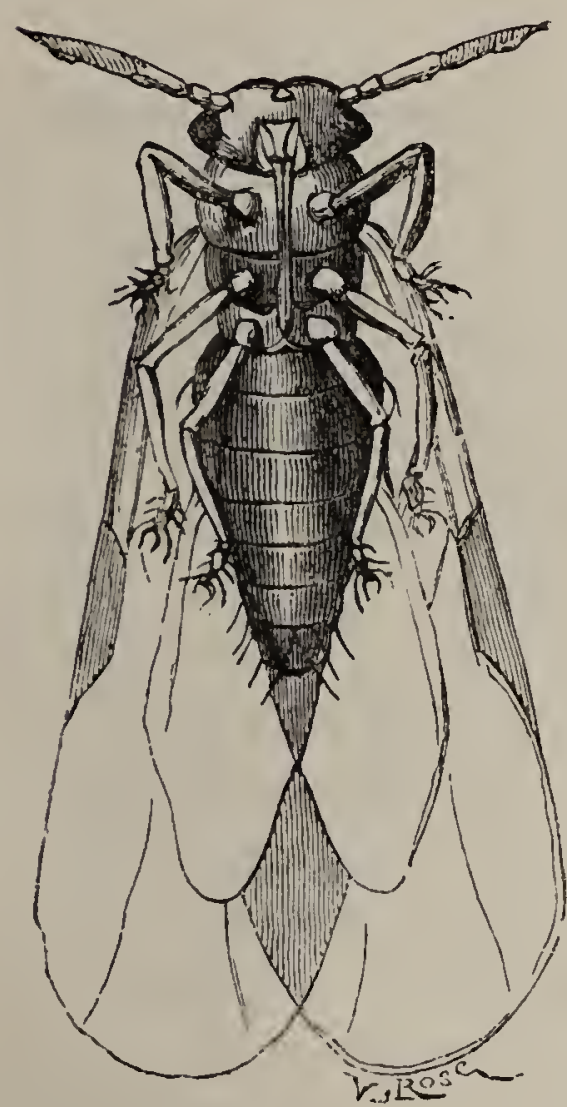

Fig. 436. - Phylloxera vastatrix ailé, vu par la face ventrale.

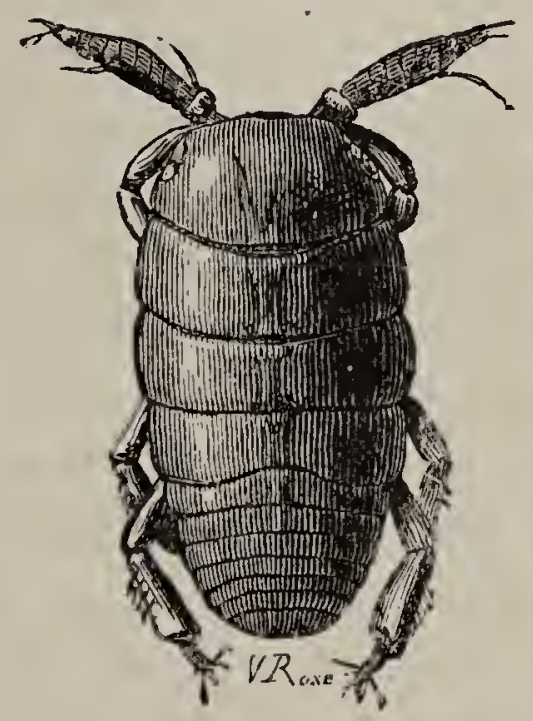

Fig. 137. - Phylloxera vasiatrix aptère, femelle.

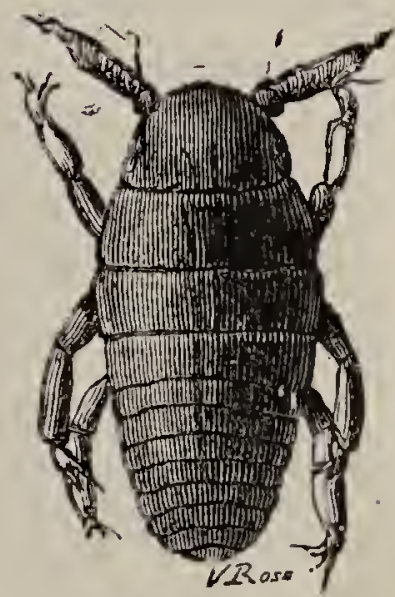

Fig. 438. - Phylloxera vastatrix aptère, femelle.

produit, et des dangers qu'il fait courir à la prospérité commerciale d'une grande partie de notre pays, que nous avons. cru devoir en donner la figure pour ceux de nos lecteurs qui habitent des pays vinicoles.

La reproduction se fait chez cet insecte avec une effrayante rapidité par des femelles aptères, sans qu'il soit besoin de fécondation. Plus tard se développent des individus ailés qui 
s'accouplent et vont, porlés par les vents, pondre au loin des œufs qui donneront naissance à d'autres phylloxeras aptères.

Pour rechercher la présence du phylloxera sur des racines de vigne, il suffit, sur des racines fraîches, d'écarter les lamelles d'écorces et, en examinant les crevasses avec une bonne loupe, on y découvre des phylloxeras de tout âge, souvent entourés d'une large zone d'œufs, fixés sur le bois dans lequel ils ont implanté leur long suçoir qui, à l'état de repos, est appliqué contre le sternum de l'insecte (Pelletan). 


\section{CHAPITRE XVII}

\section{GARAGTÉRES PRINGIPAUX DES MUGUS}

Du mucus considlépé en générar. - On donne le nom collectif de mucus, dit M. Robin, à toutes les sécrétions qui proviennent du tissu mince des membranes muqueuses et des glandes ouvertes à leur surface, tant que le produit de ces dernières n'a pas de caractères spéciaux qui lui méritent un nom particulier. Ce qui différencie les glandes, des muqueuses, c'est que la sécrétion des glandes est presque toujours intermittente, tandis que les surfaces muqueuses sécrètent constamment. C'est pourquoi, dans un certain nombre de cas, on peut obtenir le mucus sans la sécrétion glandulaire à laquelle il est ordinairement mélangé. Ainsi que l'ont dit MM. Duval et Lereboullet, le mucus est aux surfaces muqueuses ce que la desquammation furfuracée de l'épiderme est à la surface cutanée. Bien plus, quand la couche cornée de l'épidèrme n'existe pas, la peau devient identique à une muqueuse et elle donne naissance à un véritable mucus. C'est ainsi que la peau des poissons fournit rapidement, sans glandes spéciales, une quantité considérable de mucus sur toute sa surface; c'est ainsi que la peau humaine se comporte elle-même, lorsque l'épiderme, ayant été détruit ou notablement altéré, elle donne naissance à ce liquide muqueux qui suinte si abondamment dans les affections cutanées (loc. cit., p. 197 et suiv.).

Caractères principaux des mucus. - Ils sont généralement visqueux, épais, et ont une consistance filante; leur teinte est tantôt grisâtre et demi-transparente. Ils renferment un principe variant suivant leur origine, auquel on a donné le nom GUIJE DE MICROGRAPHIE. 
de mucosine. Ce principe est coagulé par l'action de certains réactifs. Les mucus, tiennent en outre, en suspension des cellules épithéliales, provenant des muqueuses qui les ont sécrétées. Sous l'influence de la moindre irritation, on voit apparaître dans les mucus, des globules blancs (mucus nasal, buccal, vésical); ils ne diffèrent pas des globules blancs ordinaires et ne méritent pas le nom spécìal qu'on leur a donné, de globules muqueux.

Les mucus peuvent renfermer des corps étrangers, tels que des granulations graisseuses, des algues, des infusoires, des vibrions. Dans le tube digestif, ils peuvent renfermer des débris de matières alimentaires (Robin, Traité des humeurs).

Caracières de la mucosine. - Quand on examine au microscope de la mucosine, ou mucine de certains auteurs, on voit qu'elle présente des stries parallèles, onduleuses, non entrecroisées, à moins qu'il n'y ait eu superposition. Sous l'influence de l'acide acétique, qui coagule la mucosine, cette striation devient très nette. Toutefois, il est utile de noter que, lorsque la mucosine s'est gonflée au contact d'un liquide, l'urine, par exemple, ces stries sont plus difficiles à apercevoir ; quelquefois la mucosine se présente à demi concrète, sous l'influence de certains troubles; ce cas se présente fréquemment pour le mucus intestinal, surtout chez les personnes ordinairement constipées; on l'a noté également dans la vessie. Le mucus concret peut alors revêtir certaines formes qui pourraient le faire confondre avec des parasites.

Rappelons ici ce que nous avons déjà dit au chapitre Sperme : la spermatine, cornme la mucosine, se gonfle au contact de l'eau, mais elle n'est pas rendue striée par l'acide acétique.

Les mucus renfermant un certain nombre de sels, il n'est pas rare que ceux-ci se déposent et forment, avec le mucus, des petits grumeaux de structure amorphe, ou renfermant quelques cristaux. C'est ainsi que le mucus nasal renferme quelquefois des rhinolithes; le mucus des voies lacrymales peut donner naissance à des dacryolithes. Ges petits calculs sont généralement de nature calcaire et ont une gangue formée de mucosine. 
Mucus nasal. - Très variable dans sa consistance et dans - sa couleur, le mucus masal est tantôt fluide, filant, tantôt il se présente sous forme de grumeaux demi-solides, conservant dans ces divers états, un certain degré de viscosité, quelquefois même un certain degré de ténacité et de résistance à la dilacération. Quand il coule très fluide, il devient absolument transparent, mais quand il augmente de consistance, sa couleur varie du gris jaunâtre au jaune verdâtre. Quand le mucus nasal présente cette dernière coloration, il le doit à la présence d'un grand nombre de leucocytes. Il n'en contient pas à l'état normal, ou du moins un nombre excessivement faible, il ne devient muco-pus que dans les cas d'inflammation de la muqueuse pituitaile. Outre les leucocytes, on rencontre encore des cellules épithéliales prismatiques, en plus ou moins grande quantité : des cellules épithéliales à cils vibratiles peuvent également être rencontrées dans le mucus nasal; elles proviennent de la muqueuse des fosses nasales, ou membrane de Schneider. On distingue en outre un grand nombre de granulations moléculaires dont l'origine, dit M. Robin, n'a pas été nettement déterminée; sous

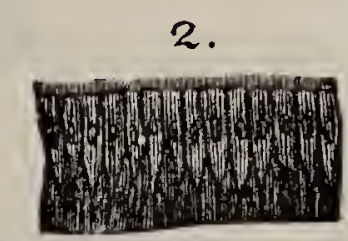

Fig. 439. - Épithéjium vibratile de Ia muqueuse de Schneider (Kölli. ker).

l'influence de l'acide acétique, le mucus nasal prend un aspect nettement strié.

Les taches produites par le mucus nasal varient de couleur suivant que celui-ci est à l'état physiologique ou pathologique; le linge peut prendre les colorations diverses que nous avons signalées plus haut. Les taches produiles par le mucus nasal donnent une certaine raideur au linge. Voici, d'après M. Gosse, la marche à suivre pour étudier les taches produites par le mucus nasal. Quand le mucus nasal peut se détacher en écailles, on met une de ces écailles sur une lame de verre avec un peu d'eau distillée. Ces fragments se gonflent au bout d'un temps variable, quinze ou trente minutes, et donnent de petites boules de mucus, épaisses, blanchâtres et transparentes. L'acide acétique donnera au mucus un aspect strié plus ou moins net; on y découvrira également des granulations moléculaires, des cellules d'épithélium cylindrique à cils vibratiles 
et d'épithélium nucléaire. Il ne faut pas perdre de vue que l'on pourra rencontrer dans les taches produites par du mucus nasal, des leucocytes, des poussières, des grains de tabac ainsi que des éléments anatomiques empruntés à un péu de mucus

A
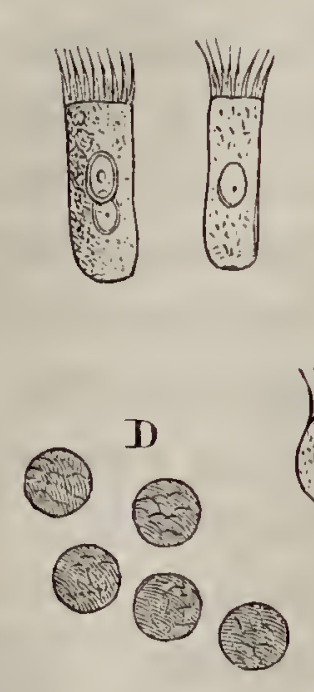
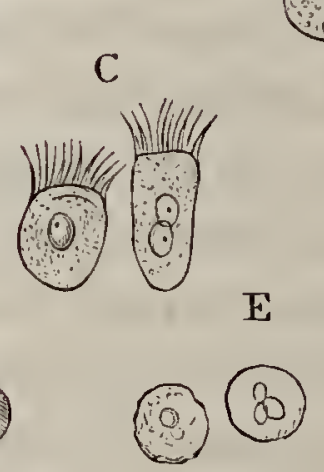

B

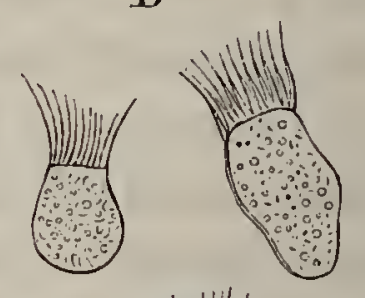

Fig. 440. - Éléments cellulaires d'un liquide de coryza aigu. - A. Cellules cylindriques ou prismatiques de la muqueuse de Schneider détachées, ayant lcurs cils vibratiles. B. Cellules déformées encore pourvues de cils. - C. Cellules ayant des noyaux. - D. Globules de pus. - E. Les mêmes, traités par l'acide acétique. - F. Globules rouges de sang. (D'après Laboulbène, Anat. Path.)

bronchique. On peut également constater la présence de poils provenant de l'orifice des fosses nasales.

Dans le cas où il n'aurait pas été possible d'enlever des écailles de mucus nasal, on revivifiera les taches en les faisant tremper pendant un temps variable dans de l'eau distillée.

Mucus lacrymal ou conjonctival. - Ce mucus est mixte puisqu'il contient à la fois le produit de sécrétion de la muqueuse conjonctivale et le produit sécrété par les glandes lacrymales. Le liquide recueilli à la surface de la conjonctive est grisâtre, transparent; au moment même où on le retire, il est incolore. L'eau le coagule, c'est une propriété très caractéristique; au contact de l'eau, il devient demi-solide et blanc comme l'albumine coagulée, avec moins de consistance (Ch. Robin).

Le mucus conjon ctival tient en suspension quelques cellules épithéliales pavimenteuses. Si la conjonctive est enflammée, il se produit de nombreux leucocytes. On remarque encore 
Chapitre XVII. - CARAGTÉRES PRINGIPAUX DES MUCUS. 709 dans le mucus conjonctival coagulé par l'eau, des granulations graisseuses isolées ou disposées en séries; ces granulations proviendraient probablement des glandes de Meibomius, d'après M. Ch. Robin.

Les larmes peuvent former sur le linge des taches encore apparentes après la dessiccation. Ces taches renferment des éléments empruntés au mucus conjonctival et aux larmes elles-mêmes. On sait en effet que les larmes renferment une proportion notable de chlorure de sodium. Les taches produites par les larmes sont en général assez petites et offrent, comme un assez grand nombre d'autres, une grande ressemblance avec les taches spermatiques. Pour les étudier, on les met en contact avec une faible quantité d'eau, et on exprime même le fragment de tissu, à l'aide d'un agitateur en verre par exemple. Après évaporation presque complète, on peut apercevoir des cristaux de chlorure de sodium, quelques cellules épithéliales, molles, friables, très granuleuses, prismatiques, plutôt que pavimenteuses, cellules qui proviennent de la glande lacrymale. Ces tachées peuvent également contenir des cils et des corps étrangers, comme des filaments d'étoffe ou des grains de poussière (Gosse, p. 42).

De la salive. - Le mucus buccal, complexe puisqu'il renferme des produits de sécrétion étrangers, est généralement alcalin. Presque toujour's mélangé à de la salive, il tient en suspension des cellules épithéliales pavimenteuses et des leucocyles. La salive mixte, éest-à-dire produite par les différentes glandes salivaires, a la propriété de donner de la transparence aux leucocytes et d'y faire apparaître des noyaux, comme s'ils avaient subi l'action de l'eau. En même temps, dit M. Robin, les granulations moléculaires qui sont dans leur intérieur offrent un mouvement brownien assez énergique, et ils cessent de présenter toute trace d'expansion sarcodique ou amébiforme. Dans certains cas, surtout quand le mucus est acide, il renferme des petits filaments de Leptothrix.

Nous ne nous occuperons ici que de la salive mixte. Lorsque, par un procédé artificiel quelconque, on excite la sécrétion salivaire, et qu'on recueille le fluide sécrété dans un verre à expériences par exemple, il ne tarde pas à se séparer en trois 
couches. La premièréest formée d'un liquidécumeux et filant; la seconde, d'une épaisseur plus considérable, est transparente et moins visqueuse que la précédente. Enfin, la troisième couche est formée par un dépôt gris blanchâtre, composé de cellules épithéliales de la bouche en grand nombre, de quelques leucocytes, de gouttelettes ou de granulations graisseuses. On y rencontre en outre des débris alimentaires venant de l'interstice des dents, tels que cellules végétales, fibres musculaires, grains de fécule, etc. D’après M. Robin, outre quelques vibrions, on y rencontrerait également des tubes de l'algue filiforme de la bouche, le Leptothrix buccalis (Ch. Robin).

Les taches produites par la salive ressemblent, au premier abord, à des taches de sperme. Tantôt blanches, tantôt jaunâtres, elles rendent le tissu qui les porte plus ou moins résistant. D'après le 1) ${ }^{\mathrm{r}}$ Gosse, quand ces taches sont revivifiées au contact de l'eau, elles exhaleraient quelquefois une odeur spermatique. Nous savons combien ce caractère est fugace. En laissant évaporer spontanément l'eau dans laquelle ont baigné ces taches, on y trouverait au microscope, d'après Donné, des cristaux sur la nature desquels on n'est pas encore bien fixé. L'élément, le plus abondant, est la cellule épithéliale, provenant de l’épithélium buccal. Nous avons déjà insisté sur la forme des cellules que l'on peut facilement étudier. Outre les leucocytes qui accompagnent les cellules épithéliales, on peut rencontrer des fragments de matière alimentaire et des corpuscules amorphes.

Du mucus laryngo-bronchique; des crachats. - Ce mucus est le produit de sécrétion des glandes qui tapissent la muqueuse laryngienne et la muqueuse trachéo-bronchique (1). Très légèrement visqueux, propriété qu'il doit à la mucosine, il est transparent et tient en suspension un petit nombre de cellules épithéliales, surtout prismatiques, et quelques rares leucocytes. A son passage dans le pharynx et dans la bouche, il s'y joint des cellules épithéliales pavimenteuses.

Dans certains cas le mucus trachéo-bronchique prend l'état concret et pourrait être confondu avec de fausses membranes

(1) V. Robin, Traité res humeurs. 
diphthéritiques. Tandis que l'acide acétique donne au mucus concret, l'aspect strié caractéristique, les pseudo-membranes diphthéritiques, comme la fibrine, prennent au contact de l'acide acétique, un aspect homogène et deviennent gélatineuses. On peut ainsi distinguer, dit M. Robin, les leucocytes, les noyaux d'épithélium, les cellules épithéliales englobées par la fibrine, au fur et à mesure qu'a eu lieu sa coagulation.

Pour l'étude des crachats nous suivrons la classification donnée par M. Robin dans son Traité des humeurs.

Crachats muqueux. - Outre le mucus, ces crachats renferment en outre des leucocytes. Ils sont plus ou moins visqueux, généralement transparents; quelquefois ils sont spumeux. Ces différents états tiennent à des modifications pathologiques de la mucosine, dans la bronchite aiguë par exemple; aussi ces éléments renferment ou non, des cellules globuleuses ou cylindriques, à cils vibratiles; ces cellules offrent un ou plusieurs noyaux. Quelquefois même les cils de ces cellules sont encore doués de mouvement. Les crachats séreux ne présentent généralement pas d'éléments anatomiques particuliers.

Crachats perlés. - Sous l'influence de légères congestions du larynx, il s'accumule dans les ventricules une certaine quantité de mucus demiconcret. Ce fait se produit surtout

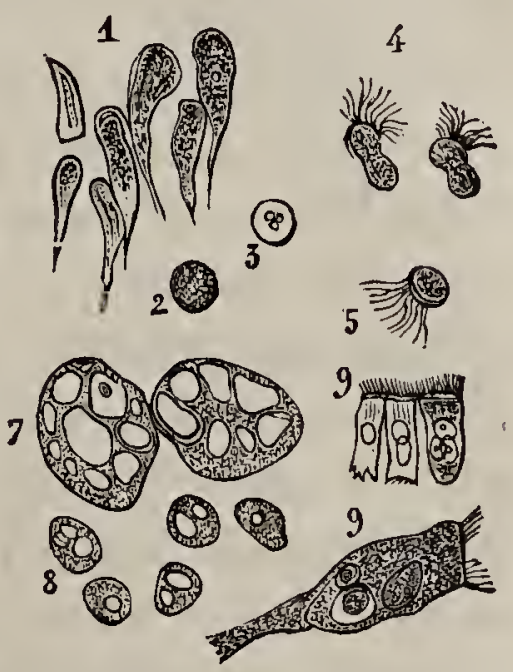

Fig. 441. - Éléments contenus dans les crachats muqueux (d'après Hérard et Cornil) dans les cas d'inflammation des voies pulmonaires. - 1. Cellules cylindriques. - 2,3 . Leucocytes. - 4. Cellules à cils vibratiles. -5 . Les mêmes devenues sphériques. - 7 et 8. - Cellules en voie de dégénéreseence muqueuse, hydropiques, présentaut plusieurs cavités centrales. -9 . Cellules cylindriques à noyaux multiples. lorsque l'on a longtemps parlé, et il faut faire un hem plus ou moins énergique, pour s'en débarrasser. On rend ce mucus concret sous forme de petites boules bleuâtres, quelquefois légèrement colorées en rouge par des hémorrhagies superficielles. Il n'est pas rare de voir ces crachats perlés complètement colorés en noir, par du noir de fumée ou d'autres particules colorées. Le mucus demi-concret qui constitue ces 
crachats, englobe des granulations graisseuses, des noyaux libres d'épithélium, avec ou sans nucléole et toujours des cellules épithéliales plus ou moins régulières, isolées ou réunies en lamelles pavimenteuses ou sphériques, contenant des granulations graisseuses, ou des granulations de noir de fumée. Les leucocytes qui contiennent ces crachats perlés sont plus ou moins granuleux et parfois contiennent des granulations de charbon. Pour s'assurer, dit M. Robin, que ces granulations sont bien du noir de fumée, il suffit de traiter la préparation par de l'acide sulfurique, qui gonfle les cellules épithéliales, les rend pâles et dissout toutes les granulations, excepté les granulations de noir de fumée. Ces molécules de noir de fumée sont d'autant plus abondantes que l'on est resté plus longtemps dans une pièce où il y a des lampes fumeuses, ou des veilleuses.

Crachats rouillés de la pneumonee. - A l'état normal les alvéoles du poumon ne fournissent rien à l'expectoration, mais quand il $y$ a des foyers de congestion ou d'inflammation, il se produit dans le poumon un mucus particulier qui se mêle au mucus bronchique. Ces crachats doivent leur couleur plus ou moins rougeâtre aux hématies qu'ils renferment; à côté des hématies il y a une quantité variable de leucocytes.

Crachats purulents. - Nous insisterons peu sur cette variété de crachats; ils présentent des caractères cliniques particuliers, précieux à noter, pour l'étude desquels nous renvoyons à l'ouvrage de M. Robin. Un simple examen microscopique fait aisément reconnaître leur nature.

Crachats nummulaires. - Ces crachats sont considérés. comme un des signes de la phthisie. Leur nom fait pressentir leur forme. Ge sont des masses puriformes, à bords arrondis et circulaires et d'égal diamètre. Généralement isolés les uns des autres, ces crachats surmontent un mucus plus ou moins visqueux.

Il n'est pas rare de trouver dans ces crachats des débris de fibres élastiques recourbées sur elles-mêmes et provenant du parenchyme pulmonaire qui se détruit et donne naissance aux cavernes creusées aux dépens du tissu pulmonaire. Les fibres élastiques résistent au travail de mortification. MM. Du- 
val et Lereboullet conseillent de traiter ces crachats par la soude caustique ou l'ammoniaque. Le mucus devient transparent et les fibres apparaissent. On les reconnaît à leur forme ondulée en spirale, à leur double contour, à leur résistance aux réactifs, enfin à leur coloration sous l'influence du rose d'aniline (p. 301).

Parfois ces fibres élastiques, au lieu d'être isolées, forment des faisceaux de fibres entre lesquels, on peut apercevoir les éléments qui caractérisent la fonie ulcéreuse du parenchyme pulmonaire, ce sont des débris de vaisseaux oblitérés, et surtout une grande abondance de corpuscules granuleux, ayant la forme et le caractère des globules de pus, d'autres plus petits déformés, quelques-uns infiltrés de granulations noirâtres, d'autres enfin presque globulaires renfermant quelque-

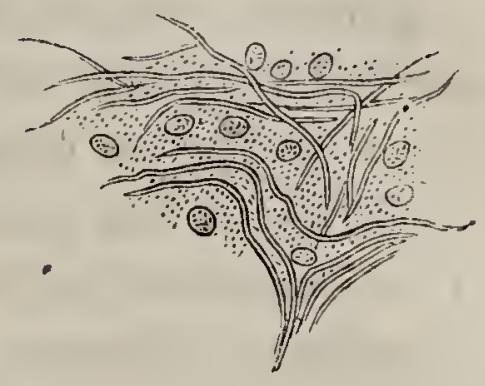

Fig. 442. - Fibres élastiques et globules de pus ratatinés provenant de l'expectoration d'un phthisique. fois des cristaux d'hémato-cristalline (Duval et Lereboullet).

Crachats fétides. - Dans la gangrène pulmonaire, l'haleine et les crachats du malade prennent une odeur fétide si caractéristique, qu'on ne peut s'y méprendre, lorsqu'une fois déjà on l'a perçue. La couleur de ces crachats varie du blanc laiteux au jaune verdâtre et du jaune verdâtre à la couleur chocolat. Dans le premier cas, ils contiennent des grauulations graisseuses et des leucocytes; quand le nombre des leucocytes augmente, ils deviennent jaune verdâtre. Aux globules blancs peuvent se joindre des débris de parenchyme pulmonaire. Si ces crachats renferment du sang, ils peuvent prendre une coloration chocolat ou acajou. On y trouve également des fragments microscopiques de tissu pulmonaire. Ces crachats exhalent une odeur de matière animale putréfiée d'une fétidité extrême.

A l'article Sperme nous avons démontré par une observation de M. Brouardel, à quels caractères on pouvait reconnaître des taches produites par' des crachats. Qu'on n'oublie pas que l'on peut rencontrer dans ceux-ci, outre des débris de matières alimentaires, des grains de tabac et du sperme. 
Des cristaux que l'on peut rencontrer dans les crachats. Chlorure de sodium, aurait été quelquefois rencontré dans les crachats des pneumoniques, sous forme de cristaux cubiques.

Cholestérine. - A été rencontrée rarement.

Margarine. - Aurait été observée sous forme d'aiguilles très fines, formant des réseaux très élégants, solubles dans l'éther. Ces cristaux seraient surtout fréquents dans les crachats fétides.

Leucine et Tyrosine. - Ces deux substances peuvent se rencontrer à l'état cristallisé dans l'expectoration des phthisiques et daris la gangrène pulmonaire.

Cristaux ron encore déterminés. - Leyden a signalé dans l'asthme bronchique, d'après Duval et Lereboullet, des cristaux incolores, brillants, formant une pyramide double, peu refringents, se brisant facilement, insolubles dans l'eau froide, solubles dans l'eau bouillante, résistant à l'éther, à l'alcoool, solubles dans l'acide acétique, l'acide tartrique, l'acide phosphorique: Ces cristaux ont déjà été signalés par Charcot et Vulpian (Gaz. hebd., 1860).

Oxalate de chaux. - Outre les cristaux précédents, on a trouvé dans les crachats de l'asthme bronchique, des cristaux d'oxalate de chaux, seulement, tandis que ces premiers étaient permanents, les seconds étaient transitoires, et n'étaient pas accompagnés d'oxalurie (Archiv. für Klin. méd. t. XXI, p. 435, et Gaz. hebd., 20 septembre 78).

Pour les parasites que l'on peut rencontrer dans les crachats, voir le chapitre consacré aux parasites. 


\section{CHAPITRE XVIII}

DES MATIERES VOMIES, OU PROJETÉES SEULEMENT EN DEHORS DE LA GAVITÉ BUGGALE (STRANGULATION) ; DES SUBSTANGES ALIMENTAIRES, OU TOXIQUES, QUE L'ON PEUT TROUVER DANS L'ESTOMAC.

L'examen des vomissements (1) peut fournir des renseignements précieux au clinicien et au médecin légiste. Les vomissements d'un malade peuvent éclairer le diagnostic et dans un cas d'empoisonnement, non seulement ils peuvent faire connaître immédiatement la nature du poison, s'il s'agit par exemple d'un fruit toxique, mais encore servir à le déceler microscopiquement, ou avec l'aide de la chimie.

Outre les vomissements provoqués par des substances toxiques, il peut s'en produire par l'efret de causes diverses. Sous l'influence de maladies inflammatoires de la muqueuse stomacale, on peut voir se produire des vomissements spumeux et filants, presque uniquement formés de salive et de mucus stomacal. On y trouve quelques rares leucocytes, des cellulesépithéliales pavimenteuses (provenant de la bouche), ainsi que des cellules globuleuses infiltrées de granulations et présentant un large noyau périphérique; ces cellules (Duval et Lereboullet) paraissent provenir des canalicules des glandes salivaires.

L'acide acétique donne difficilement au mucus l'aspect strié caractéristique.

Lorsque l'estomac a subi une action locale violente, comme dans l'empoisonnement par la teinture de cantharides, par exemple, les vomissements qui suivent l'ingestion du poi-

(1) Voy. Duval et Lereboullet, p. 239. 
son sont tellement visqueux, que l'on peut pour ainsi dire les détacher du sol sans les diviser. L'alcool seul peut, en provoquant une gastrite aiguë, donner naissance à des vomissements muqueux présentant les mêmes caractères.

Vomissements cholériques. - Ils sont ordinairement très séreux et fluides. Ils contiennent des grains riziformes et quelques flocons de mucus. Les granulations riziformes renferment quelques leucocytes agglutinés par le mucus et un assez petit nombre de cellules épithéliales déformées granuleuses, infiltrées de graisse. On trouve également des cellules paraissant provenir de l'épithélium de la muqueuse stomacale, en voie de dégénération granulo-graisseuse, ainsi que des granulations, les unes protéiques, les autres graisseuses, ainsi que des parasites.

Vomissements alimentaires. - On comprend combien peut être grande, la variété des substances introduites dans l'estomac que l'on peut retrouver dans les vomissements. Les connaissances acquises en anatomie végétale et animale, permettront de reconnaître les substances ingérées. La difficulté sera d'autant plus grande que les aliments auront séjourné plus longtemps dans l'estomac; quand les matières auront été vomies aussilôt après leur ingestion, elles auront conservé des caractères propres à les faire reconnaître. Les fibres musculaires striées résisteront d'autant moins qu'elles auront été préalablement soumises à une cuisson moins complète; ordinairement elles sont facilement reconnaissables. Les végétaux, l'amidon, résistent plus longtemps à l'action du suc gastrique; il en est de même de l'albumine coagulée. Simplement maintenus à l'état de fusion dans l'estomac, les corps gras reprennent par le refroidissement leur consistance normale. Les élytres de la cantharide, quand elles ne sont pas très finement pulvérisées, résistent à l'action du suc gastrique et peuvent être reconnues à leurs reflels particuliers. Si l'insecte a été grossièrement pulvérisé, on peut même reconnaître des fragments d'antennes ou de pattes. Dans un cas d'empoisonnement par un fruit vénéneux, celui de la belladone, par exemple, il sera possible de reconnaître la nature du fruit et de diriger plus sûrement la médication. M. L. Bruneau aurait 
trouvé dans des vomissements d'une femme urémique, de la tyrosine, sous forme de longues aiguilles brillantes et réunies en amas.

Si l'on peut reconnaître facilement un certain nombre de substances alimentaires, il en est cependant dont les caractères sont tellement modifiés par la cuisson qu'ils deviennent difficiles à.retrouver et qu'il est besoin d'une grande expérience, unie à beaucoup de sagacité, pour arriver à une détermination certaine. Nous recommandons dans ce cas de toujours procéder par comparaison et d'éclairer le résultat de l'examen microscopique, par celui de la substance que l'on pense avoir retrouvée.

Vomissements bilieux et fécalöides. - Les vomissements bilieux se reconnaissent surtout par l'action des réactifs chimiques propres à déceler soit les acides biliaires, soit les matières colorantes de la bile. Quelquefois ces vomissements renferment des calculs biliaires (v. page 483), rarement des cristaux de Taurine (v. page 474).

Dans certains cas d'étranglement interne, ou lorsque des matières fécales ont été ingérées (aliénation mentale, hystérie), on peut avoir des vomissements renfermant des matières fécales. Sauf dans le second cas, les matières fécales ne sont presque jamais solides; ordinairement, elles ont une consistance pâteuse ou demi-liquide; elles renferment des débris de matières alimentaires incomplètement digérées. Leur odeur spéciale met également sur la voie du diagnostic. Ces vomissements peuvent également contenir des cellules prismatiques agglutinées formant par leur agglomération une masse qui simule une coiffe de villosités intestinales et qui suffisent, d'après MM. Duval et Lereboullet, pour faire supposer que des matières provenant de l'intestin grêle, ont été évacuées par le romissement.

Vomissements sanguins. - Lorsque le sang est vomi pour ainsi dire à l'état de pureté, sa détermination n'offre aucune difficulté. D'autres fois, au contraire, le sang n'est vomi qu'après avoir séjourné un certain temps dans l'estomac, il a alors une coloration variant entre la couleur chocolat et celle de la suie. L'examen microscopique permet toujours de retrou- 
ver des globules plus ou moins profondément altérés, ains que des filaments fibrineux. Outre ces éléments appartenant au sang, on peut trouver des débris de substances alimentaires. Lorsqu'il y a dans l'estomac des ulcérations cancéreuses, ou non, on peut retrouver des cellules caractéristiques appartenant à la muqueuse stomacale.

Vomissements purulents. - Il arrive assez fréquemment que des malades atteints d'abcès de l'arrière-gorge, avalent involontairement une certaine quantité de pus

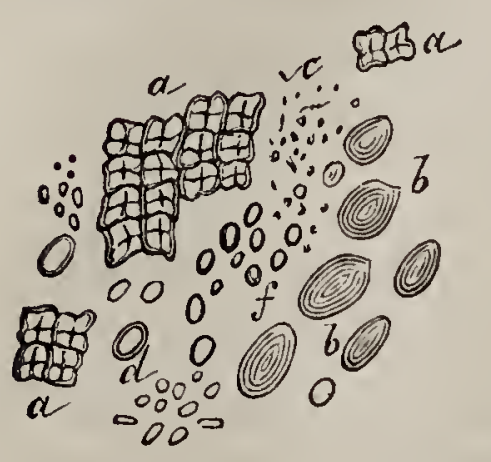

Fig. 443. - Produits de vomissements (d'après L. Beale). - a. Sarcine. b. Grains d'amidon. $-c$. Vibrioniens. - $d$. Sporules diverses. - $f$. Gouttes de graisse. qu'ils vomissent ensuile. L'examen microscopique n'offre aucune difficulté; il en est de même quand le pus a sa source dans l'estomac même (v. Pus).

Parasites des vomissements. - On en rencontre un assez grand nombre dans les matières : vomies comme ils ont déjà été décrits dans ce manuel, nous ne ferons que les signaler. La Sarcine y a été rencontrée, ainsi que l'Oïdium du muguet, le Leptothrix buccalis, des Torulacées. Enfin les vomissements peuvent renfermer un grand nombre de bactéries.

Substances toxiques que lon pent retrouver dans les romissements. - Quelquefois, dans les empoisonnements, surtout quand ils sont volontaires, on peui trouver des fragments de la substance toxique employée. C'est ainsi que l'on a trouvé dans les matières vomies soil des fragments d'acide arsénieux, soit des cristaux de sels toxiques. L'analyse chimique devra toujours corroborer l'examen microscopique. On trouvera sur l'examen chimique des vomissements des renseignements utiles dans le livre de MM. Mathias Duval et Lereboullet, ainsi que dans la partie chimique de l'ouvrage de Briand et Chaudé, due à notre savant maître M. Bouis. On comprendra sans peine combien il est important d'être familiarisé avec la forme cristalline que peuvent affecter les substances toxiques.

Des matières recueillies directement dans l'estomac. Dans une autopsie médico-légale, on peut être appelé à se prononcer sur la nature des substances contenues dans l'estomac. 
Il ne nous est pas possible d’énumérer toutes les substances que l'on peut rencontrer, et nous rappelons les conseils que nous avons donnés plus haut. L'exemple que nous donnons ci-après, montrera combien ces recherches sont délicates et avec quelle prudence clles doivent être conduites.

On verra que dans l'observation suivante, due à l'obligeance de M. G. Pennelier, du Muséum de Rouen, l'analyse microscopique a été faite d'une façon très remarquable et que le savant expert a contrôlé chacun de ses résultats.

\section{RAPPORT I}

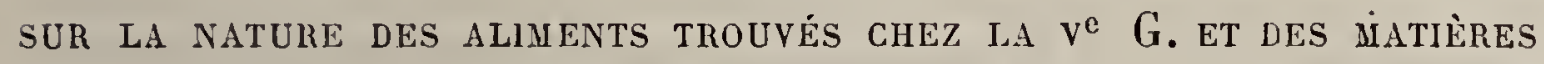
RECUEILLIES DANS SON ESTONAC.

Nous soussigné, Georges Pennetier, docteur en médecine, demeurant à Rouen, etc., etc., chargé de déterminer la nature des aliments trouvés chez la veuve G. et des matières recueillies dans son estomac, en avons reçu deux flacons et nous sommes transporté dans notre laboratoire du Muséum d'histoire naturelle, où nous arons procédé aux recherches et aux observations microscopiques nécessaires.

Examen du contenu du facon $n^{0} 2$. - Les aliments trouvés chez la veuve $G$. et contenus, dans le flacon $\mathrm{n}^{\circ} 2$, consistent dans un mélange d'une notable quantité d'oseille avec une très faible proportion de viande et un fragment de, salsifis, provenant de la partie du collet.

L'examen microscopique de ces matières dont il est d'ailleurs facile de constater la nature à l'œil nu, ne laisse aucun doute à cet égard.

Examen du contenu du flacon $n^{0}$ 1. - L'observation à l'œil nu des matières recueillies dans l'estomac et contenues dans le flacon $n^{\circ} 1$, permet d'y soupçonner la présence d'une très grande quantité d'oseille, de quelques fragments de salsifis, provenant de la partie infërieure du collet et d'une notable quantité d'un fruit pulpeux, tel que la pomme ou la poire.

Une vingtaine de préparations microscopiques, faites dans le but de contrôler ce premier aperçu et de le compléter, s’il y avait lieu, a fourni les résultats suivants (ces préparations ont été conservées et mises à la disposition de la justice):

l'examen d'un fragment d'épicarpe, attenant à la partie calicinale du fruit et que son aspect plus ou moins fortement coloré, indique manifestement avoir été cuit devant le feu, permet de reconnaitre la présence de petites cellules rectangulaires, granuleuses, incolores ou plus ou moins colorées en jaune, jaune rouge et rouge brun, 
accolées les unes aux autres sans solution de continuitć et mesurant de $0^{\mathrm{mm}}, 01933$ à $0^{\mathrm{mm}}, 022$ ' dans leur grand diamètre et de $0^{\mathrm{mm}}, 0096$ à $0^{\mathrm{mm}}, 0192$ dans leur petit diamètre (Voir les préparations 2,,, 10 et 12 bis). (Collection du Muséum de Rouen.)

Les deux dernières ont été prises dans la partie calicinale et $l a$ préparation 12 bis contient plusicurs agglomérations de cellules pierreuses dont les parois épaisses sont creusées de canalicules dirigés de la cavité centrale vers la surface.

Les neuf préparations éliquetées $n^{\circ} 1$, proviennent de la partie pulpeuse située à la face inférieure du fragment d'épicarpe sus-décrit. Elles permettent de reconnaitre:

$1^{\circ}$ La présence de cellules polyédriques accolées mais facilement isolables, à parois extrêmement minces et dont les arêtes plus ou moins accidentées et en rapport avec la compression réciproque des cellules, des espaces polygonaux. Ces cellules, dont le grand diamètre de $0^{\mathrm{m} \text { ın }}, 096$ à $0^{\mathrm{mm}}, 176$ et le petit diamètre de $0^{\mathrm{mm}}, 08$ à $0^{\mathrm{mm}}, 144$, présentent toutes, un certain nombre de replis et contiennent des granulations jaunes plus ou moins foncées, agglomérées par places.

$2^{\circ}$ Des faisceaux vasculaires;

$3^{\circ}$ Des tubes cloisonnés provenant du mycélium de champignons microscopiques et dus probablement à un commencement de pourriture du fruit;

$4^{\circ}$ De nombreux grains d'amidon de blé intacts, ou légèrement allérés ou gonflés, colorables en bleu par l'iode et reconnaissables à leur forme circulaire ou lenticulaire, ainsi qu'au diamètre des plus gros, mesurant de $0^{\mathrm{mm}}, 04$, à $0^{\mathrm{mm}}, 05$.

Un fragment végétal isolé, d'aspect charnu et du volume d'une petite noisette, a été trouvé composé de cellules, absolument semblables à celles des préparations précédentes, mais d'un diamètre plus considérable et à granulations non colorées; provenant, par conséquent d'une partie du mésocarpe plus profondément située et n'ayant pas subi l'action directe du feu. Ces cellules dont les dimensions atteignent jusqu'à $0^{\mathrm{mm}}, 368$ sur $0^{\mathrm{mm}}, 2566$, sont les unes arrondies, les autres plus" ou moins allongées, d'autres enfin, rectangulaires et rétrécies en forme d'onglet, à l'une de leurs extrémités, suivant le mode de compression réciproque qu'elles ont éprouvé. Ces cellules parenchymateuses sont accompagnćes de nombreux granules d'amidon de blé (Voir les deux préparations $n^{\circ} 3$ ).

La préparation $n^{\circ} 8$, faite avec un fragment de nature évidemment végétale, aplati et d'aspect corné, est composé de longues fibres à cloisons très rapprochées et d'un diamètre de $0^{\mathrm{mm}}, 0096$. Ces fibres, qui sont disposées en plusieurs couches superposées, sont parallèles entre elles dans la mème couche et s'entrecroisent avec celles des couches sous-jacentes.

Elles correspondent manifestement à l'endocarpe du fruit dont nous avons ainsi retrouvé les différentes parties constituantes, épicarpe, mésocarpe et endocarpe. 
L'examen d'un débris végétal, rappelant un morceau de salsifis et formé d'une couche filandreuse, formée de faisceaux isolables, à laquelle adhère un petit fragment pulpeux a montré les éléments anatomiques suivants : faisceaux vasculaires, dans lesquels dominent les vaisseaux rayés (partic filandreuse), cellules polyédriques, contiguës, arêtes peu tranchées, remplies de granulations également disséminées et mesurant de $0^{\mathrm{mm}}, 0$ วั2 2 à $0^{\mathrm{mm}}, 11$, dans leur grand diamètre et de $0^{\mathrm{mm}}, 0573$ à $0^{\mathrm{mm}}, 066$ dans leur petit (partie pulpeuse). Ces cellules sont accompagnées de granules d'amidon de blé (Voir les préparations 4 et 4 bis).

Les débris de feuilles que contenait également, bien qu'en minime partie, l'estomac de la veuve G., sont composés de faisceaux, de trachées déroulables, circulant au milieu de cellules d'un vert jaunâtre.

Un grand nombre de grains d'amidon de blé, se rencontre encore dans cette préparation. (Voir la préparation $n^{\circ} 6$, et la comparer à celle $\mathrm{n}^{\circ} \cdot 10$, faite avec de l'oseille cuite pour servir de terme de comparaison.)

Enfin, au nombre des matières alimentaires sus-désignées, se trouve un fragment d'épiderme végétal, à l'une des faces duquel adhère une mince couche pulpeuse et qui parait brûlé en certains points. A l'observation microscopique, la partic superficielle apparait composée de cellules polyédriques, dont les parois épaisses, sont formées de plusicurs couches superposées. Ces parois ont une épaisseur variant de $0^{\mathrm{mm}}, 013$ a $0^{\mathrm{mm}}, 016$ et circonscrivent des mailles de $0^{\mathrm{mm}}, 03$ à $0^{\mathrm{mm}}, 04$. La partic pulpeuse est formée de grandes cellules, les unes arrondies et les autres polyédriques, à surface totalement recouverte de marbrures. Ces cellules dont les dimensions varient. dans les limites suivantes : grand diamètre de $0^{\mathrm{mm}}, 8$ à $0^{\mathrm{mm}}, 16$; petit diamètre, de $0^{\mathrm{mm}}, 048$ à $0^{\mathrm{mm}}, 096$, sont colorables en bleu par l'iode mais ne contiennent aucun grain de fécule distinct. Ces caractères physsiques, microscopiques et microchimiques sont ceux que présente la pomme de terre cuite sous la cendre. Au milieu de la préparation qui a été conservée et qui porte les numéros 7 et 7 bis, on remarque, comme dans les précédentes, des grains intacts d'amidon de blé.

\section{CONCLUSIONS.}

L'examen de la portion d'aliments recueillis dans l'estomac de la veuve $G$. et renfermée dans le flacon $n^{\circ} 1$ y fait donc reconnaitre :

$1^{\circ}$ Une notable proportion de pomme cuite. L'extrême rareté, des cellules pierreuses qui n'ont été rencontrées que dans une seule préparation correspondant à la partie calicinale, ne permet pas de confondre les cellules parenchymateuses sus décrites avec celles de la poire qui présentent cependant avec elles une grande analogie. Les cellules pierreuses qui, par leur accumulation, forment les grains durs 
des poires, ne sont pas localisées à la partie calicinale mais disséminées dans la pulpe.

$2^{\circ}$ De la pomme de terre cuite, également devant le feu, ce que prouvent les parties carbonisces de la surface.

$3^{\circ}$ De l'amidon de blé, non cuit et presque inaltéré.

$4^{\circ}$ De l'oseille, en très faible quantité.

$7^{\circ} \mathrm{Du}$ salsifis en très faible proportion.

De là, je conclus :

$1^{\circ}$ Que la femme G. a dù manger à une heure assez éloignée de sa mort, les aliments contenus dans le flacon n 2 . Ces dernier's sont, en effet, en grande partie digérés : la viande totalement dissoute par le suc gastrique fait défaut; or, il résulte des expériences de M. Beaumont, que les viandes bonillies, sont digérées en quatre heures, l'oseille ne se retrouve qu'en minime proportion et le fragment de salsifis qui a résisté au travail de la digestion, est surtout composé des parties de la racine les plus réfractaires.

$2^{\circ}$ Que l'ingestion de la pomme de terre, de la pomme et de l'amidon de blé, doit correspondre à un moment beaucoup plus rapproché de la mort. Les cellules de pomme de terre et de pomme n'offrent, en effet, ainsi que leur contenu, aucune différence avec les mèmes parties de la pomme de terre et de la pomme cuiles, pour servir de terme de comparaison (voir préparation no 22) et, les granules d'amidon de blé sont encore presque tout intacts.

$3^{\circ}$ Que la femme G. n'a certainement pas fait usage à son dernier repas, des aliments recueillis chez elle et contenus dans le flacon $11^{\circ} 2$.

En foi de quoi, nous avons signé le présent rapport que nous déclarons fait en honneur et conscience.

Rouen, le 27 mai 1878.

\section{G. Pennetier.}

\section{RAPPORT II}

RAPPORT SUR LA NATUKE DES TACHES TROUVÉES SUR UNE PORTE VITRÉE ET UN MONTANT DE GETTE MÊHE PORTE, SAISIS AU DOMIGILE DES INGULPÉS.

Nous soussignés, Georges Pennetier, docteur en médecine demeurant à Rouen, etc., etc., et Jules Clouet, expert chimiste, demeurant en cette même ville, etc., certifions que, en vertu d'une commission de M. Francis Gougeon, juge d'Instruction près le tribunal civil de Rouen, en dute dư 4 avril 1878, serment préalablement prêté de remplir le mandat qui allait nous être confié en honneur el conscience, 
Nous avons procédé à l'examen de deux pic̀ces à conviction, saisies par la justice à la Neuville-champ-d'Oissel, le 3 avril dernier, au domicile des époux H., inculpés d'assassinat.

Ces pièces consistent en une porte vitrée et un montant en bois, et nous avons pour mission de rechercher si les taches que l'on trouve sur ces objets, n'étaient pas constituées par des débris humains et spécialement par du tissu musculaire.

Lors du transport de la justice, auquel l'un de nous assistait, ces taches étaient molles, s'aplatissaient sous la pression du doigt et offraient une teinte jaune rougeâtre, plus ou moins foncée. Elles ont une épaisseur variable et semblent avoir été faites par une matière projetée.

Nous avons extrait pour la soumettre à l'examen microscopique, une portion de ces taches qui étaient en grande partie desséchées et offraient plus de consistance que le jour de la saisie.

Ces taches ont donné lieu à cinquante préparations microscopiques qui ont été conservées et restent à la disposition de la justice, avec la partie réservée pour une autre expertise s'il y a lieu.

Examen de la porte vitrée. - Cette porte qui a $1^{\mathrm{m}}, 9$ ä de hauteur et s'ouvrait de la cuisine dans la chambre à coucher, offre à considérer: 10 Une face peinte en blanc, donnant dans la chambre, portant la serrure et recouverte d'un rideau blanc ; $2^{\circ}$ une face peinte en grisbrun, correspondant à la cuisine et munie de la poignée de la clanche.

Nous n'avons rien trouvé sur la première qui soit de nature à attirer l'attention; les taches que nous avions it examiner sont ioutes situées sur l'autre face.

Elles siègent sur la boiserie et sur les vitres. On leș trouve sur la traverse horizontale supérieure, à $0^{\mathrm{m}}, 10$ du bord libre; sur le montant vertical, au-dessus de la clanche, à vingt, trente-huit, quarante, quarante-cinq, et cinquante centimètres de haut et sur les deux carreaux supérieurs.

La traverse supérieure porte une tache qui a donné lieu à cinq préparations microscopiques. Elles sont toutes composées de cellules polyédriques, plus ou moins régulières, accolées mais facilement isolables par une légère pression, de dimensions diverses, mesurant fréquemment en diamètres $0^{\mathrm{mm}}, 176$ ou $0^{\mathrm{mm}}, 224$ : ces cellules, à parois extrêmement minces, présentent des replis et des granulations agglomérées par places, jaunes plus ou moins foncées. Elles proviennent du mésocarpe d'un fruit pulpeux, tel que la pomme ou la poire.

Indépendamment de ces cellules et de quelques faisceaux vasculaires, on ne rencontre sur cette tache que deux ou trois grains d'amidon de blé, autant de grains de pollen, et un brin de duvet d'oiseau (Voir les préparations $n^{\circ} 13$ ).

Les taches, situées à $20,38,40$ et 4 š centimètres de la limite supérieure du montant, sont composées des mêmes éléments, sauf, le 
duvet, et dans des proportions semblables. A ces derniers sont joints quelques débris calcinés provenant de la partie superficielle du mésocarpe. Ces taches ont donné lieu aux vingt préparations numérotées, $15,16,17$ et 18 .

A cinquante centimètres de la traverse supérieure, se trouve une tache à laquelle correspondent huit préparations composées des mêmes éléments cellulaires, souvent un peu plus foncés, auxquels sont joints des faisceaux vasculaires et de nouveaux débris calcinés. Comme précédemment on ne rencontre qu'exceptionnellement quelques grains d'amidon de blé ou de pollen et quelques fragments de duvet (Voir les préparations 14 et 14 bis.)

Mais sur la préparation numérotée, 14 bis, on voit à côté des éléments précédents et de quelques débris brûlés, un groupe de trois cellules pierreuses dont le grand diamètre mesure $0^{\mathrm{mm}}, 048$ et dont les parois épaisses sont canaliculées.

Enfin le carreau supérieur voisin, porte également des taches dont quelques-unes sont saillantes mais un plus grand nombre sans saillie et, paraissant résulter de la dessication d'une substance liquide; elles sont formées des mêmes cellules parenchymateuses isolées ou réunies, de faisceaux vasculaires semblables, de quelques grains de pollen et de rares granules d'amidon de blé (Voir les préparations portant le n. 18).

Examen du montant isolé. - Cette pièce correspondant du côté de la cuisine, au montant de la porte vitrée mesure deux mètres de longueur, sur neuf centimètres de largeur et trois d'épaisseur. Elle est recouverte sur sa face libre par une couche de peinture identique à celle de la porte.

Les taches qu'elle présente se trouvent à vingt, soixante-quinze, quatre-vingt, et quatre vingt-cinq centimètres de l'extrémité supérieure.

Ces taches sont exclusivement composées des mêmes éléments que celles de la porte vitrée, à l'exception toutefois des cellules pierreuses, mais on y rencontre une plus grande proportion de débris carbonisés. L'amidon de blé y est également fort rare (Voir les 20 préparations numérotées 20 et 21).

\section{CONCLUSIONS.}

De cés observations nous pouvons conclure :

$1^{\circ}$ Que ces taches ne sont pas dues à du tissu musculaire, ni à aucun autre tissu de nature animale.

$2^{\circ}$ Qu'elles sont principalement produites par de la pomme cuite. La rareté des cellules pierreuses que nous n'avons trouvées qu'au nombre de trois et dans une seule préparation empêche de confondre les cellules parenchymateuses observées avec celles de la poire. Ces cellules pierreuses doivent être rapportées à la région calicinale 
du fruit, seule partie de la pomme qui présente cet élément anatomique. Enfin, les fragments calcinés et les cellules parenchymateuses, fortement colorées, rencontrées dans un certain nombre de taches, indiquent suffisamment que le fruit a été cuit devant le feu.

3. Qu'indépendamment de la pomme cuite, les taches contiennent, en faible proportion, des grains d'amidon de blé et de pollen de fleur.

N. B. Une série de préparations, faites avec de la pomme cuite (Voir préparations n. 22) a été jointe à celles qui sont relatées aux taches, afin de servir de terme de comparaison).

En foi de quoi, nous avons signé le présent rapport, que nous. déclarons fait en honneur et conscience.

Rouen le 31 mai 1878.

G. Pennetier. 


\section{CHAPITRE XIX}

\section{QUELQUES EXEMPLES DES TACHES DONT ON PEUT AVOIR A DETERMINER LA NATURE}

Taches de matière cérébrale. - Lorsque la boîte crânienne a été ouverte par l'effet d'un choc violent, la matière cérébrale peut être projetée assez loin, dans des sens divers et elle peut

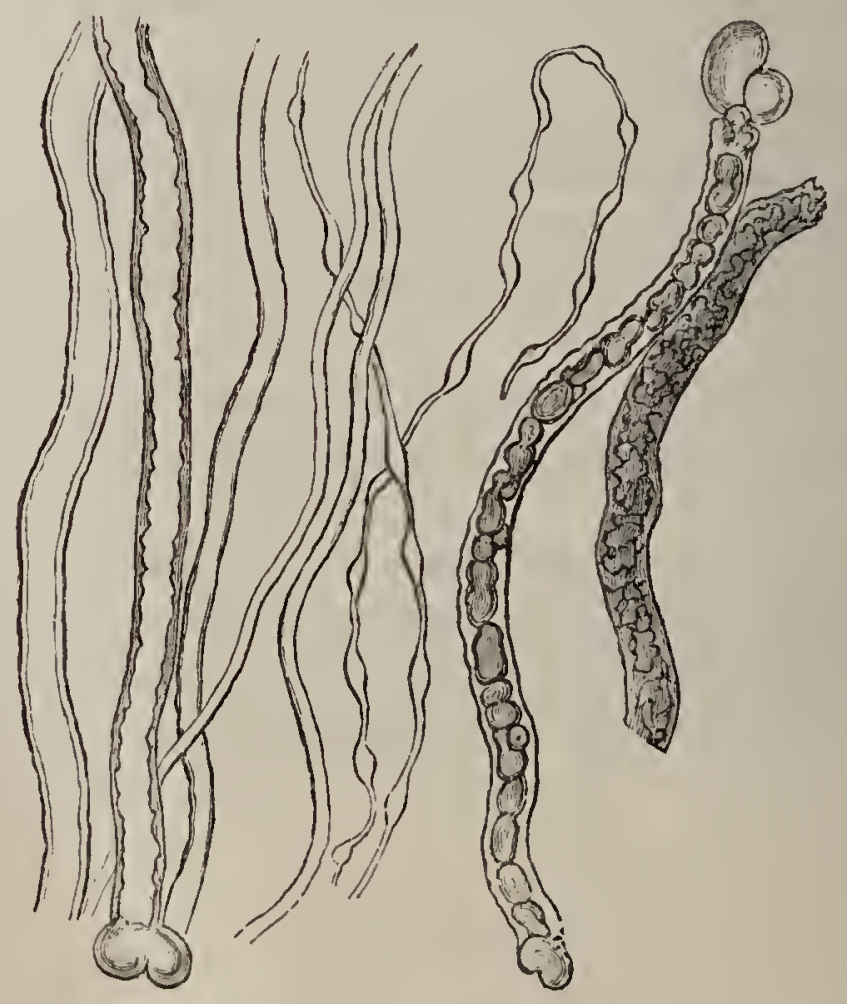

Fig. 444. - Tubes nerveux de l'homme grossis 3 วo fois. - Parmi eux quatre tubes fins (dont deux variqueux), un tube moyen, à simple eontour, f̧et quatre gros; de ces derniers deux sont à double entour, et deux ont un contenu granuleux. (Kölliker.)

se dessécher. Des fragments de matière cérébrale peuvent également rester adhérents, soit à l'objet qui a servi à briser le crâne, tel que pierre, bâton, arme contondante, etc., soit sur du linge ou sur le sol. Dans ces différentes circonstances, il 
peut être utile de déterminer si c'est bien de la matière cérébrale que l'on a sous les yeux.

- On considère généralement dans la matière cérébrale deux éléments principaux, des tubes nerveux et des cellules nerveuses. Les tubes nerveux sont constitués d'une partie centrale (cylinder-axis, fibrilles primitives), et d'une substance qui l'enveloppe comme le suif la mèche d'une chandelle, et à la-

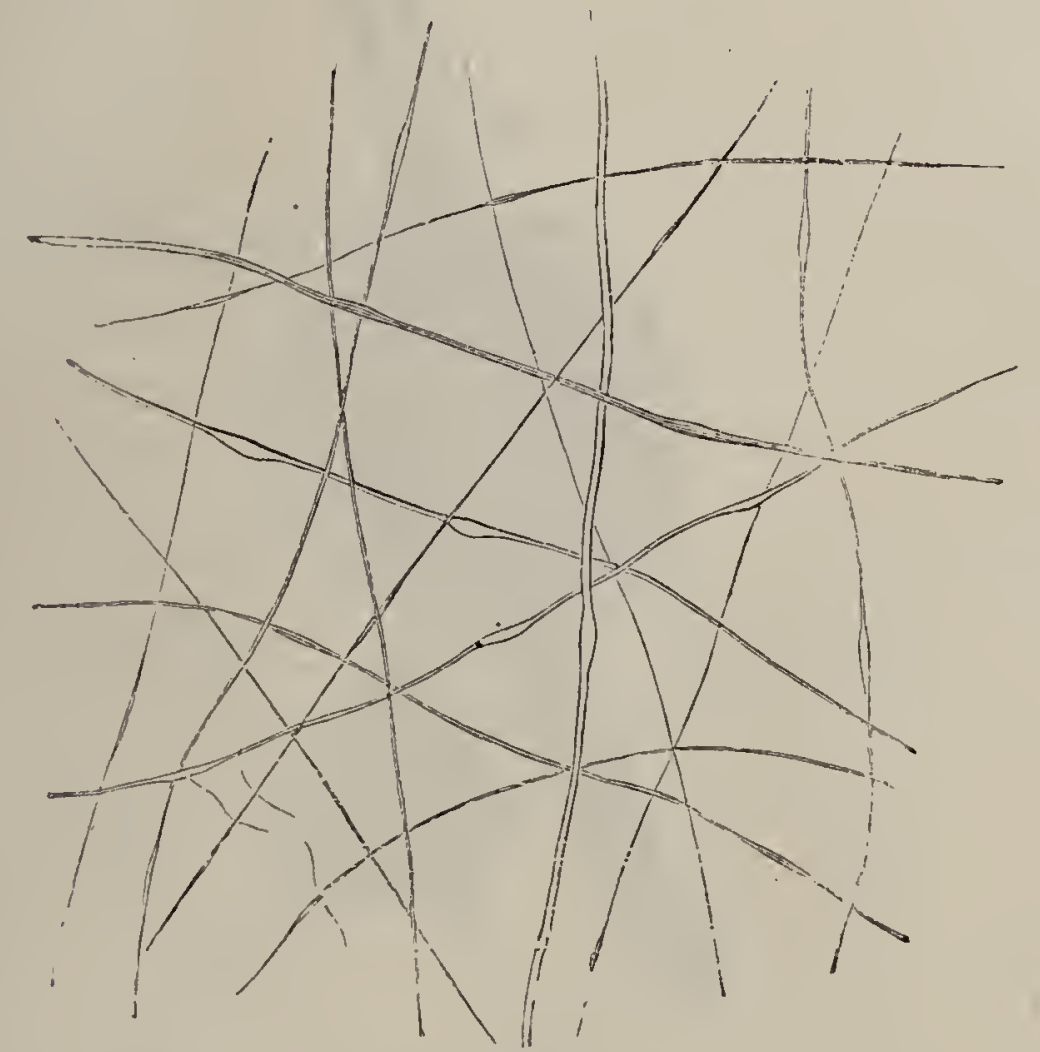

Fig. 443̆. - Tubes nerveux fins de la substance blanche du cerveau devenus variqucux. (Gr.350/l) (Külliker.)

quelle on a donné le nom de myéline, ou de substance médullaire. Quand on l'observe à la lumière transmise, la myéline offre un double contour. Après la mort, en vertu d'une sorte de phénomène de liquation, la myéline s'écoule goutte à goutte, les bords des tubes nerreux perdent, leur parallélisme et offrent des varicosités plus ou moins saillantes. Le tube nerveux présente aussi des renflements fusiformes placés de distance en distance, ce qui permet, dit M. G. Pouchet, de les distinguer comme tubes nerveux de très minces filaments sur la nature desquels on eût éprouré sans cela quelque embarras.

Les cellules nerveuses ont un contenu finement granulé, assez consistant et souvent mêlé de pigment (Kölliker). Elles 
renferment un noyau très apparent, contenant lui-même un nucléole. Elles ont des formes rariables : on en distingue qui sont rondes, pyriformes, fusiformes et étoilées. Ces cellules présentent des prolongements plus ou moins multiples; aussi

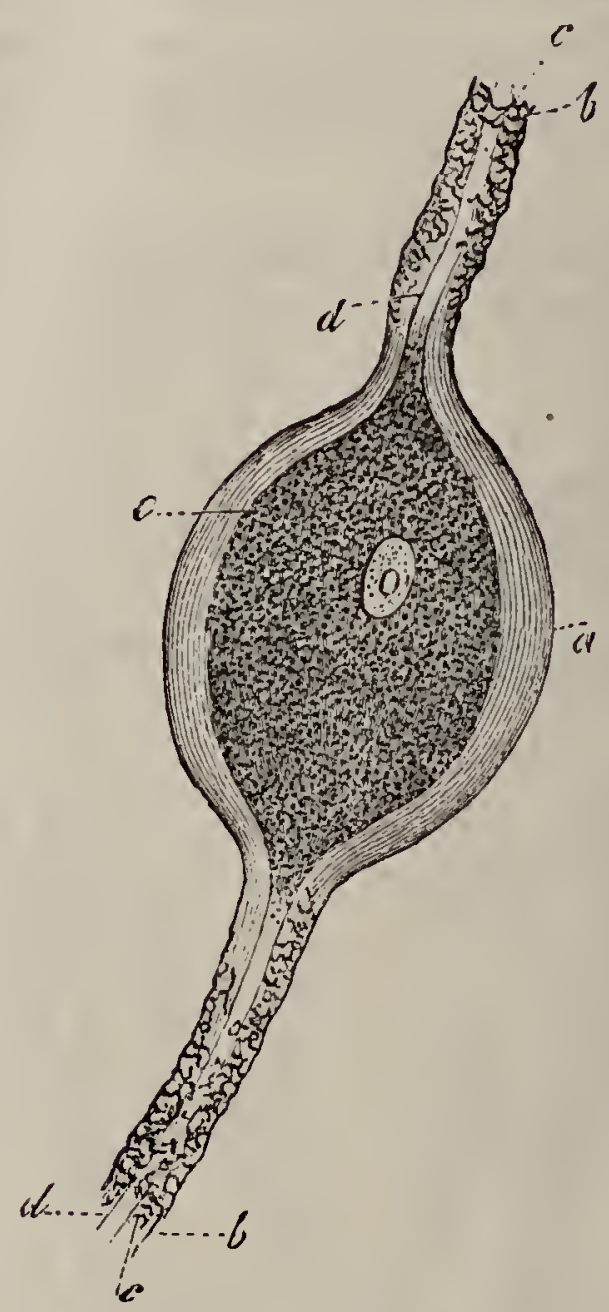

Fig. 446. - Globule ganglionnaire (bipolaire) du broehet, dont les deux extrémités sont terminées en tubes nerveux à bords funcés (traité par l'acide arsénieux et grossi 350 fois). - $a$. Enveloppe du globule. $-b$. Gaîne nerveuse. $-c$. Moelle nerveuse. - $d$. Cylindres de l'axe qui se continuent avec le contenu $e$ du globule ganglionnaire, lequel, en se rétraetant est écarté de l'enveloppe. (Kölliker.)

on les a divisées en cellules multipolaires, bipolaires et même apolaires. Mais, ainsi que le fait remarquer M. G. Pouchet, sauf dans les cellules ganglionnaires, l'existence des cellules unipolaires n'a pas encore été démontrée, et il conviendrait de rejeter sur des accidents de préparation, l'existence de certaines cellules absolument dépourvues de prolongement (cellules rondes de Kölliker). Il serait impossible, dit M. G. Pouchet dans l'état actuel de nos connaissances, de nous figurer le fonctionnement d'un élément nerveux qui serait ainsi dépourvu de toute relation de continuité avec des points exté- 
CHAPITRE XIX. - DES TAGHES.

rieurs à l'élément lui-même, d'où il doit recevoir l'incitation ou bien auxquels il doit la transmettre.

Ces cellules s'altèrent rapidement, ce qui fait que dans la matière cérébrale desséchée ou altérée, il est très difficile de les retrouver.

Les tubes nerveux réunis entre cux en faisceaux ou entrela-

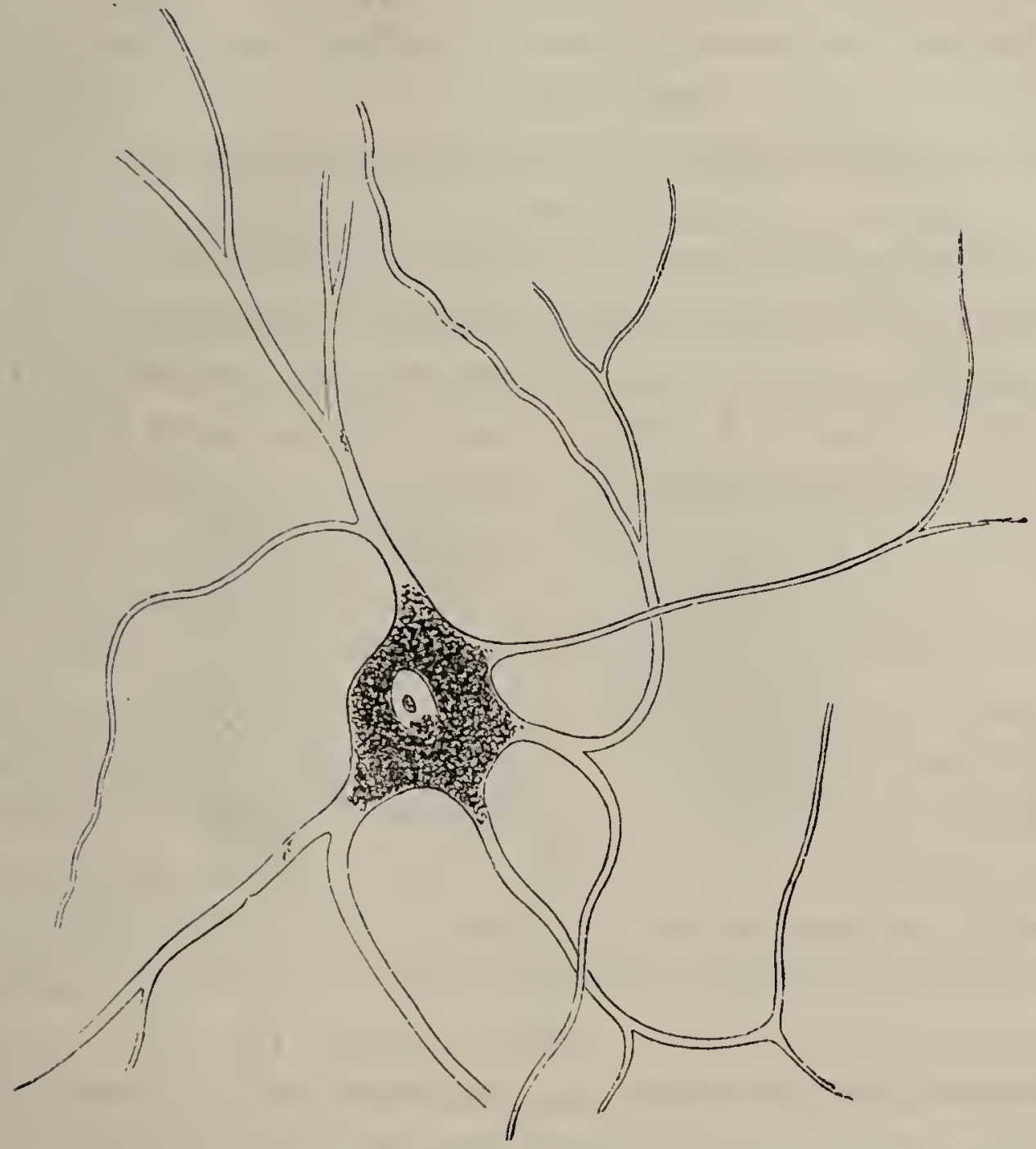

Fig. 447. - Cellules nerveuses de la substanee grise du plancher du sinus rhomboïdal de l'homme, grossissement de 3 วั0. D. (Külliker.)

cés, et associés à du tissu conjonctif et à des vaisseaux capillaires, constituent ce qu'on appelle la substance blanche de la moelle et du cérveau; elle forme également les nerfs, mais ceux-ci sont en outre enfermés dans une gaîne que l'on appelle névrilème.

Les cellules nerveuses dominent surtout dans la substance grise, elles sont accompagnées de fibres nerveuses, en nombre plus ou moins considérable, ainsi que du tissu conjonctif qui 
sert de support aux éléments nerveux. Les tubes nerveux sont abondants, dans la plupart des ganglions, dans la substance grise de la moelle épinière, tandis que l'on ne rencontre presque exclusivement que des cellules nerveuses, dans l'écorce grise du cerveau et du cervelet (Kölliker). Ces simples notions permettront de bien comprendre ce qui va suivre.

Les taches de matière cérébrale prennent une coloration variable, suivant les conditions au milieu desquelles elles ont été produites, ou se sont desséchées. Si elles contiennent du sang en quantité appréciable, elles peuvent prendre une coìration rouge sale, rappelant celle de la rouille; généralement elles sont d'un gris jaunâtre. Elles se ramollissent dans l'eau distillée froide, se gonflent et se laissent facilement dissocier. Pour examiner des taches formées de matière cérébrale, M. Robin conseille d'employer un grossissement d'au moins cinq cents diamètres. Pendant la dessiccation, les tubes nerveux éprouvent une altération en vertu de laquelle la myéline, disparaissant en certains points, laisse à nu le cylinder-axis (cylindre-axe) qui la traverse, comme on voit dans certains ipecacuanhas, le tissu ligneux apparầlre sur une certaine longueur, complètement dépourvu de la partie corticale de la racine. Il suffit donc de faire macérer un fragment, même très petit, de matière cérébrale dans de l'eau distillée pendant deux ou trois heures et de le dilacérer avec soin à l'aide d'aiguilles fines, l'examen microscopique permettra de reconnaître la présence de tubes nerveux plus ou moins altérés. Ces tubes peuvent être entrecroisés en tous sens, courbés ou rectilignes ou flexueux. La myéline se présente sous la forme de gouttes peu nombreuses, de volume et de forme très variables, mais d'apparences très nettes.

On constate en outre dans ces taches, d'après Gosse, des vibrions souvent en nombre considérable, ainsi que des filaments d'algues microscopiques. Un grand nombre de substances étrangères, peuvent se trouver accidentellement mêlées à ces taches, suivant l'objet qui leur sert de support.

Lorsque du sang a été mêlé à de la matière cérébrale, un retrouve au milieu des tubes nerveux des hématies plus oı moins prolondément altérées, que l'on reconnaîtra aux carac- 
tères que nous avons donnés, lorsque nous avons étudié le sang. Dans ce cas particulier, au lieu d'eau distillée, il faut employer une dissolution de sulfate de soude.

Des taches produites par le jaune d'neuf (voir Orfila, Briand et Chaudé, Gosse). - Ces taches se présentent si fréquemment dans la vie commune, qu'on a souvent l'occasion de les étudier. Elles sont d'un jaune d'or, quelquefois jaune orangé, communiquent au tissu qui les porte, une certaine raideur. Généralement elles offrent un degré appréciable de transparence, et lorsqu'elles sont desséchées, elles peuvent s'enlever par écailles de dimensions variables.

Examinées au microscope, elles présentent des amas de granulations graisseuses, de larges gouttes d'huile du jaune, ainsi que des goultes d'huile contenues dans des granulations. Les

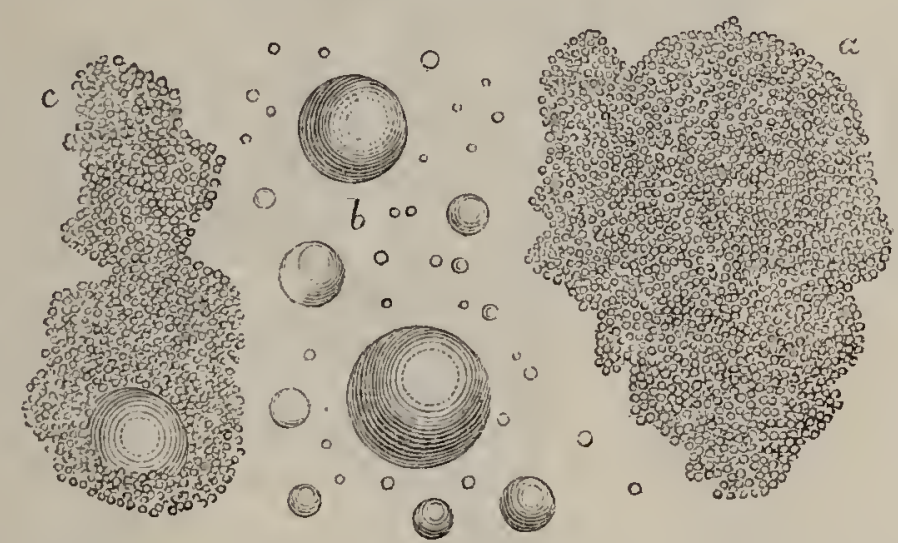

Fig. 448. - Jaune d'œuf desséehé. - $a$. Amas de granulations graisseuses du jaune. $b, b$. Gouttes d'huile jaune. - $c$. Goutte d'huile contenue dans un amas de granulations (d'après Ch. Robin.)

amas réguliers diffèrent de ceux dú caséum et de toute autre substance, par leur plus grande opacité et par leur état granuleux parfaitement uniforme, excepté, lorsque de grandes gouttes d'huile se trouvent enclavées dans leur épaisseur; ces dernières ont une teinte un peu ambrée.

Taches formées par la gronsse et par le tissu adipeux. Nous avons déjà donné quelques notions sur le tissu adipeux, de sorte qu'il nous suffira de rappeler que la graisse est contenue dans des cellules à parois minces et transparentes qui laissent apercevoir leur contenu jaunâtre. Ces cellules sont parfois agglomérées, autour d'elles rampent des vaisseaux capillaires. Ce sont les lobules graisseux. 
Quand on traite une tache de graisse par de l'éther, de la benzine, on dissout le corps gras, et après évaporation, on peut constater au microscope la présence de globules de graisse, sur lesquels on peut faire agir les différents réactifs qui servent à la détermination des corps gras.

Nous ne connaissons jusqu'ici qu'une seule observation de tache formée par du tissu adipeux. L'examen en a été fait par
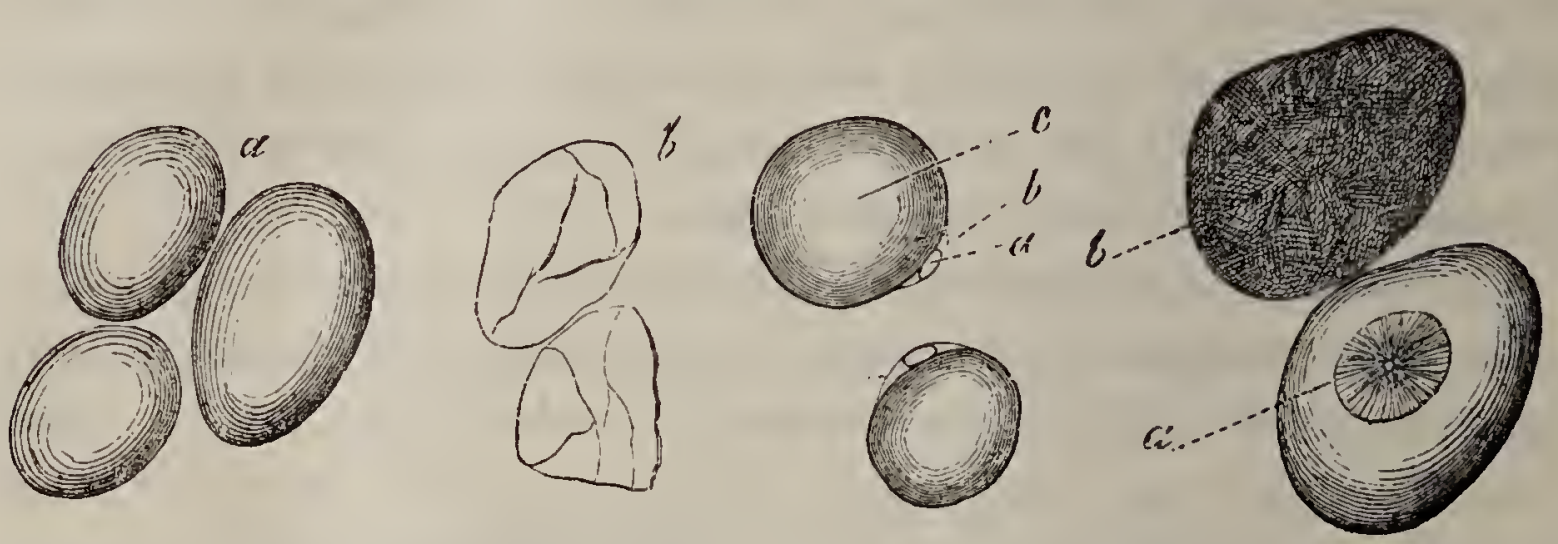

Fig. 449. - Cellules adipeuses normales Fig. 450. - Deux Fig. 451. - Cellules graisde la mamelle (grossics 350 fois.) $a$. Sans réactifs. - $b$. Traitées par l'éther qui a enlevé la graisse et laissé seulement l'enveloppe mince et plissée.

cellulcs adipeuses tirées de la moclle du fémur de l'homme. $a$. Noyau. $-b$. Mlembrane de la cellule. - $c$. Goutte de graissc (grossissement, 350. D.) seuses renfermant des cristaux de margarine (gros(sies 350 fois). - a. Cellule qui contient une étoile formée d'aiguilles cristallisées, comme on en trouve quelquefois dans la graisse normale. $-b$. Cellule entièrement remplie de cristaux prise dans un lobule graisseux blane d'un individu émacié.

M. Robin, auquel nous empruntons la description suivante : Cette tache se trouvait sur une porte grisâtre; elle était longue de $0^{\mathrm{m}} 09$ sur 1 à 2 millimètres de large, épaisse de 1 millimètre et rougeâtre, mais non rouge brun, ni à surface brillante comme les taches brillantes, comme les taches de sang. Après en avoir fait macérer une partie dans de l'eau pendant dix minutes, elle avait pris une teinte d'un blanc jaunâtre légèrement grisâtre, s'était gonflée et affectait un aspect filamenteux. Ayant examiné cette tache à un grossissement de trois cents diamètres, M. Robin vit qu'elle était constituée par les éléments suivants: les amas de cellules étaient réunis par des fibres lamineuses arrondies ou aplaties (dites fibres du tissu cellulaire). Ges fibres isolées se présentent sous la forme de 
filaments pâles non granuleux, à bords parallèles, non ramifiés, décrivant des flexuosités en général régulières. Les faisceaux de ces fibres étaient pour la plupart striés longitudinalement; quelques-unes, par suite d'un travail d'altération, n'étaient pas - striées. L'acide acétique les a gonflés, ramollis, rendus trans-

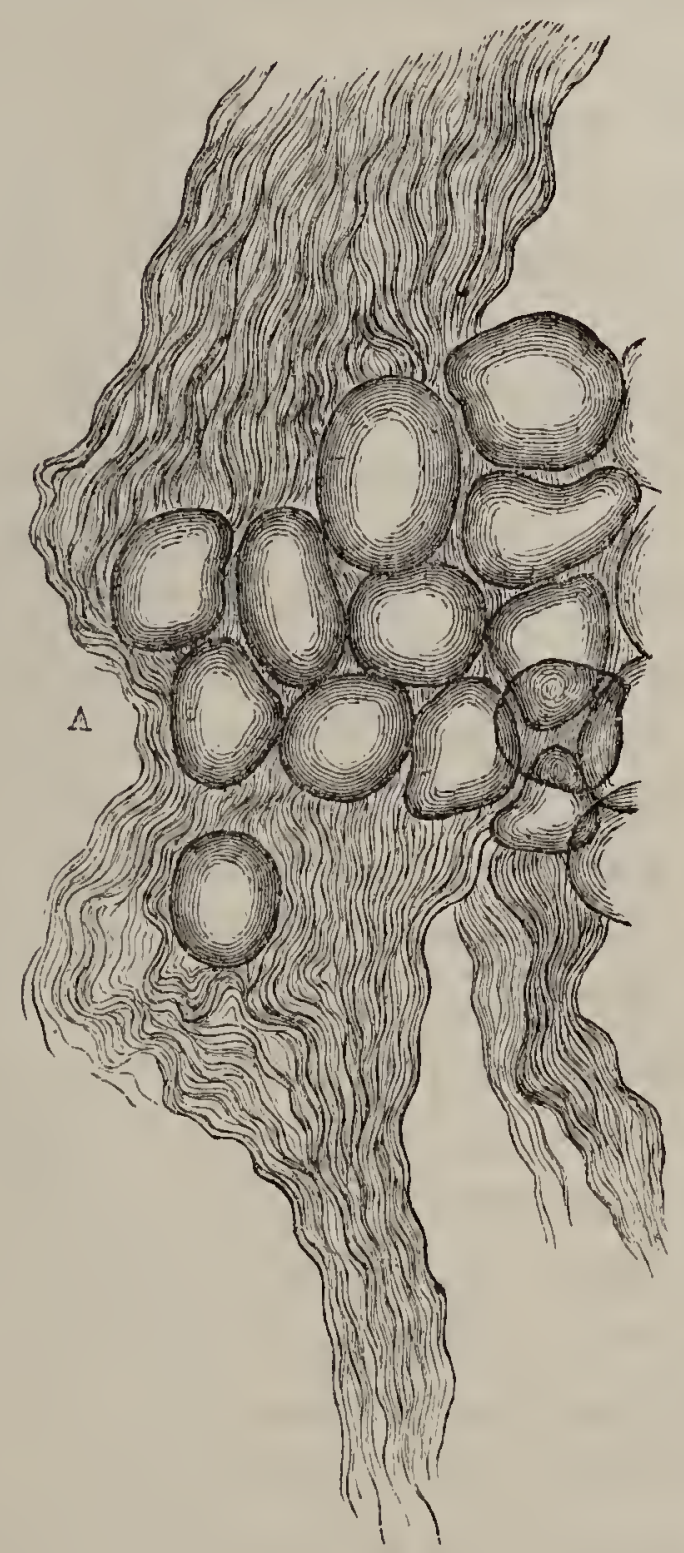

Fig. 452. - Tissu conjonctif lâche de l'homme, renfermant des cellules adipeuses. Grusst, de 8 so D. (Kölliker.)

parents, gélatiniformes et réduits en une masse homogène. On a pu alors constater la présence de fibres élastiques jaunâtres très flexueuses à bords foncés, qui n'étaient pas attaquées par l'acide.

Les cellules entourées par les fibres étaient sphériques ou ovoïdes à la périphérie des petits amas, et polyédriques au centre. Leur diamètre variait de $0^{\mathrm{mm}} 010$ à $0^{\mathrm{mm}} 071$; mais les 
plus nombreux avaient $0^{\mathrm{mm}} 006$. Lẹr contour était net, formé, leur centre clair, jaunâtre, homogène. Rompues il s'en est écoulé une matière liquide, huileuse, qui était contenue dans une paroi mince, homogène et transparente. On voyait aussi dans la préparation des gouttes de même rature. que ce liquide et provenant de la rupture accidentelle d'autres cellules. Dans l'épaisseur ou à la surface d'un certain nombre de ces cellules, M. Robin a constaté la présence de petits groupes de fines aiguilles, contiguës et rayonnant autour d'un centre commun, caractères que présente la margarine lorsqu'elle se sépare des autres principes de la graisse.

Ces différents caractères appartiennent au tissu adipeux. Dans les expériences diverses que firent les experts sur du tissu adipeux de mouton et de bœuf, ils constatèrent les caractères suivants: les faisceaux des fibres laminées, entre les globules formés par les cellules adipeuses, sont en moins grande quantité. Les lobules sont plus volumineux et plus pressés les uns contre les autres. Les cellules sont plus grandes, leur diamètre était de $0^{\mathrm{mm}} 095$ à $0^{\mathrm{mm}} 114$; quelques-unes étaient ovoïdes et présentaient un petit diamètre de $0^{\mathrm{mm}} 081$. Les cellules polyédriques à angles mousses, quoique isolées, se séparaient plus facilement les unes des autres, leur's bords étaient plus foncés. Chez le mouton, leur centre jaunissait moins la lumière qu'il réfractait, et il la jaunissait davantage chez le bœuf. Le contenu des cellules était moins homogène, moins clair, et l'on ne pouvait le faire écouler en gouttelettes huileuses, par la compression et par la rupture des cellules, ce qui tenait à la température. En effet, à $+10^{\circ}$, le liquide huileux de l'homme passe à l'état solide, tandis que chez le bœuf la graisse se fige à $+21^{\circ}$; chez le porc à $+23^{\circ}$ et chez le mouton à $+20^{\circ}$. Ces variations dans la température où s'opère la solidification, tiennent à la plus ou moins grande proportion de stéarine (D Gosse).

Taches produites par l'écoulement blennorlnagione. Ces taches ont une coloration différente, suivant la période de la maladie pendant laquelle le liquide purulent a été émis ; généralement elles ne sont pas d'une grande dimension, à moins que plusieurs de ces taches aient fusionné. Leur colo- 
ration varie du jaune blanchâtre au jaune verdâtre; parfois elle ressemblent au premier abord à des taches de sperme. Elles donnent au linge une certaine résistance et peuvent, lorsqu'elles sont suffisamment épaisses, s'écailler sous l'influence d'un contact un peu rude. On traite ces taches, comme nous l'avons indiqué, par l'eau distillée; lorsqu'elles ont absorbé par capillarité une quantité d'eau suffisante on racle avecla lame d'un scalpel et on examine au microscope arec un grossissement de 300 diamètres. Les globules de pus dominent, et on voit également des cellules épithéliales provenant du canal de l'urèthre. Outre ces éléments on rencontre de nombreux vibrions, mais ils n'ont pas de signification particulière, comme on serait tenté de le croire, d'après les recherches de Donné.

Taches produives paro đlea excrénnents de punaise. - Ces taches ont été étudiées avec beaucoup de soin par M. Ch. Robin (Voir Briand et Chaudé), qui en a donné la description suivante: Par leur aspect extérieur, ces taches pouvaien têtre confondues avec des taches de sang, dont elles se distinguent facilement au microscope. Quelques heures de séjour dans une dissolution de sulfate de soude, suffisent pour désagréger ces excréments, qui se présentent sous la forme d'une poussière d'un brun rougeâtre, ou tirant sur le noir. Recueillie à l'aide d'une pipette et portée sous le microscope, cette poussière se montre formée de petites granulations desséchées, variant de rolume depuis $0^{\mathrm{mm}} 001$ jusqu'à $0^{\mathrm{mm}} 010$ : elles sont sphériques ou ovoïdes d'un brun rouge, plus clair au centre qu'à la circonférence qui est moins nettement déterminée. Elles sont isolées ou en groupes de volume variable; on en trouve souvent qui sont brisées par le milieu, suivant leur épaisseur. Ces amas sont plus ou moins traversés par la lumière, ou sont complètement opaques.

Sèches, ces gouttelettes son t accompagnées de cristaux d'un aspect analogue à ceux des éléments organiques; ce sont des lamelles en losanges, à arêtes très nettes, isolées ou diversement entrecroisées; quelques-unes sont allongées sous forme d'aiguilles, isolées, ou réunies en faisceaux. Quelques cristaux tendent à prendre la forme prismatique. On trouve souvent ces 
cristaux lamelleux ou aciculaires, formant des groupes plus ou moins volumineux, ou hérissant la périphérie de quelques amas considérables de gouttelettes sphériques.

Ces cristaux ne se trouvent dans aucune autre espèce de taches que celles de fientes de punaises; ils concourent, arec les gouttelettes desséchées, à leur donner un aspect tout à fait

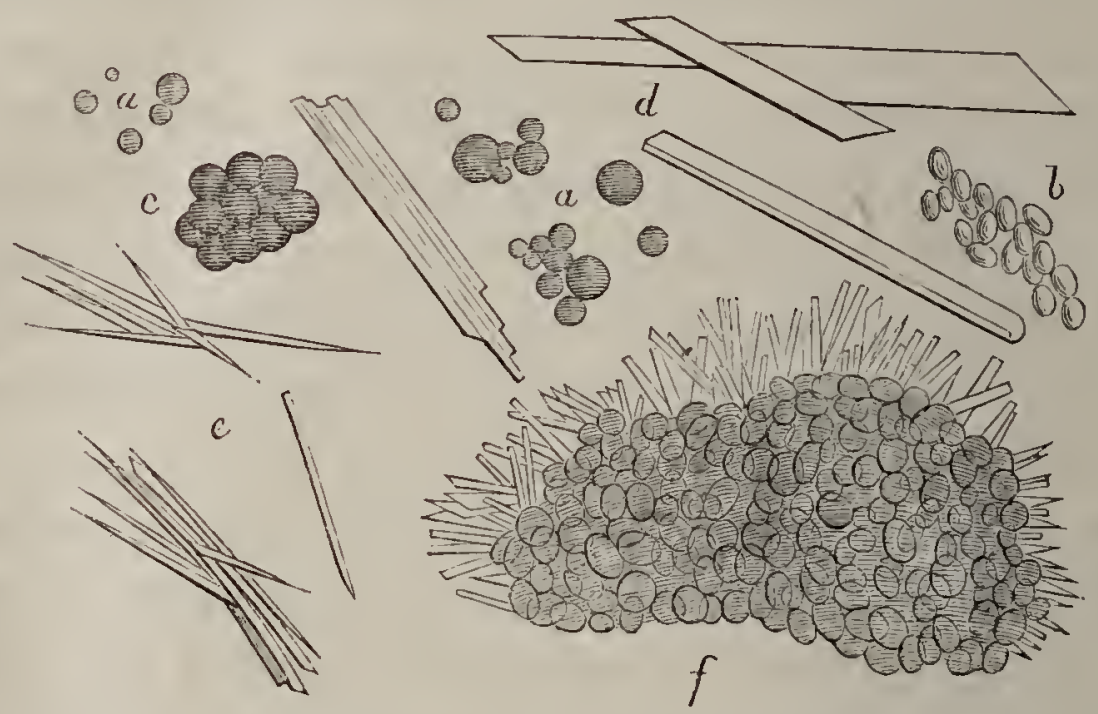

Fig. 4ว3. - Excréments de punaise. - $a$, $a$. Goutles sèches ou globules sonvent creux d'un brun jaunûtre, aggglomérés ou isolés, variant en diamètre depuis 0,001 , jusqu'à 0,010. - b. Amas daus lequel les gouttes sèches ou globules brisés ressemblent sur le bord à un deni-cercle ouvert. - $c$. Amas plus foncés noirâtres. - $d$. Lamelles cristallines losangiques. - $e$. Aiguilles de volume variable isolées ou groupées. - $f$. Lamelles et aiguilles partant de la périphérie d'un amas volumineux; disposition fréquente (d'après (ih. Robin.)

particulier. Lorsque les excréments de punaise existent sur des papiers de tenture, la préparation est toujours mêlée de globules sphériques volumineux de $0^{\mathrm{mm}} 0 \mathrm{a}$ à $0^{\mathrm{mm}} 10$, isolés ou réunis, qui sont une des formes confuses de cristallisation de la céruse et de quelques autres carbonates métalliques ou du carbonate calcaire (loc. cit., p. 739).

waches produites par les excréments dé mouches et de puces (Robin, Briand et Chaudé, p. 739). — Comme les précédentes, ces taches peuvent être confondues avec des taches de sang. Leur largeur varie d'un demi-millimètre à 1 millimètre environ. Quand on examine ces taches au microscope, on voit qu'elles sont composées d'une malière homogène, amorphe, transparente, incolore, gonflée, puis dissociée ou dissoute par l'eau, tenant empâtés les granules colorants de ces parcelles. Ceux-ci forment presque exclusivement les taches; ils sont très 
rapprochés les uns des autres. Leur coloration est variable; les uns sont d'un brun jaunâtre ou ayant des reflets verdâtres, ou rougeâtres, peu prononcés. Tous réfractent fortement la lumière et sont brillants au centre; comme les globules de matière grasse, ils sont insolubles dans l'eau et dans l'acide acétique, et se dissolvent presque tous dans l'alcool chaud et dans l'éther. Quelques petits cristaux courts et aiguillés les accompagnent; leur composition chimique n'est pas encore déterminée.

Taches de boue. - Rien n'est plus variable que la composition de ces taches, on comprend qu'elles présenteront des caractères spéciaux suivant le milieu dans lequel elles auront été produites. Les taches de boue dans une grande ville seront différentes de celles observées à la campagne ; la nature du sòl apportera également beaucoup de variété dans leur composition. Les débris végétaux y sont généralement abondants, mais on peut y rencontrer une foule de corps étrangers.

MM. Robin et Tardieu ont examiné ces taches et ont surtout appelé l'attention sur les corpuscules minéraux qu'elles renferment en grande abondance. Ce sont de petits grains anguleux à facettes multiples, disséminés dans la tache. Parmi ces grains, les uns ont un aspect cristallin, d'autres, au contraire, sont amorphes et de coloration variable, à contours épais et noirâtres. Leur diamètre est extrêmement variable. L'eau ne les dissout pas; l'acide acétique ne les attaque que faiblement en dégageant quelques bulles de gaz peu abondantes.

Ces taches peuvent également contenir des grains de charbon qui résistent à l'action des réactifs; on y rencontre également des granulations rougeâtres, peu solubles dans l'acide acétique, mais très solubles dans l'acide chlorhydrique, ce sont très vraisemblablement des particules ferrugineuses.

On peut également y rencontrer des cellules d'épiderme. ainsi que des fragments d'étoffe, de duvet d'oiseau, etc., etc. 


\section{CHAPITRE XX}

\section{SUR L'EXAMEN MICROSGOPIQUE DES EAUX}

Les eaux, surtout celles qui sont stagnantes, renferment une foule d'organismes vivants, soit végétaux (algues diatömées, etc.), soit animaux. Nous ne nous occuperons pas ici des végétaux proprement dits; ils ont été étudiés dans les premières parties de ce livre, nous nous bornerons à donner quelques indications sur les microzoaires et les infusoires que l'on trouve dans les eaux.

Sous l'influence des matières organiques, empruntées surtout au règne végétal, les eaux stagnantes ne tardent pas à se peupler d'une foule d'animalcules, dont le rôle au point de vue de l'hygiène est très important. C'est ainsi, pour ce qui regarde les animaux domestiques, que l'on a attribué certaines épidémies à l'infection des animaux par les organismes qu'ils absorbaient avec les eaux non potables. Le rôle des eaux dans la contagion des maladies n'est pas encore absolument connu, néanmoins les faits acquis à la science sont de nature à faire de l'étude de cette question une des plus importantes pour l'hygiéniste et le médecin. C'est ainsi que, pour ce qui regarde la diarrhée de Cochinchine, il a été démontré que c'était par l'usage de l'eau, que l'on absorbait les embryons et les œufs des parasites qui, par leur développement ultérieur, causaient chez l'homme une affection d'une gravité extrême. Dans un travail publié en 1874, intitulé : Trois ans en Cochinchine, le $\mathrm{D}^{\mathrm{r}}$ Sourrouille avait appelé l'attention sur les danger's qu'il y avait pour nos soldats et pour les Européens en général, de faire usage de l'eau des fleuves de la Cochinchine, et il conseillait avec raison d'imiter les indi- 
gènes, qui ne boivent ces eaux qu'après leur avoir fait subir l'ébullition simple ou avec des feuilles de thé. Plus récemment, dans un ouvrage que nous avons cité, le $\mathrm{D}^{\mathrm{r}}$ Dounon est revenu avec beaucoup de force sur cette question, et a montré que les eaux dont faisaient usage les Européens contenaient des anguillules, des organismes inférieurs, des œufs microscopiques. La filtration seule est impuissante à débarrasser ces eaux de ces hôtes dangereux. L'auleur exprime le désir de voir l'examen microscopique donner la démonstration complète de l'idée qu'il soutient. Les Annamites et les Chinois, qui ne font jamais usage de l'eau des puits ou des fleuves, n'ont pas la dyssenterie; il en est de même-de ceux des Européens qui boivent uniquement l'eau qui leur est apportée d'Europe.

Nous rappellerons également que les eaúx ont été considérées avec raison comme le véhicule des œufs et des embryons d'un certain nombre de parasites. On ne saurait donc examiner de trop près les eaux qui doivent servir à l'alimentation. Si les entozoaires nématoïdes sont plus fréquents chez les enfants que chez les adultes, dit M. Robin, cela tient à ce que l'eau, dans ces conditions d'âge et de lieu, est bue plus souvent qu'ailleurs sans avoir été filtrée.

Lorsque nous avons parlé du sang, nous avons donné d'une façon très brève quelques indications sur les vibrions, nous n'y reviendrons donc pas. Dans les eaux corrompues, on trouve presque uniquement des bactéries et des vibrioniens, parmi lesquels nous citerons le $B$. punctum, le $B$. termo, $B$. Pastorii, B. bacillus; on y rencontre également le Vibrio rugula, et le $V$. bacillus. On y observe encore le Spirillum volutans, Sp. plicatile, Sp. ondula (1).

Les eaux qui ne renferment que ces microzoaires sont impropres à l'alimentation. Outre ces bactéries et ces vibrioniens on y rencontre encore quelques monadiens.

D'une façon générale on peut dire que tous les infusoires supérieurs aux monadiens, tels que les paraméciens qui vont être étudiés ci-après, se rencontrent dans les eaux que l'on

(1) Nous ne considérons pas les bactéries et les vibrions comme appartenant au règne animal, mais bien comme des végétaux à des états de développement différents. 
peut boire sans grand danger, abstraction faite des œufs et des embryons de parasites et d'helminthes. Toutefois, il y a encore sur ce point bien des observations à faire, et il est à désirer que des recherches soient dirigées dans ce sens. Nous avons pensé être utiles à nos lecteurs, en leur donnant quelques détails sur les microzoaires que l'on trouve dans les eaux, afin de rendre plus faciles les observations qu'ils seraient tentés d'entreprendre. Ajoutons que les espèces d'infusoires varient, suivant les plantes aquatiques qui vivent dans les eaux, suivant les saisons de l'année, et également suivant la nature des terrains. Les eaux stagnantes sur un sol calcaire, dit M. Robin, contiendront, avec les charas, des infusoires qu'on cherche vainement dans les eaux d'une contrée argileuse, lesquelles auront également leurs animaux particuliers, de même que les eaux ferrugineuses, celles des tourbières, celles des fossés entourant les habitations, les canaux.

Infusoires (1). - Ce nom a été donné en 1764, par Wrisberg, aux innombrables animalcules que l'on trouve dans les eaux stagnantes, véritables infusions naturelles. Au fur et à mesure que les microscopes devenaient plus parfaits, on a distrait des infusoires, des végétaux, comme les Algues, les Diatomées, etc. Pour certaines espèces l'accord ne s'est pas encore complètement fait, et cela se comprend, si l'on songe quà la limite les divisions entre les êtres vivants, si elles existent encore, ne sont pas toujours très nettement tranchées. La substance fondamentale des infusoires consiste en une masse gélatineuse, plus ou moins dense, parfois très nettement différenciée en organes distincts. Cette masse, de nature albuminoïde, généralement incolore, mais pouvant affecter des colorations diverses, comme le jaune, le bleu, le rouge ou le brun, a été appelée Sarcode par Dujardin.

On a tiré un caractère différentiel important de l'action de l'ammoniaque sur cette substance. Tandis que les infusoires animaux ou infusoires vrais se dissolvent dans l'ammoniaque, les infusoires végétaux, zoopores, protophytes, ne s'y dissolvent pas, mais leurs mouvements s'y arrêtent. Après la mort le Sarcode disparaît, et se dissout le plus souvent (Pelletan, loc. cit., p. 600 et suivantes). On a établi deux grandes divisions parmi les infusoires.

La première comprend les Infusoires cilies ou infusoires à tourbil-

(1) Pour plus de détails consulter le livre de M. Pelletan, au chapitre spécial duquel nous avons fait de larges emprunts. Consulter également le magnifique ourrage de M. de Fromentel. Paris, cliez G. Masson. 
lon (Microzoa vorticosa, Fromentel). lls ont été ainsi nommés parce qu'ils sont munis de cils vibratiles, de cirrhes et de poils, qui servent à l'animal pour se mouvoir dans le liquide ambiant, et en même temps pour déterminer un tourbillon qui amène à la bouche les corpuscules dont il fait sa nourriture.

La seconde division comprend les Infusoires flagellés (Microzoa nutantia, Fromentel) auxquels il faut adjoindre les Infusoires cilioflagellès, c'est-à-dire possédant à la fois des cils et des flagellums. Les Infusoires flagellés ne portent qu'un ou deux filaments allongés (flagellum) à l'aide desquels l'infusoire se dirige par une série d'oscillations, amène sa nourriture à un orifice considéré comme la bouche et qui est, dans quelques cas, très dilficile à apercevoir. Le corps est constitué par une masse sarcodique qui change faci-

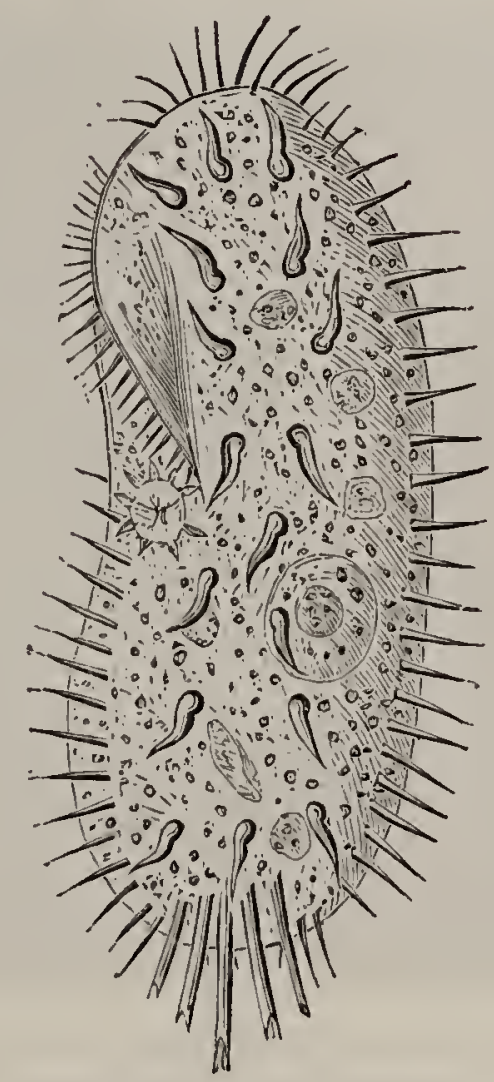

Fig. 454. - Stylonychia Mylilus. - Infusoire marcheur et sauteur présentant des cirrhes autour de la bouehe, des soies et des styles autour du corps et à la partie postérieure. des cornicules à la surface. Longueur, $0 \mathrm{~mm}, 155$; largeur, $0^{\mathrm{mm}}, 066$.

lement de forme, el dans laquelle on ne distingue, d'après Pelletan, qu'un seul organe, qui est la vésicule contractile.

La masse sarcodique qui constitue le corps de linfusoire est revêtue d'une cuticule (Cohn) que l'on peut mettre en évidence, chez les Kolpodes et les Paraméciens, à l'aide de l'alcool (P.). Ce tégument prend chez certains infusoires, Coleps, la consistance d'une véritable carapace, mais le plus souvent il est marqué de stries ou de ponctuations formant des lignes longitudinales ou obli- 
ques. Sur ces stries ou sillons sont fixés des appendices, de volume et de longueur variables. Très fins, ils constituent les cils vibratiles; plus gros et plus raides, ils prennent le nom de cirrhes, qui servent à la progression de l'animal.

Certains infusoires sont en outre munis de styles ou soies longues et raides, dont les usages sont divers, mais qui servent en particulier à certains infusoires pour faire des sauts brusques dans le liquide (Infusoires sauteurs); on observe enfin des cornicules, ou cils plus courts, très forts, larges à la base, pointus à l'extrémité, doués de mouvements indépendants à l'aide desquels l'infusoire peut pro-

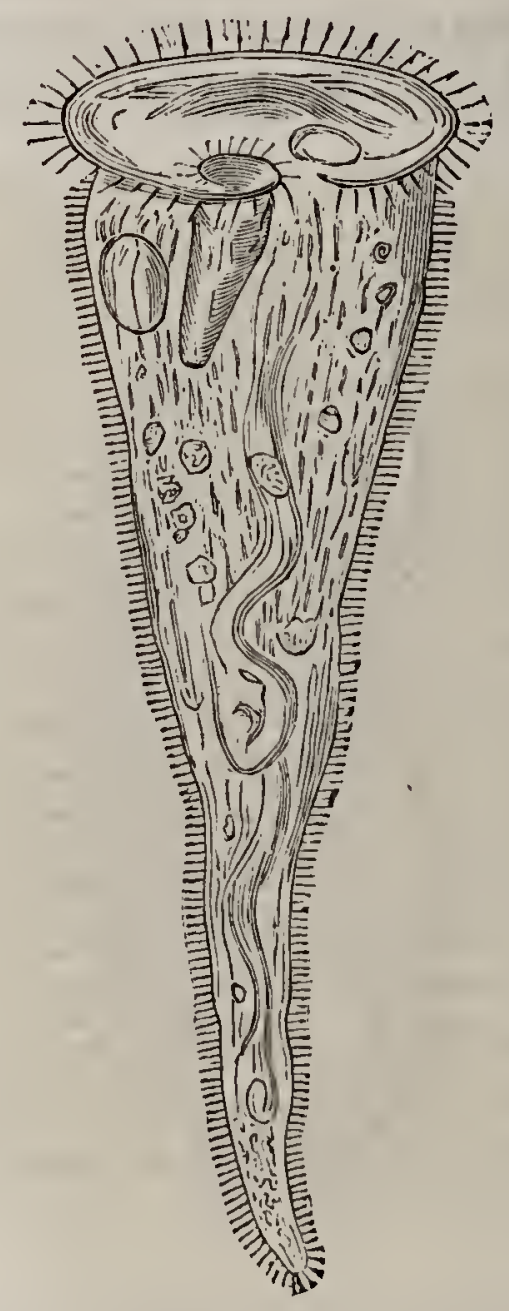

Fig. 455. - Stentor polymorphus en extension. Longueur, $0^{\mathrm{mm}}, 240$.

gresser sur des objets immergés (Infusoires marcheur's). Ces différents organes, d'après 11 . de Fromentel, ne seraient pas fixés sur la cuticule, mais sur de petits points brillants sous-jacents, qu'il considère comme des mamelons musculaires. L'ensemble de ces mamelons formerait autour du corps de l'infusoire une couche éminemment contraclile, à laquelle cet observateur a donné le nom de Myose.

Cette disposition des mamelons musculaires est surtout visible chez le Stentor polymorphus et chez les Vorticella convallaria. Le, 
CHAPITRE XX. - EXAMEN MIGROSGOPIQUE DES EAUX. 743

Stentor est un très gros infusoire, qui a une forme conique, évasé à son extrémité supérieure, lorsqu'il est à l'état d'extension. Grâce au mouvement de ses cirrhes, fixés sur les bords de son pavillon, il détermine un tourbillon violent, qui a pour but d'attirer les corpuscules environnants. Les plus petits pénètrent dans la cavité buccale du Stentor, tandis que les plus gros, s'ils ne conviennent pas à l'infusoire, sont rejetés par une fente qui interrompt la couronne à son milieu. Le corps tout entier est recouvert de cils vibratiles, dont les points d'insertion correspondent à ces mamelons musculaires, dont nous avons parlé plus haut, et qui deviennent saillants quand l'animal se contracte brusquement.

Ces insertions musculaires sont surtout visibles sur les vorticelles dont la forme élégante est en même temps très caractérislique.

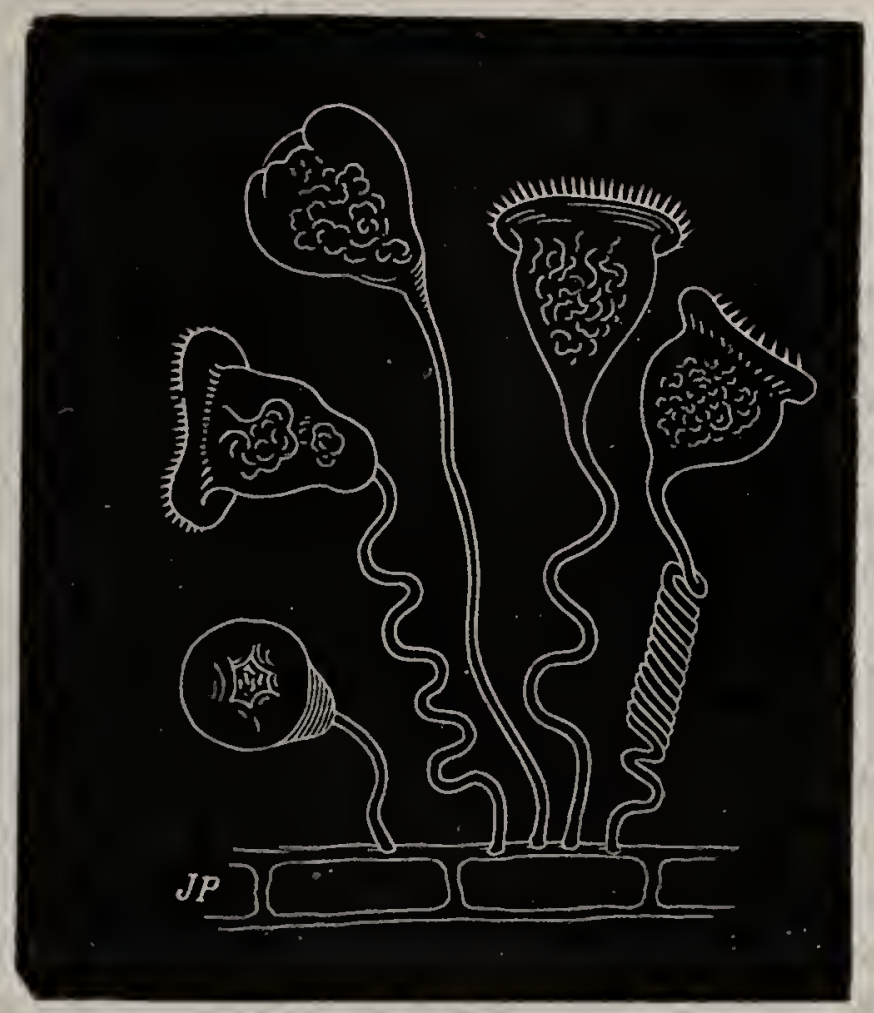

lïg. 456. - Groupe de Vorticelles (Vorticella convallaria) à divers degrés de développement et de contraction.

Non seulement le corps de l'infusoire est contractile, mais le pédoncule l'est également. Formé par un prolongement du tégument, il aurait la forme d'un tube creux, dans lequel la myose serait disposée suivant une ligne spirale, de sorte que le pédoncule se contracterait comme un ressort à boudin.

La situation occupée par la bouche chez les Infusoires est variable: tantôt elle est située à l'extrémité antérieure de l'individu (Vorticelliens), soit obliquement, soit à la partie moyenne du corps.

Les Infusoires se servent avec beaucoup d'adresse des cirrhes buccaux pour saisir et palper les corps qui doivent servir à leur 
nourriture. On peut à l'aide de l'artifice suivant suivre dans l'infusoire la marche du corps absorbé. Il suffit (Pelletan, p. 605) de mettre dans l'eau habitée par les Infusoires du carmin finement broyé ; ceux-ci avalent ces corpuscules colorés, qui teignent leur tube digestif; les organes de la digestion ne paraissent pas avoir des parois très distinctes.

Quant à la vésicule contractile dont nous avons parlé plus haut, elle constitue un organe dans lequel on s'accorde à reconnaître l'élément principal de la circulation, une sorte de cœur. Cet appareil est surtout visible chez les infusoires de grande taille, comme une paramécie ou un kolpode.

D'aprìs M. Balbiani, les organes de reproduction seraient représentés par un noyau contenant le plus souvent un nucléole, quelquefois distinct du noyau. Le noyau et le nucléole sont compris dans la masse sarcodique qui constitue l'infusoire. Pour M. Balbiani le noyau serait un organe de reproduction femelle, tandis que le nucléole serait un organe mâle. La reproduction se ferait de deux manières : par division binaire longitudinale ou oblique et quelquefois transversale, et enfin, chez quelques grands infusoires, par copulation, chez les Paraméciens par exemple (Pour plus de détails, voir Pelletan, loc. cit., p. 608 et 609 ).

Les Infusoires ont en général la propriété de s'enkyster, c'est-à-dire de sécréter autour d'eux une membrane dans laquelle ils s'enferment, formant ainsi une cellule close ou kyste, à l'abri duquel certains infusoires subissent des transformations, ou se mettent à l'abri des causes de destruction. Un marais vient-il à se dessécher, dit le docteur Gerbe, la plupart des infusoires qui le peuplaient s'enkystent, et attendent ainsi des circonstances plus favorables. C'est à cet état qu'on les trouve quelquefois dans les poussieres emportées par les vents à de grandes distances. Lor'squ'ils trouvent des conditions d'humidité favorables, ils reprennent leur activité.

Les Infusoires sont doués de mouvements volontaires et leurs actions paraissent être la résultante de certains calculs, s'il nous est permis, à propos d'infusoires, de nous servir d'une semblable expression, au même titre que les actes volontaires d'animaux d'un volume plus considérable.

$\Lambda$ près avoir indiqué succinctement les points principaux de l'histoire des Infusoires, nous domnons ci-après les caractères des espèces les plus communes, renvoyant pour les détails plus complets au livre de M. de Fromentel, et à l'ouvrage du docteur Pelletan.

$\Lambda$. Infusoires oscillants ( $l$. nutantia, de Fromentel). Les Infusoires oscillants comprennent eux-mèmes les infusoires Flagellès, c'est-à-dire ceux chez lesquels on u'observe qu'un ou deux flugellums, mais pas de cils vibratiles, et enfin les Cılıo-flagelles, ceux qui présentent it lit fois des flagellums et des cils.

Le groupe des infusoires flagellés contient des individus excessi- 
vement ténus; leur corps est arrondi et formé par un ou deux flagellums, à la base desquels on peut quelquefois distinguer une ligne en forme de bouche. Ils sont munis d'une vésicule contractile et se reproduisent par division.

On trouve l'été, dans l'eau pure et même dans l'eau de mer, les Monas atomus, M. lens, $M$. guttula; on les rencontre également dans les détritus.

Les Cercomonas se distinguent par un corps allongé et muni d'un long flagellum. On les rencontre non seulement dans les infusions végétales, mais encore dans les liquides animaux comme le mucus intestinal (V. p. 603). On trouve en grand nombre dans les eaux stagnantes des Euglena. L'Euglena ou Bodo viridis est coloré en vert par la chlorophylle, aussi est-il considéré comme de nature végétale par un cerlain nombre d'auteurs. On le rencontre dans les eaux croupies et colorées en vert.

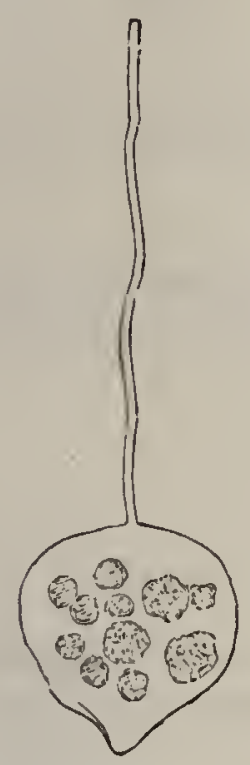

Fig. 45\%. - Euglena ou Bodo viridis.

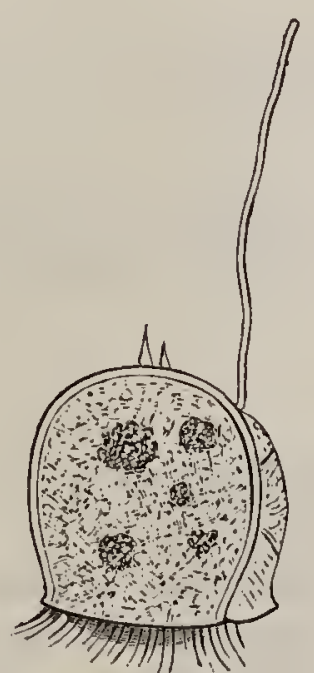

Fig. 40̈8. - Dinophysis ovata.

Les Cilio-llagellés ont une structure plus compliquée; la coque ou cuirusse, dont ils sont fréquemment revêtus à l'état adulte, est composée de deux valves, égales ou inégales, souvent prolongées en. cornes plus ou moins grandes. Comme leur nom l'indique, ils portent un ou plusieurs flagellums, et une ou plusieurs rangées de cils vibratiles. La figure ci-dessus de Dinophysis ovata donnera un spécimen de ces infusoires marins.

B. Les Infusoires ciliés sont plus avancés en organisation; ils ont en général la forme d'une urne ou d'un pavillon de trompe; les cirrhes dont ils sont munis déterminent un violent tourbillon qui a pour but d'attirer vers la bouche de l'infusoire les particules dont il fait sa nourriture. Ces infusoires, en vertu de leur contractilité, peuvent revenir sur eux-mêmes et prendre la forme d'une boule.

Les infusoires ciliés comprennent trois familles : les Vorticel- 
liens, que l'on trouve en été dans les eaux stagnantes sur les plantes aquatiques (fig. $40 \% 6$ ) ;

Les Vaginicoliens, parmi lesquels nous citerons le Cothurnia,

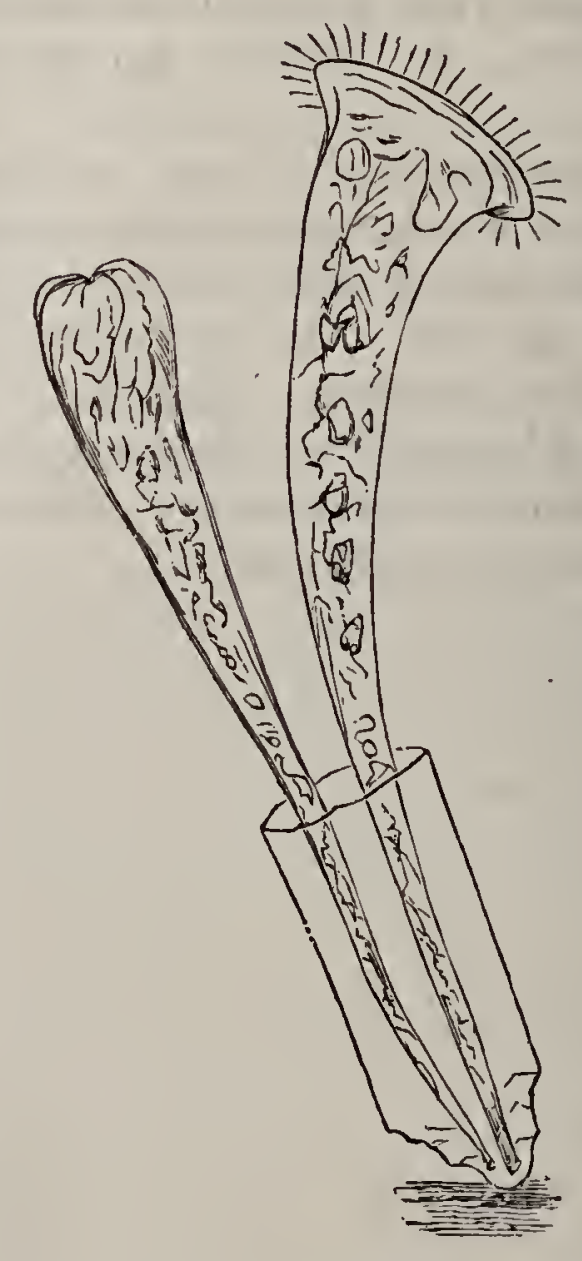

Fig. 4599. - Cothurnia. - Deux individus dans une mème coque tubulaire hyaline, l'un en extension, l'autre en contraction. Longueur, $0 \mathrm{~mm}, 238$. (P).

qui habite une sorte de tube, auquel il est fixé, celui-ci étant luimême attaché aux corps solides (fig. 459) ;

Les Stentoriens, ainsi nommés parce qu'ils sont pour ainsi dire les géants de ce monde microscopique. Quelques-uns d'entre eux peuvent atteindre un quart de millimètre, ce qui les rend visibles à l'œil nu (fig. 455). Cet infusoire est commun dans les étangs.

Les infusoires ciliés appartenant aux autres familles ont le corps à peu près rigide, ou incomplètement contractile.

Les Haltériens sont caractérisés par les Halteria, dont le corps arrondi ou couronné par un cercle de cirrhes buccaux est entouré comme d'une ceinture de longs cils, dont ils se servent pour exécuter de véritables sauts dans les liquides (fig. 460).

Les Kéroniens, dont le genre le plus important est formé par les Kerona, qui sont munis à la fois de cirrhes pour la natation et de cornicules pour la marche; très communs dans la mare de Porchefontaine. Le corps de tous ces infusoires est plus ou moins allongé, 
CHAPITRE XX. - EXAMEN MIGROSGOPIQUE DES EAUX. 747 ellipsoïde, quelquefois triangulaire et aplati. Leur bouche est bordée de cirrhes et située dans une sorte de dépression qui coupe dans une direction plus ou moins oblique la moitié antérieure du

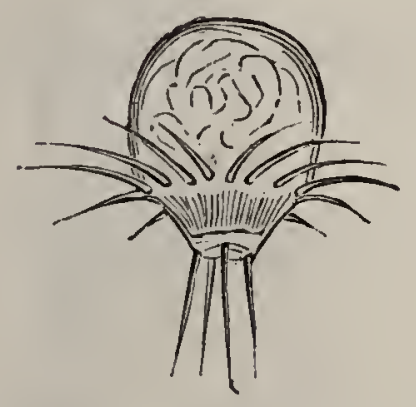

Fig. 400. - Halteria grandinella.

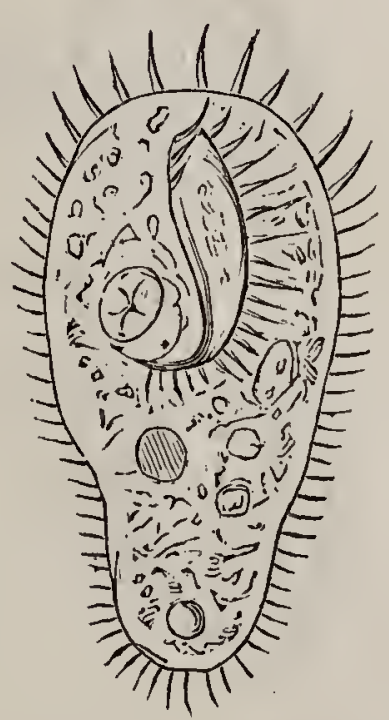

Fig. 461. - Oxytricha crassa.

corps. Le Stylonychia mylilus (fig. 4ă4) et l'Oxytricha crassı (fig. 461) nous donnent des exemples de cette structure particulière.

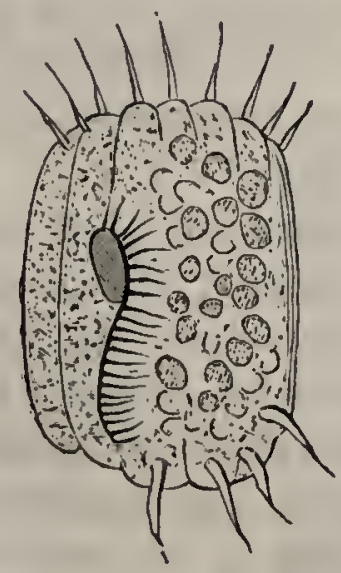

rig, 462. - Plasconia cithara de faee.

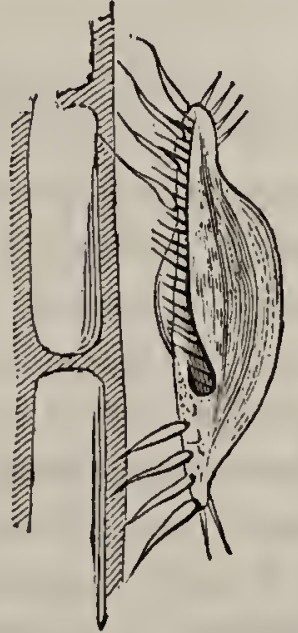

Fig. 463. $\rightarrow$ Plasconia cithara de profil.

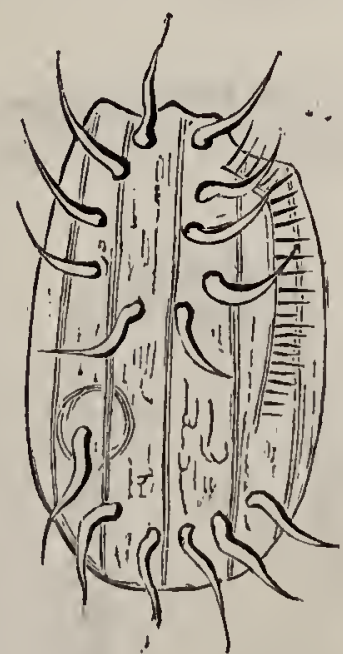

Fig. 464. - Aspidisca lynceus.

D'autres infusoires appartenant aux Kéroniens ont une sorte de cuirasse, dont la durée ne dépasse cependant pas celle des infusoires, et tombe en diffluence après la mort de l'animalcule. Tels sont le Plxsconia cithara et l'Aspidisca lynceus (fig. 462, 463 et 464).

Les Vassuliens ont un appareil particulier placé à l'orifice buccal. Il paraît formé par des bâtonnets disposés en forme de nasse. Cet organe très dilatable semble dentelé à son orifice antérieur ou 
externe par les extrémités saillantes des bâtonnets (Pelletan, p. 619). Tels sont le Chilodon cucullulus et le Nassula flava (fig. 4630 et 466).

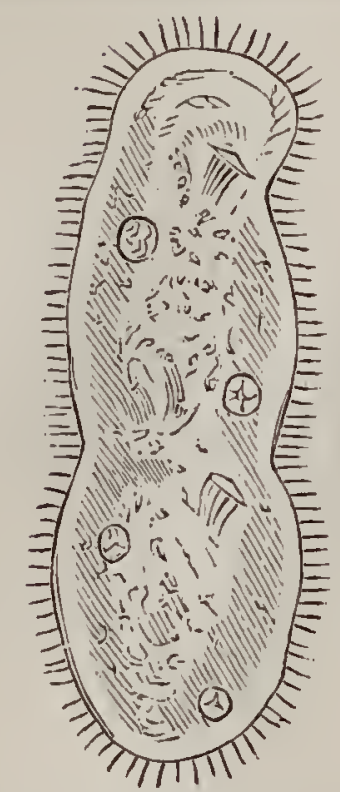

Fig. 465. - Chilodon cucullulus en voie de division. On voit les deux bouches en forme de nasse des deux individus en voie de séparation. Les deux vésicules contractiles extrêmes, en haut à gauche, en bas à droite, existaient dans l'individu primitif; les deux vésicules moyennes, droite et gauche, sont de récente formation. $(\mathrm{P}$.)

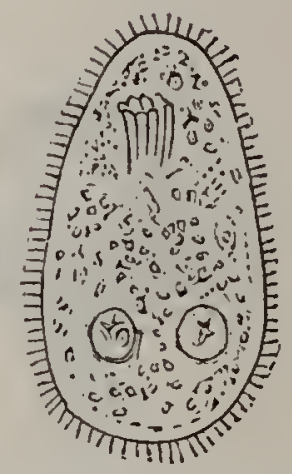

Fig. 466. - Nassula flava.

Les Erviliens sont des infusoires dont le tégument est le plus souvent aplati et formant deux valves. lls sont surtout caractérisés par une sorte d'appendice faisant fonction de pied

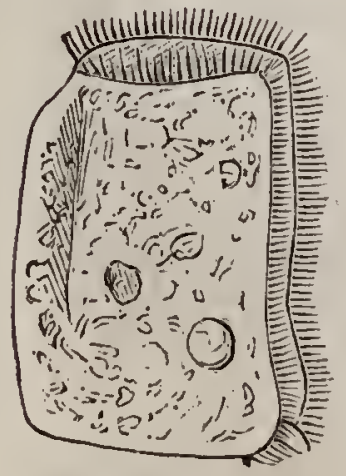

Fig. 467. - AEgizia legumen. avec lequel l'infusoire peut se fixer.

L'Agizia legumen, espèce cuirassée et à deux valves, qui vit dans les eaux douces, donne une idee exacte de cette famille d'infusoires (fig. 467 ).

Les Lacrymariens forment une famille très nombreuse possédant des individus de grande taille et d'une observation facile. Ces infusoires sont également contractiles, mais à un moindre degré que les Vorticelles et les Stentors, puisqu'ils ne peurent faire rentrer à l'intérieur leurs organes externes. Lá disposition des sillons que porte leur tégument est intéressante à étudier. En effet, suivant que cette disposition est longitudinale ou oblique, les fibres musculaires qui correspondent à ces stries, ainsi que les cils qu'elles portent, sont également longitudinaux ou obliques. Il en résulte que les espèces dont les sillons et les rangées ciliaires sont obliques ou spirales nagent en tournant autour de leur axe, tandis que celles dont les rangées ciliaires sont longitudinales nagent sans tourner sur 
CHAPITRE XX. - EXAMEN MICROSCOPIQUE DES EAUX. 749 elles-mêmes. On distingue les Lacrymaria qui sont des infusoires d'eau douce, dont la taille est souvent considérable. La partie anté-

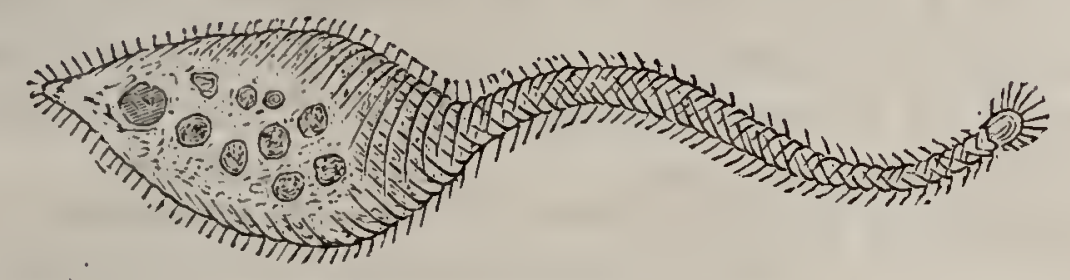

Fig. 468. - Lacrymaria olor.

rieure du corps est constituée par un prolongement terminé par une

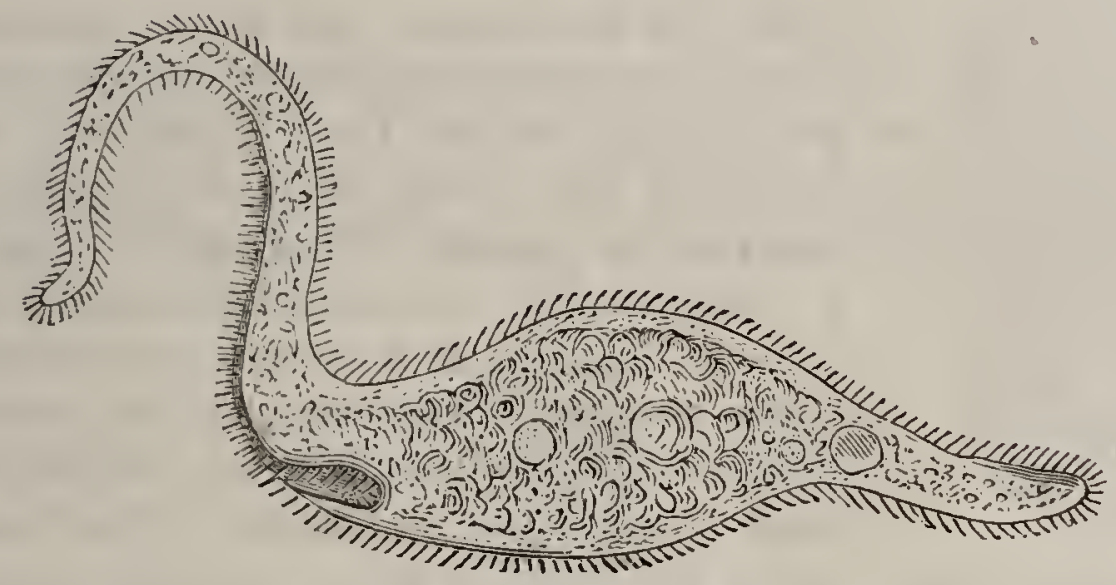

Fig. 469.-Amphileptus Cycuus.

sorte d'appendice, à l'extrémité duquel est placé l'orifice des tubes
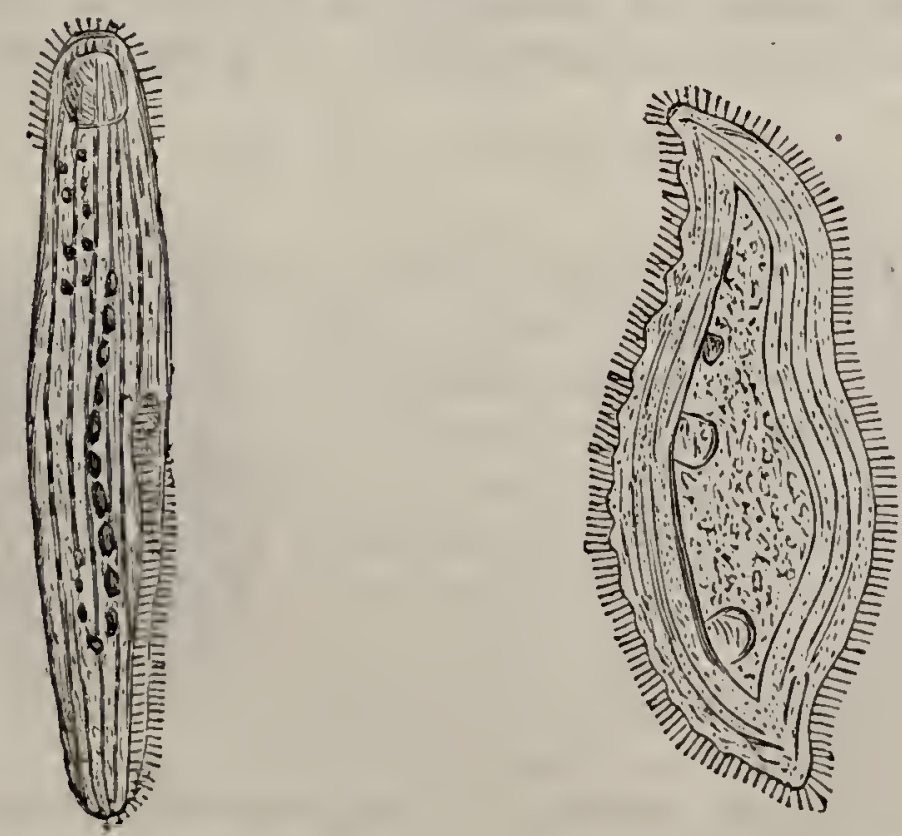

Fig. 470. - Spirostomum ambiguum. Fig. 471. - Loxophyllum meleagris. digestifs. On peut suivre la marche des substances alimentaires 
à travers ce long col, qu'elles dilatent par leur passage. Le Phialina a le col moins long et la bouche est située à la base de l'appendice qui termine le cou. Chez les Amphileptus, la bouche est située à la base du col. Les Spirostomum ont une forme vermiculaire; leur tégument est strié obliquement. Ce qui sert à distinguer surtout les Loxophyllum, c'est la zone transparente ou limbe qui les entoure. La figure 471 montre leurs deux vésicules contractiles.

Les Paraméciens ont été divisés de la façon suivante :

$1^{\circ}$ Les Paraméciens vrais qui ont un œso-

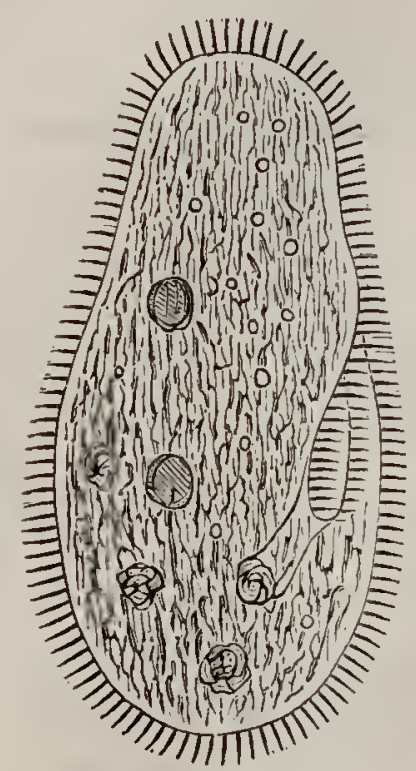

Fig. 472. - Paramecium aurelia. phage développé et visible;

$2^{\circ}$ Les Bursariens, qui n'ont pas d'œsophage visible, mais dont la bouche est toujours largement béante;

$3^{\circ}$ Les Euchéliens, qui ont la bouche petite et ordinairement fermée et ne présentent pas d'œsophage visible. Les Paraméciens ont généralement une forme ovalaire souvent acuminée vers la pointe; ils sont très communs. Le $P$. aurelia peut être considéré comme le type de cette famille. Il a le corps cilié et est muni d'une longue frange buccale non terminée en spire. La bouche aboutit à un œsophage long et droit. On voit sur la figure $4 \tau 2$ les deux vésicules contractiles dans lesquelles on parvient mieux que chez les autres infusoires à observer les vacuoles qui s'y ouvrent et se dilatent lors de la systole de la vésicule.

Le $\boldsymbol{P}$. coli (Malmsten) vit dans le gros intestin de l'homme, on le trouve dans les matières diarrhéiques (V. Matières fécales).

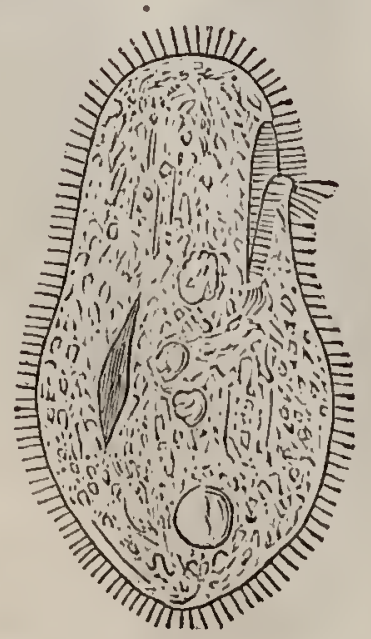

Fig. 473. - Kolpoda cucullus.

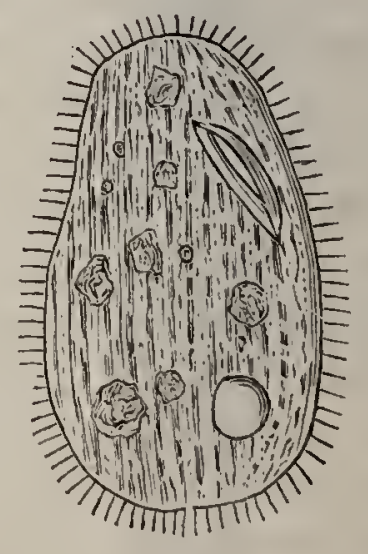

Fig. 474. - Glaucoma scintillans.

Les Bursariens sont caractérisés par une vaste cavité buccale en entonnoir, garnie de cils sur ses bords et portant dans sa cavité une 
crête garnie de cirrhes plus vigoureux (V. Parasites des organes génitaux de la femme).

Les Kolpodes sont des infusoires très communs et assez petits; on les trouve dans presque toutes les eaux stagnantes, et ils apparaissent rapidement dans les infusions végétales. Ils sont ovalaires et, au lieu de la crète buccale des Bursariens, ont la lèvre inférieure ciliée.

Parmi les Euchéliens, nous ne citerons que le genre Glaucoma, dont la bouche est latérale et munie de deux lèvres vibratiles. Le Glaucoma scintillans se développe rapidement dans les infusions végétales (fig. 474).

Les Colépiens (Ehrenberg) forment une classe tout à fait particulière dans les Infusoires. Ils ont une forme symétrique dont le corps est protégé par une cuirasse. A l'encontre de ce que l'on observe pour les autres infusoires, celte cuirasse survit à l'animalcule, et on la retrouve dans le dépôt abandonné par l'eau qui a contenu des Coleps; elle est percée d'un grand nombre de petits trous par lesquels passent les cils de l'animalcule. La bouche, à l'ex-

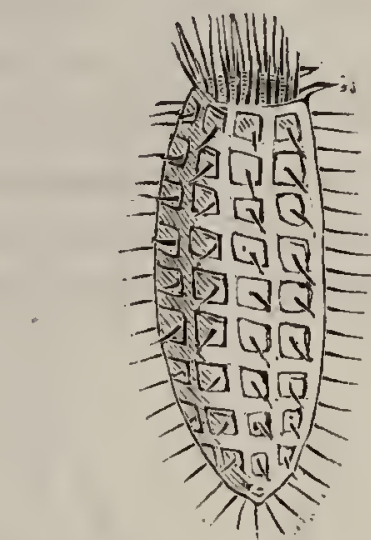

Fig. 475. - Coleps hirhus.

trémité antérieure du corps, est entourée d'une couronne de cils.

Outre les Infusoires on trouve encore dans les caux stagnantes des ètres microscopiques appelés Hhizopodes. Ils se présentent sous l'aspect d'amas gélatineux, de forme variáble, qui ont la propriété de se déplacer, de se déformer et d'émettre des prolongements. C'est à l'aide de ces formations successives qu'ils englobent les corpuscules qui peuvent servir à leur nourriture. Ce sont des amibes. Ils n'ont ni bouche, ni anus, ni tube digestif. Deux amibes qui se rencontrent peuvent se confondre et ne plus former qu'un être unique; de même, si un amibc est sectionné accidentellement en deux parties, chacune d'elles se comporte comme s'il n'était rien arrivé. Quelques espèces sont plus élevées en organisation et émettent des prolongements rétractiles que l'on appelle des pseudlopodes. Lorsque ces expansions tentaculiformes se rencontrent, clles se soudent entre 
elles et forment autour de la masse centrale un réseau dans les mailles glutineuses duquel s'invisquent les corpuscules qui servent à leur nourriture. Ceux-ci sont entrainés par un courant vers la masse centrale; des courants marchant en sens inverse vont du centre vers les pseudopodes. Les Amibes appartiennent aux Réticu-
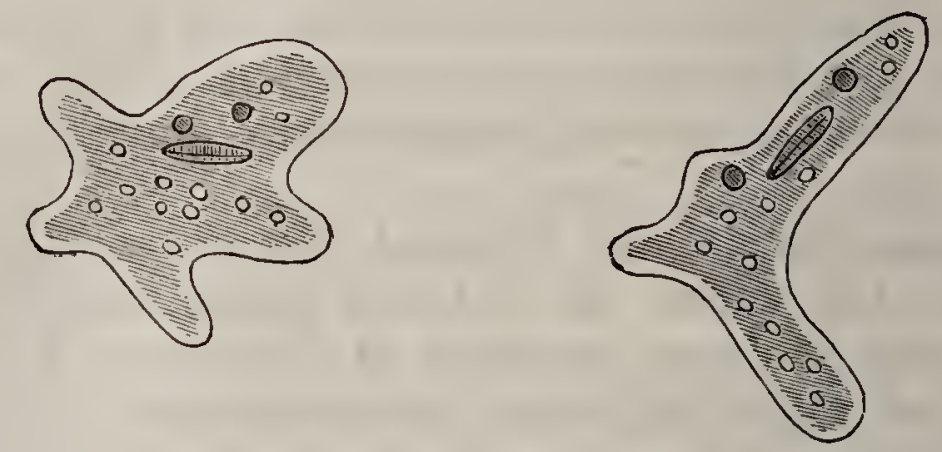

Fig. 476 et 477 . - Amæba princeps. - Deux formes successives du même animal qui a absorbé deux granules verts et une diatomée.

lariés, qui renferment des types plus parfaits, qui sont renfermés dans une sorte de coque percée d'un orifice par lequel passe une sorte de tentacule, qui émet à son tour des pseudopodes. A un moment donné le tentacule et les pseudopodes rentrent dans la coque.

On trouve encore souvent dans les mares et sur les plantes aquatiques des Radiolariés, qui sont caractérisés par la présence d'une vésicule contractile faisant souvent hernie en dehors; de la

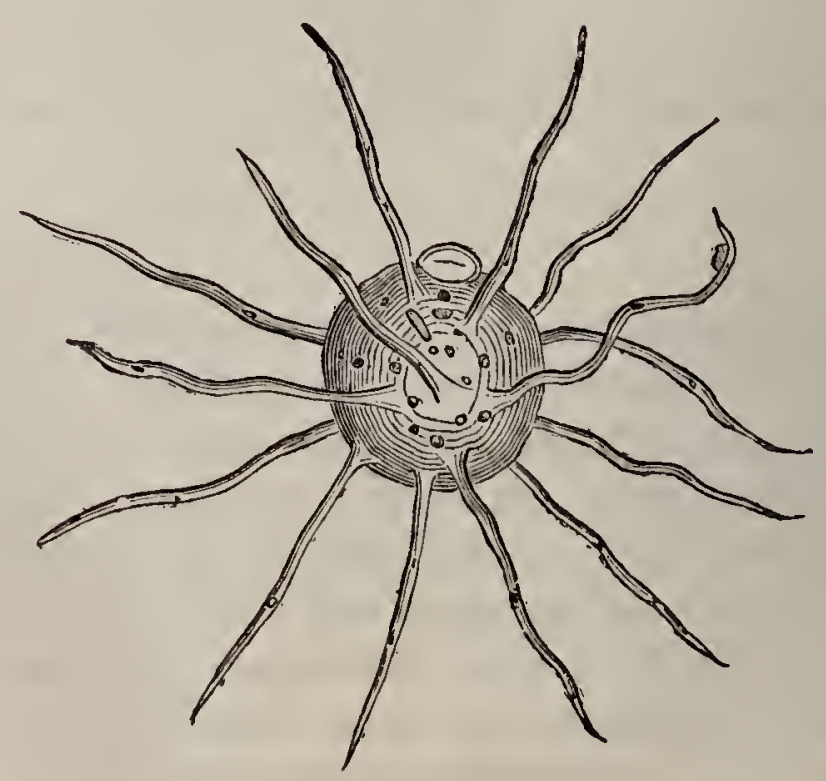

Fig. 478. - Actinophrys Sol.

masse centrale partent en rayonnant un certain nombre de pseudopodes. Les Actinoplirys donnent une idée exacte de ce groupe. Lorsqu'un infusoire vient à rencontrer l'une de ces expansions, il y reste 
agglutiné; lorsque le microzoaire par ses efforts tend à s'échapper, le pseudopode voisin vient au secours du premier. Le corpuscule est ainsi dirigé jusqu’à la masse centrale où il est englobé.

IRotateurs. - Ces microzoaires sont très communs, on les trouve au milicu des plantes aquatiques, des corps submergés, dans les eaux stagnantes, sur l'enduit des vasques des jardins publics, etc. Ils sont supéricurs en organisation aux Infusoires et aux Rhizo-

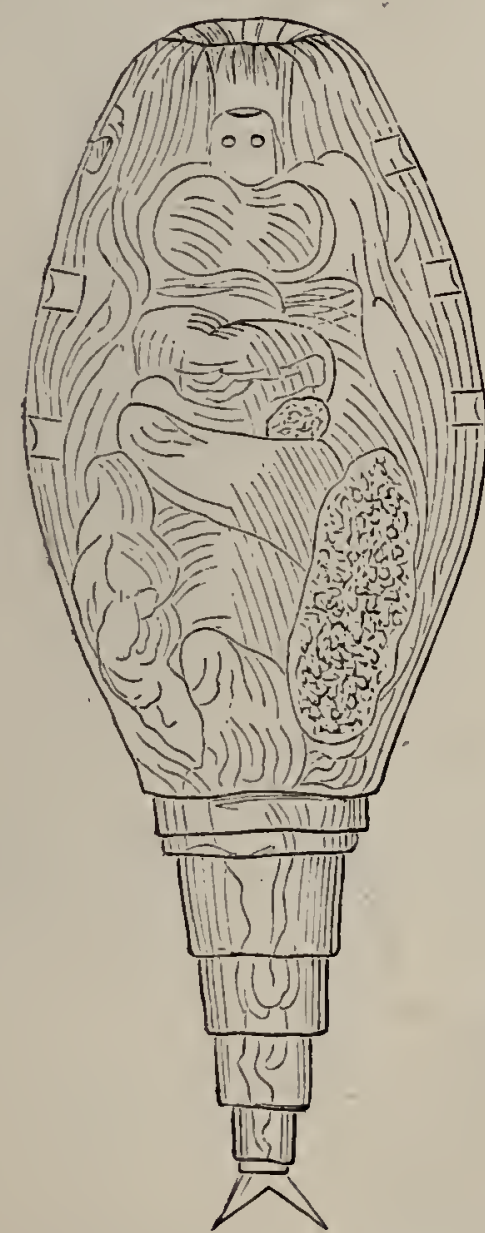

$\mathrm{B}$

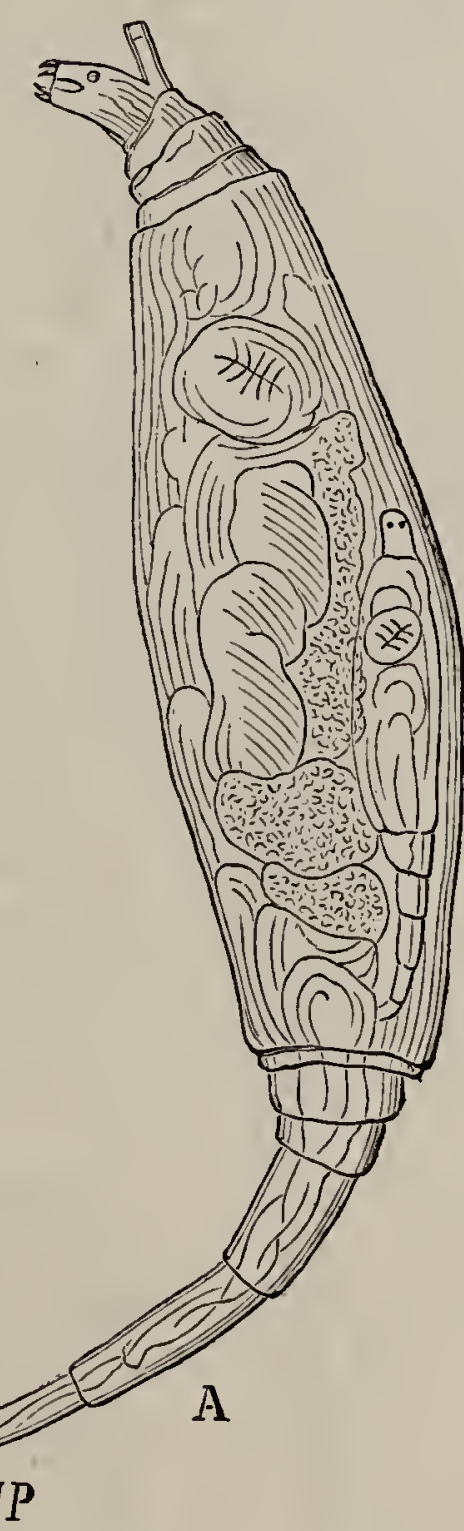

lig. 479. - Rotifer vulgaris. - A. Animal allongé; l'appareil rotateur est rétracté (l'ovaire contient un jeune). - B. Animal à demi contracté. (P.)

podes. On connait leur résistance à la dessiccation, propriété qu'ils partagent avec d'autres animalcules et des spores végétales. Ils peuvent être conservés plusieurs mois complètement desséchés en état de mort apparente, et retrouver tous les attributs de la vie, lorsque de nouveau ils sont mis en contact avec de l'eau. Comme le fait observer le docteur Pelletan, ces alternatives de dessiccation et d'humidité semblent constituer pour ces êtres microscopiques des 
conditions normales. C'est ainsi qu'on les trouve au milieu des plantes qui croissent sur les toits, où ils sont successivement soumis à l'action du soleil et à celle de la pluie; quelques-uns d'entre eux
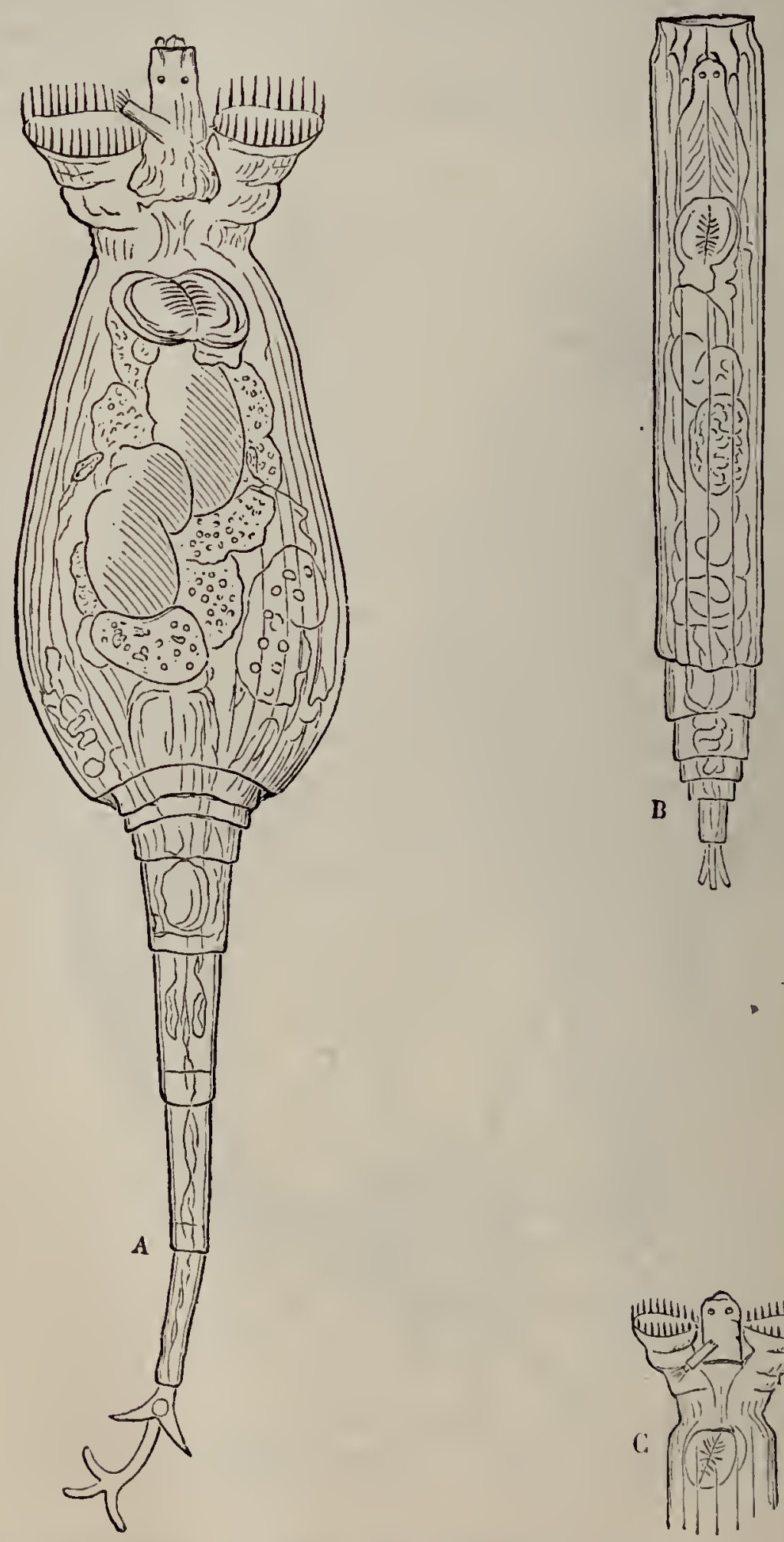

Fig. 480. - A. Rotifer inflatus. - B. Actinurus Neptunius. - C. Partie antérieure.

sont presque visibles à l'œeil nu, puisqu'ils atteignent un demi-millimèlre. Le corps des Rolateurs est ordinairement allongé, et ils peuvent à l'exemple des sangsues se fixer alternativement par la 
partie supérieure et par la partie inféricure de leur corps. Ils ont une tête amincie portant une sorte de rostre, muni de cirrhes en forme de crochets dont le rolilère paraît se servir pour se fixer aux objets qui l'entourent.

Sur la tête on remarque également deux points rouges qu'Erhenberg a décrits comme des yeux rudimentaires; le corps se renfle ensuite et au-dessus de la tête on voit passer, sur le côté, un petit appendice en forme de tube terminé par un bouquet de soies courtes qui peuvent rentrer dans l'appendice comme dans une gaîne. Suirant que l'animal est dans un état plus ou moins complet d'extension, le corps est plus ou moins globuleux et se termine par une queue ou pied qui peut s'allonger d'une façon considérable, grâce à la propriété que possède son tégument, comme celui de tout le corps, d'être formé d'anneaux qui rentrent les uns dans les autres à la manière des tubes d'une lorgnette. Le dernier article de la queue porte deux petites pièces ou cornicules pointues par le bout qui peuvent se rapprocher ou s'écarter. Ces deux pièces ne paraissent pas servir à la fixation de l'animal, c'est grâce à une ventouse situćn à leur base qu'il peut se fixer aux objets environnants. Outre les cornicules et la ventouse, la queue porte encore un organe rétractile qui dépasse les cornicules et ressemble à une main formée de trois doigts, à l'aide desquels il palpe les objets avant d'y appliquer les cornicules. Les Actinurus ont la queue munie de trois longues baguettes divergentes; les deux cornicules situées plus haut sont elles-mêmes formées de trois articles placés bout à bout. Quand le Rotifère se met en quête de sa nourriture et qu'il nage, sa tête se renverse et s'ouvre pour laisser passer des organes circulaires bordés de cirrhes vibratiles, qui se mettent à tourner comme des roues dentées, arec une grande vitesse. Par l'action de ces

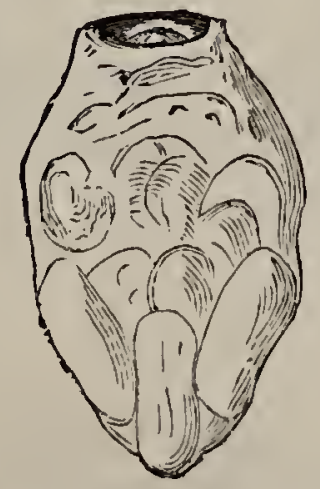

Firg. 4\$1. - Rotifer vulgaris, contracté et desséché. (Longr. 0:m , 123.; larg. 0mm,094.)

mourements vibratoires, le Rotifère détermine un tourbillon, qui amène les particules nutritives jusque dans l'osophage garni de cils vibratiles. Le Rotifère se sert également de cet appareil pour nager avec rilesse.

Grîce au pouroir contractile de leur tissu, les Rotifères peurent 
prendre une forme globuleuse; c'est celle qu'ils affectent lorsqu'ils sont soumis à la dessiccation. La tête et ses appendices rentrent dans le corps; il en est de même de la queue. Tous les Rotateurs ne sont pas contractiles au même degré; il en est dont le tégument est solide et ne recouvre qu'incomplètement les parties saillantes de la tête et de la queue.

Les IBrachioniens diffèrent des Rotifériens par différentes particularités anatomiques et en particulier par la disposition des disques munis de cirrhes vibratiles. Le corps de certaines espèces de Brachions est recouvert d'une carapace sécrétée par l'animal et à laquelle restent agglutinés les corpuscules qui sont amenés à son contact par l'appareil rotateur. (Pour plus de détails, V. Pelletan, loc. cit., p. 637 et suivantes.) Les Brachioniens se trouvent dans les mêmes conditions que les Rotifériens.
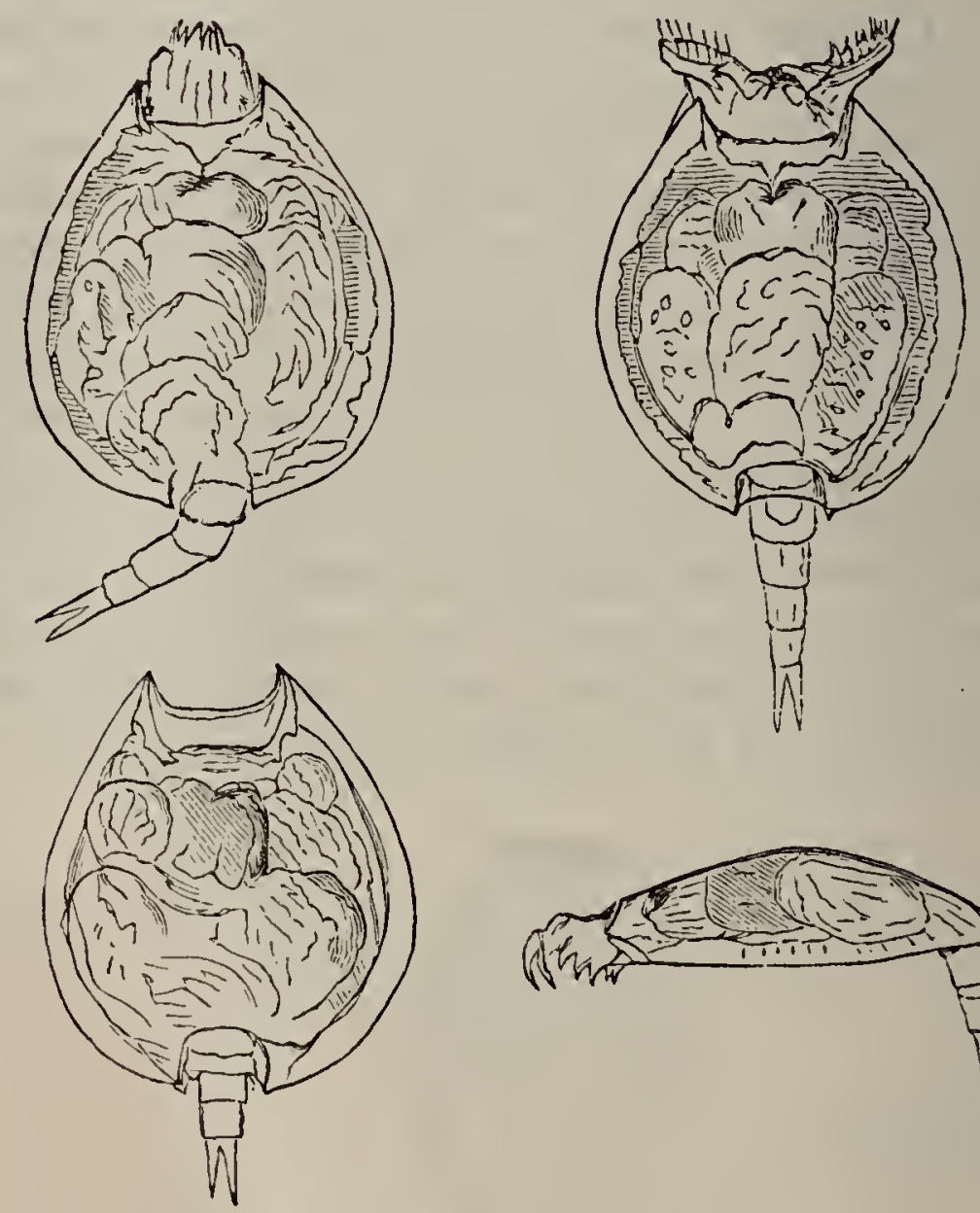

Fig. 482. - Brachioms ovatus. - En haut à gauche et en bas à droite, animal vu de face et de profil; dans les deux autres tigures, l'animal est d'une part complètement développé, avee ses disques rotateurs, et de l'autre, presque complètement rétracté. (Longueur $0 \mathrm{~mm}, 174$.$) (P.)$

A côté d'eux on rencontre également les Tardigrades qui ont comme les Rotifères la propriété de prendre la forme d'un globule. sous l'irrfluence de la dessiccation. Ils ont la forme de petits vers formés de cinq segments plus ou moins distincts. Le premier paraît constituer la tête, les quatre autres sont munis chacun 
d'une paire de pattes très courtes en forme de manchon et armées de deux ongles doubles ou de quatre ongles simples en crochets. Doyère a établi trois genres dans les Tardigrades : $1^{\circ}$ le genre Emydium; $2^{\circ}$ le genre Milnesium; $3^{\circ}$ le genre Marrobiotus. On les classe dans l'ordre des Acariens.

Nous avons vu que la plupart de ces êtres microscopiques se trouvent dans des eaux stagnantes, mais non putréfiées. Ils sont surtout très abondants dans les bassins où l'on cultive des plantes aquatiques; on peut les conserver à la condition de remplacer l'eau au fur et à mesure qu'elle s'évapore, et en y entretenant des plantes aquatiques vivantes qui s'opposent à la putréfaction. Les mouvements très rapides des Infusoires rendent leur examen difficile, il faut attendre que la goutte d'eau placée sur le porte-objet se soit évaporée en partie; les Infusoires, commençant à souffrir, ont des mouvements moins brusques, ce qui rend leur examen plus facile (1). Cette observation s'applique aux Rotifères, aux Brachions, etc.

On trouve encore dans les eaux vives et plus rarement dans certaines eaux stagnantes de très petits crustacés. Ils appartiennent aux groupes suivants: Branchiopodes, Phyllopodes, Entomostracés. Ces articulés ont tantôt une carapace formée de deux valves comme les Moules, d'autres au contraire ont une carapace formée d'une pièce unique. Leur corps se compose de segments semblables entre eux et portent des appendices qui sont des pattes-nageoires, des pattes-mâchoires ou des pattes-branchies, suivant la position qu'elles occupent. Le nombre de ces organes varie entre deux et soixante paires; il s'ensuit que leur mode de progression est variable, les uns procèdent par sauts brusques, ce qui leur a valu le nom de puces d'eau; lesautres au contraire ont des mouvements moins saccadés et peuvent nager en avant et en arrière et de côté.

Les Cypris forment une espèce très commune que l'on rencontre fréquemment dans les eaux des citernes, des puits, etc. Ils ont une carapace bivalve, par l'entrebâillement de laquelle sortentles pattes et les antennes. Au moindre danger ces crustacés s'enferment dans leur carapace. (Pour plus de dé-

(1) L'addition de quelques gouttes d'eau iodée rend leur observation moins difficile. 
tails, voir Pelletan, p. 747.) Les Cythères, qui ressemblent beaucoup aux Cypris, se rencontrent dans l'eau de mer.

On trouve très fréquemment dans les eaux douces, dans les

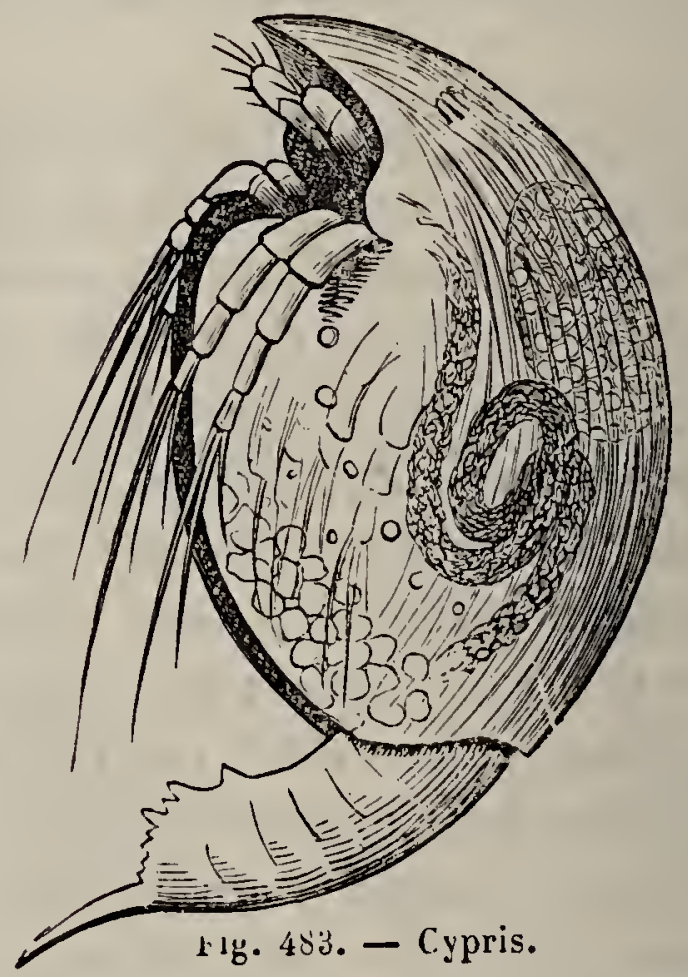

citernes, dans les puits, dans les eaux stagnantes, dans les ton-

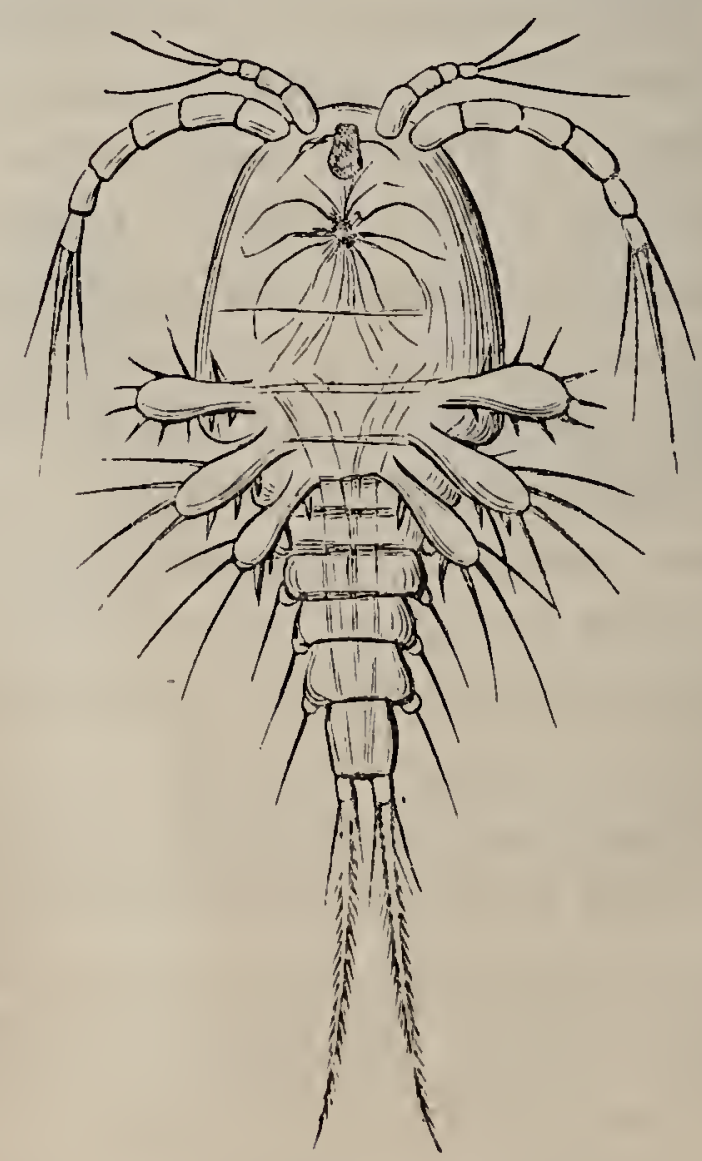

Fig. 45' - - Cyclops.

neaux d'arrosage, elc, une espèce de Cyclops appelée le 
Cyclops quadricornis. Ces crustacés sont ainsi nommés paece qu'ils ont un groupe d'ocelles qui ressemble à un œil unique. La carapace recouvre tout le céphalo-thorax, ne laissant au-dessous que le passage des pattes, qui sont au nombre de cinq paires; ils ont en outre des pattes-mâchoires, des mandibules, et deux paires d'antennes.

La Daphnie puce d'eau (Daphnia pulex) se trouve également dans presque toutes les eaux douces. La carapace de ce crustacé est bivalve. Cette espèce est également monocle. Le corps tout entier est enfermé dans la carapace.

Ce crustacé, qui n'est pas microscopique, attendu qu'il a presque un centimètre de long, pullule dans les ruisseaux, surtout dans les sources d'eau vive, dont il est en quelque sorte la caractéristique. C'est la crevette d'eau douce, rulgairement appelée encore puce d'eau. Il est reconnaissable à son corps comprimé latéralement, à son abdomen conformé de façon à agir comme un ressort, et à projeter l'animal en avant; ce dernier nage sur le flanc.

On trouvera dans l'ouvrage de Pelletan des détails très curieux sur le mode de fécondation des crustacés (loc. cit., p. 749). Ils éprouvent une série de mues qui tendent à les rapprocher de plus en plus de la forme définitive qu'ils doivent conserver. Ces cruslacés microscopiques peuvent être conservés de la même façon que les Acariens.

On signale encore dans les eaux douces des Aracinnides de l'ordre des Acariens, famille des Hydracinines, Atax, etc., qui pendant une partie de leur vie sont parasites de mollusques et d'insectes aquatiques.

\section{Conservation des Infusoires.}

Nous devons à II. A. Certes, inspecteur des finances et naturiliste distingué, un procédé qui permet de conserver les Infusoires. Pour plus d'exactitude, nous reproduirons presque intégralement la note présentée à l'Académie des sciences par ce savant histologiste

"Malgré les travaux d'Ehrenberg, de Claparède et Lachmann, de Balbiani, de Stein, etc., les micrographes n'ont jusqu'à présent à leur disposition aucun moyen d'obtenir des préparations permanentes d'Infusoires. Ces préparations offriraient cependant de nom- 
breux avantages : dessins plus exacts; possibilité de faire usage de la photographie; facilités plus grandes de reconnaître, de mesurer et de compter les cils et les appendices les plus délicats des Infusoires, de saisir et de fixer dans leur forme et dans leurs diverses transformations les individus en voie de fissiparité ou de conjugaison; de faire voyager les préparations et de créer des collections qui font actuellement défaut dans tous les muséums de l'Europe.

"Le procédé décrit ci-dessous repose essentiellement sur l'emploi des vapeurs d'acide osmique. Il ne paraît pas que cette méthode, bien connue en histologie, ait jamais été appliquée à la fixation et à la conservation des Infusoires. Je dois cependant mentionner deux Mémoires, relatifs l'un et l'autre aux Noctiluques, et dans lesquels l'acide osmique est signalé comme le réactif le mieux approprié à l'étude de ces organismes microscopiques, fort voisins des Infusoires. Le plus ancien (1866) est de M. Schultze; le second, tout récent (1878), de M. Vignal (1).

"Les Infusoires sont fixés instantanément dans leur forme par l'acide osmique ; les moindres détails, cils, cirrhes, flagellum, armature buccale, peuvent être observés avec les plus forts grossissements, lorsque les préparations sont réussies, comme elles doivent l'être ; le plus souvent les Euglènes et les Paramécies vertes conservent leur couleur caractéristique. Le noyau et le nucléole, colorés artificiellement, se détachent nettement et montrent, lorsqu'il y a lieu, les curieux phénomènes si bien décrits par M. Balbiani dans le Mémoire couronné par l'Académie en 1862.

“ I'après les réactifs employés et les précédents histologiques, on est en droit d'espérer que ces préparations se conserveront indéfiniment.

"Je ne saurais affirmer que toutes les espèces d'Infusoires sont susceptibles d'être préparées à l'acide osmique; je constaterai seulement que, parmi celles que j'ai rencontrées dans ces derniers temps, je n'en ai trouvé aucune que je n'aie réussi à conserver d'une manière plus ou moins parfaite. La principale difficulté paraît être d'obtenir les Infusoires à tissu rétractile, tels que les Stentors, les Vorticelles, etc., dans un état de complète extension.

"Procédés. - Pour la fixation des Infusoires, je fais usage d'une solution d'acide osmique (2) à 2 pour 100 . Le point important est de faire agir le réactif promptement et avec une certaine force. Deux moyens permeltent d'atteindre ce résultat avec quelque certitude; le

(1) Recherches histologiques et physiologiques sur les Noctiluques, par M. Vignal, répétiteur à l'École des Hautes Études (Archives de physsiologie, 1878).

(2) L'acide osmique est toxique; ses vapeurs peuvent déterminer une irritation et même une inflammation de la conjonctive. On doit donc le manier avec certaines précautions. Pour sa préparation et son emploi, consulter le Traité technique d'IIstologie, par L. Ranvier (p. 5 et 55). 
premier, qui convient dans la plupart des cas, consiste à exposer aux vapeurs d'acide osmique, les Infusoires préalablement déposés sur une lame de verre. En règle générale, cette exposition ne doit pas dépasser dix à trente minutes.

"Pour les Infusoires très contractiles, j’opère différemment et j’obtiens le contact immédiat de l'acide osmique en déposant une goutte du réactif sur la lamelle elle-même, avant d'en recouvrir la goutte d'eau qui les renferme.

"Quel que soit le procédé, il faut que les Infusoires ne soient soumis à l'action du réactif qu'après avoir repris leurs allures normales, qu'une secousse interrompt momentanément.

"Une fois la lamelle posée, on doit éviter tout déplacement qui pourrait écraser des organismes aussi délicats. Pour atteindre ce résultat, on soutire, avec du papier joseph, le liquide qui se trouve en. excès. On amène ainsi un certain degré de compression que l'on peut graduer avec un peu d'habitude, et qui a l'avantage de rendreles Infusoires plus transparents. Ceci fait, on lute deux des bords parallèles de la lamelle, soit avec la paraffine, soit avec le baume du Canada. Ce n'est que lorsque la préparation est ainsi mise à l'abri de tout accident mécanique que l'on fait arriver la matière colorante et le liquide conservateur.

"Les résultats obtenus avec le bleu soluble d'aniline sont loin de valoir ceux auxquels on arrive par l'emploi de l'éosine et surtout du picrocarminate de Ranvier. On peut colorer directement avec le picrocarminate les Infusoires préalablement fixés par l'acide osmique; mais, lorsqu'il est employé seul, on n'est pas maître du degré de coloration, et souvent il arrive que les préparations deviennent opaques. Après plusieurs essais, je me suis arrèté à un mélange de glycérine et de picrocarminate avec lequel on obtient une coloration constante au degré voulu :

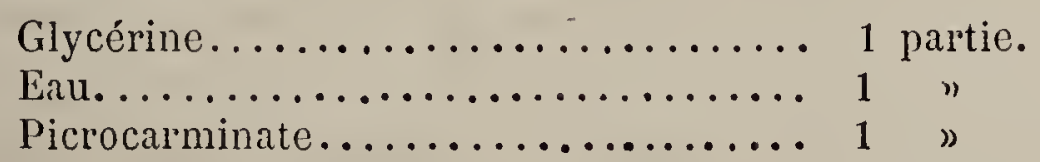

" Introduite brusquement la glycérine, même diluée, produit le plus souvent un retrait anormal des tissus qui ne disparait pas toujours avec le temps. Dans son Traité d'Histologie, M. Ranvier donne un moyen très simple d'éviter cet inconvénient, moyen que jai employé avec succès pour les organismes les plus délicats, tels que les Oxytriches et les Stentors, ll consiste à placer dans une.chambre humide les préparations lutées ainsi qu'il est dit ci-dessus et à déposer une goutte de glycérine carminée sur le bord de la préparation. L'eau s'évapore très lentement et au bout de vingt-quatre heures se trouve remplacée par la glycérine diluée. On peut alors, par le même procédé, remplacer la glycérine diluée par de la glycérine 
concentrèe, qui assure plus efficacement la conservation des préparations.

"Tous les modes de fermeture peuvent être appliquís aux préparations faites d'après les procédés que j’indique. Il y a cependant avantage à se servir de baume de Canada desséché et dissous dans le chloroforme. L'Infusoire que l'on veut examiner peut, en effet, se trouver sur le bord de la lamelle. Ce vernis, mince et parfaitement transparent, n'empèche nullement l'observation avec les plus forts grossissements.»

Examen microscopique des eatux de pluie (1). - Pour faire cet examen, il est nécessaire d'employer au moins un grossissement de 500 diamètres. On aperçoit alors dans l'eau un grand nombre de corpuscules divers, appartenant au règne animal, végétal ou minéral; des grains de sable, de calcaire, de charbon, des débris d'étoffe, de bois, des parcelles animées de mouvement brownien, des grains de fécule, des grains de pollen, et quelquefois des bactéries. M. G. Tissandier, qui faisait ses observations au bord de la mer, a même rencontré une stellaire microscopique à douze rayons. Ainsi que nous le verrons dans le chapitre suivant, la nature des corpuscules que l'on trouve dans les eaux de pluie varie suivant les lieux où les observations sont faites.

Corpuscules contenus dans l'eau de rosée. - G. Tissandier (loc. cit., p. 30) a étudié au microscope des gouttes de rosée recueillies sur un brin d'herbe, ou formées artificiellement au moyen d'un mélange réfrigérant placé dans un tube de verre ; cet auteur a également fait usage d'éther à travers lequel il faisait passer un courant d'air. Cette eau de rosée renfermait des corpuscules indéterminés et animés d'un double mouvement de trépidation et de progression très intense, des microzoaires, des bactéries et des monades. Les produits végétaux seraient également très abondants, et M. Tissandier y aurait reconnu des grains de pollen, des grains de fécule, des sporules, des mousses, etc. Cet auteur a également figuré dans son ouvrage, des produits ayant l'aspect de mousses et de moisissures, d'un beau jaune clair ou d'un vert très tendre; des algues, des corpuscules minéraux à surface angulaire,

(1) G. Tissandicr, Les Poussières de l'air. Paris, 157 . 
CHAPITRE XX. - EXAMEN MICROSCOPIQUe des EAUX. 763 très noirs, des corps amorphes très transparents, de la silice, etc. Les déterminations de G. Tissandier manquent un peu de précision pour ce qui regarde les substances végétales, il y aurait sur ce point de nouvelles recherches à faire.

Les nombreux corpuscules que l'on rencontre dans les eaux de pluie, dans la rosée, proviennent de l'air ; c'est donc dans l'air qu'il faut chercher l'origine de ces différents produits. Nous nous trouvons ainsi naturellement conduits à faire l'étude des poussières contenues dans l'air. 


\section{CHAPITRE XXI}

\section{GORPUSCULES ET MIASMES DE L'AIR}

Nous prendrons pour guide, dans cette étude, le très remarquable travail publié par le regretté F.-A. Pouchet, en 1870 (1). Cet illustre naturaliste, auquel la science est redevable de si belles découvertes, a fait faire de grands progrès à la micrographie de l'air.

Méthodes expérimentales. - De nombreux procédés ont été donnés pour recueillir les poussières de l'air. De tous, la méthode indiquée par F.-A. Pouchet, est certainement la plus pratique. Son appareil modifié consiste en un flacon aspirateur rempli d'eau, et par conséquent d'une capacité facile à déterminer. On fait communiquer ce flacon à l'aide d'un tube, soit avec une cloche, ouverte à sa partie supérieure, ou avec un flacon à large ouverture. L'air entre avec plus ou moins de vitesse dans cette cloche ou. dans ce flacon, suivant que l'écoulement de l'eau est plus rapide, par un tube effilé à son extrémité inférieure, le tube à entonnoir des appareils de chimie. On fait arriver l'extrémité du tube à peu de distance d'une lamelle porte-objet, sur laquelle on a préalablement déposé une goutte de glycérine. Les corpuscules contenus dans l'air sont ainsi projetés sur la goutte de glycérine, et peuvent être examinés au microscope et soumis à l'action de différents réactifs. Cet appareil, nous le répétons, est très simple et d'un emploi très commode.

On trouvera, dans le livre de G. Tissandier, la description de grands appareils, qui offrent certainement des avantages, mais qui ne sont pas transportables comme l'aéroscope de Pouchel, dans une salle d'hôpital ou dans un endroit quelconque.

II. Pasteur, pour étudier les poussières de l'air, a employé un ap-

(1) Aéroscopie. - Les corpuscules et les miasmes de l'air, par F.-A. Pouchet. Rouen, 1870 . 
pareil et une méthode différents. Son appareil se compose d'abord d'un tube qui passe à travers une fenêtre, par exemple, et communique au dehors. Ce tube renferme une petite bourre de coton-poudre, à travers laquelle passe l'air extérieur en s'y dépouillant des poussières qu'il contient. L'appel d'air est déterminé à l'aide d'un aspirateur, dont la disposition varie suivant que l'on a besoin ou non de connaitre le volume ded'air qui a passé par le tube. Après l'expérience, la bourre de coton-poudre est dissoute dans l'éther; les

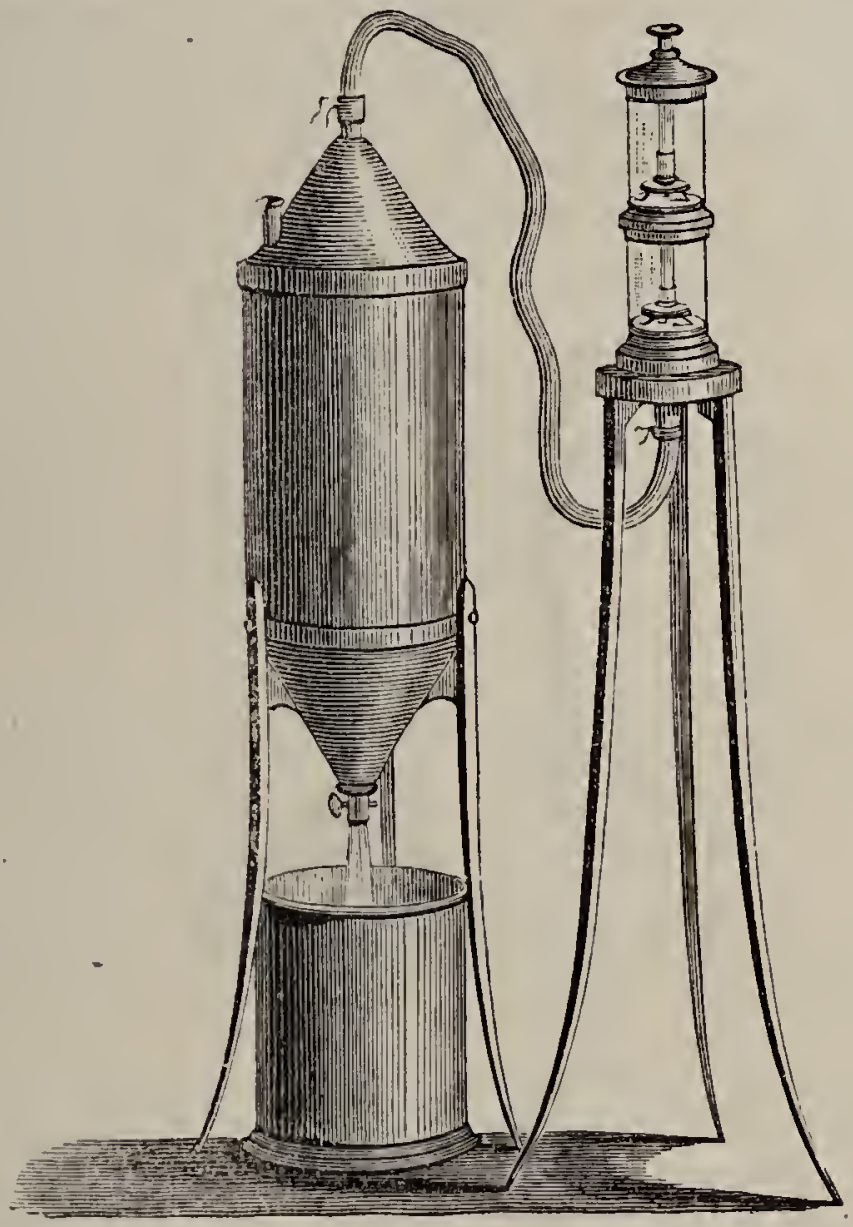

Fig. 485. - Aéroscope de Pouchet. (Grand modèle.)

poussières sont recueillies par décantation et examinées all microscope après des lavages successifs.

Un autre procédé également pratique donne aussi de bons résultats; il consiste à faire barboter de l'air dans de l'eau distillée, parfaitement pure et renfermée dans des tubes en U. Les corpuscules en suspension dans l'atmosphère se déposent et peuvent être examinés au microscope.

Quand un rayon de soleil pénètre dans une pièce relativement peu éclairée, il est d'observation vulgaire que les particules solides de l'atmosphère, animées d'un mourement incessant sous l'action d'une lumière éclatante, deviennent visibles à l'œil nu. Il suffit d'agiter un objet quelque peu volumineux, de frapper sur une partie quelconque 
du vêtement pour augmenter le nombre des corpuscules de ce nuage lumineux. Partout où l'air est agité, partout où l'activité et l'industrie humaines sont portées à leur maximum, comme dans nos grandes villes, l'air contient un plus grand nombre encore de corpuscules microscopiques.

M. Boussingault, cité par Tissandier, s'exprime ainsi : “L'imagination se figure aisément, mais non pas sans un cerlain dégoût, tout ce que renferment ces poussières que nous respirons sans cesse, et que l'on a parfaitement caractérisées en les nommant les immondices de l'atmosphère. Elles établissent en quelque sorte le contact entre les individus les plus éloignés les uns des autres, et bien que leur proportion, leurs effets, leur nature, soient des plus variés, ce

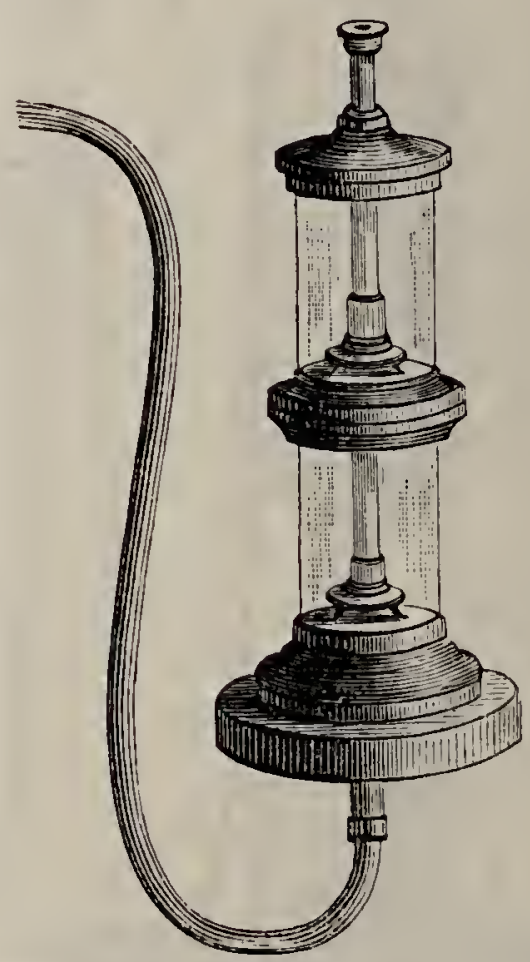

Fig. 486. - Récepteur de l’aéroscope de Pouchet.

n'est pas trop s'avancer que de leur attribuer une partie de l'insalubrité qui se manifeste ordinairement dans de grandes agglomérations d'hommes."

M. Pasteur s'exprime ainsi (Annales de physique et de chimie, t. LXIV, $3^{\mathrm{e}}$ série, 1862). "Une petite bourre de coton, exposée pendant vingt-quatre heures au courant d'air de la rue d'Ulm, pris à quelques mètres du sol, pendant l'été, après une succession de beaux jours, rassemble plusieurs milliers de corpuscules organisés, pour une aspiration d'un litre d'air environ par minute. Du reste ce résultat varie infiniment avec l'état de l'atmosphère, si l'on opère avant ou après la pluie, par un temps calme ou agité, de jour ou pendant la nuit, à une petite distance ou à une grande distance du sol. Enfin que l'on imagine les mille et une causes qui peuvent augmenter ou 
CIAPITRE XXI. - CORPUSCULES ET MIASIIES DE L'AIR. 767

diminuer le nombre de ces particules solides que tout le monde a aperçues dans un rayon du soleil qui pénètre dans une chambre obscure, et l'on comprendra tout ce qu'il peut y avoir de changements dans les résultats qui précèdent.

"Ces manifestations fort simples permettent de reconnaître qu'il y a constamment, dans l'air commun, un nombre variable de corpuscules, dont la forme et la structure annoncent quils sont organisés. Leurs dimensions s'élèvent depuis les plus petits diamètres jusqu'à $\frac{1}{100} \grave{a} \frac{1, a ̆}{100}$ et davantage de millimètre. Les uns sont parfaitement sphériques, les autres ovoïdes, leurs contours sont plus ou moins nettement creusés. Beaucoup sont tout à fait translucides, à contours nets, ressemblant tellement aux spores des moisissures les plus communes, que le plus habile micrographe ne pourrait y voir de différence.»

Laissons parler maintenant l'éloquent naturaliste rouennais qui, dans toutes ces questions, a apporté dans l'observation une exactitude vraiment admirable.

"Ce qui flotte dans le rayon de lumiere, ce ne sont pas les introuvables germes des panspermistes, mais ce sont : des débris de notre globe et de sa tunique de verdure; des débris de nos habitations et de tous nos édifices; des débris de nos vètements et de notre nourriture; enfin des débris d'animaux mêlés à des débris de notre propre substance. Pour des œufs et des semences, il est impossible qu'il n'y en ait pas aussi, mais on ne les y rencontre que comme de rares exceptions, comme on y rencontre parfois quelques cadarres d'animaux ou de plantes microscopiques. Nous sommes déjà assez effrayés, en voyant toutes ces particules qui doivent être humées à chaque instant par nous; mais ne serions-nous pas plus épouvantés encore, si, comme le veulent quelques savants aujourd'hui, tout cela n'élait composé que de légions d'œufs ou de spores, dont les produits ront envahir notre organisme."

Lair, comme nous l'avons vu plus haut, n'est pas toujours aussi riche en corpuscules organiques; la pluie, la neige, la grêle, les grands courants aériens, servent en quelque sorte à son épuration. "La neige, dit F.-A. Pouchet (loc. cit., p. 6), est le meilleur épurateur de l'air que l'on puisse citer; les flocons spongieux, formés d'éloiles cristallines entassées, récoltent dans leur chute lente et racillante les corpuscules qui se rencontrent sur leur passage. Ceux-ci, cependant, malgré leur nombre immense, n'en altèrent pas l'extrême blancheur, et 
ce n'est que lorsqu'elle fond et les condense à sa surface, qu'ils en souillent la pureté. Tout le monde est frappé de la couche épaisse de matière noire et sale, qui, au dégel, couvre les monceaux de neige en train de fondre au milieu de nos places publiques. Sans y faire beaucoup d'attention, on rapporte cette souillure à la boue des environs ou à la poussière, C'est là une grande erreur. Cette couche noire, qui ternit la neige naguère si blanche, n'est absolument formée que par les corpuscules de l'atmosphère que celle-ci a recueillis et qu'elle met à nu par sa liquéfaction. L'expérience démontre cela évidemment. Si vous mettez sous une cloche de verre, un ample morceau de neige blanche et pure, venant de tomber, aussitôt que celle-ci commence à fondre, elle prend une couleur noire qui devient d'autant plus foncée que sa liquéfaction s'avance davantage. Cette tunique de détritus, soumise à l'examen microscopique, donne à l'observateur le spectacle le plus extraordinaire et le plus varié. C'est un amas de corpuscules de toute nature, récoltés en masse depuis la région des nuages jusqu’à la surface du sol. "

Le 24 février 1860 , Pouchet, ayant observé l'eau résultant de la fusion de la neige tombée à Rouen, y trouva en abondance des parcelles de fumée, de la fécule de blé, une matière verte organisée, provenant, d'après lui, de l'enduit verdàtre qui recouvrait le monument où cette neige avait été recueillie; des grains de silice, de calcaire, de ces infusoires enkystés ou œufs de 0,0325 de diamètre, trois navicules, trois bacillaires et deux bactériums, quelques grains de pollen, des filaments de laine, et un brin de duvet d'oiseau. II. Yung (Nature, 21 septembre 1878) donne l'exemple suivant de l'épuration de l'air par la neige. Après une chute abondante de neige, cet observateur ouvrit deux tubes, renfermant un bouillon de viande, qui avait été maintenu un temps suffisant pour détruire les germes qu'il aurait pu contenir. Ces tubes avaient été fermés au chalumeau, selon le procédé classique. Le bouillon n'a pas tardé à se troubler et prit l'aspect laiteux indiquant la présence de nombreuses bactéries, puis, après quinze jours, les bactéries étant mortes et peu à peu déposées au fond du tube, le bouillon a repris sa clarté première et l'a conservée, sans qu'il s'y développât ultéricurement d'autres organismes, comme cela a toujours lieu, lorsqu'on ourre ces tubes dans les conditions ordinaires. L'auteur en tire cette conclusion que la neige avait complètement balayć l'atmosphère, à l'exception des germes de bactéries, et que c'est pour cette raison 
CHaltrRe XXI. - CORPUSCULES ET MIASMES DE L'AIR. 769 qu'elle contenait un grand nombre de spores. Ces spores ont donné naissance à des champignons qui se sont multipliés dans les conditions diverses où M. Yung les a placés.

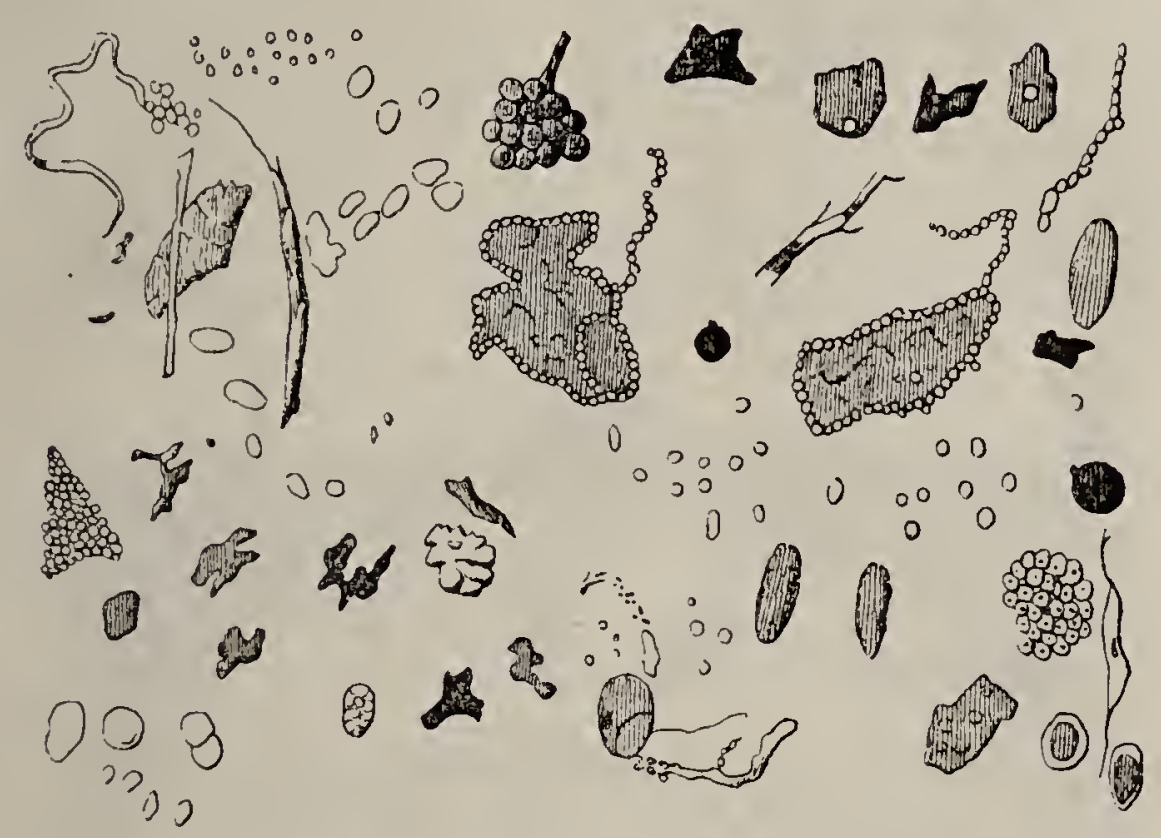

Fig. 487. - Mòle A. Poussières de la neige du MIòle, ramassées le 2ú férrier 1878. (Yung.)

Gaston Tissandier (loc. cit., p. 20) a reconnu dans la neige tombée en France du 16 décembre 1874 au $2 \partial$ du même mois, la présence

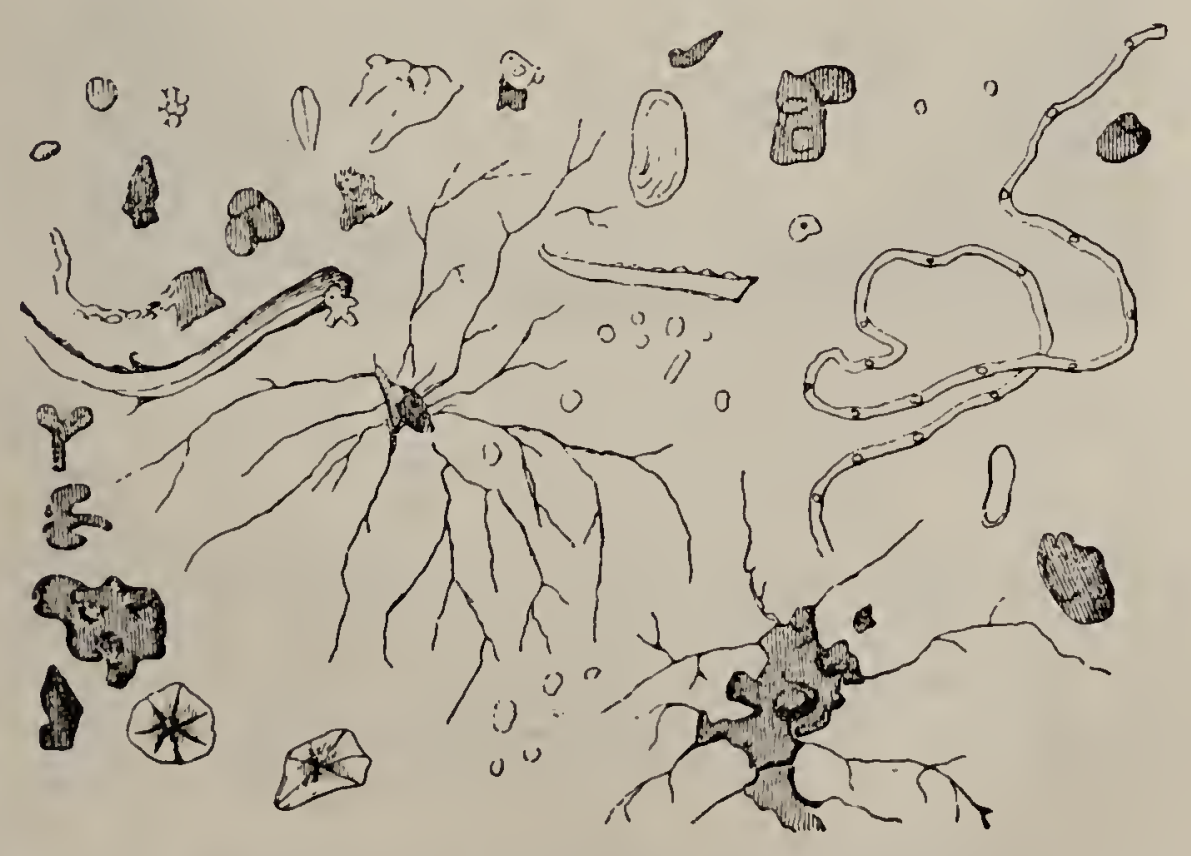

lig. 488. - Môle B. Neige ramassée au IIòle le 24 février 18z8. (Yung.)

de substances étrangères très abondantes, et metlant en évidence l'existence de matières salines étrangères. On recueillit au sommet gUIDE DE MICHOGRAPHIE. 
des tours de Notre-Dame les premières neiges du 16 décembre 18i4,

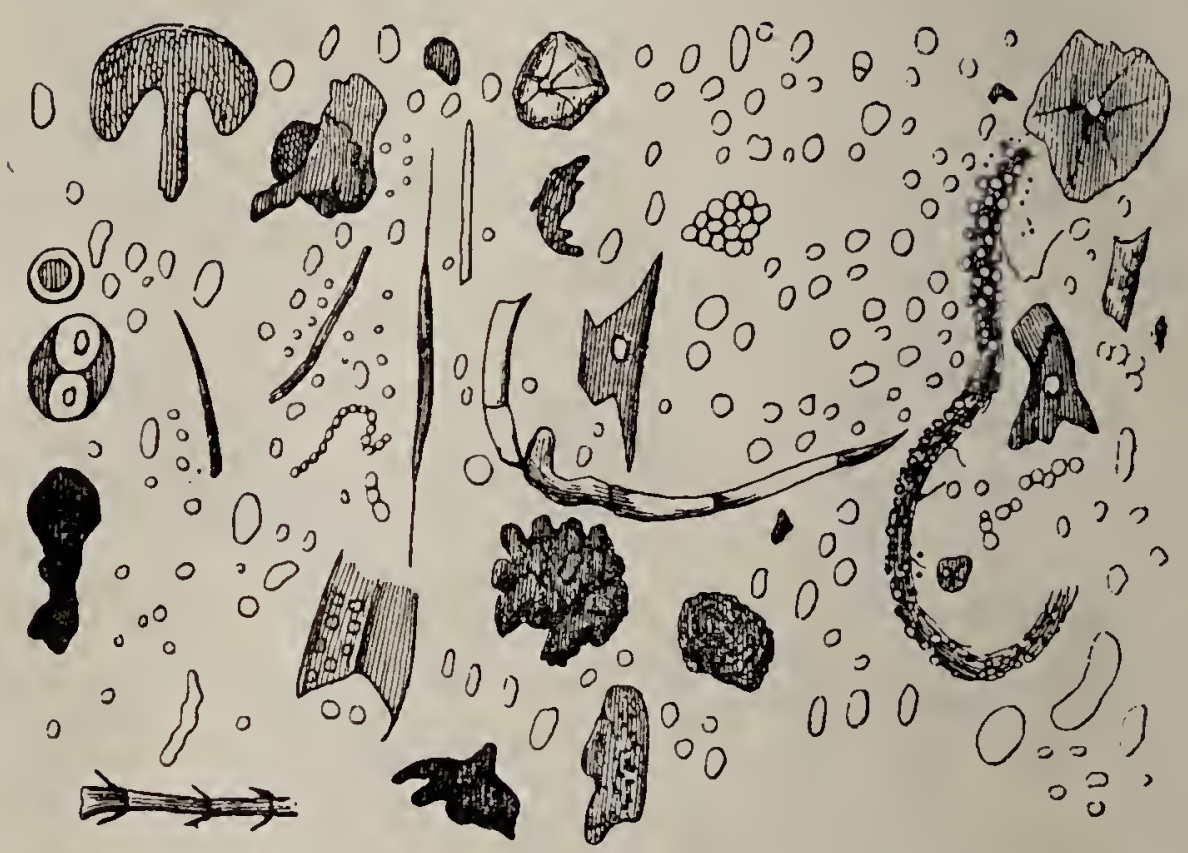

Fig. 489. - Mòle C. Poussières contenues dans la neige ramassée au Môle le 24 février 1878. (Yung.)

en ayant soin de ne prélever que les couches superficielles, n'offrant aucun contact avec les objets terrestres. Une goutte d'eau obtenue

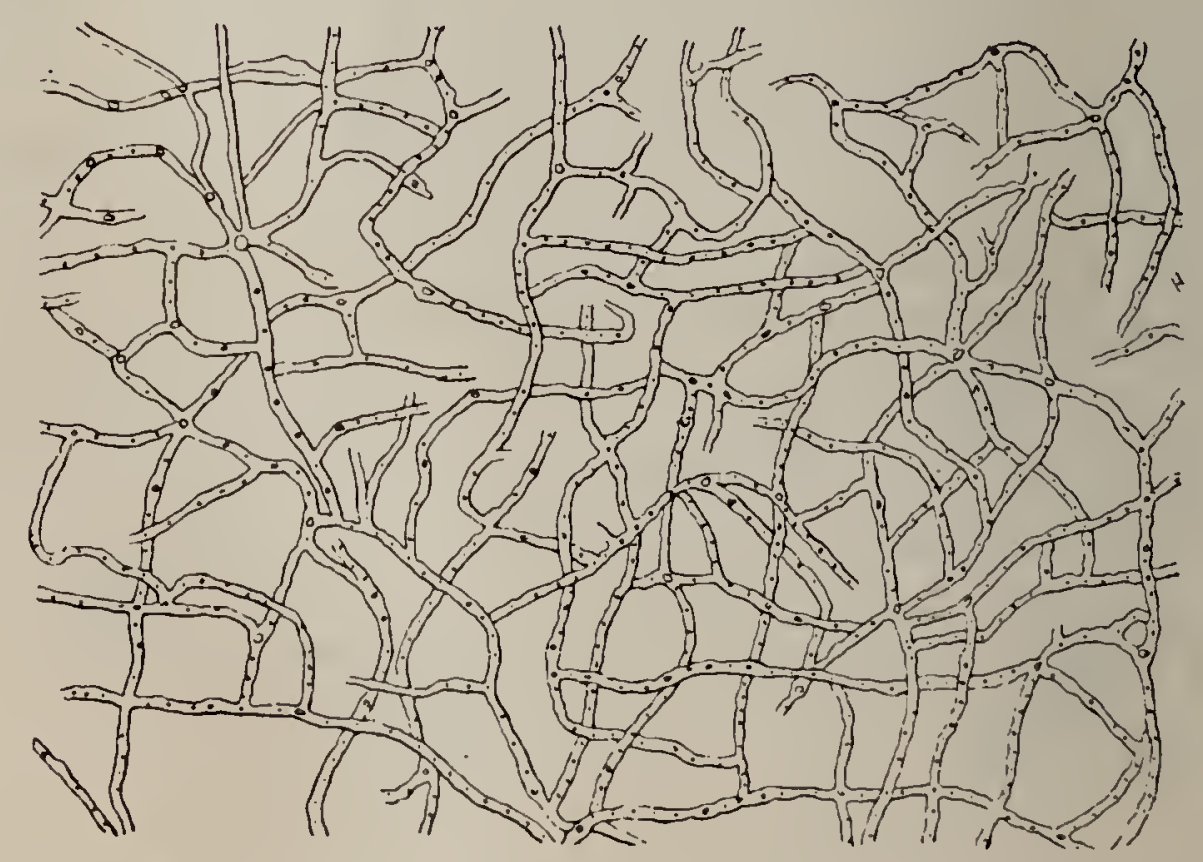

Fig. 490. - Môle D. Végétation observée au mieroscope dans la neige du Môle, après quatre jours en vase elos dans le laboratoire. (Yung.)

par la fusion de cette neige examinée au microscope, avec un grossissement de 500 diamètres, renfermait un nombre considérable. 
CHAPITRE XXI. - GORPUSCULES ET MLASMLS DE L'AIR. 771

de corpuscules. Il en fut à peu près de même pour une goutte d'eau provenant de la campagne.

G. Tissandier a analysé chimiquement le résidu de l'évaporation de l'eau provesant de la neige.

Déjà, M. Boussingault, dans les analyses d'eau de neige, y avait reconnu la présence du nitrate d'ammoniaque et l'avait dosé. G. Tissandier a mis en évidence la présence de ce composé par une méthode qu'il décrit ainsi : "Si l'on verse une goutte d'eau de neige sur une lamelle de verre et qu'on la laisse s'évaporer spontanément dans un air desséché, on aperçoit au microscope, dans le résidu

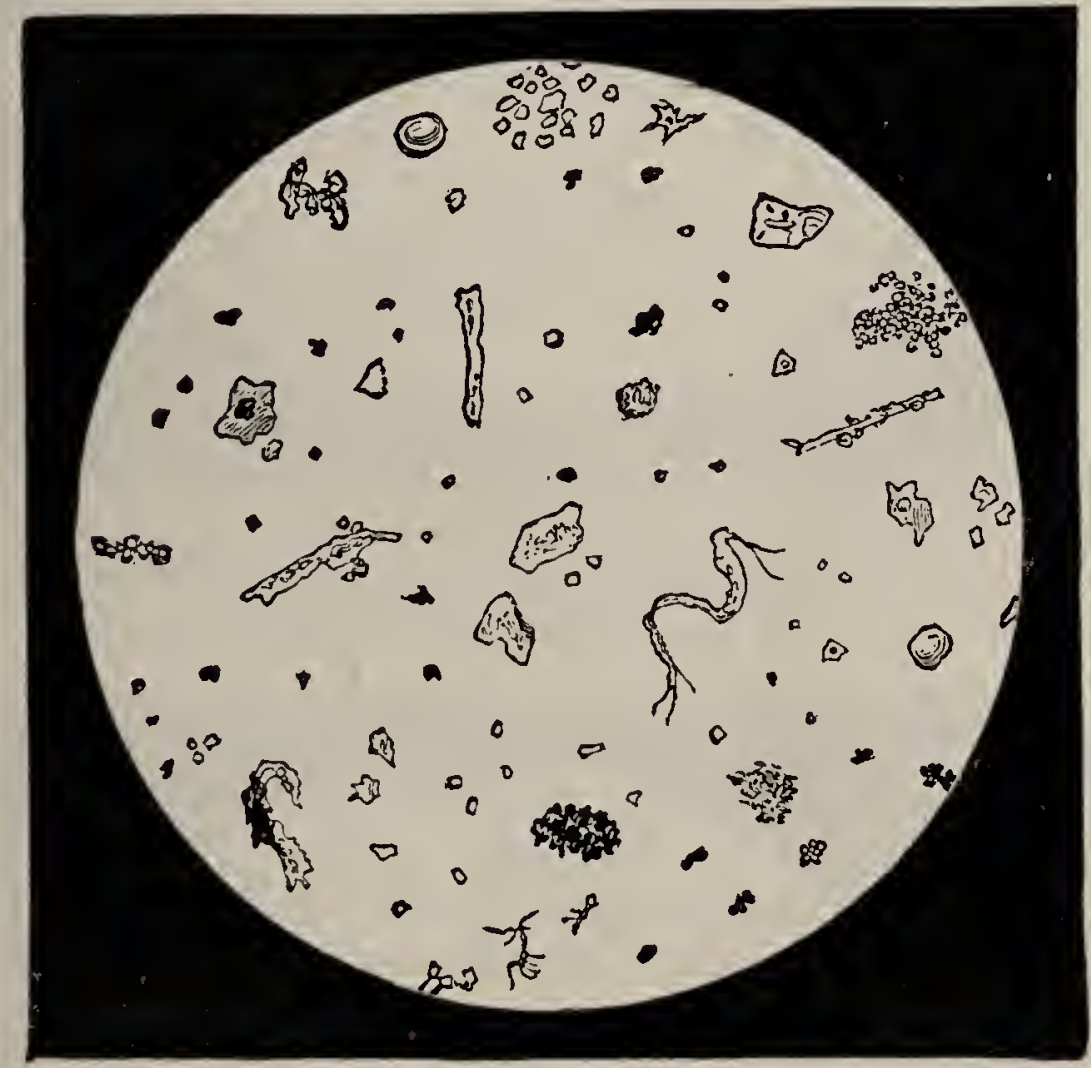

Fig. 491. - Goulte d'eau de neige vue au microscope, 500/1. (G. Tissandier.)

obtenu, des cristallisations très remarquables : tantôt ce sont de longues aiguilles, extrêmement minces, entremêlées de prismes droits à base hexagonale qui prennent naissance; tantôt on aperçoit des étoiles à six branches et des cristallisations aux contours indécis, ou les prismes se détachent d'une tige centrale, pour servir de bases à d'autres dentelures. Les figures ci-jointes (p. 773) ont été dessinées par M. Tissandier sous un grossissement de $500 \mathrm{D}$.

Pendant que les cristaux abandonnés par l'eau de neige se réunissent vers les bords extérieurs de la goutte, les corpuscules se rassemblent au centre. Ces cristaux, dit M. Tissandier, sont bien formés par du nitrate d'ammoniaque; ils se dissolvent dans l'alcool, se. dé- 
composent par la chaleur sans laisser de résidu, et renferment de l'acide nitrique el de l'ammoniaque. Outre ces cristaux de nitrate d'ammoniaque, M. Tissandier a vu aussi quelquefois des cubes nettement definis qui appartenaient probablement au chlorure de sodium. Cel observateur a vu également des prismes à quatre faces, qu'il u'a pas déterminćs; toutefois ses observations tendraicnt à les lui faire considérer comme du sulfate de soude (comples rendus de l'Académie des sciences, 4 janvier $187 \%$, et loc. cit., p. '24). La figure $49 千$ représente des cristaux obtenus à l'observatoire de Sainte-llarie du Mont. Ces c istaux sont finement dentelés; ils ont l'aspect de fougères ou de plumules d'une grande délicatesse; il y a aussi de petits cristaux légèrement arrondis sur leurs angles et gracieusement ramifies, des croix hexagonales à six branches, etc. Ces cristaux déliquescents ne tardent pas à perdre leur forme sous l'influence de l'humidité de l'air. On a pu toutefois en fixer quelques groupements par la photomicrographie.

On trouvera représentée dans la figure 49 s̆ une cristallisation très remarquable de nitrate d'ammoniaque obtenue par l'évaporation d'eau de neige.

C'est en vain que M. E. Tissandier a essayé de reproduire artificiellement ces formes cristallines de l'azotate d'ammoniaque, il n'a jamais obtenu que des cristaux uniformes. Cet auteur allribue le mode de cristallisation particulière du nitrate d'ammoniaque, dans les eaux métćoriques, à une certaine quantité de matière organique que ces eaux contiennent.

En juillet 1876, MI. G. Tissandier examina au microscope de l'eau abandonnéc par la fusion de la gréle. Il y trouva diverses algues, divers Infusoires, sans mouvements lorsque l'observation fut faite; des corpuscules organisćs sphériques; d'autres corpuscules tris abondants, animés d'un fort mouvement de trépidation. Il y avait en outre des globules sphériques, d'une transparence complète, et qui étaient constitués par une substance ayant l'apparence gélatineuse. Après l'évaporation du liquide, M. Tissandier vit un de ces globules se contracter, sous le contact d'un petit corpuscule pierreux. Il rapproche cette observation du fait suivant rapporté par Ehrenberg: "Un administrateur de la pharmacie Hocpen, près de Bielefeld, m’a appris que le 14 janvier 1860 , M. le docteur Stohlmann avait recueilli une poussière brune, dont la neige était chargée. L'ayant examinée au microscope, il y trouva, à côté de petits cristaux en quartz, des animalcules vivants, de forme sphérique, dont les plus grands avaient la forme d'une lentille. Ce n'étaient pas des Infusoires; je ne fus pas moins surpris à l'idée d'êtres organiques vivant dans la neige fondue (1)."

(1) G. Tissandier, 10c. cit., p. 30. - Bericht über die zur Bekauntmachung geeigneten Verhandlungen der Königl Preuss. Akademia der Wissenschaften zu Berlin. 1860. 


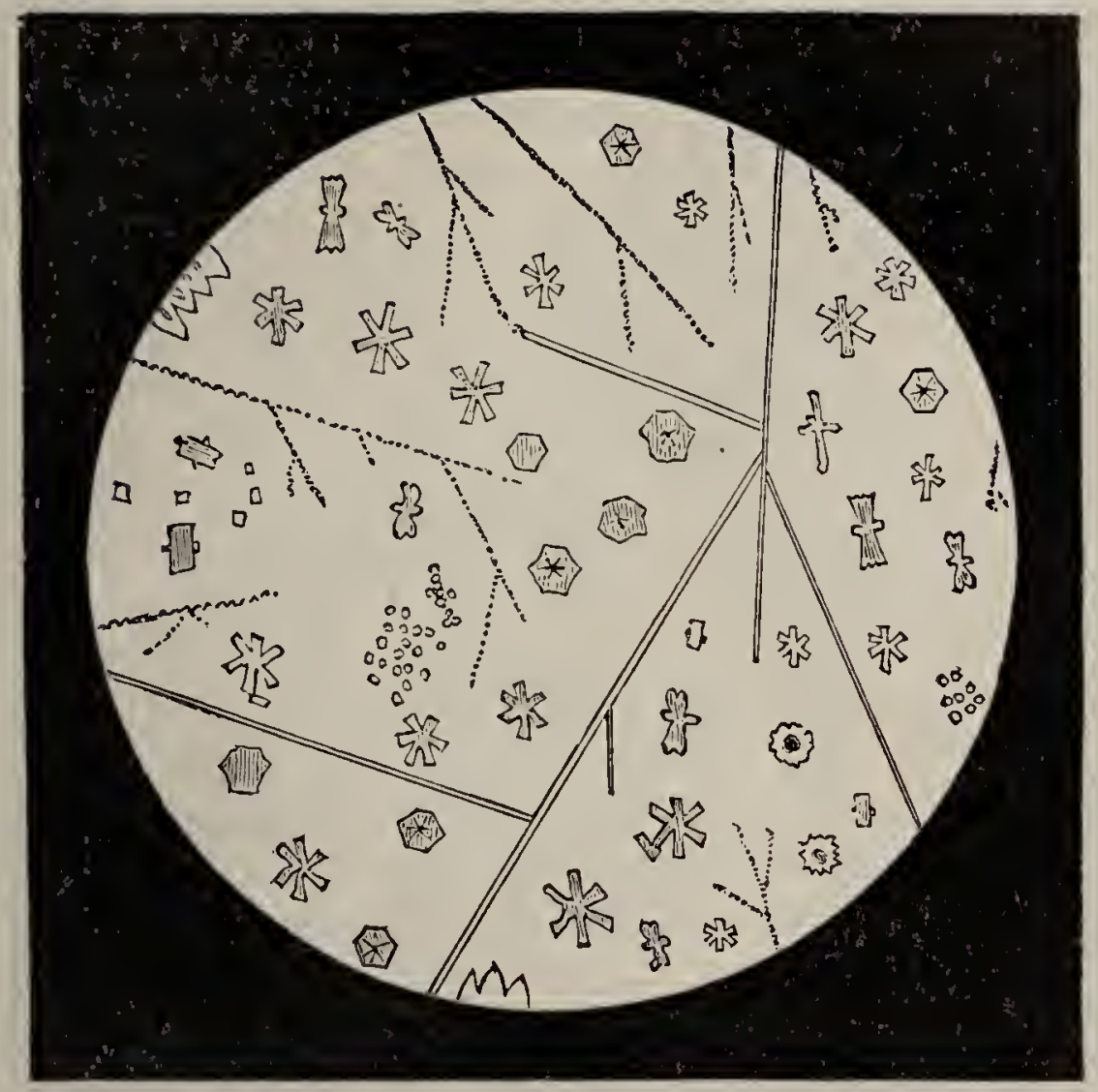

Fig. 492. - Cristallisations obtenues par l'évaporation d'une goutte d'eau de 1 eige, 500/1 (nitrate d'ammoniaque). (G. Tissandier.)

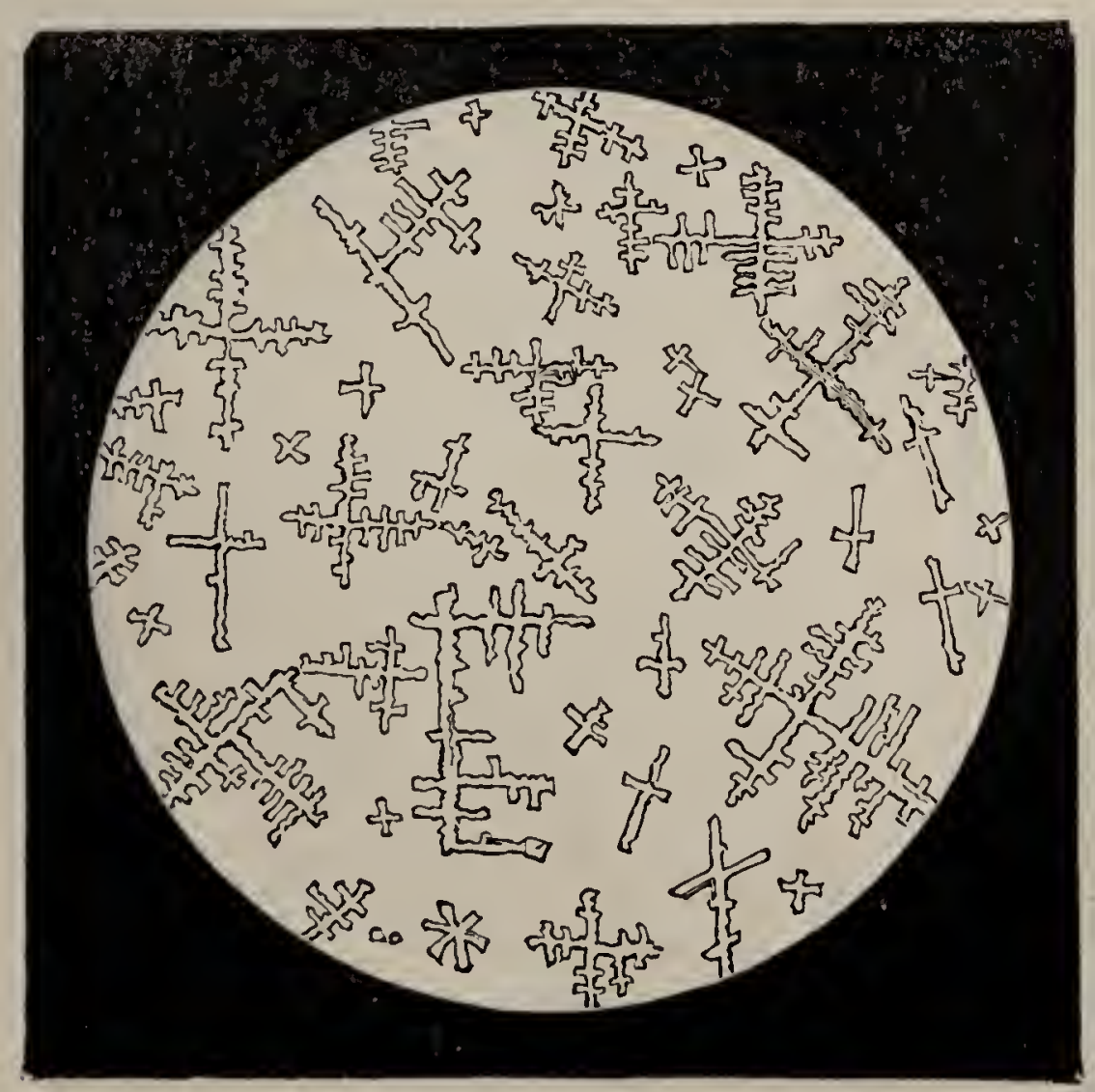

Fig. 493. - Crisłallisations obtenues par l'évaporation d'une goutte d'eau de neige, 500/1 (nitrate d'ammoniaque). (G. Tissandier.) 


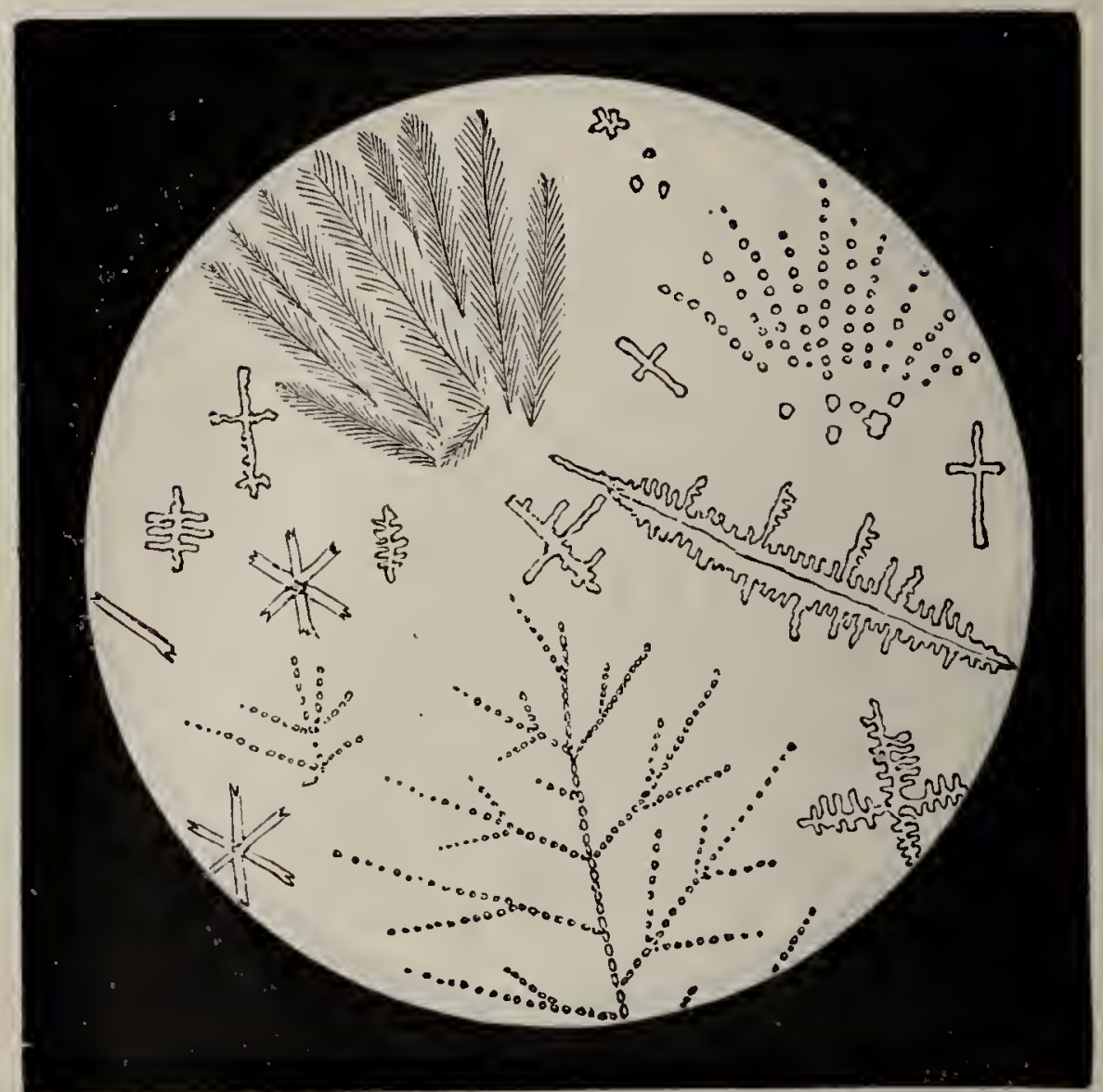

Fig. 494. - Cristallisations obtenues à sec par l'évaporation d'une goutte d'eau de pluic, 500/1. (G. Tissandier.)

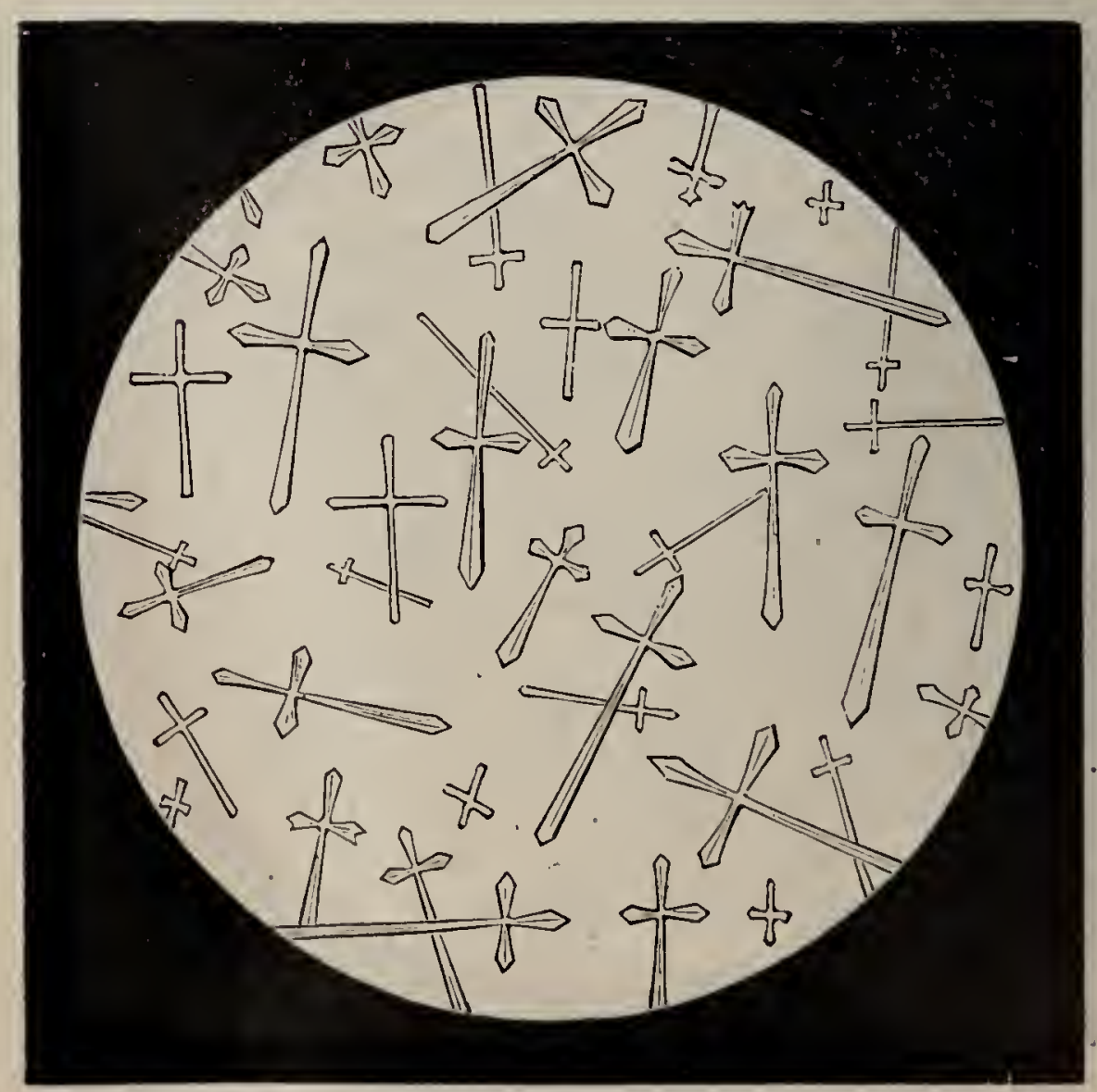

Fig. 495. - Cristallisations obtenues à sec par l'évaporation d'une goutte d'eau de neige $500 / 1$ (nitrate d'ammoniaque). (G. Tissandier.) 
Si l'eau, la neige, la grêle empruntent à l'air les différents corpuscules qu'elles entrainent, nous devons nous attendre à voir ligurer dans l'atmosphère ces différents éléments microscopiques. li-A. Pouchet divise en deux grands groupes les corpuscules de l'air : les corpuscules inorganiques et les corpuscules organiques. Ces derniers sont ordinairement représentés par des débris de plantes ou d'animaux, ou bien, plus rarement, par des cadavres entiers de ceux-ci, ou même par des animaux et des végétaux microscopiques, en pleine vie. Les corpuscules inorganiques varient de nature, suivant la constitution géologique, les matériaux avec lesquels sont construits les monuments du pays où l'air est examiné. Dans les localités où abondent les roches calcaires, les parcelles de celles-ci s'y rencontrent en masse. Sur les montagnes volcaniques, on n'observe, au contraire, que des particules provenant des roches qui les constituent, ou des corpuscules de soufre et de cendres lancés par leurs cratères. Dans les villes, ce sont des débris de nos maisons ou des peintures qui les décorent. Parmi les corpuscules inorganiques, dit encore F.-A. Pouchet, la silice, par son abondance, doit être placée au premier rang. Elle présente partout où on la rencontre des caractères certains. Sous le microscope, elle ressemble absolyment à de petits fragments de verre brisé; elle en présente les arêtes tranchantes, les pointes acérées et la transparence. D'après cet observateur, on en rencontre en si grande quantité dans l'atmosphère des grandes routes, que l'on s'étonne qu'on y puisse vivre, et que ces corpuscules acérés et tranchants pénètrent impunément dans le tissu délicat de nos poumons sans le déchirer. Parmi ces parcelles de silice, il y en a qui atteignent des dimensions assez considérables; F.-A. Pouchet en a rencontré qui ne mesurent pas moins de $0^{\mathrm{mm}}, 0 \dot{0} 0$; il est vrai qu'à côté de ces éléments, il en est d'autres d'une extrême ténuité, qui n'apparaissent au plus fort grossissement que sous la forme de granules sphériques et transparents. F.-A. Pouchet n'hésite pas à croire que ce sont ces particules de silice que les partisans de la panspermie ont prise pour des œufs et des spores.

On retrouve la mème diversité dans les corpuscules de nature organique. Ce sont les débris de végétaux qui dominent dans les forêts et dans les plaines; dans les villes, au contraire, ce sont principalement des parcelles de nos vêtements, de nos aliments, ainsi que tout ce qui forme la base de l'industrie et du commerce. Ce qui domine par-dessus tout dans l'atmosphère des villes, d'après F.-A. Pouchet, c'est la fécule. On la rencontre sous les trois états suivants : fécule normale, fécule bleue et fécule panifiée. La fécule normale n'a perdu aucun de ses caractères physiques ou chimiques. Certains observateurs inexercés avaient également pris ces grains microscopiques de fécule, pour des œufs d'animalcules.

Cette fécule est tellement abondante dans la poussière des villes, 
qu'il suffit de brosser un peu notre peau, ou de secouer nos rêtements ou notre chevelure pour en recueillir. Les feuilles des arbres en ont toute leur surface parsemée, les insectes citadins en ont très souvent un bon nombre de grains retenus par leurs poils. Si la fécule est très abondante, partout où l'on fait usage de farine de blé, les grands courants aériens la transportent à des hauteurs et à des distances considérables. C'est ainsi que F.-A. Pouchet en a recueilli au sommet du mont Blanc. "J'en ai rencontré (p. 13, loc. cit.), dans les plus inaccessibles détours de nos vieilles cathédrales gothiques, mêlée à de la poussière noircie par les siècles. J'en ai aussi rencontré dans les palais ou les hypogées de la Thébaïde, où elle datait peut-être de l'époque des Pharaons. Ici, j'en ai même trouré qui s'était insinuée à l’intérieur du crâne de certains animaux embaumés. Douée d'une puissance prodigieuse de conservation, les années semblent à peine l'altérer. Seulement celle qui remonte à une haute antiquité est moins lisse que la fécule récente. L'iode lui donne une teinte bleue plus foncée, et elle polarise moins bien la lumière. "

La fécule bleue est au contraire assez rare et on ne la rencontre guère que dans la poussière des vieux monuments et dans la fécule que la neige a enlevée aux hautes régions de l'atmosphère. Pouchet émet l'hỵpothèse que cette coloration pourrait être attribuée à l'iode, dont M. Chatin a découvert l'existence dans l'air.

La fécule panifiée est au contraire très abondante dans l'atmosphère des villes; elle erre dans les tourbillons, dit Pouchet, comme autant de miettes de pain microscopiques, qu'un observateur exercé discerne sans s'y méprendre.

Quant aux fils détachés des étoffes qui nous servent de vêtements, leur nature varie également suivant le milieu où l'observation est faite; la soie, la laine teinte de couleurs plus ou moins vives, ou des filaments grossiers de couleurs sombres, peuvent être rencontrés.

Dans l'atmosphère des villes, surtout dans celles qui ont une industrie active, on rencontre des fragments microscopiques de charbon. On reconnait facilement ces flocons de charbon à leur couleur et aux réactions négatives que nous avons déjà données. F.-A. Pouchet prétend même qu'avec l'habilude on discerne parfaitement les particules charbonneuses qui proviennent du bois de celles de la houille. Cet auteur, à propos des œufs et des spores contenus dans l'air, s'exprime ainsi :

"L'air dans lequel nous avons si souvent découvert des cadavres d'animaux microscopiques, à plus forte raison doit-il évidemment charrier quelques ouf's et quelques spores; et si parfois nous n'eussions pas surpris ceux-ci dans nos instruments, nous en admettrions l'existence $\dot{a}$ priori. 11 le faut évidemment, mais ces œufs et ces spores n'y figurent qu'en si infime nombre,qu'on n'en rencontre que par exception." 
De même que Pouchet, Ehrenberg, Burdach, de Baer et Heusche, n'ont rencontré ni les œufs ni les spores dont l'existence a été affirmée par M. Pasteur. R. Wagner et Leuckart n'ont pas été plus heureux; Schaaffhausen, de l'université de Bonn ; J. Wyman, de Cambridge (États-Unis); Bechi en Italie; Joly et Ch. Musset en France, n'ont également pas trouvé d'œufs ni de spores dans l'air. D'un autre côté, M. Pasteur et les panspermistes affirment leur existence; la question n'est donc pas encore tranchée. Si, comme le prétend Dancer, cité par Tyndall, l'air contenait 15,000 spores par décimètre cube, il n'y aurait plus de discussion possible; toutefois il ne paraît pas que d'autres observateurs aient confirmé ces résultats (1).

(1) M. Miquel a fait un certain nombre de recherches sur les microbes et les poussières organisés tenus en suspension dans l'atmosphère. Cet observateur croit pouvoir conclure : $1^{\circ}$ que le chiffre moyen des microbes de l'air, faible en liver, augmente rapidement au printemps, reste a peu près stationnaire en été et diminue en automne; $2^{\circ}$ la pluie provoque toujours la recrudescence de ces mêmes microbes.

En été, par exemple, dit M. Miqueí, à la suite d'une pluie soutenue, les instruments qui accusaient la veille 5 à 10,000 germes, en accusent plus de 100,000 le lendemain.

Voici, d'après cet auteur, la nomenclature des divers organismes que l'air cliarrie dans l'espace. Les cufs des gros Infusoires y sont rares. De l'eau de pluie introduite avec les plus grandes précautions, dans des vases plombés à col effilé ou recourbé, renferme rarement des Rotateurs, des Cyclopes, des Kerones, des Loxodes; mais on y trouve toujours des bactéries, fort souvent des Monades et quelquefois des Rhizopodes. D'un autre côté, les poussières de 40 mètres cubes ensemencées dans l'eau privée de tout germe donnent habituellement plusieurs espèces de gros Infusoires, quoiquiil soit difficile de saisir d'aborl leur's wufs, au sein des millions de germes parmi lesquels ils se trouvent égarés.

Les cellules les plus répandues dans l'air, poursuit M. Miquel, sont sans contredit les spores de Mucédinées et les semences de nombreuses productions cryptogamiques dont le diamètre varie de 2 à 20 millièmes de millimètre. Viennent ensuite les fructifications de certains champignons, dont les dimensions plus considérables atteignent parfois un dixième de millimètre; suivent les pollens de grosseur et de couleur variables; puis les grains d'amidon qui sont environ aux autres productions comme 1 est a 100. M. Miquel mentionne enfin des Algues vertes que l'air transporte quelquefois en amas volumineux. (Compte rendu de l'Acad. des siences, 1879.)

Dans un mémoire publié dans le Bulletin de la Société chimique (t. XXIX, p. 38i), M. Miquel s'est appliqué à démontrer que les germes de la Torule ammoniacale (v. p. 418) étaient répandus en abondance dans l'air de Paris, notoirement dans le parc de Montsouris. Suivant l'auteur, le meilleur moyen de se procurer la Torule ammoniacale à l'état de pureté consiste à faire bar- 
M. Ch. Robin, dans son Traité du Microscope, proteste avec raison contre l'emploi de cerlains termes de signification vague ou complexe, dont l'introduction dans le langage scientifique est de nature à faire reculer la solution de problèmes déjà très ardus.

"Le mot germe, dit cet auteur (loc. cit.,p. 871), si souvent employé par les médecins et les chimistes dans le langage général, n'a, comme le mot globule, aucune valeur scientifique, tant qu'on ne spécifie pas si le germe dont il s'agit est de nature soit régétale, soit animale :'si dans le premier cas il s'agit d'un ovule, d'un embryon sorti de l'œuf, d'une larve ou d'un animal infusoire entier, desséché ou nou ; si dans le second ce sont des spores ou des cellules de mycélium de tel ou tel groupe cryptogamique qu'on a sous les yeux. Or, on sait que si la détermination de l'espèce dont vient soit la spore ou le mycélium, soit l'ovule ou l'infusoire animal enkysté ou non, est difficile, il est toujours possible de dire si c'est un corps reproducteur animal ou végétal qui se présente. La rapide dissolution des parties animales (les enveloppes chitineuses et les épithéliums exceptés) dans l'ammoniaque, l'absolue indissolubilité, sans aucune déformation, dans

boter une cinquantaine de litres dair extérieur dans de l'urine normale stérilisée. Quatre fois sur dix la Torule apparait et fait fermenter le liquide, qui devient dès ce moment impropre à nourrir les moisissures vulgaires que l'air peut y avoir également ensemencées; il suffit alors de quelques cultures successives pour obcenir le Micrococcus urex, dans un état parfait de pureté.

M. Miquel a découvert dans l'eau d'égout puisée au grand collecteur de Clichy, un organisme de la classe des Bacillus qui possède, de même que la Torule ammoniacale, la propriété de transformer l'urée en carbonate d'ammoniaque, bien qu'il s'éloigne par son aspect pliysique de la production découverte par M. Pasteur. Ainsi la Torule se montre en chapelets de grains ou d'articles courts circulaircs (Van Tieghem, Cohn), quelquefois étranglés par leur milieu (Pasteur), tandis que le Bácillus découvert par M. Miquel. est formé de filanents très grêles, mobiles, isolés ou réunis au nombre de 2, 3, 4. La longueur moyenne de ces filaments atteint 5 ou $6 \mu$., leur largeur ćgale ì peine 7 uu 8 dixièmes de $\mu$.

Eufin, dans un milieu liumide, la Torule et ses semences meurent à une température de $54^{\circ}$ a $55^{\circ}$, maintenue pendant deux heures, tandis que le Bacillus résiste pendant le même temps ì des températures dépassant $65^{\circ}$.

Ainsi donc, deux espèces microscopiques différentes, placées dans le mẹme milieu, ont des propriétés physiologiques semblables. Pour M. Miquel, cette similitude de fonctions ne saurait surprendre depuis qu'il a été démontré qu'un certain nombre de cryptogames (Saccharomyces, Mucédinées et Mucorinces) peuvent intervertir le sucre de canne par l'intermédiaire d'un ferment inversif signalé et isolé par M. Berthelot. Il serait également intéressant de recliercher quelle part on doit réserver il l'influence des milieux, dans la transformation des formes de ces organismes inférieurs. 
ce liquide, de toutes les cellules végétales, dès qu'elles ont leur paroi cellulosique, qui pourtant arrête leurs mouvements propres quand elles en ont, donnent à cet égard des caractères différentiels très nets. Il faut toutefois noter que, lorsqu'il s'agit de spores ayant un diamètre de $0^{\mathrm{m}}, 001$ ou environ, comme celles des Leptothrix, ce moyen ne permet plus de les distinguer des granulations dites moléculaires de ce volume, qui seraient de nature cellulosique et amylacée; l'existence de celles-ci au milieu des spores est possible, mais n'est pas déterminée jusqu'à présent. »

Contrairement à l'opinion formulce par M. Pasteur et par plusieurs autres auteurs, il est possible, d'après M. Ch. Robin, de distinguer facilement dans les poussières, sous le microscope, ce qui est auf de ce qui est spore. Toute spore résiste à l'action de l'ammoniaque caustique et même à l'action de l'acide sulfurique monohydraté. Tout ovule (ou œuf) d'Infusoire, dont il vient d'être parlé, se dissout rapidement, au contraire, dans l'ammoniaque, ou dans l'acide sulfurique. Toutefois, fait observer M. Robin, il est des parties de certains Infusoires et de quelques embryons qu'elle ne dissout pas; tels sont tous leurs organes chitineux. Mais lorsque ces derniers existent, la nature animale des êtres est déjà tellement reconnaissable, d'après leurs mouvements, leur configuration, leur structure propre et leur volume, qu'il n'y a déjà plus obligation de se servir d'un réactif pour déterminer cette nature; d'autre part, si alors on l'emploie, la disposition de la masse fondamentale de l'organisme, avec conservation de ses parties squelettiques seulement, est du reste un fait très caractéristique, prouvant qu’il s'agit bien là d'un être animal, puisque rien de pareil ne se montre dans les plantes (loc. cit., p. 2:3ä).

M. Robin, considérant d'autre part que les seuls germes connus dans les inicrozoaires sont des ovules, regarde comme une hypothèse gratuite, d'admettre d'autres germes, qu'on n'aurait, d'apris lui et d'autres observateurs, jamais vus. Il n'admet pas non plus, sauf dans le cas où l'on dessèche ces ovules sur le porte-objet du microscope, qu'on en ait vu revenir de l'état sec à l'état frais dans la poussière atmosphérique. En résumé, d'après $\mathrm{M}$. Ch Robin, on ne connaît ces ovules qu'à l'élat frais, et rien, scientifiqucment parlant, n'autorise à déclarer que les corpuscules de la poussière atmosphérique, dissous par l'acide sulfurique, ressemblent en tout point aux germes des organismes les plus inférieurs et qu'ils appartiennent. sans conteste à des espèces fort nombreuses. Cela, ajoute même M. Robin, n'est certainement pas pourles microzoaires (loc.cit.,p. 87'f).

Ces considérations nous ont paru utiles à faire connaître, parce que les questions auxquelles elles s'appliquent ont divisé et divisent encore des esprits éminents. F.-A. Pouchet a 
examiné au microscope les corpuscules contenus dans l'atmosphère, de lieux très différents et très éloignés les uns des autres. Ces observations sont extrêmement instructives, et nous n'hésitons pas à les rapporter. Ce naturaliste ayant fait fonctionner son aéroscope dans un bas quartier de Constantinople, il recueillit une quantité énorme de corpuscules. Voici l'énumération des substances qui y dominaient:

De nombreux fragments de silice et d'autres parcelles minérales rouges, vertes et jaunes, de nombreux débris de costume des passants, consistant en filaments de laine, de coton, de chanvre et de soic de toutes les couleurs, blancs, bleus, jaunes, marron ou d'un beau rose; une quantité considérable de fécule de blé normale ou panifiée; enfin une énorme quantité de fragments de tissu cellulaire el vasculaire végétal provenant, la plupart, des melons d'eau, si fréquemment emplovés pour l'alimentation chez les Turcs et dont ils jettent les débris sur la voie publique. L'instrument ne recueillit jamais aucun œuf, aucune spore.

A mesure que l'on s'éloigne des grandes villes, dit F.-A. Pouchet, et que l'on gagne les solitudes de la mer ou des montagnes, on voit, successivement disparaître la fécule, la fumée et les vestiges de nos vêtements et de nos aliments.

C'est ainsi que sur le sommet de l'Etna, l'aéroscope de Pouchet ne retenait plus que des parcelles de cendres, de lave, de soufre, lancées par les cratères du volcan.

"Au milieu de la Méditerranée, entre Marseille et les Bouches de Bonifacio, l'instrument accusait encore une plus grande pureté de l'air. Celui-ci ne contenait plus que des corpuscules de silice extrêmement rares, et d'une si extraordinaire ténuité, qu'ils se rapprochaient tous de la forme sphéroïdale; aucun grain de fécule et rien qu'on puisse confondre avec un œuf ou une spore. De semblables expériences, exécutées au milieu de la mer Ionienne, donnèrent absolument les mêmes résultats."

"Les corpuscules atmosphériques que le temps amasse dans tous les monuments nous donnent les plus exactes notions sur leur situation, sur les matériaux employés à leur construction et sur l'usage auquel ils sont consacrés. Dans l'église de l'abbaye de Fécamp, construite tout en pierre, la poussière est en grande partie formée de débris calcaires provenant de l'efflorescence de la colonnade et du froissement de ses dalles. On y rencontre en outre de nombreux filaments de toute nature et de toutes couleurs, provenant des vêtements des fidèles : parmi eux, quelques poils de laine rouge ne sont évidemment que des vestiges des costumes des enfants de. chour. On y rencontre aussi de la fécule normale et de la fécule. colorée en bleu ou panifiée." 
CHAPITRE XXI. - CORPUSCULES ET MIASMES DE L'AIR. 781

I.es observations analogues faites par le naturaliste de Rouen lui ont également donné des résultats intéressants (voy. loc. cit., p. 7).

Non content de faire ces explorations dans des lieux habités,

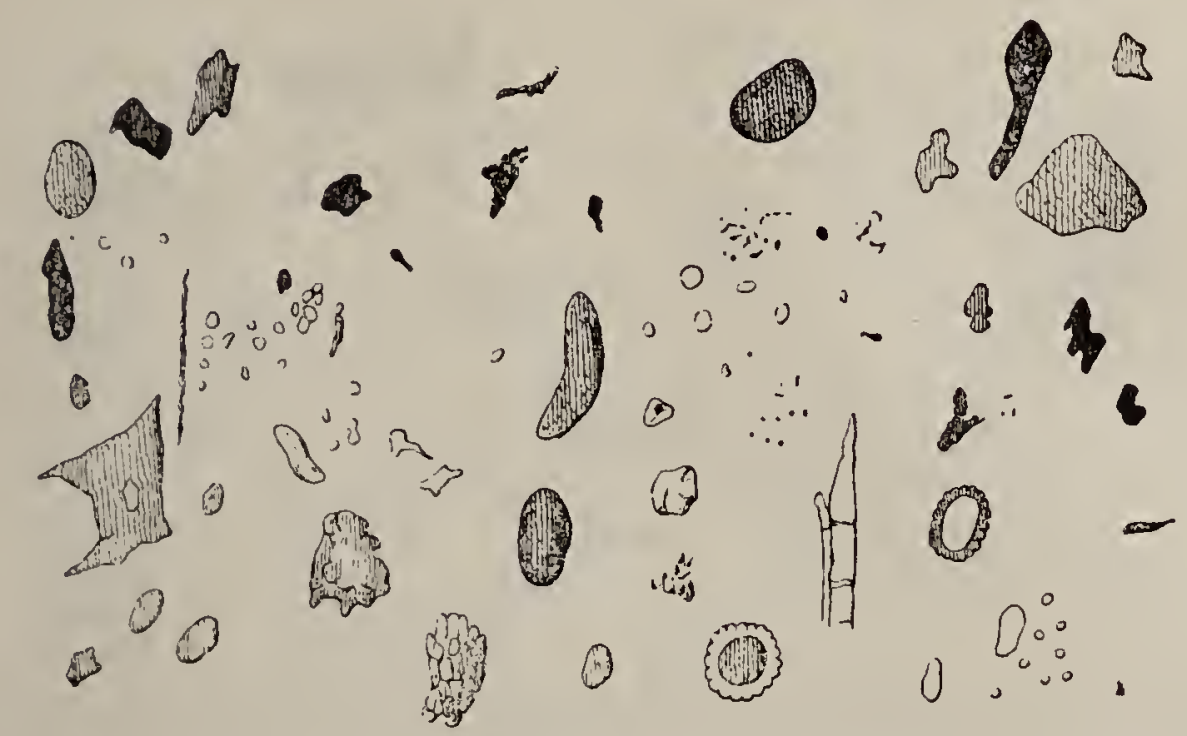

Fig. 496. - Poussières atmosphériques recueillies le 10 décembre 1878 à l'olsservatoire de Genève, à $6 \mathrm{~h}$. du soir. Baromètre, $724^{\mathrm{mm}}, 9$. Thermomètre, + 10.6. Humidité, 68 . Vent N.-E., 1. T'emps nuageux. (Yung.)

F.-A. Pouchet s'est transporté avec son aéroscope dans des solitudes uniquement peuplées de ruines. C'est ainsi qu'au milieu des restes de Thèbes, il n'a recueilli que des corpuscules siliceux provenant

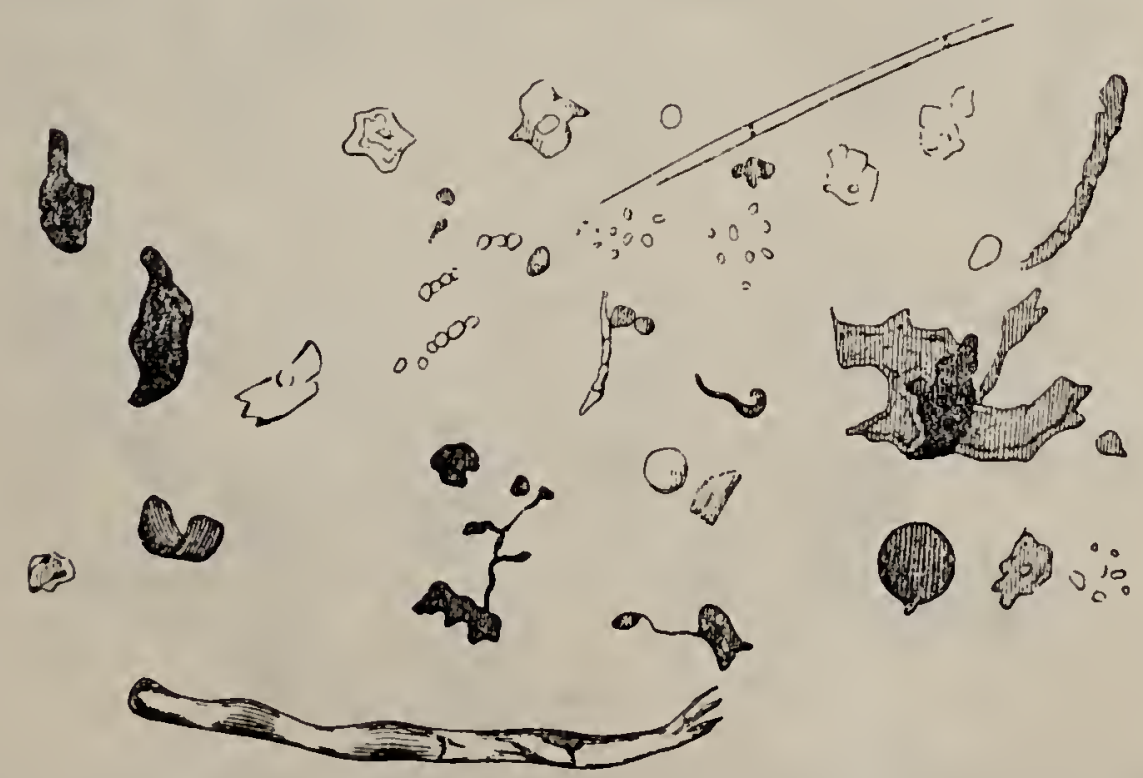

Fig. 497. - Poussières atmosphériqués recueillies le 13 décembre 1877, à 4. h. du soir. Baromètre, 728. Thermomètre, $+6 \circ, 8$. Vent S., 1. Humidite, 65. Temps couvert. (Yung.)

soit des matériaux employés à la construction de la ville, soit du sol lui-mème. Les uns avaient la forme de grains de silice à arêtes vives et tranchantes, transparents comme du cristal, et semblent 
avoir été enlevés au désert; les autres sont opalins, à angles émoussés el proviennent des détritus des colonnades de grès des temples et des palais. F.A. Pouchet y a également trouvé de la fécule de blé

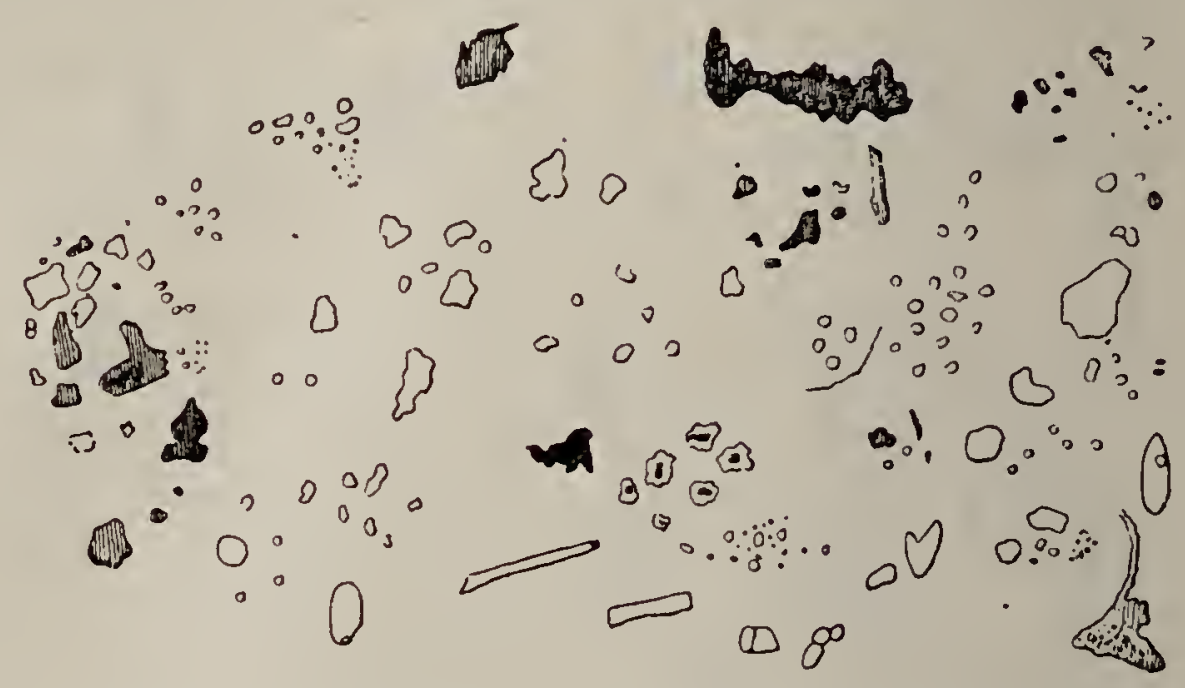

Fig. 498 - Poussières almosphériques recueillies le 22 octobre 1877 , à 6 . h. du soir. Baromètre, 731. Thermomètre, 120,5. Humidité, 40. Vent S.-S.-0., 1. Temps clair. (Yung.)

fort ancienue; des poils de laine d'un beau rouge, des poils de chameau, enfin des squelettes de bacillaires et de navicules.

"Dans le tombeau de Sésostris Ramsès II, situé au fond du dé-

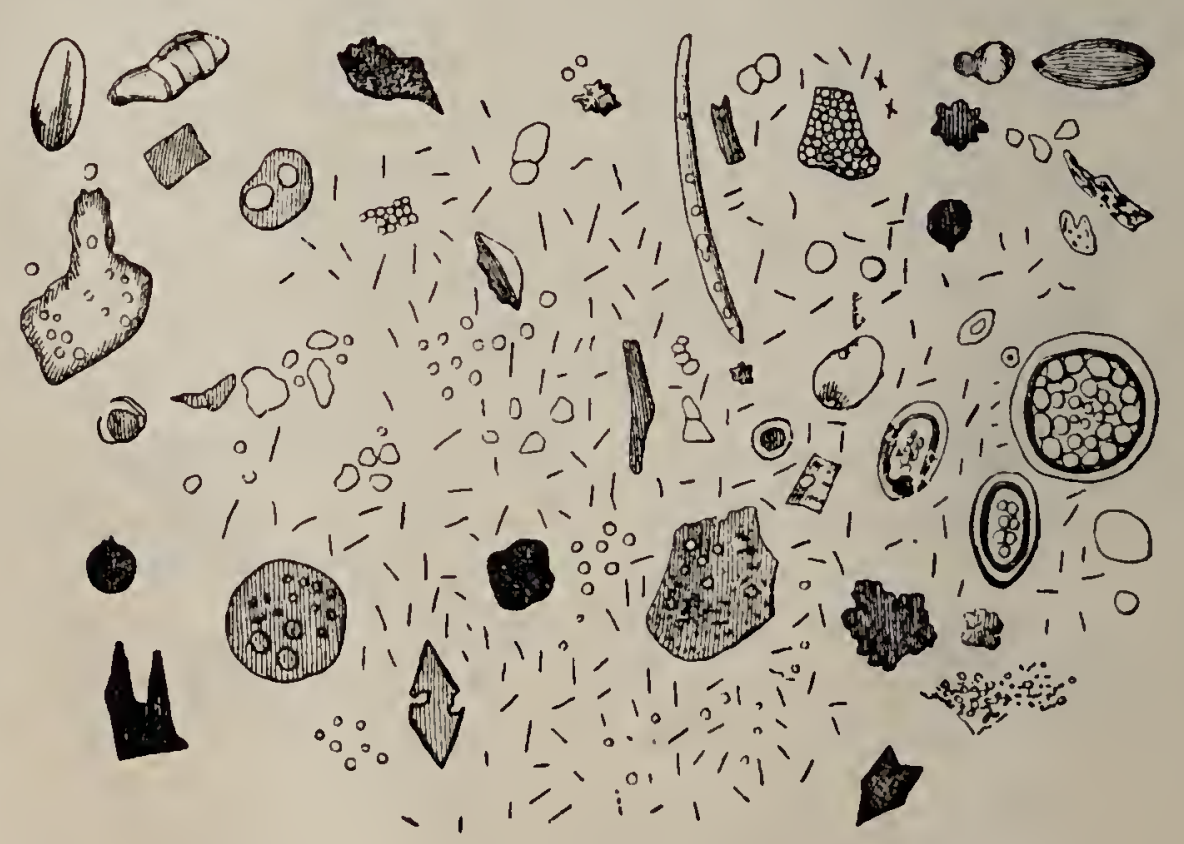

Fig. 499. - Poussières atmosphériques recueillies le 23 octobre 1877 à $8 \mathrm{~h}$. du soir. Température, $+15^{\circ}, 3$. Vent S.-0., 2. Vent violent. Ciel nuageux. (Yung.)

sert de Biban-el-Molouk, dans une vallée affreuse, brûlée par le plus ardent soleil du globe, je n'ai plus trouvé de fécule, et les autres corps organisés y étaient d'une absolue rareté. Ce qui y dominait, c'étaient des corpuscules de silice et du calcaire, mêlés à des 
GHAPITRE XXI. - CORPUSCULES ET MIASMES DE LAIR. 783 granules d'un beau vert ou d'un beau bleu, provenant de l'érosion des peintures qui ornent les chambres sépulcrales.

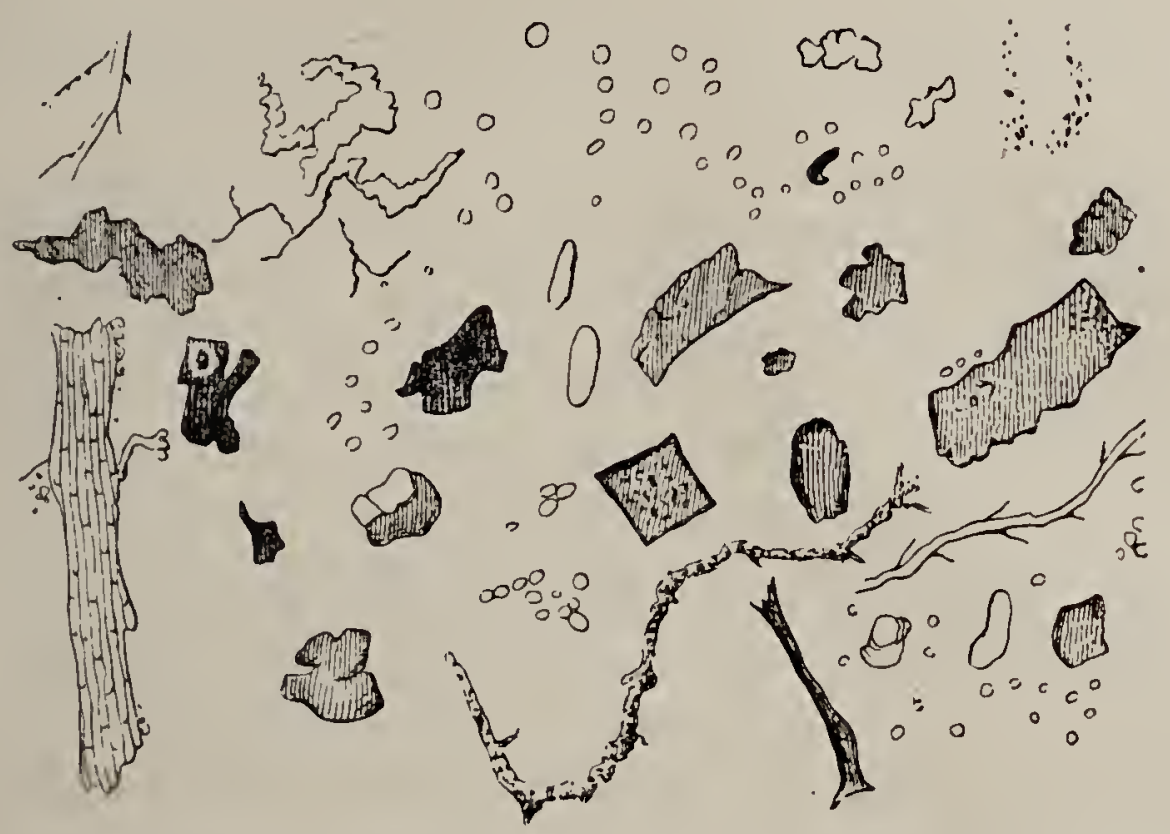

Fig. 500. - Poussières recueillies dans l'air le 18 mars 1878, de 4 h. à 8 h. du soir. Forte bise. (Yung.)

"Dans le sanctuaire de Vénus Athor, au milieu de l'air pur de

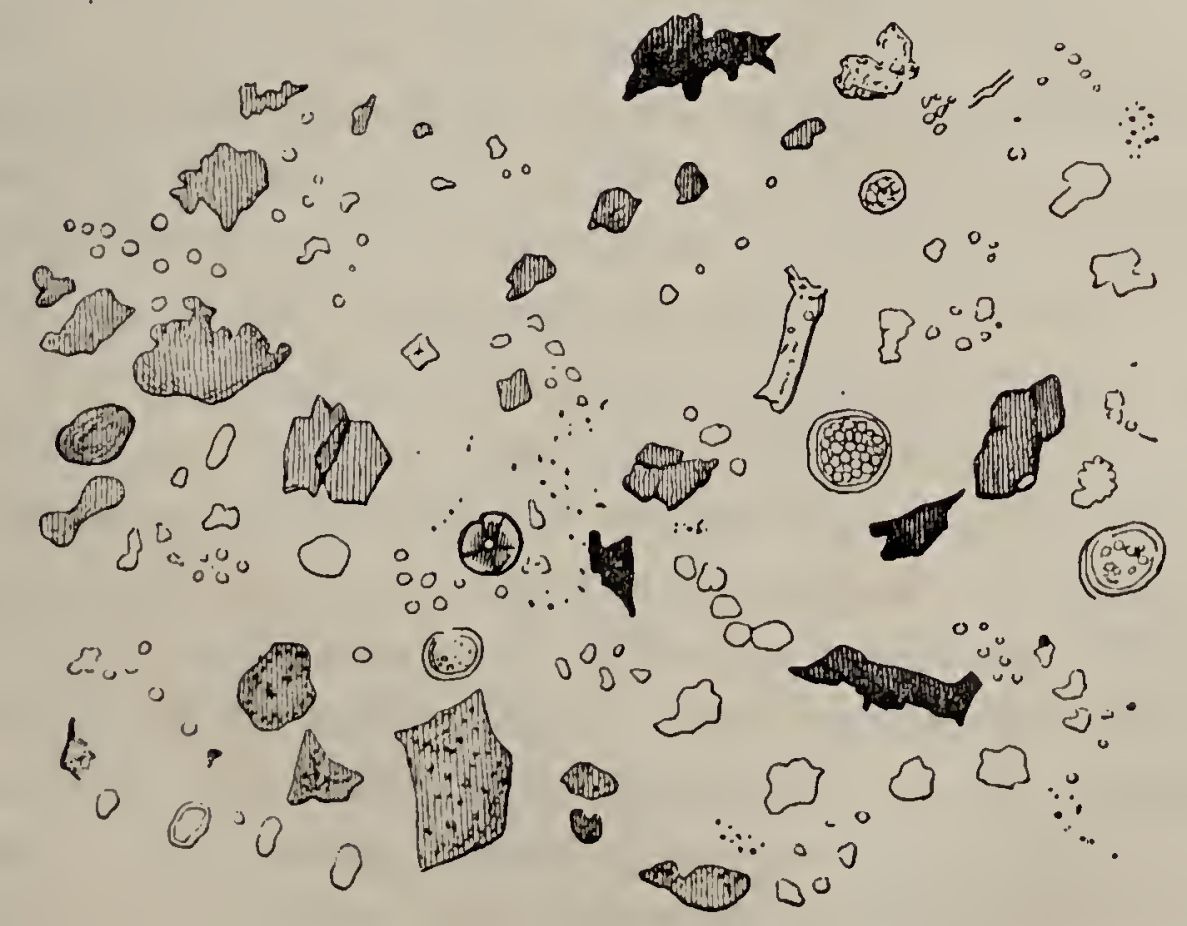

Fig. 501. - Poussières recueillıes dans l'air le 18 mars 1878, de 2 h. à 6 h. du soir. Beau temps. Bise. 'Yung.)

Philæ, les corpuscules aériens étaient fort rares et fort uniformes. lls ne se composaient guère que de parcelles de grès, provenant de 
l'efflorescence despylones et des colonnades ruinées des temples qui encombraient celte île sacrée ; puis de quclques corpuscules rouges de syénite, enlevés aux déscrts de la Nubie; enfin de quelques vestiges de limon du Nil et de plusicurs Bacillaires provenant sans doute du même fleuve. Je n'y obscrvai aucun grain de fécule. " (Loc. cit., p. 19.)

Nous trouvons dans le numéro du 21 septembre 1878 du journal la Nature, de nouvelles observations sur les corpuscules atmosphériques contenus dans l'air et dans la neige. Ces observations sont dues à M. Yung, préparateur de microscopie à l'université de Genève et ont été faites dans sette université. Cet auteur donne la préférence à l'eau sucrée sur la glycérine pour retenir les poussières; suivant lui, la solution sucréc n'altérerait pas autant les germes que la glycérine. L'eau sucrée présente l'inconvénient de s'évaporer rapidement sous l'influence du courant d'air. M. Yung conseille d'entretenir un apport d'eau sur la goutte au moyen d'un fil capillaire plongeant dans un petit verre rempli d'eau.

Nous avons reproduit, d'après le journal la Nuture, quelques-unes des figures données par M. Yung.

Applications de l'aéroscopie à l'hygiène. - Dans une foule d'industries, il se mêle à l'air, que les ouvriers respirent, des poussières qui, par un mécanisme différent, altèrent plus ou moins profondément leur santé. On a tenté par diverses améliorations de diminuer, sinon d'annihiler complètement les inconvénients attachés à la production de ces poussières, par l'emploi de masques, par l'interposition de linges, de ouate ou d'éponges mouillées, etc., par l'usage de cages de verre; mais la précaution la plus élémentaire, en même temps que la plus efficace, c'est une ventilation énergique qui renouvelle sans cesse l'air respiré par les ouvriers. Quels que soient les moyens employés, l'aéroscope fournira le moyen de voir s'ils sont suffisants. En effet, en faisant fonctionner cet appareil dans un atelier où se produisent des poussières, sur la nature desquelles on est généralement fixé, on verra si l'air inspiré est ou non capable de nuire aux personnes qui vivent dans un serrublable milieu. Les poussières peuvent agir différemment; parfois elles ont une action locale et directe sur la peau, sur les muqueuses (poudre de Cantharides, d'Euphorbe), ou bien elles agissent par action mécanique, tout en obstruant les orifices des conduits excréteurs 
des glandes cutanées el produisent ainsi des abcès; dans d'autres circonstances, chez les ouvriers qui pulvérisent des écorces, ou chez ceux qui peignent le chanvre, de fines aiguilles formées de tissu fibreux pénètrent sous la peau et provoquent des démangeaisons très vives. A côté de ces accidents purement locaux, il en existe de plus graves qui sont provoqués par l'introduction dans les voies respiratoires de particules solides très fines qui provoquent différentes affections dont la plus grave est la phthisie professionnelle. Il nous suffira de citer quelques-unes des professions dans lesquelles cette déplorable conséquence du travail a été observée, et l'on se convaincra de l'importance de ces questions que nous ne pouvons qu'effleurer. Le médecin et l'hygiéniste pourront être chargés d'exa miner la pureté de l'air dans les ateliers consacrés aux indus tries suivantes : aiguiseurs, couteliers, rémouleur's, fabricants d'aiguilles, qui sont exposés à respirer un air contenant à la fois des fragments de métal et de la poussière de grès; les orfévres, les bijoutiers, les bronzeurs, respirent également un air renfermant des corpuscules métalliques; les amidonniers, les meuniers, absorbent une grande quantité de fécule ou d'amidon, par les voies respiratoires. Les débris de nalure organique ne sont pas moins à redouter; la phthisie est fréquente chez les ouvriers brossiers, chez ceux qui battent le coton; les fleuristes, les ouvrières qui diamantent les fleurs, celles qui manient de grandes quantités de plumes, sont également exposées à des accidents plus ou moins graves. Si nous citons encore les mouleurs qui respirent un air riche en particules charbonneuses, ou en sable fin, les nacriers, qui absorbent des matières calcaires, nous n'aurons énuméré qu'une faible partie de ces professions, souvent meurtrières pour ceux qui les exercent. A côté de ces industries qui s'exercenl dans des ateliers, il en est d'autres non moins dangereuses, et les travaux publiés récemment sur la pathologie spéciale des houilleurs nous ont montré qu'il y avait encore bien des progrès à accomplir, pour mettre en harmonie les besoins de l'industrie avec les exigences de l'hygiène. F.-A. Pouchet a recherché, dans les organes respiratoires de l'homme et des animaux, les particules atmosphériques qu'ils y avaient 
fixées pendant leur vie. Get observateur éminent a trouvé dans les poumons de personnes mortes dans les hôpitaux, de la fécule normale et panifiée, des parcelles de fumée de charbon et de bois, des corpuscules de carbonates calcaires, de silice et même des parcelles de verre; beaucoup de filaments d'étoffes, de laine, de chanvre et de coton diversement colorés; des fragments de bois de teinture et beaucoup d'autres corps, variant suivant la profession exercée par les individus et les conditions au milieu desquelles ils avaient vécu.

Ajoutons que chez les houilleurs, chez les charbonniers, on trouve, dans l'appareil respiratoire, une quantité considérable de charbon.

Les animaux qui nous entourent n'échappent pas à cette loi. Chez les oiseaux, on retrouve des corpuscules solides jusque dans les os perméables à l'air. F.-A. Pouchet y a trouvé une grande quantité de fécule normale et panifiée, des parcelles de fumée, des débris de vêtement. Examinant les cavités respiratoires de poules qui avaient vécu chez des boulangers, F.-A. Pouchet y a trouvé de grandes quantités de fécule; chez des poules qui avaient vécu chez des charbonniers, il recueillit, au contraire, une notable quantité de particules charbonneuses. Un corbeau, qui avait passé une quinzaine d'années dans la forge d'un maréchal, avait tant inspiré de charbon que son squelette était tout noir. Cet auteur cite encore de nombreux exemples tout aussi convaincants et fournis par des animaux très différents.

Un grand nombre d'auteurs ont cherché dans l'air l'origine de certaines affections endémiques, telles que les fièvres paludéennes; on a prétendu également que les débris épithéliaux qui se détachent de la peau des malades atteints de scarlatine, de rougeole, de variole, pouvaient devenir des germes de contagion; l'air expiré a été également incriminé. Le microscope a rendu et rendra encore de grands services dans ces recherches, qui intéressent à un si haut degré la santé publique.

Du miasme paludéen. - Nous ne saurions quitter ce sujet sans étudier rapidement le miasme paludéen. Cette question a été traitée d'une façon très remarquable et très complète 
par M. le docteur Magnin (1). C'est à son travail que nous emprunterons les développements qui suivent. Le miasme paludéen existe-t-il et, s'il existe, en quoi consiste-t-il ? Telles sont les premières questions que l'auteur s'est tout d'abord posées.

On entend généralement, par miasme paludéen, des particules solides ou des émanations gazeuses, qui se dégagent des eaux stagnantes ou des marécages. Nous ne nous occuperons pas ici des émanations gazeuses. Comment prouver l'existence du miasme paludéen ? Les preuves qu'on a données sont de plusieurs ordres; les unes sont tirées de l'apparition de maladies, sous l'influence directe des émanations marécageuses, ou de leur transport par les vents, à des distances plus ou moins considérables. Ces considérations sont développées (p. 77) dans l'ouvrage du docteur Magnin; elles sortent de notre cadre, nous n'y insisterons pas. On a beaucoup discuté sur la nature du miasme paludéen. Certains auteurs, Eisenmann, Hirsch, Armand, ont fait jouer un rôle prépondérant à l'électricité atmosphérique ; d'autres, au contraire, comme Volta, Daniel, Moscati, Brocchi, Rigaud-del'Isle, Julia de Fontenelle, Chevreul, Sari, Boussingault, crurent pouvoir attribuer l'origine des fièvres intermittentes à la présence, dans l'air, de carbures d'hydrogène; mais Rigaud-de-l'Isle et Julia n'observèrent, dit M. Magnin, aucune différence de composition chimique entre l'air le plus malsain et l'air le plus salubre, si ce n'est la présence d'une substance d'origine organique. Pour recueillir les produits non gazeux tenus en suspension dans l'air des marais, différentes méthodes ont été mises en usage, voici les principales : on peut recueillir la rosée sur des plaques de verre disposées horizontalement, dans le voisinage d'un marais; on a également proposé de condenser à la surface de ballons remplis de glace, la vapeur d'eau contenue dans l'atmosphère d'une localité quelconque. Les méthodes que nous avons données, au début de ce livre,'pour recueillir les poussières atmosphériques, sont également applicables à ces recherches. Comme le docteur

(1) Recherches géologiques, botaniques et statistiques sur l'impaludisme dans la Dombes et le"miasme paludéen. Paris, 1876. 
Magnin le fait observer, pour que l'observation soit complète, il faut, outre l'examen microscopique et chimique, faire des inoculations ou des cultures. L'examen chimique n'a pas donné de résultats ; quant à l'analyse microscopique, elle a donné lieu à des interprétations diverses. Le docteur Magnin a soumis les différents résultats obtenus à une critique scientifique très approfondie et qui dénote, de la part de cet auteur, un esprit très droit et des connaissances très étendues. Des auteurs anciens admettent l'existence d'insectes invisibles qui, s'introduisant dans les poumons par la respiration, déterminaient l'apparition de la fièvre paludéenne. De nos jours, le mode d'action de ces organismes inférieurs, animaux ou végétaux, a été interprété différemment: pour Bouchardat, ils agiraient en sécrétant une sorte de venin; d'après Berthelot, ils produiraient un ferment, ou bien ils constitueraient le ferment lui-même, d'après Lemaire; Salisbury, Balestra, Salmi, en font de véritables parasites. M. Gigot-Suard, ayant fait passer, en 185̃ , l'air des marais dans des tubes remplis d'acide sulfurique, a constaté la présence de nombreux fragments de feuilles, de fibres, de cellules, de débris d'insectes, de Tardigrades, et même d'Infusoires entiers.

Les partisans d'un miasme de nature végétale ont fait intervenir :

$1^{\circ}$ Des spores de Champignons (Mitchell, Massy);

$2^{\circ}$ Des Algues du groupe des Palmelles (Salisbury);

$3^{\circ}$ Des Algues du groupe des Oscillaires (Hallier, Schurtz);

$4^{\circ}$ Des Algues indéterminées (Van der Corput, Balestra, Selmi, Hannon, etc.).

Nous allons suivre le docteur Magnin dans la discussion de ces différentes hypothèses (loc. cit., p. 92).

10 Spores de Champignons. - En 1849, J.-R. Nitchell aurait observé des cas de fièvre intermittente chez des individus qui avaient respiré un air chargé de spores de Champignons, qu'il aurait retrouvés dans les bronches et dans les mucosités des poumons. Toutefois, l'auteur ne donne pas des caractères qui puissent permettre de savoir, quel est le genre de cryptogame qu'il a observé. W.-A. Hammond s'est rallié à la théorie de Mitchell, et le docteur Massy, de Ceylan, aurait observé, en 1865 , que la présence dans l'atmosphère d'un grand nombre de Champignons microscopiques, ainsi 
que dans l'eau de puits, dans l'urine et dans les produits de l'expectoration des fébricitants, avait coïncidé avec une épidémie de fièvre intermittente. Mais, d'après le docteur Magnin, on ne verrait pas, dans les rapports du docteur Massy, les rapports de cause à effet signalés par ce médecin, entre les Champignons et la fièvre intermittente.

$2^{\circ}$ PaImelles. - Salisbury (The Americ. Journal of the medical sciences. Janvier 1866, Revue scientifique, 1869)a publié un travail sur l'origine de la fièvre paludéenne, dont le rententissement a été très grand. Cet auteur examinant l'expectoration des fébricitants, ainsi que l'excrétion salivaire de personnes habitant des pays à fièvres, y a trouvé au milieu de cellules diverses de Diatomées, de Desmidiées et de spores fongoïdes, d'autres petites cellules oblongues, isolées, ou agglomérées, à nucleus distinct, entourées par une enveloppe cellulaire lisse, avec un espace plus clair, en apparence vide, situé entre la paroi de la cellule et le noyau. Salisbury conclut, d'après leur apparence; que ces cellules ne sont pas des Champignons, mais des Algues ressemblant beaucoup aux Palmelles. Ces Palmelles seraient les seules formes cellulaires parmi celles qu'on aurait rencontrées dans les sécrétions examinées, qui se représentent constamment, dans les zones à malaria, tan dis qu'au contraire, les autres spores, animalcules, etc., se retrouvaient à toutes les hauteurs audessus et au-dessous de la limite des fièvres, ainsi que Salisbury l'a établi par diverses expériences. Ces Palmelles se rencontreraient également à la surface du sol des pays à fièvres. Enfin cet auteur aurait donné la fièvre à des personnes qui jusqu'alors avaient été indemnes, en plaçant, à leur proximité, de la terre couverte de Palmelles.

Le docteur Magnin trouve que Salisbury n'a donné qu'une description confuse des Algues qu'il considère comme des Palmelles; d'autre part, Salisbury n'ayant pas cultivé les Algues en dehors de leur support mécanique, rien ne prouve que ce ne soient pas les émanations de la terre elle-même qui aient occasionné de la fièvre (C. Wood). - Leydy, ainsi que l'auteur précédent, ayant vécu en contact avec des Palmelles, en ayant même absorbé à dessein ou accidentellement, n'en ont éprouvé aucun inconvénient. Ch. Wood fait remarquer en outre que les Palmelles ayant un protoplasma chlorophyllien, ne peuvent se développer dans l'obscurité et par conséquent au sein des organes de l'homme. De plus, le froid qui arrêtele développement de la malaria n'a aucune action sur les Palmelles, dont quelques espèces peuvent vivre dans la neige.

En 1872, à l'occasion de la session tenue à Lyon par le Congrès médical de France, M. le docteur Magnin, avec MM. Colrat et Fochier, a recherché sur les bords de certains étangs, les organismes décrits par Salisbury. Ces naturalistes trouvèrent en effet des Algues épondant assez exactement aux Palmelles de Salisbury, autant du 
moins, que leur description imparfaitepermet une identification (Hagnin, p. 96). Cette végétation constitue de légères efflorescences d'une épaisseur d'un demi-millimètre à peine, ressemblant à un semis de brique pilée. Ces efflorescences se trouvaient en compagnie du Protococcus viridis, espèce d'Algue uni-cellulaire, voisine des Palmelles. Sous le microscope, on trouve une masse de cellules rouge-brique, plongées dans une sorte d'atmosphère incolore et amorphe; cellules généralement ovales, quelquefois sphériques, à parois transparentes, incolores, quelquefois composées de plusieurs couches.

Le contenu consiste en sporules nombreux, très petits, à membrane d'enveloppe, souvent à double contour et munis, lorsqu'ils sont parvenus à l'âge adulte, d'un noyau fortement réfringent. La matière gélatineuse qui englobe les grosses cellules est amorphe, achroïque, transparente, quelquefois stratifiée. Elle provient de la fonte des membranes mères au fur et à mesure du développement endogène des sporules qui, à leur tour, remplissent le rôle de cellules mères, en donnant naissance à d'autres sporules.

Ces caractères montrent bien qu'il s'agit d'une Algue unicellulaire de la famille des Palmelles, répondant à la description que Salisbury a donnée de son genre Gemiasma, et de l'espèce rubra. (Magnin, loc. cit., p. 97.)

D'après M. Magnin, cette Algue serait certainement la plus commune et la plus abondante dans les pays où il y a des étangs; non seulement ce naturaliste les a rencontrées dans la Dombes, mais encore dans un grand nombre de lieux humides, sur les sols argileux aux environs de Lyon. Son habitat est celui assigné par Salisbury à ses Palmelles. Cette Algue serait, d'après M. Magnin, qui en a donné une figure, le Chlorococcum coccoma.

En comparant cette Algue au genre Gemiasma protuberans et autres palmelles de Salisbury, on acquiert la conviction que, si elles ne sont pas identiques, elles sont au moins très voisines.

M. Magnin ne s'est pas borné à ces constatations. Ayant examiné, au microscope, de la rosée condensée sur des plaques de verre, au voisinage des étangs, il n'y put découvrir aucune spore pouvant être assimilée à des cellules de Chlorococcum. Ayant fait transporter, dans différentes habitations de Lyon, des plaques de terre recouverte de cette Algue, celles-ci n'ont pas déterminé l'apparition de la fièvre intermittente. Aussi M. Magnin repousse-t-il complètement l'idée que le miasme paludéen soit constitué par les Palmelles.

Différents auteurs, MM. Van der Corput et Hannon, ont publié, comme venant à l'appui des opinions de Salisbury, des observations dans lesquelles figurent des Algues indéterminées pour la première, et nombre d'autres, comme les Vauchéries, les Conferves, les Zygnèınes, les Oscillaires, etc., à l'exclusion des Palmelles qui ne sont pas cilées.

4. Les Oscillaires ont à leur tour, et peut-être avec plus de vérité, 
été regardées comme étant la véritable origine du miasme paludéen. Cette hypothèse a été émise et défendue pour la première fois en 1867 par Hallier. Les recherches de Schurtz et de Lemaire viennent également à l'appui de cette opinion. M. Lemaire a observé, dans l'air des contrées à fièvre, de nombreux Bactéridiens que l'on considère aujourd'hui comme des Algues voisines des Oscillaires. Cet observateur ayant recueilli et examiné les particules contenues dans la vapeur d'eau, condensée à plus d'un mètre de distance de la surface de deux étangs, au moment de sa condensation, le liquide était incolore, limpide, son odeur et sa saveur rappelaient celle de l'eau des étangs. Elle était sans action sur les papiers réactifs. Elle contenait des corps sphériques, ovoïdes et fusiformes; puis un grand nombre de cellules pâles de diverses dimensions. II. Lemaire trouva en outre une quantité considćrable de très petits corps semi-transparents, de forme diverse, sphérique, ovoïdale, cylindrique, régulière ou irrégulière; ces corps lui ont paru être des microphytes et des microzoaires; enfin quelques corps bruns, qui lui parurent d'origine végétale, des grains d'amidon, de la poussière et des cristaux cubiques. La liqueur condensée fut abandonnée à la température ambiante $\left(23^{\circ}\right.$ à $30^{\circ}$ cent.) en présence d'un égal volume d'air, dans un flacon bouché.

Ce liquide, ayant été examiné au microscope treize heures après, avait une odeur marécageuse prononcée; de petites cellules étaient en voie de bourgeonnement; dans une seule goutte, on y constata la présence de 200 Bacterium termo.

Au bout de quarante heures, on observait dans ce liquide des cellules bijuguées: Bacterium, Vibrio, Spirillum, monades très nombreuses et une diminution de petits corps semi-transparents.

L'auteur est d'avis qu'il y a un rapport certain entre la diminution de ces petits corps et l'augmentation des microphytes et des microzoaires ; soixante heures après, le liquide était troublé par des nuages blanchâtres, d'odeur putride, le dépôt est entièrement formé par' des Bactéries, des Vibrions et des Spirillums immobiles. Plus tard les microphytes diminuent et sont remplacés par des animalcules.

M. Lemaire conclut ainsi : Ces recherches paraissent prouver qu'en Sologne, où règnent les fièvres paludéennes, l'air contient une quantité considérable de microphytes et de microzoaires, tandis que celui de Romainville, pays très sain, n'offre qu'une minime proportion de ces petits êtres. L'air du Jardin des Plantes diffère de celui de ces deux localités, mais il se rapproche beaucoup de celui de la Sologne. La position particulière du Jardin des Plantes, qui est voisin de la rivière de Bièvre, de deux amphithéâtres d'anatomie, d'un hôpital, explique ce résultat (1).

Le docteur Schurtz, de Zivickau, a publié une observation de la-

(1) Magnin, loc. cit., p. 105 et Comptes rendus, 17 août 1864 . 
quelle il semble résulter que des Oscillariées auraient donné la fièvre intermiltente.

Dans l'hypothèse de la nature végétale du miasme paludéen, dit sagement le docteur Nagnin, les Oscillariées semblent être les seuls organismes pouvant remplir ce rôle. Mais il ne faut pas se dissimuler qu'il n'y a que des présomptions et nulles preuves certaines.

M. le professeur Edwin Klebs (de Prague) et M. le professeur Conrard Tommasi-Crudeli (de Rome) viennent d'étudier récemment (J. d'Ilygiène, 17 juillet 1879) la malaria de la campagne romaine. Le professeur Tommasi-Crudeli avait établi par des travaux antérieurs que la malaria de Rome et de l'Ager Romanus qui entoure la ville, n'avait pas pour origine des émanations des marais, mais bien d'un très grand nombre de petites flaques d'eau (acquitrini) qui, par l'effet de la structure du sol, sc produisent sur les nombreuses collines des campagnes, romaines et dont leau devient rapidement croupissante. Les Romains avaient autrefois assaini la campagne de. Rome en la drainant. Voici quel est le procédé opératoire suivi par les deux savants: ils ont fait usage d'un puissant aspirateur qui projetait l'air sur une plaque de verre recouverte d'une couche de gélatine renfermée dans une petite boite. L'eau stagnante des régions à malaria ne paraît pas contenir en toute saison le poison morbifique, bien qu'elle puisse être fort riche en organismes inféricurs. D'un autre côté, les recherches entreprises par les auteurs du mémoire démontrent qu'une grande quantité d'eau empêche le développement du poison de la malaria en rendant inactifs les germes qu'elle renferme.

Ce qu'il y a de plus particulièrement intéressant dans les recherches de MM. Ed. Klebs et Tommasi-Crudeli, c'est qu'ils ont fait des expériences physiologiques sur les animaux. Par l'injection des liquides obtenus directement du sol, des cultures artificielles et des résidus de la filtration des liquides de ces cultures, on a produit chez les animaux soumis à l'expérience une fièvre à marche régulièrement typique, avec intermittences qui, dans certains cas, ont duré jusqu'à soixante heures et avec une élévation de la température pouvant atteindre pendant l'accès fébrile $41^{\circ}, 8$. Chez tous les animaux qui furent soumis à l'injection des liquides à malaria, on trouve un notable gonflement de la rate; l'organe avait suivi une augmentation de neuf à dix fois son volume.

Les organismes qui, d'après les observations de MII. Ed. Klebs et Tommasi-Crudeli, doivent être considérés comme la cause véritable de la malaria (car ils se retrouvent dans les liquides injectés et dans le corps des animaux infectés) appartiennent au genre Bacillus. Dans le sol des régions à malaria, on les rencontre sous forme de nombreuses spores qui réfraclent fortement la lumière, présentant une figure ovale allongée dont le plus grand diamètre est de 0,9̋̈ $\mu$. Ils 
se développent en longs filaments qui d'abord sont homogènes ; plus tard, ces filaments subissent des divisions transverses qui les rendent articulés et dans l'intérieur de leurs articles se développent de nouvelles spores. La première formation de ces spores est pariétale; puis tout l'intérieur de ces articles se remplit de petits corpuscules. Ces propriétés morphologiques ont paru répondre à une espèce particulière de Bacillus que les savants expérimentateurs proposent de nommer Bacillus malariæ, parce qu'ils l'ont vu se développer dans le corps des animaux atteints d'impaludisme. Ce Bacillus serait aérobie: il se développe également bien dans les liquides riches en matière: azotées, telles que les solutions de gélatine et d'albumine, l'urine et les liquides de l'organisme. Il se développe surtout très abondamment dans le corps des animaux injectés, surtout dans la rate et dans la moelle des os.

En 1873, M. Obermeier a démontré que la fièvre récurrente était causée par le développement dans le sang d'un spirochæete que II. Cohn a appelé Sp. Obermeieri.

M. Van Tieghem (comptes rendus. Juillet 1879) s'est appuyé sur ces faits pour donner une explication des accès et des rémissions dans la fièvre récurrente.

Dimension des poussières. - D'après tout ce qui précède on comprendra sans peine que cette dimension doit présenter des variations très grandes. M. Tissandier, qui a mesuré les poussières aériennes, à l'aide d'un micromètre de verre, divisé en centièmes de millimètre, a obtenu les résultats suivants. Quand elles sont formées de débris d'étoffes, de bois, de charbon, elles atteignent parfois une longueur de 1/10 de millimètre et plus; quand elles sont constituées par des matières minérales, silice, calcaire, argile, leur diamètre varie de $1 / 100$ à 1/1000 de millimètre et au-dessous.

on s'est demandé par quel mécanisme les particules atmosphériques, généralement plus denses que l'air, pouvaient rester en suspension dans l'atmosphère. Le calcul démontre, dit M. Tissandier, que des grains minéraux de très petite dimension, 1/100 de millimètre de diamètre par exemple, tombent encore avec une vitesse assez considérable $\left(0^{\mathrm{m}}, 66\right.$ par seconde, pour la silice en supposant une forme sphérique). Voici quelle est l'opinion donnée par Nysten.: La densité des poussières, bien qu'elle soit supérieure à celle de l'air, est diminuée par la couche gazeuse, adhérente par capillarité, à 
la surface des objets de très pelite dimension, laquelle fait corps avec eux et les suit dans leurs mouvements; il résulte de celte particularité, que l'impulsion de l'air en mouvement les entraîne et les soulève facilement, et elles vont se déposer dans les lieux où l'air est calme. (Robin et Littré, Dictionnaire.)

\section{Des corpuscules ferrugineux et mağútiques contenus dang} I'atmosphère (Tissandier, loc. cit., p. 33).

Le mode opératoire suivant a été observé par M. Tissandier, pour isoler les poussières atmosphériques, les corpuscules ferrugineux ou magnétiques. Plaçant les poussières sur une feuille de papier glacé, il y promène un aimant dans tous les sens et à plusieurs reprises, un grand nombre de corpuscules adhèrent à l'aimant. On les

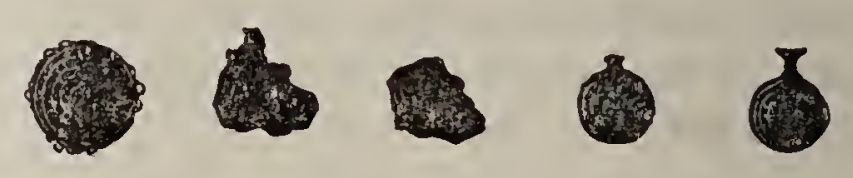

Fig. 502. - Corpuscules attirés par l'aimant, recueillis dans le sédiment de la neige du mont Blanc, à 2,700 mètres d'altitude, 500/1, juillet 1874. (G. Tissandier.)

lait tomber à l'aide d'un pinceau sur une autre feuille de papier; puis, s'aidant d'une loupe, on approche de ces poussières un second aimant. Un certain nombre s'y précipitent violemment, tandis que

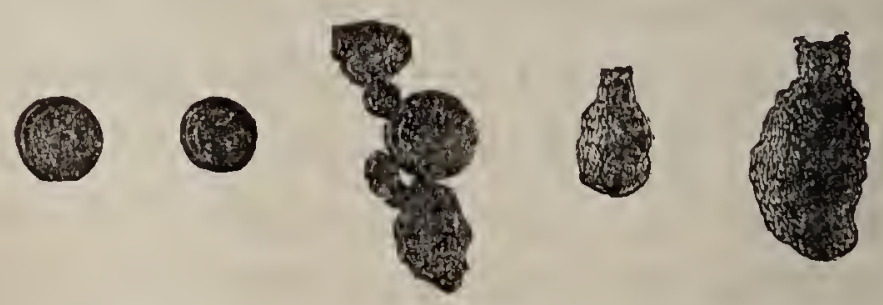

Fig. 503. - Corpuscules attirés par l'aimant recueillis dans le sédiment de la pluie tombée à Sainte-Harie du Mont (Manche), le 11 juin 1873̈,500/1. (G. Tissandier.)

celles qui n'avaient élé retenues que par adhérence, grâce à leur ténuité, restent sur le papier. Pour leur examen, M. Tissandier emploie un grossissement de 300 diamètres. Cet auteur divise ainsi ces particules attirables à l'aimant: les fragments grisâtres amorphes, de $1 / 10$ à 1/20 de millimètre; des particules noires et opaques mamelonnées, beaucoup plus petites, de $5 / 100$ à $1 / 100$ de millimètre ; particules fibreuses de même grandeur; corpuscules noirs et opaques parfaitement sphériques de 2/100 à 1/100 de millimètre de diamètre, environ; corpuscules sphériques semblables, munis d'un petit goulot. 
CHAPITRE XXI. - CORPUSGULES ET MIASMES DE L'AIR. 795

Cies corpuscules sont essentiellement formés de fer; M. Tissandier les a rencontrés dans presque toutes les poussières atmosphéricues qu’il a examinées, aussi bien dans de la neige recueillie au
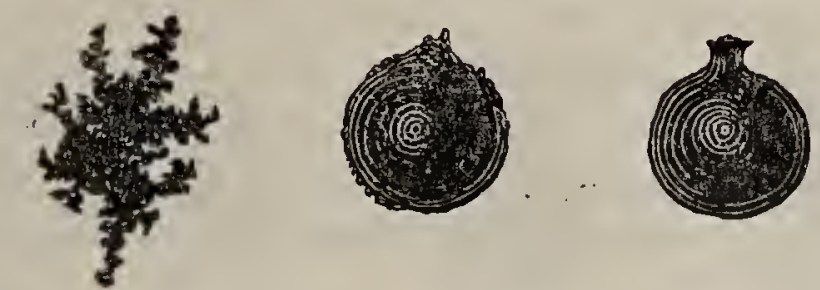

Figr. 504. - Corpuscules attirés par l'aimant recueillis dans la poussière apportée par le vent dans une des tours de Notre-Dame fermée aux visiteurs, 500/1. (G. Tissandier.)

sommet du mont Blanc, que dans le sédiment d'eaux de pluies recueillies pendant plusieurs mois à l'observatoire météréologique de SainteMlarie du Mont (Manche).

M. Young, préparateur de microscopie à l'université de Genève, a présenté à l'Académie des sciences une note qui confirme les résultats obtenus par M. Tissandier. En voici les principales conclusions: $1^{0}$ le fer existe dans toutes les poussières accumulées depuis
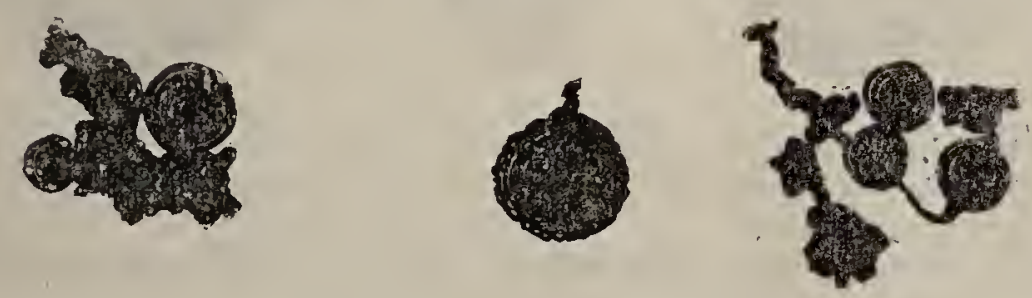

Fig. 503̈. - Corpuscules attirés par l'aimant recueillis dans la poussière apportée par le rent dans une des tours de Notre-Dame fermée aux visiteurs, 500/1. (G. Tissandier.)

des siècles dans les clochers d'église ; $2^{\circ}$ ce fer floltant dans l'atmosphère est entrainé par la neige dans sa chule, nous l'y avons retrouvé dans tous les cas par les procédés chimiques; $3^{\circ}$ nous n'avons pas rencontré dans les résidus de neige, le fer avec la forme globulaire, mais toujours en fragments irréguliers; $4^{\circ}$ ]e fer est toujours en plus forte proportion dans les neiges des régions inférieures, que dans celles recueillies à de plus grandes altitudes.

L'auteur, en suivant le procédé donné par M. Chatin, pour' la recherche de minimes quantités d'iode, n’a pas réussi à constater la présence de ce métalloïde dans les neiges qu'il a examinées. Il se propose de poursuivre ses recherches sur des masses de neige plus considérables, afin d'y constater, s'il y a lieu, la présence du nickel, du cobalt, du phosphore, comme M. Nordenskiold l'a fait pour les glaces polaires.

M. Tíssandier a étudié arec beaucoup de soin l'origine de ces poussières ferrugineuses, et il a rapporté un certain nombre 
d'exemples de chute ou de découverte de ces poussières. Si les pluies de poussière proviennent le plus souvent du sable fin des plages terrestres, il en existe d'autres qui proviennent incontestablement des débris pulvérisés des météorites.

Ces parcelles ferrugineuses peuvent provenir d'une masse de fer météorique, rendue incandescente par son frottement dans les couches aériennes; elles peuvent encore provenir de la fusion superficielle des météorites et de leur désagrégation. Nous donnons cicontre, d'après M. Tissandier, la figure d'aérolithes microscopiques

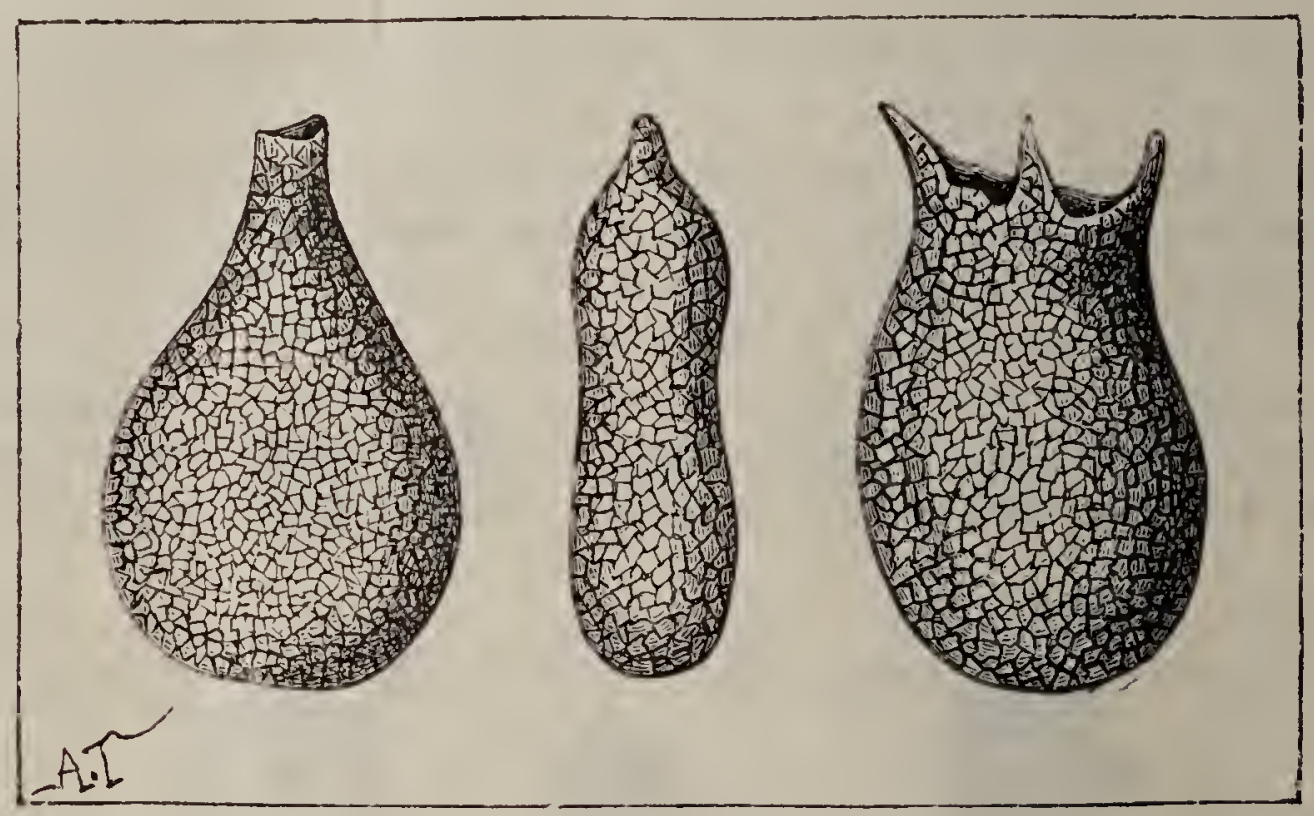

Fig. 506. - Aérolithes microscopiques très grossis (d'après Ehrenberg).

très grossis, recueillis dans les circonstances suivantes: pendant une traversée du navire Josiah-Bates, dans les eaux de la mer des Indes, au sud de Java, on vit tomber sur le pont une fine poussière que le capitaine recueillit et qui fut examinée par Maury et Ehrenberg. Ces ampoules solidifiées et creuses étaient formées de fer et d'oxyde de fer.

M. Tissandier a repris l'étude des corpuscules atmosphériques, et les a comparés à des fragments détachés de la surface des météorites. Les formes en sont variables, comme le montrent les figures données par l'auteur. Examinant au microscope des particules ferrugineuses obtenues par le grattage de la surface de météorites authentiques, provenant de la collection du Muséum, M. Tissandier a trouvé des parcelles globulaires et mamelonnées. Ces faits démontreraient donc que, parmi les poussières ferrugineuses, il en est un grand nombre qui proviennent des météorites et des étoiles filantes. "On peut supposer que ces masses mélalliques, dans leur passage au sein des espaces, se brisent en nombreux fragments, font jaillir autour d'elles des particules incandescentes de fer métallique, dont 
CHAPITRE XXI. - CORPUSCULES ET MIASMES DE L'AIR. 797

les plus petits débris, entrainés dans toutes les régions de l'air par les courants atmosphériques, tombent à la suriace entière du globe, sous forme d'oxyde de fer magnétique, plus ou moins complètement fondu. La traînée lumineuse des étoiles filantes serait due à la

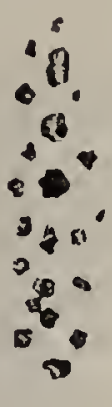

1
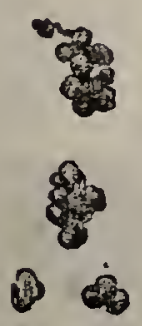

5

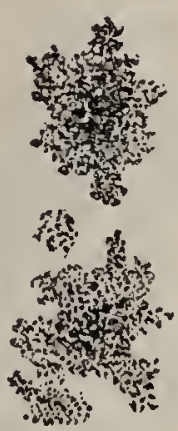

2
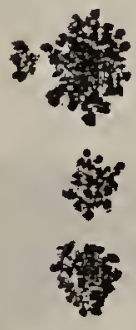

6

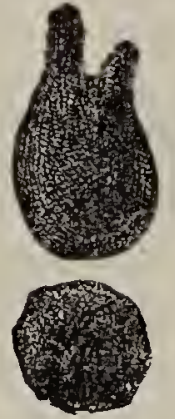

3

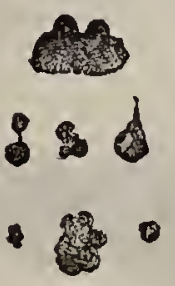

7

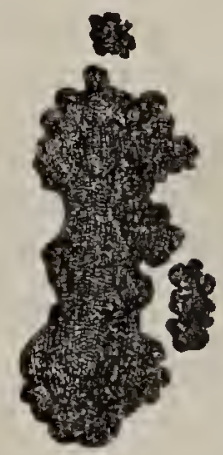

4

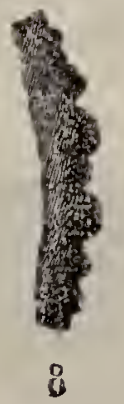

Fig. 507. - Corpuscules ferrugineux atmosphériques et fragments détachés de la surface de météorites (G. Tissandier.) - 1. Fragments très noirs et amorphes. - 2. Grains extrêmement petits groupés en amas compacts (rare). - 3. Volume plus considérable; surfaee rugueuse et mamelonnée (4). - 5. Parcelles globulaires et mamelonnées. -6 . Grains noirs très petits. - 7. Grains sphériques. - 8. Mamelons arrondis.

construction de ces innombrables particules, offrant l'aspect des étincelles de feu, qui jaillissent d'un ruban de fer quand on le brûle dans l'oxygène. " (Lnc. cit., p. כ̌3.)

Un grand nombre de particules atmosphériques ferrugineuses
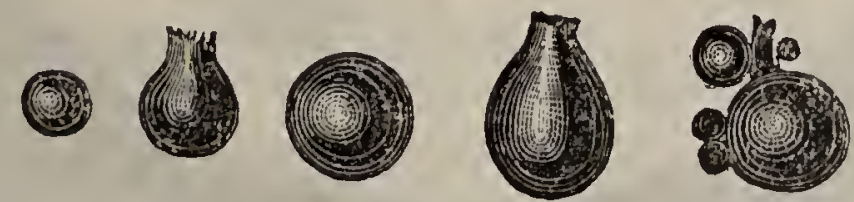

lïg. 508. - Globules d'oxyde de fer magnétique obtenus en faisart brûler de la fine limaille de fer dans une flamme d'hydrogène, 500/l. (G. Tissandier.)

ont une origine terrestre. En effet, des parcelles de fer prennent en brûlant la forme sphérique, et une masse de fer volumineuse, en se combinant au rouge avec l'oxygène, peut se diviser en fragments globulaires microscopiques. L'hydı́ogène enflammé donne égale- 
ment des sphérules avec la fine limaille de fer. Les particules ferrugineuses que l'on détache en battant le briquet, ont également la forme sphérique.

Une source abondante et terrestre de poussières ferrugineuses, c'est encore la fumée des usines aux environs desquelles on recueille sur le sol, des globules d'oxyde de fer magnétique. La terre arable, le limon du Nil, le sable de la mer, renferment également des parcelles magnétiques.

Bien que des arguments sérieux militent en faveur de l'origine terrestre des globules magnétiques, il est difficile, dit M. Tissandier, d'attribuer à cette origine l'immense quantité de sphérules que présentent les poussières ramassées dans les lieux les plus distants et dans les situations les plus diverses. C'est ainsi que l'étude des sables rapportés par la drague du fond de la mer a fourni de nouveaux exemples à l'appui de cette dernière opinion.

M. l'amiral Serres a recueilli des sédiments marins qu'il a donnés au Muséum. Les globules n'y font pas défaut; on les trouve même

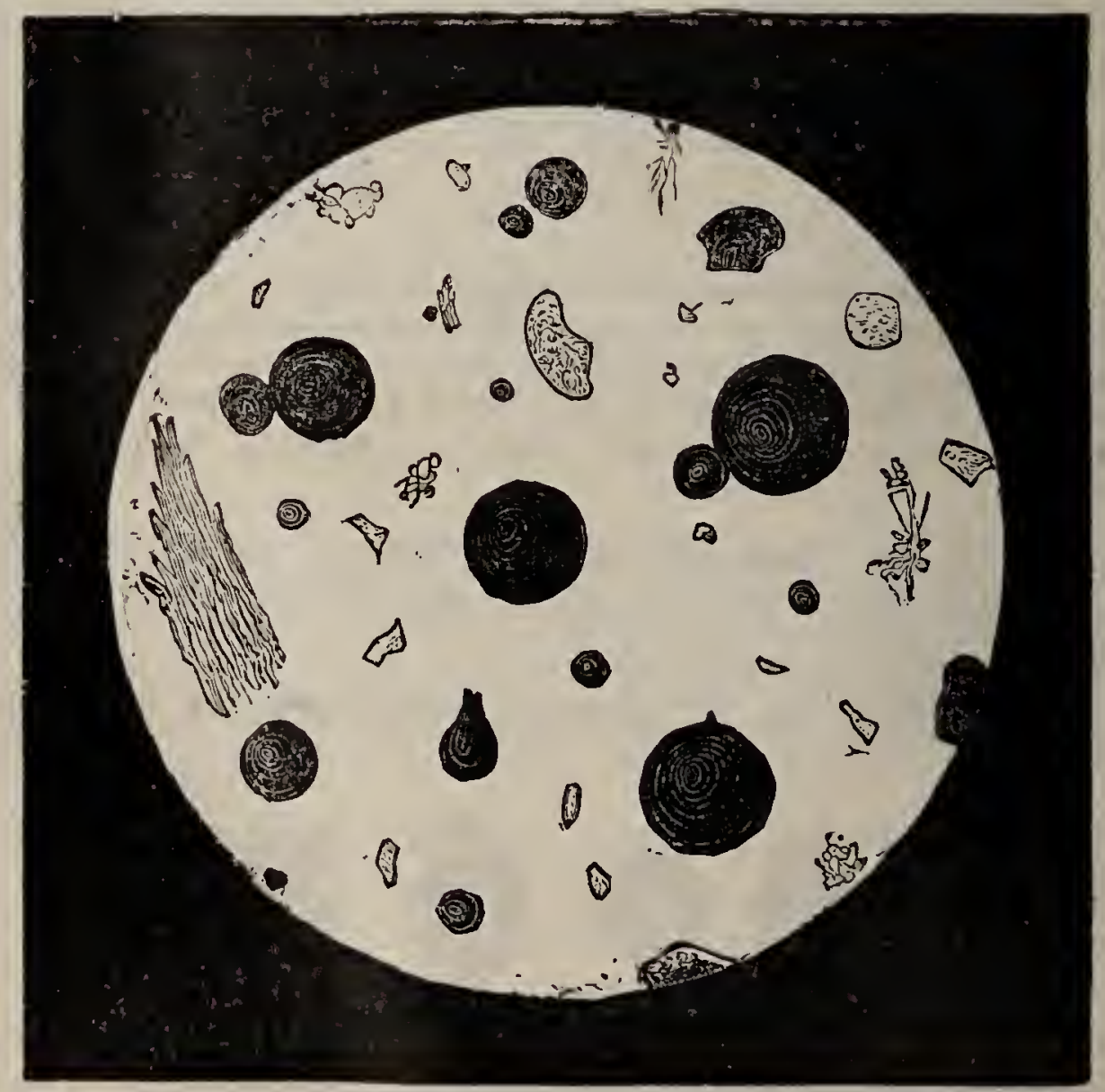

Fig. 509. - Sphérules magnétiques recueillies dans le sable du fond de la baie de la Possession (Amérique du Sud), vues au microscope. Grossissement j00/1.

avec une abondance extrême dans le sable qui fait le fond de la baic de la Possession (fig. 309); ils y atteignent $0^{\mathrm{mm}}, 056$ de diamètre. 
Dans différents échantillons de sables recueillis par M. le commandant Mouchez, sur les côtes d'Algérie, à des profondeurs diverses, on a trouvé de nombreux globules magnétiques.

MM. Stanislas Meunier et Gaston Tissandier ont trouvé d'abondantes et de belles sphérules dans le sable extrait du puits artésien de Grenelle, à 569 mètres au-dessous de la surface du sol, et qui ap-

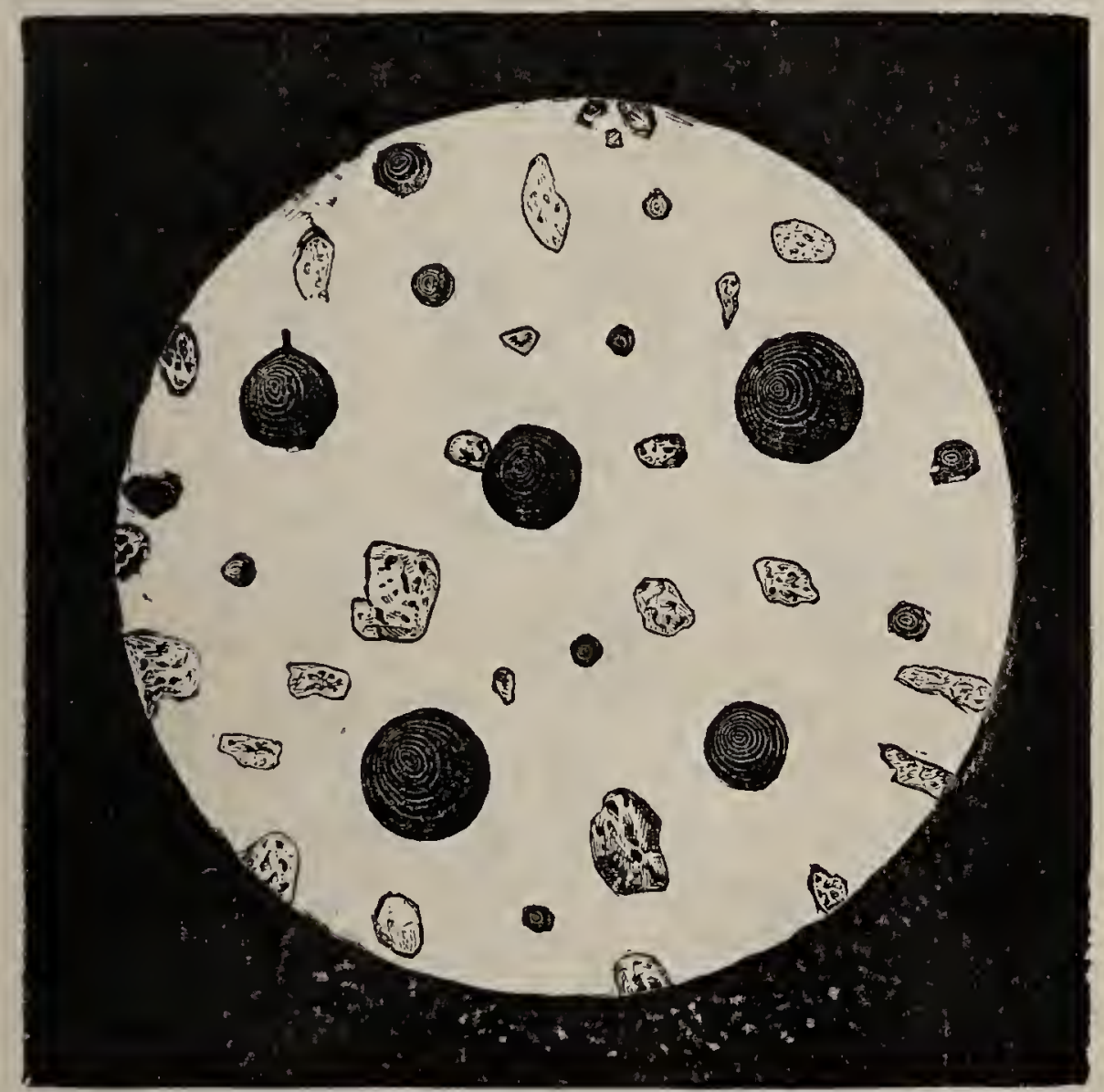

Fig. 510. - Sphérules magnétiques recueillies dans les mottes de sable du puits de Grenelle, vues au microscope. Grossissement 500/1.

partient au gault. Leurs dimensions varient de $0^{\mathrm{mm}}, 007$ à $0^{\mathrm{mm}}, 020$ (fig. כ̋10).

En résumé, ces observations montrent que les sédiments actuels de la mer, comme ceux des océans géologiques, renferment des globules semblables aux sphérules que l'atmosphère laisse constamment tomber à la surface de la terre. Ils n'ont aucun caractère différentiel et l'on est autorisé à les identifier entre cux. Il faut donc reconnaître que les couches du globe renferment des matériaux d'origine cosmique dont la chute remonte parfois à un passé des plus reculés. Comptes-rendus de l'Académie des sciences, t. LXXXVI, p. 4ว̈0.)

Des pluies de poussières. - Depuis la plus haute antiquité on a observé des pluies de poussières diversement colorées; 


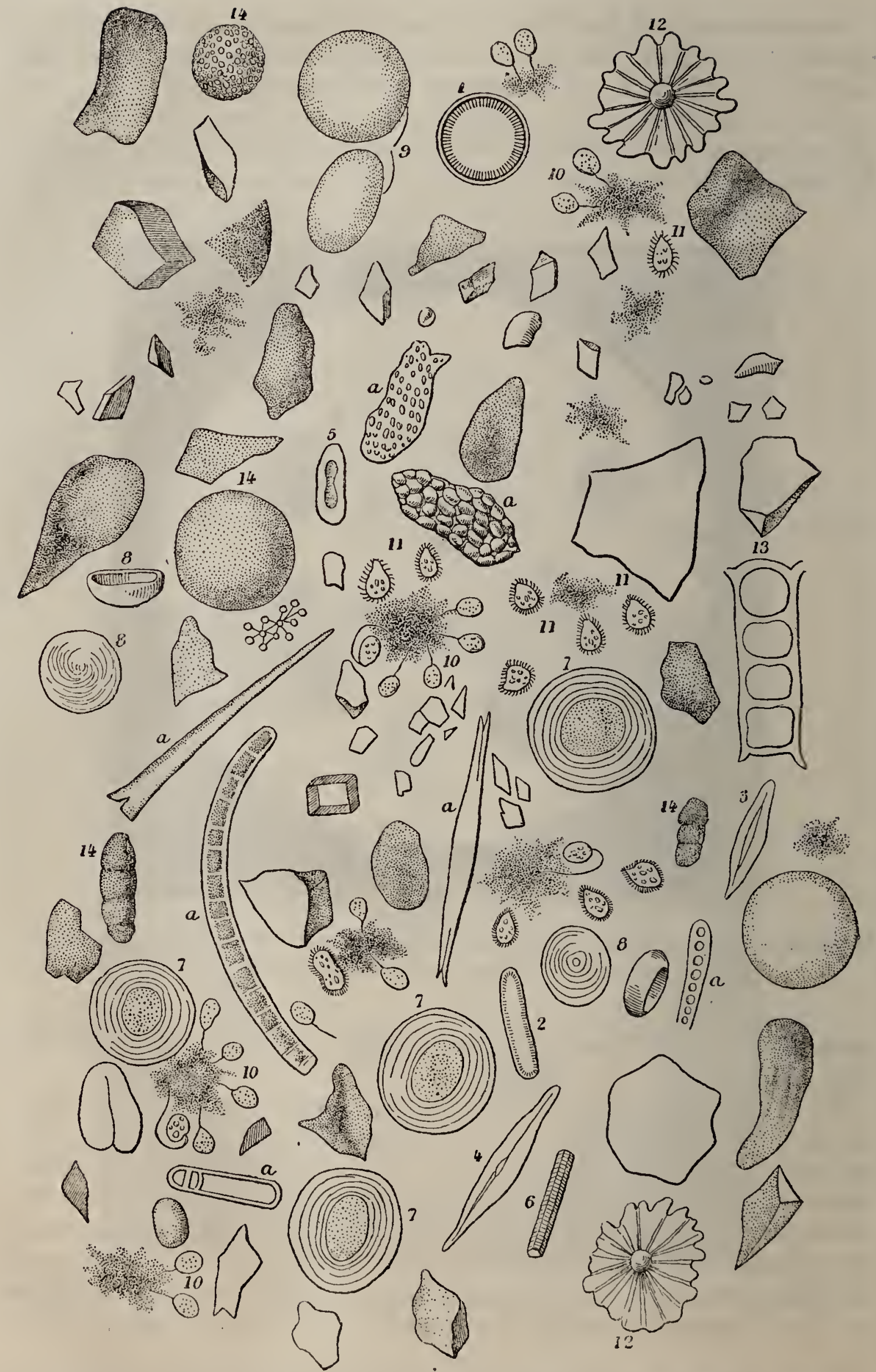

Figr. 511. - Poussières tombées en Sicile, vues au microscope (grossissement 300 diametresj. Dessin de M. 0. Silvestri. - 1. Gallionella crenata, Ehr. - 2. Sinedra encomon, thr. - 3. Pinnularia intermedia, Silv. - 4. Navicula fulva; Ehr. - 5. Lithostilidium 
il est fait mention de pluies de sang dans Homère, et de nos jours, dit M. Tissandier, il est des paysans qui croient encore à la réalité de phénomènes dus à la chute de poussières rougeâtres, très fines et de nature ferrugineuse. Sous l'influence de courants atmosphériques très violents, le sable des déserts peut-être emporté à une très grande distance. M. Tissandier donne d'après Ehrenberg de nombreux exemples de ces phénomènes, nous en citerons seulement quelques-uns. Le transport à de lointaines distances des poussières explique comment parmi les êtres organisés, que l'on trouve dans ces poussières, il en est qui appartiennent à des pays très éloignés. Ehrenberg, examinant des échantillons de neige rouge tombée dans le canton des Grisons, près du passage Bernardin, le 4 février $180 \mathrm{~s} 1$, y trouva des formes américaines, le Desmogonium guyanense (?) et l'Himantidium papilio. Dans une pluie de poussières tombée en 1834 sur les confins de la Russie et de la Chine, le conseiller d'État Weissen, de Saint-Pétersbourg, ne trouva pas de formes sibériennes, mais rien que des formes exotiques. Quelquefois ces pluies de poussières sont d'origine purement végétale; c'est ainsi que le $1^{\text {or }}$ mai $18 \check{6} 6$ à Shanghaï, en Chine, il tomba une pluie qui assombrit le jour et que l'on reconnut être composée du duvet de la semence du peuplier. En 1862, Ehrenberg analysa une poussière rouge qui était tombée sur un navire allemand, par $24^{\circ}$ ou $20^{\circ}$ de latitude nord, et $33^{\circ}$ ou $36^{\circ}$ de longilude à l'ouest du méridien de Greenwich. Cette poussière renfermait cinquante formes organiques et quatre formes inorganiques.

De ces cinquante-quatre formes, il n'y en avait qu'une qui fût inconnue : le Lithostylidium divitis, parcelle d'herbe siliceuse; toutes ces formes organiques sont d'origine terrestre; aucune ne provient de la mer. Vingt et une formes à écaille siliceuse peuvent à la rigueur vivre et se reproduire dans l'air; quant aux vingt-sept formes siliceuses, ce ne sont que des débris

clepsammidium, Thr. - 6. Spongolithis striata, Silv. - 7. Protoeoeus meteororicus Silv. - 8. Protococcus meniscus, Silv. - 9. Protococcus simplex, Silv. - 10. Vortieella convallaria, Ehr. - 11. Cyclidium solitarium, Silv. - 12. Petite étoile appartenant à un organe végétal. - 13. Fragment de Conferve (Gallionella lyrata (?), Ehr.). - 14. Fruilification de formes variées. - $a, a, a$. Fragments de Conferve, épiderme, fibre de plante phanérogame. - Les fragments angulaires représentent la partie minérale de la poussière. Les anas grumeleux répandus ȩá et là sunt formés d'une substanee organique.

GUIDE DE MICROGRAPIIE. 
d'organismes morts. Dans un échantillon de neige rouge, Ehrenberg, outre différentes formes organiques, découvrit une Discoplea atmosphxrica que l'on n'avait jamais encore vue vivante en Europe. Voici d'après cet éminent observateur la nomenclature des espèces trouvées dans les analyses de poussières faites par lui : Cryptomonas, Discoplea atlantica, Eunotia amphioxys, Gallionnella procera, Gallionnella tenerrima, Spharella nivalis, Gallionnella granulata, Lithostylidium leve, Lithostylidium rude, Gallionnella crenala, Gallionnella tceniata, Discoplea atmospharica, Pinnularia borealis, Amphidiscus trincatus, Lithostylidium crenulatum, Gallionnella distans, Lithostylidium biconcavum, Clepsammidium conicum, etc., etc.

Veige rouge. - En 1863, M. le professeur Bouis a observé une pluie et une neige rouges tombées dans l'Ariège, les Pyrénées-Orientales et en Espagne, dans la basse Catalogne, l'Aragon, etc.; les flocons de neige étaient parfois si rouges, qu'on les croyait teintés de sang. Le vent soufflait au sud. La terre, desséchée à l'air, est jaunâtre; humectée, elle devient rouge-brique. L'examen microscopique n'a montré que quelques rares débris microscopiques. M. Bouis a fait une analyse chimique de ces poussières. (M. Tissandier, loc. cit., p. 82, Comptes rendus de l'Académie des sciences, t. LVI, 186ŏ, p. 972.)

Antérieurement, $18 \times 6$ (V. Comples rendus de l'Académie des sciences, t. XXIV, 1847, p. 810), M. Decaisne avait examiné une pluie terreuse; il y a observé une assez grande quantité de corpuscules organisés, qu'il considère comme d’origine végétale; " ce sont des ruastrums, quelques clostéricées, des granules de " matière verte, etc.; puis enfin, quelques débris d’Infusoires "qui disparaissent en les soumettant à l'action de l'ammo" niaque."

M. Tissandier a examiné au microscope un échantillon d'une pluie de poussière tombée à Boulogne-sur-Mer le 2 décembre 1876. Un grossissement de 80 diamètres lui a fait voir que la matière organique qu'elle contenait était essentiellement formée de débris de différentes espèces d'Algues microscopiques; ils se trouvaient mélangés avec des grains de silice et de calcaire de $1 / 30$ à $2 / 500$ de millimètre de diamètre environ. Ayant examiné de la même façon le sable de la plage, 
CHAPITRE XXI. - GORPUSGULES ET MIASMES DE L'AIR. 803

M. Tissandier a vu qu'il était constitué par des grains minéraux 8 ou 10 fois plus volumineux, mais entre lesquels il en existait d'autres, très petits, entremêlés de fragments d'Algues semblables à ceux de la pluie de poussières. D'après M. Tissandier les tourbillons de vent, en soufflant sur la plage, ont

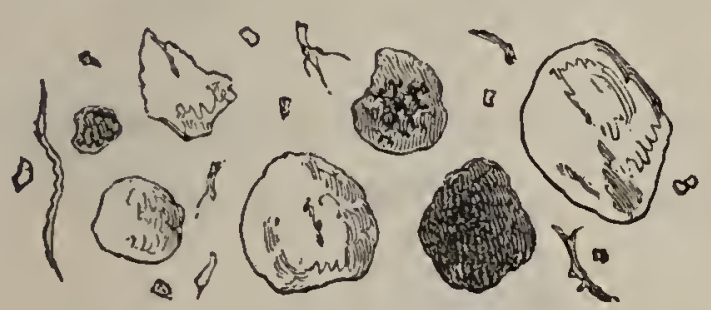

Fig. 512. - Sable de la Mauche, $80 / 1$. (G. Tissandier.)
3

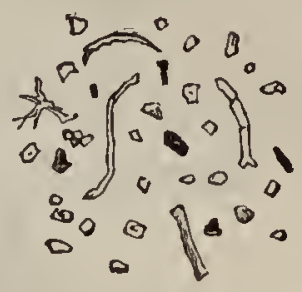

Fig. 513. - Poussière tombée à Boulogne-sur-Mer, 9 octubr e 1876. (G. Tissandier.)

enlevé dans leurs mourements de rotation les corpuscules les plus fins du sable, et ont ainsi opéré une véritable extraction des parcelles les plus ténues et les plus légères qu'il contenait.

PPluies de cendres voleaniques. - Sous l'influence des éruptions volcaniques, des masses énormes de cendres sont projetées dans l'atmosphère, et vont souvent retomber très loin de leur point d'émission et couvrent des régions entières. "De nombreux exemples, dit M. Daubrée (Tissandier, p. 99), térmoignent du transport dans l'atmosphère, jusqu'à de grandes distances, de cendres volcaniques, de sables el de poussières diverses, telles que les cendres provenant d'incendies. Je me bornerai à rappeler le sable qui s'est abattu le 7 février 1863 sur la partie occidentale des îles Canaries et qui a été, sclon toute probabilité, transporté du Sahara sur plus de 32 myriamètres. Plus récemment, la cendre de l'incendie de la ville de Chicago est arrivée aux Açores, le quatrième jour après le commencement de la catastrophe; en même temps on arait senti une odeur empyreumatique qui arait fait dire aux Açoriens que quelque grande forêt brûlait probablement sur le continent africain... "

On sait que le célèbre brouillard sec qui, en 1783 , couvrit pendant trois mois presque toute l'Europe, après avoir d'abord paru à Copenhague, où il persista 126 jours, avait pour 
cause une éruption de l'Islande, ainsi qu'on l'apprit plus tard. Le 7 septembre 1845, un transport de même origine, mais moins considérable, fut observé aux îles Shetland et aux Orcades.

Pluies de soufre. - Nous avons déjà fait allusion aux pluies de pollen de différentes espèces végétales. MM. Bureau et Poisson (Tissandier, p. 101) ont reconnu récemment qu'un
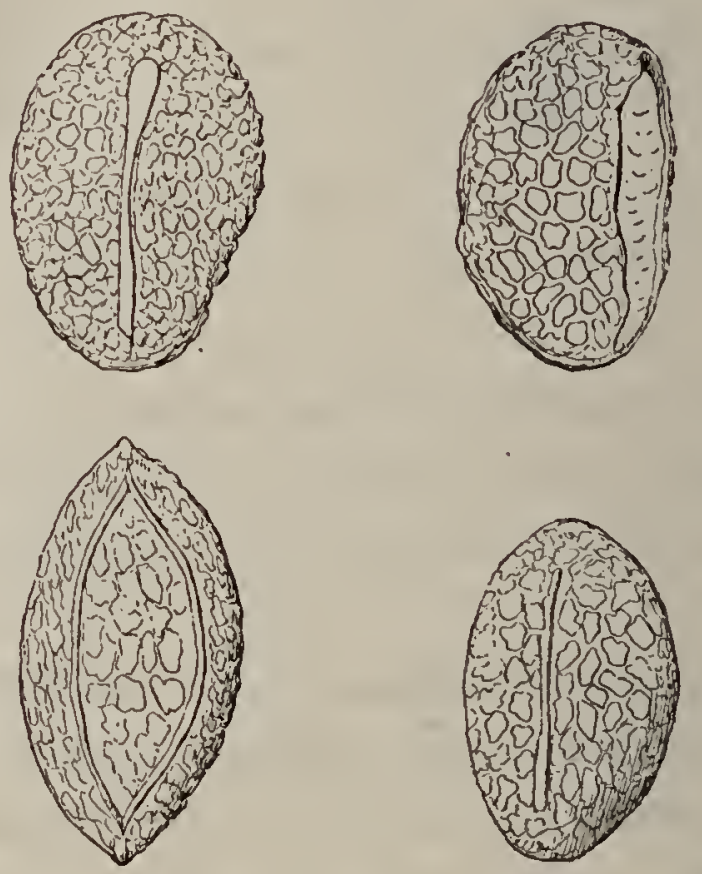

Fig. 514. - Spores de la grotte de la Réunion, $\frac{500}{1}$.

échantillon de terre combustible très légère, jaune, trouré par M. de l'Isle dans une grotte de l'île de la Réunion, était formé de grains de pollen.

On a également trouvé des insectes et de la manne dans certaines eaux de pluies (1).

(1) Obsenvations sur une pluie de sève. - Note de M. Gh. Musset (Comptes rendus, 10 février 1879). - "La sève aqueuse de la Colocasia esculenta (Schott) est émise par jets successifs et pressés. Cette émission, comme on le sait, a lieu par les larges stomates, au nombre de 1-2, situés au bas de l'acumen des feuilles en préfoliation. Lor'sque ce pliénomène s'opère dans les circonstances les plus farorables (humidité du sol, soirées et nuits fraîclıes et calmes, etc.), il est facile, comme je l'ai montré, de traire, en pressant les feuilles entre les doigts, une assez grande quantité de sève. "L'auteur a apeŕrçu, tombant sous forme de pluie fine, une quantité de gouttelettes très limpides qui, traversant les rayons du soleil, tamisés par les branches feuillues des sapinettes, devenaient visibles. 


\section{CHAPITRE XXII}

\section{EXAMEN DES GHEVEUX ET DES POILS AU POINT DE VUE DE LA MÉDEGINE LÉGALE}

L'examen des poils a une très grande importance en médecine légale. Il arrive fréquemment que l'expert a la mission de déterminer si des poils trouvés adhérents à un objet, hache, couteau, bâton, chaussures, sont des cheveux ou des poils appartenant à un animal quelconque. Des erreurs ont été commises à la suite d'un examen superficiel; c'est ainsi que des poils blancs, provenant d'un lapin, ont été pris pour des cheveux d'un vieillard, que des poils adhérant à la semelle d'une chaussure, ont été également considérés comme des cheveux, jusqu'à ce que l'examen microscopique ait montré qu'ils provenaient soit d'une vache, soit d'un cheval.

Les détails dans lesquels nous allons entrer feront mieux comprendre de quelle importance est en médecine légale la connaissance des différents caractères que présentent les poils. Jusqu'ici notre littérature médico-légale avait manqué d'un ouvrage résumant nos connaissances sur ce point de la science. Cette lacune vient d'être très heureusement comblée par le $\mathrm{D}^{\mathrm{r}}$ Johannet qui, dans sa thèse inaugurale sur le Poil humain(1), a résumé les travaux faits en France et à l'Etranger et surtout l'important ouvrage d'Otto OEsterlen, privat-docent, à l'Université de Tübingen (Tübingen, 1874). Nous ferons de très nombreux emprunts au travail du $\mathrm{D}^{\mathrm{r}}$ Johannet, tout en le complétant et en le critiquant sur certains points.

Nous commencerons par l'étude du cheveu humain, dont la parfaite connaissance s'impose à nous, si nous ne voulons

(1) Paris, Octave Doin, 1878. 
nas commettre quelque erreur grave, ainsi que nous en donnerons tout à l'heure des exemples.

Soit que l'on ait à examiner un cheveu, un poil, d'une région quelconque du corps, un cil ou un poil follet, l'attention doit se porter

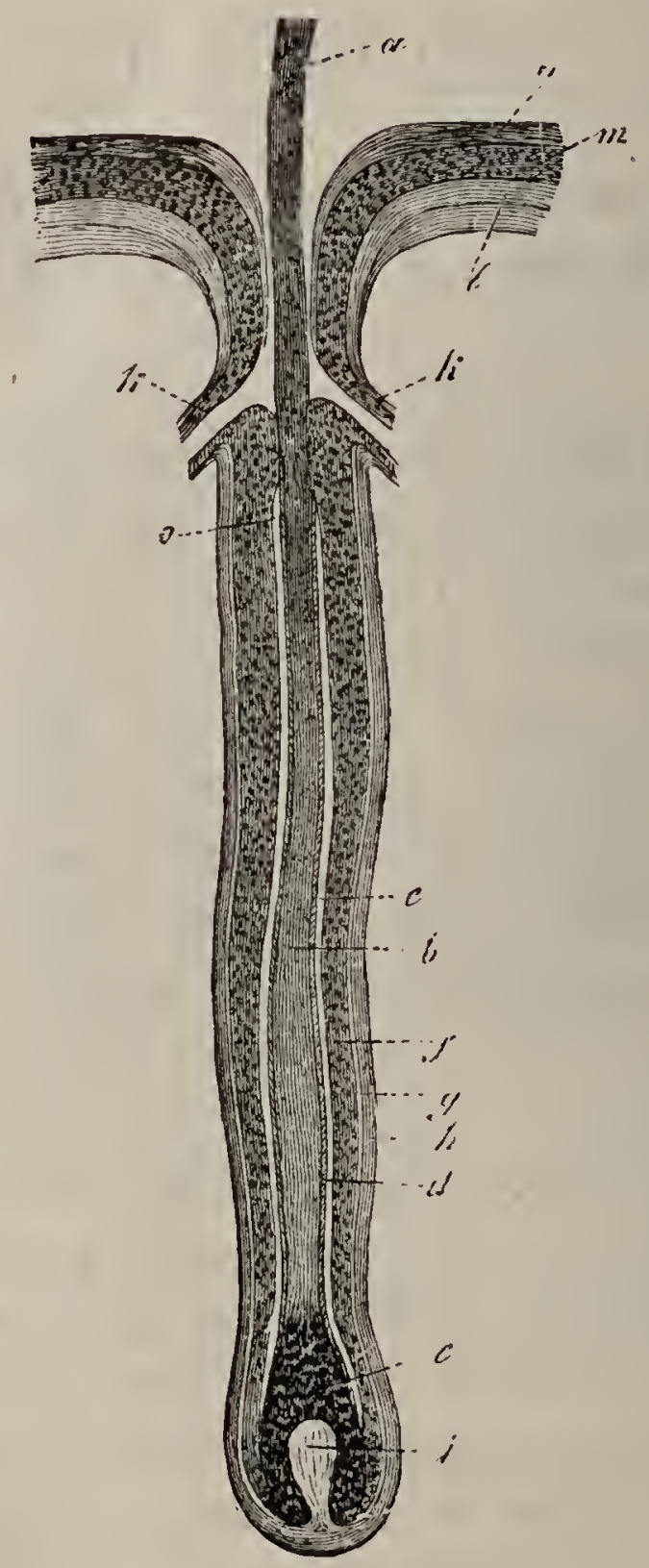

Fig. วั15. - Poil et follieule pileux de moł̌eu volume, grossis 50 fois. $-a$. Tige du poil. $-b$. Sa racine. $-c$. Bulbe pileux. $-d$. Eipiderme du poil. $-e$. Gaine interne de la racine. - f. Sa gaine externe. - $g$. Nembrane amorphe du follieule pileux. $-h$. Couches de fibres transversales et longitudinales de ce dernier. - $i$. Papille du poil. $k$. Conduits excréteurs des glandes sébacées, avee leur épithélium et leur eouehe fibreuse. - $-l$. Derme au niveau de l'embouchure du follicule pileux. - $m$. Couche muqueuse.:n. Couehe cornée de l'épiderme, s'étendant un peu dans l'intéricur du follieule.- - Terminaison de la gaine interne de la racine du poil. (Külliker.)

également sur la partie libre du poil et sur le follicule appelé communément la racine du poil, maisqui la comprend avec ses annexes.

Siructure du poil. - Le poil est surtout constitué : $1^{\circ}$ par la 
substance corticale ou fibreuse qui est l'élément fondamental; $2{ }^{\circ}$ par la moelle; $3^{\circ}$ par l'épiderme.

Pour bien étudier la substance corticale, Kölliker conseille de traiter le cheveu par l'acide sulfurique el par la chaleur; il devient alors facile de diviser la substance corticale en longues fibres aplaties. Ces libres ont pour caractères d'être rigides, friables, el de présenter des irrégularités, des dentelures de leur's bords et de leurs extrémités. Elles constituent le tissu cortical. Celui-ci est strié dans sa longueur et transparent dans les cheveux blancs, mais le plus fréquemment il contient de la matière colorante plus ou moins régulièrement distribuée, tantôt uniformément répandue dans tout le tissu, tantôt

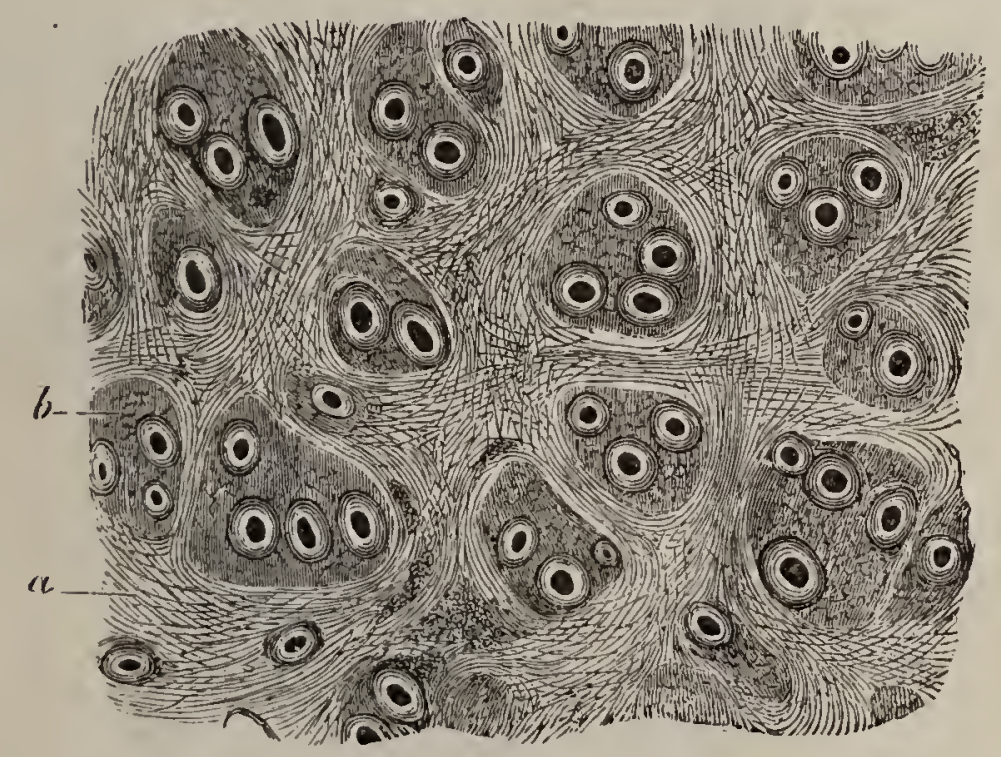

Fig. z̈16. - Section horizontale du cuir chevelu, tıaitéc par l'acide acét que (faible grossissement). - $a$. Faisceaux de tissu conjonctif entre-croisés. $-b$. Groupes de follicules pileux. (Kölliker.)

réunic en certains points sous forme de taches allongées ou granulées. Dans les cheveux blonds, les fibres isolées par le procédé indiqué plus haut sont d'une couleur claire; elles sont d'une coloration plus ou moins foncée dans les cheveux bruns ou noirs. Ces fibres elles-mèmes peuvent être considérées, d’après Kölliker, comme formées de cellules allongées et aplaties. Les taches que l'on rencontre dans le tissu cortical, abondantes surtout dans les cheveux très foncés, sont formées par des amas de granulations pigmentaires. Ce tissu doit également sa coloration à un principe colorant dissous qui imprègne complètement la substance des lamelles. Ce pigment grenu offre toutes les colorations que peuvent présenter les cheveux, depuis le jaune clair jusqu'au noir, en passant par le rouge et le brun. La matière colorante dissoute presque nulle dans les cheveux blancs est, d'après Kölliker, en petite quantité dans les cheveux blond clair ; elle est très abondante, au contraire, dans les cheveux châtains ou roux, ainsi que dans les cheveux noirs, où elle 
suffit à elle seule pour produire une coloration rouge mćlangée de brun. C'est à ces deux matières colorantes (pigment grenu et matière colorante dissoute) que les cheveux doivent leur coloration; tantôt l'une domine, tantôt l'autre; dans les cheveux très colorćs, elles sont à peu près également réparties.

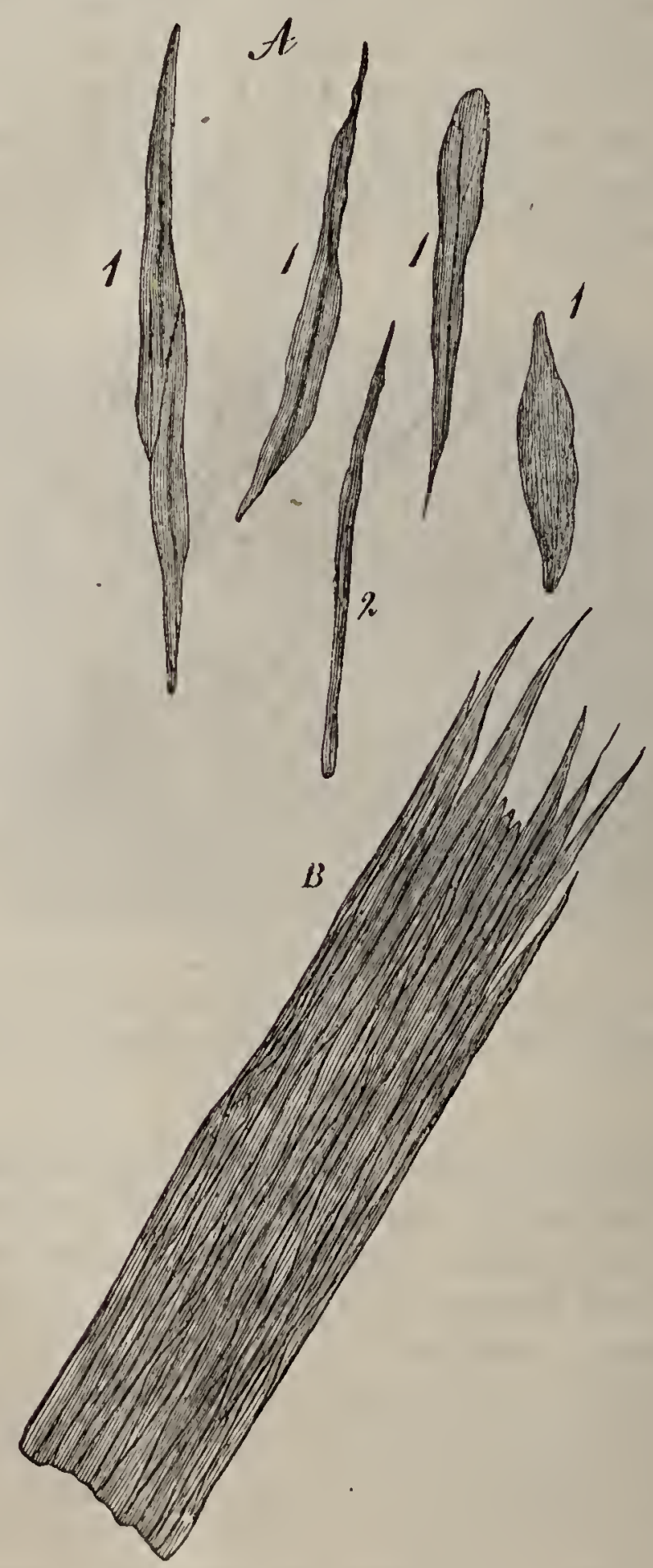

Fig. 517. - Lamelles ou fibres eellules de la substanee eortieale d'un poil traité par l'aeide sulfurique. - Grossissement de 3 ŏ $0 \mathrm{D} .-\mathrm{A}, 1$. Lamelles isolées vues de faee (trois sont isolées el deux sont unies entre elles); 2, vues de profil. - B. Couehe composée d'un grand nombre de lamelles semblables aux préeédentes. (Kölliker.)

D’après Hager, le pigment de la corde médullairc et des lacunes intrit-fibrillaires de la gaine médullaire et de la couche corticale ne 
lorme qu'en partie le fond de la nuance des cheveux. Celle-ci dépend surtout de la coloration de la couche corticale. La substance fibreuse cornée est noire ou plutôt gris foncé dans les fibres isolées des cheveux noirs, dans les cheveux roux elle est rouge, dans les cheveux

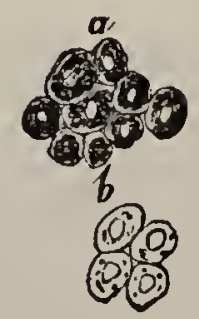

Fig. 518. - Cellules de la portion la plus profonde du bulbe, grossies 350 fois. - $a$. Celłulcs d'un bulbe coloré, à granulations pigmentaires qui cachent un peu le noyau. $-b$. Ccllules d'un cheveu blanc, à noyau distinct et renfermant peu de granulations. (Kölliker.)

châtains elle est brune, dans les cheveux blancs elle est jaune. Le degré d'intensité de ces colorations dépend de la quantilé de matière grasse élaborée par les glandes annexes du cheveu, ou ajoutée.

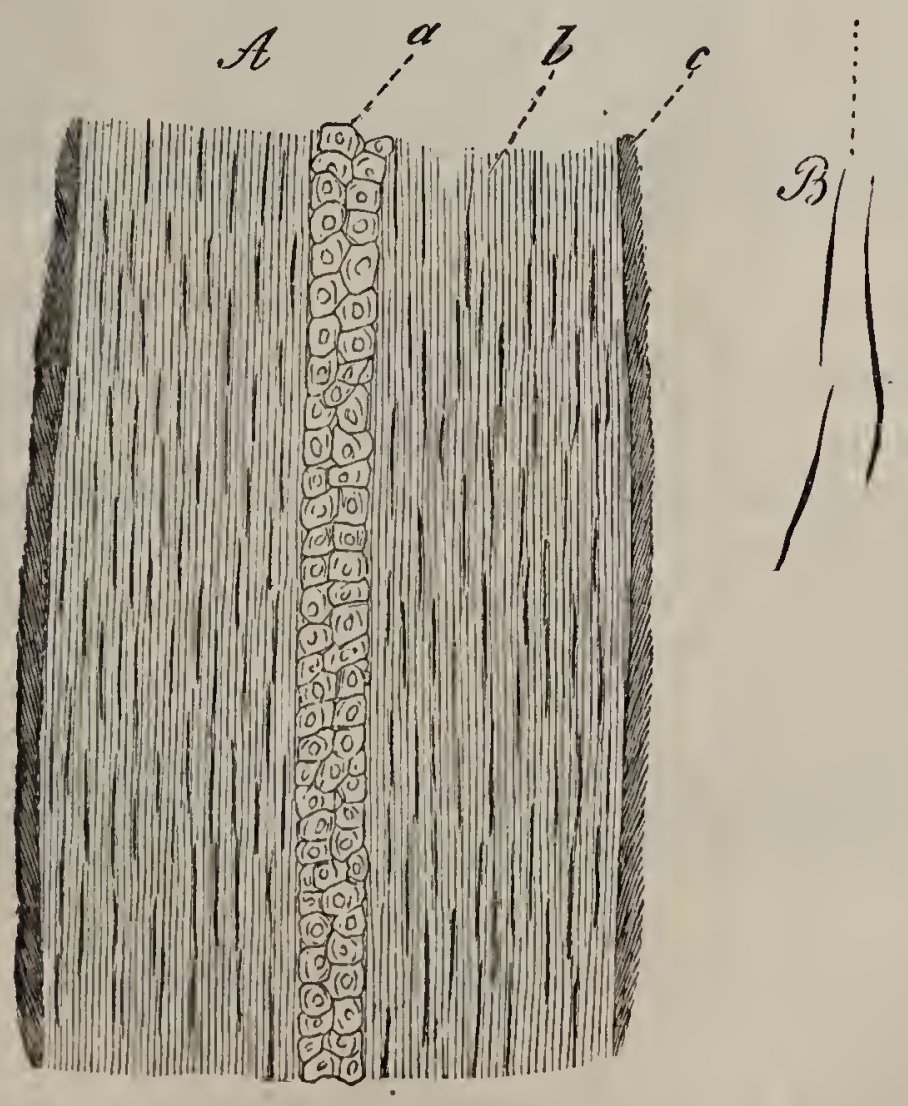

Fig. 519. - A. Fragment d'un cheveu blanc traité par la soude et grossi 330 fois. $-a$. Cellules à noyau de la moelle, sans air. - $b$. Substance corticale finement striée, avec noyaux linéaires. - $c$. Épiderme à lamelles un peu plus détachécs que d'ordinaire. B. Trois noyaux linéaires de la substance corticale, représentés isolément. (Kölliker.)

Suivant Hager, le phénomène du grisonnement des cheveux n'est pus dû à la disparition du pigment, mais se produirait par suite d'une 
élaboration moins considérable de la matière grasse, ou plutôt par une sorte de mortification de la substance corticale qui, devenant opaque, ne se laisse plus traverser par la lumière à peu près comme un écheveau de verre filé. Aussi un cheveu blanc peut-il encore contenir des cellules de pigment, dans la corde et la gaîne médullaires, comme avant sa décoloration.

Outre ces éléments, le tissu cortical présente encore des lignes foncées ou lignes de démarcation des fibres cellulaires, ou bien les noyaux mêmes de ces éléments anatomiques, comme le montre une figure ci-contre de Kölliker. Cetle structure du tissu cortical se poursuit jusque dans la moitié inférieure de la racine. Les cellules perdent de plus en plus leur structure fibreuse, tendent à devenir sphériques, et prennent des propriétés physiques différentes; l'acide acétique les altère alors qu'il élait sans action sur les éléments fibreux de la partie immédiatement supérieure du poil, et elles sont gonflées, puis dissoutes par l'action des alcalis.

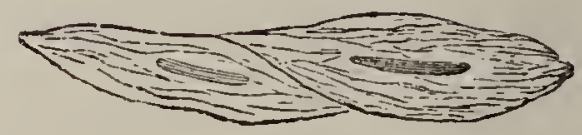

Fig. 520. - Deux cellules de l'écorce de la racine du poil (portion finement sticé, située immédiatement au-dessus du bulbe), à noyau distinct et d'un aspect strié. - Grossissement de 350 D. (Kölliker.)

Le tissu fibreux est résistant et élastique; il est de plus très hygroscopique.

L'eau oxygénée fait subir de profondes modifications à la matière colorante des cheveux; c'est par son emploi que l'on obtient ces cheveux blond clair qui ont été récemment très en faveur.

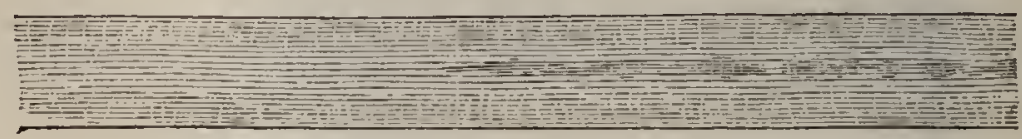

Fig. 521. - Cheveu de femme albinos.

Dans l'allinisme, il y a absence congénitale de matière colorante. Lorsque les cheveux blanchissent sous l'influence de l'âge ou d'émotions morales très vives, la décoloration se fait par la partie libre du cheveu et va progressivement jusqu'à la racine.

De la moelle. - L'existence de la moelle dans les cheveux n'est pas constante, elle manque très souvent dans les poils follets et dans les cheveux colorés, elle manque rarement, au contraire, dans les poils 
courts et gros, et dans les poils longs, ainsi que dans les cheveux blancs. (Kölliker.) Elle apparaît au-dessus du bulbe et va jusqu'au

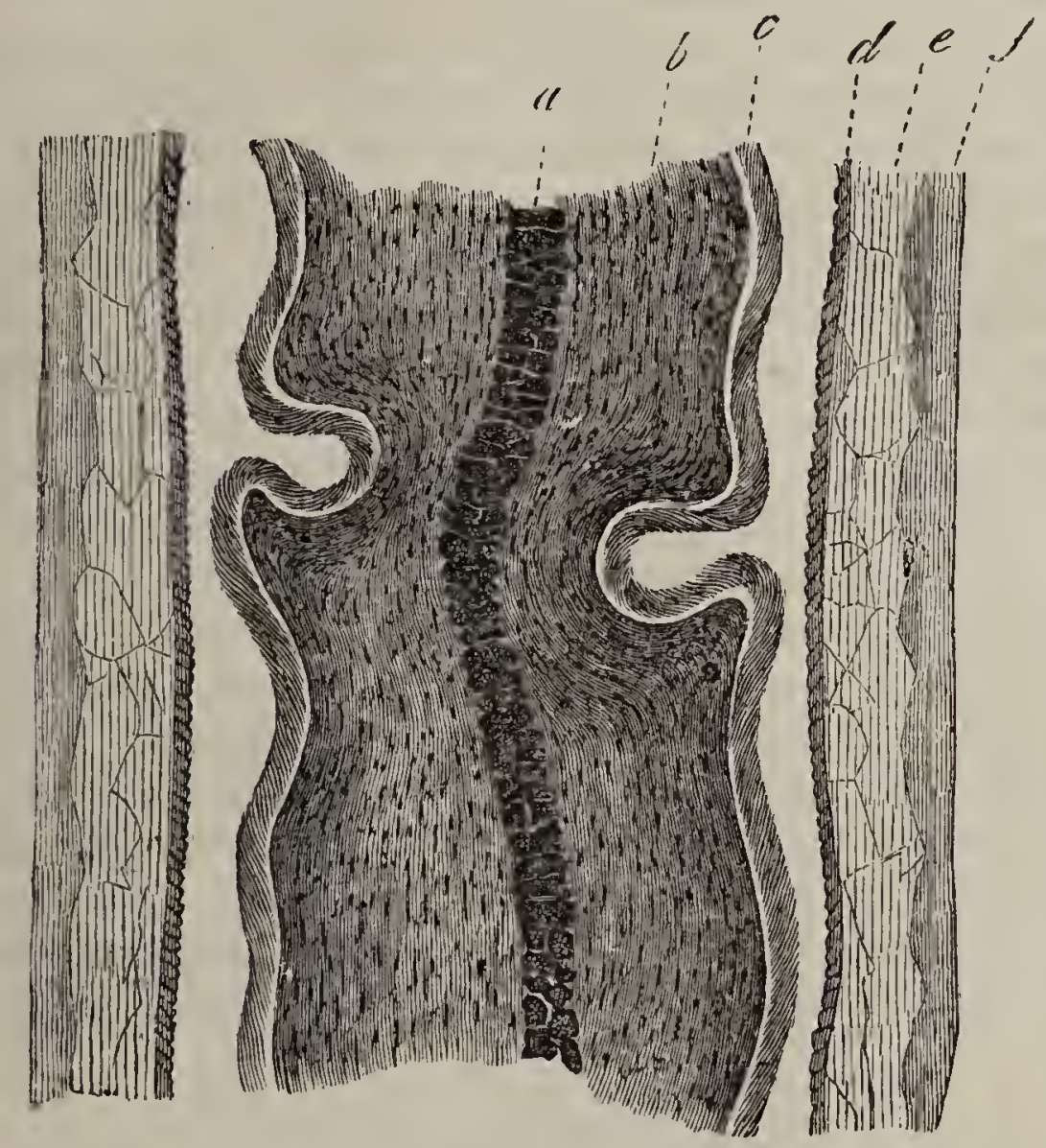

Fig. 322. - Purtion de la racine d'un cheveu foncé, traitée légèrement par la soude (grossissement de 250 diamètrees). - $a$. Moelle cncore remplie d'air, et dont les ccllules sont assez évidentes. - $b$. Écorce présentant des taches pigmentaircs. - $c$. Couchc interne de l'épiderme. - $d$. Sa couchc externe. $-e$. Couche interne de la gaine interne de la racine (souche de Huxley). - $f$. Couche externe fenêtrée de ectte gaine (couche de Henle). (Kölliker.)

voisinage de la pointe. Suivant Kölliker, elle occupe le centre du poil; mais, d'après G. Pouchet, sur certains poils à courbure sensiblement régulière (moustaches, cils, etc.), la moelle n'occupe pas le

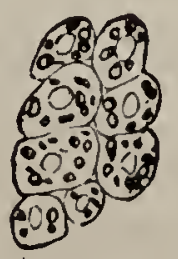

Fig. 523. - Huit cellules médullaires contenant un noyau pâle et des granulations graisscuses, prises sur un cheveu qui avait été traité par la soude ct grossies 350 fois. (Külliker.)

centre du poil, elle est légèrement reportée du côté de la convexité. Pour rendre bien apparente la structure cellulaire de la moelle, il faut, comme l'indique Kölliker, faire bouillir des cheveux 
blancs dans de la soude caustique, jusqu'à ce qu'ils se gonflent et se crispent. En dilacérant avec précaution un poil traité de cette façon, on peut isoler des cellules de la moelle.

Lorsque les cellules de la moelle reçoivent la lumière réfléchie, elles sont d'un blanc d'argent, elles sont noires au contraire à la lumière transmise. Les granulations des cellules sont formées par des petites bulles d'air qui peuvent être chassées par différents procédés, et en particulier par l'ébullition dans l'eau ou dans l'éther. C'est à la présence de ces bulles d'air que serait dù le reflet argenté de certains cheveux blancs. Quand le corps est plongé dans un bain d'eau tiède, il se dégage des poils un certain nombre de bulles de gaz.

Épiderme du poil. - Le poil tout entier possède un revêtement en contact intime avec le tissu cortical, c'est l'épiderme. Il est formé par des cellules ou lamelles imbriquées comme les tuiles d'un toit. A l'état normal, ces lamelles se révèlent à la surface du poil par des lignes foncées, plus ou moins distantes les unes des autres. Quelquefois, ces lamelles forment sur le bord du poil des dentelures très appréciables. L'emploi de l'acide sulfurique ou de la potasse donne aux bords du poil un aspect feutré dû au redressement des lamelles épidermiques. Ces lamelles sont généralement transparentes et à bords clairs, quadrilataires ou rectangulaires, montrant une sorte de tache claire rayonnée, qui est sans doute le vestige d'un noyau.
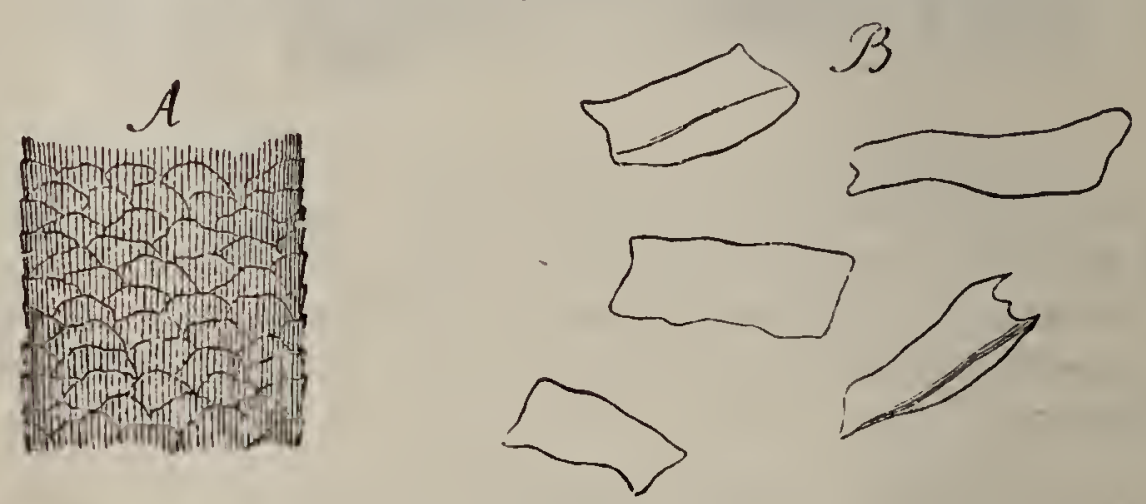

Fig. 524. - A. Surface de la tige dun cheveu blanc, grossi 160 fois. Les lignes onduleuses marquent les bords des lamelles épidermiques. - B. Lamelles épidermiques isolées á l'aide de la soude, grossies 350 fois. Elles présentent un ou deux de leurs bords plus ou moins renversés, ce qui les fait paraître foncés. (Kölliker.)

Les écailles ont leurs bords tournés vers l'extrémité libre du poil. Grâce à cette disposition, on peut reconnaître, sur un fragment de poil, quel bout regarde le sommet.

Du follicule proprement dit, paroi folliculaire. - Le follicule est com posé par deux tuniques fibreuses, l'une externe, l'autre interne, et d'une membrane amorphe. La tunique fibreuse externe détermine la forme extérieure du follicule et adhère intimement au derme par son extrémité supérieure. Formée par un tissu conjonctif, cette tunique renferme, en outre, des vaisseaux capillaires et quelques tibres nerveuses.

La tunique fibreuse interne est plus épaisse que la précédente; 
CHAPITRE XXII. - EXAMEN DES CHEVEUX ET DEj POILS. 813

elle renferme également des capillaires, mais pas d'éléments nerveux suivant Kölliker.

La troisième couche est une membrane hyaline amorphe, qui reste toujours dans le follicule quand on arrache le cheveu. Elle va en s'atténuant vers la profondeur du follicule et se perd sur le collet de la papille dont le tissu est, au contraire, continu avec celui de la paroi folliculaire.

L'implantation du follicule est généralement oblique, ce qui per-

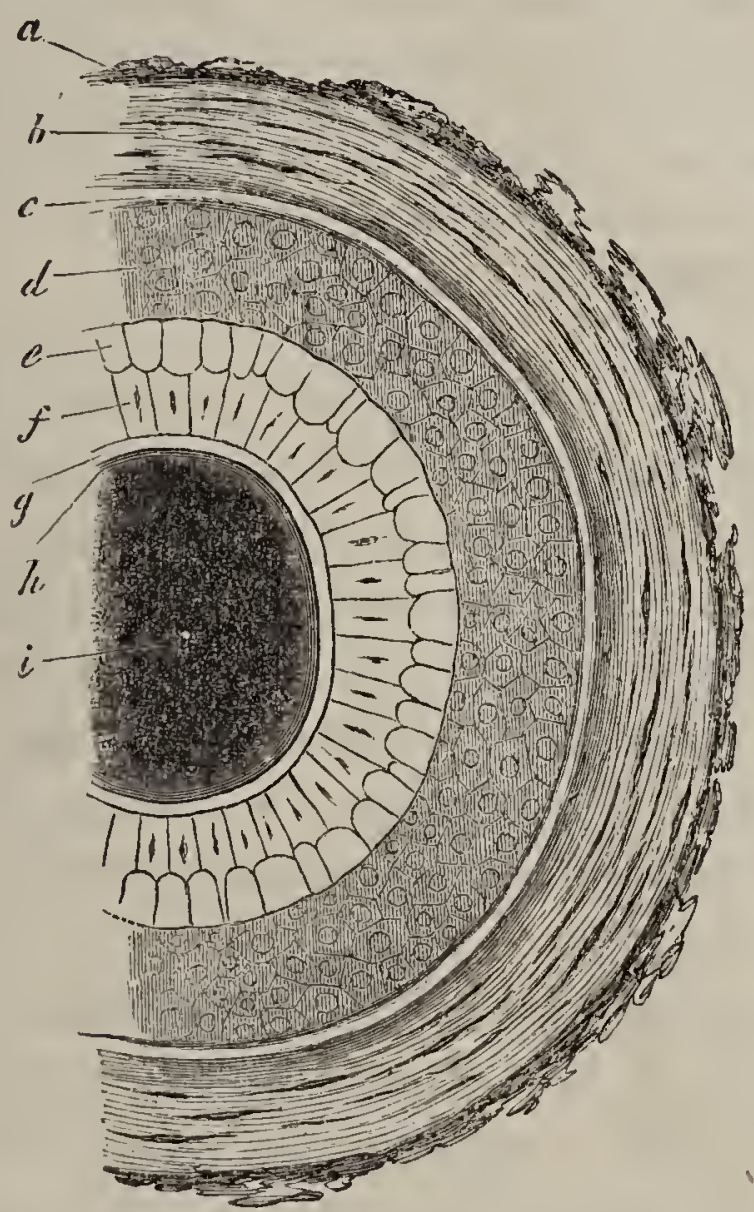

Fig. 523. - Section transversale d'un cheveu et de son fullieule un peu au-dessous de la portion moyenne de ee dernier. (Grossissement de $350 \mathrm{D}$.) - $a$. Couehe à fibres longitudinales du follicule, peu développée. $-b$. Couche à fibres transversales avec eorpuscules de tissu eonjonetif. - $c$. Membrane vitrée. - $d$. Gaine externe de la raeine. - e. Gaine interne de la raeine, couehe externe. - $f$. Couche interne de cette gaine. - g. Épiderme du follicule. - $h$. Épiderme du cheveli. $-i$. Cheveu. (KöHliker.)

met de disposer les cheveux à l'aide d'un peigne ou d'une brosse suivant une direction déterminée. Quand celte insertion est perpendiculaire, on a ce qu'on nomme vulgairement un épi.

Les glandes sébacées sont annexées aux follicules.

La papille du poil (V.fig. 515), appelée également germe du poil, est une partie du follicule qui répond aux papilles du derme. Elle est surmontée par le cheveu qui semble naître d'elle par une multiplication des éléments qui recouvrent immédiatement son tissu.

Gaines de la racine. - Situé au centre du follicule, le poil est séparé de la membrane hyaline par les gaines de la racine. La gaine $e x-$ 
terne est la continuation de la couche de Malpighi, et tapisse toute la face interne du follicule pileux. Elle est généralement plus épaisse que la gaine interne.

La gaine interne est une membrane transparente qui part du fond du follicule pour s'étendre jusqu'à son tiers supérieur, où elle se termine par un bord tranchant. Elle s'applique directement sur la gaine externe et est constituée par des cellules polygonales et allongées.

Épiderme dé la guine interne. - La gaine interne est tapissée extérieurement par une troisième couche épithéliale qui se trouve en contact immédiat avec l'épiderme du poil dont il paraît la continuation. Ses cellules offrent une disposition analogue, mais elles sont imbriquées à l'inverse, se recouvrant de telle sorte qu'elles se dépassent les unes les autres par leur bord inférieur qui reste libre du côté de l'axe du follicule.

On doit considérer deux formes de cheveux ou de poils : $1^{\circ}$ Le poil en bouton de Henle (Haarknopf), ourert inférieurement. - La racine est renflée à son extrémité inférieure (bulbe de la racine) et présente une cavité ouverte inférieurement qui coiffe ou qui embrasse la papille située au fond du follicule.

$2^{\circ}$ Le poil en massue de Henle (Haarkolben); son extrémité inférieure est ramifiée comme la racine d'un végétal et plongée directernent dans un amas épithélial se continuant avec la gaine extérieure.

En général, ces poils n'ont pas de gaine moyenne, et le cheveu ou le poil se trouve en contact direct avec la gaine externe. On rencontre quelquefois ce; poils à une certaine hauteur, dans les cavités folliculaires au fond desquelles on retrouve une papille; quelques-uns de ces mêmes cheveux présentent des débris de gaine moyenne, ce qui a fait penser qu'ils étaient des cheveux à bulbe transformé et sur le point de tomber. Gette forme de racine se rencontre dans les poils follets chez l'adulte et chez l'enfant et dans les cheveux de la mue et de l'alopécie. Elle peut être physiologique.

OEsterlen a considéré les poils en boutons de Henle comme une forme de développement inachevé, tandis que les autres (poils en massue) seraient des poils à développement achevé.

D'autres auteurs, Unna (1) en particulier, regardent ces derniers comme des poils qui sont sur le point de tomber. Les

(1) Arch. für mickr. Anatom. Bonn, 1876. 
premiers, au contraire, seraient des poils typiques, en pleine évolution et jouissant de toutes leurs propriétés physiologiques.

Aussi nous croyons ne pas pouvoir accepter dans toute leur rigueur les deux conclusions suivantes d'OEsterlen : $1^{\circ}$ un poil avec une racine ouverte n'a pas atteint le terme de son développement, il sera donc regardé comme ayant été arraché lorsqu'il s'agira d'une expertise ; $2^{\circ}$ un poil pourvu d'une racine fermée est vraisemblablement tombé de lui-même, mais peut aussi avoir été arraché avant le moment de sa chute.

De la couleur des poils. - Dans les indications que nous avons données sur la structure du poil, nous avons indiqué à quels éléments et à quel mécanisme, ils devaient leur coloration. Si la détermination de la couleur d'un poil n'offre pas grande difficulté, quand on a sous les yeux une couleur très tranchée, il n'en est pas de même lorsque l'on a à déterminer une des couleurs de transition si fréquentes. Il y a généralement un rapport assez étroitentre la coloration du poil et celle de la peau (Sappey, Broca, Pruner-Bey); cette analogie de coloration se poursuil entre le cheveu et l'iris (Broca, PrunerBey). Les trois couleur's principales des poils sont le blanc, le noir, et le rouge feu, qui par leur association, donnent naissance à ces nuances si variées que nous avons sous les yeux. On peut voir dans le musée de l'Institut anthropologique de Paris, une gamme de coloration des cheveux, faite par les soins du professeur Broca. Ces différents échantillons ont des origines très diverses et proviennent d’individus appartenant aux deux sexes, et à des races très variées. Ces diverses nuances constituent un cercle complet, passant du noir au blanc par le brun et le gris, et revenant du blanc au noir par le blond et le rouge. Les cheveux de différentes nuances sont disposés de façon a former un passage insensible du rouge vif au rouge sombre, au rouge-noir et enfin au noir. Les cheveux les plus clairs sont, comme nous l'avons vu, ceux des albinos.

M. Broca a formé un tableau chromatique numéroté, permettant de distinguer facilement les types caracléristiques.

Ce tableau renferme cinquante quatre nuances s'appliquant aux chereux et à la peau ; les vingt premiers numéros concernent également l'iris. Les vingt premières nuances sont dis- 
posées en séries régulières, à savoir : 1 - 5, nuances brunes; $6-10$, nuances vertes; $11-15$, nuances bleues ; $16-20$, nuances grises. Le reste du tableau est disposé autrement; la multiplicité et la proximité des nuances fondamentales qui relèvent de deux couleur's seulement, jaune et rouge, el de leur mélange en proportions convenables, rendant impossible cette classification, on s'est borné à confronter sur l'un des côtés du tableau les teintes les plus sombres, afin de rendre la comparaison plus facile. On a cherché à faire suivre les autres dans un certain ordre, mais cet ordre n'a pu être régulier, il a fallu plus d'une fois rendre les séries naturelles. Le $\mathrm{n}^{\circ} 48$ représente le noir absolu (Broca) (1).

Le $\mathrm{D}^{\mathrm{r}}$ Johannet insiste avec raison sur l'importance que présente ce tableau pour le médecin légiste dans les questions d'identilé. Grâce à son emploi, l'expert déterminera plus facilement et plus exactement la nuance d'un ou de plusieurs poils donnés ; il pourra même fixer cette coloration par un numćro d'ordre. La simple comparaison de deux poils mis à côté l'un de l'autre ne permettrait pas de distinguer une différence de coloration peutranchée (2).

Les poils vus en masse paraissent plus foncés que lorsqu'ils sont isolés.

Il faut encore tenir compte, dit le $\mathrm{D}^{\mathrm{r}}$ Johannet, de la direction des rayons lumineux. Une chevelure de couleur châtaine donne, par la réflexion des rayons lumineux intenses, des reflets dorés. Si on examine des cheveux au microscope, leur couleur peut se trouver également modifiée. Sous l'influence de la lumière réfractée, les cheveux noirs paraissent acajou-brun; les cheveux châtains acajou clair ; les rouges jaune clair orangés; les blancs sont transparents avec un léger reflet jaunâtre.

L'usage des corps gras tend à foncer la coloration des poils. On sait que les cheveux, surtout quand ils sont rétinis en grand nombre, offrent une résistance considérable. D'après OEsterlen, traduit par Johannet, celte résistance des cheveux mérite de fixer l'attention du médecin légiste. "Que l'on trouve

(1) Broca, Bullet. de la Société d'anthrop., sciance du 4 fóv. 1864.-Tableau chromatique, mémoires de la Société d'anthropologie, t. II, p. 123.

(2) Sćparés de l'ol'ganisme, les cheveux pâlisscnt avec le temps. 
des cheveux brisés sur un marteau, sur une pierre, cet état fragmen té des cheveux devra faire supposer l'emploi d'une telle force qu'un plan d'appui résistant, comme un os, aurait été du même coup infailliblement brisé. En outre, cette solidité démontre que les cheveux ou poils sont plutôt déracinés que brisés dans leur tige; d'où cette conséquence: quand la racine fait défaut, il est difficile a priori de croire à un ạrachement. Quand une touffe de cheveux est prise par une machine, il arrive même encore bien plus fréquemment qu'il y a arrachement du cuir chevelu, qu'avulsion simple des cheveux» 1 (1).

Le corps tout entier est couvert d'un duvet plus ou moins abondant, quelquefois si fin qu'on ne l'aperçoit que dans une certaine direction et à l'aide d'une lumière assez intense. Les seules régions dépourvues de poils sont la paume des mains et la plante des pieds, le dos des dernières phalanges des doigts et des orteils, la partie interne du prépuce, le gland et le clitoris. D'après Eschricht, les poils et surtout le duvet affecteraient une disposition spéciale tant à la tête que sur le corps et ses extrémités. Cette disposition serait analogue à celle de tourbillons, de courants, de croix.

Le $\mathrm{D}^{\mathrm{r}}$ Johannet a, d'après les travaux d'OEsterlen, rapporté les variations subies par le poil. Nous donnons ci-après le résultat de ces recherches. Les modifications que peuvent présenter les poils d'un même individu sont en rapport: $1^{\circ}$ avec le lieu d'implantation; $2^{\circ}$ avec l'äge; $3^{\circ}$ avec le sexe.

$1^{\circ}$ Variations suivant le ileu d'implantation. - G'est sur la longueur des poils d'un homme adulte qu'on s'est appuyé pour faire une classification. On distinguera donc:

$1^{\circ}$ Longs poils du crâne (cheveux);

$2^{\circ}$ Longs poils de la face (barbe);

$3^{\circ}$ Longs poils du corps (pubis, aisselle, anus);

$4^{\circ}$ Courts poils colorés de la face (cils, sourcils, vibrisses);

$5^{\circ}$ Courts poils colorés du corps (poitrine, abdomen, membres);

(1) Nous indiquons plus loin sur quelles raisons nous nous fondons pour ne pas accepter les déductions d'OEsterlen.

GUIDE dE MicrograpHie. 
$6^{\circ}$ Poils rudimentaires du duvet (presque toute la surface du corps).

C'est généralement dans cet ordre de longueur décroissante que se présentent les poils; mais il peut se produire des anomalies : $1^{\circ}$ par accroissement extraordinaire de certains poils; $2^{\circ}$ par le remplacement du duvet de certaines régions par des poils; $3^{\circ}$ par la transformation du duvet en poils (observée chez les hommes dits chiens).

L'épaisseur des poils varie suivant la région observée ; toutefois, dans une même région, on peut observer des différences. Aussi, quand on veut déterminer un caractère quelconque d'un poil appartenant à une région déterminée, faut-il faire porter l'examen sur un grand nombre de poils; un poil uni que ne saurait en aucun cas fournir de caractères suffisants, pour que l'on puisse sûrement en déduire son origine.

Ordre de décroissance dans l'épaisseur des poils chez l'homme adulte: Barbe du menton, - pubis, moustaches, - joues, sourcils, - scrotum, - aisselles, - vertex, - tempes, - cils, bregma (Wirbel des Allemands), - front, - narine, - nuque.

La couleur varierait également suivant les régions, mais ces variations ne sont pas constantes; le duvet est en général peu coloré. - Les poils de l'aisselle, ceux des organes génitaux chez la femme, sont en général moins colorés, en raison sans doute de l'action exercée d'une part, par la sueur et de l'autre, par le mucus et par l'urine. La barbe a généralement une coloration plus claire que la chevelure; les teintes blondes et rouges prédominent; au pubis, il y a prédominance des teintes extrêmes (roux et noir).

Les caractères tirés de la forme et de l'aspect du poil n'ont point de constance suffisante pour pouvoir être utilisés.

- Voici d'après OEsterlen (traduit par Johannet) le tableau de l'épaisseur des cheveux.

Epaisseur à différents points du crâne :

Chez l'homme

$=0^{\mathrm{m} m} .07 \mathrm{~s}$

$=0 \quad .068$

$=0.062$

Chez la femme

$=0 \quad .054$

$=0 \quad .076$ 
CHAPITRE XXII. - EXAMEN DES CHEVEUX ET DES POILS. 819

Chez la femme

$=0^{\mathrm{mm}} .065$

$=0 \quad .077$

$=0 \quad .058$

Chez le vieillard

$=0 \quad .050 \quad 0^{\mathrm{mm}} .063$

Chez un enfant de 1วั ans $=\begin{array}{llll}0 & .0 د 0 & 0 & .062\end{array}$

Ghez l'enfant de 6 à 18 mois $=\begin{array}{llll}0 & .034 & 0 & .034\end{array}$

Ghez l'enfant de 12 jours $=\begin{array}{llll}0 & .020 & 0 & .026\end{array}$

On a tiré la conclusion suivante de ces chiffres: " tout poil qui a plus de $0^{\mathrm{mm}}, 08$ d'épaisseur n'est pas un cheveu. "

La largeur d'un cheveu n'est pas uniforme dans toutes les parties. Le diamètre transversal atteint son maximum au centre du poil, qui va en s'effilant vers l'extrémité et vers la racine. Cette différence dans les dimensions du diamètre transversal n'est appréciable qu'à l'aide de moyens de mensuration très délicats.

L'examen de la pointe du cheveu offre de l'importance, parce que les cheveux et la barbe sont généralement les seuls qui soient soumis à l'action des ciseaux ou des rasoirs. Un cheveu qui n'a pas été coupé présente une pointe conique plus ou moins fine se fondant insensiblement avec la portion large de la tige; les longs poils du corps ont également une pointe disposée d'une façon analogue (1). L'action des ciseaux ainsi que celle des rasoirs impriment au poil des caractères semblables. Voici quels sont les caractères de la pointe des cheveux, immédiatement après la section à l'aide d'un instrument tranchant: "Surface de séparation nette, transversale ou oblique, d'où proéminent généralement quelques fibres corticales ou des écailles épidermiques. Dans les premières semaines, l'action du frottemert par la brosse ou le peigne a fait disparaître les inégalités de la surface de section. A près douze semaines, il y a encore une surface de séparation à bords nets. Puis, peu à peu le poil s'amincit de nouveau à cette extrémité libre, mais sans jamais atteindre la finesse de la pointe primitive.

(1) Cette conclusion n'est pas absolument conforme à la réalité; il suffit, en effet, d'examiner des cheveux de femme pour voir que la pointe, bien que n'ayant jamais, ou du moins depuis fort longtemps, subi l'action des ciscaux, présente toutes les variétés de déformation dues à l'usure, au frottement ou à la cassure. 
Donc, comme il n'y a pour ainsi dire pas d'homme, dans nos pays civilisés, qui ne se fasse pas couper les cheveux, on peut regarder une extrémité libre transversale ou oblique, de forme semi-ovataire et non efflée, comme caractéristique des cheveux. »

On peut cependant trouver sur la tête d'une personne dont on a coupé les cheveux, quelques-uns de ceux-ci présentant encore une pointe effilée, soit qu'en raison de leur moindre

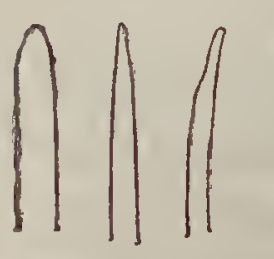

A B C D

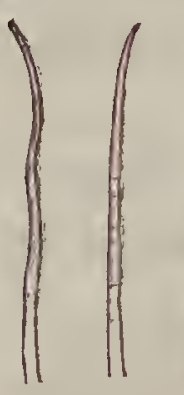

E $F$
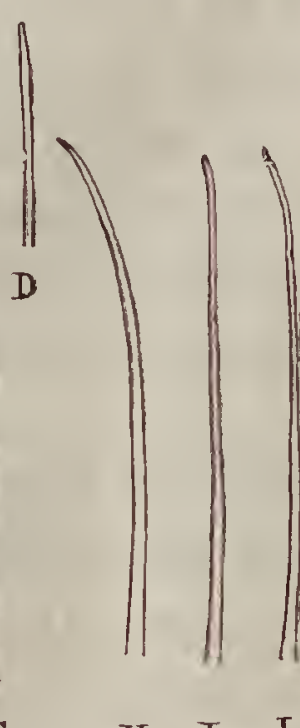
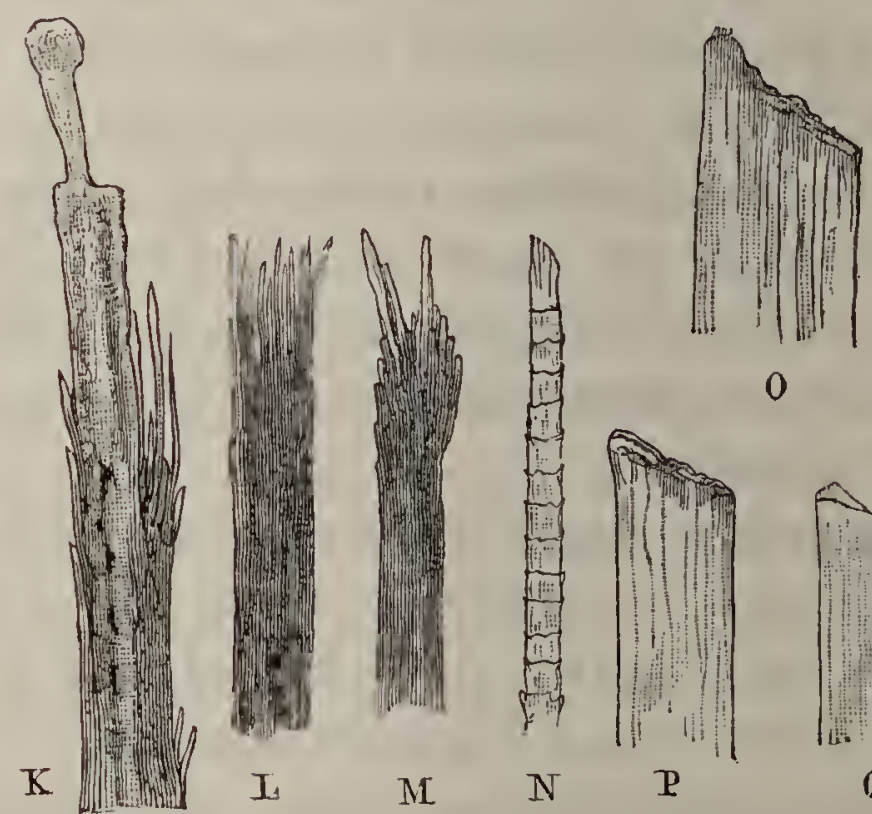

0

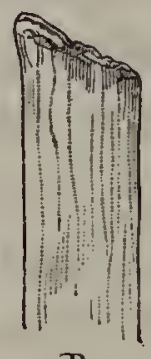

$\mathbf{P}$

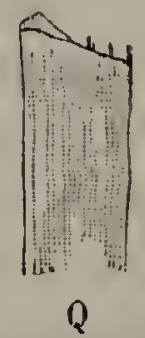

Fig. 526. - Différentes formes de pointes. - Cils, pointes. A, B, C (adultes). - D. Fœtus de 4 mois et demi. - E, F, G. Pointes de cheveux d'un enfant nouveau-né. - H, I, J. Pointes de poils de duvet recueillis sur le dos d'un enfant nouveau-né. (Ces pointes ne sont pas pures, souvent elles sont brisées ou tordues, soit en raison de leur séjour dans le liquide amniotique, soit par les onctions faites sur le nouveau-né pour le débarrasser de son enduit foetal.) - K, L, M, N. Différentes formes de pointes de cheveux de femme. 0 , P. Pointes de cheveux coupés depuis trois nois (homme). - Q. Pointe de cheveu immédiatement après la section. - Surface de séparation plus nette que dans le cas précédent. (Pour les chevcux follets la pointe est plus ou moins obtuse suivant quc le cheveu a été plus ou moins bien abrité contre le frottement.)

longueur, ils aient échappé à l'action des ciseaux, soit qu'ils appartiennent à une nouvelle poussée.Quand un cheveu a été coupé au niveau de la moelle, celle-ci n'atteint plus jamais l'extrémité du poil. (OEsterlen.)

Poils de barbe. - La longueur ne fournit pas de caractères. Épaisseur

$$
\begin{aligned}
& =0^{\mathrm{mm}}, 125 \text { (menton) } \\
& =0^{\mathrm{mm}}, 115 \text { (moustache) } \\
& =0^{\mathrm{mm}}, 104 \text { (joues) (OEsterlen). }
\end{aligned}
$$

Le caractère tiré de l'épaisseur n'est pas absolu, cependant seuls, les poils du pubis ont une épaisseur semblable $\left(0^{\mathrm{mm}}, 121\right)$. 
ChapitRe XXII. - EXAMEN DES GIIEVEux ET DES POILS. 821

Leur épaisseur est à peu près uniforme sur toute leur étendue. L'action des ciseaux et du rasoir produit, sur les poils de barbe, le même aspect que sur les cheveux.

Caractéristique d'un poil de barbe. - "Plusieurs poils étant donnés longs de 4 à 6 centimètres, larges de $0^{\mathrm{mm}}, 126$ avec tige

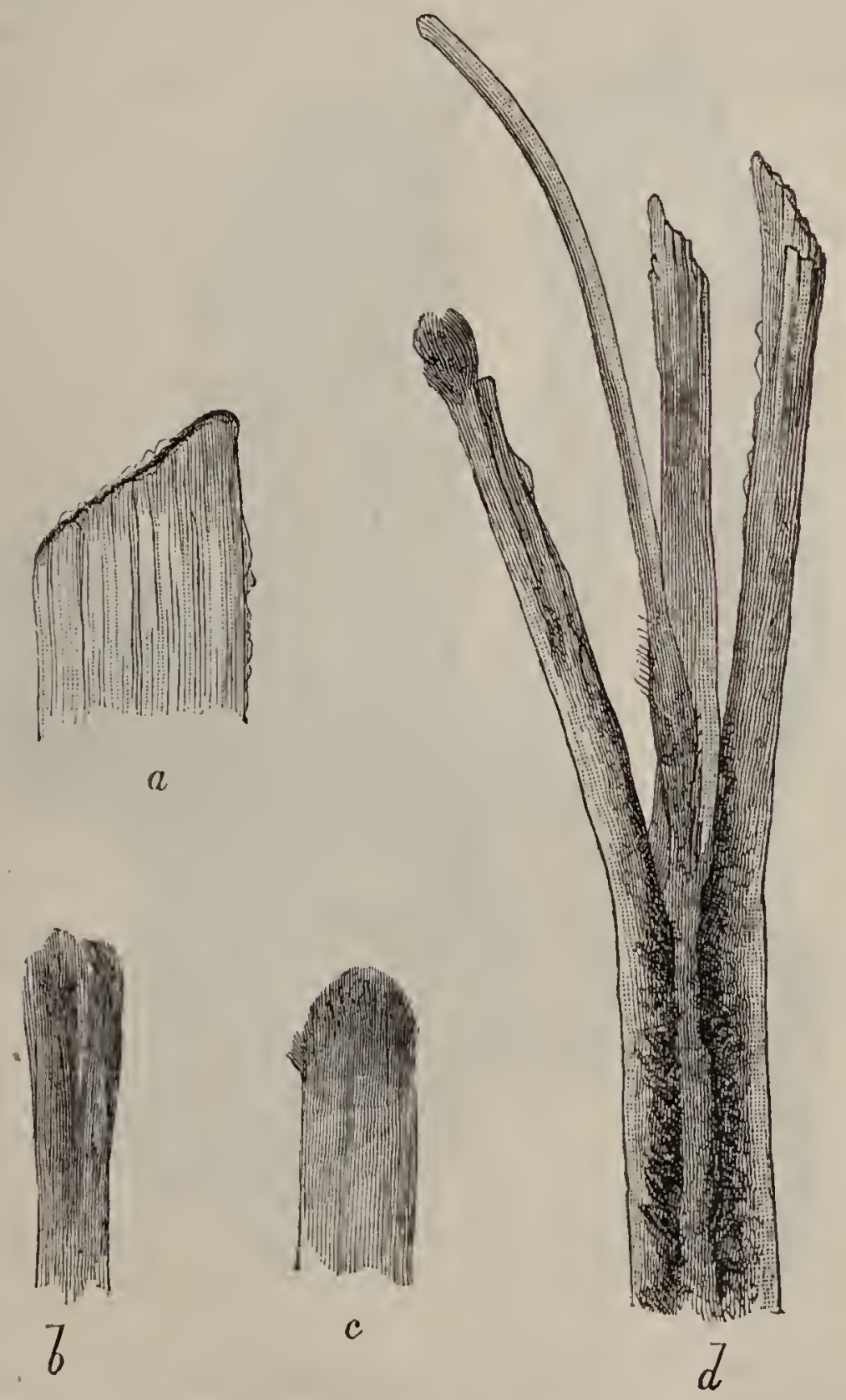

Fig. 527. - Différentes formes de pointes. - a. Pointe sectionnéc. - 6, c. Pointe en balai. - $d$. Pointe fendillée.

d'épaisseur uniforme, frisés, à pointe constituée par une surface de section oblique, non amincie, săns inégalités, peuvent être considérés comme des poils de barbe."

Poils de l'aisselle, du pubis, du scrotum, des grandes lèrres, etc. - Longueur ne dépassant guère 8 centimètres. 
Épaisseur des poils du pubis chez l'homme $=0^{\mathrm{mm}}, 121$ chez la femme $=0^{\mathrm{mm}}, 11 \stackrel{\text { o }}{ }$

Poils de l'aisselle (homme) $=0^{\mathrm{mm}}, 077$ (femme) $=0^{\mathrm{mm}}, 076$

Poils du scrotum $=0^{\mathrm{mm}}, 08 \mathrm{i}$
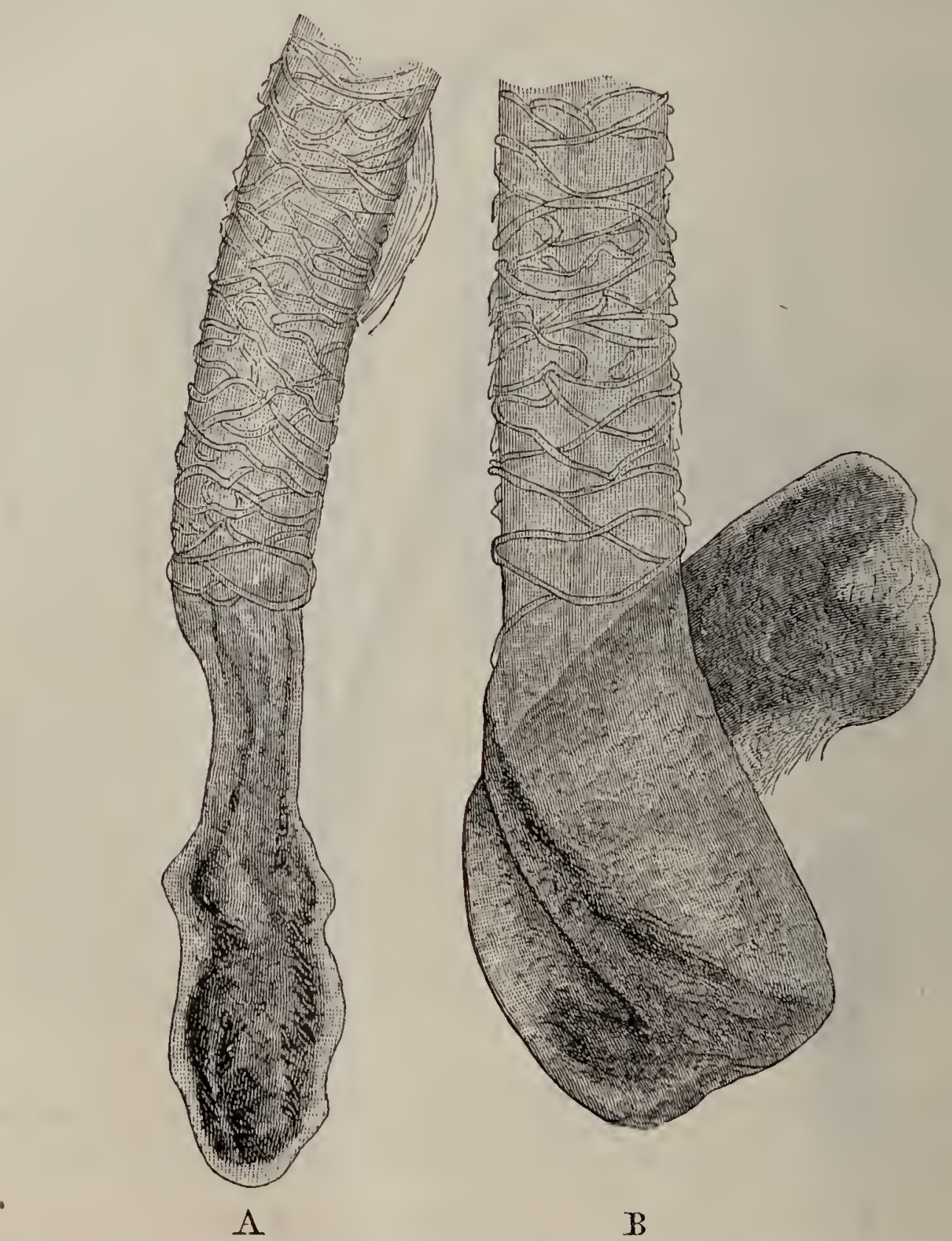

Fig. 528. - Poils de barbe (menton). - Racines obtenues par arrachement. Elles appar tiennent à deux formes différentes. - Sur la surface de la tige on voit les écailles épidermiques renversées par la traction exercée sur le poil. - $\Lambda$. Poil à bulbe plein ou en massue (Henle). - B. Poil à bulbe creux ou en bouton (Heule).

Les caractères tirés de l'épaisseur de ces poils n'ont pas une très grande importance. C'est ainsi que les poils du pubis ressemblent aux poils de la barbe, les poils de l'aisselle aux cheveux. Les poils du scrotum dépassent le diamètre ordi- 
CHAPITRE XXII. - EXAMEN DES GHEVEUX ET DES POILS. 823

naire des cheveux. On peut percevoir même à l'œil nu l'amincissement des deux extrémités du poil. Bien que la présence de la moelle soit constante, elle n'est pas caractéristique.

Les poils du pubis se distinguent par leur tendance à être crépus. La coupe est presque toujours ovale ou elliptique; la couche du périderme est inégale, noueuse, écailleuse par suite de l'enlèvement partiel de la substance cornée. Le poil du pubis des hommes est généralement plus mince que celui des

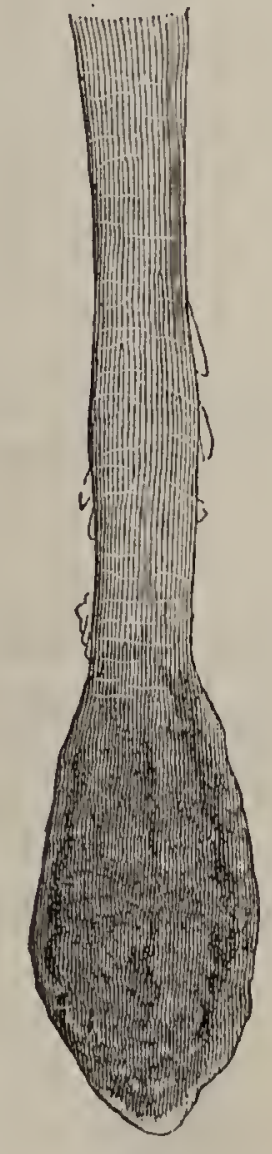

A

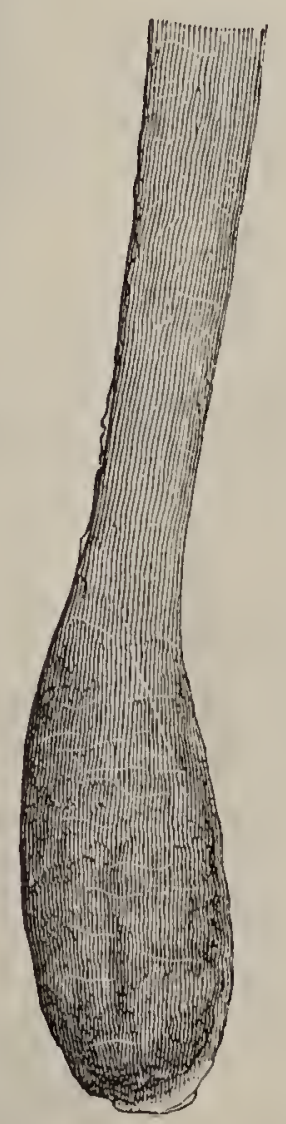

B

Fig. 329. - Puils du pubis (homme). - Raeines à bulbe plein ou en massue (tombée par le frottement de la main; peau finel.

femmes. La racine du premier est plus épaisse et noueuse; la racine du poil pubien de la femme n'est pas plus épaisse que la tige. Le poil du pubis des femmes est très facile à arracher, dit Hager, en raison de son implantation superficielle, il en est de même chez les hommes à peau fine. Réciproquement chez les femmes brunes et vigoureuses les poils du pubis sont plus solidement implantés que chez un homme blond.

La forme des pointes est très variable chez un même individu, 
ainsi qu'on peut le constater par l'inspection de la figure 530 . Il doit y avoir plus d'uniformité dans la forme des pointes lorsque le poil commence à croître, au moment de la puberté.

Nous donnons la figure de pòils du pubis d'une femme,
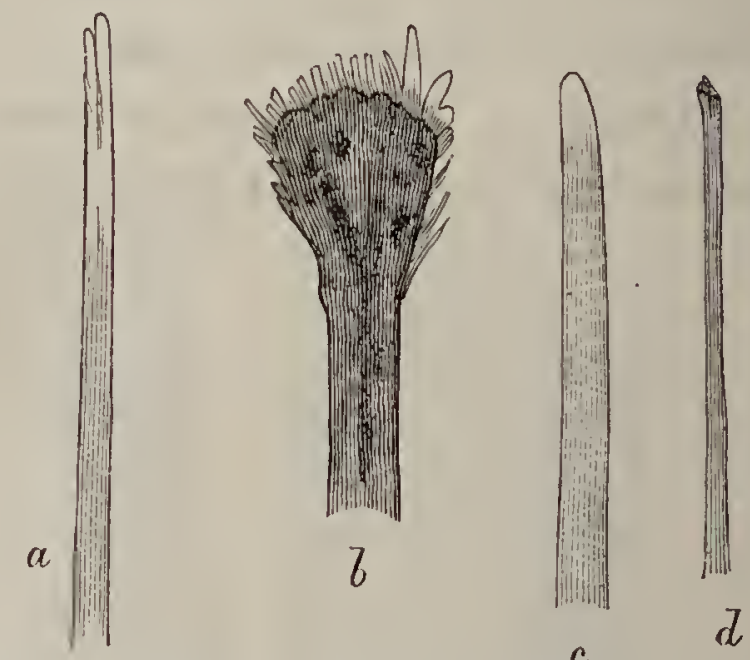

Fig. 530. - Poils du pubis (homme). - Variétés de pointes. - a. Pointe fendillée et très effilée. - $b$. Pointe en balai contenant des corps étrangers. - $c$. Pointe obtusc. d. Pointe cassée (poil fin).

recouverts de cristaux et de spermatozoïdes. Dans un cas de viol, ou de rapprochement sexuel quelconque, on peut faire des constatations identiques (fig. ̌̌31.)

Les poils de l'aisselle sont lisses à la sortie de la peau, ils sont recouverts ensuite, dans leur longueur, d'une foule

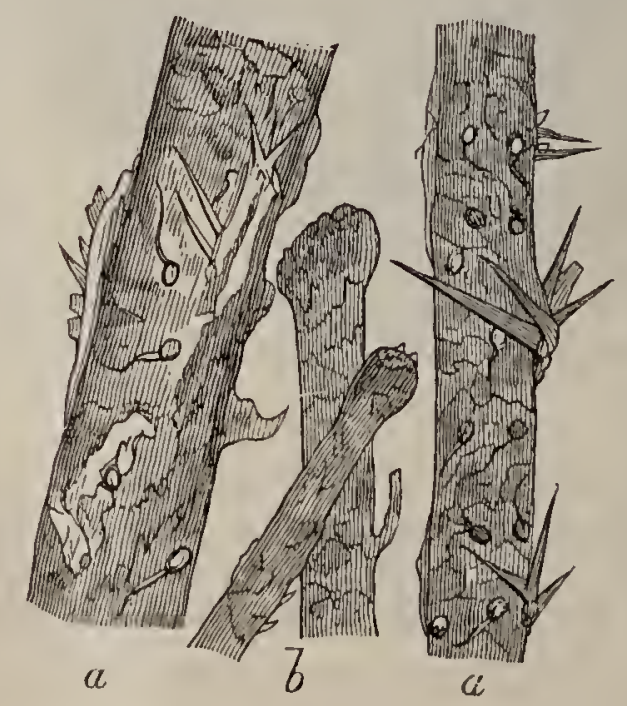

Fig. $: 331 .-a, a$. Poils du mont de Vénus avec spermatozoïdes et cristaux. - b. Puintes.

d'excroissances sous formes d'écailles ou de verrues qui résultent de la destruction partielle de l'épiderme par l'effet de la 
CHAPITRE XXI]. - EXAMEN DES GHEVEUX ET DES POILS. $82 \%$

transpiration et du frottement. La pointe est conique et émoussée, la couleur est généralement rougeâtre. (Hager.)

Les poils qui recouvrent la poitrine ressemblent beaucoup à ceux de l'aisselle. Généralement ils sont plus courts et. moins souvent rouges. La racine est charnue et épaisse. La pointe en massue.

Les poils du dos de la main de l'homme ont une pointe en massue aussi épaisse et quelquefois davantage que la tige. La racine est plus mince que la tige. Les poils de l'avant-bras et du bras leur sont semblables, seulement leur pointe est fendue par suite du frottement des habits. (Hager.)

Le poil qui recouvre les extrémités féminines ont presque toujours les caractères du duvet.

Hager pense que l'on peut distinguer les cheveux d'un homme de ceux d'une femme par la racine, qui est plus épaisse chez l'homme. Ia lessive caustique détruirait également plus rapidement les cheveux de la femme que ceux de l'homme.

Le poil des favoris est très épais et à périderme très inégal. La racine est plus mince que la tige. Le poil des favoris des hommes qui entrent facilement en transpiration, présenteraient, d'après Hager, dans la couche péridermale des élévations foncées, punctiformes.

Les poils du nez (vibrisses) seraient généralement d'un extérieur très inégal, pleins de gonflements sous forme de verrues. Ils se terminent en une pointe fine, et la racine montre sous une coupe longitudinale, la forme d'une guitare. (Hager.)

Les poils de l'intérieur de l'oreille ressemblent beaucoup à ceux du nez, seulement ils sont moins rugueux et se terminent plus en cône. (Hager.)

Les sécrétions, sueur, mucus vulvaire, urine, exercent sur les poils des modifications variables et qui ne les atteignent pas tous. De plus, l'action exercée sur les poils par les diverses sécrétions varie avec les individus. Elles agissent d'une façon analogue à l'acide sulfurique ou à la potasse en solution; leur action s'exerce surtout sur la tige et sur la pointe du poil : la cohérence des fibres corticales périphériques est détruite; il y a production sur la tige de dentelures irrégulières, de renflèment, et éparpillement de la pointe en ur 
pinceau de fibres. Le frottement du vêtement active encore cette division de l'extrémité du poil. Entre ces fragments du poil, s'arrêtent des poussières ainsi que des débris organiques qui donnent à l'extrémité du poil un aspect très variable et le fait ressembler tantôt à une massue, tantôt à une pelle, etc. (OEsterlen, Hoffmann.)

Le même phénomène peut se produire sur les poils de barbe et sur les cheveux, soit par l'effet d'une affection du cuir chevelu, ou de l'emploi intempestif de cosmétiques qui donnent au cheveu une grande fragilité.

La sueur paraît agir sur les poils en les décolorant partiellement. C'est ainsi que chez des individus bruns, on peut trouver dans les aisselles des poils roux.

Résumé des caractères des longs poils du corps. - Etant donnés des poils entiers de 4 à 8 centimètres -frisés, aplatis -d'un diamètre supérieur à $0^{\mathrm{mm}}, 1$, l'extrémité libre ne présentant pas une section nette, une pointe terminée assez brusquement (comme dans la barbe) ou bien offrant, ou contraire, un

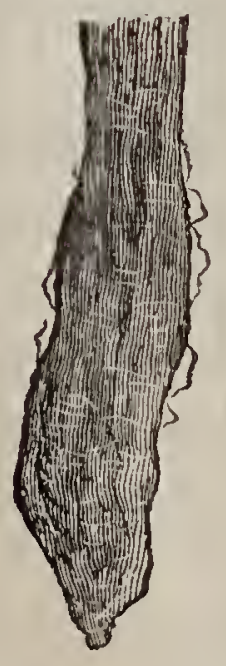

A

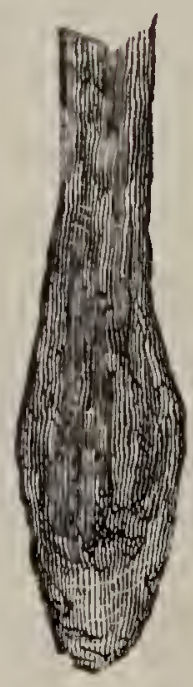

B

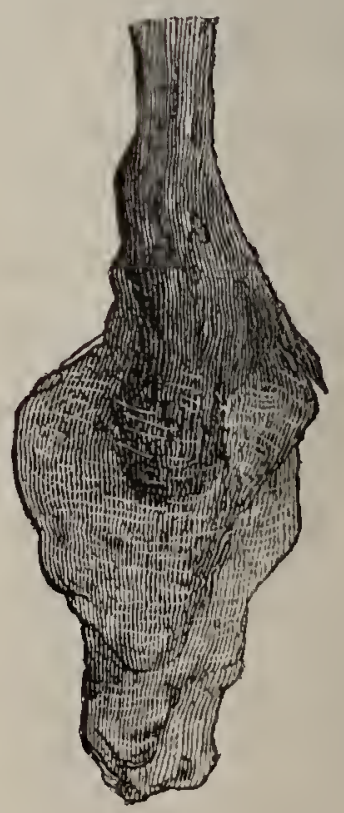

C

Fig. 532. - Cils (femmes). - Racines par arrachement a bulbe plein.

renflement irrégulier opaque, terminal : on a vraisemblablement sous les yeux des poils du pubis. Avec une largeur de tige inférieure à $0^{\mathrm{mm}}, 09$, on serait en droit de penser à des poils de l'aisselle ou du scrotum. 
CHAPITRE XXIl. - EXAMEN DES CHeVeUX ET DES POILS. 827

Généralement la tige de ces longs poils est caractérisée par des dépôts sudoraux ou autres qui les recouvrent.

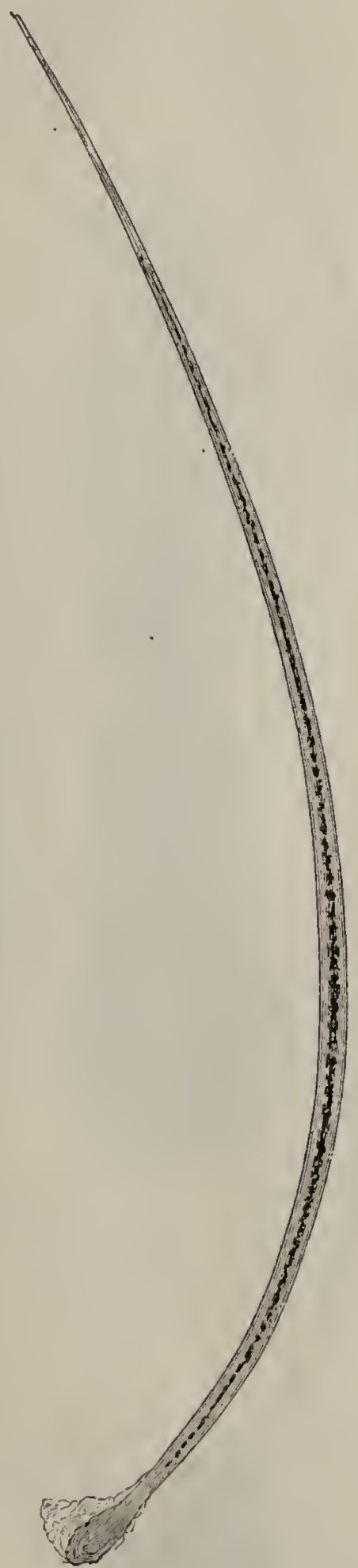

Fig. 533. - Cil (femme brune) obtenu par arrachement.

Poils courts et colorés du corps (abdomen, poitrine, membres), longueur de 1 à 2 centimètres.

Épaisseur variable, moindre sur les membres que sur le corps. 
Coloration d'autant moins prononcée que ces poils sont plus courts.

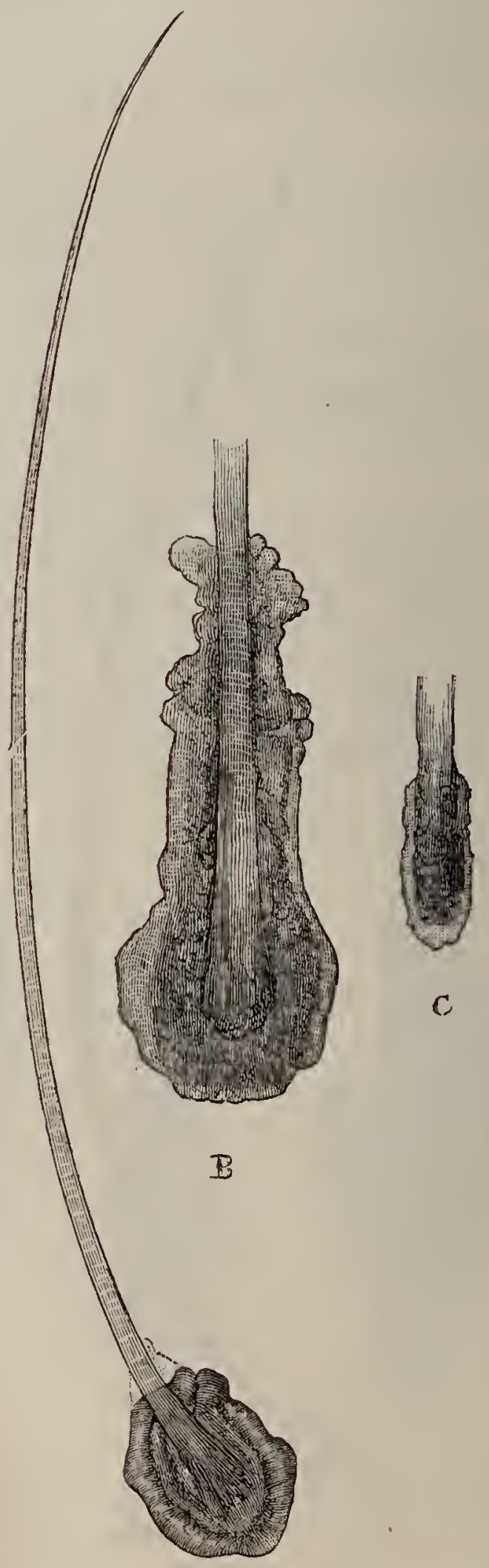

$\Lambda$

Fig. 534. - Gils. - A. Fœtus de 4 mois $1 / 2$. Cil arraché. - B. Racine complète très grossic. - C. Une autre forme de racine. - Bulbe plein avec débris de la gaine externe. 
du poil s'émousse par le frottement continu des vêtements. Cette extrémité peut alors présenter des contours anormaux très irréguliers, et se montre arrondie, demi-ovale ou en forme de bouton. Ils se distinguent des poils courts colorés de la face, par des caractères très nets.

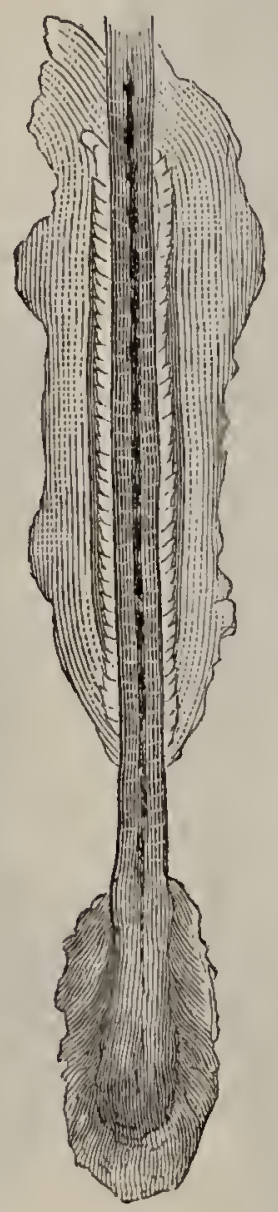

Fig. 535. - Cil (nouveau-né garçon, 10 jours). - Racinc obtenue par arrachement. - La partie, inférieure de la racine existe souvent seulc (bulbe plein avec débris des gaines externe et interne). Les cils sont plus gros quc les sourcils et vont en s'atténuant régulièrcment jusqu'à la pointc; celle-ci cst un peu moins fine que celle des sou rcils. Les cassures présentent le même aspect que pour ces derniers.

Polls courts colorés de la face. (cils, sourcils, vibris ses). Longueur de 1 centimètre au plus.

Épaisseur moyenne des sourcils chez l'homme $=0^{\mathrm{mm}}, 090$ chez la femme $=0,059$ Épaisseur moyenne des cils chez l'homme $=0,067$ chez la femme $=0,096$ Épaisseur des vibrisses chez l'homme $\quad=0$,0כ6 Suivant la remarque du $\mathrm{D}^{\mathrm{r}}$ Johannet, l'épaisseur des cils et 
des sourcils, comparés dans les deux sexes, donne un rapport inverse: de telle sorte que, tel diamètre étant donné, il peut correspondre à celui d'un sourcil d'homme ou au diamètre

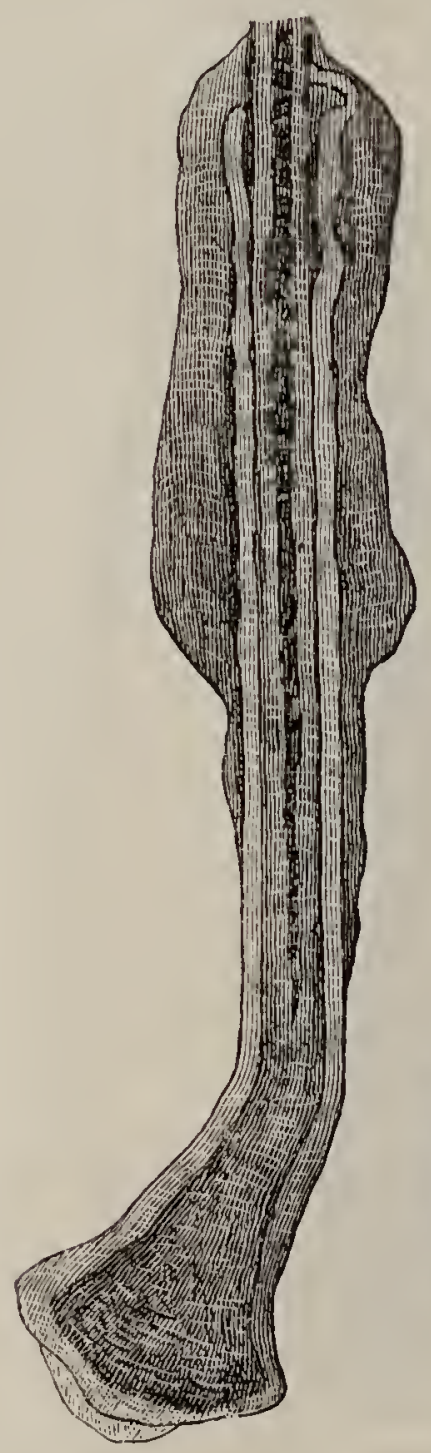

4.

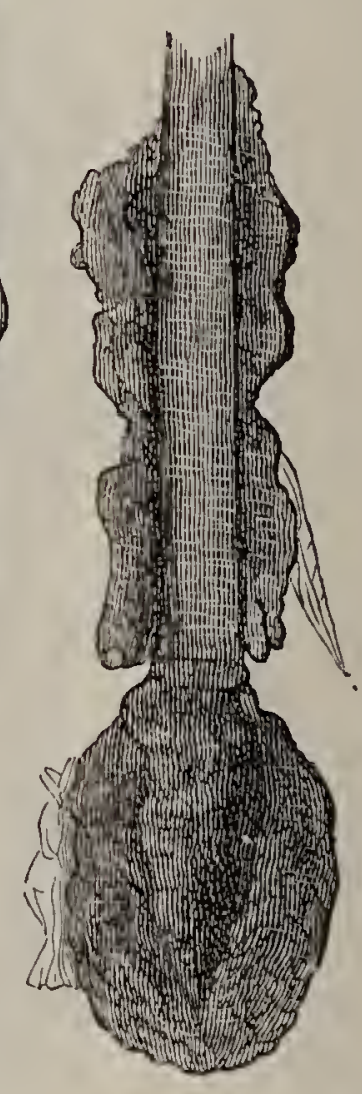

B

Fig. 536. - Sourcils (iemme). - Racines (par alrachement). - A. Bulbe creux avec débris de la gaine interne et de la gaine externe.-B. Bulbe plein arec débris de la gaine externe.

d'un cil féminin. Le caractère dominant des poils courts colorés de la face, c'est leur plus grande épaisseur au milieu de la tige qu'à ses deux extrémités. - Cette dimınution du diamètre transversal se fait brusquement en raison du peu de longueur du poil. Ce caractère suffirait à lui seul pour faire reconnaître un poil de cette nature; si on y ajoute les caractères tirés de la raideur de ces poils, de leur coloration assez foncée, 
Chapitre XXII. - EXAMEN DES CHEVEuX ET DES POILS. 831 de l'effilement de leur pointe, on aura des éléments de détermination plus précis encore.

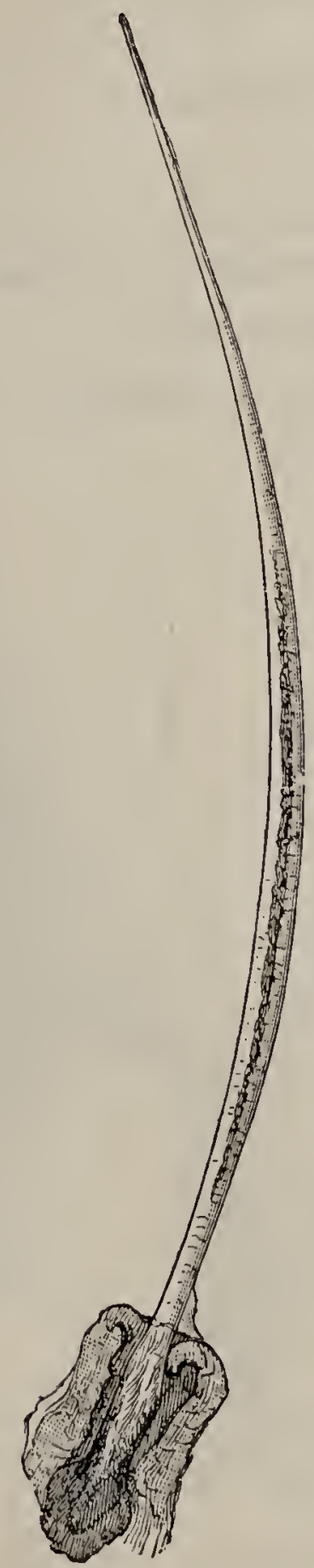

Fig. 537. - Sourcil. - Arraché avec la racine (femme).

Mensuratzons de quelques poils humains d'après Pfaff.

Duvet d'un nouveau-né de $\quad 0^{\mathrm{mm}}, 008$ à 01 $\mathrm{du}$ bras d'une jeune fille de $0^{\mathrm{mm}}, 010$

- de la lèvre supérieure d'une femme $0^{\mathrm{mm}}, 018$ 
Poils du bras d'un homme de

$0^{\mathrm{mm}}, 03$ à 0,04
$0^{\mathrm{mm}}, 04$
$0^{\mathrm{mm}}, 045 \mathrm{~s}$
$0^{\mathrm{mm}}, 06$
$0^{\mathrm{mm}}, 07$
$0^{\mathrm{mm}}, 08$
$0^{\mathrm{mm}}, 11$
$0^{\mathrm{mm}}, 12$
$0^{\mathrm{mm}}, 13 \mathrm{a} 0,14$
$0^{\mathrm{mm}}, 15$
$0^{\mathrm{mm}}, 1 \check{3}$
$0^{\mathrm{mm}}, 27$

Soie de porc

des sourcils d'un homme

des moustaches

du pubis d'une femme

des favoris

Poils de l'intérieur de l'oreille

Cheveux d'une femme

Poils de la main d'un homme

Cheveux d'homme

Poils du pubis d'un homme

- des moustaches
- du pubis d'une femme
- des favoris

Soie de porc

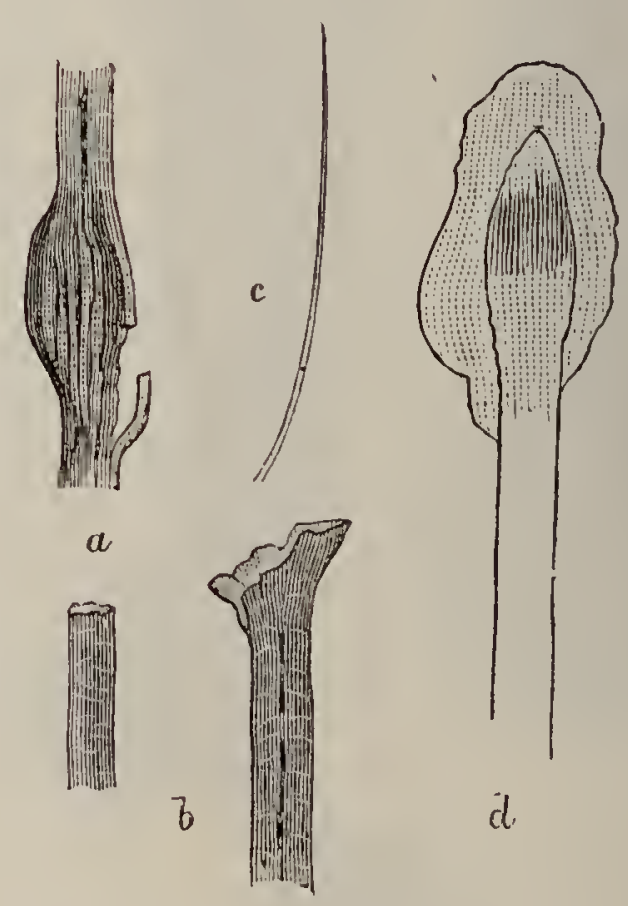

Fig. 3̈38. - Sourcils (arrachés). - Enfant de dix jours (mâle). - $a$. Cassure nette, cassure transversale incomplète en haut et à gauche. - $b$. Cassure complète en entonnoir. c. Pointe. - $d$. Racine. Les sourcils vont en s'atténuant r'égulièrement, quelques-uns contiennent de lạ moelle.

Nous répéterons, à propos de ce tableau, ce que nous avons déjà dit ailleur's, à savoir, que ces chiffres sont seulement approximatifs. En médecine légale, on se heurte à chaque instant à des exceptions, et c'est là ce qui rend les fonctions de l'expert si difficiles et si redoutables pour les autres et pour lui.

Duvet ou lanugo. - Un grand nombre de ces poils sont, 
Chapitre XXII. - EXAMEN DES CheVeuX et DES PoILS. 833 ainsi que nous l'avons dit, tellement fins qu'on ne peut les apercevoir qu'à la loupe, ou par l'intermédiaire d'une source vive de lumière. Voici d'après OEsterlen quels sont leurs principaux caractères : Ténuité extrême; absence presque complète de coloration; absence de canal médullaire; finesse excessive de la pointe.

Il suffira de jeter les yeux sur nos figures pour voir que la pointe du duvet de femme n'est pas aussi ténue qu'on pourrait le croire. L'absence de coloration n'est pas constante et il y a un certain nombre de poils qui ont un canal médullaire.

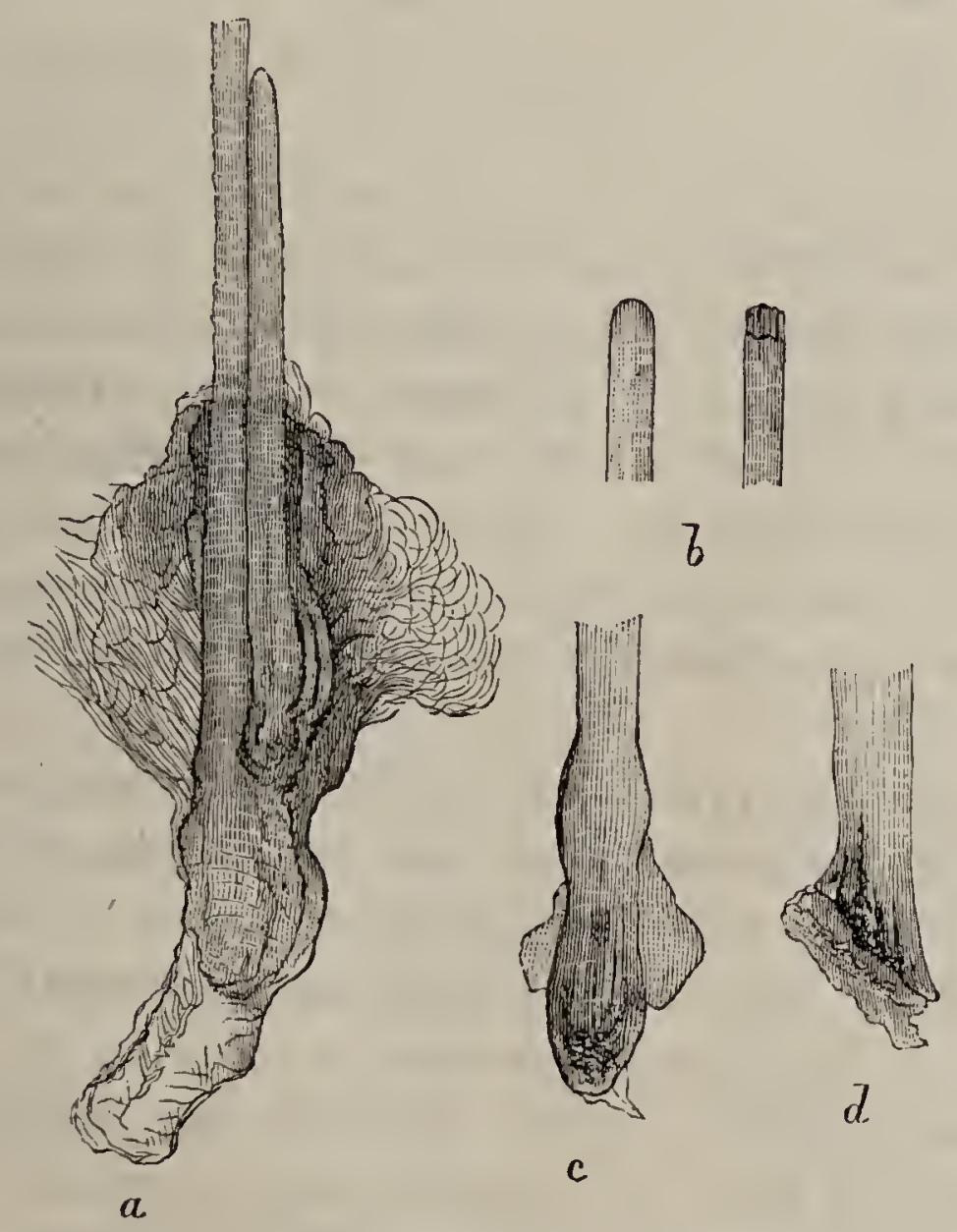

rig 539. - $a$. Duret du bras de femme par arrachement (pointe obtuse du petit poil). $b$. Pointes. $-c$. Racine. - $d$. Brisure complète.

Sur une même préparation on peut voir des pointes fines et des poinles obtuses. Les pointes arrondies sont les plus fréquentes. Les poils de duvet se brisent facilement et on enlève rarement la racine.

Voici les résultats de quelques mensurations faites par MM. Malassez et Galippe.

GUIDE DE MICROGRAPHIE. 

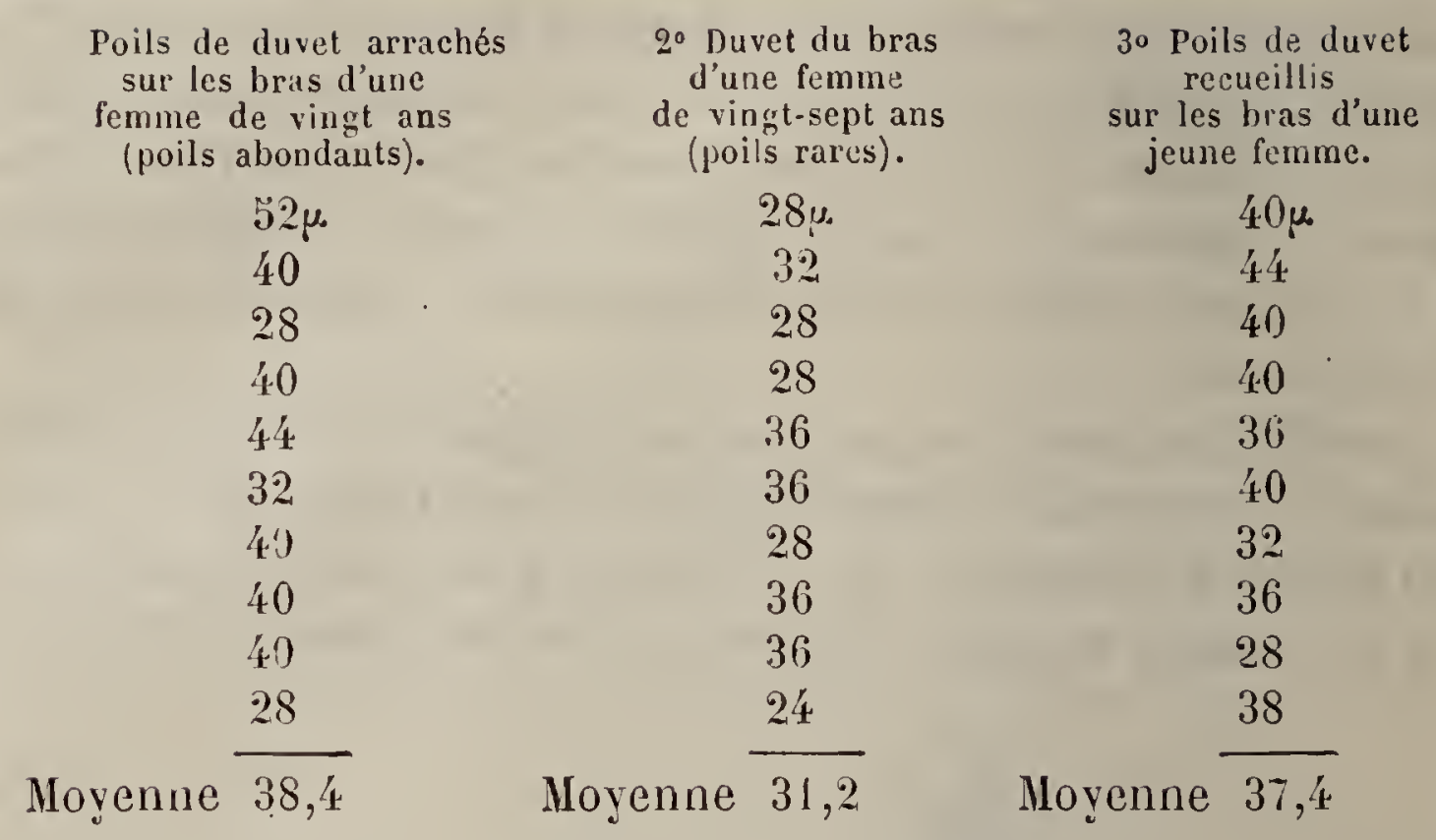

Aucun des poils du duvet de la troisième série ne possédait de canal médullaire, tandis que dans les deux exemples précédents, quelques poils avaient un canal médullaire.

Influence des âges sur les poils. - Sous l'influence du développement normal et progressif de l'individu, certairs poils de duvet acquièrent les caractères du poil proprement dit. Il en est de même des poils qui peuvent présenter un accroissement considérable, dans leur longueur et dans leur épaisseur.

Si dans la plupart des cas la décoloration des cheveux coïncide avec un âge assez avancé, des faits authentiques démontrent, sans qu'on puisse jusqu'ici expliquer le mécanisme de ce phénomène, que des cheveux peuvent blanchir en quelques heures sous l'influence d'émotions morales très vives. Par l'action des années l'organe sécréteur des cheveux cesse de fonctionner; le poil, ne recevant plus de matière colorante, blanchit. S'il ne reçoit plus du follicule les éléments nécessaires à son existence, il tombe. L'âge auquel se produisent les cheveux blancs est très variable; cependant la femme verrait ses cheveux blanchir plus tôt que ceux de l'homme. Cette décoloration se fait de bas en haut, et commence généralement dans la région temporale. La couleur des cheveux n'a guère d'influence, et les cheveux blonds blanchissent aussi bien que les cheveux bruns. Celte décoloration s'étend progressivement à toute la tête, puis à la barbe, et aux autres 
Chapitre xxil. - examen des cheveux et des polls. 835

poils du corps. Suivant la remarque d'Aristote, les poils du pubis seraient les derniers à grisonner. Cette décoloration ne détermine aucune modification dans le poil qui en est le siège.

Duvet fotal. - Ge serait, d'après OEsterlen, vers le cinquième mois de la vie intra-utérine qu'apparaîtraient les premiers poils chez le fœius. Ces poils sont très fins et presque incolores. Vers le sixième mois on trouve également sur la tête du fœtus des poils très fins, mais prenant bientôt une coloration plus foncée.

Suivant nos propres constatations les poils apparaissent souvent plus tôt chez le fœtus. C'est ainsi que nous avons pu étudier les poils chez des fœtus de trois mois et demi à quatre mois et demi. Il y a sur l'époque d'apparition des poils chez les fœtus à tenir compte, comme dans beaucoup d'autres circonstances, des différences individuelles. Souvent des enfants nés avant terme présentent un développement véritablement remarquable du système pileux; les joues, le front sont absolument couverts de duvet; comme le dit plus loin OEsterlen, il est très probable que ces poils tombent dans le liquide amniotique, vers le terme de la grossesse. Des poils de duvet, recueillis sur les joues, sur le front et sur les lèvres d'un fœtus de sept mois, nous ont présenté les caractères habituels des poils de duvet chez le nouveau-né.

Voici quelques mensurations faites sur du duvet recueilli : $1^{\circ}$ sur le dos d'un garçon au moment de sa naissance; $2^{\circ}$ sur le dos d'une fille âgée de deux jours.

$1^{0}$ Durct recueilli sur le dos d'un garçon au moment de sa naissance.

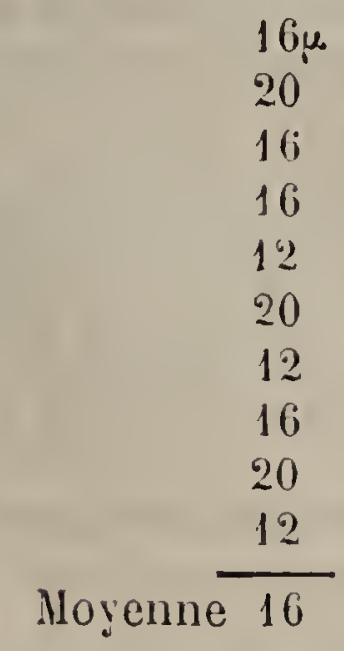

20 Dutet recueilli sur le dos d'une fille àgée de deux jour's.

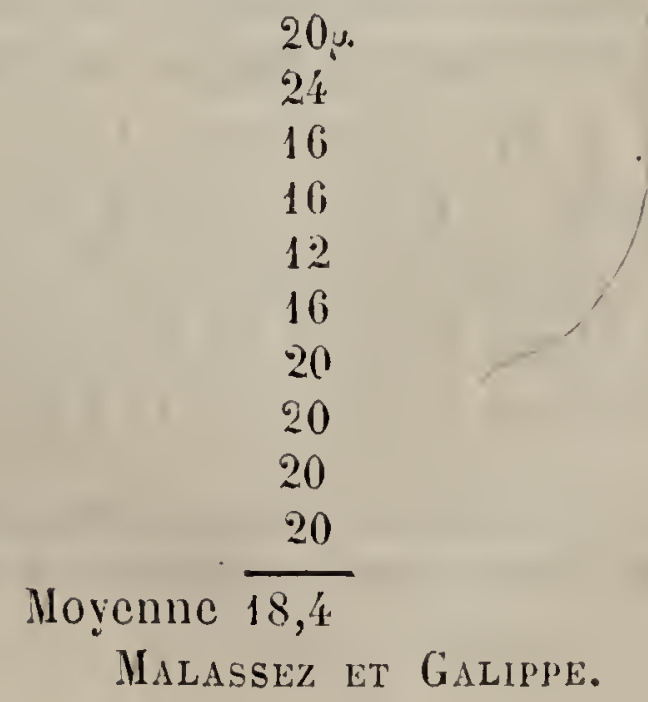


Ces poils de duvet avaient des pointes fines et régulières, aucun n'avait de moelle (V. fig. รั26).

Les poils du duvet fœtal s'arrêtent dans leur développement tandis que les cheveux continuent au contraire à croître, c'est pourquoi à la naissance de l'enfant les cheveux ont de beaucoup dépassé en longueur et en épaisseur les poils de duvet. Ces deux caractères suffiraient à les en faire distinguer si leur couleur ne s'opposait à la confusion.

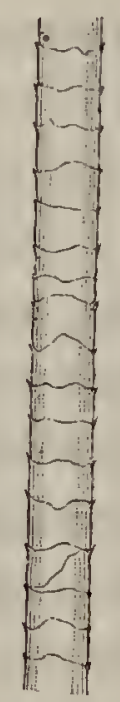

Fig. 340. - Fragment de duvet foeial.

Suivant OEsterlen, vers la fin du neuvième mois, ce duvet tomberait en grande partie dans la poche des eaux: on le retrouverait même mélangé au méconium, avec de l'épithélium, des cristaux de cholestérine, du mucus et de la graisse, dans l'intestin du foetus (Osiander, Lebius, Schulz) où il aurait pénétré grâce à des mouvements de déglutition (?).

Nous avons indiqué le rôle que jouaient les poils de duvet dans la détermination des taches formées par l'enduit fœtal (V.p. 578). OEsterlen a tiré de ses recherches la conclusion suivante : "Dans le cas où le produit de l'utérus n'aurait pas été découvert, si on trouve des taches de méconium sur les draps, le linge, etc., de la présence de poils de duvet dans ces taches, on peut conclure l'âge du fœetus non présenté (1). "

(1) G'est là une conclusion à laquelle il nous est impossible de nous rallier, pour les raisons que nous avons données en parlant du duvet. 


\section{Cheveux chez le fotus et cher le nouvenu-né.}

La détermination de la longueur et du diamètre des cheveux d'un fotus à terme ou non, peut avoir une très haute importance au point de vue médico-légal, ainsi que cela ressort si évidemment du magistral rapport de M. Malassez. En effet, dans un infanticide, suivant que l'enfant est né viable ou non, la loi porte des peines plus ou moins sévères, etc. En raison de leur résistance aux causes extérieures de destruction, les cheveux, comme dans les cas que nous citons, peuvent être le seul témoignage à invoquer contre l'inculpée. Est-il possible, dans ce cas, de tirer de la mensuration des cheveux, des éléments de diagnostic qui puissent, dans une certaine mesure, servir à la découverte de la vérité? Cela nous paraît presque indiscutable; mais, d'autre part, un expert qui n'aurait entre les mains que cette seule preuve matérielle, devrait apporter la plus grande réserve dans ses conclusions.

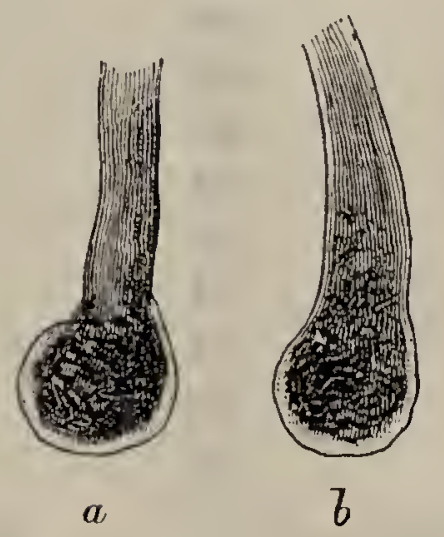

Fig. 541. - Cheveux d'un foetus de 4 mois' et demi (racines).

Ces eheveux vont en s'atténuant régulièrement. - Pointes très fines; souvent les raeiues molles sont repliées sur elles-mêmes, syit en forme de crosse, soit en faisant un tour eomplet.

On sait que rien n'est plus variable que la couleur et la quantité des cheveux que peuvent présenter les enfants, en venant au monde. Les uns ont une chevelure très fournie, très abondante, les autres, suriout ceux qui sont blonds, un rare duvet. Quoi qu'il en soit, ces cheveux présentent des caractères avec lesquels il est utile de se familiariser. La structure anatomique des cheveux des enfants nouveau-nés ne présente rien de bien particulier, non plus que la disposition de la matière colorante. 
La détermination de la longueur des cheveux chez les enfants nouveau-nés ne donne pas de résultats bien précis. Ghez un fœtus de cinq mois, les cheveux ont de 8 à 10 millimètres, chez un fœtus à terme, de 1 centimètre et demi à 2 centimètres (ces longueurs ne sont que des moyennes); chez un enfant de deux jours et demi, la longueur des cheveux était égale à 2 centimètres et demi; chez un enfant de onze jours, 2 centimètres; vingt jours, de 1 centimètre à 2 centimètres eł demi; quatorze mois, de 2 centimètres et demi à 3 centimètres.

Le sexe ne paraît exercer aucune influence sur la longueur des cheveux des enfants nouveau-nés.

Voici les résultats d'un certain nombre de mensurations pratiquées par MM. Malassez et Galippe, sur des enfants nouveau-nés.

\section{Fœtus de 4 mois.}

$20 \mu$

20

1

16

16

20

20

16

16

Moyenne $\frac{20}{18}$

\section{Fœtus de 5 mois.}

24 s.

24

28

28

20

20

29

24

28

Moyenne $\frac{24}{24}$
Enfant né à 7 mois $1 / 2$, 7 jours d'existence.

$36 \mu$

36

36

32

32

36

28

32

40

Moyenne $\frac{32}{34}$
Fœlus de 8 mois et $1 / 2$. Fœtus presque à terme.

$36 \mu$

36

28

32

36

36

36

40

Moyenne $\frac{32}{34,4}$
$36 \mu$.

32

32

28

32

32

32

36

32

$\therefore$ '.
Fœtus à terme.

\section{$44 \mu$}

36

36

32

40

48

36

40

28

36 
CHAPITRE XXII. - EXAMEN DES GHEVEUX ET DES POILS. 839

Garçon d'un jour.

$40 \mu$

40

32

28

28

28

40

28

28

20

Movenne $\overline{31,2}$
Fille de deux jours.

$36 \mu$

36

24

30

32

24

20

20

32

36
Garçon de deux jours $1 / 2$. $60 \mu$ (moelle)

72

48

68

56

52

44

68

80

48

\section{Garçon de six jours}

Garçon de cinq jours.

(blond et chauve).

\begin{tabular}{ll}
$40 \mu$ & $00 \mu$ \\
36 & 00 \\
48 & 00 \\
24 & 00 \\
36 & 00 \\
40 & 00 \\
24 & 00 \\
40 & 00 \\
48 & 00 \\
36 & 00 \\
\hline 37,2 & Moyenne 24
\end{tabular}

Filie de onze jours.

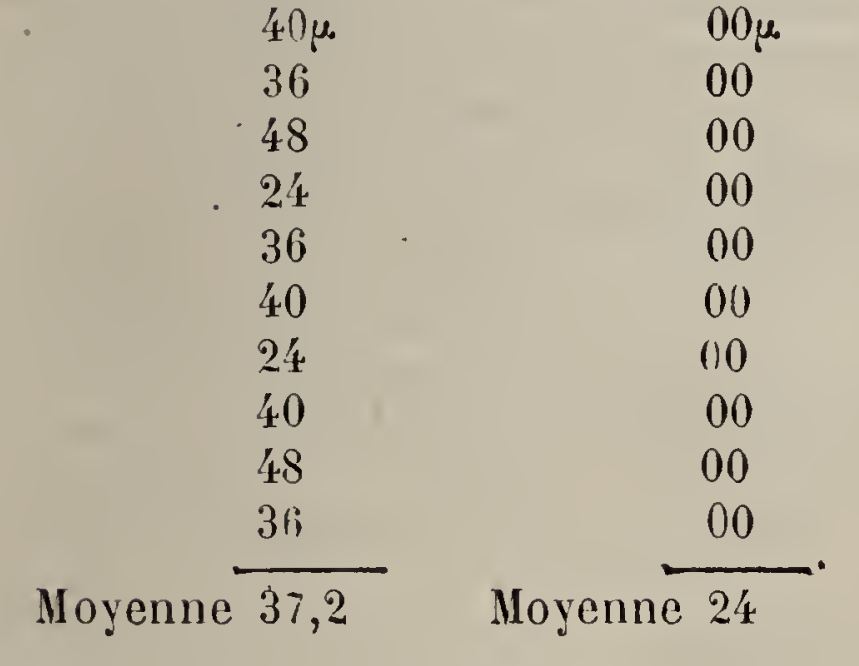

Enfant de vingt jours.

$36 \mu$.

40

36

40

24

28

24

24

Moyenne $\frac{24}{31,2}$

Enfant de quatorze mois.

$40 \mu$

36

32

40

40

36

44

40

22

44

Moyenne $\overline{3 \pi, 4}$

$44 \mu$

44

48

40

44

44

28

48

40

Noyenue $\frac{40}{42}$

On voit par les mensurations qui précèdent, combien sont importantes les différences individuelles; néanmoins on ne peut nier que surtout dans les premiers mois de la vie intrautérine, le diamètre des cheveux ne suive généralement une 
progression ascendante. Nous voulons le répéter encore, l'examen du diamètre des cheveux pourra corroborer d'autres preuves, mais à lui seul, sauf dans quelques cas particuliers, il nous paraît insuffisant pour établir d'une façon véritablement précise l'âge de l'enfant, auquel ces cheveux ont apparten $i$.

C'est ainsi que des cheveux follets recueillis sur le sommet du crâne d'une personne atteinte de calvitie, présentent les caractères des cheveux d'un fœtus de six à sept mois. Sauf les caractères de la pointe qui, dans le cas actuel, est en balai, tandis qu'au contraire, dans les cheveux du fœtus, elle est fine et plus ou moins tordue sur elle-même, nous ne voyons pas bien à quels signes on pourrait sûrement distinguer des cheveux follets d'adulte des cheveux d'un foetus.

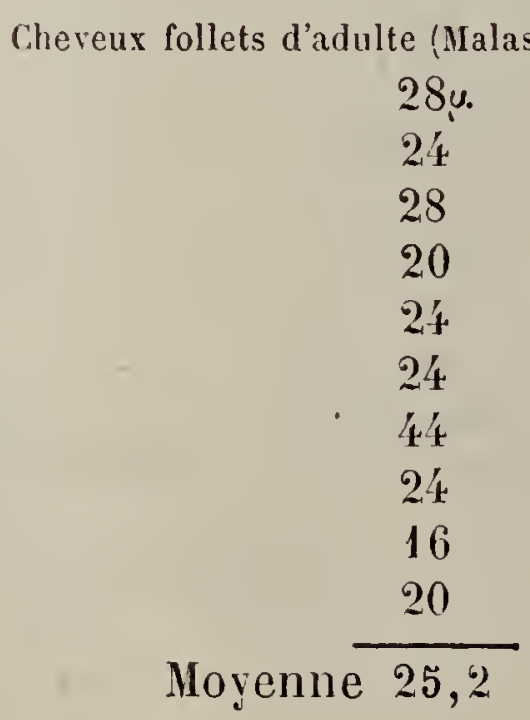

En choisissant les plus fins, on arrive à une moyenne de 15,7 .

Le plus petit n'avait que $12 \mu$, la longueur moyenne de ces cheveux est de 2 centimètres et plus. Quelques-uns ont un peu de moelle, ce qui pourrait encore servir à les distinguer des cheveux de fotus.

Nous donnons ci-après le rapport médico-légal de M. Malassez. Ce rapport a trait à la fois à l'examen de taches et à la détermination de poils. Nous n'avons pas voulu le scinder puisque, dans l'affaire même, ce double problème était posé à l'expert.

Il s'agissait d'une jeune fille accusée d'infanticide. Celle-ci 
CHAPITRE YXII. - EXAIEN DES CHEVEUX ET DES POILS. 841

prétendait que l'enfant n'était pas né viable, et qu'il n'avait pas respiré. Toutefois, comme elle portait les traces d'une déchirure du périnée, la justice ne tint pas compte des assertions de l'accusée. On avait trouvé dans un champ, une année après la suppression du part, le linge dans lequel celle-ci avait jeté l'enfant; les cheveux seuls avaient résisté, avec le linge, aux causes multiples de destruction, qui avaient entraîné la disparition de l'enfant.

M. Malassez a répondu aux questions qui lui étaient posées par la justice avec sa haute compétence et l'esprit scientifique qui est la marque des productions de ce consciencieux observateur.

Je soussigné, Louis-Charles Malassez, docteur en médecine, directeur adjoint du laboratoire d'histologie au Collège de France, commis par une ordonnance de M. Jules Gaudin, juge d'instruction au tribunal de première instance du département de la Seine, datée du 23 septembre 1878, à l'effet de procéder à l'examen d'un linge, et de se prononcer sur la question de savoir :

$1^{\circ}$ Quelle est la nature des taches dont il est maculé ; - si ce sont des taches de sang ou de matières provenant de la décomposition d'un cadavre ;

$2^{\circ}$ S'il y a trace de cheveux qui soient adhérents à cette pièce de linge :

$3^{\circ}$ En cas d'affirmation, si ces cheveux sont ceux d'un enfant nouveau-né ;

Ayant prêté serment, certifie avoir fait les examens microscopiques suivants :

\section{A. - Examen des taches.}

Le linge présente deux espèces de taches :

$1^{\circ}$ A la périphérie du linge, des petites taches verdâtres;

$2^{\circ} \mathrm{Au}$ centre, une large tache brunâtre.

La couleur verdâtre des petites taches pouvait faire supposer qu'elles étaient dues à du méconium, mais les examens microscopiques et micro-chimiques n'ont rien révélé qui puisse confirmer ou infirmer cette hypothèse.

La grande tache centrale brunâtre, ressemblant à certaines taches de sang altéré, la présence des globules sanguins, celle de la matière colorante du sang, ont été recherchées.

\section{$1^{\circ}$ Recherche des globules sanguins.}

Des fragments de serviette étant détrempés dans du sérum artifi- 
ciel (solution de sulfate de soude à 5 p. 100), on peut en détaclıer des fragments d'une matière hrunâtre que l'on dissout dans le même sérum.

Examinées au microscope, on trouve çà et là, au milieu d'éléments divers : globules de graisse, débris d'insectès et de végétaux, poussières et granulations diverses, de nature indéterminée, des globules rouges de sang.

Ils sont, en général, réunis par petits groupes; ils appartiennent au type circulaire, mais ils sont, pour la plupart, plus ou moins déformés; beaucoup ont la forme de cuvetle, quelques-uns sont sphériques. Les plus petits ont $4 \mu$. (quatre millièmes de millimètre), les plus grands $\ddot{\partial} \mu$. (cinq millièmes de millimètre); la moyenne de 13 mensurations a donné $4 \mu ., 5$. Ils sont très peu colorés.

\section{2o Recherche dela matière colorante.}

D'autres fragments de serviette sont lavés à l'eau distillée : ils donnent une solution brunâtre louche; filtrée, la solution devient transparente. Examinée au micro-spectroscope, sous des épaisseurs diverses, elle ne donne, aucune des raies d'absorption qui caractérisent la matière colorante du sang.

La solution évaporée lentement laisse une matière brune. Cette matière mêlée avec un peu de chlorure de sodium et d'acide acétitique, puis chauffée jusqu'à ébullition, ne donne pas, après refroidissement, de cristaux de chlorhydrate d'hématine.

\section{Conclusions.}

\section{$1^{\circ}$ Sur l'existence du sang.}

Les globules du sang trouvés dans la recherche $1^{\circ}$ ont, malgré les altérations qu'ils ont subies, des formes si caractéristiques, que leur présence suffit à elle seule pour affirmer avec certitude l'existence du sang sur le linge examiné.

Les résultats négatifs obtenus dans la recherche de la matière colorante du sang (recherche 2) ne sont pas contradictoires, comme on pourrait le supposer au premier abord. En effet, pour obtenir des résultats positifs dans ce genre de recherches, il faut que la matière colorante existe en certaine quantité. Or, dans le cas actuel, il peut se faire, ou qu'il y ait eu peu de sang répandu, ou que le sang répandu en certaine quantité se soit altéré, les globules perdant leur hémoglobine, l'hémoglobine se détruisant.

La première de ces deux hypothèses est peu vraisemblable en raison de l'étendue de la tache et des points divers où l'on a pu y retrouver des globules; la seconde, au contraire, est confirmée par ce fail que la tache se trouve sur un linge saisi dans un champ, qu'elle a dû, par conséquent, être exposée à toutes les intempéries de l'at- 
mosphère, lesquelles altèrent le sang. Il est même étonnant que dans de telles conditions des globules rouges aient pu se conserver aussi bien.

\section{$2^{\circ}$ Sur la quantité de sang répandu.}

Le petit nombre de globules sanguins retrouvés dans la servieite, l'absence ou la faible quantité de matière colorante du sang, prouvent qu'actuellement il existe peu de sang sur la serviette. Mais, ainsi que je viens de le dire, il a dû en exister une quantité beaucoup plus considérable à un moment donné. Toutefois, il est impossible de dire, même approximativement, quelle a été cette quantité.

\section{$2^{\circ}$ bis. - Sur l'époque à laquelle le sang a été répandu.}

L'altération du sang ne dépendant pas uniquement du temps écoulé, mais surtout des divers agents atmosphériques ou autres, auxquels il a été soumis, il est impossible de dire à quelle époque il a été répandu.

\section{$3^{\circ}$ Sur la nature du sang.}

La forme circulaire des globules trouvés sur le linge, l'absence de noyaux, montrent que ce ne sont pas des globules d'oiseaux, de poissons, ou de reptiles, ou de batraciens, mais bien des globules de mammifères; quant aux dimensions de ces globules, il est bien évident qu'elles ne sont plus ce qu'elles étaient quand ces globules étaient vivants : une sphère aplatie constitue un disque dont le diamètre est plus grand que celui de la sphère d'où il procède; de même pour les globules; lorsque de discoïdes (ce qui est leur forme normale) ils deviennent sphériques, leur diamètre diminue. Nos globules sanguins, qui tous se rapprochent plus ou moins de la forme sphérique, ont donc des diamètres plus petits que ceux qu'ils avaient lorsqu'ils étaient vivants et discoïdes. Or, en tenant compte de cette diminution de diamètre, ainsi que de la dessiccation, on voit qu'ils se rapprochent des globules humains adultes et de ceux de plusieurs de nos animaux domestiques (lapin, chien, par exemple).

Les globules sanguins des nouveau-nés diffèrent peu de ceux des adultes, mais ceux des jeunes fotus sont notablement plus volumineux. Aussi, pour que les globules trouvés sur le linge puissent être considérés comme des globules de foctus, il faudrait supposer une diminution très considérable, sur la possibilité de laquelle nous n'avons aucun renseignement.

En résumé :

$1^{\circ} \mathrm{Il}$ existe du sang sur le linge au niveau de la grande tache centrale brunâtre; il est très altéré;

$2^{\circ} \mathrm{Ce}$ sang est actuellement en petite quantité. Il est probable 
qu'il y en a eu une plus grande quantité de répandue, mais on ne saurait la déterminer ;

$4^{\circ}$ C'est du sang de mammifère. 11 est impossible de dire si c'est du sang d'homme ou de l'un de nos animaux domestiques. Il est possible que ce soit du sang de femme ou de nouveau-né, il est douteux que ce soit du sang de fœtus.

\section{B. - Examen des polls ou des cheveux.}

Plusieurs touffes des poils ou cheveux adhérents au linge ont été humectées puis montées dans de la glycérine et examinées au microscope.

Tous, ou presque tous, sont munis de leur racine et se terminent en pointe très effilée. Aucun d'eux n'a de moelle. Mesurés au micromètre, ils ont dans leur plus grande largeur de 20 à $32 \mu$. (mil. lièmes de millimètre). La moyenne de 30 mensurations a été de $24 \mu, 9$; il en a été trouvé un qui n'avait pas $12 \mu$, et.un autre qui mesurait $40 \mu$.

La matière lamelleuse blanc jaunâtre, à reflets brillants, qui englobe la racine de la plupart de ces poils ou cheveux, est constituée par des amas de cellules épithéliales paviménteuses cornées, au milieu desquelles on distingue une assez grande quantité de globules graisseux, puis des poussières et des granulations diverses.

\section{Conclusions.}

$1^{\circ}$ Le peu de longueur de ces poils ou cheveux, leur finesse, l'absence de moelle prouvent que ce sont des cheveux ou poils follets; ce ne sont donc ni des poils d'animaux, ni des cheveux ou poils humains adultes.

Les poils d'animaux ont d'une façon générale des formes différentes, des dimensions plus considérables et possèdent une moelle souvent très caractéristique. Les cheveux et poils humains adultes sont plus longs, plus larges et pourvus de moelle;

$2^{\circ}$ Leur terminaison en pointe effilée et très régulière indique qu’ils n’ont été ni usés, ni brisés ni coupés; qu’ils sont par conséquent de développement récent et doivent appartenir à un fotus ou à un nouveau-né, ce que confirme également la présence de ces amas de cellules épidermiques et de matières grasses qui englobent baaucoup d'entre eux. Ce ne sont pas des cheveux ou poils follets d'adultes. Les cheveux follets des chauves ont presque toujours leur extrémité bien fendillée ou en balai ; on en trouve parmi eux un certain nombre qui ont de la moelle et sont beaucoup plus volumineux. Les poils follets des femmes et des adolescents ont rarement la pointe effilée, étant obtus, comme usés, et parfois ils possèdent de la moelle; 
$3^{\circ}$ Les dimensions dépassent notablement celle des poils follets que l'ou rencontre sur le corps des fœtus ou des nouveau-nés, il faut en conclure que ce sont des cheveux de fœtus ou de nouveau-né.

Du reste, leur abondance à une région assez limitée de la serviette, leur réunion en touffes doivent faire penser qu'ils proviennent des régions où ils sont nombreux, comme c'est le cas pour le cuir cherelu;

$4^{0}$ Pour essayer de déterminer l'àge du fotus ou du nouveau-néauquel ces cheveux appartenaient, on peut, jusqu’à un certain point, comparer leurs dimensions à celles des cheveux provenant de fótus ou de nouveau-nés d'âges différents.

Les cheveux de cinq nouveau-nés, âgés de un à vingt jours, et ceux de quatre fotus ayant de sept à neuf mois ont présenté des épaisseurs semblables. Les plus petits cheveux avaient $20 \%$ ŏ (millièmes de millimètre) ; les plus gros $48 \mu$; les diverses moyennes ont varié entre $28 \mu$ et $37 \mu$.

D'autre part, les cheveux d'un fœtus de cinq mois ont donné $20 \mu$, comme minimum d'épaisseur, $28 \mu$ comme maximum, 24 comme moyenne, et ceux d'un fœtus de trois mois avaient, les plus petits, $16 \mu$; les plus gros $20 \mu$; en moyenne, $18 \mu$.

Les cheveux recueillis sur le linge sont donc plus gros que ceux d'un fœetus de trois à cinq mois, plus petits que ceux de fœtus viables ou de nouveau-nés. Ils proviendraient, d'après cela, d'un folus âgé de cinq à sept mois.

Toutefois, comme les comparaisons ci-dessus exposées ne portent que sur un nombre de fails relativement peu nombreux, commeles différences constatées ne sont pas très considérables, comme enfin l'accroissement des cheveux peut présenter de très grands retards (on voit des enfants nés à terme qui sont presque chauves), la conclusion précédente ne peut être présentée qu'avec la plus grande réserve.

En résumé :

Les poils ou cheveux trouvés sur le linge sont des cheveux de fœtus ou de nouveau-né.

Il est probable qu'ils proviennent d'un fœetus de cinq à sept mois, mais il est impossible d'affirmer avec certitude qu'ils n'appartenaient pas à un fœtus viable ou à un nouveau-né.

Les examens microscopiques, ci-dessus mentionnés, permettent donc les réponses suivantes aux questions posées par l'instruction :

$1^{\circ}$ Les taches qui maculent le linge saisi sont en partie, sinon complètement, des taches de sang;

$2^{\circ}$ Il existe des cheveux adhérents au linge;

$3^{\circ}$ Ces cheveux proviennent d'un fœtus ou d'un nouveau-né, plutôt d'un fœetus de cinq à sept mois que d'un fœetus viable ou nouveauné, mais il est impossible de se prononcer avec certitude sur ce deruier point.

Collège de Francc, 27 novembre 1878.

Dr L. Malassez. 


\section{Variations de la largeur du poil suivant l'âge.}

Les différences observées ne sont pas très caractéristiques.

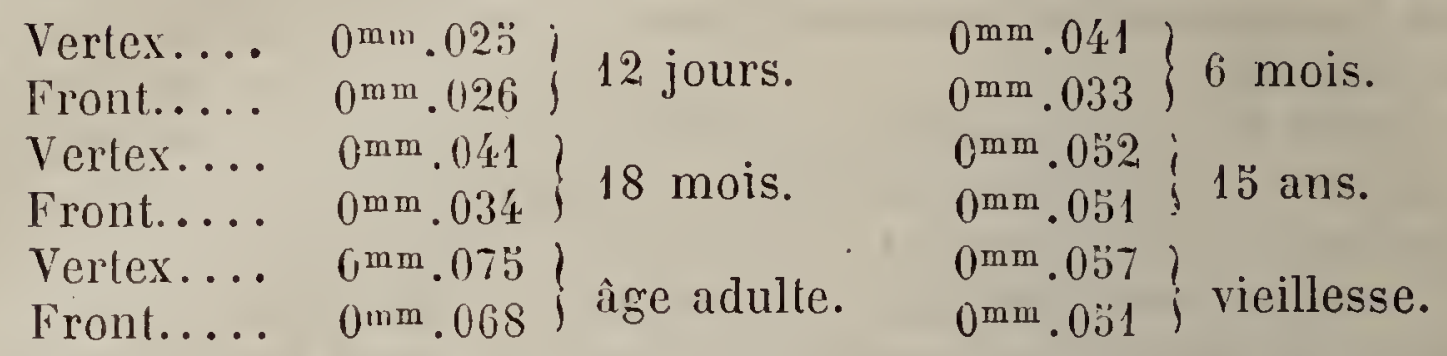

La conclusion que l'on peut tirer de ces chiffres, c'est que le diamètre transversal des cheveux augmente avec l'âge.

\section{Tariations de la longueur du poil suivant l'âge.}

La longueur croît avec l'âge. On a établi une distinction entre les poils à croissance définie et les poils à croissance indéfinie.

Poils à croissance indéfinıe.

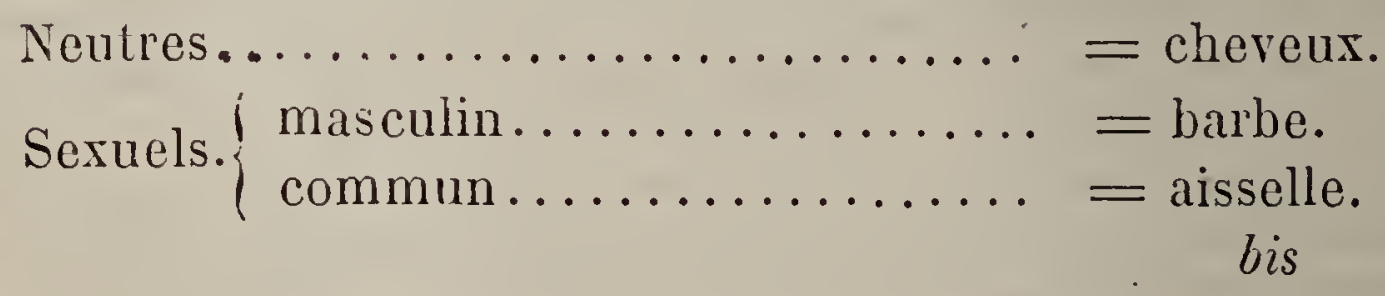

Poils'à croissance définie.

Neutres. $\left\{\begin{array}{l}\text { courts poils colorés de la face. } \\ \text { lanugo. }\end{array}\right.$

Sexuels (masculins) $\ldots \ldots \ldots \ldots \ldots \ldots=\left\{\begin{array}{l}\text { courts poils } \\ \text { colorés } d u \\ \text { corps. }\end{array}\right.$

\section{Influence du sexe sur les variations du poil.}

La longueur des cheveux, plus grande généralement chez la femme que chez l'homme, n'est pas caractéristique, attendu que, suivant les races, il est des hommes qui ont des cheveux aussi longs que ceux de la femme. 
Généralement leur pointe n'est pas aussi effilée que le dit OEsterlen, sauf pour les cheveux qui viennent de pousser et dont la pointe reste cachée entre les cheveux plus longs. Souvent ils se fendillent à leur extrémité, soit sous l'influence du peigne, soit pour toute autre cause. Ce fendillement de la pointe en trois ou quatre fragments se rencontre également dans les cheveux de l'homme et dans la barbe, surtout, chez les alopéciques. Pincus a remarqué que la longueur typique du cheveu diminuait en même temps. Le même auteur a démontré qu'il croîtsur la tête del'homme et de la femme des cheveux qui parcourent rapidement toutes les phases de leur développement. Les cheveux peuvent tomber avant d'avoir été coupés; ils peuvent être munis, ou d'une pointe très effilée, ou d'une pointe fendillée, suivant que cette pointe a été plus ou moins complètement protégée contre les frottements extérieurs.

En résumé, si l'examen des poils permet de tirer des indications plus ou moins certaines, relativement à leur lieu d'origine et suivant l'âge du porteur, il n'est pas possible, même quand on a beaucoup de poils réunis, de conclure au sexe.

\section{Du poil considéré sur le cadarre.}

Lorsque l'état particulier du corps, que nous appelons la mort, a arrêté plus ou moins brusquement le jeu de nos organes, le poil est-il complètement arrêté dans son développement, ou croît-il encore après la mort, comme certains auteur's le prétendent? Le $\mathrm{D}^{\mathrm{r}}$ Johannet (loc. cit., p. 75) a fait quelques expériences pour élucider cette question. Ses conclusions nous paraissent légitimement déduites, et il n'est pas démontré que les poils continuent de croître après la mort. Si pendant la vie, sur une région du corps où les poils présentent une certaine résistance, comme la joue ou la lèvre supérieure de l'homme, on rase avec soin les poils, de façon à ne plus sentir aucune aspérité, que l'on vienne alor's à appliquer un corps froid en ce point, on observe les phénumènes suivants: sous le nom de muscle de l'horripilation, Moleschottet Ghauveau ont décrit un petit faisceau de fibres situé du côté de l'incli- 
naison du poil, et s'insérant d'une part à la face profonde du derme, d'autre part à l'union du $1 / 3$ inférieur avec les $2 / 3$ supérieurs du follicule. Le muscle en se contractant redresse le poil et le fait saillir au-dessus de la peau, en produisant le phénomène de la chair de poule. (Vaillant, cité par Johannet. Cependant, d'après G. Pouchet et Tourneux, il ne serait pas impossible que les cheveux et les poils présentassent des systèmes musculaires propres, plus ou moins complexes selon les individus ou selon les régions du corps. Le phénomène des cheveux qui se dressent, très manifeste chez certaines personnes, sous la seule influence d'une tension d'esprit quelconque, paraît différer du soulèvement total du bulbe qui caractérise la chair de poule. Sous l'influence d'un corps froid, il y a contraction du faisceau musculaire, dont nous avons parlé plus haut, le poil se redresse et fait une légère saillie qui est sensible au frottement exercé par la main. D’après l'expérience de Johannet, ce phénomène se produit sous l'action à la fois excitante et astringente de l'eau de Cologne pure, ou d'une dissolution de tannin ou d'alun. Dans ce cas, ce serait le derme lui-même qui, sous l'influence du topique, se rétracterait et s'affaisserait, s'éloignant ainsi de la surface sectionnée $d u$ poil pour se rapprocher de sa racine; le poil paraît alors s'élever davantage au-dessus du derme; il semble s'être allongé, mais ce n'est qu'une simple apparence.

Une des propriétés les plus caractéristiques du poil, c'est. sa résistance à la putréfaction. Des cheveux d'un enfant nouveau-né ont pu séjourner pendant près de deux ans sur le sol et être retrouvés adhérant encore à un linge, alors que toutes les parties du corps, même les os, avaient disparu. La. couleur des cheveux ne paraît même pas s'altérer sensiblement.

A quelle époque les cheveuxse détachent-ils du cuir chevelu? D'après Orfila, qui a assisté à un grand nombre d'exhumations juridiques, sur des cadavres entourés d'une simple toile d'emballage, on trouve quinze jours après l'exhumation des poils encore bien adhérents à la peau. Vers le quaràntième jour, ils se laissent facilement détacher. Après deux mois le crâne, presque entièrement dénudé, est surmonté de quelques cheveux, le pubis est privé de ses parties molles, les parties laté- 
rales du scrotum portent encore quelques poils; le reste des poils est mélangé à la terre. Sur des cadavres renfermés dans des bières de sapin, après deux mois et demi la tête est presque complètement dépouillée de ses cheveux; ceux-ci sont adhérents au linceul. Vers le quatrième mois, le crâne et le tronc sont presque complètement dénudés; les poils des organes génitaux sont mélangés au putrilage formé par la désorganisation de ces différents organes.

L'influence du milieu au moins sur la résistance du cuir chevelu doit être considérable, et les chiffres donnés plus haut par Johannet, d'après Orfila, ne doivent pas être considérés comme absolus. C'est ainsi que nous nous rappelons avoir vu dans un ossuaire d'une île du Morbihan, un crâne de femme, complètement privé de toute partie molle, mais dont le cuir chevelu, encore attenant à la boîte crânienne, était presque entièrement garni de cheveux. Un certain nombre d'autres crânes présentaient la même particularité, mais à un moindre degré. Il ne nous fut pás permis d'emporter un de ces crânes, mais, d'après nos renseignements, ils devaient être relativement anciens.

Les poils mêlés à la terre conservent leurs caractères anatomiques; des opinions diverses ont été émises au sujet de l'altération de la couleur du poil. Ghevallier avait cru remarquer que sous l'influence de la putréfaction les poils devenaient plus foncés. Plus tard Hauptmann et de Sonnenscheim, émirent une opinion opposée; d'après ces observateurs les poils, au contraire, pâlissaient. Si ce dernier fait se présente peut-être le plus souvent, il ne faudrait cependant pas perdre de vue, que les métaux se localisent fréquemment dans les cheveux, et qu'il ne serait pas impossible que, sous l'influence des produits sulfurés formés pendant la putréfaction, le cheveu subisse dans sa coloration intime des modifications dues à des réactions chimiques. C'est là une simple hypothèse qu'il faudrait vérifier. Dans tous les cas, il aurait été bon de tenir compte de la nature du terrain, les cheveux devant se comporter différemment suivant la constitution du sol, son état hygrométrique, etc.

La chute des poils se ferait plus lentement sur un cadavre GUIDE DE MICROGRAPHIE. 
placé dans l'eau, que sur un corps inhumé dans les conditions ordinaires. Au bout de deux mois les cheveux adhéreraient encore faiblement, et la dénudation serait complète au bout de quatre mois. D’après Johannet, les cadavres placés dans les fosses d'aisances seraient au point de vue de l'adhérence des cheveux dans les mêmes conditions que l'orsqu'ils sont dans la terre; notons cependant qu'il a été observé que les cadavres jetés dans les fosses d'aisances résistaient plus longtemps que s'ils avaient été enterrés. Le sulfhydrate d'ammoniaque entrave la putréfaction, loin de la favoriser.

Nous avons vu qu'il n'était pas possible de se prononcer sur les caractères d'un poil, lor'squ'on n'en avait qu'un petit nombre à sa disposition. Il en est de même lorsqu'il s'agit de déterminer l'identité d'un individu, d'après la couleur d'un poil. On sait, en effet, qu'une même personne peut présenter des cheveux de couleur différente. Sur les tempes les cheveux peuvent être blonds, alors que ceux qui recouvrent les autres parties du crâne sont d'une couleur châtaine : on peut également rencontrer sur une même tête des cheveux noirs et des cheveux blancs.

Les cheveux ont parfois, en raison de la profession exercée par le porteur, une coloration artificielle spéciale. Cette coloration peut être due à une cause mécanique ou à une cause chimique. C'est ainsi que les meuniers et les boulangers ont des cheveux poudrés par l'amidon ou la farine; chez les individus qui vivent au milieu du charbon, il peut se produire une coloration noir sale. M. Robin a observé une coloration brun rougeâtre de la chevelure, chez des individus exposés à la poussière de la rouille. Ces diverses teintes sont dues à un effet purement mécanique, puisqu'elle a pour cause le dépôt de particules colorées à la surface des cheveux.

Les poussières de rouille se reconnaissent à leur forme anguleuse et irrégulière, leur insolubilité dans l'eau et leur très grande solubilite dans l'acide chlorhydrique. (Ch. Robin.) On reconnaît les particules de charbon à leur insolubilité dans les acides, et à leur forme polygonale ou triangulaire.

L'amidon se reconnaîtra facilement à sa forme d'abord et 
ensuite à sa réaction sur l'iode. Dans tous les cas les lavages restituent au poil sa coloration primitive.

Les cheveux peuvent être colorés par une sorte de teinture directe. C'est ainsi que, chèz les ouvriers qui vivent au milieu de poussières cuivreuses, les cheveux deviennent verts.

Les ouvrier's qui travajllent dans les matières colorantes ont également les cheveux colorés d'une façon spéciale (fuchsine, indigo, etc.). Quelquefois cette coloration des cheveux se produit sous l'action de phénomènes chimiques directs. La céruse, quoique blanche, pourrait donner aux cheveux une coloration noire, sous l'influence des produits sulfurés dégagés par le cuir chevelu.

A l'état normal le cheveu est souple et reçoit des glandes annexées au follicule un produit onctueux qui semble nécessaire à son développement et à sa conservation. Sous l'influence de certaines affections du cuir chevelu, et d'un état diathésique particulier, cette sécrétion ne peut plus se faire, ou du moins paraît n'être produite qu'insuffisamment. On est alors forcé de suppléer à cette insuffisance de matière onctueuse, par l'emploi de corps gras qui empêchent les cheveux de se dessècher et de se fendiller par la pointe. Cet état particulier des cheveux se produit également chez les personnes qui abusent du fer à friser. Les cheveux prennent l'aspect de cheveux artificiels.

Il se peut encore que l'on rencontre sur les cheveux des parasites végétaux, qui fourniront des éléments précieux de détermination au point de vue de l'identité. Si l'on trouvait également adhérant aux cheveux, des œufs du Pediculus capitis, on pourrait tirer de la présence de ces parasites des inductions ayant trait à la situation sociạle et aux habitudes du porteur.

Si les cheveux que l'on examine présentent les caractères particuliers de la pointe, que nous avons reconnus êlre l'indice de l'action plus ou moins récente des ciseaux et si, d'autre part, rien ne fait supposer que cet état de la pointe dépend d'une circonstance postérieure au crime, on sera naturellement amené à comparer les cheveux avec ceux de l'inculpé, si l'on a des raisons pour supposer qu'ils lui appartiennent.

Il est bien évident que cette comparaison offrira d'autant 
plus de difficulté qu'il se sera écoulé plus de temps entre le moment où les cheveux auraient été arrachés par exemple et celui où ils sont examinés. La pointe tend en effet à se reformer, comme nous l'avons indiqué plus haut, mais très lentement.

Ainsi que l'a montré OEsterlen, un expert peut avoir à se prononcer sur ce point : L'accusé pouvait-il y a un an et demi avoir des favoris? - Le coupable avait à l'époque du crime des favoris et des moustaches; et l'accusé prétendait n'avoir jamais eu de favoris. Les joues examinées ne portaient qu'un léger duvet incolore. Examinés au microscope, ces poils ne présentaient aucune altération de leur pointe, l'individu ne s'était donc jamais rasé. (OEsterlen, cité par Johannet, p. 92.)

\section{Des cheveux colorés artificiellement.}

Un accusé, dans le but de rendre impossible la constatation de son identité, peut se teindre les cheveux. Il est, alors important de constater si les cheveux ont bien été réellement teints. Orfila a étudié cette question à différents points de vue. On a en effet à résoudre plusieurs questions: $1^{\circ}$ les cheveux sontils colorés artificiellement? $2^{\circ}$ quelle substance a été employée?

Les substances qui colorent les cheveux n'agissent que sur la tige du poil, de sorte que les cellules nouvelles de la base, à mesure qu'elles se développent au-dessus du derme, présentent la coloration primitive du poil. Il suffira donc d'attendre un certain temps pour voir la base du poil prendre une coloration différente de celle de la partie antérieure. La distinction des cheveux colorés artificiellement et de ceux qui ont leur couleur naturelle, ne présente pas de réelles difficultés. Quand la teinture est bien réussie, la couleur de la tige est tellement uniforme, qu'on ne l'a retrouve jamais ainsi dans la nature.

Avec le plomb et le bismuth, la tige est noire jais et opaque; avec le nitrate d'argent, le poil, noir à l'œil, est toujours transparent (1), mais avec une coloration brun-violet. Un cheveu

(1) Pas toujours, suivant nos observations. 
CHAPITRE XXII. - EXAMEN DES CHEVEUX ET DES POILS. 853

noirci par le sulfure de bismuth ou le nitrate d'argent, additionné d'une goutte d'acide nitrique, reprend sa couleur claire primitive, de la périphéric au centre, avec formation de nombreuses bulles de gaz qui restent adhérentes au bord de la tige. Ce phénomène ne se produit pas avec un cheveu de couleur naturelle, si foncé qu'il soit, quand on se sert d'acide nitrique pour le rendre plus clair. (OEsterlen, cité par Johannet, p. 9.̈.)

$\mathrm{Si}$, au contraire, la teinture n'a pas été réussie, la teinte du cheveu n'est pas uniforme, il y a des places où la coloration naturelle reparaît avec ses caractères ordinaires. A peu de distance, il y a des différences de teinte très appréciables, tandis que sur un. cheveu naturel le passage d'une teinte à une autre se fait d'une façon insensible.

Les procédés de teinture se perfectionnent chaque jour, et les teintes que l'on peut obtenir sont assez variées. Celle que l'on recherche surtout est la couleur noire. Dans ces derniers temps, on a obtenu par différentes préparations, dont la composition n'est pas connue, et en particulier par l'emploi de l'eau oxygénée, une série de teintes variant depuis le blond jaunâtre jusqu'au blond vénitien.

Nous avons eu l'occasion d'observer chez une femme qui se décolorait les cheveux et qui avait été arrêtée et mise en prison, pendant un certain nombre de jours, que ses cheveux repoussaient noirs par la racine. Cette femme s'était servie d'eau oxygénée.

Au microscope on suivait très facilement la décoloration croissante du cheveu. A la base de celui-ci le pigment est uniformément réparti, avec sa coloration naturelle, tandis qu'au fur et à mesure que l'on s'approche de la partie décolorée par l'eau oxygénée, le cheveu devient uniformément transparent. Le pigment n'est pas détruit, il est seulement décoloré, et les caractères anatomiques du cheveu ne paraissent pas être profondément modifiés.

Méthodes le plus communément emrloyées pour la teinture des cheveux en noir. Procédés à l'aide desquels on peut reconnaître la substance employée.

$1^{\circ}$ Pommade au charbon. - On peut employer l'éther, qui 
dissout la graisse et laisse déposer le charbon que l'on reconnaîtra à ses caractères précédemment indiqués (1).

$2^{\circ}$ Nitrate de bismuth et acide sulfhydrique. - L'eau chlorée donne un précipité blanc.

$3^{\circ}$ Acétate de plomb et acide sulfhydrique. - Émploi du chlore.

4. Mélange d'oxyde de plomb, de carbonate de chaux et de chaux vive (mixture employée pour les cheveux blancs, coloration brun clair, devenant noire par l'action répétée du réactif). Le réactif employé pour décolorer les cheveux est l'acide nitrique.

$\check{\jmath}^{\circ}$ Nitrate d'argent (pour cheveux brun-rouge). Coloration d'abord d'un beau violet, puis noircissant à la lumière. L'agent décolorant est le chlore.

Dans les cheveux teints avec le nitrate d'argent, ceux dont l'imprégnation est complète sont tout à fait opaques. Ceux qui sont en voie de décoloration sont les uns jaune violacé, les autres gris noirâtre, régulièrement piquetés d'une matière colorante, couleur encre de Chine, uniformément distribuée dans le tissu du cheveu tout entier, sans localisation dans telle ou telle partie."

On ne perçoit plus les écailles épidermiques du poil, au moins dans la majorité des cas.

On a longlemps employé l'eau de chlore pour enlever aux cheveux leur coloration noire. Nous pensons que ce procédé n'est plus guère employé aujourd'hui. Il fallait faire plusieurs lavages à l'eau de chlore et l'on obtenait après l'opération une teinte de plus en plus claire. Les cheveux décolorés par ce procédé, garderaient une odeur de chlore très prononcée malgré de nombreux lavages. Nous pensons qu'actuellement, c'est l'eau oxygénée qui est le plus employée.

Cheveux postiches. - Le commerce des cheveux a pris de nos jours une très grande importance. Ces cheveux, lorsqu'ils n'ont pas été teints, présentent presque absolument les caractères de ceux que l'on rencontre sur le cadavre. Si, au contraire, ils sont teints, ils rentreront dans la catégorie des cheveux

(1) Ce procédé est complètement délaissé, au moins a Paris et dans les randes villes de France. 
CHa AITRE XXII. - EXAMEN DES CHEVEUX ET DES POILS. 8ว̈弓̆ que nous venons d'étudier précédemment. Suivant leur provenance, et il y a sur le marché de Paris des cheveux venant de toutes les parties du monde, les cheveux, ainsi que nous le verrons, peuvent présenter quelques caractères particuliers. La Chine, qui nous fournit un grand nombre de nattes, nous enverrait également. les poils longs et soyeux de la queue du yack (bos grunniens), espèce de bœuf à queue de cheval (fig. $ّ$ ४2).

On trouve, dans le commerce, des cheveux chinois remarquables par leur couleur noire magnifique, par leur longueur

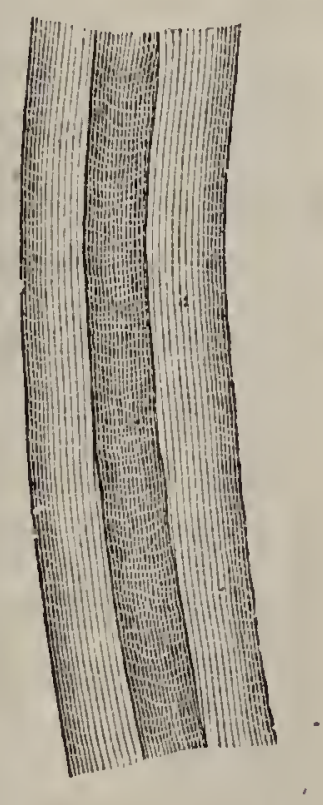

Fig. 342. - Poil du Yack.

et aussi par leur épaisseur. Très noirs par réflextion, par transparence, ces cheveux paraissent être rouges. Quand on les froisse entre les doigts, ils donnent la sensation d'un corps polyédrique, d'où le nom de cheveux carrés qu'ils portent dans le commerce. En raison de leur grosseur, ils sont peu recherchés. Ils ont en outre une odeur musquée très fine (1).

Un certain nombre de femmes qui perdent leurs cheveux pour une raison quelconque ont. l'habitude de se faire préparer des postiches, qu'elles ajoutent ensuite à leur chevelure. La comparaison de ces cheveux postiches avec ceux de leur personne, pourra dans certains cas permettre de conclure à l'identité. Si, au contraire, les cheveux postiches ont une ori-

(1) Galippe, Sur quelques particularités des cheveux (Société de biologie, 25 janv. 79 et J. des Conn. médicales pratiq., 30 janvier 1879). 
gine étrangère, la difficulté sera considérable. Le Dr Johannet cite un cas dans lequel des cheveux tombés spontanément et en grand nombre, furent remis à un posticheur pour les arranger en nálte, mais la natte fabriquée ne fut pas reconnue comme faite avec les cheveux qui lui avaient été confiés; un expert fut nommé et, après un examen comparatif des cheveux de la natte et de ceux de la plaignante, il conclut à une provenance étrangère des cheveux postiches.

Ce serait une erreur de croire que les cheveux tombés soient identiques comme coloration aux cheveux persistants de la même personne. Il suffit de comparer une natte faite avec les cheveux tombés, avec des cheveux bien portants de la même personne, pour voir que la coloration des premiers est irrégulière, plus pâle, et qu'ils n'ont pas le brillant de ceux qui sont normaux. Cela s'explique facilement; les cheveux qui tombent sont ou vieux ou malades. Dans la période plus ou moins longue qui a précédé leur chute, ils ont subi des altérations de nutrition dont ils portent encore les traces. Aussi les postiches faits avec des cheveux tombés sont-ils bien moins estimés que ceux pour lesquels on a employé des cheveux de coupe, c'est-à-dire coupés sur la tête des vivants. Les cheveux tombés rapidement à la suite d'une maladie grave (fièvre puerpérale ou fièvre typhoïde) ne présentent pas, à un aussi haut degré, les variations de couleur dont nous parlions tout à l'heure et se rapprochent davantage des cheveux normaux. L'un de nous a publié (Société de biologie, 2 ja janvier 1879) quelques observations sur les cheveux tombés et sur les cheveux coupés ( $J$. des conn. médic., 30 janvier 79), surtout au point de vue de l'odeur.

En résumé, il ne faudrait donc pas dans un cas analogue à celui cilé par le $\mathrm{D}^{\mathrm{r}}$ Johannet, conclure trop vite et cublier que les cheveux lombés ne sont pas identiques aux cheveux coupés sur le vivant, ou attenant encore au cuir chevelu.

\section{Distinction entre les poils arrachés et les poils tombés.}

Si l'on considère le poil en bouton de Henle ou à bulbe creux, on voit qu'il peut se présenter sous trois aspects différents suivant les conditions de son arrachement. 
CHAPITRE XXII. - EXAMEN DES GHEVEUX ET DES POILS. 857

$1^{\circ}$ Le poil peut être séparé de la papille (racine ouverte) et entraîner toute ou partie de sa gaine;

$2^{\circ}$ Il peut être complètement isolé de sa gaine, c'est alors un poil nu.

$3^{\circ}$ Enfin, il peut être brisé, dans l'intérieur de sa gaine, en un point plus ou moins distant du bulbe; la cassure est très irrégulière, et, pour nous servir d'une expression vulgaire, comme effilochée.

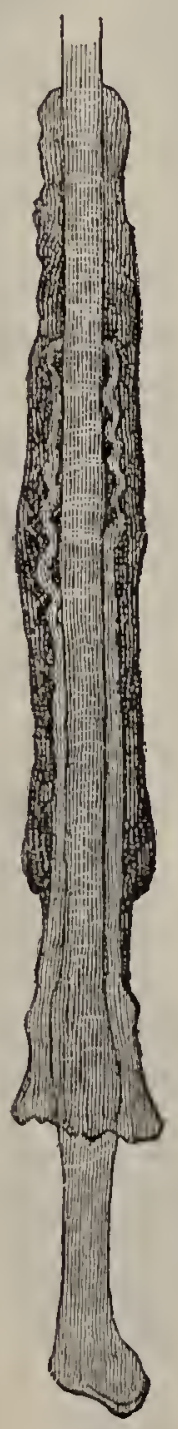

A.

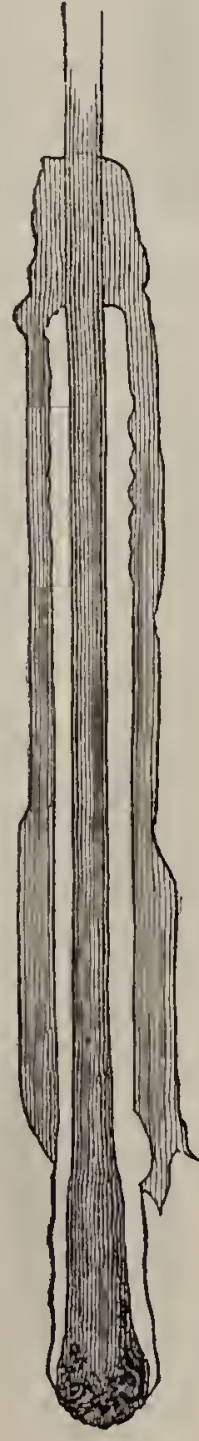

B

Fig. 543. - A, B. Cheveux arraches, avec leurs gaines externe et interne.

Le poil en massue de Henle, au moins d'après nos observations, paraîl le plus souvent s'arracher avec l'amas épithélial dans lequel il est plongé; toutefois, comme on pourra le voir d'après un certain nombre de figures, il semble également qu'on puisse l'arracher sans sa gaine, mais 
alors les expansions digitées de la racine semblent se rapprocher l'une de l'autre et la racine prend l'aspect ovoïde.

Nous avons donné les raisons pour lesquelles nous n'acceptions pas les conclusions d'OEsterlen que nous avons

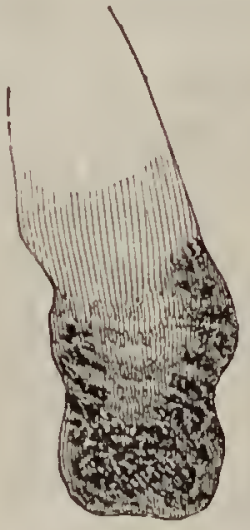

$\Lambda$

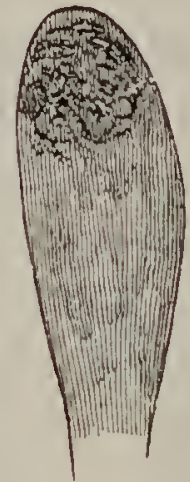

$\mathbf{B}$

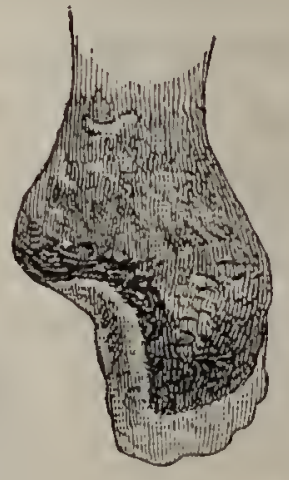

$\mathrm{C}$

Fig ớ彳 - Bulbes creux et pleins de cheveux arrachés (fenune alopécique).

rapportées plus haut. Elles sont trop absolues et ne concordent pas, suivant nous, avec l'immense majorité des faits.

Se fondant sur ces travaux de J. Pincus, ce même auteur a

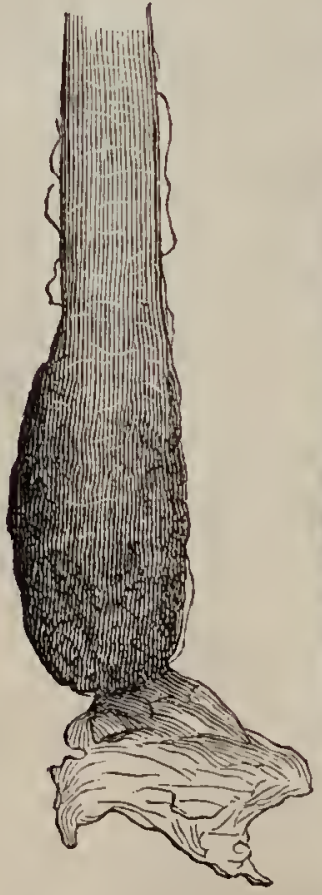

A

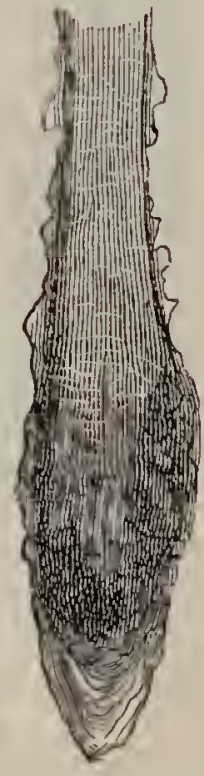

B
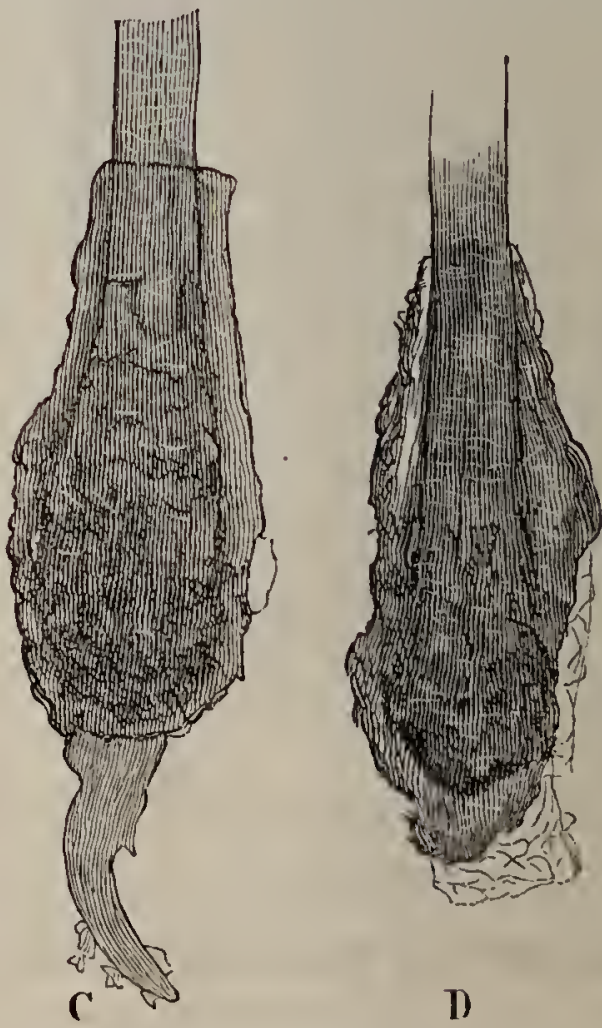

D)

Fig. 5430 . - Racines de cheveux tombés, à bulbes pleins, portant encore des débris` de la gaine externe. - A, B, C. (femme). - D (homme).

donnéle procédé suivant qui permet d'après lui de reconnaître si des cheveux sont tombés spontanément ou s'ils ont été arrachés. J. Pincus a montré que dans les cheveux qui tombent 
journellement, on en rencontre qui ont des caractères différents: les uns présentent la trace des ciseaux, c'est-à-dire l'absence d'un pointe effilée, les autres au contraire ont une pointe fine. Ces derniers seraient des cheveux dont le développement seraí imparfait, qui croîtraient plus lentement que les autres, dont ils n'alteindraient jamais la longueur, de sorte qu'ils échapperaient à l'action des ciseaux. OEsterlen nomme ces cheveux, cheveux à poinle chez l'homme, et cheveux courts chez la femme. - Leur durée serait de quatre à neuf mois, tandis que celle des autres cheveux serait de deux à quatre années.

D'après les recherches de J. Pincus, la perte journalière des cheveux s'élèverait en moyenne de $44-108$ p. $100 \mathrm{chez}$ sept hommes de 18 à 23 ans, bien portants; à 22 p. $100 \mathrm{chez}$ trois hommes de 48 à 53 ans. Le rapport entre le nombre des cheveux à pointe et le nombre des cheveux ordinaires serait :: $1: 9$ jusqu'à :: $1: 3$, chez des hommes de 31 à 54 ans.

Ghez des femmes de bonne santé, sur six séries d'expériences, la chute journalière comprenait en moyenne de 38 à 103 cheveux, mais le rapport des cheveux courts à la chute totale serait beaucoup plus grand chez la femme que chez l'homme. De ces chiffres OEsterlen a tiré les conclusions suivantes: dans les cheveux tombés on devra toujours trouver un certain nombre de cheveux à pointe pour l'homme, de cheveux courts pour la femme, au moins pour la proportion de $1 / 10$, tandis que, si les cheveux avaient été arrachés, on ne trouverait que des cheveux normaux, c'est à peine si quelques cheveux de la seconde forme s'y trouveraient mêlés.

L'examen de la surface cutanée sera également très instructif. En effet, si les cheveux sont tombés spontanément, la dénudation du derme ne sera pas nettement localisée, et le plus souvent il n'y aura qu'une simple raréfaction dans la masse des cheveux d'une région; l'arrachement au contraire détermine une dénudation locale complète. Si même l'examen a lieu peu de temps après l'arrachement des cheveux, la peau présentera encore quelques lésions, elle sera excoriée, saignante ou cicatrisée. On peut ainsi distinguer la dénudation par suite d'arrachement des poils de celle qui provient de la chute spontanée, rapide et localisée. (Johannet, p. 102.) 


\section{Poils isolés de l'organisme par solution de continuité de leur lige; détermination du mécanisme employé.}

OEsterlen, ayant eu à déterminer par quel procédé des che. veux avaient été séparés du crâne, a fait une série d'expériences dont voici les principaux résultats. Deux sortes d'instruments peuvent être mis en usage, pour briser la tige des cheveux et opérer une solution de continuité, des instruments contondants et des instruments coupants. Dans le premier cas, eu égard à la résistance extrême des poils, leur rupture par choc direct doit faire supposer l'emploi d'une force telle, qu'un plan d'appui sous-jacent, un os par exemple, serait infailliblement brisé. Ce ne sera donc que lorsqu'il existera une lésion sous-jacente que l'on sera en droit de conclure à une fragmentation de la tige des poils, comme résultat de l'emploi d'un instrument contondant.

Alors même que la solution de continuité ne serait pas complète, sous l'influence d'une force considérable employée, le poil pourrait présenter, à l'œil nu, un certain degré d'aplatissement de la tige, et un manque de cohérence des fibres qui la constituent, dont quelques-unes peuvent même proéminer au delà des bords.

D'après le même auteur, la traction exercée sur la tige d'un cheveu déterminerait l'arrachement total de celui-ci plutôt que sa brisure en un point quelconque de sa tige. - Nous avons maintes fois constaté le contraire et nous différons sur ce point complètement de l'avis d'OEsterlen — dans toutes les expériences que nous avons faites aussi bien sur des cheveux de fœtus, d'enfants nouveau-nés que d'adultes, aussi bien sur les poils follets du bras, que sur les poils follets de la tête, nous avions toujours eu quelque difficulté à nous procurer des racines et, dans la majorité des cas, les cheveux ou poils se brisaient et la racine restait implantée. Il est bien entendu que nous n'agissions jamais que sur un cheveu ou sur un poil à la fois.

Quand au contraire on saisit une véritable poignée de cheveux, les choses se passent différemment.

La résistance des cheveux nous paraît donc avoir été très 
exagérée par OEsterlen. Cette résistance varie suivant la grosseur des cheveux, suivant leur état de santé. Dans certaines diathèses, ou sous l'influence de l'application réitérée du fer à friser, les cheveux deviennent très cassants.

Lorsque d'autre part on suppose que l'instrument employé était tranchant, il reste à déterminer la nature de cet instrument. Liexamen de la forme de la coupe et de la surface de section peut quelquefois permettre de répondre; on peut, en tous cas, juger du degré de tranchant de l'instrument. Par Taction d'un couteau de poche ordinaire sur une tresse de cheveux bien tendue, on obtient d'un seul coup la section totale de la mèche. A l'œil nu, la surface de séparation paraîl parfaitement nette ; au microscope, au contraire, ces surfaces de section présentent presque toutes une proéminence de quelques fibres ou cellules corticales, en un mot une rupture par éclats, que l'on constate parfaitement à un grossissement de 2 ว $0 \mathrm{D}$.

Sur une tresse tendue modérément la section au contraire se fail par un mouvement de scie. Les cheveux sont irrégulièrement séparés; au microscope la surface de séparation est des plus inégales : dénudation médullaire d'un côté, soit amincissement en un faisceau de quelques fibres ou bien proéminence d'écailles épidermiques et de fibres, sur le pourtour de la section.

Par l'emploi des ciseaux, le résultat est à peu près le même; on a généralement un bord frangé, si l'on se sert d'un assez fort grossissement.

Avec un scalpel bien aiguisé, on obtient une surface de séparation bien nette; à peine remarque-t-on quelques dentelures avec un grossissement de $300 \mathrm{D}$. (OEsterlen, cité par Johannet.)

\section{Action du feu sur les poils et sur les chereux.}

Le $\mathrm{D}^{\mathrm{r}}$ Johannet (loc. cit., p. 10כ) a fait sur ce point des expériences que nous rapportons ci-après: Si l'on approche la tige d'un cheveu de la flamme d'une bougie, par exemple, la portion de la tige la plus voisine du foyer incandescent s'in- 
curve et blanchit. Le cheveu, examiné au microscope, présente alors en ce point, sur toute la courbe ainsi produite, un élargissement graduel, avec irrégularités des bords. La structure de la tige y est difficilement reconnaissable. Si la tige du poil a été suffisamment rapprochée de la source de chaleur, ou même s'il y a eu contact, le cheveu s'enflamme et se divise en deux tronçons: l'extrémité de celui de ces tronçons qui a subi l'influence du feu présente alors la forme suivante : une petite granulation ou renflement noir, d'un demi-millimètre de diamètre au plus, termine le poil ; immédiatement au-dessous, la tige légèrement cóudée sur une longueur de 1 millimètre, a, dans cette portion, un aspect blanchâtre, s'épaississant graduellement vers le renflement terminal. Un léger frottement suffit pour enlever ce dernier, qui paraît au microscope formé des cellules, des fibres de la tige et de granulations de charbon. La courte portion incurvée sous-jacente, de couleur blanchâtre, présente, avons-nous dit, une forme tronc-conique dont le sommet correspond au reste de la tige. Au microscope les Jords en sont irréguliers, formant des lignes ondulatoires ; on a, à peu près, l'aspect d'une racine d'un poil arraché avec ses gaines épidermiques. La surface terminale est des plus irrégulières. "

Ges caractères sont assez nets, ajoute le $\mathrm{D}^{\mathrm{r}}$ Johannet, pour que l'expert puisse dans bien des cas rapporter la séparation d'une touffe de cheveux, ou telle lésion de la peau sur laquelle les données étiologiques manquent, à l'action du feu : autour d'une plaie, la présence de poils plus petits que les autres, visiblement raccourcis par une action extérieure, sans pointe, terminés au contraire par une extrémité légèrement épaissie, coudée, blanche et raide, la présence de pareils poils doit faire diagnostiquer une brûlure. (Johannet.)

Les liquides chauds n'agiraient pas sur la tige du poil ; ils agissent seulement sur le derme et sur le follicule; il y a perte d'adhérence et chute des poils à la plus légère traction.

Quand ils ont été agglutinés par un liquide renfermant des éléments anatomiques figurés, on peut au bout d'un temps très variable, mais quelquefois considérable, retrouver ces éléments, dans un état de conservation plus ou moins parfait 
CIAPITRE XXII. - EXAMEN DES CHEVEUX ET DES POILS. 863

(globules rouges, éléments du méconium). On a également trouvé des spermatozoïdes, soit sur les poils qui garnissent les grandes lèvres de la femme, soit sur ceux des organes génitaux de l'homme. OEsterlen cite plusieurs observations dans lesquelles la présence de spermatozoïdes sur les poils du pubis de jeunes filles ont fourni la preuve que des tentatives de viol avaient été faites.

Le docteur Johannet cite, comme pouvant mettre sur la trace de l'auteur d'un viol ou d'une tentative, la présence d'un poil d'une couleur différente, trouvé sur le pubis d'une femme.

\section{Altérations pathologiques des chevenx.}

Nous n'étudierons pas les altérations pathologiques des chereux dont quelques-unes ont été indiquées dans la première partie de ce livre. Il est certain que des cheveux atteints d'une affection parasilaire rendraient plus facile la détermination de l'identité de l'individu auquel ils ont appartenu. L'alopécie est l'affection la plus fréquente et presque toujours elle est la conséquence du pityriasis capitis. Lorsqu'il atteint la partie supérieure du follicule pileux, il se fail une transformation fibreuse du follicule qui s'oblitère de bas en haut. La grossesse, les maladies graves, provoquent quelquefois des altérations plus ou moins irrémédiables du système pileux; la syphilis provoque aussi fréquemment de l'alopécie. Celle qui se produit au début el qui coïncide avec la roséole est passagère; celle qui est la conséquence des syphilides ulcéreuses se montre par place et est définitive, en raison des cicatrices laissées par ces syphilides ulcéreuses. Ce serait sortir de notre sujet que d'étudier en détail toutes ces altérations. Nous signalerons cependant à titre de curiosité une lésion patholo-, gique des cheveux décrite pour la première fois par le $D^{r}$ Osorio, de Bogota (Colombie). Celle affection, qui sévit principalement dans la province de Cauca, est caractérisée par de petites nodosités espacées sur les cheveux et excessivement dures. C'est à cause de la sensation particulière de crépitation produite par le passage du peigne, que l'on a donné à cette ma- 
ladie le nom de la Piedra. Gette affection ne serait pas contagieuse.

Le $\mathrm{D}^{\mathrm{r}}$ Desenne (Journal d'hygicine, 4 juillet 1878) a repris cette question. Voici le résultat de ses recherches :

Le cheveu traité par l'éther et monté en préparation persistante dans la glycérine offre l'aspect suivant avec un grossissement de 140 D. Les nodosités sont assez régulièrement espacées, sans toutefois conserver une disposition mathématique. Ces nodosités sont de deux genres qui semblent être un degré plus ou moins avancé de maturilé du cryptogame, ou bien elles enveloppent complètement le cheveu à la façon d'un véritable anneau fusiforme; ou bien elles ne font que l'engainer incomplètement et ne forment à sa surface que de simples monticules.

Examinées à un grossissement de 330 D., elles se décomposent en amas cellulaires à éléments polygonaux de $12 \mu$ à 1 ว $\mu$. assez régulièrement alignés, dont les interstices, nettement dessinés par un liséré noir, rappelleraient vaguement l'aspect d'une imprégnation d'argent. Ces cellules, dont le centre offr eune certaine réfringence, ne contiennent aucune trace de noyau.

En examinant attentivement les parties avoisinantes de quelquesunes de ces nodosités et faisant varier le grossissement, on aperçoit un réseau réfringent de petits bâtonnets articulés les uns avec les autres. De ces bâtonnets, les uns semblent venir se perdre dans la substance propre de la nodosité, soit par un petit renflement ampulliforme, soit par une petite grappe cellulaire ombelliforme.

On distingue aussi entre ces bâtonnets, et complètement indépendants alors, de gros globules réfringents qui semblent être des bulles graisseuses, comme on en voit survenir parfois à la surface des matières animales en macération dans la glycérine.

Ces bâtonnets sont-ils le mycelium du cryptogame dont les spores formeraient alors l'agrégation cellulaire des nodosités? Ou bien sontils indépendants? C'est ce qu'il est bien difficile de décider. Ils semblent être des Mucorinées, sans qu'on puisse toutefois l'affirmer. Notons, en passant, une disposition particulière des bâtonnets : ils s'enroulent autour du cheveu comme le ferait une plante grimpante ; le lierre, par exemple, autour d'une colonne.

Le parasite végétal est-il en relation intime avec la substance propre du cheveu, et il y a-t-il, entre les cellules épithéliales du tube capillaire, du mycelium ou des spores? Pour résoudre cette double question, M. Desenne ayant immergé un de ces cheveux dans une solution de potasse cautisque à $4.0 \mathrm{p}$. 100 pendant quelques minutes, ayant ensuite neutralisé par l'acide acétique pur et dissocié dans la glycérine, a constaté qu'en aucun point, les parties profondes du cheveu, ni le canal médullaire, n'étaient infiltrés ; que les bâtonnets 
sans doute, simplement juxtaposés à la périphérie du cheveu, avaient disparu, pour la majeure partie.

Quelques coupes, pratiquées transversalement à travers ces nodosités, ont rendu encore plus évidente l'intégrité du canal médullaire et des parties environnantes.

Les parties centrales de ces nodosités, vues sur une coupe transversale, sont formées par un stroma cellulaire semblable à celui qui recouvre leur périphérie et dans lequel on découvre quelques cavités en forme de conceptacles contenant quelques grosses cellules qui sembleraient être des thèques.

En de certains points de ces nodosités, et alors qu'on les examine de leur partie superficielle à leur partie profonde, sur un des cheveux simplement imprégnés dans la gljcérine, on rencontre quelques espaces plus clairs, plus transparents, laissant deviner des cavités profondes, tranchantsur le fond brun de la nodosité, espaces qui ne seraient alors que ces mêmes conceptacles recouverts de la couche cellulaire polygonale dont il a déjà été fait mention.

M. Desenne ajoute que rien nel'autorise à parler de leur déhiscence.

La Canitie sénile est un phénomène pathologique, mais elle peut se produire, suivant certains auteurs, sous l'influence d'émotions morales très vives. Ce fait est incontestable.

On peut voir quelquefois des poils qui, après avoir poussé blancs, poussent ensuite colorés, de sorte que l'on a une sorte:de tigrage du cheveu.

Une autre anomalie, c'est l'albinisme partiel; il est des individus qui présentent une mèche tranchant par sa blancheur sur la couleur foncée du reste de la chevelure. Cette disposition est souvent héréditaire.

\section{DESCRIPTION DU CHAMPIGNON DE L'ALOPECIE PITYRIASIQUE.}

M. le docteur Malassez a étudić avec beaucoup de soin le champignon du Pityriusis simple. Avant de donner les altérations anatomiques des cheveux, nous rapporterons les conclusions du premier mémoire de ce consciencieux micrographe. Le pityriasis simple est une affection très vulgaire, c'est cette maladie qui cause la plupart des calvities précoces. Pour recueillir les pellicules, il suffit de faire peigner au peigne fin et brosser la tête du malade au-dessus d'une feuille de papier. Pour dégraisser les pellicules, il faut les laisser un jour ou deux dans l'éther, en ayant soin d'agiter de temps à autre, et de renouveler plusieurs fois le liquide. On reconnaît que l'opération est terminée lorsque l'éther, déposé dans un peu d'eau sur une lame porte-objel, ne laisse plus voir de granulations graisseuses.

Les pellicules, une fois dégraissées sont conservées dans de l'alcool, celles que l'on garde dans du papier, et sans être dégraissées, s'altèrent. Pour les éludier, on en porte quelques-unes de l'alcool sur la lame porte-objet; on ajoute quelques gouttes d'eau filtrée pour les 
laisser s'imbiber; les plus épaisses doivent être dissociées avec les aiguilles, puis on recouvre avec la lamelle qu'on fixe avec de la paraffine.

Voici quelles sont les conclusions du premier mémoire de M. Malassez :

" $1^{\circ}$ Dans les quelques cas de pityriasis simple que j’ai examinés, j'ai toujours trouvé des champignons microscopiques;

$2^{\circ}$ Ces champignons sont uniquement constitués par des spores; ils ne possèdent pas de traces de mycélium. Ces spores sont, en général, ovoïdes et bourgeonnantes, plus rarement sphériques. Elles sont très petites; les plus grandes mesurent, en y comprenant le

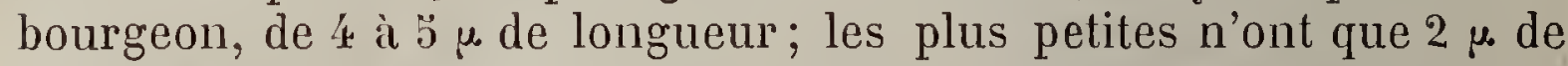
long et larges en proportion. Elles sont formées par une enveloppe et un contenu. Quelques-unes sont vides et paraissent mortes. Elles se distinguent de celles de la pelade, en ce que ces dernières sont habi : tuellement sphériques et plus volumineuses; de celles des autres champignons connus, en ce que ces dernières possèdent des tubes de mycélium;

$3^{\circ}$ Les champignons du Pityriasis habitent la couche cornée de l'épiderme; ils pénètrent dans les follicules, mais sans arriver au niveau des glandes sébacées.

Ils sont ordinairement très abondants, mais leur abondance n'est pas proportionnelle à l'intensité du pityriasis. Ils disparaissent lorsque le pityriasis guérit;

$4^{\circ}$ Ils paraissent jouer, dans la pathogénie du pityriasis, le même rôle que les autres parasites dans celles des affections cutanées, généralement considérées comme de nature parasitaire. Le pityriasis serait le produit et de l'action directe de ce champignon (phénomène d'ordre physique) et de la réaction de l'individu sous l'influence de la présence du parasite (phénomène d'ordre vital). "

Dans un second mémoire, M. Malassez a complété ses premières recherches en étudiant l'anatomie pathologique de l'alopécie pityriasique qui succėde au pityriasis chronique du cuir chevelu. Nous passerons sous silence ce qui a trait aux altérations du cuir chevelu pour ne nous occuper que des cheveux et des follicules pileux (1).

Voici le résumé du mémoire de M. Malassez :

Alopécie au premier degré. - Pityriasis capitis et pilaris. - Destruction et dilatation de la partie sus-sébacée des follicules par les pellicules pityriasiques. Quelques follicules pileux vides de cheveux; mais non encore sensiblement altérés.

Alopécie au deuxième degré. - 10 Hypertrophie concentrique et ascendante des parois folliculaires; naissance des cheveux de plus en plus loin de la papille, au milieu de cellules de la gaine externe; diminution dans leur longueur et leur largeur; perte de la moelle, diminution du pigment.

(1) Les cheveux, par suite de l'atrophie croissante des cavités folliculaires, 
2. Atrophie du derme, hypertrophie du tissu graisseux souscutané.

Alopécie au troisième degré. - Calvitic. - 10 Oblitération ascendante d'un grand nombre de follicules pileux ainsi transformés en cordons fibreux lesquels se rétractent. Disparition de la membrane interne; diminution croissante dans les dimensions des cheveux; chute définitive d'un grand nombre; atrophie de quelques glandes sébacées et de quelques muscles pileux;

$2^{\circ}$ Atrophie croissante et aspect cicatriciel du derme; augmentation du tissu graisseux sous-dermique; développement des glandes sudoripares.

L'ordre dans lequel ces lésions se sont produites, les rapports évidents qui existent entre plusieurs d'entre elles, peuvent nous donner

diminuent peu à peu de longueur, leur bulbe se rapproche de plus en plus de la surface cutanée. En même temps et pour la même raison, leur diamètre devient de plus en plus petit. Voici au point de vue du diamètre des clieveux, les changements que M. Malassez a constatés dans ses différentes préparations :

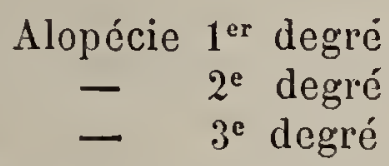

Maximum
$100 \mu$
$60 \mu$
$30 \mu$

Minimum
$90 \mu$
$30 \mu$
$20 \mu$

Leur structure est égalèment modifiée: la couche épidermique persiste, mais la substance corticale perd plus ou moins son pigment, la moelle disparait et le bulbe clıange complètement d'aspect. Toutes ces modifications paraissent se produire à partir du moment où le clieveu n'est plus en rapport avec la papille; elles sont très certainement la conséquence de ce départ. A l'état normal et tant que le cheveu est en rapport avec la papille, le cheveu naît de cet amas de jeunes cellules qui coiffe la papille et compose le bulbe. Les plus périphériques d'entre elles se transfolment rapidenınt pour constituer la gaine interne : couche externe d'abord, puis ensuite couche moyenne ou de Huxley et couche interne ou épidermique. - Les autres cellules font former le cheveu: épiderme substance corticale, substance médullaire; cette transformation se fait d'une façon très régulière.

Lorsque le cheveu a quitté la papille, il naît au milieu d'un amas de cellules appartenant à la gaîne externe. - Son extrémité bulbaire est ramifiée à la façon des racines d'un arbre; cet aspect est très net sur les coupes colorés au picro-carminale, le bulbe et ses ramifications étant colorés en jaune vif et tranclıant ainsi sur le fond rouge orangé de la masse cellulaire. - La formation des cellules du cheveu n'est plus reigulière et localisée comme à l'état normal; les cellules qui doivent se transformer en cellules corticales ne sont plus réunies en un même point, elles sont dissćminées au milieu des autres et leur transformation ne se fait plus simultanément. Les cheveux présentent parfois des renflements sur leur tige. - On trouve à ce niveau des fentes longitudinales, mais pas le champignon comme dans la tricophytie. - Ce sont des cassures indiquant une plus grande friabilité du tissu. Les cheveux en forme de pinceau que l'on observe fréquemment aussi ne sont que des cheveux brisés de cette façon. (Malassez, Archiv. de Physiolog., 1874). 
quelques explications sur la pathogénie de l'alopécie. Dans la théorie la plus généralement admise, la chute des cheveux résulte d'un défaut de nutrition par suite de l'atrophie de la papille; lorsque cette atrophie est définitive, le cheveu ne se produit plus, et le follicule s'oblitère. Cette théorie n'est pas en rapport avec les faits que nous venons de passer en revue : il n'existe pas d'atrophie de la papille au début du moins; le cheveu se produit encore alors qu'il n'est plus en rapport avec la papille ; sa chute définitive ne précède pas l'oblitération du follicule.

Le processus est tout autre, il se produit une irritation des parois folliculaires se manifestant par la chute des cheveux et l'hypertrophie des parois des follicules, et c'est cette hypertrophie qui amène l'oblitération de la cavité, la transformation fibreuse du follicule et consécutivement la chute définitive du cheveu (Malassez, Arch. de physiolog., 1874).

\section{Coupes horizontales des cheveux.}

On avait fondé, au point de vue anthropologique, des espérances assez sérieuses sur l'examen des coupes microscopiques pratiquées sur des cheveux ayant appartenu à des individus de différentes races. Nous tenons de source certaine que les résultats de très longues et de très patientes tentatives ont été très inconstants. Si dans une coupe pratiquée dans les cheveux d'un nègre on trouve des caractères différentiels assez nets, sur la tête d'un même individu on rencontrera également tous les intermédiaires, de telle sorte que l'observateur même le plus exercé, n'aura jamais entre les mains des éléments d'une détermination véritablement scientifique.

La coupe verticale des cheveux, dit Hager, donne des résultats différents et sa forme n'est pas caractéristique pour l'espèce de cheveux. Les cheveux d'un même individu peuvent donner une coupe ou ronde, ou ovale, ou triangulaire. Cette forme dépend entièrement de celle de l'ouverture à travers laquelle le cheveu a poussé.

Jusqu'à ces dernières années, c'était une opération très difficile que d'obtenir des coupes de cheveux parfaitement horizontales, mais grâce à l'emploi du collodion (Latteux), ou de la gélatine (Malassez), on obtient facilement ce résultat. 


\section{Procédé de Latteux.}

"Supposons que l'on veuille obtenir des coupes transversales de cheveux, on prend une plaque de verre et on dépose à l'une de ses extrémités une goutte de cire à cacheter, puis saisissant le cheveu dont on veut faire la coupe, on le fixe sur la cire en le faisant pénétrer au moyen d'une tige de fer ou d'une aiguille qu'on chauffe à la lampe. On fait de même pour un second et un troisième qu'on fixe les uns à côté des autres.

On prend ensuite un morceau de diachylon de la largeur de la plaque de verre et on l'applique à son extrémité opposée. L'adhérence a lieu facilement en appuyant avec la pulpe du doigt. On y dépose également une goutte de cire à cacheter et, reprenant chaque cheveu un à un, on le fixe avec la tige chauffée, par son autre extrémité, de façon à le faire adhérer à la bandelette de diachylon.

Chaque cheveu est disposé à côté de son voisin de façon qu'ils soient tous bien parallèles. Ils sont alors placés de la mème manière que les cordes d'un violon. Il s'agit de les fixer dans un milieu suffisa mment solide pour les maintenir tels qu'ils sont placés et de façon qu'ils ne puissent revenir sur eux-mêmes et devenir onduleux. Pour arriver à ce résultat nous avons essayé beaucoup de substances, mais aucune ne vaut le collodion. Voici comment on opère : les cheveux étant disposés de la façon décrite ci-dessus, on verse une couche de collodion entre les deux points où l'on a déposé les gouttes de cire. L'éther ne tarde pas à s'évaporer et il reste sur le verre une couche plus ou moins épaisse contenant les cheveux dans son épaisseur.

Il arrive quelquefois à ce moment, que les cheveux se détendent et deviennent flexueux. C'est alors qu'on détache le diachylon et le soulevant légèrement, on le fixe un peu plus loin en tirant sur les cheveux et en les tendant doucement.

On verse une nouvelle couche de collodion et on continue à opérer de la sorte jusqu'à ce qu'on ait une membrane d'un millimètre environ d'épaisseur.

On comprend que les cheveux seront disposés d'une manière tellement fixe qu'ils ne pourront aucunement bouger quelle que soit la manœuvre imprimée à la couche de collodion.

On la laisse bien sécher et on procède à la coupe de la façon suivante :

Bien qu'on puisse à la rigueur se servir du microtome ordinaire, nous préférons de beaucoup cependant l'instrument de Lelong, qui permet de maintenir plus solidement l'objet à sectionner.

On coupe dans la plaque de collodion contenant les cheveux un petit carré de un centimètre environ et on l'enferme entre une petite planclietle de bois tendre et une plaque de moelle de sureau; puis on fixe le tout entre les mors de la pince de façon que le système 
dépasse un peu le bord du plan incliné, mais soit maintenu bien fixe et bien immobile.

On opère alors pour faire la coupe, comme s'il s'agissait d'un objet ordinaire et l'on comprend facilement que le rasoir qui appuie contre la plaque de bois, ne peut manquer de couper nets les cheveux puisqu'ils ne peuvent bouger ni dans un sens ni dans un autre, maintenus qu'ils sont par le collodion qui les entoure rigoureusement.

On est sûr de la sorte d'avoir des sections absolument perpendiculaires au grand axe de chacun.

On obtient par les coupes de petites lamelles de collodion renfermant dans leur épaisseur des tranches de cheveux. On les mouille alors dans la glycérine ou mieux dans le baume de Canada, mais dans ce dernier cas, il faut éviter de les mouiller avec de l'essence de girofle, qui dissoudrait le collodion et permettrait aux coupes de venues libres de se déplacer et de perdre leur position horizontale. "

Latteux, Technique microscopique, p. 239.

Il est du reste assez facile de voir si les coupes de cheveux sont parfaitement horizontales. Lorsque l'on déplace l'objectif avec lequel on examine une coupe de cheveux, celle-ci change de plan. Si les deux surfaces de section ne sont pas parfaitement perpendiculaires entre elles, on distingue deux images; la supérieure donne une image qui se projette sans se confondre avec l'image de la section la plus inférieure. Plus la coupe est oblique, plus les surfaces de section sont éloignées l'une de l'autre. Si, au contraire, les deux surfaces de section sont parfaitement perpendiculaires entre elles, on ne roit qu'une seule image horizontale, même en faisant varier le point.

\section{Caractère des poils apparténant à quelques animaux et en particulier à ceux qui vivent auprès de l'homme.}

Il est une foule de circonstances dans lesquelles il est de la plus haute importance de donner la preuve scientifique d'une erreur d'appréciation sur l'origine de poils trouvés soit sur des vêtements, soit sur des instruments. C'est ainsi qu'on a pris pour des cheveux humains, des poils de cheval qui adhéraient à un talon de botte, qu'on a confondu des poils de lapin avec des cheveux blancs, et que c'est grâce à l'intervention 
du microscope, dans les deux cas que nous citons, que l'on a pu faire éclater l'innocence des inculpés.

Maintenant que nous connaissons l'aspect et la structure des poils humains, il nous suffira de placer un poil d'animal quelconque sous le champ du microscope, pour voir d'abord que ce n'est pas un cheveu (1).

La meilleure des descriptions ne vaut pas une bonne figure, et la figure la mieux faite ne vaut pas la réalité. Aussi nous

(1) OEsterlen appellc tout particulièrement l'attention sur le rapport d'épaisseur qui cxiste entre la tige et la corde médullaire, entre la substance corticale et la moclle. Ce serait, d'après cet auteur, un signe d'une haute importance. La corde médullaire, dit OEsterlen, existe toujour's, cela dépend de la nature du poil examiné; il $y$ a chez les animaux, comme chez l'homme, des poils qui n'ont pas de moelle. Il est vrai que la moelle manque rarement dans les poils d'animaux et que, dans les gros poils, elle s'élargit considérablement de façon à occuper la largeur du poil presque tout entière, mais il est des poils de duvet, contrairement à ce que dit OEsterlen, qui ne possèdent point de canal médullaire, et c'est bien plus au mode particulier d'imbrication des écailles ćpidermiques, qu'à l'absence do la moclle que l'on distinguera les poils de duvet des animaux, des poils de duvet de l'homme et du fotus.

Rapport de largeur entre la corde médullaire et la tige du poil chez l'homme (OEsterlen).

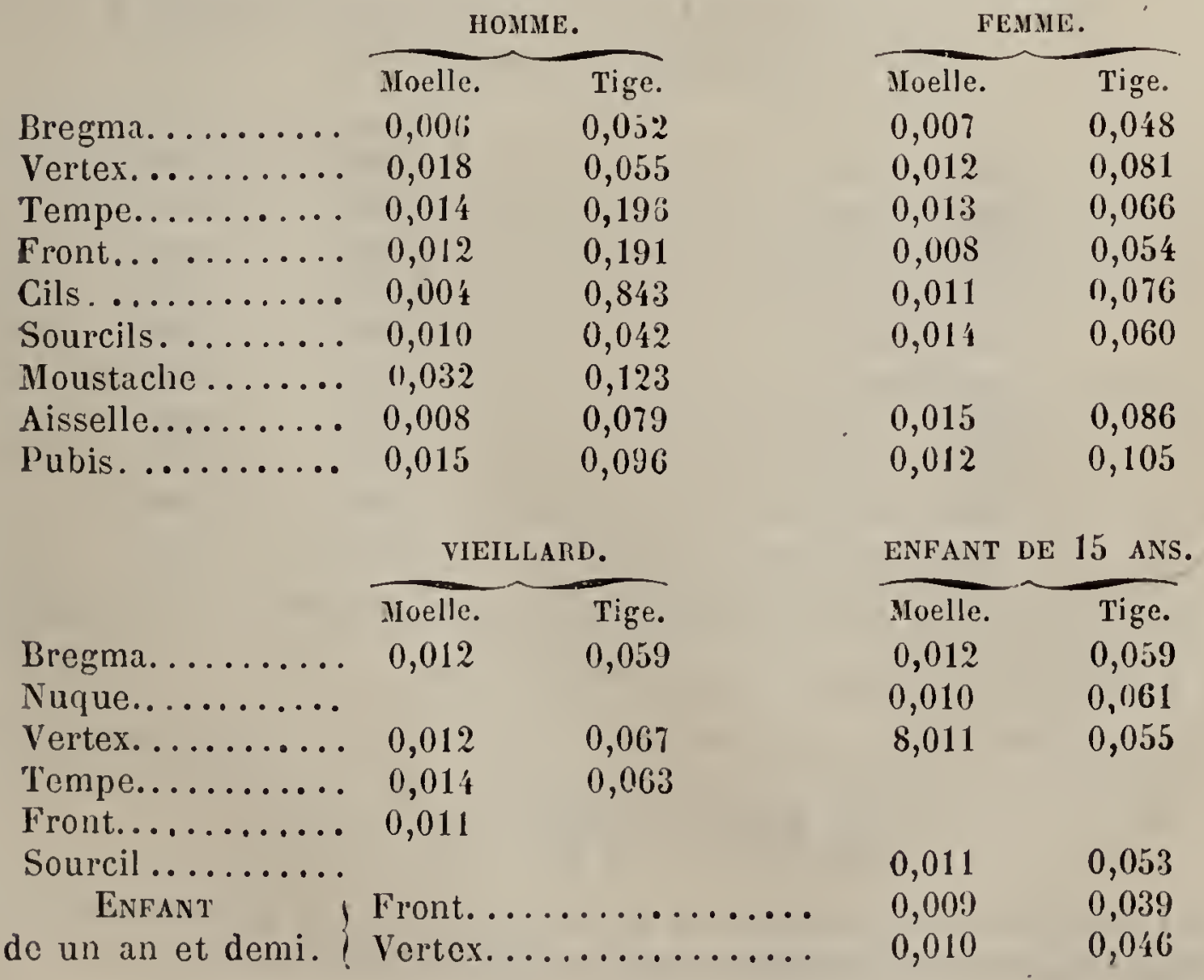


engageons nos lecteurs à se familiariser avec l'aspect des poils des animaux qui nous entourent.

Si dans une expertise médico-légale, on venait à rencontrer un poil de lapin par exemple, il faudrait immédiatement contrôler ce diagnostic, par la comparaison avec des poils de cet animal.

Nous serons donc très brefs sur ce qui concerne les poils. Les figures parleront assez d'elies-mêmes et le contrôle pour ce qui regarde les animaux domestiques est d'une très grande facilité.

Le Lièvre est chassé aussi bien pour sa fourrure que pour

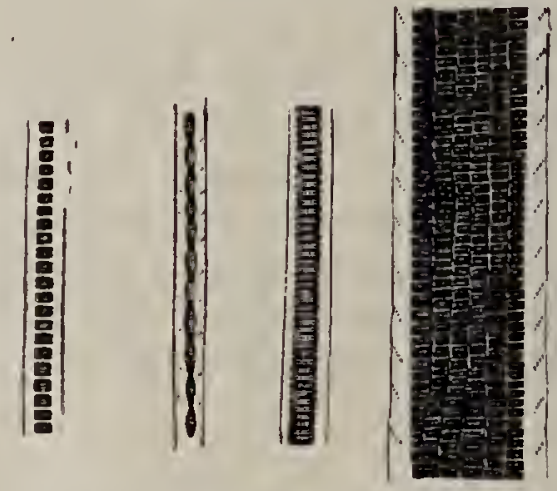

Fig. 546. - Lièvre, différentes formes du poil des pattes.

Rapport de largeur entre la corde médullaire et la tige chez différents animaux.

\begin{tabular}{|c|c|c|}
\hline Barbet........ & $\begin{array}{c}\text { Moelle. } \\
0,008\end{array}$ & $\begin{array}{c}\text { Tige. } \\
0,025\end{array}$ \\
\hline Chien (dos) $\ldots \ldots \ldots \ldots \ldots \ldots$ & 0,084 & 0,011 \\
\hline Chien (jeune) $\ldots \ldots \ldots \ldots \ldots$ & $0,00 s$ & 0,024 \\
\hline Chat (dos) $\ldots \ldots \ldots \ldots \ldots \ldots \ldots$ & 0,057 & 0,075 \\
\hline Chat (ventre)............... & 0,010 & 0,015 \\
\hline Vache $($ dos $) \ldots \ldots \ldots \ldots \ldots \ldots$ & 0,057 & 0,096 \\
\hline Lapin......... & $0,05 i$ & 0,075 \\
\hline 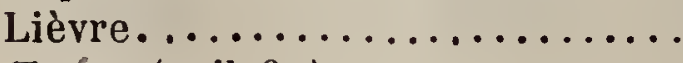 & 0,099 & 0,108 \\
\hline Taúpe (poil fin) ............. & 0,006 & 0,008 \\
\hline Taupe (poil gros).......... & $0,0: 8$ & 0,024 \\
\hline
\end{tabular}

Ainsi, chez l'homme, avec le maximum de largeur médullaire 0,832 , on a: $\frac{m}{\mathrm{~T}}=\frac{32}{123}=$ rapport de la moelle à la tige.

Avec la plus petite largeur de la corde chez l'animal (taupe) nous avons :

$$
\frac{m 6}{\mathrm{~T} 8} \text {. Lièvre }=\frac{m 99}{\mathrm{~T} 108} \text { vache }=\frac{m 57}{\mathrm{~T} 96} .
$$

Dans le cas où la coloration de la tige ne laisse pas apercevoir la corde médullaire, on emploie l'acide nitrique qui éclaircit le poil. 
Chapitre XXII. - EXAMEN DES GHeveux ET DES POILS. 873

sa chair. La Bohême fait un très grand commerce de peaux de lièvre.

Le duvet de lièvre se distingue par une imbrication oblique, qui n'est pas cependant caractéristique.

Capin. - Nous avons démontré par un exemple, qu'il était important de connaître la structure des poils du lapin. Le lapin domestique provient du lapin sauvage. La variété de son pelage est considérable. Le " lapin argenté ", qui est grisbleuâtre avec des reflets foncés ou argentés, et dont les extrémités sont noires argentées, est très estimé pour sa fourrure. La chapellerie fait un commerce considérable de poils de lapins.

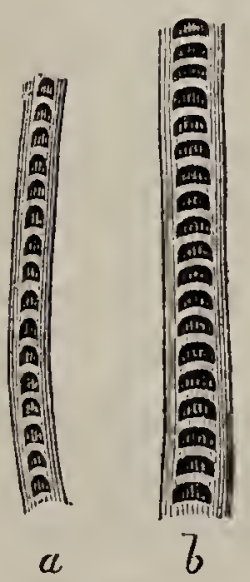

Fig. 547. - Poils de lapin. ( $a$, petit poil; $b$, poil moyen.)

Les poils de lapins sont formés d'une couche mince de substance pileuse à canal médullaire cloisonné. Sur beaucoup de rongeurs, comme les rats, les souris, les poils sont constitués d'après le même type (Robin).

Nous donnons ci-après la copie d'un rapport du docteur Ducastel, qui démontre l'importance que peut jouer la détermination d'un poil en médecine légale. Un homme âgé qui avait des habitudes d'ivresse, fut trouvé pendu et le corps couvert de plaies. On accusa de ce crime deux individus qui étaient en de mauvais termes avec la victime. Sur la blouse de l'un des inculpés, on avait trouvé des taçhes rouges que l'on avait considérées comme ayant été faites par du sang (celui de la victime) et des poils blancs, que l'on supposait avoir appartenu également à la victime.

Après le rapport de $\mathrm{M}$. le docteur Ducastel, les deux inculpés 
furent mis en liberté. Celui sur lequel pesaient les charges les plus graves, se souvint qu'il avait porté dans sa blouse de l'herbe qu'il avait recueillie pour ses lapins; les taches avaient presque toutes été produites par un suc laticifère coloré; les poils étaient des poils de lapins, etc. On supposa que la victime en état d'ivresse, après être tombée sur une herse en fer, s'était pendue volontairement.

\section{Rapport du docteur Ducastel.}

Je soussigné, docteur, etc.

Déclarer : $1^{\circ} \mathrm{Si}$ du sang trouvé sur des briques était du sang humain, ou s'il pouvait provenir d'un lapin;

$2^{\circ}$ Si des taches brunâtres qui se trouvaient sur un tablier, étaient des taches végétales;

$3^{\circ}$ Si des taches de sang trouvées sur une blouse ćtaient des taches de sang humain, et si elles pouvaient être anciennes de trois mois.

Serment préalablement prêté, etc.

Sur les briques étaient de petites taches formant croûte et présentant à la lumière réfléchie un aspect brillant et une coloration rouge brune. Après avoir détaché de ces croùtes et en avoir placé des fragments, les uns dans le liquide D de M. Bourgogne, les autres dans le sérum artificiel du docteur Malassez (Voy. sang), voici ce que j'ai pu observer :

Peu après que les fragments étaient placés dans le liquide, il se formait à leur pourtour une zone de diffusion blanchâtre dont la largeur variait avec le volume du fragment.

A l'examen microscopique, la zone de diffusion paraissait formée de granulations fines et brillantes; la masse principale présentait une coloration intense; dans son épaisseur se détachaient des corpuscules sphériques, granuleux, de huit à dix millièmes de millimètres de diamètre présentant tous les caractères des globules blancs du sang. En employant un fort grossissement, on constatait que la masse principale était formée par la réunion de corpuscules arrondis, ayant une dimension de 5 à $7 \mu$; nettement limités par des lignes droites, ces corpuscules n'étaient autres que les globules rouges du sang, mais ils se détruisaient rapidement; il fut impossible de les dissocier et de les obtenir isolés quelqu'ait été le procédé employé pour les fixer.

Quand l'action du liquide s'était prolongée quelque temps, la coloration rouge du caillot disparaissait, les lignes délimitant les corpuscules arrondis s'efliaçaient, et la masse tolale présentait un aspect 
granuleux; mais au milieu d'elle, on pouvait encore distinguer les globules blancs.

Pour constater que nous avions affaire à du sang, j'ai aussi employé le spectroscope. Ayant placé dans de l'eau distillée quelquesunes des croûtes recueillies sur les briques, j'ai obtenu une solulution rouge transparente qui, examinée au microspectroscope, donna la double raie d'absorption de l'hémoglobine : la solution, traitée par le sulfhydrate d'ammoniaque, ne donna plus que la raie unique de l'hémoglobine oxygénée.

Sur le tablier existaient un grand nombre de taches de coloration jaunâtre, la plupart mates à la lumière réfléchie, quelques-unes légèrement brillantes et formant par places de minces croûtes. Leur ayant fail subir les mêmes préparations qu'à celles recueillies sur les briques, j’ai observé des phénomènes tout différents : après que les fragments avaient été placés dans les liquides de Bourgogne et de Malassez, il ne se formait pas à leur pourtour de zone de diffusion, et ces masses offraient une coloration rousse toute différente de la coloration rouge des caillots sanguins; on n'y rencontrait aucun des éléments du sang; les principaux éléments qu'on obtenait par la dissociation, étaient des grains calcaires, des cellules végétales.

Ayant placé des fragments du tablier dans de l'eau distillée, j'ai obtenu une solution roussâtre, trouble, qui, examinée au microspectroscope, ne donna aucune raie d'absorption.

A la partie antérieure de la blouse était une croûte brunâtre, arrondie, à surface brillante, présentant l'aspect extérieur du sang. En avant recueilli quelquesfragments, et les a vant placés dans le liquide D de II. Bourgogne et dans le serum artificiel du docleur Malassez, j'ai vu se produire à leur pourtour une zone de diffusion comme pour les crontes des briques; à l'examen microscopique. j'ai pu reconnaître l'existence de globules rouges ovalaires de huit millièmes de millimètres de longueur, sur deux millièmes d'épaisseur, globules qui ne peuvent appartenir au sang de l'homme, mais à celui des oiseaux. Sur la partie postérieure de la blouse, on voyait des taches brunâtres, mates, qui n'ont présentè à l'examen microscopique aucun des caractères du sang.

Des difièrents faits que je viens d'exposer, je crois pouvoir conclure :

$1^{\circ}$ Les taches qui existent sur les briques sont des taches de sang, mais l'examen comparatif de ce sang, de sang humain et de sang de lapin desséchés, n'a pas fourni de résultats assez positifs pour qu'il soit permis d'affirmer qu'il s'agit de sang humain ou de sang de lapin.

Cependant je crois devoir signaler ici un fait qui peut être de quelque intérêt : en même temps que je détachais les croûtes des briques. j'ai pu recueillir quelques poils blanchâtres de douze à vingt millimètres de longueur; 
Ces poils examinés au microscope ont présenté une striation transversale à la pointe, une striation à la fois transversale et longitudinale vers la base; cette striation ne s'observe pas dans les poils de l'homme, mais nous l'avons retrouvée dans des poils de lapin pris pour terme de comparaison. Au milieu des poils que nous avons recueillis, s'en trouvait un blanc de vingt millimètres de longueur neviron, présentant les caractères des poils de l'homme;

$2^{\circ}$ Les différentes taches du tablier, que nous avons examinées, n'ont point présenté les caractères de taches de sang; elles renferment des cellules végétales; il semble donc admissible qu'elles sont de nature végétale;

$5^{\circ}$ Les taches de la partie antérieure de la blouse ont présenté les caractères du sang; mais ce n'étaient pas ceux du sang humain, mais bien ceux du sang des oiseaux. Cette tache pourrait remonter à trois mois.

Certifié le présent rapport sincère et véritable.

Paris, le 82 juin 1875.

R. Dugastel.

Poils du chat. - La peau du chat domestique est très employée dans le commerce des fourrures, mais elle est

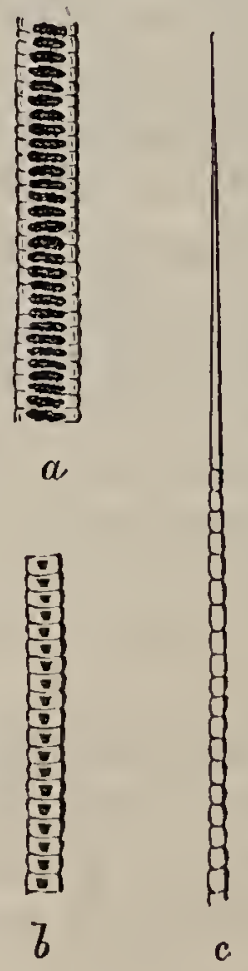

ligg. 3̈48. - Poils de chat. - $a$, de grosseur moyenne. $-b$, poil mince. $-c$, extrénité libre.

moins estimée que celle du chat angora, qui n'est qu'une variété du premier. Cette dernière dit M. Pennetier rem- 
CHAPITRE XXII. - EXAMEN DES CHEVEUX ET DES POILS. 877 place quelquefois la fourrure du renard-isatis ou bleu à laquelle elle est inférieure.

Les poils de chat, dit M. Robin, sont assez fréquents dans les poussières; ils sont assez rigides et ont des cavités médullaires analogues à celles des poils de lapin, mais plus petites et cessant d'exister loin de la pointe. Le bord des cellules de leur couche épithéliale forme à leur surface des lignes transversales bien dessinées.

Laine. - La laine est fournie par des animaux appartenant à l'ordre des ruminants : moutons, chèvres de Cachemire et d'Angora et les lamas (lama proprement dit, alpaca, vigogne).

Il y a un rapport constant entre la finesse de la peau et celle du brin de laine. Plus la peau est épaisse plus la laine est grosse.

Plus les poils de mouton sont longs et fins plus ils sont contournés sur eux-mêmes.

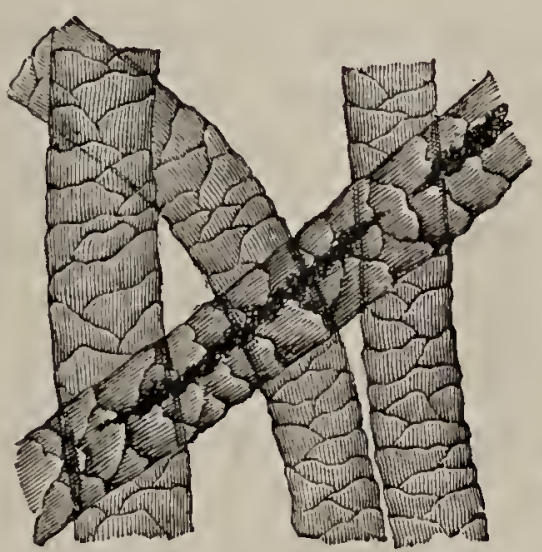

ligr. 349. - Laine vue au microscope.

Dans les poils de laine on distingue ceux de la jarre qui sont grossiers, plus gros du tiers à la moitié que ceux de la laine proprement dite. Ils sont pourvus d'un canal médullaire rempli de cellules encore reconnaissables on marquées par des granulations qu'elles renferment et qui réfractent fortement la lumière.

Nous donnons des mensurations effectuées sur des laines diverses. La laine proprement dite est toujours plus fine que la jarre; les brins sont plus transparents et dépourvus de canal central.

Une des laines les plus estimées est celle de Saxe; on 
compte jusqu'à soixante brins sur chaque millimètre de surface dans les toisons de laine électorale superfine, et cinquante-trois dans l'électorale fine; le diamètre des brins varie de $0^{\mathrm{mm}}, 01663$, à $0^{\mathrm{mm}}, 0778$ dans la première, et de $0^{\mathrm{mm}}, 01778$ à $0^{\mathrm{mm}}, 0208$ dans la seconde (Pennetier).
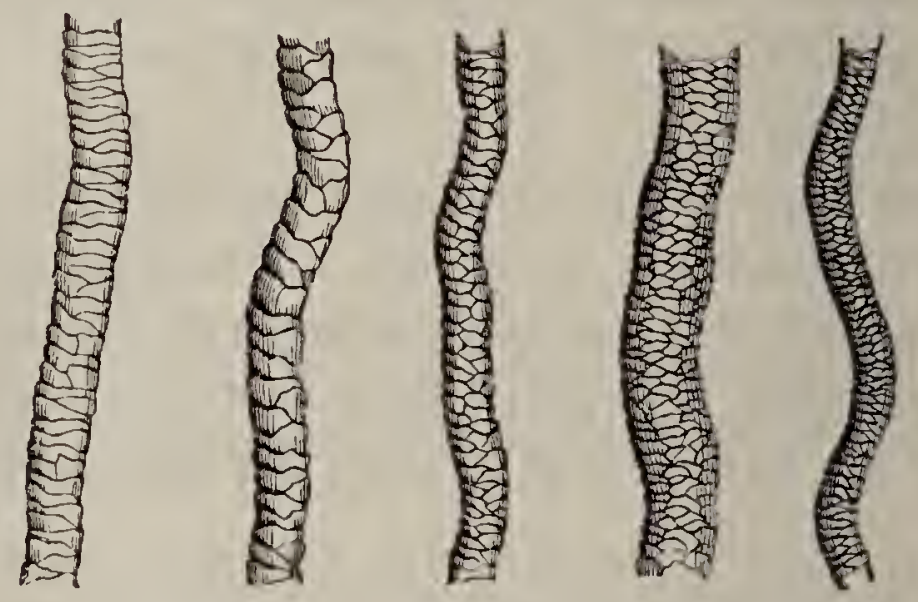

Fig. 5̋50. - Laine, formes des écailles.

M. Alcan a calculé la longueur et le diamètre de plusieurs échantillons de laines anglaises. Voici, d'après Pennetier, le résultat de ces mensurations: Yorkshire $1^{\text {re }}$ qualité, longueur 20 cent; diamètres variables de $0^{\mathrm{mm}}, 0264$ à $0^{\mathrm{mm}}, 04 \mathbf{4}$.

Yorkshire $2^{\mathrm{e}}$ qualité, longueur 20 cent.; diamètres variables de $0^{\mathrm{mm}}, 033$ à $0^{\mathrm{mm}}, 062 \check{\text {. }}$.

Leicestershire, longueur de 15 à 18 cent; diamètres variables de $0^{\mathrm{mm}}, 028$ à $0^{\mathrm{mm}}, 043$.

Les laines anglaises sont très recherchées.

Le diamètre des laines varie de ว̀ centièmes à 16 millièmes de millimètres, il varie non seulement avec les régions du corps d'où sortent les brins, mais aussi avec les races de moutons et les provenances de laines. Sous ce rapport les laines ont été divisées en cinq catégories, savoir :

Laines extra-fines.......... $0^{\mathrm{mm}}, 016$ à $0^{\mathrm{mm}}, 02$

Laines fines................ $0^{\mathrm{mm}}, 02$ à $0^{\mathrm{mm}}, 02$ ŏ

Laines intermédiaires........ $0^{\mathrm{mm}}, 020$ à $0^{\mathrm{mm}}, 033$

Laines communes.......... $0^{\mathrm{mm}}, 03$ à $0^{\mathrm{mm}}, 0 \unlhd$

Laines grosses............ $0^{\mathrm{mm}}, 0 \mathrm{~g}^{\circ}$ à $0^{\mathrm{mm}}, 10$

"Le nombre et la forme des ondulations dépendent elles- 
mêmes du diamètre. Ce nombre varie de 33 et quelquefois plus, à 8 seulement par pouce, selon le plus ou moins de finesse des laines et les ondulations les plus régulières, les plus petites et les plus rerticales se rencontrent ordinairement aussi dans les laines les plus régulièrement fines. ")

" Ce rapport constant entre le diamètre des brins et leurs proprietés physiques est de la plus haute importance et permet d'apprécier la valeur réelle des laines. La souplesse, la ténacité et l'élasticité des brins correspondent à leur diamètre; l'étoffe produite présente ordinairement des qualités d'autant plus précieuses que leur finesse est plus considérable. Un poids donné de laine donne d'ailleurs un fil d'autant plus long que les brins sont plus fins, la force du fil restant la même..."

"Un kilogramme de laine fournit souvent de 27 à 30000 mètres de fil, mais cette longueur peut être infiniment dépassée lorsque la toison est superfine. On a obtenu des résultats bien autrement remarquables avec une livre anglaise (4.53 grammes) de laine d'un mouton élevé par l'illustre naturaliste J. Banks, qui a tant perfectionné l'art agricole en Angleterre : une femme en a tiré 153399 mètres de fil, résultat qui tient du prodige; plus de 38 lieues, c'est-à-dire presque la distance de Paris à la mer (Pennetier, loc. cit). ")

Lorsqu'on examine la laine à un grossissement de $400 \mathrm{D}$. environ, elle apparaît formée de tubes dont la surface est hélissée d'écailles irrégulières. On rend ces dernières très apparentes par l'addition d'une goutte d'ammoniure de cuivre qui détermine également un faible gonflement des grains. La laine présente des stries nombreuses, extrêmement fines et parallèles à l'axe et, d'autres transversales cannelées plus ou moins visibles et rappelant assez celles des poils d'animaux carnivores. Les brins apparaissent souvent comme formés de pelits cônes ou cornets emboîtés les uns dans les autres, et dont les bords seraient irrégulièrement découpés; mais cette apparence est uniquement due à la disposition des lamelles de la surface des poils. Le bord des brins est denticulé en scie, ce qui donne aux laines la propriété de s'enchevêtrer par le foulage. Enfin, on aperçoit au centre, mais seulement sur les 
laines raides et grosses, un canal médullaire contenant de place en place un liquide coloré.

La coupe arrondie ou elliptique des brins présente soit une surface pleine limitée par une paroi plus ou moins fine (laines fines) soit un canal médullaire circulaire et de diamètre variable (laines grosses).

Les écailles superficielles dont la forme varie avec les diverses sortes de laines, ne se remarquent plus sur la pointe fine qui termine les brins de la première tonte.

Lorsqu'on soumet à l'examen microscopique, un brin de laine de suint, on le trouve recouvert de dépôts irréguliers que le lavage fait complètement disparaître. Le lavage et le filage n'altèrent nullement la structure de la laine; mais comme il est facile de le comprendre, les saillies des stries transversales disparaissent presque complètement dans la laine usée (Pennetier, loc. cit).

La laine la plus belle de France est celle de Raz. Le diamètre des laines extra-fines varie de $0^{\mathrm{mm}}, 016$ à $0^{\mathrm{mm}}, 02$, et celui des laines fines, de $0^{\mathrm{mm}}, 02$ à $0^{\mathrm{mm}}, 025$ (Pennetier).

Les laines de Bourgogne ont une longueur qui varie de 7 à 9 centimètres, et leur diamètre varie de $0^{\mathrm{mm}}, 0132$ à $0^{\mathrm{mm}}, 0352$ (Alcan).

Les laines de Champagne leur sont inférieures. Leur longueur est de 8 à 10 centimètres et leur diamètre qui, le plus souvent, est de $0^{\mathrm{mm}}, 0235$, varie de $0^{\mathrm{mm}}, 02$ à $0^{\mathrm{mm}} 026$ (Alcan).

La laine soyeuse de Mauchamp, connue sous le nom de cachemire indigène est admirable par la longueur ( 6 à 8 centim.) la souplesse, la finesse $\left(0^{\mathrm{mm}}, 015 \%\right.$ à $0^{\mathrm{mm}}, 0308$; souvent $\left.0^{\mathrm{mm}}, 022\right)$ (Alcan).

La solution de sucre additionnée d'acide sulfurique colore la laine en rose, jamais elle n'est colorée en bleu par la solution iodée additionnée d'acide sulfurique.

Laine de Vigogne. - Cette laine est extrêmement peu frisée; elle est fort douce et très remarquable par la finesse et la régularité de ses grains. Les stries et les écailles superficielles sont très difficiles à apercevoir et le diamètre des brins varie de $0^{\mathrm{mm}} 007$ à $0^{\mathrm{mm}} 01$. Les poils jarreux sont rares et présentent, comme dans l'alpaga, un canal central (Pennetier). 
GHAPITRE XXII. - EXAMEN DES CHEVEUX ET DES POILS. 881

C'est un poil doux, duveteux, couleur de cannelle et ressemblant assez dans sa structure à celui du mouton. Il est généralement mêlé d'un certain nombre de poils trois fois plus gros, qui paraissent noirs sous le microscope.

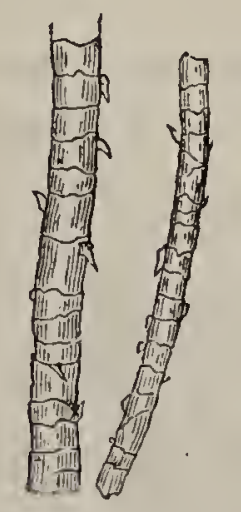

Fig. 551. - Laine de vigogne.

La vigogne du commerce est un mélange de laine et de coton. (Hager.).

Laine de chèvre. - Les brins de laine de chèvre diffèrent de ceux du mouton par leurs cellules épithéliales qui sont moins saillantes, et par les stries de leur substance propre qui, par contre, sont plus apparentes. (Pennetier.)

Laine d'alpaca. - La laine d'alpaca ou paco des Péruviens, est soyeuse, douce et résistante. Les cellules superficielles

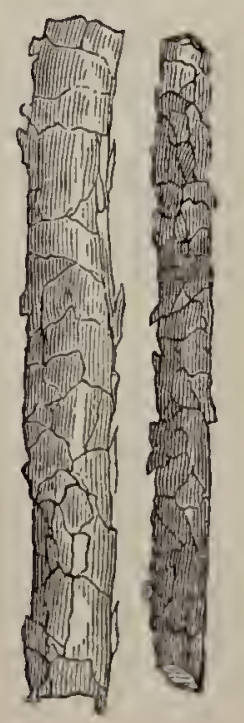

Fig. 5ร2. - Laine d'alpaca.

des poils d'alpaca sont le plus souvent complètement invisibles, leurs stries longitudinales sont toujours plus prononGUIDE DE MiCrograpHIE. 
cées et parfois les stries transversales sont également apparentes et présentent l'imbrication épithéliale des poils de chèvre. Leur diamètre, qui est assez irrégulier, varie de $0^{\mathrm{mm}}, 02$ à $0^{\mathrm{mm}}, 03$ et les poils jarreux seuls sont creusés d'un canal central.

La fourrure de la marte-zibeline est très estimée en raison de sa finesse. Les zibelines le l'Ieniséi sont surtout recherchées. Elles tendent à devenir très rares, à cause de la chasse

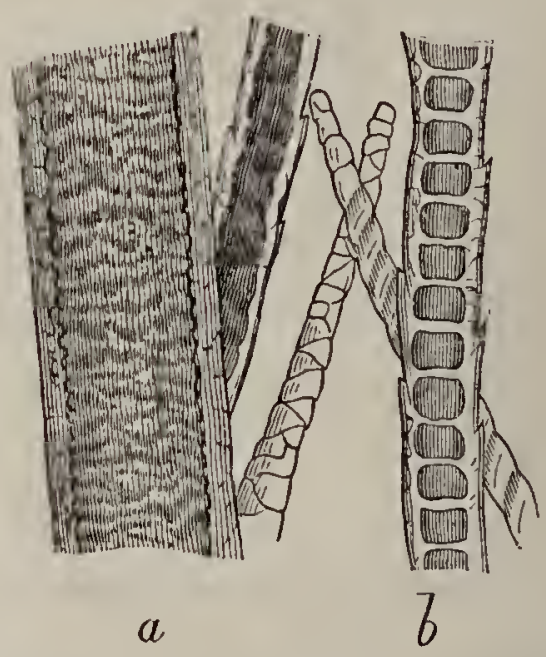

Fig. 553. - Zibeline. - $a$. Poil gros. $-b$. Poil fin et duvet.

active qui leur est faite. Comme la zibeline, la loutre est

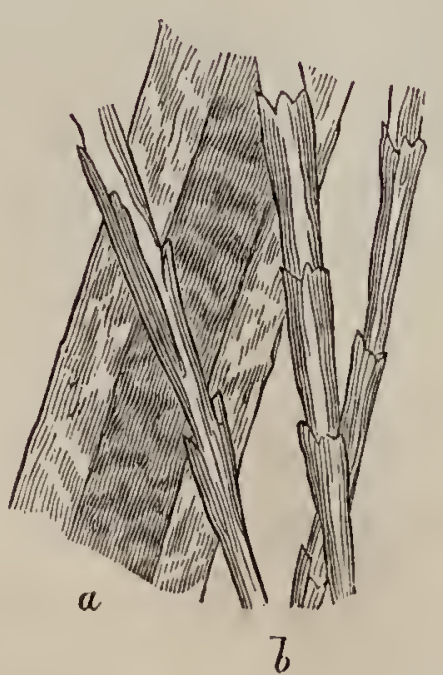

Fig. 554 - Loutre de Virginic. - a. Gros poil. - b. Duvet.

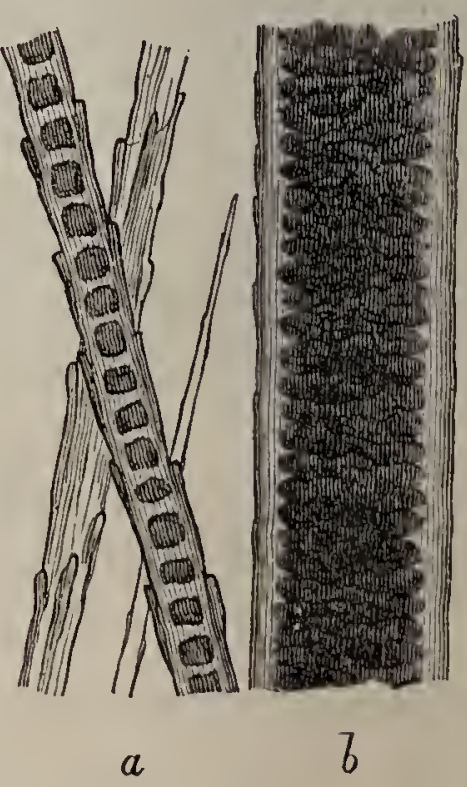

Fig. 555. - Petite loutre. $a$. Duvet. - $b$. Gros poil.

l'objet d'un très grand commerce et atteint des prix élevés. G'est la noire qui est la plus recherchée. La loutre commune 
CHAPITRE XXII. - EXAMEN DES GHEVEUX ET DES POILS. 883 ou d'Europe est moins prisée que celle de l'Amérique du Nord, du Canada et de la Virginie. La loutre de mer, qui habite les rivages de l'Amérique septentrionale et du Kamtchatka est la plus rare et la plus estimée. (Pennetier.)

Hamster. - C'est un rongeur de la grosseur d'un rat, que

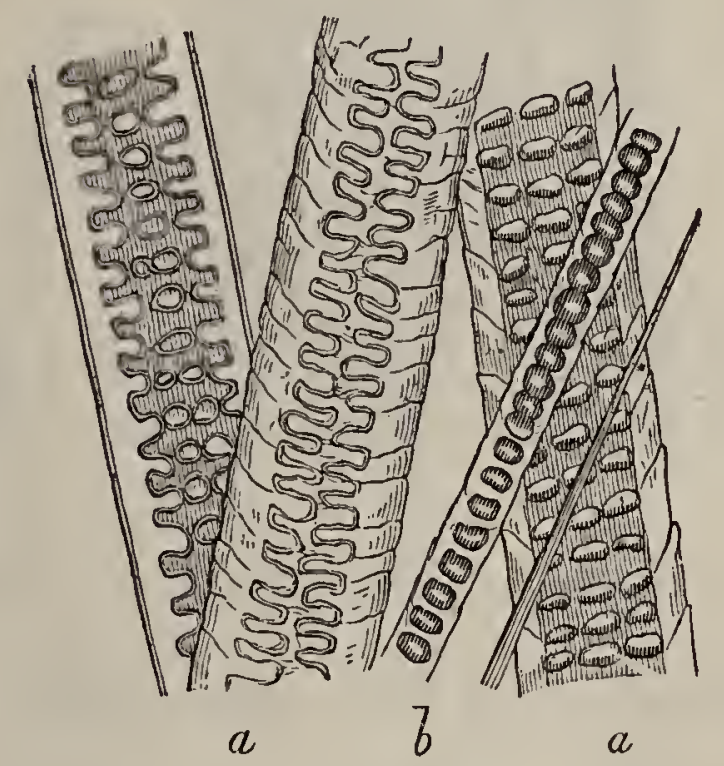

Fig. 556. - Hamster. - aa. Gros poils. - b. Duret.

l'on trouve en Alsace, en Saxe et même en Sibérie. Son pelage est composé d'un duvet long et court et de poils soyeux assez longs, noirs à l'extrémité. Leur couleur varie du brun roux au noir.

Castor. - La fourrure du castor est l'objet d'un grand

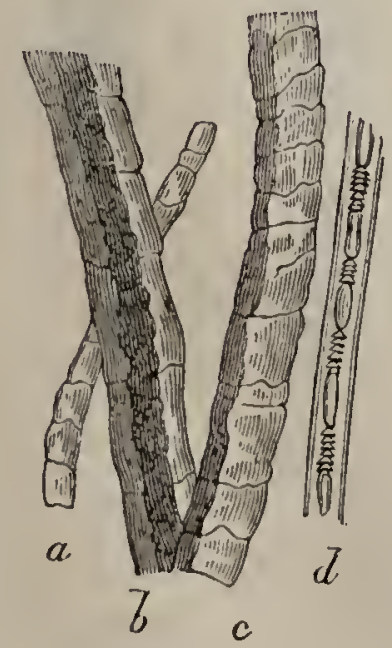

Fig. 357. - Poils de Castor. - a. Pointe. - $b, c$. Poils supérieurs. - $a, d$. l'oils de duvet.

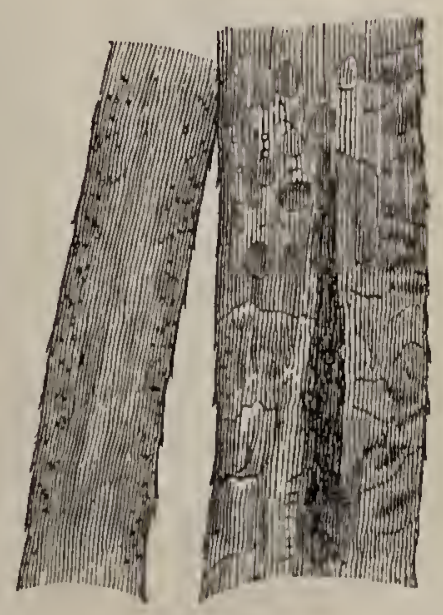

Fig. 5j8. - Castor. - Poils supéricurs. 
commerce; la majorité des peaux vient de l'Amérique septentrionale.

Renard. - Il peut être important de connaître l'aspect des

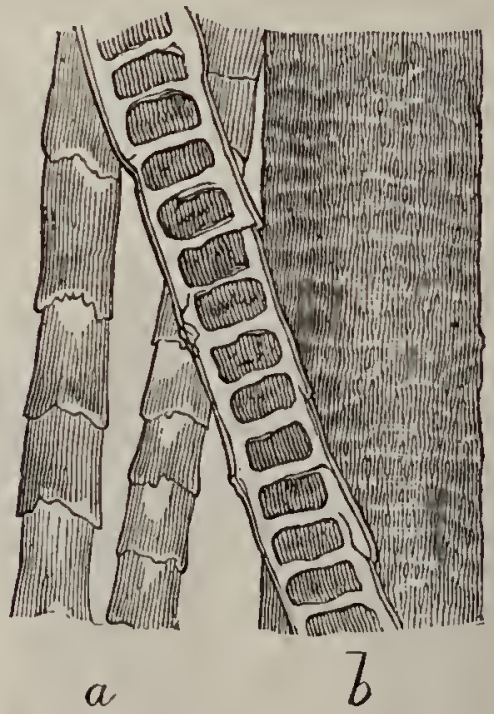

Fig. 559. - Renard. - $a$. Poils de duvet. $-b$. Poil fin.

poils du renard commun. On peut en retrouver des poils sur

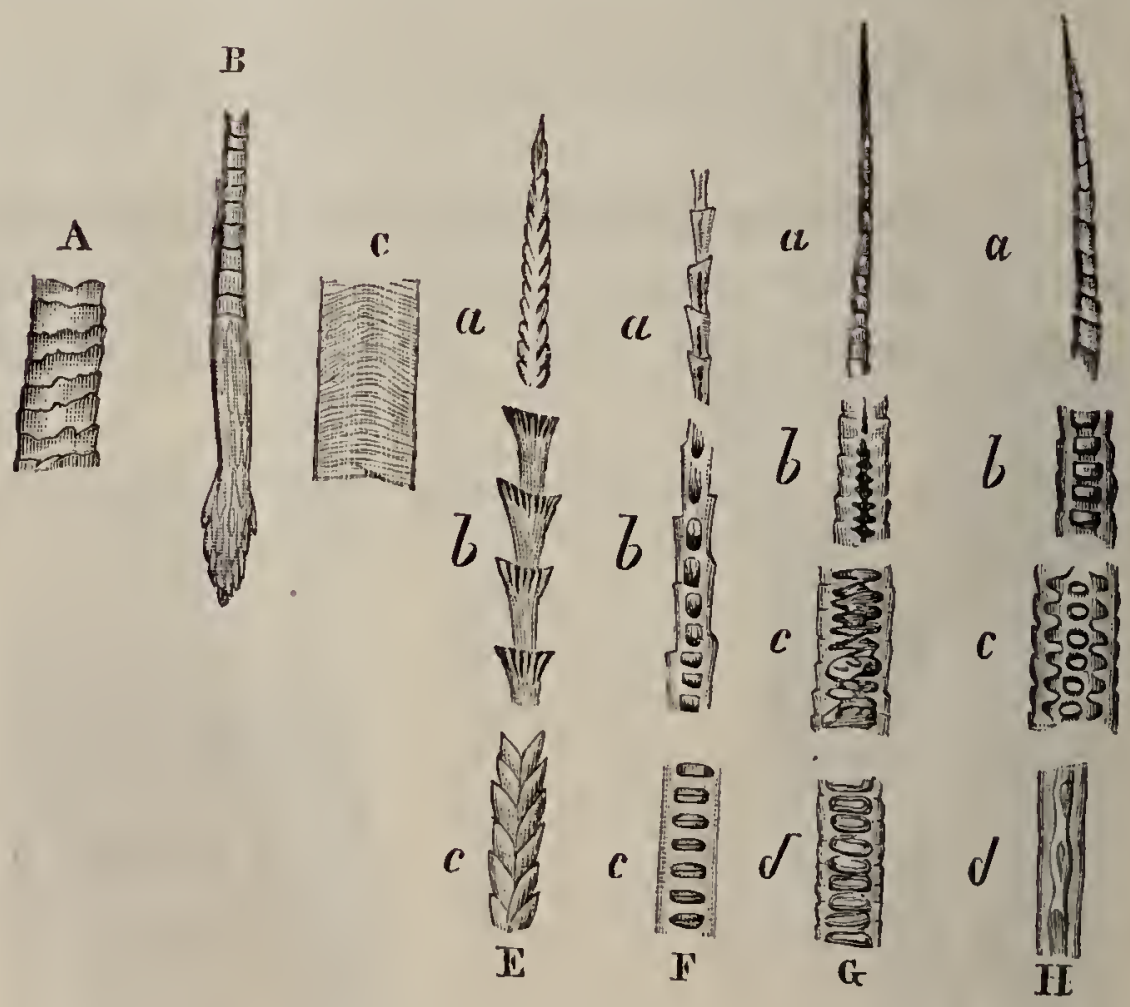

Fig. 560. - Poils de différentes espèces animales. - A. Clieveu blond, $\frac{81}{1},-$ B. Poil follet $\frac{100}{1}$. C. Barbe (homme) $\frac{50}{1}$. - E. Poil de chauve-souris. - a. Extrémité terminale. - $b$. Milieu. $-c$. Base. - F. Poil de musaraigne. - $a$. Extrémité terminale. $-b$. Milieu. - $c$. Base. - G. Poil de souris - $a$. Extrémité terminale. - $b$. Úne seule rangée de cellules. $-c$. Plusieurs rangées de cellules, milieu. - $d$. Base. - II. Poil de cobaye. - $a$. lixtrémité terminale, une rangée de cellules. - $b$. Milieu. $-c$. Plusicurs rangées de cellules. $-d$. Base. 
CHAPITRE XXII. - EXAMEN DES CHEVEUX ET DES POILS. 885 les vêtements d'un chasseur et avoir à en déterminer la nature.
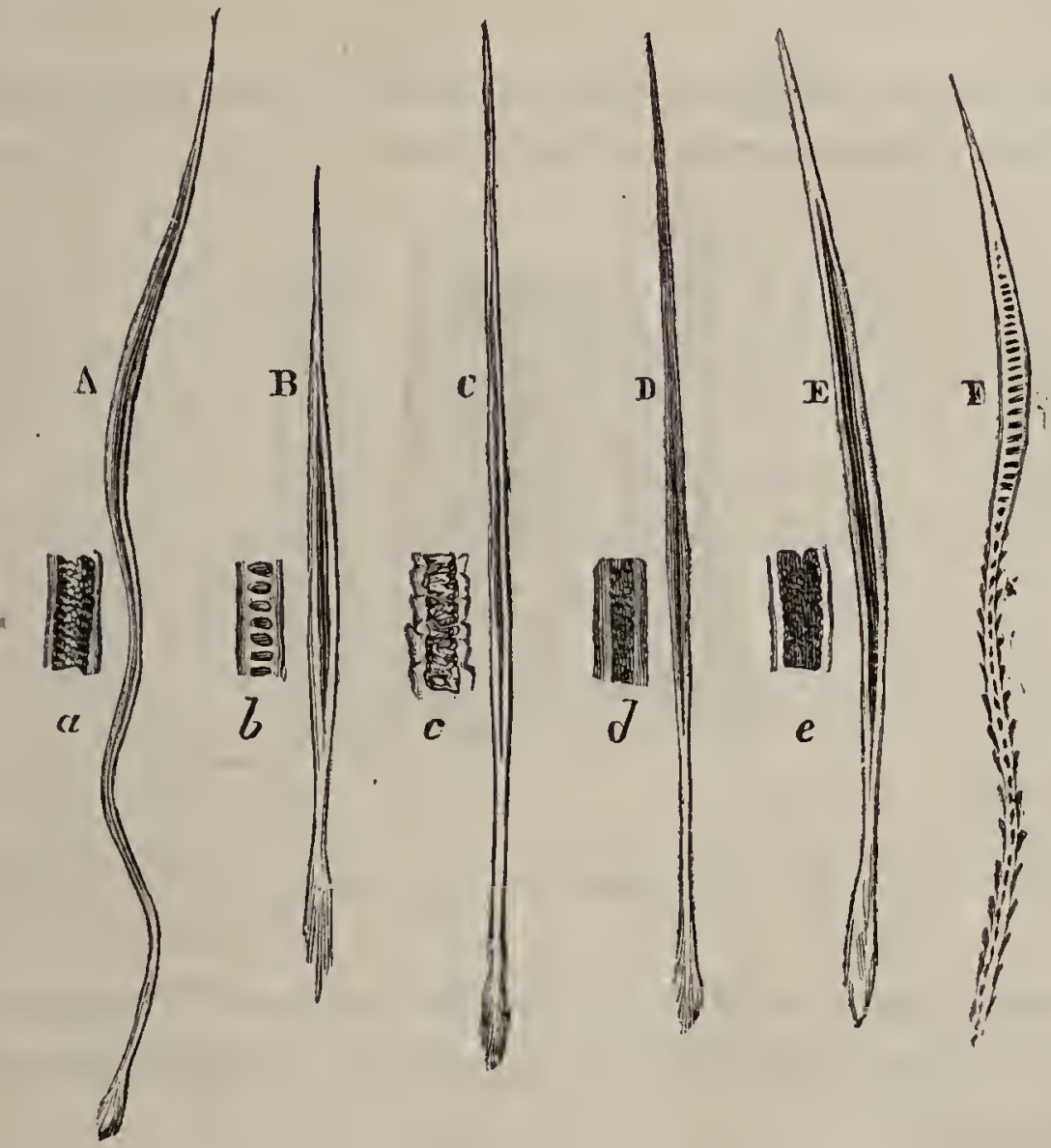

Fig. 561 . - Poils de différents animaux domestiques. - A. Lapin argenté $\frac{6}{1} ; a, \frac{60}{1} .-$

B. Souris $\frac{20}{1} ; b, \frac{70}{1}$. C. Veau $\frac{4}{1} ; c, \frac{50}{1} .-1$. Cheval $; d, \frac{50}{1} .-$ E. Chèvre blanche poil fin $\frac{2}{1}$ (Poils grossiers sont des crins); $e, \frac{30}{1} \cdot-\mathrm{F}$. Taupe $\frac{100}{1}$.

Chien domestique. - La structure des poils est la même
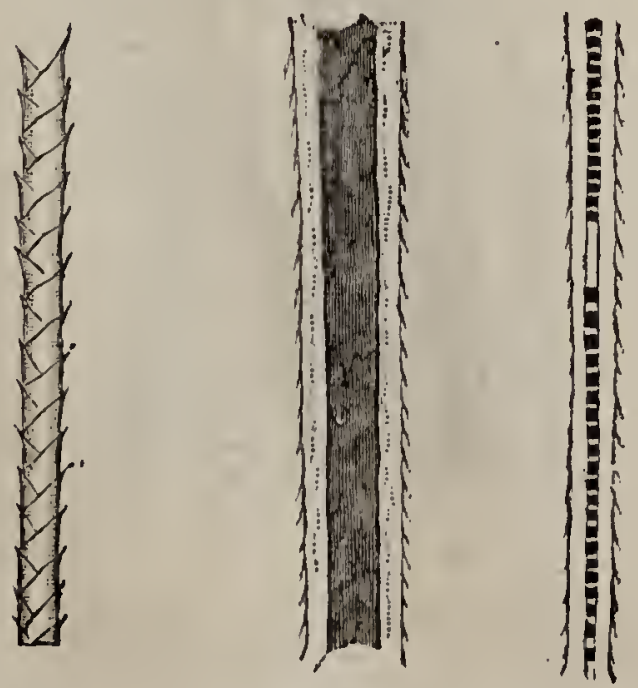

C

D

A

Fig. 362. - Chien domestique. - A. Poil lin. - B. Poil moyen. - C. Duvet. 
chez les chiens à longs poils que chez ceux à poils courts.

Les gros poils noirs et les moyens ne laissent pas passer la umière.

Quand l'air a été chassé de la moelle, on voit par transparence les cellules du cordon médulaire.

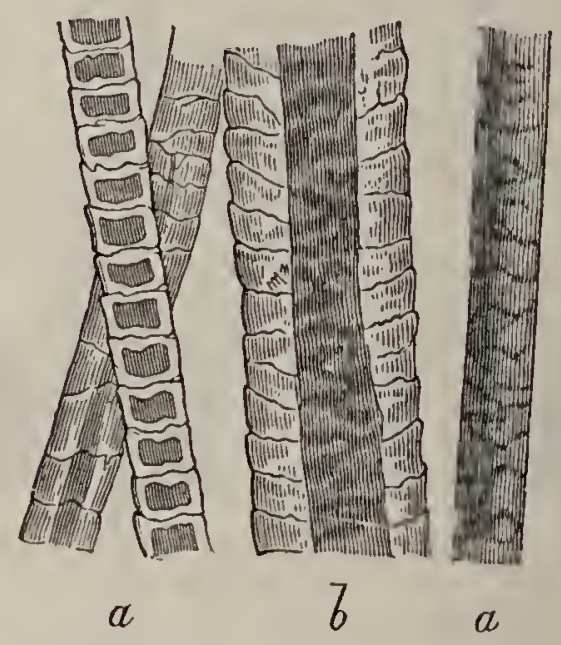

Fig. 563. - Chien de prairie. - a, a. Duvet. - b. Gros poil.

Les poils blancs sont les plus favorables à l'examen microscopique; les gros poils noirs n'ont pas de caractères différenciels très précis.

Conservation des pelleteries (Pennetier, loc. cit.). - Les fourrures et les pelleteries sont attaquées par un certain nombre d'insectes dont les larves peuvent causer des ravages considéra.

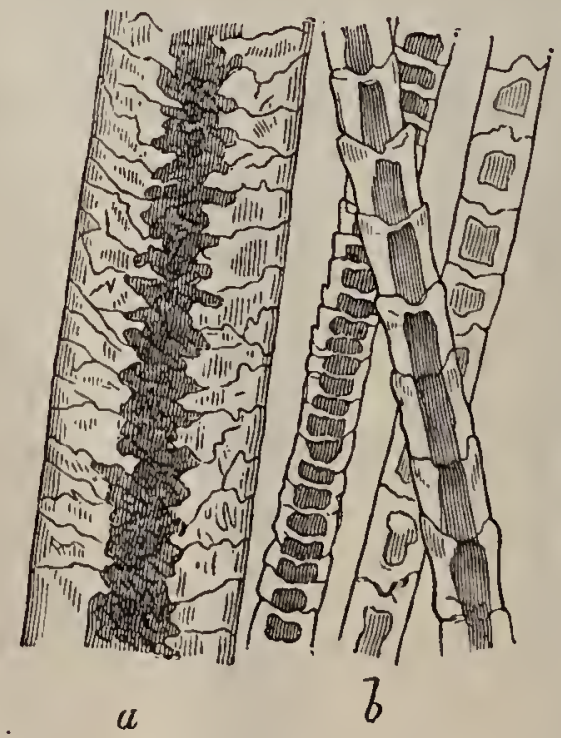

Fig. 564. - Rat musqué. - a. Crros poil. - b. Duvet.

bles. Nous ne ferons que les signaler ici, renvoyant au travail de M. Pennetier pour plus de détails. Le plus redoutable est 
le Dermeste renard. La plupart de ces larves ont des mâchoires très puissantes et sont très voraces.

Parmiles vers nous signalerons les dermestes, les anthrènes, les attagènes, les teignes des pelleteries. Ces larves; en se métamorphosant, donnent naissance à des insectes parfaits qui, s'ils sont inoffensifs par eux-mêmes, pondent des œufs en nombre considérable, qu'il est important de détruire.

A côté de ces insectes parasites, nous signalerons également des Acariens que l'on rencontre à divers états de développement. M. Pennetier signale le Cheyletus eruditus, le Glyciphagus spinipes, le Tyroglyphus longior. (Voir le chapitre des Parasites.)

Les cheveux postiches ou les cheveux coupés, sont fréquemment détériorés par un insecte dont nous n'avons pu nous procurer un exemplaire, bien qu'il soit relativement commun. L'examen d'un fourreau adhérent aux cheveux, fait par M. Mégnin, a permis de voir qu'il contenait encore la carapace d'une nymphe d'où l'insecte parfait était sorti. Avec ces seuls éléments, il n'a pas été possible à M. Mégnin de faire un diagnostic précis, et ce savant. hésite entre le Tínea sarcitella (de Linné) et le Tinea crinella (Tr.), penchant plutôt pour le second insecte.

Conservation des poils. - Les poils et les cheveux sont d'une conservation très facile. On les nettoie avec de l'éther ou de l'alcool rectifié et on les monte dans le baume de Canada, après avoir pris la précaution de les bien sécher. On peut encore employer l'eau glycérinée de préférence à l'eau sucrée en consistance sirupeuse (1).

soie. - La soie est un produit de sécrétion des chenilles de plusieurs Lépidoptères de la famille des Bombyciens.

Elle est sécrétée par un appareil glandulaire, analogue aux glandes salivaires. La matière qui constitue cette sécrétion, d'abord molle et gluante, est étirée en fil double, puis devenant unique et se durcissant à l'air. C'est ainsi qu'est formé le cocon qui doit abriter les métamorphoses de l'insecte.

On trouvera les renseignements les plus complets sur les

(1) On trouvera sur les fourrures et sur les pelleteries des renseignements très intéressants dans le livre de M. Pennetier - chez G. Masson. 
variétés commerciales de la soie, dans l'ouvrage de M. Pennetier, ainsi que dans le Dictionnaire de Chevallier et Baudrimont; dans ce dernier ouvrage est reproduit un tableau dû à MM. Wiesner et Prash, dans lequel sónt donnés les différents diamètres de cinq espèces de soie, mesurés comparativement au diamètre de la soie produite par le Bombyx mori.

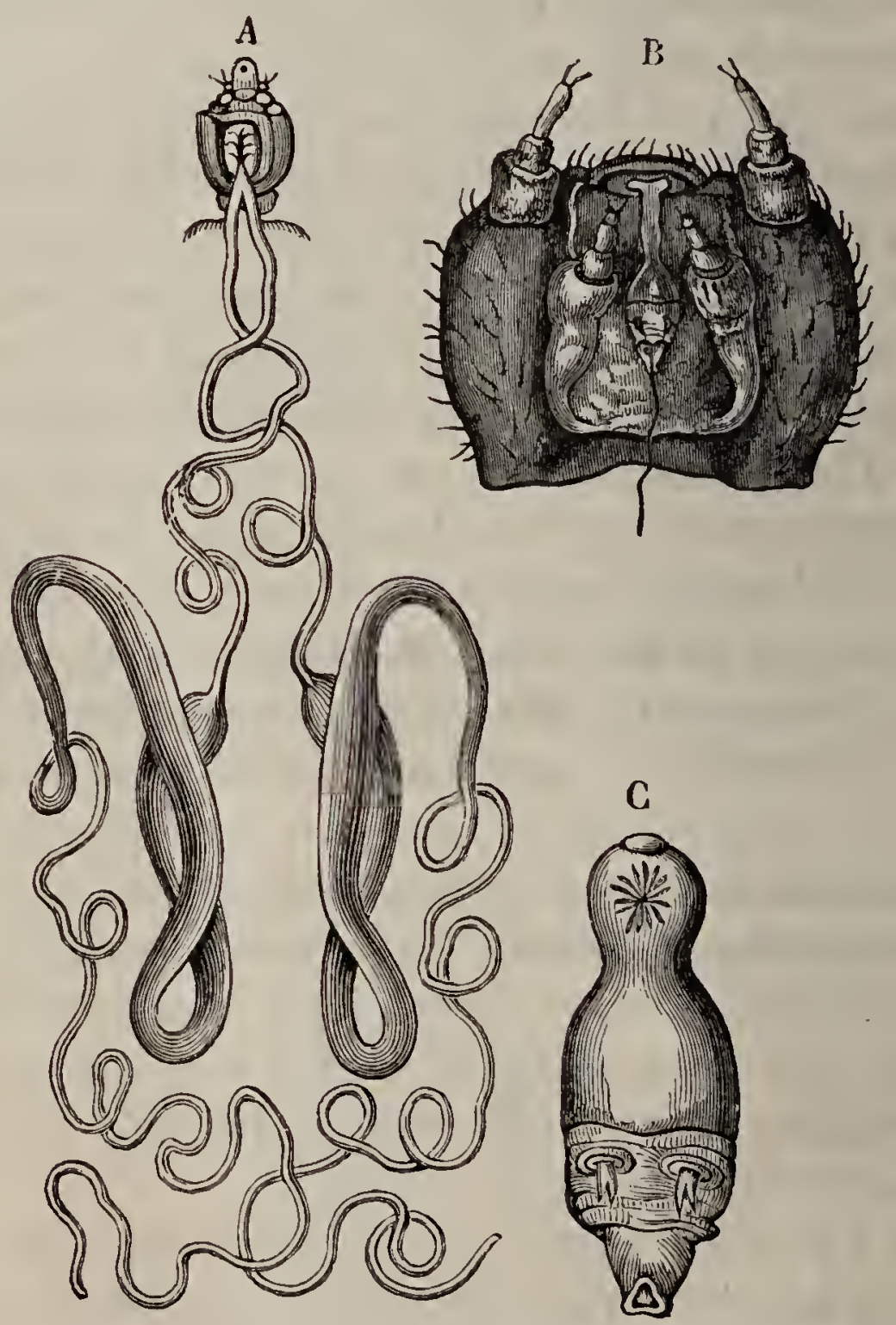

Fig. 565. - Appareil sécréteur de la soic. - A. Glandes séricipares. - B. Tète du ver à soie vue en dessous, montrant la filière et le fil qui en sort. - C. Filière vue séparément.

La soie, dit M. Wiesner, se compose de fils plus ou moins aplatis, et striés parallèlement à leur grand axe; cette striation proviendrait de ce que la masse englobée dans la substance gélatineuse est traversée par de nombreux petits canaux qui, étant remplis d'air ou d'une substance peu réfringente, paraissent opaques lorsqu'ils sont observés au micro- 
ChapiTRE XXII. - EXAMEN DES CheVEUX ET DES POILS. 889 scope (Chevallier et Baudrimont). On ne peut découvrir dans la cassure des filaments de soie aucune fibrille élémentaire.

Traitée par l'acide azotique, l'ensemble des filaments jaunit un peu, chacun se gonfle au point d'acquérir un diamètre de

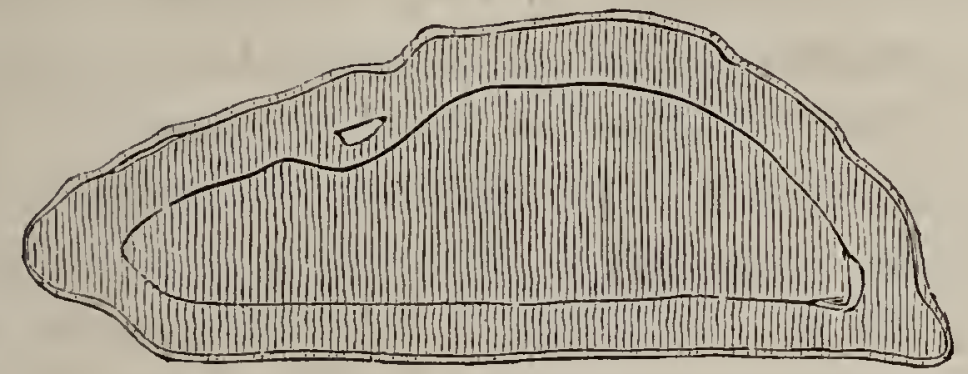

Fig. 566. - Coupe transversale du réservoir séricifique. (Grossissement 60 diamètres.)

$0^{\mathrm{mm}}, 0$ ò et plus. Cette expérience peut être faite dans la lumière polarisée. On voit alors chaque filament s'assombrir au fur et à mesure qu'il se ramollit en se gonflant et finir par disparaître. D'après Robin et Coulier, l'emploi de la lumière polarisée n'a pas granảe valeur au point de vue de la distinc-

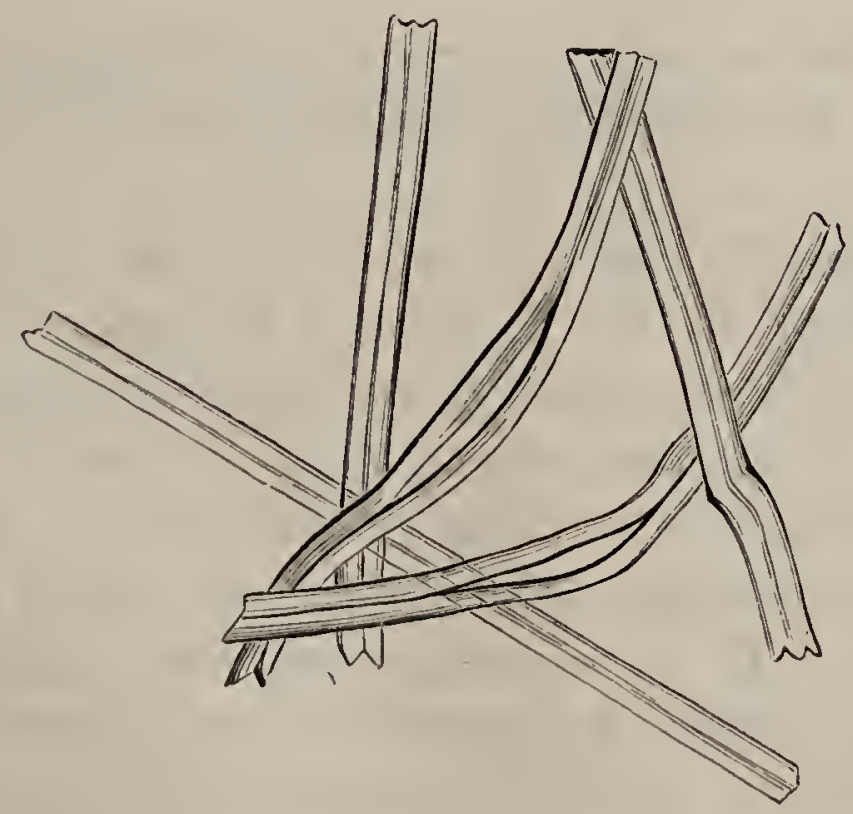

Fig. 567. - Soie de cocon vue au microscope.

tion des fibres textiles; cependant l'examen à la lumière polarisée pourrait au moins servir à différencier les variétés commerciales les unes des autres. (Chevallier et Baudrimont, p. 1022.)

D'après Hager, la soie se compose de fils doubles, brillants 
compacts, cylindriques, sans structure intérieure, ne possédant pas de cavité, à réflexion égale. La coupe d'un fil de cocon présente des contours anguleux. La soie teinte paraît en certains endroits comme aplatie ou inégale. L'absence de cavité intérieure distingue la soie de toutes les autres fibres textiles. Le mélange de sucre et d'acide sulfurique colore la soie en rose, plus vite que la laine et la dissocie rapidement. La couche extérieure, en se gonflant, montre un contour sinueux et denté. Tant que la solution n'est pas complète, on y remarque un fil longitudinal extérieur encore solide, qu'il ne faut pas confondre avec une cavité et qui est de la substance encore intacte. La soie nommée Yama-nıay montre une rayure longitudinale très prononcée et une coupe poreuse.

Soie marine. - On appelle encore la soie marine, poil de nacre. Elle est constituée par le byssus, faisceau de filaments soyeux, à l'aide duquel certains mollusques bivalves, tels que les jambonneaux, adhèrent aux corps sous-marins. (Pennetier, p. 387.)

Cette matière est sécrétée par des glandes cutanées situées à la base du prolongement contractile de l'abdomen nommé pied et est filée pa! une rainure de celui-ci.

Voici, d'après Pennetier, les caractères microscopiques et microchimiques de ce produit. L'examen du byssus d'un Pinna vexillum (Born) montre des filaments jaunes aplatis, à bords droits, à cassure nette, à surface lisse ou très finement striée longitudinalement, à diamètre variable et fort irrégulier. Ce dernier mesure de $0^{\mathrm{mm}}, 013$ à $0^{\mathrm{mm}}, 050$ et présente dans un même brin de très grandes variations, passant successivement par exemple, de $0,03 \breve{a ̀ ~} 0,048,0,0$ วั4, puis redescendant à $0,048,0,042$ pour remonter à 0,044 et 0,031 .

L'ammoniure de cuivre rend très apparentes les stries de la surface des brins qui sont très fines et fort nombreuses. Son action prolongée détermine des sinuosités sur les bords et une foule d'éraillures à la surface; il suffit même d'une légère pression pour isoler complètement les stries en des points multiples ( $f g$. 568).

L'acide sulfurique gonfle les brins el dissocie également, 
ChaPITRE XXII. - EXAMEN DES GIEVEUX ET DES POILS. 891 quoique moins fortement, les fibrilles élémentaires, de manière à produire à la surface des filaments de nombreuses boutonnières longitudinales, transversales et obliques.

Les acides acétique et chlorhydrique, l'ammoniaque et la soude, gonflent aussi les brins, qui, sous l'action suffisamment prolongée du réactif, acquièrent un diamètre allant jusqu'à $0^{\mathrm{mm}}, 075$.
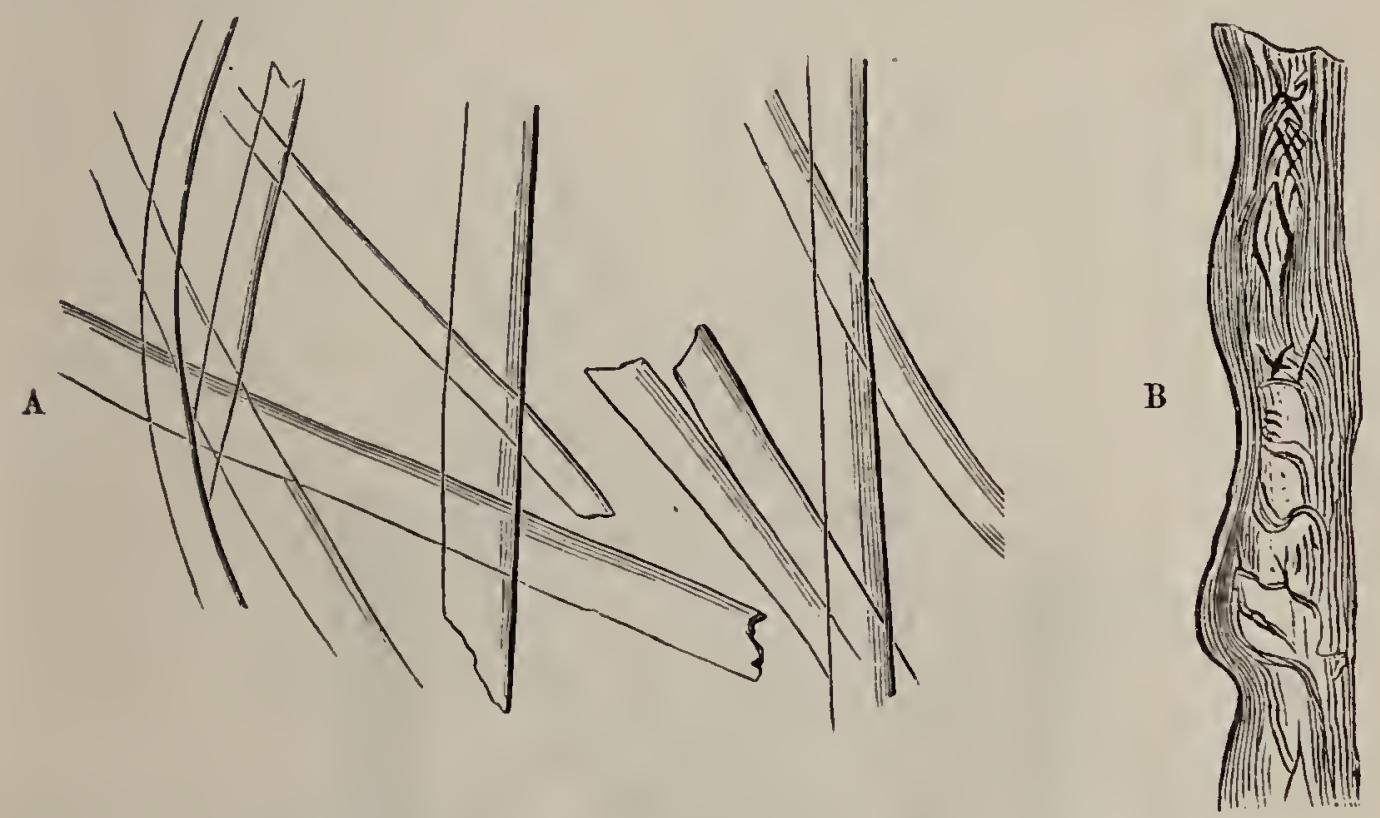

Fig. 568. - A. Soie marine. - B. La même soumise vingt-quatre heures à l'action de l'ammoniure de cuivre.

Les anciens faisaient usage de la soie marine; aujourd'hui encore il existe à Palerme des fabriques d'objets de bonneterie faits avec le byssus des jambonneaux de la Méditerranée, les Pinna nobilis et rudis principalement.

Pour plus de détails, on consultra avec fruit l'ouvrage si complet de M. Pennetier, auquel nous renvoyons le lecteur.

structure des plumes et du duvet. - Pour tout ce qui concerne l'industrie des plumes et des pelleteries d'oiseaux, on devra se reporter à l'ouvrage de M. Pennetier, où l'on trouvera des renseignements d'un grand intérêt.

Comme nous l'avons dit à propos des poussières, on truuve fréquemment des brins de plumes sur les objets exposés à l'air; il faut donc être en état de les reconnaitre. Chaque barbule de plume, dit M. Robin, est formée d'une côte, du bord inférieur de laquelle se détache une mince bordure membraneuse $(b g)$ très pâle. La côte porte de petites 
pointes vers sa terminaison $(f)$. Les barbules du côté opposé $(k)$, ou, si l'on veut, celles qui les croisent en venant de la barbe voisine $(i)$, ont cette bordure inférieure bien plus étroite et divisée bientôt en crochets qui griffent et retiennent chacun la côte de la barbule que croise celle qui les porte $(c d)$, d'où l'adhérence des barbules les unes aux autres. Près du bout de la barbule ces crochets se réduisent à une

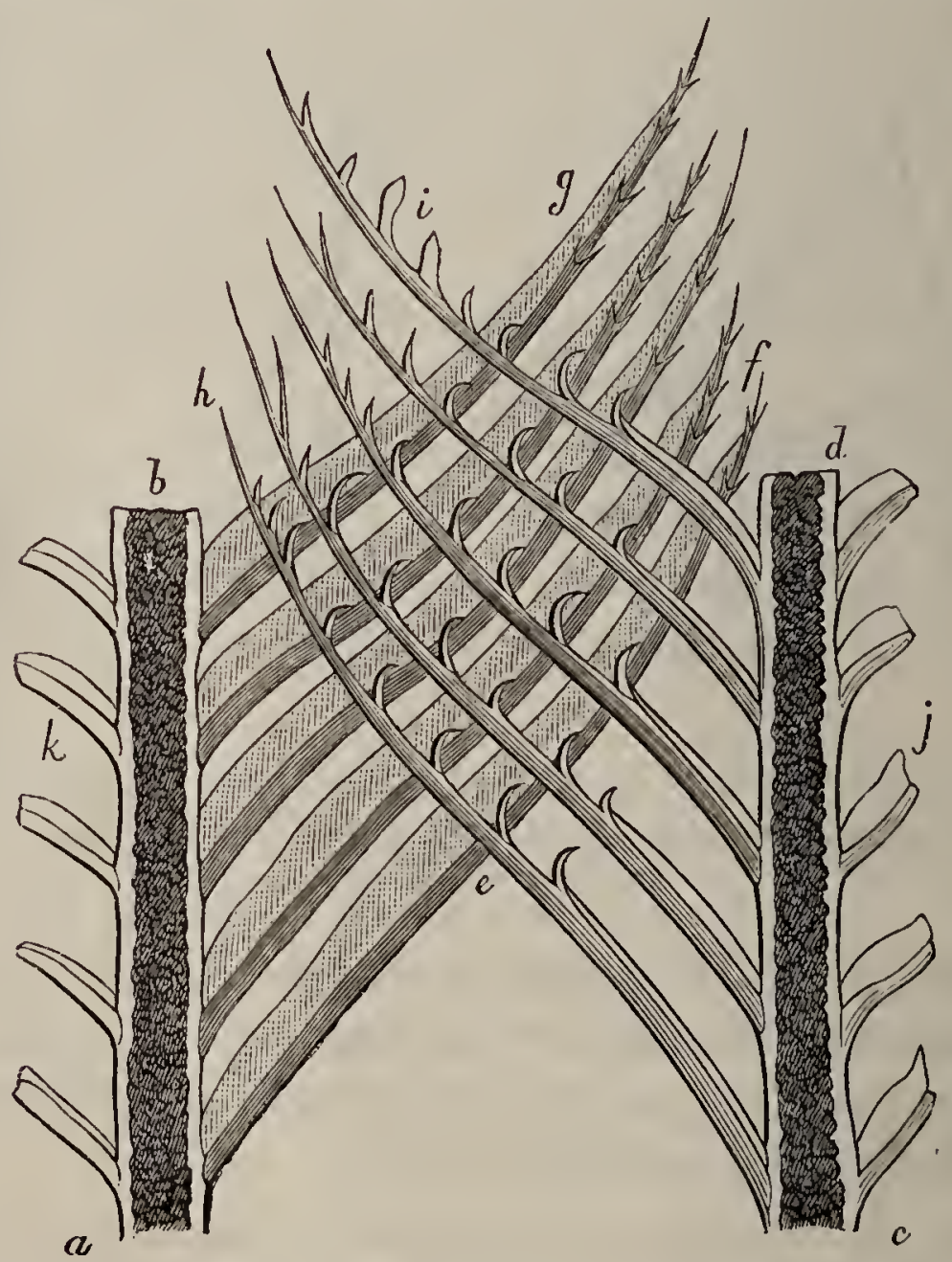

Fig. 569. - Plume tectrice d'une poule faisane, grossie 400 fois. $-a b$ et $c d$ sont les barbes de la plume portant de chaque côté une rangée de barbules, $g, j, k, e$. (D'après Ch. Robin.)

pointe presque droite, mousse ou aiguë $(h)$, ou à un étroit prolongement foliacé (i) plus ou moins long. Ces dernières dispositions se retrouvent sur toutes les plumes molles, à barbules non adhérentes les unes aux autres. Ce sont les barbules détachées, plus que les barbes, que l'on voit dans les poussières.

Dans les plumes de duvet (fig. 570) les barbules $(d, i)$ sont réduites à la côte formée de cellules allongées, soudées 
CIIAPITRE XXII. - EXAMEN DES GHEVEUX ET DES POILS. 893 bout à bout, renflées en nœud portant ou non deux petites pointes à son extrémité externe. Ces barbules sont très minces, aplaties et par suite paraissent étroites et foncées, ou rubannées et pâles, selon qu'on les voit de face $(t)$ ou de côté $(d, i)$; sur le bout des plumes molles les barbules sans crochets (b) sont aussi formées dé cellules articulées bout à

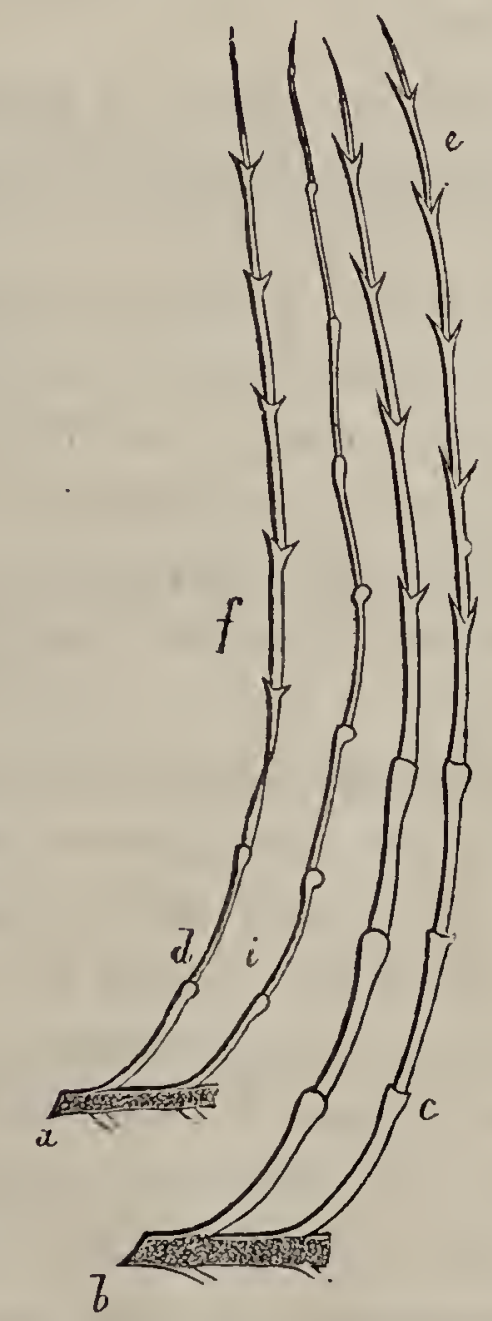

Fig. 570. - Plumes de duvet grossies 405 fois. - $a$. Barbe d'une plume de duvet placée sous les tectrices alaires du corbeau; $\ell$. Barbe d'une plume molle, à barbules sans crochet ni bordure membraneuse, non adhérentes les unes aux autres. (D'après Ch. Robin.)

bout, dont l'extrémité externe est renflée et prolongée ou non en pointe plus ou moins longue $(e)$.

On trouve souvent dans la préparation d'objets divers sur lesquels est tombée de la poussière, soit des fragments de barbe avec leurs barbules, soit des débris de ces dernières seulement. Tantôt ce sont de celles dont il vient d'être parlé $(c, d)$, d'autres fois ce sont des barbules à crochets $(e, h$, figr. 509) ou simplement à bordure membraneuse $(g)$. 


\section{APPENDICE.}

Sur les substances que l'on peut trouver dans le sillon qui sépare l'extrémité libre de l'ongle de la pulpe du doigt.

Nous n'avons pas à nous occuper ici des déformations et des colorations professionnelles de l'ongle. Cette étude a été faite au point de vue de l'identité, par le $\mathrm{P}^{\mathrm{r}}$ Tardieu et plus récemment par M. Vernois.

On comprend combien est grand le nombre des substances qui peuvent être rencontrées dans le pli sous-unguéal; le charbonnier, le boulanger, le cuisinier, le boucher, le coiffeur, portent sous leur ongle des substances qui peuvent servir à faire nettement reconnaître leur profession, dans le cas où la main, ou même un seul doigt, viendraient à être détachés; les particules charbonneuses, la farine, les substances grasses, les débris de substances alimentaires, les poils d'animaux ou des fragments de cheveux, pourront facilement être reconnus. Suivant les objets qui ont été en contact avec la main, on trouvera, dans le repli sous-unguéal, les poussières les plus variées, et les objets microscopiques les plus inattendus.

Nous avons voulu seulement signaler l'importance de cette étude, et nous ne voulons pas, quant à présent au moins, insister davantage. Il nous sulfira de donner quelques exemples empruntés aux auteurs. Chez les vidangeurs et chez les palefreniers, on trouvera des débris de matières organiques animales, et, chez ces dernier's, des poils de cheval; chez les marchands de marrons rôtis, on trouvera une poussière noire et des débris de l'enveloppe du marron imparfaitement carbonisés. On rencontrera au-dessous des ongles des ouvrières qui diamantent des fleurs avec le verre, une poussière fine et brillante. M. Tardieu a donné un procédé pour déterminer chimiquement la présence de la poudre sur les doigts et sous les ongles des combattants.

Chez les ouvriers qui travaillent les métaux, le fer ou le cuivre, on rencontre sous les ongles des particules métalliques que l'on traitera par les réactifs appropriés.

FIN. 


\title{
TABLE DES MATIÈRES
}

\author{
PREMIÈRE PARTIE
}

\section{MICROGRAPHIE BOTANIQUE}

\section{CHAPITRE PREMIER}

Wes microscopes et de leur emploi, 1 . - Microscopes simples : loupes, 2; doublets, 5. - Microscopes composés, 6. - Objectif. - Oculaire, 7. - Partie mécanique du micioscope, 8. - Pouvoir amplifiant des microscopes, 15. - Objectifs à immersion, 16. - Micronètres, 17. - Mesure du pouvoir amplifiant des microscopes, 17. - Mesure des ubjets microscopiques 19. - Grossissement, 19. - Choix du microscope, 20. - Pouvoir définissant. P. Amplifiant. P. résolvant, 20. - Test-objets, 21. - Qualités de la partie mécanique d'un bon microscope, 23. - Soins à donner au microscope, 24. - Maniement du microscope, 25. - Éclairage : par la lumière transmise, 26: par la lumière réfléchie, 27. - Mise au point, 27.Chambre claire, 31. - Reproduction des images par la chambre claire, 31. - Accessoires nécessaires pour les études microscopiques, 34. Rasoirs, 34. - Microtomes, 35. - Pinces, ciseaux, aiguilles, 36. - Couvre-objets. - Porte-objets, 37. - Préparation des objets microscopiques, 38. - Exécution des coupes minces, 38. - Coupes dans la paraffine, dans la gomme, 41. - Dilacération, 42. - Réactifs, 42. - Réactifs colorants. 42. - Réactifs durcissants, 43. - Réactifs altérants, 43. - Vélicules, 44, - Conservation des préparations, 46. - Transport sur le porte-objet, 46. Préparation de l'objet dans le liquide conservateur, 46. - Élimination de l'air de préparations, 47. - Vernis ou ciments, 48. - Poussières, bulles d'air, mouclies volantes, 49. 


\section{HISTOLOGIE VÉGÉTALE}

\section{CHAPITRE Il}

Éléments anatomiques, 51. - La Cellule, 52. - Étude de la nature chimique du protoplasma et du noyau, 53. - Réactifs, 54 _ Étude de la nature chimique de la membrane cellulaire, 57. - Réactifs, 57.- GÉNÉration des cellules, 60. - $1^{\circ}$ Par formation libre (genèse), 61. - Sujets d'étude, 61. - Mode d'examen, 62. - Exemple : genèse des premières cellüles dè l'endosperme du Phaseolus multiflorus, 63. - $2^{\circ}$ par division, 65. - A. Division binaire, 65. - Sujets d'étude, 65. - Mode d'examen, 67. Plaque nucléolaire, plaque cellulaire, 69. - Ròle du noyau dans la division, 70. - B. Division multicellulaire, 71. - $3^{\circ}$ Par rajeunissement, 73. - Étude de la cellule vivante, 74. - Protoplasma, 75. - Propriétés pliysiques, 75. - Utricule protoplasmatique, 75. - Contractilité, 77. Mouvements du protoplasma : circulation, rotation, 78. - Mouvements vibratiles et de locomotion, 80. - Mouvement brownien, 80. - Produits d'élaboration du protoplasma, 81. - $1^{\circ}$ Paroi des cellules, 81. - Forme des cellules, 82. - Cellules arrondies, ovoïdes, 83. - Cellules polyédriques, 84. - Cellules étoilées, 85. - Cellules rameuses, 86. - Cellules allongées, 87. - Fibres, 87. - Matières textiles végétales, 89. - Examen des fibres textiles, 90. - Réactifs, 91. - Caractères des fibres textiles proveuant de plantes dicotylédonées, 94. - Lin, 94. - Clianvre, 95. - Sunn, 96. - Coton, 96. - Jute, 97. - Caractères des fibres textiles provenant de plantes monocotylédonées, 98. - Alfa, Sparte, Phormium tenax, Chanvre Pite, 98. - Accroissement en épaisseur de la paroi cellulaire, 100. Stries, 100. - Marques sur les parois des cellules, 103. - Cellules ponctuées, 104. - Cellules aréolées ponctuées, 105. - Cellules rayées et réticulées, 106. - Cellules annelées et spiralées, 107. - Trachées déroulables, 108. - Lignification de la paroi cellulaire, 109. - Cuticularisation, gélification, 110. - Mucilages, 110. - Gommes, 111. - Gomme adragante, 111. - Gomme arabique, 112. - Gomme des Rosacées, 112. Dépóts de substances minérales dans ía paroi cellulaire, 113. - Dépôt de silice, 113. - Dépôt d'oxalate de cliaux, 114. - Dépôt de carbonate de chaux, (cystolithes), 115. - Contenu des cellules, 118. - Suc cellulaire, 118 . Inuline, 119. - Amidon, 120. Développement et accroissement des griins d'amidon, 121. - Caractères des diverses sortes d'amidon, 122. - 11don des céréales, 122. - Fécule de Pomme de terre, 123. - Fécules des Légumineuses, 123. - Fécules d'Alrow-root, 124. - Fécules de Sagou, 124. - Fécules de Manihot, 125. - Réactifs de l'amidon, 125. - Aleurone, 127. - Couleurs des plantes, 129. - Nature et localisation des pigments colorés, 129. - Composition chimique de la chlorophylle, 130. - Genèse et développement des corps chlorophylliens, 131.

\section{GHAPITRE III}

Organes élémentaires dérivés des cellules, 133. - Vaisseaux proprement dits, 133. - Parois des vaisseaus, 134. - Sujets d'étude, 135. - 
Vaisseaux utriculeux, 136. - Des mollocotylédonées, 137. - Des Eupholbiacées, 137. - Des Convolvulacées, 137. - Vaisseaux laticifères, 138. Caractères généraux, 138. - Laticifères des Papavélacées, 139. - Laticifères des Chicoracées, Campanulacées, etc., 141. - Laticifères des Apocynées, Asclépiadées, Sapotées, Urticées, Papayacées, 142. - Tubes cribreux, 143.

\section{CHAPITRE IV}

Tissus, 145. - Union des cellules en tissu, $145:-1^{\circ}$ dans le cas de formation de cellules par division, $145 ;-2^{\circ}$ par genèse, 146. - Dédoublement des cloisons primitives, 148. - Cavités iNtercelullaires, 149. Canaux aérifères, 149. - Lacunes aérifères, 152. - Canaux nésineux ou SÉcréteurs, 153. - Leur mode de formation, 154. - Canaux résineux des Ombellifères, 156. - Des Araliacées, Composées, Conifères, 159. - Fonves ET SYSTÈMES DE TISSus, 161. - Système tégumentaire, 162. - Epiderme; mode d'examen, 163. - Formes des cellules épidermiques, 164. - Modo de groupement des cellules épidermiques, 165. - Cuticule, 166. - Action de l'acide sulfurique sur la cuticule, 167. - Action de la potasse, 168. Dépôts cil'eux à la surface de l'épiderme, 169. - Croûtes cireuses, bâtonnets, 170. - Granulations cireuses, 171. - Sromates, 172. - Forme des stomates, 172. - Localisation des stomates, 173. - Chambre sous-stomatique, 175. - Développement des stomates, 175. - Cellules accessoires, 178. - Papilles, poils, 179. - Leurs formes, 180. - Organes de sécréTION DES VÉGÉTAUX, 182. - $1^{\circ}$ Glandes sans réservoir spécial, $183 .-$ A. Extérieures : poils glandulifères, 183 ; - à glandes unicellulaires, 184; à glandes pluricellulaires, 185; - Glandes des Labiées, 187; - Lupulin, 188; - Cullétères, 189. - B. Intérieures : unicellulaires, 189; - glandes des Laurinées, 189. - Glandes des Monimiacées et des Valérianées, 190. - $2^{\circ}$ Poils glanduleux à la base, 190 . - Urticées, Malpighiacées, 191 ; tentacules glandulifères, $192 ;-3^{\circ}$ Glandes à réservoir iacunaire, 193 . A. Extérieures : glandes du Dictamnus albus, 193.-B. Intérieures: Glandes des Aurantiacées, 194; - des Hypéricinées, Rutacées, 196; - 'Térébintlacées, Myrtacées, 197 ; - $4^{\circ}$ Glandes florales, glandes septales, 198. Hypoderme, 199. - Epiblema, 199. - Coilenchyme, 200. - Liège, périderme, 201. - Développement du périderme, 202. - Rhytidome, ienticelles, 204. - Farsceaux, 206. - Structure des faisceaux développés, 206. - Forme et répartition des Éléments constituties des faisceaux, 207. Tléments du liber des faisceaux, 207. - Écorces de Quinquina, 209. iléments du bois des faisceaux, 210. - Vaisseaux, 210. - Fibres ligneuses, 211. - Bois des Conifères, 212. - Cellules ligneuses, 213. Rapports de position entre les diférentes parties des falsceaux, 213. Faisceaux collatélaux, 214. - Faisceaux concentriques, 215. - Faisceaux des Fougèles, 216. - Faisceaux radiaires, 217. - Faisceaux incomplets, 218. - Faisceaux rudimentaires, 219. - Développement des faisceaux, 221. - Faisceaux ouverts, faisceaux fermés, 221. - Tissu Fondanental, 222. - Éléments du tissu fondamental, 223. - Cellules pierreuses, 224 . Écorces de Cannelles et d'Angusture, 225. 


\section{CHAPITRE V}

Siructure des tiges, 227. - DicotrlédonéEs a TIGE Normale, 228. Tige lic bacée, 229. - Tige ligneuse, 229. - Rayons médullaires, moelle, 230. - Accroissement en longueur des tiges des Dicolylédonées, 231. Point végétatif, 231. - Dermatogène, périblème, plérome, 231. - Accroissement transversal, 23\%. - Liber secondaire, bois secondaire, 232. - Aubier, duramen, 234. - Dicotylédo vées a thge avormale, 235. Faisceaux surnuméraires, faisceaux foliaires, 235. - Tige des MovocotyléDoNées, 238. - Tiges dépourvues d'anneau d'épaississement, 238. - Tige des Palmiers, 238. - Chaume des Graminées, 240. - Tiges pourvues d'un anncau d'épaississement, 241. - Tige des ACotylédonées Vasculdares. 242. - Tige des Fougères, 242. - Répartition des faisceaux, 243. Tige des Lycopodiacées, 245. - Tige des Équisétacées, 245. - Lacunes, 246. Accroissement terminal des tiges des Cryptogames vasculaires, $24 \pi$.

\section{CHAPITRE VI}

1

Structure de la meine, 248. - Racines des Phanéroganes et des Cirptoganes, 248. - Période primaire, 249. - Zone protectrice ou endoderme, 249. - Zone rhizogène, 251. - Période secundaire dans le développement des racines de Dicotylédonées, 252. - Racines d'Ipécacuanha, 254. - Racines des Salsepareilles, 254. - Racines aérieunes des Monocotylédonées, 255. - Velamen; membrane épidermoïdale, 255. - Accroissement én longueur des racines, 257. - Pilorhize. 257.

\section{CHAPITRE VII}

Feuilles, 259. - Structure du pétiole, 260. - Du limbe, 260. - Nervures, 260. - Parenchyme, 262. - Feuilles des Monocotylédonées, 263 ; - des Orchidées, 264; - des plantes submergées, 264. - Bourgeons, 265. Préfoliation, 266.

\section{GHAPITRE VIII}

Organes de reproduction, 267. - Cryptogames cellulaires, 267. Algues, 267. - Leur appareil végétatif, 267. - Leur reproduction, anthéridie, oogone, 26i. - Couleur des Algues, 269. - Munvements des Algues, 269. - Reproduction asexuée, 270. - Spores immobiles, 270. Zoospores, 271. - Reproduction par conjugation, 272. - Des Desmidiées et des Diatomées, 273. - Auxospore. 274. - Copulation de zoospores 275. - Fécondution, Vaucheria sessilis, Fucacées, 275. - Reproduction clez les Floridées, 276. - Sphærococcus crispus, 276. - Coralliua off., 277. - Algues parasites, 27\%. - Leptothrix buccalis, 277. - Leptomitus de l'utérus, 278. - Psorospermies, pébrine, 279. - Corpuscules de Cornalia, 279. - Cirampignons, 280. - Appareil végétatif, 281. - Appareirs de heproduction, 281. - Reproduction sexuée, 281. - Conjugation cliez 
les Mucorinées, 282. - Fécondation chez les Saprolégniées, etc., 282. Reproduction asexuée, thèques ou asques, 282. - Basides, stérigmates, 282. - Exemples de Cill. Thécasporés, 282. - Trufle, 183. - Discomycètes (Morille, Pézizes, etc.), 283. - Exemple de Basidiosporées, 284. Agaric comestible, 284. - Modifications des spores, conidies, stylospores et pycnides, 28!. - Spermaties et spermogonies, 286. - Chlamydospores, 2808. - Polymorphisme chez les Champignons, 286. - $1^{\circ}$ Champignons monoxènes, Claviceps purpurea, $2 S 6$; - Champignons hétéroxènes, OEcidium Berberidis et Puccinia graminis, 288. - Champignons parasites, 289. - $1^{\circ}$ Entophytes, Cystopus candidus, Peronospora infestans, 289. Ustilaginées, 290. - 20 Epiphytes, Oïdium Tuckeri, 290. - Ch. parasites des animaux, 290. - Teigne faveuse (Achorion Schœnlenii), 290. - Puccinia favi, 292. - Teigne tonsurante (Tricophyton tonsurans), 292. - Teigne pelade (Microsporon Audouini), 292. - Microsporon mentagrophytes, :9?. Pityriasis versiculor (Microsporon furfur), 293. - Muguet (Oidium albicans), 293. - Sarcine, 294. - Muscardine (Botrytis Bassiana), 294. Moisissures, 295. - Eurotium Aspergillus glaucus, 295. - Penicillium glaucum, 295. - Mucors, 296. - Aspergillus auricularis, 296. - Hygrocrocis arsenicus, 297. - Feruents, 297, - Saccharomyces et fermentation alcoolique, 297. - Bactériens, 298. - Formes: Torula, Leptothrix, Zooglá, Mycoderma, 299. - Fermentation acétique, 299. - Mycoderma vini, 299. - Fermentation lactique, putréfaction, 300. - Fermentation butyrique, 300. - Pustule maligne, sang de rate, etc., 300. - Bacillus Amylobacter, 300. - Fermentation ammoniacale. 300. - Micrococcus Ureæ, 301. - Bactéries pathogènes (vaccin, diphthérie, etc.), 301. Pus bleu (Bacterium ruginosum), 301. - Fermentation gallique, 301. - Mrxonycìtes, 301. - Lichens, 302. - Appareil végétutif, 302. Appareils reproducteurs; apothécies, 302. - Sorédies, 303. - Cetraria Islandica, 303. - Roccella tinctoria, 303. - CHaracÉEs; appareil végétatif, 303. - Organes reproducteurs, anthéridie, 304. - Sporocarpe, 305. II Uscinées et Cryptoganes vasculaires, 306. - Appareil végétatif, 306. Apjarcils de reproduction, 307. - Anthéridies, anthérozoïdes, 307. Archégones, 310. - Génération asexuée, sporogone, sporanges, spores, 312. - Sporogone des Muscinées, capsule, 312. - Sporanges et spores des Cryptogames vasculaires, 314. - Sores, indusie, sporanges ct spores des Fougères, 315. - Spores et élatères des Équisétacées, 316. - Fruits sporifères des Rhizocarpées, 316. - Macrospores et microspores, 317. Lycopodiacées, 317. - Phanéroganes, étude de la fleur, 318. - Diagrammes, 319. - Structure du périanthe, 319. - Structure des étamines, 320. - Filet, 320. - Anthères, 320. - Cellules fibrenses, 321. - Placentoïdes, 322. - Pollen, 322. - Intine, extine, fovilla, 323. - Pores, 323. - Plis, 323. - Grains de pollen simples et composés, 324. - Tétrades, 324 . - Pollen des Orclidées, 324 - Pollinies, caudicule, rétinacle, 325. - Pollen des Asclépiadées, 325.- Pollen des Légumineuses, 325. - Pollen des Conifères, 325. - Développement des grains de pollen, 326. - Forme des grains de pollen, 328. - Mode d'examen, 328. - Pistil ; style et stigmate, 329. - Oraire, 330. - Ovules, 330. - Ovules orthotrope, campylotrope, anatrope, 331. - Développement de l'ovaire, péricarpe, 332. - Fruit des Ombellifères, 332. - Déceloppement de l'ovule, 332. - Sac embryonnaire, 333. - Appareil filigère, 333. - Vésicules embryonnaires, 333. - Vésicules antipodes, 333. - Développement de l'embryon, 334. Suspenseur, 334. - Hypopliyse, 335. - Embryon des Coniferes, 335. - 
Graine, enveloppes, albumen, 336. - Albumen nucellaire, 337. - Cotylédons incombants et accombants, 338 .

\section{DEUXIÈME PARTIE}

\section{HISTOLOGIE ANIMALE}

\section{CHAPITRE IX}

Du sang au point de vue microscopique, 339. - Sang normal, 340. - Globules blancs, 344. - Action exercée par différents réactifs sur les glubules rouges et sur les globules blancs, 345. - Numération des globules du sang, p. 347. - Procédé de Malassez, 352. - Procédé de Hayem et Nachet, 358. - Globulins, microcystes ou petits globules, 365 . - Vésicules élémentaires de Donné et de Zimmermann, 366. - Sang à l'état pathologique, 373. - De la mélanémie, altération des globules blancs, 376. - Infusoires contenus dans le sang, 378. - Hématozoaires de l'lomme, 382. - Des globules du sang dans différentes espèces animales, 384. - Du sang extravasé, 387 .

\section{CHAPITRE $\mathrm{X}$}

Du pus. - Globules blancs, 397. - Granulations graisseuses, 398. - Hématies, 400. - Vibrions, Leptothrix, Algues (Pus bleu), 401. - Des cristaux contenus dans le pus, 402. - Concrétions cristalloides du pus, 403. Colorations anormales du pus, 403. - Muco-pus, 404.

\section{CHAPITRE XI}

Des sédiments de l'urine, 405. - Sédiments formés par des éléments anatomiques organisés, cellules épithéliales, tubuli, 406 et suivantes. - Du pus dans l'urine, 411. - Du sang dans l'urine, 412. - De la fibrine dans l'urine, 413. - Des spermatozoides dans l'urine, 413. - Végétations fongoides dans l'urine sucrée, 415. - Infusoires et Bactéries dans l'urine, 418. - De la kyestéine, 419. - De la matière grasse dans l'urine, 420. - Mucus de l'urine, énéorème, 422. - Des poussières et des corps étrangers que l'on peut rencontrer dans l'urine, 425. - Des parasites que l'on peut rencontrer dans l'urine,429.-Des sédiments de l'urine formés par des éléments non organisés et affectant la forme cristalline; urée, 433. - Acide urique, urates, 435. Urate acide d'ammoniaque, 4i3. - Urate acide de soude, 444. - Urate de magnésie,445. - Recherclie de l'acide urique dans le sang, 447. - Acide hippurique, 448. - Chlorure de sodium, 450. - Des pliosphates, 452. Phosplıate de soude, 454. - Plıosplıate ammoniaco-magnésien, 454.- Phos- 
pliate de chaux, 456. - Pliospliate de magnésie, 459. - Carbonate de chaux, 459. - De l'oxalate de chaux, 460. - Inosite, 464. - Créatine et créatinine, 465. - Cholestérine, 467. - Cystine, 470. - Xanthine, 470. - Taurine, 474. - Leucine, 475. - Tyrosine, 476. - Glucose, 477. - Matière colorante bleue de l'urine, 478. - Des calculs urinaires, 481.

- Calcul d'oxalate de chaux cristallisé, 481. - Calculs biliaires, 483.

\section{- CHAPITRE XII}

I u laît au point de vue microscopique, 484. - Du colostrum, 486. - Du lait, 494. - Des altérations du lait, 501. - Du lait en delıors de la gestation et de l'allaitement, 505. - Du liquide des tubercules de Montgomery, 509. - Du lait chez les animaux, 509. - Des colorations accidentelles du lait, 509. - Examen microscopique de la caséine, 511. Corps étrangers du lait, 512. - Du Vibrion lactique, 513. - Sucre de lait, 514. - Du beurre et de ses falsifications, 515. - Adultération des fromages, 520. - Taches formées par du fromage blanc, 521 .

\section{CHAPITRE XIII}

Du sperme, 522. - Action de différents réactifs sur les spermatozoïdes, 534. - Du sperme chez différentes espèces animales, 539. - Du sperme dans la clyptorchidie, 540. - Oblitération des voies spermatiques, 540. Du liquide des kystes spermatiques, 541 - De la spermatorrhée, 542. Examen des taches de sperme, 549. - Du sperme dans différents produits de l'économie: matières fécales, mucus, 554. - Végétaux ressemblant à des spermatozoïdes, 558 .

\section{CHAPITRE XIV}

Des produits des organes génitaux de la femme, 559. - Des lochies, 563. - Des parasites des organes génitaux de la femme, 564. Des taclıes laissées par le liquide amniotique, 572. - Des smegma, 574. Du smegma ou enduit fœtal, 575. - Epiderme fœtal, 5 i6.

\section{CHAPITRE XV}

Des matières fécales, excréments ou fèces, 580. - Du méconium, 580. - Matières fécales des enfants nourris exclusivement de lait, 585. Des matières fécales, 589. - Des modifications produites par les maladies sur les déjections intestinales; matières fécales pathologiques, 594. - Des évacuations alvines sanguinolentes et puriformes, 595. - Des concrétions intestinales et en particulier du sable intestinal, 597. - Taches de matières fécales, 600. - Des animalcules qui se forment dans l'intestin, 601. - Des parasites que l'on trouve dans les déjections des diarrhéiques, qui ont contracté leur maladie en Cochinchine, en Afrique. Anguillula stercoralis, 606. - Ankylostome duodénal, 608. - Ankylostome dyssentérique, 610. Linguatule, 613. - Strongylus sanguisuga, 615. - Larves du Carpocapsus Pomomana, 617. 


\section{CHAPITRE XVI}

Des parasites, 620. - Des nelminthes, 620. - Tænia sulium, 621. Trenia mediocanellata, trnia inermis, 633. - T. echinococcus, 639. - Bothriocephalus latus, 644. - B. cordatus, B. cristatus, 645. - Trématodes, Douve hépatique, 650. - Douve lancéolée, 653. - Douve épaisse, 653. D. hétérophye, 654. - D. ophtalmobie, 654. - D. hématobie, 654. NÉMatodes, Ascaris lombricoïdes, 656. - Oxyurus vermicularis, 657. Tricocephalus dispar, 657. - Trichina spiralis, 658. - Altérations de la viande provoquées par des larves d'insectes, 668. - Viandes charbonneuses, 668. - Viandes septicémiques, 669. - Mesures préventives prises dans quelques contrées de l'Europe, 672. - Filaria, 674. - Strongylus gigas, 675. - Syngamus trachealis, 676. - Tænia infundibuliformis, 676. - Parasites des voies respiratoires, 677. - Pseudhelminthes, 679. Acariens, 680. - Acarus scabiei, 682. - Dermatoses du cheval causées par les Acariens, 686. - Sarroptes scabiei, 686. - Psoroptes longirostris, 688. - Chorioples spathiferus, 690. - Fausses gales acariennes, 692. - Gale dermaryssique, 693. - Ixode pénétrant, 693. - Parasite accidentel de l'homme, 693. - Transmission de la gale des animaux à l'homme, contagion d'un animal à un autre, 694. - Acarus du cliat, 694. - Acarus du chien, 695. - Demodex foliicularis de l'homme, 697. - Demodex folliculorum du chien, 698. - Tyrog!yphus longior, 699. - Tyroglyphus siculus, 699. - Tyroglyphus farinx, 700. - Cheyletus eruditus, 702. - Phylloxera vastatrix, 703 .

\section{CHAPITRE XVII}

Caractères pincipaux des mucus, 705. - Du mucus considéré en général, 705. - Mucus nasal, 707. - Mucus lacrymal ou conjonctival, 709. - De la salive, 709. - Du mucus laryngo-bronchique; des crachats, 711. Des cristaux que l'on peut rencontrer dans les crachats, 714 .

\section{CHAPITRE XIIII}

Des matières vomies ou projetées seulement en dehors de In cavité buccale (strangulation). Des substaces alimentaires ou toxiques que l'on pent tronver dang lestomac, 715. Vomissements cholériques, vomissements alimentaires, 716. - Vomissements bilieux et fécaloïdes, 717. - Vomissements sanguins, 717. Vomissements purulents; Parasites des vomissements, 718. - Substances toxiques que l'on peut retrouver dans les vomissements, 718. - Des matières recucillies directement dans l'estomac, 719 .

\section{CHAPITRE XIX}

Quelques exemples des taches dont on peut nvoir à déterminer la nature, 726. - Taches de matière cérébrale, 726. - Taches produites par le jaune d'œuf, 731. - Taclıes formées par la graisse et le tissu adipeux, 731. - Taches produites par l'écoulement blemorrlıagique, 734. - Taches produites par des excréments de punaise, 735. - Taclies produites par des excréments de mouclıes et de puces, 736 . - Taclıes de boue, $73 \%$. 


\section{CHAPJTRE XX}

Sur l'examen microscopique des eanx, 738. - Infusoires, 740. Infusoires oscillants, 744. - Cercomonas, 74j. - Cilio flagellés, 745. - Infusoires ciliés, 745. - Vaginicoliens, 746. - Stentoriens, Haltériens, Kéroniens, 746. - Nassuliens, 747. - Erviliens, 7i8 - Lacrymariens, 748 . - Paraméciens, 750. - Colépiens, 751. - Rlizopodes, Amibes, 751. Radiolariés, 752. - Rotateurs, 753. - Brachioniens, 756. - Conservation des infusoires, 759. - Examen microscopique des eaux de pluie, 762. Corpuscules contenus dans l'eau de rosée, i6\%.

\section{GHAPITRE XXI}

Corpuscules et miasmes de Hir, 764. - Méthodes expérimentales, 764. - Corpuscules organiques, 767. - La neige considéré comme agent épurateur de l'air, 767. - Corpuscules organiques et corpuscules jnorganiques de l'air, 775. - Applications de l'aéroscope à l'liygiène, 784. - Du miasme paludéen, 786. - Spores de Champignon, 788. - Palmelies, 789. - Oscillaires, 790. - Dimension des poussières, 793. - Des corpuscules ferrugineux et magnétiques contenus dans l'atmosplıère, 794. - Des pluies de poussières, 799. - Neige rouge, 802. - Pluies de cendres volcaniques, 803. - Pluies de soufre, 804.

\section{CHAPITRE XXII}

\section{Ex:amen des cheveux et des poils an point de vue de la méde-} cine lógale, 805 . - Structure du poil, 806. - Substance corticale, $80 \%$ - Moelle, 810. - Épiderme, 812. - Follicule proprenent dit, 812. Gaines de la racine, 813 . - De la couleur des poils, 815. - Variation suivant le lieu d'implantation, 817. - Caractéristique d'un poil de barbe, 821. - Poils de l'aisselle, du pubis, du scrotum, des grandes lèvres, 822. - Cils, 828. - Sourcils, 830. - Mensuration de quelques poils humains d'après Pfaff, 831. - Duvet ou lanugo, 832. - Influence des âges sur les poils, 834. - Duvet fotal, 835. - Cheveux chez le foetus et chez le nouveau-né, 837. - Variations de la largeur et de la longueur du poil suivant l'âge, 846. - Influence du sexe sur les variations du poil, 846. - Du poil considélé sur le cadavre, 847. - Des clieveux colorés artificiellement, 852. - Distinction entre les poils arrachés et les poils tombés, 856. - Poils isolés de l'organisme pal' solution de continuité de leur tige; détermination du mécanisme employé, 860 . - Action du feu sur les poils et sur les cheveux, 861. - Altérations pathologịues des cheveux, 863. - La Piedra, S64. - Description du champignon de l'alopécie pityriasique, 865. Coupes horizontales des cheveux, 868. - Caractères des poils appartenant à quelques animaux et en particulier à ceux qui vivent auprès de l'homme, 870. - Lapin, 871. - Lièvre, 872. - Chat, 876. - Laines, 877. - Laino de vigogne, 880. - Laine de chèvre, 881. - Laine d'alpaca, 881. - Martezibeline, 882. - Loutle de Virginie, 88?. - Petite loutre, 883. - Hamster, 883. - Castor, 884. - Renard, 883. - Poils de différentes espèces 
animales, 884 et 885 . - Chien domestique, 885. - Conservation des pelleteries, 886. - Rat musqué, 886. - Conservation des poils, 887. - Soie, 887. - Soie marine, 890. - Structure des plumes et du duvet, 891 . - Appendice:sur les substances que l'on peut trouver dans le sillon qui sépare l'extrémité libre de l'ongle de la pulpe du doigt, 89 f́.

FIN DE LA TABLE DES Matières.

\section{ERRATUM}

Page 463, figure 315, légende, lire urate de soude au lieu d'azotate de soude. Et deux lignes plus bas, lire $f g .315$ an lieu de $f g .316$.

Page 162, remplacez la figure fis par la fiçute 38. 


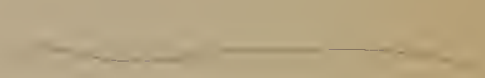





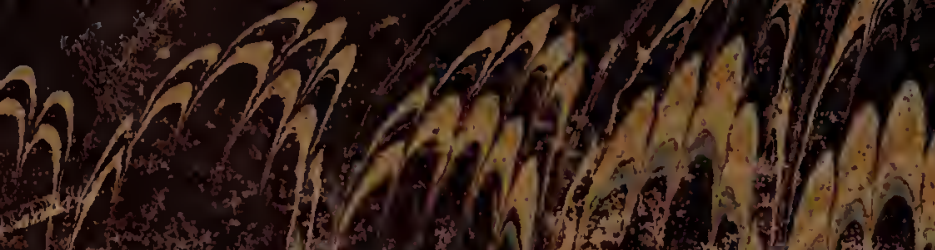

3.

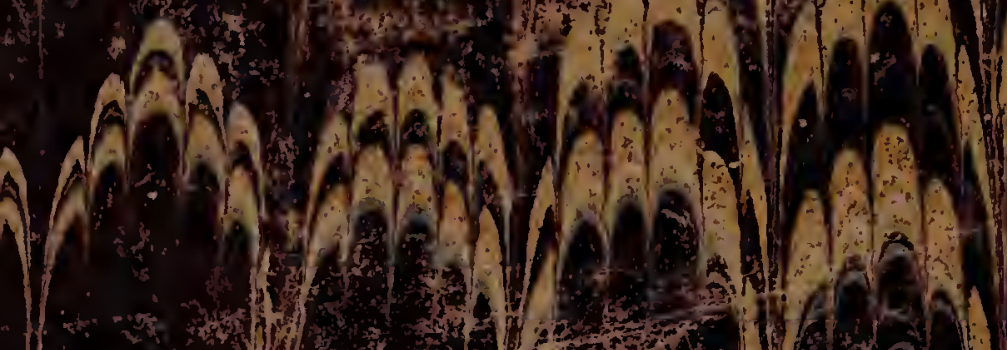

(2)

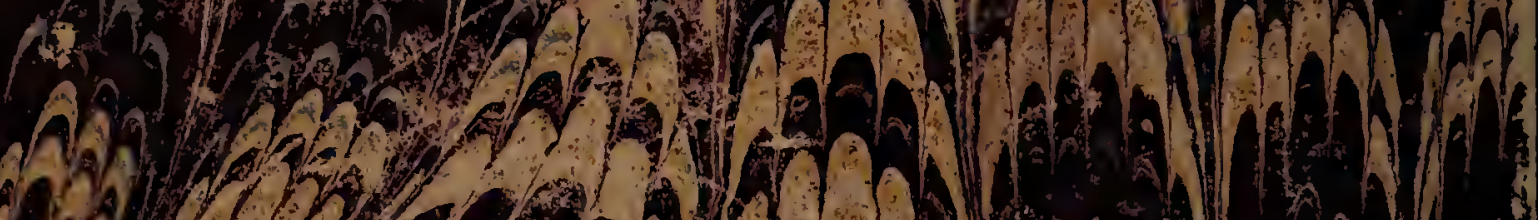

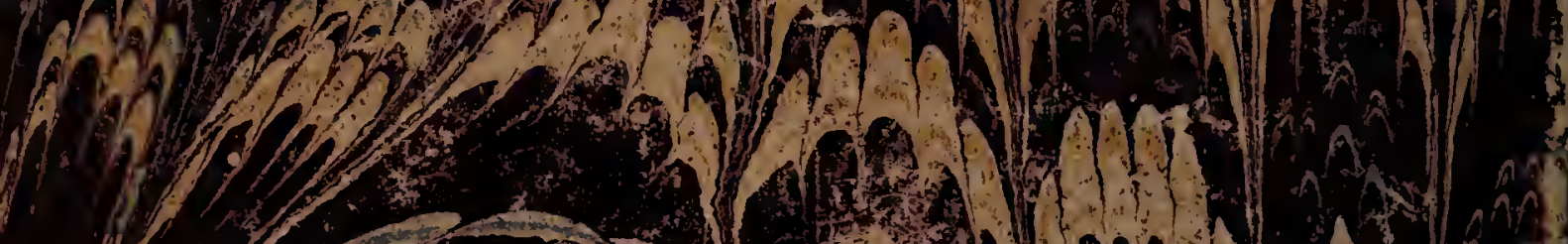

(1)

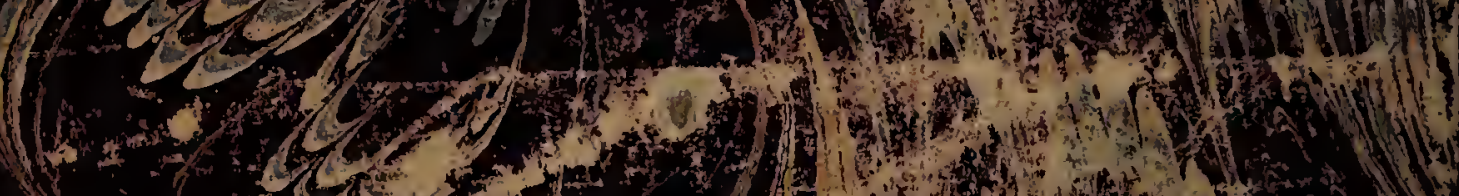

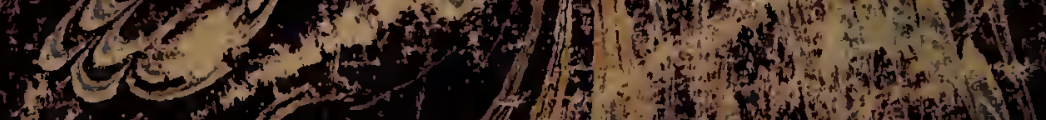

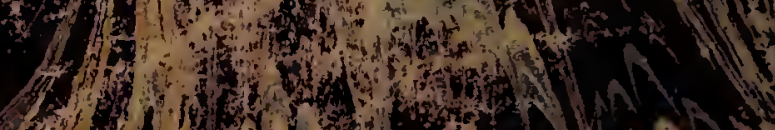

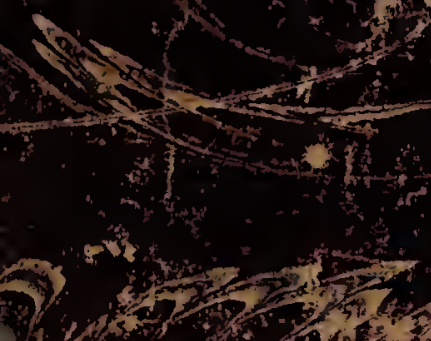

1)

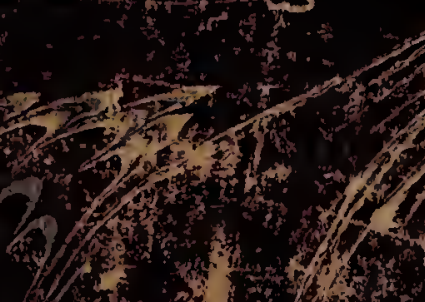

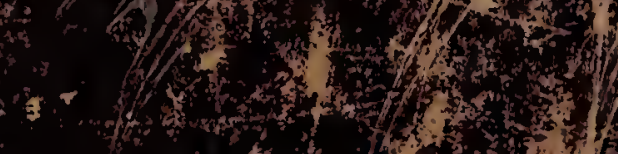

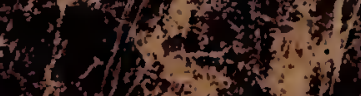

A A 3 (A)

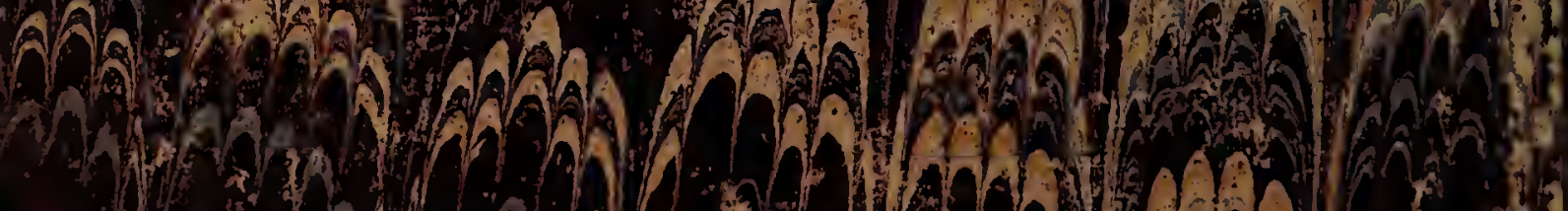

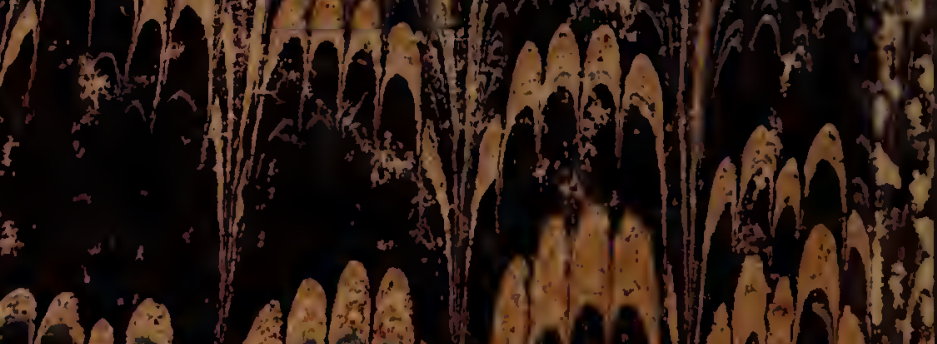

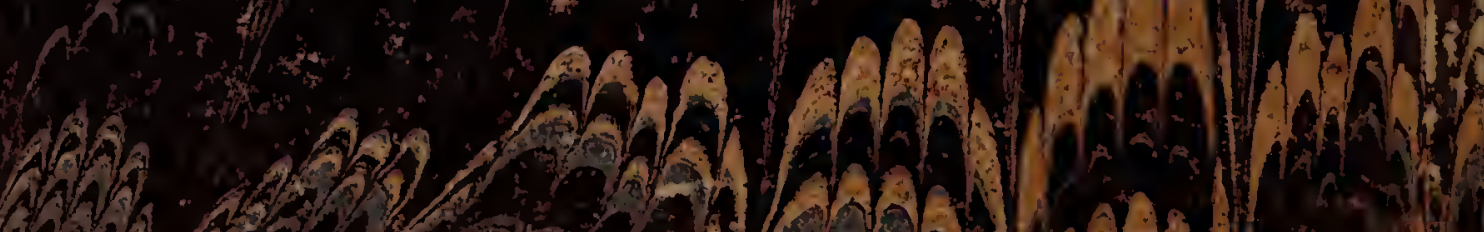

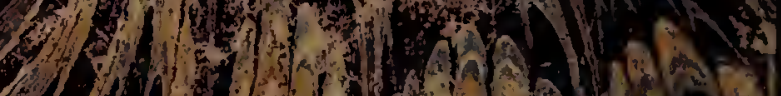

